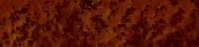

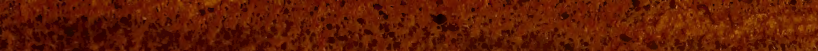
(1) thenting

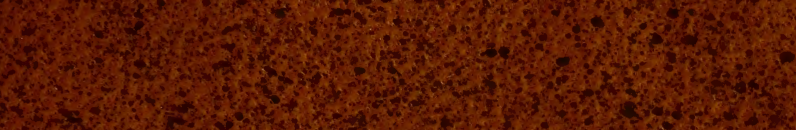

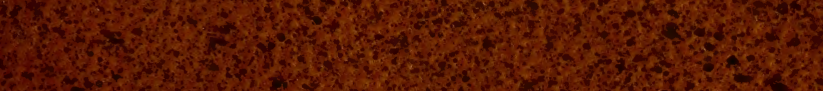

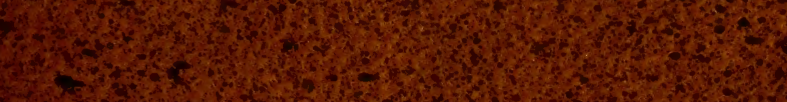

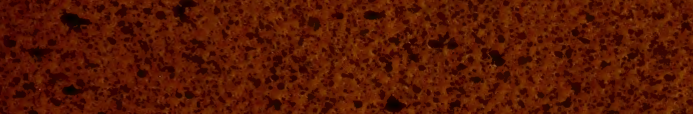

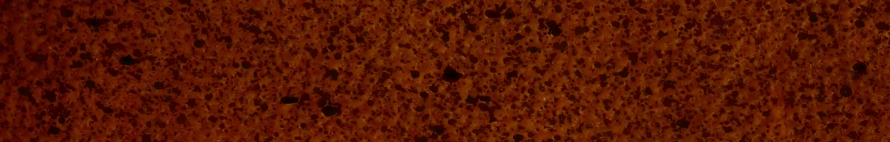




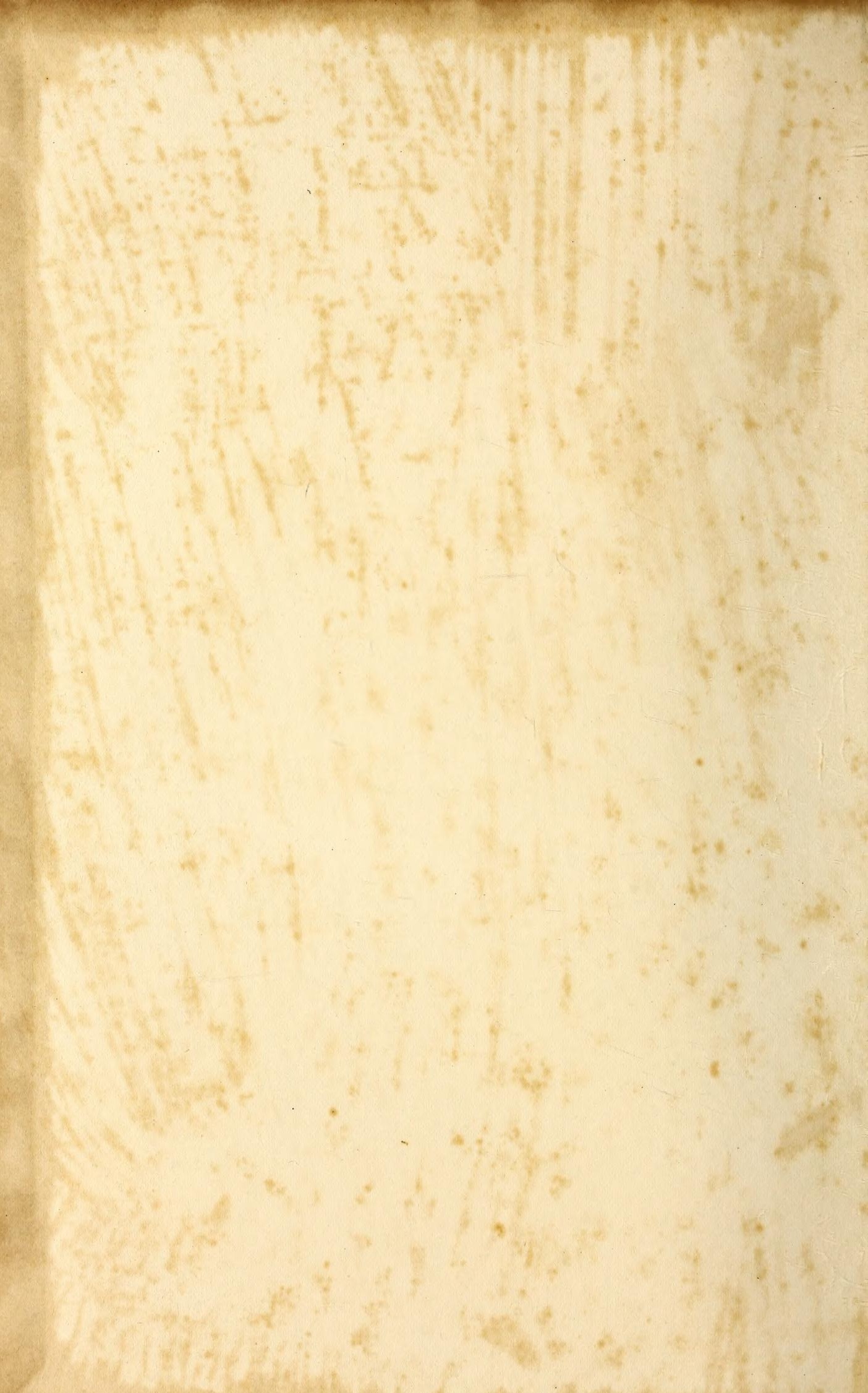


kis.

86 




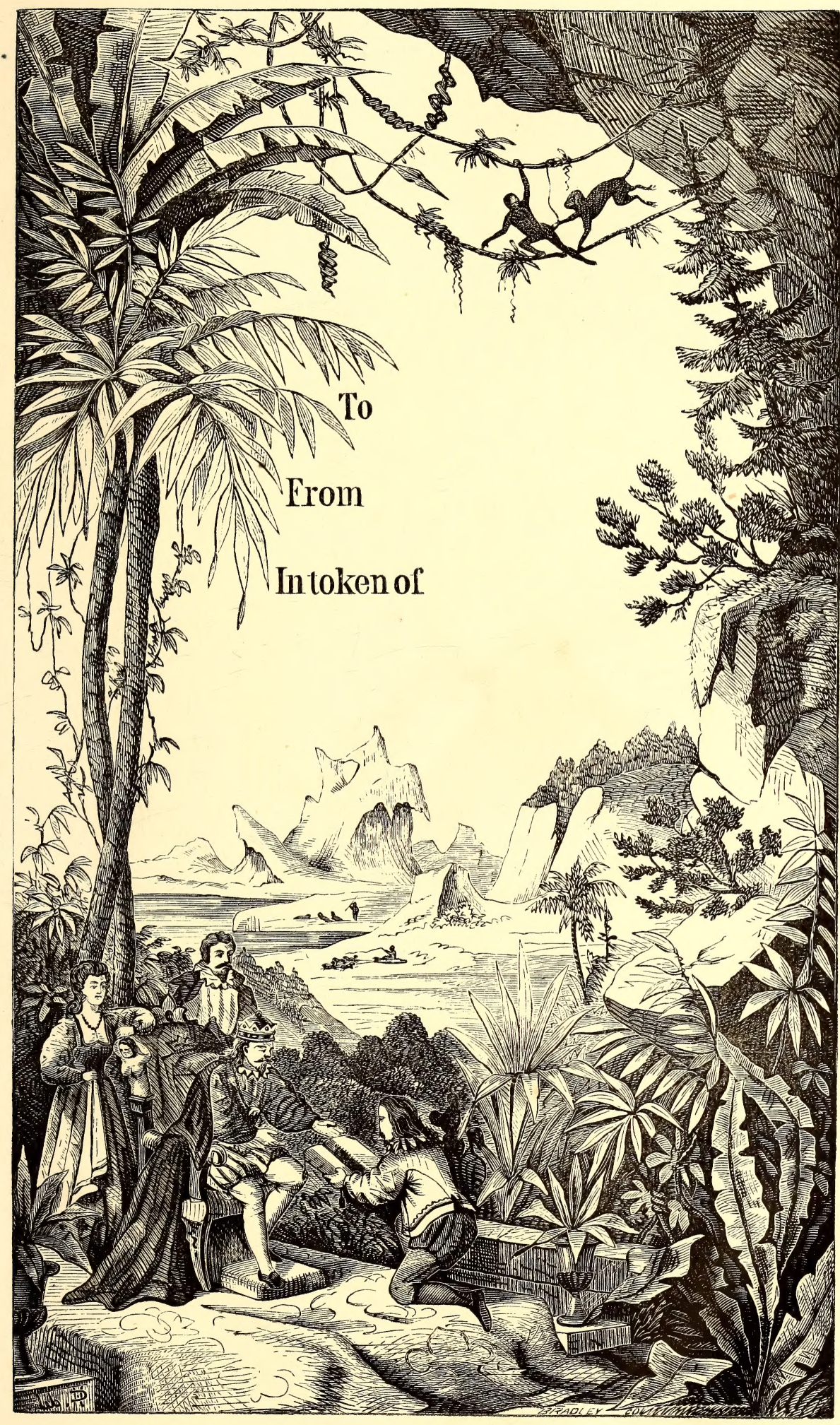





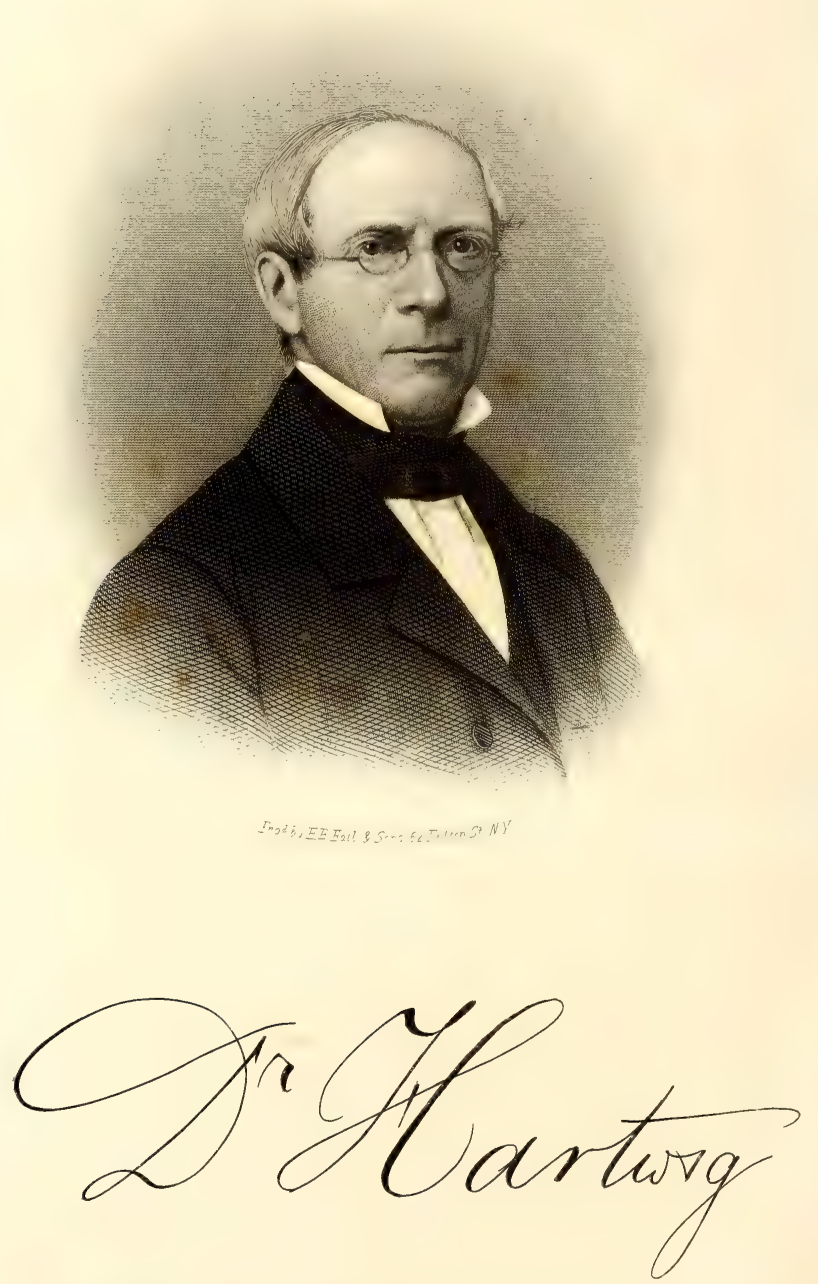
THE

\title{
POLAR AND TROPICAL
}

\section{WORLDS:}

\author{
A DESCRIPTION OF MAN AND NATURE
}

LN THF

\section{Polar and Equatorial Regions of the Globe.}

\author{
TWO VOLUMES IN ONE.
}

BMBRACING ALSO AN ACCOUNT OF THE EXPEDITIONS OF ALL THE ARCTIC EXPLORERS FROM THE DISCOVERY OF ICELAND, OVER ONE THOUSAND YEARS AGO, TO HALL'S LAST EXPEDITION IN THE NORTHERN WORLD, TOGETHER WITH THE WONDERFUL DISCOVERIES AND ADVENTURES OF AGASSIZ, LIVINGSTONE, WALLACE, AND OTHER DISTINGUISHED TRAVELERS IN THE TROPICAL COUNTRIES.

\section{BY DR. G. HARTWIG,}

Author of "The Sea and its Living Wonders," and "The Harmonies of Nature," EDITED, WITH ADDITIONAL CHAPTERS, BY

DR. A. H. GUERNSEY.

THE WHOLE SPLENDIDLY EMBELLISHED WITH NEARLY

\section{TWO HUNDRED BEAUTIFUL ILLUSTRATIONS,}

TRUE TO NATURE, FROM DESIGNS FURNISHED BY ARTISTS IN THE REGIONS TO WHICH THEY RELATE.

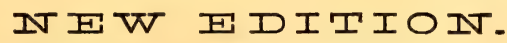

WITH AN ACCOUNT OF HALL'S LAST EXPEDITION, A SUMMARY OF ARCTIC EXPLORATIONS AND NEW MAPS OF THE ARCTIC REGIONS.

SOLD ONLY BY SUBSCRIPTION.

PUBLISHED BY

C. A. NICHOLS \& CO., SPRINGFIELD, MASS.;

HUGH HERON, CHICAGO, ILL;

KING, BOLTON, AND BUCKMASTER,

INDIANAPOLIS, IND.

1875. 
Entered according to Act of Congress, in the year 1874, by C. A. NICHOLS \& CO.,

In the Office of the Librarian of Congress, at Washington, D. C.

CLARK W. BRYAN \& CO., ELECTROTYPERS, PRINTERS AND BINDERE, SPRINGFIELD, MASS. 


\section{PREFACE.}

ONE of the most noticeable of common experiences is the acknowledged absence of intelligent and well-defined knowledge of the world in which we live. Nor is this an indication of illiteracy by any means, for in this absorbing and engrossing age only those who live lives of scholastic study or abundant leisure can keep abreast of the teeming press. The very abundance of the books relating to the history of the world and its inhabitants discourages rather than invites investigation; for, while each writer discusses his chosen specialty, and confines his researches to some particular department of travel or exploration, he who would get at the general results and gain from them a comprehensive view of the whole field, is appalled at the outset by the abundance rather than the paucity of books which claim his attention. The things which attract and interest one explorer are passed over completely by another; and so it happens that while one writer devotes himself to the natural history of the country, or countries, which he visits, another will deal with the descriptive geography and material resources, another with the manners and customs of the people, another with the physical geography and climatic conditions and limitations, and still another with the commercial possibilities and international relations. But the business or professional man, the merchant, mechanic, or farmer, has no time to follow each traveler or writer as he roams at will among his chosen fields of exploration, or describes at length the results of his labors. The practical results he would gladly become acquainted with, but he can not search for them amid a mass of comparatively unimportant details, whose mastery would require a life-time of scholastic leisure. This work of sifting out practical facts and important general laws, and arranging them in the order and sequence in which they naturally belong, if done at all, must be done for him, and that is precisely what the present work aims to do. The two forces in nature which more than any others, more, even, than all others, affect and determine the conditions of living and the range of productions, are heat and cold-the Polar and Tropical Worlds. A knowledge of the working of these forces furnishes the key to those climatic changes which are ever going on, and shows how 
we are affected in our modes of living, in our spheres of action, and even in our habits of thought, by the variations and extremes of temperature. The practical value of the climatic explorations which have been made can hardly be overestimated, and nothing has added so much to the world's knowledge of itself as what has been accomplished in this department of investigation. The long roll of those whose lives have been devoted to science and scientific work contains no names more entitled to honorable and grateful mention than those who have unlocked the mysteries of the Polar and Tropical Worlds, and have thus brought within the reach of every one facts which have a practical bearing upon everyday life as well as upon scientific studies. The grouping together of these investigations, from the discovery of Iceland a thousand years ago to the present time, presents an array of facts and observations of thrilling interest as well as vital value, and the pages of this work will be found to be replete with attraction no less than instruction. Baffin, Parry, Ross, Franklin, Kane, Hayes and Hall-fiction records no stronger experiences than were theirs in exploring the Polar World, and science has had no more faithful devotees than they. With almost the minuteness of preconcerted design, each of these men has supplemented the work of those who have preceded him, until in the summary of their successive voyages, given here, we have the whole story of life and its conditions in the regions of the lower temperatures. Turning from the Polar to the Tropical World, we find men who have braved equatorial suns as well as Arctic snows to examine and define the relations between excessive heat and vegetable, animal and social life. Agassiz and Squier in South America, and Wallace, Burton, Speke and Livingstone upon the eastern continent, have each and all made invaluable contributions to our knowledge of tropical regions; and whatever may be accomplished by future explorers, it is hardly possible that the secret mysteries of the Polar and Tropical Worlds will ever be more thoroughly revealed to us than by Captain Hall and Dr. Livingstone, whose recent sad and tragic fates, as martyrs to their chosen life-work, will never cease to be recalled with tender interest. No men in this generation have done more for science and for the world than they, and there are really no loftier places in the Temple of Fame than are occupied by the names and deeds of the guild of climatic explorers, whose experiences and discoveries are outlined and summarized in this work. 


\section{CONTENTS.}

\section{CHAPTER I.}

THE ARCTIC LANDS.

The barren Grounds or Tundri.-Abundance of animal Life on the Tundri in Summer.-Their Silence and Desolation in Winter.-Protection afforded to Vegetation by the Snow.-Flower-growth in the highest Latitudes.-Character of Tundra Vegetation.-Southern Boundary-line of the barren Grounds.-Their Extent.-The forest Zone.-Arctic Trees.-Slowness of their Growth.-Monotony of the Northern Forests.-Mosquitoes.-The various Causes which determine the Severity of an Arctic Climate.-Insular and Continental Position.-Currents.-Winds.-Extremes of Cold observed by Sir E. Belcher and Dr. Kane.-How is Man able to support the Rigors of an Arctic Winter?Proofs of a milder Climate having once reigned in the Arctic Regions.-Its Cause according to Dr. Oswald Heer.-Peculiar Beauties of the Arctic Regions. -Sunset._Long lunar Nights.-The Aurora ............................................................ Page 17

\section{CHAPTER II.}

ARCTIC LAND QUADRUPEDS AND BIRDS.

The Reindeer.-Structure of its Foot.-Clattering Noise when walking.-Antlers.-Extraordinary olfactory Powers.-The Icelandic Moss.-Present and Former Range of the Reindeer.-Its invaluable Qualities as an Arctic domestic Animal.-Revolts against Oppression.-Enemies of the Reindeer.-The Wolf.-The Glutton or Wolverine.-Gad-flies.-The Elk or Moose-deer.-The Muskox.-The Wild Sheep of the Rocky Mountains.-The Siberian Argali.-The Arctic Fox.-Its Burrows.-The Lemmings. - Their Migrations and Enemies._Arctic Anatidæ.-The Snow-bunting.The Lapland Bunting. -The Sea-eagle.-Drowned by a Dolphin...................... 34

\section{CHAPTER III.}

THE ARCTIC SEAS.

Dangers peculiar to the Arctic Sea.-Ice-fields.-Hummocks.-Collision of Ice-fields.-Icebergs.-Their Origin.-Their Size.-The Glaciers which give them Birth.-Their Beauty.-Sometimes useful Auxiliaries to the Mariner.-Dangers of anchoring to a Berg.-A crumbling Berg.-The Ice-blink. -Fogs.-Transparency of the Atmosphere.-Phenomena of Reflection and Refraction.-Causes which prevent the Accumulation of Polar Ice.-Tides.-Currents.-Ice a bad Conductor of Heat.Wise Provisions of Nature.

\section{CHAPTER IV.}

\section{ARCTIC MARINE ANIMALS.}

Populousness of the Arctic Seas. - The Greenland Whale. - The Fin Whales. - The Narwhal. The Beluga, or White Dolphin.- The Black Dolphin.-His wholesale Massacre on the Faeroe Islands.-The Orc, or Grampus.-The Seals.-The Walrus.-Its acute Smell.-History of a young Walrus.-Parental Affection.-The Polar Bear.-His Sagacity.-Hibernation of the She-bear.Sea-birds............................................................ 59

\section{CHAPTER V.} ICELAND.

Volcanic Origin of the Island.-The Klofa Jökul._Lava-streams.-The Burning Mountains of Krisuvik.-The Mud-caldrons of Reykjahlid.-The Tungo-hver at Reykholt.-The Great Geysir.-The 
Strokkr.-Crystal Pools.-The Almannagja.-The Surts-hellir.-Beautiful Ice-cave.-The Gotba Foss.-The Detti Foss.-Climate.-Vegetation.-Cattle.-Barbarous Mode of Sheep-sheering.Reindeer.-Polar Bears.-Birds.-The Eider-duck._Videy.-Vigr,-The Wild Swan.-The Raven.-The Jerfalcon.-The Giant auk, or Geirfugl.-Fish.-Fishing Season.-The White Shark. Mineral Kingdom.-Sulphur.-Peat.-Drift-wood.................................. 68

\section{CHAPTER VI.}

HISTORY OF ICELAND.

Discovery of the Island by Naddodr in 861.-Gardar.-Floki of the Ravens.--Ingolfr and Leif.-Ulfliot the Lawgiver.-The Althing.-Thingvalla.-Introduction of Christianity into the Island.-Frederick the Saxon and Thorwold the Traveller.-Thangbrand.-Golden Age of Icelandic Literature. -Snorri Sturleson.-The Island submits to Hakon, King of Norway, in 1254.-Long Series of Calamities.-Great Eruption of the Skapta Jökul in 1783.-Commercial Monopoly.-Better Times in Prospect.......................................................... 89

\section{CHAPTER VII.}

THE ICELANDERS.

Skalholt.-Reykjavik.-The Fair.-The Peasant and the Merchant.-A Clergyman in his Cups.--Haymaking.-The Icelander's Hut._Churches.-Poverty of the Clergy.-Jon Thorlaksen.-The Seminary of Reykjavik.-Beneficial Influence of the Clergy.-Home Education.-The Icelander's Winter's Evening.-Taste for Literature.-The Language.-The Public Library at Reykjavik.-The Icelandic Literary Society.-Icelandic Newspapers._Longevity._Leprosy._Travelling in Iceland._Fording the Rivers._Crossing of the Skeidara by Mr. Holland.-A Night's Bivouac.............. 98

\section{CHAPTER VIII.}

THE WESTMAN ISLANDS.

The Westmans. - Their extreme Difficulty of Access.-How they became peopled.-Heimaey. Kaufstathir and Ofanleyte.-Sheep-hoisting. - Egg-gathering.-Dreadful Mortality among the Children.-The Ginklofi.-Gentleman John.-The Algerine Pirates.-Dreadful Sufferings of the

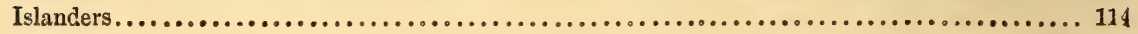

\section{CHAPTER IX.}

FROM DRONTHEIM TO THE NORTH CAPE.

Mild Climate of the Norwegian Coast.-Its Causes. - The Norwegian Peasant.-Norwegian Constitution.Romantic coast Scenery.-Drontheim.-Greiffenfeld Holıne and Väre. - The Sea-eagle.-The Herringfisheries.-The Lofoten Islands.-The Cod-fisheries.-Wretched Condition of the Fishermen.-Tromsö. -Altenfiord.-The Copper Mines._Hammerfest the most northern Town in the World.-The North Cape.............................................................. 120

\section{CHAPTER $\mathbf{x}$.}

\section{SPITZBERGEN-BEAR ISLAND-JAN MEYEN.}

The west Coast of Spitzbergen _-Ascension of a Mountain by Dr. Scoresby.-His Excursion along the Coast.-A stranded Whale.-Magdalena Bay.-Multitudes of Sea-birds._Animal Life.-Midnight Silence.-Glaciers. - A dangerous Neighborhood.-Interior Plateau._Flora of Spitzbergen. - Its Similarity with that of the Alps above the Snow-line.-Reindeer.-The hyperborean Ptarmigan.Fishes.-Coal._Drift-wood.-Discovery of Spitzbergen by Barentz, Heemskerk, and Ryp.-Brilliant Period of the Whale-fishery.-Coffins.-Eight English Sailors winter in Spitzbergen, 1630._Melancholy Death of some Dutch Volunteers.--Russian Hunters.-Their Mode of wintering in Spitzbergen.-Scharostin.-Walrus-ships from Hammerfest and Tromsö.-Bear or Cherie Island.-Bennet. -Enormous Slaughter of Walruses.-Mildness of its Climate.-Mount Misery.-Adventurous Boatvoyage of some Norwegian Sailors. -Jan Meyen.-Beerenberg........................ 131

\section{CHAPTER XI.}

NOVA ZEMBLA.

The Sea of Kara.-Loschkin.-Rosmysslow.-Lütke.-Krotow.-Pachtussow.-Sails along the eastern Coast of the Southern Island to Matoschkin Schar.-His second Voyage and Death. - Meteoro- 
logical Observations of Ziwolka.-The cold Summer of Nova Zembla. - Von Baer's scientific Voyage to Nova Zembla.-His Adventures in Matoschkin Schar.-Storm in Kostin Schar.-Sea Bath and votive Cross.-Botanical Observations.-A natural Garden.-Solitude and Silence.-A Bird Bazar.-Hunting Expeditions of the Russians to Nova Zembla..................... Page 147

\section{CHAPTER XII.}

THE LAPPS.

Their ancient History and Conversion to Christianity.--Self-denial and Poverty of the Lapland Clergy. - Their singular Mode of Preaching.-Gross Superstition of the Lapps.-The Evil Spirit of the Woods.-The Lapland Witches._Physical Constitution of the Lapps._Their Dress.-The Fjällappars.-Their Dwellings._- Store-houses._Reindeer Pens.- Milking the Reindeer.-Migration.The Lapland Dog.--Skiders, or Skates.-The Sledge, or Pulka.-Natural Beauties of Lapland.Attachment of the Lapps to their Country.-Bear-hunting.--Wolf-hunting.-Mode of Living of the wealthy Lapps.-How they kill the Reindeer._-Visiting the Fair._-Mammon Worship._Treasurehiding._" Tabak, or Braende."-Affectionate Disposition of the Lapps.-The Skogslapp.-The Fisherlapp....................................................... 156

\section{CHAPTER XIII.}

MATTHIAS ALEXANDER CASTRÉN.

His Birthplace and first Studies._Journey in Lapland, 1838. - The Iwalojoki._The Lake of Enara.The Pastor of Utzjoki.-From Rowaniémi to Kemi.-Second Voyage, 1841-44.-Storm on the White Sea.-Return to Archangel.-The Tundras of the European Samoïedes.-Mesen._-Universal Drunkenness.-Sledge Journey to Pustosersk.-A Samoïede Teacher.-Tundra Storms._Abandoned and alone in the Wilderness.-Pustosersk.-Our Traveller's Persecutions at Ustsylmsk and Ishemsk.-The Uusa.-Crossing the Ural.-Obdorsk.-Second Siberian Journey, 1845-48.-Overflowing of the Obi.-Surgut.-Krasnojarsk.-Agreeable Surprise.-Turuchansk.-Voyage down the Jenissei.-Castrén's Study at Plachina._From Dudinka to Tolstoi Noss.-Frozen Feet.-Return Voyage to the South.-Frozen fast on the Jenissei.-Wonderful Preservation.-Journey across the Chinese Frontiers, and to Transbaikalia._Return to Finland._Professorship at Helsingfors._Death

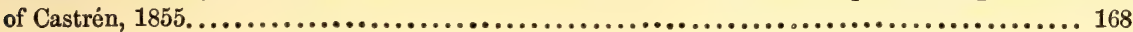

\section{CHAPTER XIV.}

THE SAMOÏEDES.

Their Barbarism._Num, or Jilibeambaertje._Shamanism._Samoïede Idols._Sjadæi._Hahe.-The Tadebtsios, or Spirits.-The Tadibes, or Sorcerers.-Their Dress. - Their Invocations.-Their conjuring Tricks.-Reverence paid to the Dead.-A Samoïede Oath.-Appearance of the Samoïedes.-Their Dress._A Samoïede Belle._Character of the Samoïedes. - Their decreasing Numbers. - Traditions of ancient Heroes. .................................................... 179

\section{CHAPTER XV.}

THE OSTIAKS.

What is the Obi?-Inundations.-An Ostiak summer Yourt.-Poverty of the Ostiak Fishermen.-A winter Yourt.-Attachment of the Ostiaks to their ancient Customs._An Ostiak Prince.-Archery. -Appearance and Character of the Ostiaks.-The Fair of Obdorsk................. 185

\section{CHAPTER XVI.}

CONQUEST OF SIBERIA BY THE RUSSIANS-THEIR VOYAGES OF DISCOVERY ALONG THE SHORES OF THE POLAR SEA.

Ivan the Terrible.-Strogonoff.-Yermak, the Robber and Conqueror.-His Expeditions to Siberia.Battle of Tobolsk - Yermak's Death.-Progress of the Russians to Ochotsk.-Semen Deshnew.Condition of the Siberian Natives under the Russian Yoke.-Voyages of Discovery in the Reign of the Empress Anna.-Prontschischtschew.-Chariton and Demetrius Laptew.-An Arctic Heroine. - Schalaurow.-Discoveries in the Sea of Bering and in the Pacific Ocean. - The Lächow Islands. Fossil Ivory.-New Siberia. - The wooden Mountains. - The past Ages of Siberia........... 191 


\section{CHAPTER XVII.}

SIBERIA-FUR-TRADE AND GOLD-DIGGINGS.

Siberia.-Its immense Extent and Capabilities._The Exiles._Mentschikoff._Dolgoro־ky._Münich._ The Criminals.-The free Siberian Peasant._Extremes of Heat and Cold._Fur-bearing Animals.The Sable.-The Ermine.-The Siberian Weasel.-The Sea-otter.-The black Fox.-The Lynx.The Squirrel.-The varying Hare.-The Suslik.-Importance of the Fur-trade for the Northern Provinces of the Russian Empire.-The Gold-diggings of Eastern Siberia.-The Taiga._Expenses and Difficulties of searching Expeditions.-Costs of Produce, and enormous Profits of successful Speculators.-Their senseless Extravagance.-First Discovery of Gold in the Ural Mountains.Jakowlew and Demidow. -Nishne-Tagilsk.............................. Page 204

\section{CHAPTER XVIII.}

MIDDENDORFF's ADVENTURES IN TAIMURLAND.

For what Purpose was Middendorff's Voyage to Taimurland undertaken?-Difficulties and Obstacles.Expedition down the Taimur River to the Polar Sea. - Storm on Taimur Lake.-Loss of the Boat.Middendorff ill and alone in $75^{\circ}$ N. Lat.-Saved by a grateful Samoiede.-Climate and Vegetation of

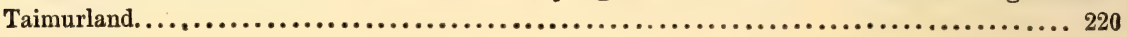

\section{CHAPTER XIX.}

THE JAKUTS.

Their energetic Nationality.-Their Descent.-Their gloomy Character.-Summer and Winter Dwellings.-The Jakut Horse.-Incredible Powers of Endurance of the Jakuts.-Their Sharpness of Vision.--Surprising local Memory.-Their manual Dexterity.-Leather, Poniards, Carpets. - Jakut Gluttons.-Superstitious Fear of the Mountain-spirit Ljeschei.-Offerings of Horse-hair.--Improvised Songs. -The River Jakut............................................. 228

\section{CHAPTER XX.}

WRANGELL.

His distinguished Services as an Arctic Explorer.-From Petersburg to Jakutsk in 1820. -Trade of Jakutsk.-From Jakutsk to Nishne-Kolymsk. - The Badarany.-Dreadful Climate of Nishne-Kolymsk._Summer Plagues._Vegetation._Animal Life.-Reindeer-hunting._Famine._Inundations. -The Siberian Dog._First Journeys over the Ice of the Polar Sea, and Exploration of the Coast beyond Cape Shelagskoi in 1821.-Dreadful Dangers and Hardships.-Matiuschkin's Sledge-journey over the Polar Sea in 1822.-Last Adventures on the Polar Sea.-A Run for Life.-Return to St. Petersburg......................................................... 233

\section{CHAPTER XXI.}

THE TUNGUSI.

Their Relationship to the Mantchou. - Dreadful Condition of the outcast Nomads. - Character of the Tungusi.-Their Outfit for the Chase.-Bear-hunting.-Dwellings.-Diet.-A Night's Halt with Tungusi in the Forest. -Ochotsk......................................... 244

\section{CHAPTER XXII.}

GEORGE WILLIAM STELLER.

His Birth.-Enters the Russian Service._Scientific Journey to Kamchatka.-Accompanies Bering on his second Voyage of Discovery.-Lands on the Island of Kaiak.-Shameful Conduct of Bering.-Shipwreck on Bering Island._Bering's Death._-Return to Kamchatka._Loss of Property._-Persecutions of the Siberian Authorities.-Frozen to Death at Tjumen.......................... 248

\section{CHAPTER XXIII.}

\section{KAMCHATKA.}

Climate.-Fertility.-Luxuriant Vegetation.-Fish.-Sea-birds._Kamchatkan Bird-catchers.-The Bay of Avatscha.-Petropaylosk.-The Kamchatkans._-Their physical and moral Qualities.-The Fritillaria Sarrana.-The Muchamor.-Bears.-Dogs................................ 254 


\section{CHAPTER XXIV.}

THE TCHUKTCHI.

The Land of the Tchuktchi.-Their independent Spirit and commercial Enterprise.-Perpetual Migrations.-The Fair of Ostrownoje. - Visit in a Tchuktch Polog. - Races. - Tehuktch Bayaderes. The Tennygk, or Reindeer Tchuktchi. - The Onkilon, or Sedentary Tchuktchi. — Their Mode of Life. Page 262

\section{CHAPTER XXV.}

BERING SEA-THE RUSSIAN FUR COMPANY-THE ALEUTS.

Bering Sea.-Unalaska._The Pribilow Islands.-St. Matthew.-St. Laurence.-Bering's Straits.-The Russian Fur Company.-The Aleuts.-Their Character.-Their Skill and Intrepidity in hunting the Sea-otter.-The Sea-bear.-Whale-chasing. -Walrus-slaughter.-The Sea-lion.............. 268

\section{CHAPTER XXVI.}

\section{ALASKA.}

Purchase of Alaska by the United States.-The Russian American Telegraph Scheme.-Whymper's Trip up the Yukon.-Dogs.-The Start.-Extempore Water-filter.-Snow-shoes.-The Frozen Yukon.-Under-ground Houses.-Life at Nulato.-Cold Weather.-Auroras.-Approach of Summer. -Breaking-up of the Ice.--Fort Yukon.-Furs.-Descent of the Yukon.--Value of Goods.-Arctic and Tropical Life.-Moose-hunting.-Deer-corrals.-Lip Ornaments.-Canoes.-Four-post Coffin. -The Kenaian Indians. - The Aleuts. - Value of Alaska........................... 277

\section{CHAPTER XXVII.}

THE ESQUIMAUX.

Their wide Extension.-Climate of the Regions they inhabit.-Their physical Appearance.-Their Dress.-Snow Huts.-The Kayak, or the Baidar-Hunting Apparatus and Weapons.-Enmity between the Esquimaux and the Red Indian.-The "Bloody Falls."-Chase of the Reindeer.-Birdcatching.-Whale-hunting.- Various Stratagems employed to catch the Seal.-The "Keep-kuttuk." -Bear-hunting. - Walrus-hunting.-Awaklok and Myouk.-The Esquimaux Dog.-Games and Sports._Angekoks.-Moral Character_-Self-reliance.-Intelligence.-Iligliuk.-Commercial Eagerness of the Esquimaux. -Their Voracity.-Seasons of Distress..................... 290

\section{CHAPTER XXVIII.}

THE FUR-TRADE OF THE HUDSON'S BAY TERRTTORIES.

The Coureur des Bois. - The Voyageur. - The Birch-bark Canoe.-The Canadian Fur-trade in the last Century. - The Hudson's Bay Company.-Bloody Feuds between the North-west Company of Canada and the Hudson's Bay Company.-Their Amalgamation into a new Company in 1821.-Reconstruction of the Hudson's Bay Company in 1863. - Forts or Houses.-The Attihawmeg. - Influence of the Company on its savage Dependents. - The Black Bear, or Baribal.-The Brown Bear.-The Grizzly Bear. - The Raccoon. - The American Glutton. - The Pine Marten. - The Pekan, or Wood-shock. - The Chinga. - The Mink. - The Canadian Fish-otter. - The Crossed Fox.-The Black or Silvery Fox. - The Canadian Lynx, or Pishu. — The Ice-hare. - The Beaver. - The Musquash............................................................ 304

\section{CHAPTER XXIX.}

THE CREE INDIANS, OR EYTHINYUWUK.

The various Tribes of the Crees. - Their Conquests and subsequent Defeat.-Their Wars with the Blackfeet.-Their Character.-Tattooing. - Their Dress. -Fondness for their Children.-The Cree Cradle.Vapor Baths.-Games.-Their veligious Ideas.-The Cree Tartarus and Elysium............ 319

\section{CHAPTER XXX.}

THE TINNE INDIANS.

The various Tribes of the Tinné Indians.-The Dog-ribs._Clothing. - The Hare Indians. - Degraded State of the Women.-Practical Socialists. - Character.-Cruelty to the Aged and Infirm...... 327 


\section{CHAPTER XXXI.}

THE LOUCHEUX, OR KUTCHIN INDIANS.

The Countries they inhabit.-Their Appearance and Dress.-Their Love of Finery.-Condition of the Women.-Strange Customs._Character. - Feuds with the Esquimaux. - Their suspicious and timorous Lives. - Pounds for catching Reindeer.-Their Lodges.................... Page 331

\section{CHAPTER XXXII.}

ARCTIC VOYAGES OF DISCOVERY, FROM THE CABOTS TO BAFFIN.

First Scandinavian Discoverer of America. - The Cabots. - Willoughby and Chancellor (1553-1554). Stephen Burrough (1556).-Frobisher (1576-1578).-Davis (1585-1587).-Barentz, Cornelis, and Brant (1594). - Wintering of the Dutch Navigators in Nova Zembla (1596-1597).-John Knight (1606).-Murdered by the Esquimaux.—Henry Hudson (1607-1609). -Baffin (1616)......... 335

\section{CHAPTER XXXIII.}

ARCTIC VOYAGES OF DISCOVERY, FROM BAFFIN TO M'CLINTOCK.

Buchan and Franklin.-Ross and Parry (1818)._Discovery of Melville Island.-Winter Harbor (1819. 1820)._Franklin's first land Journey.—Dreadful Sufferings._Parry's second Voyage (1821-1823). - Iligliuk. - Lyon (1824)._- Parry's third Voyage (1824).-Franklin's second land Journey to the Shores of the Polar Sea.-Beechey.-Parry's sledge Journey towards the Pole.-Sir John Ross's second Journey.-Five Years in the Arctic Ocean.-Back's Discovery of Great Fish River.-Dease and Simpson (1837-1839).-Franklin and Crozier's last Voyage (1845).-Dearching Expeditions.Richardson and Rae.-Sir James Ross.-Austin,-Penny.-De Haven.-Franklin's first Winterquarters discovered by Ommaney.-Kennedy and Bellot.-Inglefield.-Sir E. Belcher.-Kellett.M'Clure's Discovery of the North-west Passage.-Collinson.-Bellot's Death._Dr. Rae learns the Death of the Crews of the "Erebus" and "Terror."-Sir Leopold M'Clintock.............. 344

\section{CHAPTER XXXIV.}

\section{KANE AND HAYES.}

Kane sails up Smith's Sound in the "Advance" (1853)._Winters in Rensselaer Bay.-Dledge Journey along the Coast of Greenland. - The Three-brother Turrets. - Tennyson's Monument.-The Great Humboldt Glacier.-Dr. Hayes crosses Kennedy Channel. - Morton's Discovery of Washington Land._Mount Parry.-Kane resolves upon a second Wintering in Rensselaer Bay.-Departure and Return of Part of the Crew.-Sufferings of the Winter.-The Ship abandoned.-Boat Journey to Upernavik.-Kane's Death in the Havana (1857).-Dr. Hayes's Voyage in 1860.-He winters at Port Foulke.-Crosses Kennedy Channel.-Reaches Cape Union, the most northern known Land upon the Globe.-Koldewey.-Plans for future Voyages to the North Pole................ 365

\section{CHAPTER XXXV.}

NEWFO JNDLAND.

Its desolate Aspect.-Forests.-Marshes.-Barrens._Ponds._Fur-bearing Animals.-Severity of Climate.-St. John's.-Discovery of Newfoundland by the Scandinavians. - Sir Humphrey Gilbert.Rivalry of the English and French.-Importance of the Fisheries.-The Banks of Newfoundland.Mode of Fishing.-Throaters, Headers, Splitters, Salters, and Packers.-Fogs and Storms.-Seal-

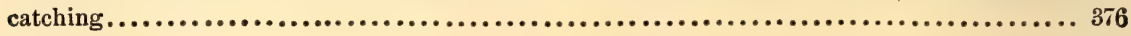

\section{CHAPTER XXXVI.}

GREENLAND.

A mysterious Region.-Ancient Scandinavian Colonists.-Their Decline and Fall.-Hans Egede.-His Trials and Success.-Foundation of Godthaab.-Herrenhuth Missionaries._Lindenow.-The Scoresbys.-Clavering.-The Danish Settlements in Greenland.-The Greenland Esquimaux.-Seal-catching.-The White Dolphin.-The Narwhal._Shark-fishery.-Fiskernasset.-Birds.-Reindeer-hunting.-Indigenous Plants._Drift-wood.-Mineral Kingdom.-Mode of Life of the Greenland Esquimaux.-The Danes in Greenland.-Beautiful Scenery.-Ice Caves................... 382 


\section{CHAPTER XXXVII.}

THE A T T R T TC OCEAN.

Comparative View of the Antarctic and Arctic Regions.-Inferiority of Climate of the former.-Its Causes. - The New Shetland Islands.--South Georgia.-The Peruvian Stream.-Dea-birds.-The Giant Petrel._The Albatross. - The Penguin.-The Austral Whale.-The Hunchback. - The Fin-back. -The Grampus.-Battle with a Whale.-The Sea-elephant.-The Southern Sea-bear.-The Sea-

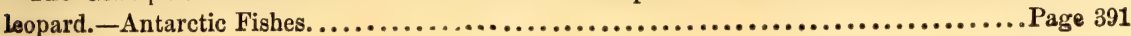

\section{CHAPTER XXXVIII.}

ANTARCTIC VOYAGES OF DISCOVERY.

Cook's Discoveries in the Antarctic Ocean.-Bellinghausen.-Weddell - Biscoe._Balleny.-Dumont d'Urville.-Wilkes.-Sir James Ross crosses the Antarctic Circle on New Year's Day, 1841.--Discovers Victoria Land.-Dangerous Landing on Franklin Island.-An Eruption of Mount Erebus.The Great Ice Barrier.-Providential Escape._Dreadful Gale.-Collision.-Hazardous Passage between two Icebergs. - Termination of the Voyage.............................. 401

\section{CHAPTER XXXIX.}

THE STRATT OF MAGELLAN.

Description of the Strait.-Western Entrance._Point Dungeness.-The Narrows.-Saint Philip's Bay. - Cape Froward.-Grand Scenery.-Port Famine.-The Sedger River._Darwin's Ascent of Mount Tarn._The Bachelor River._English Reach._-Sea Reach._-South Desolation._Harbor of Mercy.Williwaws.-Discovery of the Strait by Magellan (October 20,.1521).-Drake.-Sarmiento.-Cavendish.-Schouten and Le Maire.-Byron.-Bougainville.-Wallis and Carteret.-King and Fitzroy.-Settlement at Punta Arenas. - Increasing Passage through the Strait.-A future Highway of Commerce ........................................................ 408

\section{CHAPTER XL.}

PATAgonia AND the patagonians.

Difference of Climate between East and West Patagonia.--Extraordinary Aridity of East Patagonia.Zoology.-The Guanaco. - The Tucutuco.-The Patagonian Agouti._Vultures.-The Turkey-buzzard.-The Carrancha.-The Chimango.-Darwin's Ostrich.-The Patagonians._Exaggerated Accounts of their Stature.-Their Physiognomy and Dress.-Religious Ideas. --Superstitions. - Astronomical Knowledge.-Division into Tribes.-The Tent, or Toldo.-Trading Routes.-The great Cacique.-Introduction of the Horse.-Industry.-Amusements.-Character............... 417

\section{CHAPTER XLI.}

THE FUEGIA S.

Their miserable Condition.-Degradation of Body and Mind.-Powers of Mimicry. - Notions of Barter. -Causes of their low State of Cultivation.-Their Food.-Limpets.-Cyttaria Darwini._Constant Migrations. - The Fuegian Wigwam.-Weapons. - Their probable Origin. - Their Number, and various Tribes. - Constant Feuds. - Cannibalism.-Language.-Adventures of Fuegia Basket, Jemmy Button, and York Minster.-Missionary Labors. - Captain Gardiner.-His lamentable End.... 425

\section{CHAPTER XLII.}

\section{ChaRles FraNCIS HALL AND THE INNUITS.}

Hall's Expedition.-His early Life.-His reading of Arctic Adventure.-His Resolve.-His Arctic Outfit.-Sets sail on the "George Henry."-The Voyage.-Kudlago.-Holsteinborg, Greenland.-Population of Greenland. - Sails for Davis's Strait. - Character of the Innuits.-Wreck of the "Rescue." -Ebierbing and Tookoolito.-Their Visit to England.-Hall's first Exploration.-European and Innuit Life in the Arctic Regions.-Building an Igloo.-Almost Starred.-Fight for Food with Dogs. -Ebierbing arrives with a Seal.-How he caught it.-A Seal-feast.-The Innuits and Seals. -The Polar Bear.-How he teaches the Innuits to catch Seals.-At a Seal-hole.-Dogs as Seal-hunters.Dogs and Bears.-Dogs and Reindeers.-Innuits and Walruses.-More about Iglons._-Innuit Implements.-Uses of the Reindeer.-Innuit Improvidence.-A Deer-feast.-A frozen Delicacy._Whaleskin as Food.-Whale-gum. - How to eat Whale Ligament.-Raw Meat.-The Dress of the Innuits, 
A pretty Style.-Religious Ideas of the Innuits.-Their kindly Character. - Treatment of the Aged and Infirm.-A Woman abandoned to die.-Hall's Attempt to rescue her.The Innuit Nomads, without any form of Government.-Their Numbers Diminishing.A Sailor wanders away.-Hall's Search for him.-Finds him frozen to death.-The Ship free from Ice.-Preparations to return.-Reset in the Ice-pack.-Another Arctic Winter.Breaking up of the Ice.-Departure for Home.-Tookoolito and her Child "Butterfly."Death of "Butterfly."-Arrival at Home.-Results of Hall's Expedition.-Innuit Traditions.-Discovery of Frobisher Relics.-Hall's Second Expedition, . . . . . . . Page 433

\section{ADDITIONAL CHAPTERS.}

Chapter 43 -Summary of Arctic Explorations, ........................... 737

Chapter 44.-Hall's Last Expedition, ..................................... 757

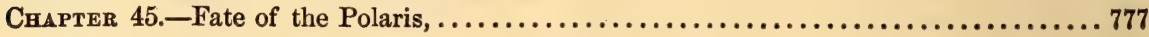

\section{THE TROPICAL WORLD.}

\section{CHAPTER I.}

THE OCEAN AND ATMOSPHERE CF THE TROPICAL WORLD.

Characteristics of the Polar and Tropical Worlds.-Geographical and Climatic Limits of the Zones.-Distribution of Land and Water.-Climatic Importance of the Ocean.-Currents of the Ocean.-The Gulf Stream.-Influence of the Gulf Stream upon the Climate of Europe.-The Sargasso Sea.-Columbus and the Gulf Stream.-The Pacific and Indian Currents.-Heat and Force.-Relative Positions of Hot and Cold Currents.-Currents of the Air.-The Trade Winds.-Atmospheric Currents and Climate.-The Calm Belt near the Equator.-Rainfall of Different Regions.-Rainy and Dry Seasons within the Tropics. -The Monsoons.-Winds as Regulators of Rains. - Annual Rainfall.-Whirlwinds.-Their Rotary Motion.-Tropical Islands.-Volcanic Islands.-Coralline Islands.-Atolls and Reefs.-Influence of the Ocean upon Life in the Tropical Islands, . . . . . . . . 471

CHAPTER II.

TABLE LANDS AND PLATEAUS OF THE TROPICAL WORLD.

Influence of Elevation upon Climate.-The Puna of Peru: Squier's Description of the Puna.The Soroche or Veta.-View from La Portada.-Effects of the Soroche.-The Sarumpe. -The Veruga Water.-Effects of the Veta on Animals.-Vegetation of the Puna.-The Llama.-The Huanacu.-The Alpaca.-The Vicuna.-Hunting the Vicuna.-The Hunts of the Ancient Incas.-Enemies of the Vicuna.-Other Native Animals.-The Ox, Horse, Mule and Sheep.-Waterfowl.-Warm Valleys.-Ranid Change of Climate According to Elevation.-Lake Titicaca: The Sacred Island of Titicaca.-Manco Capac, the First Inca. - His Journey from Lake Titicaca to Cuzcu.-Fact and Myth respecting Manco Capac.Extent of the Inca Empire.-Inca Civilization originated in the Puna, near Lake Titicaca.-The Sacred Rock on the Island.-Ruins and Relics on the Island.-The Hacienda on the Island.-The Eve of St. John.-The Bath of the Incas.-Other Sacred Islands.Ruins at Tihuanico.-Some more ancient than the Incas.-Immense Monolithic Gateways and Hewn Stones.-Inca Civilization.-The Great Military Roads.-System of Posts and Post-Stations.-The Valley of Quito: Approach to the Valley from the Pacific Coast.-A Tropical Region-Climbing the Cordillera.-Scenes by the Way.-Quito.-Climate of the Valley.-Astronomical Site.-Trees, Fruits, Vegetables, and Flowers.-Animals.-Birds.Insects, Reptiles, and Fish.-The Population of the Valley.-Indians.-Half-Breeds.Whites.-Courtesy of the People-A Polite Message.-Scenery of the Valley.-Volcanoes. - Imbabura.-Destruction of Otoralo.-Cayamba.-Guamani.-Antisana.-Sincholagua.-Cotopaxi.-The Inca's Head.-Tunguragua._- Altar. -Sangai.-Its Perpetual Eruption.-Chimborazo.-Caraguarizo.-Illinza.-Corazon.-Pichincha.-Its immense Crater. -Descent into the Crater.-Eruptions of Pichincha.-The Table-Land of Bogotá: Voyage 
up the Magdalena.-Ascent to the Plateau.-Bogotá and the Bogotános.-Traveling at Bogotá.-Table-Land of Mexico: Its Extent.-The Tierra Calienta.-The Tierra Templada. -The Tierra Fria.-The Valley of Anahuac.-The Volcanoes of Orizaba, Popocatapetl, Iztacihuatl, and Toluca.-The Sikkim Slope: Approach and Ascent.-Dorjiling.-The Sikkim Peaks.-Altitude of Kinchin-junga.-Flight of the Condor, . . . . . . . . Page 480

\section{CHAPTER III.}

SAVANNAS AND DESERTS OF THE TROPICAL WORLD.

Water and Life.-Characteristics of the Savannas.-The Llanos: The Dry Season.-Effects upon Vegetable Life.-Effects upon Animal Life.-Approach of the Rainy Season.-Revival of Vegetable and Animal Life.-Vast Migrations of Animals.-The Pampas: Horses and Cattle in the New World.-Effects of their Introduction upon the Character of the Population.-The Mauritia Palm.-Living in the Tree-tops.-The Grand Chaco.-Its Indian Inhabitants.-The Guachos.-The Lasso and Bolas.-The Plains of Southern Africa: Thorny Bushes.-Excessive Droughts.-A Great Hunting Ground.-Species of Game.-Vegetation -Watery Tubers.-Escu'Ent Gourds.-Possibility of Wells.-Water-Pits in the Kalahari.Mode of Pumping Up the Water-Livingstone's Theory of Water-Making Ants.-More Probable Explanation.-Inhabitants of Southern Africa.-The Lake Region of Equatorial Africa: Little Known.-Explorations of Livingstone and Burton.-Speke's Journey.-His Notices of the Country.-Moderate and Equable Temperature.-The Inhabitants.-Characteristics of a Real Desert.-The Atacama of Peru: Its Arid Character.-The Mule the Ship of this Desert.-The Australian Desert: Its Utter Desolation.-Sturt's Exploration.Leichardt.-Lost Rivers.-The Sahara: Extent and General Characteristics.-The Capital of Fezzan.-Perilous Adventure of Barth.-Plains and Hills.-Oases.-Luxuriant Vegetation of the Oases.-Contrasts of Light and Shade.-The Khamsin or Simoom.-Animals and Reptiles.-The Ostrich and its Chase.-Fluctuations of Animal and Vegetable Life according to the Seasons, . . . . . . . . . . . . . . . . . . . . . . 499

\section{CHAPTER IV.}

TROPICAL FORESTS.-VALLEY OF THE AMAZON.

Characteristics of the Tropical Forests.-Variety of Trees and Plants.-Aspect During the Rainy Season.-Beauty After the Rainy Season.-A Morning Concert.-Repose at Noon.Awakening at Evening.-Nocturnal Voices of the Forest.-The Amazon: Course of the River.-Size of its Basin.-The Tide at its Mouth.-Rising of the River.-Igaripes, or CanoePaths.-Inundations of the Amazon.-Vast Variety of its Vegetation.-Fishes.-Agassiz's Specimens.-Alligators and Turtles.-Turtle-Hunting._Insects.-Ants._Butterflies.-Spiders.-Lizards.-Frogs and Toads.-Snakes._Paucity of Mammalia.-The Jaguar.-Scantiness of Human Population.-Indian Tribes.-Mundurcu Tattooing.-Travelers' Accounts of the Tribes.-Men with Tails.-Orton's Summary of their Character.-His Own Experience Favorable.-He finds them Honest and Peaceable.-Agassiz's Notices of the Indians. -Their Familiarity with Animals and Plants.-Whites._Negroes.-Mixed Breeds._Agassiz and Orton on the Capacity of Amazonia, . . . . . . . . . . . . . . . . 514

\section{CHAPTEP V.}

CHARACTERISTIC FORMS OF TROPICAL VEgETATION.

General Features of Tropical Forests.-Number of Species of Plants.-The Baobab.-Its Gigantic Size.-Age of the Great Trees.-Dragon-Trees.-The Great Dragon-Tree of Orotava.-The Sycamore.-The Banyan.-The Sacred Bo-Tree.-The Oldest Historical Tree.-The Teak.-The Satin-wood.-The Sandal Tree.-The Ceiba.-The Mahogany Tree-The Mora.-The Guadua.-Bamboos.-The Aloe-The Agave.-The Cactus.-The Screw Pine.-Mimosas.-Lianas._Climbing Trees.-Epiphytes.-Water Plants.-Buttressed Trees.-Trees with Fantastic Roots.-Mangroves.-Marsh Forests. -Palms.-The Cocoa Palm.-The Sago Palm.-The Saguer Palm.-The Areca Palm.The Palmyra Palm.-The Talipot Palm.-Ratans.-The Date Palm.-Oil Palms.-Variety of Size, Form, Foliage and Fruit-Future Commercial Value of the Palm, . . . . . . . 525 


\section{CHAPTER VI.}

THE CHIEF NUTRITIV PLANTS OF THE TROPICAL WORLD.

Rice.-Aspects of Rice-Fields at Different Seasons.-The Rice-Fields of Ceylon.-Ladang and Sawa Rice.-Rice in South Carolina.-The Rice-Bird.-Paddy.-Maize.-When first brought to Europe.-Appearance of the Plant.-Its Enormous Productiveness.-Freedom from Disease.-Wide Extent of its Cultivation.-Benjamin Franklin's Account of Maize.Millet.-The Bread-Fruit.-Its Taste.-Modes of Cooking.-The Banana and Plantain.Their Great Productiveness.-The Sago Palm.-Manufacture of Sago.- Sago Bread.Cheap Living.-A Siesta and Starvation.-The Cassava.-Yams.-The Sweet Potato. -Arrow Root.-The Taro Root.-Tropical Fruits.-The Chirimoya.-The Litchi.-The Mangosteen.-The Mango.-The Durion.-Its Taste and Smell.-Large Fruit on Tall Trees, ........................................ Page 545

\section{CHAPTER VII.}

SUGAR-COFFEE-CHOCOLATE-COCA-SPICES.

Sugar: Its Importance.-The Home of the Sugar-Cane.-Ancient Theories about Sugar.-The Introduction of the Cane into Europe and America.-Characteristics of the Plant.-Made of Cultivation.-Coffee: Its Home.--Introduction into Egypt and Europe, and elsewhere.Present Coffee Countries.-Coffee Culture in Brazil.-Agassiz's Description of a Coffee Estate.-The West Indies and Ceylon.-The Coffee-Plant--Methods of Preparing the Berries.-The Enemies of the Plant.-The Golunda.-The Coffee Bug.-The Coffee Moth. -Cacao, or Chocolate: Its Culture and Preparation.-Coca: Description of the Plant.-Mode of its Use.-Its Effects.-Indian superstitions connected with it.-Cinnamon: Known to the Ancients.-Cinnamon in Ceylon.-Mode of Culture and Preparation.-General Account of this Spice:-Nutmegs and Cloves.-Enormities of the Dutch Monopoly.-Pepper.Pimento.-Ginger, . . . . . . . . . . . . . . . . . . . . . . . 559

\section{CHAPTER VIII.}

INSECTS.

Multitude of Tropical Insects.-Beetles._Dragon Flies._Leaf Moths.-The Leaf Butterfly.Fire Flies.-Insect Plagues: Mosquitoes._Chigoes, or Jiggers.-The Filaria Medinensis.The Bête Rouge.-Ticks._Land-Leeches.-The Tsetsé Fly.-The Tsalt-Salya Locusts.Cockroaches.-Enemies of the Cockroach.-Useful Insects: The Silk-Worm.-The Cochineal Insect.-The Gum-Lac Insect.-Edible and Ornamental Beetles, . . . . . . . . . . . 581

\section{CHAPTER IX.}

$$
\text { ANTS-TERMITES-ANT-EATERS-SPIDERS-SCORPIONS. }
$$

Ants: Vast Numbers of Ants in the Tropical World.-Pain caused by their Bites.-The Ponera Clavata.-The Black Fire-Ant.-The Dimiya of Ceylon.-The Red Ant of Angola.-The Vivagua of the West Indies.-The Umbrella Ant.-Household Plagues.-Troubles of Naturalists.-The Ranger Ants.-The Bashikouay of Western Africa.-House-Building Ants. -Slaveholding Ants.-Aphides, or Plant-Lice.-Insect Cow-Keepers.-Termites : Their Ravages among Books and Furniture.-Their Citadels.-Domestic Economy.-Defensive Warfare.-American Termites.-The Enemies of the Termites.-How to Catch, Cook, and Eat them.-The Marching Termite.-Ant-Eaters: The Great Ant-Bear.--His Mode of Hunting.-Mode of Defense.-Anatomical Structure.-Lesser Ant-Bears.-Manides and Pangolins.-The Aard-Vark.-Armadillos._The Porcupine Ant-Eater.-Spiders: Their Physical Structure.-Their Webs.-Means of Protection.-Mode of Catching their Prey.Maternal Instinct.-Their Enemies.-Uses of Spiders.-Scorpions: Their Aspects and Habits. - Their Venom, . . . . . . . . . . . . . . . . . . . . . . . . 594

\section{CHAPTER $\mathrm{X}$.}

\section{SERPENTS-LIZARDS-FROGS AND TOADS.}

Serpents: Rarity of Venomous Serpents.-Habits and External Characteristics of Serpents.The Labarri.-The Trigonocephalus.-Antidotes to the Poison of Serpents. - Sucking out 
the Venom.-The Poison-Fangs.-The Bush-Master.-The Echidna Ocellata.-Rattlesnakes.-Their Enemy the Hog.-The Cobra de Capello.-The Haje.-The Cerastes.Boas and Pythons.-The Boa-constrictor.-The Water Boa.-Fascination by Snakes.Henderson's Argument against It.-Thorpe's Reasons in its Favor.-Du Chaillu on the Subject.-Enemies of Serpents.-The Secretary Bird.-The Adjutant Bird.-The Mongoos. - Serpents Eating Serpents. - The Locomotion of Serpents. - Anatomy of their Jaws.-A Serpentine Meal.-Pet Serpents.-Tree Snakes.-Water Snakes.-Stories of Enormous Snakes.-Du Chaillu's Big Snake.-Wallace's Bigger One.-Lizards: The Geckoe.-Anatomy of its Feet.-Their Wide Distribution.-The Anolis.-Its Combativeness.-The Chameleon.-Its Habits, Change of Color, and Characteristics.-The Iguana.The Teju.-Water Lizards.-Flying Dragons.-The Basilisk.-Frogs and Toads: The Pipa Frog.-Tree Frogs.-Wallace's Flying Frog.-The Bahia Toad.-The Giant Toad.-The Musical Toad, ........................................... 616

\section{CHAPTER XI.}

\section{ALLIGATORS-CROCODILES-TORTOISES AND TURTLES.}

Alliyators and Crocodiles: Their Habits.-Caymen, Gavials and Crocodiles.-Mode of Seizing their Prey.-Size of Alligators.-Alligators on the Amazon.-Alligator and Crane.-ManEating Alligators.-Their Contests.-Tenacity of Life.-Laying their Eggs.-Tenderness for their Young.-Their Enemies.-Torpidity in the Dry Season.-“Playing 'Possum."Tortoises and Turtles: The Galapago Islands.-The Elephantine Tortoise.-Rate of Traveling.-Marsh Tortoises.-Manufacture of Tortoise Oil.-Turtles on the Amazon.-SeaTurtles.-Their Enemies.-Modes of Capturing Turtles.-The Green Turtle.-The Hawksbill Turtle.-Barbarous Modes of Removing the Shell, and Selling the Meat.-The Coriaceous Turtle, ..................................... 635

\section{CHAPTER XII.}

BIRD-LIFE IN THE TROPICAL WORLD.

Difficulties of the Subject.-Wide Range of Birds.-The Toucan.-Humming-Birds.-Cotingas.-The Campanero, or Bell-Bird.-The Realejo, or Organ-Bird.-The Manakins.-The Cock of the Rock.-The Troopials.-The Baltimore Oriole.-The Cassiques.-The Mock. ing-Bird.-The Toropishu._The Tunqui.-Goat-Suckers.-The Cilgero.-Flamingos.The Ibis.-Spoon-Bills.--Birds of the New and the Old World.-Sun-Birds.-Honey-Eat. ers. - The Ocellated Turkey. - The Lyre-Bird. - Birds of Paradise. - Fables respecting them.-Their Character and Habits.-Their Dancing-Parties.-Mode of Shooting and Snaring them.-The Australian Bower-Bird.-The Brush-Turkey.-The Adjutant.-The Copper-smith.-The Indian Baya.-The Tailor-Bird.-The Grosbeak.-The Korwé.Parrots.-The Brazilian Love-Parrot.-Their Powers of Mimicry._Cockatoos.-Macaws. -The Ara.-Paroquets.-The Ostrich.-His Swiftness of Foot.-Modes of Capturing it.Stratagems to Save its Young.-Its Enemies.-Its Young.-Resemblance to the Camel.Its Powers of Digestion.-Uses of its Eggs.-The Rheas.-The Cassowary.-The Emu, 645

\section{CHAPTER XIII.}

THE CLIMBERS: BATS, SLOTHS, AND SIMIXE.

Bats: Their Wonderful Organization.-The Fox-Bat-Eaten by the Malays.-Vampire Bats - Their Blood-sucking Propensities.-The Horseshoe Bat.-The Nycteribia.-The Flying Squirrel.-The Galeopithecus.-The Anomalurus.-The Sloth: Pitiful Description given of Him.-His beautiful Organization for his peculiar Mode of Life.-His rapid Movements in the Trees-His Means of Defense.-His Tenacity of Life.-The Unau-The Ai.Gigantic Primeval Sloths.-Monkeys: Good Climbers, but bad Walkers.-Imperfectly known to the Ancients.-Similitudes and Differences between Man and Apes.-The Chimpanzee.-The Gorilla.-Du Chaillu's First Encounter with a Gorilla.-The Gorilla and her Young.-The Orang-Utan, or Mias.-Wallace's Accounts of Shooting the Orang.-Their Tenacity of Life.-Size of the Orang.-The Orang as a Combatant.-The Orang fighting 
the Crocodile and Python.-Habits of the Orang.-Wallace's Young Pet Orang.-The Gibbons.-Monkeys of the Old and New Worlds.-The Semnopitheci.-The Proboscis Monkey.-The Sacred Ape of the Hindus.-The Cercopitheci.-The Magots.-The Cynocephali, or Baboons.-The Maimon.-The Great Baboon of Senegal.-The Derryas.-The Loris.-Monkeys of the New World.-Monkeys Distinguished by their Tails and Teeth.The Wourali Poison.-The Indian Blow Pipe.-Mildness of American Monkeys.-The Howling Monkeys.-The Spider-Monkeys.-The Fox-tail Monkeys.-The Saimaris.-Nocturnal Monkeys.-The Domesticated Nocturnals.-The Squirrel-Monkey, . . . . Page 669

\section{CHAPTER XIV.}

TROPICAL BEASTS AND BIRDS OF PREY.

Variety of Carnivorous Creatures.-Birds of Prey: The Condor.-His Marvelous Flight.-His Cowardice.-Modes of Capturing them.-The Turkey-Buzzard, or Carrion Vulture.-The King of the Vultures.-The Urubu.-Capable of Domestication.-The Harpy Eagle.The Sociable Vulture.-The Bacha.-The Fishing Eagle.-The Musical Sparrow-Hawk.The Secretary Eagle.-Beasts of Prey: The Lion.-Fictitious Character ascribed to him. -Mode of Seizing his Prey.-Lions and Giraffe.-Lion and Hottentot.-Andersson and a Lion.-Livingstone's narrow Escape.-Lion-Hunting in the Atlas.-By the Bushmen.-Capturing their Young.-Former and present Range of the Lion.-Lion and Rhinoceros.Livingstone's Estimate of the Lion.-The Tiger.-Their Ravages in Java.-Wide Range of the Tiger.-Tiger-Hunting in India.-Escape from a Tiger--Animals announcing the Approach of a Tiger.-Turtle-hunting Tigers.-The Panther and Leopard.-The Cheetah.The Hyena.-The Spotted and Brown Hyenas.-The Felidæ of New World.-The Jaguar. - Hunting the Jaguar.-The Cougar, or Puma.-The Ocelot.-The Jaguarandi.-The

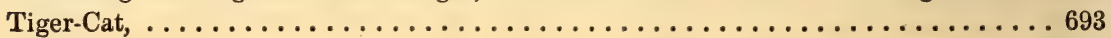

\section{CHAPTER XV.}

THE ELEPHANT-RHINOCEROS-HIPPOPOTAMUS-CAMEL-ZEBRA.

The Great Tropical Pachydermati.-The Elephant: Difference between the tame and wild Elephant.-His Instinctive Timidity.-Acuteness of His Senses.-His Sagacity in Climbing Hills.-His wonderful Trunk.-His Tusks.-Elephant Herds.-The Rogue, or Solitary Elephant.-The Asiatic and African Species.-The African Elephant tamed in Ancient Times. -Present Range of the African Elephant.-Native Modes of Hunting the African Elephant. - The Elephant and the Rifle.-Perils of Elephant-Hunters.-Elephant-Hunting in Abyssinia. -The Asiatic Elephant.-Elephant-Hunting in Ceylon.-The Panickeas, or Native ElephantHunters.-Elephantine Head-Work.-Obstinate Brutes.-The Rhinoceros: Range and Character of the Rhinoceros.-Two Species, the Black and the White.-Size of the Rhinoceros.Acuteness of its Senses.-Its winged Attendant.-Its parental Affection.-Its nocturnal Habits.-Modes of Hunting the Rhinoceros.-The One-Horned or Indian Rhinoceros.-The Two-Horned Rhinoceros of the Malay Archipelago.-Rhinoceros-Paths in Java.-The Hippopotamus: Is the Hippopotamus the Behemoth of Job?-Habits of the Hippopotamus.Its uncouth Aspect.-Rogue Hippopotami--Intelligence of the Hippopotamus.-Uses of its Skin and Teeth.-Mode of Killing the Hippopotamus.-The Camel: Its Adaptation to the Tropical Sand-Wastes.-Its Physical Organization adapted to its Mode of Life.-Its Foot and its Stomach.-Its Desert Home.-The Camel and the Arab.-The Two-Humped and One-Humped Camels.-The Camel an immemorial Serf.-Its Aspect and Temper.-The

Giraffe: Beauty of the Giraffe.-Its Means of Defense.-Its special Organization.-The Lion and the Giraffe.-The Giraffe known to the Ancients.-Zebra and Quaggas: Their Abundance in Southern Africa.-Distinction Between the Quagga and the Zebra.-Capacity for Domestication.-Their Union for Defense.-The Gnu, the Quagga, and the Zebra.-The Zebra the Tiger-Horse of the Ancients.-The African Boar.-The Malayan Babirusa.Finis, ..................................... 712 


\section{LIST OF ILLUSTRATIONS.}

1. PAGR.

2. The Tundra of Siberia, • • ' 11

3. Indian Summer Encampment, Alaska, 18

4. Rocks and Ice, . . . . . . . 20

5. Coast of Labrador, . . . . . . . 21

6. Coast of Norway, . . . . . . 22

7. Arctic Forest, . . . . . . . 23

8. Verge of Forest Region, . . . . $\quad$. 24

9. Forest Conflagration, . . . . . . 26

10. Arctic Clothing, . . . . . . . 29

11. Arctic Moonlight, . . . . . 30

12. Aurora seen in Norway, . . . . 31

13. Aurora seen in Greenland, . . . . 32

14. Group of Reindeer, . . . . . 35

15. Flks, 39

16. The Musk-ox, . . . . . . . . 40

17. Argali, . . . . . . . . . . 41

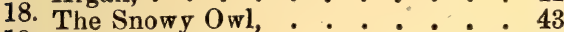

19. Bernide Goose, . . . . . . 44

20. The Sea-eagle, . . . . . . . . 44

21. Arctic Navigation, . . . . . . . 45

22. Among Hummocks, . . . . . . 46

23. Drifting on the Ice, . . . . . 47

24. Forms of Icebergs, . . . . . . . 47

25. Gothic Icebergs,. . . . . . . . 48

26. Pinnacle Icebergs, . . . . . . . 48

27. Icebergs Aground, . . . . . 49

28. Icebergs and Glacier, Frobisher Bay, 51

29. Glacier, Bute Inlet, . . . . 52

30. Scaling an Iceberg, . . . . : 53

31. An Arctic Channel, . . . . . 56

32. Open Water, . . . . . . 57

33. Glacier Discharging, . . . . . 58

34. The Whale, . . . . . . . . 60

35. The Narwhal, .. .0 .061$

36. Walruses on the Ice, . . . . . . 63

37. Home of the Polar Bear, . . . . 66

38. The Gull, . . . . . . . . . 67

39. Lava-fields, $\cdot 08$

40. Effigy in Lava, . . . . . . . . 70

41. The Strokkr, . . . . 72

42. Entrance to the Almannagja, . . . 73

43. The Almannagja, . . . . . . . 74

44. The Hrafnagja, . . . . . : 75

45. The Tintron Rock, . . . . . . . 75

46. Fall of the Oxeraa,. . . . . . 76

47. Icelandic Horses, . . . . . . . 81

48. Shooting Reindeer,. . . . . . 82

49. The Eider-duck, . . . . . . . 83

50. The Jyrfalcon, . . . . . . 85

51. The Giant Auk, . . . . . . . 86

52. Cathedral at Reykjavik, . . . . . 89

53. Thingvalla, Lögberg and Almannagja, 92

54. Reykjavik, the Capital of Iceland, 98

55. Governor's Residence, Reykjavik, . 99

56. Icelandic Houses, . . . . . 103
57. Church at Thingvalla, . . . . 105

58. The Pastor's House, Thingvalla, 106

59. The Pastor of Thingvalla,. . . . 107

60. Bridge River, Iceland, . . . . . 111

61. Icelandic Bog, . . . . . . . 113

62. Coast of Iceland, . . . . . . . 114

63. Westman Isles, . . . . . . 115

64. Home of Sea-birds, . . . . 117

65. Fishing in Norway, . . . . . . 120

66. Norwegian Farm, . . . . . . . 122

67. Steaming Along the Coast, . . . 123

68 The Puffin, . . . . . . . 124

69. The Dovrefjeld, . . . . . . . 127

70. Midnight Sun off Spitzbergen, . . 131

71. Magdalena Bay, Spitzbergen, . . . 134

72. Burial in Spitzbergen, . . . . 139

73. Arctic Fox, . . . . . . . : 140

74. Chase of the Walrus, 143

75. A glimpse of Jan Meyen's Island, . 145

76. A Samoiede Priest, . . . . . 179

77. Banks of the Irtysch, . . . . 185

78. Group of Kirghis, : : . . 188

79. View of Tagilsk, . . . . . . . 191

80. The Beach at Nicolayevsk, . . 196

81. On the Amoor, . . . . . . . 197

82. Village on the Amoor, . . . . 198

83. Koriak Yourt, . . . . . . . . 199

84. Kamchatka Sables, . . . . . 201

85. Tartar Encampment, . . . . . 204

86. Siberian Peasant,. . . . . . 207

87. View of Irkutsk, . . . . . . 209

88. A Jakut Village, . $: \quad * \quad \div 229$

89. Bering's Monument at Petropavlosk, 248

90. Church at Petropavlosk, . . . 254

91. View of Petropavlosk, . . . . . 257

92. Dogs Fishing, . . . . . . . 259

93. Dog-team, . . . . . . . . . 259

94. Dogs Towing Boat, - . 260

95. Frame-work of Tchuktchi House, . 262

96. Tehuktchi Canoe,. . . . . . 263

97. Tchuktchi Pipe, . . . . . . . 264

98. An Aleut, . . . . . . . . 268

99. View of Sitka, . . . . . . 270

100. A Baidar, . . . . . . . . 272

101. Fort St. Michael, . . . . . . 277

102. The Frozen Yukon, . . . . 279

103. Under-ground House, . . . . . 280

104. Fish-traps on the Yukon, . $: . \quad 281$

105. Aurora at Nulato, . . . . . . . 282

106. Breaking up of the Ice, . . . . 283

107. Fort Yukon, . . . . . . . 285

108. A Deer Corral, .

109. Lip Ornaments, . . . . . . . 287

110. A Baidar, . . . . . . . . 288

111. Four-post Coffin, . . . . . . . . 288

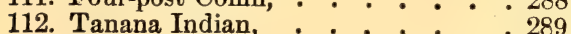


113. Winter Hut of Hunters, PAGE.

114. Fort Edmonton, North Saskatchewan, . . . . . . . . 311

115. Trader's Camp, . . . . . . . 312

116. Swamp formed by Deserted Beaver Dam, . . . . . . . . 314 117. Hunting Bison in the Snow, . . 319

118. Herd of Bison, . . . . . . . . 320

119. Driving Bison over a Precipice,. . 321

120. Watching for Crees, . . . . . 322

121. A Cree Village, . . . . . . . 324

122. The Albatross, . . . . . . . 396

123. Strait of Magellan, : . . . 408

124. A Highway of Commerce, . . . 416

125. Patagonians, . . . . . . . 417

126. Coast of Fuegia, . . . . . . 425

127. Fuegian Traders, . . . . . . . 427

128. A Fuegian and his Food, . . . . 429

129. Starvation Beach,. . . . . . . 432

130. Surveying in Greenland, . . . . 433

131. Hall and Companions, in Innuit Costume, . . . . . . . . 434

132. Kudlago, . . . . . . . . . . 436

133. Greenland Currency, . . . . 437

134. Woman and Child. (Drawn and Engraved by an Innuit,) . . . . 438

135. Festival of the Birthday of the King of Denmark, . . . . . . 439

136. Preparing Boot-soles, . . . . . 440

137. Wreck of the Rescue, . . . . . 441

138. The George Henry laid up for the Winter,

139. Storm-boun

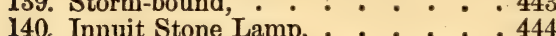

141. Fighting for Food, . . . . . . 445

142. Through the Snow, . . . 446

143. Waiting by a Seal-hole,. . . . . 447

144. Looking for Seals, . . . . . 448

145. Innuit Strategy to Capture a Seal, . 449

146. Seal-hole and Igloo, . . . . . 450

147. Waiting for a Blow, . . . . . 450

148. Dog and Seal,. . . . . . 451

149. Spearing through the Snow, . . 452

150. Dogs and Bear, . . . . . . . 453

151. Barbekark and the Reindeer, . . . 454

152. Head of Reindeer, . . . . . 454
153. Spearing the Walrus, pAar.

Walrus, . . . . 455

154. Innuit Igloos, . . • . . . . .456

155. Walrus Skull and Tusks, . . . 457

156. The Woman's Knife, •. . . 457

157. Innuit Implements, . . . . . 458

158. Finding the Dead, . . . . . 461

159. Innuit Summer Village, . 4462

160. Returning to the Ship, . . . 463

161. Over the Ice, . . . . . . .464

162. The Frozen Sailor, . . . . . .465

163. Farewell of the Innuits, . . . . 467

164. Elephants Tied Up, . . . . . . 470

165. Waterspout,. . . . . . . . 471

166. The Puna of Peru, . . . . . . 481

167. Fountain of the Incas, . . . . 488

168. Ascending the Andes, . . . . . 490

169. Cattle-Hunting on the Pampas, . . 501

170. Natives of the Kalahari, . . . . 503

171. Igaripe, or Canoe-Path, . . . . 514

172. Forest on Panama Railroad, . . . 526

173. Baobab Tree, with the Grave of

Mrs. Livingston, . . . . . 528

174. Avenue of Palms, Rio de Janeiro, . 539

175. Palms on the Middle Amazon, . . 543

I76. Manufacture of Sago, . . . . 552

177. Siesta on the Amazon, . . . . . 554

178. Robber-Crab of the Malay Archipelago, . . . . . . . 580

179. Leaf Butterfly, . . . . . . 588

180. Mosquito, Natural Size and Magnified, . . . . . . . . 585

181. A Termite Citadel, . . . 603

182 Aard Vark or Earth-Hog, . . . . 609

183. Rattlesnake Charming a Rabbit, . 622

184. Snake Charming a Squirrel, . . . 624

185. Killing the Snake-Central Africa, 628

186. Alligator and Crane, . . . . . . 637

187. Natives of Aru shooting the great

Bird of Paradise, . . . . . 654

188. African Weaver-Birds, . : . 660

189. Female Gorilla and Young, . . . 680

190. Female Orang-Outang, . . . . . 681

191. Lions Pulling Down a Giraffe, . . 699

192. An Obstinate Brute, . . . . . 720

193. A Little Head-Work, . . 721

194. Chase of the Wild Boar, . : . 735

\section{ILLUSTRATIONS OF ADDITIONAL CHAPTERS.}

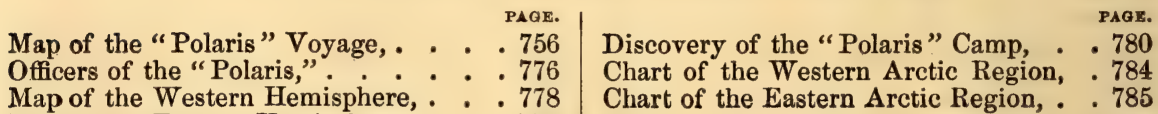




\section{THE POLAR WORLD.}

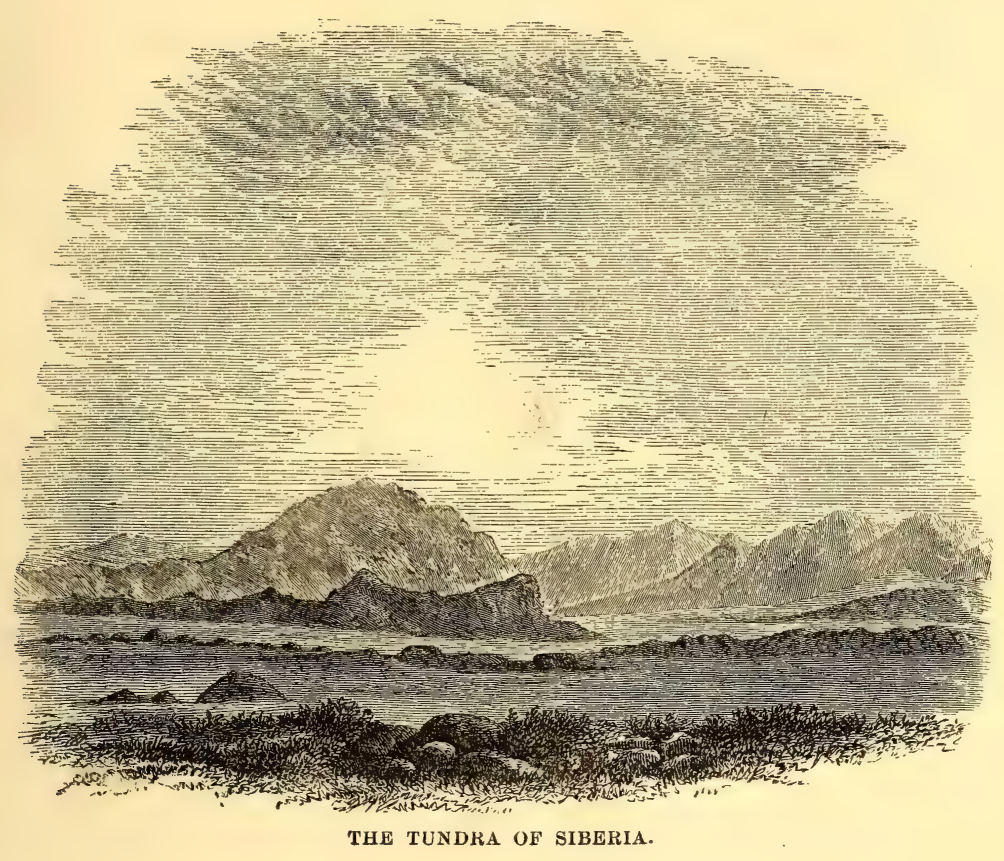

CHAPTER I.

\section{THE ARCTIC LANDS.}

The barren Grounds or Tundri.-Abundance of animal Life on the Tundri in Summer.-Their Silence and Desolation in Winter.-Protection afforded to Vegetation by the Snow.-Flower-growth in the highest Latitudes.-Character of Tundra Vegetation.-Southern Boundary-line of the barren Grounds.-Their Extent.-The forest Zone.-Arctic Trees.-Slowness of their Growth.-Monotony of the Northern Forests.-Mosquitoes.-The various Causes which determine the Severity of an Arctic Climate.-Insular and Continental Position.-Currents.-Winds._Extremes of Cold observed by Sir E. Belcher and Dr. Kane.-How is Man able to support the Rigors of an Arctic Winter?Proofs of a milder Climate having once reigned in the Arctic Regions.-Its Cause according to Dr. Oswald Heer.-Peculiar Beauties of the Arctic Regions.-Sunset.-Long lunar Nights.-The Aurora.

1 GLANCE at a map of the Arctic regions shows us that many of the A rivers belonging to the three continents-Europe, Asia, America-discharge their waters into the Polar Ocean or its tributary bays. The territories drained by these streams, some of which (such as the Mackenzie, the Yukon, the Lena, the Yenisei, and the Obi) rank among the giant rivers of the earth, form, along with the islands within or near the Arctic circle, the vast region over which the frost-king reigns supreme.

Man styles himself the lord of the earth, and may with some justice lay claim to the title in more genial lands where, armed with the plough, he compels the soil to yield him a variety of fruits; but in those desolate tracts 
which are winter-bound during the greater part of the year, he is generally a mere wanderer over its surface-a hunter, a fisherman, or a herdsman-and but few small settlements, separated from each other by immense deserts, give proof of his having made some weak attempts to establish a footing.

It is difficult to determine with precision the limits of the Arctic lands, since many countries situated as low as latitude $60^{\circ}$ or even $50^{\circ}$, such as South Greenland, Labrador, Alaska, Kamchatka, or the country about Lake Raikal, have in their climate and productions a decidedly Arctic character, while others of a far more northern position, such as the coast of Norway, enjoy even in winter a remarkably mild temperature. But they are naturally divided into two principal and well-marked zones-that of the forests, and that of the treeless wastes.

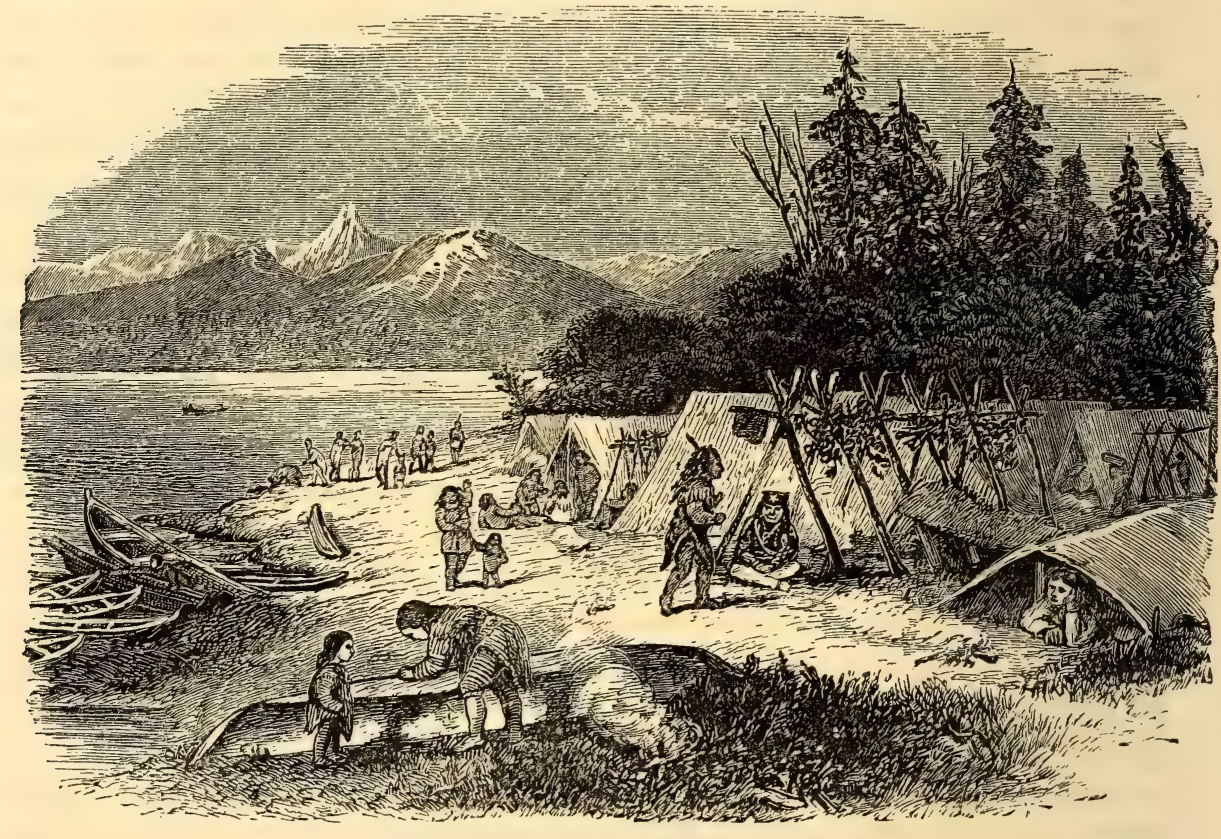

INDIAN SUMMER ENCAMPMENT, ALASKA.

The latter, comprising the islands within the Arctic Circle, form a belt, more or less broad, bounded by the continental shores of the North Polar seas, and gradually merging toward the south into the forest-region, which encircles them with a garland of evergreen coniferæ. This treeless zone bears the name of the "barren grounds," or the "barrens," in North America, and of "tundri" in Siberia and European Russia. Its want of trees is caused not so much by its high northern latitude as by the cold sea-winds which sweep unchecked over the islands or the flat coast-lands of the Polar Ocean, and for miles and miles compel even the hardiest plant to crouch before the blast and creep along the ground.

Nothing can be more melancholy than the aspect of the bouudless morasses or arid wastes of the tundri. Dingy mosses and gray lichens form the chief 
vegetation, and a few scanty grasses or dwarfish flowers that may have found a refuge in some more sheltered spot are unable to relieve the dull monotony of the scene.

In winter, when animal life has mostly retreated to the south or sought a refuge in burrows or in caves, an awful silence, interrupted only by the hooting of a snow-owl or the yelping of a fox, reigns over their vast expanse; but in spring, when the brown earth reappears from under the melted snow and the swamps begin to thaw, enormous flights of wild birds appear upon the scene and enliven it for a few months. An admirable instinct leads their winged legions from distant climes to the Arctic wildernesses, where in the morasses or lakes, on the banks of the rivers, on the flat strands, or along the fish-teeming coasts, they find an abundance of food, and where at the same time they can with greater security build their nests and rear their young. Some remain on the skirts of the forest-region; others, flying farther northward, lay their eggs upon the naked tundra. Eagles and hawks follow the traces of the natatorial and strand birds; troops of ptarmigans roam among the stunted bushes; and when the sun shines, the finch or the snow-bunting warbles his merry note.

While thus the warmth of summer attracts hosts of migratory birds to the Arctic wildernesses, shoals of salmon and sturgeons enter the rivers in obedience to the instinct that forces them to quic the seas and to swim stream upward, for the purpose of depositing their spawn in the tranquil sweet waters of the stream or lake. About this time also the reindeer leaves the forests to feed on the herbs and lichens of the tundra, and to seek along the shores fanned by the cooled sea-breeze some protection against the attacks of the stinging flies that rise in myriads from the swamps. Thus during several months the tundra presents an animated scene, in which man also plays his part. The birds of the air, the fishes of the water, the beasts of the earth, are all obliged to pay their tribute to his various wants, to appease his hunger, to clothe his body, or to gratify his greed of gain.

But as soon as the first frosts of September announce the approach of winter, all animals, with but few exceptions, hasten to leave a region where the sources of life must soon fail. The geese, ducks, and swans return in dense flocks to the south; the strand-birds seek in some lower latitude a softer soil which allows their sharp beak to seize a burrowing prey; the water-fowl forsake the bays and channels that will soon be blocked up with ice; the reindeer once more return to the forest, and in a short time nothing is left that can induce man to prolong his stay in the treeless plain. Soon a thick mantle of snow covers the hardened earth, the frozen lake, the ice-bound river, and conceals them all-seven, eight, nine months long-under its monotonous pall, except where the furious north-east wind sweeps it away and lays bare the naked rock.

This snow, which after it has once fallen persists until the long summer's day has effectually thawed it, protects in an admirable manner the vegetation of the higher latitudes against the cold of the long winter season. For snow is so bad a conductor of heat, that in mid-winter in the high latitude of $78^{\circ}$ 


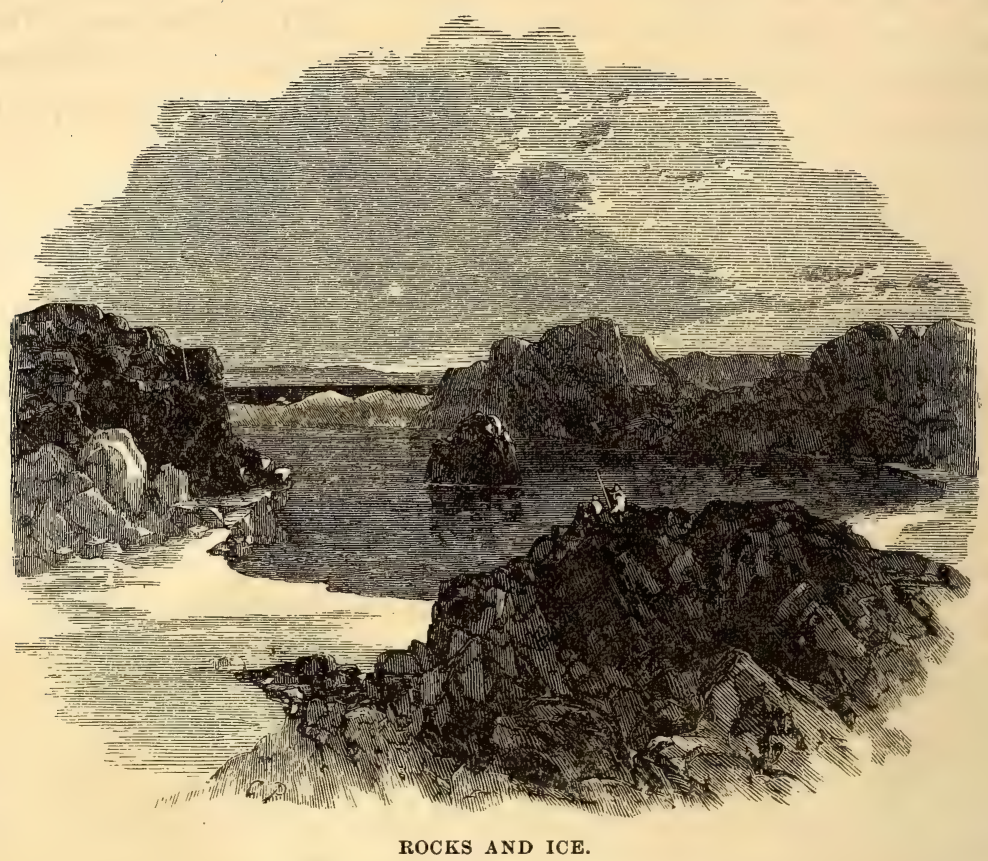

$50^{\prime}$ (Rensselaer Bay), while the surface temperature was as low as $-30^{\circ}$, Kane found at two feet deep a temperature of $-8^{\circ}$, at four feet $+2^{\circ}$, and at eight feet $+26^{\circ}$, or no more than six degrees below the freezing point of water. Thus covered by a warm crystal snow-mantle, the northern plants pass the long winter in a comparatively mild temperature, high enough to maintain their life, while, without, icy blasts-capable of converting mercury into a solid bodyhowl over the naked wilderness; and as the first snow-falls are more cellular and less condensed than the nearly impalpable powder of winter, Kane justly observes that no "eider-down in the cradle of an infant is tucked in more kindly than the sleeping-dress of winter about the feeble plant-life of the Arctic zone." Thanks to this protection, and to the influence of a sun which for months circles above the horizon, and in favorable localities calls forth the powers of vegetation in an incredibly short time, even Washington, Grinnell Land, and Spitzbergen are able to boast of flowers. Morton plucked a crucifer at Cape Constitution ( $80^{\circ} 45^{\prime} \mathrm{N}$. lat.), and, on the banks of Mary Minturn River $\left(78^{\circ} 52^{\prime}\right)$, Kane came across a flower-growth which, though drearily Arctic in its type, was rich in variety and coloring. Amid festuca and other tufted grasses twinkled the purple lychnis and the white star of the chickweed; and, not without its pleasing associations, he recognized a solitary hesperis-the Arctic representative of the wall-flowers of home.

Next to the lichens and mosses, which form the chief vegetation of the treeless zone, the cruciferæ, the grasses, the saxifragas, the caryophyllæ, and the compositæ are the families of plants most largely represented in the barren grounds or tundri. Though vegetation becomes more and more uniform on advancing to the north, yet the number of individual plants does not decrease. 
When the soil is moderately dry, the surface is covered by a dense carpet of lichens (Cornicularice), mixed in damper spots with Icelandic moss. In more tenacious soils, other plants flourish, not however to the exclusion of lichens, except in tracts of meadow ground, which occur in sheltered situations, or in the

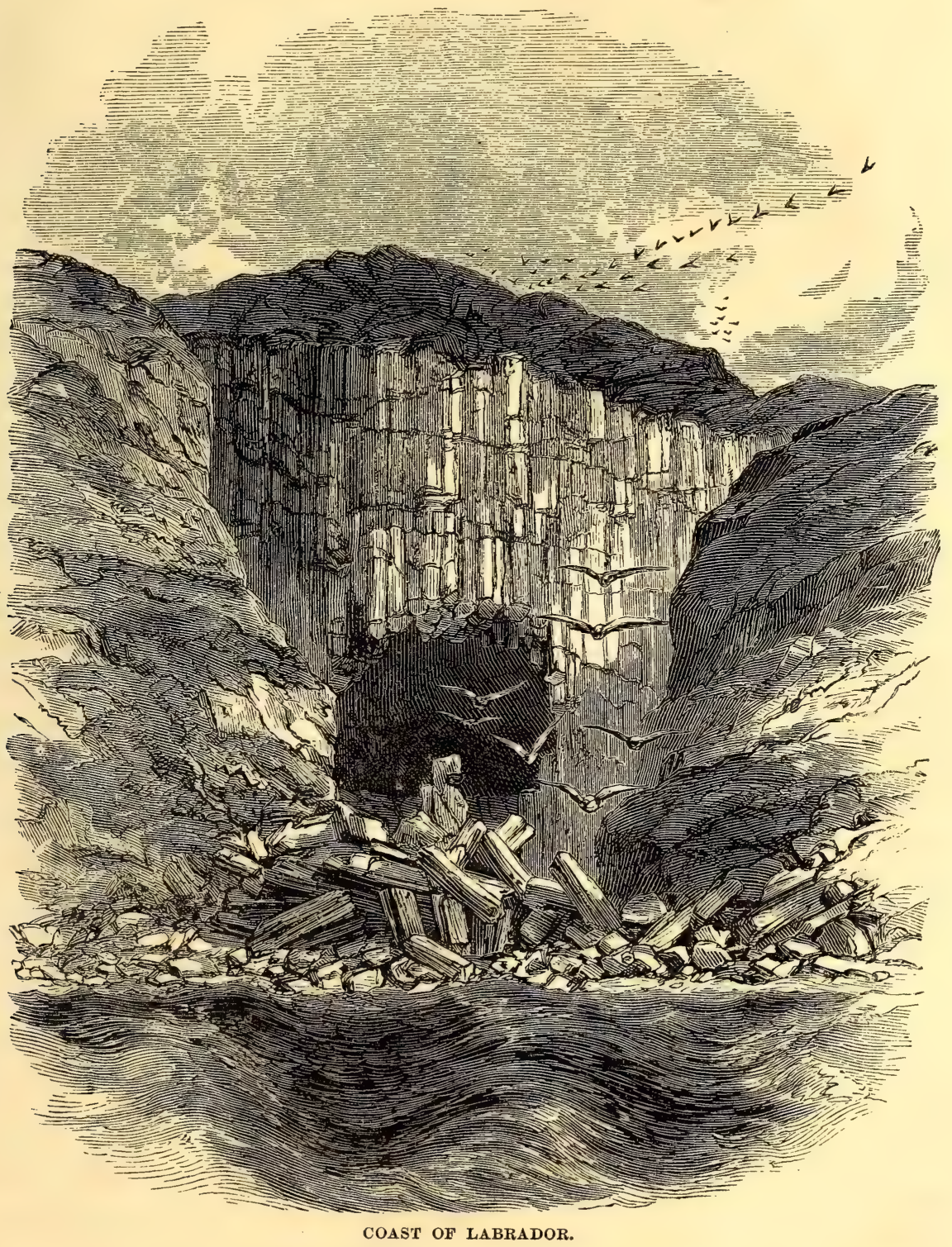

alluvial inundated flats where tall reed-grasses or dwarf willows frequently grow as closely as they can stand.

It may easily be supposed that the boundary-line which separates the tundri from the forest zone is both indistinct and irregular. In some parts where the cold sea-winds have a wider range, the barren grounds encroach consider- 
ably upon the limits of the forests; in others, where the configuration of the land prevents their action, the woods advance farther to the north.

Thus the barren grounds attain their most southerly limit in Labrador, where they descend to latitude $57^{\circ}$, and this is sufficiently explained by the position of that bleak peninsula, bounded on three sides by icy seas, and washed by cold currents from the north. On the opposite coasts of Hudson's Bay they begin about $60^{\circ}$, and thence gradually rise toward the mouth of the Mackenzie, where the forests advance as high as $68^{\circ}$, or even still farther to the north along the low banks of that river. From the Mackenzie the barrens again descend until they reach Bering's Sea in $65^{\circ} \mathrm{N}$. On the opposite or Asiatic shore, in the land of the Tchuktchi, they begin again more to the south, in $63^{\circ}$, thence continually rise as far as the Lena, where Anjou found trees in $71^{\circ} \mathrm{N}$, and then fall again toward the Obi, where the forests do not even reach the Arctic circle. From the Obi the tundri retreat farther and farther to the north, until finally, on the coasts of Norway, in latitude $70^{\circ}$, they terminate with the land itself.

Hence we see that the treeless zone of Europe, Asia, and America occupies a space larger than the whole of Europe. Even the African Sahara, or the Pampas of South America, are inferior in extent to the Siberian tundri. But the possession of a few hundred square miles of fruitful territory on the southwestern frontiers of his vast empire would be of greater value to the Czar than that of those boundless wastes, which are tenanted only by a few wretched pastoral tribes, or some equally wretched fishermen.

The Arctic forest-regions are of a still greater extent than the vast treeless plains which they encircle. When we consiner that they form an almost con-

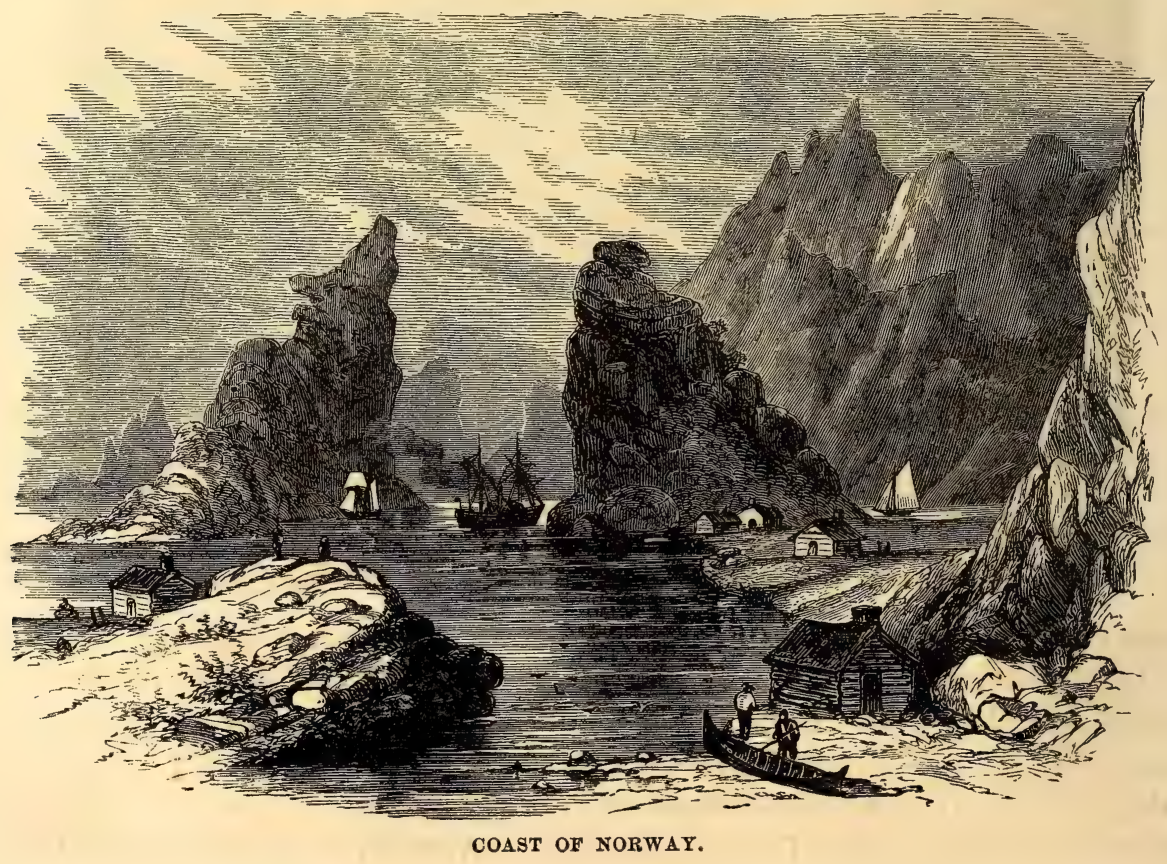




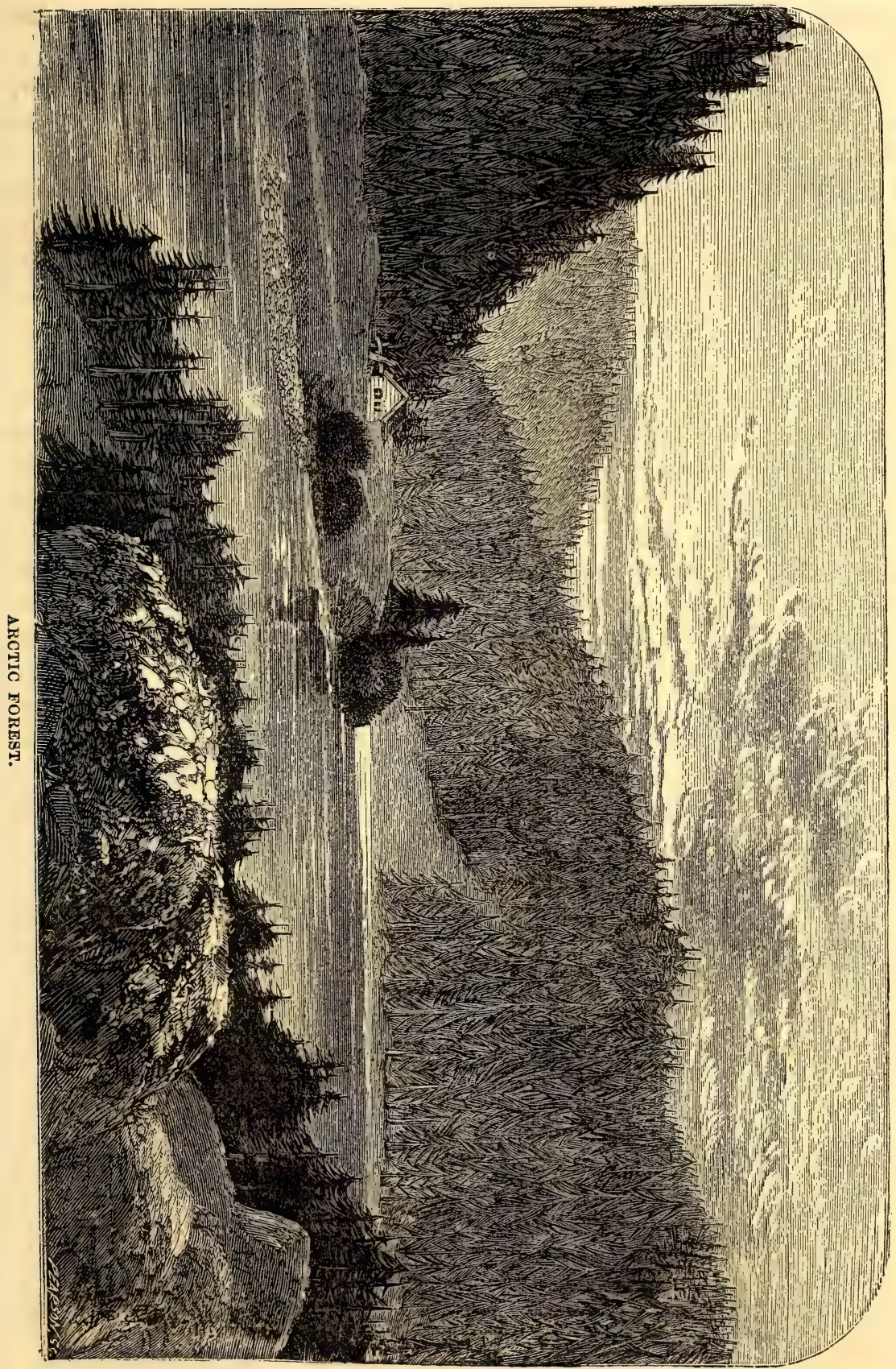

tinuous belt, stretching through three parts of the world, in a breadth of from $15^{\circ}$ to $20^{\circ}$, even the woods of the Amazon, which cover a surface fifteen times greater than that of the United Kingdom, shrink into comparative insignificance. Unlike the tropical forests, which are characterized by an immense variety of trees, these northern woods are almost entirely composed of coniferæ, and one single kind of fir or pine often covers an immense extent of 
ground. The European and Asiatic species differ, however, from those which grow in America.

Thus in the Russian empire and Scandinavia we find the Scotch fir (Pinus sylvestris), the Siberian fir and larch (Abies sibirica, Larix sibirica), the Picea obovata, and the Pinus cembra; while in the Hudson's Bay territories the woods principally consist of the white and black spruce (Abies alba and nigra), the Canadian larch (Larix canadensis, and the gray pine (Pinus banksiana). In both continents birch-trees grow farther to the north than the coniferæ, and the dwarf willows form dense thickets on the shores of every river and lake. Various species of the service-tree, the ash, and the elder are also met with in the Arctic forests; and both under the shelter of the woods and beyond their limits, nature, as if to compensate for the want of fruit-trees, produces in favorable localities an abundance of bilberries, bogberries, cranberries, etc. (Empetrum, Vaccinium), whose fruit is a great boon to man and beast. When congealed by the autumnal frosts, the berries frequently remain hanging on the bushes until the snow melts in the following June, and are then a considerable resource to the flocks of water-fowl migrating to their northern breeding-places, or to the bear awakening from his winter sleep.

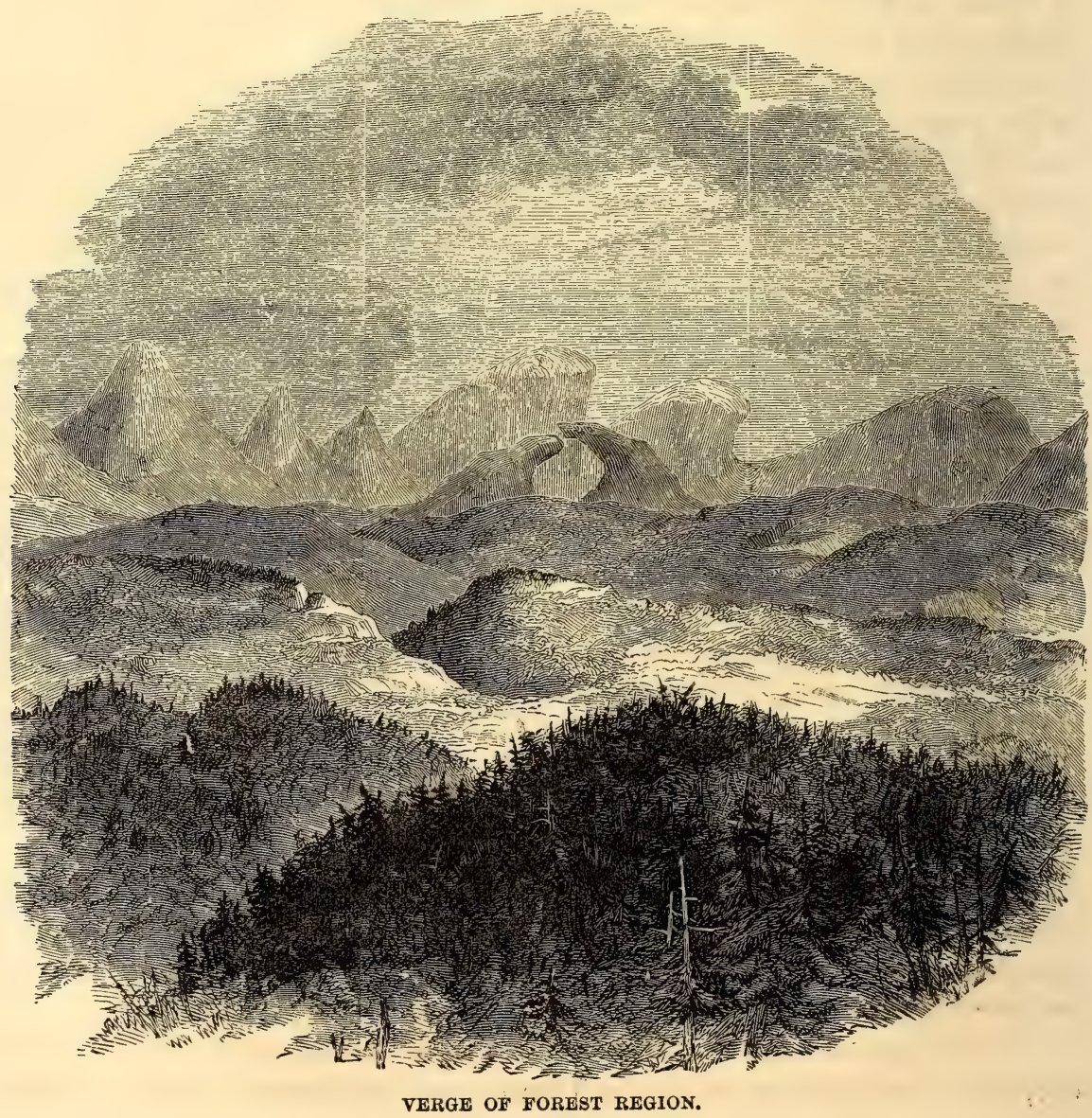


Another distinctive character of the forests of the high latitudes is their apparent youth, so that generally the traveller would hardly suppose them to be more than fifty years, or at most a century old. Their juvenile appearance increases on advancing northward, until suddenly their decrepit age is revealed by the thick bushes of lichens which clothe or hang down from their shrivelled boughs. Farther to the south, large trees are found scattered here and there, but not so numerous as to modify the general appearance of the forest, and even these are mere dwarfs when compared with the gigantic firs of more temperate climates. This phencmenon is sufficiently explained by the shortness of the summer, which, though able to bring forth new shoots, does not last long enough for the formation of wood. Hence the growth of trees becomes slower and slower on advancing to the north; so that on the banks of the Great Bear Lake, for instance, 400 years are necessary for the formation of a trunk not thicker than a man's waist. Toward the confines of the tundra, the woods are reduced to stunted stems, covered with blighted buds that have been unable to develop themselves into branches, and which prove by their numbers how frequently and how vainly they have striven against the wind, until finally the last remnants of arboreal vegetation, vanquished by the blasts of winter, seek refuge under a carpet of lichens and mosses, from which their annual shoots hardly venture to peep forth.

A third peculiarity which distinguishes the forests of the north from those of the tropical world is what may be called their harmless character. There the traveller finds none of those noxious plants whose juices contain a deadly poison, and even thorns and prickles are of rare occurrence. No venomous snake glides through the thicket; no crocodile lurks in the swamp; and the northern beasts of prey-the bear, the lynx, the wolf-are far less dangerous and blood-thirsty than the large felidæ of the torrid zone.

The comparatively small number of animals living in the Arctic forests corresponds with the monotony of their vegetation. Here we should seek in vain for that immense variety of insects, or those troops of gaudy birds which in the Brazilian woods excite the admiration, and not unfrequently cause the despair of the wanderer; here we should in vain expect to hear the clamorous voices that resound in the tropical thickets. No noisy monkeys or quarrelsome parrots settle on the branches of the trees; no shrill cicadæ or melancholy goat-suckers interrupt the solemn stillness of the night; the howl of the hungry wolf, or the hoarse screech of some solitary bird of prey, are almost the only sounds that ever disturb the repose of these awful solitudes. When the tropical hurricane sweeps over the virgin forests, it awakens a thousand voices of alarm; but the Arctic storm, however furionsly it may blow, scarcely calls forth an echo from the dismal shades of the pine-woods of the north.

In one respect only the forests and swamps of the northern regions vie in abundance of animal life with those of the equatorial zone, for the legions of gnats which the short polar summer calls forth from the Arctic morasses are a no less-intolerable plague than the mosquitoes of the tropical marshes.

Though agriculture encroaches but little upon the Arctic woods, yet the agency of man is gradually working a change in their aspect. Large tracts of 
forest are continually wasted by extensive fires, kindled accidentally or intentionally, which spread with rapidity over a wide extent of country, and con-

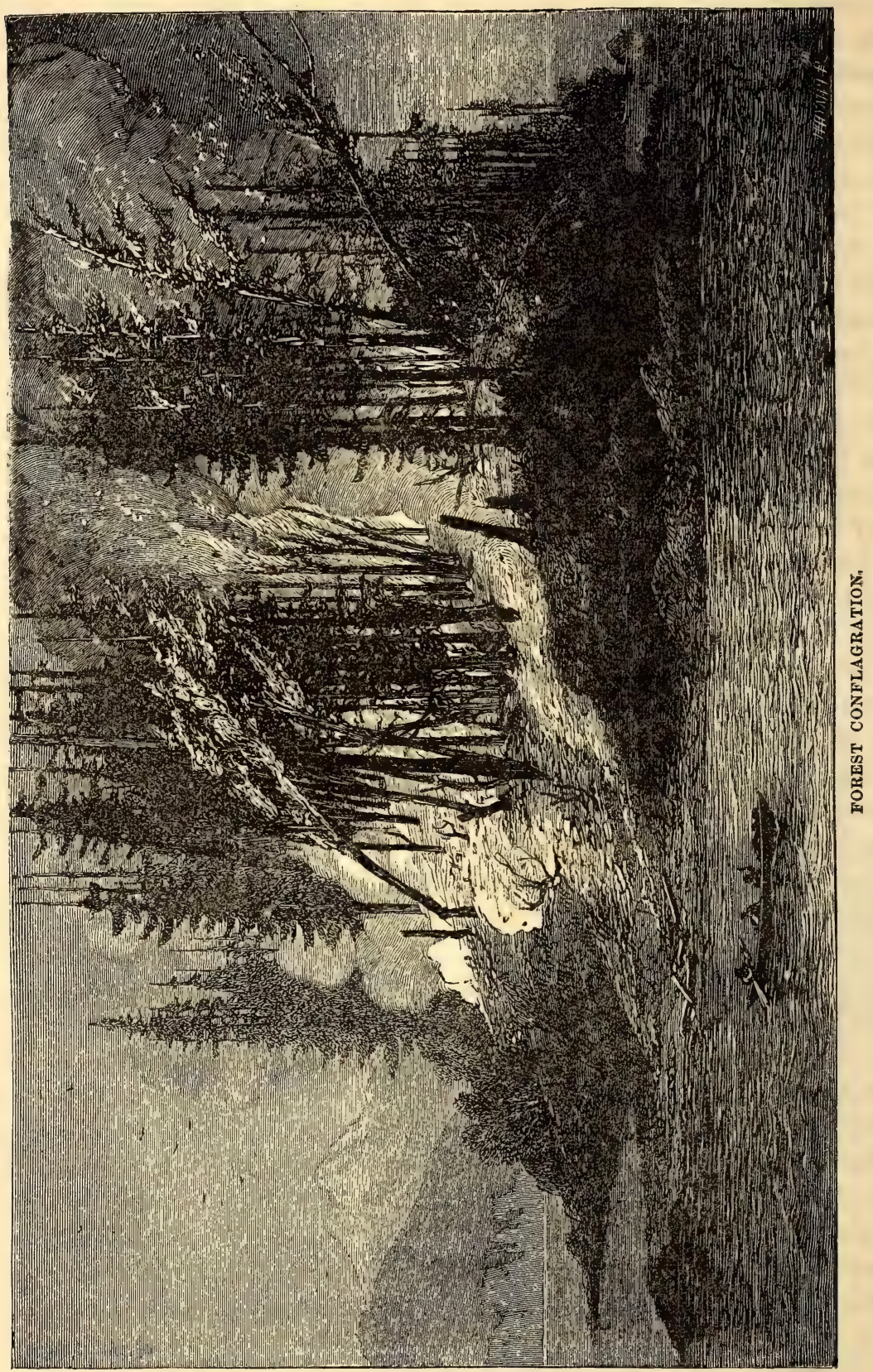

tinue to burn until they are extinguished by a heavy rain. Sooner or later a new growth of timber springs up, but the soil, being generally enriched and saturated with alkali, now no longer brings forth its aboriginal firs, but gives birth to a thicket of beeches (Betula alba) in Asia, or of aspens in America. 
The line of perpetual snow may naturally be expected to descend lower and lower on advancing to the pole, and hence many mountainous regions or elevated plateaux, such as the interior of Spitzbergen, of Greenland, of Nova Zembla, etc., which in a more temperate clime would be verdant with woods or meadows, are here covered with vast fields of ice, from which frequently glaciers descend down to the verge of the sea. But even in the highest northern latitudes, no land has yet been found covered as far as the water's edge with eternal snow, or where winter has entirely subdued the powers of vegetation. The reindeer of Spitzbergen find near $80^{\circ} \mathrm{N}$. lichens or grasses to feed upon; in favorable seasons the snow melts by the end of Jume on the plains of Melville Island, and numerous lemmings, requiring vegetable food for their subsistence, inhabit the deserts of New Siberia. As far as man has reached to the north, vegetation, when fostered by a sheltered situation and the refraction of solar heat from the rocks, has everywhere been found to rise to a considerable altitude above the level of the sea ; and should there be land at the North Pole, there is every reason to believe that it is destitute neither of animal nor vegetable life. It would be equally erroneous to suppose that the cold of winter invariably increases as we near the pole, as the temperature of a land is influenced by many other causes besides its latitude. Even in the most northern regions hitherto visited by man, the influence of the sea, particularly when favored by warm currents, is found to mitigate the severity of the winter, while at the same time it diminishes the warmth of summer. On the other hand, the large continental tracts of Asia or America that shelve toward the pole have a more intense winter cold and a far greater summer's heat than many coast-lands or islands situated far nearer to the pole. 'Thus, to cite but a few examples, the western shores of Nova Zembla, fronting a wide expanse of sea, have an average winter temperature of only $-4^{\circ}$, and a mean summer temperature but little above the freezing-point of water $\left(+36 \frac{1}{2}^{\circ}\right)$, while Jakutsk, situated in the heart of Siberia, and $20^{\circ}$ nearer to the Equator, has a winter of $-36^{\circ} 6^{\prime}$, and a summer of $+66^{\circ} 6^{\prime}$.

The influence of the winds is likewise of considerable importance in determining the greater or lesser severity of an Arctic climate. Thus the northerly winds which prevail in Baffin's Bay and Davis's Straits during the summer months, and fill the straits of the American north-eastern Archipelago with ice, are probably the main cause of the abnormal depression of temperature in that quarter ; while, on the contrary, the southerly winds that prevail during summer in the valley of the Mackenzie tend greatly to extend the forest of that favored region nearly down to the shores of the Arctic Sea. Even in the depth of a Siberian winter, a sudden change of wind is able to raise the thermometer from a mercury-congealing cold to a temperature above the freezingpoint of water, and a warm wind has been known to cause rain to fall in Spitzbergen in the month of January.

The voyages of Kane and Belcher have made us acquainted with the lowest temperatures ever felt by man. On Feb. 5, 1854, while the former was wintering in Smith's Sound $\left(78^{\circ} 37^{\prime}\right.$ N. lat.), the mean of his best spirit-thermometer showed the unexampled temperature of $-68^{\circ}$ or $100^{\circ}$ below the 
freezing-point of water. Then chloric ether became solid, and carefully prepared chloroform exhibited a granular pellicle on its surface. The exhalations from the skin invested the exposed or partially clad parts with a wreath of vapor. The air had a perceptible pungency upon inspiration, and every one, as it were involuntarily, breathed guardedly with compressed lips. About the same time (February 9 and 10, 1854), Sir E. Belcher experienced a cold of $-55^{\circ}$ in Wellington Channel $\left(75^{\circ} 31^{\prime} \mathrm{N}\right.$.), and the still lower temperature of $-62^{\circ}$ on January 13,1853 , in Northumberland Sound $\left(76^{\circ} 52^{\prime}\right.$ N.). Whymper, on December 6, 1866, experienced -58 at Nulatto, Alaska $\left(64^{\circ} 42^{\prime} \mathrm{N}\right.$.).

Whether the temperature of the air descends still lower on adrancing toward the pole, or whether these extreme degrees of cold are not sometimes surpassed in those mountainous regions of the north which, though seen, have never yet been explored, is of course an undecided question: so much is certain, that the observations hitherto made during the winter of the Arctic regions have been limited to too short a time, and are too few in number, to enable us to determine with any degree of certainty those points where the greatest cold prevails. All we know is, that beyond the Aretic Circle, and eight or ten degrees farther to the south in the interior of the continents of Asia and America, the average temperature of the winter generally ranges from $-20^{\circ}$ to $-30^{\circ}$, or even lower, and for a great part of the year is able to convert mercury into a solid body.

It may well be asked how man is able to bear the excessively low temperature of an Arctic winter, which must appear truly appalling to an inhabitant of the temperate zone. A thick fur clothing; a hut small and low, where the warmth of a fire, or simply of a train-oil lamp, is husbanded in a narrow space, and, above all, the wonderful power of the human constitution to accommodate itself to every change of climate, go far to counteract the rigor of the cold.

After a very few days the body develops an increasing warmth as the thermometer descends; for the air being condensed by the cold, the lungs inhale at every breath a greater quantity of oxygen, which of course accelerates the internal process of combustion, while at the same time an increasing appetite, gratified with a copious supply of animal food, of flesh and fat, enriches the blood and enables it to circulate more vigorously. Thus not only the hardy native of the north, but even the healthy traveller soon gets accustomed to bear without injury the rigors of an Arctic winter.

"The mysterious compensations," says Kane, "by which we adapt ourselves to climate are more striking here than in the tropics. In the Polar zone the assault is immediate and sudden, and, unlike the insidious fatality of hot countries, produces its results rapidly. It requires hardly a single winter to tell who are to be the heat-making and acclimatized men. Petersen, for instance, who has resided for two years at Upernavik, seldom enters a room with a fire. Another of our party, George Riley, with a vigorous constitution, established habits of free exposure, and active cheerful temperament, has so inured himself to the cold, that he sleeps on our sledge journeys without a blanket or any other covering than his walking suit, while the outside temperature is $-30^{\circ}$." 
There are many proofs that a milder climate once reigned in the northern regions of the globe. Fossil pieces of wood, petrified acorns and fir-cones

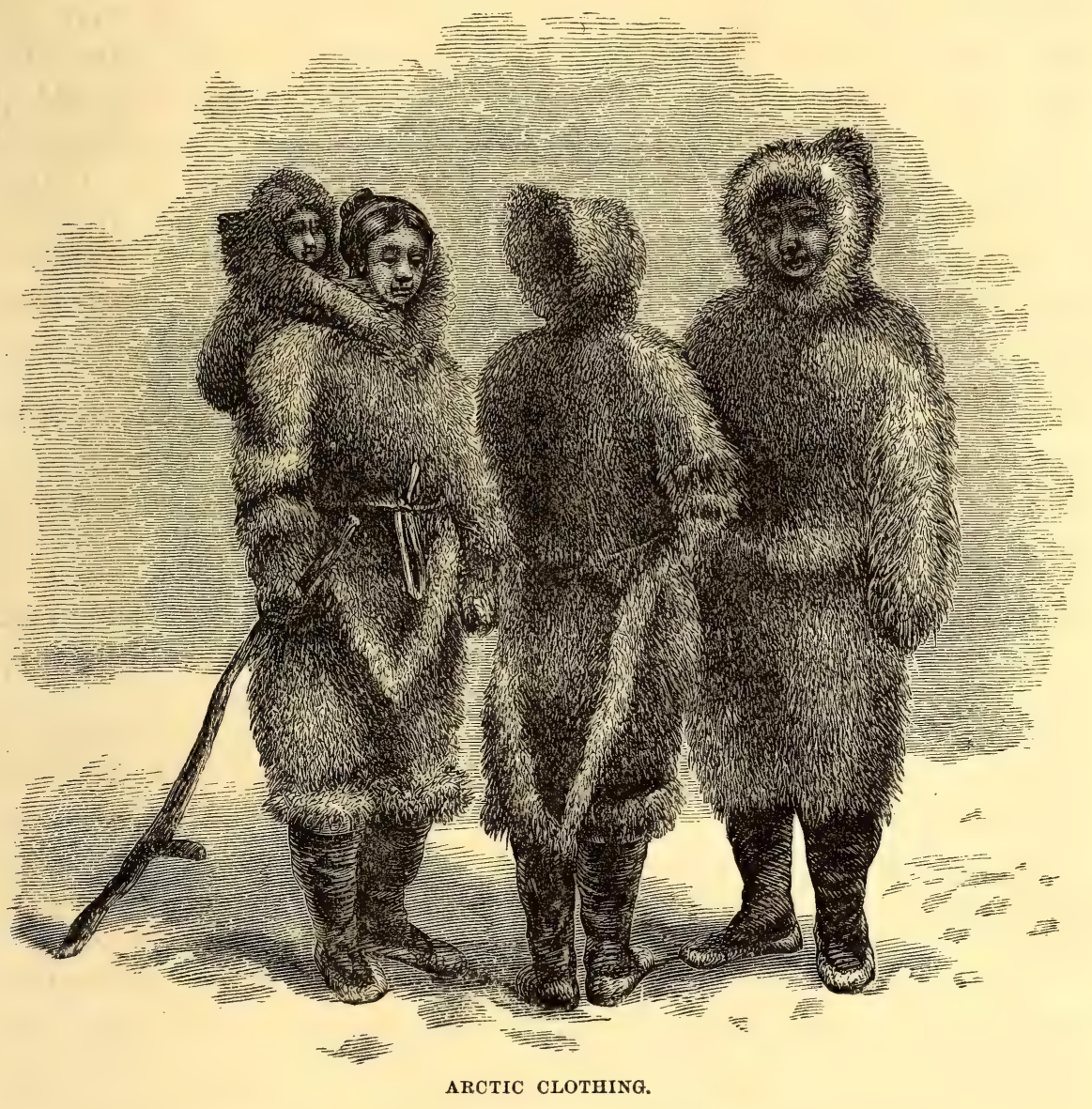

have been found in the interior of Banks's Land by M'Clure's sledging-parties. At Anakerdluk, in North Greenland $\left(70^{\circ} \mathrm{N}\right.$.), a large forest lies buried on a mountain surrounded by glaciers, 1080 feet above the level of the sea. Not only the trunks and branches, but even the leaves, fruit-cones, and seeds have been preserved in the soil, and enable the botanist to determine the species of the plants to which they belong. They show that, besides firs and sequoias, oaks, plantains, elms, magnolias, and even laurels, indicating a climate such as that of Lausanne or Geneva, flourished during the miocene period in a country where now even the willow is compelled to creep along the ground. During the same epoch of the earth's history Spitzbergen was likewise covered with stately forests. The same poplars and the same swamp-cypress (Taxodium dubium) which then flourished in North Greenland have been found in a fossilized state at Bell Sound $\left(76^{\circ} \mathrm{N}\right.$.) by the Swedish naturalists, who also discovered a plantain and a linden as high as $78^{\circ}$ and $79^{\circ}$ in King's Bay-a proof that in those times the climate of Spitzbergen can not have been colder 
than that which now reigns in Southern Sweden and Norway, eighteen degrees nearer to the line.

We know that at present the fir, the poplar, and the beech grow fifteen degrees farther to the north than the plantain-and the miocene period no doubt exhibited the same proportion. Thus the poplars and firs which then grew in Spitzbergen along with plantains and lindens must have ranged as far as the pole itself, supposing that point to be dry land.

In the miocene times the Arctic zone evidently presented a very different aspect from that which it wears at present. Now, during the greater part of the year, an immense glacial desert, which through its floating bergs and driftice depresses the temperature of countries situated far to the south, it then consisted of verdant lands covered with luxuriant forests and bathed by an open sea.

What may have been the cause of these amazing changes of climate? The readiest answer seems to be-a different distribution of sea and land; but there is no reason to believe that in the miocene times there was less land in the Arctic zone than at present, nor can any possible combination of water and dry land be imagined sufficient to account for the growth of laurels in Greenland or of plantains in Spitzbergen. Dr. Oswald Heer is inclined to seek for an explanation of the phenomenon, not in mere local terrestrial changes, but in a difference of the earth's position in the heavens.

We now know that our sun, with his attendant planets and satellites, per-

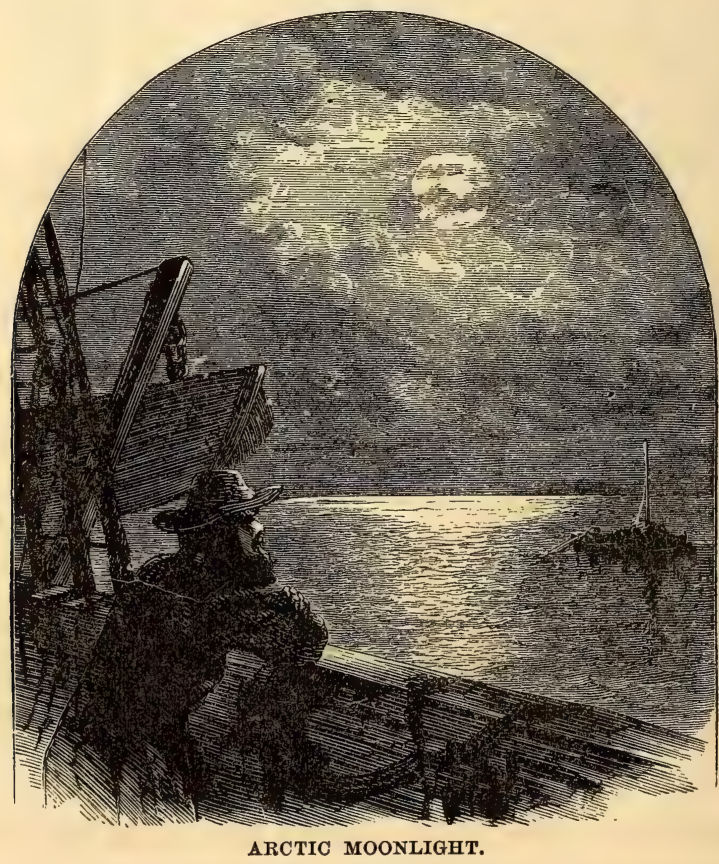

forms a vast circle, embracing perhaps hundreds of thousands of years, round another star, and that we are constantly entering new regions of space untrav- 
elled by our earth before. We come from the unknown, and plunge into the unknown; but so much is certain, that our solar system rolls at present through a space but thinly peopled with stars, and there is no reason to doubt that it may once have wandered through one of those celestial provinces where, as the telescope shows us, constellations are far more densely clustered. But, as every star is a blazing sun, the greater or lesser number of these heavenly bodies must evidently have a proportionate influence upon the temperature of space; and thus we may suppose that during the miocene period our earth, being at that time in a populous sidereal region, enjoyed the benefit of a higher temperature, which clothed even its poles with verdure. In the course of ages the sun conducted his herd of planets into more solitary and colder regions, which caused the warm miocene times to be followed by the glacial period, during which the Swiss flat lands bore an Arctic character, and finally

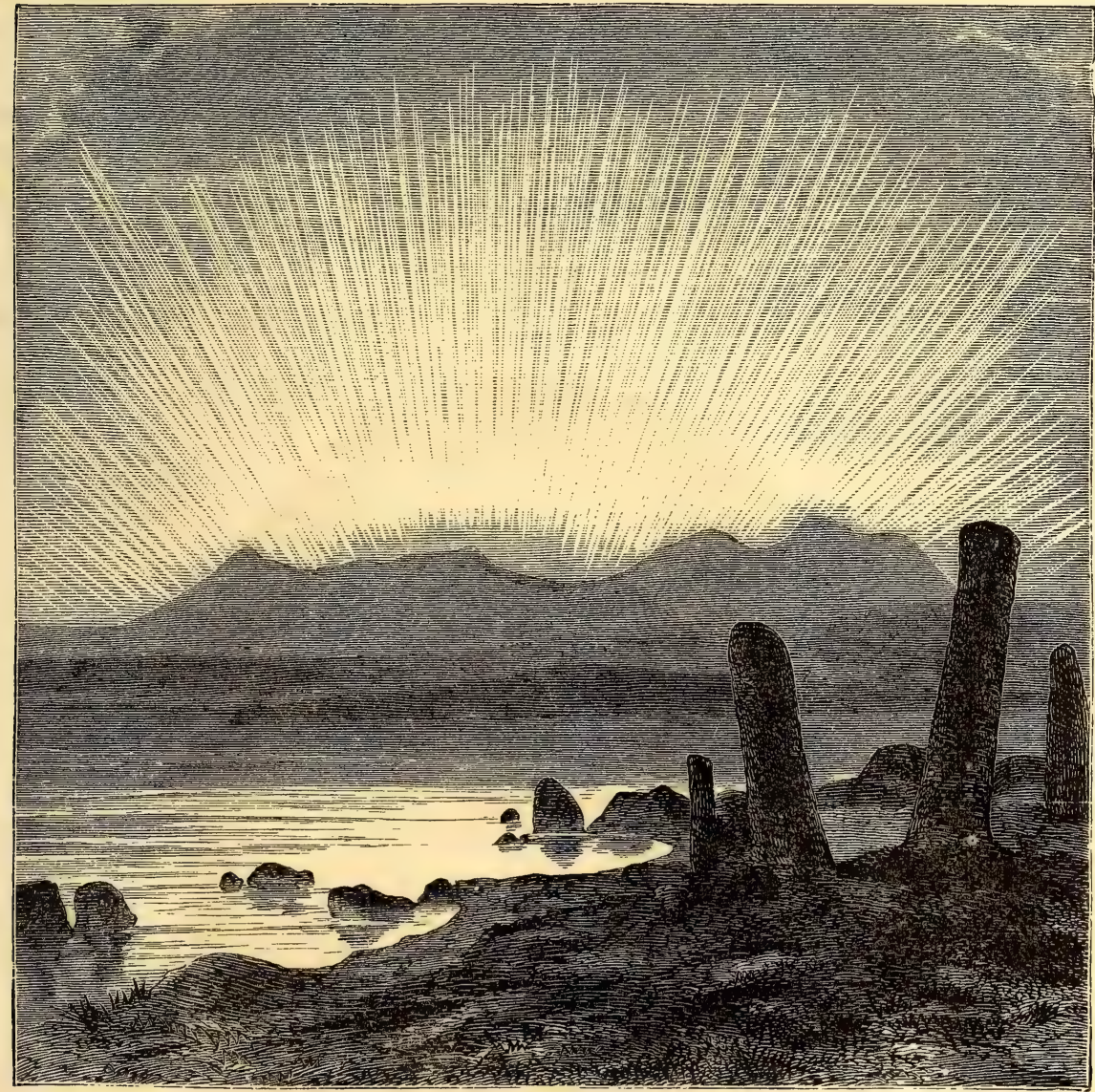

AURORA SEEN IN NORWAY.

the sun emerged into a space of an intermediate character, which determines the present condition of the climates of our globe.

Though Nature generally wears a more stern and forbidding aspect on advancing toward the pole, yet the high latitudes have many beauties of their 


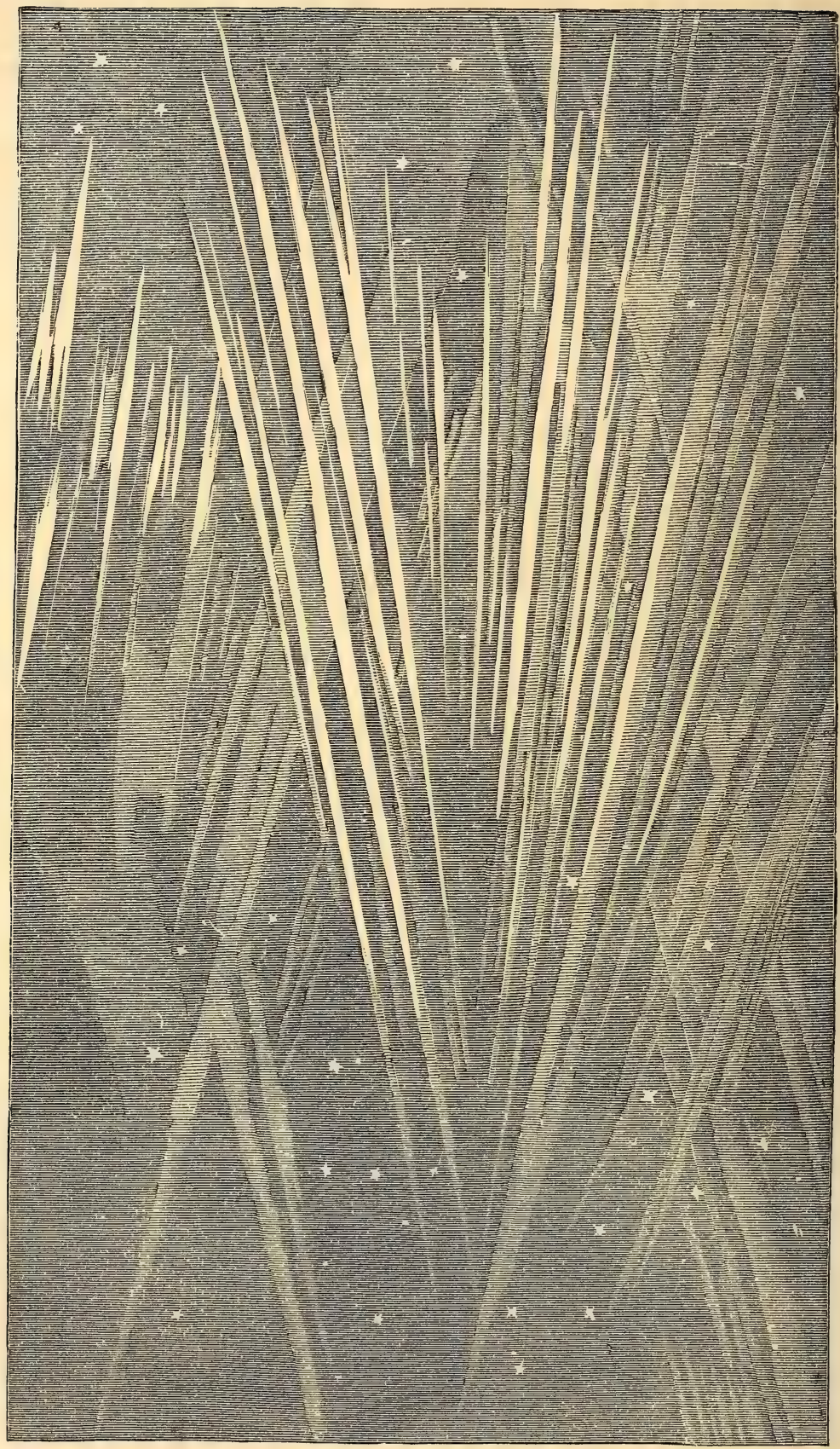

AURORA SEEN IN GREENLAND.

own. Nothing can exceed the magnificence of an Arctic sunset, clothing the snow.clad mountains and the skies with all the glories of color, or be more serenely beautiful than the clear star-light night, illumined by the brilliant moon, which for days continually circles around the horizon, never setting until 
she has run her long course of brightness. The uniform whiteness of the landscape and the general transparency of the atmosphere add to the lustre of her beams, which serve the natives to guide their nomadic life, and to lead them to their hunting-grounds.

But of all the magnificent spectacles that relieve the monotonous gloom of the Arctic winter, there is none to equal the magical beauty of the Aurora. Night covers the snow-clad earth; the stars glimmer feebly through the haze which so frequently dims their brilliancy in the high latitudes, when suddenly a broad and clear bow of light spans the horizon in the direction where it is traversed by the magnetic meridian. This bow sometimes remains for several hours, heaving or waving to and fro, before it sends forth streams of light ascending to the zenith. Sometimes these flashes proceed from the bow of light alone; at others they simultaneously shoot forth from many opposite parts of the horizon, and form a vast sea of fire whose brilliant waves are continually changing their position. Finally they all unite in a magnificent crown or copnla of light, with the appearance of which the phenomenon attains its highest degree of splendor. The brilliancy of the streams, which are commonly red at their base, green in the middle, and light yellow toward the zenith, increases, while at the same time they dart with greater vivacity through the skies. The colors are wonderfully transparent, the red approaching to a clear blood-red, the green to a pale emerald tint. On turning from the flaming firmament to the earth, this also is seen to glow with a magical light. The dark sea, black as jet, forms a striking contrast to the white snow-plain or the distant ice-mountain; all the outlines tremble as if they belonged to the unreal world of dreams. The imposing silence of the night heightens the charms of the magnificent spectacle.

But gradually the crown fades, the bow of light dissolves, the streams become shorter, less frequent, and less vivid; and finally the gloom of winter once more descends upon the northern desert. 


\section{CHAPTER II.}

\section{ARCTIC LAND QUADRUPEDS AND BIRDS.}

The Reindeer.-Structure of its Foot.-Clattering Noise when walking._Antlers._Extraordinary olfactory Powers.-The Icelandic Moss.-Present and Former Range of the Reindeer.-Its invalu. able Qualities as an Arctic domestic Animal.-Revolts against Oppression.-Enemies of the Reindeer.-The Wolf.-The Glutton or Wolverine.-Gad-flies.-The Elk or Moose-deer.-The Muskox.-The Wild Sheep of the Rocky Mountains. - The Siberian Argali.-The Arctic Fox._lts Burrows.-The Lemmings.-Their Migrations and Enemies._Arctic Anatidæ.-The Snow-bunting.The I.apland Bunting.-The Sea-eagle.-Drowned by a Dolphin.

THE reindeer may well be called the camel of the northern wastes, for it is

a no less valuable companion to the Laplander or to the Samojede than the "ship of the desert" to the wandering Bedouin. It is the only member of the numerous deer family that has been domesticated by man; but though undoubtedly the inost useful, it is by no means the most comely of its race. Its clear, dark eye has, indeed, a beautiful expression, but it has neither the noble proportions of the stag nor the grace of the roebuck, and its thick square-formed body is far from being a model of elegance. Its legs are short and thick, its feet broad, but extremely well adapted for walking over the snow or on a swampy ground. The front hoofs, which are capable of great lateral expansion, curve upward, while the two secondary ones behind (which are but slightly developed in the fallow deer and other members of the family) are considerably prolonged: a structure which, by giving the animal a broader base to stand upon, prevents it from sinking too deeply into the snow or the morass. Had the foot of the reindeer been formed like that of our stag, it would have been as unable to drag the Laplander's sledge with such velocity over the yielding snow-fields as the camel would be to perform his long marches through the desert without the broad elastic sole-pad on which he firmly paces the unstable sands.

The short legs and broad feet of the reindeer likewise enable it to swim with greater ease-a power of no small importance in countries abounding in rivers and lakes, and where the scarcity of food renders perpetual migrations necessary. When the reindeer walks or merely moves, a remarkable clattering sound is heard to some distance, about the cause of which naturalists and travellers by no means agree. Most probably it results from the great length of the two digits of the cloven hoof, which when the animal sets its foot upon the ground separate widely, and when it again raises its hoof suddenly clap against each other.

A long mane of a dirty white color hangs from the neck of the reindeer. In summer the body is brown above and white beneath; in winter, long-haired and white. Its antlers are very different from those of the stag, having broad palmated summits, and branching back to the length of three or four feet. 


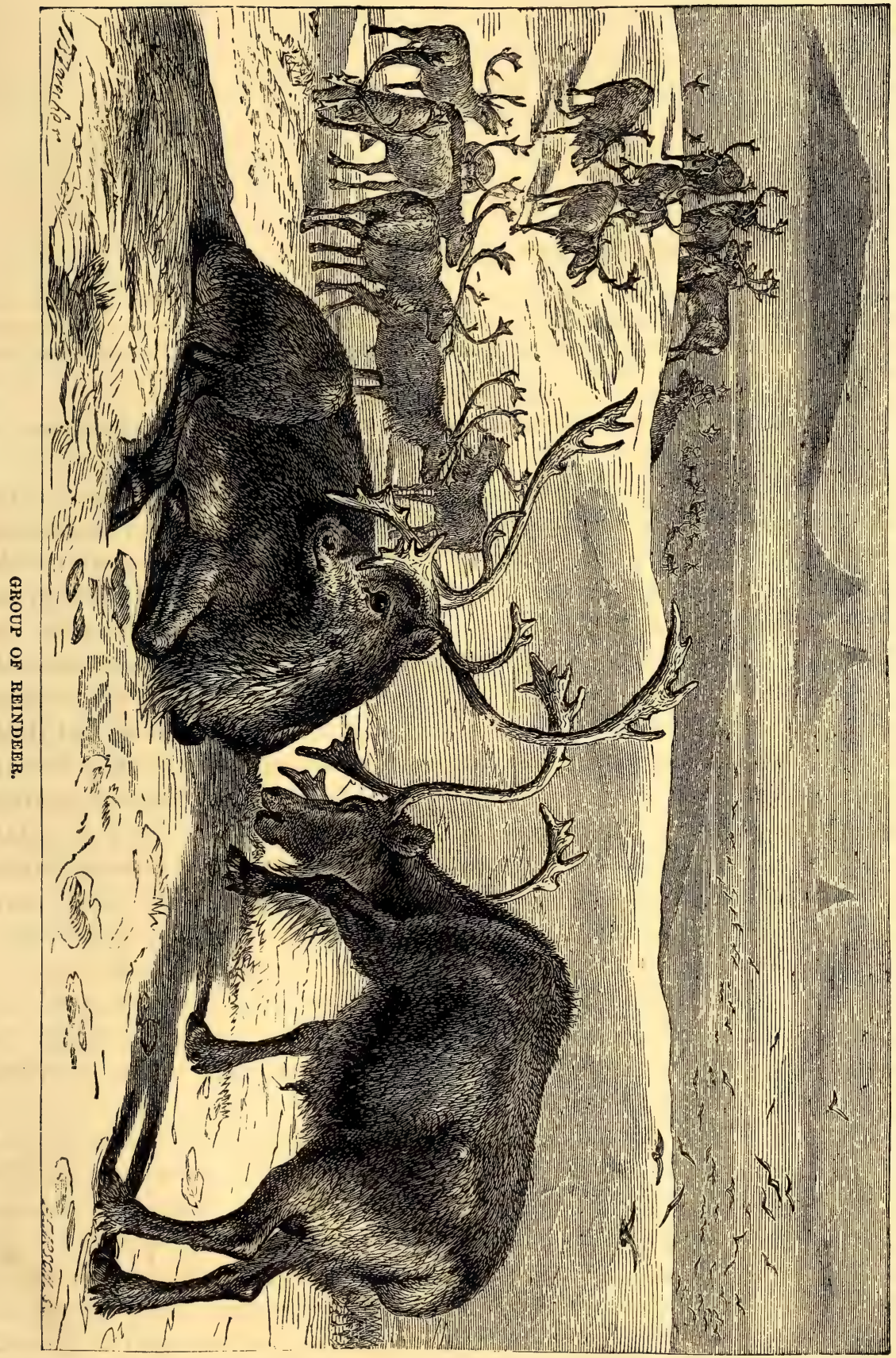

Their weight is frequently very considerable-twenty or twenty-five pounds; and it is remarkable that both sexes have horns, while in all other members of the deer race the males alone are in possession of this ornament or weapon.

The female brings forth in May a single calf, rarely two. This is small and weak, but after a few days it follows the mother, who surkles her young but a 
short time, as it is soon able to seek and to find its food. The reindeer gives very little milk - at the very utmost, after the young has been weaned, a bottleful daily; but the quality is excellent, for it is uncommonly thick and nutritious. It consists almost entirely of cream, so that a great deal of water can be added before it becomes inferior to the best cow-milk. Its taste is excellent, but the butter made from it is rancid, and hardly to be eaten, while the cheese is very good.

The only food of the reindeer during winter consists of moss, and the most surprising circumstance in his history is the instinct, or the extraordinary olfactory powers, whereby he is enabled to discover it when hidden beneath the snow. However deep the Lichen rangiferinus may be buried, the animal is aware of its presence the moment he comes to the spot, and this kind of food is never so agreeable to him as when he digs for it himself. In his manner of doing this he is remarkably adroit. Having first ascertained, by thrusting his muzzle into the snow, whether the moss lies below or not, he begins making a hole with his fore feet, and continues working until at length he uncovers the lichen. No instance has ever occurred of a reindeer making such a cavity without discovering the moss he seeks. In summer their food is of a different nature; they are then pastured upon green herbs or the leaves of trees. Judging from the lichen's appearance in the hot months, when it is dry and brittle, one might easily wonder that so large a quadruped as the reindeer should make it his favorite food and fatten upon it; but toward the month of September the lichen becomes soft, tender, and damp, with a taste like wheat-bran. In this state its luxuriant and flowery ramifications somewhat resemble the leaves of endive, and are as white as snow.

Though domesticated since time immemorial, the reindeer has only partly been brought under the yoke of man, and wanders in large wild herds both in the North American wastes, where it has never yet been reduced to servitude, and in the forests and tundras of the Old World.

In America, where it is called " caribou," it extends from Labrador to Melville Island and Washington Land; in Europe and Asia it is found from Lapland and Norway, and from the mountains of Mongolia and the banks of the Ufa, as far as Nova Zembla and Spitzbergen. Many centuries ago--probably during the glacial period-its range was still more extensive, as reindeer bones . are frequently found in French and German caves, and bear testimony to the severity of the climate which at that time reigned in Central Europe; for the reindeer is a cold-loving animal, and will not thrive under a milder sky. All attempts to prolong its life in our zoological gardens have failed, and even in the royal park at Stockholm Hogguer saw some of these animals, which were quite languid and emaciated during the summer, although care had been taken to provide them with a cool grotto to which they could retire during the warmer hours of the day. In summer the reindeer can enjoy health only in the fresh mountain air or along the bracing sea-shore, and has as great a longing for a low temperature as man for the genial warmth of his fireside in winter.

The reindeer is easily tamed, and soon gets accustomed to its master, whose society it loves, attracted as it were by a kind of innate sympathy; for, unlike 
all other domestic animals, it is by no means dependent on man for its subsistence, but finds its nourishment alone, and wanders about freely in summer and in winter without ever being inclosed in a stable. These qualities are inestimable in countries where it would be utterly impossible to keep any domestic animal requiring shelter and stores of provisions during the long winter months, and make the reindeer the fit companion of the northern nomad, whose simple wants it almost wholly supplies. During his wanderings, it carries his tent and scanty household furniture, or drags his sledge over the snow. On account of the weakness of its back-bone, it is less fit for riding, and requires to be mounted with care, as a violent shock easily dislocates its vertebral column; the saddle is placed on the haunches. You would hardly suppose the reindeer to be the same animal when languidly creeping along under a rider's weight, as when, unencumbered by a load, it vaults with the lightness of a bird over the obstacles in its way to obey the call of its master. The reindeer can be easily trained to drag a sledge, but great care must be taken not to beat or otherwise ill-treat it, as it then becomes obstinate, and quite unmanageable. When forced to drag too heavy a load, or taxed in any way above its strength, it not seldom turns round upon its tyrant, and attacks him with its horns and fore feet. To save himself from its fury, he is then obliged to overturn his sledge, and to seek a refuge under its bottom until the rage of the animal has abated.

After the death of the reindeer, it may truly be said that every part of its body is put to some use. The flesh is very good, and the tongue and marrow are considered a great delicacy. The blood, of which not a drop is allowed to be lost, is either drunk warm or made up into a kind of black pudding. The skin furnishes not only clothing impervious to the cold, but tents and bedding; and spoons, knife-handles, and other household utensils are made out of the bones and horns; the latter serve also, like the claws, for the preparation of an excellent glue, which the Chinese, who buy them for this purpose of the Russians, use as a nutritious jelly. In Tornea the skins of new-born reindeer are prepared and sent to St. Petersburg to be manufactured into gloves, which are extremely soft, but very dear.

Thus the cocoa-nut palm, the tree of a hundred uses, hardly renders a greater variety of services to the islanders of the Indian Ocean than the reindeer to the Laplander or the Samojede; and, to the honor of these barbarians be it mentioned, they treat their invaluable friend and companion with a grateful affection which might serve as an example to far more civilized nations.

The reindeer attains an age of from twenty to twenty-five years, but in its domesticated state it is generally killed when from six to ten years old. Its most dangerous enemies are the wolf, and the glutton or wolverine (Gulo borealis or arcticus), which belongs to the bloodthirsty marten and weasel family, and is said to be of uncommon fierceness and strength. It is about the size of a large badger, between which animal and the pole-cat it seems to be intermediate, nearly resembling the former in its general figure and aspect, and agreeing with the latter as to its dentition. No dog is capable of mastering a glutton, and even the wolf is hardly able to scare it from its prey. Its feet are very short, so that it can not run swiftly, but it climbs with great facility 
upon trees, or ascends even almost perpendicular rock-walls, where it also seeks a refuge when pursued.

When it perceives a herd of reindeer browsing near a wood or a precipice, it generally lies in wait upon a branch or some high cliff, and springs down upon the first animal that comes within its reach. Sometimes also it steals unawares upon its prey, and suddenly bounding upon its back, kills it by a single bite in the neck. Many fables worthy of Münchausen have been told about its voracity; for instance, that it is able to devour two reindeer at one meal, and that, when its stomach is exorbitantly distended with food, it will press itself between two trees or stones to make room for a new repast. It will, indeed, kill in one night six or eight reindeer, but it contents itself with sucking their blood, as the weasel does with fowls, and eats no more at one meal than any other carnivorous animal of its own size.

Besides the attacks of its mightier enemies, the reindeer is subject to the persecutions of two species of gad-fly, which torment it exceedingly. The one (OEstrus tarandi), called Hurbma by the Laplanders, deposits its glutinous eggs upon the animal's back. The larvæ, on creeping out, immediately bors themselves into the skin, where by their motion and suction they cause so many small swellings or boils, which gradually grow to the size of an inch or more in diameter, with an opening at the top of each, through which the larvæ may be seen imbedded in a purulent fluid. Frequently the whole back of the animal is covered with these boils, which, by draining its fluids, produce ema. ciation and disease. As if aware of this danger, the reindeer runs wild and furious as soon as it hears the buzzing of the fly, and seeks a refuge in the nearest water. The other species of gad-fly (CEstrus nasalis) lays its eggs in the nostrils of the reindeer ; and the larvæ, boring themselves into the fauces and beneath the tongue of the poor animal, are a great source of annoyance, as is shown by its frequent sniffling and shaking of the head.

A pestilential disorder like the rinderpest will sometimes sweep away whole herds. Thus in a few weeks a rich Laplander or Samojede may be reduced to poverty, and the proud possessor of several thousands of reindeer be compelled to seek the precarious livelihood of the northern fisherman.

The elk or moose-deer (Cervus alces) is another member of the cervine race peculiar to the forests of the north. In size it is far superior to the stag, but it can not boast of an elegant shape, the head being disproportionately large, the neck short and thick, and its immense horns, which sometimes weigh near fifty pounds, each dilating almost immediately from the base into a broad palmated form; while its long legs, high shoulders, and heavy upper lip hanging very much over the lower, give it an uncouth appearance. The color of the elk is a dark grayish-brown, but much paler on the legs and beneath the tail.

We owe the first description of this gigantic deer to Julius Cæsar, in whose time it was still a common inhabitant of the German forests. But the conqueror of Gaul can hardly have seen it himself, or he would not have ascribed to it a single horn, placed in the middle of the forehead, or said that both sexes are perfectly alike, for the female is smaller and has no antlers. At present the elk is still found in the swampy forests of East Prussia, Lithuania, and Po- 


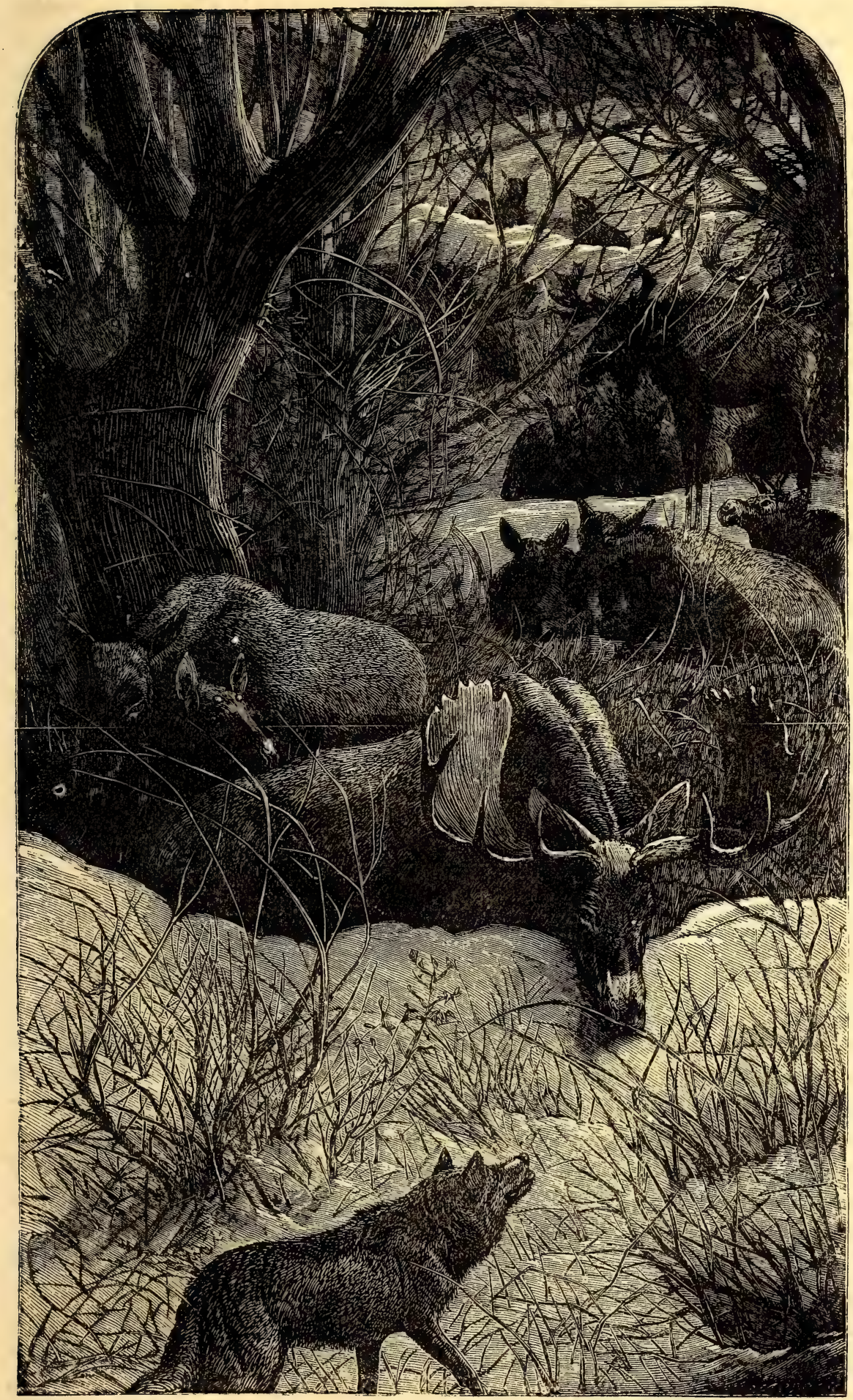


land, but it chiefly resides in the more northern woods of Russia, Siberia, and America. It is a mild and harmless animal, principally supporting itself by browsing the boughs of willows, asps, service-trees, and other soft species of wood. It does not, like the reindeer, seek a refuge against the attacks of the gad-flies, by wandering to the coasts of the sea, or retreating to the bare mountains, where it would soon perish for the want of adequate food, but plunges up to the nose into the next river, where it finds, moreover, a species of water-grass (Festuca fluitans) which it likes to feed upon. Though aaturally mild and harmless, it displays a high degree of courage, and even fe. rocity when suddenly attacked ; defending itself with great vigor, not only with its horns, but also by striking violently with its fore feet, in the use of which it is particularly dexterous. It is generally caught in traps, as it is extremely shy and watchful, and tinds an easy retreat in the swamp or the forest. The only time of the year when it can be easily chased is in the spring, when the softened snow gets covered during the night with a thin crust of ice which is too weak to bear the animal's weight.

Though not ranging so far north as the reindeer or the elk, we find in the Old World the red-deer (Cervus elaphus), in the vicinity of Drontheim, in Norway, and along with the roebuck beyond Lake Baikal, in Siberia, while in America the large-eared deer (Cervus macrotis), and the Wapiti, or Canada stag (Cervus strongylo-ceras), extend their excursions beyond $55^{\circ}$ of northern latitude. The latter is much larger and of a stronger make than the European red-deer, frequently growing to the height of our tallest oxen, and possessing great activity as well as strength. The flesh is little prized, but the hide, when made into leather after the Indian fashion, is said not to turn hard in drying after being wet-a quality which justly entitles it to a preference over almost every other kind of leather.

One of the most remarkable quadrupeds of the high northern regions is the

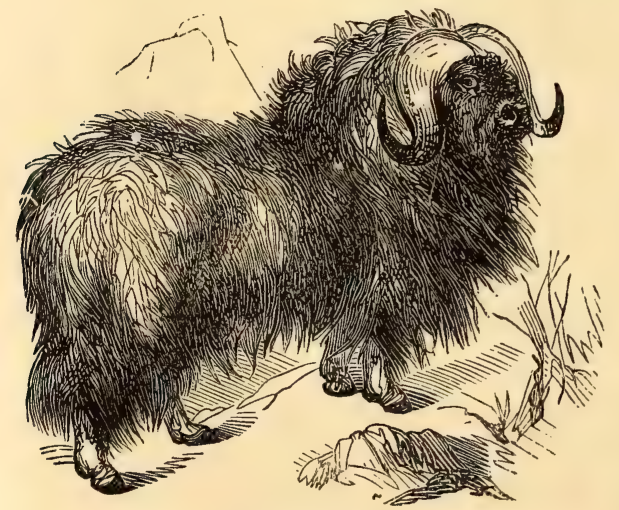

THE MUSK-OX. musk-ox (Ovibos moschatus), which by some naturalists has been considered as intermediate between the sheep and the ox. It is about the height of a deer, but of much stouter proportions. The horns are very broad at the base, almost meeting on the forehead, and curving downward between the eye and ears until about the level of the mouth, when they turn upward. Its long thick brown or black hair hanging down below the middle of the leg, and covering on all parts of the animal a fine kind of soft ash-colored

wool, which is of the finest description, and capable of forming the most beautiful fabrics manufactured, enables it to remain even during the winter beyond $70^{\circ}$ of northern latitude. In spring it wanders over the ice as far as Melville 
Island, or even Smith's Sound, where a number of its bones were found by Dr. Kane. In September it withdraws more to the south, and spends the coldest months on the verge of the forest region. Like the reindeer, it subsists chiefly on lichens and grasses. It runs nimbly, and climbs hills and rocks with great ease. Its fossil remains, or those of a very analogous species, have been discovered in Siberia: at present it is exclusively confined to the New World.

In the Rocky Mountains, from the Mexican Cordillera plateaux as far as $68^{\circ}$ N. lat., dwells the wild sheep (Ovis montana), distinguished by the almost cir. cular bend of its large, triangular, transversely striped horns, from its relative

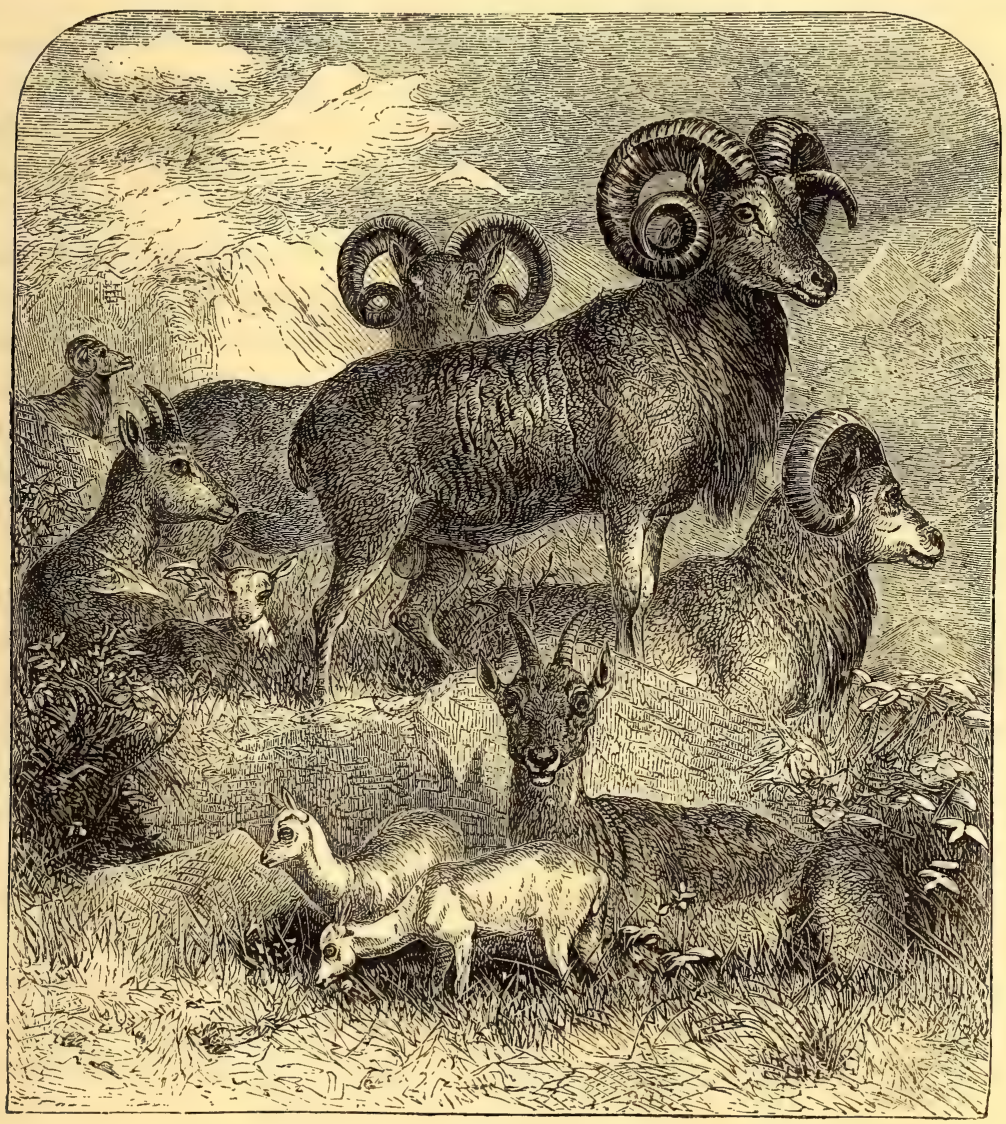

ARGALI.

the Siberian argali (Ovis argali), which is supposed to be the parent of our do. mestic sheep, and far surpasses it in size and delicacy of flesh. Both the American and the Asiatic wild sheep are in the highest degree active and vigorous, assending abrupt precipices with great agility, and, like the wild goat, going over the narrowest and most dangerous passes with perfect safety.

Among the carnivorous quadrupeds of the northern regions, many, like the lynx, the wolf, the bear, the glutton, and other members of the weasel tribe, have their head-quarters in the forests, and only occasionally roam over the tun- 
dras ; but the Arctic fox (Canis lagopus) almost exclusively inhabits the treeless wastes that fringe the Polar Ocean, and is found on almost all the islands that lie buried in its bosom. This pretty little creature, which in winter grows perfectly white, knows how to protect itself against the most intense cold, either by seeking a refuge in the clefts of rocks, or by burrowing to a considerable depth in a sandy soil. It principally preys upon lemmings, stoats, polar hares, as well as upon all kinds of water-fowl and their eggs; but when pinched by hunger, it does not disdain the carcasses of fish, or the molluses and crustaceans it may chance to pick up on the shore. Its enemies are the glutton, the snowy owl, and man, who, from the Equator to the poles, leaves no creature unmolested that can in any way satisfy his wants.

The lemmings, of which there are many species, are small rodents, peculiar to the Arctic regions, both in the New and in the Old World, where they are found as far to the north as vegetation extends. They live on grass, roots, the shoots of the willow, and the dwarf birch, but chiefly on lichens. They do not gather hoards of provisions for the winter, but live upon what they find beneath the snow. They seldom prove injurious to man, as the regions they inhabit are generally situated beyond the limits of agriculture. From the voles, to whom they are closely allied, they are distinguished by having the foot-sole covered with stiff hairs, and by the strong crooked claws with which their fore feet are armed. The best known species is the Norwegian lemming (Lemmus norwegicus), which is found on the high mountains of the Dovrefjeld, and farther to the north on the dry parts of the tundra, where it inhabits small burrows under stones or in the moss. Its long and thick hair is of a tawny color, and prettily marked with black spots. The migrations of the lemming have been grossly exaggerated by Olaus Magnus and Pontoppidan, to whom the natural history of the North owes so many fables. As they breed several times in the year, producing five or six at a birth, they of course multiply very fast under favorable circumstances, and are then forced to leave the district which is no longer able to afford them food. But this takes place very seldom, for when Mr. Brehm visited Scandinavia, the people on the Dovrefjeld knew nothing about the migrations of the lemming, and his inquiries on the subject proved equally fruitless in Lapland and in Finland. At all events, it is a fortunate circumstance that the lemmings have so many enemies, as their rapid multiplication might else endanger the balance of existence in the northern regions. The inclemencies of the climate are a chief means for keeping them in check. A wet summer, an early cold and snowless autumn destroy them by millions, and then of course years are necessary to recruit their numbers. With the exception of the bear and the hedgehog, they are pursued by all the northern carnivora. The wolf, the fox, the glutton, the marten, the ermine devour them with avidity, and a good lemming season is a time of unusual plenty for the hungry Laplander's dog. The snowy owl, whose dense plumage enables it to be a constant resident on the tundra, almost exclusively frequents those places where lemmings, its favorite food, are to be found; the buzzards are constantly active in their destruction; the crow feeds its young with lemmings; and even the poor Lap, when pressed by hunger, seizes a stick, and, 
for want of better game, goes out lemming-hunting, and rejoices when he can kill a sufficient number for his dinner.

Several birds, such as the snowy owl and the ptarmigan (Lagopus albus), which can easily procure its food under the snow, winter in the highest latitudes; but by far the greater number are merely summer visitants of the Arctic regions. After the little bunting, the first arrivals in spring are the snowgeese, who likewise are the first to leave the dreary regions of the north on their southerly migration. The common and king eider-duck, the Brent geese,

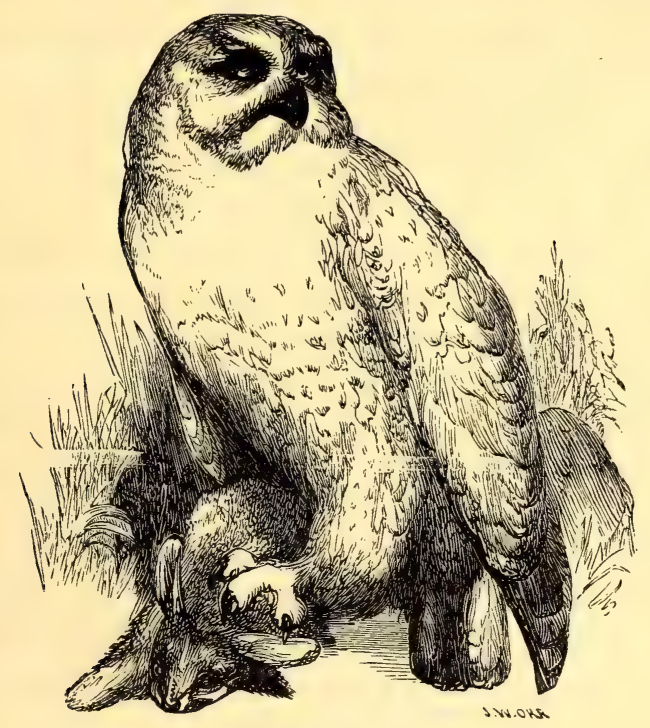

THE SNOWY OWL.

the great northern black and red throated divers, are the next to make their appearance, followed by the pintail and longtail ducks (Anas caudacuta and glacialis), the latest visitors of the season. These birds generally take their departure in the same order as they arrive. The period of their stay is but short, but their presence imparts a wonderfully cheerful aspect to regions at other times so deserted and dreary. As soon as the young are sufficiently fledged, they again betake themselves to the southward; the character of the season much influencing the period of their departure.

As far as man has penetrated, on the most northern islets of Spitzbergen, or on the ice-blocked shores of Kennedy Channel, the eider-duck and others of the Arctic anatidæ build their nests; and there is no reason to doubt that if the pole has breeding-places for them, it re-echoes with their cries. Nor need they fear to plunge into the very heart of the Arctic zone, for the flight of a goose being forty or fifty miles an hour, these birds may breed in the remotest northern solitude, and in a few hours, on a fall of deep autumn snow, convey themselves by their swiftness of wing to better feeding-grounds.

One of the most interesting of the Arctic birds is the snow-bunting (Plectrophanes nivalis), which may properly be called the polar singing-bird, as it breeds in the most northern isles, such as Spitzbergen and Novaja Zemlya, or 
on the highest mountains of the Dovrefjeld, in Scandinavia, where it enlivens the fugitive summer with its short but agreeable notes, sounding doubly sweet from the treeless wastes in which they are heard. It invariably builds its

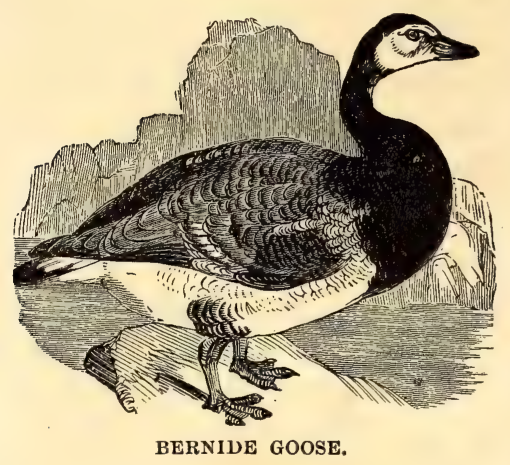
nest, which it lines with feathers and down, in the fissures of mountain rocks or under large stones, and the entrance is generally so narrow as merely to allow the parent birds to pass. The remarkably dense winter plumage of the snow-bunting especially qualifies it for a northern residence, and when in captivity it will rather bear the severest ccld than even a moderate degree of warmth. In its breeding-places it lives almost exclusively on insects, particularly gnats: during the winter it feeds on all sorts of seeds, and then famine frequently compels it to wander to a less rigorous climate.

The Lapland bunting (Centrophanes lapponicus), whose white and black plumage is agreeably diversified with red, is likewise an inhabitant of the higher latitudes, where it is frequently seen in the barren grounds and tundras. Both these birds are distinguished by the very long claw of their hind toe, a structure which enables them to run about with ease upon the snow.

Among the raptorial birds of the Arctic regions, the sea-eagle (Haliactus albicilla) holds a conspicuous rank. At his approach the gull and the auk conceal themselves in the fissures of the rocks, but are frequently dragged forth by their relentless enemy. The divers are, according to Wahlengren, more imperilled from his attacks than those sea-birds which do not plunge, for the latter rise into the air as soon as their piercing eye espies the universally dreaded tyrant, and thus escape ; while the former, blindly trusting to the element in which they are capable of finding a temporary refuge, allow him to

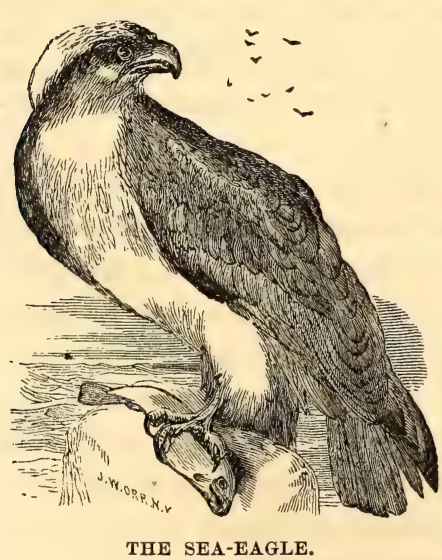
approach, and then suddenly diving, fancy themselves in safety, while the eagle is only waiting for the moment of their re-appearance to repeat his attack. Twice or thrice they may possibly escape his claws by a rapid plunge, but when for the fourth time they dive out of the water, and remain but one instant above the surface, that instant seals their doom. The sea-eagle is equally formidable to the denizens of the ocean, but sometimes too great a confidence in his strength leads to his destruction, for Kittlitz was informed by the inhabitants of Kamschatka that, pouncing upon a dolphin, he is

not seldom dragged down into the water by the diving cetacean in whose skin his talons remain fixed. 


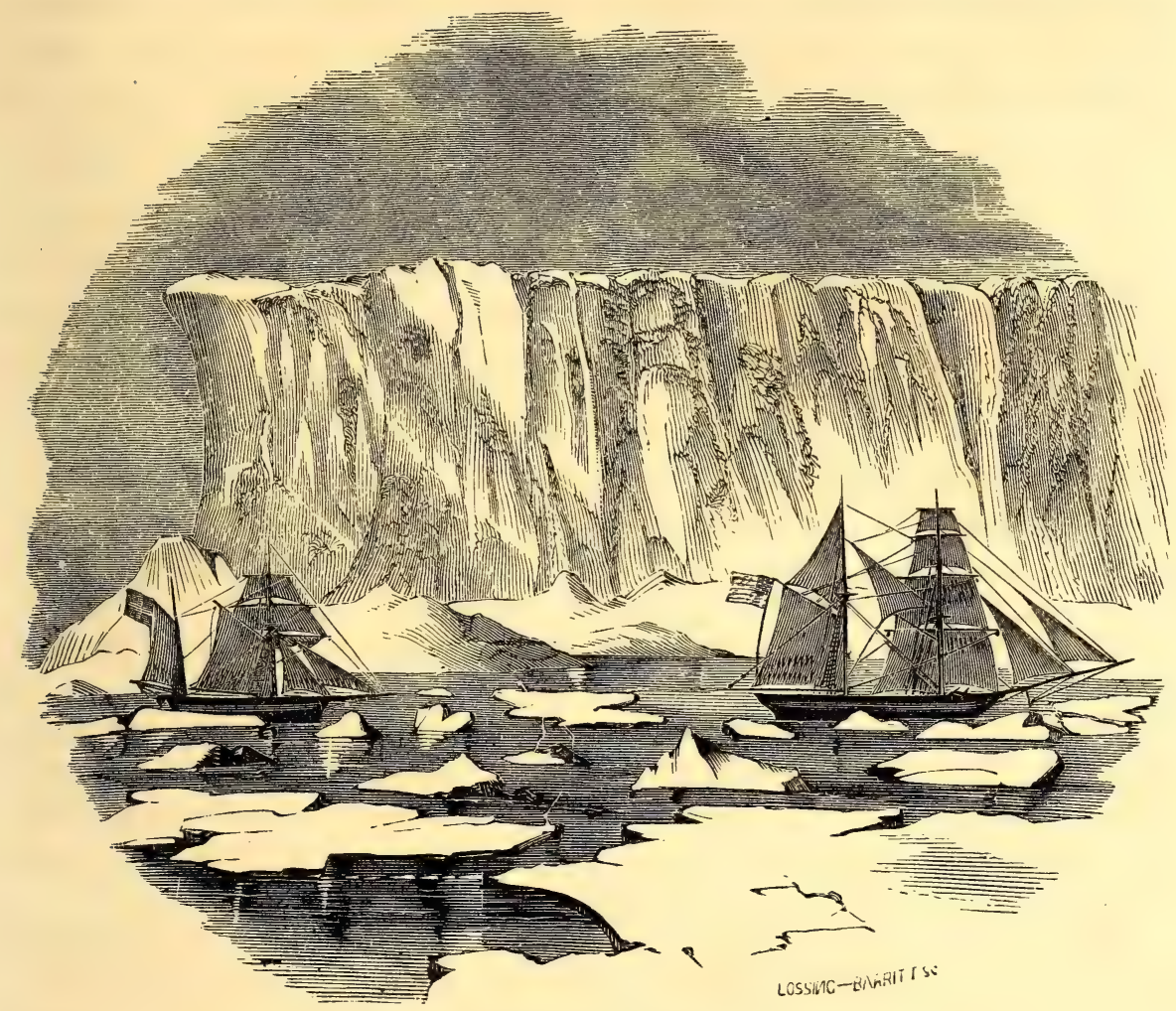

ARCTIC NAVIGATION.

\section{CHAPTER III.}

\section{THE ARCTIC SEAS.}

Dangers peculiar tó the Arctic Sea.-Ice-fields.-Hummocks.-Collision of Ice-fields.-Icebergs.-Their Origin.-Their Size.-The Glaciers which give them Birth.-Their Beauty.-Sometimes useful Auxiliaries to the Mariner.-Dangers of anchoring to a Berg.-A crumbling Berg.-The Ice-blink. -Fogs.-Transparency of the Atmosphere.-Phenomena of Reflection and Refraction.-Causes which prevent the Accumulation of Polar Ice.-Tides.-Currents.-Ice a bad Conductor of Heat.Wise Provisions of Nature.

THE heart of the first navigator, says Horace, must have been shielded with

threefold brass-and yet the poet knew but the sunny Mediterranean, with its tepid floods and smiling shores: how, then, would he have found words to express his astonishment at the intrepid seamen who, to open new vistas to science or new roads to commerce, first ventured to face the unknown terrors of the Arctic main?

In every part of the ocean the mariner has to guard against the perils of hidden shoals and sunken cliffs, but the high northern waters are doubly and trebly dangerous; for here, besides those rocks which are firmly rooted to the ground, there are others which, freely floating about, threaten to crush his vessel to pieces, or to force it along with them in helpless bondage.

The Arctic navigators have given various names to these movable shoals, 
which are the cause of so much delay and danger. They are icebergs when they iower to a considerable height above the waters, and ice-fields when they have a vast horizontal extension. A floe is a detached portion of a field; pack-ice, a large area of floes or smaller fragments closely driven together so as to oppose a firm barrier to the progress of a ship ; and drift-ice, loose ice in motion, but not so firmly packed as to prevent a vessel from making her way through its yielding masses.

The large ice-fields which the whaler encounters in Baffin's Bay, or on the seas between Spitzbergen and Greenland, constitute one of the marvels of the deep. There is a solemn grandeur in the slow majestic motion with which they are drifted by the currents to the south; and their enormous masses, as mile after mile comes floating by, impress the spectator with the idea of a boundless extent and an irresistible power. But, vast and mighty as they are, they are unable to withstand the elements combined for their destruction, and their apparently triumphal march leads them only to their ruin.

When they first descend from their northern strongholds, the ice of which they are composed is of the average thickness of from ten to fifteen feet, and their surface is sometimes tolerably smooth and even, but in general it is covered with numberless ice-blocks or hummocks piled upon each other in wild con.

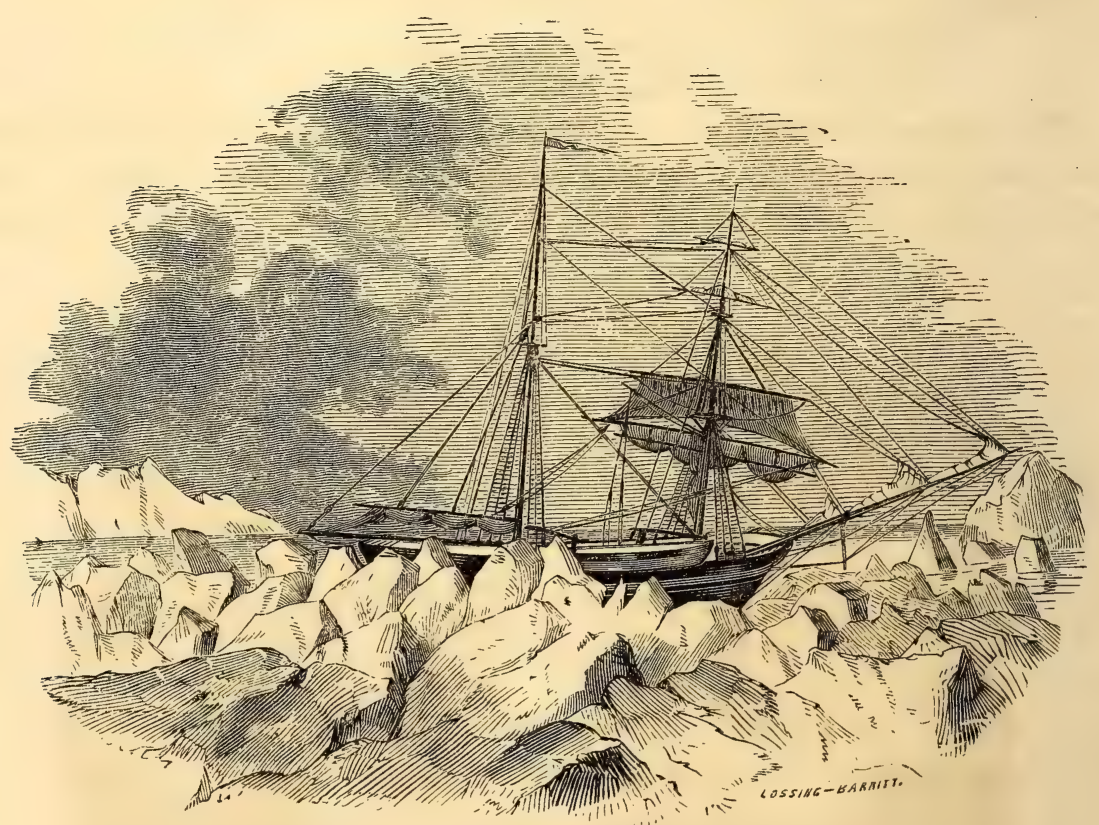

AMONG HUMMOCKS.

fusion to a height of forty or fifty feet, the result of repeated collisions before flakes and floes were soldered into fields. Before the end of June they are covered with snow, sometimes six feet deep, which melting during the summer forms small ponds or lakes upon their surface. 


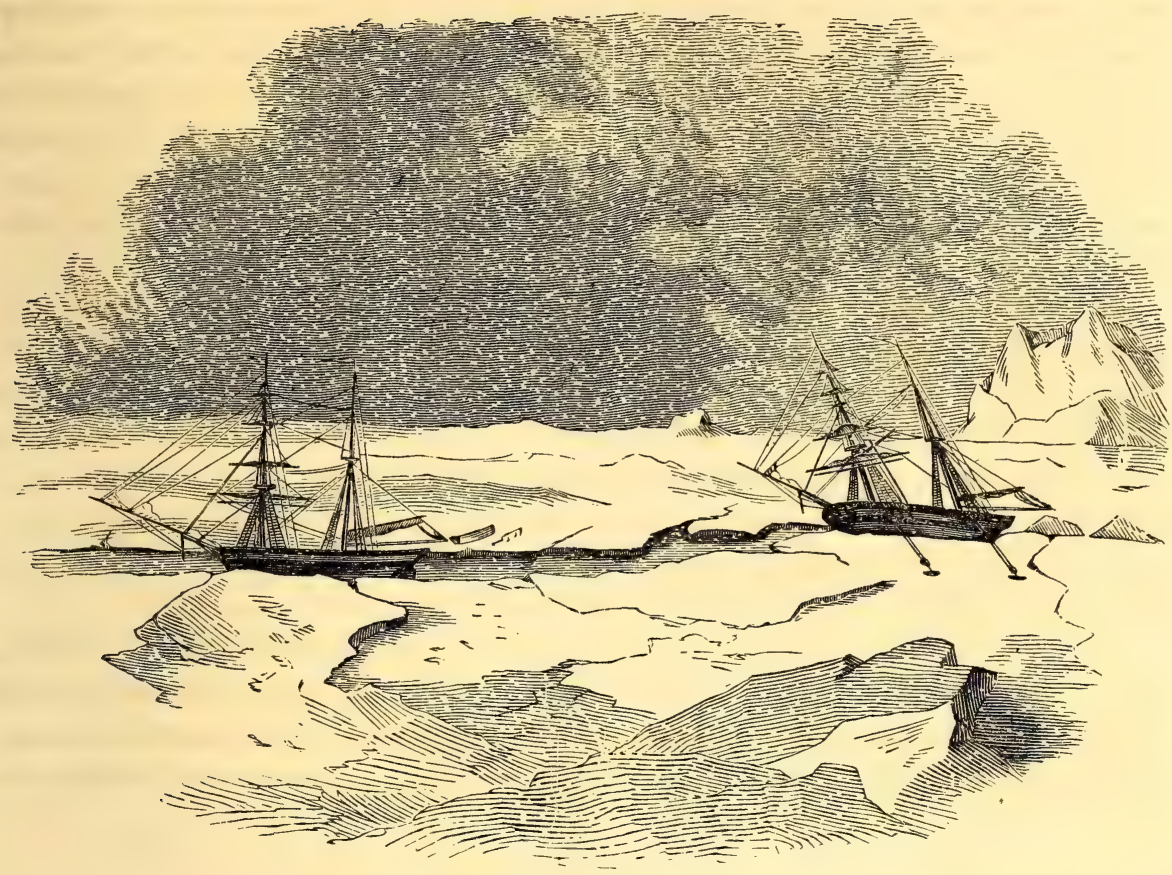

DRIFTING IN THE ICE.

Not seldom ice-fields are whirled about in rotatory motion, which causes their circumference to gyrate with a velocity of several miles per hour. When a field thus sweeping through the waters comes into collision with another

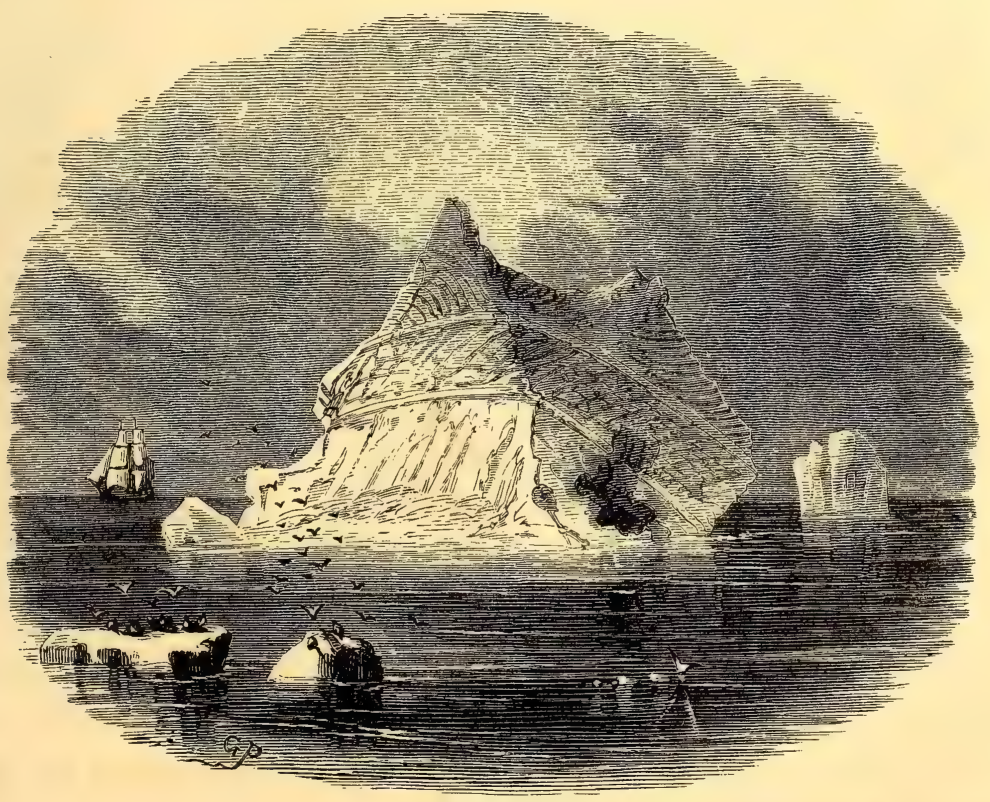

FORMS OF ICEBERGS. 
which may possibly be revolving with equal rapidity in an opposite direction - when masses not seldom twenty or thirty miles in diameter, and each weigh-

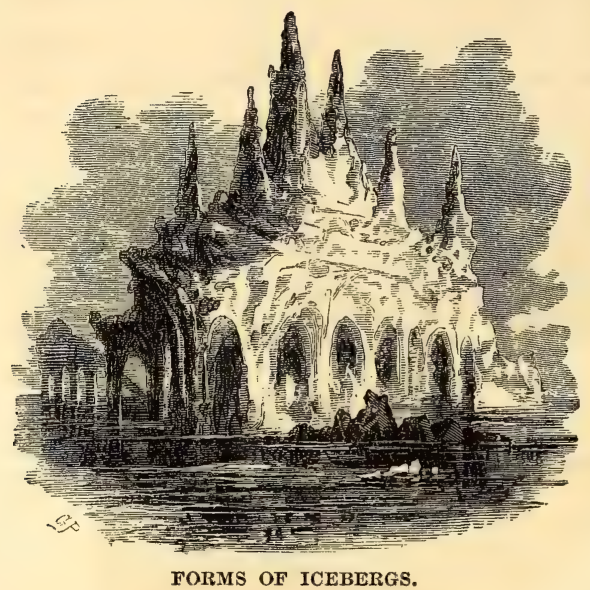

be utterly unable to resist their power. ing many millions of tons, clash together, imagination can hardly conceive a more appalling scene. The whalers at all times require unremitting vigilance to secure their safety, but scarcely in any situation so much as when navigating amidst these fields, which are more particularly dangerous in foggy weather, as their motions can not then be distinctly observed. No wonder that since the establishment of the fishery numbers of vessels have been crushed to pieces between two fields in motion, for the strongest ship ever built must needs upon the ice; some have had their hulls completely torn open; and others have been overrun by the ice, and buried beneath the fragments piled upon their wreck.

The icebergs, which, as their name indicates, rise above the water to a much more considerable height than the ice-fields, have a very different origin, as they are not formed in the sea itself, but by the glaciers of the northern highlands. As our rivers are continually pouring their streams into the ocean, so many of the glaciers or ice-rivers of the Arctic zone, descending to the water-edge, are slowly but constantly forcing themselves farther and farther into the sea. In the summer season, when the ice is particularly fragile, the force of cohesion is often overcome by the weight of the prodigious masses that overhang the sea or have been undermined by its waters; and in the winter, when the air is probably $40^{\circ}$ or $50^{\circ}$ below zero and the sea from $28^{\circ}$ to $30^{\circ}$ above, the unequal expansion of those parts of the mass ex-

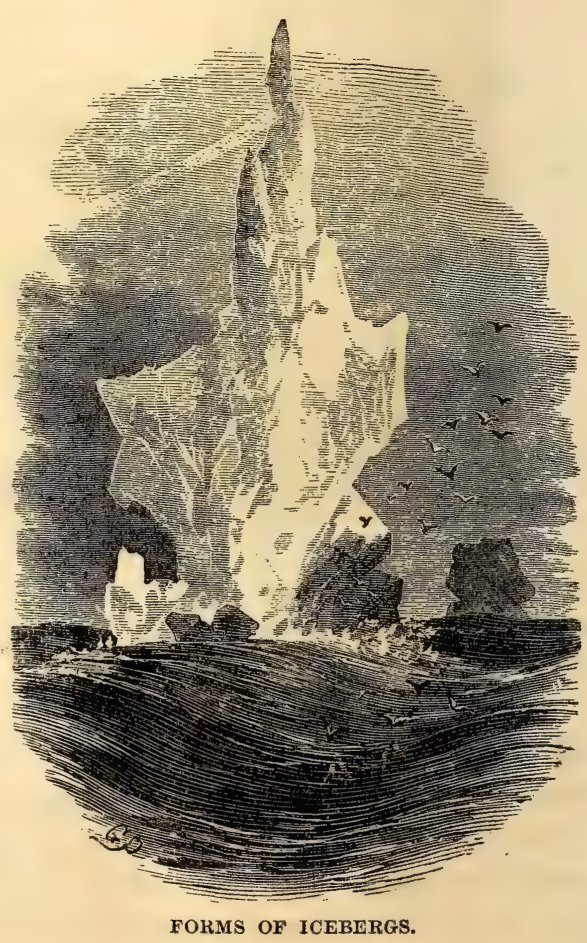
posed to so great a difference of temperature can not fail to produce the separation of large portions. 
Most of these swimming glacier-fragments, or icebergs, which are met with by the whaler in the Northern Atlantic, are formed on the mountainous west coast of Greenland by the large glaciers which discharge themselves into the fiords from Smith's Sound to Disco Bay, as here the sea is sufficiently deep to float them away, in spite of the enormous magnitude they frequently attain. As they drift along down Baffin's Bay and Davis's Strait, they not seldom run

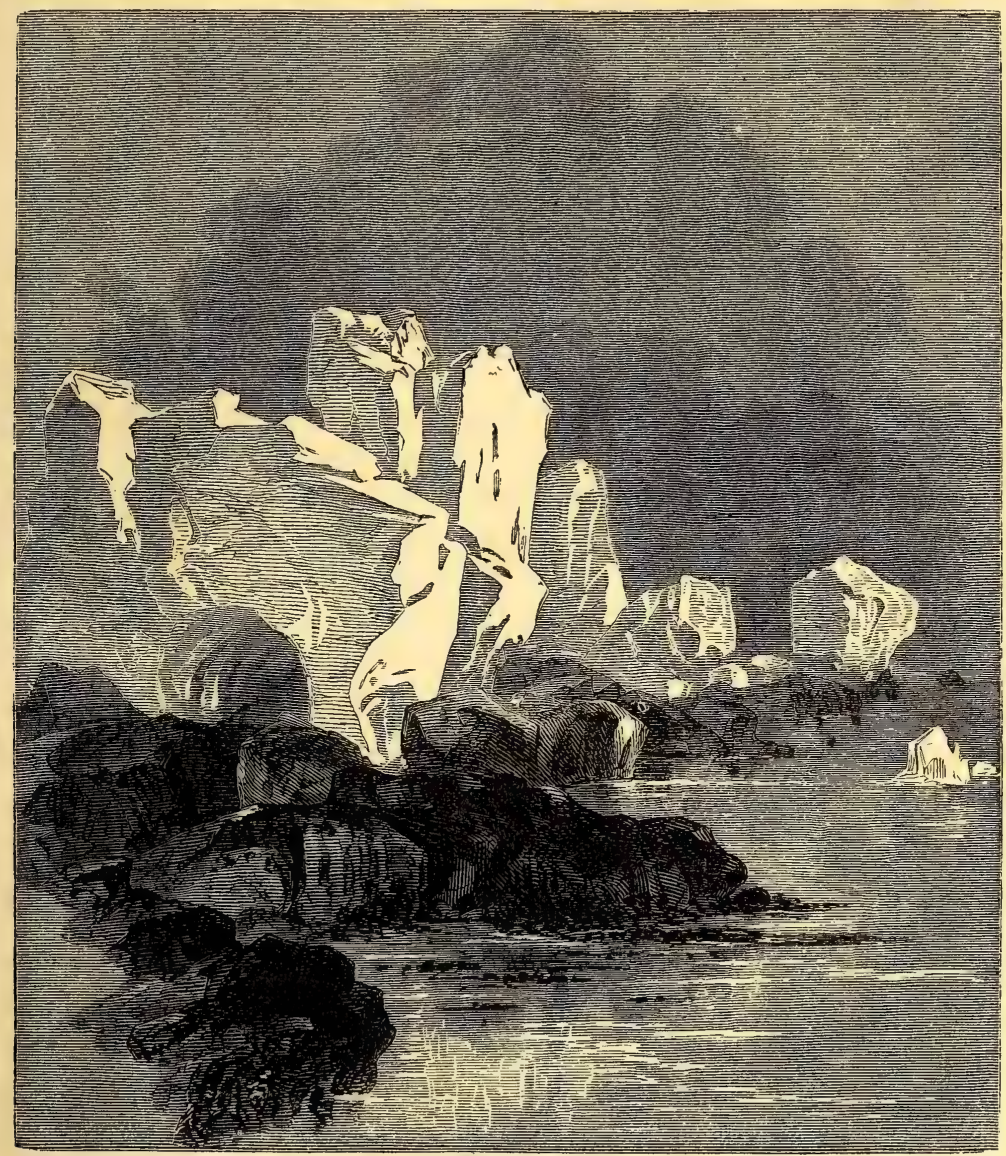

ICEBERGS AGROUND.

aground on some shallow shore, where, bidding defiance to the short summer, they frequently remain for many a year.

Dr. Hayes measured an immense iceberg which had stranded off the little harbor of Tessuissak, to the north of Melville Bay. The square wall which faced toward his base of measurement was 315 feet high, and a fraction over three-quarters of a mile long. Being almost square-sided above the sea, the same shape must have extended beneath it; and since, by measurements made two days before, Hayes had discovered that fresh-water ice floating in salt water has above the surface to below it the proportion of one to seven, this crystallized mountain must have gone aground in a depth of nearly half a mile. A 
rude estimate of its size, made on the spot, gave in cubical contents about 27,000 millions of feet, and in weight something like 2000 millions of tons !

Captain Ross in his first voyage mentions another of these wrecked bergs, which was found to be 4169 yards long, 3689 yards broad, and 51 feet high above the level of the sea. It was aground in 61 fathoms, and its weight was estimated by an officer of the "Alexander" at 1,292,397,673 tons. On ascending the flat top of this iceberg, it was found occupied by a huge white bear, who justly deeming " discretion the best part of valor," sprang into the sea be. fore he could be fired at.

The vast dimensions of the icebergs appear less astonishing when we consider that many of the glaciers or ice-rivers from which they are dislodged are equal in size or volume to the largest streams of continental Europe.

Thus one of the eight glaciers existing in the district of Omenak, in Greenland, is no less than an English mile broad, and forms an ice-wall rising 160 feet above the sea. Further to the north, Melville Bay and Whale Sound are the seat of vast ice-rivers. Here Tyndall glacier forms a coast-line of ice over two miles long, almost burying its face in the sea, and carrying the eye along a broad and winding valley, up steps of ice of giant height, until at length the slope loses itself in the unknown ice-desert beyond. But grand above all is the magnificent Humboldt glacier, which, connecting Greenland and Washington Land, forms a solid glassy wall 300 feet above the water-level, with an unknown depth below it, while its curved face extends full sixty miles in length from Cape Agassiz to Cape Forbes. In the temperate zone it would be one of the mightiest rivers of the earth; here, in the frozen solitudes of the North, it slowly drops its vast fragments into the waters, making the solitudes around re-echo with their fall.

As the Polar shores of continental America and Siberia are generally flat, and below the snow-line, they are consequently deprived both of glaciers and of the huge floating masses to which these give birth.

In a high sea the waves beat against an iceberg as against a rock; and in calm weather where there is a swell, the noise made by their rising and falling is tremendous. Their usual form is that of a high vertical wall, gradually sloping down to the opposite side, which is very low ; but frequently they exhibit the most fantastic shapes, particularly after they have been a long time exposed to the corroding power of the waves, or of warm rains pelting them from above.

A number of icebergs floating in the sea is one of the most magnificent spectacles of nature, but the wonderful beauty of these crystal cliffs never ap. pears to greater advantage than when clothed by the midnight sun with all the splendid colors of twilight.

"The bergs," says Dr. Hayes, describing one of these enchanting nights, "had wholly lost their chilly aspect, and glittering in the blaze of the brilliant heavens, seemed in the distance like masses of burnished metal or solid flame. Nearer at hand they were huge blocks of Parian marble inlaid with mammoth gems of pearl and opal. One in particular exhibited the perfection of the grand. Its form was not unlike that of the Colosseum, and it lay so far away 


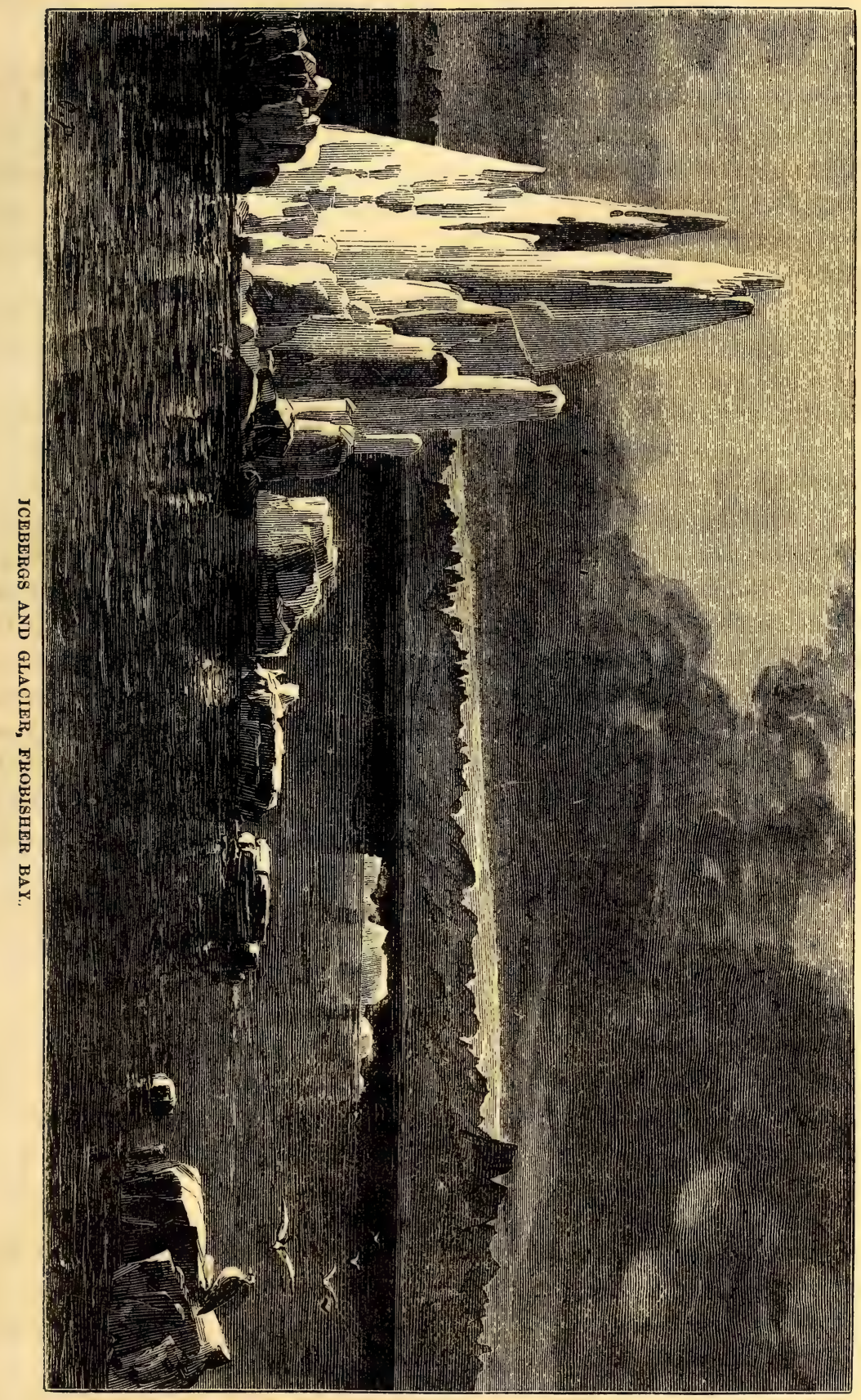

that half its height was buried beneath the line of blood-red waters. The sun, slowly rolling along the horizon, passed behind it, and it seemed as if the old Roman ruins had suddenly taken fire. In the shadow of the bergs the water was a rich green, and nothing conld be more soft and tender than the gradations of color made by the sea shoaling on the sloping tongue of a berg 


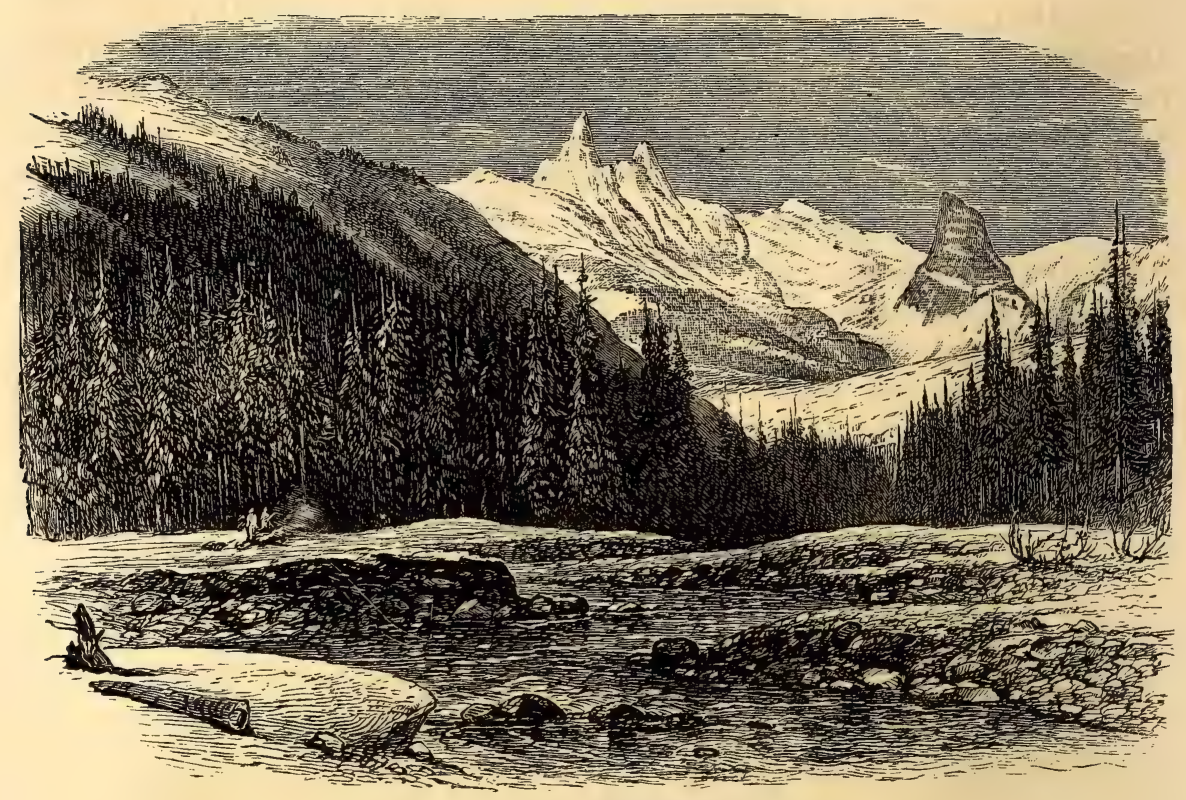

GLACIER, BUTE INLET.

close beside us. The tint increased in intensity where the ice overhung the water, and a deep cavern near by exhibited the solid color of the malachite mingled with the transparency of the emerald, while in strange contrast a broad streak of cobalt blue ran diagonally through its body. The bewitching character of the scene was heightened by a thousand little cascades which leaped into the sea from these floating masses, the water being discharged from lakes of melted snow and ice which reposed in quietude far up in the valleys separating the high icy hills of their upper surface. From other bergs large pieces were now and then detached, plunging down into the water with deafening noise, while the slow moving swell of the ocean resounded through their broken archways."

A similar gorgeous spectacle was witnessed by Dr. Kane in Melville Bay. The midnight sun came out over a great berg, kindling variously-colored fires on every part of its surface, and making the ice around the ship one great resplendency of gemwork, blazing carbuncles and rubies, and molten gold.

In the night the icebergs are readily distinguished even at a distance by their natural effulgence, and in foggy weather by a peculiar klackness in the atmosphere. As they are not unfrequently drifted by the Greenland stream considerably to the south of Newfoundland, sometimes even as far as the fortieth or thirty-ninth degree of latitude (May, 1841, June, 1842), ships sailing through the north-western Atlantic require to be always on their guard against them. The ill-fated "President," one of our first ocean-steamers, which was lost on its way to New York, without leaving a trace behind, is supposed to have been sunk by a collision with an iceberg, and no doubt many a gallant bark has either foundered in the night, or been hurled by the storm against these floating rocks. 
But though often dangerous neighbors, the bergs occasionally prove useful auxiliaries to the mariner. From their greater bulk lying below the waterline, they are either drifted along by the under-current against the wind, or, from their vast dirnensions, are not perceptibly influenced even by the strongest gale, but, on the contrary, have the appearance of moving to windward, because every other kind of ice is drifted rapidly past them. Thus in strong adverse winds, their broad masses, fronting the storm like bulwarks, not seldom afford protection to ships mooring under their lee.

Anchoring to a berg is, however, not always unattended with danger, particularly when the summer is far advanced, or in a lower latitude, as all ice becomes exceedingly fragile when acted on by the sun or by a temperate atmos-

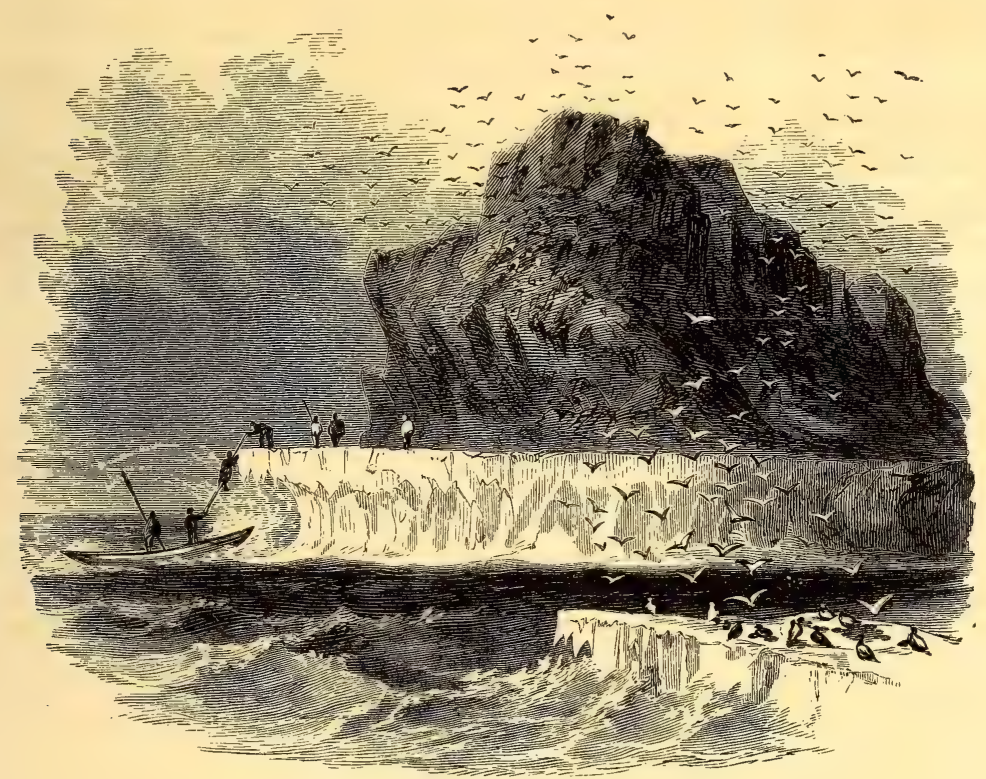

SCALING AN ICEBERG.

phere. The blow of an axe then sometimes suffices to rend an iceberg asunder, and to bury the careless seaman beneath its ruins, or to hurl him into the yawning chasm.

Thus Scoresby relates the adventure of two sailors who were attempting to fix an anchor to a berg. They began to hew a hole into the ice, but scarcely had the first blow been struck, when suddenly the immense mass split from top to bottom and fell asunder, the two halves falling in contrary directions with a prodigious crash. One of the sailors, who was possessed of great presence of mind, immediately scaled the huge fragment on which he was standing, and remained rocking to and fro on its summit until its equilibrium was restored; but his companion, falling between the masses, would most likely have been crushed to pieces if the current caused by their motion had not swept him within reach of the boat that was waiting for them.

Frequently large pieces detach themselves spontaneously from an iceherg 
and fall into the sea with a tremendous noise. When this circumstance, called "calving," takes place, the iceberg loses its equilibrium, sometimes turns on one side, and is occasionally inverted.

Dr. Hayes witnessed the crumbling of an immense berg, resembling in its general appearance the British House of Parliament. First one lofty tower came tumbling into the water, starting from its surface an immense flock of gulls; then another followed; and at length, after five hours of rolling and crashing, there remained of this splendid mass of congelation not a fragment that rose fifty feet above the water.

One of the most remarkable phenomena of the Polar Sea is the ice-blink, or reflection of the ice against the sky. A stripe of light, similar to the early dawn of morning, but without its redness, appears above the horizon, and traces a complete aërial map of the ice to a distance of many miles beyond the ordinary reach of vision. To the experienced navigator the "blink" is frequently of the greatest use, as it not only points out the vicinity of the drift-ice, but indicates its nature, whether compact or loose, continuous or open. Thus Sooresby relates that on the 7th of June, 1821, he saw so distinct an ice-blink, that as far as twenty or thirty miles all round the horizon he was able to ascertain the figure and probable extent of each ice-field. The packed ice was distinguished from the larger fields by a more obscure and yellow color; while each water-lane or open passage was indicated by a deep blue stripe or patch. By this means he was enabled to find his way out of the vast masses of ice in which he had been detained for several days, and to emerge into the open sea.

The tendency of the pack-ice to separate in calm weather, so that one might almost be tempted to believe in a mutual repulsive power of the individual blocks, is likewise favorable to the Arctic navigator. The perpetual daylight of summer is another advantage, but unfortunately the sun is too often veiled by dense mists, which frequently obscure the air for weeks together, particularly in July. These fogs, which are a great impediment to the whaler's operations, have a very depressing influence upon the spirits; and as they are attended with a low temperature, which even at noon does not rise much above freezing-point, the damp cold is also physically extremely unpleasant.

At other times the sun sweeps two or thi ee times round the pole without being for a moment obscured by a cloud, and then the transparency of the air is such that objects the most remote may be seen perfectly distinct and clear. A ship's top-gallant mast, at the distance of five or six leagues, may be discerned when just appearing above the horizon with a common perspective-glass, and the summits of mountains are visible at the distance of from sixty to a hundred miles.

On such sunny days, the strong contrasts of light and shade between the glistening snow and the dark protruding rocks produce a remarkable deception in the apparent distance of the land, along a steep mountainous coast. When at the distance of twenty miles from Spitzbergen, for instance, it would be easy to induce even a judicious stranger to undertake a passage in a boat to the shore, from a belief that he was within a league of the land. At this distance the portions of rock and patches of snow, as well as the contour of the different 
hills, are as distinctly marked as similar objects in many other countries, not having snow about them, would be at a fourth or a fifth part of the distance.

Nothing can be more wonderful than the phenomena of the atmosphere dependent on reflection and refraction, which are frequently observed in the Arctic seas, particularly at the commencement or approach of easterly winds. They are probably occasioned by the commixture, near the surface of the land or sea, of two streams of air of different temperatures, so as to occasion an irregular deposition of imperfectly condensed vapor, which when passing the verge of the horizon apparently raises the objects there situated to a considerable distance above it, or extends their height beyond their natural dimensions. Ice, land, ships, boats, and other objects, when thus enlarged and elevated, are said to loom. The lower part of looming objects are sometimes connected with the horizon by an apparent fibrous or columnar extension of their parts; at other times they appear to be quite lifted into the air, a void space being seen between them and the horizon.

A most remarkable delusion of this kind was observed by Scoresby while sailing through the open ice, far from land. Suddenly an immense amphitheatre inclosed by high walls of basaltic ice, so like natural rock as to deceive one of his most experienced officers, rose around the ship. Sometimes the refraction produced on all sides a similar effect, but still more frequently remarkable contrasts. Single ice-blocks expanded into architectural figures of an extraordinary height, and sometimes the distant, deeply indented ice-border looked like a number of towers or minarets, or like a dense forest of naked trees. Scarcely had an object acquired a distinct form, when it began to dissolve into another.

It is well known that similar causes produce similar effects in the warmer regions of the earth. In the midst of the tropical ocean, the mariner sees verdant islands rise from the waters, and in the treeless desert fantastic palmgroves wave their fronds, as if in mockery of the thirsty caravan.

When we consider the intense cold which reigns during the greatest part of the year in the Arctic regions, we might naturally expect to find the whole of the Polar Sea covered, during the winter at least, with one solid unbroken sheet of ice. But experience teaches us that this is by no means the case; for the currents, the tides, the winds, and the swell of a turbulent ocean are mighty causes of disruption, or strong impediments to congelation. Both Lieutenant de Haven and Sir Francis $\mathbf{M}^{\prime}$ Clintock* were helplessly carried along, in the depth of winter, by the pack-ice in Lancaster Sound and Baffin's Bay. A berg impelled by a strong under-current rips open an ice-field as if it were a thin sheet of glass; and in channels, or on coasts where the tides rise to a considerable height, their flux and reflux is continually opening crevices and lanes in the ice which covers the waters. That even in the highest latitudes the sea does not close except when at rest, was fully experienced by Dr. Hayes during his wintering at Port Foulke; for at all times, even when the temperature of the air was below the freezing-point of mercury, he could hear from the deck of his schooner the roar of the beating waves. From all these causes there has at no point within the Arctic Circle been found a firm ice-belt extending, 


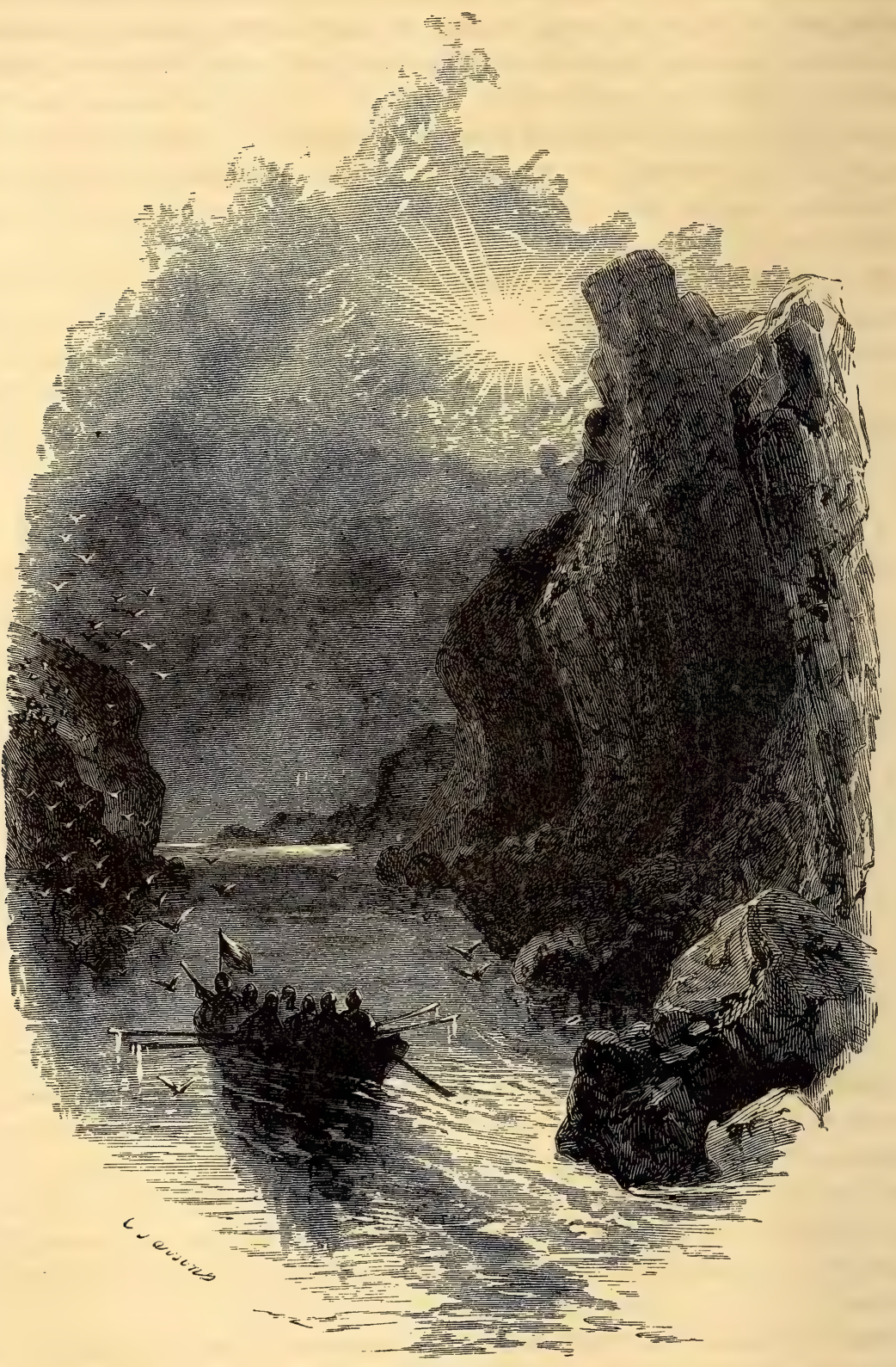

AN ARCTIC CHANNEL.

either in winter or in summer, more than from fifty to a hundred miles from land. And even in the narrow channels separating the islands of the Parry Archipelago, or at the mouth of Smith Sound, the waters will not freeze over, except when sheltered by the land, or when an ice-pack, accumulated by long continuance of winds from one quarter, affords the same protection.

But the constant motion of the Polar Sea, wherever it expands to a consider- 
able breadth, would be insufficient to prevent its total congelation, if it were not assisted by other physical causes. A magnificent system of currents is continually displacing the waters of the ocean, and forcing the warm floods of the tropical regions to wander to the pole, while the cold streams of the frigid zone are as constantly migrating toward the Equator. Thus we see the Gulf Stream flowing thruugh the broad gateway east of Spitzbergen, and forcing out a return current of cold water to the west of Spitzbergen, and through Davis's Strait.

The comparatively warm floods which, in consequence of this great law of circulation, come pouring into the Arctic seas, naturally require some time hefore they are sufficiently chilled to be converted into ice; and as sea-water has its maximum of density, or, in other words, is heaviest a few degrees above the freezing-point of water, and then necessarily sinks, the whole depth of the

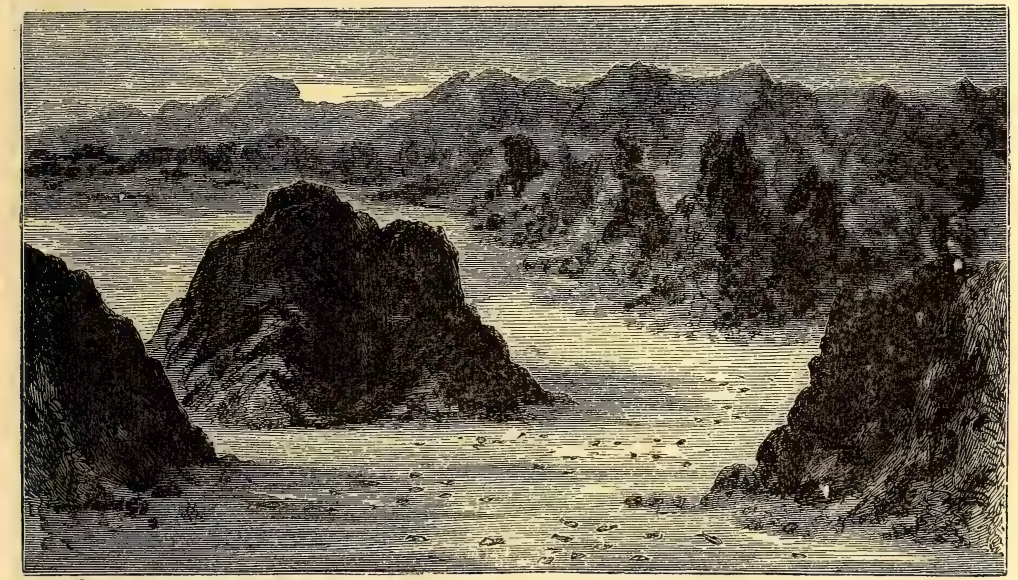

OPEN WATER.

sea must of course be cooled down to that temperature before freezing can take place. Ice being a bad conductor of heat, likewise limits the process of congelation; for after attaining a thickness of ten or fifteen feet, its growth is very slow, and probably even ceases altogether; for when floating fields, or floes, are found of a greater thickness, this increase is due to the snow that falls upon their surface, or to the accumulation of hummocks caused by their collision.

Thus, by the combined influence of these various physical agencies, bounds have been set to the congelation of the Polar waters. Were it otherwise, the Arctic lands would have been mere uninhabitable wastes; for the existence of the seals, the walrus, and the whale depends upon their finding some open water at every season of the year; and deprived of this resource, all the Esquimaux, whose various tribes fringe the coasts in the highest latitudes hitherto discovered, would perish in a single winter.

If the Arctic glaciers did not discharge their bergs into the sea, or if no currents conveyed the ice-floes of the north into lower latitudes, ice would be 
constantly accumulating in the Polar world, and, destroying the balance of nature, would ultimately endanger the existence of man over the whole surface of the globe.

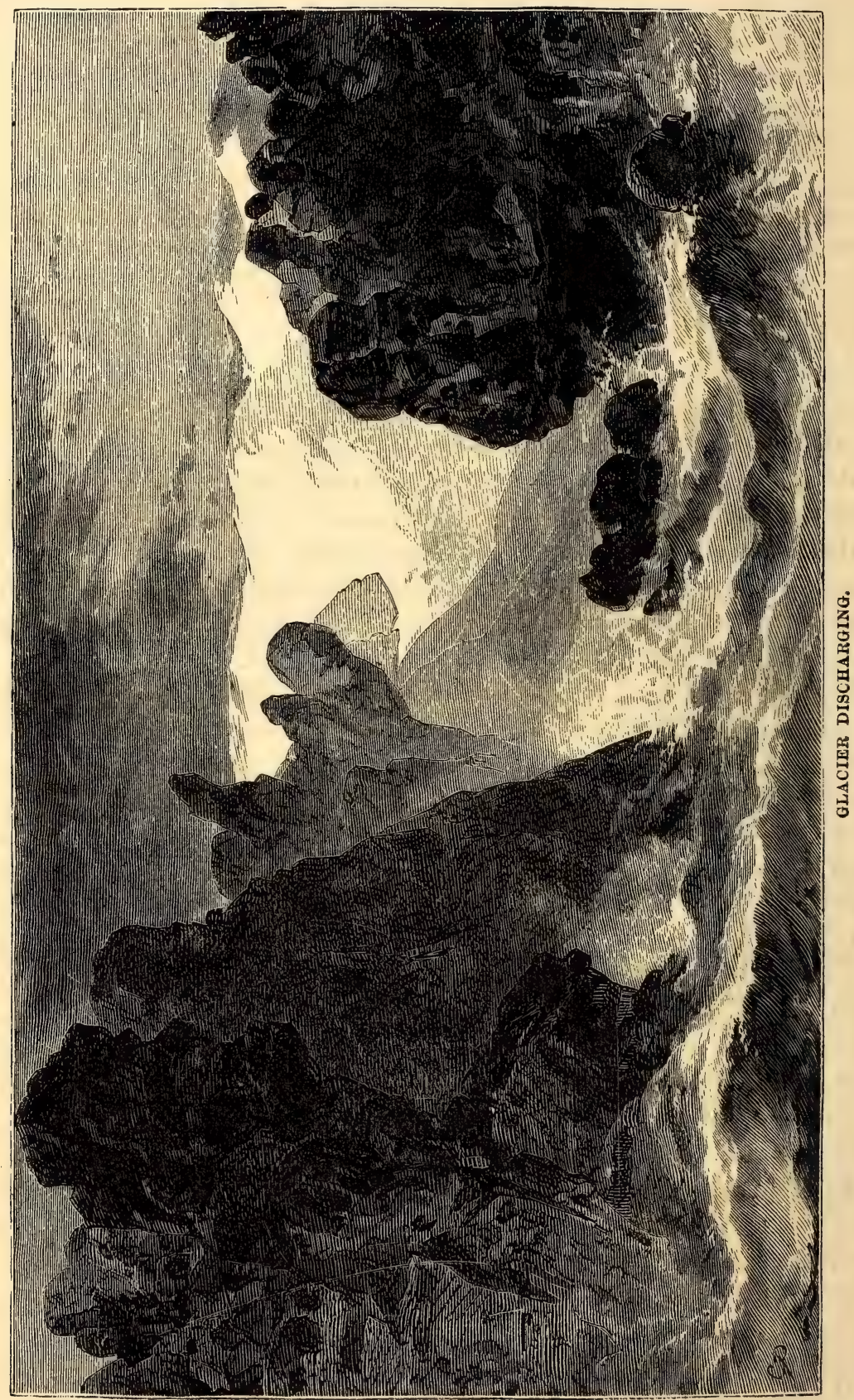




\section{CHAPTER IV.}

\section{ARCTIC MARINE ANIMALS.}

Populousness of the Arctic Seas. - The Greenland Whale. - The Fin Whales. - The Narwhal. The Beluga, or White Dolphin.-The Black Dolphin._His wholesale Massacre on the Faeroe Islands.-The Orc, or Grampus.-The Seals.-The Walrus._Its acute Snell.-History of a young Walrus.-Parental Affection.-The Polar Bear.-His Sagacity.-Hibernation of the She-bear.Sea-birds.

$\mathrm{T}$

HE vast multitudes of animated beings which people the Polar Seas form a remarkable contrast to the nakedness of their bleak and desolate shores. The colder surface-waters almost perpetually exposed to a chilly air, and frequently covered, even in summer, with floating ice, are indeed unfavorable to the development of organic life; but this adverse influence is modified by the higher temperature which constantly prevails at a greater depth; for, contrary to what takes place in the equatorial seas, we find in the Polar Ocean an increase of temperature from the surface downward, in consequence of the warmer under-currents, flowing from the south northward, and passing beneath the cold waters of the superficial Arctic current.

Thus the severity of the Polar winter remains unfelt at a greater depth of the sea, where myriads of creatures find a secure retreat against the frost, and whence they emerge during the long summer's day, either to line the shores or to ascend the broad rivers of the Arctic world. Between the parallels of $74^{\circ}$ and $80^{\circ}$ Scoresby observed that the color of the Greenland sea varies from the purest ultramarine to olive green, and from crystalline transparency to striking opacity-appearances which are not transitory, but permanent. This green semi-opaque water, whose position varies with the currents, often forming isolated stripes, and sometimes spreading over two or three degrees of latitude, mainly owes its singular aspect to small medusæ and nudibranchiate molluscs. It is calculated to form one-fourth part of the surface of the sea between the above-mentioned parallels, so that many thousands of square miles are absolutely teeming with life.

On the coast of Greenland, where the waters are so exceedingly clear that the bottom and every object upon it are plainly visible even at a depth of eighty fathoms, the ground is seen covered with gigantic tangles, which, together with the animal world circulating among their fronds, remind the spectator of the coral-reefs of the tropical ocean. Nullipores, mussels, alcyonians, sertularians, ascidians, and a variety of other sessile animals, incrust every stone or fill every hollow or crevice of the rocky ground. A dead seal or fish thrown into the sea is soon converted into a skeleton by the myriads of small crustaceans which infest these northern waters, and, like the ants in the equatorial forests, perform the part of scavengers of the deep. 
Thus we find an exuberance of life, in its smaller and smallest forms, peopling the Arctic waters, and affording nourishment to a variety of strange and bulky creatures-cetaceans, walruses, and seals-which annually attract thousands of adventurous seamen to the icy ocean.

Of these sea-mammalians, the most important to civilized man is undoubtedly the Greenland whale (Baloena mysticetus), or smooth-back, thus called from its having no dorsal fin. Formerly these whales were harpooned in considerable numbers in the Icelandic waters, or in the fiords of Spitzbergen and Danish Greenland ; then Davis's Straits became the favorite fishing-grounds ; and more recently the inlets and various channe's to the east of Baffin's Bay have been invaded; while, on the opposite side of America, several hundreds of whalers penetrate every year through Bering's Straits into the icy sea beyond, where previously they lived and multiplied, unmolested except by the Esquimaux.

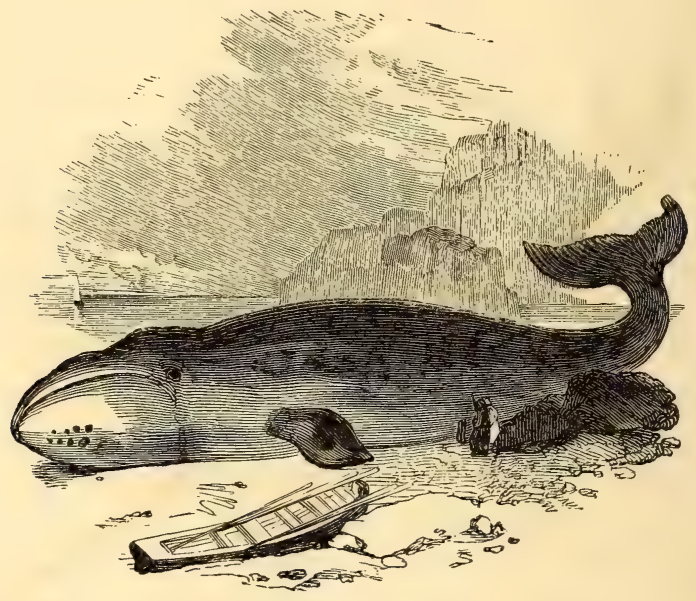

THE WHALE.

More fortunate than the smooth-back, the rorquals, or fin-whales (Balcenoptera boops, musculus, physalis, and rostratus), still remain in their ancient seats, from which they are not likely to be dislodged, as the agility of their movements makes their capture more difficult and dangerous ; while at the same time the small quantity of their fat and the shortness of their baleen render it far less remunerative. They are of a more slender form of body, and with a more pointed muzzle than the Greenland whale; and while the latter attains a length of only sixty feet, the Balcenoptera boops grows to the vast length of 100 feet and more. There is also a difference in their food, for the Greenland whale chiefly feeds upon the minute animals that crowd the olive-colored waters above described, or on the hosts of little pteropods that are found in many parts of the Arctic seas, while the rorquals frequently accompany the herring-shoals, and carry death and destruction into their ranks.

The seas of Novaja Zemlya, Spitzbergen, and Greenland are the domain of the narwhal, or sea-unicorn, a cetacean quite as strange, but not so fabulous as the terrestrial animal which figures in the arms of England. The use of the 
enormous spirally wound tusk projecting from its upper jaw, and from which it derives its popular name, has not yet been clearly ascertained, some holding it to be an instrument of defense, while others suppose it to be only an ornament or mark of the superior dignity of the sex to which it has been awarded.

Among the numerous dolphins which people the Arctic and Subarctic seas, the beluga (Delphinus leucas), improperly called the white whale, is one of the most interesting. When young it has a brown color, which gradually changes into a perfect white. It attains a length of from twelve to twenty feet, has no dorsal fin, a strong tail three feet broad, and a round head with a broad truncated snout. Beyond $56^{\circ}$ of latitude it is frequently seen in large shoals, particularly near the estuaries of the large Siberian and North American rivers, which it often ascends to a considerable distance in pursuit of the salmon. A troop of belugas diving out of the dark waves of the Arctic Sea is said to afford

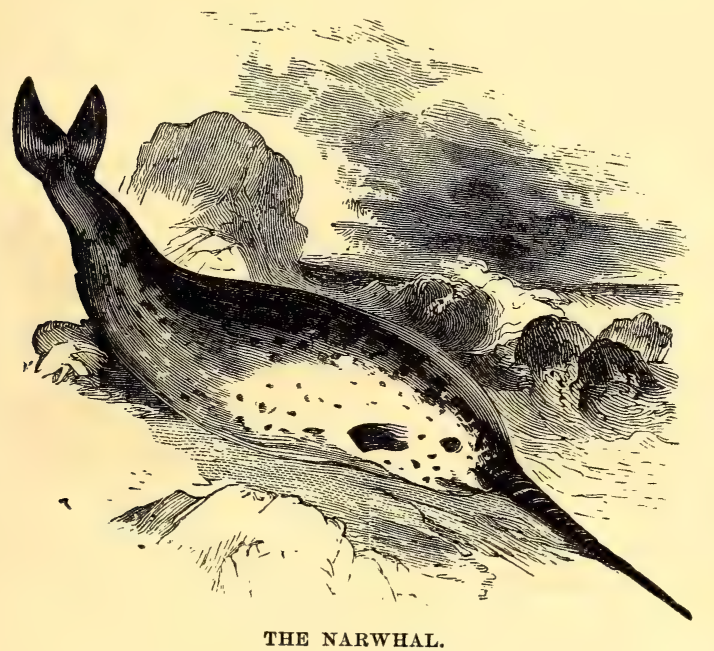

a magnificent spectacle. Their white cclor appears dazzling, from the contrast of the sombre background, as they dart about with arrow.like velocity.

The black dolphin (Globicephalus globiceps) is likewise very common in the Arctic seas, both beyond Bering's Straits and between Greenland and Spitzbergen, whence it frequently makes excursions to the south. It grows to the length of twenty-four feet, and is about ten feet in circumference. The skin, like that of the dolphin tribe in general, is smooth, resembling oiled silk; the color a bluish-black on the back, and generally whitish on the belly; the blubber is three or four inches thick.

The full-grown have generally twenty-two or twenty-four teeth in each jaw; and when the mouth is shut, the teeth lock between one another, like the teeth of a trap. The dorsal fin is about fifteen inches high, the tail five feet broad; the pectoral fins are as many, long and comparatively narrow ; so that, armed with such excellent paddles, the black dolphin is inferior to none of his relatives in swiftness. Of an eminently social disposition, these dolphins sometimes congregate in herds of many hundreds, under the guidance of several old experi. 
enced males, whom the rest follow like a flock of sheep-a property from which the animal is called in Shetland the "ca'ing whale." No cetacean strands more frequently than the black dolphin, and occasionally large herds have been driven on the shores of Iceland, Norway, and the Orkney, Shetland and Faeroe islands, where their capture is hailed as a godsend. The intelligence that a shoal of ca'ing whales or grinds has been seen approaching the coast, creates great excitement among the otherwise phlegmatic inhabitants of the Faeroe Islands. The whole neighborhood, old and young, is instantly in motion, and soon numerous boats shoot off from shore to intercept the retreat of the dolphins. Slowly and steadily they are driven toward the coast; the phalanx of their enemies draws closer and closer together ; terrified by stones and blows, they run ashore, and lie gasping as the flood recedes. Then begins the work of death, amid the loud shouts of the executioners and the furious splashings of the victims. In this manner more than 800 grinds were massacred on August 16, 1776; and during the four summer months that Langbye sojourned on the island in 1817 , 623 were driven on shore, and served to pay one-half of the imported corn. But, on the other hand, many years frequently pass without yielding one single black whale to the tender mercies of the islanders.

The ferocious orc, or grampus (Delphinus orca), is the tiger of the Arctic seas. Black above, white beneath, it is distinguished by its large dorsal fin, which curves backward toward the tail, and rises to the height of two feet or more. Measuring no less than twenty-five feet in length and twelve or thirteen in girth, of a courage equal to its strength, and armed with formidable teeth, thirty in each jaw, the grampus is the dread of the seals, whom it overtakes in spite of their rapid flight; and the whale himself would consider it as his most formidable enemy, were it not for the persecutions of man. The grampus generally ploughs the seas in small troops of four or five, following each other in close single file, and alternately disappearing and rising so as to resemble the undulatory motions of one large serpentiform animal.

The family of the seals has also numerous and mighty representatives in the Arctic waters. In the sea of Bering we meet with the formidable sealion and the valuable sea-bear, while the harp-seal, the bearded seal, and the hispid seals (Phoca groenlandica, barbata, hispida), spreading from the Parry Islands to Novaja Zemlya, yield the tribute of their flesh to numerous wild tribes, and that of their skins to the European hunter.

Few Arctic animals are more valuable to man, or more frequently mentioned in Polar voyages than the walrus or morse (Trichechus rosmarus), which, though allied to the seals, differs greatly from them by the development of the canines of the upper jaw, which form two enormous tusks projecting downward to the length of two feet. The morse is one of the largest quadrupeds existing, as it attains a length of twenty feet, and a weight of from fifteen hundred to two thousand pounds. In uncouthness of form it surpasses even the ungainly hippopotamus. It has a small head with a remarkably thick upper lip, covered with large pellucid whiskers or bristles; the neck is thick and short; the naked gray or red-brown skin hangs loosely on the ponderous and elongated trunk; and the short feet terminate in broad fin-like paddles, resembling large 
ill-fashioned flaps of leather. Its movements on land are extremely slow and awkward, resembling those of a huge caterpillar, but in the water it has all the activity of the seals, or even surpasses them in speed.

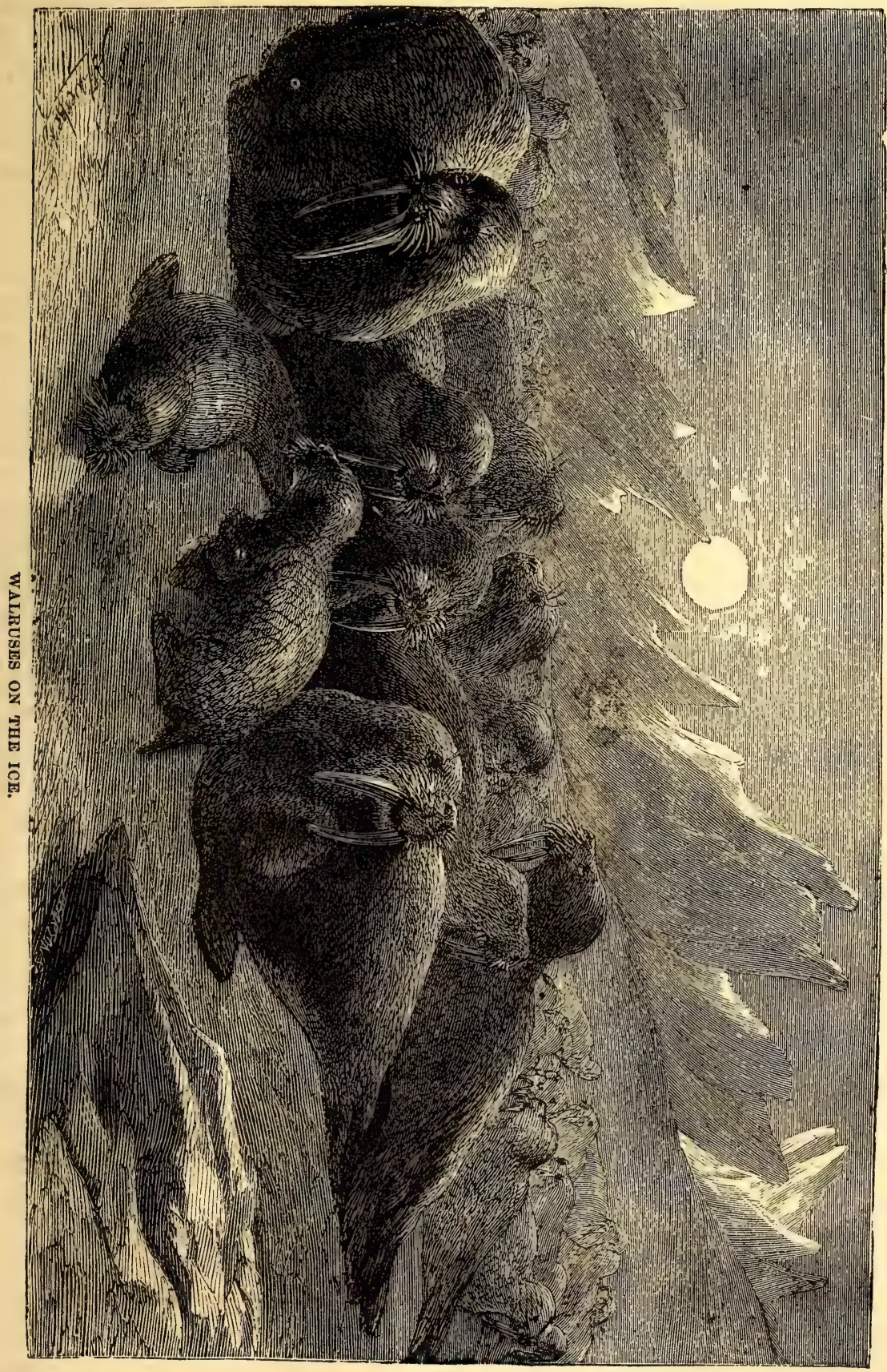

Gregarious, like the seals and many of the dolphins, the walruses love to lie on the ice or on the sand-banks, closely huddled together. On the spot where 
a walrus lands, others are sure to follow; and when the first comers block the shore, those which arrive later, instead of landing on a free spot farther on, prefer giving their friends who are in the way a gentle push with their tusks so as to induce them to make room.

Timorous and almost helpless on land, where, in spite of its formidable tusks, it falls an easy prey to the attacks of man, the walrus evinces a greater degree of courage in the water, where it is able to make a better use of the strength and weapons bestowed upon it by nature. Many instances are known where walruses, which never attack but when provoked, have turned upon their assailants, or have even assembled from a distance to assist a wounded comrade.

Like the seals, the walrus is easily tamed, and of a most affectionate temper. This was shown in a remarkable nanner by a young walrus brought alive from Archangel to St. Petersburg in 1829. Its keeper, Madame Dennebecq, having tended it with the greatest care, the grateful animal expressed its pleasure whenever she came near it by an affectionate grunt. It not only followed her with its eyes, but was never happier than when allowed to lay its head in her lap. The tenderness was reciprocal, and Madame Dennebecq used to talk of her walrus with the same warmth of affection as if it had been a pet lapdog.

That parental love should be highly developed in animuls thus susceptible of friendship may easily be imagined. Mr. Lamont, an English gentleman whom the love of sport led a few years since to Spitzbergen, relates the case of a wounded walrus who held a very young calf under her right arm. Whenever the harpoon was raised against it, the mother carefully shielded it with her own body. The countenance of this poor animal was never to be forgotten: that of the calf expressive of abject terror, and yet of such a boundless confidence in its mother's power of protecting it, as it swam along under her wing, and the old cow's face showing such reckless defiance for all that could be done to herself, and yet such terrible anxiety as to the safety of her calf. This parental affection is shamefully misused by man, for it is a common artifice of the walrus-hunters to catch a young animal and make it grunt, in order tu attract a herd.

The walrus is confined to the coasts of the Arctic regions, unless when driftice, or some other accident, carries it away into the open sea. Its chief resorts are Spitzbergen, Nova Zembla, North Greenland, the shores of Hudson's and Baffin's bays; and on the opposite side of the Polar Ocean, the coasts of Bering's Sea, and to the north of Bering's Straits, the American and Asiatic shores from Point Barrow to Cape North. It has nowhere been found on the coasts of Siberia from the mouth of the Jenisei to the last-mentioned promontory, and on those of America from Point Barrow to Lancaster Sound; so that it inhabits two distinct regions, separated from each other by vast extents of coast. Its food seems to consist principally of marine plants and shell-fish, though Scoresby relates that he found the remains of fishes, or even of seals, in its stomach.

As the Polar bear is frequently found above a hundred miles from the nearest land, upon loose ice steadily drifting into the sea, it seems but fair to assign 
him a place among the marine animals of the Arctic zone. He hunts by scent, and is constantly running across and against the wind, which prevails from the northward, so that the same instinct which directs his search for prey also serves the important purpose of guiding him in the direction of the land and more solid ice. His favorite food is the seal, which he surprises crouching down with his fore paws doubled underneath, and pushing himself noiselessly forward with his hinder legs until within a few yards, when he springs upon his victim, whether in the water or upon the ice. He can swim at the rate of three miles an hour, and can dive to a considerable distance. Though he attacks man when hungry, wounded, or provoked, he will not injure him when food more to his liking is at hand. Sir Francis $\mathrm{M}^{\prime} \mathrm{C}$ Clintock relates an anecdote of a native of Upernavik who was out one dark winter's day visiting his sealnets. He found a seal entangled, and whilst kneeling down over it upon the ice to get it clear, he received a slap on the back-from his companion as he supposed; but a second and heavier blow made him look smartly round. He was horror-stricken to see a peculiarly grim old bear instead of his comrade. Without taking further notice of the man, Bruin tore the seal out of the net, and began his supper. He was not interrupted, nor did the man wait to see the meal finished, fearing, no doubt, that his uninvited and unceremonious guest might keep a corner for him.

Many instances have been observed of the peculiar sagacity of the Polar bear. Scoresby relates that the captain of a whaler, being anxious to procure a bear without wounling the skin, made trial of the stratagem of laying the noose of a rope in the snow, and placing a piece of kreng, or whale's carcass, within it. A bear, ranging the neighboring ice, was soon enticed to the spot. Approaching the bait, he seized it in his mouth; but his foot, at the same moment, by a jerk of the rope, being entangled in the noose, he pushed it off with the adjoining paw, and deliberately retired. After having eaten the piece he carried away with him, he returned. The noose, with another piece of kreng, being then replaced, he pushed the rope aside, and again walked triumphantly off with the kreng. A third time the noose was laid, and this time the rope was buried in the snow, and the bait laid in a deep hole dug in the centre. But Bruin, after snuffing about the place for a few minutes, scraped the snow away with his paw, threw the rope aside, and escaped unhurt with his prize.

'The she-bear is taught by a wonderful instinct to shelter her young under the snow. Towards the month of December she retreats to the side of a rock, where, by dint of scraping and allowing the snow to fall upon her, she forms a cell in which to reside during the winter. There is no fear that she should be stifled for want of air, for the warmth of her breath always keeps a small passage open, and the snow, instead of forming a thick uniform sheet, is broken by a little hole, round which is collected a mass of glittering hoar-frost, caused by the congelation of the breath. Within this strange nursery she produces her young, and remains with them beneath the snow until the month of March, when she emerges into the open air with her baby bears. As the time passes on, the breath of the family, together with the warmth exhaled from their 


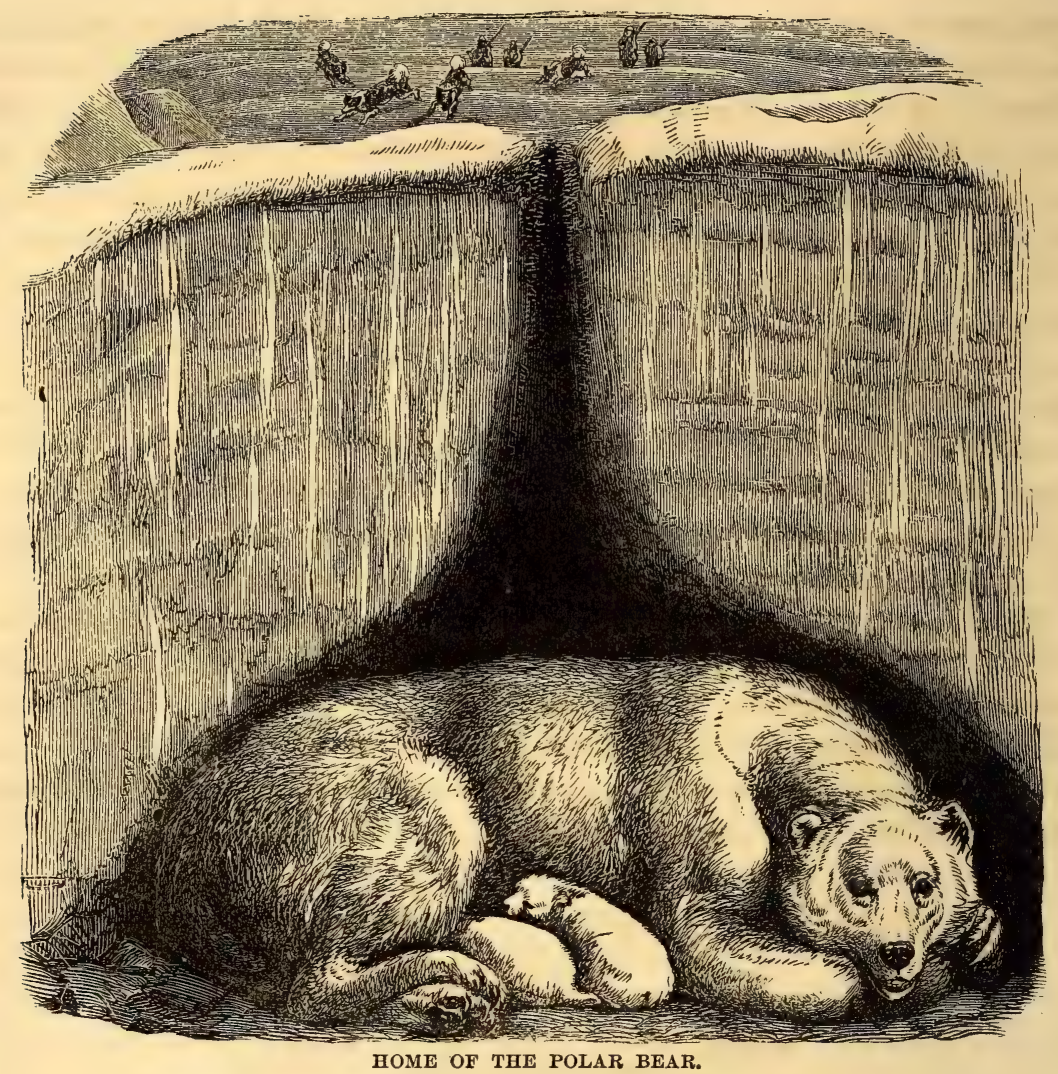

bodies, serves to enlarge the cell, so that with their increasing dimensions the accommodation is increased to suit them. As the only use of the snow-burrow is to shelter the young, the male bears do not hibernate like the females, but roam freely about during the winter months. Before retiring under the snow, the bear eats enormously, and, driven by an unfailing instinct, resorts to the most nutritious diet, so that she becomes prodigiously fat, thus laying in an internal store of alimentary matter which enables her not only to support her own life, but to suckle her young during her long seclusion, without taking a morsel of food. By an admirable provision of nature, the young are of wonderfully small dimensions when compared with the parent; and as their growth, as long as they remain confined in their crystal nursery, is remarkably slow, they consequently need but little food and space.

The Polar bear is armed with formidable weapons, and a proportionate power to use them. His claws are two inches in length, and his canine teeth, exclusive of the part in the jaw, about an inch and a half. Thus the hoards of provisions which are frequently deposited by Arctic voyagers to provide for some future want, have no greater enemy than the Polar bear. "The final cache," says Kane, "which I relied so much upon, was entirely destroyed. It had been built with extreme care, of rocks which had been assembled by very heavy labor, and adjusted with much aid, often, from capstan-bars as levers. 
The entire construction was, so far as our means permitted, most effective and resisting. Yet these tigers of the ice seemed hardly to have encountered an obstacle. Not a morsel of pemmican remained, except in the iron cases, which being round, with conical ends, defied both claws and teeth. They had rolled and pawed them in every direction, tossing them about like footballs, although over eighty pounds in weight. An alcohol can, strongly iron-bound, was dashed into small fragments, and a tin can of liquor smashed and twisted almost into a ball. The claws of the beast had perforated the metal and torn it up as with a chisel. They were too dainty for salt meats; ground coffee they had an evident relish for; old canvas was a favorite, for some reason or other; even our flag, which had been reared 'to take possession' of the waste, was gnawed down to the very staff. They had made a regular frolic of it; rolling our bread-barrels over the ice; and, unable to masticate our heavy India-rubber cloth, they had tied it up in unimaginable hard knots."

Numbers of sea-birds are found breeding along the Arctic shores as far as man has hitherto penetrated; some even keep the sea in the high latitudes all the winter, wherever open water exists. On the most northern rocks the razorbill rears its young, and the fulmar and Ross's gull have been seen in lanes of water beyond $82^{\circ}$ lat. As the sun gains in power, enormous troops of puffins, looms, dovekies, rotges, skuas, burgermasters, Sabine's gulls, kittiwakes, ivory

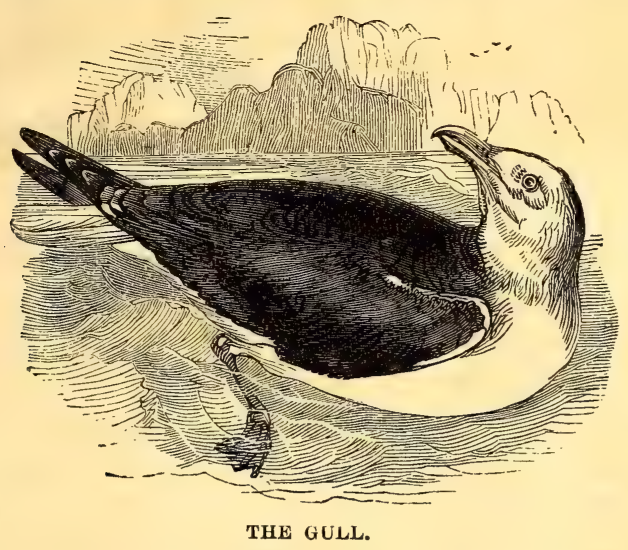

gulls, and Arctic terns, return to the north. There they enjoy the long summer day, and revel in the abundance of the fish-teeming waters, bringing life and animation into solitudes seldom or perhaps never disturbed by the presence of man, and mingling their wild screams with the hoarse-resounding surge or the howling of the storm. In many localities they breed in such abundance, that it may be said, almost without exaggeration, that they darken the sun when they fly, and hide the waters when they swim. 


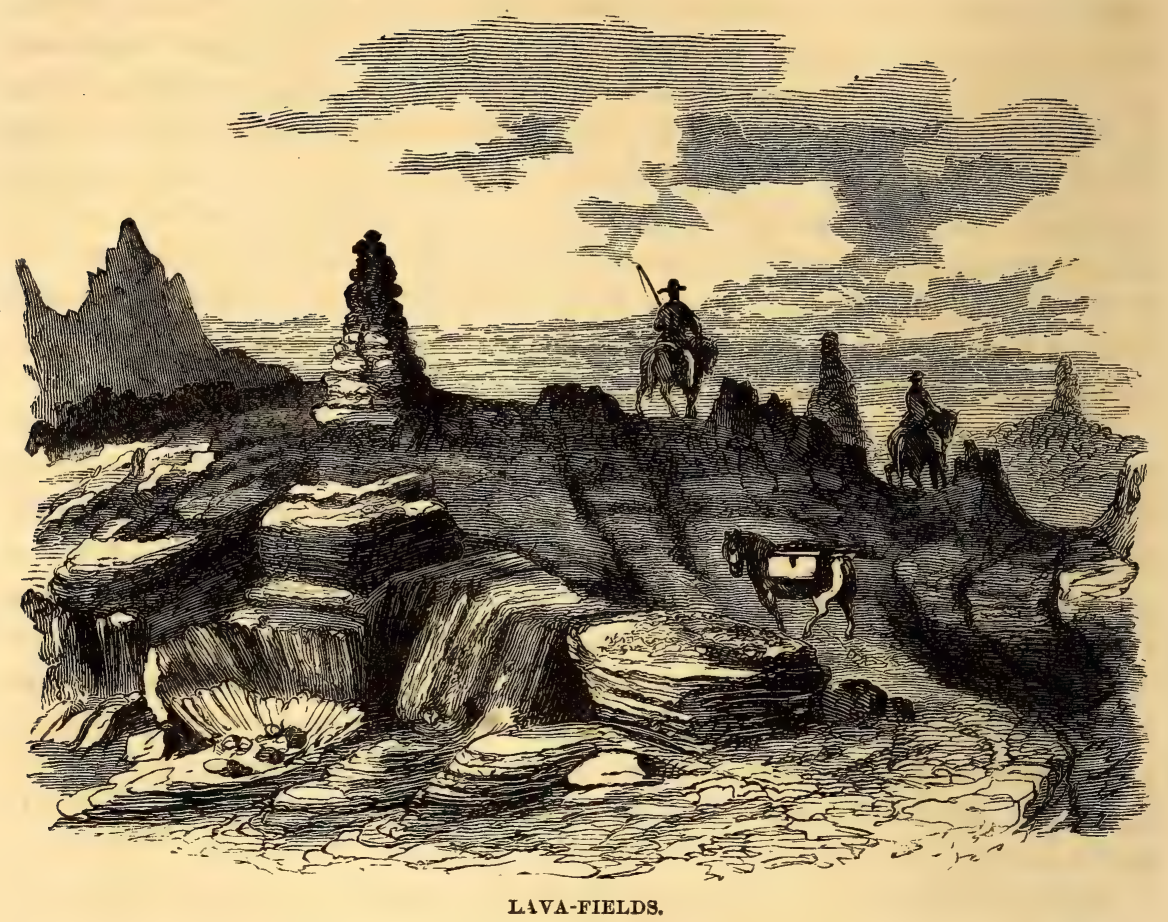

\section{CHAPTER V.}

\section{ICELAND.}

Volcanic Origin of the Island.-The Klofa Jökul.-Lava-streams.-The Burning Mountains of Krisu. vik.-The Mud-caldrons of Reykjahlid.-The Tungo-hver at Reykholt.-The Great Geysir.-The Strokkr.-Crystal Pools. - The Almannagja.-The Surts-hellir.-Beautiful Ice-cave.-The Gotha Foss.-The Detti Foss.-Climate.-Vegetation.-Cattle.-Barbarous Mode of Sheep-sheering.Reindeer.-Polar Bears.-Birds.-The Eider-duck.-Videy.-Vigr.-The Wild Swan.-The Raven.-The Jerfalcon.-The Giant auk, or Geirfugl.-Fish.-Fishing Season.-The White Shark. Mineral Kingdom.-Sulphur.-Peat.-Drift-wood.

TCELAND might as well be called Fireland, for all its 40,000 square miles 1 have originally been upheaved from the depths of the waters by volcanic power. First, at some immeasurably distant period of the world's history, the small nucleus of the future island began to struggle into existence against the superincumbent weight of the ocean; then, in the course of ages, cone rose after cone, crater was formed after crater, eruption followed on eruption, and lava-stream on lava-stream, until finally the Iceland of the present day was piled up with her gigantic "jökuls," or ice-mountains, and her vast promontories, stretching like huge buttresses far out into the sea.

In winter, when an almost perpetual night covers the wastes of this fire-born land, and the waves of a stormy ocean thunder against its shores, imagination can hardly picture a more desolate scene; but in summer the rugged nature of Iceland invests itself with many a charm. Then the eye reposes with de. 
light on green valleys and crystal lakes, on the purple hills or snow-capped mountains rising in Alpine grandeur above the distant horizon, and the stranger might almost be tempted to exclaim with her patriotic sons, "Iceland is the best land under the sun." That it is one of the most interesting-through its history, its inhabitants, and, above all, its natural curiosities-no one can doubt. It has all that can please and fascinate the poet, the artist, the geologist, or the historian; the prosaic utilitarian alone, accustomed to value a country merely by its productions, might turn with some contempt from a land without corn, without forests, without mineral riches, and covered for about two-thirds of its surface with bogs, lava-wastes, and glaciers.

The curse of sterility rests chiefly on the south-eastern and central parts of the island. Here nothing is to be seen but deserts of volcanic stone or immense ice-fields, the largest of which-the Klofa Jökul-alone extends over more than 4000 square miles. The interior of this vast region of névè and glacier is totally unknown. The highest peaks, the most dreadful volcanoes of the island, rise on the southern and south-western borders of this hitherto inaccessible waste; the Oraefa looking down from a height of 6000 feet upon all its rivals - the Skaptar, a name of dreadful significance in the annals of Iceland, and farther on, like the advanced guards of this host of slumbering fires, the Katla, the Myrdal, the Eyjafjalla, and the Hecla, the most renowned, though not the most terrible, of all the volcanoes of Iceland.

As the ice-fields of this northern island far surpass in magnitude those of the Alps, so also the lava-streams of Atna or Vesuvius are insignificant when compared with the enormous masses of molten stone which at various periods have issued from the craters of Iceland. From Mount Skjaldebreith, on hoth sides of the lake of Thingvalla as far as Cape Reykjanes, the traveller sees an uninterrupted lava-field more than sixty miles long, and frequently from twelve to fifteen broad; and lava-streams of still more gigantic proportions exist in many other parts of the island, particularly in the interior. In general, these lava-streams have cooled down into the most fantastic forms imaginable. "It is hardly possible," says Mr. Holland, "to give any idea of the general appearance of these once molten masses. Here a great crag has toppled over into some deep crevasse, there a huge mass has been upheaved above the fiery stream which has seethed and boiled around its base. Here is every shape and figure that sculpture could design or imagination picture, jumbled together in grotesque confusion, whilst everywhere myriads of horrid spikes and sharp shapeless irregularities bristle amidst them."

By the eruptions of the Icelandic volcanoes many a fair meadow-land has been converted into a stony wilderness; but if the subterranean fires have frequently brought ruin and desolation over the island, they have also endowed it with many natural wonders.

In the "burning mountains" of Krisuvik, on the south-western coast, a whole hill-slope, with a deep narrow gorge at its foot, is covered with innumerable boiling springs and fumaroles, whose dense exhalations, spreading an intolerable stench, issue out of the earth with a hissing noise, and completely hide the view. 


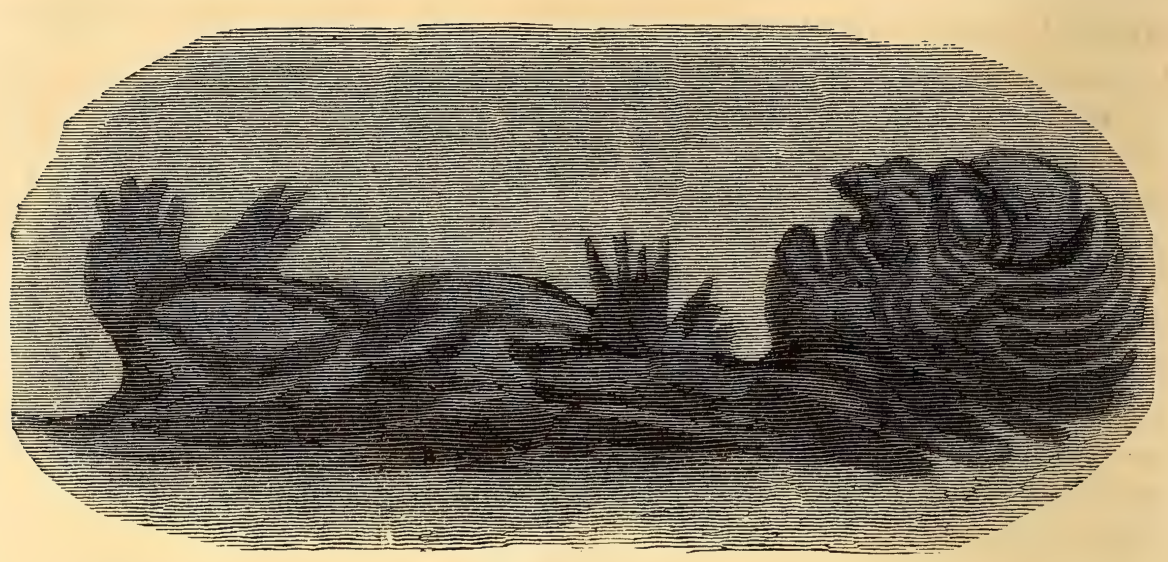

EFFIGY IN LAVA.

The Námar, or boiling mud-caldrons of Reykjahlid, situated among a range of mountains near the Myvatn (Gnat-Lake), in one of the most solitary spots in the north of the island, on the border of enormous lava-fields and of a vast unknown wilderness, exhibit volcanic power on a still more gigantic scale. There are no less than twelve of these seething pits, all filled with a disgusting thick slimy gray or black liquid, boiling or simmering with greater or less vehemence, and emitting dense volumns of steam strongly impregnated with sulphurous gases. Some sputter furiously, scattering their contents on every side, while in others the muddy soup appears too thick to boil, and after remaining quiescent for about half a minute, rises up a few inches in the centre of the basin, emits a puff of steam, and then subsides into its former state. The diameter of the largest of all the pits can not be less than fifteen feet; and it is a sort of mud Geysir, for at intervals a column of its black liquid contents, accompanied with a violent rush of steam, is thrown up to the height of six or eight feet. Professor Sartorius von Waltershausen, one of the few travellers who have visited this remarkable spot, says that the witches in Macbeth could not possibly have desired a more fitting place for the preparation of their infernal gruel than the mud-caldrons of Reykjahlid.

Among the hot or boiling springs of Iceland, which in hundreds of places gush forth at the foot of the mountains, some are of a gentle and even flow, and can be used for bathing, washing, or boiling, while others of an intermittent nature are mere objects of curiosity or wonder. One of the most remarkable of the latter is the Tungo-hver, at Reykholt, in the "valley of smoke," thus named from the columns of vapor emitted by the thermal springs which are here scattered about with a lavish hand. It consists of two fountains within a yard of each other-the larger one vomiting a column of boiling water ten feet high for the space of about four minutes, when it entirely subsides, and then the stnaller one operates for about three minutes, ejecting a column of about five feet. The alternation is perfectly regular in time and force, and there are authentic accounts of its unfailing exactitude for the last hundred years.

But of all the springs and fountains of Iceland there is none to equal, either in grandeur or renown, the Great Geysir, which is not merely one of the curi- 
osities of the country, but one of the wonders of the earth, as there is nothing to compare to it in any other part of the world.

At the foot of the Laugafjall hill, in a green plain, through which several rivers meander like threads of silver, and where chains of dark-colored mountains, overtopped here and there by distant snow-peaks, form a grand but melancholy panorama, dense volumes of steam indicate from afar the site of a whole system of thermal springs congregated on a small piece of ground which does not exceed twelve acres. In any other spot, the smallest of these boiling fountains would arrest the traveller's attention, but here his whole mind is absorbed by the Great Geysir. In the course of countless ages this monarch of springs has formed, out of the silica it deposits, a mound which rises to about thirty feet above the general surface of the plain, and slopes on all sides to the distance of a hundred feet or thereabouts from the border of a large circular basin situated in its centre, and measuring about fifty-six feet in the greatest diameter and fifty-two. feet in the narrowest. In the middle of this basin, forming as it were a gigantic funnel, there is a pipe or tube, which at its opening in the basin is eighteen or sixteen feet in diameter, but narrows considerably at a little distance from the mouth, and then appears to be not more than ten or twelve feet in diameter. It has been probed to a depth of seventy feet, but it is more than probable that hidden channels ramify farther into the bowels of the earth. The sides of the tube are smoothly polished, and so hard that it is not possible to strike off a piece of it with a hammer.

Generally the whole basin is found filled up to the brim with sea-green water as pure as crystal, and of a temperature of from $180^{\circ}$ to $190^{\circ}$. Astonished at the placid tranquillity of the pool, the traveller can hardly believe that he is really standing on the brink of the far-famed Geysir; but suddenly a subterranean thunder is heard, the ground trembles under his feet, the water in the basin begins to simmer, and large bubbles of steam rise from the tube and burst on reaching the sarface, throwing up small jets of spray to the height of several feet. Every instant he expects to witness the grand spectacle which has chiefly induced him to visit this northern land, but soon the basin becomes tranquil as before, and the dense vapors produced by the ebullition are wafted away by the breeze. These smaller eruptions are regularly repeated every eighty or ninety minutes, but frequently the traveller is obliged to wait a whole day, or even longer, before he sees the whole power of the Geysir. A detonation louder than usual precedes one of these grand eruptions; the water in the basin is violently agitated ; the tube boils vehemently ; and suddenly a magnificent column of water, clothed in vapor of a dazzling whiteness, shoots up into the air with immense impetuosity and noise to the height of seventy or eighty feet, and, radiating at its apex, showers water and steam in every direction. A second eruption and a third rapidly follow, and after a few minutes the fairy spectacle has passed away like a fantastic vision. The basin is now completely dried up, and on looking down into the shaft, one is astonished to see the water about six feet from the rim, and as tranquil as in an ordinary well. After about thirty or forty minutes it again begins to rise, and after a few hours reaches the brim of the basin, whence it flows down the slope of the mound 
into the Hvita, or White River. Soon the subterraneous thunder, the shaking of the ground, the simmering above the tube, and the other phenomena which attend each minor eruption, begin again, to be followed by a new period of rest, and thus this wonderful play of nature goes on day after day, year after year, and century after century. The mound of the Geysir bears witness to its immense antiquity, as its water contains but a minute portion of silica.

After the Geysir, the most remarkable fountain of these Phlegrsean fields is the great Strokkr, situated about four hundred feet from the former. Its tube,

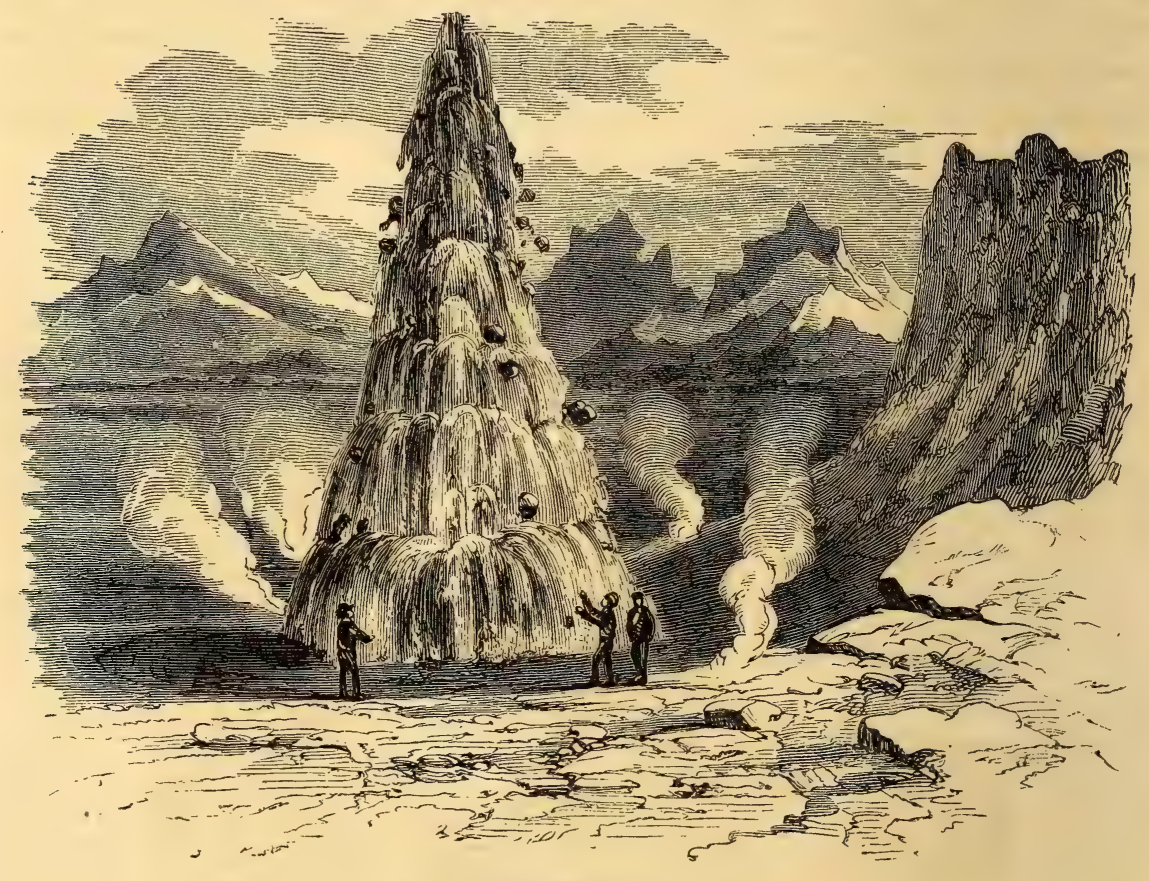

THE STROKKR.

the margin of which is almost even with the general surface, the small mound and basin being hardly discernible, is funnel-shaped, or resembling the flower of a convolvulus, having a depth of forty-eight feet, and a diameter of six feet at the mouth, but contracting, at twenty-two feet from the bottom, to only eleven inches. The water stands from nine to twelve feet under the brim, and is gen. erally in violent ebullition. A short time before the beginning of the eruptions, which are more frequent than those of the Great Geysir, an enormous mass of steam rushes from the tube, and is followed by a rapid succession of jets, sometimes rising to the height of 120 or 150 feet, and dissolving into silvery mist. A peculiarity of the Strokkr is that it can at any time be provoked to an eruption by throwing into the orifice large masses of peat or turf; thus choking the shaft, and preventing the free escape of the steam. After the lapse of about ten minutes, the boiling fluid, as if indignant at this attempt upon its liberty, heaves up a column of mud and water, with fragments of peat, as black as ink. 
About 150 paces from the Great Geysir are several pools of the most beautifully clear water, tinting with every shade of the purest green and blue the fantastical forms of the silicious travertin which clothes their sides. The slightest motion communicated to the surface quivers down to the bottom of these crystal grottoes, and imparts what might be called a sympathetic tremor of the water to every delicate incrustation and plant-like efflorescence. "Aladdin's Cave could not be more beautiful," says Preyer ; and Mr. Holland remarks that neither description nor drawing is capable of giving a sufficient idea of the singularity and loveliness of this spot. In many places it is dangerous to approach within several feet of the margin, as the earth overhangs the water, and is hol. low underneath, supported only by incrustations scarcely a foot thick. A plunge into waters of about $200^{\circ}$ would be paying rather too dearly for the contemplation of their fairy-like beauty.

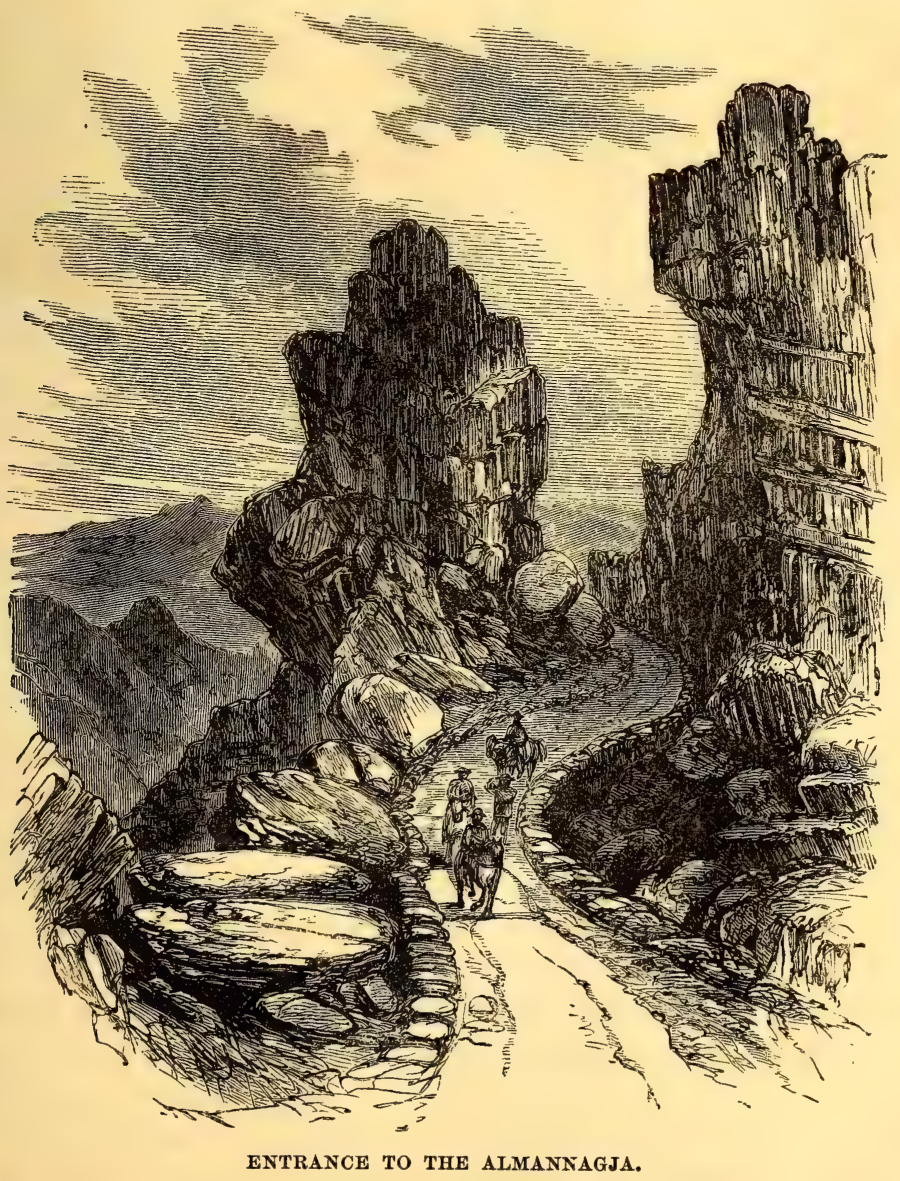

The gigantic chasm of the Almannagja is another of the volcanic wonders of Iceland. After a long and tedious ride over the vast lava-plain which extends between the Skalafell and the lake of Thingvalla, the traveller suddenly finds himself arrested in his path by an apparently insurmountable obstacle, for the 
enormous Almannagja, or Allman's Rift, suddenly gapes beneath his feet-a colossal rent extending above a mile in length, and inclosed on both sides by abrupt walls of black lava, frequently upward of a hundred feet high, and separated from about fifty to seventy feet from each other.

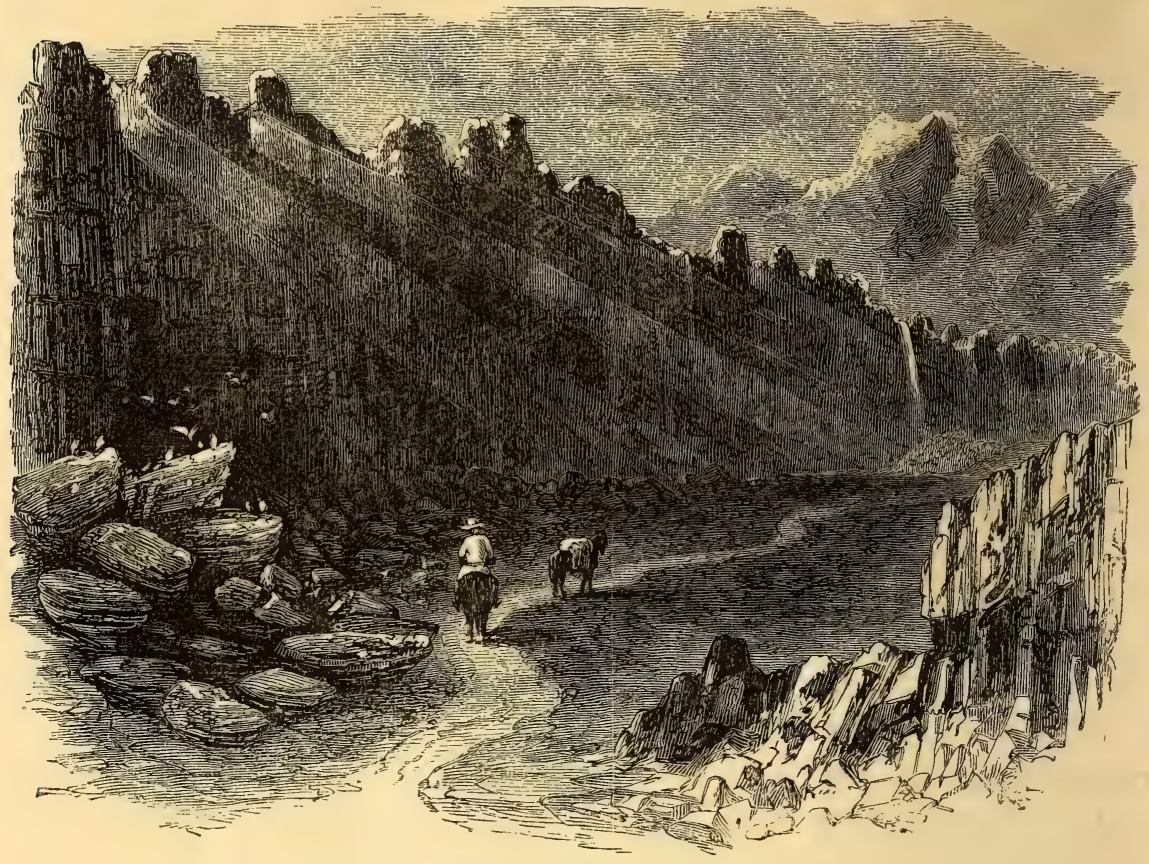

THE ALMANNAGJA.

A corresponding chasm, but of inferior dimensions, the Hrafnagja, or Raven's Rift, opens its black rampart to the east, about eight miles farther on; and both form the boundaries of the verdant plain of Thingvalla, which by a grand convulsion of nature has itself been shattered into innumerable small parallel crevices and fissures fifty or sixty feet deep.

Of the Hrafnagja Mr. Ross Browne says : "A toilsome ride of eight miles brought us to the edge of the Pass, which in point of rugged grandeur far surpasses the Almannagja, though it lacks the extent and symmetry which give the latter such a remarkable effect. Here was a tremendous gap in the earth, over a hundred feet deep, hacked and shivered into a thousand fantastic shapes; the sides a succession of the wildest accidents; the bottom a chaos of broken lava, all tossed about in the most terrific confusion. It is not, however, the extraordinary desolation of the scene that constitutes its principal interest. The resistless power which had rent the great lava-bed asunder, as if touched with pity at the ruin, had also flung from the tottering cliffs a causeway across the gap, which now forms the only means of passing over the great Hrafnagja. No human hands could have created such a colossal work as this; the imaglnation is lost in its massive grandeur; and when we reflect that miles of an almost impassable country would otherwise have to be traversed in order to 


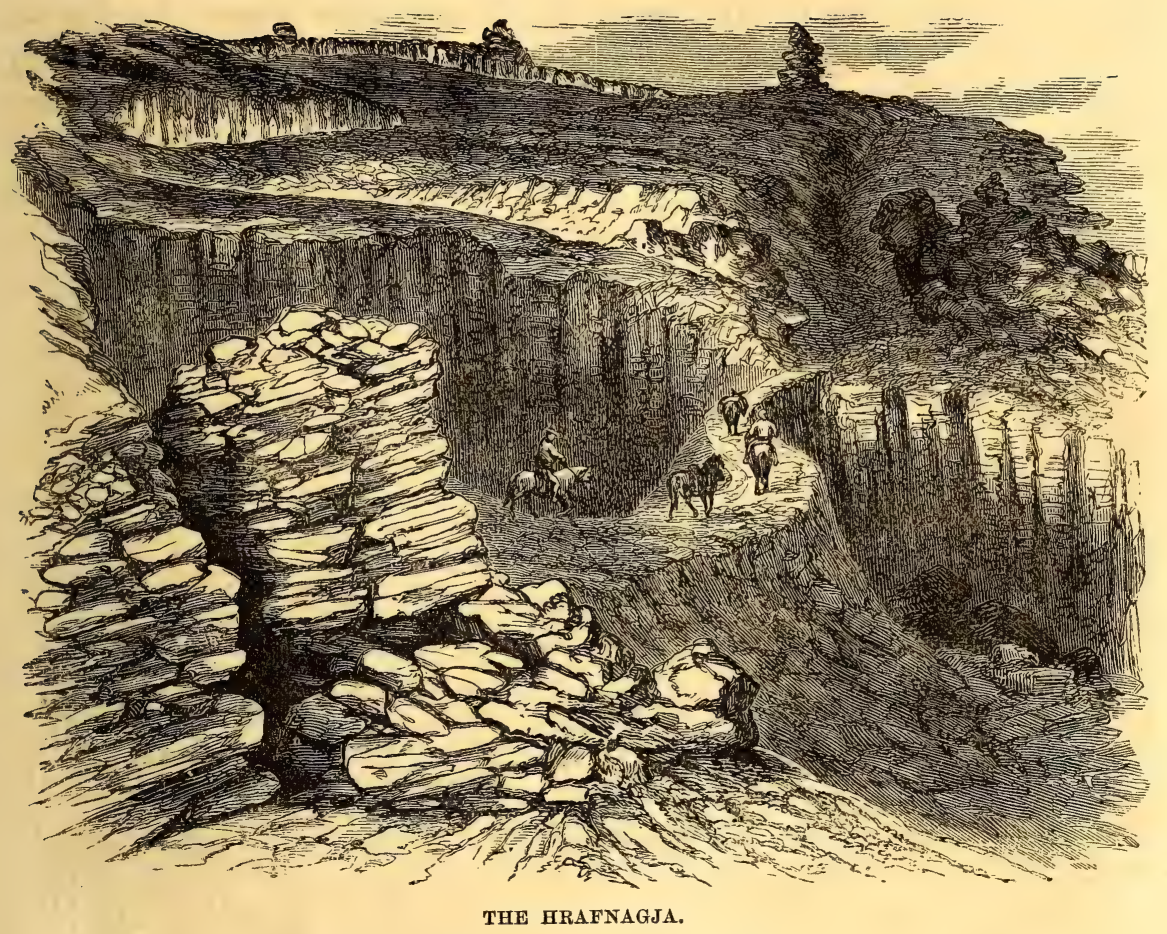

reach the opposite side of the gap, the conclusion is irresistible that in the bat tle of the elements Nature still had a kindly remembrance of man.

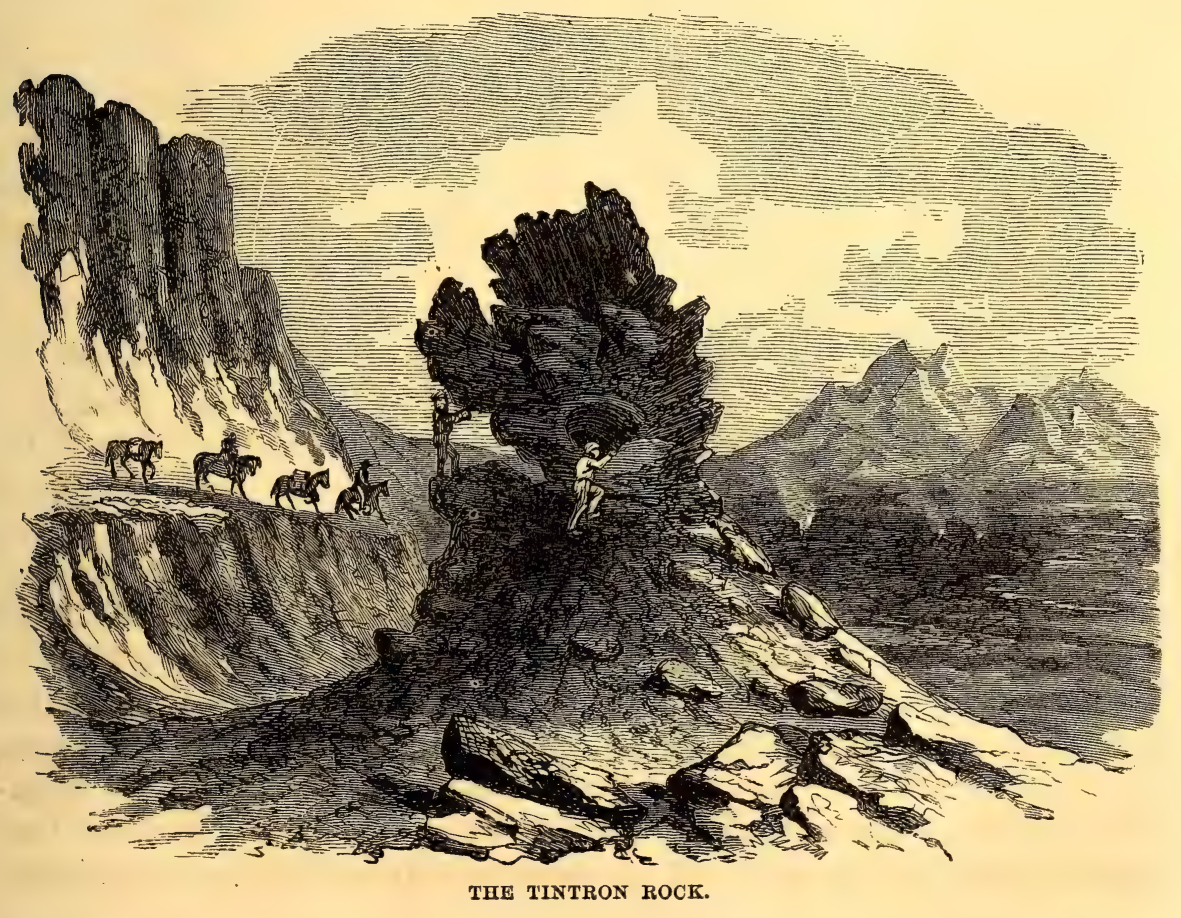


"Five or six miles beyond the Hrafnagja, near the summit of a dividing ridge, we came upon a very singular volcanic formation, called the Tintron. It stands, a little to the right of the trail, on a rise of scoria and burnt earth, from which it juts up in rugged relief to the height of twenty or thirty feet. This is, strictly speaking, a huge clinker, not unlike what comes out of a grate -hard, glassy in spots, and saraggy all over. The top part is shaped like a shell; in the centre is a hole about three feet in diameter, which opens into a vast subterranean cavity of unknown depth. Whether the Tintron is an extinct crater, through which fires shot out of the earth in by-gone times, or an isolated mass of lava, whirled through the air out of some distant volcano, is a question that geologists must determine. The probability is that it is one of those natural curiosities so common in Iceland which defy research. The whole country is full of anomalies-bogs where cne would expect to find dry land, and parched deserts where it would not seem strange to see bogs; fire where water ought to be, and water in the place of fire."

"Ages ago," says Lord Dufferin, "some vast commotion shook the foundations of the island; and bubbling up from sources far away amid the inland hills, a fiery deluge must have rushed down between their ridges, until, escaping from the narrower gorges, it found space to spread itself into one broad sheet of molten stone over an entire district of country, reducing its varied surface to one vast blackened level. One of two things then occurred: either,

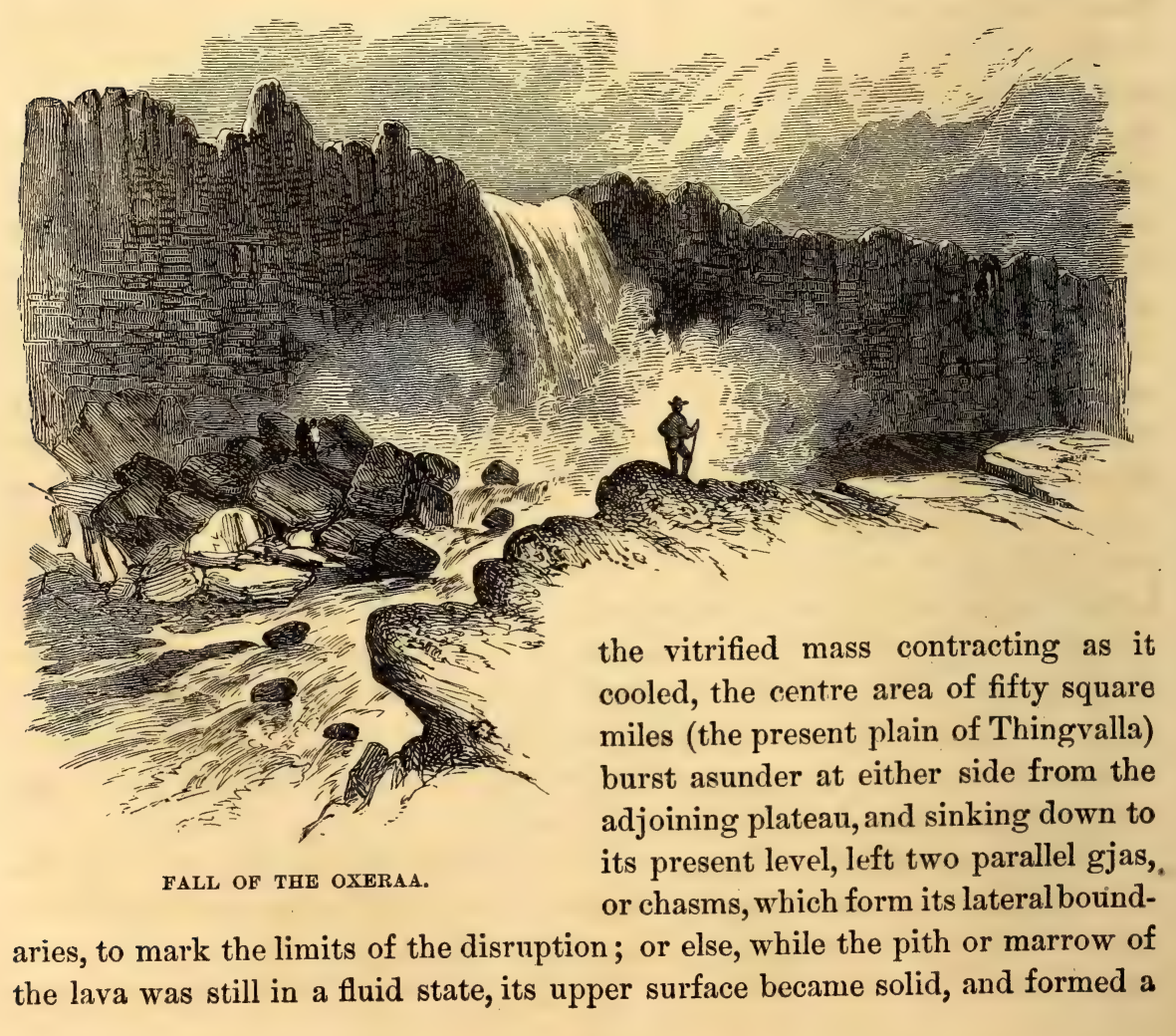


roof, beneath which the molten stream flowed on to lower levels, leaving a vast cavern into which the upper crust subsequently plumped down." In the lapse of years, the bottom of the Almannagja has become gradually filled up to an even surface, covered with the most beautiful turf, except where the river Oxeraa, bounding in a magnificent cataract from the higher plateau over the precipice, flows for a certain distance between its walls. At the foot of the fall the waters linger for a moment in a dark, deep, brimming pool, hemmed in by a circle of ruined rocks, in which anciently all women convicted of capital crimes were immediately drowned. Many a poor crone, accused of witcheraft, has thus ended her days in the Almannagja. As may easily be imagined, it is rather a nerve-trying task to descend into the chasm over a rugged lava-slope, where the least false step may prove fatal; but the Icelandic horses are so sure-footed that they can safely be trusted. From the bottom it is easy to distinguish on the one face marks and formations exactly corresponding, though at a different level, with those on the face opposite, and evidently showing that they once had dovetailed into each other, before the igneous mass was rent asunder.

Two leagues from Kalmanstunga, in an immense lava-field, which probably originated in the Bald Jökul, are situated the renowned Surts-hellir, or caves of Surtur, the prince of darkness and fire of the ancient Scandinavian mythology. The principal entrance to the caves is an extensive chasm formed by the falling in of a part of the lava-roof ; so that, on descending into it, the visitor finds himself right in the mouth of the main cavern, which runs in an almost straight line, and is nearly a mile in length. Its average height is about forty, and its breadth fifty feet. The lava-crust which forms its roof is about twelve feet thick, and has the appearance of being stratified and columnar, like basaltic pillars, in its formation. Many of the blocks of lava thus formed have become detached and fallen into the cavern, where they lie piled up in great heaps, and heavily tax the patience of the traveller, who has to scramble over the rugged stones, and can hardly avoid slipping and stumbling into the holes between them, varied by pools of water and masses of snow. But after having toiled and plodded to the extremity of this dismal cavern, his perseverance is amply rewarded by the sight of an ice-grotto, whose fairy beauty appears still more charming, in contrast with its gloomy vestibule. From the crystal floor rises group after group of transparent pillars tapering to a point, while from the roof brilliant icy pendants hang down to meet them. Columns and arches of ice are ranged along the crystalline walls, and the light of the candles is reflect. ed back a hundred-fold from every side, till the whole cavern shines with astonishing lustre. Mr. Holland, the latest visitor of the Surts-hellir, declares he never saw a more brilliant spectacle; and the German naturalist, Preyer, pronounces it one of the most magnificent sights in nature, reminding him of the fairy grottoes of the Arabian Nights' Tales.

From the mountains and the vast plateau which occupies the centre of the island, numerous rivers descend on all sides, which, fed in summer by the melting glaciers, pour enormous quantities of turbid water into the sea, or convert large alluvial flats into morasses. Though of a considerable breadth, their 
course is frequently very short, particularly along the southern coast, where the jokuls from which they derive their birth are only separated from the sea by a narrow foreland. In their impetuous flow, they not seldom bear huge blocks of stone along with them, and cut off all communication between the inhabitants of their opposite banks.

The chief rivers of Iceland are, in the south, the Thiorsa and the Hvita, which are not infernor in widtn to the Rhine in the middle part of its course; * in the north, the Skjalfandafljot and the Jökulsa and the Jökulsa i Axarfirdi, large and rapid streams above a hundred miles long; and in the east the Lagarfliot. As may be expected in a mountainous country, containing many glacier-fed rivers, Iceland has numerous cascades, many of them rivalling or surpassing in beauty the far-famed falls of Switzerland.

One of the most celebrated of these gems of nature is the Goda-foss, in the northern part of the island, formed by the deep and rapid Skjalfandafljot, as it rushes with a deafening roar over rocks fifty feet high into the caldron below; but it is far surpassed in magnificence by the Dettifoss, a fall of the Jökulsa $i$ Axarfirdi.

"In some of old earth's convulsions," says its discoverer, Mr. Gould,--for from its remote situation, deep in the northern wilds of Iceland, it had escaped the curious eye of previous travellers-" the crust of rock has been rent, and a frightful fissure formed in the basalt, about 200 feet deep, with the sides columnar and perpendicular. The gash terminates abruptly at an acute angle, and at this spot the great river rolls in. The wreaths of water sweeping down; the frenzy of the confined streams where they meet, shooting into each other from either side at the apex of an angle; the wild rebound when they strike a head of rock, lurching out half way down; the fitful gleam of battling torrents, obtained through a veil of eddying vapor; the Geysir-spouts which blow up about seventy feet from holes whence basaltic columns have been shot by the force of the descending water; the blasts of spray which rush upward and burst into fierce showers on the brink, feeding rills which plunge over the edge as soon as they are born; the white writhing vortex below, with now and then an ice-green wave tearing through the foam to lash against the walls; the thunder and bellowing of the water, which make the rock shudder under foot, are all stamped on my mind with a vividness which it will take years to efface. The Almannagja is nothing to this chasm, and Schaffhausen is dwarfed by Dettifoss."

The ocean-currents which wash the coasts of Iceland from opposite directions have a considerable influence on its climate. The south and west coasts, fronting the Atlantic, and exposed to the Gulf Stream, remain ice-free even in winter, and enjoy a comparatively mild temperature, while the cold Polar current, flowing in a south-western direction from Spitzbergen to Jan Mayen and Iceland, conveys almost every year to the eastern and northern shores of the island large masses of drift-ice, which sometimes do not disappear before July or even August. According to Dr. Thorstensen, the mean annual temperature of the air at Reykjavik is $+40^{\circ}$, and that of the sea $+42^{\circ}$, while according to Herr von Scheele the mean annual temperature at Akureyre, on the north coast, 
is only $+33^{\circ}$, though even this shows a comparatively mild climate in so high a latitude. But if Iceland, thanks to its insular position and to the influence of the Gulf Stream, remains free from the excessive winter cold of the Arctic continents, its summer, on the other hand, is inferior in warmth to that which reigns in the interior of Siberia, or of the Hudson's Bay territories.

The mean summer temperature at Reykjavik is not above $+54^{\circ}$; during many years the thermometer never rises a single time above $+80^{\circ}$; sometimes even its maximum is not higher than $+59^{\circ}$; and, on the northern coast, snow not seldom falls even in the middle of summer. Under such circumstances, the cultivation of the cereals is of course impossible; and when the drift-ice remains longer than usual on the northern coasts, it prevents even the growth of the grass, and want and famine are the consequence.

The Icelandic summer is characterized by constant changes in the weather, rain continually alternating with sunshine, as with us in April. The air is but seldom tranquil, and storms of terrific violence are of frequent occurrence. Towards the end of September winter begins, preceded by mists, which finally descend in thick masses of snow. Travelling over the mountain-tracks is at this time particularly dangerous, although cairns or piles of stone serve to point out the way, and here and there, as over the passes of the Alps, small huts have been erected to serve as a refuge for the traveller.

In former times Iceland could boast of forests, so that houses and even ships used to be built of indigenous timber; at present it is almost entirely destitute of trees, for the dwarf shrubberies here and there met with, where the birch hardly attains the height of twenty feet, are not to be dignified with the name of woods. A service-tree (Sorbus ancuparia) fourteen feet high, and measuring three inches in diameter at the foot, is the boast of the governor's garden at Reykjavik ; it is, however, surpassed by another at Akureyre, which spreads a full crown twenty feet from the ground, but never sees its clusters of berries ripen into scarlet.

The damp and cool Icelandic summer, though it prevents the successful cultivation of corn, is favorable to the growth of grasses, so that in some of the better farms the pasture-grounds are hardly inferior to the finest meadows in England. About one-third of the surface of the country is covered with vegetation of some sort or other fit for the nourishment of cattle; but, as yet, art has done little for its improvement-ploughing, sowing, drainage, and levelling being things undreamt of. With the exception of the grasses, which are of paramount importance, and the trees, which, in spite of their stunted proportions, are of great value, as they supply the islanders with the charcoal needed for shoeing their horses, few of the indigenous plants of Iceland are of any use to man. The Angelica archangelica is eaten raw with butter; the matted roots or stems of the Menyanthes trifoliata serve to protect the backs of the horses against the rubbing of the saddle; and the Icelandic moss, which is frequently boiled in milk, is likewise an article of exportation. The want of better grain frequently compels the poor islanders to bake a kind of bread from the seeds of the sand-reed (Elymus arenarius), which on our dunes are merely picked by the birds of passage; and the oarweed or tangle (Laminaria sac- 
charina) is prized as a vegetable in a land where potatoes and turnips are but rarely cultivated.

When the first settlers came to Iceland, they found but two indigenons land-quadrupeds: a species of field-vole (Arvicola oeconomus) and the Arctic fox ; but the seas and shores were no doubt tenanted by a larger number of whales, dolphins, and seals than at the present day.

The ox, the sheep, and the horse which accompanied the Norse colonists to their new home, form the staple wealth of their descendants; for the number of those who live by breeding cattle is as three to one, compared with those who chiefly depend on the sea for their subsistence. Milk and whey are almost the only beverages of the Icelanders. Without butter they will eat no fish; and curdled milk, which they eat fresh in summer and preserve in a sour state during the winter, is their favorite repast. Thus they set the highest value on their cattle, and tend them with the greatest care. In the preservation of their sheep, they are much hampered by the badness of the climate, by the scantiness of winter food, and by the attacks of the eagles, the ravens, and the foxes, more particularly at the lambing season, when vast numbers of the young animals are carried off by all of them. The wool is not sheared off, but torn from the animal's back, and woven by the peasantry, during the long winter evenings, into a kind of coarse cloth, or knit into gloves and stockings, which form one of the chief articles of export.

"While at breakfast," says Mr. Shepherd, "we witnessed the Icelandic method of sheep-shearing. Three or four powerful young women seized, and easily threw on their backs the struggling victims. The legs were then tied, and the wool pulled off by main force. It seemed, from the contortions of some of the wretched animals, to be a cruel method; but we were told that there is a period in the year when the young wool, beginning to grow, pushes the old out before it, so that the old coat is easily pulled out." The number of heads of cattle in the island is about 40,000 , that of the sheep 500,000 .

The horses, which number from 50,000 to 60,000 , though small, are very robust and hardy. There being no wheel carriages on the island, they are merely used for riding and as beasts of burden. Their services are indispensable, as without them the Icelanders would not have the means of travelling and carrying their produce to the fishing villages or ports at which the annual supplies arrive from Copenhagen. In winter the poor animals must find their own food, and are consequently mere skeletons in spring; they, however, soon recover in summer, though even then they have nothing whatever but the grass and small plants which they can pick up on the hills.

The dogs are very similar to those of Lapland and Greenland. Like them, they have long hair, forming a kind of collar round the neck, a pointed nose, pointed ears, and an elevated curled tail, with a temper which may be characterized as restless and irritable. Their general color is white.

In the year 1770 thirteen reindeer were brought from Norway. Ten of them died during the passage, but the three that survived have multiplied so fast that large herds now roam over the uninhabited wastes. During the winter, when hunger drives them into the lower districts, they are frequently shot; 


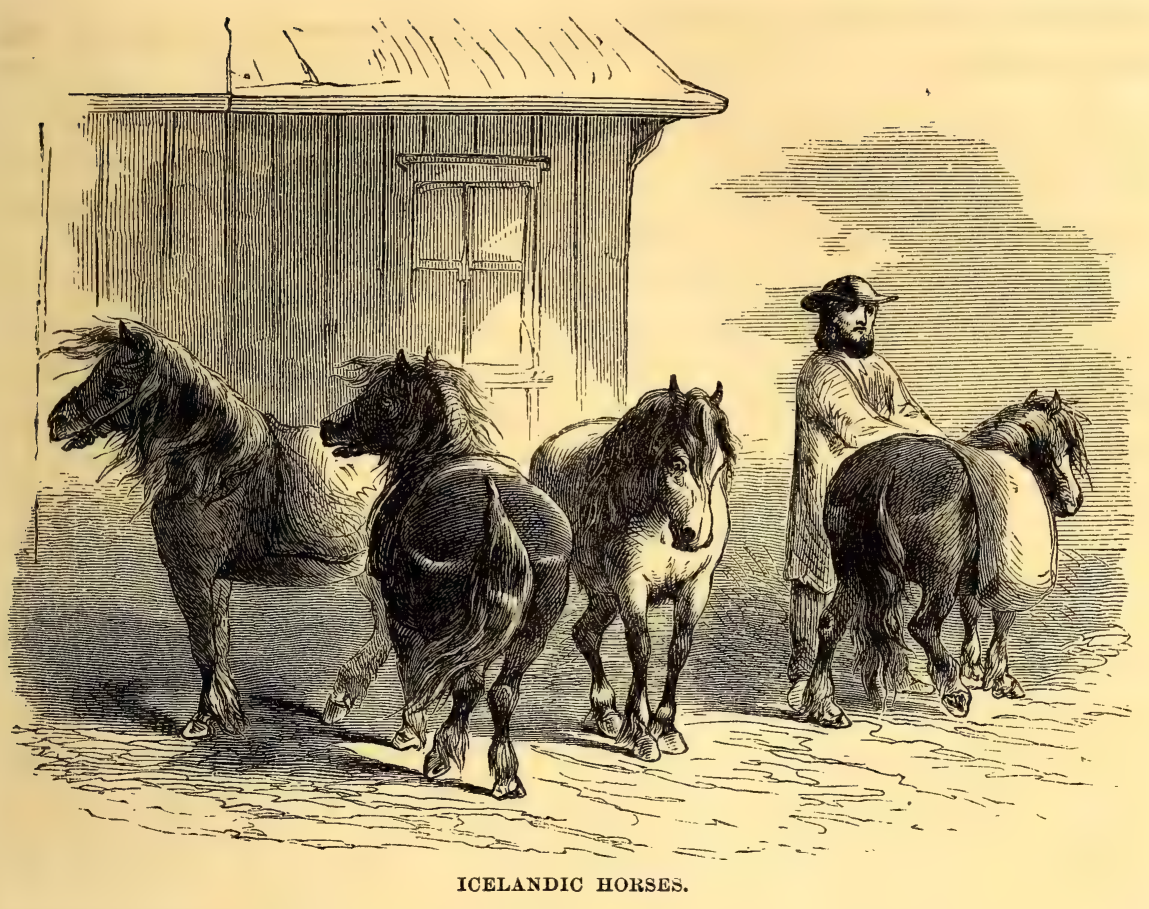

but no attempts have been made to tame them; for, though indispensable to the Laplander, they are quite superfluous in Iceland, which is too rugged and too much intersected by streams to admit of sledging. They are, in fact, generally considered as a nuisance, as they eat away the Icelandic moss, which the islanders would willingly keep for their own use.

The Polar bear is but a casual visitor in Iceland. About a dozen come drifting every year with the ice from Jan Mayen, or Spitzbergen, to the northern shores. Ravenous with hunger, they immediately attack the first herds they meet with ; but their ravages do not last long, for the neighborhood, arising in arms, soon puts an end to their existence.

In Iceland the ornithologist finds a rich field for his favorite study, as there are no less than eighty-two different species of indigenous birds, besides twentyone that are only casual visitors, and six that have been introduced by man.

The swampy grounds in the interior of the country are peopled with legions of golden and king plovers, of snipes and red-shanks; the lakes abound with swans, ducks, and geese of various kinds; the snow-bunting enlivens the solitude of the rocky wilderness with his lively note, and, wherever grass grows, the common pipit (Anthus pratensis) builds its neat little nest, well lined with horsehair. Like the lark, he rises singing from the ground, and frequently surprises the traveller with his melodious warbling, which sounds doubly sweet in the lifeless waste.

The eider-duck holds the first rank among the useful birds of Iceland. Its chief breeding-places are small flat islands on various parts of the coast, where it is safe from the attacks of the Arctic fox, such as Akurey, Flatey, and Videy, 
which, from its vicinity to Reykjavik, is frequently visited by travellers. All these breeding-places are private property, and several have been for centuries

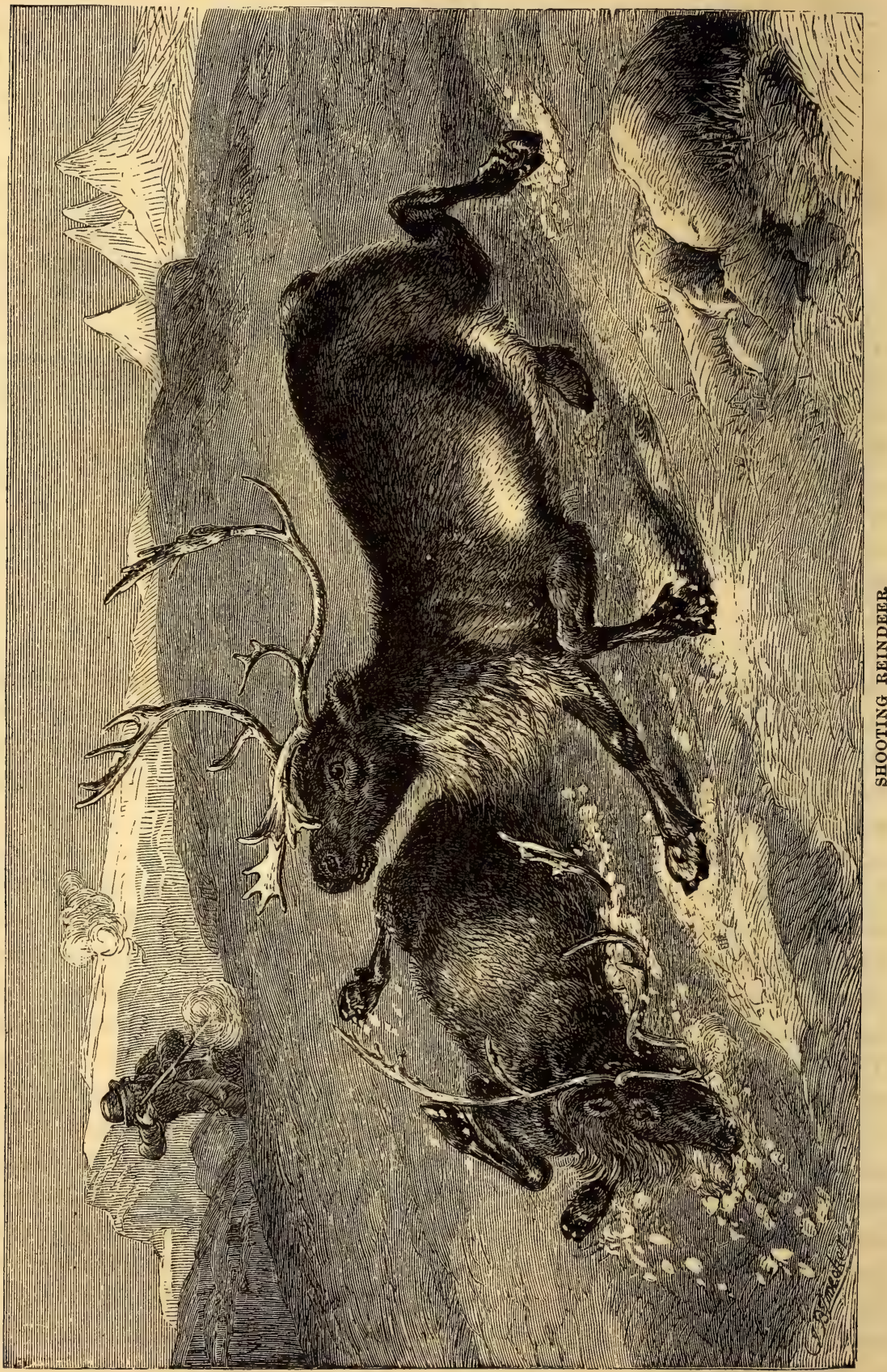

in the possession of the same families, which, thanks to the birds, are among the wealthiest of the land. It may easily be imagined that the eider-ducks are guarded with the most sedulous care. Whoever kills one is obliged to pay a 


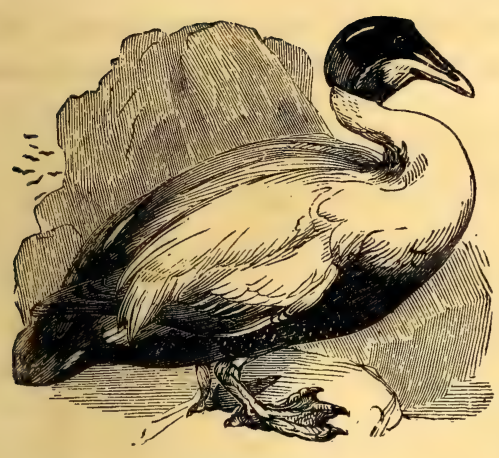

EIDER-DUCK.

fine of thirty dollars; and the secreting of an egg, or the pocketing of a few downs, is punished with all the rigor of the law. The chief occupation of Mr. Stephenson, the aged proprietor of Videy, who dwells alone on the islet, is to examine through his telescope all the boats that approach, so as to be sure that there are no guns on board. During the breeding season no one is allowed to land without his special permission, and all noise, shouting, or loud speaking is strictly prohibited. But, in spite of these precautions, we are informed by recent travellers that latterly the greater part of the ducks of Videy have been tempted to leave their old quarters for the neighboring Engey, whose proprietor hit upon the plan of laying hay upon the strand, so as to afford them greater facilities for nest-building. The eider-down is easily collected, as the birds are quite tame. The female having laid five or six pale greenish-olive eggs, in a nest thickly lined with her beautiful down, the collectors, after carefully removing the bird, rob the nest of its contents, after which they replace her. She then begins to lay afresh, though this time only three or four eggs, and again has recourse to the down on her body. But her greedy persecutors once more rifle her nest, and oblige her to line it for the third time. Now, however, her own stock of down is exhausted, and with a plaintive voice she calls her mate to her assistance, who willingly plucks the soft feathers from his breast to supply the deficiency. If the cruel robbery be again repeated, which in former times was frequently the case, the poor eider-duck abandons the spot, never to return, and seeks for a new home where she may indulge her maternal instinct undisturbed.

Mr. Shepherd thus describes his visit to Vigr, in the Isafjardardjup, one of the head-quarters of the eider-duck in the north of Iceland: "As the island was approached, we could see flocks upon flocks of the sacred birds, and could hear their cooings at a great distance. We landed on a rocky wave-worn shore, against which the waters scarcely rippled, and set off to investigate the island. The shore was the most wonderful ornithological sight conceivable. The ducks and their nests were everywhere in a manner that was quite alarming. Great brown ducks sat upon their nests in masses, and at every step started up from under our feet. It was with difficulty that we avoided treading on some of the nests. The island being but three-quarters of a mile in width, the opposite shore was soon reached. On the coast was a wall built of large stones, just above the high-water level, about three feet in height, and of considerable thickness. At the bottom, on both sides of it, alternate stones had been left out, so as to form a series of square compartments for the ducks to make their nests in. Almost every compartment was occupied; and, as we walked along the shore, a long line of ducks flew out one after another. The surface of the water also was perfectly white with drakes, who welcomed their brown wives with loud and clamorous cooing. When we arrived at the farmhouse we were 
cordially welcomed by its mistress. The house itself was a great marvel. The earthern wall that surrounded it and the window embrasures were occupied by ducks. On the ground, the house was fringed with ducks. On the turf-slopes of the roof we could see ducks; and a duck sat in the scraper.

"A grassy bank close by had been cut into square patches like a chessboard (a square of turf of about eighteen inches being removed, and a hollow made), and all were filled with ducks. A windmill was infested, and so were all the outhouses, mounds, rocks, and crevices. The ducks were everywhere. Many of them were so tame that we could stroke them on their nests; and the good lady told us that there was scarcely a duck on the island which would not allow her to take its eggs without flight or fear. When she first became possessor of the island, the produce of down from the ducks was not more than fifteen pounds' weight in the year, but, under her careful nurture of twenty years, it had risen to nearly one hundred pounds annually. It requires about one pound and a half to make a coverlet for a single bed, and the down is worth from twelve to fifteen shillings per pound. Most of the eggs are taken and pickled for winter consumption, one or two only being left to hatch."

Though not so important as the eider, the other members of the duck family which during the summer season enliven the lakes and swamps of Iceland are very serviceable. On the Myvatn, or Gnat Lake, one of their chief places of resort, the eggs of the long-tailed duck, the wild duck, the scoter, the common goosander, the red-breasted merganser, the scaup-duck, etc., and other anserines are carefully gathered and preserved in enormous quantities for the winter, closely packed in a fine gray volcanic sand.

The wild swan is frequently shot or caught for his feathers, which bring in many a dollar to the fortunate huntsman. This noble bird frequents both the salt and brackish waters along the coast and the inland lakes and rivers, where it is seen either in single pairs or congregated in large flocks. To build its nest, which is said to resemble closely that of the flamingo, being a large mound, composed of mud, rushes, grass, and stones, with a cavity at top lined with soft down, it retires to some solitary, uninhabited spot. Much has been said in ancient times of the singing of the swan, and the beauty of its dying notes; but, in truth, the voice of the swan is very loud, shrill, and harsh, though when high in the air, and modulated by the winds, the note or whoop of an assemblage of them is not unpleasant to the ear. It has a peculiar charm in the unfrequented wastes of Iceland, where it agreeably interrupts the profound silence that reigns around.

The raven, one of the commonest land-birds in Iceland, is an object of aversion to the islanders, as it not only seizes on their young lambs and eider-ducks, but also commits great depredations among the fishes laid out to dry upon the shore. Poles to which dead ravens are attached, to serve as a warning to the living, are frequently seen in the meadows; and the Icelander is never so happy as when he has succeeded in shooting a raven. This, however, is no easy task, as no bird is more cautious, and its eyes are as sharp as those of the eagle. Of all Icelandic birds, the raven breeds the earliest, laying about the middle of March its five or six pale-green eggs, spotted with brown, in the inaccessible 
crevices of rocks. Towards the end of June, Preyer saw many young ravens grown to a good size, and but little inferior to the old ones in cunning.

In the gloomy Scandinavian mythology the raven occupies a rank equal to that of the eagle in the more cheerful fables of ancient Greece. It was dedicated to Odin, who, as the traditional history of Iceland informs us, had two ravens, which were let loose every morning to gather tidings of what was going on in the world, and which on returning in the evening perched upon Odin's shoulders to whisper the news in his ear; the name of one was Hugin, or spirit; of the other, Mumin, or memory. Even now many superstitious notions remain attached to the raven; for the Icelanders believe this bird to be not only acquainted with what is going on at a distance, but also with what is to happen in future, and are convinced that it foretells when any of the family is about to die, by perching on the roof of the house, or wheeling round in the air with a continual cry, varying its voice in a singular and melodious manner.

The white-tailed sea-eagle is not uncommon in Iceland, where he stands in evil repute as a kidnapper of lambs and eider-ducks. He is sometimes found dead in the nets of the fishermen; for, pouncing upon a haddock or salmon, he gets entangled in the meshes, and is unable to extricate himself. The skins of the bird, which seems to attain a larger size than in Great Britain, most likely from being less disturbed by man, are sold at Reykjavik and Akureyre for from three to six rix-dollars.

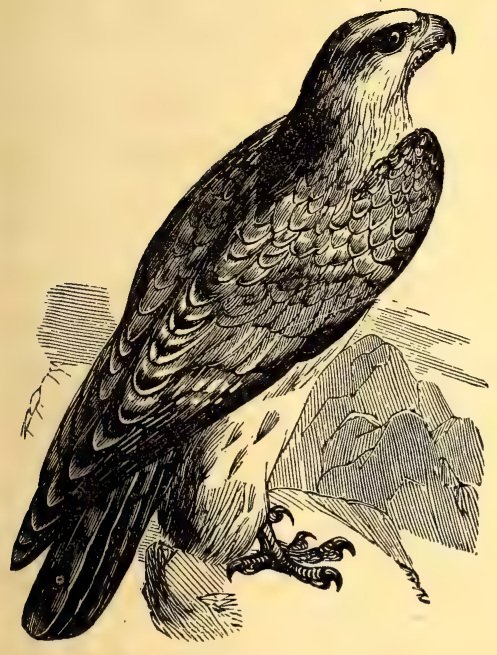

THE JYRFALCON.

The jyrfalcon (Falco gyrfalco), generally considered as the boldest and most beautiful of the falcon tribe, has its head-quarters in Iceland. As long as the noble sport of falconry was in fashion, for which it was highly esteemed, the trade in falcons was worth from 2000 to 3000 rix-dollars annually to the islanders, and even now high prices are paid for it by English amateurs.

The rarest bird of Iceland, if not entirely extinct, is the Giant-auk, or Geirfugl. The last pair was caught about seventeen years ago near the Geirfuglaskers, a group of solitary rocks to the south of the Westman Isles, its only known habitat besides some similar cliffs on the north-eastern coast. Since that time it is said to have been seen by some fishermen; but this testimony is extremely doubtful, and the question of its existence can only be solved by a visit to the Geirfuglaskers themselves -an undertaking which, if practicable at all, is attended with extreme difficulty and danger, as these rocks are completely isolated in the sea, which even in calm weather breaks with such violence against their abrupt declivities that for years it must be absolutely impossible to approach them.

In 1858 two English naturalists determined at least to make the attempt, and settled for a season in a small hamlet on the neighboring coast, eager to 


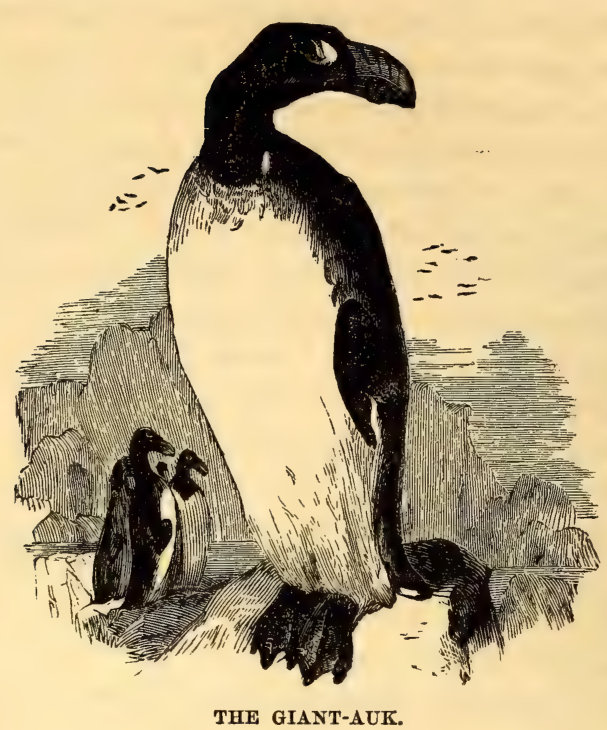

seize the first opportunity for storming the Geirfugl's stronghold. They waited for several months, but in vain, the stormy summer being more than usually unfavorable for their undertaking; and they were equally unsuccessful in the north, whither they had sent an Icelandic student specially instructed for the purpose. The giant-auk is three feet high, and has a black bill four inches and a quarter long, both mandibles being crossed obliquely with several ridges and furrows. Its wings are mere stumps, like those of the Antarctic penguins. Thirty pounds have been paid for its egg, which is larger than that of any other European bird; and there is no knowing the price the Zoological Society would pay for a live bird, if this truly " rara avis" could still be found.

The waters of Iceland abound with excellent fish, which not only supply the islanders with a great part of their food and furnish them with one of their chief articles of exportation, but also attract a number of foreign seamen. Thus about 300 French, Dutch, and Belgian fishing-sloops, manned with crews amounting in all to 7000 men, annually make their appearance on the southern and western coasts of Iceland, particularly those of the Guldbringe Syssel, or gold-bringing country: thus named, not from any evidence of the precious metal, but from the golden cod-harvests reaped on its shores. Between thirty and forty English fishing-smacks yearly visit the northern coast. When they have obtained a good cargo they run to Shetland to discharge it, and return again for more.

The Icelandic fishing-season, which begins in February and ends in June, occupies one-half of the male inhabitants of the island, who come flocking to the west, even from the remotest districts of the north and east, to partake of the rich harvest of the seas. Many thus travel for more than 200 miles in the midst of winter, while the storm howls over the naked waste, and the pale sun scarcely dispels for a few hours the darkness of the night. In every hut where they tarry on the road they are welcome, and have but rarely to pay for their 
entertainment, for hospitality is still reckoned a duty in Iceland. On reaching the fishing-station, an agreement is soon made with the proprietor of a boat. They usually engage to assist in fishing from February 12 to May 12, and receive in return a share of the fish which they help to catch, besides forty pounds of flour and a daily allowance of sour curds, or " skier."

All the men belonging to a boat generally live in the same damp and narrow hut. At daybreak they launch forth, to brave for many hours the inclemencies of the weather and the sea, and while engaged in their hard day's work their sole refreshment is the chewing of tobacco or a mouthful of skier. On returning to their comfortless hut, their supper consists of the fishes of inferior quality they may have caught, or of the heads of the cod or ling, which are too valuable for their own consumption. These are split open and hung upon lines, or exposed on the shore to the cold wind and the hot sun; this renders them perfectly hard, and they keep good for years. In this dried state the cod is called stockfish. About the middle of May the migratory fishermen return to their homes, leaving their fish which are not yet quite dry to the care of the fishermen dwelling on the spot. Towards the middle of June, when the horses have so far recovered from their long winter's fast as to be able to bear a load, they come back to fetch their stockfish, which they convey either to their own homes for the consumption of their own families, or to the nearest port for the purpose of bartering it against other articles. Haddocks, flatfish, and herrings are also very abundant in the Icelandic seas; and along the northern and northwestern coasts the basking shark is largely fished for all the summer. Strong hooks baited with mussels or pieces of fish, and attached to chains anchored at a short distance from the shore, serve for the capture of this monster, which is scarcely, if at all, inferior in size to the white shark, though not nearly so formidable, as it rarely attacks man. The skin serves for making sandals; the coarse flesh is eaten by the islanders, whom necessity has taught not to be overnice in their food; and the liver, the most valuable part, is stewed for the sake of its oil.

"We had observed," says Mr. Shepherd, "that the horrible smell which infested Jsa-fjordr varied in intensity as we approached or receded from a certain black-looking building at the northern end of the town. On investigating this building, we discovered that the seat of the smell was to be found in a mass of putrid sharks' livers, part of which were undergoing a process of stewing in a huge copper. It was a nuisome green mass, fearful to contemplate. The place was endurable only for a few seconds; yet dirty-looking men stirred up the mass with long poles, and seemed to enjoy the reeking vapors."

The salmon of Iceland, which formerly remained undisturbed by the phlegmatic inhabitants, are now caught in large numbers for the British market. A small river bearing the significant name of Laxaa, or Salmon River, has been rented for the trifling sum of $£ 100$ a year by an English company, which sends every spring its agents to the spot well provided with the best fishing apparatus. The captured fish are immediately boiled, and hermetically packed in tin boxes, so that they can be eaten in London almost as fresh as if they had just been canght. 
The mineral kingdom contributes but little to the prosperity of Iceland. It affords neither metals, nor precious stones, nor rock-salt, nor coal; for the seams of "surturbrand," or "lignite," found here and there, are too unimportant to be worked. The solfataras of Krisuvik and Husavik, though extremely interesting to the geologist, likewise furnish sulphur in too impure a condition or too thinly scattered to afford any prospect of being worked with success, not to mention the vast expense of transport over the almost impassable lava-tracks that separate them from the nearest ports. In 1839-40, when, in consequence of the monopoly granted by the Neapolitan Government to a French company, sulphur had risen to more than three times its usual price, Mr. Knudsen, an enterprising Danish merchant, undertook to work the mines of Krisuvik, but even then it would not answer.

In 1859, a London company, founded by Mr. Bushby,-who having explored the sulphur districts, had raised great expectations on what he considered their dormant wealth,-renewed the attempt, but after a year's trial it was abandoned as perfectly hopeless. The "solfataras of Iceland," says Professor Sartorius of Waltershausen, "can not compete with those of Sicily, where more sulphur is wantonly wasted and trodden under foot than all Iceland possesses. While the "Namars" of the north, which are far richer than those of Krisuvik, annually furnish scarcely more than ten tons, the sulphur mines of Sicily produce at least 50,000 , and, if necessary, could easily export double the quantity."

As coal is too expensive a fuel for any but the rich in the small sea-port towns, and peat, though no doubt abundantly scattered over the island, is dug only in a few places, the majority of the people make use of singular substitutes. The commonest is dried cow's and sheep's dung; but many a poor fisherman lacks even this "spicy" material, and is fain to use the bones of animals, the skeletons of fishes or dried sea-birds, which, with a stoical contempt for his olfactory organs, he burns, feathers and all. There is, however, no want of fuel in those privileged spots where drift-wood is found, and here the lava hearth of the islander cheerfully blazes either with the pine conveyed to him by the kindly Polar currents from the Siberian forests, or with some tropical trunk, wafted by the Gulf Stream over the Atlantic to his northern home. 


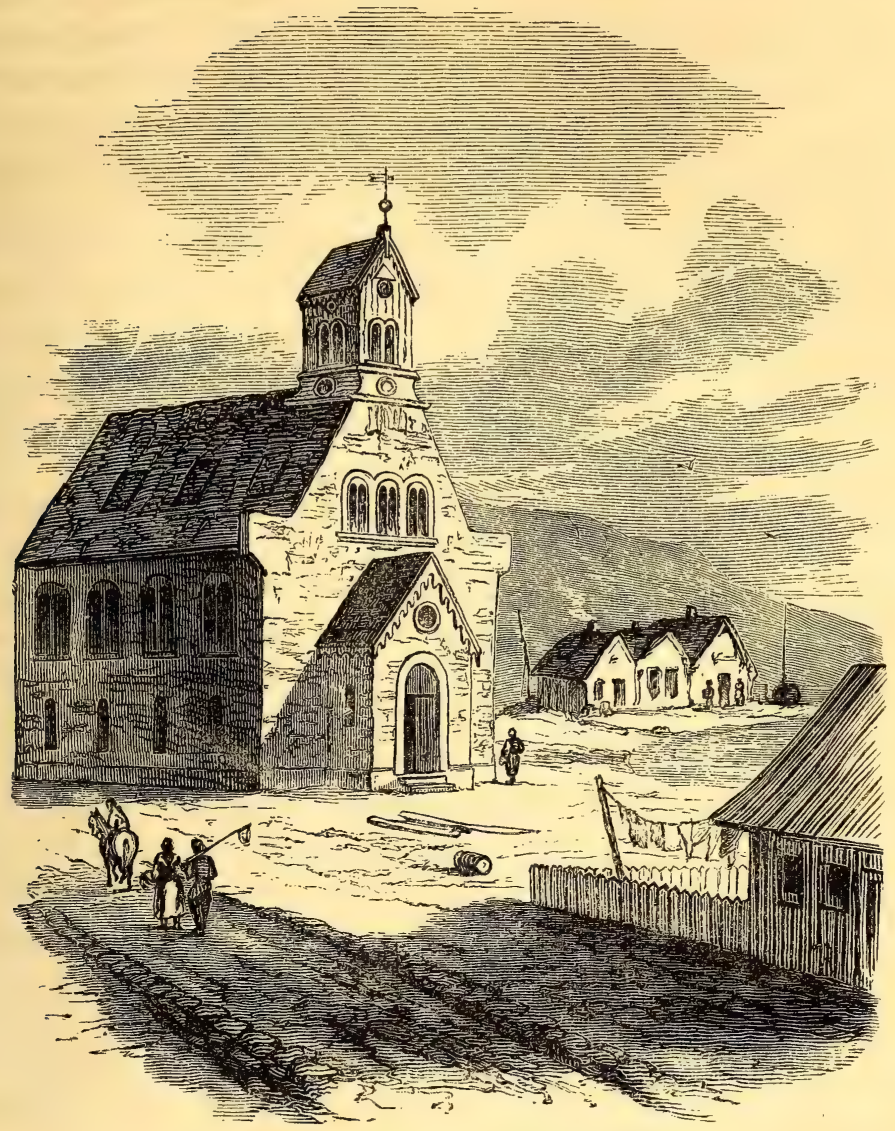

CATHEDRAL AT REYKJAVIK.

\section{CHAPTER VI.}

\section{HISTORY OF ICELAND.}

Discovery of the Island by Naddodr in 861.-Gardar.-Floki of the Ravens.--Ingolfr and Leif.-Ulfliot the Lawgiver.-The Althing.-Thingvalla.-Introduction of Christianity into the Island.-Frederick the Saxon and Thorwold the Traveller.-Thangbrand.-Golden Age of Icelandic Literature.--Snorri Sturleson.-The Island submits to Hakon, King of Norway, in 1254.-Long Series of Calamities.Great Eruption of the Skapta Jökul in 1783.-Commercial Munopoly.-Better Times in Prospect.

THE Norse vikings were, as is well known, the boldest of navigators. They possessed neither the sextant nor the compass; they had neither charts nor chronometers to guide them; but trusting solely to fortune, and to their own indomitable courage, they fearlessly launched forth into the vast ocean. Many of these intrepid corsairs were no doubt lost on their adventurous expeditions, but frequently a favorable chance rewarded their temerity, either with some rich booty or some more glorious discovery.

Thus in the year 861, Naddodr, a Norwegian pirate, while sailing from his native coast to the Faeroe Islands, was drifted by contrary winds far to the 
north. For several days no land was visible-nothing but an interminable waste of waters; when suddenly the snow-clad mountains of Iceland were seen to rise above the mists of the ocean. Soon after Naddodr landed with part of his crew, but discovered no traces of man in the desert country. The viking tarried but a short time on this unpromising coast, on which he bestowed the appropriate name of Snowland.

Three years later, Gardar, another northern freebooter, while sailing to the Hebrides, was likewise driven by stormy weather to Iceland. He was the first circumnavigator of the island, which he called, after himself, Gardar's holm, or the island of Gardar. On his return to his native port, he gave his countrymen so flattering an account of the newly-discovered land, that Floki, a famous viking, resolved to settle there. Trusting to the augury of birds, Floki took with him three ravens to direct him on his way. Having sailed a certain distance beyond the Faeroe Islands, he gave liberty to one of them, which immediately returned to the land. Proceeding onward, he loosed the second, which, after circling for a few minutes round the ship, again settled on its cage, as if terrified by the boundless expanse of the sea. The third bird, on obtaining his lib. erty a few days later, proved at length a faithful pilot, and flying direct to the north, conducted Floki to Iceland. As the sea-king entered the broad bay which is bounded on the left by the huge Snäfells Jökul, and on the right by the bold promontory of the Guldbringe Syssel, Faxa, one of his companions, remarked that a land with such noble features must needs be of considerable extent. To reward him for this remark, which flattered the vanity or the ambition of his leader, the bay was immediately named Faxa Fiord, as it is still called to the present day. The new colonists, attracted by the abundance of fish they found in the bay, built their huts on the borders of a small outlet, still bearing the name of Rafna Fiord, or the Raven's Frith ; but as they neglected to make hay for the winter, the horses and cattle they had brought with them died of want. Disappointed in his expectations, Floki returned home in the second year, and, as might naturally have been expected from an unsuccessful settler, gave his countrymen but a dismal account of Iceland, as he definitely named it.

Yet, in spite of his forbidding description, the political disturbances which took place about this time in Norway led to the final colonization of the island. Harold Haarfager, or the Fair-haired, a Scandinavian yarl, having by violence and a successful policy reduced all his brother-yarls to subjection, first consolidated their independent domains into one realm, and made himself absoluce master of the whole country. Many of his former equals submitted to his yoke; but others, animated by that unconquerable love of liberty innate in men who for many generations have known no superior, preferred seeking a new home across the ocean to an ignominious vassalage under the detested Harold. Ingolfr and his cousin Leif were the first of these high-minded nobles that emigrated (869-870) to Iceland.

On approaching the southern coast, Ingolfr cast the sacred pillars belonging to his former dwelling into the water, and vowed to establish himself on the spot to which they should be wafted by the waves. His pious intentions were for the time frustrated, as a sudden squall separated him from his penates, and 
forced him to locate himself on a neighboring promontory, which to this day bears the name of Ingolfrshofde. Here he sojourned three years, until the followers he had sent out in quest of the missing pillars at length brought him the joyful news that they had been found on the beach of the present site of Reykjavik, whither, in obedience to what he supposed to be the divine summons, he instantly removed. Ingolfr's friend and relative Leif was shortly after assassinated by some Irish slaves whom he had captured in a predatory descent on the Hibernian coast. The surviving chieftain deplored the loss of his kinsman, lamenting "that so valiant a man should fall by such villains," but found consolation by killing the murderers and annexing the lands of their victim. When, in course of time, he himself felt his end approaching, he requested to be buried on a hill overlooking the fiord, that from that elevated site his spirit might have a better view of the land of which he was the first inhabitant.

Such are the chronicles related in the "Landnama Bok," or "Book of Occupation," one of the earliest records of Icelandic history.

Ingolfr and his companions were soon followed by other emigrants desirous of escaping from the tyranny of Harold Haarfager, who at first favored a movement that removed far beyond the sea so many of his turbulent opponents, but subsequently, alarmed at the drain of population, or desirous of profiting by the exodus, levied a fine of four ounces of silver on all who left his dominions to settle in Iceland. Yet such were the attractions which the island at that time presented, that, in spite of all obstacles, not half a century elapsed before all its inhabitable parts were occupied, not only by Norwegians, but also by settlers from Denmark and Sweden, Scotland and Ireland.

The Norwegians brought with them their language and idolatry, their customs and historical records, which the other colonists, but few in numbers, were compelled to adopt. At first the udal, or free land-hold system of their own country, was in vigor, but every leader of a band of emigrants being chosen, by force of circumstances, as the acknowledged chief of the district occupied by himself and companions, speedily paved the way for a demi-feudal system of vassalage and subservience. As the arrival of new settlers rendered the possession of the land more valuable, endless contests between these petty chiefs arose for the better pastures and fisheries. To put an end to this state of anarchy, so injurious to the common weal, Ulfliot the Wise was commissioned to frame a code of laws, which the Icelanders, by a single simultaneous and peaceful effort, accepted as their future constitution.

The island was now divided into four provinces and twelve districts. Each district had its own judge, and its own popular "Thing," or assembly; but the national will was embodied and represented by the "Althing," or supreme parliament of Iceland, which annually met at Thingvalla, under an elective president, or "Logmathurman," the chief magistrate of this northern republic.

On the banks of the river Oxeraa, where the rapid stream, after forming a magnificent cascade, rushes into the lake of Thingvalla, lies the spot where, for many a century, freemen met to debate, while despotic barbarians still reigned over the milder regions of Europe. Isolated on all sides by deep volcanic chasms, which some great revolution of nature has rent in the vast lava-field 


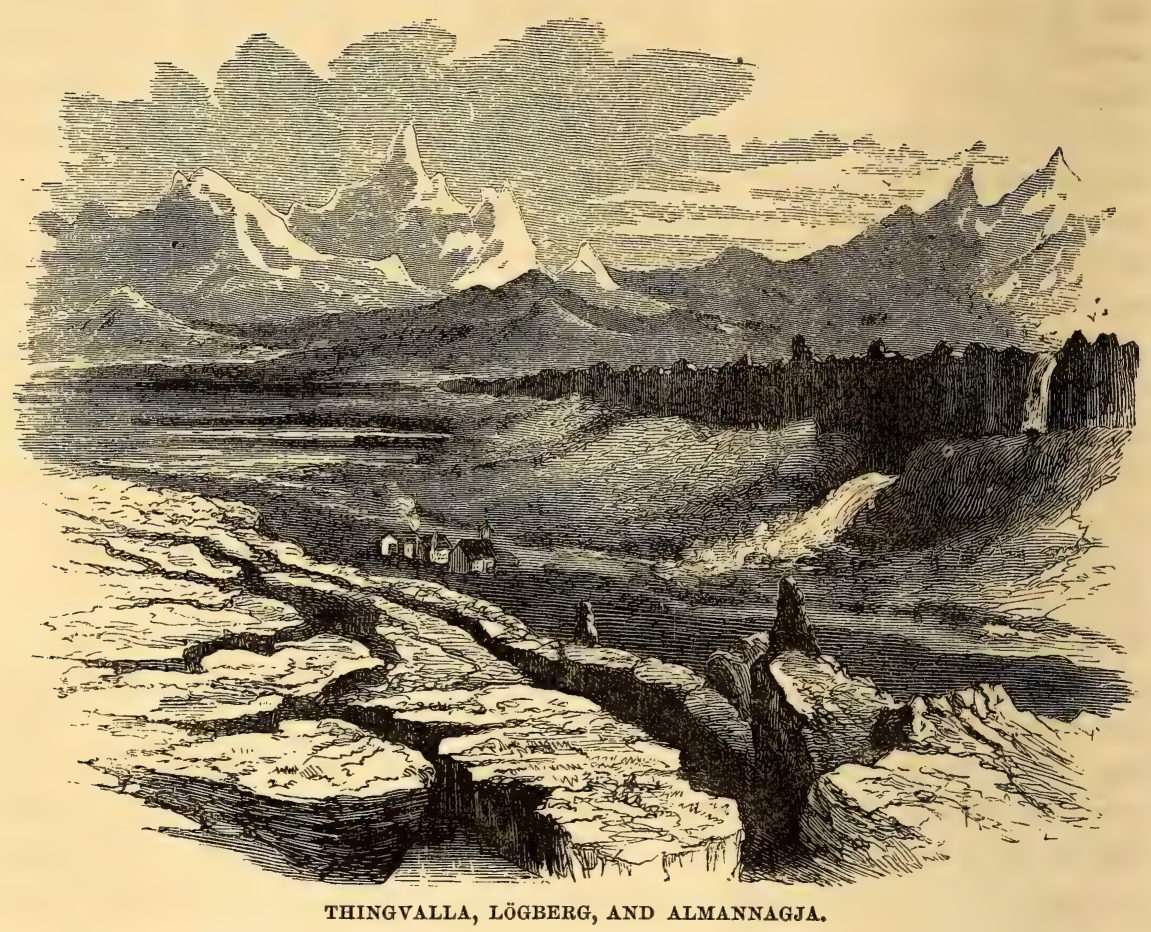

around, and embosomed in a wide circle of black precipitous hills, the situation of Thingvalla is extremely romantic, but the naked dark-colored rocks, and the traces of subterranean fire visible on every side, impart a stern melancholy to the scene. The lake, the largest sheet of water in the island, is about thirty miles ir circumference; its boundaries have undergone many changes, especially during the earthquakes of the past century, when its northern margin collapsed, while the opposite one was raised. The depth of its crystal waters is very great, and in its centre rise two small crater-islands, the result of some unknown eruption. The mountains on its south bank have a picturesque appearance, and large volumes of steam issuing from several hot sources on their sides prove that, though all be tranquil now, the volcanic fires are not extinct. Only a few traces of the ancient Althing are left-three small mounds, where sat in state the chiefs and judges of the land-for as the assembly used to pitch their tents on the borders of the stream, and the deliberations were held in the open air, there are no imposing ruins to bear witness to a glorious past. But though all architectural pomp be absent, the scene hallowed by the recollections of a thousand years is one of deep interest to the traveller. The great features of nature are the same as when the freemen of Iceland assembled to settle the affairs of their little world; but the raven now croaks where the orator appealed to the reason or the passions of his audience, and the sheep of the neighboring pastor crop undisturbed the grass of desecrated Thingvalla.

Mr. Ross Browne thus describes the scene: "After a slight repast I walked out to take a look at the Lögberg, or Rock of Laws, which is situated about 
half a mile from the church. This is, perhaps, of all the objects of historical association in Iceland, the most interesting. It was here the judges tried criminals, pronounced judgments, and executed their stern decrees. On a small plateau of lava, separated from the general mass by a profound abyss on every side, save a narrow neck barely wide enough for a foothold, the famous "Thing" assembled once a year, and, secured from intrusion in their deliberations by the terrible chasm around, passed laws for the weal or woe of the people. It was only necessary to guard the causeway by which they entered; all other sides were well protected by the encircling moat, which varies from thirty to forty feet in width, and is half filled with water. The total depth to the bottom, which is distinctly visible through the crystal pool, must be sixty or seventy feet. Into this yawning abyss the unhappy criminals were cast, with stones around their necks, and many a long day did they lie beneath the water, a ghastly spectacle for the crowd that peered at them over the precipice. All was now as silent as the grave. Eight centuries had passed, and yet the strange scenes that had taken place here were vividly before me. I could imagine the gathering crowds, the rising hum of voices; the pause, the shriek, and plunge; the low murmur of horror, and then the stern warning of the lawgivers and the gradual dispersing of the multitude. The dimensions of the plateau are four or five hundred feet in length by an average of sixty or eighty in width. The surface is now covered with a fine coating of sod and grass, and furnishes good pasturage for the sheep belonging to the pastor."

Christianity was first preached in Iceland about the year 981, by Friedrich, a Saxon bishop, to whom Thorwald the traveller, an Icelander, acted as interpreter. Thorwald having been treated with great severity by his father, Kodran, had fled to Denmark, where he had been converted by Friedrich. He returned with the pious bishop to his paternal home, where the solemn service of the Christians made some impression on Kodran, but still the obstinate pagan could not be prevailed upon to renounce his ancient gods. "He must believe," said he, "the word of his own priest, who was wont to give him excellent advice." "Well, then," replied Thorwald, " this venerable man whom I have brought to thy dwelling is weak and infirm, while thy well-fed priest is full of vigor. Wilt thou believe in the power of our God if the bishop drives him hence?" Friedrich now cast a few drops of holy water on the priest, which immediately burnt deep holes into his skin, so that he fled, uttering dreadful curses. After this convincing proof, Kodran adopted the Christian faith. But persuasion and miracles acted too slowly for the fiery Thorwald, who would willingly have converted all Iceland at once with fire and sword. His sermons were imprecations, and the least contradiction roused him to fury. Unable to bear so irascible an associate, the good bishop Friedrich, giving up his missionary labors, returned to Saxony. As to Thorwald, his restless disposition led him to far-distant lands. He visited Greece and Syria, Jerusalem and Constantinople, and ultimately founded a convent in Russia, where he died in the odor of sanctity.

Soon after Thangbrand was sent by the Norwegian king, Olaf Truggeson, as 
missionary to Iceland. His method of conversion appears to have been very like that of his erratic predecessor; for while he held the cross in one hand, he grasped the sword with the other. "Thangbrand," says an ancient chronicler, "was a passionate, ungovernable person, and a great manslayer, but a good scholar and clever. He was two years in Iceland, and was the death of three men before he left it."

Other missionaries of a more evangelical character took his place, and proved by their success that mild reasoning is frequently a far more effectual means of persuasion than brutal violence. They made a great number of proselytes, and the whole island was now divided into two factions ready to appeal to the sword for the triumph of Christ or of Odin. But before coming to this dreadful extremity, the voice of reason was heard, and the contending parties agreed to submit the question to the decision of the Althing.

The assembly met, and the momentous debate was proceeding, when suddenly a loud crash of subterranean thunder was heard, and the earth shook under their feet. "Listen!" exclaimed a follower of Odin, " and beware of the anger of our gods: they will consume us with their fires, if we venture to question their authority." The Christian party hesitated ; but their confidence was soon restored by the presence of mind of their chief orator, Thorgeir, who, pointing to the lava-fields around, asked with whom the gods were angry when these rocks were melted : a burst of eloquence which at once decided the question in favor of the Cross.

The new faith brought with it a new spirit of intellectual development, which attained its highest splendor in the twelfth century. Classical studies were pursued with the utmost zeal, and learned Icelanders travelled to Germany and France to extend their knowledge in the schools of Paris or Cologne. The Icelandic bards, or scalds, were renowned throughout all Scandinavia; they frequented the courts of Sweden, Denmark, and Norway, and were everywhere received with the highest honors.

The historians, or sagamen, of Iceland were no less renowned than its scalds. They became the annalists of the whole Scandinavian world, and the simplicity and truth by which their works are distinguished fully justify their high reputation. Among the many remarkable men who at that time graced the literature of the Arctic isle, Sämund Frode, the learned author of the "Voluspa" (a work on the ancient Icelandic mythology) and the "Havamal" (a general chronicle of events from the beginning of the world); Are Thorgilson, whose "Landnama Bok" relates with the utmost accuracy the annals of his native land; and Gissur, who about the year 1180 described his voyages to the distant Orient, deserve to be particularly mentioned; but great above all in genius and fame was Snorri Sturleson, the Herodotus of the North, whose eventful life and tragic end would well deserve to be recounted at greater length.

Gifted with the rarest talents, and chief of the most powerful family of the island, Snorri was elected in 1215 to the high office of Logmathurman; but disgusting his sturdy countrymen by his excessive haughtiness, he was obliged to retire to the court of Hakon, king of Norway. During this exile he collected the materials for his justly celebrated "Heimskringla," or Chronicle of the 
Kings of Norway. Returning home in 1221, he was again named Logmathurman; but as he endeavored to pave the way for the annexation of his native country to the Norwegian realm, his foreign intrigues caused a rising against his authority, and he was once more compelled to take refuge in Norway. Here he remained several years, until the triumph of his own faction allowed him to return to his family estate at Reikholt, where he was murdered on a dark September night in the year 1241. Thus perished the most remarkable man Iceland ever has produced. The republic itself did not long survive his fall ; for, weary of the interminable feuds of their chiefs, the people voluntarily submitted to Hakon in 1254, and the middle of the thirteenth century was signalized by the transfer of the island to the Norwegian crown, after three hundred and forty years of a turbulent but glorious independence.

From that time the political history of the Icelanders offers but little interest. With their annexation to a European monarchy perished the vigor, restlessness, and activity which had characterized their forefathers; and though the Althing still met at Thingvalla, the national spirit had fled. It was still further subdued by a long chain of calamities-plagues, famines, volcanic eruptions, and piratical invasions--which, following each other in rapid succession, devastated the land and decimated its unfortunate inhabitants.

In 1402 that terrible plague, the memory of which is still preserved under the name of the "Black Death," carried off nearly two-thirds of the whole population, and was followed by such an inclement winter that nine-tenths of the cattle in the island died. The miseries of a people suffering from pestilence and famine were aggravated by the English fishermen, who, in spite of the remonstrances of the Danish government, frequented the defenseless coast in considerable numbers, and were in fact little better than the old sea-robbers who first colonized the island, plundering and burning on the main, and holding the wealthy inhabitants to ransom. Their predatory incursions were frequently repeated during the seventeenth century, and even the distant Mediterranean sent its Algerine pirates to add to the calamities of Iceland.

The eighteenth century was ushered in by the small-pox, which carried off sixteen thousand of the inhabitants. In the middle of the century-severe winters following in rapid succession-vast numbers of cattle died, inducing a famine that again swept away ten thousand inhabitants.

Since the first colonization of Iceland, its numerous volcanoes had frequently brought ruin upon whole districts-twenty-five times had Hecla, eleven times Kötlugiá, six times Trölladyngja, five times Oraefa, vomited forth their torrents of molten stone, without counting a number of submarine volcanic explosions, or where the plain was suddenly rent and flames and ashes burst out of the earth; but the eruption of Skaptar Jökul in 1783 was the most frightful visitation ever known to have desolated the island. The preceding winter and spring had been unusually mild, and the islanders looked forward to a prosperous summer; but in the beginning of June repeated tremblings of the earth, increasing in violence from day to day, announced that the subterranean powers that had long been slumbering under the icy mantle of the Skaptar were ready to awake. All the neighboring peasants abandoned their huts and erected 
tents in the open field, anxiously awaiting the result of these terrific warnings. On the 9th, immense pillars of smoke collected over the hill country toward the north, and, rolling down in a southerly direction, covered the whole district of Sitha with darkness. Loud subterranean thunders followed in rapid succession, and innumerable fire-spouts were seen leaping and flaring through the dense canopy of smoke and ashes that enveloped the land. The heat raging in the interior of the volcano melted enormous masses of ice and snow, which caused the river Skapta to rise to a prodigious height; but on the 11th torrents of fire usurped the place of water, for a vast lava-stream breaking forth from the mountains, flowed down in a southerly direction, until reaching the river, a tremendous conflict arose between the two hostile elements. Though the channel was six hundred feet deep and two hundred feet wide, the lava-flood pouring down one fiery wave after another into the yawning abyss, ultimately gained the victory, and, blocking up the stream, overflowed its banks. Crossing the low country of Medalland, it poured into a great lake, which after a few days was likewise completely filled up, and having divided into two streams, the unexhausted torrent again poured on, overflowing in one direction some ancient lava-fields, and in another re-entering the channel of the Skapta and leaping down the lofty cataract of Stapafoss. But this was not all, for while one lavaflood had chosen the Skapta for its bed, another, descending in a different direction, was working similar rum along the banks of the Hverfisfliot. Whether the same crater gave birth to both, it is impossible to say, as even the extent of the lava-flow can only be measured from the spot where it entered the inhabited districts. The stream which followed the direction of Skapta is calculated to have been about fifty miles in length by twelve or fifteen at its greatest breadth; that which rolled down the Hverfisfliot, at forty miles in length by seven in breadth.

Where it was inclosed between the precipitous banks of the Skapta, the lava is five or six hundred feet thick, but as soon as it spread out into the plain its depth never exceeded one hundred feet. The eruption of sand, ashes, pumice, and lava continued till the end of August, when at length the vast subterranean tumult subsided.

But its direful effects were felt for a long time after, not only in its immediate vicinity, but over the whole of Iceland, and added many a mournful page to her long annals of sorrow. For a whole year a dun canopy of cinder-laden clouds hung over the unhappy island. Sand and ashes, carried to an enormous height into the atmosphere, spread far and wide, and overwhelmed thousands of acres of fertile pasturage. The Faeroes, the Shetlands, and the Orkneys were deluged with volcanic dust which perceptibly contaminated even the skies of England and Holland. Mephitic vapors obscured the rays of the sun, and the sulphurous exhalations tainted both the grass of the field and the waters of the lake, the river, and the sea, so that not only the cattle died by thousands, but the fish also perished in their poisoned element. The unhealthy air, and the want of food-for hunger at last drove them to have recourse to untanned hides and old leather-gave rise to a disease resembling scurvy among the un. fortunate Icelanders. The head and limbs began to swell, the bones seemed 
to be distending. Dreadful cramps forced the patient to strange contortions. The gums loosened, the decomposed blood oozed from the mouth and the ulcerous skin, and a few days of torment and prostration were followed by death.

In many a secluded vale whole families were swept away, and those that escaped the scourge had hardly strength sufficient to bury the dead.

So great was the ruin caused by this one eruption that in the short space of two years no less than 9336 men, 28,000 horses, 11,461 cattle, and 190,000 sheep-a large proportion of the wealth and population of the island-were swept away.

After this dreadful catastrophe followed a long period of volcanic rest, for the next eruption of the Eyjafialla did not take place before 1821. A twelfth eruption of Kötlugja occurred in 1823, the twenty-sixth of Hecla in 1845-46; and ultimately the thirteenth of Kötlugja in 1860. Since then there has been repose; but who knows what future disasters may be preparing beneath those icy ridges and fields of snow of Skapta and his frowning compeers, where no human foot has ever wandered, or how soon they may awaken their dormant thunders?

Besides the sufferings caused by the elements, the curse of monopoly weighed for many a long year upon the miserable Icelanders. The Danish kings, to whom on the amalgamation of the three Scandinavian monarchies the allegiance of the people of Iceland was passively transferred, considered their poor dependency as a private domain, to be farmed out to the highest bidder. In the 16th century the Hanseatic Towns purchased the exclusive privilege of trading with Iceland; and in 1594 a Danish company was favored with the monopoly, for which it had to pay the paltry sum of 16 rix-dollars for each of the ports of the island.

In the year 1862 a new company paid 4000 dollars for the Icelandic monopoly; but at the expiration of the contract, each of the ports were farmed out to the highest bidder-a financial improvement which raised the revenue to 16,000 dollars a year, and ultimately to 22,000 . The incalculable misery produced by the eruption of the Skapta had at least the beneficial consequence that it somewhat loosened the bonds of monoply, as it now became free to every Danish merchant to trade with the island; but it is only since April, 1855, that the last restrictions have fallen and the ports of Iceland been opened to the merchants of all nations. It is to be hoped that the beneficial effects of free trade will gradually heal the wounds caused by centuries of neglect and misfortune; but great progress must be made before Iceland can attain the degree of prosperity which she enjoyed in the times of her independence.

Then she had above a hundred thousand inhabitants, now she has scarcely half that number; then she had many rich and powerful families, now mediocrity or poverty is the universal lot; then she was renowned all over the North as the seat of learning and the cradle of literature, now, were it not for her remarkable physical features, no traveller would ever think of landing on her rugged shores. 


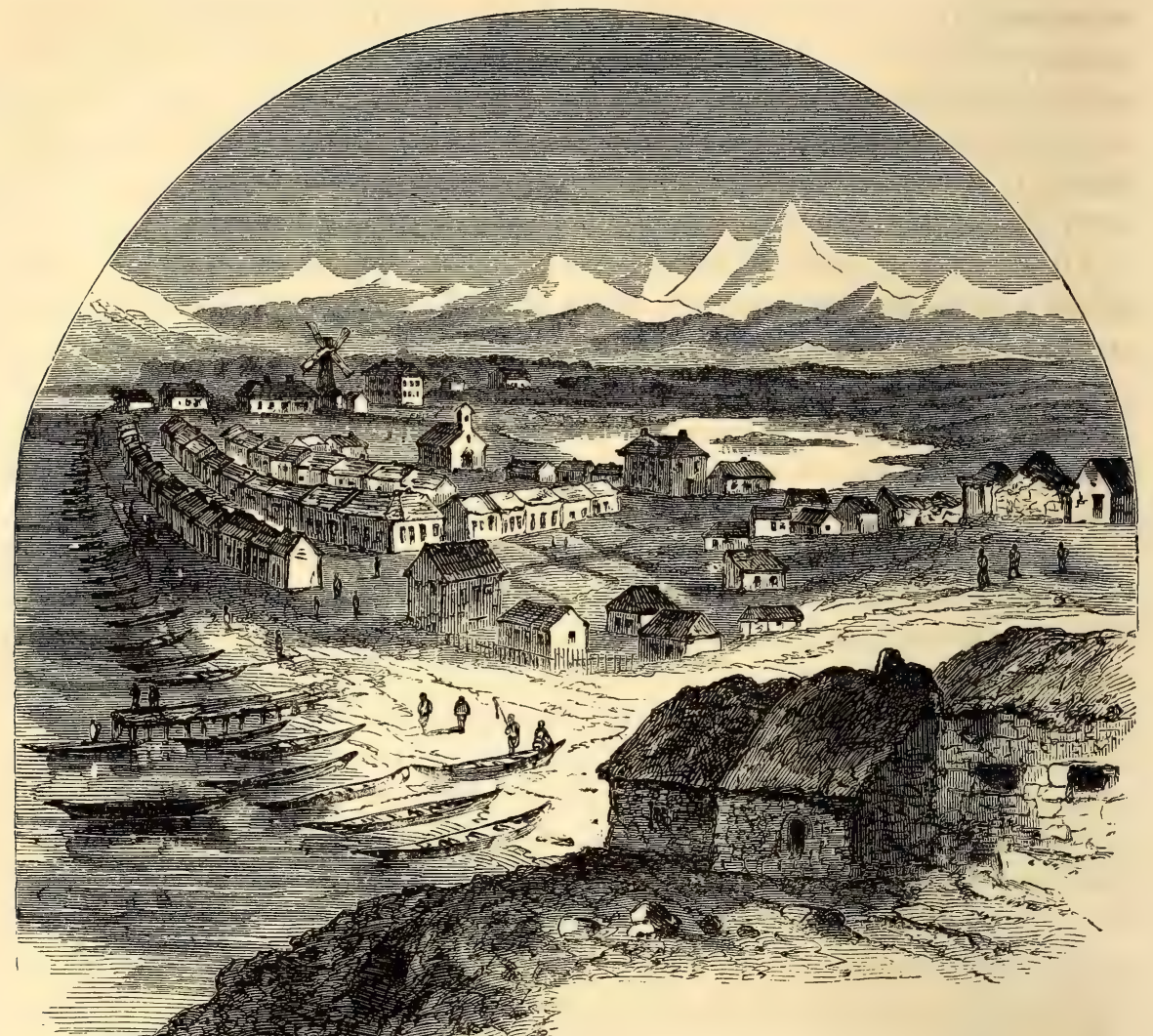

CHAPTER VII.

\section{THE ICELANDERS.}

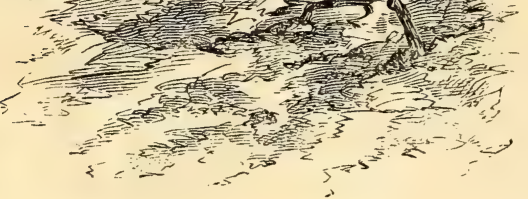

REYKJAVIK, THE CAPITAL OF ICELAND.

Skalholt.-Reykjavik. - The Fair.-The Peasant and the Merchant.-A Clergyman in his Cups. -Hay-making. - The Icelander's Hut.-Churches.-Poverty of the Clergy.-Jon Thorlaksen. -The Seminary of Reykjavik.-Beneficial Influence of the Clergy.-Home Education.-The Icelander's Winter's Evening.-Taste for Literature. -The Language.-The Public Library at Reykjavik.-The Icelandic Literary Society.-Icelandic Newspapers.-Longevity._Leprosy.-Travelling in Iceland.-Fording the Rivers.-Crossing of the Skeidara by Mr. Holland.-A Night's Bivouac.

VEXT to Thingvalla, there is no place in Iceland so replete with historical 1 interest as Skalholt, its ancient capital. Here in the eleventh century was founded the first school in the island; here was the seat of its first bishops; here flourished a succession of great orators, historians, and poets; Isleif, the oldest chronicler of the North; Gissur, who in the beginning of the twelfth century had visited all the countries of Europe and spoke all their languages; the philologian Thorlak, and Finnur Johnson, the learned author of the "Ecclesiastical History of Iceland." The Cathedral of Skalholt was renowned far and wide for its size, and in the year 1100, Latin, poetry, music, and rhetoric, the four liberal arts, were taught in its school, more than they were at that time 
in many of the large European cities. As a proof how early the study of the ancients flourished in Skalholt, we find it recorded that in the twelfth century a bishop once caught a scholar reading Ovid's " Art of Love;" and as the story relates that the venerable pastor flew into a violent passion at the sight of the unholy book, we may without injustice conclude that he must have read it himself in some of his leisure hours, to know its character so well.

Of all its past glories, Skalholt has retained nothing but its name. The school and the bishopric have been removed, the old church has disappeared, and been replaced by a small wooden building, in which divine service is held once a month; three cottages contain all the inhabitants of the once celebrated city, and the extensive churchyard is the only memorial of its former importance. Close by are the ruins of the old school-house, and on the spot where the bishop resided a peasant has erected his miserable hovel.

But the ever-changing tide of human affairs has not bereft the now lonely place of its natural charms, for the meadow-lands of Skalholt are beautifully imbedded in an undulating range of hills, overlooking the junction of the Bruara and Huita, and backed by a magnificent theatre of mountains, among which Hecla and the Eyjafialla are the most prominent.

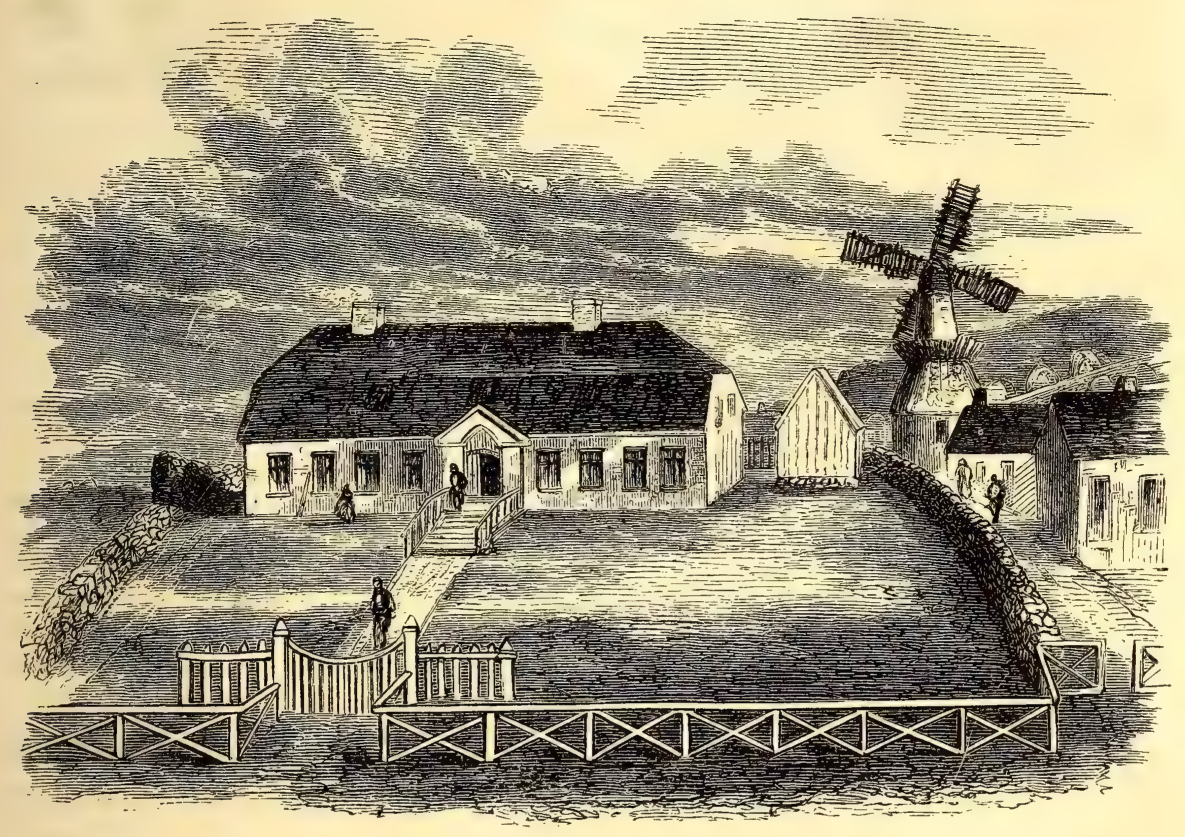

GOVERNOR'S RESIDENCE, REYKJAVIK.

Reykjavik, the present capital of the island, has risen into importance at the expense both of Skalholt and Thingvalla. At the beginning of the present century the courts of justice were transferred from the ancient seat of legislature to the new metropolis, and in 1797 the bishoprics of Hoolum and Skalholt, united into one, had their seats likewise transferred to Reykjavik. The ancient school of Skalholt, after having first migrated to Bessestadt, has also been 
obliged to follow the centralizing tendency, so powerful in our times, and now contributes to the rising fortunes of the small sea-port town.

But in spite of all these accessions, the first aspect of Reykjavik by no means corresponds to our ideas of a capital. "The town," says Lord Dufferin, "consists of a collection of wooden sheds, one story high-rising here and there into a gable end of greater pretensions-built along the lava-track, and flanked at either end by a suburb of turf huts. On every side of it extends a desolate plain of lava that once must have boiled up red-hot from some distant gateway of hell, and fallen hissing into the sea. No tree or bush relieves the dreariness of the landscape, and the mountains are too distant to serve as a background to the buildings; but before the door of each merchant's house facing the sea there flies a gay little pennon; and as you walk along the silent streets, whose dust no carriage-wheel has ever desecrated, the rows of flower-pots that peep out of the windows, between curtains of white muslin, at once convince you that, notwithstanding their unpretending appearance, within each dwelling reign the elegance and comfort of a woman-tended home."

Twenty years since, Reykjavik was no better than a wretched fishing-village, now it already numbers 1400 inhabitants, and free-trade promises it a still greater increase for the future. It owes its prosperity chiefly to its excellent port, and to the abundance of fish-banks in its neighborhood, which have induced the Danish merchants to make it their principal settlement. Most of them, however, merely visit it in summer like birds of passage, arriving in May with small cargoes of foreign goods, and leaving it again in August, after having disposed of their wares. Thus Reykjavik must be lonely and dreary enough in winter, when no trade animates its port, and no traveller stays at its solitary inn; but the joy of the inhabitants is all the greater when the return of spring re-opens their intercourse with the rest of the world, and the delight may be imagined with which they hail the first ship that brings them the long-expected news from Europe, and perhaps some wealthy tourist, eager to admire the wonders of the Geysirs.

The most busy time of the town is, however, the beginning of July, when the annual fair attracts a great number of fishermen and peasants within its walls. From a distance of forty and fifty leagues around, they come with long trains of pack-horses; their stock-fish slung freely across the animals' backs, their more damageable articles close pressed and packed in boxes or skin bags.

The greater part of the trade in this and other small sea-ports-such as Akreyri, Hafnafjord, Eyrarbacki, Berufjord, Vapnafjord, Isafjord, Grafaros, Budenstadit, which, taken all together, do not equal Reykjavik in traffic and population-is carried on by barter.*

Sometimes the Icelander desires to be paid in specie for part of his produce, but then he is obliged to bargain for a long time with the merchant, who of course derives a double profit by an exchange of goods, and is loth to part with

* In 1855, Iceland imported, among others, 65,712 pieces of timber, 148,038 lbs. of iron, 37,700 lbs. hemp, 15,179 fishing-lines, 20,342 lbs. salt, 6539 tons of coal.

The chief exportations of the same year were, tallow, 932,906 lbs., wool, 1,569,323 lbs., 69,305 pairs of stockings, 27,109 pairs of gloves, 12,712 salted sheepskins, $4116 \mathrm{lbs}$. eider-downs, 25,000 lbs. other feathers, 244 horses, and 24,079 ship's pounds (the ship's pound $=320$ lbs.) salt fish. 
his hard cash. The dollars thus acquired are either melted down, and worked into silver massive girdles, which in point of execution as well as design are said, on good authority,* to be equal to any thing of the kind fashioned by English jewellers, or else deposited in a strong-box, as taxes and wages are all paid in produce, and no Icelander ever thinks of investing his money in stocks, shares, or debentures.

He is, however, by no means so ignorant of mercantile affairs as to strike at once a bargain with the Danish traders. Pitching his tent before the town, he first pays a visit to all the merchants of the place. After carefully noting their several offers (for as each of them invariably treats him to a dram, he with some justice mistrusts his memory), he returns to his caravan and makes his calculations as well as his somewhat confused brain allows him. If he is accompanied by his wife, her opinion of course is decisive, and the following morning he repairs with all his goods to the merchant who has succeeded in gaining his confidence.

After the business has been concluded, the peasant empties one glass to the merchant's health, another to a happy meeting next year, a third to the king, a fourth because three have been drunk already. At length, after many embraces and protestations of eternal friendship, he takes his leave of the merchant. Fortunately there is no thief to be found in all Iceland; but in consequence of these repeated libations, one parcel has not been well packed, another negligently attached to the horse, and thus it happens that the poor peasant's track is not unfrequently marked with sugar, coffee-beans, salt, or flour, and that when he reaches home, he finds some valuable article or other missing.

It would, however, be doing the Icelanders an injustice to regard them as generally intemperate; for though within the last twelve years the population has increased only ten per cent., and the importation of brandy thirty, yet the whole quantity of spirits consumed in the island amounts to less than three bottles per annum for each individual, and, of this allowance, the people of Reykjavik and of the other small sea-ports have more than their share, while many of the clergy and peasantry in the remoter districts hardly ever taste spirituous liquors. Dr. Hooker mentions the extraordinary effect which a small portion of rum produced on the good old incumbent of Middalr, whose stomach had been accustomed only to a milk-diet and a little coffee. "He begged me," says the doctor, $\nmid$ " to give him some rum to bathe his wife's breast; but having applied a portion of it to that purpose, he drank the rest without being at all aware of its strength, which, however, had no other effect than in causing this clerical blacksmith, $₫$ with his lame hip, to dance in the most ridiculous manner in front of the house. The scene afforded a great source of merriment to all his family except his old wife, who was very desirous of getting him to bed, while he was no less anxious that she should join him in the dance."

Dr. Hooker justly remarks that this very circumstance is a convincing proof how unaccustomed this priest was to spirituous liquors, as the quantity taken could not have exceeded a wine-glass full.

* Barrow, "Visit to Iceland," 1834.

+ "Journal of a Tour in Iceland," p. 110.

† All the clergymen are blacksmiths, for a reason that will be stated hereafter. 
After his visit to the fair, the peasant sets about hay-making, which is to him the great business of the year, for he is most anxious to secure winter fodder for his cattle, on which his whole prosperity depends. The few potatoes and turnips about the size of marbles, or the cabbage and parsley, which he may chance to cultivate, are not worth mentioning; grass is the chief, nay, the only produce of his farm, and that Heaven may grant clear sunshiny days for hay-making is now his daily prayer.

Every person capable of wielding a scythe or rake is pressed into the work. The best hay is cut from the "tún," a sort of paddock comprising the lands adjoining the farm-house, and the only part of his grounds on which the peasant bestows any attention, for, in spite of the paramount importance of his pastureland, he does but little for its improvement, and a meadow is rarely seen, where the useless or less nutritious herbs are not at least as abundant as those of a better quality. The "tún" is encircled by a turf or stone wall, and is seldom more than ten acres in extent, and generally not more than two or three. Its surface is usually a series of closely-packed mounds, like graves, most unpleasant to walk over, the gutter, in some places, being two feet in depth between the mounds. After having finished with the "tún," the farmer subjects to a process of cutting all the broken hillsides and boggy undrained swamps that lie near his dwelling. The blades of the scythes are very short. It would be inpossible to use a long-bladed scythe, owing to the unevenness of the ground.

The cutting and making of hay is carried on, when the weather will permit, through all the twenty-four hours of the day. When the hay is made it is tied in bundles by cords and thongs, and carried away by ponies to the earthen houses prepared for it, which are similar to and adjoin those in which the cattle are stalled. "It is a very curious sight," says Mr. Shepherd, " to see a string of hay-laden ponies returning home. Each pony's halter is made fast to the tail of the preceding one, and the little animals are so enveloped in their burdens that nothing but their hoofs and the connecting ropes are visible, and they look as though a dozen huge haycocks, feeling themselves sufficiently made, were crawling off to their resting-places."

When the harvest is finished the farmer treats his family and laborers to a substantial supper, consisting of mutton, and a soup of milk and flour; and although the serious and taciturn Icelander has perhaps of all men the least taste for music and dancing, yet these simple feasts are distinguished by a placid serenity, no less pleasing than the more boisterous mirth displayed at a southern vintage.

Almost all labor out-of-doors now ceases for the rest of the year. A thick mantle of snow soon covers mountain and vale, meadow and moor ; with every returning day, the sun pays the cold earth a decreasing visit, until, finally, he hardly appears above the horizon at noon; the wintry storm howls over the waste, and for months the life of the Icelander is confined to his hut, which frequently is but a few degrees better than that of the filthy Lap.

Its lower part is built of rude stones to about the height of four feet, and between each row layers of turf are placed with great regularity, to serve instead of mortar, and keep out the wind. A roof of such wood as can be pro- 


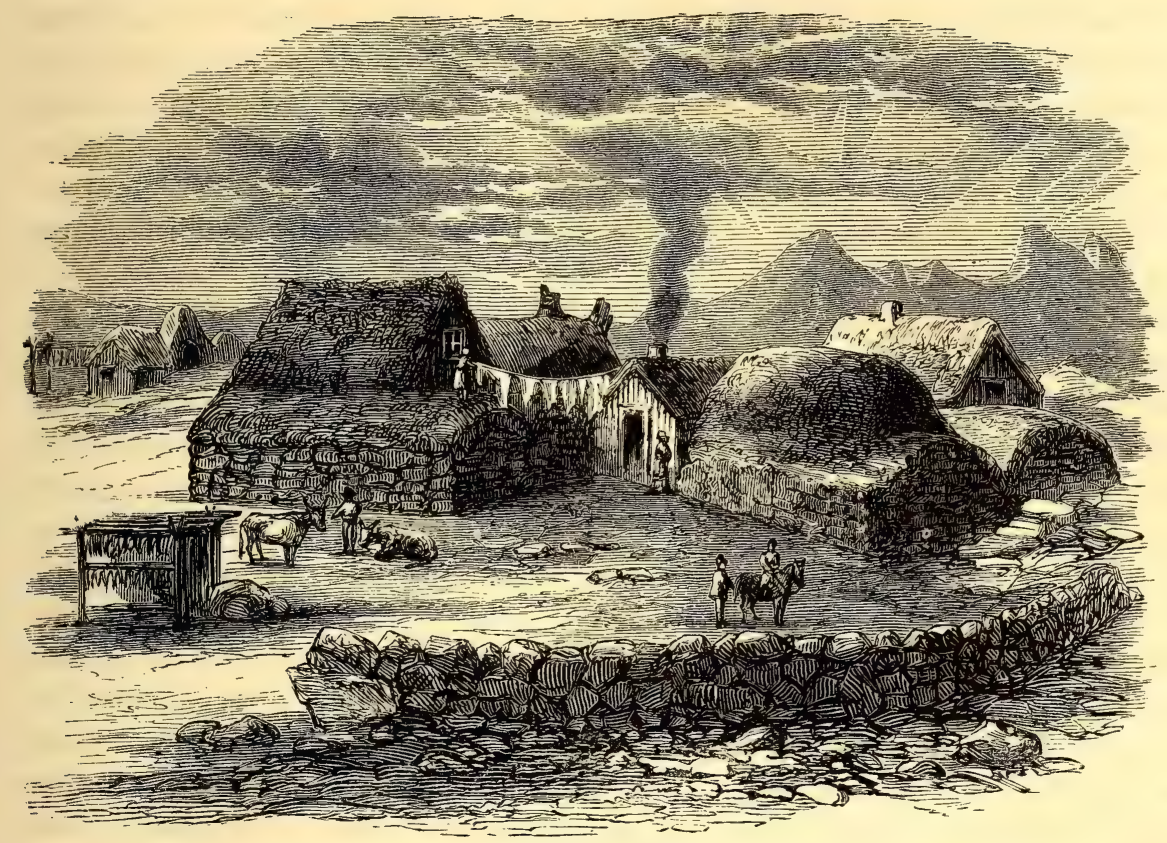

ICELANDIC HOUSES.

cured rests upon these walls, and is covere? with turf and sods. On one side (generally facing the south) are several gable ends and doors, each surmounted with a weather-cock. These are the entrances to the dwelling-house proper, to the smithy, store-room, cow-shed, etc. A long narrow passage, dark as pitch, and redolent of unsavory odors, leads to the several apartments, which are separated from each other by thick walls of turf, each having also its own roof, so that the peasant's dwelling is in fact a conglomeration of low huts, which sometimes receive their light through small windows in the front, but more frequently through holes in the roof, covered with a piece of glass or skin. The floors are of stamped earth; the hearth is made of a few stones clumsily piled together; a cask or barrel, with the two ends knocked out, answers the purpose of a chimney, or else the smoke is allowed to escape through a mere hole in the roof.

The thick turf walls, the dirty floor, the personal uncleanliness of the inhabitants, all contribute to the pollution of the atmosphere. No piece of furniture seems ever to have been cleaned since it was first put into use; all is disorder and confusion. Ventilation is utteriy impossible, and the whole family, frequently consisting of twenty persons or more, sleep in the same dormitory, as well as any strangers who may happen to drop in. On either side of this apartment are bunks three or four feet in width, on which the sleepers range themselves.

Such are in general the dwellings of the farmers and clergy, for but very few of the more wealthy inhabitants live in any way according to our notions of comfort, while the cots of the poor fisherman are so wretched that one can hardly believe them to be tenanted by human beings. 
The farm-houses are frequently isolated, and, on account of their grass-covered roofs and their low construction, are not easily distinguished from the neighboring pasture-grounds; where four or five of them are congregated in a grassy plain, they are dignified with the name of a village, and become the residence of a Hrepstior, or parish constable.

Then also a church is seldom wanting, which however is distinguished from the low huts around merely by the cross planted on its roof. An Icelandic house of prayer is generally from eight to ten feet wide, and from eighteen to twenty-four long; but of this about eight feet are devoted to the altar, which is divided off by a partition stretching across the church, and against which stands the pulpit. A small wooden chest or cupboard, placed at the end of the building, between two very small square windows not larger than a common-sized pane of glass, constitutes the communion-table, over which is generally a miserable representation of the Lord's Supper painted on wood. The height of the walls, which are wainscoted, is about six feet, and from them large wooden beams stretch across from side to side. On these beams are placed in great disorder a quantity of old Bibles, psalters, and fragments of dirty manuscripts. The interior of the roof, the rafters of which rest on the walls, is also lined with wood. On the right of the door, under which one is obliged to stoop considerably on entering, is suspended a bell, large enough to make an intolerable noise in so small a space. A few benches on each side the aisle, so crowded together as almost to touch one another, and affording accommodation to thirty or forty persons when squeezed very tight, leave room for a narrow passage.

These churches, besides their proper use, are also made to answer the purpose of the caravanseras of the East, by affording a night's lodging to foreign tourists. They are indeed neither free from dirt, nor from bad smells; but the stranger is still far better off than in the intolerable atmosphere of a peasant's hut.

Mr. Ross Browne thus describes the church and parsonage at Thingvalla; "The church is of modern construction, and, like all I saw in the interior, is made of wood, painted a dark color, and roofed with boards covered with sheets of tarred canvas. It is a very primitive little affair, only one story high, and not more than fifteen by twenty feet in dimensions. From the date on the weather-cock it appears to have been built in 1858. The congregation is supplied by the tew sheep-ranches in the neighborhood, consisting at most of half a dozen families. These unpretending little churches are to be seen in the vicinity of every settlement throughout the whole island. Simple and homely as they are, they speak well. for the pious character of the people.

"The pastor of Thingvalla and his family reside in a group of sod-covered huts close by the church. These cheerless little hovels are really a curiosity, none of them being over ten or fifteen feet high, and all huddled together with. out the slightest regard to latitude or longitude, like a parcel of sheep in a storm. Some have windows in the roof, and some have chimneys; grass and weeds grow all over them, and crooked by-ways and dark alleys run among them and through them. At the base they are walled up with big lumps of lava, and two of them have board fronts, painted black, while the remainder are 


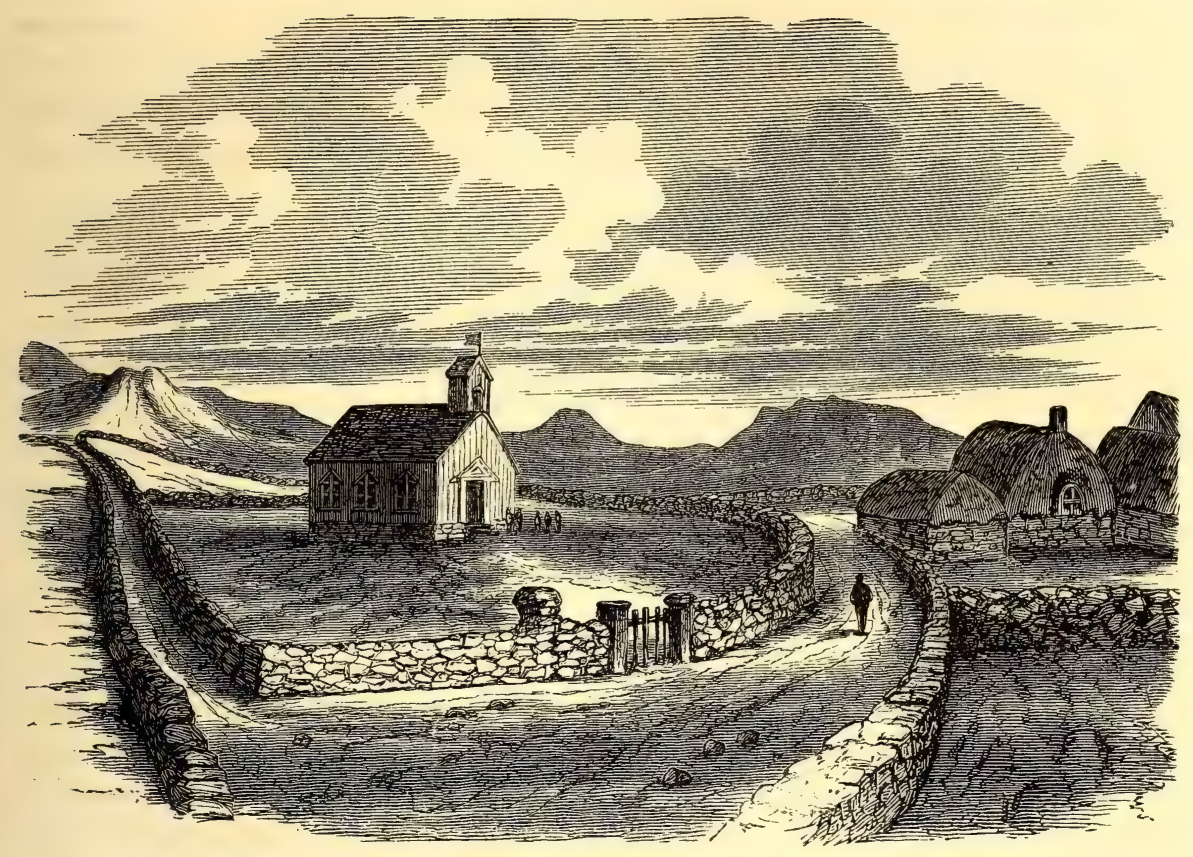

ChURCH AT thingValla.

patched up with turf and rubbish of all sorts, very much in the style of a stork's nest. A low stone wall encircles the premises, but seems to be of little use as a barrier against the encroachments of live-stock, being broken up in gaps every few yards. In front of the group some attempt has been made at a pavement, which, however, must have been abandoned soon after the work was commenced. It is now littered all over with old tubs, pots, dish-cloths, and other articles of domestic use.

"The interior of this strange abode is even more complicated than one would be led to expect from the exterior. Passing through a dilapidated doorway in one of the smaller cabins, which you would hardly suppose to be the main entrance, you find yourself in a long dark passage-way, built of rough stone, and roofed with wooden rafters and brushwood covered with sod. The sides are ornamented with pegs stuck in the crevices between the stones, upon which hang saddles, bridles, horse-shoes, bunches of herbs, dried fish, and various articles of cast-off clothing, including old shoes and sheepskins. Wide or nar. row, straight or crooked, to suit the sinuosities of the different cabins into which it forms the entrance, it seems to have been originally located upon the track of a blind boa-constrictor. The best room, or rather house-for every room is a house-is set apart for the accommodation of travellers. Another cabin is occupied by some members of the pastor's family, who bundle about like a lot of rabbits. The kitchen is also the dog-kennel, and occasionally the sheep-house. A pile of stones in one corner of it, upon which a few twigs or scraps of sheep-manure serve to make the fire, constitute the cooking apartment. The floor consists of the original lava-bed, and artificial puddles composed of 
slops and offal of diverse unctuous kinds. Smoke fills all the cavities in the air not already occupied by foul odors, and the beams, and posts, and rickety old bits of furniture are dyed to the core with the dense and variegated atmosphere around them. This is a fair specimen of the whole establishment, with the exception of the travellers' room. The beds in these cabins are the chief articles of luxury."

The poverty of the clergy corresponds with the meanness of their churches. The best living in the island is that of Breide'-Bolstadr, where the nominal stipend amounts to 180 specie dollars, or about $£ 40$ a year; and Mr. Holland states that the average livings do not amount to more than $£ 10$ for each parish in the island. The clergymen must therefore depend almost entirely for subsistence on their glebe land, and a small pittance to which they are entitled for the few baptisms, marriages, and funerals that occur among their parishioners. The bishop himself has only 2000 rix-dollars, or £200, a year, a miserable pittance to make a decent appearance, and to exercise hospitality to the clergy who visit Reykjavik from distant parts.

It can not be wondered at that pastors thus miserably paid are generally obliged to perform the hardest work of day laborers to preserve their families from starving, and that their external appearance corresponds less with the dignity of their office than with their penury. Besides hay-making and tending the cattle, they may be frequently seen leading a train of pack-horses from a fishingstation to their distant hut. They are all blacksmiths also from necessity, and the best sheers of horses on the island. The feet of an Iceland horse would be cut to pieces over the sharp rock and lava, if not well shod. The great resort of the peasantry is the church; and should any of the numerous horses have lost a shoe, or be likely to do so, the priest puts on his apron, lights his little charcoal fire in his smithy (one of which is always attached to every parsonage), and sets the animal on his legs again. The task of getting the necessary char-

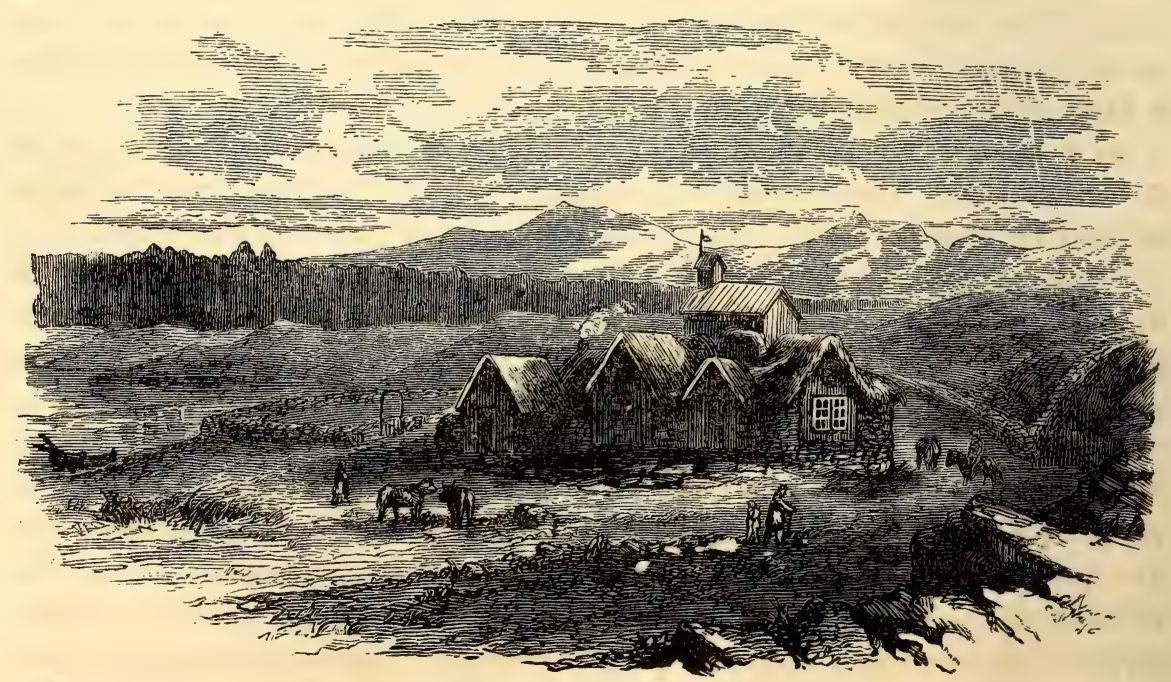

THE PASTOR's HOUSE, THINGVAlla. 
coal is not the least of his labors, for whatever the distance may be to the nearest thicket of dwarf-birch, he must go thither to burn the wood, and to bring it home when charred across his horse's back. His hut is scarcely better than that of the meanest fisherman; a bed, a rickety table, a few chairs, and a chest or two, are all his furniture. This is, as long as he lives, the condition of the Icelandic clergyman, and learning, virtue, and even genius are but too frequently buried under this squalid poverty.

But few of my readers have probably ever heard of the poet Jon Thorlakson, but who can withhold the tribute of his admiration from the poor priest of Backa, who with a fixed income of less than $£ 6$ a year, and condemned to all the drudgery which I have described, finished at seventy years of age a translation of Milton's "Paradise Lost," having previously

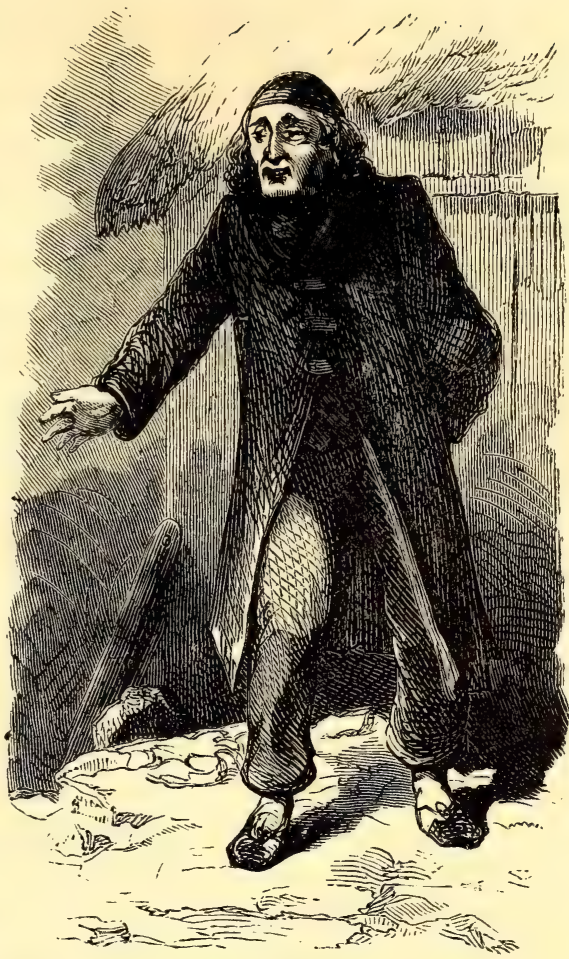

THE PASTOR OF THINGVALLA. translated Pope's "Essay on Man."

Three of the first books only of the "Paradise Lost" were printed by the Icelandic Literary Society, when it was dissolved in 1796, and to print the rest at his own expense was of course impossible. In a few Icelandic verses, Thorlakson touchingly alludes to his penury :- "Ever since I came into this world I have been wedded to Poverty, who has now hugged me to her bosom these seventy winters, all but two ; and whether we shall ever be separated here below is only known to Him who joined us together."

As if Providence had intended to teach the old man that we must hope to the last, he soon after received the unexpected visit of Mr. Henderson, an agent of the British and Foreign Bible Society, who thus relates his interview :

"Like most of his brethren at this season of the year, we found him in the meadow assisting his people in hay-making. On hearing of our arrival, he made all the haste home which his age and infirmity would allow, and bidding us welcome to his lowly abode, ushered us into the humble apartment where he translated my countrymen into Icelandic. The door is not quite four feet in height, and the room may be about eight feet in length by six in breadth. At the inner end is the poet's bed, and close to the door, over against a small window, not exceeding two feet square, is a table where he commits to paper the effusions of his Muse. On my telling him that my countrymen would not have forgiven me, nor could I have forgiven myself, had I passed through this part of the island without paying him a visit, he replied that the translation of Mil- 
ton had yielded him many a pleasant hour, and often given him occasion to think of England."

This visit was followed by agreeable consequences for the venerable bard. The Literary Fund soon afterwards sent him a present of $£ 30$, a modest sum according to our ideas, but a mine of wealth in the eyes of the poor Icelandic priest. His life, however, was now near its close, as it is stated in a short view "Of the Origin, Progress, and Operations of the Society," dated March $3 \mathrm{~d}, 1821$, that " the poet of Iceland is now in his grave ; but it is satisfactory to know that the attention, in this instance, of a foreign and remote society to his gains and his fortunes was highly gratifying to his feelings, and contributed not immaterially to the comfort of his concluding days."

He wrote a letter in very elegant Latin, expressing his heartfelt gratitude for the kindness and generosity of the Society, so accordant with the character of the British nation, and accompanied it with a MS. copy of his translation. The latter was first printed in Iceland in 1828 , but his own original poems did not appear before 1842 .

The school where most of the Icelandic clergymen, so poor and yet generally so respectable in their poverty, are educated, is that of Reykjavik, as few only enjoy stipends which enable them to study at Copenhagen. There they live several years under a milder sky, they become acquainted with the splendor of a large capital, and thus it might be supposed that the idea of returning to the dreary wastes of their own land must be intolerable. Yet this is their ardent desire, and, like banished exiles, they long for their beloved Iceland, where privation and penury await them.

In no Christian country, perhaps with the sole exception of Lapland, are the clergy so poor as in Iceland, but in none do they exert a more beneficial influence.

Though the island has but the one public school at Reykjavik, yet perhaps in no country is elementary education more generally diffused. Every mother teaches her children to read and write, and a peasant, after providing for the wants of his family by the labor of his hands, loses no opportunity, in his leisure hours, of inculcating a sound morality. In these praiseworthy efforts the parents are supported by the pastor.

He who, judging from the sordid condition of an Icelandic hut, might imagine its inhabitants to be no better than savages, would soon change his opinion were he introduced on a winter evening into the low, ill-ventilated room where the family of a peasant or a small landholder is assembled. Vainly would he seek a single idler in the whole company. The women and girls spin or knit; the men and boys are all busy mending their agricultural implements and household utensils, or else chiselling or cutting with admirable skill ornaments or snuff-boxes in silver, ivory, or wood. By the dubious light of a tallow lamp, just making obscurity visible, sits one of the family, who reads with a loud voice an old "saga" or chronicle, or maybe the newest number of the "Northurfari," an Iceland literary almanac, published during the last few years by Mr. Gisle Brinjulfsson. Sometimes poems or whole sagas are repeated from memory, and there are even itinerant story-tellers, who, like the trouba- 
dours and trouvères of the Middle Ages, wander from one farm to another, and thus gain a scanty livelihood. In this manner the deeds of the ancient Icelanders remain fixed in the memory of their descendants, and Snorre Sturleson, Sämund, Frodi, and Eric Rauda are unforgotten. Nine centuries have elapsed; but every Icelander still knows the names of the proud yarls who first peopled the fiords of the island; and the exploits of the brave vikings who spread terror and desolation along all the coasts of Europe still fill the hearts of the peaceful islanders of our days with a glow of patriotic pride.

Where education is so general, one may naturally expect to find a high degree of intellectual cultivation among the clergy, the public functionaries, and the wealthier part of the population. Their classical knowledge is one of the first things that strike the stranger with astonishment. He sees men whose appearance too frequently denotes an abject poverty conversant with the great authors of antiquity, and keenly alive to their beauties. Travelling to the Geysirs, he is not seldom accosted in Latin by his guide, and stopping at a farm, his host greets him in the same language.

I have specially named Jon Thorlakson, but Iceland has produced and still produces many other men who, without the hope of any other reward but that which proceeds from the pure love of literature, devote their days and nights to laborious studies, and live with Virgil and Homer under the sunny skies of Italy and Greece. In the study of the modern languages, the Icelanders are as far advanced as can be expected from their limited intercourse with the rest of the world.

The English language, in which they find so many words of their own and so many borrowed from the Latin, is cultivated by many of the clergy. The German they find still more easy; and as all the Scandinavian languages proceed from the same root, they have no difficulty in understanding the Danish and the Norwegian tongues. Of all the modern languages or dialects which have sprung from the ancient Norse, spoken a thousand years ago all over Denmark, Sweden, and Norway, none has undergone fewer changes than the Icelandic. In the sea-ports it is mixed up with many Danish words and phrases, but in the interior of the island it is still spoken as it was in the times of Ingolfr and Eric the Red, and in the whole island there is no fisherman or day laborer who dees not perfectly understand the oldest writings.

It may easily be imagined that among a people so fond of literature, books must be in great request. Too poor to be constantly increasing their small collections of modern publications, or of old "sagas" or chronicles, by new acquisitions, one assists the other. When the peasant goes on Sundays to church, he takes a few volumes with him, ready to lend his treasures to his neighbors, and, on his part, selects from among those which they have brought for the same purpose. When he is particularly pleased with a work, he has it copied at home, and it may be here remarked that the Icelanders are frequently most excellent calligraphists.

The foundation of a public library at Reykjavik in 1821, at the instigation of the learned Professor Rafn of Copenhagen, was a great boon to the people. It is said to contain about 12,000 volumes, which are kept under the roof of the 
cathedral. Books are freely lent for months, or even for a whole year, to the inhabitants of remote districts. This liberality is, of course, attended with some inconvenience, but it has the inestimable advantage of rendering a number of good works accessible to numerous families too poor to purchase them.

Another excellent institution is the New Icelandic Literary Society, founded in 1816. It has two seats, one in Copenhagen, the other in Reykjavik, and its chief object is the publication of useful works in the language of the country. Besides an annual grant of 100 specie dollars (£24) awarded to it by the Danish Government, its income is confined to the yearly contributions of its members, ${ }^{*}$ and with this scanty means it has already published many excellent works.

Though remote from the busy scenes of the world, Iceland has three newspapers, the Thyodtholfr and the Islendingur, which appear at Reykjavik, and the Northri, which is published at Akreyri, on the borders of the Polar Ocean. The Islendingur is said to contain many excellent articles, but it would sorely task the patience of those who are accustomed to the regular enjoyment of the "Times" at breakfast; as it sometimes appears but once in three weeks, and then again, $s \mathrm{~s}$ if to make up for lost time, twice in eight days.

In spite of their ill-ventilated dwellings and the hardships entailed upon them by the severity of the climate, the Icelanders frequently attain a good old age. Of the 2019 persons who died in 1858, 25 had passed the age of ninety, and of these 20 belonged to the fair sex. The mortality among the child en is; however, very considerable; 993 , or nearly one-half of the entire number having died before the age of five in the year above-mentioned. Cutaneous affections are very common among Icelanders, as may easily be supposed from their sordid woollen apparel and the uncleanliness of their huts; and the northern leprosy, or "likthra," is constantly seeking out its victims among them. This dreadful disease, which is also found among the fishermen in Norway, in Greenland, in the Faeroes, in Lapland, and, in short, wherever the same mode of life exists, begins with a swelling of the hands and feet. The hair falls off; the senses become obtuse. Tumors appear on the arms and legs, and on the face, which soon loses the semblance of humanity. Severe pains shoot through the joints, an eruption covers the whole body, and finally changes into open sores, ending with death. He whom the leprosy has once attacked is doomed, for it mocks all the efforts of medical art. Fortunately the victirns of this shocking complaint are rather objects of pity than of disgust, and as it is not supposed to be contagious, they are not so cruelly forsaken by their relations as their fellow-sufferers in the East. In the hut of the priest of Thingvalla, Marmier saw a leper busy grinding corn. Some of the poorest and most helpless of these unfortunate creatures find a refuge in four small hospitals, where they are provided for at the public expense.

Since a regular steam-boat communication has been opened between Iceland, Denmark, and Scotland, the number of tourists desirous of viewing the

* Their number in 1860 was 991 . During his voyage to Iceland in 1850 Prince Napoleon was named honorary president, a distinction he shares with the Bishop of Reykjavik. Among the 46 honorary members I find the name of Lord Dufferin. 
matchless natural wonders of the island has considerably increased. But travelling in the island itself is still attended with considerable difficulties and no trifling expense, to say nothing of the want of all comforts; so that most of its visitors are content with a trip to Thingvalla and the Geysir, which are but a couple of days' journey from Reykjavik, and very few, like Mr. Holland, make the entire circuit of the island, or, like Mr. Shepherd, plunge into the terra incognita of its north-western peninsula. The only mode of travelling is on horseback, as there are no roads, and therefore no carriages in Iceland. The distances between the places are too great, the rivers are too furious, and the bogs too extensive to allow of a walking tour being made. Even the tourist with the most modest pretensions requires at least two riding horses for himself, two for his guide, and two packhorses ; and when a larger company travels, it always forms a cavalcade of from twenty to thirty horses, tied head to tail, the chief guide mounted on the first and leading the string, the other accelerating its motions by gesticulation, sundry oaths, and the timely application of the whip. The way, or the path, lies either over beds of lava, so rugged that the horses are allowed to pick their way, or over boggy ground, where it is equally necessary to avoid those places into which the animals might sink up to their belly, but which, when left to themselves, they are remarkably skillful in detecting. With the solitary exception of a few planks thrown across the Bruera, and a kind of swing bridge, or klafr, contrived for passing the rapid Jökulsa, there are no bridges over the rivers, so that the only way to get across is to ride through them-a feat which, considering the usual velocity of their current, is not seldom attended with considerable danger, as will be seen by the following account of the crossing of the Skeidara by Mr. Holland.

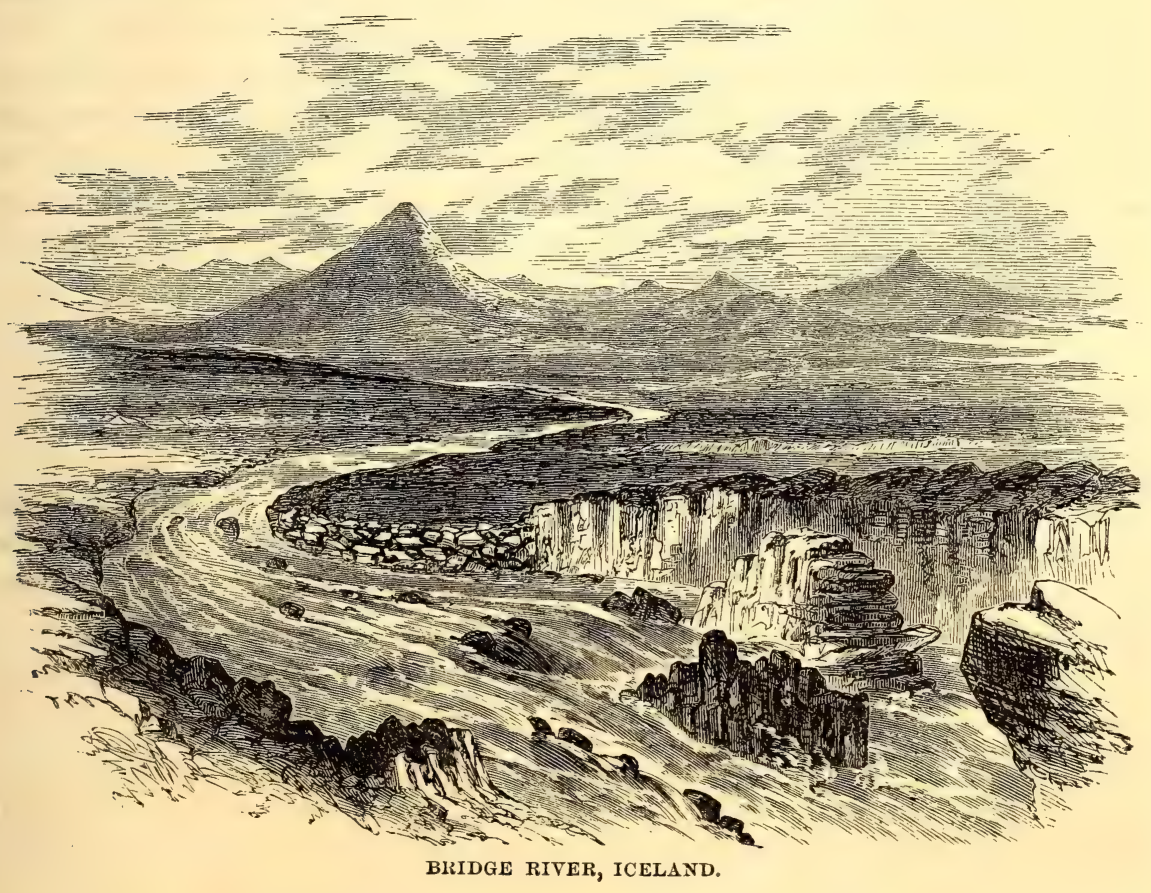


"Our guide," says this intrepid traveller, "urged on his horse through the stream, and led the way towards the mid-channel. We followed in his wake, and soon were all stemming the impetuous and swollen torrent. In the course of our journey we had before this crossed a good many rivers more or less deep, but all of them had been mere child's play compared to that which we were now fording. The angry water rose high against our horses' sides, at times almost coming over the tops of their shoulders. The spray from their broken crests was dashed up into our faces. The stream was so swift that it was impossible to follow the individual waves as they rushed past us, and it almost made us dizzy to look down at it. Now, if ever, is the time for firm hand or rein, sure seat, and steady eye; not only is the stream so strong, but the bottom is full of large stones, that the horse can not see through the murky waters; if he should fall, the torrent will sweep you down to the sea-its white breakers are plainly visible as they run along the shore at scarcely a mile's distance, and they lap the beach as if they waited for their prey. Happily, they will be disappointed. Swimming would be of no use, but an Icelandic waterhorse seldom makes a blunder or a false step. Not the least of the risks we ran in crossing the Skeidara was from the masses of ice carried down by the stream from the Jökul, many of them being large enough to knock a horse over.

"Fortunately we found much less ice in the centre and swiftest part of the river, where we were able to see and avoid it, than in the side channels. How the horses were able to stand against such a stream was marvellous; they could not do so unless they were constantly in the habit of crossing swift rivers. The Icelanders who live in this part of the island keep horses known for their qualities in fording difficult rivers, and they never venture to cross a dangerous stream unless mounted on a tried water-horse. The action of the Icelandic horses when crossing a swift river is very peculiar. They lean all their weight against the stream, so as to resist it as much as possible, and move onward with a peculiar side-step. This motion is not agreeable. It feels as if your horse were marking time without gaining ground, and the progress made being really very slow, the shore from which you started seems to recede from you, whilst that for which you are making appears as far as ever.

"When we reached the middle of the stream, the roar of the waters was so great that we could scarcely make our voices audible to one another; they were overpowered by the crunching sound of the ice, and ine bumping of large stones against the bottom. Up to this point a diagonal line, rather down stream, had been cautiously followed; but when we came to the middle, we turnea our horses' heads a little against the stream. As we thus altered our course, the long line of baggage-horses appeared to be swung round altogether, as if swept off their legs. None of them, however, broke away, and they continued their advance without accident, and at length we all reached the shore in safety."

After a day's journey in Iceland, rest, as may well be supposed, is highly acceptable. Instead of passing the night in the peasant's hut, the traveller, when no church is at band, generally prefers pitching his tent near a running 
stream on a grassy plain; but sometimes, in consequence of the great distance from one habitable place to another, he is obliged to encamp in the midst of a bog where the poor horses find either bad herbs, scarcely fit to satisfy their hunger, or no food at all. After they have been unloaded, their fore legs are bound together above their hoofs, so as to prevent them straying too far, while their masters arrange themselves in the tent as comfortably as they can.

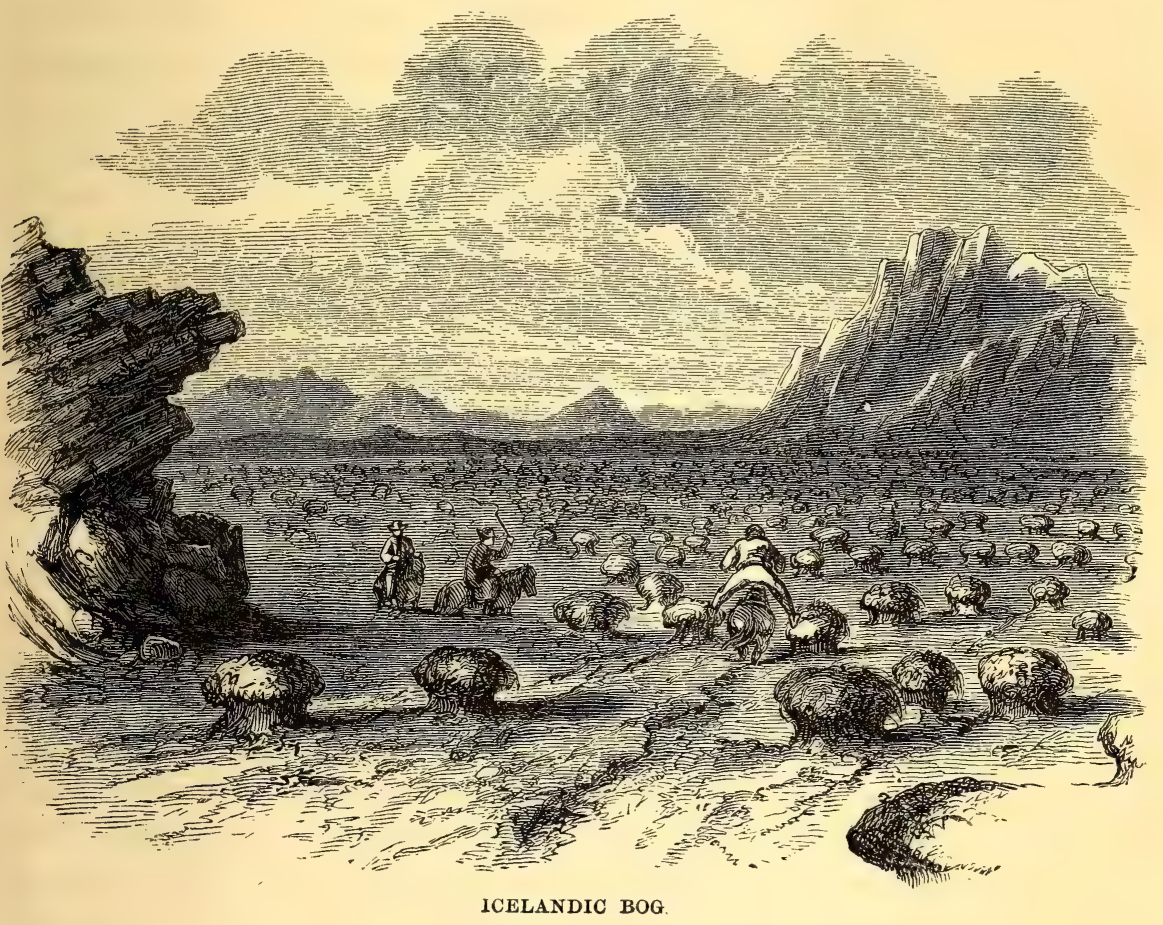




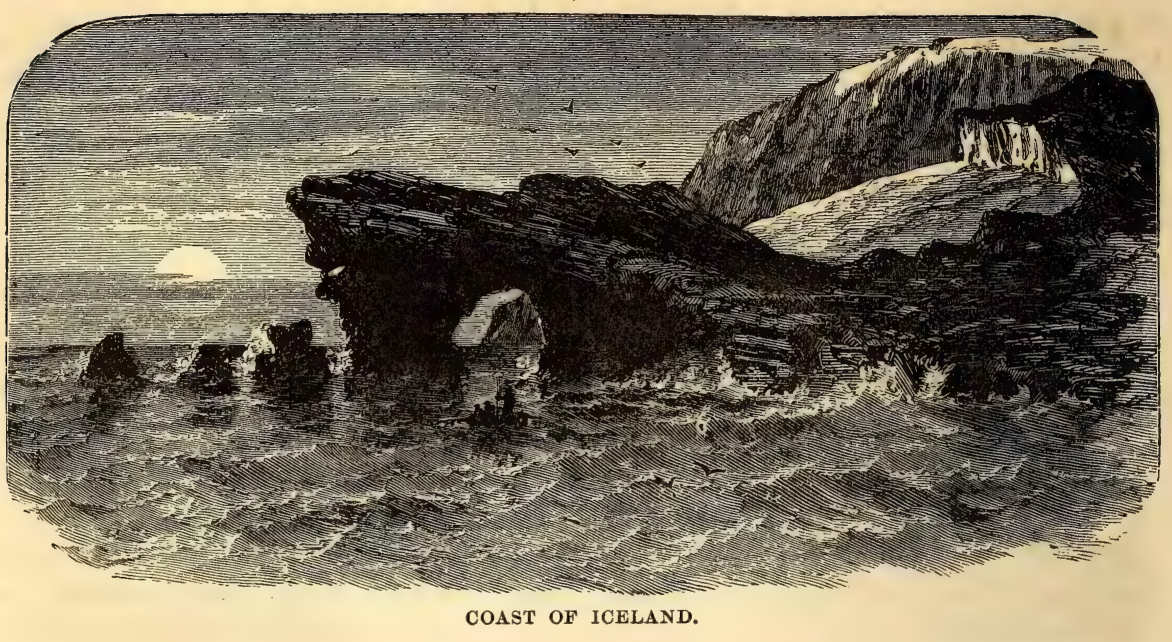

\section{CHAPTER VIII. \\ THE WESTMAN ISLANDS.}

The Westmans.-Their extreme Difficulty of Access.-How they became peopled.-Heimaey. Kaufstathir and Ofanleyte.- Sheep-hoisting.-Egg-gathering.-Dreadful Mortality among the Children.-The Ginklofi.-Gentleman John.-The Algerine Pirates.-Dreadful Sufferings of the Islanders.

$\mathbf{R}$

ISING abruptly from the sea to a height of 916 feet, the small Westman

Islands are no less picturesque than difficult of access. Many a traveller while sailing along the south coast of Iceland has admired their towering rockwalls, but no modern tourist has ever landed there. For so stormy a sea rolls between them and the mainland, and so violent are the currents, which the slightest wind brings forth in the narrow channels of the archipelago, that a landing can be effected only when the weather is perfectly calm. The Drifanda foss, a cascade on the opposite mainland, rushing from the brow of the Eyafyalla range in a column of some 800 or 900 feet in height, is a sort of barometer, which decides whether a boat can put off with a prospect of gaining the Westmans. In stormy weather the wind eddying among the cliffs converts the fall, though considerable, into a clond of spray, which is dissipated in the atmosphere, so that no cascade is visible from the beach. In calm weather the column is intact, and if it remains so two days in succession, then the sea is usually calm enough to allow boats to land, and they venture out. As theIcelanders, through stormy weather, are frequently cut off from Europe, so the inhabitants of the Westmans are still more frequently cut off from Iceland, and it is seldom more than once a year that the mails are landed direct. The fero letters from Denmark (for the correspondence is in all probability not very active) are landed in Iceland at Reykjavik, and thence forwarded to the islands by boat, as chance may offer, for, during the whole winter and the greater part 
of the summer, communication is impossible. It will now be understood why tourists are so little inclined to visit the Westmans, despite the magnificence of their coast scenery, for who has the patience to tarry in a miserable hut on the opposite mainland till the cascade informs him that they are accessible, or is inclined to run the risk of being detained by a sudden change of the weather for weeks or even months on these solitary rocks?

Mr. Ross Browne thus describes the general aspect of the coast of Iceland: "Nothing could surpass the desolate grandeur of the coast as we approached the point of Reykjaness. It was of an almost infernal blackness. The whole country seemed uptorn, rifted, shattered, and scattered about in a vast chaos of ruin. Huge cliffs of lava split down to their bases toppled over the surf. Rocks of every conceivable shape, scorched and blasted with fire, wrested from the main and hurled into the sea, battled with the waves, their black scraggy points piercing the mist like giant hands upthrown to smite or sink in a fierce death-struggle. The wild havoc wrought in the conflict of elements was appalling. Birds screamed over the fearful wreck of matter. The surf from the inrolling waves broke against the charred and shattered desert of ruin with a terrific roar. Columns of spray shot up over the blackened fragments of lava, while in every opening the lashed waters, discolored by the collision, seethed and surged as in a huge caldron."

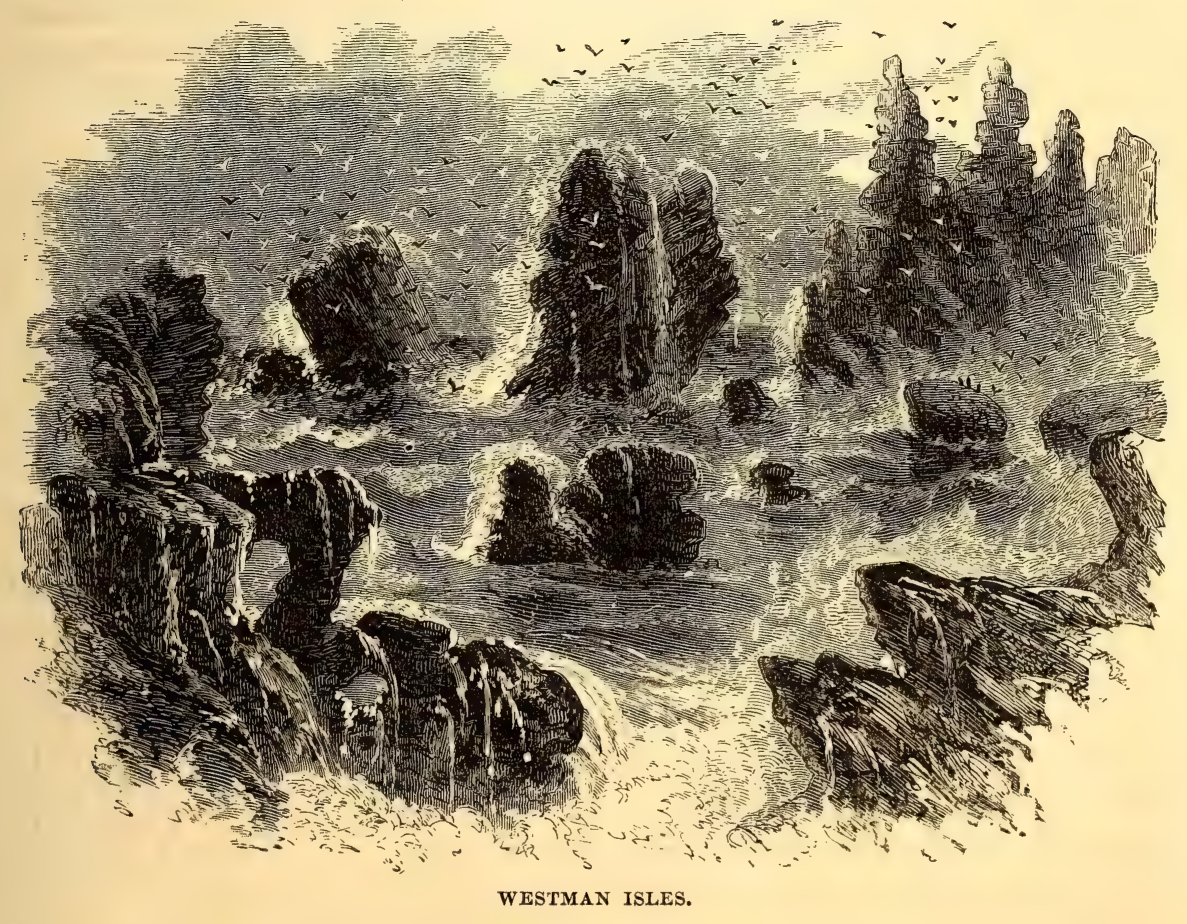

Of the Westman Islands, he says: "Towards noon we made the Westman Isles, a small rocky group some ten miles distant from the main island. A fishing and trading establishment, owned by a company of Danes, is located 
on one of these islands. The Arcturus touches twice a year to deliver and receive a mail. On the occasion of our visit, a boat came out with a hardy-looking crew of Danes to receive the mail-bag. It was doubtless a matter of great rejoicing to them to obtain news from home. I had barely time to make a rough outline of the islands as we lay off the settlement. The chief interest attached to the Westman group is, that it is supposed to have been visited by Columbus in 1477 , fifteen years prior to his voyage of discovery to the shores of America."

The puffin, or the screeching sea-mew, seem the only inhabitants for which nature has fitted the Westmans, and yet they have a history which leads us back to the times when Iceland itself first became known to man.

About 875, a few years after Ingolfr followed his household gods to Reykjavik, a Norwegian pirate, perchance one of the associates of that historical personage, landed on the coast of Ireland, attacked with fire and sword the defenseless population, captured forty or fifty persons, men, women, and children, and carried them off as slaves. The passage must have been any thing but pleasant, for it gave the Hibernians such a foretaste of the wretchedness that awaited them in Iceland, their future abode, that, taking courage from despair, they rose on their captors, threw them overboard, and went ashore on the first land they met with.

A day of rare serenity must have witnessed their arrival on the Westmans, a spot which of all others seemed most unlikely to become their home. Why they remained there, is a secret of the past; most likely they had no other alternative, and freedom on a rock was, at all events, better than slavery under a cruel viking.

Thus these weather-beaten islets were first peopled by men from the west, whence they derive their name, and it is supposed that the present inhabitants are the descendants of those children of Erin. No one will be inclined to envy them the heritage bequeathed to them by their fathers.

The Westmans are fourteen in number; but of these only one, called Heimaey, or Home Island, is inhabited. It is fifteen miles from the coast of Iceland, and forty-five from Hecla. Though larger than all the others put together, its entire surface is not more than ten square miles. It is almost surrounded with high basaltic cliffs, and an otherwise iron-bound shore; its interior is covered with black ashy-looking cones, bearing undoubted evidence of volcanic action; in fact, the harbor, which lies on its north-east side, and is only accessible to small craft, is formed out of an old crater, into which the sea has worn an entrance. The inhabitants are located in two villages; Kaufstathir, on a little grassy knoll near the landing-place, and Ofanleyte, on the grassy platform of the island. Only three of the other islets produce any vegetation or pasturage, and it is said that on one of these the sheep are hoisted with a rope out of the boats by an islander, who, at the risk of his neck, has climbed to the top of the precipitous rock. The others are mere naked cliffs or basaltic pillars, the abode of innumerable sea-birds, which, when accessible, are a precious resource to the islanders. For, as may well be supposed, the scanty grass lands afford nourishment but to a few cows and sheep; and as the unruly waters too often prevent 
their fishing-boats from putting to sea, they depend in a great measure for their subsistence upon the sea-birds, in whose capture they exhibit wonderful courage and skill. In the egg-season they go to the top of the cliff, and, putting a rope round a man's waist, let him down the side of the perpendicular rock, one, two, or three hundred feet; on arriving at the long, narrow, horizontal shelves, he proceeds to fill a large bag with the brittle treasures deposited by the birds. When his bag is full, he and his eggs are drawn to the top by his companions. If the rope breaks, or is cut off by the sharp corners of the rock, which, however, happens but seldom, nothing can save the luckless fowler, who is either precipitated into the sea, or dashed to pieces on the rocks below.

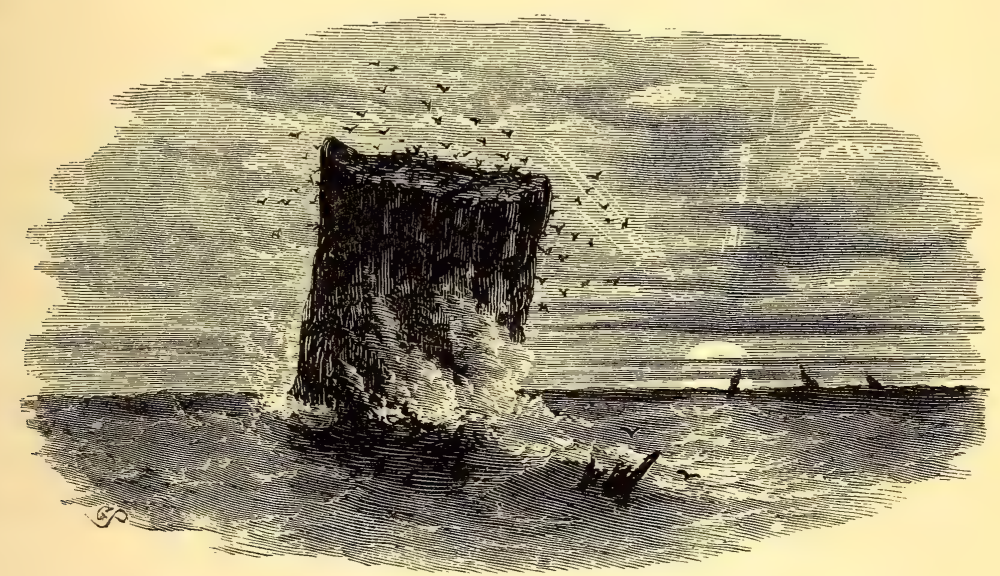

HOME OF SEA-BIRDS.

At a later period in the season they go and get the young birds, and then they have often desperate battles with the old ones, who will not give up fighting for their offspring till their necks are broken, or their brains knocked out with a club. Where the cliffs are not accessible from the top, they go round the bottom in boats, and show a wonderful agility and daring in scaling the most terrible precipices.

In summer they get the eggs and the fresh meat of the young birds, which they also salt for the winter. The feathers form their chief article of export, besides dried and salted codfish, and with these they procure their few necessaries and luxuries, consisting principally of clothing, tobacco and snuff, spirits, fish-hooks and lines, and salt. As there is no peat on these islands, nor dried fish-bones in sufficient quantity, they also make use of the tough old sea-birds as fuel. For this purpose they split them open, and dry them on the rocks.

The Westmans form a separate Syssel, or county, and they have a church, and usually two clergymen. Their church was rebuilt of stone, at the expense of the Danish Government, in 17\%4, and is said to be one of the best in Iceland. 
Unfortunately the two clergymen to whom the spiritual care of the islanders is confided seem to have but a very indifferent flock, for their neighbors on the mainland give rather a bad character to the inhabitants of Heimaey, describing them as great sluggards and drunkards.

The population, which was formerly more considerable, amounts to about 200 souls, but even this is more than might be expected from the dreadful mortality which reigns among the children. The eggs and the oily flesh of sea-birds furnish a miserable food for infants, particularly when weaned, as is here customary, at a very early age; but the poor islanders have nothing else to give them, except some fish, and a very insufficient quantity of cow's or sheep's milk. This unhealthy diet, along with the boisterous air, gives rise to an incurable infantile disease, called Ginklofi (tetconus). Its first symptoms are squinting and rolling of the eyes, the muscles of the back are seized with incipient cramps and become stiff. After a day or two lock-jaw takes place, the back is bent like a bow, either backward or forward. The lock-jaw prevents swallowing, and the cramps become more frequent and prolonged until death closes the scene. The same disease is said to decimate the children on St. Kilda in consequence of a similar mode of life.

The only means of preserving the infants of Heimaey from the Ginklofi, is to send them as soon as possible to the mainland to be reared, and thus a long continuance of bad weather is a death-warrant to many.

Who would suppose that the Westman Islanders, doubly guarded by their poverty and almost inaccessible cliffs, could ever have become the prey of freebooters? and yet they have been twice attacked and pillaged, and well-nigh exterminated by sea-rovers.

I have already mentioned, in a previous chapter, that before the discovery of the banks of Newfoundland, the English cod-fishers used to resort in great numbers to the coasts of Iceland, where some of them-now and then-appeared also in the more questionable character of corsairs. One of these worthies, who, like Paul Clifford, or Captain Macheath, so effectually united the suaviter in modo with the fortiter in re, as to have merited the name of "Gentleman John," came to the Westmans in 1614 and set the church on fire, after having previously removed the little that was worth taking. After this exploit he returned to Great Britain, but King James I. had him hung, and ordered the church ornaments which he had robbed to be restored to the poor islanders. It was, however, written in the book of fate that they were not to enjoy them long, for in 1627 , a vessel of Algerine pirates, after plundering several places on the eastern and southern coasts of Iceland, fell like a thunderbolt on Heimaey. These miscreants, compared with whom John was a "gentleman" indeed, cut down every man who ventured to oppose them, plundered and burnt the new-built church, and every hovel of the place, and carried away about 400 prisoners-men, women, and children. One of the two clergymen of the island, Jon Torsteinson, was murdered at the time. This learned and pious man had translated the Psalms of David and the Book of Genesis into Icelandic verse, and is spoken of as the "martyr" in the history of the land. The other clergyman, Olaf Egil- 
son, with his wife and children, and the rest of the prisoners, was sold into slavery in Algiers. The account of his sufferings and privations, which he wrote in the Icelandic language, was afterwards translated and published in Danish.

It was not until 1636 , nine years after their capture, that the unfortunate Heimaeyers were released, and then only by being ransomed by the King of Denmark. Such was the misery they had endured from their barbarous taskmasters, that only thirty-seven of the whole number survived, and of these but thirteen lived to return to their native island. 


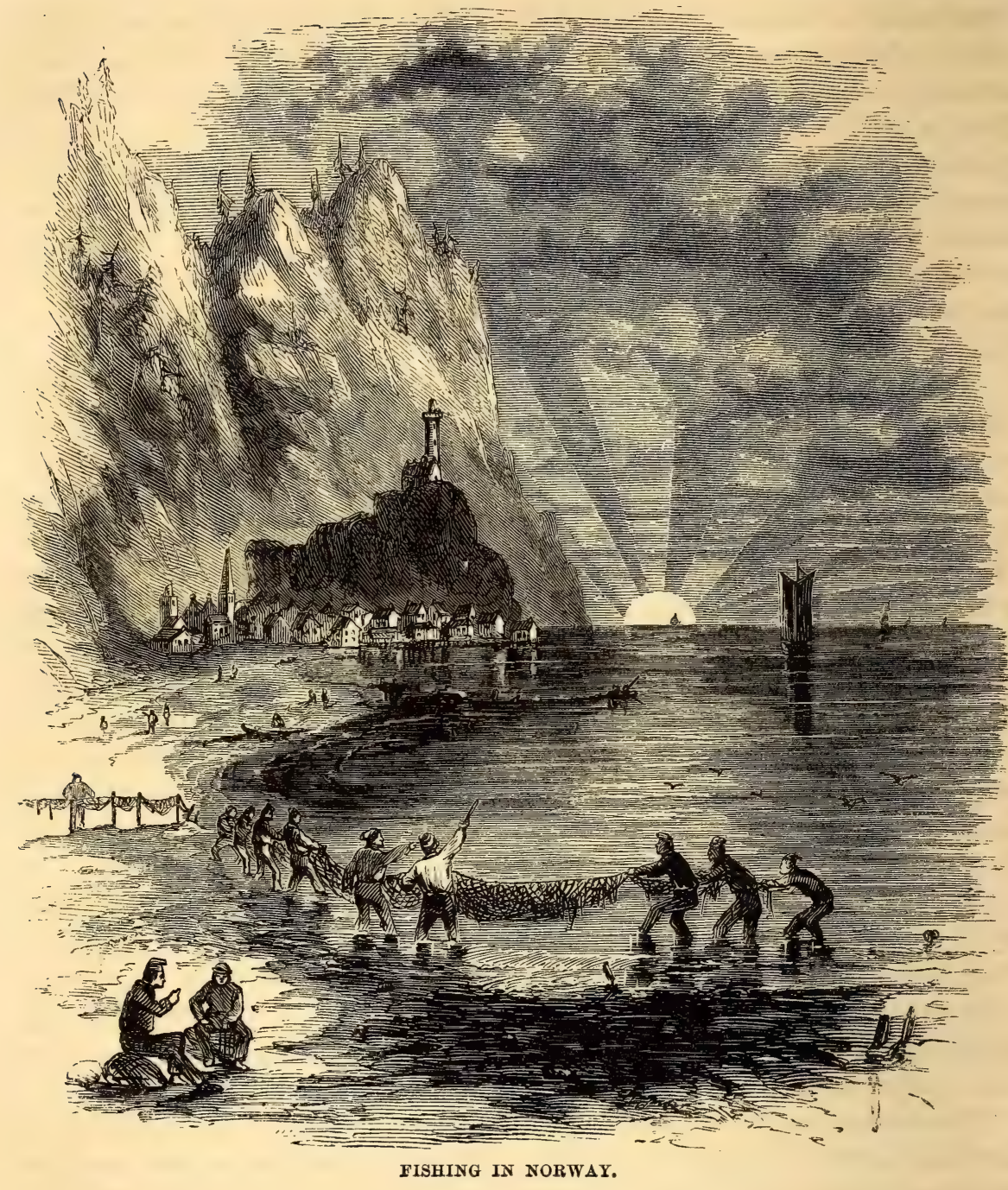

\section{CHAPTER IX.}

\section{FROM DRONTHEIM TO THE NORTH CAPE.}

Mild Climate of the Norwegian Coast.-Its Causes.-The Norwegian Peasant.-Norwegian Constitution.Romantic coast Scenery.-Drontheim.—Greiffenfeld Holme and Väre.-The Sea-eagle.-The Herringfisheries. - The Lofoten Islands. - The Cod-fisheries. - W retched Condition of the Fishermen.-Tromso-Altenfiord.-The Copper Mines.-Hammerfest the most northern Town in the World.-The North Cape.

F all the lands situated either within or near the Arctic Circle none enjoys a more temperate climate than the Norwegian coast. Here, and nowhere else throughout the northern world, the birch and the fir-tree climb the mountain-slopes to a height of 700 or 800 feet above the level of the sea, as far as the 
70th degree of latitude; here we still find a flourishing agriculture in the interior of the Malanger Fjord in $69^{\circ}$. On the opposite side of the Polar Ocean extends the inaccessible ice belt of East Greenland; Spitzbergen and Nova Zembla are not 400 miles distant from Talvig and Hammerfest, and yet these ports are never blocked with ice, and even in the depth of winter remain constantly open to navigation. What are the causes which in this favored region banish the usual rigors of the Arctic zone? How comes it that the winter even at the North Cape (mean temperature $+22^{\circ}$ ) is much less severe than at Quebec (mean temperature $+14^{\circ}$ ), which is situated $25^{\circ}$ of latitude nearer to the equator?

The high mountain chains which separate Norway from Sweden and Finland, and keep off the eastern gales issuing from the Siberian wastes, while its coasts lie open to the mild south-westerly winds of the Atlantic, no doubt account in some measure for the comparative mildness of its climate; but the main cause of this phenomenon must no doubt be sought for in the sea. Flowing into the Atlantic Ocean between Florida and Cuba, the warm Gulf Stream traverses the sea from west to east, and although about the middle of its course it partly turns to the south, yet a considerable portion of its waters flows onward to the north-east, and streaming through the wide portal between Iceland and Great Britain, eventually reaches the coasts of Norway. Of course its warmth diminishes as it advances to the north, but this is imparted to the winds that sweep over it, and thus it not merely brings the seeds of tropical plants from Equatorial America to the coasts of Norway, but also the far more important advantages of a milder temperature.

The soil of Norway is generally rocky and sterile, but the sea amply makes up for the deficiencies of the land, and with the produce of their fisheries, of their forests, and their mines, the inhabitants are able to purchase the few foreign articles which they require. Though poor, and not seldom obliged to reap the gifts of nature amidst a thousand hardships and dangers, they envy no other nation upon earth.

The Norwegian peasant is a free man on the scanty bit of ground which he has inherited from his fathers, and he has all the virtues of a freeman-an open character, a mind clear of every falsehood, a hospitable heart for the stranger. His religious feelings are deep and sincere, and the Bible is to be found in every hut. He is said to be indolent and phlegmatic, but when necessity urges he sets vigorously to work, and never ceases till his task is done. His courage and his patriotism are abundantly proved by a history of a thousand years.

Norway owes her present prosperity chiefly to her liberal constitution. The press is completely free, and the power of the king extremely limited. All privileges and hereditary titles are abolished. The Parliament, or the "Storthing," which assembles every three years, consists of the "Odelthing," or Upper House, and of the "Logthing," or Legislative Assembly. Every new law requires the royal sanction; but if the Storthing has voted it in three successive sittings, it is definitively adopted in spite of the royal veto. Public education is admirably cared for. There is an elementary school in every village, and where the population is too thinly scattered, the schoolmaster may truly be said 
to be abroad, as he wanders from farm to farm, so that the most distant families have the benefit of his instruction. Every town has its public library, and in many districts the peasants annually contribute a dollar towards a collection of books, which, under the care of the priest, is lent out to all subscribers. No Norwegian is confirmed who does not know how to read, and no Norwegian is allowed to marry who has not been confirmed. He who attains his twentieth year without having been confirmed has to fear the House of Correction. Thus ignorance is punished as a crime in Norway, an excellent example for far richer and more powerful nations.

The population of Norway amounts to about $1,350,000$, but these are very unequally distributed ; for while the southern province of Aggerhuus has 513,000 inhabitants on a surface of 35,200 square miles, Nordland has only 59,000 on 16,325 , and Finmark, the most northern province of the land, but 38,000 on 29,925 , or hardly more than one inhabitant to every square mile. But even this scanty population is immense when compared with that of Eastern Siberia or of the Hudson s Bay territories, and entirely owes its existence to the mildness of the climate and the open sea, which at all seasons affords its produce to the fisherman.

It is difficult to imagine a more secluded, solitary life than that of the "bonders," or peasant proprietors, along the northern coasts of Norway. The farms, confined to the small patches of more fruitful ground scattered along the fjords, at the foot or on the sides of the naked mountains, are frequently many miles distant from their neighbors, and the stormy winter cuts off all communication

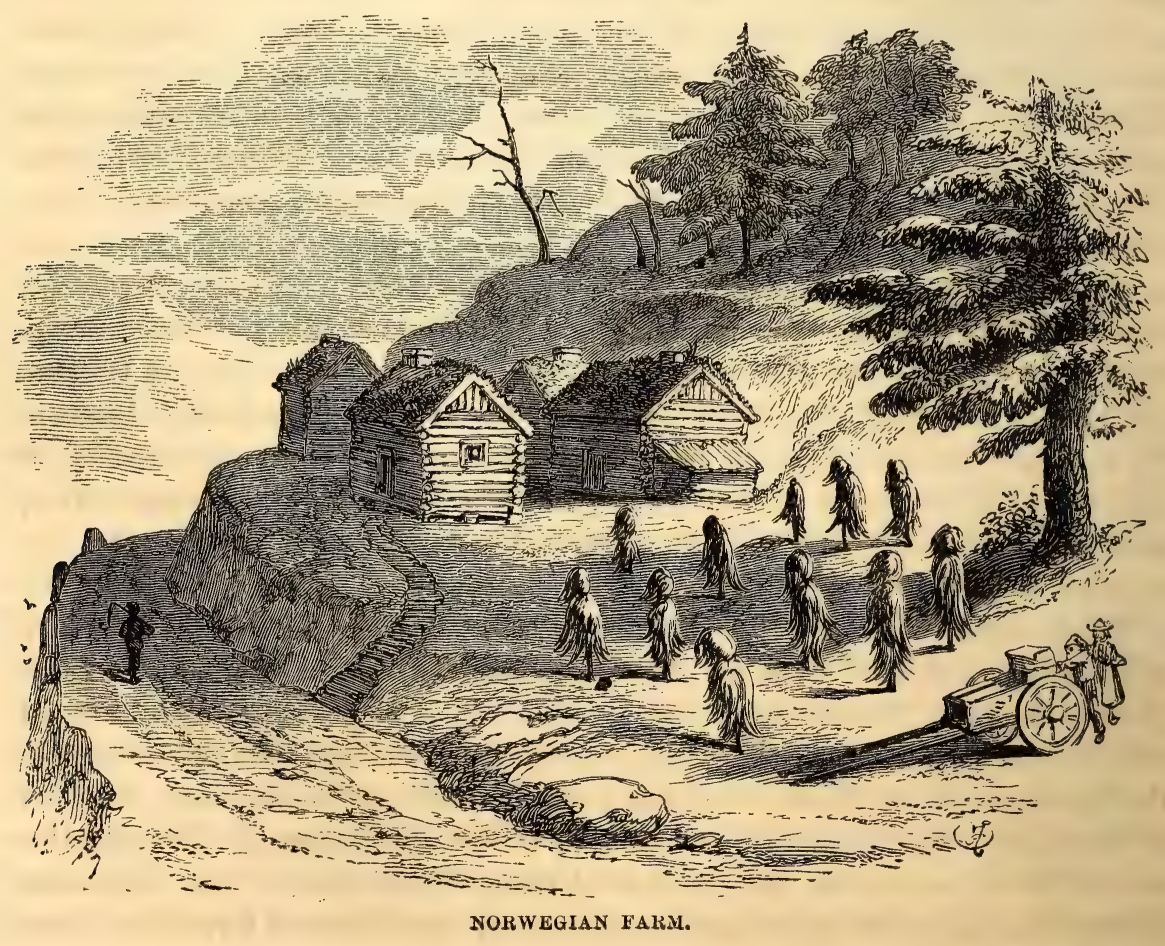




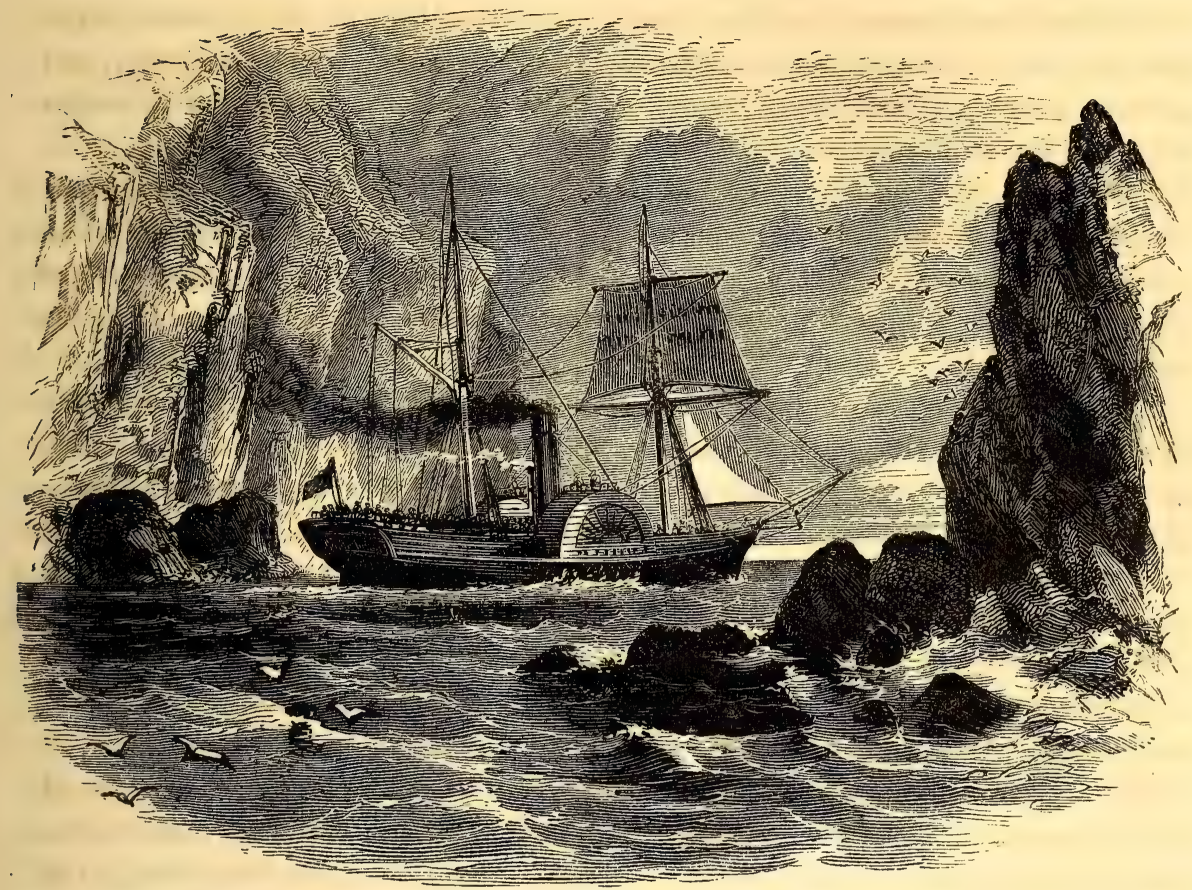

Steaming along the COAST.

between them. Thus every family, reduced to its own resources, forms as it were a small commonwealth, which has but little to do with the external world, and is obliged to rely for its happiness on internal harmony, and a moderate competency. Strangers seldom invade their solitude, for they are far from the ordinary tracks of the tourist, and yet a journey from Drontheim to Hammerfest and the North Cape affords many objects of interest well worthy of a visit. The only mode of communication is by sea, for the land is everywhere intersected by deep fjords, bounded by one continuous chain of precipitous cliffs and rocks, varying from one thousand to four thousand feet in height. Formerly, even the sea-voyage was attended with considerable difficulties, for the miserable "yoegt," or Scandinavian sloop, the only means of conveyance at the disposal of the traveller, required at the best of times at least a month to perform the voyage from Drontheim to Hammerfest, and in case of stormy weather, or contrary wind, had often to wait for weeks in some intermediate port. Now, however, a steamer leaves the port of Drontheim every week, and conveys the traveller in five or six days to the remote northern terminus of his journey.

Innumerable isles of every size, from a few yards in diameter to as many miles, stud the line of coast, and between these and the mainland the steamer ploughs its way. Sometimes the channel is as narrow as the bed of a river, at others it expands into a mighty lake, and the ever-varying forms of the isles, of the fjords, and of the mountains, constantly open new and magnificent prospects to the view. One grand colossal picture follows upon another, but unfortunately few or none show the presence of man. From time to time only some fishing-boat makes its appearance on the sea, or some wooden farm-house rises 
on the solitary beach. On advancing farther to the north, the aspect of nature becomes more and more stern, vegetation diminishes, man is more rarely seen, and the traveller feels as if he were on the point of entering the gloomy regions of perpetual death.

With the sole exception of Archangel, Drontheim is the most populous and important town situated in so high a latitude as $63^{\circ} 24^{\prime}$. Although the cradle of ancient Scandinavian history, and the residence of a long line of kings, it looks as if it had been built but yesterday, as its wooden houses have frequently been destroyed by fire. The choir of its magnificent cathedral, built in the eleventh century, and once the resort of innumerable pilgrims who came flocking to the shrine of St. Olave from all Scandinavia, is the only remaining memorial of the old Tronyem of the Norse annalists and scalds. The modern town has a most pleasing and agreeable appearance, and the lively colors with which the houses are painted harmonize with the prosperity of its inhabitants, which is due in a great measure to its thriving fisheries, and to the rich iron and copper mines in its neighborhood. The tall chimneys of many smelting-huts, iron foundries, and other manufactories, bear evidence that modern industry has found its way to the ancient capital of Norway. In point of picturesque beauty, the bay, on a peninsula of which the town is situated, does not yield to that of Naples. Up and down, in every direction, appear the villas of the merchant, and ships of all burden riding at anchor in the bay, and boats passing and repassing. In a small island of the bay, fronting the town, is the celebrated castle of Munkholm, where in former times many a prisoner of state has bewailed the loss of his liberty. Here, among others, Greiffenfeld, who had risen from obscurity to the rank of an all-powerful minister, was incarcerated for eighteen years (1680-98.)

At Hildringen, where the potato is still cultivated with success, and barley ripens every four or five years, begins the province of Nordland, which extends from $65^{\circ}$ to $69^{\circ} 30^{\prime} \mathrm{N}$. lat. The mostly uninhabited isles along the coast are called "Holme," when rising like steep rocks out of the water, and "Väre" when flat and but little elevated above the level of the sea. The latter are the

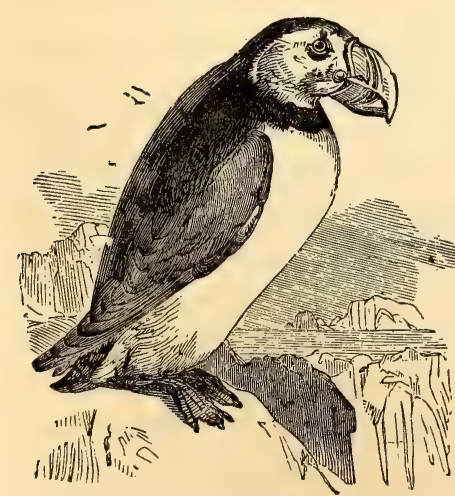

THE PUFEIN. breeding-places of numberless sea-fowls, whose eggs yield a welcome harvest to the inhabitants of the neighboring mainland or of the larger islands. A well-stocked egg-vär is a valuable addition to a farm, and descends from father to son, along with the pasture-grounds and the herds of the paternal land. When the proprietor comes to plunder the nests, the birds remain quiet, for they know by experience that only the superfluous eggs are to be removed. But not unfrequently strangers land, and leave not a single egg behind. Then all the birds, several thousands at once, rise from their nests and fill the air with their doleful cries. If such

disasters occur repeatedly they lose courage, and, abandoning the scene of their misfortunes, retire to another vär. Most of these birds are sea-gulls (Maasfugl, 
or Maage), their eggs are large, and of a not disagreeable taste. The island of Lovunnen is the favorite breeding-place of the puffin, which is highly esteemed on account of its feathers. This silly bird is very easily caught. The fowler lets down an iron hook, or sends a dog trained on purpose into the narrow clefts or holes of the rock, where the puffins sit crowded together. The first bird being pulled out, the next one bites and lays hold of his tail, and thus in succession, till the whole family, clinging together like a chain, is dragged to light.

This rocky coast is also much frequented by the sea-eagle, who is very much feared over the whole province, as he not only carries away lambs and other small animals, but even assails and not seldom overpowers the Norwegian oxen. His mode of attack is so singular that if Von Buch had not heard it so positively and so circumstantially related in various places, situated at great distances from each other, he would willingly have doubted its truth. The eagle darts down into the waves, and then rolls about with his wet plumage on the beach until his wings are quite covered with sand. Then he once more rises into the air and hovers over his intended victim. Swooping down close to him, he claps his wings, flings the sand into the eyes of the unfortunate brute, and thoroughly scares it by repeated blows of his pinions. The blinded ox rushes away to avoid the eagle's attacks, until he is completely exhausted or tumbles down some precipitous cliff.

The sea-coast from Alsten to Rodoë, which is crossed by the Arctic Circle, is particularly rich in herrings, as it furnishes more than one-half of the fish exported to Bergen.

In respect of the capital invested, the cod-fishery must be regarded as the most important of the Norwegian deep-sea fisheries, but in the number of hands emplcyed, the herring-fishery takes precedence The number of men actually engaged in the latter is not less than 60,000 , and considerably more than double that number are directly or indirectly interested in the result of their operations. The herrings taken in 1866 filled 750,000 barrels, each weighing 224 lbs., the largest catch ever taken on the Norwegian coast, at least in recent years. As the movements of the fish are extremely erratic, large shoals being found one year in a part of the coast where none will be seen the year following, the fishermen are forced to move from place to place, and formerly the herrings frequently escaped altogether for want of hands to capture them. Now this difficulty is in a great measure removed. Telegraph stations are erected at different places on the coast, from which the movements of the shoals are carefully watched; and field telegraphs are kept in readiness to be joined on to the main line, so as to summon the fishermen from every part of the country on the first appearance of the fish at any new point. The best time for the herring-fishery is from January to March, and in 1866, 200,000 barrels, or more than one-fourth of the total catch, were caught between Feb. ruary 11 th and 14 th.

At the northern extremity of the province of Nordland, between $68^{\circ}$ and $69^{\circ} \mathrm{N}$. lat., are situated the Lofoten Islands, or Vesteraalen Oerne, which are separated from the mainland by the Vestfjord. This broad arm of the sea is 
remarkable both for its violent currents and whirlpools, among which the Maelstrom has attained a world-wide celebrity, and also from its being the most northerly limit where the oyster has been found. But it is chicfly as the resort of the cod that the Vestfjord is of the highest importance, not only to Nordland, but to the whole of Norway. No less than 6000 boats from all parts of the coast, manned probably by more than half of the whole adult male population of Nordland, annually assemble at Vaage, on the island of Ost Vaagoe, and besides these, more than 300 yoegts, or larger fishing-sloops, from Bergen, Christiansand, and Molde, appear upon the scene. The banks of Newfoundland hardly occupy more hands than the fishing-grounds of the Vestfjord, which, after the lapse of a thousand years, continue as prolific as.ever;* nor is there an instance known of its having ever disappointed the fisherman's hopes. In Harold Haarfagr's times, Vaage was already renowned for its fisheries, and several yarls had settled in this northern district, to reap the rich harvest of the seas. At a later period, under the reign of Saint Olave (1020), the annual Parliament of Nordland was held at Vaage, and, in 1120, the benevolent King Eystein, brother of Sigurd the Crusader, caused a church to be erected here in honor of his saintly predecessor, along with a number of huts, to serve as a shelter to the poor fishermen, a deed which he himself prized more highly than all his chivalrous brother's warlike exploits in the East, for "these men," said he, "will still remember in distant times that a King Eystein once lived in Norway."

The reason why the fish never cease visiting this part of the coast is that the Lofoten Isles inclose, as it were, an inland or mediterranean sea, which only communicates with the ocean by several narrow channels between the islands, and where the fish find the necessary protection against stormy weather. They assemble on three or four banks well known to the fishermen, seldom arriving before the middle of January, and rarely later than towards the end of February. They remain in the sheltered fjord no longer than is necessary for spawning, and in April have all retired to the deeper waters, so that the whole of the fishing season does not last longer than a couple of months. The fish are either caught by hooks and lines, or more frequently in large nets about twenty fathoms long and seven or eight feet broad, buoyed with pieces of light wood, and lested with stones, so as to maintain a vertical position when let down in the water. The fish, swimming with impetuous speed, darts into the meshes, which effectually bar his retreat. The nets are always spread in the evening, and hauled up in the morning; for as long as it is daylight, the fish sees and avoids them, even at a depth of sixty or eighty fathoms. A single haul of the net frequently fills half the boat, and the heavy fish would undoubtedly tear the meshes if they were not immediately struck with iron hooks, and flung into the boat as soon as they are dragged to the surface.

Claus Niels Sliningen, a merchant of Borgund, first introduced the use. of these nets in the year 1685, an innovation which more than doubled the total

* In 1866 the total catch of cod was $21,000,000$, about 12,000,000 of which were salted (clip fish), and the remainder dried (stock-fish); each fish making on an average 2 lbs. of clip-fish, and one-fourth less of stock-fish. 
produce of the fisheries. But (as with all useful inventions) loud complaints were raised against him in Norway, and as late as 1762 no nets were allowed at Drontheim, "to prevent the ruin of the poor people who had not the capital to provide themselves with them."

The life of a fisherman is everywhere full of privations and dangers, but nowhere more so than at the Lofoten Islands. Here, after toiling on the stormy sea for many hours, he has nothing but the miserable shelter of a damp, filthy, over-crowded hut, which affords him neither the rest nor the warmth needed after his fatiguing day's work. Even the iron-framed sons of the North are frequently unable to resist such continuous hardships, and bring home with them the seeds of contagion and death. Malignant fevers have frequently decimated the population of Norway, and their origin may generally be traced to

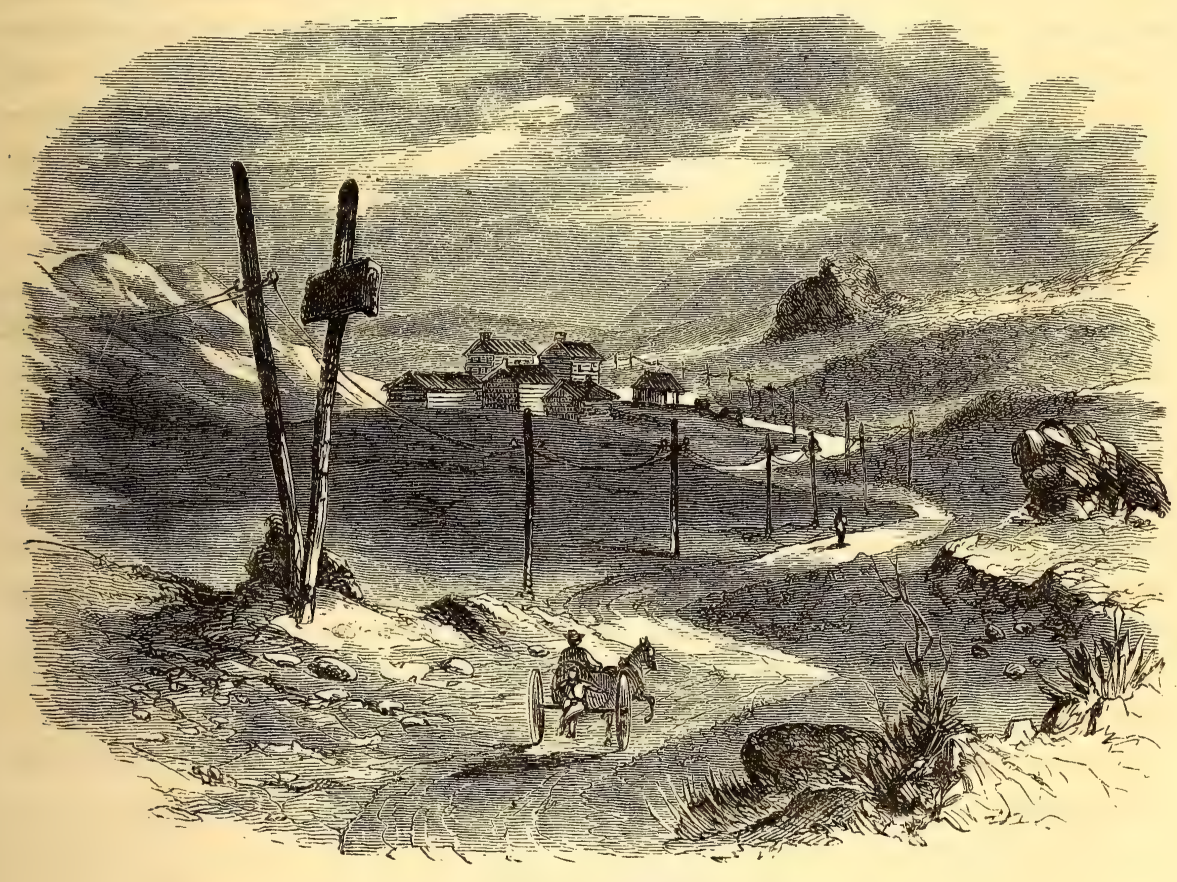

THE DOVREFJELD.

the fishing-grounds. "The Arab and the Persian," says Leopold ron Buch, "build caravanseras for the wayfarers through the desert; the inhabitants of the Alps have founded 'hospices' on the summits of the mountain passes; and the Norwegian has erected houses of refuge on Dovrefjeld, but none for the fishermen of Lofoten. Near Rodoë there is a large hospital for the sick of Nordland; would it not be as well to build houses in Lofoten, so as not to crowd the hospitals and churchyards ?" This was written at the beginning of the present century, but the poor fishermen are still as neglected as ever, for a more recent traveller, Marmier, beheld with pity the wretched huts in which they spend three winter months far from their families.

In the channel between Hvalö and the mainland lies, in $69^{\circ} 45^{\prime} \mathrm{N}$. lat., the 
small island of Tromsö, where about fifty years since only a few fishermen resided, whose huts have gradually expanded into a thriving little town of about 3000 inhabitants, along the shore opposite the mainland. Its staple exports are dried and salted cod, and train-oil. The livers of the cod are put in open barrels and placed in the sun, and the melted portion which rises to the surface is skimmed off, being the purest oil. The coarse refuse is boiled in great iron pots by the side of the sea, and yields the common "train-oil." The muscular matter which remains is collected into barrels and exported as a powerful manure; some of it is sent to England.

The town consists mainly of one long straggling street, following the windings of the shore, and has a picturesque appearance from the harbor. The houses are all of wood painted with lively colors, and the roofs, mostly covered with grass, diversified with bright clusters of yellow and white flowers, look pretty in summer. Tromsö has a Latin school, and even boasts of a newspaper, the Tromsö. Tidende et Blan for Nordland og Finmarken ("The Tromsö Gazette, a paper for Nordland and Finmark"). This paper is published twice a week; and as only one mail arrives at Tromsö every three weeks, the foreign news is given by instalments, spreading over six successive numbers, until a fresh dispatch arrives.

The island of Tromsö is beautifully situated, being on all sides environed by mountains, so that it seems to lie in the midst of a huge salt lake. Its surface rises in gentle slopes to a tolerable elevation, and no other Arctic isle contains richer pasturage, or dwarf plantations of greater luxuriance. Many meadows are yellow with buttercups and picturesque underwood, and the heathy hills are covered with shrubs, bearing bright berries of many hues. The pride of the Tromsöites in their island and town, and their profound attachment to it, are remarkable. No Swiss can be more enthusiastically bound to his mountains and vales, than they are to their circumscribed domain.

To the north of Tromsö lies the broad and deep Altenfjord, whose borders are studded with numerous dwellings, and where the botanist meets with a vegetation that may well raise his astonishment in so high a latitude. Here the common birch-tree grows 1450 feet, and the Vaccinium myrtillus 2030 feet above the level of the sea; the dwarf birch (Betula nana) still vegetates at a height of 2740 feet, and the Arctic willow is even found as high as 3500 feet, up to the limits of perennial snow.

Alten is moreover celebrated through its copper-mines. A piece of ore having been found by a Lap-woman in the year 1825, accidentally fell into the hands of Mr. Crowe, an English merchant in Hammerfest. This gentleman immediately took measures for obtaining a privilege from Government for the working of the mines, and all preiliminaries being arranged, set off for London, where he founded a company, with a capital of $£ 75,000$. When Marmier visited the Altenfjord in 1842, more than 1100 workmen were employed in these most northerly mining-works of the world, and not seldom more than ten English vessels at a time were busy unloading coals at Kaafjord for the smelting of the ores. New copper-works had recently been opened on the opposite side of the bay at Raipass, and since then the establishment has considerably increased. 
Hammerfest, the capital of Finmark, situated on the west side of the island of Hvalö, in $70^{\circ} 39^{\prime} 15^{\prime \prime}$, is the most northern town in the world. Half a century since, it had but 44 inhabitants; at present its population amounts to 1200 . As at Tromsö, very many of the houses, forming one long street winding round the shore, have grass sown on their roofs, which gives the latter the appearance of little plots of meadows. With us the expression, "he sleeps with grass above his head," is equivalent to saying "he is in his grave;" but here it may only mean that he sleeps beneath the verdant roof of his daily home. Many large warehouses are built on piles projecting into the water, with landing-quays before them; and numerous ranges of open sheds are filled with reindeer skins, wolf and bear skins, walrus tusks, reindeer horns, train-oil, and dried fish, ready for exportation. The chief home traffic of Hammerfest consists in barter with the Laps, who exchange their reindeer skins for brandy, tobacco, hardware, and cloth. Some enterprising merchants annually fit out vessels for walrus and seal hunting at Spitzbergen and Bear Island, but the principal trade is with Archangel, and is carried on entirely in "lodjes," or White Sea ships, with three single upright masts, each hoisting a huge try-sail. These vessels supply Hammerfest with Russian rye, meal, candles, etc., and receive stock-fish and train-oil in exchange. Sometimes, also, an English ship arrives with a supply of coals.

The fishing-grounds off the coast of Finmark, whose produce forms the staple article of the merchants of Hammerfest, are scarcely inferior in importance to those of Lofoten, the number of cod taken here in 1866 amounting to 15,000,000. A great part of the fish is purchased by the Russians as it comes out of the water. Of the prepared cod, Spain takes the largest quantity, as in 1865 upwards of $44,000,000$ lbs. of clip-fish (nearly the whole yield for the year) was consigned to that country. Of the dried variety, 10,000,000 lbs. were exported to the Mediterranean, and upwards of $4,000,000 \mathrm{lbs}$. more to Italy. Sweden and Holland come next in order, the supply in each case being over 5,000,000 lbs. Great Britain takes scarcely any stock-fish, but 1,500,000 lbs. of clip-fish, and the large export to the West Indies is almost entirely composed of the latter article.

The winter, though long and dark, has no terrors for the jolly Hammerfesters, for all the traders and shopkeepers form a united aristocracy, and rarely a night passes without a feast, a dance, and a drinking-bout. The day when the sun re-appears is one of general rejoicing; the first who sees the great luminary proclaims it with a loud voice, and every body rushes into the street to exchange congratulations with his neighbors. The island of Hvalö has a most dreary, sterile aspect, and considerable masses of snow fill the ravines even in summer. The birch, however, is still found growing 620 feet above the sea, but the fir has disappeared.

It may well be supposed that no stranger has ever sojourned in this interesting place, the farthest outpost of civilization towards the Pole, without visiting, or at least attempting to visit, the far-famed North Cape, situated about sixty miles from Hammerfest, on the island of Magerö, where a few Norwegians live in earthen huts, and still manage to rear a few heads of cattle. The voyage to this magnificent headland, which fronts the sea with a steep rock-wall nearly a 
thousand feet high, is frequently difficult and precarious, nor can it be scaled without considerable fatigue; but the view from the summit amply rewards the trouble, and it is no small satisfaction to stand on the brink of the most northern promontory of Europe.

"It is impossible," says Mr. W. Hurton, "adequately to describe the emotion experienced by me as I stepped up to the dizzy verge. I only know that I devoutly returned thanks to the Almighty for thus permitting me to realize one darling dream of my boyhood. Despite the wind, which here blew violently and bitterly cold, I sat down, and wrapping my cloak around me, long contemplated the spectacle of Nature in one of her sublimest aspects. I was truly alone. Not a living object was in sight; beneath my feet was the boundless expanse of ocean, with a sail or two on its bosom at an immense distance; above me was the canopy of heaven, flecked with fleecy cloudlets; the sun was luridly gleaming over a broad belt of blood-red mist; the only sounds were the whistling of the wandering winds and the occasional plaintive scream of the hovering sea-fowl. The only living creature which came near me was a bee, which hummed merrily by. What did the busy insect seek there? Not a blade of grass grew, and the only vegetable matter on this point was a cluster of withered moss at the very edge of the awful precipice, and this I gathered, at considerable risk, as a memorial of the visit." 


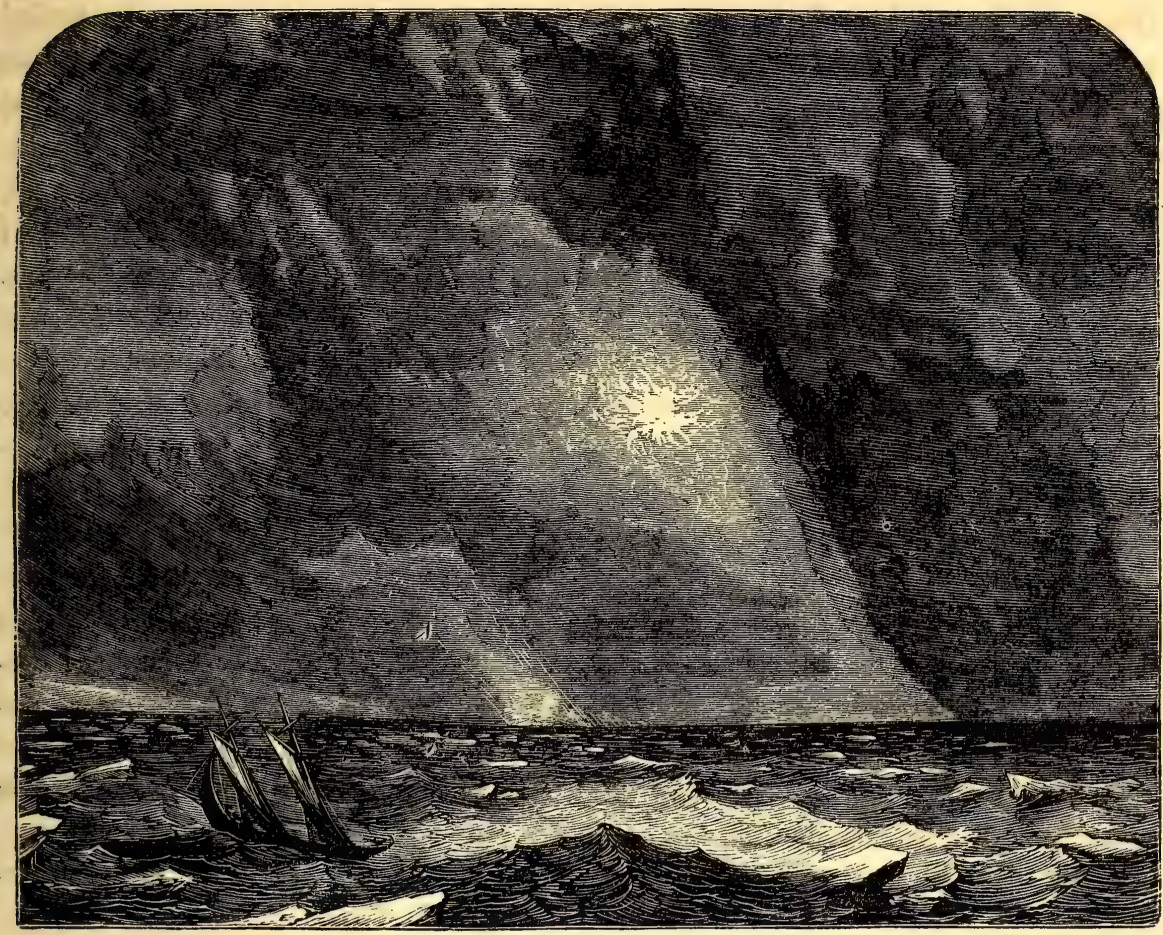

MUDNIGHT SUN OFF SPITZBERGEN.

\section{CHAPTER $\mathrm{X}$.}

\section{SPITZBERGEN-BEAR ISLAND-JAN MEYEN.}

The west Coast of Spitzbergen.-Ascension of a Mountain by Dr. Scoresby.-His Excursion along the Coast._A stranded Whale.-Magdalena Bay._Multitudes of Sea-birds._Animal Life._Midnight Silence.-Glaciers.-A dangerous Neighborhood.-Interior Plateau._Flora of Spitzbergen. - Its Similarity with that of the Alps above the Snow-line.-Reindeer.-The hyperborean Ptarmigan.Fishes._Coal._Drift-wood.-Discovery of Spitzbergen by Barentz, Heemskerk, and Ryp._Brilliant Period of the Whale-fishery._Coffins._Einht English Sailors winter in Spitzbergen, 1630._Melancholy Death of some Dutch Volunteers.-Russian Hunters.-Their Mode of wintering in Spitzbergen.-Scharos in.-Walrus-ships from Hammerfest and Tromsö._-Bear or Cherie Island.-Bennet. --Enormous Slanghter of Walruses. -Mildness of its Climate.-Mount Misery.-Adventurous Boatvoyage of some Norwegian Sailors.-Jan Meyen.-Beerenberg.

THE archipelago of Spitzbergen consists of five large islands: West Spitz 1 bergen, North-east Land; Stans Foreland, Barentz Land, Prince Charles Foreland; and of a vast number of smaller ones, scattered around their coasts. Its surface is about equal to that of two-thirds of Scotland; its most southern point ( $76^{\circ} 30^{\prime} \mathrm{N}$. lat.) lies nearer to the Pole than Melville Island; and Ross Islet, at its northern extremity $\left(80^{\circ} 49^{\prime} \mathrm{N}\right.$. lat.), looks out upon the unknown ocean, which perhaps extends without interruption as far as the Straits of Bering.

Of all the Arctic countries that have hitherto been discovered, Grinnell 
Land and Washington alone lie nearer to the Pole; but while these ice-blocked regions can only be reached with the utmost difficulty, the western and north-western coasts of Spitzbergen, exposed to the mild south-westerly winds, and to the influence of the Gulf Stream, are frequently visited, not only by walrus-hunters and Arctic explorers, but by amateur travellers and sportsmen.

The eastern coasts are far less accessible, and in parts have never yet been accurately explored. As far as they are known, they are not so bold and indented as the western and north-western coasts, which, projecting in mighty capes or opening a passage to deep fjords, have been gnawed into every variety of fantastic form by the corroding power of an eternal winter, and justify, by their endless succession of jagged spikes and break-neck acclivities, the name of Spitzbergen, which its first Dutch discoverers gave to this land of "serrated peaks."

The mountains on the west coast are very steep, many of them inaccessible, and most of them dangerous to climb, either from the smooth hard snow with which they are encrusted even in summer, or from the looseness of the disintegrated stones which cover the parts denuded by the sun, and give way under the slightest pressure of the foot.

More than one daring seaman has paid dearly for his temerity in venturing to scale these treacherous heights. The supercargo, or owner, of the very first Dutch whaler that visited Spitzbergen (1612) broke his neck in attempting to climb a steep mountain in Prince Charles Foreland, and Barentz very nearly lost several of his men under similar circumstances. Dr. Scoresby, who in the course of his whaling expeditions touched at Spitzbergen no less than seventeen times, was more successful in scaling a mountain 3000 feet high, near Mitre Cape, though the approach to the summit was by a ridge so narrow that he could only advance by sitting astride upon its edge. But the panorama which he beheld, after having attained his object, amply repaid him for the danger and fatigue of clambering for several hours over loose stones, which at every step rolled with fearful rapidity into the abyss beneath.

"The prospect," says the distinguished naturalist, " was most extensive and grand. A fine sheltered bay was seen to the east of us; an arm of the same on the north-east; and the sea, whose glassy surface was unruffled by a breeze, formed an immense expanse on the west; the icebergs, rearing their proud crests almost to the tops of the mountains between which they were lodged, and defying the power of the solar beams, were scattered in var ious directions abour the sea-coast and in the adjoining bays. Beds of snow and ice, filling extensive hollows and giving an enamelled coat to adjoining valleys, one of which, commencing at the foot of the mountain where we stood, extended in a continued line towards the north as far as the eye could reach; mountain rising above mountain, until by distance they dwindled into insignificance; the whole contrasted by a cloudless canopy of deepest azure, and enlightened by the rays of a blazing sun, and the effect aided by a feeling of danger-seated, as we were, on the pinnacle of a rock, almost surrounded by tremendous precipices; all united to constitute a picture singularly sublime.

"Our descent we found really a very hazardous, and in some instances a 
painful undertaking. Every movement was a work of deliberation. Having, by much care and with some anxiety, made good our descent to the top of the secondary hills, we took our way down one of the steepest banks, and slid forward with great facility in a sitting posture. Towards the foot of the hill an expanse of snow stretched across the line of descent. This being loose and soft, we entered upon it without fear, but on reaching the middle of it, we came to a surface of solid ice, perhaps a hundred yards across, over which we launched with astonishing velocity, but happily escaped without injury. The men, whom we left below, viewed this latter movement with astonishment and fear."

After this perilous descent, Scoresby continued his excursion on the flat land next the sea, where he found scattered here and there many skulls and other bones of sea-horses, whales, narwhals, foxes, and seals. Two Russian lodges, formed of logs of pine, with a third in ruins, were also seen; the former, from a quantity of fresh chips about them and other appearances, gave evidence of having been recently inhabited. These huts were built upon a ridge of shingle adjoining the sea. Among the boulders heaped upon the shore, numerous seabirds had built their nests or laid their eggs, which they defended with loud cries and determined courage against the attacks of gulls. The only insect he perceived was a small green fly, but the water along the coast was filled with medusæ and shrimps. The strong north-west winds had covered the strand with large heaps of Fucus vesiculosus and Laminaria saccharina, the same which the storms also cast out upon our shores.

The view of this high northern life was extremely interesting, but Dr. Scoresby was still further rewarded by the discovery of a dead whale, found stranded on the beach, which, though much swollen and not a little putrid, proved a prize worth at least $£ 400$. By a harpoon found in its body, it appeared to have been struck by some of the fishers on the Elbe, and having escaped from them, it had probably stranded itself on the spot where it was found. When the first incision was made, the oil gushed forth like a fountain. It was a slow and laborious work to transport the blubber to the ship, which on account of the dangerous nature of the coast was obliged to remain two miles off at sea. After five boat-loads had safely been brought on board, the wind suddenly changed, so that the ship was driven far out to sea, and the boat reached her with great difficulty.

Of the numerous fjords of Spitzbergen, once the busy resort of whole fleets of whalers, and now but rarely visited by man, none has been more accurately described by modern Arctic voyagers than the magnificent harbor of Magdalena Bay. Here the Dorothea and the Trent anchored in 1818, on their way to the North Pole; here also the French naturalists, who had been sent out in the corvette La Recherche (1835-36) to explore the high northern latitudes, sojourned for several weeks.

The number of the sea-birds is truly astonishing. On the ledges of a high rock at the head of the bay Beechey saw the little auks (Arctica alle) extend in an uninterrupted line full three miles in length, and so closely congregated that about thirty fell at a single shot. He estimated their numbers at about 
4,000,000. When they took flight they darkened the air; and at the distance of four miles their chorus could distinctly be heard.

On a fine summer's day, the bellowing of the walruses and the hoarse bark

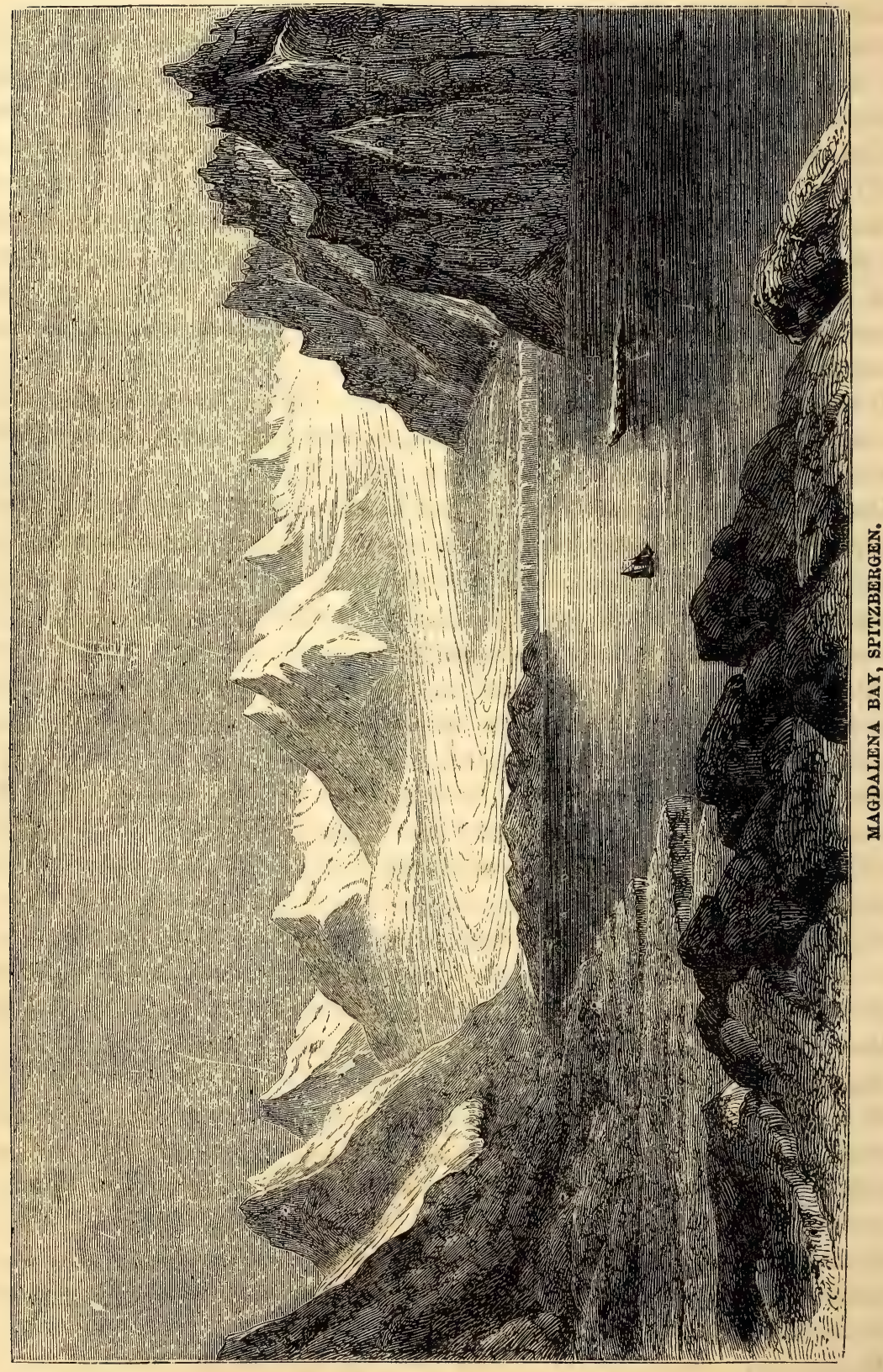

of the seals are mingled with the shrill notes of the auks, divers, and gulls. Although all these tones produce a by no means harmonious concert, yet they have a pleasing effect, as denoting the happy feelings of so many creatures. 
When the sun verges to the pole, every animal becomes mute, and a silence broken only by the bursting of a glacier reigns over the whole bay-a remarkable contrast to the tropical regions, where Nature enjoys her repose during the noonday heat, and it is only after sunset that life awakens in the forest and the field.

Four glaciers reach down this noble inlet: one, called the Wagon Way, is 7000 feet across at its terminal cliff, which is 300 feet high, presenting a magnificent wall of ice. But the whole scene is constructed on so colossal a scale that it is only on a near approach that the glaciers of Magdalena Bay appear in all their imposing grandeur. In clear weather the joint effect of the ice under the water, and the reflection of the glacier-wall above, causes a remarkable optical delusion. The water assumes a milk-white color, the seals appear to gambol in a thick cream-like liquid, and the error only becomes apparent when, on leaning over the side of the boat, the spectator looks down into the transparent depth below.

It is extremely dangerous to approach these cliffs of ice, as every now and then large blocks detach themselves from the mass, and frequently even a concussion of the air is enough to make them fall.

During the busy period of Spitzbergen history, when its bay used to be frequented by whalers who anchored under the glacier-walls, these ice-avalanches often had disastrous consequences. Thus, in the year 1619, an English ship was driven by a storm into Bell Sound. While it was passing under a precipice of ice, a prodigious mass came thundering down upon it, broke the masts, and threw the ship so violently upon one side that the captain and part of the crew were swept into the sea. The captain escaped unhurt, but two sailors were killed and several others wounded.

One day a gun was fired from a boat of the Trent when about half a mile from one of the glaciers of Magdalena Bay. Immediately after the report of the musket, a noise resembling thunder was heard in the direction of the icestream, and in a few seconds more an enormous mass detached itself from its front, and fell into the sea. The men in the boat, supposing themselves to be beyond the reach of its influence, were tranquilly contemplating the magnificent sight, when suddenly a large wave came sweeping over the bay, and cast their little shallop to a distance of ninety-six feet upon the beach.

Another time, when Franklin and Beechey had approached one of these icewalls, a huge fragment suddenly slid from its side, and fell with a crash into the sea. At first the detached mass entirely disappeared under the waters, casting up clouds of spray, but soon after it shot up again at least 100 feet above the surface, and then kept rocking several minutes to and fro. When at length the tumult subsided, the block was found to measure no less than 1500 feet in circumference; it projected 60 feet above the water, and its weight was calculated at more than 400,000 tons.

Besides the glaciers of Magdalena Bay, Spitzbergen has many others that protrude their crystal walls down to the water's edge; and yet but few icebergs, and the largest not to be compared with the productions of Baffin's Bay, are drifted from the shores of Spitzbergen into the open sea. The reason is 
that the glaciers usually terminate where the sea is shallow, so that no very large mass if dislodged can float away, and they are at the same time so frequently dismembered by heavy swells that they can not attain any great size.

The interior of Spitzbergen has never been explored. According to the Swedish naturalists, * who climbed many of the highest mountains in various parts of the coast, all the central regions of the archipelago form a level iceplateau, interrupted only here and there by denuded rocks, projecting like islands from the crystal sea in which they are imbedded. The height of this plateau above the level of the ocean is in general from 1500 to 2000 feet, and from its frozen solitudes descend the various glaciers above described. During the summer months, the radiation of the sun at Spitzbergen is always very intense, the thermometer in some sheltered situations not seldom rising at noon to $62^{\circ}, 67^{\circ}$, or even $73^{\circ}$. Even at midnight, at the very peak of the high mountain ascended by Scoresby, the power of the sun produced a temperature several degrees above the freezing-point, and occasioned the discharge of streams of water from the snow-capped summit. Hence, though even in the three warmest months the temperature of Spitzbergen does not average more that $34 \frac{1}{2}^{\circ}$, yet in the more southern aspects, and particularly where the warmth of the sun is absorbed and radiated by black rock-walls, the mountains are not seldom bared at an elevation nearly equal to that of the snow-line of Norway, and various Alpine plants and grasses frequently flourish, not only in sheltered situations at the foot of the hills, but even to a considerable height, wherever the disintegrated rocks lodge and form a tolerably good soil.

The Flora of Spitzbergen consists of about ninety-three species of flowering or phenogamous plants, which generally grow in isolated tufts or patches; but the mosses which carpet the moist lowlands, and the still more hardy lichens, which invest the rocks with their thin crusts or scurfs as far as the last limits of vegetation, are much more numerous. Some of the plants of Spitzbergen are also found on the Alps beyond the snow-line, at elevations of from 9000 to 10,000 feet above the level of the sea. According to Mr. Martins, nothing can give a better idea of Spitzbergen than the vast circus of névé, in the centre of which rises the triangular rock known to the visitors of Chamouny as the Jardin or the Courtil. Let the tourist, placed on this spot at a time when the sun rises but little above the horizon, or better still, when wreaths of mist hang over the neighboring mountains, fancy the sea bathing the foot of the amphitheatre of which he occupies the centre, and he has a complete Spitzluergen prospect before him. Supposing him to be a botanist, the sight of the Ranunculus glacialis, Cerastium alpinum, Arenaria biflora, and Erigeron uniflorus will still further increase the illusion.

The only esculent plant of Spitzbergen is the Cochlearia fenestrata, which here loses its acrid principles, and can be eaten as a salad. The grasses which

* Within the last few years, no less than three scientific expeditions have been sent out to Spitzbergen at the expense of the Swedish Government. During the summer of 1858, Messrs. Otto Torell, Guennerstedt, and Nordenskjold visited the western parts of the archipelago. In 1861 the whole coast, from Ice Sound to Dove Bay in North-east Land was accurately investigated by Messrs. Torell, Maimgren, Chydenius, etc., and in 1864 Messrs. Nordenskjold, Duner, and Malmgren visited the southern shores and Wjde Jan's Water. A fourth expedition has just left the port of Gothenburg (June, 1868) 
Keilhau found growing near some Russian huts in Stans Foreland are during the summer a precious resource for the reindeer, which, though extremely shy, make their appearance from time to time in every part of the land from the Seven Islands to South Cape, and are more abundant than could have been ex. pected. The Polar bears are probably their only native enemies on these islands, and their fleetness furnishes them with ample means of escape from a pursuer so clumsy on land. Lord Mulgrave's crew killed fifty deer on Vogelsang, a noted hunting-place, and on Sur Edward Parry's polar expedition about seventy deer were shot in Treurenberg Bay by inexperienced deer-stalkers, and without the aid of dogs. During the winter these large herbivora live on the Icelandic moss which they scent under the snow, but it may well be asked where they find shelter in a naked wilderness without a single tree. In May and June they are so thin as scarcely to be eatable, but in July they begin to get fat, and then their flesh would everywhere be reckoned a delicacy.

Besides the reindeer, the only land-quadrupeds of Spitzbergen are the Polar bear, the Arctic fox, and a small field-mouse, which in summer has a mottled, and in winter a white fur.

Of the birds, the hyperborean ptarmigan (Lagopus hyperborea), which easily procures its food under the snow, undoubtedly winters in Spitzbergen, and probably also the lesser red-pole, which perhaps finds grass seeds enough for its subsistence during the long polar nights, while the snow-bunting (Plectrophanes nivalis), and the twenty species of water-fowl and waders that frequent the shores of the high northern archipelago during the summer, all migrate southward when the long summer's day verges to its end.

Until very lately the Spitzbergen waters were supposed to be poor in fishes, though the numerous finbacks, which towards the end of summer frequent the southern and south-western coasts, and, unlike the large smooth-back whales, chiefly live on herrings, as well as the troops of salmon-loving white dolphin seen about the estuaries of the rivers, sufficiently proved the contrary, not to mention the herds of seals, and the hosts of ichthyophagous sea-birds that breed on every rocky ledge of the archipelago. Phipps and Scoresby mention only three or four species of fishes occurring in the seas of Spitzbergen, while the Swedish naturalist Malmgren, the first who seems to have paid real attention to this interesting branch of zoology, collected no less than twenty-three species in 1861 and 1864. The northern shark (Scymnus microcephalus) is so abundant that of late its fishery has proved highly remunerative. The first ship which was fitted out for this purpose in 1863 by Hilbert Pettersen, of Tromsö, returned from Bell and Ice Sounds with a full cargo of sharks' livers, and in 1865 the same enterprising merchant sent out no less than five shark-ships to Spitzbergen. The cod, the common herring, the shell-fish, the halibut have likewise been caught in the waters of the archipelago, and there is every reason to believe that their fishery, which has hitherto been entirely neglected, might be pursued with great success.

The mineral riches of Spitzbergen are, of course, but little known. Coal of an excellent quality, which might easily be worked, as it nearly crops out on the surface at a short distance from the sea, has, however, been discovered 
lately by Mr. Blomstrand in King's Bay, and sirnilar strata exist in various parts of Bell Sound and Ice Sound. Large quantities of drift-wood, probably from the large Siberian rivers, are deposited by the currents, particularly on the north coasts of North-east Land, and on the southern coasts of Stans Foreland. In English Bay Lord Dufferin saw innumerable logs of unhewn timber, mingled with which lay pieces of broken spars, an oar, a boat's flagstaff, and a few shattered fragments of some long-lost vessel's planking.

Most probably the Norwegians had their attention directed at a very early period to the existence of a land lying to the north of Finmarken by the troops of migratory birds which they saw flying northward in spring, and by the casual visits of sea-bears, which the drift-ice carried to the south. There can be no doubt that they were the first discoverers of Spitzbergen, but their history contains no positive records of the fact, and it was not before the sixteenth century that Europe first became acquainted with that desolate archipelago. Sir Hugh Willoughby may possibly have seen it in 1559 , but it is certain that on June 19, 1596, Barentz, Heemskerke, and Ryp, who had sailed in two ships from Amsterdam to discover the north-eastern passage to India, landed on its western coast, and gave it the name it bears to the present day. In the year 1607 it was visited by the unfortunate Henry Hudson, and four years later the first English whalers were fitted out by the Russia Company in London to fish in the bays of Spitzbergen, or East Greenland, as it was at that time called, being supposed to be the eastern prolongation of that vast island. Here our countrymen met with Dutchmen, Norwegians, and Biscayans from Bayonne and the ports of Northern Spain, and commercial rivalry soon led to the usual quarrels. In the year 1613 James I. granted the Russia Company a patent, giving them the exclusive right to fish in the Spitzbergen waters, and seven ships of war were sent out to enforce their pretensions. The Dutch, the Norwegians, and the Biscayans were driven away; a cross with the name of the King of England was erected on the shore, and Spitzbergen received the name of "King James his Newland." This triumph, however, was but of short duration, and after a struggle, in which none of the combatants gained any decisive advantage, all parties came at last to an amicable agreement. The English received for their share the best stations on the south-western coast, along with English Bay and Magdalena Bay. The Dutch were obliged to retreat to the north, and chose Amsterdam Island, with Smeerenberg Bay, as the seat of their operations. The Danes or Norwegians established their head-quarters on Dane's Island; the Hamburgers, who also came in for their share, in Hamburg Bay; and the French or Biscayans on the north coast, in Red Bay. At present a right or smooth-backed whale rarely shows itself in the Spitzbergen waters, but at that time it was so abundant that frequently no less than forty whalers used to anchor in a single bay, and send out their boats to kill these cetaceans, who came there for the purpose of casting their young in the sheltered friths and channels. The fat of the captured whales was immediately boiled in large kettles on the shore, and the bays of Spitzbergen presented a most animated spectacle during the summer season.

Numerous coffins-an underground burial being impossible in this frost. 


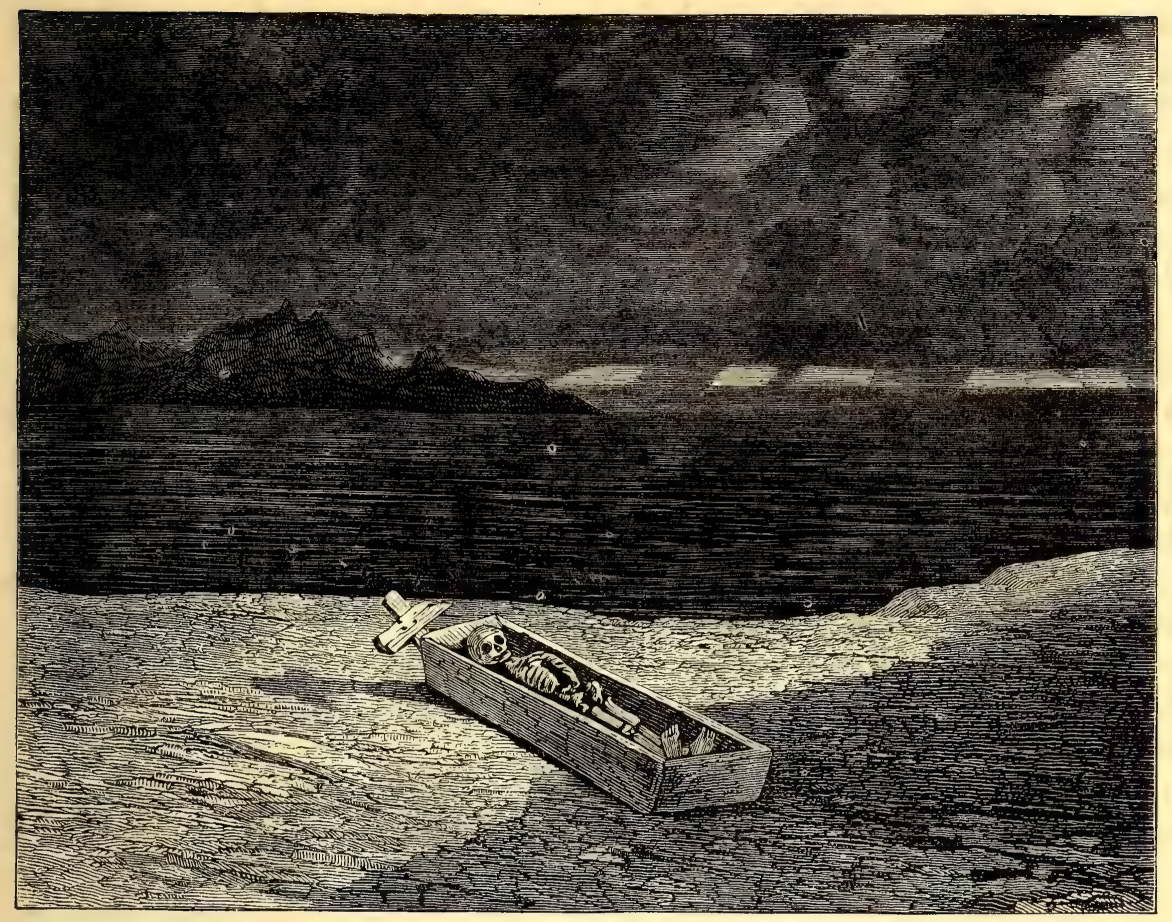

BURIAL IN SPITZBERGEN.

hardened earth-still hear witness to those busy times, and also to the great mortality among the fishermen, caused doubtless by their intemperate habits. They are particularly abundant at Smeerenberg, where Admiral Beechey saw upwards of one thousand of them; boards with English inscriptions were erected over a few, but the greater number were Dutch, and had been deposited in the eighteenth century. Some coffins having been opened, the corpses were found in a state of perfect preservation, and even the woollen caps and stockings of the mariners, who might perhaps have rested for more than a century on this cold earth, were still apparently as new as if they had been but recently put on.

In the seventeenth century the English and the Dutch made several attempts to establish permanent settlements in Spitzbergen. The Russia Company tried to engage volunteers by the promise of a liberal pay, and as none came forward, a free pardon was offered to criminals who would undertake to winter in Bell Sound. A few wretches, tired of confinement, accepted the proposal, but when the fleet was about to depart, and they saw the gloomy hills, and felt the howling north-eastern gales, their hearts failed them, and they entreated the captain who had charge of them to take them back to London and let them be hanged. Their request to be taken back was complied with, but the company generously interceded for them, and obtained their pardon.

Some time after, in the year 1630, an English whaler landed eight men in Bell Sound to hunt reindeer. They remained on shore during the night, but meanwhile a storm had arisen, and on the following morning their ship had 
vanished out of sight. It was towards the end of August, and they had no hope of rescue at this advanced period of the year.

Their despair may be imagined, but they soon recovered their courage, and wisely determined to make preparations for the impending winter, instead of losing time in useless lamentations. Their first care was to lay in a stock of food, and in a short time they had killed nineteen reindeer and four bears. Fortunately they found in Bell Sound the necessary materials for the erection of a hut. A large shed fifty feet long and thirty-eight broad had been built as a workshop for the men of the Russia Company, and they very judiciously constructed their small hut of stones and thick planks within this inclosed space. They thus gained a better protection against the icy wind and room for exercise during stormy weather, one of the best preservatives against the scurvy. They made their beds and winter dresses of the skins of the animals they had killed, sewing them together with needles made of bone splinters, and using disentangled rope-ends as thread.

Their hut was ready by September 12, and to preserve their supply of meat as long as possible, they lived four days of the week on the offal of whales' fat which lay scattered. about in great plenty. From October $\& 6$ to February 15 they saw no sun, and from the 13th to the 31st of December no twilight. The new year began with excessive cold: every piece of metal they touched stuck to their fingers like glue, and their skin became blistered when exposed to the air. The re-appearance of the sun was as a resurrection from death. To increase their joy, they saw two bears on the ice, one of which they killed, but they found, what has since been frequently experienced by others, that the

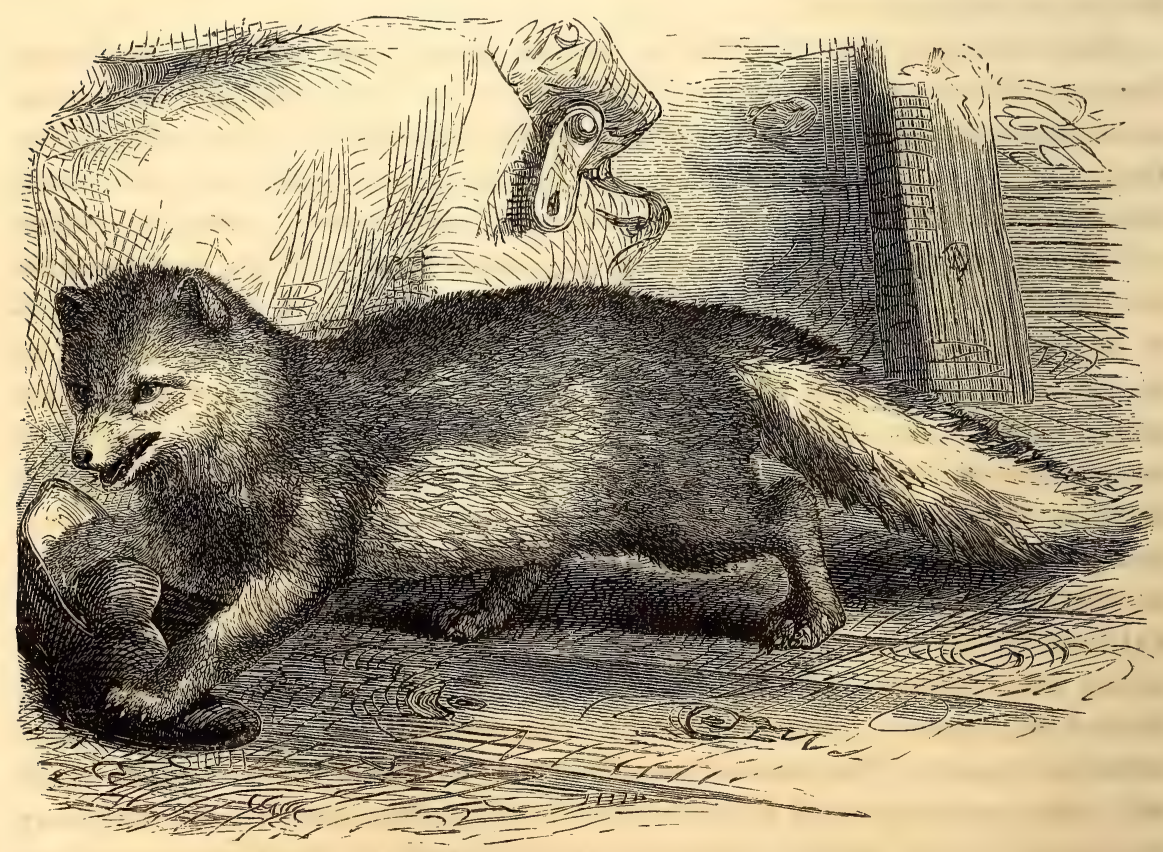

ARCTIC FOX. 
liver of the animal has poisonous qualities, or is at least very unwholesome, for, after eating it, they were all attacked with a kind of eruptive fever, and their skin peeled off. Towards the middle of March their provisions were well-nigh exhausted, but the Polar bears appearing more frequently, replenished their stock. Soon also the migratory birds arrived from the south, the foxes crept out of their burrows, and many were caught in traps. On June 5 the ice began to break up, and on the following morning one-half of the bay was open. A gale forced them to seek the shelter of their hut. There, seated round the fire, they spoke of their approaching delivery, when suddenly a loud halloo was heard. They immediately rushed out into the open air, and hardly believed their eyesight, for they were greeted by their comrades of the previous summer, and saw their own well-known ship at anchor in the bay. Thus were these brave-hearted men rescued after a ten months' exile in the latitude of $77^{\circ}$.

The possibility of wintering in Spitzbergen having thus been proved, some volunteers belonging to the Dutch fleet were induced by certain emoluments to attempt the same enterprise on Amsterdam Island; but, less fortunate than their predecessors, they all fell victims to the scurvy. A diary which they left behind recorded the touching history of their sufferings. "Four of us," these were its last words, " are still alive, stretched out flat upon the floor, and might still be able to eat if one of us had but the strength to rise and fetch some food and fuel, but we are all so weak, and every movement is so painful, that we are incapable of stirring. We constantly pray to God soon to release us from our sufferings, and truly we can not live much longer without food and warmth. None of us is able to help the others, and each must bear his burden as well as he can."

Since that time both the English and the Dutch have given up the idea of forming permanent settlements in Spitzbergen, but scarcely a year passes that some Russians and Norwegians do not winter in that high northern land. As far back as the seventeenth century, the former used to send out their clumsy but strongly-built "lodjes" of from 60 to 160 tons from the ports of Archangel, Mesen, Onega, Kola, and other places bordering the White Sea, to chase the various animals of Spitzbergen, the reindeer, the seal, the beluga, but chiefly the walrus, the most valuable of all. These vessels leave home in July, or as soon as the navigation of the White Sea opens, and as the shortness of the season hardly allows them to return in the same year, they pass the winter in some sheltered bay. Their first care on landing is to erect a large cross on the shore, a ceremony they repeat on leaving, and such is their religious faith that under the protection of that holy symbol they mock all the terrors of the Arctic winter. Near the place where their vessels are laid up, they build a large hut from twenty to twenty-five feet square, which is used as a station and magazine; but the huts used by the men who go in quest of skins, and which are erected at distances of from ten to fifty versts along the shore, are only seven or eight feet square. The smaller huts are usually occupied by two or three men, who take care to provide themselves from the store-house with the necessary provisions for the winter. Scoresby visited several of these huts, some con- 
structed of logs, others of deal two inches in thickness. They are of the same kind as those used by the peasants in Russia, and, being taken out in pieces, are erected with but little trouble in the most convenient situation. The stoves are built with bricks, or with clay found in the country. During the stay of the hunters, they employ themselves in killing seals or walruses in the water, and bears, foxes, deer, or whatever else they meet with on land. Each ship is furnished with provisions for eighteen months, consisting of rye flour for bread, oatmeal, barley-meal, peas, salt beef, salt cod, and salt halibut, together with curdled milk, honey, and linseed oil ; besides which, they enjoy the flesh of the animals which they kill. Their drink consists chiefly of quas, a national bev. erage made from rye flou and water; malt or spirituous liquors being entirely forbidden, to prevent drunkenness, as, when they were allowed it, they drank so immoderately that their work was often altogether neglected. Their fuel for the most part is brought with them from Russia, and drift-wood is used for the same purpose.

The hunters, seldom travelling far in winter, make their short excursions on foot on snow-skates, and draw their food after them on hand-sledges. Not seldom they are overtaken by terrific snowstorms, which force them to throw themselves flat upon the ground, and sometimes even cost them their lives. Their best preservation against the scurvy is bodily exercise; they also use the Cochlearia fenestrata, which grows wild in the country, either eating it without any preparation, or drinking the liquor prepared from it by infusion in water. Yet, in spite of all their precautions, they often fall a prey to this terrible scourge. In the year 1771, Mr. Steward, of Whitby, landed in King's Bay to gather drift-wood, and found a Russian hut. After having vainly called for admittance, they opened it, and found a corpse stretched out on the ground, its face covered with green mould. Most likely the unfortunate man, having buried all his comrades, had, as the last survivor, found no one to perform the same kind office for himself. Generally the Russian hunters, after spending the winter in Spitzbergen, return home in the following August or September; but their stop is often prolonged during several years; and Scharostin, a venerable Russian, who died in 1826 in Ice Sound, is deservedly remarkable for having spent no less than thirty-two winters of his long life in that high northern land, where he once remained during fifteen consecutive years. Surely this man ought to have been crowned king of Spitzbergen-

On a throne of rocks, in a robe of clouds,

With a diadem of snow!

Every year, at the beginning of summer, about a dozen vessels leave the ports of Hammerfest and Tromsö for Spitzbergen. Formerly it was a very common thing for them to procure three cargoes of walrus and seals in a season, and less than two full cargoes was considered very bad luck indeed; now, however, it is a rare thing to get more than one cargo in a season, and many vessels return home after four months' absence only half full. Yet, in spite of this diminution, the numbers of walruses still existing in that country are very considerable, particularly on the northern banks and skerries, which are only accessible in open 
seasons, or perhaps once in every three or four summers, when the persecuted animals get a little time to breed and replenish their numbers.

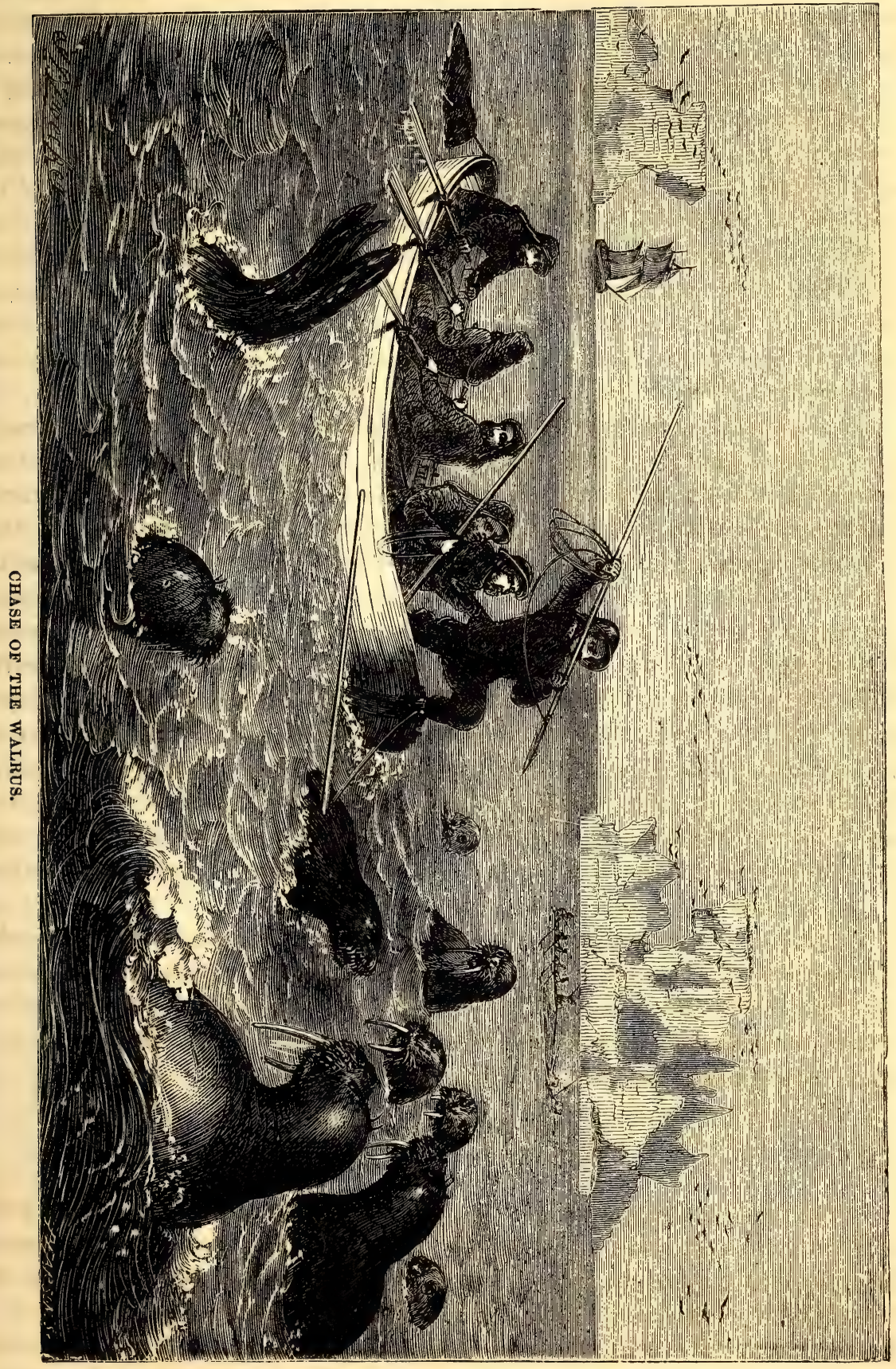

About midway between Hammerfest and Spitzbergen lies Bear Island, orig. ınally discovered by Barentz on June 9, 1596. Seven years later, Stephen Ben- 
net, a shipmaster in the service of the Muscovy Company, while on a voyage of discovery in a north-easterly direction, likewise saw Bear Island on August 16. Ignorant of its previous discovery by Barentz, he called it Cherie Island, after Sir Francis Cherie, a member of the company, and to this day both names are used.

Bennet found some walruses on its desert shores, and returned in the following year with a vessel fitted out by a merchant of the name of Welden, to wage war with these sea-monsters. His first operations were not very successful. Of a herd of at least a thousand walruses, he killed no more than fifteen, and a later attack upon an equally enormous troop raised the entire number of his victims to no more than fifty. Their tusks alone were brought away, and along with some loose ones collected on the beach formed the chief produce of the expedition. At first the unwieldy creatures were fired at, but as the bullets made no great impression on their thick hides, grapeshot was now discharged into their eyes, and the blinded animals were finally killed with axes.

In the following year Welden himself proceeded to Bear Island, and the art of walrus-killing gradually improving by practice, this second expedition proved far more profitable than the first. Care had also been taken to provide large kettles and the necessary fuel to boil their fat on the spot, so that besides the tusks a quantity of oil was gained. In 1606 Bennet again appeared on the field of action, and the dexterity of the walrus-hunters had now become so great that in less than six hours they killed more than 700, which yielded twenty-two tons of oil. During the following voyage, Welden, who seems to have acted in partnership with Bennet, each taking his turn, killed no less than 1000 walruses in seven hours. Thus Bear Island proved a mine of wealth to these enterprising men, and though the walruses are not now so abundant as in the good old times, yet they are still sufficiently numerous to attract the attention of speculators. Every year several expeditions proceed to its shores from the Russian and Norwegian ports, and generally some men pass the winter in huts erected on its northern and south-eastern coasts.

Considering its high northern latitude of $75^{\circ}$, the climate of Bear Island is uncommonly mild. According to the reports of some Norwegian walrus-hunters, who remained there from 1824 to 1826 , the cold was so moderate during the first winter that, until the middle of November, the snow which fell in the night melted during the daytime. It rained at Christmas, and seventy walruses were killed during Christmas week by the light of the moon and that of the Aurora. Even in February the weather was so mild that the men were able to work in the open air under the same latitude as Melville Island, where mercury is a solid body during five months of the year. The cold did not become intense before March, and attained its maximum in April, when the sea froze fast round the island, and the white bears appeared which had been absent during the whole winter. The second winter was more severe than the first, but even then the sea remained open until the middle of November-evidently in consequence of the prevailing south-westerly winds. The greater part of Bear Island is a desolate plateau raised about 100 or 200 feet above the sea. Along its western shores rises a group of three mountains, supposed to be about 200 feet high. 
and towards the south it terminates in a solitary hill to which the first discoverers gave the appropriate name of Mount Misery. At the northern foot of this terrace-shaped elevation the plateau is considerably depressed, and forms a kind of oasis, where grass (Poa pratensis), enlivened with violet cardamines and white polygonums and saxifragas, grows to half a yard in height. The general character of the small island is, however, a monotony of stone and morass, with here and there a patch of snow, while the coasts have been worn by the action of the waves into a variety of fantastic shapes, bordered in some parts by a flat narrow strand, the favorite resort of the walrus, and in others affording convenient breeding-places to hosts of sea-birds. In Coal Bay, four parallel seams of coal, about equidistant from each other, are visible on the vertical rockwalls, but they are too thin to be of any practical use.

Bear Island has no harbors, and is consequently a rather dangerous place to visit. During the first expedition sent out from Hammerfest, it happened that some of the men who had been landed were abandoned by their ship, which was to have cruised along the coast while they were hunting on shore. But the current, the wind, and a dense fog so confused the ignorant captain that, leaving them to their fate, he at once returned to Hammerfest. When the men became aware of their dreadful situation, they determined to leave the island in their boat, and taking with them a quantity of young walrus flesh, they luckily reached Northkyn after a voyage of eight days. It seems almost incredible that these same people immediately after revisited Bear Island in the same ship, and

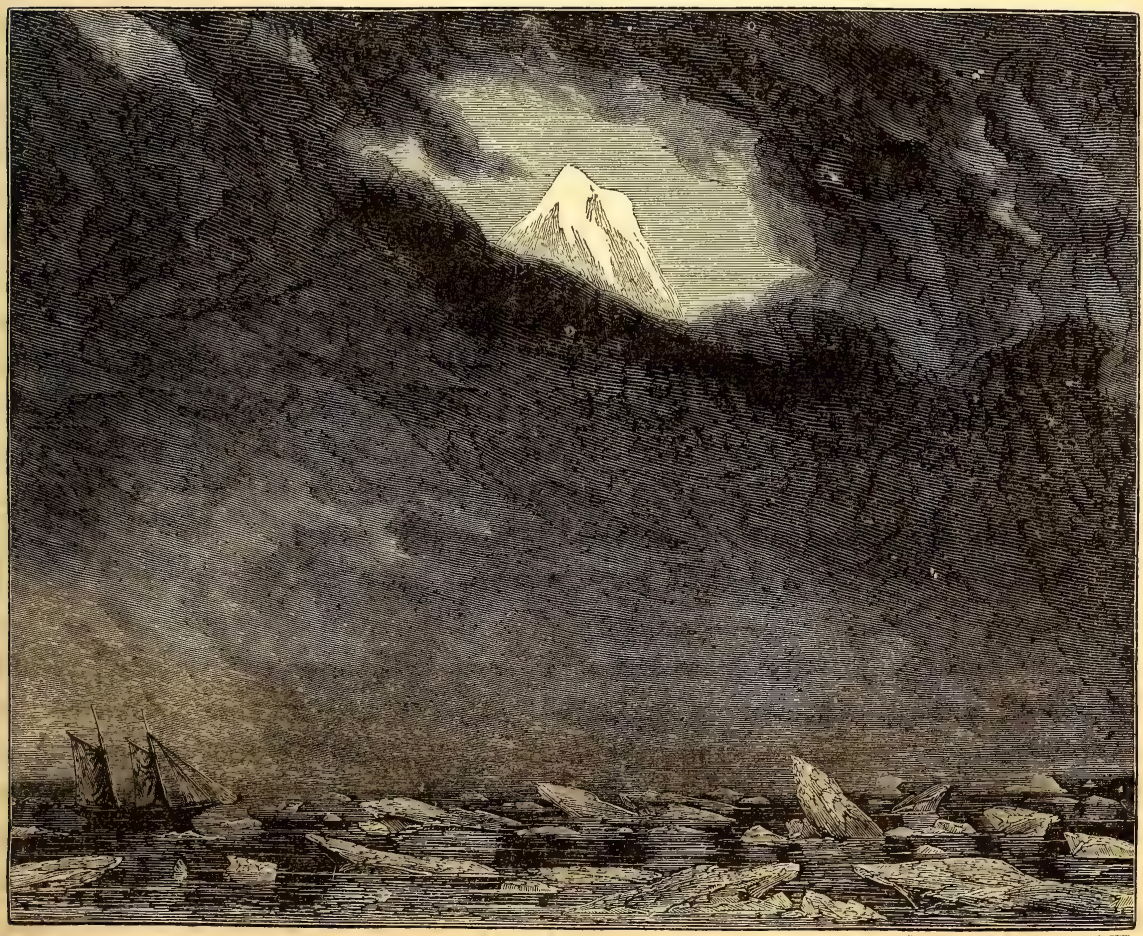

A GLIMPSE OF JAN MEYEN'S ISLAND. 
were again obliged to return to Norway in the same boat. The ship had anchored in the open bay of North Haven, and having taken in its cargo, consisting of 180 walruses, which had all been killed in a few days, was about to leave, when a storm arose, which cast her ashore and broke her to pieces. The Russians had built some huts in the neighborhood, and the provisions might probably have been saved, but rather than winter in the island the crew resolved to venture home again in the boat. This was so small that one-half of them were obliged to lie down on the bottom while the others rowed; the autumn was already far advanced, and they encountered so savage a storm that an English ship they fell in with at the North Cape vainly endeavored to take them on board. After a ten days' voyage, however, they safely arrived at Magerö, thus proving the truth of the old saying that "Fortune favors the bold." The distance from Bear Island to North Cape is about sixty nautical miles.

In a straight line between Spitzbergen and Iceland lies Jan Meyen, which, exposed to the cold Greenland current, almost perpetually veiled with mists, and surrounded by drift ice, would scarcely ever be disturbed in its dreary solitude but for the numerous walrus and seal herds that frequent its shores. The icebears and the wild sea-birds are its only inhabitants ; once some Dutshmen attempted to winter there, but the scurvy swept them all away. Its most remarkable features are the volcano Esk and the huge mountain Beerenberg, towering to the height of 6870 feet, with seven enormous glaciers sweeping down its sides into the sea. 


\title{
CHAPTER XI.
}

\author{
NOVA ZEMBLA.
}

The Sea of Kara.-Loschkin.-Rosmysslow.-Lütke.-Krotow.-Pachtussow.-Sails along the oastern Coast of the Southern Island to Matoschkin Schar.-His second Voyage and Death.-Meteorological Observations of Ziwolka.-The cold Summer of Nova Zembla. - Von Baer's scientific Voyage to Nova Zembla.-His Adventures in Matoschkin Schar.-Storm in Kostin Schar.-Sea Bath and votive Cross.-Botanical Observations. - A natural Garden.- Solitude and Silence.-A Bird Bazar.-Hunting Expeditions of the Russians to Nova Zembla.

THE sea of Kara, bounded on the west by Nova Zembla, and on the east by 1 the vast peninsula of Tajmurland, is one of the most inhospitable parts of the inhospitable Polar Ocean. For all the ice which the east-westerly marine currents drift during the summer along the Siberian coasts accumulates in that immense land-locked bay, and almost constantly blocks the gate of Kara, as the straits have been named that separate Nova Zembla from the island of Waigatz.

The rivers Jenissei and Obi, which remain frozen over until late in June, likewise discharge their vast masses of ice into the gulf of Kara, so that we can not wonder that the eastern coast of Nova Zembla, fronting a sea which opposes almost insuperable obstacles to the Arctic navigator, has remained almost totally unknown until 1833, while the western coast, exposed to the Gulf Stream, and bathed, in summer at least, by a vast open ocean, has long been traced in all its chief outlines on the map.

The walrus-hunter Loschkin is indeed said to have sailed along the whole eastern coast of Nova Zembla in the last century, but we have no authentic records of his voyage, and at a later period Rosmysslow, who, penetrating through Mathew's Straits, or Matoschkin Schar, found Nova Zembla to consist of two large islands, investigated but a small part of those unknown shores. From 1819 to 1824 the Russian Government sent out no less than five expeditions to the sea of Kara; the famous circumnavigator Admiral Lütke endeavored no less than four times to advance along the eastern coast of Nova Zembla, but all these efforts proved fruitless against the superior power of a stormy and ice-blocked sea. Yet in spite of these repeated failures, two enterprising men-Klokow, a chief inspector of forests, and Brandt, a rich merchant of Archangel-fitted out three ships in 1832 for the purpose of solving the mysteries of the sea of Kara.

One of these vessels, commanded by Lieutenant Krotow, was to penetrate through Mathew's Straits, and, having reached their eastern outlet, to sail thence across the sea to the mouth of the Obi and the Jenissei; but nothing more was heard of the ill-fated ship after her first separation from her companions at Kanin Nos.

The second ship, which was to sail along the western coast of Nova Zembla, and, if possible, to round its northern extremity, was more fortunate, for 
though it never reached that point, it returned home with a rich cargo of walrus-teeth.

The third ship, finally, under Pachtussow's command, was to penetrate through the gate of Kara, and from thence to proceed along the eastern coast. When Pachtussow, according to his instructions, had reached the straits, all his efforts to effect a passage proved ineffectual. It was in vain he more than once steered to the east; the stormy weather and large masses of drift ice constantly threw him back, the short summer approached its end, and thus he was obliged to put off all further attempts to the next year, and to settle for the winter in Rocky Bay within the gate of Kara. A small hut was built out of the drift-wood found on the spot, and joined by means of a gallery of sail-cloth to a bathing-room, that indispensable comfort of a Russian. The laying of traps, in which many Arctic foxes were caught, and the carrying of the wood, which had sometimes to be fetched from a distance of ten versts, occupied the crew during fair weather. In April a party under Pachtussow's command set out for the purpose of exploring the western coast. On this expedition they were overtaken on the twenty-fourth day of the month by a terrible snowstorm, which obliged them to throw themselves flat upon the ground to avoid being swept away by the wind. They remained three days without food under the snow, as it was impossible for them to reach the dépôt of provisions buried a few versts off.

On June 24 the gate of Kara was at length open, and Pachtussow would gladly have sailed through the passage, but his ship was fast in the ice. He therefore resolved, in order to make the best use of his time, to examine the eastern coast in a boat, and reached in this manner the small Sawina River, where he found a wooden cross with the date of 1742. Most likely it had been placed there by Loschkin, his predecessor on the path of discovery. $\mathrm{He}$ now returned with his boat to the ship, which, after an imprisonment of 297 days, was at length, July 11 , able to leave the bay.

On Stadolski Island, near Cape Menschikoff, they found a wretched hut, which proved that they were not the first to penetrate into these deserts. But the hut was tenantless, and a number of human bones were strewn over the ground. One of Pachtussow's companions now related that in 1822 a Samojede, named Mawei, had gone with his wife and children to Nova Zembla, and had never returned. On gathering the bones, they were found to compose the skeletons of two children and of a woman, but no remains could be discovered of the man. Most likely the unfortunate savage had been surprised by a snowstorm, or had fallen a prey to a hungry ice-bear, on one of his excursions, and his family, deprived of their support, had died of hunger in the hut.

On July 19 they reached the river Stawinen, and on the 21st Lütke's Bay, where a number of white dolphins and seals of an unknown species were found. Here contrary winds arrested the progress of the navigators during eighteen days. On August 13 Pachtussow entered Matoschkin Schar, and reached its western mouth on the 19th. Thus he succeeded at least in circumnavigating the southern island, which no one had achieved before him, and as his exhausted provisions did not allow him to spend a second winter in Nova Zembla, he 
resolved to return at once to Archangel. But contrary winds drove him to the island of Kolgujew, and thence to the mouth of the Petschora, where, on September 3, a dreadful storm at length shattered his crazy vessel. The crew found refuge in a hut, but this also was filled by the water; so that they had to wade several versts before they could reach the dry land.

Pachtussow now travelled by way of Archangel and Onega to St. Petersburg, where he communicated the results of his journey to the Minister of Marine, who gave him a most flattering reception, well merited by his ability and courage. The success he had already obtained encouraged the hope that a second expedition would be able to complete the undertaking, and consequently, by an imperial order, the schooner Krotow and a transport were fitted out, with which Pachtussow once more sailed from the port of Archangel on August 5. His instructions were to winter in Mathew's Straits, and thence to attempt in the following summer the exploration of the eastern coast of the northern island. The winter hut he built at the western entrance of the straits was ready for his reception by October 20. It was of stately dimensions, for a Nova Zembla residence-25 feet long, 21 broad, 8 feet high in the centre, 5 at the sides, and consisted of two compartments, one for the officers and the other for the crew. They found the cold very endurable, but were rather incommoded by the smoke, which did not always find a ready passage through the opening in the roof. Sometimes the snow accumulated in such masses, or the storm raged so furiously round the hut, that they could not leave it for eight days running, and frequently the hole in the roof had to serve them for a door.

Eleven white bears were killed about the hut during the winter; one on the roof, another in the passage. Pachtussow, well aware that occupation is the best remedy against melancholy, kept his crew in constant activity. They were obliged to fetch wood from distances of ten or eleven versts, not seldom during a cold of $-36^{\circ}$, which, thanks to their thick fur dresses, they bore remarkably well, particularly as a temperature lower than $-25^{\circ}$ never occurred, unless during perfectly calm weather. He also made them lay fox-traps at considerable distances from the hut, and amused them with shooting at a mark and gymnastic exercises. By this means he succeeded in preserving their health, and warding off the attacks of the scurvy.

As early as April the indefatigable Pachtussow fitted out two sledge-parties, for the exploration of the eastern coast. The one, consisting of seven men, he commanded in person; the other was led by the steersman Ziwolka. Both parties travelled in company as far as the eastern entrance of the straits, whero one of the huts in which Rosmysslow had wintered seventy years before was still found in a good condition.

Pachtussow now returned for the purpose of accurately surveying the straits, while Ziwolka proceeded along the east coast, with a small tent and provisions for a month. All his men had Samojede dresses, but they were already so hardened that they did not wear the upper coat with the hood even during the night, although snow-storms not seldom occurred. Once their boots were frozen so hard that they could not pull them off before they had been previously thawed, and as drift-wood was nowhere to be found, they were obliged to 
burn the poles of their tent, and to keep their feet over the fire until the leather became soft. On May 18, the thirty-fourth day of his journey, Ziwolka returned to his commander, after having explored the east coast northward to a distance of 150 versts.

Meanwhile Pachtussow had been busy building a boat eighteen feet long, with which he intended to proceed along the western coast to the northern extremity of the island, and, the elements permitting, to return to the straits along its eastern shores. About the beginning of June the migratory birds made their appearance, and introduced a very agreeable change in the monoton. ous fare of the navigators, who, a few weeks later, enjoyed the sight of bloom. ing flowers, and gathered antiscorbutic herbs in large quantities.

Thus the high northern land had assumed its most friendly aspect, and looked as cheerfully as it possibly could, when, on July 11, Pachtussow and Ziwolka set out for the north with the boat and the transport, the schooner being left behind in the straits with the surgeon and a few invalids. At first the wind and weather favored their course, but on July 21 the boat was smashed between two pieces of ice, so that they had hardly time to escape upon the land with the nautical instruments, a sack of flour, and some butter.

In this unpleasant situation they were obliged to remain for thirteen days, until at last a walrus-hunter appeared, who took the shipwrecked explorers on board, and brought them safely back to their winter-quarters on August 22.

Thus this first attempt ended in complete disappointment, and the season was already too far advanced to permit of its renewal. Yet Pachtussow, resolving with praiseworthy zeal to make the most of the last days of the short summer, set out again on August 26 for the eastern entrance of the straits, and proceeded along the coast, until he was stopped by the ice at some distance beyond the small islands which bear his name.

Convinced of the fruitlessness of all further efforts, Pachtussow bade adieu with a sorrowful heart to the coast, which still stretched out before him in un. discovered mystery, and sailed back again to Archangel on September 20. Soon after his return he fell ill, and four weeks later his mourning friends carried him to his grave.

The Arctic Ocean is so capricious that in the following year the walrushunter Issakow, of Kem, who had no discoveries in view, was able to round without difficulty the north-eastern extremity of Nova Zembla, but, fearful of encountering the dangers of that dreadful coast, he almost immediately returned.

During the two winters he spent in Nova Zembla, the steersman Ziwolka had daily consulted the thermometer, and the result of his observations gave to the western entrance of Mathew's Straits a mean annual temperature of $+17^{\circ}$.

Thus Nova Zembla is colder than the west coast of Spitzbergen, which, although still farther to the north, is more favorably situated with regard to the winds and currents, and from five to ten degrees warmer than the high north. ern parts of Siberia and continental America, which sustain a comparatively numerous population, while Nova Zembla is uninhabited. Hence this want, and the circumstance thrat the vegetation of these islands scarcely rises a span 
above the ground, while the forest region still penetrates far within the confines of the colder continental regions above mentioned, are to be ascribed not to the low mean annual temperature of Nova Zembla, but to the unfavorable distribution of warmth over the various seasons of the year. For although high Northern Siberia and America have a far colder winter, they enjoy a considerably warmer summer, and this it is which in the higher latitudes determines the existence or the development of life on the dry land. During the winter the organic world is partly sheltered under the snow, or else it migrates, or it produces within itself sufficient warmth to defy the cold-and thus a few degrees more or less at that time of the year are of no material consequence, while the warmth of summer is absolutely indispensable to awaken life and determine its development.

The comparatively mild winter of Nova Zembla (no less than thirty-three degrees warmer than that of Jakutsk) is therefore of but little benefit to vegetable life, which on the other hand suffers considerably from a summer inferior even to that of Melville Island and Boothia Felix. A coast where the sun, in spite of a day of several months' continuance, generates so small a quantity of heat, and where yet some vegetation is able to flourish, must necessarily be well worthy the attention of botanists, or rather of all those who take an interest in the geographical distribution of plants. For if in the primitive forests of Brazil the naturalist admires the effects of a tropical sun and an excessive humidity in producing the utmost exuberance of vegetation, it is no less interesting for him to observe how Flora under the most adverse circumstances still wages a successful war against death and destruction.

Thus a few years after Pachtussow's expedition, the desire to explore a land so remarkable in a botanical point of view, and to gather new fruits for science in the wilderness, induced Herr von Baer, though already advanced in years, to undertake the journey to Nova Zembla.

Accompanied by two younger naturalists, Mr. Lehmann and Mr. Röder, the celebrated Petersburg academician arrived on July 29, 1837, at the western entrance of Mathew's Straits, sailed through them the next day in a boat, and reached the sea of Kara, where he admired a prodigious number of jelly-fishes (Pleurobrachia pileus) swimming about in the ice-cold waters, and displaying a marvellous beauty of coloring in their ciliated ribs. This excursion might, however, have had very disagreeable consequences, for a dreadful storm, blowing from the west, prevented their boat from returning, and forced them to pass the night with some walrus-hunters, whom they had the good-fortune to meet with. On the following day the storm abated, so that the return could be attempted; they were, however, obliged to land on a small island in the Beluga Bay, where, wet to the skin, and their limbs shaking with cold, they fortunately found a refuge in the ruins of a hut in which Rosmysslow had wintered in 1767. Meanwhile the wind had veered to the east, accompanied by a very disagreeable cold rain, which on the mountains took the form of snow; they were now, however, able to make use of their sail, and arrived late at night at the spot where their ship lay at anchor, completely wet, but in good health and spirits.

"We could esteem ourselves happy," says Von Baer, "in having paid so 
slight a penalty for neglecting the precaution, so necessary to all travellers in Nova Zembla, of providing for a week when you set out for a day's excursion."

On August 4, after a thorough botanical examination of the straits, the party proceeded along the west coast. The wind, blowing from the north, brought them to the Kostin Schar, a maze of passages between numerous islets, where the walrus-hunters in Nova Zembla chiefly assemble.

On August 9 an excursion was made up the river Nechwatowa, where they rested in a hut which had been erected by some fisherman employed in catching "golzi," or Arctic salmon. On returning to the ship, a dreadful storm arose from the north-east, which lasted nine days, and, very fortunately for the botanists, caught them in the Kostin Schar, and not on the high sea. Although they were anchored in a sheltered bay, the waves frequently swept over the deck of their vessel, and compelled them to remain all the time in their small, low cabin. Only once they made an attempt to land, but the wind was so strong that they could hardly stand. Their situation was rendered still more terrible and anxious, as part of the crew which had been sent out hunting before the storm began had not yet returned.

When at last the storm ceased, winter seemed about to begin in good earnest. Every night ice formed in the river, and the land was covered with snow, which had surprised the scanty vegetation in its full bloom. At length the hunters returned, after having endured terrible hardships, and now preparations were made for a definitive departure. A general bath was taken, without which no anchorage in Nova Zembla is ever left, and, according to ancient custom, a votive cross was likewise erected on the strand, as a memorial of the expedition.

On August 28 the anchors were weighed, but they were soon dropped again in the Schar, to examine on a small island the vegetable and animal products of the land and of the shore. The former offered but few objects of interest, but they were astonished at the exuberance of marine life. After having been detained by a thick fog in this place for several days, they at length sailed towards the White Sea, where they were obliged by contrary winds to run into Tri Ostrowa. Dreary and desolate as the tundras at this extreme point of Lapland had appeared to them on their journey outward, they were now charmed with their green slopes, a sight of which they had been deprived in Nova Zembla.

On September 11 they at length reached the port of Archangel, with the agreeable prospect of passing the winter in a comfortable study at St. Petersburg instead of spending it, like Barentz and his associates, as might easily have happened, in a wretched hut beyond the 70th degree of northern latitude.

Having thus briefly sketched Von Baer's adventures, I will now notice some of the most interesting scientific results of his journey.

The rocky west coast of Nova Zembla has about the same appearance as the analogous part of Spitzbergen, for here also the mountains, particularly in the northern island, rise abruptly to a height of three or four thousand feet from the sea, while the eastern coast is generally flat. In both countries, angular blocks of stone, precipitated from the summits, cover the sides of the hills, and frequently make it impossible to ascend them. In fact, no rock, however hard 
or finely grained, is able to withstand the effects of a climate where the summer is so wet and the winter so severe. Nowhere in Nova Zembla is a grasscovered spot to be found deserving the name of a meadow. Even the foliaceous lichens, which grow so luxuriantly in Lapland, have here a stunted appearance; but, as Von Baer remarks, this is owing less to the climate than to the nature of the soil, as plants of this description thrive best on chalky ground. The crustaceous lichens, however, cover the blocks of augite and porphyry with a motley vesture, and the dingy carpet with which Dryas octopetala invests here and there the dry slopes, formed of rocky detritus, reminds one of the tundras of Lapland.

The scanty vegetable covering which this only true social plant of Nova Zembla affords is, however, but an inch thick, and can easily be detached like a cap from the rock beneath.

On a clayey ground in moist and low situations, the mosses afford a protection to the polar willow (Salix polaris), which raises but two leaves and a catkin over the surface of its covering.

Even the most sparing sheet of humus has great difficulty to form in Nova Zembla, as in a great number of the plants which grow there the discolored leaf dries on the stalk, and is then swept away by the winds, so that the land would appear still more naked if many plants, such as the snow ranunculus (Ranunculus nivalis), were not so extremely abstemious as to require no humus at all, but merely a rocky crevice or some loose gravel capable of retaining moisture in its interstices.

But even in Nova Zembla there are some more favored spots. Thus when Von Baer landed at the foot of a high slate mountain fronting the south-west, and reflecting the rays of the sun, he was astonished and delighted to see a gay mixture of purple silenes, golden ranunculuses, peach-colored parryas, white cerastias, and blue palemones, and was particularly pleased at finding the wellknown forget-me-not among the ornaments of this Arctic pasture. Between these various flowers the soil was everywhere visible, for the dicotyledonous plants of the high latitudes produce no more foliage than is necessary to set off the colors of the blossoms, and have generally more flowers than leaves.

The entire vegetation of the island is confined to the superficial layer of the soil and to the lower stratum of the air. Even those plants which in warm climates have a descending or vertical root have here a horizontal one, and none, whether grasses or shrubs, grow higher than a span above the ground.

In the polar willow, a single pair of leaves sits on a stem about as thick as a straw, although the whole plant forms an extensive shrub with numerous ramifications. Another species of willow (Salix lanata) attains the considerable height of a span, and is a perfect giant among the Nova Zembla plants, for the thick subterranean trunk sometimes measures two inches in diameter, and can be laid bare for a length of ten or twelve feet without finding the end. Thus in this country the forests are more in than above the earth.

This horizontal development of vegetation is caused by the sun principally heating the superficial sheet of earth, which imparts its warmth to the stratum of air immediately above it, and thus confines the plants within the narrow 
limits which best suit their growth. Hence also the influence of position on vegetation is so great that, while a plain open to the winds is a complete desert, a gentle mountain slope not seldom resembles a garden.

The absence of all trees or shrubs, or even of all vigorous herbage, imparts a character of the deepest solitude to the Nova Zembla landscape, and inspires even the rough sailor with a kind of religious awe. "It is," says Von Baer, "as if the dawn of creation had but just begun, and life were still to be called into existence." The universal silence is but rarely broken by the noise of an animal. But neither the cry of the sea-mew, wheeling in the air, nor the rustling of the lemming in the stunted herbage are able to animate the scene. No voice is heard in calm weather. The rare land-birds are silent as well as the insects, which are comparatively still fewer in number. This tranquillity of nature, particularly during serene days, reminds the spectator of the quiet of the grave; and the lemmings seem like phantoms as they glide noiselessly from burrow to burrow. In our fields even a slight motion of the air becomes visible in the foliage of the trees or in the waving of the corn; here the low plants are so stiff and immovable that one might suppose them to be painted. The rare sand-bee (Andrena), which on sunny days and in warm places flies about with languid wings, has scarcely the spirit to hum, and the flies and gnats, though more frequent, are equally feeble and inoffensive.

As a proof of the rarity of insects in Nova Zembla, Von Baer mentions that not a single larva was to be found in a dead walrus which had been lying at least fourteen days on the shore. The hackneyed phrase of our funeral sermons can not therefore be applied to these high latitudes, where even above the earth the decay of bodies is extremely slow.

However poor the vegetation of Nova Zembla may be, it still suffices to nourish a number of lemmings, which live on leaves, stems, and buds, but not on roots. The slopes of the mountains are often undermined in all directions by their burrows. Next to these lemmings, the Arctic foxes are the most numerous quadrupeds, as they find plenty of food in the above-mentioned little rodents, as well as in the young birds, and in the bodies of the marine animals which are cast ashore by the tides. White bears are scarcely ever seen during the summer, and the reindeer seems to have decreased in numbers, at least on the west coast, where they are frequently shot by the Russian morse-hunters.

The hosts of sea-birds in some parts of the coast prove that the waters are far more prolisic than the land. The foolish guillemots (Uria troile), closely congregated in rows, one above the other, on the narrow ledges of vertical rock-walls, make the black stone appear striped with white. Such a breedingplace is called by the Russians a bazar. Dn the summit of isolated cliffs, and suffering no other bird in his vicinity, nestles the large gray sea-mew (Larus glaucus), to whom the Dutch whale-catchers have given the name of "burghermaster." While the ice-bear is monarch of the land animals, this gull appears as the sovereign lord of all the sea-birds around, and no guillemot would venture to dispute the possession of a dainty morsel claimed by the imperious burghermaster.

This abundance of the sea has also attracted man to the desert shores of 
Nova Zembla. Long before Barentz made Western Europe acquainted with the existence of Nova Zembla (1594-96), the land was known to the Russians as a valuable hunting or fishing ground; for the Dutch discoverer met with a large number of their vessels on its coast. Burrough, who visited the port of Kola in 1556, in search of the unfortunate Willoughby, and thence sailed as far as the mouth of the Petschora, likewise saw in the gulf of Kola no less than thirty lodjes, all destined for walrus-hunting in Nova Zembla.

Whether, before the Russians, the adventurous Norsemen ever visited these desolate islands, is unknown, but so much is certain, that ever since the times of Barentz the expeditions of the Muscovites to its western coast have been uninterruptedly continued. As is the case with all fishing speculations, their success very much depends upon chance. The year 1834 was very lucrative, so that in the following season about eighty ships, with at least 1000 men on board, sailed for Nova Zembla from the ports of the White Sea, but this time the results were so unsatisfactory that in 1836 scarce half the number were fitted out. In 1837 no more than twenty vessels were employed, and Von Baer relates that but one of them which penetrated into the sea of Kara made a considerable profit, while all the rest, with but few exceptions, did not pay one-half of their expenses.

The most valuable animals are the walrus and the white dolphin, or beluga. Among the seals, the Phoca albigena of Pallas distinguishes itself by its size, the thickness of its skin, and its quantity of fat; Phoca groenlandica and Phoca hispida rank next in estimation. The Greenland whale never extends his excursions to the waters of Nova Zembla, but the fin-back and the grampus are frequently seen.

The Alpine salmon (Salmo alpinus), which towards autumn ascends into the mountain-lakes, is caught in incredible numbers; and, finally, the beangoose (Anser segetum) breeds so frequently, at least upon the southern island, that the gathering of its quill-feathers is an object of some importance. 


\title{
CHAPTER XII.
}

\author{
THE LAPPS.
}

Their ancient History and Conversion to Christianity.-Self-denial and Poverty of the Lapland Clergy. -Their singular Mode of Preaching.-Gross Superstition of the Lapps.-The Evil Spirit of the Woods.-The Lapland Witches._Physical Constitution of the Lapps.-Their Dress.-The Fjalllappars.-Their Dwellings._-Store-houses.-Reindeer Pens._Milking the Reindeer.-Migration.The Lapland Dog.-Skiders, or Skates.-The Sledge, or Pulka.-Natural Beauties of Lapland.Attachment of the Lapps to their Country.-Bear-hunting.-Wolf-hunting.--Mode of Living of the wealthy Lapps.-How they kill the Reindeer.-Visiting the Fair.-Mammon Worship.--Treasurehiding.- "Tabak, or Braende."-Affectionate Disposition of the Lapps.-The Skogslapp.-The Fisherlapp.

THE nation of the Lapps spreads over the northern parts of Scandinavia 1 and Finland from about the 63d degree of latitude to the confines of the Polar Ocean; but their number, hardly amounting to more than twenty thousand, bears no proportion to the extent of the vast regions in which they are found. Although now subject to the crowns of Russia, Sweden, and Norway, they anciently possessed the whole Scandinavian peninsula, until the sons of Odin drove them farther and farther to the north, and, taking possession of the coasts and valleys, left them nothing but the bleak mountain and the desolate tundra. In the thirteenth century, under the reign of Magnus Ladislas, King of Sweden, their subjugation was completed by the Birkarls, a race dwelling on the borders of the Bothnian Gulf. These Birkarls had to pay the crown a slight tribute, which they wrung more than a hundred-fold from the Lapps, until at length Gustavus I. granted the persecuted savages the protection of more equitable laws, and sent missionaries among them to relieve them at the same time from the yoke of their ancient superstitions. In 1600 Charles IX. ordered churches to be built in their country, and, some years after, his son and successor, the celebrated Gustavus Adolphus, founded a school for the Lapps at Pitea, and ordered several elementary works to be translated into their language. In the year 1602, Christian IV., King of Denmark and Norway, while on a visit to the province of Finmark, was so incensed at the gross idolatry of the Lapps that he ordered their priests or sorcerers to be persecuted with bloody severity. A worthy clergyman, Eric Bredal, of Drontheim, used means more consonant with the spirit of the Gospel, and, having instructed several young Lapps, sent them back again as missionaries to their families. These interpreters of a purer faith were, however, received as apostates and traitors by their suspicious countrymen, and cruelly murdered, most likely at the instigation of the sorcerers. In 1707 Frederic IV. founded the Finmark mission, and in 1716 Thomas Westen, a man of rare zeal and perseverance, preached the Gospel in the wildest districts of the province. Other missionaries and teachers followed his example, and at length succeeded in converting the Lapps, and in some measure conquering their ancient barbarism. Nothing 
can be more admirable than the self-denial and heroic fortitude of these ministers of Christ, for to renounce all that is precious in the eyes of the world to follow nomads little better than savages through the wilds of an Arctic country surely requires a courage not inferior to that of the soldier

Who seeks preferment at the cannon's mouth.

The Lapland schoolmaster enjoys an annual salary of twenty-five dollars, and receives besides half a dollar for every child instructed. But the priest is not much better off, as his stipend amounts to no more than thirty dollars in money, and to about 150 dollars in produce. Among this miserably paid clergy there are, as in Iceland, men worthy of a better lot. The famous Löstadius was priest at Karesuando, seventy-five leagues from Tromsö, the nearest town, and a hundred leagues from Tornea. His family lived upon rye bread and fishes, and but rarely tasted reindeer flesh. Chamisso mentions another Lapland priest who had spent seven years in his parish, which lay beyond the limits of the forest region. In the summer he was completely isolated, as then the Lapps wandered with their herds to the cool shores of the icy sea; and in the winter, when the moon afforded light, he travelled about in his sledge, frequently bivouacking at the temperature of freezing mercury, to visit his Lapps. During all that time his solitude had been but twice broken by civilized man; a brother had come to see him, and a botanist had strayed to his dwelling. $\mathrm{He}$ well knew how to appreciate the pleasure of such meetings, but neither this pleasure nor any other, he said, was equal to that of seeing the sun rise again above the horizon after the long winter's night.

It is a singular custom that the pastors preaching to the Lapps deliver their harangues in a tone of voice as elevated as if their audience, instead of being assembled in a small chapel, were stationed upon the top of a distant mountain, and labor as if they were going to burst a bloodvessel. Dr. Clarke, who listened to one of these sermons, which lasted one hour and twenty minutes, ventured to ask the reason of the very loud tone of voice used in preaching. The minister said he was aware that it must appear extraordinary to a stranger, but that, if he were to address the Laplanders in a lower key, they would consider him as a feeble and impotent missionary, wholly unfit for his office, and would never come to church; that the merit and abilities of the preacher, like that of many a popular politician, are always estimated by the strength and power of his lungs.

Though the Lapps (thanks to the efforts of their spiritual guides) hardly even remember by name the gods of their fathers-Aija, Akka, Tuona-they still pay a secret homage to the Saidas, or idols of wood or stone, to whom they were accustomed to sacrifice the bones and horns of the reindeer. They are in fact an extremely superstitious race, faithfully believing in ghosts, witcheraft, and above all in Stallo, or Troller, the evil spirit of the woods.

Many of them, when about to go hunting, throw a stick into the air, and then take their way in the direction to which it points. The appearance of the Aurora borealis fills them with terror, as they believe it to be a sign of divine wrath, and generally shout and howl during the whole duration of 
the grand phenomenon, which their ignorance connects with their own petty existence.

The pretended gift of being able to predict future events is common among the Laplanders. The sorcerers fall into a magic sleep, during which their soul wanders. In this state, like the somuambules of more polished nations, they reveal things to come or see what passes at a distance. Men and women affect the power of fortune-telling by the common trick of palmistry, or by the inspection of a cup of liquor; and this, to insure the greatest possible certainty, must be a cup of brandy, which at once explains the whole business of the prophecy. The Lapland witches pretended, or perhaps still pretend, to the power of stilling the wind or causing the rain to cease, and such was their reputation that English seamen trading to Archangel made it a point to land and buy a wind from these poor creatures.

The Lapps are a dwarfish race. On an average, the men do not exceed five feet in height, many not even reaching four, and the women are considerably less. Most of them are, however, very robust, the circumference of their chest nearly equalling their height. Their complexion is more or less tawny and copper-colored, their hair dark, straight, and lank, its dangling masses adding much to the wildness of their aspect. They have very little beard, and as its want is considered a beauty, the young men carefully eradicate the scanty supply given them by nature.

Their dark piercing eyes are generally deep sunk in their heads, widely separated from each other, and, like those of the Tartars or Chinese, obliquely slit towards the temples. The cheek-bones are high, the mouth pinched close, but wide, the nose fiat. The eyes are generally sore, either in consequence of the biting smoke of their huts or of the refraction from the snow, so that a Lapp seldom attains a high age without becoming blind. Their countenances generally present a repulsive combination of stolidity, low cunning, and obstinacy. Hogguer, who dwelt several months among them, and saw during this time at least 800 Lapps, found not twenty who were not decidedly ugly; and Dr. Clarke says that many of them, when more advanced in years, might, if exhibited in a menagerie of wild beasts, be considered as the long-lost link between man and ape.

Their legs are extremely thick and clumsy, but their hands are as small and finely shaped as those of any aristrocrat. The reason for this is that from generation to generation they never perform any manual labor, and the very trifling work which they do is necessarily of the lightest kind. Their limbs are singularly flexible, easily falling into any posture, like all the Oriental nations, and their hands are constantly occupied in the beginning of conversation with filling a short tobacco-pipe, the head being turned over one shoulder to the person addressed. Such are the traits by which the whole tribe is distinguished from the other inhabitants of Europe, and in which they differ from the other natives of the land in which they live.

The summer garb of the men consists of the "poesk," a sort of tunic, generally made of a very coarse light-colored woollen cloth, reaching to the knees, and fastened round the waist with a belt or girdle. Their woollen caps are shaped 
precisely like a night-cap, or a Turkish fez, with a red tassel and red worsted band round the rim, for they are fond of lively hues strongly contrasted. Their boots or shoes are made of the raw skin of the reindeer, with the hair outward, and have a peaked shape. Though these shoes are very thin, and the Lapp wears no stockings, yet he is never annoyed by the cold or by striking against stones, as he stuffs them with the broad leaves of the Carex vesicaria, or cyperus grass, which he cuts in summer and dries. This he first combs and rubs in his hands, and then places it in such a manner that it covers not only his feet but his legs also, and, being thus guarded, he is quite secure against the intense cold. With this grass, which is an admirable non-conductor of heat, he likewise stuffs his gloves in order to preserve his hands. But as it wards off the cold in winter, so in summer it keeps the feet cool, and is consequently used at all seasons. The women's apparel differs very little from that of the other sex, but their girdles are more ornamented with rings and chains. In winter both sexes are so packed up in skins as to look more like bears than human beings, and, when squatting according to the fashion of their country, exhibit a mound of furs, with the head resting upon the top of it.

According to their different mode of life, the Lapps may be aptly subdivided into Fjällappars, or Mountain Lapps; Skogslappars, or Wood Lapps; and Fisherlapps.

The Fjällappars, who form the greater and most characteristic part of the nation, lead an exclusively pastoral life, and are constantly wandering with their herds of reindeer from place to place, for the lichen which forms the chief food of these animals during the greater part of the year is soon cropped from the niggard soil, and requires years for its reproduction. For this reason, also, this people do not herd together, and never more than three or four families pitch their huts, or tuguria, upon the same spot. Of course the dwelling of the nomad Lapp harmonizes with his vagrant habits; a rude tent, which can easily be taken to pieces, and as easily erected, is all he requires to shelter his family and chattels. It consists of flexible stems of trees, placed together in a conical form, like a stack of poles for hops, and covered in the summer with a coarse cloth, in winter with additional skins, to be better fenced against the inclemencies of the climate. To form the entrance, a part of the hanging, about eighteen inches wide at the bottom, and terminating upward in a point, is made to turn back as upon hinges. The hearth, consisting of several large stones, is in the centre, and in the roof immediately above it is a square opening for the escape of smoke and the admission of rain, snow, and air. All the light which the den receives when the door is closed comes from this hole. The diameter of one of these conical huts generally measures at its base no more than six feet; its whole circumference, of course, does not exceed eighteen feet, and its extreme height may be about ten feet. The floor is very nearly covered with reindeer skins, on which the inmates squat during the day and sleep at nights, contract. ing their limbs together and huddling round their hearth, so that each individual of this pigmy race occupies scarcely more space than a dog. On the side of the tent are suspended a number of pots, wooden bowls, and other household utensils; and a small chest contains the holiday apparel of the family. Such 
are the dwellings of those among the Laplanders who are called wealthy, and who sometimes possess very considerable property.

Near the tent is the dairy or store-house of the establishment. It consists of nothing more than a shelf or platform, raised between two trees, so as to be out of the reach of the dogs or wolves. The means of ascent to this treasury of curds, cheese, and dried reindeer flesh, is simply a tree stripped of its branches, but presenting at every foot or so knobs, which serve the same purpose as staves on a ladder, the tree being obliquely reared against the platform.

Another characteristic feature of a Lapp encampment is found in the inclosures in which the reindeer are penned during the night or for the purpose of milking. These are circus-like open places, each of a diameter of about one hundred and fifty feet, and are formed by stumps of trees and poles set upright on the ground, and linked together by horizontal poles. Against the latter are reared birch poles and branches of trees, varying from six to ten feet in height, without the slightest attempt at neatness, the whole being as rude as well can be-a sufficient security against the wolves being all that its builders desire. The milking of a herd of reindeer presents a most animated scene. When they have been driven within the inclosure, and all outlets are secured, a Lapp, selecting a long thong or cord, takes a turn of both ends round his left hand, and then gathers what sailors call the bight in loose folds, held in his right. He now singles out a reindeer, and throws the bight with unerring aim over the antlers of the victim. Sometimes the latter makes no resistance, but in general the moment it feels the touch of the thong it breaks away from the spot, and 1s only secured by the most strenuous exertions. Every minute may be seen an unusually powerful deer furiously dragging a Lapp round and round the inclosure, and sometimes it fairly overcomes the restraint of the thong, and leaves its antagonist prostrate on the sod. This part of the scene is highly exciting, and it is impossible not to admire the trained skill evinced by all the Lapps, women as well as men. The resistance of the deer being overcome, the Lapp takes a dexterous hitch of the thong round his muzzle and head, and then fastens him to the trunk of a prostrate tree, many of which have been brought within the level inclosure for that especial purpose. Men and women are indiscriminately engaged both in singling out milch reins and in milking them. Every one is fully occupied, for even the little children are practising the throwing of the lasso, in which they evince great dexterity, although their strength is insufficient to hold the smallest doe.

When the pasture in the neighborhood is fully exhausted, which generally takes place in about a fortnight, the encampment is broken up, to be erected again on some other spot. In less than half an hour the tent is taken to pieces, and packed with all the household furniture upon the backs of reindeer, who by long training acquire the capacity of serving as beasts of burden. On the journey they are bound together, five and five, with thongs of leather, and led by the women over the mountains, while the father of the family precedes the march to select a proper place for the new epcampment, and his sons or servants follow with the remainder of the herd.

Towards the end of spring the Lapps descend from the mountains to the 
sea. When they approach its borders, the reindeer, sniffing the sea air from a distance, rush tumultuously to the fjord, where they take long draughts of the salted water. This, as the Lapps believe, is essential to their health. As the summer advances, and the snow melts, they ascend higher and higher into the mountains. At the approach of winter they retreat into the woods, where, with the assistance of their dogs and servants, they have enough to do to keep off the attacks of the wolves. The reindeer dog is about the size of a Scotch terrier, but his head bears a wonderful resemblance to that of the lynx. His color varies considerably, but the hair is always long and shaggy. Invaluable as are his services, he is nevertheless treated with great cruelty.

For their winter journeys the Lapps use sledges or skates. One of their skates, or "skiders," is usually as long as the person who wears it; the other is about a foot shorter. The feet stand in the middle, and to them the skates are fastened by thongs or withes. The skiders are made of fir-wood, and covered with the skins of young reindeer, which obstruct a retrograde movement by acting like bristles against the snow-the roots pointing towards the fore part of the skate, and thus preventing their slipping back. With these skiders, the Lapp flies like a bird over the snow, now scaling the mountains by a tortuous ascent, and now darting down into the valley:

\section{Ocior cervis et agente nimbos}

Ocior Euro.

Such is the rapidity of his course that he will overtake the swiftest wild beasts ; and so violent the exercise that, during the most rigorous season of the year, when earnestly engaged in the chase, he will divest himself of his furs. A long pole with a round ball of wood near the end, to prevent its piercing too deep in the snow, serves to stop the skater's course when he wishes to rest. The Laplander is no less expert in the use of the sledge, or "pulka," which is made in the form of a small boat with a convex bottom, that it may slide all the more easily over the snow ; the prow is sharp and pointed, but the sledge is flat behind. The traveller is swathed in this carriage like an infant in a cradle, with a stick in his hand to steer the vessel, and disengage it from the stones or stumps of trees which it may chance to encounter in the route. He must also balance the sledge with his body, to avoid the danger of being overturned. The traces by which this carriage is fastened to the reindeer are fixed to a collar about the animal's neck, and run down over the breast between the fore and hind legs, to be connected with the prow of the sledge; the reins managed by the traveller are tied to the horns, and the trappings are furnished with little bells, the sound of which the animal likes. With this draught at his tail, the reindeer will travel sixty or seventy English miles in a day; often persevering fifty miles without intermission, and without taking any refreshment, except occasionally moistening his mouth with the snow. His Lapland driver knows how to find his way through the wilderness with a surprising certainty; here a rock, there a fir-tree, is impressed as a landmark on his faithful memory, and thus, like the best pilot, he steers his sledge to the distant end of his journey. Frequently the Aurora lights him on his way, illumining the snow-covered 
landscape with a magic brilliancy, and investing every object with a dream-like, supernatural beauty.

But even without the aid of this mysterious coruscation, Lapland is rich in grand and picturesque features, and has all the romance of the mountain and the forest. In summer countless rivulets meander through valleys of alpine verdure, and broad pellucid rivers rush down the slopes in thundering cataracts, embracing islands clothed with pine-trees of incomparable dignity and grace. Whoever has grown up in scenes like these, and been accustomed from infancy to the uncontrolled freedom of the nomad state, receives impressions never to be erased; and thus we can not wonder that the wild Laplander believes his country to be a terrestrial paradise, and feels nowhere happy but at home.

In the year 1819 a Scotch gentleman attempted to acclimatize the reindeer in Scotland, and induced two young Laplanders to accompany the herd which he had bought for that purpose. The reindeer soon perished, and the Laplanders would have died of nostalgia if they had not been sent home by the first opportunity. Prince Jablonowsky, a Polish nobleman, who travelled about thirty years since through a part of Russian Lapland, took a Lapp girl with him to St. Petersburg. He gave her a superior education, and she was well treated in every respect. She made rapid progress, and seemed to be perfectly reconciled to her new home. About two years after her arrival, it happened that a Russian gentleman, who possessed extensive estates near the capital, bought a small herd of reindeer, which arrived under the guidance of a Lapp family. As it was winter-time, and these people had brought with them their tents, their sledges, and their snow-shoes, they soon became objects of curiosity, and crowds of fashionable visitors flocked to their encampment; among others, the good-natured prince, who imprudently conducted his pupil, the young Lapland girl, to see her countrymen, an interview which he supposed would give her great pleasure. But from that moment she became an altered being; she lost her spirits and her appetite, and, in spite of every care and attention, her health declined from day to day. One morning she disappeared, and it was found on inquiry that she had returned to her family, where she remained ever after.

Another very remarkable instance of the Laplanders' love of their country is related by Hogström. During the war of Gustavus III. with Russia, a young Laplander enlisted in a regiment which was passing through Tornea. He served in several campaigns as a common soldier, was made a sergeant in consequence of his good conduct and courage; and having given himself the greatest trouble to improve his education and acquire military knowledge, at length, after twenty years of service, attained the rank of captain in the Swedish army. After this long time spent in the civilized world, and having become accustomed to all its enjoyments and comforts, he felt a strong desire to revisit his family and his country. Scarcely had he seen his native mountains, and spent a few days among his countrymen and the reindeer, than he at once quitted the service, and resumed the nomad life of his youth.

The Laplander's chief desire is for peace and tranquillity. Exposed to all the privations of a vagrant life, and to every inclemency of weather, he endures 
the greatest hardships with equanimity, desiring only not to be disturbed in the enjoyment of the little that is his-not to be interfered with in his old customs and habits.

Yet this same peaceful Laplander, who has so easily submitted to a foreign yoke, is one of the boldest hunters, and not only pursues the elk or the wild reindeer, but engages in single combat with the bear. Like all the other Arctic nations of Russia and Siberia, he has strange notions about this animal, which in his opinion is the most cunning and gifted of all created beings. Thus he supposes that the bear knows and hears all that is said about him, and for this reason he takes good care never to speak of him disrespectfully. It may seem strange that he should venture to slay an animal which ranks so high in his es. teem; but the temptation is too strong, as its flesh has an excellent flavor, and its fur, though not near so valuable as that of the American black bear, is still worth from fifteen to twenty dollars.

At the beginning of winter, the bear, as is well known, retires either into a rocky cave, or under a cover of branches, leaves, and moss, and remains there without food, and plunged in sleep until the next spring recalls him to a more active existence. After the first fall of snow, the Lapp hunters go into the forest and look out for traces of the bear. Having found them, they carefully mark the spot, and returning after a few weeks disturb the slumbering brute, and excite him to an attack. It is not considered honorable to shoot him while sleeping; and in many parts of Lapland the hunter who would kill a bear with any other weapon but a lance would be universally despised. Hogguer accompanied two Lapps, well-armed with axes and stout lances with barbed points, on one of these bear-hunts. When about a hundred paces from the lair the company halted, while one of the Lapps advanced shouting, telling his comrades to make as much noise as they could. When about twenty paces from the cavern, he stood still and flung several stones into it. For some time all was quiet, so that Hogguer began to fear that the lair was deserted, when suddenly an angry growl was heard. The hunters now redoubled their clamor, until slowly, like an honest citizen disturbed in his noonday slumbers, the bear came out of his cavern. But this tranquillity did not lasst long, for the brute, as soon as he perceived his nearest enemy, uttered a short roar and rushed upon him. The Lapp coolly awaited the onset with his lance in rest, until the bear, coming quite near, raised himself on his haunches and began to strike at him with his fore paws. The hunter bent down to avoid the strokes, and then suddenly rising, with a s!ure eye and with all his might, plunged his lance into the heart of the bear. During this short conflict the Lapp had received a slight wound on the hand, but the marks of the bear's teeth were found deeply impressed upon the iron of the lance. According to an ancient custom, the wives of the hunters assemble in the hut of one of them; and as suon as they hear the returning sportsmen, begin chanting or howling a song in praise of the bear. When the men, laden with the skin and flesh of the animal, approach, they are received by the women with opprobrious epithets, and forbidden ingress through the door; so that they are obliged to make a hole in the wall, through which they enter with their spoils. This comedy, which is meant to pacify the manes 
of the victim, is still acted, though not so frequently as formerly; but the custom of begging the bear's pardon with many tears is completely out of date. The animal's interment, however, still takes place with all the ancient honors and ceremonies. After having been skinned, and its flesh cut off, the body is buried in anatomical order-the head first, then the neck, the fore paw, etc. This is done from a belief in the resurrection of the bear, who having been decently buried, will, it is hoped, allow himself to be killed a second time by the same Lapp; while a neglect of the honors due to him would exasperate the whole race of bears, and cause them to wreak a bloody vengeance on the disrespectful hunter.

The wolf is treated with much less ceremony. Many a wealthy Lapp, the owner of a thousand reindeer, has been reduced to poverty by the ravages of this savage beast, which is constantly prowling about the herds. Hence one of the first questions they put to each other when they meet is, "Lekor rauhe ?" "Is it peace?"- which means nothing more than, "Have the wolves molested you ?" Such is their detestation of these animals that they believe them to be creatures of the devil, contaminating all that touches them while alive. Thus they will never shoot a wolf, as the gun that killed him would ever after be accursed.

At the first alarm that wolves have appeared, the neighbors assemble, and the chase begins. For miles they pursue him over hills and valleys on their "skiders," and kill him with clubs, which they afterwards burn. They will not even defile themselves with skinning him, but leave his hide to the Finnish or Russian colonists, who, being less scrupulous or superstitious, make a warm cloak of it, or sell it for a few dollars at the fair.

Among the Fjall Lapps there are many rich owners of 1000 or 1500 reindeer, 300 of which fully suffice for the maintenance of a family. In this case the owner is able to kill as many as are necessary for providing his household with food and raiment, while the sale of the superfluous skins and horns enables him to purchase cloth, flour, hardware, and other necessary articles-not to forget the tobacco or the brandy in which he delights. The price of the entire carcass of a reindeer, skin and all, varies from one to three dollars Norsk (four shillings and sixpence to thirteen shillings and sixpence). A fine skin will always sell for one dollar in any part of the North. It will thus be seen that a Lapp possessing a herd of 500 or 1000 deer is virtually a capitalist in every sense of the word, far richer than the vast majority of his Norwegian, Swedish, or Russian fellow-subjects, although they all affect to look upon him with su. preme contempt.

The daily food of the mountain Laplanders consists of the fattest reindeer venison, which they boil, and eat with the broth in which it has been cooked. Their summer diet consists of cheese and reindeer-milk. The rich also eat bread baked upon hot iron plates.

Their mode of killing the reindeer is the method used by the butchers in the South of Italy - the most ancient and best method of slaying cattle, because it is attended with the least pain to the animal, and the greatest profit to its possessor. They thrust a sharp-pointed knife into the back part of the head between the horns, so as to divide the spinal marrow from the brain. The beast 
instantly drops, and dies without a groan or struggle. As soon as it falls, and appears to be dead, the Laplander plunges the knife dexterously behind the offshoulder into the heart; then opening the animal, its blood is found in the stomach, and ladled out into a pot. Boiled with fat and flour, it is a favorite dish.

An important epoch in the life of the Fjall Lapp is his annual visit to one of the winter fairs held in the chief towns or villages which the more industrious Swedes, Norwegians, or Fins have founded on the coasts here and there, or in the well-watered valleys of his fatherland, and which he attends frequently from an immense distance. After a slight duty to Government has been paid, business begins ; but as every bargain is ratified with a full glass of brandy, his thoughts get confused before the day is half over-a circumstance which the cunning merchant does not fail to turn to account. On awaking the next morning, the vexation of the nomad at his bad bargains is so much the greater, as no people are more avowed mammon-worshippers than the Lapps, or more inclined to sing, with our Burns :-

O wae on the siller, it is sae prevailin "!

Their sole object seems to be the amassing of treasure for the sole purpose of hoarding it. The avarice of a Lapp is gratified in collecting a number of silver vessels or pieces of silver coin; and being unable to carry this treasure with him on his journeys, he buries the whole, not even making his wife acquainted with the secret of its deposit, so that when he dies the members of his family are often unable to discover where he has hidden it. Some of the Lapps possess a hundred-weight of silver, and those who own 1500 or 1000 reindeer have much more; in short, an astonishing quantity of specie is dispersed among them. Silver plate, when offered to them for sale, must be in a polished state, or they will not buy it; for such is their ignorance, that when the metal, by being kept buried, becomes tarnished, they conceive that its value is impaired, and exchange it for other silver, which being repolished, they believe to be new. The merchants derive great benefit from this traffic.

Brandy and tobacco are the chief luxuries of the Lapps. The tobacco-pipe is never laid aside except during meals; it is even used by the women, who also swallow spirits as greedily as the men; in fact, both sexes will almost part with life itself for the gratification of dram-drinking. If you walk up to a Lapp, uncouthly squatted before his tent, his very first salutation is made by stretching forth a tawny hand and demanding, in a whining tone, "Tabak" or "Braendi." Dr. Clarke relates an amusing instance of their propensity for spirituous liquors. On his very first visit to one of their tents, he gave the father of the family about a pint of brandy, thinking he would husband it with great care, as he had seen him place it behind him upon his bed near the skirting of the tent. The daughter now entered, and begged for a taste of the brandy, as she had lost her share by being absent. The old man made no answer, but when the request was repeated, he slyly crept round the outside of the tent until he came to the spot where the brandy was, when, thrusting his arm beneath the skirting, he drew it out, and swallowed the whole contents of the bottle at a draught. 
The practice of dram-drinking is so general that mothers pour the horrid dose down the throats of their infants. Their christenings and funerals become mere pretexts for indulging in brandy. But their mild and pacific disposition shows itself in their drunkenness, which is manifested only in howling, jumping, and laughing, and in a craving for more drams with hysteric screams until they fall senseless on the ground-while at the same time they will suffer kicks, cuffs, blows, and provocations of any kind without the smallest irascibility. When sober they are as gentle as lambs, and the softness of their language, added to their effeminate shrill tone of voice, remarkably corresponds with their placable disposition. An amiable trait in the character of the Lapp is the warmth of his affection towards his wife, his children, and his dependents. Nothing can exceed the cordiality of their mutual greetings after separations, and it is to be feared that but few married men in England could match the Lapp husband who assured Castrén that during thirty years of wed. lock no worse word had passed between himself and his wife than "Loddadsham," or "My little bird."

In spite of his fatiguing life, and the insufficient shelter afforded him by his hut, the Fjall Lapp is generally vigorous and healthy, and not seldom lives to a hundred years age. Continual exercise in the open air braces his constitution, his warm clothing protects him against the cold of winter, and his generous meat diet maintains his strength. To prevent the scurvy, he eats the berries of the Empetrum nigrum or Rubus chamcemorus, and mixes the stems of the Angelica among his food. But his chief remedy against this and every other bodily evil is warm reindeer-blood, which he drinks with delight as a universal panacea.

The Skogs Lapp, or Forest Lapp, occupies an intermediate grade between the Fjall Lapp and the Fisher Lapp, as fishing is his summer occupation, and hunting and the tending of his reindeer that of the winter months. His herds not being so numerous as those of the Fjall Lapp, he is not driven to constant migration to procure them food; but they require more care than his divided pursuits allow him to bestow upon them, and hence he inevitably descends to the condition of the Fisher Lapp. Lästadius describes his life as one of the happiest on eartl_-as a constant change between the agreeable pastime of fishing and the noble amusement of the chase. He is not, like the Mountain Lapp, exposed to all the severity of the Arctic winter, nor so poor as the Fisher Lapp. He is often heard to sing under the green canopy of the firs.

The villages of the Fisher Lapps-as they are found, for instance, on the banks of Lake Enara--afford a by no means pleasing spectacle.

About the miserable huts, which are shapeless masses of mingled earth, stones, and branches of trees, and scarcely equal to the dwellings of the wretched Fuegians, heaps of stinking fish and other offal caint the air with their pestilential odors. When a stranger approaches, the inmates come pouring out of their narrow doorway so covered with dirt and vermin as to make him recoil with disgust. Not in the least ashamed, however, of their appearance, they approach the stranger and shake his hand according to the code of Lapp politeness. After this preliminary, he may expect the following ques- 
tions: "Is peace in the land? How is the emperor, the bishop, and the captain of the district?" The more inquisitive of the filthy troop then ask after the home of the stranger, and being told that it is beyond the mountains, they further inquire if he comes from the land where tobacco grows. For as our imagination loves to wander to the sunny regions,

Where the citron and olive are fairest of fruit,

And the voice of the nightingale never is mute;

so the fancy of the Lapp conceives no greater paradise than that which produces the weed that, along with the brandy-bottle, affords him his highest luxury. 


\section{CHAPTER XIII. \\ MATTHIAS ALEXANDER CASTREN.}

His Birthplace and first Studies.-Journey in Lapland, 1838. - The Iwalojoki.-The Lake of Enara.The Pastor of Utzjoki.-From Rowaniémi to Kemi.-Second Voyage, 1841-44.-Storm on the White Sea.-Return to Archangel.-The Tundras of the European Samoïedes._Mesen._Universal Drunkenness.-Sledge Journey to Pustosersk.-A Samö̈ede Teacher.-Tundra Storms._Abandoned and alone in the Wilderness.-Pustosersk.-Our Traveller's Persecutions at Ustsylmsk and Ishemsk.-The Uusa._Crossing the Ural.-Obdorsk.-Second Siberian Journey, 1845-48.-Overflowing of the Obi.-Surgut.-Krasnojarsk.-Agreeable Surprise.-Turuchansk.-Voyage down the Jenissei._Castrén's Study at Plachina.-From Dudinka to Tolstoi Noss._Frozen Feet.-Return Voyage to the South.-Frozen fast on the Jenissei.-Wonderful Preservation.-Journey across the Chinese Frontiers, and to Transbaikalia.-Return to Finland.-Professorship at Helsingfors.-Death of Castrén, 1855.

MATTHIAS ALEXANDER CASTREN, whose interesting journeys form the subject of the present chapter, was born in the year 1813, at Rowanièmi, a Finland village situated about forty miles from the head of the Gulf of Bothnia, immediately under the Arctic Circle; so that, of all men who have attained celebrity, probably none can boast of a more northern birthplace. While still a scholar at the Alexander's College of Helsingfors, he resolved to devote his life to the study of the nations of Finnish origin (Fins, Laplanders, Samoïedes, Ostiaks, etc.); and as books gave but an insufficient account of them, each passing year strengthened his desire to visit these tribes in their own haunts, and to learn from themselves their languages, their habits, and their history.

We may imagine, therefore, the joy of the enthusiastic student, whom poverty alone had hitherto prevented from carrying out the schemes of his youth, when Dr. Ehrström, a friend and medical fellow-student, proposed to take him as a companion, free of expense, on a tour in Lapland. No artist that ever crossed the Alps on his way to sunny Italy could feel happier than Castrén at the prospect of plunging into the wildernesses of the Arctic zone.

On June 25, 1838, the friends set out, and arrived on the 30 th at the small town of Muonioniska, where they remained six weeks-a delay which Castrén put to good account in learning the Lapp language from a native catechist. At length the decreasing sun warned the travellers that it was high time to continue their journey, if they wished to see more of Lapland before the winter set in; and after having, with great difficulty, crossed the mountain ridge which forms the water-shed between the Gulf of Bothnia and the Polar Sea, they embarked on the romantic Iwalojoki, where for three days and nights the rushing waters roared around them. In spite of these dangerous rapids, they were obliged to trust themselves to the stream, which every now and then threatened to dash their frail boat to pieces against the rocks. Armed with long oars, they were continually at work during the daytime to guard against 
this peril ; the nights were spent near a large fire kindled in the open air, without any shelter against the rain and wind.

The Iwalo River is, during the greater part of its course, encased between high rocks; but a few miles before it discharges itself into the large Lake of Enara, its valley improves into a fine grassy plain. Small islands covered with trees divide the waters, which now flow more tranquilly; soon also traces of culture appear, and the astonished traveller finds in the village of Kyrö, not wretched Lapland huts, but well-built houses of Finnish settlers, with green meadows and cornfields.

The beautiful Lake of Enara, sixty miles long and forty miles broad, is so thickly studded with islands that they have never yet been counted. After the travellers had spent a few days among the Fisher Lapps who sojourn on its borders, they proceeded northward to Utzjoki, the limit of their expedition, and one of the centres of Lapland civilization, as it boasts of a church, which is served by a man of high character and of no little ability. On accepting his charge, this self-denying priest had performed the journey from Tornea in the depth of winter, accompanied by a young wife and a female relation of the latter, fifteen years of age. He had found the parsonage, vacated by his predecessor, a wretched building, distant some fifteen miles from the nearest Lapp habitation. After establishing himself and his family in this dreary tenement, he had returned from a pastoral excursion to find his home destroyed by a fire, from which its inmates had escaped with the loss of all that they possessed. A miserable hut, built for the temporary shelter of the Lapps who resorted thither for divine service, afforded the family a refuge for the winter. He had since contrived to build himself another dwelling, in which our party found him, after five years' residence, the father of a family, and the chief of a happy household. Gladly would the travellers have remained some time longer under his hospitable roof, but the birds of passage were moving to the south, warning them to follow their example.

Thus they set out, on August 15, for their homeward voyage, which proved no less difficult and laborious than the former. At length, after wandering through deserts and swamps-frequently wet to the skin, and often without food for many hours-they arrived at Rowanièmi, where they embarked on the Kemi River.

"With conflicting feelings," says Castrén, "I descended its stream ; for every cataract was not only well-known to me from the days of my earliest childhood, but the cataracts were even the only acquaintances which death had left me in the place of my birth. Along with the mournful impressions which the loss of beloved relations made upon my mind, it was delightful to renew my intercourse with the rapid stream and its waterfalls-those boisterous playfellows, which had often brought me into peril when a boy: Now, as before, it was a pleasant sport to me to be hurried along by their tumultuous waters, and to be wetted by their spray. The boatmen often tried to persuade me to land before passing the most dangerous waterfalls, and declared that they could not be answerable for my safety. But, in spite of all their remonstrances, I remained in the boat, nor had I reason to repent of my boldness, for 
He who is the steersman of all boats granted us a safe arrival at Kemi, where our Lapland journey terminated."*

In 1841 Castrén published a metrical translation, into the Swedish language, of the "Kalewala," a cycle of the oldest poems of the Fins ; and at the end of the same year proceeded on his first great journey to the land of the European Samoïedes, and from thence across the northern Ural Mountains to Siberia. In the famous convent of Solovetskoi, situated on a small island in the White Sea, he hoped to find a friendly teacher of the Samoïede language in the Archimandrite Wenjamin, who had labored as a missionary among that savage people, but the churlish dignitary jealously refused him all assistance; and as the tundras of the Samoïedes are only accessible during the winter, he resolved to turn the interval to account by a journey among the Terski Lapps, who inhabit the western shores of the White Sea. With this view, in an evil hour of the 27 th June, 1842, though suffering at this time from illness severe enough to have detained any less persevering traveller, he embarked at Archangel in a large cornladen vessel, with a reasonable prospect of being landed at Tri Ostrowa in some twenty-four hours; but a dead calm detained him eight days, during which he had no choice but to endure the horrible stench of Russian sea-stores in the cabin or the scorching sun on deck. At length a favorable wind arose, and after a few hours' sailing nothing was to be seen but water and sky. Soon the Terski coast came in view, with its white ice-capped shore, and Castrén hoped soon to be released from his floating prison, when suddenly the wind changed, and, increasing to a storm, threatened to dash them on the cliffs of the Solovetskoi Islands.

"Both the captain and the ship's company began to despair of their lives; and prayers having been resorted to in vain, to conjure the danger, general drunkenness was the next resource. The captain, finding his own brandy too weak to procure the stupefaction he desired, left me no peace till I had given him a bottle of rum. After having by degrees emptied its contents, he at length obtained his end, and fell asleep in the cabin. The crew, following his example, dropped down one by one into their cribs, and the ship was left without guidance to the mercy of the winds and waves. I alone remained on deck, and gloomily awaited the decisive moment. But I soon discovered that the wind was veering to the east, and, awaking the captain from his drunken lethargy, sent him on deck, and took possession of his bed. Exhausted by the dreadful scenes of the day, I soon fell into a deep slumber; and when I awoke the following morning, I found myself again on the eastern coast of the White Sea, at the foot of a high sheltering rock-wall."

Continued bad weather and increasing illness now forced Castrén to give up his projected visit to the Lapps, and when he returned to Archangel, both his health and his purse were in a sad condition. He had but fifteen roubles in his pocket, but fortunately found some Samoiede beggars still poorer than himself, one of whom, for the reward of an occasional glass of brandy, consented to become at once his host, his servant, and his private tutor in the Samoiede lan- 
guage. In the hut and society of this savage he passed the remainder of the summer, his health improved, and soon also his finances changed wonderfully for the better-the Government of Finland having granted him a thousand silver roubles for the prosecution of his travels. With a light heart he continued his linguistic studies until the end of November, when he started with renewed enthusiasm for the land of the European Samoïedes. These immense tundras extend from the White Sea to the Ural Mountains, and are bounded on the north by the Polar Sea, and on the south by the region of forests, which here reaches as high as the latitudes of $66^{\circ}$ and $67^{\circ}$.

The large river Petschora divides these dreary wastes into two unequal halves, whose scanty population, as may easily be imagined, is sunk in the deepest barbarism. It consists of nomadic Samoïedes, and of a few Russians, who inhabit some miserable settlements along the great stream and its tributary rivers.

To bury himself for a whole year in these melancholy deserts, Castrén left Archangel in November, 1842. As far as Mesen, 345 versts north of Archangel, the scanty population is Russ and Christian. At Mesen civilization ceases, and farther north the Samoïede retains for the most part, with his primitive habits and language, his heathen faith-having, in fact, borrowed nothing from occasional intercourse with civilized man but the means and practice of drunkenness. Castrén's first care, on his arrival at Mesen, was to look for a Samoïede interpreter and teacher; but he was as unsuccessful here as at Somsha, a village some forty versts farther on, where drunkenness was the order of the day. He took the most temperate person he could find in all Somsha into his service, but even this moderate man would, according to our ideas, have been accounted a perfect drunkard. He now resolved to try the fair sex, and engaged a female teacher, but she also could not remain sober. At length a man was introduced to him as the most learned person of the tundra, and at first it seemed as if he had at length found what he wanted; but after a few hours the Samoiede began to get tired of his numerous questions, and declared himself ill. He threw himself upon the floor, wailed and lamented, and begged Castrén to have pity on him, until at length the incensed philologist turned him out-of-doors. Soon after he found him lying dead drunk in the snow before the "Elephant and Castle" of the place.

Thus obliged to look for instruction elsewhere, Castrén resolved to travel, in the middle of winter, to the Russian village of Pustosersk, at the mouth of the Petschora, where the fair annually attracts a number of Samoiedes. During this sledge-journey of 700 versts, he had to rest sometimes in the open air on the storm-beaten tundra, and sometimes in the rickety tent of the Samoiede, or in the scarcely less wretched hut of the Russian colonist-where the snow penetrated through the crevices of the wall, where the flame of the light flickered in the wind, and a thick cloak of wolf-skin afforded the only protection against the piercing cold of the Arctic winter.

For this arduous tour, two sledges, with four reindeer attached to each, were employed-the traveller's sledge, which was covered, being attached to an uncovered one occupied by the guide. The Kanin Tundra stretched out before 
them, as they flew along, almost as naked as the sea, of which they saw the margin in the east; and had not the wind here and there driven away the snow which Heaven in its mercy strews over this gloomy land, they might have been in doubt on which element they were travelling. Daily, from time to time, some dwarf firs made their appearance, or clumps of low willows, which generally denote the presence of some little brook slowly winding through the flat tundra.

The village of Ness, on the north coast, was the first halting-place, and here Castrén flattered himself he had at length found what his heart desired, in the person of a Samoiede teacher who knew Russian, and was gifted with a clearer head than is usually possessed by his race.

"The man was conscious of his superiority, and while acting as a professor looked down with contempt upon his weaker brethren. Once, some other Samoiedes venturing to correct one of his translations, he commanded them to be silent, telling them they were not learned. I tried by all possible means to secure the services of this Samoïede phenomenon. I spoke kindly with him, I paid him well, gave him every day his allowance of brandy, and never once forbade him to get drunk when he felt inclined to do so. Yet, in spite of all my endeavors to please, he felt unhappy, and sighed for the liberty of the tundra. 'Thou art kind, and I love thee,' said he one day to me, 'but I can not endure confinement. Be therefore merciful, and give me my freedom.'

"I now increased his daily pay and his rations of brandy, sent for his wife and child, treated his wife also with brandy, and did all I could to dispel the melancholy of the Samoïede. By these means I induced him to remain a few days longer with me.

"While I was constantly occupying him, the wife was busy sewing Samoïede dresses, and sometimes assisted her husband in his translations. I often heard her sighing deeply, and having asked for the reason, she burst into tears, and answered that she grieved for her husband, who was thus imprisoned in a room. 'Thy husband,' was my reply, 'is not worse off than thyself. Tell me, what do you think of your own position?' 'I do not think of myself-I am sorrowful for my husband,' was her ingenuous reply. At length both the husband and the wife begged me so earnestly to set them at liberty that I allowed them to depart."

On the way from Pjoscha to Pustosersk, after Castrén had once more vainly endeavored to discover that rara avis, a Samoïede teacher, he became thoroughly acquainted with the January snow-storms of the tundra: "The wind arose about noon, and blew so violently that we could not see the reindeer before our sledges. The roof of my vehicle, which at first had afforded me some protection, was soon carried away by the gale. Anxious about my fate, I questioned my guides, whenever they stopped to brush off the snow which had accumulated upon me, and received the invariable answer,. 'We do not know where we are, and see nothing.' We proceeded step by step, now following one direction, now another, until at length we reached a river well known to the guides. The leader of the first sledge hurried his reindeer down the precipitous bank, and drove away upon the ice to seek a more convenient descent; but as he did not return, the other guide likewise left me to look after his companion, and thus I 
was kept waiting for several hours on the tundra, without knowing where my guides had gone to.

"At first I did not even know that they had left me, and when I became aware of the fact, I thought that they had abandoned me to my fate. I will not attempt to describe my sensations; but my bodily condition was such, that when the cold increased with the approach of night, I was seized with a violent fever. I thought my last hour was come, and prepared for my journey to another world."

The re-appearance of the guides relieved Castrén of his anxiety, and when the little party reached some Samoïede huts, the eldest of the guides knelt down at the side of our traveller's sledge and expressed his joy in a prayer to God, begging Castrén to join him in his thanksgivings, "for He, and not I, has this night saved thee."

The next morning, as the weather seemed to improve, and the road (along the Indiga River) to the next Russian settlement was easy to find, Castrén resolved to pursue his journey. "But the storm once more arose, and became so dreadfully violent that I could neither breathe nor keep my eyes open against the wind. The roaring of the gale stupefied my senses. The moist snow wetted me during the day, and the night converted it into ice. Half frozen, I arrived after midnight at the settlement. The fatigues of the journey had been such that I could scarcely stand; I had almost lost my consciousness, and my sight had suffered so much from the wind that I repeatedly ran with my forehead against the wall. The roaring of the storm continually resounded in my ears for many hours after."

A few days later Castrén arrived at Pustosersk, undoubtedly one of the dreariest places in the world. With scarcely a trace of arboreal vegetation, the eye, during the greater part of the year, rests on an interminable waste of snow, where the cold winds are almost perpetually raging. The storms are so violent as not seldom to carry away the roofs of the huts, and to prevent the wretched inhabitants from fetching water and fuel. In this Northern Eden our indefatigable ethnologist tarried several months, as it afforded him an excellent opportunity for continuing his studies of the language, manners, and religion of the Samoïedes, who come to the fair of Pustosersk during the winter, to barter their reindeer skins for flour and other commodities, and at the same time to indulge in their favorite beverage--brandy. At length the Samoïedes retired, the busy season of the place was evidently at an end, and Castrén, having no further inducement to remain at Pustosersk, left it for the village of Ustsylmsk, situated 150 versts higher up the Petschora, where he hoped still to find some straggling Samoïedes. The road to Ustsylmsk leads through so desolate a region, that, according to the priests of the neighborhood, it can not have beerı originally created by God with the rest of the world, but must have been formed after the Deluge. Near Ustsylmsk ( $65^{\circ} 30^{\prime} \mathrm{N}$. lat. $)$ the country improves, as most of the northern trees grow about the place; but, unfortunately, a similar praise can not be awarded to its inhabitants, whom Castrén found to be the most brutal and obstinate Raskoiniks (or sectarians) he had ever seen. Without in the least caring for the Ten Commandments, and indulging in every vice, these 
absurd fanatics fancied themselves better than the rest of mankind, because they made the sign of the cross with the thumb and the two last fingers, and stood for hours together before an image in stupid contemplation. Our homeless traveller soon became the object of their persecutions; they called him "wizard," "a poisoner of rivers and wells," and insulted him during his walks. At length they even attempted to take his life, so that he thought best to retreat to Ishemsk, on the Ishma, a hundred versts farther to the south. But, unfortunately, his bad reputation had preceded him, and although the Isprawnik (or parish official) and his wife warmly took his part, the people continued to regard him with suspicion.

Towards the end of June Castrén ascended the Petschora and its chief tributary, the Uusa, as far as the village of Kolwa, where he spent the remainder of the summer, deeply buried as usual in Samoïede studies. Beyond Kolwa, which he left on September 16 for Obdorsk, there is not a single settlement along the Uusa and its tributaries.

As he ascended the river, the meadows on its low banks appeared colored with the gray tints of autumn. Sometimes a wild animal started from its lair, but no vestige of man was to be seen. Countless flocks of wild ducks and geese passed over the traveller's head, on their way southward.

After many a tedious delay, caused by storms and contrary winds, Castrén reached (on September 27) a wretched hut, about forty versts from the Ural, where he was obliged to wait a whole month, with fourteen other persons, until the snow-track over the mountains became practicable for sledges.

The total want of every comfort, the bad company, the perpetual rain, and the dreary aspect of the country, made his prolonged stay in this miserable tenement almost unbearable. At length, on October 25, he was able to depart, and on November 3 he saw the Ural Mountains raising their snow-capped summits to the skies. "The weather is mild," said his Samoïede driver, "and thou art fortunate, but the Ural can be very different." He then described the dreadful storms that rage over the boundary-chain which separates Europe from Asia, and how they precipitate stones and rocks from the mountain-tops.

This time the dreaded pass was crossed in safety, and on November 9, 1843, Castrén arrived at Obdorsk, on the Obi, exhausted in strength and shattered in health, but yet delighted to find himself in Asia, the land of his early dreams. Obdorsk-the most northerly colony in Western Siberia, and, as may easily be imagined, utterly deficient in all that can be interesting to an ordinary traveller-was as much as a university to the zealous student, for several thousands of Samoïedes and Ostiaks congregate to its fair from hundreds of versts around.

No better place could possibly be found for the prosecution of his researches; but the deplorable condition of his health did not allow him to remain as long as he would have desired at this fountain-head of knowledge. He was thus obliged to leave for Tobolsk, and to return in March, 1844, by the shortest road to Finland.

In the following summer (1845) we again find him on the banks of the Irtysch and the Obi, plunged in Ostiak studies with renewed energy and enthu- 
siasm. After having sojourned for several weeks at Toropkowa, a small island. at the confluence of these two mighty streams, he ascended the Obi in July as far as Surgut, where he arrived in the beginning of August.

In consequence of the overflowing of its waters, the river had spread into a boundless lake, whose monotony was only relieved, from time to time, by some small wooded island or some inundated village. The rising of the stream had spread misery far and wide, for many Ostiak families had been obliged to abandon their huts, and to seek a refuge in the forests. Those who had horses and cows had the greatest difficulty to keep them alive; and as all the meadows were under water, and the autumn, with its night-frosts, was already approaching, there was scarcely any hope of making hay for the winter.

As Castrén proceeded on his journey, the low banks of the river rose above the waters, and appeared in all their wild and gloomy desolation. The number of inhabitants along the Obi is utterly insignificant when compared with the wide extent of the country; and as hunting and fishing are their chief occupations, nothing is done to subdue the wilderness. The weary eye sees but a dull succession of moors, willow bushes, dry heaths, and firs on the higher grounds. Near every flourishing tree stands another bearing the marks of decay. The young grass is hemmed in its growth by that of the previous year, which even in July gives the meadow a dull ash-gray color. Cranes, wild ducks, and geese are almost the only living creatures to be seen. From Siljarski to Surgut, a distance of 200 versts, there are but three Russian villages; and the Ostiaks, who form the main part of the population, generally live along the tributary rivers, or erect their summer huts on the smaller arms of the Obi, where they can make a better use of their very imperfect fishing implements than on the principal stream.

Surgut, once a fortress, and the chief town of the Cossack conquerors of Siberia, is now reduced to a few miserable huts, scattered among the ruins of repeated conflagrations.

Here Castrén remained till September 24, occupied with the study of the various dialects of the neighboring Ostiak tribes, and then ascended the Obi as far as Narym, a distance of 800 versts. Most of the fishermen had already retired from the banks of the river, and a death-like stillness, rarely interrupted by an Ostiak boat rapidly shooting through the stream, reigned over its waters.

Fortunately the weather was fine, at least during the first days of the journey; and the green river-banks, the birds singing in the trees, and the sunbeams glancing over the wide mirror of the Obi, somewhat enlivened the monotony of the scene.

After having enjoyed at Narym a remarkably mild Siberian winter, as no crows had been frozen to death, and having increased his knowledge of the Ostiak dialects, Castrén proceeded in the following spring, by way of Tomsk, to Krasnojarsk, on the Jenissei, where he arrived in April, 1846, and was welcomed in a most agreeable and unexpected manner. It will be remembered that during his stay at Ishemsk, in the tundra of the Samoïedes, he found warm-hearted friends and protectors against the insane bigotry of the Raskolniks in the Isprawnik and his young and amiable wife. Of the latter it might truly be said 
that she was like a flower born to blush unseen in the desert. Remarkably eloquent, she was no less talented in expressing her thoughts by writing; and yet she was only the daughter of a serf who had been exiled to Krasnojarsk, and had spent a great part of a small property, acquired by industry and economy, in the education of his gifted daughter. The Isprawnik, a young Pole of insinrating manners, having gained her affections, she had accompanied him to Ishemsk as his wife.

From what Castrén had told her three years since about his future plans, she knew that he would probably arrive about this time at Krasnojarsk, and had written a letter, which reached its destination only a few hours before him. It was to her father, earnestly begging him to pay every attention to the homeless stranger. The feelings of Castrén may easily be imagined when the old man knocked at his door, and brought him these friendly greetings from a distance of 6000 versts.*

But his stay at Krasnojarsk was not of iong duration, for he was impatient to proceed northward, for the purpose of becoming acquainted with the tribes dwelling along the Jenissei, after having studied their brethern of the Obi. From June till the end of July, his literary pursuits detained him at Turuchansk, where, in the vicinity of the Arctic Circle, he had much to suffer from the heat and the mosquitoes. In the beginning of August the signs of approaching winter made their appearance, the cold north wind swept away the leaves from the trees, the fishermen retired to the woods, and the ducks and geese prepared to migrate to the south. And now Castrén also took leave of Turuchansk-not however, like the birds, for a more sunny region, but to bury himself still deeper in the northern wilds of the Jenissei. Below Turuchansk the river begins to flow so languidly, that when the wind is contrary, the boat must be dragged along by dogs, and advances no more than from five to ten versts during a whole day. Thus the traveller has full time to notice the willows on the left bank, and the firs on the right; the ice-blocks, surviving memorials of the last winter, which the spring inundations have left here and there on the banks of the vast stream; and the countless troops of wild birds that fly with loud clamor over his head.

About 365 versts below Turuchansk is situated Plachina, the fishing-station of a small tribe of Samoïedes, among whom Castrén tarried three weeks. He had taken possession of the best of the three huts of which the place consisted, but even this would have been perfectly intolerable to any one but our zealous ethnologist. Into his study the daylight penetrated so sparingly through a small hole in the wall, that he was often obliged to write by the light of a resinous torch in the middle of the day.

The flame flickering in the wind, which blew through a thousand crevices, affected his eyes no less severely than the smoke, which at the same time rendered respiration difficult. Although the roof had been repaired, yet during every strong rain-and it rained almost perpetually-he was obliged to pack up his papers, and to protect himself from the wet as if he had been in the open air. From this delightful residence, Castrén, still pursuing his study of the Samoï-

* The verst is about three-fifths of a mile. 
ede dialects, proceeded down the river to Dudinka, and finally, in November, to Tolstoi Noss, whose pleasant climate may be judged of by the fact that it is situated in the latitude of $71^{\circ}$. This last voyage was performed in a "balok," or close sledge, covered with reindeer skins. The tediousness of being conveyed like a corpse in a dark and narrow box, induced him to exchange the "balok" for an open sledge ; but the freezing of his feet, of his fingers, and of part of his face, soon caused him to repent of his temerity. As soon as this accident was discovered at the next station, Castrén crept back again into his prison, and was heartily glad when, after a nine days' confinement, he at length arrived at Tolstoi Noss, which he found to consist of four wretched huts. Here again he spent several weeks studying by torchlight, for the sun had made his last appearance in November, and the day was reduced to a faint glimmering at noon. In January we find him on his return-voyage to Turuchansk, a place which, though not very charming in itself, appeared delightful to Castrén after a six months' residence in the tundras beyond the Arctic Circle.

Turuchansk can boast at least of seeing some daylight at all seasons of the year, and this may be enjoyed even within-doors, for Turuchansk possesses no less than four houses with glass windows. Longing to reach this comparatively sunny place, Castrén, against his usual custom, resolved to travel day and night without stopping, but his impatience well-nigh proved fatal to him. His Samo ede guide had not perceived in the dark that the waters of the Jenissei, over which they were travelling, had oozed through fissures in the ice, and inundated the surface of the river far and wide. Thus he drove into the water, which of course was rapidly congealing; the reindeer were unable to drag the sledge back again upon the land, and Castrén stuck fast on the river, with the agreeable prospect of being frozen to death. From this imminent danger he was rescued by a wonderful circumstance. Letters having arrived from the Imperial Academy of St. Petersburg, a courier had been dispatched from Turuchansk to convey them to Castrén. This courier fortunately reached him while he was in this perilous situation, helped him on land, and conducted him to a Samoïede hut, where he was able to warm his stiffened limbs.

After such a journey, we can not wonder that, on arriving at Turuchansk, he was so tormented with rheumatism and toothache as to be obliged to rest there several days. With sore joints and an aching body, he slowly proceeded to Jeniseisk, where he arrived on April 3, 1847, in a wretched state of health, which however had not interrupted his Ostiak studies on the way. I rapidly glance over his subsequent travels, as they are but a repetition of the same privations and the same hardships, all cheerfully sustained for the love of knowledge. Having somewhat recruited his strength at Jeniseisk, he crossed the Sajan Mountains to visit some Samoïedes beyond the Russian frontier-a journey which, besides the usual fatigues, involved the additional risk of being arrested as a spy by the Chinese authorities; and the year after he visited Transbaikalia, to make inquiries among the Buriat priests about the ancient history of Siberia.

Having thus accomplished his task, and thoroughly investigated the wild nations of the Finnish race from the confines of the Arctic Sea to the Altaï-a task 
which cost him his health, and the best part of his energies-he longed to breathe the air of his native country. But neither the pleasures of home, nor a professorship at the University of Helsingfors, richly earned by almost supernuman exertions, were able to arrest the germs of disease, which journeys such as these could scarcely fail to plant even in his originally robust constitution. After lingering some years, he died in 1855 , universally lamented by his countrymen, who justly mourned his early death as a national loss. 


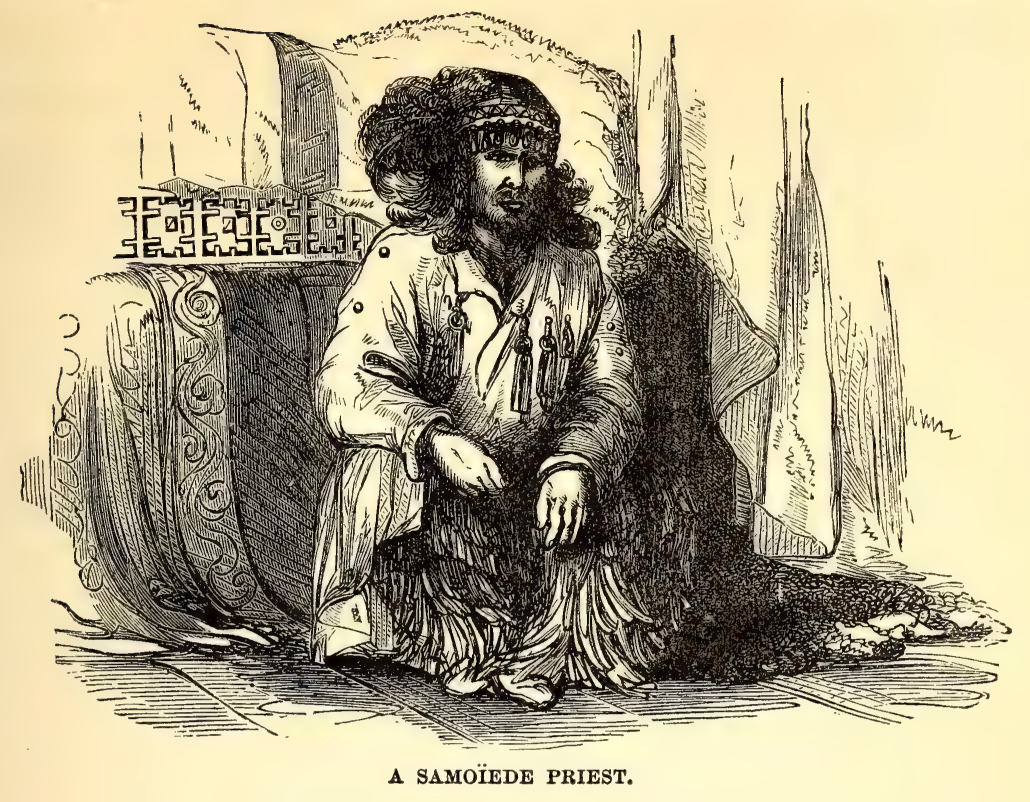

CHAPTER XIV.

THE SAMOÏEDES.

Their Barbàrism.-Num, or Jilibeambaertje.-Shamanism.-Samo"ede Idols.-Sjadæi.-Hahe.-The Tadebtsios, or Spirits. - The Tadibes, or Sorcerers.-Their Dress. - Their Invocations. - Their conjuring Tricks.-Reverence paid to the Dead._A Samoïede Oath.-Appearance of the Samoïedes.-Their Dress._A Samo:ede Belle._Character of the Samoïedes. - Their decreasing Numbers._Traditions of ancient Heroes.

THE Samoïedes, the neighbors of the Laplanders, are still farther removed 1 from civilized society, and plunged in even deeper barbarism. The wildest tundras and woods of Northern Russia and Western Siberia are the home of the Samoïede. With his reindeer herds he wanders over the naked wastes, from the eastern coast of the White Sea to the banks of the Chatanga, or hunts in the boundless forests between the Obi and the Jenissei. His intercourse with the Russians is confined to his annual visit at the fairs of such miserable settlements as Obdorsk and Pustosersk, where, far from improving by their company, he but too often becomes the prey of their avarice, and learns to know them merely as cheats and oppressors. Protestant missionaries have long since brought instruction to the Laplander's hut, but the majority of the less fortunate Samoiedes still adhere to the gross superstitions of their fathers. They believe in a Supreme Being-Num, or Jilibeambaertje-who resides in the air, and, like the Jupiter of old, sends down thunder and lightning, rain and snow; and as a proof that something of a poetic fancy is to be found even among the most savage nations, they call the rainbow "the hem of his garment." As this deity, however, is too far removed from them to leave them any hope of gain- 
ing his favor, they never think of offering him either prayer or sacrifice. But, besides Num, there are a great many inferior spirits, or idols, who directly interfere in human concerns-capricious beings, who allow themselves to be influenced by offerings, or yield to magical incantations; and to these, therefore, the Samoïede has recourse when he feels the necessity of invoking the aid or averting the wrath of a higher Power.

The chief of all Samoïede idols is in the island of Waygatz-a cold and melancholy Delos-where it was already found by old Barentz. This idol is a mere block of stone, with its head tapering to a point. It has thus been fashioned, not by a mortal artist, but by a play of nature. After this original the Samoiedes have formed many idols of stone or wood of various sizes, which they call "Sjadæi," from their possessing a human physiognomy ( $j j a)$. These idols they dress in reindeer skins, and ornament them with all sorts of colored rags. But a resemblance to the human form is not the necessary attribute of a Samoiede idol; any irregularly-shaped stone or tree may be thus distinguished. If the object is small, the savage carries it everywhere about with him, carefully wrapped up; if too cumbersome to be transported, it is reserved as a kind of national deity. As with the Ostiaks, each Samoïede tribe has in its train a peculiar sledge--the Hahengan-in which the household idols (or Hahe) are placed. One of these Penates protects the reindeer, another watches over the health of his worshippers, a third is the guardian of their connubial happiness, a fourth takes care to fill their nets with fish. Whenever his services are required, the Hahe is taken from his repository, and erected in the tent or on the pastureground, in the wood or on the river's bank. His mouth is then smeared with oil or blood, and a dish with fish or flesh is set before him, in the full expectation that his good offices will amply repay the savory repast. When his aid is no longer necessary, he is put aside without any further ceremony, and as little noticed as the Madonna of the Neapolitan fisherman after the storm has ceased.

The Hahe, or idols, are very convenient objects of reverence to the Samoïede, as he can consult them, or ask their assistance, without being initiated in the secrets of magic; while the Tadebtsios, or invisible spirits, which everywhere hover about in the air, and are more inclined to injure than to benefit man, can only be invoked by a Tadibe, or sorcerer, who, like the Cumæan Sibyl, works himself into a state of ecstatic frenzy. When his services are required, the first care of the Tadibe is to invest himself with his magical mantle-a kind of shirt made of reindeer leather, and hemmed with red cloth. The seams are covered in a similar manner, and the shoulders are decorated with epaulettes of the same gaudy material. A piece of red cloth veils the eyes and face-for the Tadibe requires no external organs of sight to penetrate into the world of spirits -and a plate of polished metal shines upon his breast.

Thus accoutred, the Tadibe seizes his magical drum, whose sounds summon the spirits to his will. Its form is round, it has but one bottom, made of reindeer skin, and is more or less decorated with brass rings and other ornaments, according to the wealth or poverty of its possessor. During the ceremony of invocation, the Tadibe is generally assisted by a disciple, more or less initiated 
in the magic art. They either sit down, or walk about in a circle. The chief sorcerer beats the drum, at first slowly, then with increasing violence, singing at the same time a few words to a mystic melody. The disciple immediately falls in, and both repeat the same monotonous chant.

At length the spirits appear, and the consultation is supposed to begin; the Tadibe from time to time remaining silent, as if listening to their answers, and but gently beating his drum, while the assistant continues to sing. Finally, this mute conversation ceases, the song changes into a wild howling, the drum is violently struck, the eye of the Tadibe glows with a strange fire, foam issues from his lips-when suddenly the uproar ceases, and the oracular sentence is pronounced. The Tadibes are consulted not only for the purpose of recovering a strange reindeer, or to preserve the herd from a contagious disorder, or to obtain success in fishing; the Samoïede, when a prey to illness, seeks no other medical advice; and the sorcerer's drum either scares away the malevolent spirits that cause the malady, or summons others to the assistance of his patient.

The office of Tadibe is generally hereditary, but individuals gifted by nature with excitable nerves and an ardent imagination not seldom desire to be initiated in these supernatural communications. No one can teach the candidate. His morbid fancy is worked upon by solitude, the contemplation of the gloomy aspect of nature, long vigils, fasts, the use of narcotics and stimulants, until he becomes persuaded that he too has seen the apparitions which he has heard of from his boyhood. He is then received as a Tadibe with many ceremonies, which are held in the silence of the night, and invested with the magic drum. Thus the Tadibe partly believes in the visions and fancies of his own overheated brain. Besides dealing with the invisible world, he does not neglect the usual arts of an expert conjuror, and knows by this means to increase his influence over his simple-minded countrymen. One of his commonest tricks is similar to that which has been practised with so much success by the Brothers Davenport. He sits down, with his hands and feet bound, on a reindeer skin stretched out upon the floor, and, the light being removed, begins to summon the ministering spirits to his aid. Strange unearthly noises now begin to be heardbears growl, snakes hiss, squirrels rustle about the hut. At length the tumult ceases, the audience anxiously awaits the end of the spectacle, when suddenly the Tadibe, freed from his bonds, steps into the hut-no one doubting that the spirits have set him free.

As barbarous as the poor wretches who submit to his guidance, the Tadibe is incapable of improving their moral condition, and has no wish to do so. Under various names--Schamans among the Tungusi, Angekoks among the Esquimaux, medicine-men among the Crees and Chepewyans, etc.-we find similar magicians or impostors assuming a spiritual dictatorship over all the Arctic nations of the Old and the New World, wherever their authority has not been broken by Christianity or Buddhism; and this dreary faith still extends its influence over at least half a million of souls, from the White Sea to the extremity of Asia, and from the Pacific to Hudson's Bay.

Like the Ostiaks and other Siberian tribes, the Samoïedes honor the memory of the dead by sacrifices and other ceremonies. They believe that their de- 
ceased friends have still the same wants, and pursue the same occupations, as when in the land of the living; and thus they place in or about their graves a sledge, a spear, a cooking-pot, a knife, an axe, etc., to assist them in procuring and preparing their food. At the funeral, and for several years afterwards, the relations sacrifice reindeer over the grave. When a person of note, a prince, a Starschina, the proprietor of numerous herds of reindeer, dies (for even among the miserable Samoïedes we find the social distinctions of rich and poor), the nearest relations make an image, which is placed in the tent of the deceased, and enjoys the respect paid to him during his lifetime. At every meal the image is placed in his former seat, and every evening it is undressed and laid down in his bed. During three years the image is thus honored, and then buried; for by this time the body is supposed to be decayed, and to have lost all sensation of the past. The souls of the Tadibes, and of those who have died a violent death, alone enjoy the privilege of immortality, and after their terrestrial life hover about in the air as unsubstantial spirits.

Yet in spite of this privilege, and of the savory morsels that fall to their share at every sacrificial feast, or of the presents received for their services, the Tadibes are very unhappy beings. The ecstatic condition into which they so frequently work themselves shatters their nerves and darkens their mind. Wild looks, bloodshot eyes, an uncertain gait, and a shy manner, are among the effects of this periodical excitement.

Like the Ostiaks, the Samoïedes consider the taking of an oath as an action of the highest religious importance. When a crime has been secretly committed against a Samoïede, he has the right to demand an oath from the suspected person.

If no wooden or stone Hahe is at hand, he manufactures one of earth or snow, leads his opponent to the image, sacrifices a dog, breaks the image, and then addresses him with the following words:- "If thou hast committed this crime, then must thou perish like this dog." The ill consequences of perjury are so much dreaded by the Samoïdes-who, though they have but very faint ideas of a future state, firmly believe that crime will be punished in this life, murder with violent death, or robbery by losses of reindeer-that the true criminal, when called upon to swear, hardly ever submits to the ceremony, but rather at once confesses his guilt and pays the penalty.

The most effectual security for an oath is that it should be solemnized over the snout of a bear-an animal which is highly revered by all the Siberian tribes, from the Kamchatkans to the Samoïedes, as well as by the Laplanders. Like the Laplanders, they believe that the bear conceals under his shaggy coat a human shape with more than human wisdom, and speak of him in terms of the highest reverence. Like the Lapps also, when occasion offers, they will drive an arrow or a bullet through his skin; but they preface the attack with so many compliments that they feel sure of disarming his anger.

The appearance of the Samoïedes is as wild as the country which they inhabit. The dwarfish stature of the Ostiak, or the Lapp, thick lips, small eyes, a low forehead, a broad nose so much flattened that the end is nearly upon a level with the bone of the upper jaw (which is strong and greatly elevated), 
raven-black shaggy hair, a thin beard, and a yellow-brown complexion, are their characteristic features, and in general they do nothing to improve a form which has but little natural beauty to boast of. The Samoiede is satisfied if his heavy reindeer dress affords him protection against the cold and rain, and cares little if it be dirty or ill-cut; some dandies, however, wear furs trimmed with cloth of a gaudy color. The women, as long as they are unmarried, take some pains with their persons; and when a Samoïede girl, with her small and lively black eyes, appears in her reindeer jacket tightly fitting round the waist, and trimmed with dog-skin, in her scarlet moccasins, and her long black tresses ornamented with pieces of brass or tin, she may well tempt some rich admirer to offer a whole herd of reindeer for her hand. For among the Samoïedes no father ever thinks of bestowing a portion on his daughter: on the contrary, he expects from the bridegroom an equivalent for the services which he is about to lose by her marriage. The consequence of this degrading custom is that the husband treats his consort like a slave, or as an inferior being. A Samoïede, who had murdered his wife, was quite surprised at being summoned before a court of justice for what he considered a trifling offense; "he had honestly paid for her," he said, "and could surely do what he liked with his own."

The senses and faculties of the Samoïedes correspond to their mode of life as nomads and hunters. They have a piercing eye, delicate hearing, and a steady hand: they shoot an arrow with great accuracy, and are swift runners. On the other hand, they have a gross taste, generally consuming their fish or their reindeer flesh raw ; and their smell is so weak that they appear quite insensible to the putrefying odors arising from the scrapings of skins, stinking fish, and other offal which is allowed to accumulate in and about their huts.

The Samoïede is good-natured, melancholy, and phlegmatic. He has, indeed, but indistinct notions of right and wrong, of good and evil ; but he possesses a grateful heart, and is ready to divide his last morsel with his friend. Cruelty, revenge, the darker crimes that pollute so many of the savage tribes of the tropical zone, are foreign to his character. Constantly at war with a dreadful climate; a prey to ignorance and poverty, he regards most of the things of this life with supreme indifference. A good meal is of course a matter of importance in his eyes; but even the want of a meal he will bear with stoical apathy, when it can only be gained by exertion, for he sets a still higher value on repose and sleep.

A common trait in the character of all Samoïedes is the gloomy view which they take of iife and its concerns; their internal world is as cheerless as that which surrounds them. True men of ice and snow, they relinquish, without a murmur, a life which they can hardly love, as it imposes upon them many privations, and affords them but few pleasures in return.

They are suspicious, like all oppressed nations that have much to suffer from their more crafty or energetic neighbors. Obstinately attached to their old customs, they are opposed to all innovations; and they have been so often deceived by the Russians, that they may well be pardoned if they look with a mistrustful eye upon all benefits coming from that source.

The wealth of the Samoïedes consists in the possession of herds of reindeer, 
and P. von Krusenstern, in 1845, calculated the number owned by the Samo. iedes of the Lower Petschora, near Pustosersk, at 40,000 head-a much smaller number than what they formerly had, owing to a succession of misfortunes. The Russian settlers along that immense stream and its tributaries gradually obtain possession of their best pasture-grounds, and force them to recede within narrower and narrower limits. Thus many have been reduced to the wretched condition of the Arctic fisherman, or have been compelled to exchange their ancient independence for a life of submission to the will of an imperious master.

The entire number of the European and Asiatic Samoïedes is estimated at no more than about 10,000 , and this number, small as it is when compared to the vast territory over which they roam, is still decreasing from year to year. Before their subjugation by the Russians, the Samoïedes were frequently at war with their neighbors, the Ostiaks, the Woguls, and the Tartars, and the rude poems which celebrate the deeds of the heroes of old are still sung in the tents of their peaceful descendants. The minstrel, or trowbadour-if I may be allowed to use these names while speaking of the rudest of mankind-is seated in the centre of the hut, while the audience squat around. His gesticulations endeavor to express his sympathy with his hero. His body trembles, his voice quivers, and during the more pathetic parts of his story, tears start to his eyes, and he covers his face with his left hand, while the right, holding an arrow, directs its point to the ground. The audience generally keep silence, but their groans accompany the hero's death; or when he soars upon an eagle to the clouds, and thus escapes the malice of his enemies, they express their delight by a triumphant shout. 


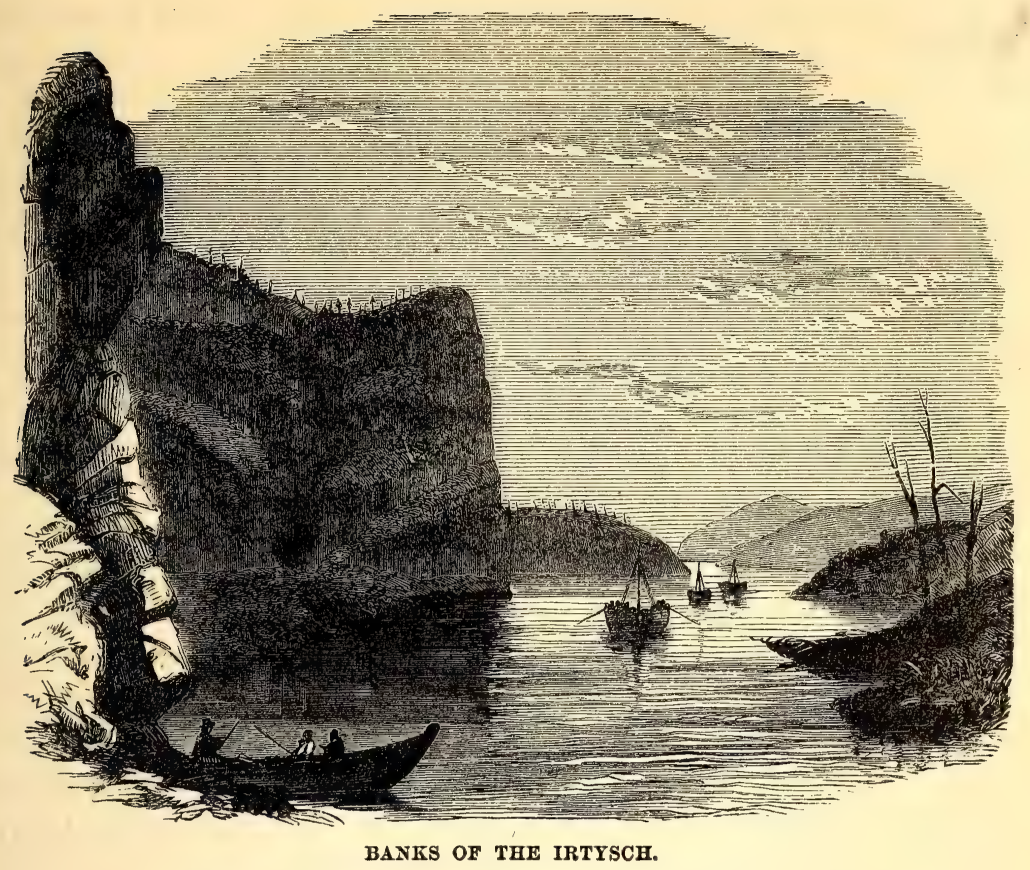

\section{CHAPTER XV.}

\section{THE OSTIAKS.}

What is the Obi?-Inundations.-An Ostiak summer Yourt.-Poverty of the Ostiak Fishermen.-A winter Yourt.-Attachment of the Ostiaks to their ancient Customs.-An Ostiak Prince.-Archery. -Appearance and Character of the Ostiaks.-The Fair of Obdorsk.

WHAT is the Obi?- "One of the most melancholy rivers on earth," say the few European travellers who have ever seen it roll its turbid waters through the wilderness, "its monotonous banks a dreary succession of swamps and dismal pine-forests, and hardly a living creature to be seen, but cranes, wild ducks, and geese." If you address the same question to one of the few Russians who have settled on its banks, he answers, with a devout mien, "Obi is our mother ;" but if you ask the Ostiak, he bursts forth, in a laconic but energetic phrase, "Obi is the god whom we honor above all our other gods."

To him the Obi is a source of life. With its salmon and sturgeon he pays his taxes and debts, and buys his few luxuries; while the fishes of inferior quality which get entangled in his net he keeps for his own consumption and that of his faithful dog, eating them mostly raw, so that the perch not seldom feels his teeth as soon as it is pulled out of the water. In spring, when the Obi and its tributaries burst their bonds of ice, and the floods sweep over the plains, the Ostiak is frequently driven into the woods, where he finds but little to appease his hunger; at length, however, the waters subside, the flat banks 
of the river appear above their surface, and the savage erects his summer hut close to its stream. This hovel has generally a quadrangular form, low walls, and a high pointed roof, made of willow-branches covered with large pieces of bark. These, having first been softened by boiling, are sewn together, so as to form large mats or carpets, easily rolled up and transported. The hearth, a mere hole inclosed by a few stones, is in the centre, and the smoke escapes through an aperture at the top. Close to the hut there is also, generally, a small store-house erected on high poles, as in Lapland ; for the provisions must be secured against the attacks of the glutton, the wolf, or the owner's dogs.

Although the Obi and its tributaries-the Irtysch, the Wach, the Wasjugan-abundantly provide for the wants of the Ostiaks, yet those who are exclusively fishermen vegetate in a state of the greatest poverty, in indolence, drunkenness, and vice. The wily Russian settlers have got them completely in their power, by advancing them goods on credit, and thus securing the produce of their fisheries from year to year. During the whole summer Russian speculators from Obdorsk, Beresow, and Tobolsk sail about on the Obi, to receive from their Ostiak debtors the salmon and stargeon which they have caught, or to fish on their own account, which, as having better nets and more assistance, they do with much greater success than the poor savages.

The Russian Government has, indeed, confirmed the Ostiaks in the possession of almost all the land and water in the territories of the Lower Obi and Irtysch, but the Russian traders find means to monopolize the best part of the fisheries; for ignorance and stupidity, in spite of all laws in their favor, are nowhere a match for mercantile cunning.

At the beginning of winter the Ostiaks retire into the woods, where they find at least some protection against the Arctic blasts, and are busy hunting the sable or the squirrel; but as fishing affords them at all times their chief food, they take care to establish their winter huts on some eminence above the reach of the spring inundations, near some small river, which, through holes made in the ice, affords their nets and anglers a precarious supply. Their winter yourt is somewhat more solidly constructed than their summer residence, as it is not removed every year. It is low and small, and its walls are plastered with clay. Light is admitted through a piece of ice inserted in the wall or on the roof. In the better sort of huts, the space along one or several of the walls is hung with mats made of sedges, and here the family sits or sleeps. Sometimes a small antechamber serves to hang up the clothes, or is used as a repository for household utensils. Besides those who live solely upon fishes and birds of passage, there are other Ostiaks who possess reindeer herds, and wander in summer to the border of the Polar sea, where they also catch seals and fish. When winter approaches, they slowly return to the woods. Finally, in the more southerly districts, there are some Ostiaks who, having entirely adopted the Russian mode of life, cultivate the soil, keep cattle, or earn their livelihood as carriers.

In general, however, the Ostiak, like the Samoïede, obstinately withstands all innovations, and remains true to the customs of his forefathers. He has been so often deceived by the Russians that he is loth to receive the gifts of 
civilization from their hands. He fears that if his children learn to read and write, they will no longer be satisfied to live like their parents, and that the school will deprive him of the support of his age. He is no less obstinately attached to the religion of his fathers, which in all essential points is identical with that of the Samoïedes. In some of the southern districts, along the Irtysch, at Surgut, he has indeed been baptized, and hangs up the image of a saint in his hut, as his Russian pope or priest has instructed him to do; but his Christianity extends no farther. Along the tributaries of the Obi, and below Obdorsk, he is still plunged in Schamanism.

Like the Samoïedes, the Ostiaks, whose entire number amounts to about 25,000, are subdivided into tribes, reminding one of the Highland clans. Each tribe consists of a number of families, of a common descent, and sometimes comprising many hundred individuals, who, however distantly related, consider it a duty to assist each other in distress. The fortunate fisherman divides the spoils of the day with his less fortunate clansman, who hardly thanks him for a gift which he considers as his due. In cases of dispute the Starschina, or elder, acts as a judge; if, however, the parties are not satisfied with his verdict, they appeal to the higher authority of the hereditary chieftain or prince-a title which has been conferred by the Empress Catherine II. on the Ostiak magnates, who, from time immemorial, have been considered as the heads of their tribes. These princes are, of course, subordinate to the Russian officials, and bound to appear, with the Starschinas, at the fairs of Beresow or Obdorsk, as they are answerable for the quantity and quality of the various sorts of furs which the Ostiaks are obliged to pay as a tribute to Government. Their dignity is hereditary, and, in default of male descendants, passes to the nearest male relation. It must, however, not be supposed that these princes are distinguished from the other Ostiaks by their riches or a more splendid appearance ; for their mode of life differs in no way from that of their inferiors in rank, and, like them, they are obliged to fish or to hunt for their daily subsistence.

On entering the hut of one of these dignitaries, Castrén found him in a ragged jacket, while the princess had no other robe of state but a shirt. The prince, having liberally helped himself from the brandy-bottle which the traveller offered him, became very communicative, and complained of the sufferings and cares of the past winter. He had exerted himself to the utmost, but without success. Far from giving way to indolence in his turf-hut, he had been out hunting in the forest, after the first snow-fall, but rarely pitching his barktent, and frequently sleeping in the open air. Yet, in spite of all his exertions, he had often not been able to shoot a single ptarmigan. His stores of meal and frozen fishes were soon exhausted, and sometimes the princely family had been reduced to eat the flesh of wolves.

The Ostiaks are excellent archers, and, like all the other hunting tribes of Siberia, use variously constructed arrows for the different objects of their chase. Smaller shafts, with a knob of wood at the end, are destined for the squirrels and other small animals whose fur it is desirable not to injure; while large arrows, with strong triangular iron points, bring down the wolf, the bear, and 
sometimes the fugitive exile. For, to prevent the escape of criminals sentenced to banishment in Siberia, the Russian Government allows the Ostiaks to shoot any unknown person, not belonging to their race, whom they may meet with on their territory. Although well aware of this danger, several exiles have attempted to escape to Archangel along the border of the Arctic sea; but they either died of hunger, or were devoured by wild beasts, or shot by the Ostiaks. There is but one instance known of an exile who, after spending a whole year on the journey, at length reached the abodes of civilized man, and he was pardoned in consideration of the dreadful sufferings he had undergone.

The Ostiaks are generally of a small stature, and most of them are dark-complexioned, with raven-black hair like the Samoïedes; some of them, however, have a fairer skin and light-colored hair. They have neither the oblique eyes nor the broad projecting cheek-bones of the Mongols and Tungus, but bear a greater resemblance to the Finnish, Samoïede, and Turkish cast of countenance. They are a good-natured, indolent, honest race; and though they are extremely dirty, yet their smoky huts are not more filthy than those of the Norwegian or Icelandic fisherman. As among the Samoïedes, the women are in a very degraded condition, the father always giving his daughter in marriage to the highest bidder. The price is very different, and rises or falls according to the circumstances of the parent; for while the rich man asks fifty reindeer for his child, the poor fisherman is glad to part with his daughter for a few squirrelskins and dried sturgeon.

Before taking leave of the Ostiaks, we will still tarry a moment at the small town of Obdorsk, which may be considered as the capital of their country, and entirely owes its existence to the trade carried on between them and the Russians. Formerly the merchants from Beresow and Tobolsk used merely to visit the spot, but the difficulties of the journey soon compelled them to establish permanent dwellings in that dreary region. A certain number of exiles serves to increase the scanty population, which consists of a strange inedley of various nations, among whom Castrén found a Calmuck, a Kirghis, and a Polish cook,

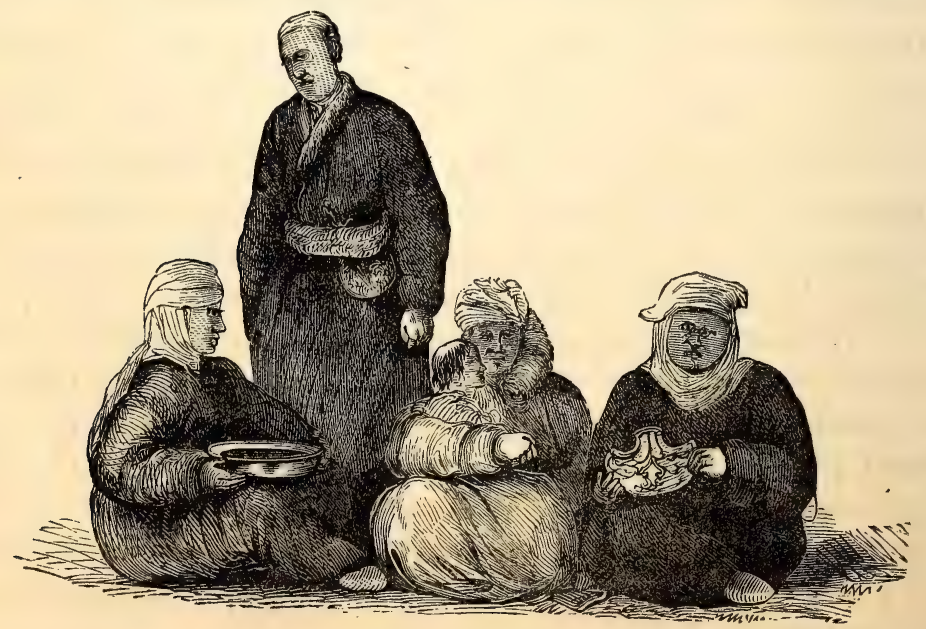

GROUP OF KIRGHIS. 
who bitterly complained that he had but few opportunities of showing his skill in a town where people lived $a$ la Ostiak. In fact, most of the Russian inhabitants of the place have in so far adopted the Ostiak mode of life, as to deem the cooking of their victuals superfluous. When Castrén, on his arrival at Obdorsk, paid a visit to a Tobolsk merchant, who had been for some time settled in the place, he found the whole family lying on the floor, regaling on raw fish, and the most civilized person he met with told him that he had tasted neither boiled nor roast flesh or fish for half a year. Yet fine shawls and dresses, and now no doubt the crinoline and the chignon, are found amidst all this barbarism. Edifices with the least pretensions to architectural beauty it would of course be vain to look for in Obdorsk. The houses of the better sort of Russian settlers are two-storied, or consisting of a ground-floor and garrets; but as they are built of wood, and are by no means wind-tight, the half-famished Ostiaks, who have settled in the town, are probably more comfortably housed in their low turf-huts than the prosperous Russian inhabitants of the place. The latter make it their chief occupation to cheat the Ostiaks in every possible way; some of them, however, add to this profitable, if not praiseworthy occupation, the keeping of reindeer herds, or even of cows and sheep.

The fair lasts from the beginning of winter to February, and during this time the Ostiaks who assemble at Obdorsk pitch their oark-tents about the town. With their arrival a new life begins to stir in the wretched place. Groups of the wild sons and daughters of the tundra, clothed in heavy skins, make their appearance, and stroll slowly through the streets, admiring the high wooden houses, which to them seem palaces. But nothing is to be seen of the animation and activity which usually characterize a fair. Concealing some costly fur under his wide skin mantle, the savage pays his cautious visit to the trader, and makes his bargain amidst copious libations of brandy. He is well aware that this underhand way of dealing is detrimental to his interests ; that his timorous disposition shrinks from public sales, and frequently he is not even in the situation to profit by competition; for among the thousands that flock to the fair, there are but very few who do not owe to the traders of Obdorsk much more than they possess, or can ever hope to repay. Woe to the poor Ostiak whose creditor should find him dealing with some other trader!--for the seizure of all his movable property, of his tent and household utensils, would be the least punishment which the wretch turned adrift into the naked desert would have to expect. The fair is not opened before Government has received the furs which are due to it, or at least a guarantee for the amount from the merchants of the place. Then the magazines of the traders gradually fill with furs -with clothes of reindeer skin ready made, with feathers, reindeer flesh, frozen sturgeon, mammoth tusks, etc. For these goods the Ostiaks receive flour, baked bread, tobacco, pots, kettles, knives, needles, brass buttons and rings, glass pearls, and other trifling articles. An open trade in spirits is not allowed; but brandy may be sold as a medicine, and thus many an Ostiak takes advantage of the fair for undergoing a cure the reverse of that which is recommended by hydropathic doctors. 
Towards the end of February, when the Ostiaks have retired into the woods - where they hunt or tend their reindeer herds until the opening of the fishingseason recalls them to the Obi-the trader prepares for his journey to Irbit, where he hopes to dispose of his furs at an enormous profit, and Obdorsk is once more left until the following winter to its death-like solitude. 


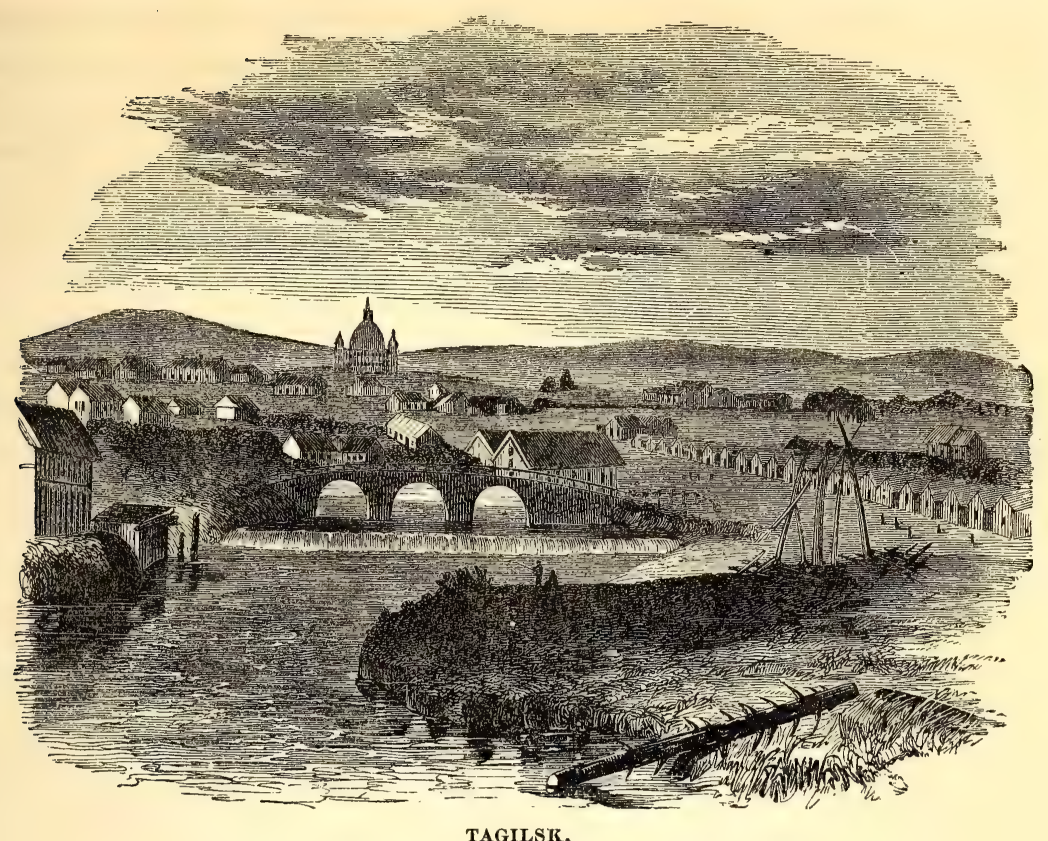

CHAPTER XVI.

- CONQUEST OF SIBERIA BY THE RUSSIANS-THEIR VOYAGES OF DISCOVERY ALONG THE SHORES OF THE POLAR SEA.

Ivan the Terrible.-Strogonoff.-Yermak, the Robber and Conqueror.-His Expeditions to Siberia.-. Battle of Tobolsk.-Yermak's Death._Progress of the Russians to Ochotsk.-Semen Deshnew.Condition of the Siberian Natives under the Russian Yoke.-Vovages of Discovery in the Reign of the Einpress Anna.-Prontschischtschew.-Chariton and Demetrius Laptew.-An Arctic Heroine. -Schalaurow.-Discoveries in the Sea of Bering and in the Pacific Ocean. - The Lächow Islands.-Fossil Ivory.-New Siberia.-The wouden Mountains.-The past Ages of Siberia.

$\mathrm{T}$ the beginning of the thirteenth century, the now huge Empire of Russia was confined to part of her present European possessions, and divided into several independent principalities, the scene of disunion and almost perpetual warfare. Thus when the country was invaded, in 1236, by the Tartars, under Baaty Khan, a grandson of the famous Gengis Khan, it fell an easy prey to its conquerors. The miseries of a foreign yoke, aggravated by intestine discord, lasted about 250 years, until Ivan Wasiljewitsch I. (1462-1505) became the deliverer of his country and laid the foundations of her future greatness. This able prince subdued, in 1470, the Great Novgorod, a city until then so powerfui as to have maintained its independence, both against the Russian grand princes and the Tartar khans; and, ten years later, he not only threw off the yoke of the Khans of Khipsack, but destroyed their empire. The conquest of Constantinople by the Turks placed the spiritual diadem of the ancient Cæsars on his 
head, and cansed him, as chief of the Greek orthodox Church, to exchange his old title of Grand Prince for the more significant and imposing one of Czar.

His grandson, Ivan Wasiljewitsch II., a cruel but energetic monarch, conquered Kasan in 1552, and thus completely and permanently overthrew the dominion of the Tartars. Two years later he subdued Astrakhan, and plinted the Greek cross on the borders of the Caspian Sea, where until then only the Crescent had been seen.

In spite of the inhuman cruelty that disgraced his character, and earned for him the name of Terrible, Ivan sought, like his illustrious successor, Peter the Great, to introduce the arts and sciences of Western Europe into his barbarous realm, and to improve the Russian manufactures by encouraging German artists and mechanics to settle in the country. It was in his reign that Chancellor discovered the passage from England to the White Sea, and Ivan gladly seized the opportunity thus afforded. Soon after this the port of Archangel was built, and thus a new seat was opened to civilization at the northern extremity of Europe.

After the conquest of Kasan, several Russians settled in that province; among others, a merchant of the name of Strogonoff, who established some salt-works on the banks of the Kama, and opened a trade with the natives. Among these he noticed some strangers, and having heard that they came from a councry ruled by a Tartar Khan, who resided in a capital called Sibir, he sent some of his people into their land. These agents returned with the finest sable skins, which they had purchased for a trifling sum ; and Strogonoff, not so covetous as to wish to keep all the advantage of his discovery to himself, immediately informed the Government of the new trade he had opened. He was rewarded with the gift of considerable estates at the confluence of the Kama and Tschinsova, and his descendants, the Counts Strogonoff, are, as is well known, reckoned among the richest of the Russian nobility.

Soon after Ivan sent some troops to Siberia, whose prince, Jediger, acknowledged his supremacy, and promised to pay him an annual tribute of a thousand sable skins. But this connection was not of long duration, for a few years after Jediger was defeated by another Tartar prince, named Kutchum Khan; and thus, after Russian influence had taken the first step to establish itself beyond the Ural, it once more became doubtful whether Northern Asia was to be Christian or Mohammedan. The question was soon after decided by a fugitive robber.

The conquests of Ivan on the Caspian Sea had called into life a considerable trade with Bokhara and Persia, which, however, was greatly disturbed by the depredations of the Don Cossacks, who made it their practice to plunder the caravans. But Ivan, not the man to be trifled with by a horde of freebooters, immediately sent out a body of troops against the Don Cossacks, who, not venturing to meet them, sought their safety in flight. At the head of the fugitives, whose number amounted to no less than 6000 men, was Yermak Timodajeff, a man who, like Cortez or Pizarro, was destined to lay a new empire at the feet of his master. But while the troops of the Czar were following his track, Yermak was not yet dreaming of future conquests; his only aim was to escape the executioner; and he considered himself extremely fortunate when, leaving his 
pursuers far behind, he at length arrived on the estates of Strogonoff. Here he was well received-better, no doubt, than if he had come single-handed and defenseless; and Strogonoff having made him acquainted with Siberian affairs, he at once resolved to try his fortunes on this new scene of action. As the tyranny of Kutchum Khan had rendered him odious to his subjects, he hoped it would be an easy task to overthrow his power; the prospect of a rich booty of sable skins was also extremely attractive; and, finally, there could be no doubt that the greatest dangers were in his rear, and that any choice was better than to fall into the hands of Ivan the Terrible. Strogonoff, on his part, had excellent reasons for encouraging the adventure. If it succeeded, a considerablo part of the profits was likely to fall to his share; if not, he at least was rid of his unbidden guest.

Thus Yermak, in the summer of 1578, advanced with his Cossacks along the banks of the Tschinsova into Siberia. But, either from a want of knowledge of the country, or from not having taken the necessary precautions, he was overtaken by winter before he could make any progress; and when spring appeared, famine compelled him to return to his old quarters, where, as may easily be imagined, his reception was none of the most cordial. But, far from losing courage from this first disappointment, Yermak was firmly resolved to persevere. He had gained experience-his self-confidence was steeled by adversity; and when Strogonoff attempted to refuse him further assistance, he pointed to his Cossacks with the air of a man who has the means of enforcing obedience to his orders. This time Yermak took better measures for insuring success; he compelled Strogonoff to furnish him with an ample supply of provisions and ammunition, and in the June of the following year we again find him, with his faithful Cossacks, on the march to Siberia. But such were the impediments which the pathless swamps and forests, the severity of the climate, and the hostility of the natives opposed to his progress, that towards the end of 1580 his force (now reduced to 1500 men) had reached no farther than the banks of the Tara. The subsequent advance of this little band was a constant succession of hardships and skirmishes, which caused it to melt away like snow in the sunshine; so that scarcely 500 remained when, at the confluence of the Tobol and the Irtysch, they at length reached the camp of Kutchum Khan, whose overwhelming numbers seemed to mock their audacity.

But Yermak felt as little fear at sight of the innumerable tents of the Tartar host, as the wolf when meeting a herd of sheep. He knew that his Cossacks, armed with their matchlocks, had long since disdained to count their enemies, and, fully determined to conquer or to die, he gave the order to attack. A dreadful battle ensued, for though the Tartars only fought with their bows and arrows, yet they were no less brave than their adversaries, and their vast superiority of numbers made up for the inferior quality of their weapons. The struggle was long doubtful-the Tartars repeating attack upon attack like the waves of a storm-tide, and the Cossacks receiving their assaults as firmly and immovably as rocks; until, finally, the hordes of Kutchum Khan gave way to their stubborn obstinacy, and his camp and all its treasures fell into the hands of the conquerors. 
The subsequent conduct of Yermak proved that he had all the qualities of a general and a statesman, and that his talents were not unequal to his fortunes. Without losing a single moment, he, immediately after this decisive battle, sent part of his small band to occupy the capital of the vanquished Kutchum, for he well knew that a victory is but half gained if one delays to reap its fruits. The Cossacks found the place evacuated, and soon after Yermak made his triumphal entry into Sibir. His weakness now became a source of strength, for, daunted by the wonderful success of this handful of strangers, the people far and wide came to render him homage. The Ostiaks of the Soswa freely consented to yield an annual tribute of 280 sable skins, and other tribes of the same nation, who were more backward in their submission, were compelled by his menaces to pay him a tax, or jassak, of eleven skins for every archer.

It was not without reason that Yermak thus sought to collect as many of these valuable furs as he possibly could, for his aim was to obtain from Ivan a pardon of his former delinquencies, by presenting him with the richest spoils of his victories, and he well knew that it would be impossible for him to maintain his conquests without further assistance from the Czar. Great was Ivan's astonishment when an envoy of the fugitive robber brought him the welcome gift of 2400 sable skins, and informed him that Yermak had added a new province to his realm. He at once comprehended that the hero who with small means had achieved such great successes, was the fittest man to consolidate or enlarge his acquisitions; he consequently not only pardoned all his former offenses, but confirmed him in the dignity of governor and commander-in-chief in the countries which he had subdued. Thus Yermak's envoy, having been received with the greatest distinction at Moscow, returned to his fortunate master with a robe of honor which had been worn by the Czar himself, and the still more welcome intelligence that re-enforcements were on the march to join him.

Meanwhile Yermak had continued to advance into the valley of the Obi beyond its confluence with the Irtysch; and when at length his force was augmented by the arrival of 500 Russians, he pursued his expeditions with increasing audacity. On his return from one of these forays, he encamped on a small island in the Irtysch. The night was dark and rainy, and the Russians, fatigued by their march, relied too much upon the badness of the weather or the terror of their name. But Kutchum Khan, having been informed by his spies of their want of vigilance, crossed a ford in the river, and falling upon the unsuspecting Russians, killed them all except one single soldier, who brought the fatal intelligence to Sibir. Yermak, when he saw his warriors fall around him like grass before the scythe, without losing his presence of mind for a moment, cut his way through the Tartars, and endeavored to save himself in a boat. But in the medley he fell into the water and was drowned.

By the orders of Kutchum, the body of the hero was exposed to every indignity which the rage of a barbarian can think of; but after this first explosion of impotent fury, his followers, feeling ashamed of the ignoble conduct of their chief, buried his remains with princely pomp, and ascribed miraculous powers to the grave in which they were deposited. The Russians have also erected a 
monument to Yermak in the town of Tobolsk, which was built on the very spot where he gained his first decisive victory over Kutchum. It is inscribed with the dates of that memorable event, and of the unfortunate day when he found his death in the floods of the Irtysch. His real monument, however, is all Siberia from the Ural to the Pacific; for as long as the Russian nation continues to exist, it will remember the name of Yermak Timodajeff. The value of the man became at once apparent after his death, for scarcely had the news of the disaster arrived, when the Russians immediately evacuated Sibir, and left the country. But they well knew that this retreat was to be but temporary, and that the present ebb of their fortunes would soon be followed by a fresh tide of success. After a few years they once more returned, as the definitive masters of the country. Their first settlement was Tjumen, on the Tara, and before the end of 1587 Tobolsk was founded. They had, indeed, still many a conflict with the Woguls and Tartars, but every effort of the natives to shake off the yoke proved fruitless.

As gold had been the all-powerful magnet which led the Spaniards from Hispaniola to Mexico and Peru, so a small fur-bearing animal (the sable) attracted the Cossacks farther and farther to the east; and although the possession of fire-arms gave them an immense advantage over the wild inhabitants of Siberia, yet it is as astonishing with what trifling means they subdued whole nations, and perhaps history affords no other example of such a vast extent of territory having been conquered by so small a number of adventurers.

As they advanced, small wooden forts (or ostrogs) were built in suitable places, and became in their turn the starting-posts for new expeditions. The following dates give the best proof of the uncommon rapidity with which the tide of conquest rolled onward to the east. Tomsk was founded in 1604; and the ostrog Jeniseisk, where the neighboring nomads brought their sable skins to market, in 1621. The snow-shoes of the Tunguse, which they sometimes saw ornamented with this costly fur, induced the Cossacks to follow their hordes, of which many had come from the middle and inferior Tunguska, and thus, in 1630, Wassiljew reached the banks of the Lena. In 1636 Jelissei Busa was commissioned to ascend that mighty river, and to impose jassak on all the natives of those quarters. He reached the western mouth of the Lena, and after navigating the sea for twenty-four hours came to the Olekma, which he ascended. In 1638 he discovered the Tana, on whose banks he spent another winter; and in 1639, resuming his voyage eastward by sea, he reached the Tchendoma, and wintering for two years among the Jukahirs, made them also tributary to Russia.

In that same year another party of Cossacks crossed the Altai Mountains, and, traversing forests and swamps, arrived at the coasts of the inhospitable Sea of Ochotsk; while a third expedition discovered the Amoor, and built a strong ostrog, called Albasin, on its left bank. The report soon spread that the river rolled over gold-sand, and colonists came flocking to the spot, both to collect these treasures, and to enjoy the fruits of a milder climate and of a more fruitful soil. But the Chinese destroyed the fort in 1680, and carried the garrison prisoners to Peking. 
Albasin was soon after rebuilt; but as Russia at that time had no inclination to engage in constant quarrels with the Celestial Empire about the possession of a remote desert, all its pretensions to the Amoor were given up by the treaty of Nertschinsk (1689). This agreement, however, like so many others, was doomed to last no longer than it pleased the more powerful of the contracting parties to keep it, and came to nothing as soon as the possession of the Amoor territory became an object of importance, and the increasing weakness of China was no longer able to dispute its possession. Thus, when Count Nicholas Mourawieff was appointed Governor-general of Eastern Siberia in 1847, one of his first cares was to appropriate or annex the Amoor. He immediately sent a surveying expedition to the mouth of the river, where, in 1851, regardless of the remonstrances of the Chinese Government, he ordered the sta-

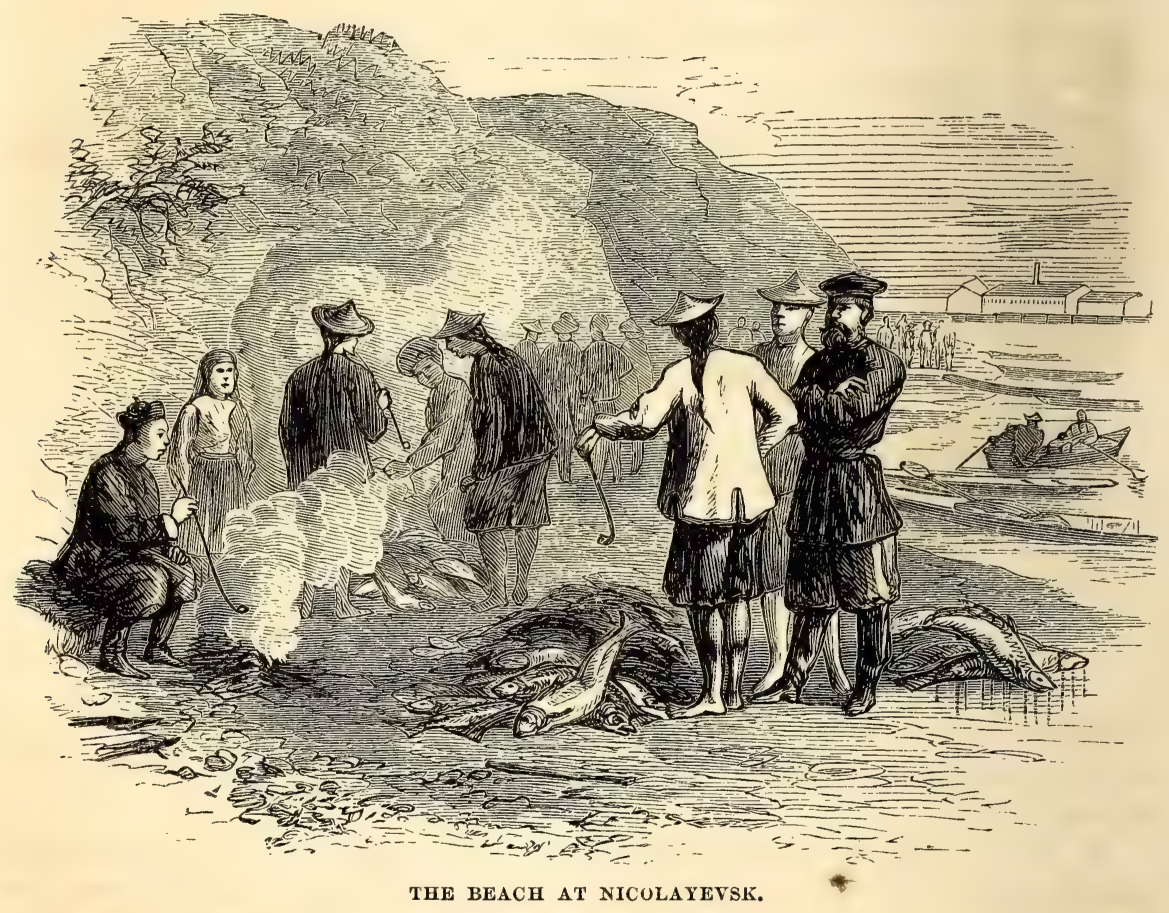

tions of Nicolayevsk and Mariinsk to be built; and in 1854 he himself sailed down the Amoor, with a numerous flotilla of boats and rafts, for the purpose of personally opening this new channel of intercourse with the Pacific. Other expeditions soon followed, and the Chinese, finding resistance hopeless, ceded to Russia in the year 1858, by the treaty of Aigun, the left bank of the Amoor as far as the influx of the Ussuri, and both its banks below the latter river. Thus the Czar found some consolation for the losses of the Crimean campaign in the acquisition of a vast territory in the distant East, which, though at present a mere wilderness, may in time become a flourishing colony.

In 1644, a few years after the discovery of the Amoor, the Cossack Michael Staduchin formed a winter establishment on the delta of the Kolyma, which has 


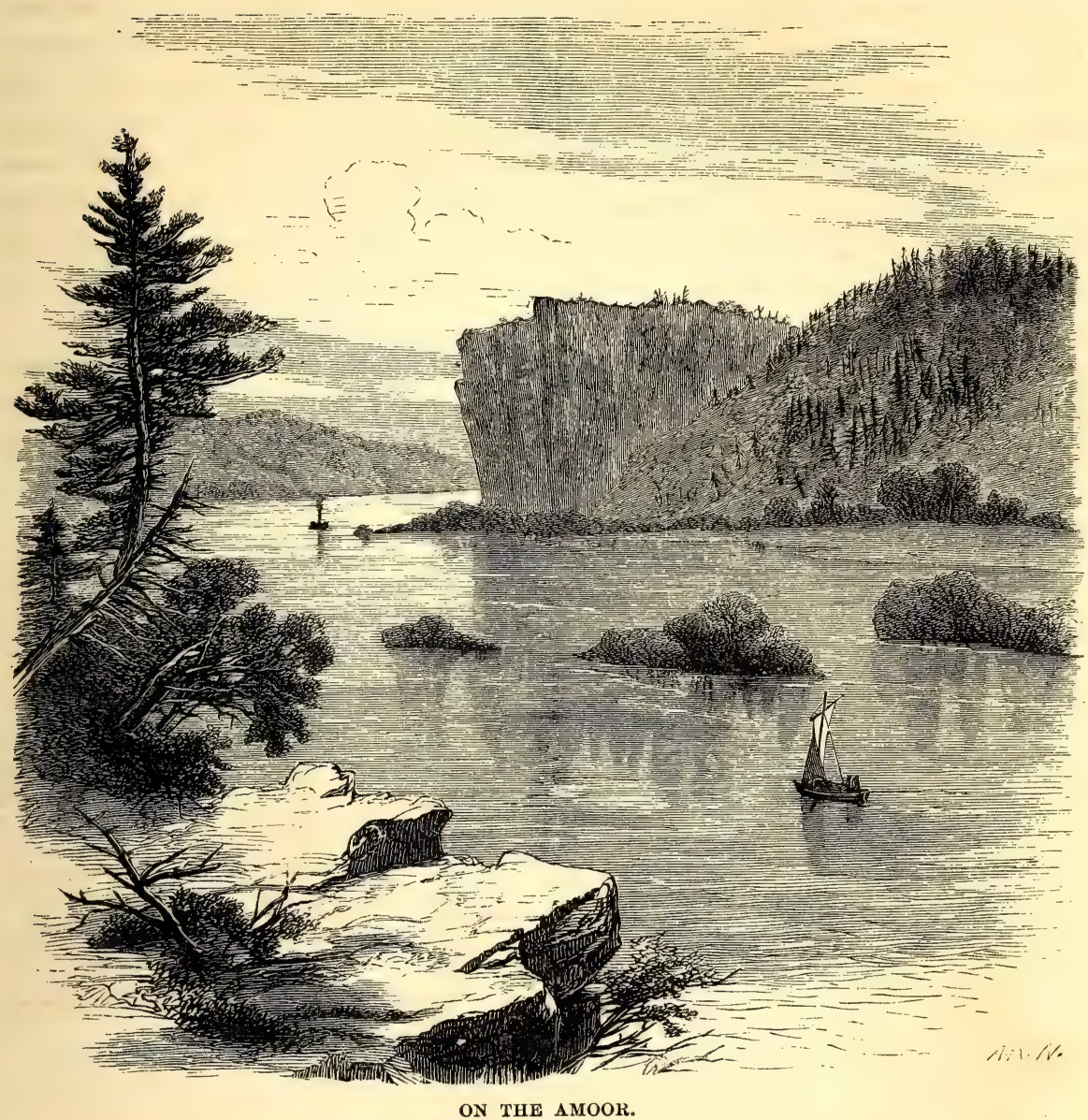

expanded into the town of Nishnei-Kolymsk, and afterwards navigated the sea eastward to Cape Schelagskoi, which may be considered as the north-eastern cape of Siberia.

In 1648 Semen Deschnew sailed from the Kolyma with the intention of reaching the Anadyr by sea, and by this remarkable voyage-which no one else, either before or after him, has ever performed-discovered and passed through the strait, which properly should bear his name, instead of Bering's, who, sailing from Kamchatka northward in 1728, did not go beyond East Cape, being satisfied with the westerly trending of the cape beyond the promontory. Some of Deschnew's companions subsequently reached Kamchatka, and were put to death by the people of that peninsula, which was conquered, in 1699, by Atlassoff, a Cossack officer who came from Jakutsk.

After having thus rapidly glanced at the progress of the Russian dominion from the Ural to the Sea of Ochotsk, it may not be uninteresting to inquire whether the natives had reason to bless the arrival of their new masters, or to curse the day when they were first made to understand the meaning of the word jassak, or tribute. Unfortunately, history tells us that, while the con- 
querors of Siberia were fully as bold and persevering as the companions of Cortez and Pizarro, they also equalled them in avarice and cruelty. Under their iron yoke whole nations, such as the Schelagi, Aniujili, and Omoki, melted away; others, as the Woguls, Jukahires, Koriaks, and Itälmenes, were reduced to a scanty remnant.

The history of the subjugation of the Itälmenes, or natives of Kamchatka, as described by Steller, may suffice to show how the Cossacks made and how they abused their conquests.

When Atlassoff, with only sixteen men, came to the river of Kamchatka, the Itälmene chieftain inquired, through a Koriak interpreter, what they wanted, and whence they came; and received for answer that the powerful sovereign, to whom the whole land belonged, had sent them to levy the tribute which they owed him as his subjects. The chieftain was naturally astonished at this information, and offering the strangers a present of costly furs, he requested them to leave the country, and not to repeat their visit. But the Cossacks thought proper to remain, and built a small wooden fort, Verchnei Ostrog, whence they fell on the neighboring villages, robbing or destroying all they could lay hands upon. Exasperated by these acts, the Itälmenes resolved to attack the fort; but as the wary Cossacks had kept up a friendly intercourse with some of them, and had moreover ingratiated themselves with the women, the plans of their enemies were always revealed to them in proper time, and led to a still greater tyranny. At length the savages appeared before the ostrog in such overwhelming numbers that the Cossacks began to lose courage;

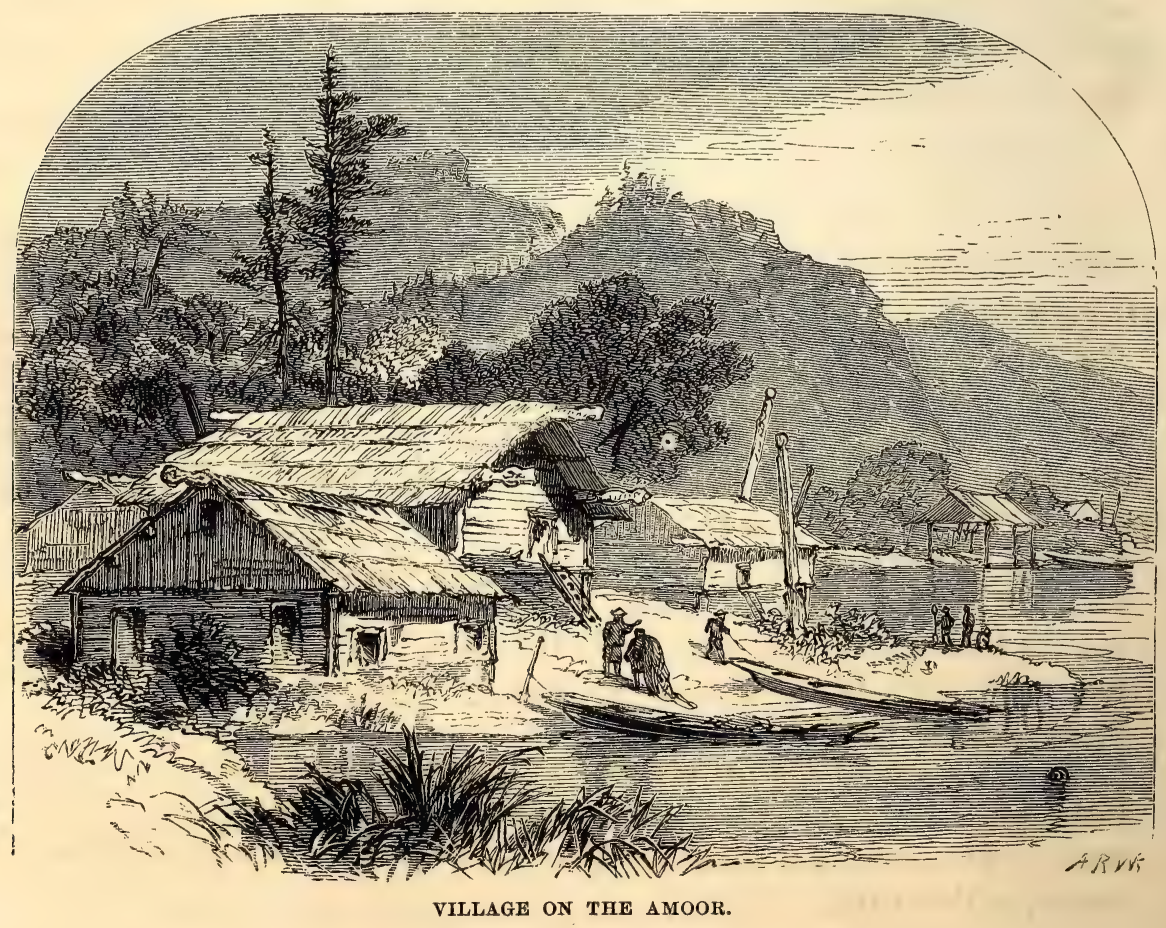




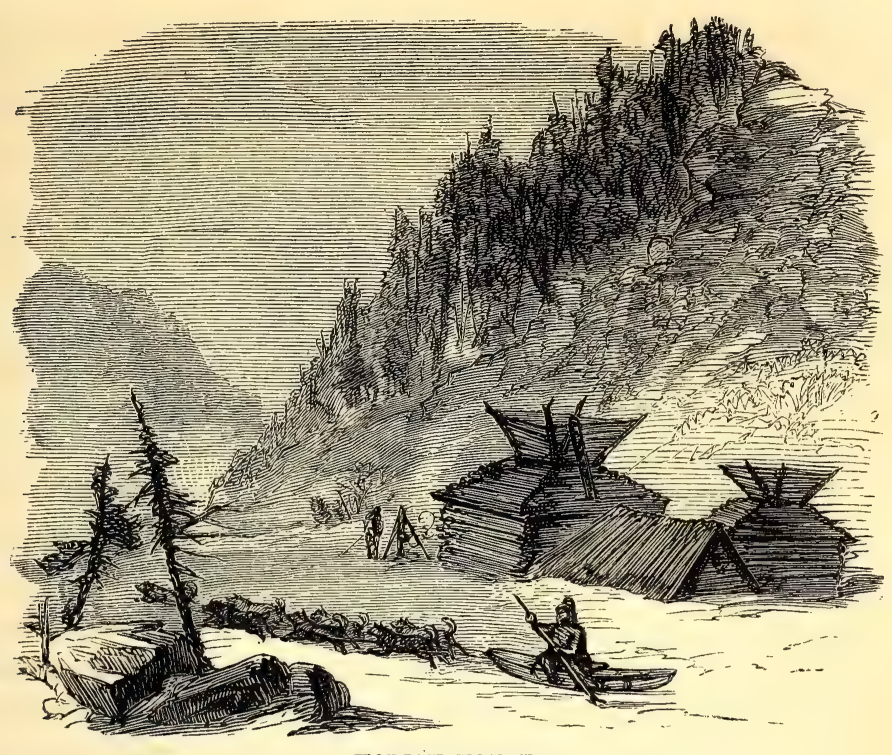

KORIAK YOURT.

yet by their superior tactics they finally managed to gain a complete victory, and those who escaped their bullets were either drowned or taken prisoners, and then put to death in the most cruel manner.

Convinced that a lasting security was impossible as long as the natives retained their numbers, the Cossacks lost no opportunity of goading them to revolt, and then butchering as many of them as they could. Thus, in less than forty years, the Kamchatkans were reduced to a twelfth part of their original numbers; and the Cossacks, having made a solitude, called it peace.

In former times the nomads of the North used freely to wander with their reindeer herds over the tundra, but after the conquest they were loaded with taxes, and confined to certain districts. The consequence was that their reindeer gradually perished, and that a great number of wandering herdsmen were now compelled to adopt a fisherman's life-a change fatal to many.

It would, however, be unjust to accuse the Russian Government of having willfully sought the ruin of the aboriginal tribes; on the contrary, it has constantly endeavored to protect them against the exactions of the Cossacks, and in order to secure their existence, has even granted them the exclusive possession of the districts assigned to them. Thus the Ostiaks and Samoïedes, the Koriaks and the Jakuts, have their own land, their own rivers, forests, and tundri. But if it is a common saying in European Russia "that heaven is high, and the Czar distant," it may easily be imagined that beyond the Ural the weak indigenous tribes found the law but a very inefficient barrier against the rapacity of their conquerors.

Thus, in spite of the Government, the jassak was not unfrequently raised, under various pretenses, to six or ten times its original amount; and the natives were, besides, obliged to bring the best of their produce, from considerable distances, to the ostrog. 
Nor could the Government prevent the accumulation of usurious debts, nor the leasing of the best pasturages or fishing-stations for a trifling sum quite out of proportion to their value; so that the natives no longer had the means of feeding their herds, and sank deeper and deeper into poverty.

And if we consider, finally, of what elements Yermak's band was originally composed, we can easily conceive that, under such masters, the lot of the Siberian natives was by no means to be envied.

The year 1734 opens a new epoch in the history of Siberian discoveries. Until then they had been merely undertaken for purposes of traffic; bold Cossacks and Promyschlenniki (or fur-hunters) had gradually extended their excursions to the Sea of Bering; but now, for the first time, scientific expeditions were sent out, for the more accurate investigation of the northern coasts of Siberia.

Prontschischtschew, who sailed westward from the Lena to circumnavigate the icy capes of Taimurland, was accompanied by his youthful wife, who wintered with him at the Olenek, in $72^{\circ} 54^{\prime}$ of latitude, and in the following summer took part in his fruitless endeavors to double those most northerly points of Asia. He died in consequence of the fatigues he had to undergo, and a few days after she followed him to the grave. A similar example of female devotion is not to be met with in the annals of Arctic discovery.

After Prontschischtschew's death, Lieutenant Chariton Laptew was appointed to carry out the project in which the former had failed. Having been repulsed by the drift-ice, he was obliged to winter on the Chatanga (1739-40); but renewed the attempt in the following summer, which however exposed him to still severer trials. The vessel was wrecked in the ice; the crew reached the shore with difficulty, and many of them perished from fatigue and famine before the rivers were sufficiently frozen to enable the feeble survivors to return to their former winter-station at Chatanga. Notwithstanding the hardships which he and his party had endured, Laptew prosecuted the survey of the promontory in the following spring.

Setting out with a sledge-party across the Tundra on April 24, 1741, he reached Taimur Lake on the 30th; and following the Taimur River, as it flows from the lake, ascertained its mouth to be situated in lat. $75^{\circ} 36^{\prime} \mathrm{N}$. On August 29 he safely returned to Jeniseisk, after one of the most difficult voyages ever performed by man. The resolution with which he overcame difficulties, and his perseverance amid the severest distresses, entitle him to a high rank among Arctic discoverers.

While Chariton Laptew was thus gaining distinction in the wilds of Taimurland, his brother, Dimitri Laptew, was busy extending geographical knowledge to the east of the Lena. He doubled the Sviatoi-noss, wintered on the banks of the Indigirka, surveyed the Bear Islands, passed a second winter on the borders of the Kolyma, and in a fourth season extended his survey of the coast to the Baranow Rock, which he vainly endeavored to double during two successive summers. After having passed seven years on the coasts of the Polar Ocean, he returned to Jakutsk in 1743. 
Fourteen years later, Schalaurow, a merchant of Jakutsk, who sailed from the Jana in a vessel built at his own expense, at length succeeded in doubling the Baranow Rock, and proceeded eastward as far as Cape Schelagskoi, which prevented his farther progress. After twice wintering on the dreary Kolyma, he resolved, with admirable perseverance, to make a third attempt, but his crew would no longer follow him. From a second sea-journey, which he undertook in $\mathbf{1 7 6 4}$ to that cape, he did not return. "His unfortunate death is the more to be lamented," says Wrangell, "as he sacrificed his property and life to a disinterested aim, and united intelligence and energy in a remarkable degree." On his map, the whole coast from the Jana to Cape Schelagskoi is marked, with an accuracy which does him the greatest honor. In 1785 Billings and Sarytchew were equally unsuccessful in the endeavor to sail round the cape which had defeated all Schalaurow's endeavors; nor has the voyage been accomplished to the present day.

As the sable had gradually led the Russian fur-hunters to Kamchatka, so the still more valuable sea-stter gave the chief impulse to the discovery of the Aleutic chain and the opposite continent of America. When Atlassow and his band arrived at Kamchatka by the end of the seventeenth century, they found the sea-otter abounding on its coasts ; but the fur-hunters chased it so eagerly that, before the middle of the eighteenth century, they had entirely extirpated it in that country. On Bering's second voyage of discovery (1741-42), it was again found in considerable numbers. Tschirigow is said to have brought back 900 skins, and on Bering's Island 700 sea-otterswhose skins, according to present pri-

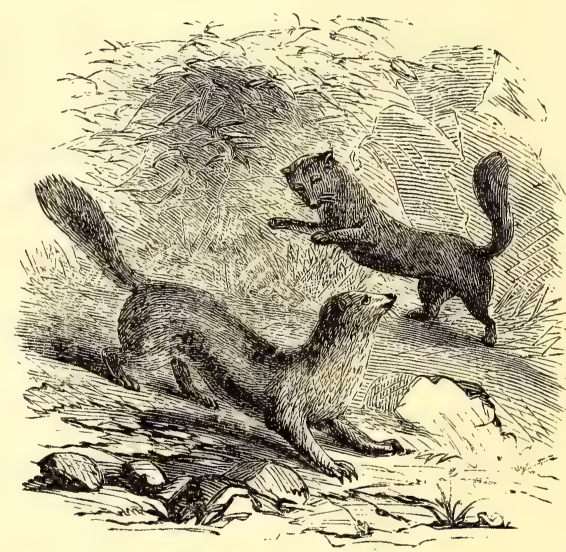

KAMCHATKA SABLES. ces, would be worth about $£ 20,000$-were killed almost without trouble. These facts, of course, encouraged the merchants of Jakutsk and Irkutsk to undertake new expeditions.

Generally, several of them formed an association, which fitted out some hardly seaworthy vessel at Ochotsk, where also the captain and the crew, consisting of fur-hunters and other adventurers, were hired. The expenses of such an expedition amounted to the considerable sum of about 30,000 roubles, as pack-horses had to transport a great part of the necessary outfit all the distance from Jakutsk, and the vessel generally remained four or five years on the voyage. Passing through one of the Kurile Straits, these expeditions sailed at first along the east coast of Kamchatka, bartering sables and sea-otters for reindeer skins and other articles; and as the precious furs became more rare, ventured out farther into the Eastern Ocean. Thus Michael Nowodsikoff discovered the Western Aleuts in 1745 ; Paikoff the Fox Islands in 1759; Adrian Tolstych almost all the islands of the central group, which still bear his name, in 1760 ; 
Stephen Glottoff the island of Kadiak in 1763, and Krenitzin the peninsula of Aljaska in 1768. When we consider the scanty resources of these Russian navigators, the bad condition of their miserable barks, their own imperfect nautical knowledge, and the inhospitable nature of the seas which they traversed, we can not but admire their intrepidity.

In the Polar Sea there are neither sables nor otters, and thus the islands lying to the north of Siberia might have remained unknown till the present day, if the search after mammoth-teeth had not, in a similar manner, led to their discovery.

In March, 1770, while a merchant of the name of Lächow was busy collecting fossil ivory about Cape Sviatoinoss, he saw a large herd of deer coming over the ice from the north. Resolute and courageous, he at once resolved to follow their tracks, and after a sledge-journey of seventy versts, he came to an island, and twenty versts farther reached a second island, at which, owing to the roughness of the ice, his excursion terminated. He saw enough, however, of the richness of the two islands in mammoth-teeth, to show him that another visit would be a valuable speculation; and on making his report to the Russian Government, he obtained an exclusive privilege to dig for mammoth-bones on the islands which he had discovered, and to which his name had been given. In the summer of 1773 he consequently returned, and ascertained the existence of a third island, much larger than the others, mountainous, and having its coasts covered with drift-wood. He then went back to the first island, wintered there, and returned to Ustjansk in spring with a valuable cargo of mammoth-tusks.

There hardly exists a more remarkable article of commerce than these remains of an extinct animal. In North Siberia, along the Obi, the Jenissei, the Lena, and their tributaries, from lat. $58^{\circ}$ to $70^{\circ}$, or along the shores of the Polar Ocean as far as the American side of Bering Strait, the remains of a species of elephant are found imbedded in the frozen soil, or become exposed, by the annual thawing and crumbling of the river-banks. Dozens of tusks are frequently found together, but the most astonishing deposit of mammoth-bones occurs in the Lächow Islands, where, in some localities, they are accumulated in such quantities as to form the chief substance of the soil. Year after year the tuskhunters work every summer at the cliffs, without producing any sensible diminution of the stock. The solidly-frozen matrix in which the bones lie thaws to a certain extent annually, allowing the tusks to drop out or to be quarried. In $1821,20,000 \mathrm{lbs}$. of the fossil ivory were procured from the island of New Siberia.

The ice in which the mammoth remains are imbedded sometimes preserves their entire bodies, in spite of the countless ages which must have elapsed since they walked on earth. In 1799 the carcass of a mammoth was discovered so fresh that the dogs ate the flesh for two summers. The skeleton is preserved at St. Petersburg, and specimens of the woolly hair-proving that the climate of Siberia, though then no doubt much milder than at present, still required the protection of a warm and shaggy coat-were presented to the chief museums of Europe.

The remains of a rhinoceros, very similar to the Indian species, are likewise 
found in great numbers along the shores, or on the steep and sandy river-banks of Northern Siberia, along with those of fossil species of the horse, the muskox, and the bison, which have now totally forsaken the Arctic wilds.

The Archipelago of New Siberia, situated to the north of the Lächow Islands, was discovered by Sirowatsky in 1806, and since then scientifically explored by Hedenström in 1808, and Anjou in 1823. These islands are remarkable no less for the numerous bones of horses, buffaloes, oxen, and sheep scattered over their desolate shores, than for the vast quantities of fossil-wood imbedded in their soil. The hills, which rise to a considerable altitude, consist of horizontal beds of sandstone, alternating with bituminous beams or trunks of trees. On ascending them, fossilized charcoal is everywhere met with, incrusted with an ash-colored matter, which is so hard that it can scarcely be scraped off with a knife. On the summit there is a long row of beams resembling the former, but fixed perpendicularly in the sandstone. The ends, which project from seven to ten inches, are for the most part broken, and the whole has the appearance of a ruinous dike. Thus a robust forest vegetation once flourished where now only hardy lichens can be seen; and many herbivorous animals feasted on grasses where now the reindeer finds but a scanty supply of moss, and the polar bear is the sole lord of the dreary waste. 


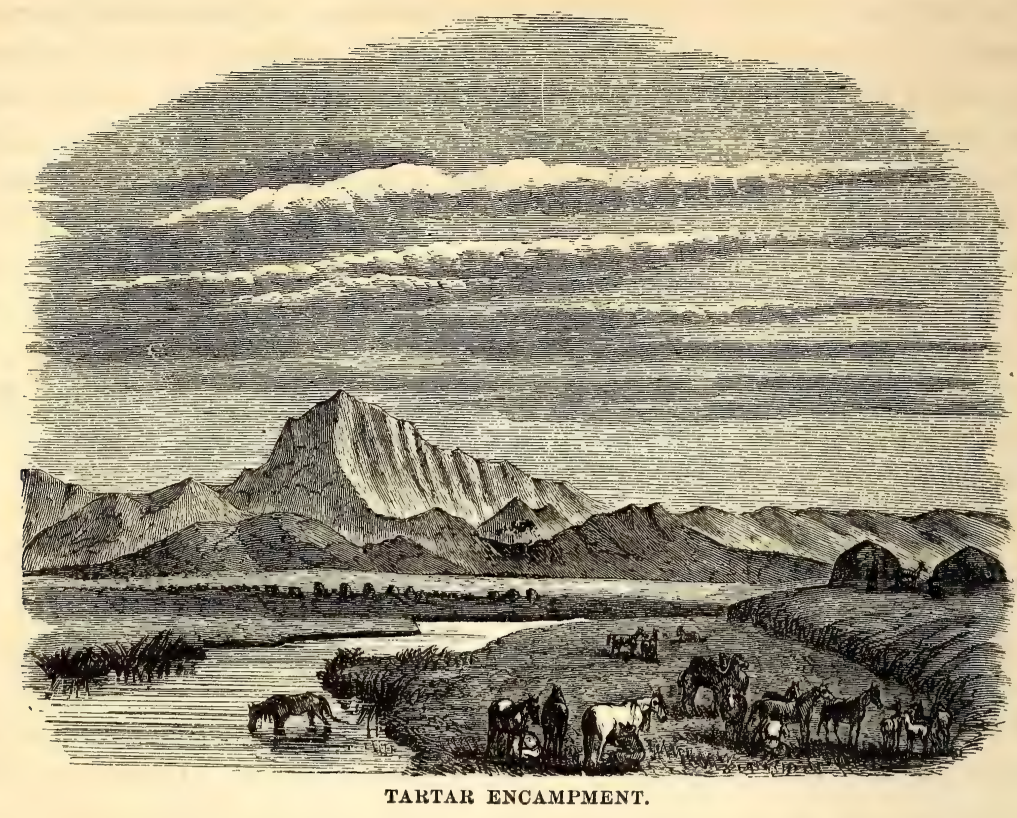

\title{
CHAPTER XVII.
}

\author{
SIBERIA-FUR-TRADE AND GOLD-DIGGINGS.
}

Siberia.-Its immense Extent and Capabilities._The Exiles.-Mentschikoff._Dolgoronky.-Münich.— The Criminals. - The free Siberian Peasant._Extremes of Heat and Cold._Fur-bearing Animals.The Sable.-The Ermine.-The Siberian Weasel.-The Sea-otter.-The black Fox.-The Lynx.The Squirrel.-The varying Hare.-The Suslik.-Importance of the Fur-trade for the Northern Provinces of the Russian Empire.-The Gold-diggings of Eastern Siberia.-The Taiga._Expenses and Difficulties of searching Expeditions.-Costs of Produce, and enormous Profits of successful Speculators.-Their senseless Extravagance.-First Discovery of Gold in the Ural Mountains.Jakowlew and Demidow.-Nishne-Tagilsk.

SIBERIA is at least thirty times more extensive than Great Britain and Ire$\checkmark$ land, but its scanty population forms a miserable contrast to its enormous size. Containing scarcely three millions of inhabitants, it is comparatively three hundred times less peopled than the British Islands. This small population is, moreover, very unequally distributed, consisting chiefly of Russians and Tartars, who have settled in the south or in the milder west, along the rivers and the principal thoroughfares which lead from the territory of one large stream to the other. In the northern and eastern districts, as far as they are occupied, the settlements are likewise almost entirely confined to the riverbanks; and thus the greater part of the enormous forest-lands, and of the interminable tundras, are either entirely uninhabited by man, or visited only by the huntsman, the gold-digger, or the migratory savage.

And yet Siberia has not been so niggardly treated by Nature as not to be 
able to sustain a far more considerable population. In the south there are thousands of square miles fit for cultivation; the numbers of the herds and flocks might be increased a hundred-fold, and even the climate would become milder after the labor of man had subdued the chilling influences of the forest and the swamp. But it is easier to express than to realize the wish to see Siberia more populous, for its reputation is hardly such as to tempt the free colonists to settle within its limits; and thus the Russian Government, which would willingly see its more temperate regions covered with flourishing towns and villages, can only expect an increase of population from the slow growth of time, aided by the annual influx of the involuntary emigrants which it sends across the Ural to the East.

Many a celebrated personage has already been doomed to trace this melancholy path, particularly during the last century, when the all-powerful favorite of one period was not seldom doomed to exile by the next palace revolution. This fate befell, among others, the famous Prince Mentschikoff. In a covered cart, and in the dress of a peasant, the confidential minister of Peter the Great, the man who for years had ruled the vast Russian Empire, was conveyed into perpetual banishment. His dwelling was now a simple hut, and the spade of the laborer replaced the pen of the statesman. Domestic misfortunes aggravated his cruel lot. His wife died from the fatigues of the journey; one of his daughters soon after fell a victim to the smallpox; his two other children, who were attacked by the same malady, recovered. He himself died in the year 1729, and was buried near his daughter at Beresow, the seat of his exile. Like Cardinal Wolsey, after his fall he remembered Grod, whom he had forgotten during the swelling tide of his prosperity. He considered his punishment as a blessing, which showed him the way to everlasting happiness. He built a chapel, assisting in its erection with his own hands, and after the services gave instruction to the congregation. The inhabitants of Beresow still honor his memory, and revere him as a saint. They were confirmed in this belief by the circumstance that his body, having been disinterred in 1821, was found in a state of perfect preservation, after a lapse of ninety-two years.

One day, as his daughter walked through the village, she was accosted by a peasant from the window of a hut. This peasant was Prince Dolgorouky, her father's enemy-the man who had caused his banishment, and was now, in his turn, doomed to taste the bitterness of exile. Soon after the princess and her brother were pardoned by the Empress Anna, and Dolgorouky took possession of their hut. Young Mentschikoff was finally reinstated in all the honors and riches of his father, and from him descends, in a direct line, the famous defender of Sebastopol.

Marshal Münich, the favorite of the Empress Anna, was doomed, in his sixtieth year, to a Siberian exile, when Elizabeth ascended the throne. His prison consisted of three rooms-one for his guards or jailers, the second for their kitchen, the third for his own use. A wall twenty feet high prevented him from enjoying the view even of the sky. The man who had once governed Russia had but half a rouble daily to spend; but the love of his wife-who, 
although fifty-five years old, had the courage and the self-denial to accompany him in his banishment-alleviated the sorrows of his exile. The venerable couple spent twenty-one years in Siberia, and on their return from exile, fiftytwo children, grandchildren, and great-grandchildren, were assembled to meet them at Moscow. The revolution which placed Catherine the Second on the throne had nearly once more doomed the octogenarian statesman to banishment, but he fortunately weathered the storm, and died as governor of St. Petersburg.

In this century, also, many an unfortunate exile, guiltless at least of ignoble crimes, has been doomed to wander to Siberia. There many a soldier of the grande armée has ended his life; there still lives many a patriotic Pole, banished for having loved his country " not wisely but too well;" there also the conspirators who marked with so bloody an episode the accession of Nicholas, have had time to reflect on the dangers of plotting against the Czar.

Most of the Siberian exiles are, however, common criminals-such as in our country would be hung or transported, or sentenced to the treadmill : the assassin, the robber-to Siberia; the smuggler on the frontier, whose free-trade principles injure the imperial exchequer-to Siberia; even the vagabond who is caught roaming, and can give no satisfactory account of his doings and intentions, receives a fresh passport-to Siberia.

Thus the annual number of the exiles amounts to about 12,000, who, according to the gravity of their offenses, are sent farther and farther eastward. On an average, every week sees a transport of about 300 of these "unfortunates," as they are termed by popular compassion, pass through Tobolsk. About one-sixth are immediately pardoned, and the others sorted. Murderers and burglars are sent to the mines of Nertschinsk, after having been treated in Russia, before they set out on their travels, with fifty lashes of the knout. In former times their nostrils used to be torn off, a barbarity which is now no longer practised.

According to Sir George Simpson's "Narrative of a Journey Round the World" (1847), Siberia is the best penitentiary in the world. Every exile who is not considered bad enough for the mines-those black abysses, at whose entrance, as at that of Dante's hell, all hope must be left behind-receives a piece of land, a hut, a horse, two cows, the necessary agricultural implements, and provisions for a year. The first three years he has no taxes to pay, and, during the following ten, only the half of the usual assessment. Thus, if he choose to exert himself, he has every reason to hope for an improvement in his condition, and at the same time fear contributes to keep him in the right path; for he well knows that his first trespass would infallibly conduct him to the mines, a by no means agreeable prospect. Under the influence of these stimulants, many an exile attains a degree of prosperity which would have been quite beyond his reach had he remained in European Russia.

Hofmann gives a less favorable account of the Siberian exiles. In his opinion, the prosperity and civilization of the country has no greater obstacle than the mass of criminals sent to swell its population. In the province of Tomsk, which seems to be richly stocked with culprits of the worst description, all the 
wagoners belong to this class. They endeavored to excite his compassion by hypocrisy. "It was the will of God!" is their standing phrase, to which they tried to give a greater emphasis by turning up the whites of their eyes. But, in spite of this pious resignation to the Divine will, Hofmann never met with a worse set of drunkards, liars, and thieves.

As to the free Siberian peasant, who is generally of exile extraction, all

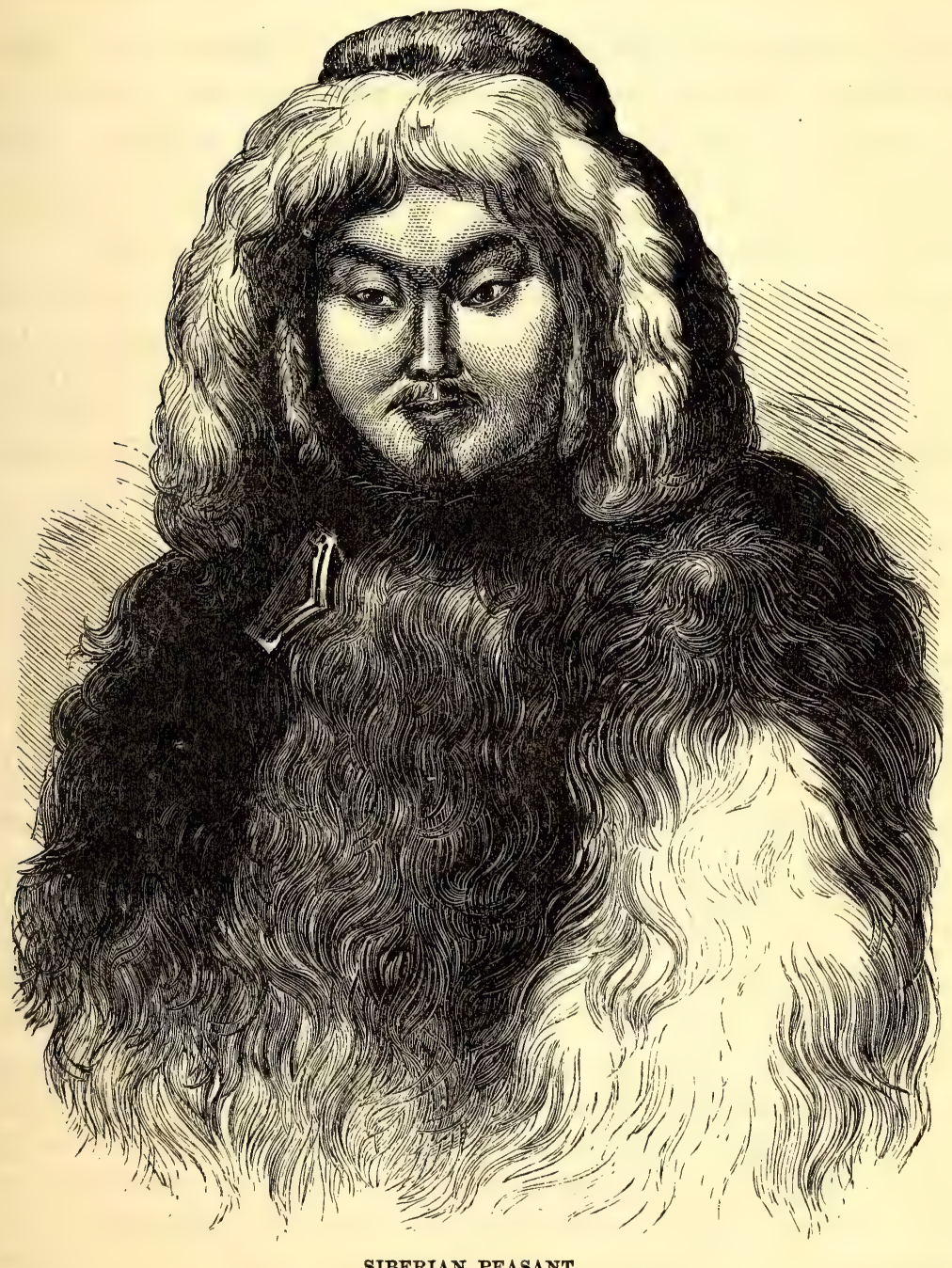

SIBERIAN PEASANT.

travellers are agreed in his praise. "As soon as one crosses the Ural," says Wrangell, "one is surprised by the extreme friendliness and good-nature of the inhabitants, as much as by the rich vegetation, the well-cultivated fields, and the excellent state of the roads in the southern part of the government of Tobolsk. Our luggage could be left without a guard in the open air. ' $\mathrm{Ne}$ boss!' 'Fear not!' was the answer when we expressed some apprehension; 
'there are no thieves among us.' This may appear strange, but it must be remembered that the Tomsk wagoners, described above, are located far more to the east, and that every exiled criminal has his prescribed circuit, the bounds of which he may not pass without incurring the penalty of being sent to the mines.

According to Professor Hansteen, the Siberian peasants are the finest men of all Russia, with constitutions of iron. With a sheepskin over theîr shirt, and their thin linen trowsers, they bid defiance to a cold of $30^{\circ}$ and more. They have nothing of the dirty avarice of the European Russian boor; they have as much land as they choose for cultivation, and the soil furnishes all they require for their nourishment and clothing. Their cleanliness is exemplary. Within the last thirty years the gold-diggings have somewhat spoilt this state of primitive simplicity, yet even Hofmann allows that the West-Siberian peasant has retained much of the honesty and hospitality for which he was justly celebrated.

Besides agriculture, mining, fishing, and hunting, the carriage of merchandise is one of the chief occupations of the Siberians, and probably, in proportion to the population, no other country employs so large a number of wagoners and carriers. The enormous masses of copper, lead, iron, and silver produced by the Altai and the Nertschinsk mountains, have to be conveyed from an immense distance to the Russian markets. The gold from the East-Siberian diggings is indeed easier to transport, but the provisions required by the thousands of workmen employed during the summer in working the auriferous sands, have to be brought to them, frequently from a distance of many hundred versts.

The millions of furs, from the squirrel to the bear, likewise require considerable means of transport; and, finally, the highly important caravan-trade with China conveys thousands of bales of tea from Kiachta to Irbit. Siberia has indeed many navigable rivers, but a glance at the map shows us at once that they are so situated as to afford far less facilities to commerce than would be the case in a more temperate climate. They all flow northward into an inhospitable sea, which is forever closed to navigation, and are themselves ice-bound during the greater part of the year. Enormous distances separate them from each other, and there are no navigable canals to unite them.

On some of the larger rivers steam-boats have indeed been introduced, and railroads are talked of; but there can be no doubt that, for many a year to come, the cart and the sledge will continue to be the chief means of transport in a country which, in consequence of its peculiar geographical position, is even in its more southern parts exposed to all the rigors of an Arctic winter.

Thus at Jakutsk $\left(62^{\circ} \mathrm{N}\right.$. lat.), which is situated but six degrees farther to the north than Edinburgh $\left(55^{\circ} 58^{\prime}\right)$, the mean temperature of the coldest month is $-40^{\circ}$, and mercury a solid body during one-sixth part of the year; while at Irkutsk $\left(52^{\circ} 16^{\prime} \mathrm{N}\right.$. lat.), situated but little farther to the north than Oxford $\left(51^{\circ} 46^{\prime}\right)$, the thermometer frequently falls to $-30^{\circ}$, or even $-40^{\circ}$; temperatures which are of course quite unheard of on the banks of the Isis. For these dreadful winters in the heart of Siberia, and under comparatively low degrees of latitude, there are various causes. The land is, in the first place, an immense 
plain slanting to the north; moreover, it is situated at such a distance from the Atlantic, that beyond the Ural the western sea-winds, which bring warmth to our winters, assume the character of cold land-winds; and, finally, it merges in the south into the high Mongolian plateau, which, situated 4000 feet above the level of the sea, has of course but little warmth to impart to it in winter; so that, from whatever side the wind may blow at that season, it constantly conveys cold. But in summer the scene undergoes a total change. Under the influence of the sun circling for months round the North Pole, floods of warmth are poured into Central Siberia, and rapidly cause the thermometer to rise; no neighboring sea refreshes the air with a cooling breeze; whether the wind come from the heated Mongolian deserts, or sweep over the Siberian plains, it imbibes warmth on every side. Thus the terrible winter of Jakutsk is followed by an equally $\mathrm{im}$ moderate summer $\left(58^{\circ} 3^{\prime}\right)$, so that rye and barley are able to ripen on a soil which a few feet below the surface is perpetually frozen.

The boundless woods of Siberia harbor a number of fur-bearing animals whose skins form one of the chief products of the country. Among these persecuted denizens of the forest, the sable (Martes zibellina), which closely resembles the pine-marten (Martes abietum) in shape and size, deserves to be particularly noticed, both for the beauty of its pelt, and its importance in the fur-trade. Sleeping by day, the sable hunts his prey by night; but though he chiefly relishes animal food, such as hares, young birds, mice, and eggs, he also feeds on

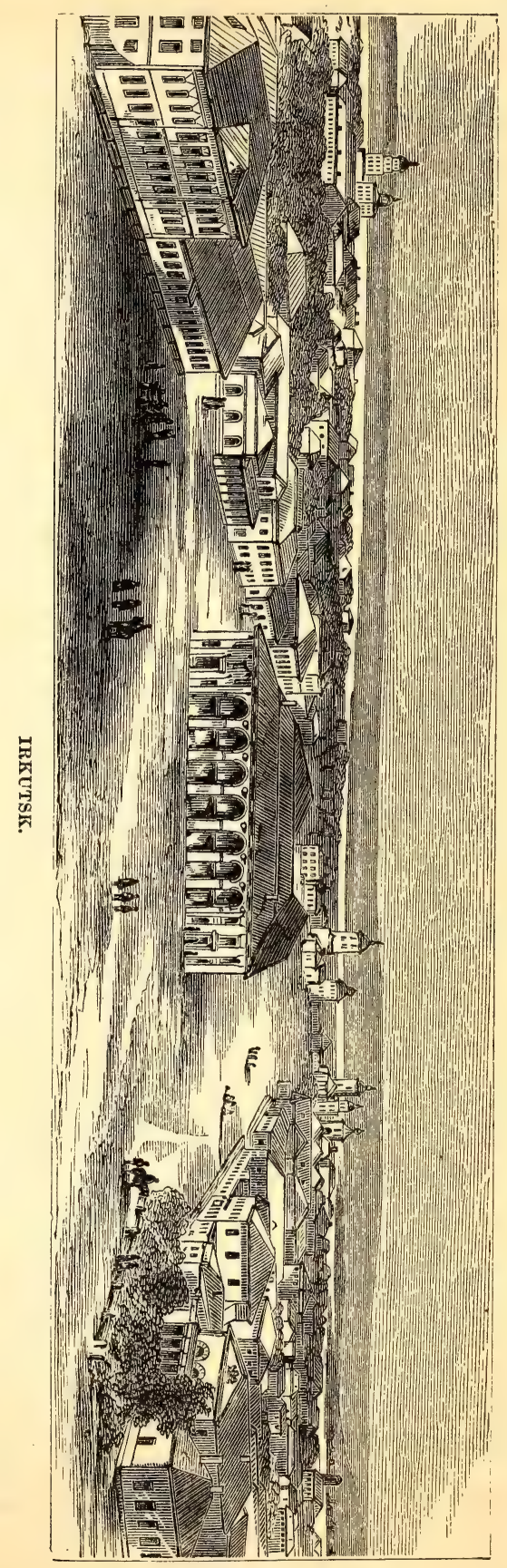
berries, and the tasteful seeds of the Pinus cembra. His favorite abode is near the banks of some river, in holes of the earth, or beneath the roots of trees. Incessant persecution has gradually driven him into the most inaccessible forests; 
the days are no more when the Tunguse hunter willingly gave for a copper kettle as many sable skins as it would hold, or when the Kamchatkan trapper, could easily catch seventy or eighty sables in one winter; but Von Baer still estimates the annual produce of all Siberia at 45,000 skins. The finest are caught in the forests between the Lena and the Eastern Sea, but Kamchatka furnishes the greater number. A skin of the finest quality is worth about forty roubles on the spot, and at least twice as much in St. Petersburg or Moscow, particularly when the hair is long, close, and of a deep blackish-brown, with a thick brown underwool. Skins with long dark hair tipped with white are highly esteemed, but still more so those which are entirely black-a color to which the Russians give the preference, while the Chinese have no objection to reddish tints. In consequence of this difference of taste, the sables from the Obi, which are generally larger but of a lighter color, are sent to Kiachta, while the darker skins, from Eastern Siberia, are directed to St. Petersburg and Leipsic.

The chase of the sable is attended with many hardships and dangers. The skins are in the highest perfection at the commencement of the winter; accordingly, towards the end of October, the hunters assemble in small companies, and proceed along the rivers in boats, or travel in sledges to the place of rendezvous-taking with them provisions for three or four months. In the deep and solitary forest they erect their huts, made of branches of trees, and bank up the snow round them, as a further protection against the piercing wind. They now roam and seek everywhere for the traces of the sable, and lay traps or snares for his destruction. These are generally pitfalls, with loose boards placed over them, baited with fish or flesh; fire-arms or cross-bows are more rarely used, as they damage the skins. The traps must be frequently visited, and even then the hunter often finds that a fox has preceded him, and left but a few worthless remuants of the sable in the snare. Or sometimes a snow-storm overtakes him, and then his care must be to save his own life. Thus sable-hunting is a continual chain of disappointments and perils, and at the end of the season it is frequently found that the expenses are hardly paid. Until now the sable has been but rarely tamed. One kept in the palace of the Archbishop of Tobolsk was so perfectly domesticated, that it was allowed to stroll about the town as it liked. It was an arch-enemy of cats, raising itself furiously on its hind-legs as soon as it saw one, and showing the greatest desire to fight it.

In former times the ermine (Mustela erminea) ranked next to the sable as the most valuable fur-bearing animal of the Siberian woods; at present the skin is worth no more than from five to eight silver kopeks at Tobolsk, so that the whole produce of its chase hardly amounts to 200,000 roubles. This little animal resembles in its general appearance the weasel, but is considerably larger, as it attains a length of from twelve to fourteen inches. Its color, which is reddish-brown in summer, becomes milk-white during the winter in the northern regions, with the exception of the tip of the tail, which always remains black. Its habits likewise greatly resemble those of the weasel; it is equally alert in all its movements, and equally courageous in defending itself when attacked. It lives on birds, poultry, rats, rabbits, leverets, and all kinds of smaller animals, 
and will not hesitate to attack a prey of much greater size than itself. Although various species of ermine are distributed over the whole forest region of the north, yet Siberia produces the finest skins. The largest come from the Kolyma, or are brought to the fair of Ostrownoje by the Tchutchi, who obtain them from the coldest regions of America.

The Siberian weasel (Viverra siberica), which is much smaller than the ermine, is likewise hunted for its soft and perfectly snow-white winter dress-the tip of the tail not being black, as in the latter.

The sea-otter, or kalan (Enhydris lutris), the most valuable of all the Russian fur-bearing animals, as 110 silver roubles is the average price of a single skin, is nearly related to the weasel tribe. The enormous value set upon the glossy, jet-black, soft, and thick fur of the kalan sufficiently explains how the Russian hunters have followed his traces from Kamchatka to America, and almost entirely extirpated him on many of the coasts and islands of Bering's Sea and the Northern Pacific, where he formerly abounded. His habits very much resemble those of the seal; he haunts sea-washed rocks, lives mostly in the water, and loves to bask in the sun. His hind feet have a membrane skirting the outside of the exterior toe, like that of a goose, and the elongated form of his flexible body enables him to swim with the greatest celerity. The love of the sea-otters for their young is so great that they reckon their own lives as nothing to protect them from danger; and Steller, who had more opportunities than any other naturalist for observing their habits, affirms that, when deprived of their offspring, their grief is so strong that in less than a fortnight they waste away to skeletons. On their flight they carry their young in their mouths, or drive them along before them. If they succeed in reaching the sea, they begin to mock their baffled pursuer, and express their joy by a variety of antics. Sometimes they raise themselves upright in the water, rising and falling with the waves, or holding a fore paw over their eyes, as if to look sharply at him ; or they throw themselves on their back, rubbing their breast with their fore paws; or cast their young into the water, and catch them again, like a mother playing with her infant. The sea-otter not only surpasses the fish-otter by the beauty of his fur, but also in size, as he attains a length of from three to four feet, exclusive of the tail. His food consists of small fishes, molluscs, and crustaceous animals, whose hard calcareous covering his broad grinders are well adapted to crush.

Next to the sea-otter, the black fox, whose skin is of a rich and shining black or deep brown color, with the longer or exterior hairs of a silvery-white, furnishes the most costly of all the Siberian furs. The average price of a single skin amounts to 60 or 70 silver roubles, and rich amateurs will willingly pay 300 roubles, or even more, for those of first-rate quality. The skin of the Siberian red fox, which ranks next in value, is worth no more than 20 roubles; the steel-gray winter dress of the Siberian crossed fox (thus named from the black cross on his shoulders), from 10 to 12 roubles; and that of the Arctic fox, though very warm and close, no more than 6 or 8 .

The bear family likewise furnishes many skins to the Siberian furrier. That of the young brown bear (Ursus arctos) is highly esteemed for the trimming 
of pelisses; but that of the older animal has little value, and is used, like that of the polar bear, as a rug or a foot-cloth in sledges.

The lynx is highly prized for its very thick, soft, rust-colored winter dress, striped with darker brown. It attains the size of the wolf, and is distinguished from all other members of the cat tribe, by the pencils of long black hair which tip its erect and pointed ears. It loves to lie in ambush for the passing remdeer or elk, on some thick branch at a considerable distance from the ground. With one prodigious bound it leaps upon the back of its victim, strikes its talons into its flesh, and opens with its sharp teeth the arteries of its neck.

Though singly of but little value, as a thousand of its skins are worth no more than one sea-otter, the squirrel plays in reality a far more important part in the Siberian fur-trade than any of the before-mentioned animals, as the total value of the gray peltry which it furnishes to trade is at least seven times greater than that of the sable. Four millions of gray squirrel skins are, on an average, annually exported to China, from two to three millions to Europe, and the home consumption of the Russian Empire is beyond all doubt still more considerable, as it is the fur most commonly used by the middle classes. The European squirrels are of inferior value, as the hair of their winter dress is still a mixture of red and gray; in the territory of the Petschora, the gray first becomes predominant, and increases in beanty on advancing towards the east. The squirrels are canght in snares or traps, or shot with blunted arrows. Among the fur-bearing animals of Siberia, we have further to notice the varying hare, whose winter dress is entirely white, except the tips of the ears, which are black; the Baikal hare; the ground-squirrel, whose fur has fine longitudinal dark-brown stripes, alternating with four light-yellow ones; and the suslik, a species of marmot, whose brown fur, with white spots and stripes, fetshes a high price in China. It occurs over all Siberia as far as Kamchatka. Its burrows are frequently nine feet deep; this, however, does not prevent its being dug out by the hunters, who likewise entrap it in spring when it awakes from its winter sleep.

Summing together the total amount of the Russian fur-trade, Von Baer estimates the value of the skins annually brought to the market by the Russian American Fur Company at half a million of silver roubles, the produce of European Russia at a million and a half, and that of Siberia at three millions. As agriculture decreases on advancing to the north, the chase of the fur-bearing animals increases in importance. Thus, in the most northern governments of European Russia-Wjatka, Wologda, Olonez, and Archangel-it is one of the chief occupations of the inhabitants. In Olonez about four hundred bears are killed every year, and the immense forests of Wologda furnish from one hundred to two hundred black foxes, three hundred bears, and three millions of squirrels.

Although the sable and the sea-otter are not so numerous as in former times, yet, upon the whole, the Russian fur-trade is in a very flourishing condition; nor is there any fear of its decreasing, as the less valuable skins-such as those of the squirrels and hares, which from their numbers weigh most heavily in the balance of trade-are furnished by rodents, which multiply very rapidly, 
and find an inexhaustible supply of food in the forests and pasture-grounds of Siberia.

The chase of the fur-bearing animals affords the North-Siberian nomadssuch as the Ostiaks, Jakuts, Tungusi, and Samoïedes-the only means of procuring the foreign articles they require; hence it taxes all their ingenuity, and takes up a great deal of their time. On the river-banks and in the forests they lay innumerable snares and traps, all so nicely adapted to the size, strength, and peculiar habits of the various creatures they are intended to capture, that it would be almost impossible to improve them. An industrious Jakut will lay about five hundred various traps as soon as the first snow has fallen; these he visits about five or six times in the course of the winter, and generally finds some animal or other in every eighth or tenth snare.

The produce of his chase he brings to the nearest fair, where the tax-gatherer is waiting for the jassak, which is now generally paid in money (five paper roubles =four shillings). With the remainder of his gains he purchases iron kettles, red cloth for hemming his garments, powder and shot, rye-meal, glass pearls, tobacco, and brandy - which, though forbidden to be sold publicly, is richly supplied to him in private - and then retires to his native wilds. From the smaller fairs, the furs are sent by the Russian merchants to the larger staple places, such as Jakutsk, Nertschinsk, Tobolsk, Kiachta, Irbit, Nishne-Novgorod, and tinally St. Petersburg and Moscow; for by repeatedly sorting and matching the size and color of the skins, their value is increased.

About thirty years ago firs were still the chief export article of Siberia-to China, European Russia, and Western Europe-but since then the discovery of its rich auriferous deposits has made gold its most important produce. The precious metal is found on the western slopes of the Ural chain and in West Siberia; but the most productive diggings are situated in East Siberia, where they give occupation to many thousands of workmen, and riches to a few successful speculators.

The vast territory drained by the Upper Jenissei and its tributaries, the Superior and the Middle Tunguska, consists for the greater part of a dismal and swampy primeval forest, which scarcely thirty years since was almost totally unknown. A few wretched nomads and fur-hunters were the only ińhabitants of the Taiga-as those sylvan deserts are called-and squirrel skins seemed all they were ever likely to produce. A journey through the Taiga is said to be one of the most fatiguing and tedious tours which it is possible to make. Uphill and down-hill, a narrow path leads over a swampy ground, into which the horses sink up to their knees. The rider is scarcely less harassed than the patient animal which carries him over this unstable soil. No bird enlivens the solitary forest with its song; the moaning of the wind in the crowns of the trees alone interrupts the gloomy silence. The eternal sameness of the scene -day after day one constant succession of everlasting larches and fir-trees-is as wearying to the mind as the almost impassable road to the body.

But suddenly the sound of the axe or the creaking of the water-wheel is heard; the forest opens, a long row of huts extends along the banks of a rivulet, and hundreds of workmen are seen moving about as industrious as a hive 
of bees. What is the cause of all this activity - of this sudden change from a death-like quiet to a feverish life? These are the gold-fields; the sands of these swampy grounds are mixed, like those of the Pactolus, with gold, and their fortunate possessors would not exchange them for the finest meadows, cornfields, or vineyards.

Fedor Popow, a hunter of the province of Tomsk, is said to have been the first discoverer of gold in Siberia ; and Government having granted permission to private persons to search for the precious metal, a few enterprising men directed their attention to the wild spurs of the Sajan Mountains. A brilliant success rewarded their endeavors. In the year 1836 an exploring-party, sent out by a merchant named Jakin Resanow, discovered a rich deposit of auriferous sand near the banks of the Great Birussa ; and in 1839-40, similar deposits were found along several of the tributaries of the Upper Tunguska, and still farther to the north, on the Oktolyk, a rivulet that flows into the Pit.

The expenses of a searching-party amount, on an average, to 3000 silver roubles $(£ 600)$; and as very often no gold whatever is found, these hazardous explorations not seldom put both the purse and the perseverance of their undertakers to a severe trial. Thus Nikita Maesnikow had spent no less than 260,000 silver roubles $(£ 52,000)$ in fruitless researches, when he at length discovered the rich gold-field on the Peskin, which, as we shall presently see, amply remunerated him for his previous losses.

Of the difficulties which await the gold-searchers, a faintidea may be formed, on considering that the whole of the auriferous region, which far surpasses in size most of the European kingdoms, consists of one vast forest like that above described. Patches of grass-land on which horses can feed are of very rare occurrence, and damp moss is the only bed the Taiga affords. As the gold-searchers are very often at work some hundreds of versts from the nearest village, they are obliged to carry all their provisions along with them. Their clothes are almost constantly wet, from their sleeping in the damp forest, from the frequent rains to which they are exposed, and from their toiling in the swampy ground. Scarcely have they dug a few feet deep when the pit fills with water, which they are obliged to pump out as fast as it gathers, and thus standing up to their knees in the mud, they work on until they reach the solid rock, for then only can they be certain that no auriferous layer has been neglected in their search. When we consider, moreover, that all this labor is very often totally useless, their perseverance can not but be admired; nor is it to be wondered at that exploring-parties have sometimes encamped on the site of rich gold-deposits without examining the spot, their patience having been exhausted by repeated failures in the vicinity. When the winter, with its deep snowfalls, suddenly breaks in upon the searchers, their hardships become dreadful. The frost and want of food kill their horses, their utensils have to be left behind; and dragging their most indispensable provisions along with them on small sledges, they are not seldom obliged to wade for weeks through the deep snow before they reach some inhabited place.

But even the severity of a Siberian winter does not prevent the sending out of exploring-parties. Such winter explorations are only fitted out for the more 
accurate examination of very swampy auriferous grounds that have been discovered in the previous year, and where it is less difficult to work in the frozen soil than to contend with the water in summer. A winter-party travels without horses, the workmen themselves transporting all that they require on light sledges. They are obliged to break up the obdurate soil with pickaxes, and the sand thus loosened has to be thawed and washed in warm water. After their day's work, they spend the night in huts made of the branches of trees, where they sleep on the hard ground. It requires the iron constitution of a Siberian to bear such hardships, to which many fall a prey, in spite of their vigorous health.

A gold-deposit having been found, the fortunate discoverer obtains the grant of a lot of ground, 100 sashens (600 feet) broad, and 2500 sashens (or 5 versts) long. Two adjoining lots are never granted to the same person, but a subsequent purchase or amalgamation is permitted. At first Government was satisfied with a moderate tax of 15 per cent. of the produce; subsequently, however, this was doubled, until within the last few years, when, the gold production having been found to decrease, the primitive impost was returned to, or even reduced to 5 per cent. for the less productive mines. Besides this tax, from four to eight gold roubles per pound of gold, according to the richness of the diggings, have to be paid for police expenses. Only a twelve years' lease is granted, after which the digging reverts to the crown, and a new lease has to be purchased. As the severe climate of the Taiga limits the working-time to four months (from May to September), the period of the concession is thus in reality not more than four years.

The first care of the lessee is, of course, to collect the necessary provisions and working apparatus. The distant steppe of the Kirghese furnishes him with dried or salted meat; his iron utensils he purchases in the factories of the Ural; the fairs of Irbit and Nishne-Novgorod supply him with every other article; and rye-meal and fishes he easily obtains from the Siberian peasants or traders. By water and by land, all these various stores have to be transported in summer to the residence or establishment of the gold-digger on the border of the Taiga. The transport through the Taiga itself takes place during the winter, on sledges, at a very great cost; and the expense is still more increased if time has been lost through inattention, as then all that may still be wanting has to be conveyed to the spot on the backs of horses.

Most of the men that are hired for working in the diggings are exiles-the remainder generally free peasants, who have been reduced in their circumstances by misfortunes or misconduct. The procuring of the necessary workmen is an affair of no small trouble and expense. Before every summer campaign the agents of the gold-diggers travel about the country like recruitingsergeants, and after giving many fair words and some hand-money, they take the passport of the man engaged as a security for his appearance. But although a passport is an indispensable document in Siberia, yet it not seldom happens that the workman finds means to obtain a new one under some other name, and, engaging himself to a new master, defrands the first of his hand-money.

It may be easily imagined that, as the workmen only consist of the refuse 
of society, the greatest discipline is necessary to keep them in order. The system of a secret police, so cherished by all arbitrary governments, is here extended to its utmost limits; scarcely has a suspicious word fallen among the workmen, when the director is immediately informed of it, and takes his measures accordingly. Every man knows that he is watched, and is himself a spy upon his companions.

Hofmann relates an instance of a plot singularly nipped in the bud. In one of the gold-diggings on the Noiba, the workmen, at the instigation of an underoverseer, had refused to perform a task assigned to them. It was to be feared that the spirit of insubordination would gain ground, and extend over all the neighboring diggings. The director, consequently, sent at once for military assistance ; this, however, proved to be unnecessary, for when the Cossacks arrived at the Noiba, a thunder-storm arose, and at the very moment they came riding up to the digging a flash of lightning killed the ringleader in the midst of the mutineers. As soon as the men recovered from the first shock of their surprise and terror, they all exclaimed, "This is the judgment of God!" and, without any further hesitation, at once returned to their duty.

Besides free rations, the ordinary wages of a common workman are 15 roubles banco, or 12 shillings a month, but more experienced hands receive 50 or even 60 roubles. The pay dates from the day when the workman makes his appearance at the residence, and thenceforward, also, his rations are served out to him. They consist of a pound of fresh or salt meat, or an equivalent portion of fish on fasting-days, cabbage and groats for soup, besides fresh rye-bread and quas (the favorite national beverage) ad libitum. The whole number of workmen employed in a gold-digging subdivide themselves into separate societies, or artells. Each of these elects a chief, or head-man, to whom the provisions for his artell are weighed out, and to whom all the other common interests are intrusted. The sale of spirituous liquor is strictly forbidden, for its use would render it impossible to maintain order; and, according to law, no gin-shop is allowed to be opened within 60 versts of a digging.

The pay and the liberal rations received would alone be insufficient to allure workmen to the diggings, for, as we have seen, the voyage there and back is extremely irksome, and the labor very fatiguing. An excellent plan has consequently been devised for their encouragement. The contract of each workman distinctly specifies the quantity of his daily work, consisting of a certain number of wheelbarrows of sand-from 100 to 120 , according to the distance from the spot where it is dug to the place where it is washed out-each reckoned at three pouds,* which one party has to fill, another to convey to the wash-stands, and a third to wash.

The task is generally completed by noon, or early in the afternoon. For the labor they perform during the rest of the day, or on Sundays and holidays, they receive an extra pay of two or three roubles for every solotnik of gold they wash. Every evening the workmen come with the produce of their free labor to the office, the gold is weighed in their presence, and the artell credited for the amount of its share. This free-work is as advantageous for the mas-

\footnotetext{
* The poud is equal to 40 pounds. The poud is divided into 96 solotniks.
} 
ters as the laborers. The former enjoy a net profit of eight or ten roubles per solotnik, and all the working expenses are of course put to the charge of the contract labor; and the latter earn a great deal of money, according to their industry or good-luck, for when fortune favors an artell, its share may amount to a considerable sum. During Hofmann's stay at the Birussa, each workman of a certain artell earned in one afternoon 72 roubles, and the Sunday's work of another of these associations gave to each of its members 105 roubles, or $£ 4$. The artisans--who, though employed in a gold-mine, are not engaged in digging or washing the auriferous sand-are also rewarded from time to time by a day's free-labor in places which are known to be rich. On one of these occasions a Cossack on the Oktolyk received 300 roubles for his share of the gold that was washed out of 49 wheelbarrows of sand. These of course are extraordinary cases, but they show how much a workman may gain; and being of course exaggerated by report, are the chief inducements which attract the workmen, and keep them to their duty.

If the free-labor is unproductive, many of the workmen desert or give up free-labor altogether, and in both cases the master is a loser. To prevent this, it is customary, in many of the diggings, to pay the workmen a fixed sum for their extra work.

At the end of the season the workmen are paid off, and receive provisions for their home-journey. Generally, the produce of their summer's labor is spent, in the first villages they reach, in drinking and gambling; so that, to be able to return to their families, they are obliged to bind themselves anew for the next season, and to receive hand-money from the agent, who, knowing their weakness, is generally on the spot to take advantage of it. After spending a long winter full of want and privations, they return to the Taiga in spring, and thus, through their own folly, their life is spent in constant misery and hard labor.

During the winter the digging is deserted, except by an under-overseer and a few workmen, who make the necessary preparations for the next campaign, receive and warehouse the provisions as they arrive, and guard the property against thieves or wanton destruction. The upper-overseer or director, meanwhile, is fully occupied at the residence in forwarding the provisions and stores that have arrived there during the summer to the mine, in making the necessary purchases for the next year, in sending his agents about the country to engage new workmen; and thus the winter is, in fact, his busiest time. With the last sledge transport he returns to the digging, to receive the workmen as they arrive, and to see that all is ready for the summer. As his situation is one of great trust and responsibility, he enjoys a considerable salary. Maesnikow, for instance, paid his chief director 40,000 roubles a year; and 6000 or 8000 roubles, besides free station, and a percentage of the gold produced, is the ordinary emolument.

It is thus evident that the expenses of a Siberian gold-mine are enormous, but when fortune favors the undertaker he is amply rewarded for his outlay; an annual produce of 10,15 , or 20 pouds of gold is by no means uncommon. In the year 1845,458 workmen employed in the gold-mine of Mariinsk, be- 
longing to Messrs. Golubdow and Kusnezow, produced 81 pouds $19 \frac{1}{3} \mathrm{lbs}$. of the much-coveted metal; in the year 1843 the mine of Olginsk, belonging to Lieutenant Malewinsky, yielded 82 pouds $37 \frac{1}{4} \mathrm{lbs}$; and in 1844, the labor of 1014 workmen, employed in the mine of Kresdowosdwishensk, belonging to Messrs. Kusnezow and Schtschegolow, produced no less than 87 pouds $14 \mathrm{lbs}$. of gold. But even Kresdowosdwishensk has been distanced by the mine of Spasky, situated near the sources of the Peskin, which, in the year 1842, yielded its fortunate possessor, the above-mentioned Counsellor Nikita Maesnikow (one of the few men who were already extremely rich before the Siberian auriferous deposits were discovered), the enormous quantity of 100 pouds of gold! From 1840 to 1845, Maesnikow extracted from this mine no less than 348 pouds $6 \mathrm{lbs}$. of gold, worth $4,135,174$ silver roubles, or about $£ 640,000$. Still more recently, in 1860, the Gawrilow mine, belonging to the house of Rjasanow, produced $102 \frac{1}{2}$ pouds of pure gold.

But in Siberia, as elsewhere, mining operations are frequently doomed to end in disappointment, particularly if the space destined to be worked in the following summer has not been carefully examined beforehand, as the ore is often very unequally distributed. A speculator, having discovered a gold-mine, examined four or five samples of the sand, which gave a highly satisfactory result. Delighted with his good-fortune, he made his arrangements on a grand scale, and collected provisions for 500 workmen; but when operations began, it was found that he had, unfortunately, hit upon a small patch of auriferous sand, the vicinity of which was totally void of gold, so that his 500 workmen produced no more than a few pounds of ore, and he lost at least $£ 10,000$ by his adventure.

The entire gold produce of East Siberia amounted, in 1845, to 848 pouds $36 \mathrm{lbs} .$, and in 1856 to about 1100 pouds ; but latterly, in consequence of the increasing wages and dearness of provisions, which has caused many of the less productive mines to be abandoned, it has somewhat diminished. In 1860, 31,796 men, 919 women, and 8751 horses and oxen, were employed in the Siberian gold-mines.

As may easily be imagined, the discovery of these sources of wealth in the desert has caused a great revolution in the social state of Siberia. The riches so suddenly acquired by a few favorites of fortune, have raised luxury to an unexampled height, and encouraged a senseless prodigality. Some sterlets* having been offered for 300 roubles to a miner suddenly raised from penury to wealth, "Fool!" said the upstart, with the superb mien of a conquering hero, to the fish-dealer, "wilt thou sell me these excellent sterlets so cheap? Here are a thousand roubles; go, and say that thou hast dealt with me!"

The small town of Krasnojarsk, romantically situated on the Jenissei, is the chief seat of the rich miners. Here may be seen the choicest toilettes, the most showy equipages, and champagne (which in Siberia costs at least $£ 1$ a bottle) is the daily beverage of the gold aristocracy. Unfortunately, Krasnojarsk had, until very recently, not a single bookseller's shop to boast of; and

* A species of sturgeon highly esteemed by epicures. 
while thousands were lavished on vanity and sensual enjoyments, not a rouble was devoted to the improvement of the mind.

Less rich in gold than the province of Jeniseisk, but richer in copper and iron, and above all in platina, is the Ural, where mining industry was first introduced by Peter the Great, in the last years of the seventeenth century, and has since acquired a colossal development. Though gold was discovered in the Uralian province of Permia as early as 1745 , yet its production on a large scale is of more modern date. In the year 1816 the whole quantity of gold furnished by the Ural amounted only to 5 pouds 35 lbs., while in 1834 it had increased to 405 pouds.

The discovery of the precious metals on the estates of the large mine-proprietors of the Ural, who already before that time were among the wealthiest men of the empire, has increased their riches to an enormous extent, and given a European celebrity to the names of Jakowlew and Demidoff. Werch Issetsk and Werchne Tagilsk, in the province of Permia, belonging to the Jakowlew family, have an extent of more than three millions of acres, with a population of 11,000 souls. Besides iron and copper, their chief produce, these estates yielded, in 1834, 58 pouds of gold.

Nishne-Tagilsk, belonging, since 1725, to the Demidoffs, is a still more magnificent possession; for it may truly be said, that perhaps nowhere in the world are greater mineral riches congregated in one spot than here, where, besides vast quantities of iron and copper, the washing of the sands produced, in 1834 no less than 29 pouds of gold, and 113 pouds 3 lbs. of platina. The estate extends over four millions of acres, and its population, in 1834, amounted to 20,000 souls.

The town of Nishne-Tagilsk has about 15,000 inhabitants, and Helmersen ("Travels in the Ural") praises the Demidoffs for their zeal in carrying the civilization of Europe to the wilds of the Ural. In an excellent elementary school, 150 boys are clothed, fed, and educated at their expense. Those pupils who distinguish themselves by their abilities are then sent to a higher school, such as the Demidoff Lyceum in Jaroslaw, or the University of Moscow, and after the termination of their studies obtain a situation on the estates of the family. The palace of the Demidoffs has a fine collection of paintings by the first Italian masters ; but it is seldom if ever inhabited by the proprietors, who prefer Florence and Paris to the Ural. The founder of the family was an eminent gunsmith of the town of Tula, whose abilities gained him the favor of Peter the Great, and the gift of the mines on which the colossal fortune of his descendants has been raised. 


\section{CHAPTER XVIII.}

\section{MIDDENDORFF'S ADVENTURES IN TAIMURLAND.}

For what Purpose was Middendorff's Voyage to Taimurland undertaken ?-Difficulties and Obstacles.Expedition down the Taimur River to the Polar Sea.-Storm on Taimur Lake.-Loss of the Boat.Middendorff ill and alone in $75^{\circ} \mathrm{N}$. Lat.-Saved by a grateful Samoïede.-Climate and Vegetation of Taimurland.

$\mathrm{N}$ following the contours of the Siberian coast, we find to the east of Nova Zembla a vast tract of territory projecting towards the Pole, and extending its promontories far into the icy sea. This country-which, from its principal river, may be called Taimurland-is the most northern, and, I need hardly add, the most inhospitable part of the Old World. The last huts of the Russian fishermen are situated about the mouth of the Jenissei, but the whole territory of the Taimur River, and the regions traversed by the lower course of the Chatanga and the Päsina, are completely uninhabited.

Even along the upper course of these two last-named rivers, the population is exceedingly scanty and scattered; and the few Samoïedes who migrate during the summer to the banks of the Taimur, gladly leave them at the approach of winter, the cold of which no thermometer has ever measured. As may easily be imagined, Taimurland has but few attractions for the trader or the furhunter, but for the naturalist it is by no means without interest.

We have seen in a former chapter how Von Baer, prompted by the disinterested love of science, travelled to Nova Zembla to examine the productions of a cold insular summer beyond the 70th degree of latitude. The instructive results of his journey rendered it doubly desirable to obtain information about the effects of summer in a continental climate, situated if possible still farther to the north; and as no region could be better suited to this purpose than the interior of the broad mass of Taimurland, the Academy of Sciences of St. Petersburg resolved to send thither a scientific expedition. Fortunately for the success of the undertaking, Von Middendorff, the eminent naturalist, whose offer of service was gladly accepted, was in every respect the right man in the right place; for to the most untiring scientific zeal, and an unwavering determination, he joined a physical strength and a manual dexterity rarely found united with learning. In the Lapland moors he had learned to bivouac for nights together, while chasing the waterfowl, and on foot he was able to tire the best-trained walrus-hunter. He understood how to construct a boat, and to steer it with his own hand, and every beast or bird was doomed that came within reach of his unerring ball. In one word, no traveller ever plunged into the Arctic wilds more independent of baggage, followers, or the means of transport.

On April 4 we find Middendorff, accompanied by Mr. Brandt, a Danish forester, and a single servant, on the ice of the Jenissei between Turuchansk and 
Dudino. Here his companions were attacked by measles; but as it was high time to reach the Chatanga before the melting of the snow, the patients were carefully packed up in boxes lined with skins, and the whole party-whose numbers, meanwhile, had been increased by the addition of a topographer and of three Cossacks-emerged from the region of forests on April 13, having to face a cold of $-36^{\circ}$, and a storm that almost overturned their sledges. With Tunguse guides they traversed the tundra in a north-easterly direction as far as the Päsina, and thence passing on from one Samoïede horde to another, at length reached Koronnoie Filippowskoi $\left(71^{\circ} 5^{\prime}\right.$ lat.) on the Boganida, an affluent of the Cheta, which is itself a tributary of the Chatanga. Here a halt was made, partly because all the party except Middendorff were by this time attacked with the reigning epidemic, and partly to wait for the Samoïedes, whom they intended to join on their summer migration to the north. During this interval Middendorff made an excursion to the Chatanga, for the purpose of gathering information about the voyage down that river, and to make the necessary preparations. In the village of Chatangsk, however, he found nearly all the inhabitants suffering from the measles; and as no assi tance was to be expected from them, he resolved to alter his route, and to proceed as soon as possible to the River Taimur, which would in all probability afford him the best means for penetrating to the extreme confines of continental Asia. As this most northerly river of the Old World lies far beyond the boundaries of arboreal growth, a boat-frame of twelve feet on the keel had to be made at Koronnoie before setting out. Brandt was left behind with part of the company, to make a prolonged series or meteorological observations, and to gather as complete a collection as possible of the animals and plants of the country, while Middendorff started on his adventurous tour (May 19) with sixty-eight reindeer, under the guidance of a few Samoiedes on their progress to the north, and accompanied only by the topographer, an interpreter, and two Cossacks. The difficulties of this journey, since a boat-frame, fuel, provisions, physical instruments, apparatuses for the preservation of objects of natural history, forming altogether a load for many sledges, had to be transported along with the travellers, would have been great at all times, but were now considerably increased by the epidemic having also seized the tribe of Samoïedes which Middendorff expected to find near the small River Nowaia, and which was to guide him farther on to the Taimur. At length, after a search of three days, he found the remnant of the horde, which had been decimated and reduced to a deplorable condition by the epidemic. In vain he sought for the well-known faces of the chief personages of the horde, with whom he had negotiated on the Boganida— " they were all dead." Of thirty-five persons, one only was completely healthy; a second could hardly crawl about; but the others lay prostrate in their tents, coughing and groaning under their skin corerings. Leaving seven corpses on the road, they had advanced by slow journeys to join Middendorff, until they broke down, so that instead of receiving aid at their hands, he was now obliged to help them in their distress-an assistance which they amply repaid, as we shall see in the sequel.

Unfortunately the illness had prevented the Samoïede women from sewing together, as they had promised, the skins that were necessary to complete the 
covering of the travellers' tent, so that they had much to suffer during a violent snow-storm, which raged from May 27 to 30 . Thus after another long delay and an irreparable loss of time, considering the extreme shortness of the summer, Middendorff was not able to start from the Nowaia before May 31. The softening of the snow rendered the advance of the sledges extremely difficult, so that it was not before June 14 that he reached the Taimur at a considerable distance above the point where the river discharges its waters into the lake. Encamping on a steep declivity of its bank, Middendorff now set about building his boat. On June 30 the ice on the river began to break up, and on July 5 the navigation of the stream was free. By the light of the midnight sun the boat was launched, and christened "The Tundra," to commemorate the diffculties of its construction in the deserts of $74^{\circ} \mathrm{N}$. lat. Constant north winds retarded the voyage down the river and over the lake, beyond which the Taimur, traversing a hilly country, is inclosed within steep and picturesque rocks. The increasing rapidity of the stream now favored the travellers, and the storms were less troublesome between the mighty rock-walls; but unfortunately Middendorff, instead of being able, as he had expected, to fill his nets with fish as he advanced, and to establish dépôts for his return journey, found himself obliged to consume the provisions he had taken with him in the boat. On August 6 the first night-frost took place, and from that time was regularly repeated. Yet in spite of these warnings, Middendorff continued his journey down the river, and reached the sea on August 24, in $76^{\circ} \mathrm{N}$. lat. But now it was high time to return.

"The fear of leaving my undertaking half unfinished," says Middendorff, " had hitherto encouraged me to persevere. The great distance from any human habitation, the rapid stream, against which we had now to contend, and the advanced season, with its approaching dark nights and frosts, made our return an imperative necessity, and I could have but little reliance on our remaining strength. The insufficient food and the fatigues of our journey, often prolonged to extreme exhaustion, had reduced our vigor, and we all began to feel the effects of our frequent wading through cold water, when, as often happened, our boat had grounded upon a shallow, or when the flat mud-banks of the river gave us no other alternative for reaching the dry land. It was now also the second month since we had not slept under a tent, having all the time passed the nights behind a screen erected on the oars of the boat, as a shelter against the wind. Provided with a good load of drift-wood, collected on the shore of the Polar Ocean, we began our return voyage on August 26. The borders of the river were already incrusted with ice. Wading became extremely irksome, the river having meanwhile fallen above six feet, and the shallows frequently forcing us to step into the water and pull the boat along.

"Fortunately the wind remained favorable, and thus by rowing to the utmost of our strength, and with the assistance of the broad sails of our 'Tundra,' we surmounted two rapids which, encased between abrupt rocks, seemed to defy our utmost efforts.

"On the 31st, a malicious gust of wind, bursting out of a narrow gorge, threw our boat against the rocks and broke the rudder. The frost and wet, 
together with the shortness of our provisions, tried us sorely. Not a day passed without sleet and snow.

“On September 5, while endeavoring to double during a violent storm a rocky island at the northern extremity of Lake Taimur, one wave after another dashed into the boat, which I could only save by letting her run upon a sandbank. The violent wind, with a temperature of only $+27^{\circ}$ at noon, covered our clothes with solid ice-crusts. We were obliged to halt four days till the storm ceased; our nets and my double-barrelled gun proved daily more and more unsuccessful, so that hunger combined with cold to render our situation almost intolerable. On the 8th, while on the lookout for ptarmigan, I saw through my telescope a long stripe of silver stretching over the lake, and, returning to my comrades, informed them that we must absolutely set off again the next morning, regardless of wind and weather.

"On the following day the ominous indications of the telescope rendered it necessary to approach the more open west side of the lake; which I followed until stopped by the ice, along whose borders I then sailed in order to reach the river, which must still be open. Meanwhile the wind had completely fallen, and, to our astonishment, we saw the water in our wake cover itself with a thin crust of ice as soon as we passed. The danger of freezing fast in the middle of the lake was evident."

Unfortunately, while endeavoring to reach the river, the boat was crushed between two ice floes, and was with great difficulty dragged on shore. The only chance of rescue now was to meet with some Samoïedes on the upper course of the river, for these nomads never wander northward beyond the southern extremity of the lake, and from this our travellers were still at a great distance.

"We made a large hand-sledge," continues Middendorff, " and set off without loss of time on the 10th, in spite of the rainy weather, which had completely dissolved the sparing snow upon the hills. The sharp stones cut into our sledge-runners like knives, and after having scarcely made three versts, the vehicle fell to pieces. The bad weather forced us to stop for the night. The fatigues of our boat-journey, the want of proper food, and mental anxiety, had for several weeks been undermining my health : a total want of sleep destroyed the remainder of my strength, so that, early on the 11th, I felt myself quite unable to proceed."

In this extremity Middendorff adopted with heroic self-denial the best and only means for his own preservation and that of his comrades. If, by departing without loss of time, they were fortunate enough to reach the Samoïedes before these nomads had left the Taimur country for the south, he also might be rescued; if they found them very late, they at least might expect to save their lives; if the Samoïedes could not be found, then of course the whole party was doomed. Thus Middendorff resolved to separate at once from his comrades. A remnant of flesh extract, reserved for extreme cases, was divided into five equal portions; the naturalist's dog, the faithful companion of all his previous journeys, was killed, though reduced to a mere skeleton, and his scanty Alesh similarly distributed among the party. The blood and a soup made of the 
bones served for the parting repast. Thus of his own free-will, the winter hav. ing already set in, Middendorff, ill and exhausted, remained quite alone in the icy desert, behind a sheltering rock, in $75^{\circ} \mathrm{N}$. lat., several hundred versts from all human dwellings, almost without fuel, and with a miserable supply of food. The three first days he was still able to move. He saw the lake cover itself completely with ice, and the last birds depart for the south. Then his strength utterly failed him, and for the next three days he was unable to stir. When he was again able to move, he felt an excessive thirst. He crawled to the lake, broke the ice, and the water refreshed him. But he was not yet free from disease, and this was fortunate, as want of appetite did not make him feel the necessity of food. Now followed a succession of terrible snow-storms, which completely imprisoned the solitary traveller, but at the same time afforded him a better shelter against the wind.

"My companions," he writes in a letter to a relation, "had now left me twelve days; human assistance could no longer be expected; I was convinced that I had only myself to rely upon, that I was doomed, and as good as numbered with the dead. And yet my courage did not forsake me. Like our squirrels, I turned myself according to the changes of the wind. During the long sleepless nights fancy opened her domains, and I forgot even hunger and thirst. Then Boreas broke roaring out of the gullies as if he intended to sweep me away into the skies, and in a short time I was covered with a comfortable snowmantle. Thus I lay three days, thinking of wretches who had been immured alive, and grown mad in their dreadful prison. An overwhelming fear of insanity befell me-it oppressed my heart--it became insupportable. In vain I attempted to cast it off-my weakened brain could grasp no other idea. And now suddenly-like a ray of light from heaven-the saving thought flashed upon me.

"My last pieces of wood were quickly lighted-some water was thawed and warmed-I poured into it the spirits from a flask containing a specimen of natural history, and drank. A new life seemed to awaken in me; my thoughts returned again to my family, to the happy days $I$ had spent with the friends of my youth. Soon I fell into a profound sleep-how long it lasted I know notbut on awakening I felt like another man, and my breast was filled with gratitude. Appetite returned with recovery, and I was reduced to eat leather and birch-bark, when a ptarmigan fortunately came within reach of my gun. Having thus obtained some food for the journey, I resolved, although still very feeble, to set out and seek the provisions we had buried. Packing some articles of dress. my gun and ammunition, my journal, etc., on my small hand-sledge, I proceeded slowly, and frequently resting. At noon I saw, on a well-known declivity of the hills, three black spots which I had not previous!y noticed, and as they changed their position, I at once altered my route to join them. We approached each other-and, judge of my delight, it was Trischun, the Samoïede chieftain, whom I had previously assisted in the prevailing epidemic, and who now, guided by one of my companions, had set out with three sledges to seek me. Eager to serve his benefactor, the grateful savage had made his reindeer wander without food over a space of 150 versts where no moss grew. 
"I now heard that my companions had fortunately reached the Samoïedes four days after our separation; but the dreadful snow-storms had prevented the nomads from coming sooner to my assistance, and had even forced them twice to retrace their steps.

"On September 30 the Samoïedes brought me to my tent, and on October 9 we bade the Taimur an eternal farewell. After five months we hailed with delight, on October 20, the verge of the forest, and on the following day we reached the smoky hut on the Boganida, where we had left our friends."

Having thus accompanied Middendorff on his adventurous wanderings through Taimuria, I will now give a brief account of his observations on the climate and natural productions of this northern land.

The remark of Saussure that the difference of temperature between light and shade is greatest in summer, and in the high latitudes, was fully confirmed by Middendorff. While the thermometer marked $-37^{\circ}$ in the shade, the hillsides exposed to the sun were dripping with wet, and towards the end of June, though the mean temperature of the air was still below the freezing-point of water, the snow had already entirely disappeared on the sunny side of the Taimur River. Torrents came brawling down the hills; the swollen rivers rose forty or sixty feet above their winter level, and carried their icy covering along with them to the sea.

On August 3, in the very middle of the short Taimurian summer, in $74^{\circ} 15^{\prime}$ of latitude, Middendorff hunted butterflies under the shelter of a hill, bare-foot. ed and in light under-clothes. The thermometer rose in the sun to $+68^{\circ}$, and close to the ground to $+86^{\circ}$, while at a short distance on a spot exposed to the north-eastern air-current it fell at once to $+27^{\circ}$.

The moisture of the air was very remarkable. In May thick snow-fogs almost perpetually obscured the atmosphere, so that it was impossible to ascertain the position of the sun. It appeared only in the evening, or about midnight, and then regularly a perpendicular column of luminous whiteness descended from its orb to the earth, and, widening as it approached the horizon, took the form and the appearance of a colossal lamp-flame, such as the latter appears when seen through the mists of a vapor bath. From the same cause parhelia and halos were very frequent.

During the daytime the snow-fogs, in perpetual motion, either entirely veiled the nearest objects, or magnified their size, or exhibited them in a dancing motion. In June the snow-fog became a vapor-fog, which daily from time to time precipitated its surplus of moisture in form of a light rain, but even then the nights, particularly after eleven o'clock, were mostly serene.

Experience proved, contrary to Arago's opinion, that thunder-storms take place within the Arctic zone. The perpetual motion of the air was very remarkable. The sun had merely to disappear behind a cloud to produce at once a gust of wind. Towards the end of August, the southern and the northern aircurrents, like two contending giants, began to strive for the mastery, until finally the storms raged with extreme violence. But in these treeless deserts their fury finds nothing to destroy.

It is impossible to form any thing like a correct estimate of the quantity of 
snow which annually falls in the highest latitudes. So much is certain that it can not be small, to judge by the violence and swelling of the rivers in spring. The summits of the hills, and the declivities exposed to the reigning winds, are constantly deprived of snow, which, however, fills up the bottom of the valleys to a considerable height. Great was Middendorff's astonishment, while travelling over the tundra at the end of winter, to find it covered with no more than two inches, or at the very utmost half a foot, of snow; the dried stems of the Arctic plants everywhere peeping forth above its surface. This was the natural consequence of the north-easterly storms, which, sweeping over the naked plain, carry the snow along with them, and form the snow-waves, the compass of the northern nomads.

It is extremely probable that, on advancing towards the pole, the fall of snow gradually diminishes, as in the Alps, where its quantity likewise decreases on ascending above a certain height.

On measuring the thickness of the ice, Middendorff was very much surprised to find it nowhere, both in the lakes and on the river, thicker than eight feet, and sometimes only four and a half; its thickness being constantly proportionate to the quantity of snow with which it was covered. At first he could hardly believe that this simple covering could afford so efficacious a protection against the extreme cold of winter in the 74 th degree of latitude, but the fact is well known to the Samoïedes, who, whenever they require water, always make the hole where the snow lies deepest.

The tundras of Taimuria were found to consist principally of arid plateaux and undulating heights, where the vegetation can not conceal the boulders and the sand of which the crust of the earth is formed.

The withered tips of the grasses scarcely differ in color from the dirty yellow-brown moss, and the green of the lower part of the stalks appears as through a veil. Nothing can be of a more dreary monotony than this vegetation when spread over a wide surface; but in the hardly perceptible depressions of the plains where the spring water is able to collect, a fresher green gains the upper hand, the stalks are not only longer, but stand closer together, and the grass, growing to a height of three or even four inches, usurps the place of the moss. Here and there small patches of Dryas octopetala, or Cassiope tetragona, and much more rarely a dwarf ranunculus, diversify the dingy carpet, yet without being able to relieve its wearisome character. But very different, and indeed truly surprising, is the aspect of the slopes which, facing the Taimur lake or river, are protected against the late and early frosts. Here considerable patches of ground are covered with a lively green, intermingled with gayly-colored flowers, such as the brilliant yellow Sieversia, the elegant Oxytropis, the blue and white Saxifragas, the red Armeria alpina, and a beautiful new species of Delphinium. All these various flowers are not dwarfs of stunted growth, for Polemones, Sisymbrias, Polygonums, and Papavers above a foot high decorate the slopes, and Middendorff found an islet in the Taimur covered like a field with a Senecio, of which some of the most conspicuous specimens were more than a foot and a half high, and bore no less than forty flowers above an inch in diameter.

The progress of vegetation is uncommonly rapid, so that, as Middendorff re- 
marks, if any one wishes to see the grass grow, he must travel to the Taimur. Scarcely do the first leaves peep forth when the blossoms also appear, as if, conscious of the early approach of autumn, they felt the necessity of bringing their seeds to a rapid maturity under this wintry sky.

With regard to the animal creation, the general law of polar uniformity was fully confirmed in Taimurland. The same lemmings were found which people the whole north of Asia and America, and as high as $75^{\circ} \mathrm{N}$. lat. they found the traces of the snow-hare, which inhabits the complete circle of the Arctic regions of the globe. The Arctic fox, everywhere at home in the treeless wastes, is here also pursued by the northern glutton; and following the herds of the reindeer, the wolves, and the Samoïedes, roams up and down the tundra. The ptarmigan, which in Scandinavia and on Melville Island feeds on berries and buds, appears also as a summer visitor at the mouth of the Taimur in $75^{\circ} 4^{\prime} \mathrm{N}$. lat., and the ivory gull of the northern European seas likewise builds its nest on the rocks of that distant shore.

The more vigorous vegetation on the sheltered declivities of the Taimur provides food for a comparatively greater number of insects than is found on the coasts of Nova Zembla. Bees, hornets, and three different species of butterflies, buzzed or hovered round the flowers, and caterpillars could be gathered by dozens on the tundra, but their mortal enemies had pursued them even here; and ichneumon flies crept out of most of them. Two spiders, several flies, gnats, and tipulæ, a curculio, and half a dozen carabi completed Middendorff's entomological list, to which, no doubt, further researches would have considerably added.

Thus, at the northern extremity of Asia, as in every other part of the world, the naturalist finds the confirmation of the general law that, where the means of life are given, life is sure to come forth. 


\title{
CHAPTER XIX.
}

\author{
THE JAKU'TS.
}

Their energetic Nationality.-Their Descent.-Their gloomy Character.-Summer and Winter Dwell. ings.-The Jakut Horse.--Incredible Powers of Endurance of the Jakuts.--Their Sharpness of Vision.-Surprising local Memory.--Their manual Dexterity.--Leather, Poniards, Carpets._Jakut Gluttons.-Superstitious Fear of the Mouniain-spirit Ljeschei.-Offerings of Horse-hair.-Improvised Songs.-The River Jakut.

$\mathrm{T}$ EE Jakuts are a remarkably energetic race, for though subject to the Muscovite yoke, they not only successfully maintain their language and manners, but even impose their own tongue and customs upon the Russians who have settled in their country. Thus in Jakutsk, or the "capital of the Jakuts," as with not a little of national pride and self-complacency they style that dreary city, their language is much more frequently spoken than the Russian, for almost all the artisans are Jakuts, and even the rich fur-merchant has not seldom a Jakut wife, as no Russian now disdains an alliance with one of that nation.

At Amginskoie, an originally Russian settlement, Middendorff found the greatest difficulty in procuring a guide able to speak the Russian language, and all the Tunguse whom he met with between Jakutsk and Ochotsk understood and spoke Jakut, which is thus the dominant language from the basin of the Lena to the extreme eastern confines of Siberia. In truth, no Russian workman can compete with the Jakuts, whose cunning and effrontery would make it difficult even for a Jew to prosper among them.

Though of a Mongolian physiognomy, their language, which is said to be intelligible at Constantinople, distinctly points to a Turk extraction, and their traditions speak of their original seats as situated on the Baikal and Angora, whence, retreating before more powerful hordes, they advanced to the Lena, where in their turn they dispossessed the weaker tribes which they found in possession of the country. At present their chief abode is along the banks of that immense river, which they occupy at least as far southward as the Aldan. Eastward they are found on the Kolyma, and westward as far as the Jenissei. Their total number amounts to about 200,000, and they form the chief part of the population of the vast but almost desert province of Jakutsk.

They are essentially a pastoral people, and their chief wealth consists in horses and cattle, though the northern portion of their nation is reduced to the reindeer and the dog. Besides the breeding of horses, the Russian fur-trade has developed an industrial form of the hunter's state, so that among the Jakuts property accumulates, and we have a higher civilization than will be found elsewhere in the same latitude, Iceland, Finland, and Norway alone excepted. Of an unsocial and reserved disposition, they prefer a solitary settlement, but at the same time they are very hospitable, and give the stranger who 
claims their assistance a friendly welcome. Villages consisting of several huts, or yourts, are rare, and found only between Jakutsk and the Aldan, where the population is somewhat denser. Beyond the Werchojansk ridge the solitary huts are frequently several hundred versts apart, so that the nearest neighbors sometimes do not see each other for years.

In summer the Jakut herdsmen live in urossy, light conical tents fixed on poles and covered with birch rind, and during the whole season they are perpetually employed in making hay for the long winter.

In $62^{\circ} \mathrm{N}$. lat., and in a climate of an almost unparalleled severity, the rearing of their cattle causes them far more trouble than is the case with any other pas. toral people. Their supply of hay is frequently exhausted before the end of the winter, and from March to May their oxen must generally be content with willow and birch twigs or saplings.

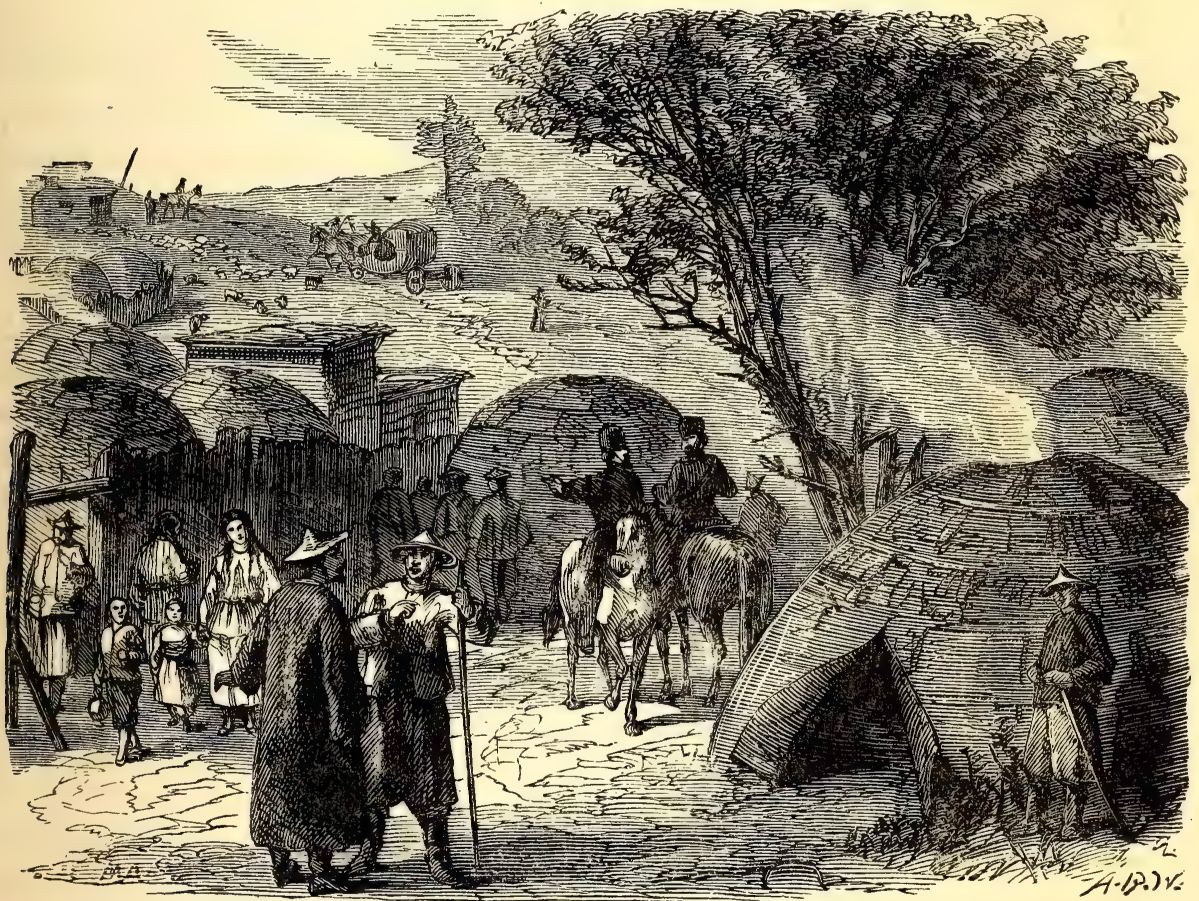

A JAKUT VILLAGE.

At the beginning of the cold season the Jackut exchanges his summer tent for his warm winter residence, or yourt, a hut built of beams or logs, in the form of a truncated pyramid, and thickly covered with turf and clay. Plates of ice serve as windows, and are replaced by fish-bladders or paper steeped in oil, as soon as the thaw begins. The earthen floor, for it is but rarely boarded, is generally sunk two or three feet below the surface of the ground. The seats and sleeping berths are ranged along the sides, and the centre is occupied by the tschuwal, or hearth, the smoke of which finds its exit through an aperture in the roof. Clothes and arms are suspended from the walls, and the whole premi- 
ses exhibit a sad picture of disorder and filth. Near the yourt are stables for the cows, but when the cold is very severe, these useful animals are received into the family room. As for the horses, they remain night and day without a shelter, at a temperature when mercury freezes, and are obliged to feed on the withered autumnal grass which they find under the snow. These creatures, whose powers of endurance are almost incredible, change their hair in summer like the other quadrupeds of the Arctic regions. They keep their strength, though travelling perhaps for months through the wilderness without any other food than the parched, half-rotten grass met with on the way. They retain their teeth to old age, and remain young much longer than our horses. "He who thinks of improving the Jakut horse," says Von Middendorff, "aims at something like perfection. Fancy the worst conceivable roads, and for nourishment the bark of the larch and willow, with hard grass-stalks instead of oats; or merely travel on the post-road to Jakutsk, and see the horses that have just run forty versts without stopping, and are covered with perspiration and foam, eating their hay in the open air without the slightest covering, at a tem. perature of $-40^{\circ} . "$

But the Jakut himself is no less hardened against the cold than his faithful horse. "On December 9," says W rangell, "we bivouacked round a fire, at a temperature of $-28^{\circ}$, on an open pasture-ground, which afforded no shelter against the northern blast. Here I had an excellent opportunity for admiring the unparalleled powers of endurance of our Jakut attendants. On the longest winter journey they take neither tents nor extra covering along with them, not even one of the larger fur-dresses. While travelling, the Jakut contents himself with his usual dress; in this he generally sleeps in the open air; a horse rug stretched out upon the snow is his bed, a wooden saddle his pillow. With the same fur jacket, which serves him by daytime as a dress, and which he pulls off when he lies down for the night, he decks his back and shoulders, while the front part of his body is turned towards the fire almost without any covering. He then stops his nose and ears with small pieces of skin, and covers his face so as to leave but a small opening for breathing-these are all the precautions he takes against the severest cold. Even in Siberia the Jakuts are called 'men of iron.' Often have I seen them sleeping at a temperature of $-4^{\circ}$ in the open air, near an extinguished bivouac fire, and with a thick icerind covering their almost unprotected body."

Most of the Jakuts have an incredible sharpness of vision. One of them told Lieutenant Anjou, pointing to the planet Jupiter, that he had often seen yonder blue star devour a smaller one, and then after a time cast it out again.* Their local memory is no less astonishing; a pool of water, a large stone, a solitary bush imprints itself deeply into their remembrance, and guides them after a lapse of years through the boundless wilderness. In manual dexterity they surpass all other Siberian nations, and some of their articles, such as their poniards and their leather, might figure with credit in any European exhibition. Long before the Russian conquest they made use of the iron ore on the

* Humboldt likewise mentions an artisan of Breslau whose sight was so sharp as to enable him to point out the position of Jupiter's satellites. 
Wilui to manufacture their own knives and axes, which, either from the excellence of the material or of the workmanship, rarely break, even in the severest cold-a perfection which the best Sheffield ware does not attain. Since time immemorial they have been acquainted with the art of striking fire with flint and steel, an invention unknown even to the ancient Greeks and Romans. Their leather is perfectly water-tight, and the women make carpets of white and colored skins, which are even exported to Europe. It is almost superfluous to mention that a people so capable of bearing hardships, so sharp-witted, and so eager for gain as the Jakuts must needs pursue the fur-bearing animals with which their forests abound with untiring zeal and a wonderful dexterity.

The horse renders the Jakut services not less important than those of the reindeer to the Samoïede or the Lapp. Besides using it for carrying or riding, the Jakut makes articles of dress out of its skin, and fishing-nets of its hair; boiled horse-meat is his favorite food, and sour mare's milk, or kumyss, his chief beverage. Of the latter he also makes a thick porridge, or salamat, by mixing it with rye-flour, or the inner rind of the larch or fir tree, to which he frequently adds dried fish and berries, and, to render it perfect, a quantity of rancid fat, of which he is immoderately fond. He is in fact a gross feeder, and some professional gluttons are capable of consuming such astonishing masses as to shame the appetite even of an Esquimaux. During his stay at Jakutsk, Sir George Simpson put the abilities of two distinguished artists to the test, by setting two pouds of boiled beef and a poud of melted butter before them. Each of them got a poud of meat for his share; the butter they were allowed to ladle out and drink ad libitum. The one was old and experienced, the other young and full of zeal. At first the latter had the advantage. "His teeth are good," said the elder champion, "but with the assistance of my saint (crossing himself), I will soon come up to him."

When about half of their task was finished, Sir George left his noble guests to the care and inspection of his secretary, but when he returned a few hours after, he was informed that all was consumed, while the champions, stretched out on the floor, confirmed the secretary's report, and expressed their thanks for the exorbitant meal they had enjoyed by respectfully kissing the ground. After one of these disgusting feats, the gorged gluttons generally remain for three or four days plunged in a torpid state like boa snakes, without eating or drinking, and are frequently rolled about on the ground to promote digestion. It may also be noticed, as a proof of the low state of intellectual culture among the Jakuts, that at every wedding among the richer class two professed virtuosi in the art of gormandizing are regularly invited for the entertainment of the guests. One of them is treated at the bridegroom's expense, the other at that of the bride, and the party whose champion gains the victory considers it as a good omen for the future.

The Jakuts, besides being a pre-eminently pastoral people, are also the universal carriers to the east of the Lena. For beyond Jakutsk, the only roads are narrow paths leading through swamps, dense forests, or tangled bushes, so that the horse affords the only means of reaching the more even and lower 
countries where reindeer or dogs can be attached to sledges. Without the Jakut and his horse, the Russian would never have been able to penetrate to the Sea of Ochotsk, and from thence to the Aleutian chain ; but for him, they never would have settled on the Kolyma, nor have opened a commercial intercourse with the Tchuktchi and the western Esquimaux.

Before the possession of the Amoor had opened a new road to commerce, thousands of pack-horses used annually to cross the Stanowoi hills on the way to Ochotsk; and when we consider the dreadful hardships of the journey, we can not wonder that the road was more thickly strewn with the skeletons of fallen horses than the caravan routes through the desert with the bones of famished camels. But the Jakut fears neither the icy cold of the bivouac nor the pangs of hunger, which, in spite of his wolfish voracity, he is able to support with stoical fortitude. He fears neither the storm on the naked hill, nor the gloom of the forest, nor the depth of the morass; and, bidding defiance to every thing else, fears only the invisible power of "Ljeschei," the spirit of the mountain and the wood. The traveller wonders when he sees on an eminence crowned with firs an old tree from whose branches hang bunches of horse-hair. The Jakut who leads the caravan soon explains the mystery. He dismounts, and plucking a few hairs from the mane of his horse, attaches them with a great show of respect to a branch, as an offering to propitiate the favor of Ljeschei on the journey. Even those Jakuts who pass for Christians still pay this mark of respect to the dethroned divinity of their fathers; and there can be no doubt that they still retain the old belief in Schamanism, and an abject fear of all sorts of evil spirits.

While travelling they sing almost perpetually melancholy tunes, corresponding with the habitual gloom of their national character. The text has more variety and poetry, and generally celebrates the beauties of nature, the stately growth of the pine, the murmuring of the brook, or the grandeur of the mountain. The singers are mostly improvisatores, and to conciliate the favor of Ljeschei, they praise the desert through which they pass as if it were a paradise.

Like the impoverished Samoïede or Lapp, the indigent Jakut, who possesses neither cattle nor horses, settles near some stream. His only domestic animal is his dog, who carries the fish on a light sledge from the river-bank to his hut, or follows him into the woods on his hunting expeditions. With the skins of fur-bearing animals he pays his jassak, and is glad if the surplus allows him to indulge from time to time in the luxury of a pipe of Circassian tobacco. 


\section{CHAPTER XX.}

\section{WRANGELL.}

His distinguished Services as an Arctic Explorer.-From Petersburg to Jakutsk in 1820.-Trade of Jakutsk.-From Jakutsk to Nishne-Kolymsk. - The B darany.-Dreadful Climate of Nishne-KoJymsk.-Summer Plagues.-Vegetation.-Animal Life.-Reindeer-hunting.-Famine._Inundations. - The Siberian Dog. - First Journeys over the Ice of the Polar Sea, and Exploration of the Coast beyond Cape Shelagskoi in 1821.-Dreadful Dangers and Hardships._Matiuschkin's Sled re-journey over the Polar Sea in 1822. - Last Adventures on the Polar Sea.-A Run for Life.-Return to St. Petersburg.

THE expeditions which had been sent out during the reign of the Empress

Anna for the exploration of the Arctic shores of Eastern Siberia, had performed their task so badly as to leave them still almost totally unknown. To fill up this blank in geography, the Emperor Alexander ordered two new expeditions to be fitted out in 1820 for the purpose of accurately ascertaining the limits of these extreme frontiers of his immense empire. Of the one which, under Lieutenant Anjou, commenced its operations from the mouth of the Jana, and comprised within its range New Siberı and the other islands of the Lächow group, but little has been communicated to the public, all his papers having been accidentally burned; but the travels of Lieutenant von Wrangell, the commander of the second expedition, have obtained a world-wide celebrity. Starting from the mouths of the Kolyma, he not only rectified the errors of the coast-line of Siberia, from the Indigirka in the west to Koliutschin Island in the east, but more than once ventured in a sledge upon the Polar Ocean, in the hopes of discovering a large country supposed to be situated to the northward of Kotelnoi and New Siberia.

Wrangell left St. Petersburg on March 23, 1820, and experiencing in his journey of 3500 miles repeated alternations of spring and winter, arrived at Irkutsk, where the garcens were in full flower, on May 20.

After a month's rest, a short journey brought him to the banks of the Lena, on which he embarked on June 27, to descend to Jakutsk, which he reached on July 27. This small town of 4000 inhabitants bears the gloomy stamp of the frigid north, for though it has a few good houses, its dwellings chiefly consist of the winter yourts of the Jakuts, with turf-covered roofs, doors of skins, and windows of talc or ice. The only "sight" of this dreary place is the old ruinous ostrog or wooden fort built by the Cossacks, the conquerors of the country, in 1647. Jakutsk is the centre of the interior trade of Siberia. To this place are brought, in enormous quantities, furs of all kinds, walrus-teeth, and mammoth-tusks, from distances of many thousand versts, to an amount of half a million pounds.

The commercial sphere of the Jakutsk merchants is of an immense extent. During a cold of ten and twenty degrees they set out for the Lächow Isles, for 
the fair of Ostrownoje, for Ochotsk, or Kjachta. Jakutsk merchants were the first who ventured in crazy ships across the Sea of Kamchatka, and discovered the island of Kadjiak, eighty degrees of longitude from their home.

On September 12 Wrangell left Jakutsk, where regular travelling ends, as from thence to Kolymsk, and generally throughout Northern Siberia, there are no beaten roads. The utmost that can be looked for are foot or horse tracks leading through morasses or tangled forests, and over rocks and mountains. Travellers proceed on horseback through the hilly country, and, on reaching the plains, use sledges drawn either by reindeer or dogs.

In this manner Wrangell crossed from the basin of the Lena to that of the Yana, never experiencing a higher temperature than $+2^{\circ}$, and frequently enduring a cold of more than $-12^{\circ}$, during the journey over the intervening hills, and then turning eastward, traversed the Badarany, a completely uninhabited desert, chiefly consisting of swamps. These Badarany never entirely dry up, even after the longest summer-drought. At that time a solid crust is formed, through which the horses frequently break, but they are preserved from totally sinking in the mire by the perpetually frozen underground. Nothing can be more dismal and dreary than the Badarany. As far as the eye reaches, nothing is to be seen but a covering of dingy moss, relieved here and there on some more elevated spots by wretched specimens of dwarf-larches. The winter is the only season for traversing this treacherous waste, but woe to the traveller should he be overtaken by a snow-storm, as for miles and miles there is no shelter to be found but that of some ruinous powarni, or post-station.

At length, fifty-two days after leaving Jakutsk, Wrangell arrived on November 2 at Nishne-Kolymsk, the appointed head-quarters of the expedition, where he was welcomed with a cold of $-40^{\circ}$, or $\tau 2^{\circ}$ below the freezing-point of water.

Even in Siberia the climate of this place is ill-reputed for its severity, which is as much due to its unfavorable position as to its high latitude $\left(68^{\circ} \mathrm{N}\right.$.). The town stands on a low swampy island of the Kolyma, having on the west the barren tundra, and on the north the Arctic Ocean, so that the almost constant north-west winds have full scope for their violence, and cause frequent snow-storms even in summer.

The mean temperature of the whole year is only $+14^{\circ}$. The river at NishneKolymsk freezes early in September, but lower down, where the current is less rapid, loaded horses can sometimes cross on the ice as early as August 20, nor does the ice ever melt before June.

Although the sun remains fifty-two days above the horizon, the light, obscured by almost perpetual mists, is accompanied with little heat, and the solar disc, compressed by refraction into an elliptical form, may be looked at with the naked eye without inconvenience. In spite of the constant light, the common order of the parts of the day is plainly discernible. When the sun sinks down to the horizon, all nature is mute; but when, after a few hours, it rises in the skies, every thing awakens, the few little birds break out in feeble twitter, and the shrivelled flowers venture to open their petals.

Although winter and summer are in reality the only seasons, yet the inhab- 
itants fancy they have spring when about noon the rays of the sun begin to make themselves felt, which generally takes place about the middle of March, but this so-called spring has frequent night-frosts of twenty degrees. Their autumn is reckoned from the time when the rivers begin to freeze over, that is, from the first days of September, when a cold of thirty degrees is already by no means uncommon. As may easily be supposed in a climate like this, the vegetation of summer is scarcely more than a struggle for existence.

In the latter end of May the stunted willow-bushes put out little wrinkled leaves, and those banks which slope towards the south become clothed with a semi-verdant hue; in June the temperature at noon attains $72^{\circ}$; the flowers show themselves, and the berry-bearing plants blossom, when sometimes an icy blast from the sea destroys the bloom. The air is clearest in July, and the temperature is usually mild, but then a new plague arises for the torment of man. Millions and millions of mosquitoes issue from the swamps of the tundra, and compel the inhabitants to seek refuge in the dense and pungent smoke of the "dymokury," or large heaps of fallen leaves and damp wood, which are kindled near the dwellings and on the pasture-grounds, as the only means of keeping off those abominable insects.

These tormentors, however, are not without use, for they compel the reindeer to migrate from the forests to the sea-shore and the ice, thus exposing them to the attack of the hunters, and they also prevent the horses from straying in the plains, and wandering beyond the protection of the smoke.

Scarcely is the mosquito plague at an end, when the dense autumn fogs rising fiom the sea spoil the enjoyment of the last mild hours which precede the nine months' winter. In January the cold increases to $-45^{\circ}$; breathing then becomes difficult; the wild reindeer, the indigenous inhabitant of the Polar region, withdraws to the thickest part of the forest, and stands there motionless, as if deprived of life.

With the $22 \mathrm{~d}$ November begins a night of thirty-eight days, relieved in some degree by the strong refraction and the white of the snow, as well as by the moon and the aurora. On the 28th December the first pale glimmering of dawn appears, which even at noon does not obscure the stars. With the re-appearance of the sun the cold increases, and is most intense in February and March at the rising of the sun. Even in winter completely clear days are very rare, as the cold sea-wind covers the land with mists and fogs.

The character of the vegetation corresponds with that of the climate. Moss, stunted grass, dwarfish willow-shrubs, are all that the place produces. The neighboring valleys of the Aniuj, protected by mountains against the sea-wind, have a somewhat richer flora, for here grow berry-bearing plants, the birch, the poplar, absinthe, thyme, and the low-creeping cedar. This poverty, however, of the vegetable world is strongly contrasted with the profusion of animal life over these shores and on the Polar Sea. Reindeer, elks, bears, foxes, sables, and gray squirrels fill the upland forests, while stone-foxes burrow in the low grounds. Enormous flights of swans, geese, and ducks arrive in spring, and seek deserts where they may moult and build their nests in safety。 Eagles, owls, and gulls pursue their prey along the sea-coast; ptarmigan run in troops 
among the bushes; little snipes are busy among the brooks. In the morasses the crows gather round the huts of the natives; and when the sun shines in spring, the traveller may even sometimes hear the note of the finch, and in autumn that of the thrush. But the landscape remains dreary and dead; all denotes that here the limits of the habitable earth are passed, and one asks with astonishment what could induce human beings to take up their abode in so comfortless a region?

In the district of Kolymsk, which surpasses in size many a European kingdom, the population, at the time of Wrangell's visit, consisted of 325 Russians, 1034 Jakuts, and 1139 Jukahires of the male sex, of whom 2173 had to pay the jassak, consisting of 803 fox and 28 sable skins, worth 6704 roubles, besides which they were taxed to the amount of 10,847 roubles in money Thus the liussian double-eagle made, and no doubt still makes, the poor people of Kolymsk pay rather dear for the honor of living under the protection of its talons.

The Cossacks, in virtue of their descent from the original conquerors of the country, enjoy the enviable privilege of being tax free; they are, however, obliged to render military service when required. They form the small garrison of Nishne-Kolymsk, and every year twenty-five of them repair to the fai: of Ostrownoje, to keep the wild Tchuktchi in check. The Russians are chiefly the descendants of fur-hunters or of exiles; and though they have adopted the native clothing and mode of life, they are still distinguishable by their more muscular frame. The women, who are somewhat better-looking than the female Jakuts and Jukahires, are fond of music, and their traditional songs dwell on the beauties of nature - the rustling brook, the flowery mead, the nightingale's note-all things belonging to a world of which they have no idea.

The dwellings of the Russians are hardly to be distinguished from the youris of the native tribes. They are made of drift-wood, and, as may easily be imagined, are very small and low. The interstices are carefully stopped up with moss, and the outside is covered with a thick layer of clay. An external mud wall rises to the height of the roof to keep off the wind. In a hut like this Wrangell spent many a winter month, but when the cold was very intense, he was not able to lay aside any part of his fur clothing, thongh sitting close to a large fire. When he wanted to write he had to keep the inkstand in hot water; and at night, when the fire was allowed to go out for a short time, his bedclothes were always covered with a thick snow-like rime.

The existence of the people of Kolymsk depends upon fishing and hunting, in which they are assisted by their dogs. These faithful, but cruelly-treated animals, are said to resemble the wolf, having long, pointed, projecting noses, sharp and upright ears, and long bushy tails. Their color is black, brown, reddish-brown, white, and spotted, their howling that of a wolf. In summer they dig holes in the ground for coolness, or lie in the water to escape the mos. quitoes; in winter they burrow in the snow, and lie curled up, with their noses covered with their bushy tails. The preparation of these animals for a journey must be carefully attended to; for a fortnight at least they should be put on a small allowance of hard food, to convert their superfluous fat into firm flesh; they must also be driven from ten to twenty miles daily, after which they havo 
heen known to travel a liundred miles a day without being injured by it. A team consists commonly of twelve dogs, and it is of importance that they should be accustomed to draw together. The quick and steady going of the team, as well as the safety of the traveller, mainly depends on the docility and sagacity of the foremost $\mathrm{dog}$ or leader. No pains are therefore spared in his education, so that he may understand and obey his master's orders, and prevent the rest from starting off in pursuit of the stone-foxes or other animals that may chance to cross their path. Their usual food is frozen fish, and ten good her. rings are said to be a proper daily allowance for each dog while on duty. When not actively employed, they are obliged to content themselves with offal, and towards spring, when the winter's provisions are generally exhausted, they suffer the keenest hunger.

This season is also a hard time for the wandering tribes of the neighborhood. Then they flock to Nishne-Kolymsk, and to the other Russian settlements on the Kolyma, but here also famine stares them in the face. There is, indeed, a public corn magazine, but the price of flour is raised by the cost of transport to such an exorbitant height, as to be completely beyond the reach of the majority of the people. Three such dreadful springs did Wrangell pass at Kolymsk, witnessing scenes of misery never to be forgotten.

But when the distress of the people has reached its highest point, relief is generally at hand. Troops of migratory birds come from the south, and furnish some food for the despairing population. The supply is increased in June, when the ice breaks on the Kolyma, for in spite of the faultiness of the nets and the want of skill of the fishermen, the river is the principal source of plenty during the summer, and supplies, moreover, the chief provisions for the following winter. But with these gifts the Kolyma brings the plague of inundations, so that during the summer of 1822 Wrangell was obliged to spend a whole week on the flat roof of his hut.

The chief resource of the Jukahires of the Rirer Aniuj is the reindeer chase, the success of which mainly decides whether famine or some degree of comfort is to be their lot during the coming winter. The passage of the reindeer takes place twice a year; in spring, when the mosquitoes compel them to seek the sea-shore, where they feed on the moss of the tundra, and in autumn, when the increasing cold forces them to retire from the coast. The spring migration, which begins about the middle of May, is not very profitable, partly because the animals are meagre, and their furs in bad condition, and partly because it is more difficult to kill them as they pass the frozen rivers. The chief hunting is in August and September, when the herds, consisting each of several thousand deer, return to the forests. They invariably cross the river at a particular spot, where a flat sandy bank makes their landing easier; and here they press more closely together, under the guidance of the strongest animals of the herd.

The passage takes place after some hesitation, and in a few minutes the river is covered with swimming reindeer. The hunters, hidden in creeks or behind stones and bushes, now shoot forth in their small boats and wound as many as they can. While they are thus busy, they run some risk of being overturned in the turmoil, for the bucks defend themselves with their horns, their 
teeth, and their hind legs, while the roes generally attempt to spring with their fore feet upon the edge of the boat. When the hunter is thus overset, his only chance of safety is to cling to a strong animal, which safely brings him to the shore. But the dexterity of the hunters renders such accidents rare. A good hunter will kill a hundred reindeer and more in half an hour. In the mean time the other boats seize the killed animals, which become their property, while those that are merely woundea and swim ashore belong to the hunters, who, in the midst of the tumult, where all their energies are taxed to the ut. most, direct their strokes in such a manner as only severely to wound the larger animals. The noise of the horns striking against each other, the waters tinged with blood, the cries of the hunters, the snorting of the affrighted animals, form a scene not to be described.

The people of the Aniuj were already suffering great distress when, on September 12, 1821, the eagerly-expected reindeer herds made their appearance on the right bank of the river. Never had such a multitude been seen; they covered the hills, and their horns might have been mistaken at a distance for a moving forest. In a short time numbers of the Siberian tribes had assembled, ready to destroy them. But the wary animals, alarmed by some circumstance or other, took another road, and, leaving the banks of the river, vanished on the mountains. The despair of the people may be imagined; some lamented aloud and wrung their hands, others threw themselves upon the ground and scratched up the snow, others stood motionless like statues-a dreadful image of the universal misery. The later fishing-season likewise failed in this deplorable year, and many hundreds died in the following winter.

While the men of Kolymsk are busily employed during the short summer In hunting, fishing, and hay-making, the women wander over the country, particularly in the mountains, to gather edible roots, aromatic herbs, and berries of various kinds, which latter, however, do not every year arrive at maturity. The berry-gathering here, like the vintage elsewhere, is a time of merriment. The younger women and girls go together in large parties, passing whole days and nights in the open arr. When the berries are collected, cold water is poured over them, and they are preserved in a frozen state for a winter treat. Social parties are not unknown at Kolymsk, and are perhaps not less entertaining than in more refined communities. Floods of weak tea (for the aromatic leaves "which cheer, but not inebriate," are very dear at Kolymsk) form the staple of the entertainment; and as sugar is also an expensive article, cvery guest takes a lump of candy in his mouth, lets the tea which he sips flow by, and then replaces it upon the saucer. It would be considered very unmannerly were he to consume the whole piece, which thus is able to do duty at more than one soirée. Next to tea, brandy is a chief requisite of a Kolymsk party.

The busiest time at Kolymsk is in February, when the caravan from Jakutsk arrives on its way to the fair of Ostrownoje. It consists of about twenty merchants, each of whom leads from ten to forty sumpter horses. This is the time not only for sale and purchase, but also for hearing the last news from the provincial capital Jakutsk, and receiving intelligence six months old from Moscow and St. Petersburg. 
From this short account of Kolymsk life it may well be imagined what a sensation ii must háve made in so secluded a place when Wrangell arrived there in November, and informed the people that he was come to spend the better part of the next three years among them.

The winter was passed in preparation for the next spring expeditions, for during the long Arctic night the darkness prevents travelling, and the snow acquires a peculiar hardness or sharpness from the extreme cold, so that ther, four times the number of dogs would be needed. But as in summer the thawing is likewise a hindrance, Wrangell had in reality only about ten weeks every year, from March till the end of May, for the accompiishment of ris task.

As may easily be supposed, it was no easy matter to make the necessary arrangements for an expedition requiring some hundreds of dogs, and provisions for several weeks; but such was the energy displayed by Wrangell and his colleagues, that on February 19, 1821, they were able to start on their first journey over the ice of the Polar Sea, which they reached on the 25th. Nine sledges, with the usual team of twelve dogs to each, were provided for the present excursion, six of which were to carry provisions and stores, to be distributed in different dépôts, and then to return. The provisions for the dogs consisted of 2400 fresh herrings, and as much "jukola" as was equivalent to 8150 dried herrings. The increasing cold and the violence of the wind made travelling very difficult. To guard the dogs from being frozen, the drivers were obliged to put clothing on their bodies, and a kind of boots on their feet, which greatly impeded their running. At times the frost was so intense that the mercury congealed while Wrangell was making his observations. $\mathrm{He}$ thus describes the manner in which he passed the nights on the Polar Sea in his tent:-

"Between tea and supper the sledge-drivers went out to attend and feed their dogs, which were always tied up for the night, lest they should be tempted away by the scent of some wild animal. Meanwhile, we were engaged in comparing our observations, and in laying down on the map the ground which we had gone over in the course of the day; the severe cold, and the smoke which usually filled the tent, sometimes made this no easy task. Supper always consisted of a single dish of fish or meat soup, which was boiled for us all in the same kettle, out of which it was eaten. Soon after we had finished our meal, the whole party lay down to sleep. On account of the cold we could not lay aside any part of our travelling-dress, but we regularly changed our boots and stockings every evening, and hung those we had taken off, with our fur caps and gloves, on the tent-poles to dry. This is an essential precaution, particularly in respect to stockings, for with damp clothing there is the greatest risk of the part being frozen. We always spread the bear-skins between the frozen ground and ourselves, and the fur coverings over us, and, being well tired, we usually slept very soundly. As long as all the sledge-drivers continued with us, we were so crowded that we had to place ourselves like the spokes of a wheel, with our feet towards the fire and our heads against the tent wall. In the morning we generally rose at six, lit the fire, and washed ourselves before it with fresh snow; we then took tea, and immediately afterwards dinner 
(which was similar to the supper of the night before). The tent was then struck, and every thing packed and stowed on the sledges, and at nine we usually took our departure."

The chief impediments to journeying on the ice were found to be the hummocks, often eighty feet high, which lie in ridges at certain distances, parallel perhaps to the shore. Along the line or lines where the ice is periodically broken, it is forced by pressure and the tossing of a tempestuous sea into those irregular ridges through which Wrangell had sometimes to make a way with crowbars for half a mile. The "polinyas," or spaces of open water in the midst of the ice, offered less hindrance, as they might be avoided; but in this neighborhood, and sometimes even where no hole in the ice was visible, layers of salt were met with, which cut the dogs' feet, and at the same time increased the labor of the draft, the sledges moving over the salt with as much difficulty as they would over gravel.

In spite of all these hindrances, Wrangell extended his exploration of the coast fifty versts beyond Cape Shelagskoi, where the want of fuel and provisions compelled him to return. The dépôts which he had made as he adranced, were found partly devoured by the stone-foxes and gluttons, so that the party was compelled to fast during the two last days of the journey. After an absence of three weeks Nishne-Kolymsk appeared like a second Capua to Wrangell, but time being precious he allowed himself but a few days' rest, and started afresh, on March 26, for Cape Shelagskoi, with the intention of pen etrating as far as possible to the north on the ice of the Polar Sea. The car avan consisted of twenty-two sledges, laden with fuel and provisions for thirty days, including food for 240 dogs. So imposing a train had certainly never been seen before in these desolate regions, for the part of the coast between the Kolyma and Cape Shelagskoi is wholly uninhabited; on one side the occasional excursions of the Russians terminate at the Baranow rocks, and on the other the Tchuktchi do not cross the larger Baranow River. The intervening eighty versts of coast are never visited by either party, but considered as neutral ground. On April 1 Wrangell reached the borders of the Polar Sea, and proceeding northward to $71^{\circ} 31^{\prime}$, found the thickness of the ice, which he measured by means of a hole, to be about a foot, very rotten, and full of salt; the soundings, twelve fathoms, with a bottom of soft green mud. The wind increasing in violence, he heard the sound of the water beneath, and felt the undulatory motion of the thin crust of ice.

"Our position," says the bold explorer, "was at least an anxious one; the more so as we could take no step to avoid the impending danger. I believe few of our party slept, except the dogs, who alone were unconscious of the great probability of the ice being broken up by the force of the waves. Next day, the wind having fallen, I had two of the best sledges emptied, and placed in them provisions for twenty-four hours, with the boat and oars, some poles and boards, and proceeded northward to examine the state of the ice; directing M. von Matiuschkin, in case of danger, to retire with the whole party as far a might be needful, without awaiting my return. After driving through the thick brine with much difficulty for seven versts, we came to a number of large 
fissures, which we rassed with some trouble by the aid of the boards which we had brought with us. At last the fissures became so numerous and so wide that it was hard to say whether the sea beneath us was really still covered by a connected coat of ice, or only by a number of detached floating fragments, having everywhere two or more feat of water between them. A single gust of wind would have been sufficient to drive these fragments against each other, and being already thoroughly saturated with water, they would have sunk in a few minutes, leaving nothing but sea on the spot where we were standing. It was manifestly useless to attempt going farther; we hastened to rejoin our companions, and to seek with them a place of greater security. Our most northern latitude was $71^{\circ} 43^{\prime}$ at a distance of 215 versts in a straight line from the lesser Baranow rock." After rejoining his companions, and while still on the frozen sea, so thick a snow-storm came on that those in the hindmost sledge could not see the leading ones. Unable either to pitch their tent or to light a fire, they were exposed during the night to the whole fury of the storm, with a temperatere of $+7^{\circ}$, without tea or soup, and with nothing to quench their thirst or satisfy their hunger but a few mouthfuls of snow, a little rye biscuit, and a half-spoilt fish. On April 28 they arrived at Nishne-Kolymsk, after an absence of thirty-six days, during which they had travelled above 800 miles with the same dogs, men and animals having equally suffered from cold, hunger, and fatigue.

Neither discomfort, however, nor danger prevented Wrangell from undertaking a third excursion in the following spring. He had great difficulty in procuring the necessary dogs, a disease which raged among them during the winter having carried off more than four-fifths of these useful animals. At length his wants were supplied by the people of the Indigirka, where the sickness had not extended, and on March 14, 1822, he again set out for the borders of the Polar Sea. During this expedition a large extent of coast was accurately surveyed by Wrangell, who sent out his worthy assistant Matiuschkin, with two companions, in an unloaded sledge, to see if any farther advance could be made to the north. Having accomplished ten versts, Matiuschkin was stopped by the breaking up of the ice. Enormous masses, raised by the waves into an almost vertical position, were driven against each other with a dreadful crash, and pressed downward by the force of the billows to re-appear again on the surface covered with the torn-up green mud which here forms the bottom of the sea. It would tire the reader were $I$ to relate all the miseries of their return voyage; suffice it to say that, worn out with hunger and fatigue, they reached Nishne-Kolymsk on May 5, after an absence of fifty-seven days. Such sufferings and perils might have excused all further attempts to discover the supposed land in the Polar Sea, but nothing daunted by his repeated failures, Wrangell determined on a fourth expedition in 1823, on which he resolved to start from a more easterly point. On reaching the coast, the obstacles were found still greater than on his previous visits to that fearful sea. The weather was tempestuous, the ice thin and broken. It was necessary at times to cross wide lanes of water on pieces of ice; at times the thin ice bent beneath the weight of the sledges, which were then saved only by the sagacity of the dogs, 
who, aware of the danger, ran at their greatest speed until they found a solid footing. At length, about sixty miles from shore, they arrived at the edge of an immense break in the ice, extending east and west farther than the eye could reach.

"We climbed one of the loftiest hummocks," says Wrangell, "whence we obtained an extensive view towards the north, and whence we beheld the wide ocean spread before our gaze. It was a fearful and magnificent, but to us a melancholy spectacle! Fragments of ice of enormous size floated on the surface of the water, and were thrown by the waves with awful violence against the edge of the ice-field on the farther side of the channel before us. The collisions were so tremendous that large masses were every instant broken away, and it was evident that the portion of ice which still divided the channel from the open ocean would soon be completely destroyed. Had we attempted to ferry ourselves across upon one of the floating pieces of ice, we should not have found firm footing upon our arrival. Even on our own side fresh lines of water were continually forming, and extending in every direction in the field of ice behind us. We could go no farther. With a painful feeling of the impossibility of overcoming the obstacles which nature opposea to us. our last hope vanished of discovering the land, which we yet believed to exist. We saw ourselves compelled to renounce the object for which we had striven through three years of hardships, toil, and danger. We had done what honor and duty demanded; further attempts would have been absolutely hopeless, and I decided to return."

They turned, but already the track of their advance was scarcely discernible, as new lanes of water had been formed, and fresh hummocks raised by the sea. To add to their distress, a storm arose, which threatened every moment to swallow up the ice island, on which they hoped to cross a wide space of water which separated them from a firmer ground.

"We had been three long hours in this position, and still the mass of ice beneath us held together, when suddenly it was caught by the storm, and hurled against a large field of ice; the crash was terrific, and the mass beneath us was shattered into fragments. At that dreadful moment, when escape seemed impossible, the impulse of self-preservation, implanted in every living being, saved us. Instinctively we all sprang at once on the sledges, and urged the dogs to their full speed. They flew across the yielding fragments to the field on which we had been stranded, and safely reached a part of it of firmer character, on which were several hummocks, where the dogs immediately ceased running, conscious, apparently, that the danger was past. We were saved! We joyfully embraced each other, and united in thanks to God for our preservation from such imminent peril."

But their misfortunes did not end here; they were cut off from the deposit of their provisions; they were 360 versts from their nearest magazines, and the food for the dogs was now barely sufficient for three days. Their joy may be imagined when, after a few versts' travelling, they fell in with Matiuschkin and his party, bringing with them an abundant supply of provisions of all kinds.

To leave nothing undone which could possibly be effected, Wrangell ad- 
vanced to the eastward along the coast, past Cape North, seen in Cook's last voyage, and proceeded as far as Koliutschin Island, where he found some Tchuktchi, who had come over from Bering's Straits to trade.

With this journey terminated Wrangell's labors on the coasts, or on the surface of the Polar Sea, and, at the beginning of the following winter, we find him taking a final leave of Nishne-Kolymsk. On January 10, 1824, he arrived at Jakutsk, and a few months later at Petersburg. If we consider the difficulties he had to encounter, and his untiring zeal and courage in the midst of privations and dangers, it is only fair to admit that his name deserves to be ranked among the most distinguished explorers of the Arctic world. 


\section{CHAPTER XXI.}

\section{THE TUNGUSI.}

Their Relationship to the Mantchou. - Dreadful Condition of the outcast Nomads. - Character of the Tungusi.-Their Outfit for the Chase.-Bear-hunting. - Dwellings.-Diet.-A Night's Halt with Tungusi in the Forest.-Ochotsk.

$\mathrm{T}$ HOUGH both belonging to the same stock, the fate of the Tungusi and Mantchou has been very different; for at the same time when the latter conquered the vast Chinese Empire, the former, after having spread over the greatest part of East Siberia, and driven before them the Jakuts, the Jukahiri, the Tchuktchi, and many other aborigmal tribes, were in their turn subjugated by the mightier Russians. In the year 1640 the Cossacks first encountered the Tungusi, and in 1644 the first Mantchou emperor mounted the Chinese throne. The same race which here imposes its yoke upon millions of subjects, there falls a prey to a small number of adventurers. However strange the fact, it is, however, easily explained, for the Chinese were worse armed and less disciplined than the Mantchou, while the Tungusi had nothing but bows and arrows to oppose to the Cossack fire-arms; and history (from Alexander the Great to Sadowa) teaches us that victory constantly sides with the best weapons.

In their intellectual development we find the same difference as in their fortunes between the Mantchou and the Siberian Tungusi. Two hundred and fifty years ago the former were still nomads, like their northern kinsfolk, and could neither read nor write, and already they have a rich literature, and their language is spoken at the court of Peking; while the Tungusi, oppressed and sunk in poverty, are still as ignorant as when they first encountered the Cossacks.

According to their occupations, and the various domestic animals employed by them, they are distinguished by the names of Reindeer, Horse, Dog, Forest, and River Tungusi; but although they are found from the basins of the Upper, Middle, and Lower Tunguska to the western shores of the Sea of Ochotsk, and from the Chinese frontiers and the Baikal to the Polar Ocean, their whole number does not amount to more than 30,000, and diminishes from year to year, in consequence of the ravages of the small-pox and other epidemic disorders transmitted to them by the Russians. Only a few rear horses and cattle, the reindeer being generally their domestic animal; and the impoverished Tunguse, who has been deprived of his herd by some contagious disorder or the ravages of the wolves, lives as a fisherman on the borders of a river, assisted by his dog, or retires into the forests as a promyschlenik, or hunter. Of the miseries which here await him, Wrangell relates a melancholy instance. In a solitary hut in one of the dreariest wildernesses imaginable, he found a 
Tunguse and his daughter. While the father, with his long snow-shoes, was pursuing a reindeer for several days together, this unfortunate girl remained alone and helpless in the hut-which even in summer afforded but an imperfect shelter against the rain and wind-exposed to the cold, and frequently to hunger, and without the least occupation. No wonder that the impoverished Tungusi not seldom sink into cannibalism. Neither the reindeer nor the dogs, nor the wives and children of their more fortunate countrymen, are secure from the attacks and voracity of these outcasts, who, in their turn, are treated like wild beasts, and destroyed without mercy. A bartering trade is, however, carried on with them, but only at a distance, and by signs; each party depositing its goods, and following every motion of the other with a suspicious eye.

The Russian Government, anxious to relieve the misery of the impoverished nomads, has given orders to settle them along the river-banks, and to provide them with the necessary fishing implements; but only extreme wretchedness can induce the Tunguse to relinquish the free life of the forest. His careless temper, his ready wit, and sprightly manner, distinguish him from the other Siberian tribes-the gloomy Samoïede, the uncouth Ostiak, the reserved Jakut -but he is said to be full of deceit and malice. His vanity shows itself in the quantity of glass beads with which he decorates his dress of reindeer leather, from his small Tartar cap to the tips of his shoes. When chasing or travelling on his reindeer through the woods, he of course lays aside most of his finery, and puts on large water-tight boots, or sari, well greased with fat, to keep off the wet of the morass. His hunting apparatus is extremely simple. A small axe, a kettle, a leathern bag containing some dried fish, a dog, a short gun, or merely a bow and a sling, is all he requires for his expeditions into the forest. With the assistance of his long and narrow snow-shoes, he flies over the dazzling plain, and protects his eyes, like the Jakut, with a net made of black horse-hair. He never hesitates to attack the bear single-handed, and generally masters him. The nomad Tunguse naturally requires a movable dwelling. His tent is covered with leather, or large pieces of pliable bark, which are easily rolled up and transported from place to place. The yourt of the sedentary Tunguse resembles that of the Jakut; and is so small that it can be very quickly and thoroughly warmed by a fire kindled on the stone hearth in the centre. In his food the Tunguse is by no means dainty. One of his favorite dishes consists of the contents of a reindeer's stomach mixed with wild berries, and spread out in thin cakes on the rind of trees, to be dried in the air or in the sun. Those who have settled on the Wiluj and in the neighborhood of Nertschinsk, likewise consume large quantities of brick tea, which they boil with fat and berries into a thick porridge, and this unwholesome food adds no doubt to the yellowness of their complexion.

But few of the Tungusi have been converted to Christianity, the majority being still addicted to Shamanism. They do not like to bury their dead, but place them, in their holiday dresses, in large chests, which they hang up between two trees. The hunting apparatus of the deceased is buried beneath the chest. No ceremonies are used on the occasion, except when a Shaman happens to be in the neighborhood, when a reindeer is sacrificed, on whose 
flesh the sorcerer and the relations regale themselves, while the spirits to whom the animal is supposed to be offered are obliged to content themselves with the smell of the burnt fat. As among the Samoïedes or the Ostiaks, woman is a marketable ware among the Tungusi. The father gives his daughter in marriage for twenty or a hundred reindeer, or the bridegroom is obliged to earn her hand by a long period of service.

In East Siberia the Tungusi divide with the Jakuts the task of conveying goods or travellers through the forests, and afford the stranger frequent opportunities for admiring their agility and good-humor. On halting after a day's journey, the reindeer are unpacked in an instant, the saddles and the goods ranged orderly on the ground, and the bridles collected and hung on branches of trees. The hungry animals soon disappear in the thicket, where they are left to provide for themselves. The men, who meanwhile have been busy with their axes, drag a larch-tree or two to the place of encampment. The smaller branches are lopped off and collected to serve as beds or seats upon the snow, while the resinous wood of the larger trunks is soon kindled into a lively fire. The kettle, filled with snow, is suspended from a strong forked branch placed obliquely in the ground over the fire, and in a few minutes the tea is ready-for the Tungusi proceed every evening according to the same method, and are consequently as expert as long and invariable practice can make them. Comfortably seated on his reindeer saddle, the traveller may now amuse himself with the dances, which the Tungusi accompany with an agreeable song; or if he choose to witness their agility in athletic exercises, it only costs him a word of encouragement, and a small donation of brandy. Two of the Tungusi hold a rope, and swing it with all their might, so that it does not touch the ground. Meanwhile a third Tunguse skips over the rope, picks up a bow and arrow spans the bow and shoots the arrow, without once touching the rope. Some particularly bold and expert Tungusi will dance over a sword which a person lying on his back on the ground is swinging about with the greatest rapidity. Should our traveller be a friend of chess, the Tungusi are equally at his service, as they are passionately fond of this noblest of games, especially in the Kolymsk district. Like all other Siberian nomads, they visit at least once a year the various fairs which are held in the small towns scattered here and there over their immense territory-such as Kirensk, Olekminsk, Bargusin, Tschita, and Ochotsk, which, before the opening of the Amoor to trade, was the chief port of East Siberia.

Ochotsk is one of the dreariest places imaginable; at least no traveller who ever visited it has a word to say in its favor. Not a single tree grows for miles and miles around, and the wretched huts of which the town is composed lie in the midst of a swamp, which in summer is a fruitful source of malaria and pestilence. The River Ochota, at whose mouth Ochotsk is situated, does not break up before the end of May, and the ice-masses continue to pass the town till the 15 th or 20 th of June. Soon after begins the most unpleasant time of all the year, or "buss" of the Siberians, characterized by thick fog and a perpetual drizzling rain. The weather clears up in July, but as early as August the night-frosts cover the earth with rime. Salmon, of which no less than 
fourteen different species live in the Sea of Ochotsk, are the only food which the neighborhood affords; all other necessaries of life come from Jakutsk, and are of course enormously dear. Meat appears only from time to time on the tables of the wealthier merchants, and bread is an article of luxury. No wonder that the scurvy ravages every winter a place so ill-provisioned, and that at the time when the first caravan of pack-horses is expected to cross the Aldan Mountains, the people of Ochotsk, unable to restrain their impatience, go out a long way to meet it. As the former trade of the place has now no doubt been transferred to the settlements on the Amoor, it may well be supposed that Ochotsk has lost most of its former inhabitants, who can only be congratulated on their change of residence. 


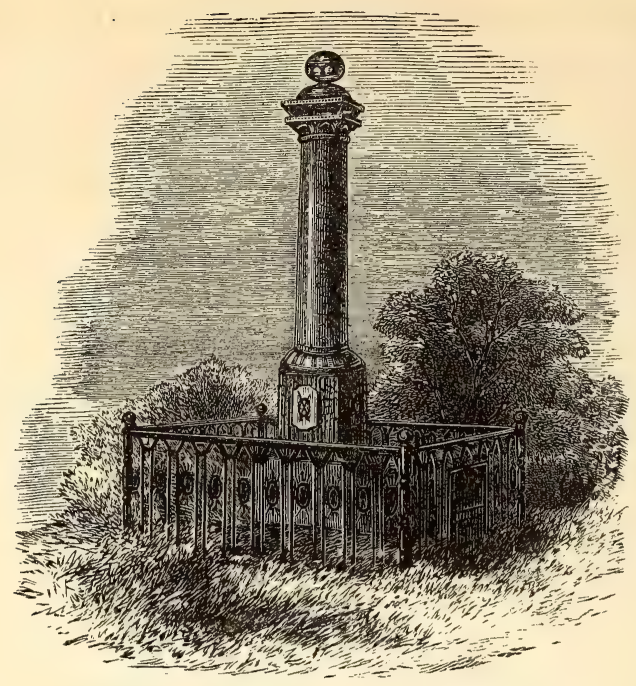

BERING'S MONUMENT AT PETROPAULOVSK.

\section{CHAPTER XXII.}

\section{GEORGE WILLIAM STELLER.}

His Birth.-Enters the Russian Service._Scientific Journey to Kamchatka.-Accompaniea Bering on his second Voyage of Discovery.-Lands on the Island of Kaiak.-Shameful Conduct of Bering.-Shipwreck on Bering Island.-Bering's Death.-Return to Kamchatka.-Loss of Property.-Persecutions of the Siberian Authorities.-Frozen to Death at Tjumen.

YEORGE WILLIAM STELLER, one of the most distinguished natural. $\mathcal{G}$ ists of the past century, was born at Winsheim, a small town in Franconia, in the year 1709. After completing his studies at the universities of Wittenberg and Halle, he turned his thoughts to Russia, which, since the reforms of Czar Peter the Great, and the protection which that monarch and his successors afforded to German learning, had become the land of promise for all adventurous spirits.

Having been appointed surgeon in the Russian army, which at that time was besieging Danzig, he went with a transport of wounded soldiers, after the surrender of that town, to St. Petersburg, where he arrived in 1734. Here his talents were soon appreciated; after a few years he was named a member of the Imperial Academy of Sciences, and sent by Government, in 1738, to examine the natural productions of Kamchatka. The ability and zeal with which he fulfilled this mission is proved by the valuable collections which he sent to the Academy, and by his numerous memoirs, which are still read with interest in the present day.

In 1741 he accompanied Bering on his second voyage of discovery, the object of which was to determine the distance of America from Kamchatka, and to ascertain the separation or the junction of both continents in a higher 
latitude - a question which his first voyage had left undecided. Nothing could be more agreeable to a man like Steller, than the prospects held out to him by an expedition to unknown regions; and we can easily imagine the delight with which the naturalist embarked on board of the "Saint Peter," commanded by Bering in person. Accompanied by the "Saint Paul," under Tschirigow, they sailed on June 4 from the Bay of Avatscha.

The expedition had cost ten years of preparation, and brought misery and ruin upon many of the wild Siberian tribes, for all that was necessary for the outfit had to be conveyed by compulsory labor from the interior of the continent over mountains and rivers, through dense forests and pathless wilds, and it seemed from the very beginning of the voyage as if the curses of the unfortunate natives clung to it. Much valuable time had been lost, for the ships ought to have sailed at least a month earlier, and Bering, who from illness constantly kept to his cabin, was by no means a fit commander for a scientific expedition.

After a few days a dense fog separated the vessels, which were never to meet again; and as the "St. Peter" held her course too much to the south, the Aleutic chain remained undiscovered, and the first land was only sighted after four weeks in the neighborhood of Bering's Bay. During the whole of this passage Steller had to endure all the vexations which arrogant stupidity could inflict upon a man anxious to do his duty. It was in vain that he repeatedly pointed out the signs which indicated the presence of land not far to the north, in vain that he entreated the commander to steer but one day in that direction. At last, on July 15, the high mountains of America were seen to rise above the horizon, and the vessel anchored on the 19th near to the small island of Kaiak.

On the following day a boat was sent out to fetch some fresh water, but it was with the utmost difficulty that Steller could obtain permission to join the party. All assistance was obstinately denied him, and accompanied by his only servant, a Cossack, he landed on the unknown shore, eager to make the most of the short time allotted him for his researches. He immediately directed his steps towards the interior, and had scarcely walked a mile when he discovered the hollowed trunk of a tree, in which, a few hours before, the savages had boiled their meat with red-hot stones. He also found several pots filled with esculent herbs, and a wooden instrument for making fire, like those which are used by the inhabitants of Kamchatka. Hence he conjectured that the aborigines of this part of the American coast must be of the same origin as the Kamchatkans, and that both countries must necessarily approach each other towards the north, as the inhabitants could not possibly traverse such vast extents of ocean in their rudely-constructed boats.

Pursuing his way, Steller now came to a path which led into a dense and shady forest. Before entering, he strictly forbade his Cossack to act without commands, in case of a hostile encounter. The Cossack had a gun, with a knife and hatchet; Steller himself only a Jakut poniard, which he had taken with him to dig out plants or stones. After half an hour's walking, they came to a place strewn with grass. This was inmediately removed, and a roof' or plat- form discovered, consisting of strips of bark laid upon poles and covered with 
stones. This platform opened into a cellar containing a large quantity of smoked fishes, and a few bundles of the inner bark of the larch or fir tree, which, in case of necessity, serves as food throughout all Siberia. There were also some arrows, dyed black and smoothed, of a size far superior to those used in Kamchatka.

After Steller, in spite of the danger of being surprised by the savages, had accurately examined the contents of the cellar, he sent his Cossack back again to the place where the boatmen were watering. He gave him specimens of the various articles which he had found, ordering him to take them to Captain Bering, and to request that two or three men might be sent to him for further assistance. In the mean time, though quite alone, he continued his investigations of the strange land, and having reached the summit of a hill, he saw smoke rising from a forest at some distance. Overjoyed at the sight, for he now could hope to meet with the natives and to complete his knowledge of the island, he instantly returned to the landing-place with all the eagerness of a man who has something important to communicate; and as the boat was just about to leave, told the sailors to inform the captain of his discovery, and to beg that the small pinnace, with a detachment of armed men, might be sent out to him.

Meanwhile, exhausted with fatigue, he sat down on the beach, where he described in his pocket-book some of the more delicate plants he had collected, which he feared might speedily wither, and regaled himself with the excellent water. After waiting for about an hour, he at length received an answer from Bering, telling him to return immediately on board, unless he chose to be left behind; and we can easily imagine the indignation of the disappointed naturalist at this shameful command.

On the morning of July 21, Bering, contrary to his custom, appeared on deck, ordered the anchors to be weighed, and gave directions to sail back again on the same course. The continent he had discovered was not even honored with a single visit, so that Steller could not help telling the Russians they had merely come thus far for the purpose of carrying American water to Asia. Any conscientious commander would have continued to sail along the unknown shore, or, considering that the season was already far advanced, would have determined to winter there, and to pursue his discoveries next spring; but, unfortunately for Bering and his companions, the course he adopted proved as disastrous as it was dishonorable.

Three months long the ship was tossed about by contrary winds and storms; the islands of the Aleutic chain, though frequently seen through the mists, were but seldom visited; the scurvy broke out among the dispirited, ill-fed crew, their misery increased from day to day, and their joy may be imagined when at length, on November 5 , a land was seen which they firmly believed to be Kamchatka-though in reality it was merely the desert of Bering's Island, situated a hundred miles from that peninsula. Even those who were nearly half dead crept upon deck to enjoy the welcome sight ; every one thanked God, and the ignorant officer, convinced that they were at the entrance of the Bay of Avatscha, even named the several mountains; but 
their mistake soon became apparent when, on rounding a small promontory, some well-known islets were missed. As they had no doubt, however, that the land was really Kamchatka, and the bad weather and the small number of hands fit to do duty rendering it difficult to reach the Gulf of Avatscha, it was resolved to run into the bay that lay before them, and to send notice from thence to Nishne-Kamchatsk of their safe arrival.

Steller was among the first to land, and probably the very first of the party who discovered the mistake of the excellent navigators to whom the expedition had been intrusted. Sea-otters came swimming to him from the land, and he well knew that these much-persecuted animals had long since disappeared from the coast of Kamchatka. The number of Arctic foxes, too, who showed no fear at his approach, and the sea-cows gambolling in the water, were sure signs that the foot of man had not often trodden this shore. Steller was also the first to set the good example of making the best of a bad situation, instead of uselessly bewailing his misfortunes. He began to erect a hut for the following winter, and formed an association with several of the crew, who, whatever might await them, promised to stand by each other.

During the following days the sick were gradually conveyed on shore. Some of them died on board as soon as they were brought into the open air, others in the boat, others as soon as they were landed. "On all sides," says Steller, in his interesting account of this ill-fated voyage, "nothing was to be seen but misery. Before the dead could be buried, they were mangled by the foxes, who even ventured to approach the helpless invalids who were lying without cover on the beach. Some of these wretched sufferers bitterly complained of the cold, others of hunger and thirst-for many had their gums so swollen and ulcerated with the scurvy as to be unable to eat."

"On November 13," continues the naturalist, "I went out hunting for the first time with Messieurs Plenisner and Betge; we killed four sea-otters, and did not return before night. We ate their flesh thankfully, and prayed to God that He might continue to provide us with this excellent food. The costly skins, on the other hand, were of no value in our eyes; the only objects which we now esteemed were knives, needles, thread, ropes, etc., on which before we had not bestowed a thought. We all saw that rank, science, and other social distinctions were now of no avail, and could not in any way contribute to our preservation: we therefore resolved, before we were forced to do so by necessity, to set to work at once. We introduced among us five a community of goods, and regulated our housekeeping in such a manner as not to be in want before the winter was over. Our three Cossacks were obliged to obey our orders, when we had decided upon something in common; but we began to treat them with greater politeness, calling them by their names and surnames, and we soon found that Peter Maximowitsch served us with more alacrity than formerly Petrucha (a diminutive of Peter).

"Nov. 14.-The whole ship's company was formed into three parties. The one had to convey the sick and provisions from the ship; the second brought wood; the third, consisting of a lame sailor and myself, remained at home- 
the former busy making a sledge, while $I$ acted as cook. As our party was the first to organize a household, I also performed the duty of bringing warm soup to some of our sick, until they had so far recovered as to be able to help themselves.

"The barracks being this day ready to receive the sick, many of them were transported under roof; but for want of room, they lay everywhere on the ground, covered with rags and clothes. No one could assist the other, and nothing was heard but lamentations and curses-the whole affording so wretched a sight, as to make even the stoutest heart lose courage. On November 15 all the sick were at length landed. We took one of them, named Boris Sänd, into our hut, and by God's help he recovered within three months.

"The following days added to our misery, as the messengers we had sent out brought us the intelligence that we were on a desert island, without any communication with Kamchatka. We were also in constant fear that the stormy weather might drive our ship out to sea, and along with it all our provisions, and every hope of ever returning to our homes. Sometimes it was impossible to get to the vessel for several days together, so boisterous was the surge; and about ten or twelve men, who had hitherto been able to work, now also fell ill. Want, nakedness, frost, rain, illness, impatience, and despair, were our daily companions."

Fortunately the stormy sea drove the ship upon the strand, better than it could probably have been done by human efforts. Successively many of the scorbutic patients died, and on December 8 the unfortunate commander of the expedition paid his debt to nature.

Titus Bering, by birth a Dane, had served thirty-six years with distinction in the Russian navy, but age and infirmities had completely damped his energies, and his death is a warning to all who enter upon undertakings above their strength.

In the mean time the whole ship's company had established itself for the winter in five subterranean dwellings; the general health was visibly improving, mereiy by means of the excellent water, and by the fresh meat furnished by sea-otters, seals, and manatees; and the only care now was to gain sufficient strength to be able to undertake the work of deliverance in spring.

In April the shipwrecked mariners began to build a smaller ship out of the timbers of the "St. Peter," and, such was the alacrity with which all hands set to work, that on August 13 they were able to set out.

"When we were all embarked," says Steller, "we first perceived how much we should be inconvenienced for want of room; the water-casks, provisions, and baggage taking up so much space, that our forty-two men (the three ship's officers and myself were somewhat better off in the cabin) could hardly creep between them and the deck. A great quantity of the bedding and clothing had to be thrown overboard. Meanwhile we saw the foxes sporting about our deserted huts, and greedily devouring remnants of fat and meat.

"On the 14th, in the morning, we weighed anchor, and steered out of the 
bay. The weather being beautiful, and the wind favorable, we were all in good spirits, and, as we sailed along the island, pointed out to each other the well-known mountains and valleys which we had frequently visited in quest of game or for the purpose of reconnoitring. Towards evening we were opposite the farthest point of the island, and on the 15th, the wind continuing favorable, we steered direct towards the Bay of Avatscha. About midnight, however, we perceived, to our great dismay, that the vessel began to fill with water from an unknown leak, which, in consequence of the crowded and overloaded state of the vessel, it was extremely difficult to find out. The pumps were soon choked by the shavings left in the hold, and the danger rapidly increased, as the wind was strong and the vessel badly built. The sails were immediately taken in; some of the men removed the baggage to look for the leak, others kept continually pouring out the water with kettles, while others again cast all superfluous articles overboard. At length, after the lightening of the ship, the carpenter succeeded in stopping the leak, and thus we were once more saved from imminent danger. . . On the 17th we sighted Kamchatka, but as the wind was contrary, we did not enter the harbor before the evening of the $27 \mathrm{th}$.

"In spite of the joy we all felt at our deliverance, yet the news we heard on our arrival awakened in us a host of conflicting emotions. We had been given up for lost, and all our property had passed into other hands, and been mostly carried away beyond hope of recovery. Hence joy and sorrow alternated within a few moments in our minds, though we were all so accustomed to privation and misery, as hardly to feel the extent of our losses."

In the year 1744 Steller was ordered to return to St. Petersburg; but his candor had made him powerful enemies. Having reached Novgorod, and rejoicing in the idea of once more mixing with the civilized world, he was suddenly ordered to appear before the imperial court of justice at Irkutsk, on the charge of having treacherously sold powder to the enemies of Russia. Thus obliged to return once more into the depths of Siberia, he was at length dismissed by his judges, after waiting a whole year for their verdict.

Once more on his way to St. Petersburg, he had already reached Moscow, when he was again summoned to appear without delay before the court of Irkutsk. A journey to Siberia is, under all circumstances, an arduous undertaking; what, then, must have been Steller's feelings when, instead of enjoying the repose he had so well merited, he saw himself obliged to retrace his steps for the fourth time, for the purpose of vindicating his conduct before a rascally tribunal? On a very cold day his Cossack guards stopped to refresh themselves with some brandy at an inn by the road-side, and Steller, who remained in the sledge waiting for their return, fell asleep, and was frozen to death.

He lies buried near the town of Tjumen, and no monument apprises the naturalist, whom the love of knowledge may lead into the Siberian wilds, that his unfortunate predecessor was thus basely requited after years of exertion in the interests of science. 


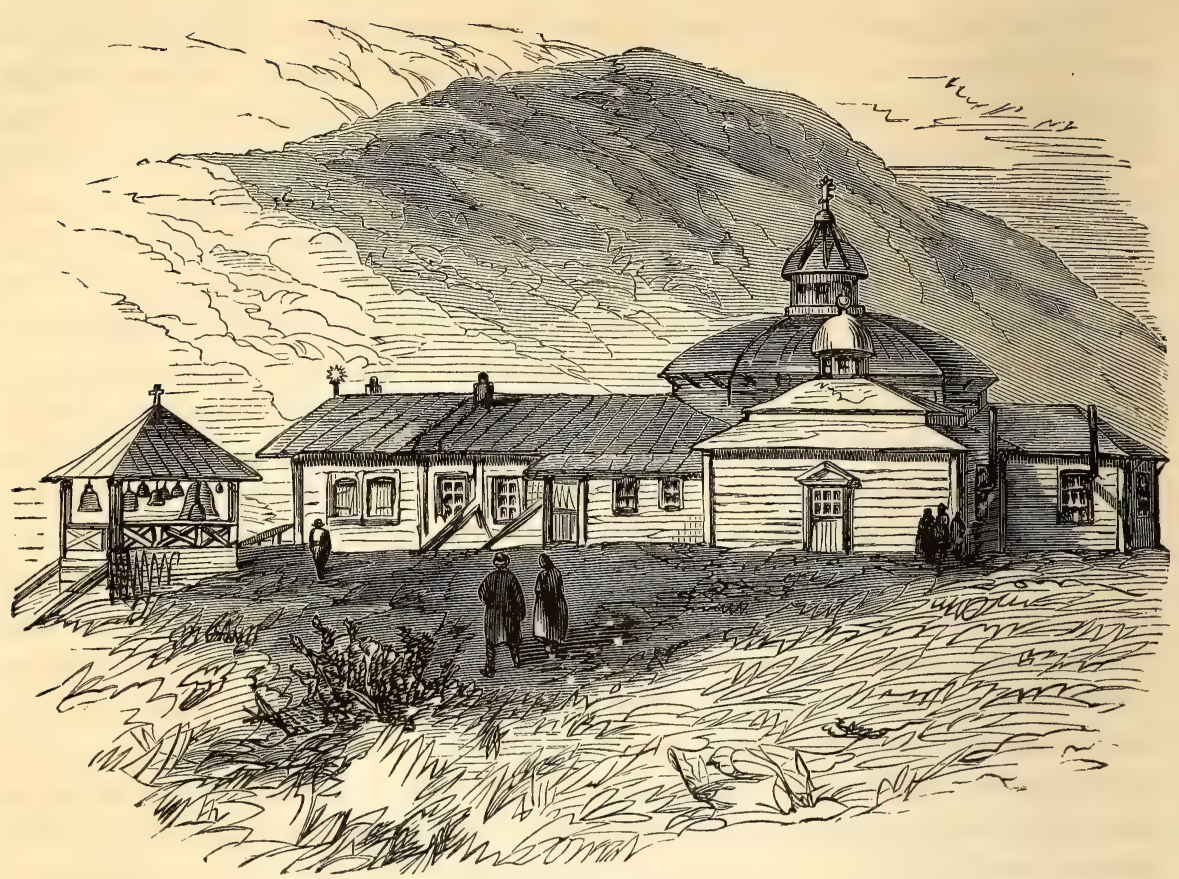

CHURCH AT PETROPAVLOSK.

\section{CHAPTER XXIII.}

\section{KAMCHATKA.}

Climate.-Fertility.-Luxuriant Vegetation.-Fish.-Sea-birds. - Kamchatkan Bird-catchers.-The Bay of Avatscha.-Petropaylosk.-The Kamchatkans.-Their physical and moral Qualities.-The Fritillaria Sarrana.-The Muchamor.-Bears.-Dogs.

TTHE peninsula of Kamchatka, though numbering no more than 6000 or 7000 1 inhabitants, on a surface equalling Great Britain in extent, has so many natural resources that it could easily maintain a far greater number. The climate is much more temperate and uniform than that of the interior of Siberia, being neither so excessively cold in winter, nor so intensely hot in summer; and though the late and early night-frosts, with the frequent fogs and rains, prevent the cultivation of corn, the humid air produces a very luxuriant herbaceous vegetation. Not only along the banks of the rivers and lakes, but in the forest glades, the grass grows to a height of more than twelve feet, and many of the Compositæ and Umbelliferæ attain a size so colossal that the Heraclium dulce and the Senecio cannabifolius not seldom overtop the rider on horseback. The pasture-grounds are so excellent that the grass can generally be cut thrice during the short summer, and thus a comparatively small extent of land affords the winter supply for all the cattle of a hamlet. Though the cold winds prevent the growth of trees along the coast, the more inland mountain slopes and valleys are clothed with woods richly stocked with sables and squirrels. 
No country in the world has a greater abundance of excellent fisheries. In spring the salmon ascend the rivers in such amazing numbers, that on plunging a dart into the stream one is almost sure to strike a fish; and Steller affirms that the bears and dogs of Kamchatka catch on the banks more fish with their paws and mouths than man in other countries, with all his cunning devices of net or angle. As the various birds of passage do not all wander at the same time to the north, so also the various kinds of fishes migrate, some sooner, others later, and consequently profusion reigns during the whole of the summer. Ermann was astonished at this incalculable abundance of the Kamchatkan rivers, for in one of them, when the water was only six inches deep, he saw multitudes of Chaekos (Slagocephalus) as long as his arm partly stranded on the banks, partly still endeavoring to ascend the shallow stream. As the waters contain such an incredible multitude of fishes, we can not wonder that the rocky coasts of the peninsula swarm with sea-fowl, whose breeding and roosting places are as densely peopled as any others in the world. At the entrance of the Avatscha Bay lies a remarkable labyrinth of rocks, separated from each other by narrow channels of water, like the intricate streets of an old-fashioned city. The flood has everywhere scooped out picturesque cavities and passages in these stupendous masses of stone, and the slightest wind causes the waves to beat with terrific violence against their feet. Every ledge, platform, and projection, every niche, hollow, and crevice is peopled with sea-birds of strange and various forms. In the capture of these birds the Kamchatkans display an intrepidity equal to that of the islanders of St. Kilda or Feroe, and trust solely to their astonishing agility in climbing. Barefooted, without ropes or any other assistance, they venture down the steepest declivities, which are frequently only accessible from the top, as the foaming breakers cut off all access from below. The left arm clasps a basket, which they fill with eggs as they advance, while the right hand grasps a short stick with an iron hook to drag the birds from the crevices of the rock. When a bird is caught, a dexterous grip wrings its neck, and it is then attached to the girdle of the fowler. In this manner an expert climber will kill in one day from seventy to eighty birds, and gather above a hundred eggs.

Thus the population of Kamchatka is quite out of proportion to the riches of its pastures and waters. Its scanty inhabitants are moreover concentrated on a few spots along the chief rivers and bays, so that almost the whole peninsula is nothing but an uninhabited wilderness.

Before the conquest of the country by the Russians it had at least twenty times its present population, but the cruelty of the Cossacks and the ravages of the small-pox caused it to melt away almost as rapidly as that of Cuba or Hayti after the arrival of the Spaniards. At that time the sable and the sea-otter were considered of far greater importance than man; and unfortunately Russia has too many deserts to people, before she can think of repairing past errors and sparing inhabitants for this remotest corner of her vast Asiatic empire.

As the peninsula is too distant from the highways of the world to attract the tide of emigration, it is also seldom visited by travellers. The few stran- 
gers, however, who have sailed along the coasts, or made excursions into the in. terior of the country, speak with enthusiasm of the boldness of its rocky prom. ontories, the magnificence of its bays and mountains, and only regret that during the greater part of the year an Arctic winter veils the beauties of the landscape under mists and snow.

Throughout its whole length Kamchatka is traversed by an Alpine chain rising in some of its peaks to a height of 14,000 or 16,500 feet, and numbering no less than 28 active volcanoes along with many others whose fires are extinct. A land thus undermined with subterranean fires must be possessed of many mineral riches, but as yet no one has ever thought of seeking for them or putting them to use.

Owing to the great humidity of the climate and the quantities of rain attracted by the mountains, Kamchatka abounds in springs. In the lowlands they gush forth in such numbers as to render it very difficult to travel any distance on foot or horseback, even in winter, as they prevent the rivers from freezing. No doubt many a mineral spring-cold, tepid, or warm-that would make the fortune of a German spa, here flows unnoticed into the sea.

Kamchatka has many excellent harbors, and the magnificent Bay of Avatscha would alone be able to afford room to all the navies of the world. Its steep rocky shores are almost everywhere clothed with a species of beech (Betula Ermanni), intermingled with luxuriant grasses and herbs, and the higher slopes are generally covered with a dense underwood of evergreens and shrubs of deciduous foliage, whose changes of color in autumn tinge the landscape with yellow, red, and brown tints. But the chief beauty of the Bay of Avatscha is the prospect of the distant mountains, forming a splendid panorama of fantastic peaks and volcanic cones, among which the Streloshnaja Sopka towers pre-eminent to the height of 14,000 feet. Close to this giant, but somewhat nearer to the coast, rises the active volcano of Avatscha, which frequently covers the whole country with ashes.

The vast Bay of Avatscha forms several minor creeks : among others the haven of St. Peter and Paul, one of the finest natural harbors in the world, where the Russians have established the seat of their government in the small town of Petropavlosk, which hardly numbers 500 inhabitants, but has acquired some celebrity from the unsuccessful attack of the English and French forces in 1854.

Mr. Knox thus describes Petropavlosk: "To make a counterfeit Petropavlosk, take a $\log$ village in the backwoods of a western state in America, and place it near a little harbor, where the ground slopes gently to the water. Arrange most of the houses along a single unpaved street, and drop the rest in a higgledy-piggledy fashion on the sloping hillside. All buildings must be but one story high, and those of the poorer sort thatched with grass. The better class may have iron or board roofs painted for preservation. The houses of the officials and the foreign merchants may be commodious, and built of hewn timber, but the doors of all must be low, and heavily constructed, to exclude the winter cold. Every dwelling must contain a brick stove that presents a side to each of two or three rooms. In winter this stove will maintain a temperature of about 68 degrees in all the rooms it is intended to warm." 


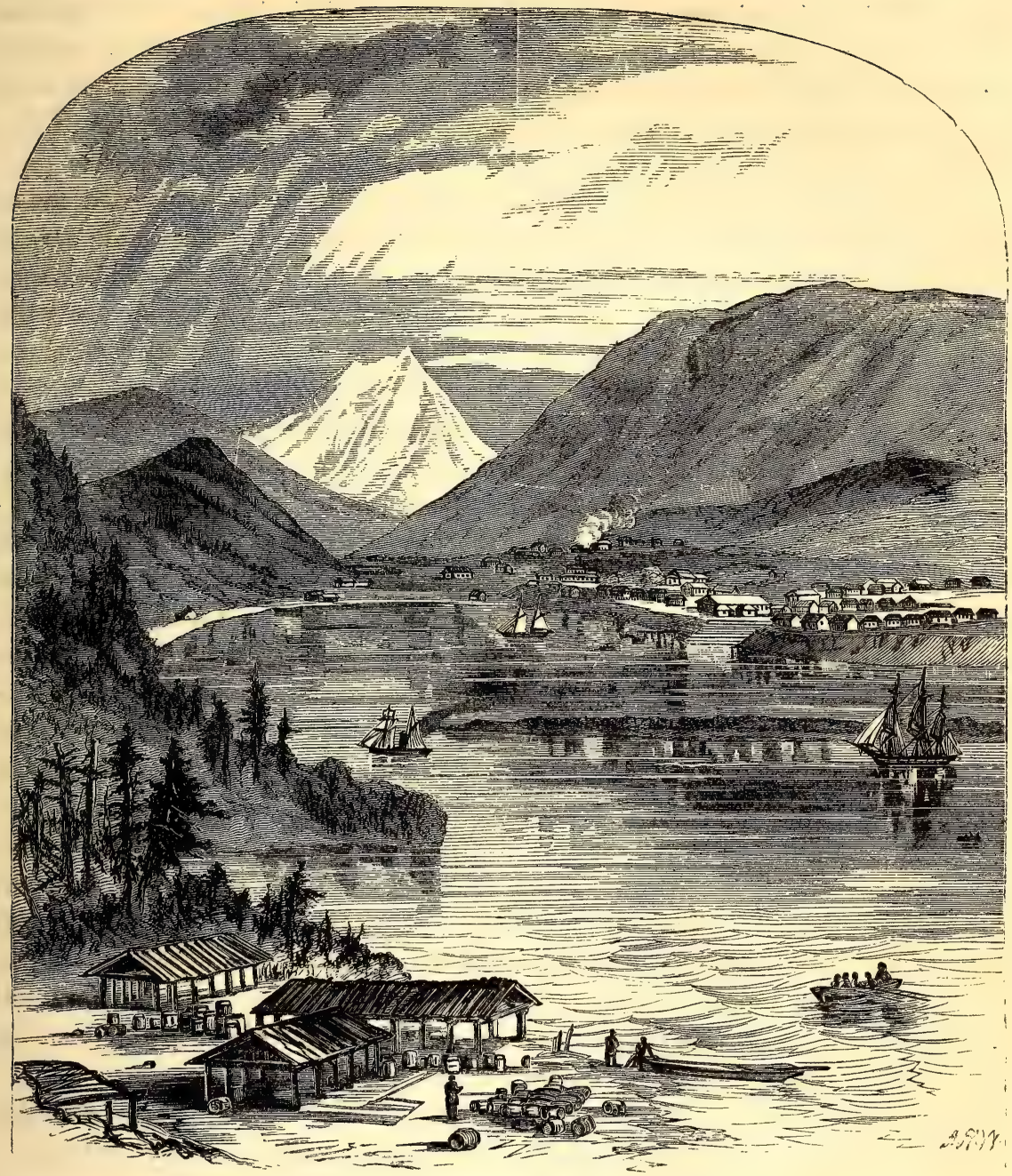

PETROPAVLOSK.

Besides some Jakut immigrants, the chief stock of the scanty population of the country consists of the descendants of the primitive Kamchatkans, who, in spite of frequent intermarriages with their conquerors the Cossacks, have still retained many of their ancient manners. They are of a small stature, but broadshouldered, their cheek-bones are prominent, their jaws uncommonly broad and projecting, their noses small, their lips very full, their hair black. The color of the men is dark brown, or sometimes yellow; the women have fairer complexions, which they endeavor to preserve by means of bears' guts, stuck upon their faces in spring with fresh lime, so as not to be burned by the sun. They also paint their cheeks with a sea-weed, which, when rubbed upon them with fat, gives them a beautiful red color.

The Kamchatkans are a remarkably healthy race. Many of them attain an age of seventy or eighty years, and are able to walk and to work until their 
death. Their hair seldom turns gray before their sixtieth year, and even the oldest men have a firm and elastic step. The weight of their body is greater than that of the Jakuts, though the latter live on milk and flesh, while fish is the almost exclusive food of the Kamchatkans. The round tubercles of the Fritillaria sarrana, a species of lily with a dark purple flower, likewise play an important part in their diet, and serve them instead of bread and meal. "If the fruits of the bread-fruit tree," says Kittlitz-who has seen both plants in the places of their growth-" are pre-eminent among all others, as affording man a perfect substitute for bread, the roots of the Sarrana, which are very similar in taste, rank perhaps immediately after them. The collecting of these tubers in the meadows is an important summer occupation of the women, and one which is rather troublesome, as the plant never grows gregariously, so that each root has to be sought and dug out separately with a.knife. Fortunately the wonderful activity of the Siberian field-vole facilitates the labor of gathering the tubers. These remarkable animals burrow extensive winter nests, with five or six store-houses, which they fill with various roots, but chiefly with those of the Sarrana. To find these subterranean treasures, the Kamchatkans use sticks with iron points, which they strike into the earth. The contents of three of these nests are as much as a man can carry on his back. A species of fungus, called muchamor, affords a favorite stimulant. It is dried and eaten raw. Besides its exhilarating effects, it is said to produce, like the Peruvian Coca, a remarkable increase of strength, which lasts for a considerable time.

Fishing and hunting supply all the wants of the Kamchatkans, for they have not yet learned to profit in any degree worth mentioning by the luxuriance of their meadow-lands. They pay their taxes and purchase their foreign luxuries -meal and tea, tobacco and brandy-with furs. The chase of the costly sea. otter (which from excessive persecution had at one time almost become extinct) has latterly improved. Besides the fur animals, they also hunt the reindeer, the argali, the wolf, and the bear, whose skins supply them with clothing.

Bears abound in Kamchatka, as they find a never-failing supply of fishes and berries, and Ermann assures us that they would long since have extirpated the inhabitants, if (most probably on account of the plenty in which they live) they were not of a more gentle disposition than any others in the world. In spring they descend from the mountains to the mouths of the rivers, to levy their tribute on the migratory troops of the fishes, frequently eating only the heads. Toward autumn they follow the fishes into the interior of the country as they ascend the streams.

The most valuable domestic animal in Kamchatka is the dog, who has the usual characters of the Esquimaux race. He lives exclusively on fish, which he catches very dexterously. From spring to autumn he is allowed to roam at iiberty, no one troubling himself about him; but in October, every proprietor collects his dogs, binds them to a post, and lets them fast for a time, so as to deprive them of their superfluous fat, and to render them more fit for running. During the winter they are fed with dried fish every morning and evening, but while travelling they get nothing to eat, even though they run for hours. Their strength is wonderful. Generally no more than five of them are harnessed to a 


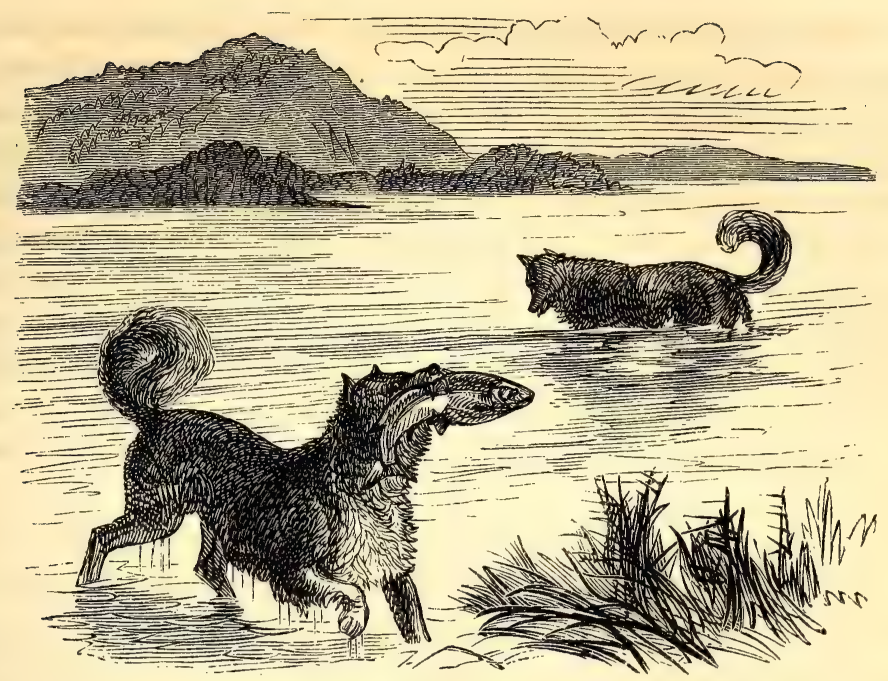

DOGS FISHRNG.

sledge, and will drag with ease three full-grown persons, and sixty pounds' weight of luggage. When lightly laden, such a sledge will travel from 30 to 40 versts in a day over bad roads and through the deep snow; on even roads, from 80 to 140. The horse can never be used for sledging, on account of the deep snow, into which it would sink, and of the numerous rivers and sources, which are either never frozen, or merely covered with a thin sheet of ice, unable to bear the weight of so large an animal.

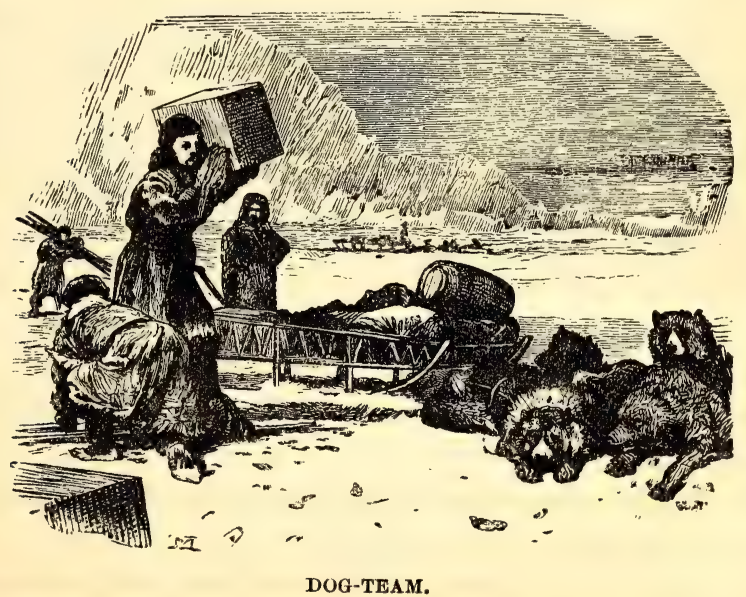

Travelling with dogs is, however, both dangerous and difficult. Instead of the whip, the Kamchatkans use a crooked stick with iron rings, which, by their jingling, give the leader of the team the necessary signals. When the dogs do not sufficiently exert themselves, the stick is cast among them to rouse them to greater speed; but then the traveller must be dexterous enough to 
pick it up again while the sledge shoots along. During a snow-storm the dogs keep their master warm, and will lie quietly near him for hours, so that he has merely to prevent the snow from covering him too deeply and suffocating him. The dogs are also excellent weather prophets, for when, while resting, they dig holes in the snow, a storm may with certainty be expected.

The sledge-dogs are trained to their future service at a very early period. Soon after birth they are placed with their mother in a deep pit, so as to see neither man nor beast, and, after having been weaned, they are again condemn. ed to solitary confinement in a pit. After six months they are attached to a sledge with other older dogs, and, being extremely shy, they run as fast as they can. On returning home, they are again confined in their pit, where they

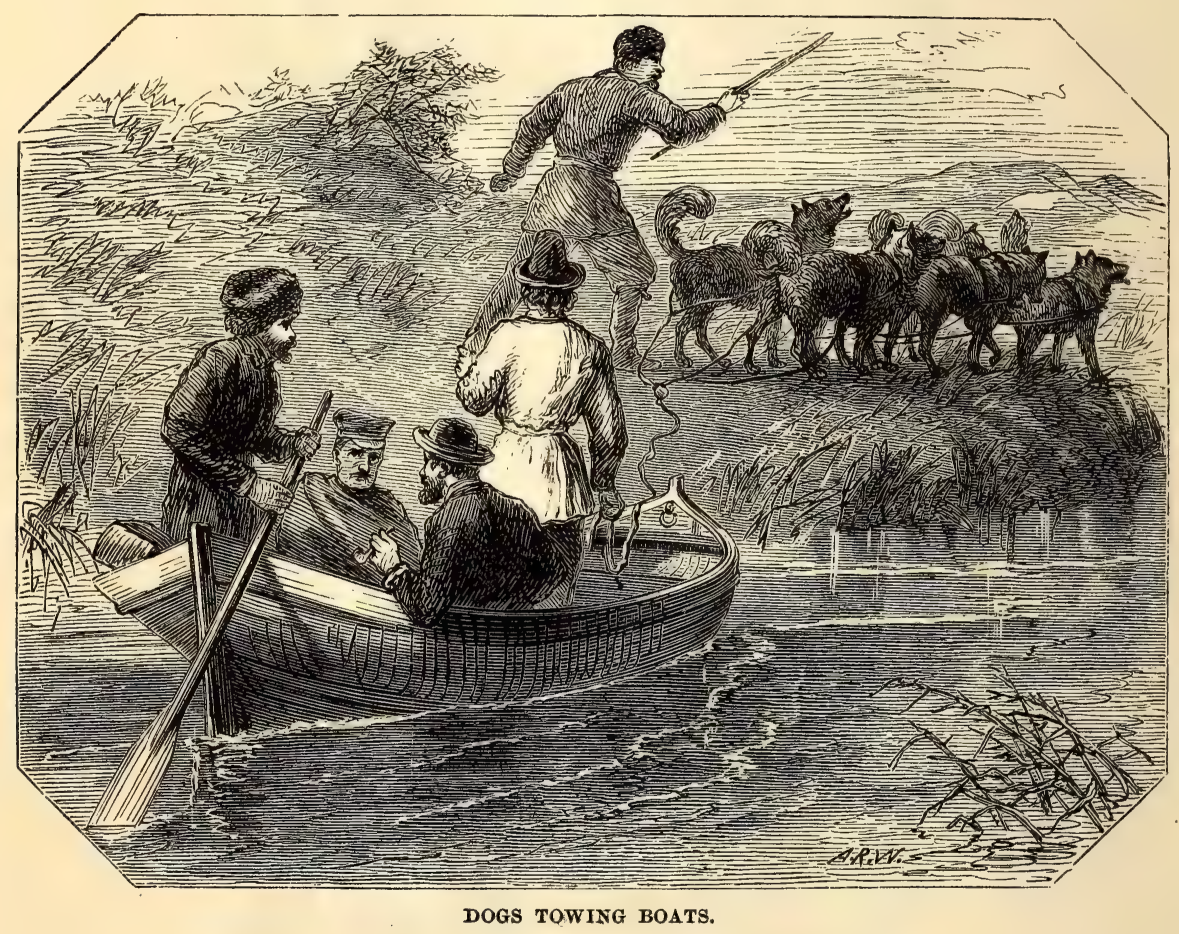

remain until they are perfectly trained, and able to perform a long journey. Then, but not before, they are allowed their summer liberty. This severe education completely sours their temper, and they constantly remain gloomy, shy, quarrelsome, and suspicious.

To return to the Kamchatkans: travellers praise their good-nature, their hospitality, and their natural wit. Of a sanguine disposition, they are happy and content in their poverty, and have no cares for the morrow. Being extremely indolent, they never work unless when compelled. They readily adopt strange manners, and no doubt education might produce valuable results in so pliable and sharp-witted a race. Unfortunately the Russians and Cossacks who have settled among them do not afford them the best examples. They 
have long since been converted to the Greek Church, but it is supposed that baptism has not fully effaced all traces of Shamanism. Formerly they had many gods, the chief of whom was Kutka, the creator of heaven and earth. But far from honoring Kutka, they continually ridiculed him, and made him the constant butt of their satire. Kutka, however, had a wife, Chachy, who was endowed with all the intelligence in which her spouse was supposed to be deficient, and who, as is the case in many mortal housekeepings, was constantly exerting her ingenuity in repairing the blunders of her lord and master. 


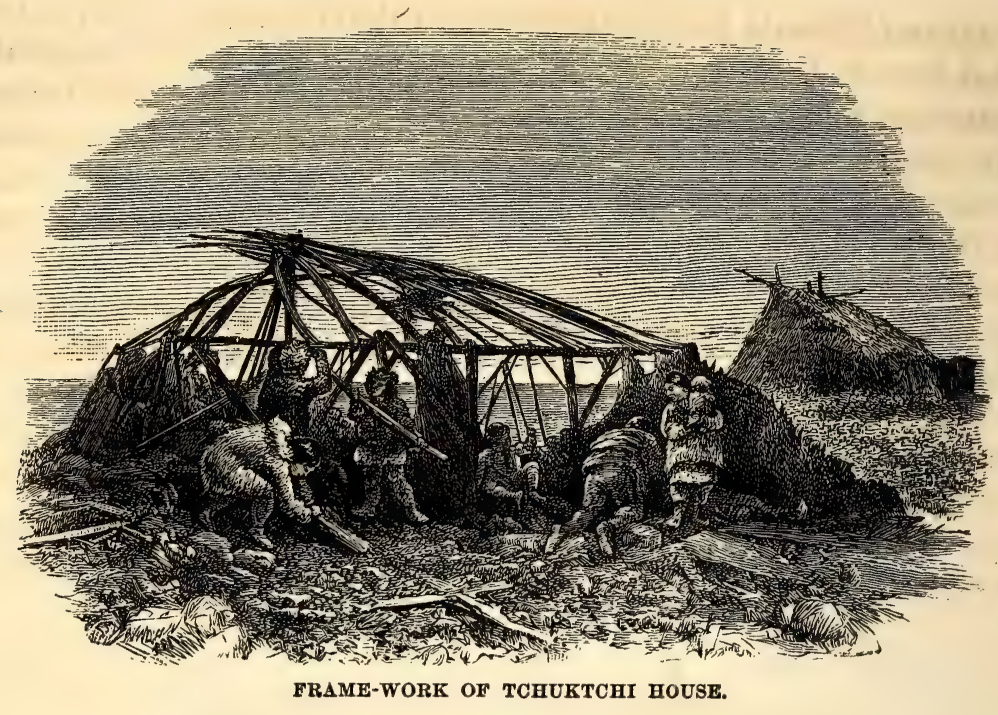

\section{CHAPTER XXIV.}

\section{THE TCHUKTCHI.}

The Land of the Tchuktchi.-Their independent Spirit and commercial Enterprise.-Perpetual Migrations.-The Fair of Ostrownoje.-Visit in a Tchuktch Polog.-Races.-Tchuktch Bayaderes.-The Tennygk, or Reindeer Tchuktchi.-The Onkilon, or Sedentary Tchuktchi.-Their Mode of Life.

$\mathbf{A}^{\mathrm{T}}$ the extreme north-eastern point of Asia, bounded by the Polar Ocean A on one side and the Sea of Bering on the other, lies the land of the Tchuktchi. The few travellers who have ever visited that bleak promontory describe it as one of the dreariest regions of the earth. The climate is dreadfully cold, as may be expected in a country confined between icy seas. Before July 20th there is no appearance of summer, and winter already sets in about August 20th. The lower grounds shelving to the north are intersected with numerous streams, which, however, enjoy their liberty but a short time of the year; the valleys are mostly swampy and filled with small lakes or ponds; while on the bleak hill-slopes the Vaccinium and the dwarf birch or willow sparingly vegetate under a carpet of mosses and lichens. The eastern, northeastern, and partly also the southern coasts abound with walruses, sea-lions, and seals, while the reindeer, the argali, the wolf, and the Arctic fox occupy the land. During the short summer, geese, swans, ducks, and wading-birds frequent the marshy grounds; but in winter the snow-owl and the raven alone remain, and constantly follow the path of the nomadic inhabitants. In this desolate nook of the Old World lives the only aboriginal people of North Asia which has known how to maintain its liberty to the present day, and which, proud of its independence, looks down with sovereign contempt upon its relations, the Korjaks, who, without offering any resistance, have yielded to the authority of Russia. 
The rulers of Siberia have indeed confined the Tchuktchi within narrow limits, but here at least they obey no foreign ruler, and wander, unmolested by the stranger, with their numerous reindeer herds, over the naked tundras. A natural distrust of their powerful neighbors has rendered them long unwilling to enter into any commercial intercourse with the Russians, and to meet them at the fair of Ostrownoje, a small town, situated not far from their frontiers, on a small island of the Aniuj, in $68^{\circ} \mathrm{N}$. lat.

This remotest trading-place of the Old World is not so unimportant as might be supposed, from the sterile nature of the country, for the Tchuktchi are not satisfied, like the indolent Lapps or Samoïedes, with the produce of their reindeer herds, but strive to increase their enjoyments or their property by an active trade. From the East Cape of Asia, where, crossing Bering's Straits in boats covered with skins, they barter furs and walrus-teeth from the natives of America, the Tchuktchi come with their goods and tents drawn on

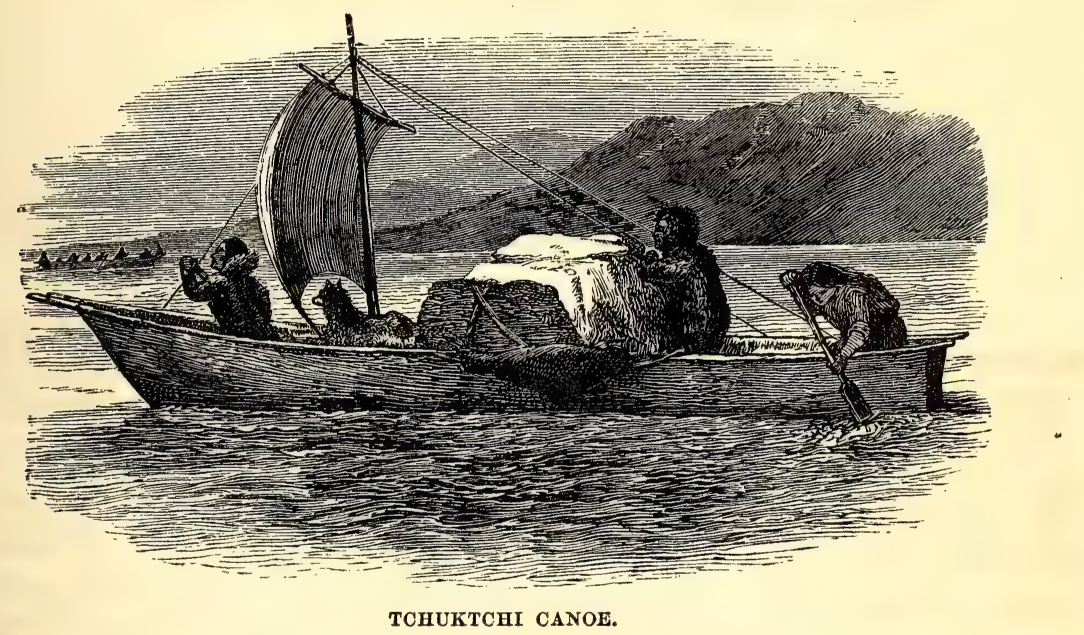

sledges to the fair of Ostrownoje. Other sledges laden with lichens, the food of the reindeer, follow in their train, as in their wanderings, however circuitous, they not seldom pass through regions so stony and desert as not even to afford these frugal animals the slightest repast. Thus regulating their movements by the wants of their herds, they require five or six months for a journey which, in a direct line, would not be much longer than a thousand versts, and are almost constantly wandering from place to place, though, as they always carry their dwellings along with them, they at the same time never leave home. One of these snail-like caravans generally consists of fifty or sixty families, and one fair is scarcely at an end when they set off to make their arrangements for the next.

Tobacco is the primum mobile of the trade which centres in Ostrownoje. Their pipes are of a peculiar character, larger at the stem than the bowl, which holds a very small quantity of tobacco. In smoking, they swallow the fumes of the tobacco, and often, after six or eight whiffs, fall back completely intoxi- 


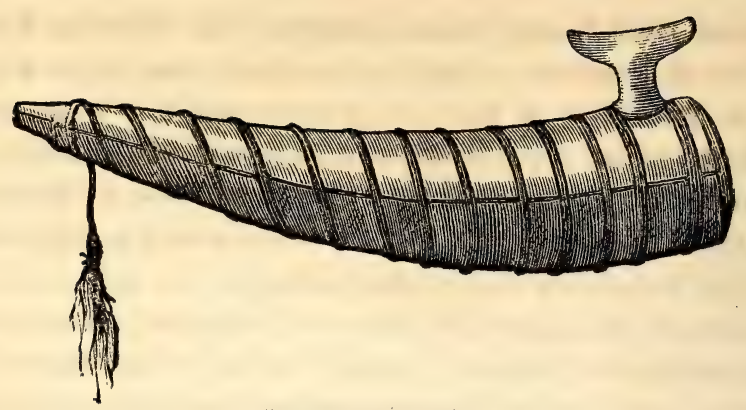

TCHUKTCHI PIPE.

cated for the time. The desire to procure a few of its narcotic leaves induces the American Esquimaux, from the Icy Cape to Bristol Bay, to send their produce from hand to hand as far as the Gwosdew Islands in Bering's Straits, where it is bartered for the tobacco of the Tchuktchi, and these again principally resort to the fair of Ostrownoje to purchase tobacco from the Russians. Generally the Tchuktchi receive from the Americans as many skins for half a poud, or eighteen pounds, of tobacco-leaves as they afterwards sell to the Russians for two pouds of tobacco of the same quality. These cost the Russian merchant about 160 roubles at the very utmost, while the skins which he obtains in barter are worth at least 260 at Jakutsk, and are more than double that sum at St. Petersburg.

The furs of the Tchuktchi principally consist of black and silver-gray foxes, stone-foxes, gluttons, lynxes, otters, beavers, and a fine species of marten which does not occur in Siberia, and approaches the sable in value. They also bring to the fair bear-skins, walrus-thongs and teeth, sledge-runners of whale-ribs, and ready-made clothes of reindeer skin. The American furs are generally packed in sacks of seal-skin, which are made in an ingenious manner by extracting the bones and flesh through a small opening made in the abdomen.

The Russian traders on their part bring to the fair, besides tobacco, ironware-particularly kettles and knives-for the Tchuktchi, and tea, sugar, and various stuffs for their countrymen who have settled along the Kolyma.

But Ostrownoje attracts not only Tchuktchi and Russians; a great num. ber of the Siberian tribes from a vast circuit of 1000 or 1500 versts-Jukahires, Lamutes, Tungusi, Tschuwanzi, Koriaks - also come flocking in their sledges, drawn partly by dogs, partly by horses, for the purpose of bartering their commodities against the goods of the Tchuktchi. Fancy this barbarous assembly meeting every year during the intense cold and short days of the beginning of March. Picture to yourself the fantastic illumination of their red watch-fires blazing under the starry firmament, or mingling their ruddy glare with the Aurora flickering through the skies, and add to the strange sight the hollow sound of the Shaman's drum, and the howling of several hundreds of hungry dogs, and you will surely confess that no fair has a more original character than that of Ostrownoje. A government commissary, assisted by some Cossacks, superintends the fair, and receives the inconsiderable market-tax which the Tchuktehi pay to the Emperor. 
All preliminaries having been arranged, the orthodox Russians repair to the chapel for the purpose of hearing a solemn mass, after which, the hoisting of a flag on the tower of the ostrog announces the opening of the market. At this welcome sign, the Tchuktchi, completely armed with spears, bows, and arrows, advance with their sledges, and form a wide semicircle round the fort, while the Russians, and the other visitors of the fair, ranged opposite to them, await in breathless silence the tolling of the bell, which is to begin the active business of the day. At the very first sound, each trader, grotesquely laden with packages of tobacco, kettles, knives, or whatever else he supposes best able to supply some want, or to strike some fancy of the Tchuktchi, rushes as fast as he can towards the sledges, and in the jumble not seldom knocks down a competitor, or is himself stretched at full length on the snow. But, unmindful of the loss of cap and gloves, which he does not give himself time to pick up, he starts afresh, to make up for the delay by redoubled activity. Before he reaches the first Tchuktch, his eloquence breaks forth in an interminable flow, and in a strange jargon of Russian, Tchuktch, and Jakute, he praises the excellence of his tobacco or the solidity of his kettles. The imperturbable gravity of the Tchuktch forms a remarkable contrast with the greedy eagerness of the Russian trader ; without replying to his harangue, he merely shakes his head if the other offers him too little for his goods, and never for an instant loses his self-possession: while the Russian, in his hurry, not seldom hands over two pouds of tobacco for one, or pockets a red fox instead of a black one. Although the Tchuktch have no scales with them, it is not easy to deceive them in the weight, for they know exactly by the feeling of the hand whether a quarter of a pound is wanting to the poud. The whole fair seldom lasts longer than three days, and Ostrownoje, which must have but very few stationary inhabitants indeed (as it is not even mentioned in statistical accounts, which cite towns of seventeen souls), is soon after abandoned for many months to its ultra-Siberian solitude.

But before we allow the Tchuktchi to retire to their deserts, we may learn something more of their habits by accompanying Mr. Matiuschkin-Wrangell's companion-on a visit to the ladies of one of their first chiefs. "We enter the outer tent, or ' namet,' consisting of tanned reindeer skins supported on a slender frame-work. An opening at the top to let out the smoke, and a kettle in the centre, announce that antechamber and kitchen are here harmoniously blended into one. But where are the inmates? Most probably in that large sack made of the finest skins of reindeer calves, which occupies, near the kettle, the centre of the 'namet.' To penetrate into this 'sanctum sanctorum' of the Tchuktch household, we raise the loose flap which serves as a door, creep on all fours through the opening, cautiously re-fasten the flap by tucking it under the floor-skin, and find ourselves in the reception or withdrawing room-the ' polog.' A snug box no doubt for a cold climate, but rather low, as we can not stand upright in it, and not quite so well ventilated as a sanitary commissioner would approve of, as it has positively no opening for light or air. A suffocating smoke meets us on entering, we rub our eyes, and when they have at length got accustomed to the biting atmosphere, we perceive, by the gloomy light of a 
train-oil lamp, the worthy family squatting on the floor in a state of almost complete nudity. Without being in the least embarrassed, Madame Leütt and her daughter receive us in their primitive costume: but to show us that the Tchuktchi know how to receive company, and to do honor to their guests, they immediately insert strings of glass beads in their greasy hair. Their hospitality equals their politeness; for, instead of a cold reception, a hot dish of boiled reindeer-flesh, copiously irrigated with rancid train-oil by the experienced hand of the mistress of the household, is soon after smoking before us. Unfortunately our effeminate taste is not up to the haut gout of her culinary art, and while Mr. Leütt does ample justice to the artistic talent of his spouse, by rapidly bolting down pieces as large as a fist, we are hardly able to swallow a morsel."

During his visit at Ostrownoje, Matiuschkin had a favorable opportunity of becoming acquainted with the sports of the Tchuktchi, the chieftain, Makomol, having set out prizes for a race. These consisted of a valuable silver fox, a first-rate beaver skin, and two fine walrus-teeth. Nothing can be more admirable than the fleetness of the reindeer or the dexterity of their drivers; and the agility displayed in the foot-race by the Tchuktchi, running at full speed, in their heavy winter dresses, over a distance of fifteen versts, gives a high idea of their muscular powers. After the races, the spectators are treated to a grand choregraphic display. The Arctic bayaderes, muffled from head to foot in their stiff skin garments, form a narrow circle, slowly moving their feet backward and forward, and fiercely gesticulating with their hands, whilst their faces are distorted into a thousand horrible grimaces. The singing that accompanies the ballet has no doubt its charm for native ears, but to strangers it seems no better than a kind of grunt. The representation is closed by three first-rate artistes executing a particularly farorite dance. The faces of their countrymen express the same intense admiration with which a European dilettante follows the graceful pirouettes of a Taglioni, while the Russian guests see only three greasy monsters alternately rushing towards each other and starting back, until at length they stop from sheer exhaustion. As a token of their satisfaction, the Russians regale the fair performers with a cup of brandy. and a roll of tobacco, and both parties take leave of each other with mutual protestations of satisfaction and friendship.

Though most of the Reindeer or nomadic Tchuktchi have been baptized, yet Wrangell supposes the ceremony to have been a mere financial speculation on their part, and is convinced that the power of the Shamans is still as great as aver. An epidemic had carried off a great number of persons, and also whole herds of reindeer. In vain the Shamans had recourse to their usual conjurations, the plague continued. They consulted together, and directed that one of their most respected chiefs, named Kotschen, must be sacrificed, to appease the irritated spirits. Kotschen was willing to submit to the sentence, but none could be found to execute it, until his own son, prevailed on by his father's exhortations, and terrified by his threatened curse, plunged a knife into his heart, and gave his body to the Shamans.

Polygamy is general among the Tchuktchi, and they change their wives as often as they please. Still, though the women are certainly slaves, they are al- 
lowed more influence, and are subjected to less labor than among many savages. Among other heathenish and detestable customs, is that of killing all deformed children, and all old people as soon as they become unfit for the hardships and fatigues of a nomad life. Two years before Wrangell's arrival at Kolyma there was an instance of this in the case of one of their richest chiefs. Waletka's father became infirm and tired of life, and was put to death at his own express desire by some of his nearest relations.

Besides the wandering, or Reindeer Tchuktchi, who call themselves Tennygk, there are others, dwelling in fixed habitations along the borders of the sea at Bering's Straits and the Gulf of Anadyr, who differ considerably from the former in appearance and language. These Onkilon, or stationary Tchuktchi, belong to the wide-spread Esquimaux family, and, like most of their race, subsist by hunting the whale, the walrus, and the seal. They live in a state of abject dependence on the nomad Tchuktchi, and are poor, like all fishermen, while some of the Tennygk chieftains possess several thousands of reindeer, and are continually adding to their wealth by trade. Of course there is an active exchange of commodities between the two; the Onkilon furnishing thongs of walrus hide, walrus-teeth, train-oil, etc., and receiving reindeer skins, or ready-made clothes of the same material, in return.

They live in small settlements or villages spread along the coast; their huts, raised on frame-works of whale-rib and covered with skins, resemble a large irregular cone reposing on its side, with the apex directed to the north, and the base shelving abruptly to the south. Here is the small opening, closed by a flap of loose skin, which serves as a door, while the smoke escapes and the light enters through a round hole in the roof. At the farther or northern end of this structure is a second low square tent, covered with double reindeer skins, the polog, which in winter serves both as the dining and bed room of the family.

The Onkilon catch seals in a kind of net made of leather straps, which they spread out under the ice, and in which the animal entangles itself with the head or flippers. When the walrus, which is particularly abundant about Koliutschin Island, creeps on shore, they steal upon it unawares, cut off its retreat, and kill it with their spears. Like the Esquimaux, they use dogs to drag their sledges.

The number of the Tchuktchi is greater than one might expect to find in so sterile a country. According to the Russian missionaries, there were, some years back, 52 ulusses or villages of the Onkilon, with 1568 tents, and 10,000 inhabitants; and Wrangell tells us that the Tennygk are at least twice as numerous, so that the entire population of the land of the Tchuktchi may possibly amount to 30,000 . 


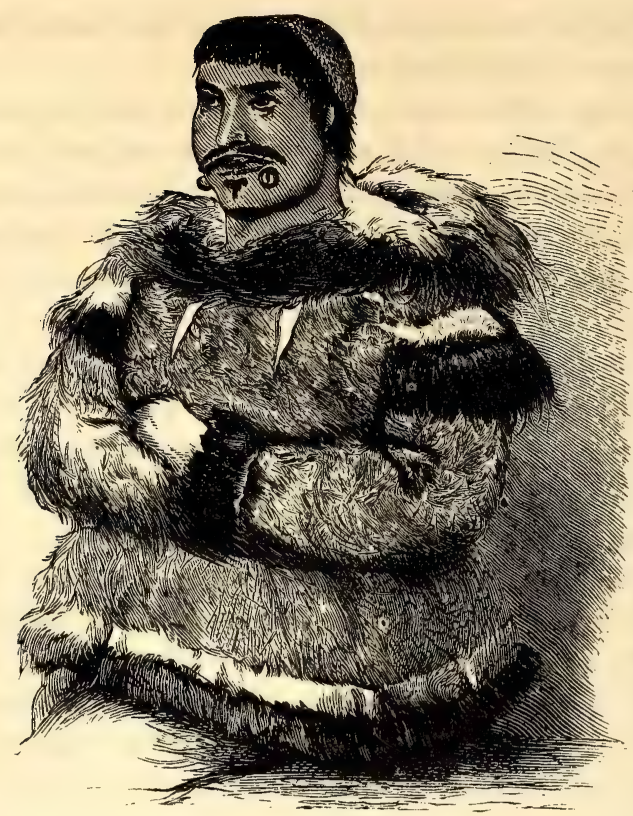

AN ALEUT.

\section{CHAPTER XXV.}

\section{BERING SEA-THE RUSSIAN FUR COMPANY-THE ALEUTS.}

Bering Sea._Unalaska.-The Pribilow Islands.-St. Matthew.-St. Laurence.-Bering's Straits,-The Russian Fur Company.-The Aleuts. - Their Character.-Their Skill and Intrepidity in hunting the Sea-otter.-The Sea-bear.-Whale-chasing.-Walrus-slaughter.-The Sea-lion.

$\mathrm{B}^{\mathrm{T}}$ ERING SEA is extremely interesting in a geographical point of view, as the temperature of its coasts and islands exhibits so striking a contrast with that part of the Arctic Ocean which extends between Greenland, Iceland, Norway, and Spitzbergen, and affords us the most convincing proof of the benefits we owe to the Gulf Stream, and to the mild south-westerly winds which sweep across the Atlantic. While through the sea between Iceland and Scotland, a part of the warmth generated in the tropical zone penetrates by means of marine and aërial currents as far as Spitzbergen and the western coast of Nova Zembla, the Sea of Bering is completely deprived of this advantage. The long chain of mountainous islands which bounds it on the south serves as a barrier against the mild influence of the Pacific, and instead of warm streams mixing with its waters, many considerable rivers and deep bays yearly discharge into it enormous masses of ice. Thus as soon as the navigator enters Bering Sea he perceives at once a considerable fall in the temperature, and finds himself suddenly transferred from a temperate oceanic region to one of a decidedly Arctic character. In spite, therefore, of their comparatively southerly position (for the Straits of Bering do not even reach the Arctic Circle, and the Andrianow Islands are ten degrees farther to the south than 
the Feroës), those frigid waters are, with regard to climate, far less favorably situated than the seas of Spitzbergen.

The same gradual differences of temperature and vegetation which we find in Unalaska, the Pribilow Islands, St. Laurence, and the Straits of Bering, within $10^{\circ}$ of latitude, occur in the Shetland Islands, Iceland, Bear Island, and Spitzbergen at distances of almost $20^{\circ}$; so that in the Sea of Bering the increase of cold on advancing to the north is about twice as rapid as in the waters between North Europe-and North America.

The long and narrow peninsula of Aliaska, which forms the south-eastern boundary of this inhospitable sea, shows us its influence in a very marked degree, for while the climate of the northern side of that far-projecting landtongue has a decidedly Arctic character, its southern coasts fronting the $\mathrm{Pa}$ cific enjoy a temperate climate. The mountain-chain which, rising to a height of five or six thousand feet, forms the backbone of the peninsula, serves as the boundary of two distinct worlds, for while the northern slopes are bleak and treeless like Iceland, the southern shores are covered from the water's edge with magnificent forests. While on the northern side the walrus extends his excursions down to $56^{\circ} 30^{\prime} \mathrm{N}$. lat., on the southern exposure the hummingbird is seen to flit from flower to flower as high as $61^{\circ}$, the most northerly point it is known to attain.

The Feroë Islands $\left(64^{\circ} \mathrm{N}\right.$. lat. $)$ have undoubtedly a no very agreeable climate to boast of, but they may almost be said to enjoy Italian skies when compared with Unalaska $\left(54^{\circ} \mathrm{N}\right.$. lat.), the best known of the Aleutian chain.

The Scandinavian archipelago is frequently obscured with fogs, but here they are perpetual from April to the middle of July. From this time till the end of September the weather improves, as then the southerly winds drive the foggy region more to the north, and enable the sun to shine during a few serene days upon the bleak shores of Unalaska. But soon the Polar air-streams regain the supremacy, and a dismal veil once more shrouds the melancholy island. Of Sitka, the chief town of Aliaska, Mr. Whymper says: "It enjoys the unenviable position of being about the most rainy place in the world. Rain ceases only when there is a good prospect of snow." Snow generally begins to fall early in October, and snow-storms occur to the very end of May. There are years in which it rains continually during the whole winter. In the Feroës some service-trees are to be seen twelve feet high or more, while nothing like a tree ever grew in Unalaska. The difference between the temperatures of the summer and winter, which in the Feroës is confined to very narrow limits, is much more considerable in Unalaska, though here also the moderating influence of the sea makes itself felt. Thus in summer the thermometer rarely rises above $66^{\circ}$, but on the other hand in winter it still more rarely falls below $-2^{\circ}$.

Of course no corn of any kind can possibly ripen in a climate like this, but the damp and cool temperature favors the growth of herbs. In the moist lowlands the stunted willow-bushes are stifled by the luxuriant grasses; and even on the hills, the vegetation, which is of a decidedly Alpine character, covers the earth up to the line of perpetual snow; while several social plants, such 
as the Lupinus nootkeanus and the Rhododendron kamtschadalicum, decorate these dismal regions with their brilliant color. The lively green of the meadows reminds one of the valley of Urseren, so well known to all Alpine tourists.

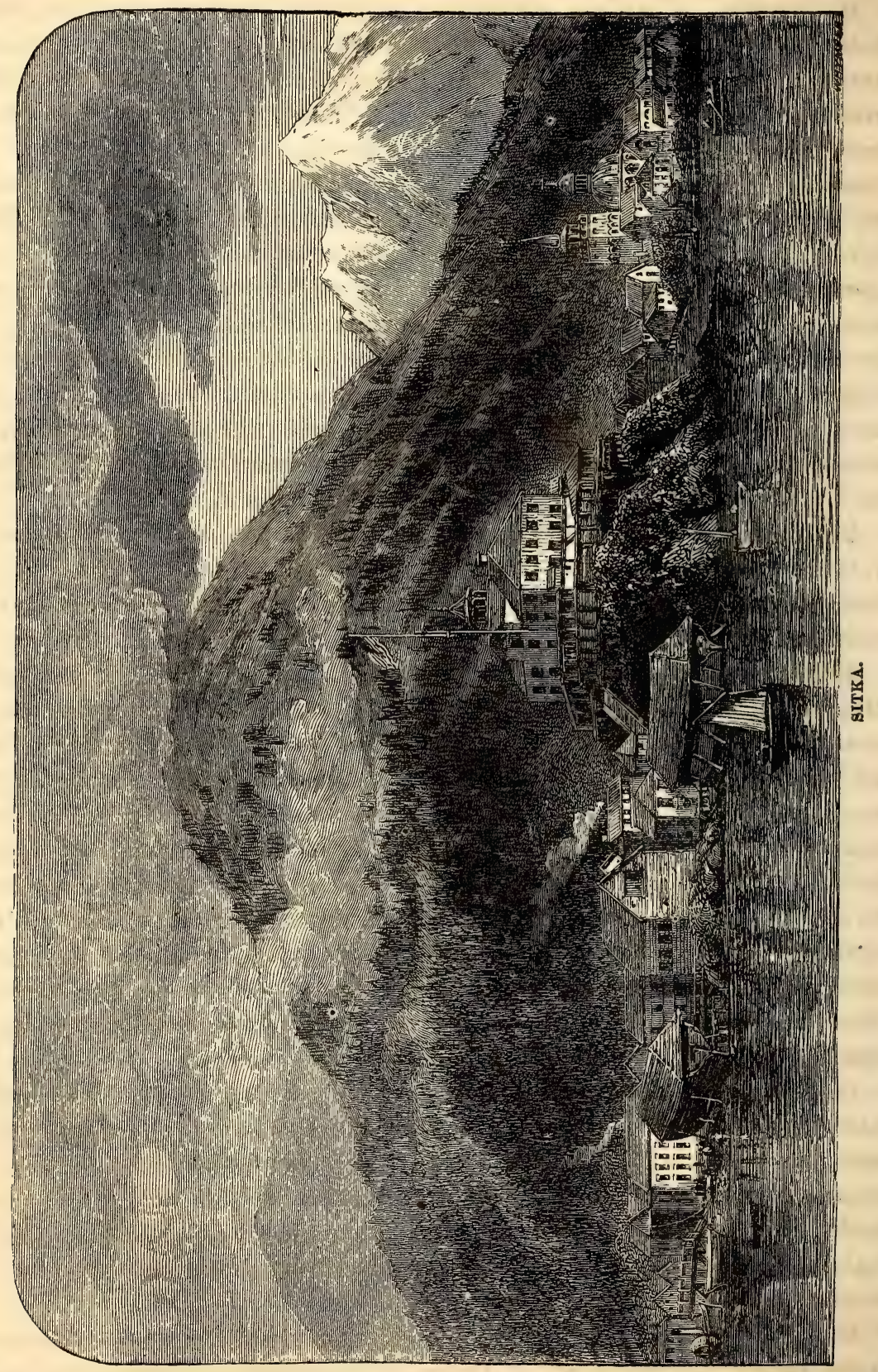

The mosses and lichens begin already at Unalaska to assume that predominance in the Flora which characterizes the frigid zone.

A few degrees to the north of the Aleutian chain, which extends in a long 
line from the promontory of Aliaska to Kamchatka, are situated the Pribilow Islands, St. George and St. Paul, which are celebrated in the history of the furtrade, the former as the chief breeding-place of the sea-bear, the latter as that of the sea-lion. Chamisso was struck with their wintry aspect, for here no sheltered valleys and lowlands promote, as at Unalaska, a more vigorous vegetation. The rounded backs of the hills and the scattered rocks are covered with black and gray lichens; and where the melting snows afford a sufficient moisture, sphagnum, mosses, and a few weeds occupy the marshy ground. The frozen earth has no springs, and yet these desolate islands have a more southerly situation than the Orkneys, where barley grows to ripeness. Before these islands were discovered by the Russians they had been for ages the undisturbed home of the sea-birds and the large cetacean seals. Under Russian superintendence, some Aleuts have now been settled on both of them. The innumerable herds of sea-lions, which cover the naked shores of St. George as far as the eye can reach, present a strange sight. The guillemots have taken possession of the places unoccupied by their families and fly fearlessly among them, or nestle in the crevices of the wave-worn rock-walls, or between the large boulders which form a bank along the strand.

Still farther to the north lies the uninhabited island of St. Matthew $\left(62^{\circ}\right.$ N. lat.). A settlement was once attempted; but as the animals which had been reckoned upon for the winter supply of food departed, the unfortunate colonists all died of hunger.

Fogs are so frequent about the island of St. Laurence that navigators have often passed close by it $\left(65^{\circ} \mathrm{N}\right.$. lat.) without seeing it. Chamisso was surprised at the beauty and the numbers of its dwarfish flowering herbs, which reminded him of the highlands of Switzerland, while the neighboring St. Laurence Bay, in the land of the Tchuktchi, was the image of wintry desolation. In July the lowlands were covered with snow-fields, and the few plants bore the Alpine character in the most marked degree. Under this inclement sky, the mountains, unprotected by vegetation, rapidly fall into decay. Every winter splits the rocks, and the summer torrents carry the fragments down to their feet. The ground is everywhere covered with blocks of stone, unless where the sphagnum, by the accumulation of its decomposed remains, has formed masses of peat in the swampy lowlands.

On sailing through Bering's Straits, the traveller may see, in clear weather, both the Old and the New World. On both sides rise high mountains, precipitously from the water's edge in Asia, but separated from the sea by a broad alluvial belt on the American side. The sea is deepest on the Asiatic border, where the current, flowing from the south with considerable rapidity, has also the greatest force. Here also whales may be often seen, and large herds of walruses.

In former times the baidar of the Esquimaux was the only boat ever seen in the straits, and since Semen Deshnew, who first sailed round the eastern point of Asia, European navigators had but rarely passed them to explore the seas beyond; but recently this remotest part of the world has become the scene of an active whale-fishery. 


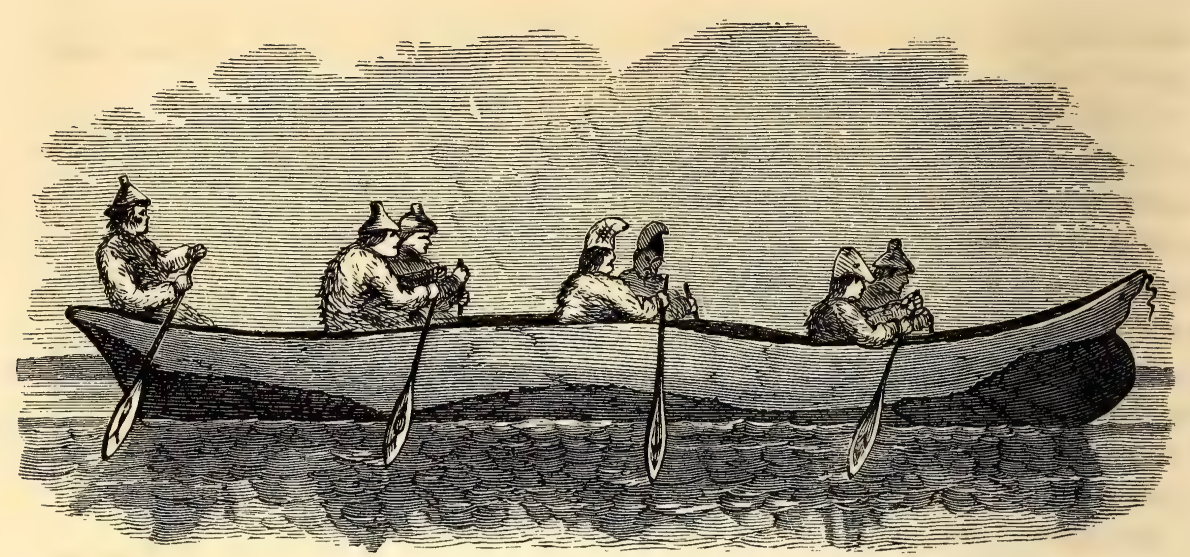

A BAIDAR.

The shores of Bering Sea are naked and bleak, and the numerous volcanoes of the Aleutian chain pour out their lava-streams over unknown wildernesses. But the waters of the sea are teeming with life. Gigantic algæ, such as are never seen in the torrid zone, form, round the rocky coasts, vast submarine forests. A host of fishes, whales, walruses, and seals, fill the sea and its shores, and innumerable sea-birds occupy the cliffs. But these treasures of the ocean, which for ages furnished the Aleuts and other wild tribes with the means of existence, have also been the cause of their servitude. Had the sea-otter not existed, the wild children of the soil might possibly still be in possession of their ancient freedom; and but for the sea-bear and the walrus, the whale and the seal, the banners of the Czar would scarcely have met the flag of England on the continent of America.

As the whole fur-trade of the Hudson's Bay Territory is concentrated in the hands of one mighty company, thus also one powerful association enjoys the exclusive commerce of the eastern possession of Russia. The regions under the authority of the Russian Fur Company* occupy an immense space, as they comprise not only all the islands of Bering Sea, but also the American coasts down to $55^{\circ} \mathrm{N}$. lat. The extreme points of this vast territory are situated at a greater distance from each other than London from Tobolsk, but the importance of its trade bears no proportion to its extent.

The company, which was founded in the year 1799, under the Emperor Paul, had, in 1839, thirty-six hunting settlements on its own territory (the Kurile Islands, the Aleutic chain, Aliaska, Bristol Bay, Cook's Inlet, Norton Sound, etc.), besides a chain of agencies from Ochotsk to St. Petersburg. Its chief seat is New Archangel, on Sitka, one of the many islands of King George III.'s Archipelago, first accurately explored by Vancouver. The magnificent Bay of Norfolk, at the head of which the small town is situated, greatly resembles a Norwegian fjord, as we here find the same steep rock-

* Since last year [1867] the Russian Government has sold her American possessions to the United States, but as it is not yet known how far the interests of the Russian Fur Company have been affected by the change, I may be allowed to speak of her in the present tense. 
walls bathing their precipitous sides in the emerald waters, and clothed with dense pine forests wherever a tree can grow.

A number of islets seattered over the surface of the bay add to the beauty of the scene. The furs collected by the company are chiefly those of seabears, sea-otters, foxes, beavers, bears, lynxes, American martens, etc., and are partly furnished by the subjects of its own territory (Aleuts, Kadjacks, Kenaïzes, Tchugatchi, Aliaskans), who are compelled to hunt on its account, and partly obtained by barter from the independent tribes of the mainland, or from the Hudson's Bay Company. The greater part is sent to Ochotsk or the Amoor, and from thence through Siberia to St. Petersburg; the rest to the Chinese ports, where the skins of the young sea-bear always find a ready market.

Of all the aboriginal tribes which inhabit the vast territory of Russian America, the most worthy of notice is that of the Aleuts. Less fortunate than their independent relatives, the Esquimaux of the north-who in the midst of privations maintain an imperturbable gayety of temper-these islanders have been effectually spirit-broken under a foreign yoke. In 1817 the cruel treatment of their masters had reduced them to about a thousand; since that time their number has somewhat increased, the company having at length discovered that man is, after all, the most valuable production of a land, and that if depopulation increased still further, they would soon have no more hunters to supply them with furs.

Every Aleut is bound, after his eighteenth year, to serve the company three years; and this forced labor-tax does not seem at first sight immoderate, but if we consider that the islanders, to whom every foreign article is supplied from the warehouses of the company, are invariably its debtors, we can not doubt that as long as the Aleut is able to hunt, he is obliged to do so for the wages of a slave. The Bishop Ivan Weniaminow, who resided ten years at Unalaska, draws a picture of this people which exhibits evident marks of a long servitude. They never quarrel among each other, and their patience is exemplary. Nothing can surpass the fortitude with which they endure pain. On the other hand, they never show excessive joy; it seems impossible to raise their feelings to the pitch of delight. Even after a long fast, a child never grasps with eagerness the proffered morsel, nor does it on any occasion exhibit the mirth so natural to its age.

In hunting the marine animals, the Aleuts exhibit a wonderful skill and intrepidity. To catch the sea-otter, they assemble in April or May at an appointed spot, in their light skin boats, or baidars, and choose one of their most respected chiefs for the leader of the expedition, which generally numbers from fifty to a hundred boats. Such hunting-parties are annually organized from the Kurile Islands to Kadjack, and consequently extend their operations over a line of 3000 miles. On the first fine day the expedition sets out and proceeds to a distance of about forty versts from the coast, when the baidars form into a long line, leaving an interval of about 250 fathoms from boat to boat, as far as a sea-otter diving ont of the water can be seen, so that a row of thirty baidars occupies a space of from ten to twelve versts. When the 
number of the boats is greater, the intervals are reduced. Every man now looks upon the sea with great attention. Nothing escapes the eye of the Aleut; in the smallest black spot appearing but one moment over the surface of the waters, he at once recognizes a sea-otter. The baidar which first sees the animal rows rapidly towards the spot where the creature dived, and now the Aleut, holding his oar straight up in the air, remains motionless on the spot. Immediately the whole squadron is on the move, and the long, straight line changes into a wide circle, the centre of which is occupied by the baidar with the raised oar. The otter, not being able to remain long under water, reappears, and the nearest Aleut immediately greets him with an arrow. This first attack is seldom mortal ; very often the missile does not even reach its mark, and the sea-otter instantly disappears. Again the oar rises from the next baidar; again the circle forms, but this time narrower than at first; the fatigued otter is obliged to come oftener to the surface, arrows fly from all sides, and finally the animal, killed by a mortal shot, or exhausted by repeated wounds, falls to the share of the archer who has hit it nearest to the head. If several otters appear at the same time, the boats form as many rings, provided their number be sufficiently great.

The boldest of all hunters, the Aleuts of the Fox Islands, pursue the sea-otter also in winter. If, during the summer chase, the rapidity and regularity with which all the movements are performed, and the sure eye and aim of the archers command the spectator's admiration, this winter chase gives him occasion to wonder at their courage. During the severest winter-storms the otter shelters himself on the shore of some small uninhabited island or on a solitary rock, and after having carefully ascertained that no enemy is near, coils himself up and falls asleep. While the storm still rages, two Aleuts approach the rock in two single baidars from the leeward. The hunter in the foremost baidar stands upright, a gun or a club in his hand, and waits in this position till a wave brings him near to the summit of the rock. He now springs on land, and while his companion takes care of the baidar, approaches the sleeping otter and shoots it or kills it with his club. With the assistance of his companion who has remained on the water, he springs back into his baidar as soon as the crest of a wave brings it within his reach.

The sea-bear is nearly as valuable as the sea-otter to the fur company, as the woolly skin of the young animal is the only one of the whole seal tribe which is reckoned among the finer peltry. The sea-bears are chiefly killed on the Commodore and Pribilow islands, particularly on St. Paul, where they are hunted by a certain number of Aleuts located there under Russian superintendence. The chase begins in the latter part of September, on a cold, foggy day, when the wind blows from the side where the animals are assembled on the rocky shore. The boldest huntsmen open the way, then follow the older people and the children, and the chief personage of the band comes last, to be the better able to direct and survey the movements of his men, who are all armed with clubs. The main object is to cut off the herd as quickly as possible from the sea. All the grown-up males and females are spared and allowed to escape, but most of the young animals are sentenced to death. Those 
which are only four months old (their furs being most highly prized) are doomed without exception; while of the others that have attained an age of one, two, or three years, only the males are killed. For several days after the massacre, the mothers swim about the island, seeking and loudly wailing for their young.

From October $5 \mathrm{St}$. Paul is gradually deserted by the sea-bears, who then migrate to the south and re-appear towards the end of April, the males arriving first. Each seeks the same spot on the shore which he occupied during the preceding year, and lies down among the large stone blocks with which the flat beach is covered. About the middle of May the far more numerous females begin to make their appearance, and the sea-bear families take full possession of the strand. Each male is the sultan of a herd of females, varying in number according to his size and strength; the weaker brethren contenting themselves with half a dozen, while some of the sturdier and fiercer fellows preside over harems 200 strong. Jealousy and intrusion frequently give rise to terrible battles. The full-grown male sea-bear, who is about four or five times larger than the female, grows to the length of eight feet, and owes his name to his shaggy blackish fur, and not to his disposition, which is far from being cruel or savage.

Armed with a short spear, a single Aleut does not hesitate to attack the colossal whale. Approaching cautiously from behind in his baidar until he reaches the head, he plunges his weapon into the animal's flank under the fore fin, and then retreats as fast as his oar can carry him. If the spear has penetrated into the flesh, the whale is doomed; it dies within the next two or three days, and the currents and the waves drift the carcass to the next shore. Each spear has its peculiar mark by which the owner is recognized. Sometimes the baidar does not escape in time, and the whale, maddened by pain, furiously lashes the water with his tail, and throws the baidar high up into the air, or sinks it deep into the sea. The whale-fishers are highly esteemed among the Aleuts, and their intrepidity and skill well deserve the general admiration. Of course many of the whales are lost. In the summer of 1831,118 whales were wounded near Kadjack, of which only forty-three were found. The others may have been wafted far out into the sea to regale the sharks and sea-birds, or driven to more distant shores, whose inhabitants no doubt gladly welcomed their landing. Wrangell informs us that since 1833 the Russians have introduced the use of the harpoon, and engaged some English harpooners to teach the Aleuts a more profitable method of whale-catching, but we are not told bow the experiment has succeeded.

The company, besides purchasing a great quantity of walrus-teeth from the Tchuktchi of the Bering's Straits and Bristol Bay, send every year a detachment of Aleuts to the north coast of Aliaska, where generally a large number of young walruses, probably driven away by the older ones, who prefer the vicinity of the polar ice, spend the summer months.

The walruses herd on the lowest edge of the coast which is within reach of the spring tides. When the Aleuts prepare to attack the animals, they take leave of each other as if they were going to face death, being no less afraid of the tusks of the walruses than of the awkwardness of their own companions. 
Armed with lances and heavy axes, they stealthily approach the walruses, and having disposed their ranks, suddenly fall upon them with loud shouts, and endeavor to drive them from the sea, taking care that none of them escape into the water, as in that case the rest would irresistibly follow and precipitate the huntsmen along with them. As soon as the walruses have been driven far enough up the strand, the Aleuts attack them with their lances, striking at them in places where the hide is not so thick, and then pressing with all their might against the spear, to render the wound deep and deadly. The slaughtered animals tumble one over the other and form large heaps, whilst the huntsmen, uttering furious shouts and intoxicated with carnage, wade through the bloody mire. They then cleave the jaws and extract the tusks, which are the chief objects of the slaughter of several thousand walruses, since neither their flesh nor their fat is made use of in the colony. The carcasses are left on the shore to be washed away by the spring tides, which soon efface the mark of the massacre, and in the following year the inexhaustible north sends new victims to the coast.

Sir George Simpson, in his "Overland Journey round the World," relates that the bales of fur sent to Kiachta are covered with walrus hide; it is then made to protect the tea-chests which find their way to Moscow, and after all these wanderings, the far-travelled skin returns again to New Archangel, where, cut into small pieces and stamped with the company's mark, it serves as a medium of exchange.

The skin of the sea-lion (Otaria Stelleri) has but little value in the furtrade, as its hair is short and coarse, but in many other respects the unwieldy animal is of considerable use to the Aleut. Its hide serves to cover his bai. dar; with the entrails he makes his water-tight kamleika, a wide, long shirt which he puts on over his dress to protect himself against the rain or the spray; the thick webs of its flippers furnish excellent soles for his boots, and the bristles of its lip figure as ornaments in his head-dress. 


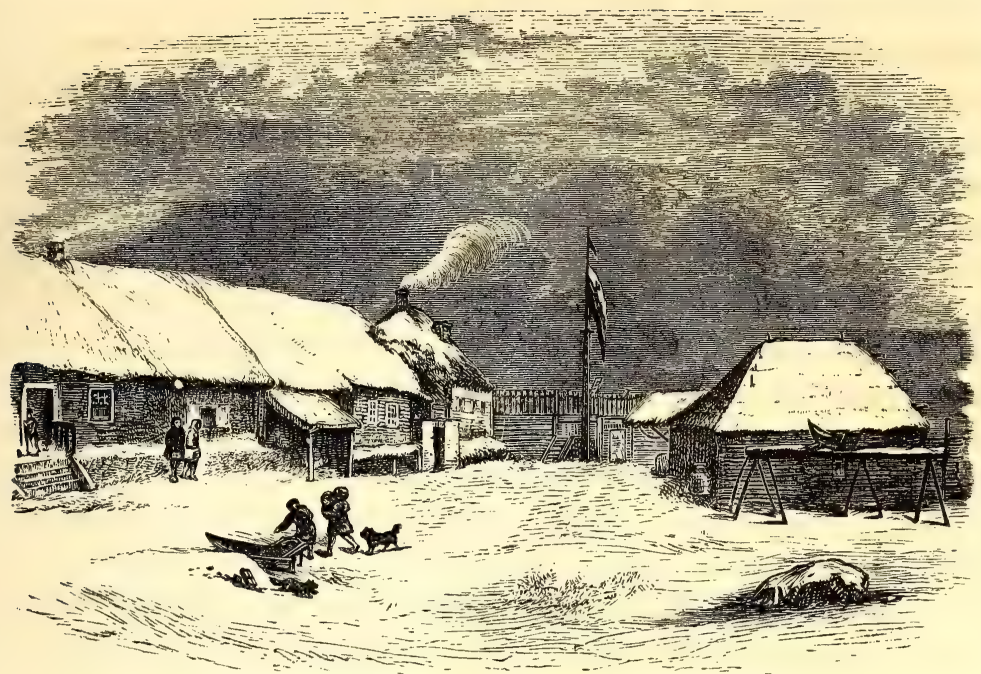

FORT ST. MICHAEL.

\section{CHAPTER XXVI.}

\section{ALASKA.}

Purchase of Alaska by the United States.-The Russian American Telegraph Scheme._Whymper's Trip up the Yukon.--Dogs.--The Start.-Extempore Water-filter.-Snow-shoes.-The Frozen Yukon.-Under-ground Houses.-Life at Nulato.--Cold Weather.--Auroras.--Approach of Summer. -Breaking-up of the Ice.--Fort Yukon.-Furs.-Descent of the Yukon.-Value of Goods.-Arctic and Tropical Life.-Moose-hunting.-Deer-corrals.-Lip Ornaments.-Canoes.-Four-post Coffin. -The Kenaian Indians.-The Aleuts.-Value of Alaska.

TN 1867 the Russian Government sold to the United States all of its possessions in America, comprising an area of more than 500,000 square miles, equal in extent to France, Germany, and Great Britain, stretching from $54^{\circ} 40^{\prime}$ north latitude to the Arctic Ocean. The sum paid was about seven and a quarter millions of dollars. In this purchase is included Mount St. Elias, the highest peak in North America, rising to a height of more than 18,000 feet, and one of the loftiest single peaks on the globe. The real value of this new acquisition was quite unknown to both buyer and seller. In the southern part, and on the islands, there is considerable vegetation and forests of large trees; and it is said that there is some mineral wealth. But the greater part of the territory is essentially Arctic. It now bears the designation of the Territory of Alaska, an abbreviation of Aliaska, the name of the peninsula stretching into the North Pacific Ocean.

Little information has as yet been gained of this region. The most important is the result of a journey up the River Yukon, performed in 1866 by Mr. Frederick Whymper, an artist connected with the Telegraph Expedition. This telegraph enterprise was undertaken in the confident expectation that the ca- 
bles laid directly across the Atlantic would fail, and that telegraphic communications between London and New York must be mainly by land. The proposed line, starting from the mouth of the Amoor, to which point it was already constructed, should bend around the head of the Sea of Okotsch, thence run eastward and northward through Kamchatka to the $63 \mathrm{~d}$ degree of north latitude, then cross the narrow Strait of Bering, and run southward through what was then Russian America, British Columbia, Washington Territory, and Oregon, to San Francisco; thence across the American continent to New York. A dispatch from London to New York by this route would travel something more than 25,000 miles, while the distance in a straight line across the Atlantic was about 3000 miles. The company undertaking this enterprise had surveyed a considerable part of the distance, and expended some millions of dollars, when it was announced that the Atlantic cable was a success, and the work was abandoned.

In the mean while Mr. Whymper undertook a trip up the great River $\mathrm{Yu}$ kon. This is essentially an Arctic river, though its mouth is far southward of the Arctic Circle. It is probably the greatest of the Arctic rivers, and in length and volume of water is exceeded by not more than six rivers of the globe.

The party of which Mr. Whymper was one consisted of six Europeans and three Indians. In October, 1865, they started from Unalachleet, on Norton Sound. A trip of 200 miles would bring them to Nulato, a Russian tradingpost 700 miles from the mouth of the river, which here runs alrnost parallel with the coast.

They were to travel on foot over frozen rivers and through deep snow. To convey their supplies they had four sledges, each drawn by five dogs. Such a team will draw about 350 pounds. The dogs of this region are not of a good class. Mr. Whymper thinks they have in them quite as much of the wolf as of the dog. Their usual food is fish; their regular daily allowance in winter is a dried salmon a day: in summer they are expected to fish for themselves. They will, however, eat almost any thing, and, if they can get enough, will grow fat upon it. They even took kindly to beans, provided they were boiled soft-a thing which Kane could never induce his Esquimaux dogs to undertake.

They set out on the 27th of October at 11 o'clock-that is, just after sunrise-the thermometer standing at $30^{\circ}$ below freezing-point. Their trip was begun a little too early, for the deep snow had not become packed hard, and a bit of thaw would transform it into slush; and the streams which they had to cross were not all frozen over. Fortunately, they had a light skin boat, which not only stood them in good stead now, but served them afterwards for more than a thousand miles of winter travel. Whenever they came to a frozen stream, the Indians would break a hole through the ice to get a draught of water. They always filled up the hole with loose snow, through which they sucked the water. This they said was to filter out the little red worms with which they said the water was infested.

The travellers wore snow-shoes; the use of which, although indispensable in going over the soft snow, is very fatiguing, obliging the wearers to lift a dozen pounds of snow at every step. Sometimes they had to break a path for the 
sledges. The men would go on ahead for a space, then return and start on again, thus traversing the distance three times. Often they could not accomplish more than ten miles a day.

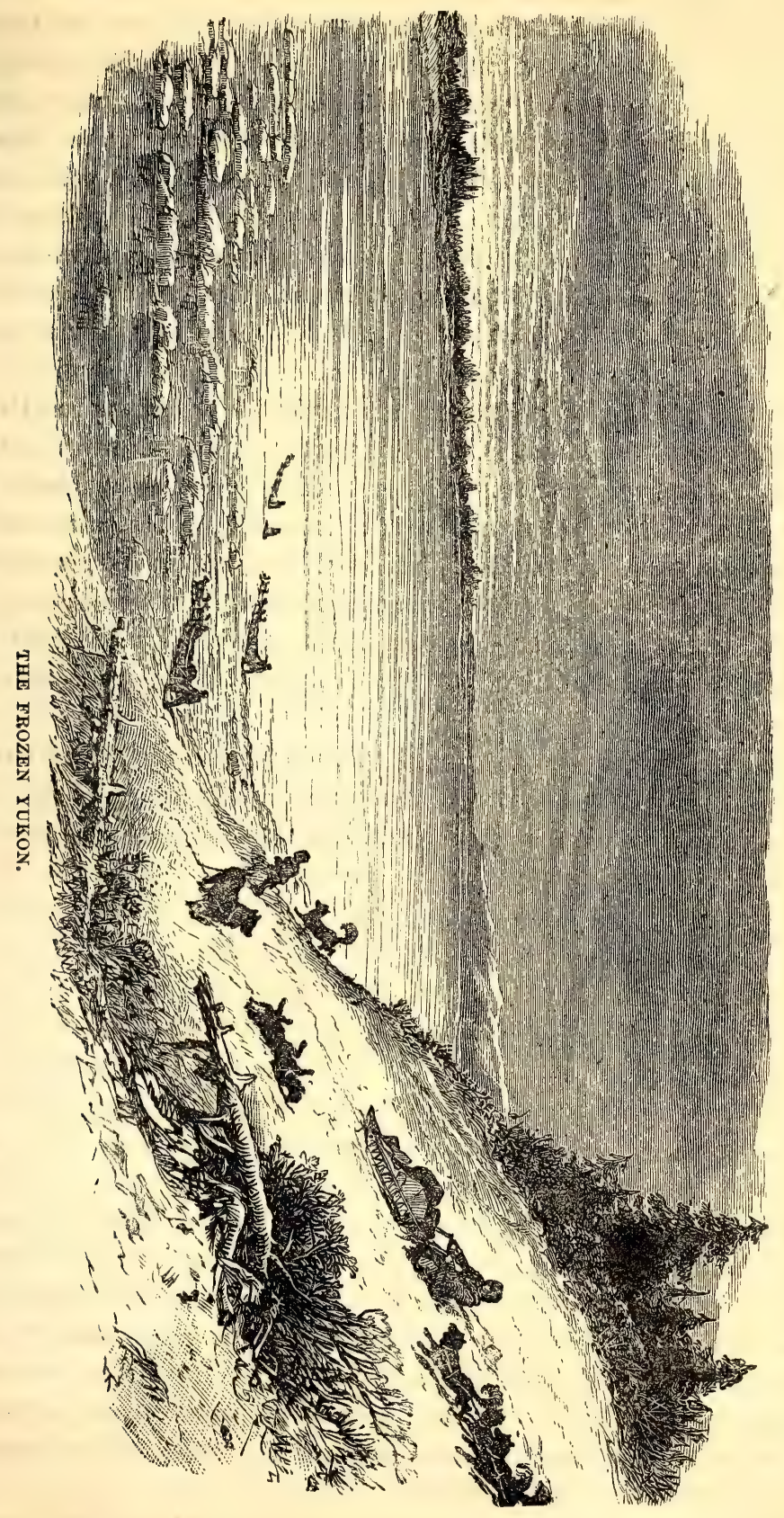

At noon on the 11th of November, a fortnight after starting, they caught in the distance a glimpse of a faint bluish streak, varying the white monotony 
of the scene. This they knew marked the course of the great river towards which they were tending. Pushing eagerly on, at sunset they broke out of the woods, shot down a steep bank, and stood on an immense plain of snow-covered ice. It was the Yukon, frozen solidly over as far as the eye could reach, except that here and there was a faint streak of open water. From bank to bank the distance was more than a mile, and this they afterwards found was the normal breadth of the river for seven hundred, miles below, and a thousand miles above. Not unfrequently it spread out into broad lagoons four or five miles wide. The Yukon is one of the great rivers of the globe. In length and volume of water it is exceeded only by the Amazon, the Mississippi, and perhaps the Plata. It exceeds the Nile, the Ganges, the Volga, the Amoor, and has affluents to which the Rhine and Rhone are but brooks. It rises far within the British Possessions, and its head-waters almost interlock with those of the Mackenzie, which empties into the Arctic Ocean. A portage of only eighty miles intervenes between these rivers at points where each is navigable for boats forty feet long, and drawing two feet of water. Over this portage the Hudson's Bay Company transport upon men's backs the goods for trading with the Indians on the Upper Yukon. Mr. Whymper thinks that a flat-bottomed stern-wheel steamer, like those used on the Upper Mississippi, could ascend the Yukon for eighteen hundred miles, and tap the whole fur-bearing region. But as the river is frozen solid for eight months out of the twelve, the steamer could hardly make more than one trip a year.

The travellers stopped two days at the Indian winter village of Coltog. The houses were built mainly under-ground. First, a little shanty is put up, under which a hole like a well is dug; thence a branch like a sewer runs some yards, along which one must crawl on hands and knees to reach the proper dwelling,

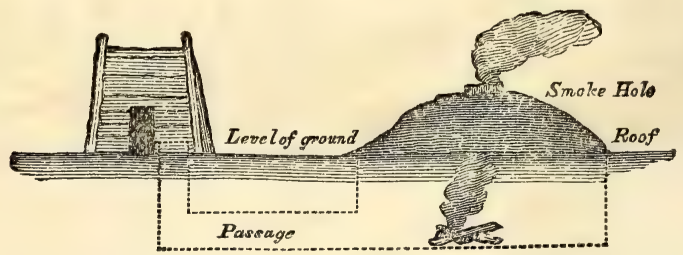

UNDER-GROUND HOUSE.

which is a square hole in the earth, over which is raised a low dome-shaped roof, with a hole in the top to let out the smoke of the fire, which is built directly underneath. When the fire gets low the smoke-hole is covered with a skin, which keeps in not only the heat but the manifold scents engendered by the crowded occupancy. The slight heat from below makes the roof a favorite trysting-place for the dogs, and every now and then one comes tumbling down through the smoke-hole upon the fire below, adding the odor of singed hair to those arising from stale fish, old skin garments, and other unnamable abominations. Coltog is a rather favorable sample of an Indian winter village in Alaska.

From Coltog the travellers proceeded up the river two days' journey to $\mathrm{Nu}$ lato, the most northern and most inland of the Russian Company's fur-posts. 
It stands in latitude $65^{\circ}$, and longitude $158^{\circ}$, upon a level slip of land bounded on two sides by the great river and one of its main branches. Notwithstanding the high latitude, trees of considerable size grow there, and during the brief summer the grass is luxuriant, and berries abound. The post is a little fortress, surrounded by a picket, which is closed at night to exclude the Indians, who camp around in large numbers. The house appropriated to the travellers was built of logs, forming one side of the little square. The windows were of sealgut instead of glass; and as there is during the winter only two or three hours of daylight, the light was never any of the best. By caulking the floor with moss, and carpeting it with skins, the main room was kept comfortably warm, except near the fioor. If one hung a damp garment from the rafters it would steam at the top, while frozen stiff at the bottom. The temperature at the roof was sometimes $65^{\circ}$, while near the floor it was $4^{\circ}$. Water for daily use was hauled on a sledge from the river. To get at it, they were obliged to break through solid ice four feet thick. Nevertheless, the Indians contrive to catch immense quantities of fish by constructing a weir of wicket-work, and keeping holes open in the ice.

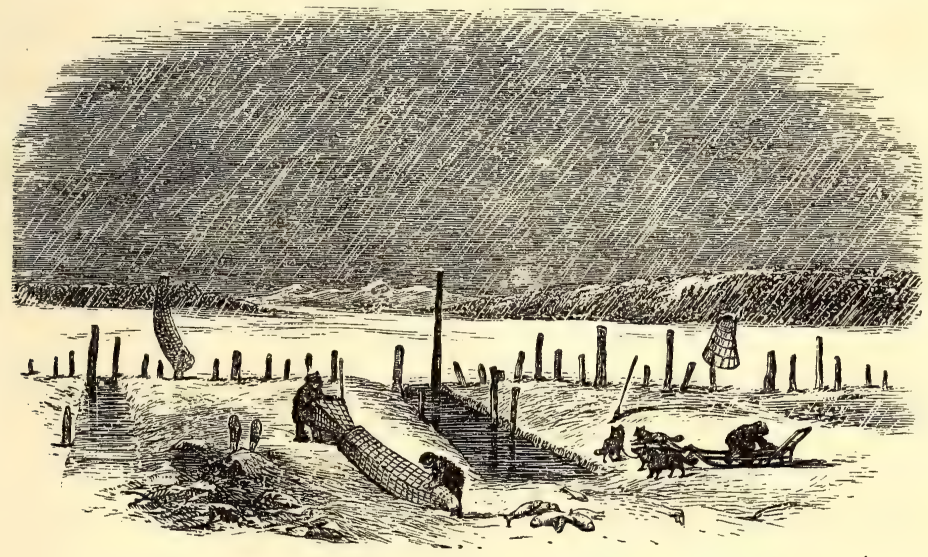

FISH-TRAPS UN THE YUT̃ON.

Winter fairly set in soon after the party had taken up their abode at Nulato. On the $2 \mathrm{~d}$ of November the thermometer indicated the moderate temperature of $2^{\circ}$ above zero. It suddenly fell to $20^{\circ}$ below zero, and kept on steadily falling until the 5 th of December, when it sunk to $58^{\circ}$ below zero, that is, ninety degrees below the freezing-point of water. This was the coldest day, but there were during December and January eleven days when the thermometer sunk below the freezing-point of mercury. It is to be noted that after a certain point the human system seems to take little additional note of the temperature as indicated by the thermometer. When the mercury froze, $72^{\circ}$ below the freezing-point of water, it did not seem very cold, provided there was no wind; while one day when the thermometer was $44^{\circ}$ higher, we find this note: "A north wind blew, and made us feel the cold very decidedly. It is wonderful how searching the wind is in this northern climate; each little seam, slit, or 
tear in your fur or woollen clothing makes you aware of its existence, and one's nose, ears, and angles generally are the special sufferers." One day when the thermometer stood at $10^{\circ}$, an expedition started off for the coast : and once when it was at $32^{\circ}$, a half-clad Indian came to the post with his child, no better

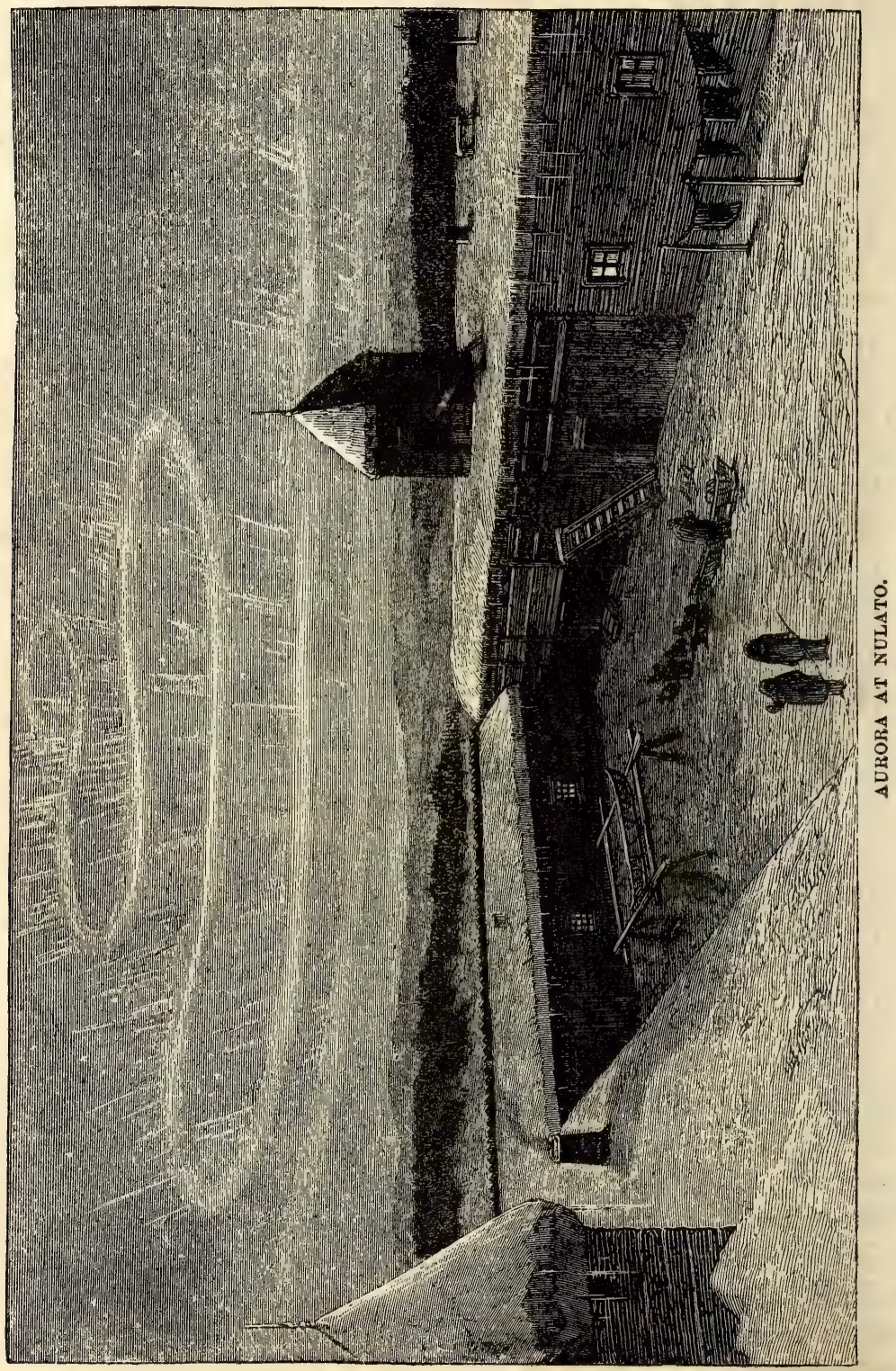

clad, bringing some game; he did not seem to think the day remarkably cold. The shortest day of the winter was December 21, when the sun was an hour and fifty minutes above the horizon.

During the winter Mr. Whymper made many capital sketches out-of-doors, while the temperature was sixty degrees below freezing-point. Among these 
is a remarkable aurora borealis on the 21 st of December. It was not the conventional arch, but a graceful, undulating, ever-changing snake of pale electric

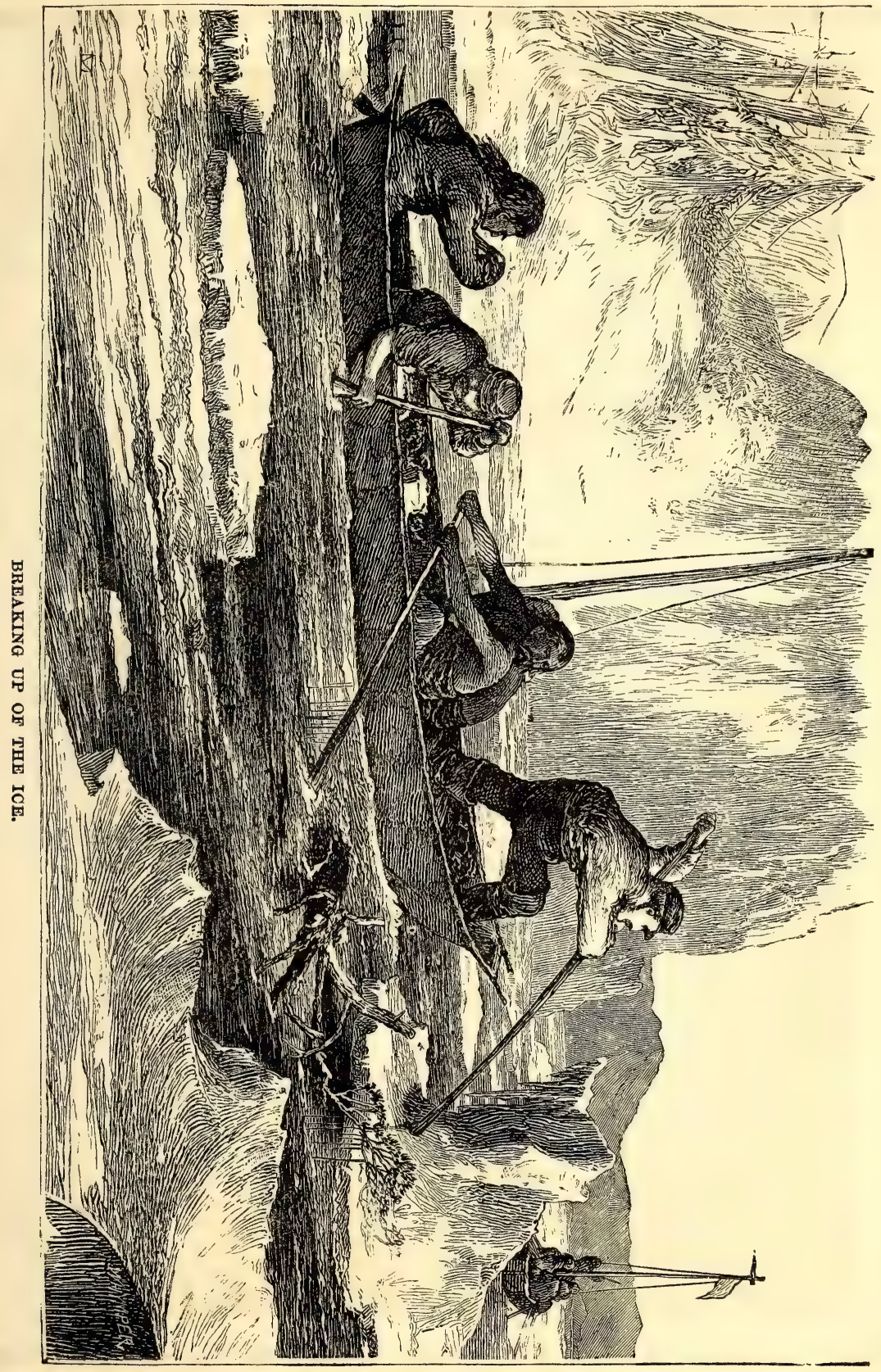

light; evanescent colors, pale as those of a lunar rainbow, ever and again flitting through it, and long streamers and scintillations moving upward to the bright stars, which shone distinctly through its hazy ethereal form. The night 
was beautifully calm and clear; cold, but not intensely so, the thermometer standing at $+16^{\circ}$.

So passed the long winter months. Early in April there came signs of sum. mer-for in the Arctic regions there is properly no spring or autumn. "On the 9th flies made their appearance. Next day the willows were seen budding. But for another fortnight the weather was variable. On the 28th the first goose put in his appearance. But for another fortnight the ice in the river remained unbroken. The first sign of breaking up was on the 12th of May. That day mosquitoes showed themselves. Next day came swallows and wild geese in abundance. Still another fortnight, during which a steady stream of broken ice came down, bearing with it whole trees torn up from the banks. On the 24th of May the river was tolerably clear of ice.

The Russians had already got ready for a trading-excursion up the Yukon to an Indian trading-place 240 miles above, the farthest point ever visited by them. They had a huge skin boat, fitted with mast and sail, manned by eight men, carrying, besides men and provisions, two tons of goods. The Arnericans went with them, though meaning to go far beyond. They had their own little boat, laden with six or seven hundred pounds of stores of all kinds. The river was still full of ice and drift-wood. A large tree would sometimes pass under the bow of the Russian boat, and fairly lift it out of the water. These skin boats seem to be the best of all for this kind of navigation. They give way without harm to a blow which would break through a bark canoe.

One can scarcely conceive the rapidity with which summer comes on in these regions. On the 27th of May the river was yet full of ice. Ten days after they had to lie by during the noontide heat, the thermometer standing at $80^{\circ}$ in the shade.

The Americans reached Fort Yukon on the 9th of June, having, in twentynine days, rowed and tracked six hundred miles. A few weeks later, with the current in their favor, they descended the same space in seven days. Fort $\mathrm{Yu}$ kon lies a little within what was formerly Russian America, and the Hudson's Bay Company paid a small sum for the privilege of its occupancy. Here the Americans remained a month, being hospitably entertained. The fort had quite a civilized look. There were freshly-plastered walls, glazed windows, open fireplaces, magazines, store-houses, and a great fur-room. Camped around were Indians of many tribes, locally designated as "Foolish Folks," "Wood Folks," "Birch-bark Folks," "Rat Folks," "Hill Folks," and the like. Some wore their native costumes; others were tricked out in the odds and ends of civilized attire. The fur-room was a rare sight. From the beams hung marten-skins by the thousand, while the cheaper sorts were lying in huge heaps on the floor. Skins are here the regular currency. The beaver is the unit, estimated at about half a dollar. Two martens count as one beaver, and so on by a recognized scale. Fox-skins are numerous. The most valuable is that of the black fox, worth twenty times more than any other. There is a story that an unlucky employé of the company once bought the skin of a white fox, which the Indian seller had cunningly dyed black, paying for it more pounds than he should have paid shillings. The overplus was deducted from his salary. 
On the 8th of July the travellers started on their return journey, under a salute from their hospitable hosts. They canoed down the river day and night, only stopping two or three times a day to prepare their tea and cook their fish. It was a holiday excursion, the current sweeping them along at the rate of four

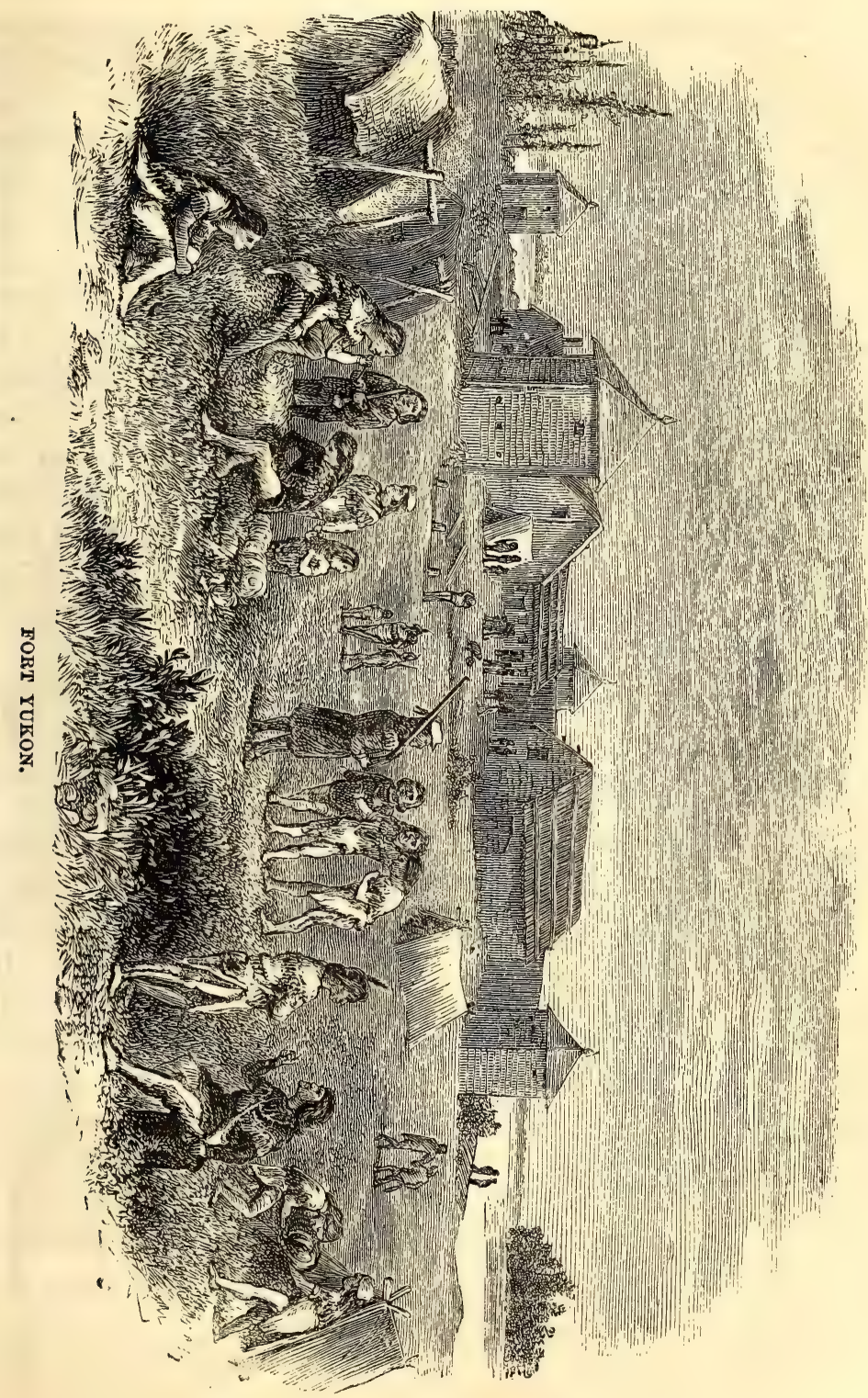

miles an hour. Once, by aid of rowing, they made forty-five miles in seven hours. They followed the river clear to its mouth. For the seven hundred miles below Nulato, near where they had struck the river on their upward journey, the region is comparatively poor. It lies out of the way of traders; fish are plenty and cheap enough. Five needles were considered a fair price 
for a thirty-pound salmon; and, says Mr. Whymper, "tobacco went farther than we had ever known it to do before." On the 23d of July they reached the mouth of the river, whence two days' sailing up the coast brought them to St. Michael's. The whole voyage of 1300 miles between Fort Yukon and St.

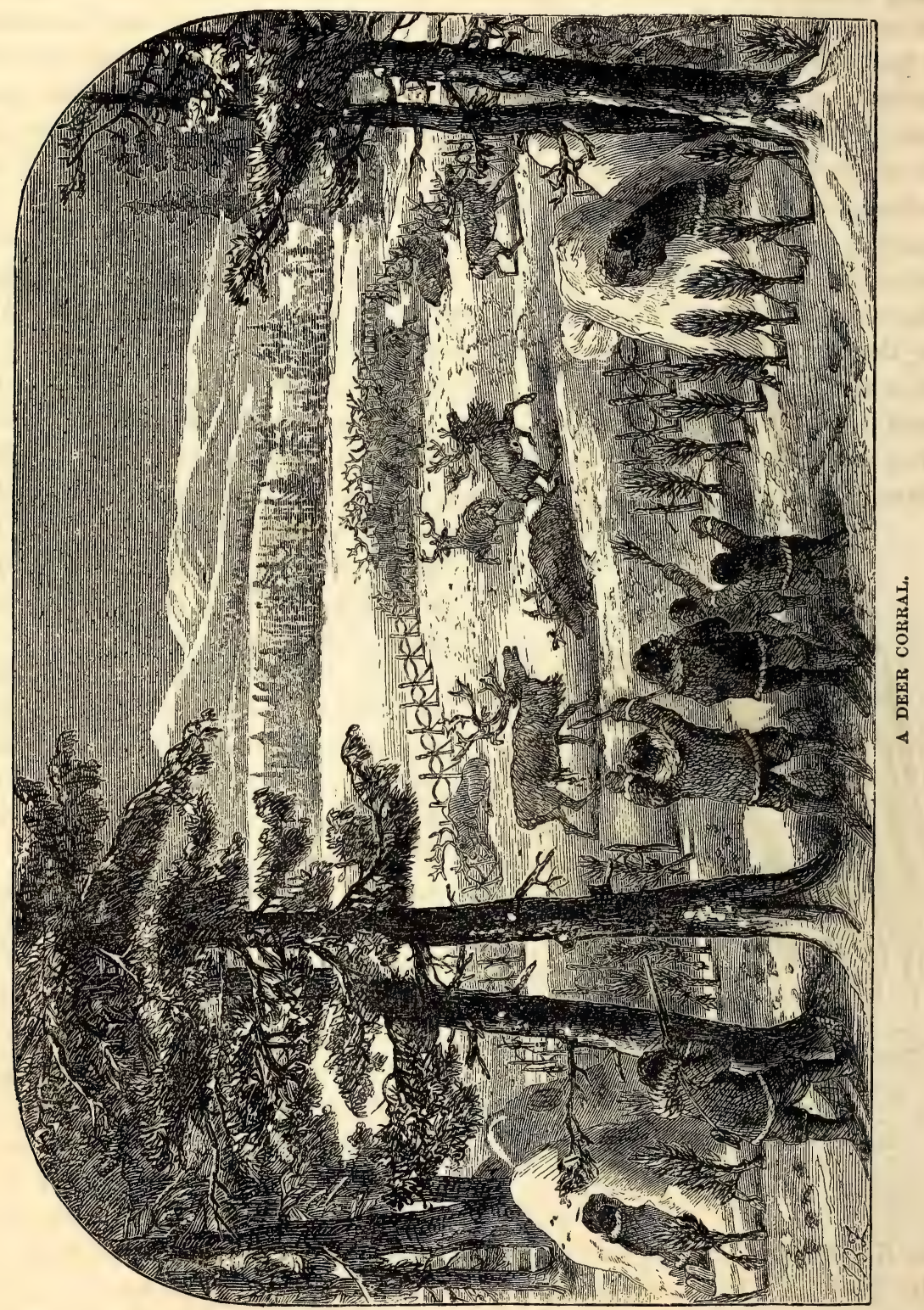

Michael's had taken fifteen and a half days. At St. Michael's they were told that the telegraphic enterprise had been abandoned, and that all employed in it were to return to California.

The result of this expedition adds considerably to our knowledge of the 
Arctic regions. It confirms what has been told us by Richardson, Kane, Hall, and all other Arctic explorers as to the superabundance of animal life existing in certain seasons in the northern regions. Strange as it may seem, tropical and semi-tropical countries are almost bare of living creatures. Strain and his party wandered for weeks through the thick forests of Central America, never seeing an animal, and rarely a bird, and the river appeared to be alnost destitute of fish. But life abounds in the Arctic regions. The rivers swarm with fish almost begging to be caught. The Kamchatdales have reindeer by the thousand. Whymper and his friends, during their brief stay at Nulato, bought the skins of eight hundred white hares with which to cover their blankets; the Indians had used the flesh for food. Moose-meat, varied by beaver, is the standing food of those who have got tired of salmon. The delicacies are a moose's nose and a beaver's tail. So abundant are the moose on the Yukon that the natives think it hardly worth while to waste powder and shot in killing them. When an Indian in his canoe comes upon a moose swimming in the water, he gives chase until the creature is fatigued, and then stabs it to the heart with his knife. They have also an ingenious way of corralling deer. They build a long elliptical inclosure of stakes upon a trail made by the deer. Between each pair of stakes is a slip-noose. A herd of deer is driven into this

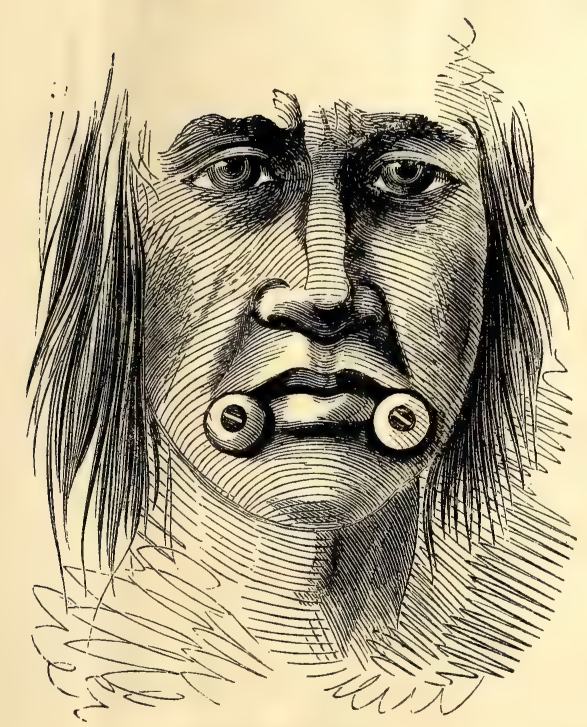

LIP ORNAMENTS. inclosure; they try to run out between the stakes, get caught by the nooses, and so fall a ready prey to the guns of the hunters.

The native population of Alaska is estimated at about 60,000 . From the southern boundary up to Mount St. Elias and on the islands live the Koloschians, estimated at 20,000. They are of middling stature, of copper-colored complexion, with round faces, thick lips, and black hair. The men wear various ornaments in their ears and noses; the women, when young, insert a piece of ivory in a slit made in the under lip, increasing it in size from year to year, until at last the ornament gets to be four inches wide, projecting six inches from the side of the face. The baidars or canoes of the Koloschians are dug out of a single tree, and will carry from twelve to fifty persons. They are usually propelled by paddles, though upon long voyages they are rigged with two or more masts and sails of matting or canvas. They, and indeed all of the tribes, do not bury their dead, but deposit their remains in an oblong box raised upon posts, with the canoe and other possessions of the deceased over the box.

Next northward of the Koloschians come the Kenaians, who stretch almost 


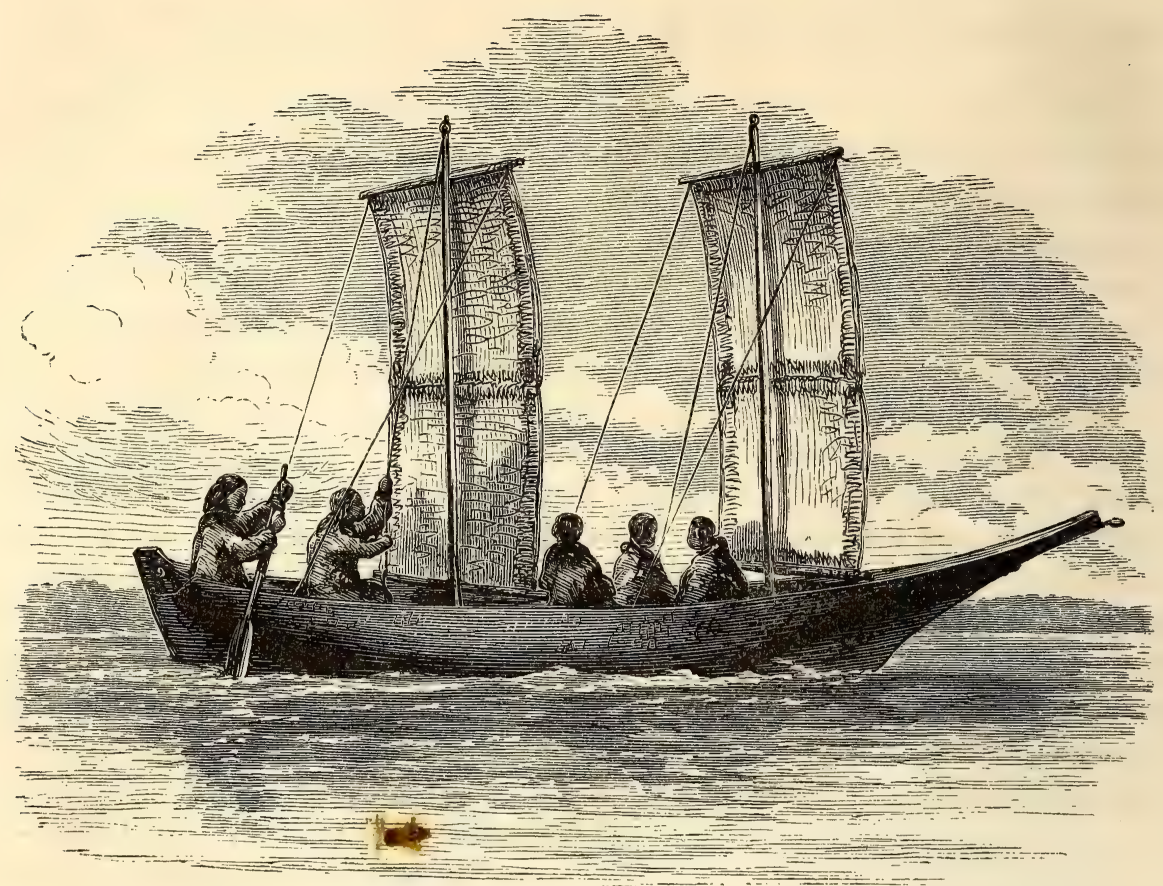

A BAIDAR.

across the continent to Hudson's Bay. Those living upon the Yukon call them Co-yukons, that is, People of the Great River, "Yukon" in their language signifying river. They are much feared by the surrounding tribes, and have often

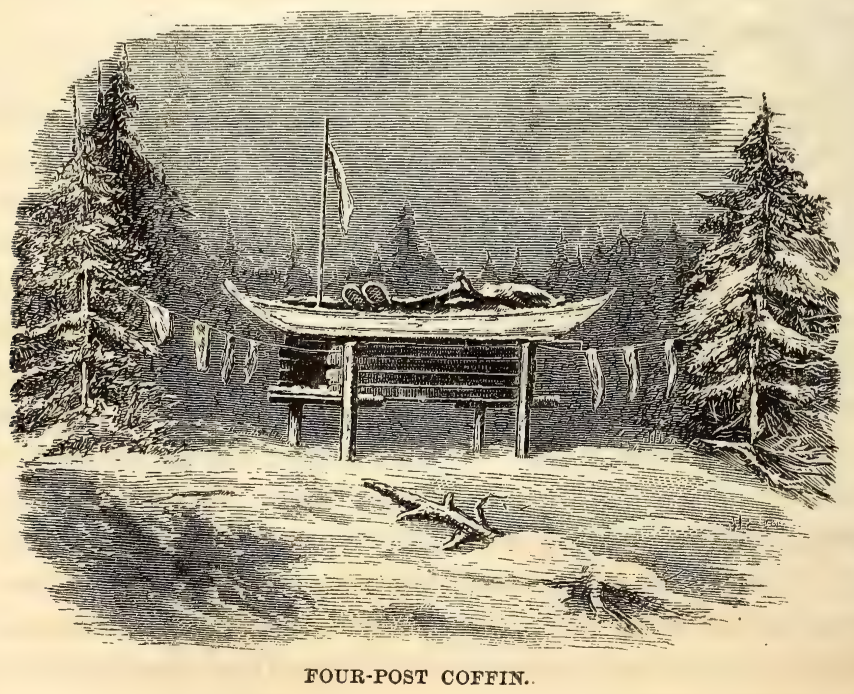

given no little trouble to their Russian masters. Many of these wear a bone ornament stuck through the septum of the nose. 


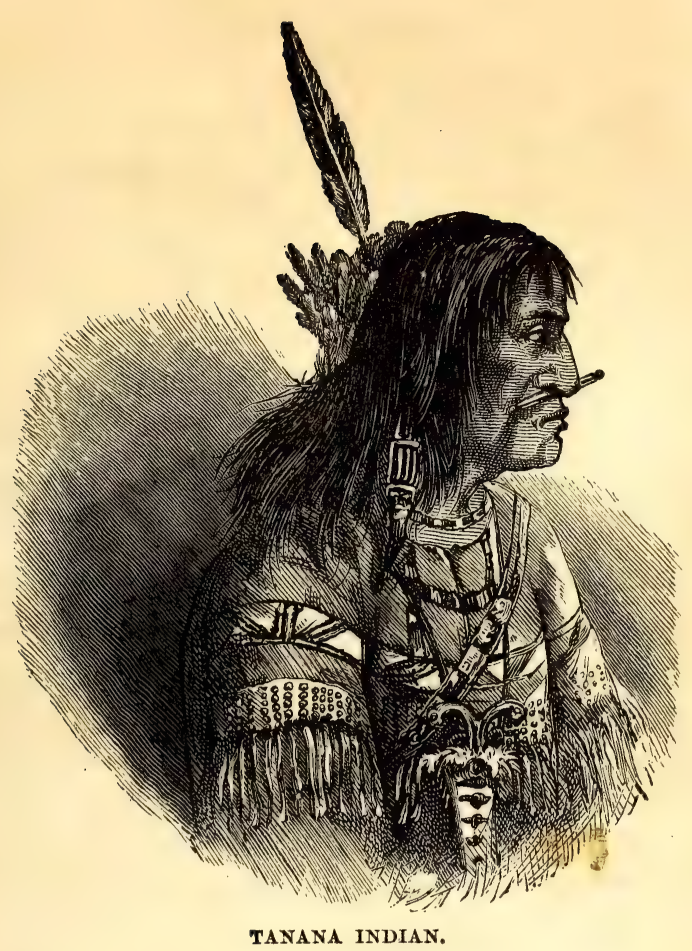

The Aleuts, who inhabit the Aleutian Islands are, to a considerable extent, of mixed blood, Russian and Koloschian. They have advanced in civilization far beyond any other of the Esquimaux race. Not a few of them have received a fair education, and among the priests of the Greek Church there are not a few who go through the service of the church in the Greek language, with a full understanding of the words of the service.

Quite nine-tenths of the whole territory of Alaska is purely Arctic, and is not only uninhabited but uninhabitable. The other tenth is now sparsely inhabited, and there is little reason to suppose that the population will ever be greatly beyond its present number. Except in special cases, the possible population of a country is measured by its agricultural capacity. Leaving out of view the extreme northern parts of Alaska, the best accounts as yet accessible show that at St. Michael's lettuce, parsnips, and turnips can be raised by sowing them in beds. At Fort Yukon potatoes not much larger than cherries can be raised. At Sitka potatoes will grow a little larger. On some of the islands the inhabitants can even venture upon barley. The forest-trees, which flourish in isolated parts, will soon be exhausted, as far as any profitable use of them is concerned. Fish and furs constitute almost the sole value of Alaska. The fisheries are among the most valuable in the world. The furs will soon be exhausted, unless prompt measures are taken to prevent the capture of fur-bearing animals in the breeding season. 


\title{
CHAPTER XXVII.
}

\author{
THE ESQUIMAUX.
}

Their wide Extension.-Climate of the Regions they inhabit.-Their physical Appearance.-Their Dress.-Snow Huts.-The Kayak, or the Baidar.-Hunting Apparatus and Weapons.-Enmity between the Esquimaux and the Red Indian.-The "Bloody Falls."-Chase of the Reindeer.-Birdcatching.-Whale-hunting.-Various Stratagems employed to catch the Seal.-The "Keep-kuttuk." -Bear-hunting. - Walrus-hunting.-Awaklok and Myouk.-The Esquimaux Dog.-Games and Sports.-Angekoks._Moral Character.-Self-reliance.-Intelligence.-Iligliuk._Commercial Eagerness of the Esquimaux.-Their Voracity.-Seasons of Distress.

$\mathrm{O}$ $\mathrm{F}$ all the uncivilized nations of the globe none range over a wider space than the Esquimaux, whose various tribes extend from Greenland and Labrador, over all the coasts of Arctic America, to the Aleutic chain and the extreme north-eastern point of Asia. Many are independent, others subject to the Russian, Danish, or British rule. In Baffin's Bay and Lancaster Sound they accost the whale-fisher; they meet him in the Icy Sea beyond Bering's Straits ; and while their most southerly tribes dwell as low as the latitude of Vienna, others sojourn as high as the 80th degree of northern latitude, and probably roam even still higher on the still undiscovered coasts beyond-a nearness to the pole no other race is known to reach.

The old Scandinavian settlers in Greenland expressed their dislike for them in the contemptuous name of Skraelingers (screamers or wretches); the seamen of the Hudson's Bay ships, who trade annually with the natives of Northern Labrador and the Savage Islands, have long called them "Seymos" or "Suckemos," names evidently derived from the cries of "Seymo," or "Teymo," with which they greet the arrival of the ships; they speak of themselves simply as "Inuit," or men.

With few exceptions the whole of the vast region they inhabit lies beyond the extremest limits of forest growth, in the most desolate and inhospitable countries of the globe. The rough winds of the Polar Sea almost perpetually blow over their bleak domains, and thus only a few plants of the hardest nature-lichens and mosses, grasses, saxifragas, and willows-are able to subsist there, and to afford a scanty supply of food to a few land animals and birds. Ill indeed would it fare with the Esquimaux, if they were reduced to live upon the niggardly produce of the soil; but the sea, with its cetaceans and fishes, amply provides for their wants. Thus they are never found at any considerable distance from the ocean, and they line a considerable part of the coasts of the Arctic seas without ever visiting the interior.

It may easily be supposed that a race whose eastern branches have for several centuries been under the influence of the Danes and English, while in the extreme west it has long been forced to submit to Russian tyranny, and whose central and northern tribes rarely come into contact with Europeans, must 
show some variety in its manners and mode of life, and that the same descrip. tion is not applicable in all points to the disciples of the Moravian brothers in Labrador or Greenland, to the Greek-Catholic Aleuts, and to the far more numerous heathen Esquimaux of continental America, or of the vast archipelago beyond its northern shores. Upon the whole, however, it is curious to observe how exactly, amidst all diversity of time and place, these people have preserved unaltered their habits and manners. The broad, flat face, widest just below the eyes, the forehead generally narrow and tapering upward; the eyes narrow and more or less oblique; all indicate a Mongol or Tartar type, differing greatly from the features of the conterminous Red Indian tribes. Their complexion, when relieved from smoke and dirt, also approaches more nearly to white than that of their copper-colored neighbors. Most of the men are rather under the medium English size, but they can not be said to be a dwarfish race. Thus Simpson saw in Camden Bay three Esquimaux who measured from five feet ten inches to six feet; and among the natives of Smith Strait, Kane, a rather short man, met with one a foot taller than himself. The females, however, are all comparatively short. The Esquimaux are all remarkably broad-shouldered, and though their muscles are not so firm as those of the European seamen, yet they surpass in bodily strength all the other natives of America. In both sexes the hands and feet are remarkably small and well-formed. From exercise in hunting the seal and walrus, the muscles of the arms and back are much developed in the men, who are moreover powerful wrestlers. When young, the Esquimaux looks cheerful and good-humored, and the females exhibit, when laughing, a set of very white teeth. Could they be induced to wash their faces, many of these savage beauties would be found to possess a complexion scarcely a shade darker than that of a deep brunette; but though disinclined to ablutions, for which the severity of their climate may serve as an excuse, they are far from neglecting the arts of the toilette.

Unlike the Hare Indian and Dog-Rib females, in whom the hard rule of their lords and masters has obliterated every trace of female vanity, the Esquimaux women tastefully plait their straight, black, and glossy hair; and hence we may infer that greater deference is paid to them by the men. They also generally tattoo their chin, forehead, and cheeks, not, however, as in the South Sea Islands, with elaborate patterns, but with a few simple lines, which have a not unpleasing effect.

From Bering's Straits eastward as far as the Mackenzie, the males pierce the lower lip near each angle of the mouth, and fill the apertures with labrets of blue or green quartz, or of ivory resembling buttons. Many also pierce the septum of the nose, and insert a dentalium shell or ivory needle. Like the Red Indians, they are fond of beads, but their most common ornament consists in strings of teeth of the fox, wolf, or musk-ox-sometimes many hundreds in number-which are either attached to the lower part of the jacket, or fastened as a belt round the waist.

Their dress is admirably adapted to the severity of their climate. With their two pair of breeches made of reindeer or seal skin, the outer one having the hair outside and the inner one next the body, and their two jackets-of 
which the upper one is provided with a great hood-with their water-tight seal-skin boots, lined with the downy skins of birds, and their enormous gloves, they bid defiance to the severest cold, and even in the hardest weather pursue their occupations in the open air whenever the moon is in the sky, or during the doubtful meridian twilight. The women are perfect in the art of making water-tight shirts, or "kamleikas," of the entrails of the seal or walrus, which in summer serve to replace their heavy skin jackets. They also sew their boots so tight that not the slightest wet can penetrate, and with a neatness of which the best shoemaker in Europe might be proud. The dress of the two sexes is much alike, the outer jacket having a pointed skirt before and behind, but that of the females is a little longer. The women also wear larger hoods, in which they carry their children; and sometimes (as in Labrador) the inner boot has in front a long, pointed flap to answer the same purpose.

The Esquimaux are equally expert in the construction of their huts. As soon as the lengthening days induce the tribes about Cape Bathurst and the mouth of the Mackenzie to move seaward on the ice to the seal-hunt, a marvellous system of architecture comes into use, unknown among any other American nations. The fine pure snow has by that time acquired, under the action of the winds and frosts, sufficient coherence to form an admirable light building material, which the Esquimaux skillfully employ for the erection of most comfortable dome-shaped houses. A circle is first traced on the smooth surface of the snow, and slabs for raising the walls cut from within, so as to clear a space down to the ice, which is to form the floor of the dwelling, and whose evenness was previously ascertained by probing. The slabs for the dome are cut from some neighboring spot. The crevices between the slabs are plugged up, and the seams closed, by throwing a few shovelfuls of loose snow over the fabric. Two men generally work together, and when the dome is completed the one within cuts a low door and creeps out. The walls being only three or four inches thick, admit a very agreeable light, which serves for ordinary purposes; if more is required, a window of transparent ice is introduced. The proper thickness of the walls is of some importance; one of a few inches excludes the wind, yet keeps down the damp so as to prevent dripping from the interior. The furniture of this crystal hut is also formed of snow (the seats, the table, the sleeping-places), and, when covered with skins, is very comfortable. By means of antechambers and porches, with the opening turned to leèward, warmth is insured, and social intercourse facilitated by contiguous building, doors of communication, and covered passages. By constant practice the Esquimaux can raise such huts almost as quickly as we could pitch a tent. When $\mathrm{M}^{\mathrm{r}} \mathrm{Clintock}$ for a few nails hired four Esquimaux to build a hut for his party, they completed it in an hour, though it was eight feet in diameter and five and a half feet high.

In spite of its fragile materials, this snow-house is dnrable, for the wind has little effect on its dome-like form, and it resists the thaw until the sun acquires a very considerable power. Of course a strong fire could not possibly be made within, but such is not needed by the Esquimaux. The train-oil lamp suffices to dry his wet clothes and boots when he returns from hunting; and the crowd- 
ing of the inmates engenders a sufficiently high temperature to keep him warm. Having also a decided predilection for raw flesh and fat, he requires no great expenditure of fuel to cook his dinner. The lower part of his dwelling being under the surface of the snow, likewise promotes its warmth.

But of whatever materials the hut of the Esquimaux may be constructedof snow, as I have just described, or, as is frequently the case, of stones, or earth, or drift-wood-everywhere, from Bering's Straits to Smith Sound, it is equally well adapted to the climate and to crrcumstances. Thus when Dr. Scoresby landed in 1822 on the eastern coast of Greenland, he discovered some deserted Esquimaux huts, which gave proof both of the severity of the climate, and of the ingenuity evinced in counteracting its rigors. A horizontal tunnel about fifteen feet long, and so low as to render it necessary to creep through on hands and feet, opens with one end to the south, and leads through the other into the interior of the hut. This rises but little above the surface of the earth, and, as it is generally overgrown with moss or grass, is scarcely to be distinguished from the neighboring soil. The floor of the tunnel is frequently on a level with that of the hut, but often also it is made to slant downward and upward, so that the colder, and consequently heavier, air without is still more effectually kept off from the warmer air within; and thus the Esquimaux, without ever having studied physics, make a practical use of one of its fundamental laws. But their most ingenious invention is unquestionably that of the one-seated boat, the "kayak," or the "baidar." A light, long, and narrow frame of wood, or seal or walrus bone, is covered water-tight with sealskin, leaving but one circular hole in the middle. In this the Esquimaux sits with outstretched legs, and binds a sack (which is formed of the intestines of the whale, or of the skins of young seals, and fits in the opening) so tightly round his middle, that even in a heavy sea not a drop of water can penetrate into the boat. Striking with his light oar (which is paddled at each extremity) alternately to the right and to the left, his. spear or harpoon before him, and maintaining his equilibrium with all the dexterity of a rope-dancer, he flies like an arrow over the water; and should a wave upset him, he knows how to right himself by the action of the paddle. The "oomiak," or women's boat, likewise consists of a frame-work covered with seal-skins, and is roomy enough to hold ten or twelve people, with benches for the women who row or paddle. The mast supports a triangular sail made of the entrails of seals, and easily distended by the wind. The men would consiaer it beneath their dignity to row in one of these omnibus boats; they leave this labor entirely to the women, who, to the tact of a monotonous song, slowly propel the oomiak through the water. Judging of foreign customs by their own, the Esquimaux between the Mackenzie and Coppermine rivers made the strange mistake, as Sir John Richardson relates, of supposing that the English sailors whom they saw rowing in company were women. One of them even asked whether all white females had beards.

The weapons of the Esquimaux, and their various fishing and hunting implements, likewise show great ingenuity and skill. Their oars are tastefully inlaid with walrus-teeth; they have several kinds of spears or darts, adapted to 
the size of the various animals which they hunt; and their elastic bows, strongly bound with strings of seal-gut, drive a six-foot arrow with unerring certainty to a distant mark. To bring down a larger animal, the shaft is armed with a sharp flint or a pointed bone; if intended to strike a bird, it is smaller, and blunted.

The harpoons and lances used in killing whales or seals have long shafts of wood or of the narwhal's tooth, and the barbed point is so constructed that, when the blow takes effect, it is left sticking in the body of the animal, while the shaft attached to it by a string is disengaged from the socket, and becomes a buoy of wood. Seal-skins, blown up like bladders, are likewise used as buoys for the whale-spears, being adroitly stripped from the animal so that all the natural apertures are easily made air-tight.

With equal industry and skill the Esquimaux put to use almost every part of the land and marine animals which they chase. Knives, spear-points, and fish-hooks are made of the horns and bones of the deer. The ribs of the whale are used in roofing huts or in the construction of sledges, where drift-timber is scarce. Strong cord is made from strips of seal-skin hide, and the sinews of musk-oxen and deer furnish bow-strings, or cord to make nets or snares. In default of drift-wood, the bones of the whale are employed for the construction of their sledges, in pieces fitted to each other with neatness, and firmly sewed together.

During the long confinement to their huts or "igloos" in the dark winter months, the men execute some very fair figures in bone, and in walrus or fossil ivory, besides making fish-hooks, knife-handles, and other instruments neatly of these materials, or of metal or wood.

Thus in all these respects the Esquimaux are as superior to the Red Indians as they are in strength and personal courage; and yet no Norwegian can more utterly despise the filthy Lapp, and no orthodox Mussulman look down with greater contempt upon a "giaour," than the Loucheux or Cheppewayan upon the Esquimaux, who in his eyes is no better than a brute, and whom he approaches only to kill.

In his "Voyage to the Coppermine River" Hearne relates a dreadful instance of this bloodthirsty hatred. The Indians who accompanied him having heard that some Esquimaux had erected their summer huts near the mouth of that river, were at once seized with a tiger-like fury. Hearne, the only European of the party, had not the power to restrain them, and he might as well have attempted to touch the heart of an ice-bear as to move the murderous band to pity. As craftily and noiselessly as serpents they drew nigh, and, when the midnight sun verged on the horizon, with a dreadful yell they burst on the huts of their unsuspecting victims. Not one of them escaped, and the monsters delighted to prolong the misery of their death-struggle by repeated wounds. An old woman had both her eyes torn out before she received the mortal blow. A young girl fled to Hearne for protection, who used every effort to save her, but in vain. In 1821 some human skulls lying on the spot still bore testimony to this cruel slaughter, and the name of the "Bloody Falls," given by Hearne to the scene of the massacre, will convey its memory to distant ages. No wonder 
that the hate of the Esquimaux is no less intense, and that they also pursue the Indians, wherever they can, with their spears and arrows, like wild beasts.

"Year after year," says Sir John Richardson, "sees the Esquimaux on the Polar coast of America occupied in a uniform circle of pursuits. When the rivers open in spring, they proceed to the rapids and falls to spear the salmon, which at that season come swimming stream upward. At the same time, or earlier in more southern localities, they hunt the reindeer, which drop their young on the coasts and islands while the snow is only partially melted. Where the open country affords the huntsman no opportunity of approaching his game unperceived, deep pits are dug in the snowy ravines, and superficially covered with snow-tablets. The wind soon effaces the traces of the human hand, and thus many reindeer are snared."

In summer the reindeer are killed partly by driving them from islands or narrow necks of land into the sea, and then spearing them from their kayaks, and partly by shooting them from behind heaps of stones raised for the purpose of watching them, and imitating their peculiar bellow or grunt. Among the various artifices which they employ for this purpose, one of the most ingenious consists in two men walking directly from the deer they wish to kill, when the animal almost always follows them. As soon as they arrive at a large stone, one of the men hides behind it with his bow, while the other, continuing to walk on, soon leads the deer within range of his companion's arrows.

The multitudes of swans, ducks, and geese resorting to the morasses of the northern coasts to breed, likewise aid in supplying the Esquimaux with food during their short but busy summer of two months. For their destruction a very ingenious instrument has been invented. Six or eight small balls made of walrus-tooth and pierced in the middle are separately attached to as many thongs of animal sinew, which are tied together at the opposite end. When cast into the air the diverging balls describe circles-like the spokes of a wheel -and woe to the unfortunate bird that comes within their reach.

On the coasts frequented by whales, the month of August is devoted to the pursuit of these animals; a successful chase insuring a comfortable winter to a whole community. Their capture requires an association of labor; hence along the coasts of the Polar Sea the Esquimaux unite their huts into villages, for whose site a bold point of coast is generaily chosen, where the water is deep enough to float a whale.

When one of these huge creatures is seen lying on the water, a dozen kayaks or more cautiously paddle up astern of him, till a single canoe, preceding the rest, comes close to him on one quarter, so as to enable the men to drive the spear into the animal with all the force of both arms. This spear has a long line of thong and an inflated seal-skin attached to it. The stricken whale immediately dives; but when he re-appears after some time, all the canoes again paddle towards him, some warning being given by the seal-skin buoy floating on the surface. Each man being furnished like the first, they repeat the blow as often as they find an opportunity, till perhaps every line has been thus employed. After chasing him in this manner sometimes for half a day, he is at length so wearied by the resistance of the buoys and exhausted by loss of 
blood as to be obliged to rise more and more often to the surface, and is finally killed and towed ashore.

Though in many parts seals are caught at every season of the year, yet the great hunt takes place in spring, when they play in the open lanes near the coasts, or come out on the ice to bask in the sun. In spite of their wariness, they are no match for the Esquimaux, who have carefully studied all their habits from infancy. Sometimes the hunter approaches them by imitating their forms and motions so perfectly that the poor animals are not undeceived until one of them is struck with his lance; or else, by means of a white screen pushed forward on a sledge, the hunter comes within range and picks out the best-conditioned of the band. As the season draws near midsummer, the seals are more approachable; their eyes being so congested by the glare of the sun that they are sometimes nearly blind. In winter they are assaulted whiie working at their breathing-holes or when coming up for respiration.

If an Esquimaux has any reason to suppose that a seal is busy gnawing beneath the ice, he immediately attaches himself to the place, and seldom leaves it, even in the severest frost, till he has succeeded in killing the animal. For this purpose he first builds a snow-wall about four feet in height, to shelter him from the wind, and seating himself under the lee of it, deposits his spears, lines, and other implements upon several little forked sticks inserted into the snow, in order to prevent the smallest noise being made in moving them when wanted. But the most curious precaution consists in tying his own knees together with a thong so securely as to prevent any rustling of his clothes, which might otherwise alarm the animal. In this situation a man will sit quietly sometimes for hours together, attentively listening to any noise made by the seal, and sometimes using the "keep-kuttuk" in order to ascertain whether the animal is still at work below. This simple little instrument-which affords another striking proof of Esquimaux ingenuity-is merely a slender rod of bone (as delicate as a fine wire, that the seal may not see it), nicely rounded, and having a point at one end and a knob at the other. It is inserted into the ice, and the knob remaining above the surface, informs the fisherman by its motion whether the seal is employed in making his hole; if not, it remains undisturbed, and the attempt is given up in that place. When the hunter supposes the hole to be nearly completed, he cautiously lifts his spear (to which the line has been previously attached), and as soon as the blowing of the seal is distinctly heard-and the ice consequently very thin-he drives it into him with the force of both arms and then cuts away with his "panna," or well-sharpened knife, the remaining crust of ice, to enable him to repeat the wounds and get him out. The "neituk" (Phoca hispida), being the smallest seal, is held, while struggling, either simply by hard, or by putting the line round a spear with the point stuck into the ice. For the "oguke" (Phoca barbata), the line is passed round the man's leg or arm; and for a walrus, round his body, his feet being at the same time firmly set against a hummock of ice, in which position these people can, from habit, hold against a very heavy strain. A boy of fifteen is equal to the killing of a "neituk," but it requires a full-grown person to master either of the larger animals. This sport is not without the danger which adds to the ex- 
eitement of success, particularly if the creature struck by the hunter be a large seal or walrus ; for woe betide him if he does not instantly plant his feet firmly in the ice, and throw himself in such a position that the strain on the line is as nearly as possible brought into the direction of the length of the spine of his back and axis of his lower limbs. A transverse pull from one of these powerful animals would double him up across the air-hole, and perhaps break his back; or if the opening be large, as it often is when the spring is advanced, ho would be dragged under water and drowned.

As the Polar bear is as great a seal-hunter as the Esquimaux, one of the usual methods employed by the latter to catch these bears is to imitate the motions of the seal by lying flat on the ice until the bear approaches sufficiently near to insure a good aim; but a gun is necessary to practise this stratagem with success. Seeman ("Voyage of the Herald") mentions another ingenious mode of capturing the bear by taking advantage of the well-known voracity of the animal, which generally swallows its food without much mastication. A thick and strong piece of whalebone, about four inches broad and two feetlong, is rolled up into a small compass, and carefully enveloped in blubber, forming a round ball. It is then placed in the open air at a low temperature, where it soon becomes hard and frozen. The natives, armed with their knives, bows, and arrows, together with this frozen bait, proceed in quest of the bear. As soon as the animal is seen, one of the natives discharges an arrow at it; the monster, smarting from this assault, chases the party, then in full retreat, until, meeting with the frozen blubber dropped in his path, he greedily swallows it, and continues the pursuit-doubtless fancying that there must be more where that came from. The natural heat of the body soon causes the blubber to thaw, when the whalebone, thus freed, springs back, and frightfully lacerates the stomach. The writhing brute falls down in helpless agony, and the Esquimaux, hurrying to the spot, soon put an end to his sufferings.

The Esquimaux of Smith Sound hunt the bear with the assistance of their dogs, which are carefully trained not to engage in contest with the bear, but to retard his flight. While one engrosses his attention ahead, a second attacks him in the rear, always alert, and each protecting the other; and thus it rarely happens that they are seriously injured, or that they fail to delay the animal until their masters come up. If there be two hunters, the bear is killed easily; for one makes a feint of thrusting a spear at the right side, and as the animal turns with his arms towards the threatened attack, the left is unprotected, and receives the death-wound. But if the hunter is alone, he grasps the lance firmly in his hands, and provokes the animal to pursue him by moving rapidly across its path, and then running as if to escape. But hardly is its long, unwieldy body extended for the chase, than, with a rapid jump, the hunter doubles on his track, and runs back towards his first position. The bear is in the act of turning after him again, when the lance is plunged into the left side below the shoulder. So dexterously has this thrust to be made, that an unpractised hunter has often to leave his spear in the side of his prey and run for his life; but even then, if well-aided by the dogs, a cool, skillful man seldom fails to kill his adversary. 
While the seal, narwhal, and white whale furnish the staple food of the more southern Greenlander, the walrus is the chief resource of the Smith Sound Esquimaux. The manner of hunting this animal depends much on the season of the year. In spring, or the breeding-season, when the walr'xs is in his glory, he is taken in two ways. Sometimes he has risen by the side of an iceberg, where the currents have worn away the floe, or through a tide crack, and, enjoying the sunshine too long, finds his retreat cut off by the freezing up of the opening; for like the seal, the walrus can only work from below at his breathing-hole. When thus caught, the Esquimaux, who with keen huntercraft are scouring the floes, scent him out by their dogs and spear him. Frequently the female and her calf, accompanied by the grim-visaged father, are seen surging, in loving trios, from crack to crack, and sporting in the openings. While thus on their tour, they invite their vigilant enemies to the second method of capture. This also is by the lance and harpoon; but it often becomes a regular battle, the male gallantly fronting the assault, and charging the hunters with furious bravery. In the fall, when the pack is but partially closed, the walrus are found in numbers, hanging around the neutral region of mixed ice and water, and, as this becomes solid with the advance of winter, following it more and more to the south.

The Esquimaux at this season approach them over the young ice, and assail them in cracks and holes with harpoon and line. This fishery, as the season grows colder, darker, and more tempestuous, is fearfully hazardous. Kane relates how, during a time of famine, two of his Esquimaux friends, Awaklok and Myouk, determined to seek the walrus on the open ice. They succeeded in killing a large male, and were returning to their village, when a north wind broke up the ice, and they found themselves afloat. The impulse of a European would have been to seek the land; but they knew that the drift was always most dangerous on the cuast, and nrged their dogs towards the nearest iceberg. They reached it after a struggle, and, by great efforts, made good their landing, with their dogs and the half-butchered carcass of the walrus. It was at the close of the last moonlight of December, and a complete darkness settled around them. They tied the dogs down to knobs of ice, to prevent their losing their foothold, and prostrated themselves, to escape being blown off by the violence of the wind. At first the sea broke over them, but they gained a higher level, and built a sort of screen of ice. On the fifth night afterwards, so far as they could judge, one of Myouk's feet was frozen, and Awaklok lost his great toe by frost bite. But they did not lose courage, and ate their walrus-meat as they floated slowly to the south. It was towards the close of the second moonlight, after a month's imprisonment, such as only these iron men could endure, that they found the berg had grounded. They liberated their dogs as soon as the young ice could bear their weight, and attaching long lines to them, which they cut from the hide of the dead walrus, they succeeded in hauling themselves through the water-space which always surrounds an iceberg, and reaching safe ice. They returned to their village like men raised from the dead, to meet a welcome, but to meet famine along with it. 
In the form of their bodies, their short pricked ears, thick furry coat, and bushy tail, the dogs of the Esquimaux so nearly resemble the wolf of these regions, that when of a light or brindled color, they may easily at a little distance be mistaken for that animal ; but an eye accustomed to both, perceives that the wolf always keeps his head down and his tail between his legs in running, whereas the dogs almost always carry their tails handsomely curled over the back. Their hair in the winter is from three to four inches long; but besides this nature furnishes them during this rigorous season with a thick under-coating of close, soft wool, which enables them to brave the most inclement weather. They do not bark, but have a long melancholy howl, like that of the wolf. When drawing a sledge, they have a simple harness of deer or seal skin going round the neck by one bight, and another for each of the fore legs, with a single thong leading over the back, and attached to the sledge as a trace. Though they appear at first sight to be huddled together without regard to regularity, considerable attention is really paid to their arrangement, particularly in the selection of a dog of peculiar spirit and sagacity, who is allowed by a longer trace to precede the rest as leader, and to whom, in turning to the right or left, the driver usually addresses himself, using certain words as the carters do with us. To these a good leader attends with admirable precision (especially if his own name be repeated at the same time), looking behind over his shoulder with great earnestness, as if listening to the directions of the driver, who sits quite low on the fore part of the sledge, his whip in hand, and his feet overhanging the snow on one side.

On rough ground, as among hummocks of ice, the sledge would be frequently overturned if the driver did not repeatedly get off, and, by lifting or drawing it to one side, steer it clear of those obstacles. At all times, indeed, except on a smooth and well-made road, he is pretty constantly employed thus with his feet, and this, together with his never-ceasing vociferations and frequent use of the whip, renders the driving of one of these vehicles by no means a pleasant or easy task.

" The whip,' says Kane, who from assiduous practice at length attained a considerable proficiency in its use, "is six yards long, and the handle but sixteen inches-a short lever to throw out such a length of seal-hide. Learn to do it, however, with a masterly sweep, or else make up your mind to forego driving sledges; for the dogs are guided solely by the lash, and you must be able to hit not only any particular dog of a team of twelve, but to accompany the feat also with a resounding crack. After this you find that, to get your lash back, involves another difficulty; for it is apt to entangle itself among the dogs and lines, or to fasten itself cunningly round bits of ice, so as to drag you head over heels into the snow. The secret by which this complicated set of requirements is fulfilled consists in properly describing an are from the shoulder with a stiff elbow, giving the jerk to the whip-handle from the hand and wrist alone. The lash trails behind as you travel, and when thrown forward is allowed to extend itself without an effort to bring it back. You wait patiently, after giving the projectile impulse, until it unwinds its slow length, reaches the end of its tether, and cracks to tell you that it is at its journey's end. Such a crack on 
the ear or fore foot of an unfortunate dog is signalized by a howl quite unmis. takable in its import."

The mere labor of using this whip is such that the Esquimanx travel in couples, one sledge after the other. The hinder dogs follow mechanically, and thus require no whip; and the drivers change about so as to rest each other.

In the summer, when the absence of snow prevents the use of sledges, the dogs are still made useful, on journeys and hunting excursions, by being employed to carry burdens in a kind of saddle-bags laid across their shoulders. A stout dog thus accoutred will accompany his master laden with a weight of about twenty or twenty-five pounds.

The scent of the Esquimaux dog is excellent, and this property is turned to account in finding the seal-holes, which they will discover entirely by the smell at a very great distance. The track of a single deer upon the snow will in like manner set them off at full gallop at least a quarter of a mile before they arrive at it, and with the same alacrity they pursue the bear or the musk-ox. Indeed, the only animal which they are not eager to chase is the wolf, of which they seem to have an instinctive dread, giving notice at night of their approach to the huts by a loud and continued howl.

In spite of their invaluable services, they are treated with great severity by their masters, who never caress them, and, indeed, scarcely ever take any notice of them except to punish them. But notwithstanding this rough treatment, the attachment of the dogs to their masters is very great, and this they display, after a short absence, by jumping up and licking their faces all over with extreme delight.

It may be supposed that among so cheerful a people. as the Esquimaux there are many games or sports practised. One of their exhibitions consists in making hideous faces by drawing both lips into the mouth, poking forward the chin, squinting frightfully, occasionally shutting one eye, and moving the head from side to side as if the neck had been dislocated.

Another performance consists in repeating certain words with a guttural tone resembling ventiloquism, staring at the same time in such a manner as to make their eyes appear ready to burst out of their sockets with the exertion. Two or more will sometimes stand up face to face, and, with great quickness and regnlarity, respond to each other, keeping such exact time that the sound appears to come from one throat instead of several. They are fond of music, both vocal and instrumental, but their singing is not much better than a howl.

The Esquimaux have neither magistrates nor laws, yet they are orderly in their conduct towards each other. The constitution of their society is patriarchal, but there is no recognition of mastership except such as may be claimed by superior prowess. The rule of the head of a family lasts only as long as he has vigor enough to secure success in hunting. When his powers of mind and body are impaired by age, he at once sinks in the social scale, associates with the women, and takes his seat in the oomiak. They rarely quarrel among themselves, and settle their disputes either by boxing, the parties sitting down and striking blows alternately until one of them gives in, or before a court of honor, where, after the accuser and the accused have richly abused and ridi- 
culed each other, the case is decided by the priests or "angekoks." These wonder-workers, who enjoy a great reputation as sorcerers, soothsayers, or medicine-men, employ ventriloquism, swallow knives, extract stones from various parts of their bodies, and use other deceptions to impress their dupes with a high opinion of their supernatural powers. Like the members of the learned professions elsewhere, they have a certain language or jargon of their own, in which they communicate with each other. The heathen Esquimaux do not appear to have any idea of the existence of one Supreme Being, but believe in a number of spirits, with whom on certain occasions the angekoks pretend to hold mysterious intercourse. Even in Old Greenland the influence and teachings of the missionaries have not entirely obliterated the old superstitions, and the mysteries of the angekok, though not openly recognized near the Danish settlements, still hold their secret power over many a native who is professedly a Christian.

Captain Hall highly praises the good-nature of the Esquimaux; but in their behavior to the old and infirm they betray the insensibility, or rather inhumanity, commonly found among savage nations, frequently abandoning them to their fate on their journeys, and allowing them to perish in the wilderness.

Among themselves "Tiglikpok" (he is a thief) is a term of reproach, but they steal without scruple from strangers, and are not ashamed when detected, nor do they blush when reproved. Parry taxes them with want of gratitude; and though they have no doubt rendered good services to many of our Aretic navigators, yet sometimes, when they fancied themselves the stronger party, they have not hesitated to attack or to murder the strangers, and their good behavior can only be relied upon as long as there is the power of enforcing it.

One of the most amiable traits of their character is the kindness with which they treat their children, whose gentleness and docility are such as to occasion their parents little trouble, and to render severity towards them quite unnecessary. Even from their earliest infancy they possess that quiet disposition, gentleness of demeanor, and uncommon evenness of temper for which, in mature age, they are for the most part distinguished. "They are just as fond of play," says Parry, "as any other young people, and of the same kind, only that while an English child draws a cart of wood, an Esquimaux of the same age has a sledge of whalebone; and for the superb baby-house of the former, the latter builds a miniature hut of snow, and begs a lighted wick from her mother's lamp to illuminate the little dwelling."

When not more than eight years old, the boys are taken by their fathers on their sealing excursions, where they begin to learn their future business; and even at that early age they are occasionally intrusted to bring home a sledge and dogs from a distance of several miles over the ice. At the age of eleven we see a boy with his water-tight boots, a spear in his hand, and a small coil of line at his back, accompanying the men to the fishery under every circumstance; and from this time his services daily increase in value to the whole tribe.

In intelligence and susceptibility of civilization the Esquimaux are far su- 
perior to the neighboring Indians. They have such a good idea of the hydrog. raphy and bearings of the sea-coasts which they frequent as to draw accurate charts of them. Thus Parry, in his second voyage, was guided in his operations by the sketches of the talented Iligliuk; and while Beechey was at Kotzebue Sound, the natives constructed a chart of the coast upon the sand, first marking out the coast-line with a stick, and regulating the distance by the day's journey. The hills and ranges of mountains were next shown by elevations of sand or stone, and the islands represented by heaps of pebbles, their propor. tions being duly attended to. When the mountains and islands were erected, the villages and fishing-stations were marked by a number of sticks placed upright, in imitation of those which are put up on the coast wherever these people fix their abode. In this manner a complete hydrographical plan was drawn from Cape Derby to Cape Krusenstern.

The Esquimaux have an decided predilection for commercial pursuits, and undertake long voyages for the purposes of trade. Thus on the continental line of coast west of the Mackenzie, the Point Barrow Esquimaux proceed every summer, with sledges laden with whale or seal oil, whalebone, walrustusks, thongs of walrus hide, and seal-skins, to the Colville River, where they meet the Esquimaux from Kotzebue Sound, who offer them in exchange articles procured from the Tchuktchi in the previous summer, such as iron and copper kettles, knives, tobacco, beads, and tin for making pipes. About ten days are spent in bartering, dancing, and revelry, on the flat ground between the tents of each party, pitched a bow-shot apart. The time is one of pleasant excitement, and is passed nearly without sleep. About July 20 this friendly meeting is at an end: the Kotzebue Sound Esquimaux ascend the Colville on their way homeward, while those from Point Barrow descend to the sea, to pursue their voyage eastward to Barter Reef, where they obtain in traffic from the eastern Esquimaux various skins, stone lamps, English knives, small white beads, and, lately, guns and ammunition, which in the year following they exchange for the Kotzebue Sound articles at the Colville, along with the produce of their own sea-hunts.

In this manner, articles of Russian manufacture, originally purchased at the fair of Ostrownoje by the Tchuktchi, or from the factors of the Russian Fur Company on Sledge Island, in Bering's Straits, find their way from tribe to tribe along the American coast as far as Repulse Bay, and compete among the tribes of the Mackenzie with articles from Sheffield or Birmingham.

A hunter's life is always precarious-a constant alternation between abundance and want; and though the Esquimaux strikes many a seal, white-fish, or walrus in the course of the year, yet these animals do not abound at all seasons, and there are other causes, besides improvidence, which soon exhaust the stores laid by in times of abundance. Active exercise and constant exposure to cold are remarkable promoters of atomic change in the human body, and a very large supply of food is absolutely necessary to counterbalance the effects of a rapid organic combustion. As a matter of curiosity, Parry once tried how much an Esquimaux lad would, if freely supplied, consume in the course of a day. The following articles were weighed before being given to him: 
he was twenty hours in getting through them, and certainly did not consider the quantity extraordinary.

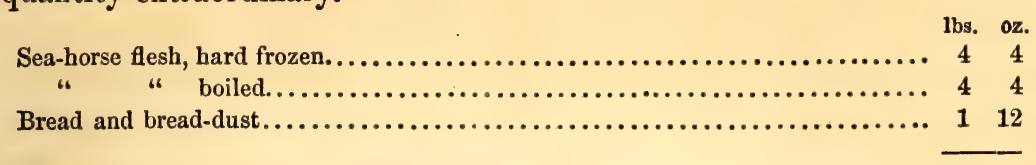

Total of solids

104

The fluids were in fair proportion, viz., rich gravy soup, $1 \frac{1}{4}$ pint; raw spirits, 3 wine-glasses; strong grog, 1 tumbler ; water, 1 gallon 1 pint.*

Kane averages the Esquimaux ration in a season of plenty at eight or ten pounds a day, with soup and water to the extent of half a gallon, and finds in this excessive consumption-which is rather a necessity of their peculiar life and organization than the result of gluttony-the true explanation of the scarcity from which they frequently suffer. In times of abundance they hunt indomitably without the loss of a day, and stow away large quantities of meat. An excavation is made either on the mainland-or, what is preferred, on an island inaccessible to foxes-and the flesh is stacked inside and covered with heavy stones. One such cache which Kane met on a small island contained the flesh of ten walruses, and he knew of others equally large. But by their ancient custom, all share with all; and as they migrate in numbers as their necessities prompt, the tax on each particular settlement is not seldom so excessive that even considerable stores are unable to withstand the drain, and soon make way for pinching hunger, and even famine.

* Captain Hall, who in his search after the remains of the Franklin expedition spent several years among the Esquimaux, and had so far aequired their appetite that he was able to consume 9 lbs. of meat a day without any inconvenience. 


\section{CHAPTER XXVIII.}

\section{THE FUR-TRADE OF THE HUDSON'S BAY TERRITORIES.}

The Coureur des Bois. - The Voyageur. - The Birch-bark Canoe.-The Canadian Fur-trade in the last Century.-The Hudson's Bay Company.-Bloody Feuds between the North-west Company of Canada and the Hudson's Bay Company. - Their Amalgamation into a new Company in 1821.-Reconstruction of the Hudson's Bay Company in 1863.-Forts or Houses.-The Attihawmeg. - Influence of the Company on its savage Dependents.-The Black Bear, or Baribal.-The Brown Bear. - The Grizzly Bear. - The Raccoon.-The American Glutton.-The Pine Marten.-The Pekan, or Woodshock. - The Chinga.-The Mink.-The Canadian Fish-otter.-The Crossed Fox.-The Black or Silvery Fox.-The Canadian Lynx, or Pishu.-The Ice-hare.-The Beaver.-The Musquash.

A $\mathrm{S}$ the desire to reach India by the shortest road first made the civilized world acquainted with the eastern coast of North America, so the extension of the fur-trade has been the chief, or rather the only, motive which originally led the footsteps of the white man from the Canadian Lakes and the borders of Hudson's Bay into the remote interior of that vast continent.

The first European fur-traders in North America were French Canadianscoureurs des bois-a fitting surname for men habituated to an Indian forestlife. Three or four of these "irregular spirits" agreeing to make an exped1tion into the backwoods would set out in their birch-bark canoe, laden with goods received on trust from a merchant, for a voyage of great danger and hardship, it might be of several years, into the wilderness.

On their return the merchant who had given them credit of course received the lion's share of the skins gathered among the Hurons or the Iroquois; the small portion left as a recompense for their own labor was soon spent, as sailors spend their hard-earned wages on their arrival in port; and then they started on some new adventure, until finally old age, infirmities, or death prevented their revisiting the forest.

The modern "voyageur," who has usurped the place of the old "coureurs," is so like them in manners and mode of life, that to know the one is to become acquainted with the other. In short, the voyageur is merely a coureur subject to strict law and serving for a fixed pay; while the coureur was a voyageur trading at his own risk and peril, and acknowledging no control when once beyond the pale of European colonization.

The camel is frequently called the "ship of the desert," and with equal justice the birch-bark canoe might be named the "camel of the North American wilds." For if we consider the rivers which, covering the land like a net-work, are the only arteries of communication; the frequent rapids and cataracts; the shallow waters flowing over a stony ground whose sharp angles would infallibly cut to pieces any boat made of wood; and finally the surrounding deserts, where, in case of an accident, the traveller is left to his own resources, we must come to the conclusion that in such a country no intercourse could possibly be 
carried on without a boat made of materials at once flexible and tough, and capable moreover of being easily repaired without the aid of hammer and nails, of saw and plane. This invaluable material is supplied by the rind of the paperbirch, a tree whose uses in the Hudson's Bay territories are almost as manifold as those of the palm-trees of the tropical zone. Where the skins of animals are rare, the pliant bark, peeled off in large pieces, serves to cover the Indian's tent. Carefully sewn together, and ornamented with the quills of the porcupine, it is made into baskets, sacks, dishes, plates, and drinking-cups, and in fact is, in one word, the chief material of which the houschold articles of the Crees are formed. The wood serves for the manufacture of oars, snow-shoes, and sledges ; and in spring the sap of the tree furnishes an agreeable beverage, which, by boiling, may be inspissated into a sweet syrup. Beyond the Arctic Circle the paper-birch is a rare and crooked tree, but it is met with as a shrub as far as $69^{\circ} \mathrm{N}$. lat. It grows to perfection on the northern shores of Lake Superior. near Fort William, where the canoes of the Hudson's Bay Company are chietly manufactured.

A birch-bark canoe is between thirty and forty feet long, and the rinds of which it is built are sewn together with filaments of the root of the Canadian fir. In case of a hole being knocked into it during the journey, it can be patched like an old coat, and is then as good as new. As it has a flat bottom, it does not sink deep into the water; and the river must be almost dried up which could not carry such a boat. The cargo is divided into bales or parcels of from 90 to 100 pounds; and although it frequently amounts to more than four tons, yet the canoe itself is so light that the crew can easily transport it upon their shoulders. This crew generally consists of eight or ten men, two of whom must be experienced boatmen, who receive double pay, and are placed one at the helm, the other at the poop. When the wind is fair, a sail is unfurled, and serves to lighten the toil.

The Canadian voyageur combines the light-heartedness of the Frenchman with the apathy of the Indian, and his dress is also a mixture of that of the Red-skins and of the European colonists. Frequently he is himself a mixture of Gallic and Indian blood-a so-called "bois-brûlé," and in this case doubly light-hearted and unruly. With his woollen blanket as a surcoat, his shirt of striped cotton, his pantaloons of cloth, or his Indian stockings of leather, his moccasins of deer-skin, and his sash of gaudily-dyed wool, in which his knife, his tobacco-bag, and various other utensils are stuck, he stands high in his own esteem. His language is a French jargon, richly interlarded with Indian and English words-a jumble fit to drive a grammarian mad, but which he thinks so euphonious that his tongue is scarcely ever at rest. His supply of songs and anecdotes is inexhaustible, and he is always ready for a dance. His politeness is exemplary: he never calls his comrades otherwise than "mon frère," and "mon cousin." It is hardly necessary to remark that he is able to handle his boat with the same ease as an expert rider manages his horse.

When after a hard day's work they rest for the night, the axe is immediately at work in the nearest forest, and in less than ten minutes the tent is erected 
and the kettle simmering on the fire. While the passengers-perhaps some chief trader on a voyage to some distant fort, or a Back or a Richardson on his way to the Polar Ocean-are warming or drying themselves, the indefatigable "voyageurs" drag the unloaded canoe ashore, turn it over, and examine it carefully, either to fasten again some loose stitches, or to paint over some damaged part with fresh resin. Under the cover of their boat, which they turn against the wind, and with a flaming fire in the foreground, they then bid defiance to the weather. At one o'clock in the morning "Lève! lève! lève!" is called: in half an hour the encampment is broken up, and the boat reladen and launched. At eight in the morning a halt is made for breakfast, for which three-quarters of an hour are allowed. About two in the afternoon half an hour's rest suffices for a cold dinner. Eighteen hours' work and six hours rest make out the day. The labor is incredible; yet the "voyageur" not only supports it without a murmur, but with the utmost cheerfulness. Such a life requires, of course, an iron constitution. In rowing, the arms and breast of the "voyageur" are exerted to the utmost; and in shallow places he drags the boat after him, wading up to the knees and thighs in the water. Where he is obliged to force his way against a rapid, the drag-rope must be pulled over rocks and stumps of trees, through swamps and thickets; and at the portages the cargo and the boat have to be carried over execrable roads to the next navigable water. Then the "voyageur" takes upon his back two packages, each weighing 90 pounds, and attached by a leathern belt running over the forehead, that his hands may be free to clear the way; and such portages sometimes occur ten or eleven times in one day.

For these toils of his wandering life he has many compensations, in the keen appetite, the genial sensation of muscular strength, and the flow of spirits engendered by labor in the pure and bracing air. Surely many would rather breathe with the "voyageur" the fragrance of the pine forest, or share his rest upon the borders of the stream, than lead the monotonous life of an artisan, pent up in the impure atmosphere of a city.

During the first period of the American fur-trade the "coureurs des bois" used to set out on their adventurous expeditions from the village "La Chine," one of the oldest and most famous settlements in Canada, whose name points to a time when the St. Lawrence was still supposed to be the nearest way to China. How far some of them may have penetrated into the interior of the continent is unknown; but so much is certain, that their regular expeditions extended as far as the Saskatchewan, 2500 miles beyond the remotest European settlements. Several factories or forts protected their interests on the banks of that noble river; and the French would no doubt have extended their dominion to the Rocky Mountains or to the Pacific if the conquest of Canada by England, in 1761, had not completely revolutionized the fur-trade. The change of dominion laid it prostrate for several years, but our enterprising countrymen soon opened a profitable intercourse with the Indian tribes of the west, as their predecessors had done before them. Now, however, the adventurous "coureur des bois," who had entered the wilds as a semi-independent trader, was obliged to serve in the pay of the British merchant, and to follow him, as his "voya- 
geur," deeper and deeper into the wilderness, until finally they reached on the Athabasca and the Churchill River the Indian hunters who used to sell their skins in the settlements of the Hudson's Bay Company.

This company was founded in the year 1670 by a body of adventurers and merchants under the patronage of Prince Rupert, second cousin of Charles II. The charter obtained from the Crown was wonderfully liberal, comprising not only the grant of the exclusive trade, but also of full territorial possession to all perpetuity of the vast lands within the watershed of Hudson's Bay. The Company at once established some forts along the shores of the great inland sea from which it derived its name, and opened a very lucrative trade with the Indians, so that it never ceased paying rich dividends to the fortunate shareholders until towards the close of the last century, when, as I have already mentioned, its prosperity began to be seriously affected by the energetic competition of the Canadian fur-traders.

In spite of the flourishing state of its affairs, or rather because the monopoly which it enjoyed allowed it to prosper without exertion, the Company, as long as Canada remained in French hands, had conducted its affairs in a very indolent manner, waiting for the Indians to bring the produce of their chase to the Hudson's Bay settlements, instead of following them into the interior and stimulating them by offering greater facilities for exchange.

For eighty years after its foundation the Company possessed no more than four small forts on the shores of Hudson's Bay; and only when the encroachments of the Canadians at length roused it from its torpor, did it resolve likewise to advance into the interior, and to establish a fort on the eastern shore of Sturgeon Lake, in the year 1774. Up to this time, with the exception of the voyage of discovery which Hearne (1770-71) made under its auspices to the mouth of the Coppermine River, it had done but little for the promotion of geographical discovery in its vast territory.

Meanwhile the Canadian fur-traders had become so hateful to the Indians that these savages formed a conspiracy for their total extirpation.

Fortunately for the white men, the small-pox broke out about this time among the Redskins, and swept them away as the fire consumes the parched grass of the prairies. Their unburied corpses were torn by the wolves and wild dogs, and the survivors were too weak and dispirited to be able to undertake any thing against the foreign intruders. The Canadian fur-traders now also saw the necessity of combining their efforts for their mutual benefit, instead of ruining each other by an insane competition; and consequently formed, in 1783, a society which, under the name of the North-west Company of Canada, at first consisted of sixteen, later of twenty partners or shareholders, some of whom lived in Canada, while the others were scattered among the various stations in the interior. The whole Canadian fur-trade was now greatly developed; for while previously each of the associates had blindly striven to do as much harm as possible to his present partners, and thus indirectly damaged his own interests, they now all vigorously united to beat the rival Hudson's Bay Company out of the field. The agents of this North-west Company, in defiance of their charter, were indefatigable in exploring the lakes and woods, 
the plains and the mountains, for the purpose of establishing new trading-stations at all convenient points.

The most celebrated of these pioneers of commerce, Alexander Mackenzie, reached, in the year 1789, the mouth of the great river which bears his name, and saw the white dolphins gambol about in the Arctic Sea. In a second voyage he crossed the Rocky Mountains, and followed the course of the Fraser River until it discharges its waters into the Georgian Gulf opposite to Vancouver's Island. Here he wrote with perishable vermilion the following in. scription on a rock-wall fronting the gulf:-

\section{A. Mackenzie \\ arrived from Canada by land, 22 July, 1792.}

The words were soon effaced by wind and weather, but the fame of the explorer will last as long as the English language is spoken in America.

The energetic North-west Company thus ruled over the whole continent from the Canadian Lakes to the Rocky Mountains, and in 1806 it even crossed that barrier and established its forts on the northern tributaries of the Colum. bia River. To the north it likewise extended its operations, encroaching more and more upon the privileges of the Hudson's Bay Company, which, roused to energy, now also pushed on its posts farther and farther into the interior, and established in 1812 a colony on the Red River to the south of Winipeg Lake, thus driving, as it were, a sharp thorn into the side of its rival. But a power like the North-west Company, which had no less than 50 agents, 70 interpreters, and 1120 voyageurs in its pay, and whose chief managers used to appear at their annual meetings at Fort William, on the banks of Lake Superior, with all the pomp and pride of feudal barons, was not inclined to tolerate this encroachment; and thus, after many quarrels, a regular war broke out between the two parties, which, after two years' duration, led to the expulsion of the Red River colonists and the murder of their governor, Semple. This event took place in the year 1816, and is but one episode of the bloody feuds which continued to reign between the two rival companies until 1821. At first sight it may seem strange that such acts of violence should take place between British subjects and on British soil, but then we must consider that at that time European law had little power in the American wilderness.

The dissensions of the fur-traders had most deplorable consequences for the Redskins; for both companies, to swell the number of their adherents, lavishly distributed spirituous liquors--a temptation which no Indian can resist.

The whole of the hunting-grounds of the Saskatchewan and Athabasca were but one scene of revelry and bloodshed. Already decimated by the small-pox, the Indians now became the victims of drunkenness and discord, and it was to be feared that if the war and its consequent demoralization continued, the most important tribes would soon be utterly swept away.

The finances of the belligerent companies were in an equally deplorable state; the produce of the chase diminished from year to year with the in- 
crease of their expenditure; and thus the Hudson's Bay Company, which used to gratify its shareholders with dividends of 50 and 25 per cent., was unable,

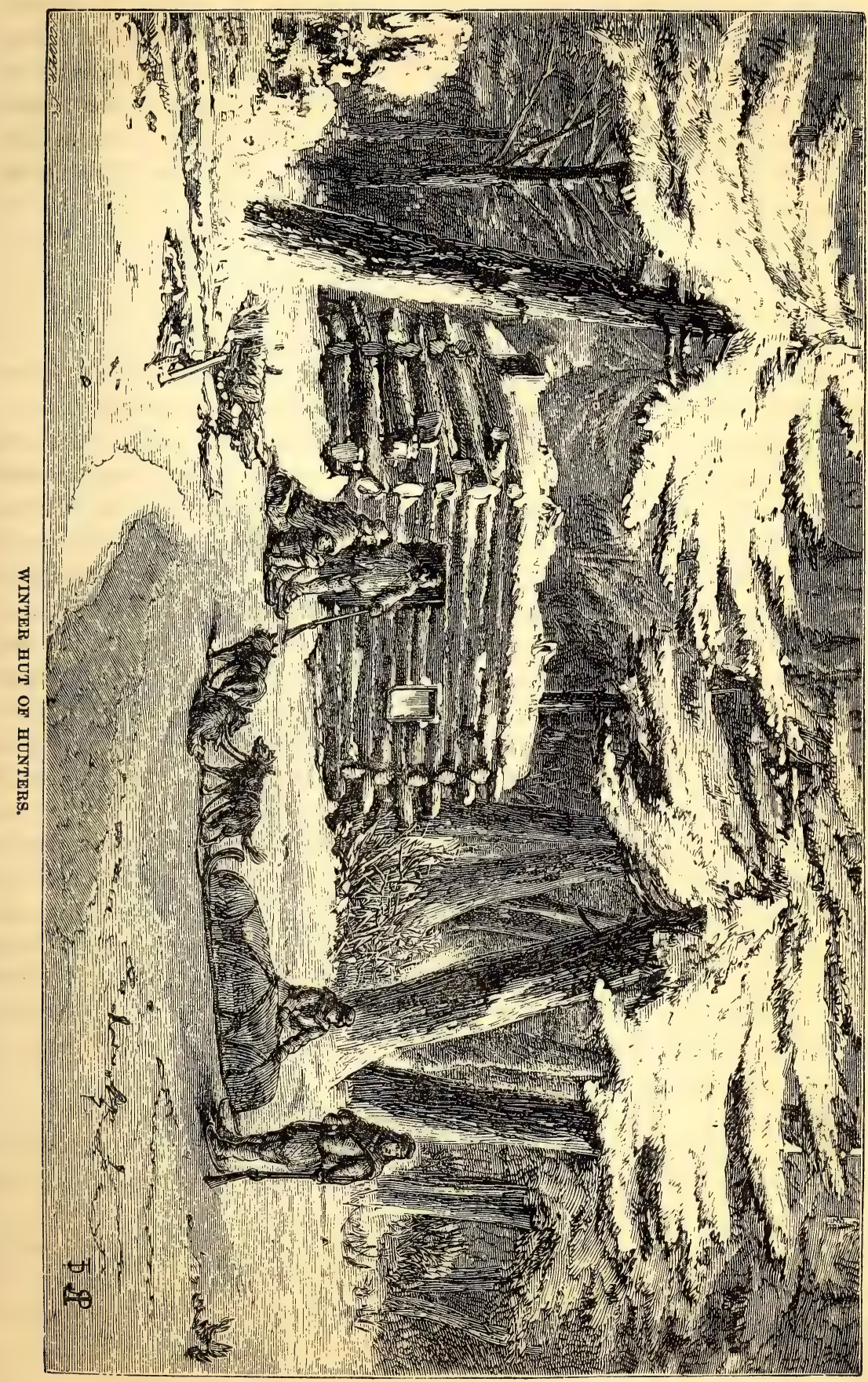

from 1808 to 1814, to distribute a single shilling among them. At length wisdom prevailed over passion, and the enemies came to a resolution which, if 
taken from the very beginning, would have saved them both a great deal of treasure and many crimes. Instead of continuing to swing the tomahawk, they now smoked the calumet, and amalgamated in 1821, under the name of the "Hudson's Bay Company," and under the wing of the charter. The British Government, as a dowry to the impoverished couple, presented them with a license of exclusive trade throughout the whole of that territory which, under the name of the Hudson's Bay and North-west territories, extends from Labrador to the Pacific, and from the Red River to the Polar Ocean. This license was terminable in 21 years, but in 1838 it was renewed again for the same period. The good effects of peace and union soon became apparent, for after a few years the Company was enabled to pay half-yearly dividends of five per cent., and the Indians, to whom brandy was now no longer supplied unless as a medicine, enjoyed the advantages of a more sober life.

About 1848 the Imperial Government, fearing that Vancouver's Island might be annexed by the United States, resolved to place it under the management of the Hudson's Bay Company. This was accordingly done in 1849. A license of exclusive trade and management was granted for ten years, terminable therefore in 1859 (the time of expiration of the similar license over the Indian territory).

These were the palmy days of the Hudson's Bay Company. They held Rupert's Land by the royal charter, which was perpetual; they held Vancouver's Island and the whole Indian territory to the Pacific by exclusive licenses, terminable in 1859; and thus maintained under their sole sway about 4,000,000 square miles - a realm larger than the whole of Europe.

For the ten years ending May 31, 1862, the average net annual profits of the Company amounted to $£ 81,000$ on a paid-up capital of $£ 400,000$, but a portion only of this income was distributed as dividend.

In 1863 the Company was reconstructed, with a capital of $£ 2,000,000$, for the purpose of enlarging its operations-such as opening the southern and more fruitful districts of the Saskatchewan or the Winipeg to European colonization; but the northern, and by far the larger portion of the vast domains over which, after the dismemberment of British Columbia and the Stikine territory, it still holds sway, have too severe a climate ever to be cultivated, and, unless their mineral wealth be made available, must ever be what they are now-a fur-bearing region of gloomy pine-forests, naked barren-grounds, lakes, and morasses.

Over this vast extent of desert the Company has established about 150 trading-posts, called "houses," or "forts," which, however, consist merely of a few magazines and dwelling-houses, protected by a simple wall, stockade, or palisade sufficiently strong to resist any sudden attack of the Indians. Among the tribes, with whom a friendly intercourse has long subsisted, and whose fidelity may implicitly be trusted, no guard is ever kept, and it is only in forts more recently built in remote parts that precautions are taken.

These forts are always situated on the borders of a lake or river, both for facility of transport and for the purpose of catching fish, particularly the species of Coregonus, or white-fish, which, from its importance to all the natives of 
Rupert's Land between the great Canada lakes and the Arctic Sea, the Crees call Attihawmeg, or the "reinfleer of the waters." In many of the trading-

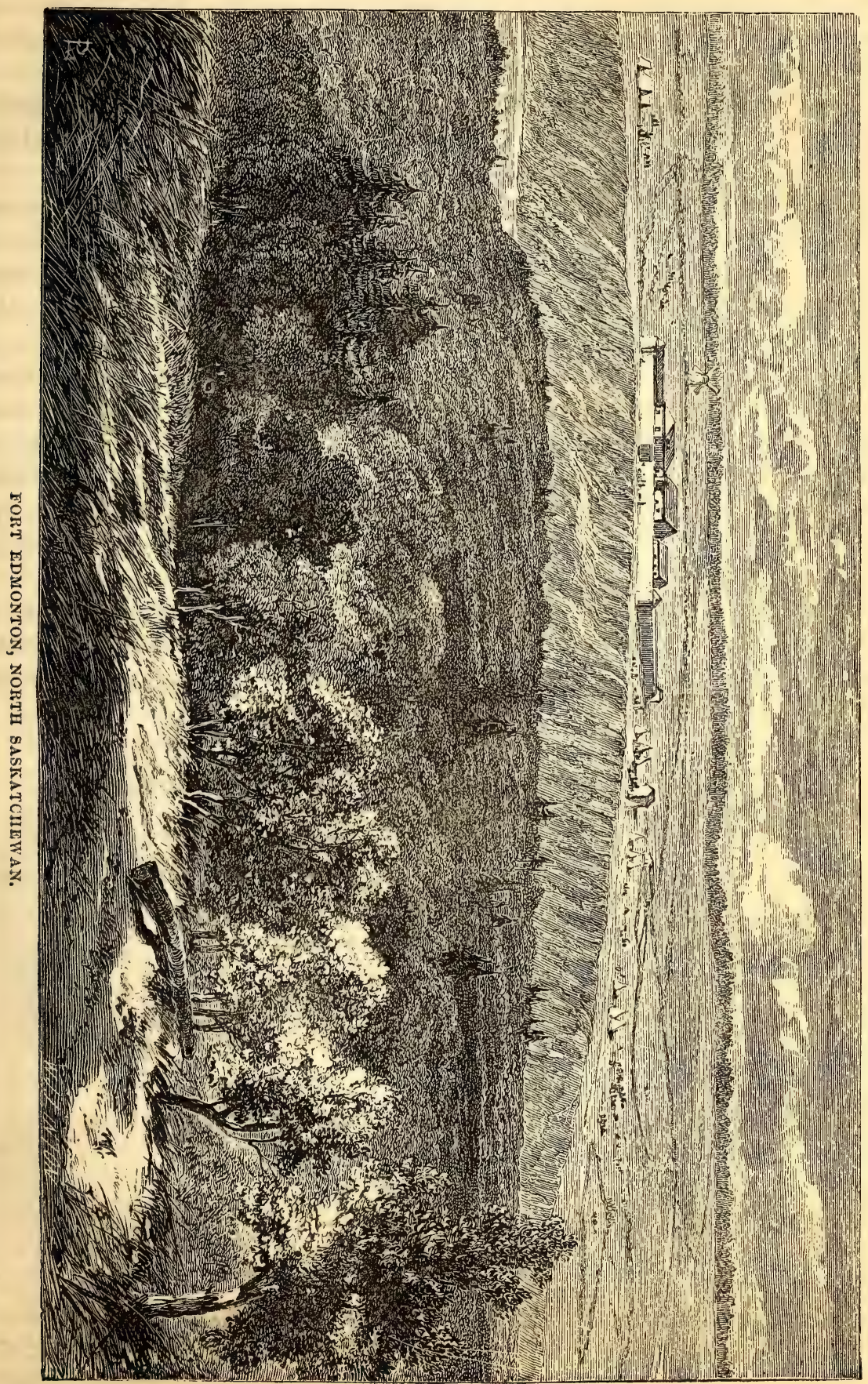

posts it forms the chief food of the white residents; and it is asserted that though deprived of bread and vegetables, a man may live upon it for months or 
even years without tiring. According to Sir John Richardson, no fish in any country or sea excels the white-fish in flavor and wholesomeness, and it is the most beneficial article of diet to the Red Indians near the Arctic Circle, being obtained with more certainty than the reindeer, and with less change of abode in summer and winter.

Each of the principal forts is the seat of a chief factor, or general administrator of a district, and of a chief trader, who transacts the business with the Indians.

Besides these principal functionaries-out of whom the governor is chosen -the Company employed, in 1860, 5 surgeons, 87 clerks, 67 postmasters, 1200 permanent servants, and 500 voyageurs, besides temporary employés of different ranks, so that the total number of persons in its pay was at least 3000 . Besides this little army of immediate dependents, the whole male Indian popu. lation of its vast territory, amounting to about 100,000 hunters and trappers, may be considered as actively employed in the service of the Company. Armed vessels, both sailing and steam, are employed on the north-west coast to carry on the fur-trade with the warlike natives of that distant region. More than twenty years ago this trade alone gave employment to about 1000 men, occupying 21 permanent establishments, or engaged in navigating five armed sailing vessels and one armed steamer, varying from 100 to 300 tons in burden.

The influence of the Company over its savage dependents may justly be called beneficial. Both from motives of humanity and self-interest, every effort is made to civilize them. No expense is spared to preserve them from the

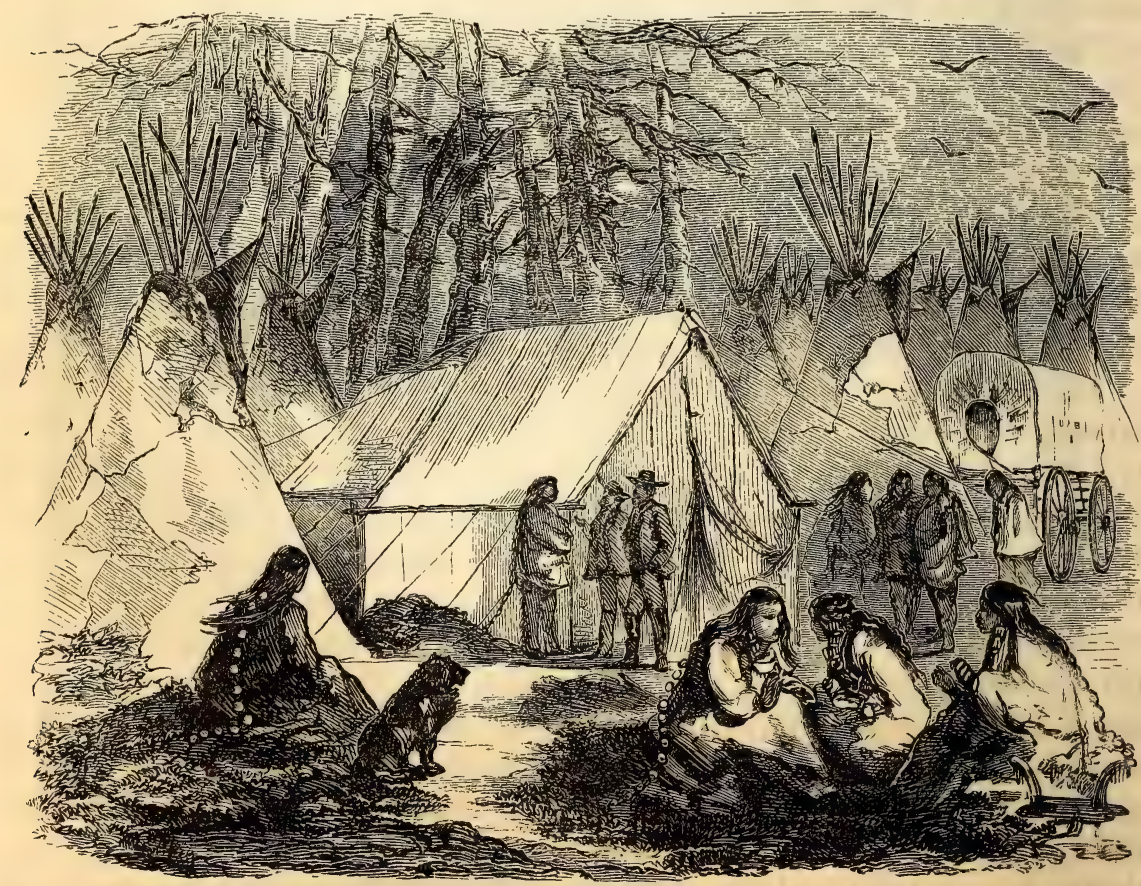

TRADER'S CAMP. 
want into which their improvidence too often plunges them; and the example of an inflexible straightforwardness serves to gain their confidence. This moral preponderance, and the admiration of the Indian for the superior knowledge and arts of the Europeans, explain how a mere handful of white men, scattered over an enormous territory, not only lead a life of perfect security, but exercise an almost absolute power over a native population outnumbering them at least several hundred times. The Indians have in course of time acquired many new wants, and have thus become more and more dependent on the white traders. The savage hunter is no longer the free, self-dependent man, who, without any foreign assistance, was able to make and manufacture, with his own hands, all the weapons and articles needed for his maintenance. Without English firearms and fishing-gear, without iron-ware and woollen blankets, he could no longer exist, and the unfortunate tribe on which the Company should close its stores would soon perish for want. "History," says Professor Hind, "does not furnish another example of an association of private individuals exerting a powerful influence over so large an extent of the earth's surface, and administering their affairs with such consummate skill and unwavering devotion to the original objects of their incorporation."

The standard of exchange in all mercantile transactions with the natives is a beaver skin, the relative value of which, as originally established by the traders, differs considerably from the present worth of the articles represented by it; but the Indians are averse to change. They receive their principal outfit of clothing and ammunition on credit in the autumn, to be repand by their winter hunts; the amount intrusted to each of the hunters varying with their reputations for industry and skill.

The furs which, in the course of the year, are accumulated in the various forts or trading-stations, are transported in the short time during which the rivers and lakes are navigable, and in the manner described at the beginning of the chapter, to York Factory, or Moose Factory, on Hudson's Bay, to Montreal or Vancouver, and shipped from thence mostly to London. From the more distant posts in the interior, the transport often requires several seasons; for travelling is necessarily very slow when rapids and portages continually interrupt navigation, and the long winter puts a stop to all intercourse whatever.

The goods from Europe, consisting (besides those mentioned above) of printed cotton or silk handkerchiefs, or neck-cloths, of beads, and the universal favorite tobacco, require at least as much time to find their way into the distant interior; and thus the Company is not seldom obliged to wait for four, five, or six years before it receives its returns for the articles sent from London. It must, however, be confessed, that it amply repays itself for the tediousness of delay, for Dr. Armstrong was told by the Esquimaux of Cape Bathurst-a tribe in the habit of trading with the Indians from the Mackenzie, who are in direct communication with the Hudson's Bay Company's agents-that for three silver-fox skins-which sometimes fetch as high a price as twenty-five or thirty guineas apiece at the annual sale of the Company-they had got from the traders cooking utensils which might be worth eight shillings and sixpence!

The value of the skins annually imported into England by the Company 
amounts to about $£ 150,000$ or $£ 200,000$. Besides, many of its furs are bartered for Russian-American peltry, and a large quantity is exported direct to China.

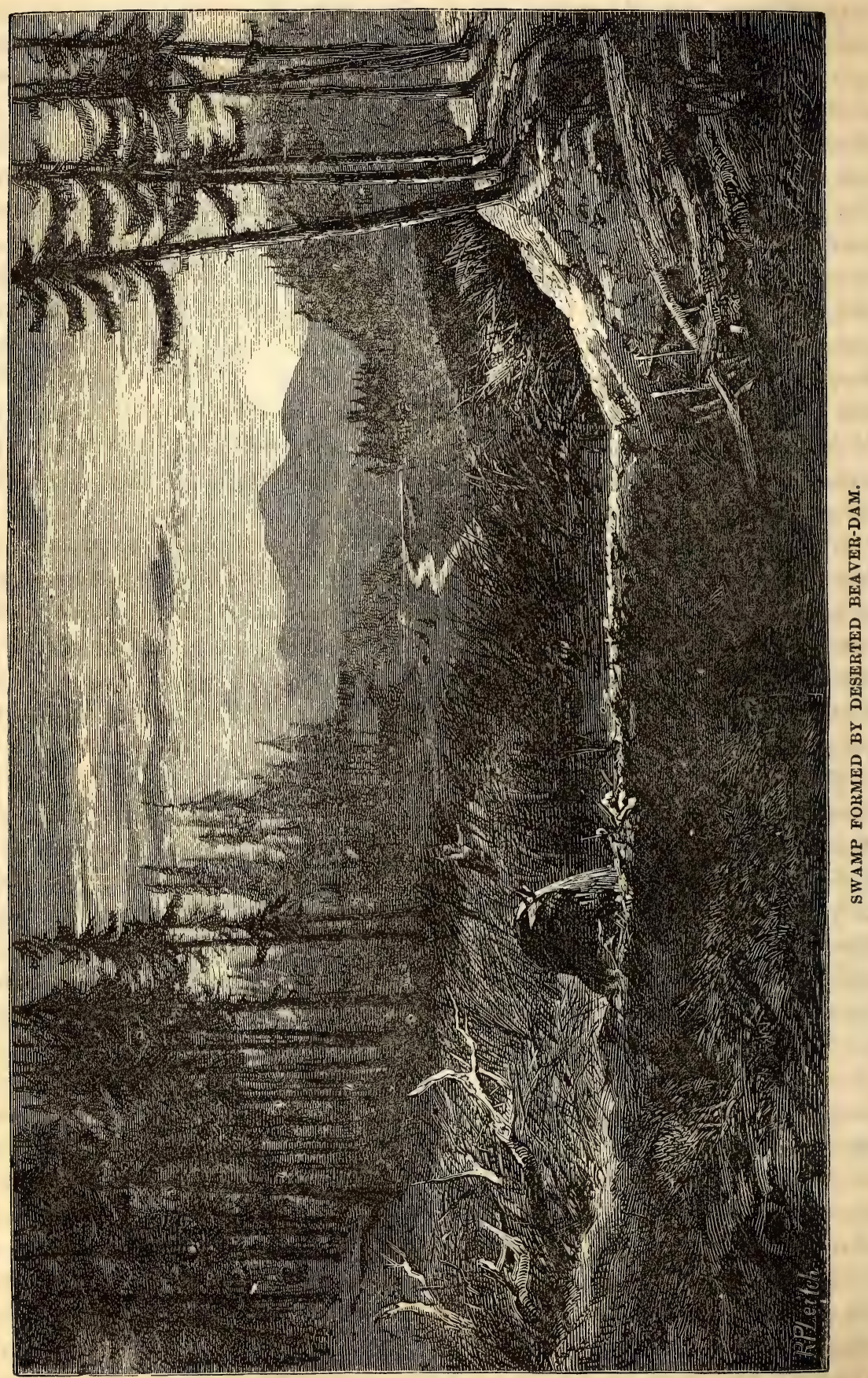

After this brief account of one of the most remarkable mercantile associations of any age, some remark on the chief fur-bearing animals of the Hudson's 
Bay territory may not be without interest. Among these, the black bear, muskwa, or baribal (Ursus americanus), is one of the most valuable, as his long hair-unlike that of the brown or the white bear-is beautifully smooth and glossy. He inhabits the forest regions of North America, but migrates accord. ing to the seasons. In spring he seeks his food in the thickets along the banks of the rivers or lakes; in summer he retreats into the forests; in winter he either wanders farther to the south, or hollows out a kind of lair beneath the root of an overthrown tree, where, as the cold is more or less severe, he either finds a retreat after his excursions, or hibernates buried in the snow. He feeds chiefly on berries, grain, acorns, roots, eggs, and honey; though, when pressed by hunger, he will attack other quadrupeds. He climbs upon trees or rocks with great agility, and, being very watchful, is not easily got at in summer. Sometimes, however, his caution brings about his destruction; for, from fear of some possible danger, or at the slightest noise, he rises on his hind legs to look over the bushes under which he lies concealed, and thus offers a mark to the bullet of the hunter. In the winter, when the snow betrays his traces, he is more easily shot, and his skin and flesh are then also in the best condition. In spite of his apparent clumsiness and stolidity, the muskwa is more alert than the brown bear, whom he nearly approaches in size; he runs so fast that no man can overtake him, and is an excellent swimmer and climber. When attacked, he generally retreats as fast as possible into the forest; but if escape is impossible, he turns furiously upon his pursuers, and becomes exceedingly dangerous. Dogs alone are incapable of mastering him, as he is always ready to receive them with a stroke of his fore paw; but they are very useful in driving him up a tree, and thus giving the hunter an opportunity of hitting him in the right spot. When in a state of captivity, the baribal, in his mild and goodhumored disposition, is distinguished from the brown and white bear. His fur is also much more valuable than that of the brown bear.

It is not yet fully ascertained whether the American brown bear is identical with that of Europe ; the resemblance, however, is close. In summer he wanders to the shores of the Polar Sea, and indulges more frequently in animal food than the baribal. He is even said to attack man when pressed by hunger ; but all those whom Sir John Richardson met with ran away as soon as they saw him.

As the grizzly bear (Ursus ferox) is found on the Rocky Mountains up to the latitude of $61^{\circ}$, he undoubtedly deserves a place among the sub-arctic animais. The skin of this most formidable of the ursine race, who is about nine feet long, and is said to attain the weight of eight hundred pounds, is but little prized in the fur-trade. He is the undoubted monarch of his native wilds, for even the savage bison flies at his approach.

Although the raccoon (Procyon lotor) is more commonly found in Canada and the United States, yet he is also an inhabitant of the Hudson's Bay territories, where he is met with up to $56^{\circ} \mathrm{N}$. lat. This interesting little animal, which, like the bears, applies the sole of its foot to the ground in walking, has an average length of two feet from the nose to the tail, which is about ten inches long. Its color is grayish-brown, with a dusky line running from the top of 
the head down the middle of the face, and ending below the eyes. The tail is very thickly covered with hair, and is annulated with several black bars on a yellowish-white ground. Its face is very like that of the fox, whom it equals in cunning, while its active and playful habits resemble those of the monkey. Its favorite haunts are the woods, near streams or lakes, for one of its most marked peculiarities, from which it has received its specific name of lotor, or the washer, is its habit of plunging its dry. food into water before eating it. The raccoon devours almost any thing that comes in his way-fruits and grain of all sorts, birds' nests, mice, grasshoppers, beetles : while the waters yield him fishes, crabs, and oysters, which he is very expert in opening. His fur forms no inconsiderable article of commerce, and is very fashionable in Russia. In 1841, 111,316 raccoon skins were imported into St. Petersburg, and more than half a million were stapled in Leipzig, intended, no doubt, for smuggling across the frontier.

The fur of the American glutton, or wolverine, is much used for muffs and linings; yet, from its being a notorious robber of their traps, the animal is as much hated by the Indian hunters as the dog-fish by the northern fishermen.

The Hudson's Bay territories can not boast of the sable, but the American pine marten (Martes abietum) is not much inferior in value, as its dark-brown fur is remarkably fine, thick, and glossy. It frequents the woody districts, where it preys on birds, and all the smaller quadrupeds from the hare to the mouse. Even the squirrel is incapable of escaping the pine marten, and after having vaulted and climbed from tree to tree, sinks at last exhausted into its gripe.

The pekan, or woodshock (Martes canadensis), the largest of the marten family, is also the one which most richly supplies the fur-market. It is found over the whole of North America, and generally lives in burrows near the banks of rivers, as it principally feeds on the small quadrupeds that frequent the water.

Several species of ermine inhabit the Hudson's Bay territories, but their skins are of no great importance in the fur-trade. Like many other species of the marten family, they eject, when irritated or alarmed, a fluid of a fetid odor; but in this respect they are far surpassed by the chinga (Mephitis chinga), whose secretion has so intolerable a smell that the least quantity suffices to produce nausea and a sense of suffocation. This animal is frequently found near Hudison's Bay, whence it extends farther to the north. In spite of the formidakle means of defense with which it has been armed by nature, it is of use to man, for its black and white striped fur (which, as may easily be supposed, never appears in the European market) provides the Indians with coverings or tobacco-pouches. Before seizing the chinga, they irritate it with a long switch until it has repeatedly emptied the glands from which the noxious vapor issues; then suddenly springing upon it, they hold it up by the tail and dispatch it.

The mink (Vison americanus), another member of the weasel family, is one of the most important fur-bearing animals of the Hudson's Bay territories. It resembles the small European fish-otter (Vison lutreola), but its skin is far more valuable-the brown hair with which it is covered being much softer and thick- 
er. As its toes are connected by a small web, it is an excellent swimmer, and as formidable to the salmon or trout in the water as to the hare on land.

The Canadian fish-otter (Lutra canadensis) far surpasses the European species, both in size and in the beauty of its glossy brown skin. It occurs as far northward as $66^{\circ}$ or $67^{\circ}$ lat., and is generally taken by sinking a steel trap near the mouth of its burrow. It has the habit of sliding or climbing to the top of a ridge of snow in winter, or of a sloping moist bank in summer, where, lying on the belly, with the fore feet bent backward, it gives itself with the hind legs an impulse which sends it swiftly down the eminence. This schoolboy sport it continues for a long time.

The red fox (Vulpes fulvus), which is found throughout the Hudson's Bay territories, has likewise a much finer fur than our common fox. It is of a bright ferruginous red on the head, back, and sides; beneath the chin it is white, while the throat and neck are of a dark gray, and the under parts of the body, toward the tail, are of a very pale red. The crossed fox (Canis decussatus), thus named from the black cross on its shoulders, is still more valuable; its skın-the color of which is a sort of gray, resulting from the mixture of black and white hair-being worth four or five guineas. Peltry still more costly is furnished by the black or silvery fox (Canis argentatus), whose copious and beautiful fur is of a rich and shining black or deep brown color, with the longer or exterior hairs of a silvery white. Unfortunately it is of such rare occurrence that not more than four or five are annually brought to a trading-post.

The Canada lynx, or pishu (Lynx canadensis), is smaller than the European species, but has a finer fur, those skins being most valued which approach to a pale or whitish color, and on which the spots are most distinct. It chiefly feeds on the hare (Lepus americanus), which is not much larger than a rabbit, and is found on the banks of the Mackenzie as far north as $68^{\circ}$ or $69^{\circ}$.

Still nearer to the Pole, the ice-hare (Lepus glacialis) ranges as far as the Parry Islands ( $75^{\circ} \mathrm{N}$. lat.), where it feeds on the arctic willow, and other high northern plants. Its favorite resorts are the stony districts, where it easily finds a refuge; in winter it burrows in the snow. In summer its back is grayish white, but as the cold increases, it becomes white, with the exception of the tips of the ears, which remain constantly black.

Formerly the beaver (Custor fiber) was the most important of the fur-bearing animals of the Hudson's Bay territories. In the year 1743, 127,000 beaver skins were exported from Montreal to La Rochelle, and 26,700 by the Hudson's Bay Company to London. At present, the exportation hardly amounts to onethird of this quantity. As the beaver chiefly lives on the barks of the willow, the beech, and the poplar, it is not found beyond the forest region; but along the banks of the Mackenzie it reaches a very high latitude.

The musk-rat, ondatra or musquash (Fiber zibethicus)-which is about the size of a small rabbit, and of a reddish-brown color-is called by the Indians the younger brother of the beaver, as it has similar instincts. Essentially a bank-haunting animai, it is never to be seen at any great distance from the water, where it swims and dives with consummate ease, aided greatly by the webs which connect the hinder toes. It drives a large series of tunnels into 
the bank, branching out in various directions, and having several entrances, all of which open under the surface of the water. If the animal happens to live upon a marshy and uniformly wet soil, it becomes a builder, and lives in curiously-constructed huts, from three to four feet in height, plastered with great neatness in the inside, and strengthened externally with a kind of basket-work of rushes, carefully interlaced together. The judgment of the animal shows itself in the selection of the site, invariably choosing some ground above the reach of inundation, or else raising its hut on an artificial foundation; for, though obliged to reside near flat, submerged banks, where the soft soil is full of nourishing roots, it requires a dry home to rest in.

In winter the musquash villages-for the huts are sometimes built in such numbers together as to deserve that name-are generally covered with thick snow, under which this rodent is able to procure water, or to reach the provisions laid up in its storehouse. Thus it lives in ease and plenty, for the marten is too averse to the water, and the otter too bulky to penetrate into its tunnels. But when the snow melts, and the huts of the musquash appear above the ground, the Indian, taking in his hand a large four-barbed spear, steals up to the house, and driving his weapon through the walls, is sure to pierce the animals inside. Holding the spear firmly with one hand, he takes his tomahawk from his belt, dashes the house to pieces, and secures the inmates. Another method employed by the Indians to capture the musquash is to block up the different entrances to their tunnels, and then to intercept the animals as they try to escape. Sometimes the gun is used, but not very frequently, as the musquash is so wary that it dives at the least alarm, and darts into one of its holes. The trap, however, is the ordinary means of destruction. The soft and glossy fur of the musquash, though worth no more than from $6 d$. to $9 d$., is still a not inconsiderable article of trade, as no less than half a million skins are annually imported into England for hat-making; nor is there any fear of the musquash being extirpated, in spite of its many enemies, as it multiplies very fast, and is found near every swamp or lake with grassy banks as far as the confines of the Polar Sea. 


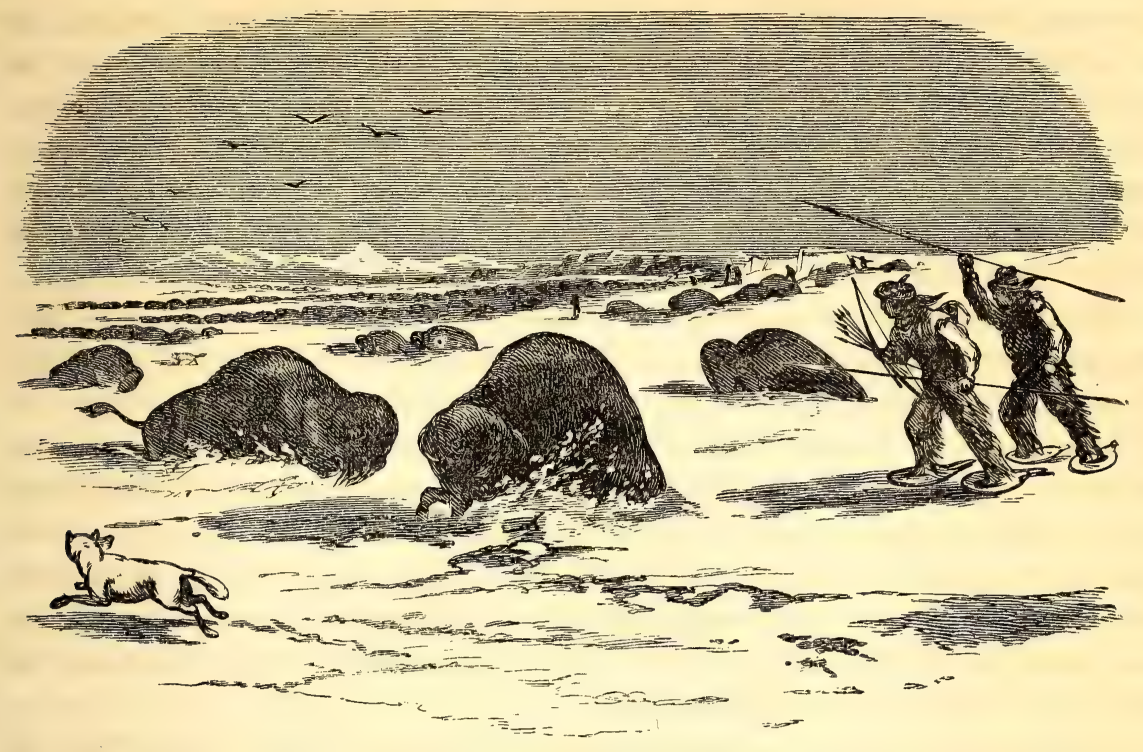

HUNTING BISON IN THE SNOW.

\section{CHAPTER XXIX.}

THE CREE INDIANS, OR EYTHINYUWUK.

The various Tribes of the Crees. - Their Conquests and subsequent Defeat. - Their Wars with the Blackfeet.-Their Character. - Tattooing. - Their Dress._-Fondness for their Children.-The Cree Cradle.Vapor Baths._Games.-Their religious Ideas.-The Cree Tartarus and Elysium.

$\mathrm{T}$

HE various tribes of the Crees, or Eythinyuwuk, range from the Rocky Mountains and the plains of the Saskatchewan to the swampy shores of Hudson's Bay. Towards the west and north they border on the Tinné, towards the east and south, on the Ojibbeway or Sauteurs, who belong like them to the great family of the Lenni-lenape Indians, and inhabit the lands between Lake Winipeg and Lake Superior.

About sixty years since, at the time when Napoleon was deluging Europe with blood, the Crees likewise played the part of conquerors, and subdued even more extensive, though less valuable domains.

Provided with fire-arms, which at that time were unknown to their northern and western neighbors, they advanced as far as the Arctic Circle, imposing tribute on the various tribes of the Tinné. But their triumphs were not more durable than those of the great European conqueror.

The small-pox broke out among them and swept them away by thousands. Meanwhile the Tinné tribes had remained untouched by this terrible scourge; and as the agents of the Hudson's Bay Company, advancing farther and farther to the west and north, had likewise made them acquainted with the use of firearms, they in their turn became the aggressors, and drove the Crees before them. 
Their former conquerors now partly migrated to the south, and leaving the forest region, where they had hunted the reindeer and the elk, spread over the prairies of the Saskatchewan, where they now pursued the herds of bison, sometimes driving them over a precipice, or chasing them on foot through the snow. But in their new abodes they became engaged in constant feuds with their new neighbors the Assiniboins and Blackfeet, who of course resented their intrusion.

The romance in which the manners and character of the Indians are portrayed might lead us to attribute to these people a loftiness of soul for which it would be vain to look in the present day, and which without much skepticism we may assert they never really possessed. Actions prompted only by the caprice of a barbarous people have been considered as the results of refined sentiment; and savage cunning, seen through the false medium of prejudice, assumed the nobler proportions of a far-sighted policy. But though the history of the wars of the Indians among themselves and with the Europeans affords but few instances of heroism, it abounds in traits of revolting cruelty, and in pictures of indescribable wretchedness.

A large party of Blackfeet once made a successful foray in the territory of the Crees. But meanwhile the latter surprised the camp where the aggressors had left their wives and children; and thus, when the Blackfeet returned to their tents, they found desolation and death where they looked for a joyful welcome. In their despair they cast away their arms and their booty, and retired to the mountains, where for three days and nights they wailed and mourned.

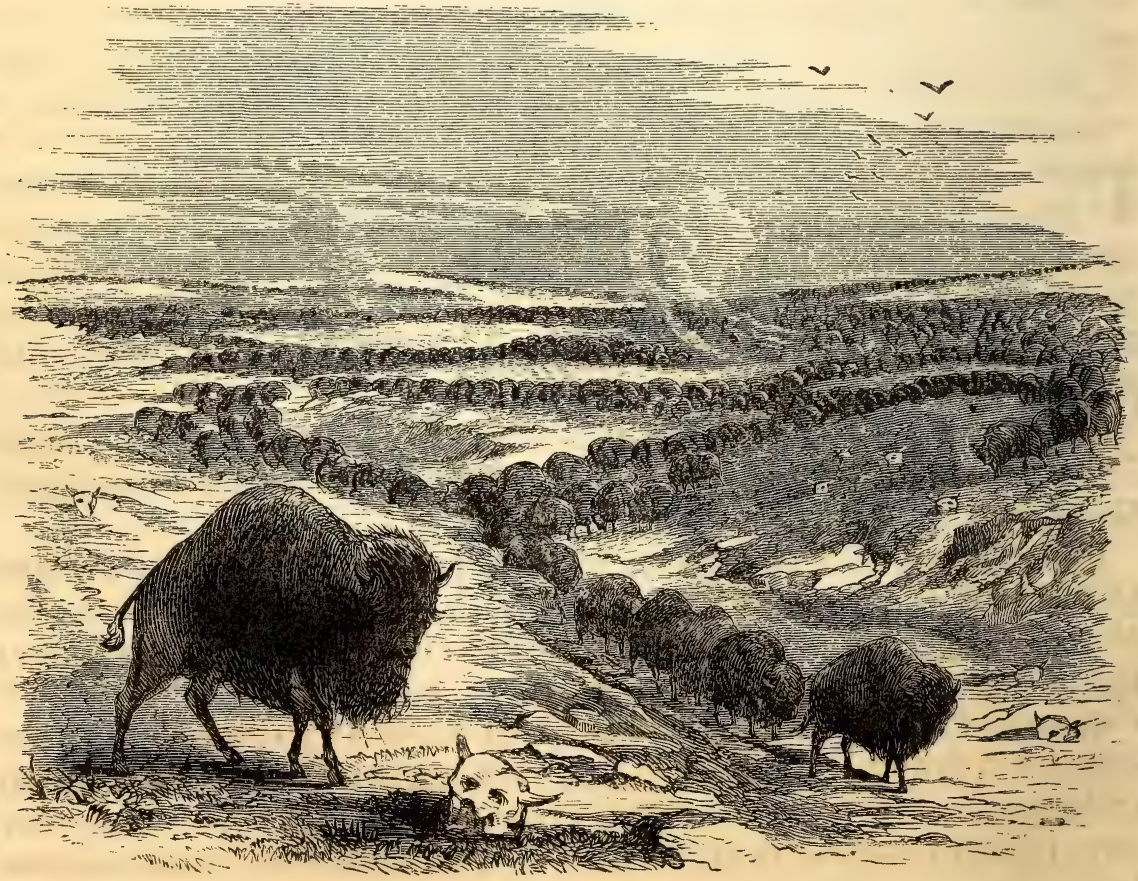

A HERD OF BISON. 


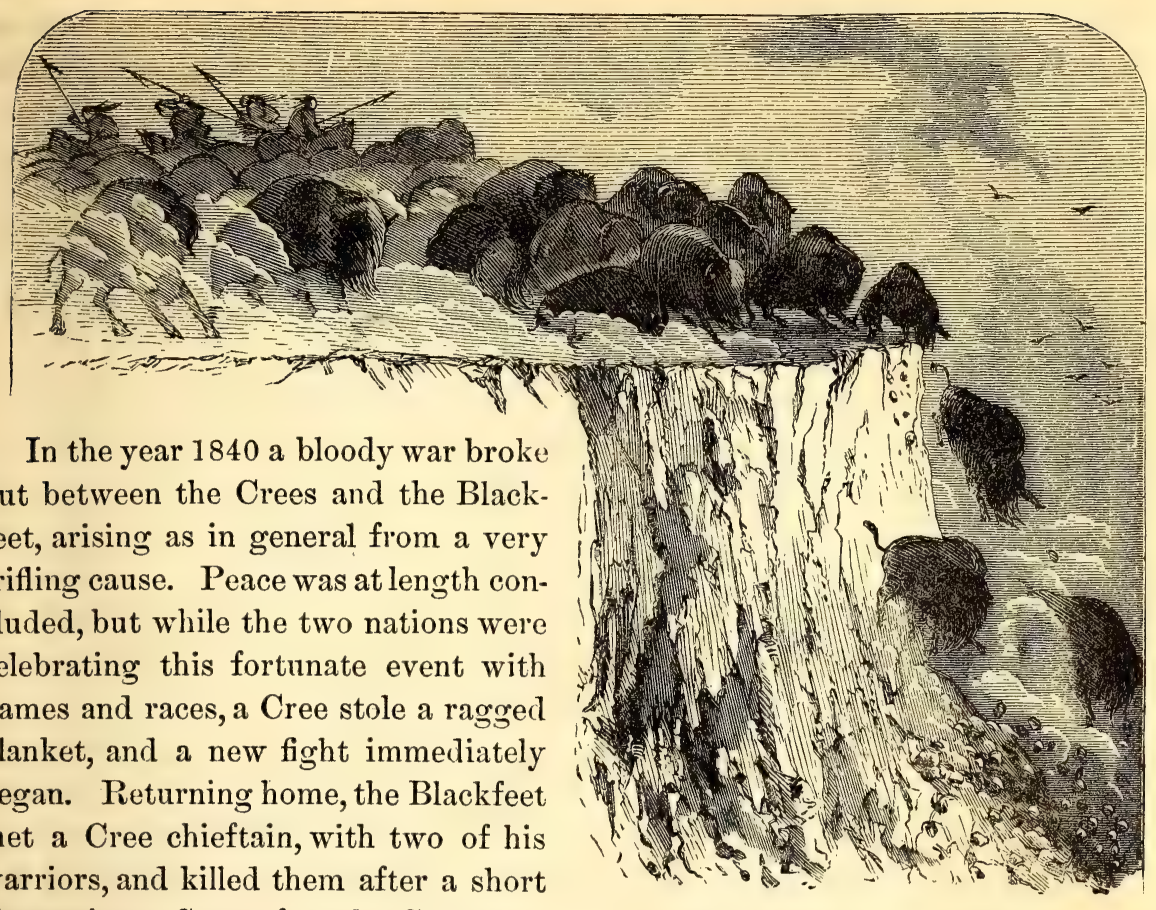

altercation. Soon after the Crees sur-

DRIVING BISON OVER A PRECIPICE. prised and murdered some of the Blackfeet, and thus the war raged more furiously than ever. Sir George Simpson, who was travelling through the country at the time, visited the hut of a Cree who had been wounded in the conflict at the peace meeting. As in his flight he bent over his horse's neck, a ball had struck him on the right side, and remained sticking near the articulation of the left shoulder. In this condition he had already lain for three-and-thirty days, his left arm frightfully swollen, and the rest of his body emaciated to a skeleton. Near the dying savage, whose glassy eye and contracted features spoke of the dreadful pain of which he disdained to speak, lay his child, reduced to skin and bones, and expressing by a perpetual moaning the pangs of illness and hunger, while most to be pitied perhaps of this wretched family was the wife and mother, who seemed to be sinking under the double load of care and fatigue. During the night the "medicine-man" was busy beating his magic drum and driving away the evil spirits from the hut.

Although the Crees show great fortitude in enduring hunger and the other evils incident to a hunter's life, yet any unusual accident dispirits them at once, and they seldom venture to meet their enemies in open warfare, or even to surprise them, unless they have a great advantage in point of numbers. Instances of personal bravery like that of the Esquimaux are rare indeed among them. Superior in personal appearance to the Tinné, they are less honest, and though perhaps not so much given to falsehood as the Tinné, are more turbulent and more prompt to invade the rights of their countrymen, as well as of neighboring nations. 
Tattooing is almost universal among them. The women are in general content with having one or two lines drawn from the corners of the mouth towards

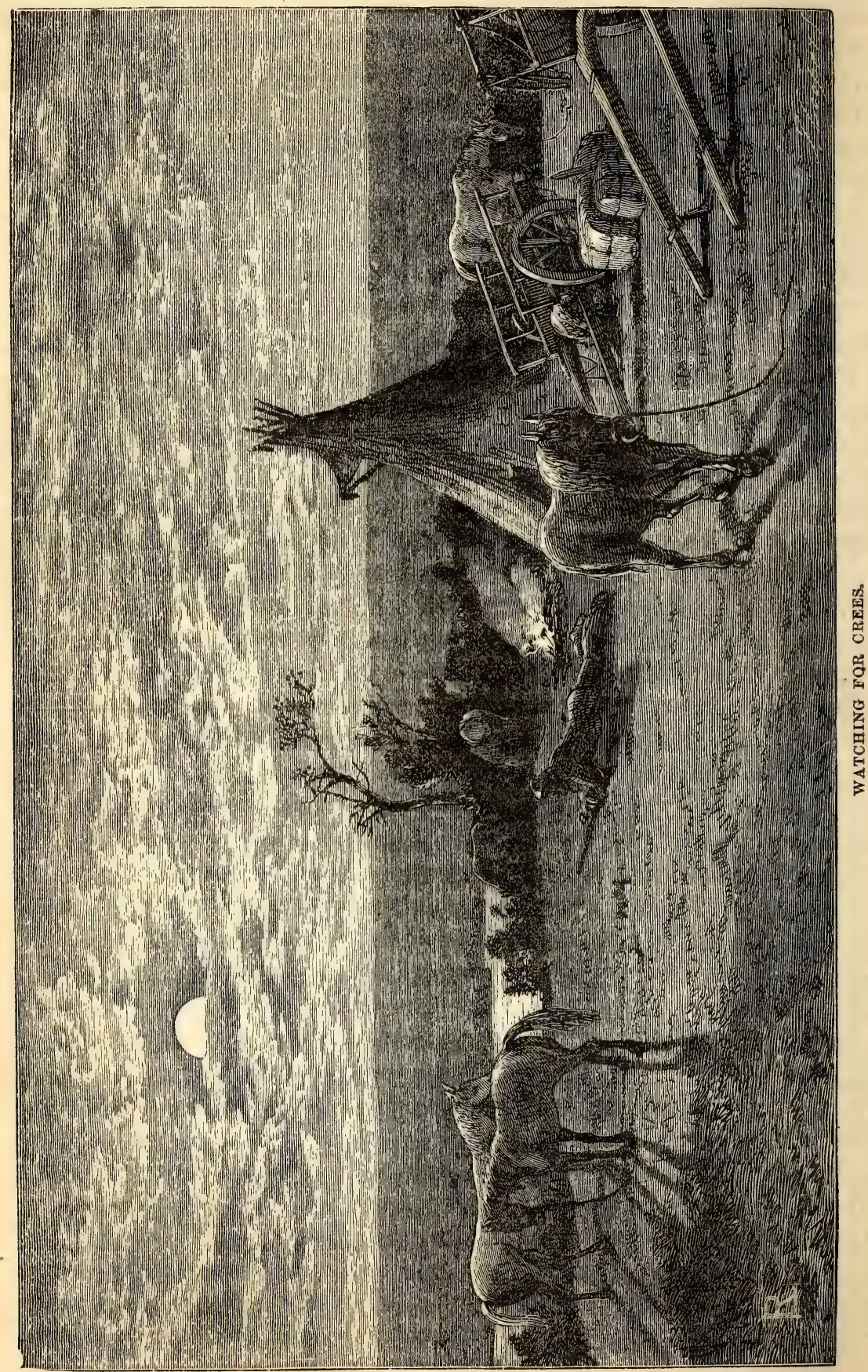

the angles of the lower jaw, but some of the men have their bodies covered with lines and figures. It seems to be considered by most rather as a proof of 
courage than an ornament, as the operation is both painful and tedious. The lines on the face are formed by dexterously running an awl under the cuticle, and then drawing a cord, dipped in charcoal and water, through the canal thus formed. The punctures on the body are made by needles of various sizes, set in a frame. A number of hawk-bells attached to this frame serve, by their noise, to cover the groans of the sufferer, and probably for the same reason the process is accompanied with singing. An indelible stain is produced by rubbing a little finely-powdered willow-charcoal into the puncture. A half-breed, whose arm was amputated by Sir John Richardson, declared that tatooing was not only the more painful operation of the two, but rendered infinitely more difficult to bear by its tediousness, having lasted, in his case, three days.

The Crees are also fond of painting their faces with vermilion and charcoal. In general the dress of the male consists of a blanket thrown over the shoulders, a leathern shirt or jacket, and a piece of cloth tied round the middle. The women have in addition a long petticoat, and both sexes wear a kind of wide hose, which, reaching from the ankle to the middle of the thigh, are suspended by strings to the girdle. These hose, or "Indian stockings," are commonly ornamented with beads or ribands, and from their convenience have been universally adopted by the white residents, as an essential part of their winter-clothing. Their shoes, or rather soft boots (for they tie round the ankle), are made of dressed moose-skins; and during the winter they wrap several pieces of blanket round their feet. They are fond of European articles of dress, such as great-coats, shawls, and calicoes, which, however showy they may be at first, are soon reduced to a very filthy condition by their custom of greasing the face and hair with soft fat or marrow. This practice they say preserves the skin soft, and protects it from cold in the winter and the mosquitoes in summer; but it renders their presence disagreeable to Europeans who may chance to be seated near them in a close tent and near a hot fire.

The Cree women are not in general treated harshly by their husbands: a great part of the labor, however, falls to the lot of the wife. She makes the hut, cooks, dresses the skins, and for the most part carries the heaviest load; but when she is unable to perform her task, the husband does not consider it beneath his dignity to assist her.

The Crees are extremely indulgent to their children. The father never chastises them; and the mother, though more hasty in her temper, seldom bestows a blow on a troublesome child.

The cradle in use among them is well adapted to their mode of life, and is one of their neatest articles of furniture, being generally ornamented with beads and bits of scarlet cloth, but it bears a very strong resemblance in its form to a mummy-case. The infant is placed in this bag, having its lower extremities wrapped up in soft sphagnum, or bog-moss, and may be hung up in the tent or to the branch of a tree, without the least danger of tumbling out; or, in a journey may be suspended on the mother's back by a band which crosses the forehead so as to leave her hands free. The sphagnum forms a soft elastic bed, which absorbs moisture very readily, and affords such a protection from the winter cold that its place would be ill supplied by any other material. 


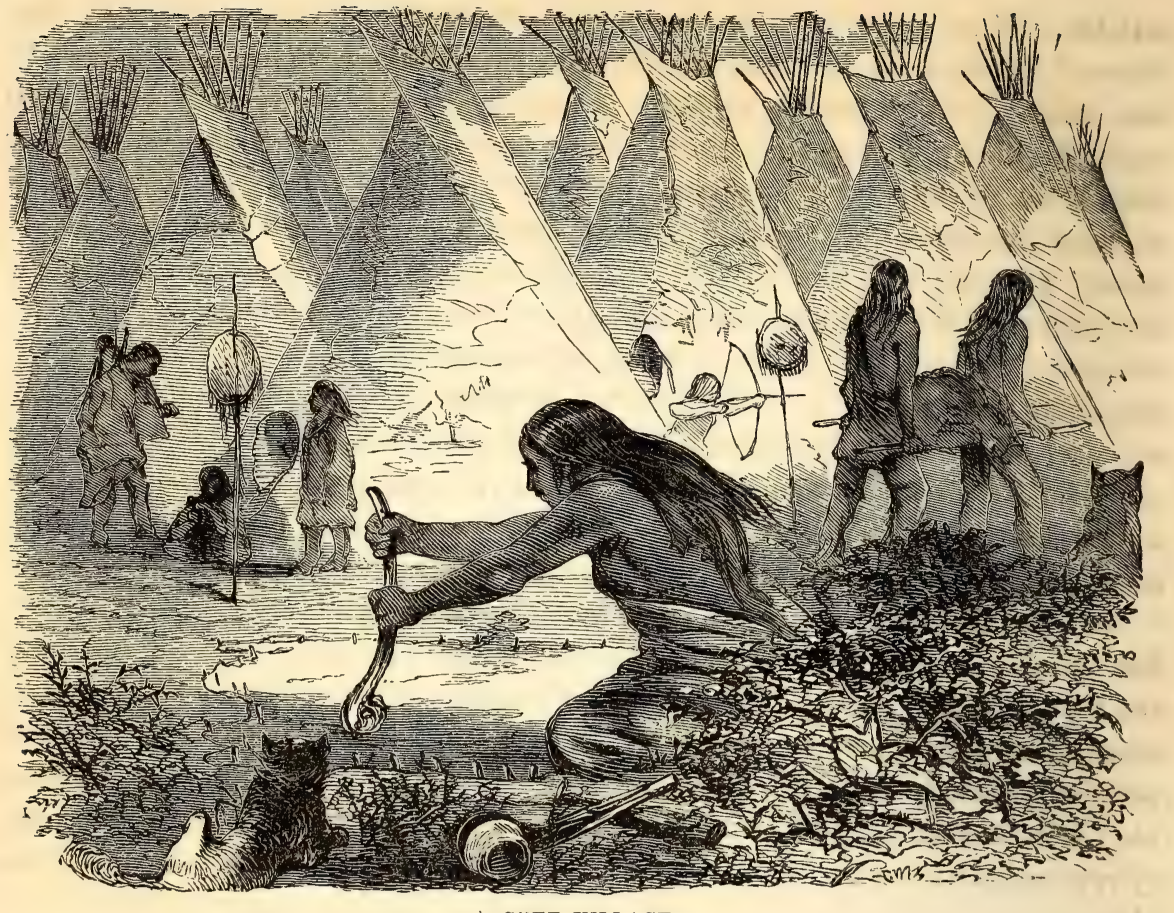

a cree village.

The ordinary wigwams, skin tents, or "lodges" of the Tinné and Crees are exactly alike in form, being extended on poles set up in a conical manner; but as a general rule the tents of the latter are more commodinus and more frequently supplied with a fresh lining of the spray of the balsam-fir. They also occasionally erect a larger dwelling of lattice-work, covered with birch-bark, in which forty men or more can assemble for feasting, debating, or performing some of their religious ceremonies. The entire nation of the Eythinyuwuk cultivate oratory more than their northern neighbors, who express themselves more simply and far less fluently.

Vapor baths are in common use with the Crees, and form one of the chief remedies of their medicine-men. The operator shuts himself up with his patient in the small sweating-house-in which red-hot stones besprinkled with water, and having a few leaves of a species of prunus strewed around them, produce a damp atmosphere of a stifling heat-and shampoos him, singing all the time a kind of hymn. As long as the medicine-man can hold out, so long must the patient endure the intense heat of the bath, and then, if the invalid be able to move, they both plunge into the river. If the patient does not recover, he is at least more speedily released from his sufferings by this powerful remedy.

The Crees are a vain, fickle, improvident, indolent, and ludicrously boastful race. They are also great gamblers, but, instead of cards or dice, they play with the stones of a species of prunus. The difficulty lies in guessing the number of stones which are tossed out of a small wooden dish, and the hunters will spend whole nights at this destructive sport, staking their most valuable 
articles. They have, however, a much more manly amusement, termed the "cross," although they do not engage even in it without depositing considerable stakes. An extensive meadow is chosen for this sport, and the articles staked are tied to a post, or deposited in the custody of two old men. The combatants being stripped and painted, and each provided with a kind of racket, in shape resembling the letter $\mathrm{P}$, with a handle about two feet long, and a head loosely wrought with net-work, so as to form a shallow bag, range themselves on different sides. A ball being now tossed up in the middle, each party endeavors to drive it to their respective goals, and much dexterity and agility is displayed in the contest. When a nimble runner gets the ball in his cross, he sets off towards the goal with the utmost speed, and is followed by the rest, who endeavor to jostle him and shake it out, but, if hard pressed, he discharges it with a jerk, to be forwarded by his own party or bandied back by their opponents until the victory is decided by its passing the goal.

Neither the Esquimaux nor the Tinné have any visible objects of worship, but the Crees carry with them small wooden figures rudely carved, or merely the tops of a few willow-bushes tied together, as the representatives of a malicious, or at least capricious being, called Kepoochikann. Their most common petition to this being is for plenty of food, but as they do not trust entirely to his favor, they endeavor at the same time to propitiate the animal, an imaginary representative of the whole race of larger quadrupeds that are objects of the chase.

Though often referring to the Kitche-manito, the "Great Spirit," or "Master of Life," they do not believe that he cares for his creatures, and consequently never think of praying to him. They have no legend about the creation, but they speak of a deluge caused by an attempt of the fish to drown Woesack-ootchacht, a kind of demi-god, with whom they had quarrelled. Having constructed a raft, this being embarked with his family and all kinds of birds and beasts. After the flood had continued for some time, he ordered several waterfowl to dive to the bottom. They were all drowned; but a musk-rat, dispatched on the same errand, returned with a mouthful of mud, out of which Woesackootchacht, imitating the mode in which the rats construct their houses, formed a new earth. First a small conical hill of mud appeared above the water; byand-by, its base gradually spreading out, it became an extensive bank, which the rays of the sun at length hardened into firm land. Notwithstanding the power that Woesack-ootchacht here displayed, his person is held in very little reverence by the Indians, who do not think it worth while to make any effort to avert his wrath.

Like the Tinné, the Crees also have a Tartarus and an Elysium. The souls of the departed are obliged to scramble with great labor up the sides of a steep mountain, upon attaining the summit of which they are rewarded with the prospect of an extensive plain abounding in all sorts of game, and interpersed here and there with new tents pitched in pleasant situations. While they are absorbed in the contemplation of this delightful scene, they are descried by the inhabitants of the happy land, who, clothed in new skin dresses, approach and welcome, with every demonstration of kindness, those Indians who have led 
good lives, but the bad Indians are told to return from whence they came, and without more ceremony are hurled down the precipice.

As yet Christianity has made but little progress among the Indians of British North America, its benefits being hitherto confined to the Ojibbeways of Lake Huron, and to a small number of the Crees of the Hudson's Bay territory. The well-fed Sauteurs of the Winipeg are as disinclined to be converted as the buffalo-hunters of the prairies. 


\title{
CHAPTER XXX.
}

\author{
THE TINNE INDIANS.
}

The various Tribes of the Tinné Indians. - The Dog-ribs._Clothing. - The Hare Indians. - Degraded State of the Women.-Practical Socialists.-Character.-Cruelty to the Aged and Infirm.

THE Tinné Indians, whose various tribes range from the Lower Mackenzie 1 to the Upper Saskatchewan, and from New Caledonia to the head of Chesterfield Inlet, occupy a considerable part of the territories of the Hudson's Bay Company. To their race belong the Strongbows of the Rocky Mountains; the Beaver Indians, between Peace River and the west branch of the Mackenzie; the Red-knives, thus named from the copper knives of which their native ores furnish the materials, and who roam between the Great Fish River and the Coppermine; the Hare Indians, who inhabit the thickly wooded district of the Mackenzie from Slave Lake downward; the Dog-ribs, who occupy the inland country on the east from Martin Lake to the Coppermine; the Athabascans, who frequent the Elk and Slave Rivers, and many other tribes of inferior note.

The Tinné, in general, have more regular features than the Esquimaux, and, taken on the whole, exhibit all the characteristics of the red races dwelling farther south; but their utter disregard of cleanliness and their abject behavior (for when in the company of white people they exhibit the whine and air of inveterate mendicants) give them a wretched appearance. Mackenzie, the first European who became acquainted with the Dog-ribs, describes them as an ugly emaciated tribe, covered with dirt and besmeared with grease from head to foot. More than sixty years have passed since Mackenzie's journey, but his account of them is true to the present day. The women are even uglier and more filthy than the men, for the latter at least paint their unwashed faces and wear trinkets on festive occasions, while the females leave even their hair without any other dressing than wiping their greasy hands on the matted locks, when they have been rubbing their bodies with marrow. The clothing of the men in summer consists of reindeer leather dressed like shammy, which, when newly made, is beautifully white and soft. "A shirt of this material," says Sir John Richardson, to whom we are indebted for the best account of the various nations inhabiting the Hudson's Bay territory, "cut evenly below, reaches to the middle; the ends of a piece of cloth secured to a waist-band hang down before and behind; the hose, or Indian stockings, descend from the top of the thigh to the ankle, and a pair of moccasins or shoes of the same soft leather with tops which fold round the ankle, complete the costume. When the hunter is equipped for the chase he wears, in addition, a stripe of white hare-skin, or of the belly part of a deer-skin, in a bandana round the head, with his lank, black elf-locks streaming from beneath; a shot-pouch suspended by an embroidered belt, a fire-bag or tobacco-pouch tucked into the girdle, and a 
long fowling-piece thrown carelessly across the arm, or balanced on the back of the neck. The several articles here enumerated are ornamented at the seams and hems with leather thongs wound round with porcupine quills, or more or less embroidered with bead-work, according to the industry of the wife or wives. One of the young men, even of the slovenly Dog-ribs, when newly equipped, and tripping jauntily over the mossy ground with an elastic step, displays his slim and not ungraceful figure to advantage. But this fine dress once donned is neither laid aside nor cleaned while it lasts, and soon acquires a dingy look, and an odor which betrays its owner at some distance. In the camp a greasy blanket of English manufacture is worn over the shoulders by day, and forms with the clothes the bedding by night."

In winter they clothe themselves with moose or reindeer skins, retaining the hair, while a large robe of the same material is thrown over the shoulders, and hangs down to the feet in place of the blanket. The women's dress resembles the men's, but the skirt is somewhat longer, and generally accompanied by a petticoat which reaches nearly to the knee. The form of dress here described is common to the whole Tinné nation, and also to the Crees, but the material varies with the district. Thus moose-deer, red-deer, and bison leather are in use among the more southern and western tribes, and the Hare Indians make their skirts of the skins of the animal from which they derive their surname. As this, however, is too tender to be used in the ordinary way, it is torn into narrow strips, twisted slightly, and plaited or worked into the required shape. Such is the closeness and fineness of the fur that these hare-skin dresses are exceedingly warm, notwithstanding the closeness of their texture.

The Hare Indian and Dog-rib women are certainly at the bottom of the scale of humanity in North America. Not that they are treated with cruelty, but that they are looked upon as inferior beings, and in this belief they themselves acquiesce. In early infancy the boy discovers that he may show any amount of arrogance towards his sisters, who, as soon as they can walk, are harnessed to a sledge, while the tiny hunter struts in his snow-shoes after the men and apes their contempt of the women. All the work, except hunting and fishing, falls to their share; yet they are in general not discontented with their lot.

It would be vain to look among the Dog-ribs for the stoicism popularly attributed to the Indians, for they shrink from pain, shed tears readily, and are very timorous; but all, young and old, enjoy a joke heartily, and when young are lively and cheerful. When bands of their nation meet each other after a long absence, they perform a kind of dance. A piece of ground is cleared for the purpose, and the dance frequently lasts for two or three days, the parties relieving each other as they get tired. The two bands commence the dance with their backs turned to each other, the individuals following one another in Indian file, and holding the bow in the left hand and an arrow in the right. They approach obliquely after many turns, and when the two bands are closely back to back, they feign to see each other for the first time, and the bow is instantly transferred to the right hand and the arrow to the left, signifying that it is not their intention to use them against their friends. Their dancing, which 
they accompany by a chorus of groans, compared by Sir John Richardson to the deep sigh of a pavior as he brings his rammer down upon the pavement, has not the least pretensions to grace; their knees and body are half bent, and, from their heavy stamping, they appear as if desirous of sinking into the ground.

The Dog-ribs are practical socialists, and their wretched condition results in a great measure from this cause. All may avail themselves of the produce of a hunter's energy or skill, and do not even leave him the distribution of his own game. When it becomes known in a camp that deer have been killed, the old men and women of each family sally forth with their sledges and divide the quarry, leaving the owner nothing but the ribs and tongue-all he can claim of right. Unable to restrain their appetite, all the community feast in times of abundance, however little many of the men (and there are not a few idle ones) may have contributed to the common good. Taught by frequent sufferings, the more active hunters frequently withdraw from the worthless drones, leaving them at some fishing-station, where, with proper industry, they may subsist comfortably. Fish-diet is, however, not agreeable to their taste, and as soon as reports of a successful chase arrive, a general movement to the hunting-ground ensues. If on their march the craving multitude discover a hoard of meat, it is devoured on the spot; but they are not always so fortunate. The deer and the hunters may have gone off, and then they are obliged to retrace their steps, many perishing by the way.

The Dog-ribs are not conspicuous for hospitality。 When a stranger enters a tent he receives no welcome and proffer of food, though he may help himself from a piece of meat hanging on the wall or join the repast. Though great liars, they do not steal the white man's property like the Esquimaux and Crees, and when visiting a fort, they may be trusted in any of the rooms. As to their religious belief, the majority of the nation recognize a Great Spirit, while others doubt his existence, assigning as a reason their miserable condition. They are in great fear of evil spirits, which, as they imagine, assume the forms of the bear, wolf, and wolverine, and in the woods, waters, and desert places they fancy they hear them howling in the winds or moaning by the graves of the dead. They never make offerings to the Great Spirit, but deprecate the wrath of an evil being by the promise of a sacrifice, or by scattering a handful of deer-hair or a few feathers. They believe in a state of future happiness or torment. The soul, after death, crosses a broad river in a boat, and thus endeavors to reach the opposite shore, which is adorned with all the beauties of paradise. If laden with crime, the boat sinks under the weight, and the unfortunate soul, immersed in water, strives in vain to reach the blissful abode from which it is forever banished.

Formerly when a Tinné warrior died, it was customary for the family to abandon every article they possessed, and betake themselves, in a perfectly destitute condition, to the nearest body of their own people or trading-post. The advice of traders is gradually breaking down this absurd practice, which would alone suffice to keep this people in a state of perpetual poverty. In other respects also, European influence begins to make itself felt. Since 1846 Roman Catholic missionaries are at work among the Chepewyans, and have taught many 
of their converts to read and write. The Athabascans had formerly but a small breed of dogs, now a stouter race has, in some respects, ameliorated the condition of the females, and the introduction of the horse, which has more recently taken place, holds out prospects of a still greater improvement. The Tinné are as giddy and thoughtless as children. When accompanied by a white man they will perform a long journey carefully, but can not be depended upon to carry letters, however high the reward may be that has been promised them on reaching their destination, as the least whim suffices to make them forget their commission.

They are generally content with one wife at a time, and none but the chiefs have more than two. The successful wrestler takes the wife of his weaker countryman, who consoles himself for his loss by endeavoring to find one weaker than himself.

Tender and affectionate parents, the Tinné are totally indifferent to the sorrows of helpless age. During the stay of Sir George Back at Fort Reliance, an old woman arrived there on Easter Sunday, clothed in ragged reindeer skins, worn down to a skeleton, and grasping with both her hands a stick to support her body, bent double by age and want. The story of the poor creature was soon told. She had become a burden to her family; her former services had all been forgotten, and she had been told " that though she still seemed to live, she was in reality dead, and must be abandoned to her fate. In the new fort she might find assistance, for the white strangers were powerful medicine-men." This had happened a month before, and all this time she had slowly crept along, appeasing her hunger with the berries she found here and there on the way. When she reached the fort it was too late; she died a few days after her arrival. 


\section{CHAPTER XXXI.}

\section{THE LOUCHEUX, OR KUTCHIN INDIANS.}

The Countries they inhabit.-Their Appearance and Dress. - Their Love of Finery.-Condition of the Women.-Strange Customs. - Character.-Feuds with the Esquimaux.-Their suspicious and timorous Lives.-Pounds for catching Reindeer.-Their Lodges.

N the banks of the Lower Mackenzie, to the west of Great Bear Lake, in the territories drained by the Peel River and by the Upper Yukon, dwell the Loucheux, or Kutchin Indians, whose language is totally different from that of the other North American tribes, and whose customs and manners also vary considerably from those of all their neighbors, both Red-skins and Esquimaux.

They are an athletic and fine-looking people, with regular features and s complexion of a lighter copper color than that of the other Red Indians, so that many of their women would be reckoned handsome in any country. The females tattoo their chins and use a black pigment when they paint their faces, while the men employ both red and black on all occasions of ceremony, and always to be ready, each carries a small bag with red clay and black lead suspended to his neck. Most commonly the eyes are encircled with black, a stripe of the same runs down the middle of the nose, and a blotch is daubed on the upper part of each cheek. The forehead is crossed by many narrow red stripes, and the skin is streaked alternately with red and black.

The outer shirt of the Kutchin is made of the skins of tawn reindeer, dressed with the hair on after the manner of the Hare, Dog-rib, and other Chepewyan tribes, but resembles in form the analogous garment of the Esquimaux, being furnished with peaked skirts, though of smaller size. The men wear these skirts before and behind; the women have larger back skirts, but none in front. In winter shirts of hare-skin are worn, and the pantaloons of deer-skin have the fur next the skin.

None of the neighboring nations pay so much attention to personal cleanliness, or are so studious in adorning their persons. A broad band of beads is worn across the shoulders and breast of the shirt, and the hinder part of the dress is fringed with tassels wound round with dyed porcupine quills and strung with the silvery fruit of the oleaster (Elocagnus argentea); a stripe of beads, strung in alternate red and white squares, ornament the seams of the trowsers, and bands of beads encircle the ankles. The poorer sort, or the less fortunate hunters, who are unable to procure these costly trinkets in the same enviable abundance as the rich, strive to wear at least a string of beads, and look down with contemptuous pity upon the still more needy class, which is reduced to adorn itself with porcupine quills only.

In consequence of this passionate fondness for beads, these ornaments serve 
as a medium of exchange among the Kutchin, and Sir John Richardson remarks that no such near approach to money has been invented by the nations to the eastward of the Rocky Mountains. The standard bead, and one of the most value, is a large one of white enamel, manufactured in Italy only, and is with difficulty procured in sufficient quantity to satisfy the demand, as beads are more prized than English cloth and blankets.

Another article very much in request among the Kutchin is the large ribbed dentalium shell which is collected in the archipelago between Oregon and Cape Fairweather, and passes by trade from tribe to tribe until it finds its way at length to the Yukon. With this shell they adorn their mittens, and even attach it to their guns, which have been lately introduced, and are in great demand. All men carry powder and ball, whether they own a gun or not, and obtain for it a share of the game.

The tribes on the Yukon tie their hair behind in a cue, or "chignon," and daub it with grease, and the down of geese and ducks, until, by the repetition of the process continued from infancy, it swells to an enormous thickness, so that the weight of the accumulated load of hair, dirt, and ornaments causes the wearer to stoop forward habitually. The tail-feathers of the eagle and fishing-hawk are stuck into the hair on the back of the head, and are removed only when the owner retires to sleep, or when he wishes to wave them to and fro in a dance.

The principal men have two or three wives each, while the bad hunters are obliged to remain bachelors. A good wrestler, however, even though poor, can always obtain a wife.

The women do all the drudgery in winter except cooking, and do not eat till the husband is satisfied. In summer they labor little, except in drying meat or fish for its preservation. The men alone paddle while the women sit as passengers, and husbands even carry their wives to the shore on their arms, that they may not wet their feet-an instance of gallantry almost unparalleled in savage life. The Esquimaux women row their own "oomiaks," and the Chepewyan women assist the men in paddling their canoes. On the whole, the social condition of the Kutchin women is far superior to that of the Tinné women, but scarcely equal to that of the Esquimaux dames.

They do not carry their children in their hoods or boots like the Esquimaux, nor do they stuff them into a bag with moss like the Tinné and Crees, but they place them in a seat of birch-bark, with a back and sides like those of an armchair, and a pommel in front resembling the peak of a Spanish saddle, by which they hang it from their back. The child's feet are bandaged to prevent them growing, small feet being thought handsome, and consequently short unshapely feet are characteristic of the people of both sexes. A more ridiculous or insane custom can hardly be imagined among a nation of hunters.

The Kutchin are a lively, cheerful people, fond of dancing and singing, in which they excel all other Indians ; leaping, wrestling, and other athletic exercises are likewise favorite amusements. They are inveterate talkers. Every new-comer arriving at a trading-post makes a long speech, which must not be interrupted. The belief in Shamanism is still in full vigor among them. 
Though a treacherous people, they have never yet imbrued their hands in European blood, but there are frequent feuds among their various tribes, by which one-half of the population of the banks of the Yukon has been cut off within the last twenty years. From a constant dread of ambuscade, they do not travel except in large parties; and thus a perpetual feeling of insecurity embitters their lives, which are already rendered sufficiently hard by the severity of an Arctic climate. The agents of the Hudson's Bay Company have endeavored by good advice, and the distribution of large presents, to establish peace, but have only met with partial success.

Like the Tinné, the Kutchin are in a state of perpetual warfare with the Esquimaux; and though they always charge the latter with treachery, yet there can be no doubt that the accusation might, with full justice, be retorted upon themselves. One of the hostile encounters, mentioned by Sir J. Richardson, deserves notice, on account of its resemblance in some particulars to the meeting of Joab and Abner, recorded in the Second Book of Samuel. A party of each of the two nations having met on the banks of a river, the young men of both parties rose up as if for a friendly dance. The stream glides peacefully along, the setting sun gilds the pine forest and sparkles in the waters; all nature breathes peace. But the Esquimaux having, according to their custom, concealed their long knives in the sleeves of their deer-skin shirts, suddenly draw them in one of the evolutions of the dance and plunge them into their opponents. A general conflict ensues, in which the Kutchin, thanks to their guns, ultimately prove victorious. "Another incident," says Sir John Richardson, " which occurred on the banks of the Yukon in 1845, gives us a farther insight into the suspicious and timorous lives of these people. One night four strangers from the lower part of the river arrived at the tent of an old man who was sick, and who had with him only two sons, one of them a mere boy. The newcomers entered in a friendly manner, and when the hour of repose came, lay down; but as they did not sleep, the sons, suspecting from their conduct that they meditated evil, feigned a desire of visiting their moose-deer snares. They intimated their purpose alond to their father and went out, taking with them their bows and arrows. Instead, however, of continuing their way into the wood, they stole back quietly to the tent, and listening on the outside, discovered, as they fancied, from the conversation of the strangers, that their father's life was in danger. Knowing the exact position of the inmates, they thereupon shot their arrows through the skin covering of the tent and killed two of the strange Indians; and the other two, in endeavoring to make their escape by the door, shared the fate of their companions. This is spoken of in the tribe as an exceedingly brave action."

During the summer the Yukon Kutchin dry, for their winter use, the whitefish (Coregonus albus), which they catch by planting stakes across the smaller rivers and narrow parts of the lakes and closing the openings with wicker-baskets. They take the moose-deer in snares, and towards spring mostly resort to the mountains to hunt reindeer and lay in a stock of dried venison. On the open pasture-grounds frequented by this animal they construct large pounds. Two rows of posts firmly planted in the ground, and united by the addition of 
strong horizontal bars into a regular fence, extend their arms for nearly the length of a mile in the form of a Roman V. The extremity of the avenue is closed by stakes with sharp points sloping towards the entrance, on which the reindeer, driven together and hotly pursued by the Indians, may impale themselves in their desperate flight. The structure is erected with great labor, as the timber has to be transported into the open country from a considerable distance. Some of these may be a century old, and they are the hereditary possession of the families or tribes by whom they were originally constructed.

But in spite of all their contrivances and the use of fire-arms, the Kutchin, whose numbers on the banks of the Yukon are estimated at about a thousand men and boys able to hunt, are frequently reduced to great distress. Hence the old and infirm are mercilessly left to their fate when game is scarce, and famine makes itself felt. Attempts have been vainly made to better the condition of the northern Indians by inducing them to tame the reindeer. Their superstition is one of the obstacles against this useful innovation, for they fear that were they to make some of the reindeer their captives, the remainder would immediately leave the country. " And why," they add, "should we follow like slaves a herd of tame animals, when the forest and the barren ground provide ns with the elk, the wild reindeer, and the musk-ox, and our rivers and lakes are filled with fishes that cost us nothing but the trouble of catching them ?"

Each family possesses a deer-skin tent or lodge, which in summer, when in quest of game, is rarely erected. The winter encampment is usually in a grove of spruce-firs; the ground being cleared of snow, the skins, which are prepared with the hair, are extended over flexible willow poles which take a semicircular form. This hemispherical shape of lodges is not altogether unknown among the Chepewyans and Crees, being that generally adapted for their vapor baths, framed of willow poles, but their dwelling-places are conical, as stiff poles are used for their construction.

When the tent is erected the snow is packed on outside to half its height, and it is lined equally high within with the young spray of the spruce-fir, that the bodies of the inmates may not rest against the cold wall. The doorway is filled up by a double told of skin, and the apartment has the closeness and warmth but not the elegance of the Esquimaux snow hut, which it resembles in shape. Though only a very small fire is kept in the centre of the lodge, yet the warmth is as great as in a log-house. The provisions are stored on the outside under fir branches and snow, and further protected from the dogs by sledges being placed on top. 


\section{CHAPTER XXXII.}

ARCTIC VOYAGES OF DISCOVERY, FROM TIIE CABOTS TO BAFFIN.

First Scendinavian Discoverer of America. - The Cabots. - Willoughby and Chancellor (1553-155t).Stephen Burrough (1556). - Frobisher (1576-1578).-Davis (1585-1587). - Barentz, Cornelis, and Brant (1594).-Wintering of the Dutch Navigators in Nova Zembla (1596-1597). - John Knight (1606). - Murdered by the Esquimaux. - Henry Hudson (1607-1609). -Baffin (1616).

ONG before Columbus sailed from the port of Palos (1492) on that ever11 memorable voyage which changed the geography of the world, the Scandinavians had already found the way to North America. From Greenland, which was known to them as early as the ninth century, and which they began to colonize in the year 985, they sailed farther to the west, and gradually extend. ed their discoveries from the coasts of Labrador, Nova Scotia, and Newfound. land, to those of the present State of Rhode Island, which, from the wild vines they there found growing in abundance, they called the "good Vinland."

But a long series of disasters destroyed their Greenland colonies about the end of the fourteenth century, and as Scandinavia itself had at that time but very little intercourse with the more civilized nations of Southern Europe, it is not to be wondered at that, despite the discoveries of Günnbjorn and Eric the Red, the great western continent remained unknown to the world in general.

One of the first consequences of the achievements of Columbus was the rediscovery of the northern part of America, for the English merchants longed to have a share of the commerce of India; and as the Pope had assigned the eastern route to the Portuguese and the western one to the Spaniards, they resolved to ascertain whether a third and shorter way to the Spice Islands, or to the fabulous golden regions of the east, might not be found by steering to the north-west. In pursuance of these views John and Sebastian Cabot sailed in 1497 from Bristol, at that time our first commercial port, and discovered the whole American coast from Labrador to Virginia. They failed indeed in the object of their mission, but they laid the first foundations of the future colonial greatness of England.

A second voyage, in 1498, by Sebastian Cabot alone, without the companionship of his father, had no important results, but in a third royage which he undertook in search of a north-west passage, at Henry VIII.'s expense, in 1516 or 1517 , it is tolerably certain that that great navigator discovered the two straits which now bear the names of Davis and Hudson.

The French expeditions of Verazzani (1523) and Jacques Cartier (1524), however memorable in other respects, having been as unsuccessful as those of Cortereal (1500) or Gomez (1524) in discovering the desired north-western passage, Sebastian Cabot, who in 1549 was created Grand Pilot of England, started in his old age another idea, which has become almost equally momentous in 
the history of Arctic discovery - the search for a north-eastern route to China. Accordingly, in the year 1553, a squadron of three small vessels, under the command of Sir Hugh Willoughby, Chancellor, and Durfoorth, set sail from Ratcliffe, with the vain hope of reaching India by sailing round North Asia, the formation and vast extent of which were at that time totally unknown.

Off Senjan, an island on the Norwegian coast in lat. $69 \frac{1}{2}^{\circ}$, the ships parted company in a stormy night, never to meet again. Willoughby and Durfoorth reached the coast of Nova Zembla, and ultimately sought a harbor in Lapland on the west side of the entrance into the White Sea, where the captaingeneral, officers, and crews of both ships were miserably frozen to death, as some Russian fishermeu ascertained in the following spring. How long they sustained the severity of the weather is not known, but the journals and a will found on board the "Admiral" proved that Sir Hugh Willoughby and most of that ship's company were alive in January, 1554. They died the victims of inexperience; for had they, as Sir John Richardson remarks, been skilled in hunting and clothing themselves, and taken the precaution moreover of laying in at the beginning of the winter a stock of mossy turf such as the country produces for fuel, and above all had they secured a few of the very many seals and belugæ which abounded in the sea around them, they might have preserved their lives and passed an endurable winter.

Chancellor was either more fortunate or more skillful, for after having long been buffeted about by stormy weather, he eventually reached St. Nicholas, in the White Sea. From thence he proceeded overland to Moscow, and delivered his credentials to the Czar, Ivan Vasilovitch, from whom he obtained many privileges for the company of merchants who had fitted out the expedition. In 1554 he returned to England, and shortly afterwards was sent back to Russia by Queen Mary for the purpose of negotiating a treaty of commerce between the two nations. Having satisfactorily accomplished his mission, he once more set sail from the White Sea, accompanied by a Muscovite ambassador. But this time the return voyage was extremely unfortunate, for Chancellor, after losing two of his vessels off the coast of Norway, was carried by a violent tempest into the Bay of Pitsligo, in Scotland, where his ship was wrecked. He endeavored to save the ambassador and himself in a boat, but the small pinnace was upset; and although the Russian safely reached the strand, the Englishman, after having escaped so many dangers in the Arctic Ocean, was drowned within sight of his native shores.

In 1556 the Muscovy Company fitted out the Serchthrift pinnace, under the command of Stephen Burrough, for discovery towards the River Obi and farther search for a north-east passage. This small vessel reached the strait between Nova Zembla and Vaigats, called by the Russians the Kara Gate, but the enormous masses of ice that came floating through the channel compelled it to return.

In spite of these repeated disappointments, the desire to discover a northern route to India was too great to allow an enterprising nation like the English to abandon the scheme as hopeless.

Thus in the days of Elizabeth the question of the north-west passage was 
again revived, and Martin Frobisher, who had solicited merchants and nobles during fifteen years for means to undertake "the only great thing left undone in the world," sailed in the year 1576 with three small vessels of 35,30 , and 10 tons, on no less an errand than the circumnavigation of Northern America. The reader may smile at the ignorance which encouraged such efforts, but he can not fail to admire the iron-hearted man who ventured in such wretched nutshells to face the Arctic seas. The expedition safely reached the coasts of Greenland and Labrador, and brought home some glittering stones, the lustre of which was erroneously attributed to gold. This belief so inflamed the zeal for new expeditions to "Meta Incognita," as Frobisher had named the coasts he had discovered, that he found no difficulty in equipping three ships of a much larger size, that they might be able to hold more of the anticipated treasure. At the entrance of the straits which still bear his name, he was prevented by the gales and drift-ice from forcing a passage to the sea beyond, but having secured about 200 tons of the supposed golden ore, the expedition was considered eminently successful. A large squadron of fifteen vessels was consequently fitted out in 1578 for a third voyage, and commissioned not only to bring back an untold amount of treasure, but also to take out materials and men to establish a colony on those desolate shores. But this grand expedition, which sailed with such extravagant hopes, was to end in disappointment. One of the largest vessels was crushed by an iceberg at the entrance of the strait, and the others were so beaten about by storms and obstructed by fogs that they were at length glad to return to England without having done any thing for the advancement of geographical knowledge. The utter worthlessness of the glittering stones having meanwhile been discovered, Frobisher relinquished all further attempts to push his fortunes in the northern regions, and sought new laurels in a sunnier clime. He accompanied Drake to the West Indies, commanded subsequently one of the largest vessels opposed to the Spanish Armada, and ended his heroic life while attacking a small French fort in behalf of Henry IV. during the war with the League.

The discovery of the North-western Passage was, however, still the great enterprise of the day, and thus sundry London merchants again "cast in their adventure," and sent out John Davis, in 1585, with his two ships, "Sunshine" and "Moonshine," carrying, besides their more necessary equipments, a band of music "to cheer and recreate the spirits of the natives." Davis arrived in sight of the south-western coast of Greenland, where he saw a high mountain (Sukkertoppen) towering like a cone of silver over the fog which veiled the dismal shore. The voyagers were glad to turn from the gloomy scene, and to steer through the open water to the north-west, where, on August 6, they discovered land in latitude $66^{\circ} 40^{\prime}$ altogether free from "the pesters of ice, and ankered in a very fair rode." A friendly understanding was established with the Esquimaux, and a lively traffic opened, the natives eagerly giving their skins and furs for beads and knives, until a brisk wind separated the strange visitants from their simple-minded friends. The remainder of the season was spent in exploring Cumberland Sound and the entrance to Frobisher's and Hudson's Straits. 
In the following year Davis undertook a second voyage to the north-west, for which the "Sunshine" and "Moonshine" were again engaged, with two other vessels. On June 29, 1586, he landed on the coast of Greenland, in latitude $64^{\circ}$, and soon after steered to the west. The enormous ice-floes which, as is well known, come drifting from Baffin s Bay until the season is far advanced, opposed his progress. For some days he coasted these floating islands, when a fog came on, during which ropes, sails, and cordage were alike fast frozen, and the seamen, hopeless of accomplishing the passage, warned their commander that "by his over-boldness he might cause their widows and fatherless children to give him bitter curses."

Touched by this appeal, Davis ordered two of his ships to return home, and pushing on in the "Moonshine" with the boldest of his followers, he reached the American shore, which he coasted from $67^{\circ}$ to $57^{\circ}$ of latitude. Off the coast of Labrador two of his sailors were killed by the natives, and September being ushered in by violent gales, he gave up further attempts for the year, and returned to England.

On June 16, 1587, we once more find him on the coast of Greenland, in his old tried bark the "Sunshine," in company with the "Elizabeth" and a pinnace. The supplies for this third voyage being furnished under the express condition that the expenses should be lightened as much as possible by fishing at all suitable times, the two larger ships were stationed for the purpose near the part of the coast which they had formerly visited, while Davis steered forward in the small and ill-conditioned vessel which alone remained at his disposal. He first sailed along the Greenland coast as far as $72^{\circ}$ lat., where, having fairly entered Baffin's Bay, he named the point at which he touched Sanderson's Hope, in honor of his chief patron, and then steered to the west, until he once more fell in with the ice-barrier which had prevented his progress the year before. Time and perseverance, however, overcame all obstacles, and by July 19 he had crossed to the opposite side of the strait which bears his name. He then sailed for two days up Cumberland Strait-which, it will be remembered, he discovered on his first expedition-but believing this passage to be an inclosed gulf, he returned, and again passing the entrance to Hudson's Bay without an effort to investigate it, repaired to the rendezvous appointed for the two whaling-vessels to meet him on their way to England. But who can paint his astonishment and consternation when he found that his companions had sailed away, leaving him to find his way home in his miserable pinnace, which, however, landed him safely on his native shores? This was the last of the Arctic voyages of that great navigator, for the spirit of the nation was chilled by his three successive disappointments; and all the zeal with which he pleaded for a fourth expedition proved fruitless.

He subsequently made five voyages to the East Indies, and was killed on December 27, 1605, on the coast of Malacca, in a fight with the Malays.

Seven years after Davis's iast Arctic voyage the Dutch made their first appearance on the scene of northern discovery. This persevering people had just then succeeded in casting off the Spanish yoke, and was now striving to gain, by the development of his maritime trade, a position among the neighboring 
states, which the smallness of its territory seemed to deny to it. All the known avenues to the treasures of the south were at that time too well guarded by the fleets of Portugal and Spain to admit of any rivalry; but if fortune favored them in finding the yet unexplored northern passage to India, they might still hope to secure a lion's share in that most lucrative of trades.

Animated by this laudable spirit of enterprise, the merchants of Amsterdam, Enkhuizen, and Middelburg fitted out in 1594 an expedition in quest of the north-eastern passage, which they intrusted to the command of Cornelius Corneliszoon, Brant Ysbrantzoon, and William Barentz, one of the most experienced seamen of the day. The three vessels sailed from the Texel on June 6 , and having reached the coast of Lapland, separated into two divisions; Barentz choosing the bolder course of coasting the west side of Nova Zembla as far as the islands of Orange, the most northerly points of the archipelago; while his less adventurous comrades were contented to sail along the Russian coast until they reached a strait, to which they gave the very appropriate name of Vaigats, or "Wind-hole." Forcing their way through the ice, which almost constantly blocks up the entrance to the Kara Sea, they saw, on rounding a promontory at the other end of the strait, a clear expanse of blue open sea, stretching onward as far as the eye could reach, while the continent trended away rapidly towards the south-east. They now no longer doubted that they had sailed round the famous Cape Tabin-a fabulous headland, which, according to Pliny (an indisputable authority in those times of geographical ignorance), formed the northern extremity of Asia, from whence the voyage was supposed to be easy to its eastern and southern shores. Little did Brant and Cornelius dream that within the Arctic Circle the Asiatic coast still stretched $120^{\circ}$ to the east; and fully trusting their erroneous impressions, they started in full sail for Holland, eager to bring to their countrymen the news of their imaginary success. Off Russian Lapland they fell in with Barentz, who, having arrived at the northern extremity of Nova Zembla-a higher latitude than any navigator is recorded to have reached before-had turned back before strong opposing winds and floating ice, and the three vessels returned together to Texel.

Such were the hopes raised by the discovery of the imaginary Cape Tabin that, losing sight of their habitual caution, the merchants of Middelburg, Enkhuizen, Rotterdam, and Amsterdam immediately fitted out a fleet of six ships, laden with all sorts of merchandise fit for the Indian market. A little yacht was added, which was to accompany the fleet as far as that promontory, and thence to return with the good news that the squadron had been left steering with a favorable wind right off to India. But, as may well be supposed, these sanguine hopes, built on the unsubstantial fabric of a vision, were doomed to a woful disappointment, for the "Wind-hole Strait," doing full justice to its name, did not allow the vessels to pass; and after fruitless efforts to force their way through the ice-blocks which obstructed that inhospitable channel, they returned crestfallen to the port whence they had sailed a few months before with such brilliant expectations.

Although great disappointment was felt at this failure, the scheme of sailing 
round Cape Tabin to India was, however, not abandoned by the persevering Amsterdamers ; and, on May 16, 1596, Heemskerk, Barentz, and Cornelis Ryp once more started for the north-east. Bear. Island and Spitzbergen were discovered, whereupon the ships separated, Cornelis and Heemskerk returning to Holland, while Barentz, slowly making his way through the fog and ice, advanced to the most northern point of Nova Zembla, the crew being encouraged by the tidings that from the high cliffs of Orange Island clear open water had been seen to the south-east. The effort to reach this inviting channel was frustrated by the ice, which gathered about the ship as it lay near shore, and gradually collecting under and around it, raised it far above the level of the sea. All hope of return before the next summer now vanished, but these brave sailors submitted with resignation to their fate, "though much grieved," says Gerrit de Veer, who was himself an eye-witness of all the incidents he relates, " to live there all that cold winter, which we knew would fall out to be extremely bitter." Fortunately a quantity of drift-wood was found on the strand, which served the Dutchmen both for the construction of a small hut and for fuel.

As early as September the ground was frozen so hard that they tried in vain to dig a grave for a dead comrade, and their cramped fingers could hardly build the hut, which was the more necessary, as the vessel, cracking under the pressure of the ice, gave signs of speedily breaking up altogether. By the middle of October the rude dwelling was completed, and though its accommodation was scanty, they were glad to take up their abode in it at once. The best place by the central fire was assigned to a sick comrade, while all the rest arranged their beds as best they could on shelves which had been built round the walls. An examination into the state of their provisions showed the necessity of reducing their daily rations of bread, cheese, and wine, but by setting traps they caught a good many Arctic foxes, which gave them an occasional supply of fresh food. The sun had now entirely taken his departure, and the long winter night of the $75^{\circ} 43^{\prime}$ of latitude set in, during which snowdrifts and impetuous winds confined them to their miserable hut.

"We looked pitifully one upon the other," says De Veer, "being in great fear that if the extremity of the cold grew to be more and more, we should all die there of cold, for that what fire soever we made would not warm us."

The ice was now two inches thick upon the walls, and even on the sides of their sleeping cots and the very clothes they wore were whitened with frost. Yet in the midst of all their sufferings these brave men maintained cheerful hearts; and so great was their elasticity of spirit that, remembering January 5 was Twelfth Eve, they resolved to celebrate it as best they might. " And then," says the old chronicler, "we prayed our Maister that we might be merry that night, and said that we were content to spend some of the wine that night which we had spared, and which was our share (one glass) every second day, and whereof for certaine days we had not dranke, and so that night we made merry and drew for king. And therewith we had two pounds of meal, whereof we made pancakes with oyle, and every man had a white biscuit which we sopt in the wine. And so supposing that we were in our owne country and 
amongst our friends, it comforted us well as if we had made a great banquet in our owne house. And we also made trinkets, and our gunner was king of Novaya Zemlya, which is at least 800 miles long and lyeth between two seas."

On January 24 the edge of the sun appeared above the horizon, and the sight was a joyful one indeed. Now also the furious snow-storm ceased, and though the severity of the cold continued unabated, they were better able to brave the outer air and to recruit their strength by exercise. With the return of daylight the bears came again about the house, and some being shot, afforded a very seasonable supply of grease, so that they were able to burn lamps and pass the time in reading.

When summer returned it was found impossible to disengage the ice-bound vessel, and the only hopes of escaping from this dreary prison now rested on two small boats, in which they finally quitted the scene of so much suffering on June 14, 1596. On the fourth day of their voyage their barks became surrounded by enormous masses of floating ice, which so crushed and injured them that the crews, giving un all hope, took a solemn leave of each other. But in this desperate crisis they owed their preservation to the presence of mind and agility of De Veer, who, with a well-secured rope, leaped from one ice-block to another till he reached a larger floe, on which first the sick, then the stores, the crews, and finally the boats themselves were fairly landed. Here they were obliged to remain while the boats underwent the necessary repairs, and during this detention upon a floating ice raft the gallant Barentz closed the eventful voyage of his life. He died as he had lived, calmly and bravely, thinking less of himself than of the welfare of his fellow-sufferers, for his last words were directions as to the course in which they were to steer. His death was bitterly mourned by the rough men under his command, and even the prospect of a return to their homes could not console them for the loss of their beloved leader. After a most tedious passage (for by July 28 they had only reached the southern extremity of Nova Zembla) they at length, at the end of August, arrived at Kola, in Russian Lapland, where, to their glad surprise, they found their old comrade, John Cornelison Ryp, with whom they returned to Amsterdam.

Meanwhile the spirit of discovery had once more recovered in England from the chill thrown upon it by so many previous disappointments. In 1602, Weymouth, while attempting to sail up the promising inlet, now so well-known as the entrance to Hudson's Bay, was repulsed by a violent storm, and in 1606 a melancholy issue awaited the next expedition to the north-west, which sailed under the command of John Knight, a brave and experienced sailor. Driven by stormy weather among the drift-ice on the coast of Labrador, Knight was fain to take shelter in the first cove that presented itself, and lost no time in ordering his damaged ship of forty tons to be drawn high up on the dry sand beyond the tide mark, where she might undergo the necessary repairs.

This position, however, not proving satisfactory, he manned his boat next day, and while the rest of the crew were busy at work, sailed across to the other side of the inlet to seek for some more convtnient anchorage. Leaving two men in charge of the boat, he landed with his mate and three of his men to 
explore the strange coast. They climbed the steep acclivity of the shore, lingered for a moment on the summit of the cliffs, and before disappearing on the other side exchanged greetings of farewell with their messmates in the boat, who little imagined that it was a parting forever. Evening came on, and then darkened into night; muskets were fired and trumpets sounded, but no answer was made, and eleven o'clock arriving without any sign or signal of the missing party, the men who had tarried on shore mournfully returned to the ship with the dismal tidings of the loss of their brave commander and his comrades.

During this melancholy night, passed in alternate lamentations and plans for search and rescue, the ice had so accumulated in the channel which the unfortunate Knight crossed the day before, that though the boat was speedily rigged for the expedition, and the party who occupied it were one and all uncontrollably eager to start, the morning light convinced the most sanguine of the utter impossibility of forcing their way across the gulf. Thus passed two wretched days of uncertainty, rendered doubly miserable by the inactivity to which they were condemned, when on the night of the second day the little encampment was attacked by a large party of natives, whose hostility left no doubt about the fate which had befallen their missing friends. A volley of musketry soon dispersed the savages, but fearing future attacks, the crew, now only eight in number, at once resolved to put to sea in their crazy bark, which, though deprived of its rudder, and so leaky that the pumps were obliged to be constantly at work, safely carried them to Newfoundland.

In the year 1607 Henry Hudson made the first attempt to sail across the North Pole, a plan started in 1527 by Robert Thorne, but not yet acted upon by any one during the eighty years that had since passed. He reached the east coast of Greenland in $73^{\circ}$ of latitude, and then proceeded to the northern extremity of Spitzbergen, but all his efforts to launch forth into the unknown ocean beyond were baffled by the ice-fields that opposed his progress.

In his next voyage (1608) he vainly tried for the north-east passage, but his third voyage (1609), which he performed in the service of the Dutch, led to the discovery of the magnificent river which still bears his name, and at whose mouth the "Empire City" of the great American republic has arisen.

In April, 1610, we find him setting sail on the last and most celebrated of his voyages. In all but its commander, this expedition was miserably inade. quate to the object of its mission, for it consisted only of one vessel of fifty-five tons provisioned for six months, and manned by a crew who speedily proved themselves to be utterly unworthy of their leader. On entering Hudson's Straits, the large masses of ice which encumbered the surface of the water and the thickness of the constant fogs made them lose all courage, and they earnestly begged their commander to return at once to England. But Hudson pressed on until at last his little bark emerged into a vast open water rippling and sparkling in the morning sunshine. Hudson's Bay expanded before him, and the enraptured discoverer was fully convinced that the north-western route to India now lay open to the mariners of England.

It was the beginning of August, and the dastardly crew considering the passage effected, urged an immediate return; but Hudson was determined on 
completing the adventure, and wintering, if possible, on the sunny shores of India. For three months he continued tracking the south coasts of that vast northern Mediterranean, but all his hopes of finding a new channel opening to the south proved vain, until at length the ship was frozen in on November 10 in the south-east corner of James's Bay. A dreary winter awaited the ice-bound seamen, with almost exhausted provisions, and unfortunately without that heroic patience and concord which had sustained the courage of Barentz and his companions under trials far more severe. But spring came at last, and revived the spirits of their leader. His ship was once more afloat, once more his fancy indulged in visions of the sunny East, when, as he stepped on deck on the morning of June 21, his arms were suddenly pinioned, and he found himself in the power of three of his men.

Inquiry, remonstrance, entreaty, command, all failed to draw a word from the stubborn mutineers, and Hudson resigned himself bravely to his fate, and, with the quiet dignity of a noble nature, looked on calmly at the ominous preparations going forward. A small open boat was in waiting, and into this Hudson-his hands being previously tied behind his back-was lowered; some powder and shot and the carpenter's box came next, followed by the carpenter himself, John King, whose name ought to be held in honorable remembrance, as he alone among the crew remained true to his master. Six invalids were also forced into the boat, which was then cut adrift, and the vessel sailed onward on its homeward course. Nothing more was ever heard of Hudson; but the ringleaders of that dark conspiracy soon paid a terrible penalty. Some fell in a fight with the Esquimaux, and others died on the homeward voyage, during which they suffered from the extremest famine.

The account of the great expanse of sea which had been reached gave new vigor to the spirit of discovery, and new expeditions sallied forth (Sir Thomas Button, 1612, Gibbons, 1614, Bylot, 1615), to seek along the western shores of Hudson's Bay the passage which was to open the way to India. All efforts in this direction were of course doomed to disappointment, but Baffin, who sailed in 1616, with directions to try his fortune beyond Davis's Straits, enriched geography with a new and important conquest by sailing round the enormous bay which still bears his name. During this voyage he discovered the entrances of Smith's, Jones's, and Lancaster Sounds, without attempting to irvestigate these broad highways to fields of later exploration. He believed them to be mere inclosed gulfs, and this belief became so firmly grounded in the public mind that two full centuries elapsed before any new attempt was made to seek for a western passage in this direction, while Jens Munk, a Dane, sent out in 1619 with two good vessels, under the patronage of his king, Christian IV.; Fox and James (1631-1632), Knight and Barlow (1719), Middleton (1741), Moor and Smith (1746), confined their efforts to Hudson's Bay, and, by their repeated disappointments, made all expeditions in quest of a north-western passage appear well-nigh as chimerical as those of the knight-errants of romance. 


\section{CHAPTER XXXIII.}

\section{ARCTIC VOYAGES OF DISCOVERY, FROM BAFFIN TO M'CLINTOCK.}

Buchan and Franklin.-Ross and Parry 1818). - Discovery of Melville Island.-Winter Harbor (18121820). - Franklin's first land Journey._- Dreadful Sufferings. - Parry's second Voyage (1821-1823). - Iligliuk._- Lyon (1824). - Parry's third Voyage (1824)._Franklin's second land Journey. to the Shores of the Polar Sea.-Beechey.-Parry's sledge Journey towards the Pole.-Sir John Ross's second Journey.-Five Years in the Arctic Ocean.-Back's Discovery of Great Fish River.-Dease and Simpson (1837-1839).-Franklin and Crozier's last Voyage (1845).-Dearching Expeditions.Richardson and Rae.-Sir James Ross.-Austin.-Penny.-De Haven.-Franklin's first Winterquarters discovered by Ommaney.-Kennedy and Bellot.-Inglefield.-Sir E. Belcher.-Kellett.M'Clure's Discovery of the North-west Passage.-Collinson.-Bellot's Death.-Dr. Rae learns the Death of the Crews of the "Erebus" and "Terror."-Sir Leopold M'Clintock.

$\mathrm{T}$

HE failure of Captain Phipps (afterwards Lord Mulgrave) in the Spitzbergen seas (1773), and that of the illustrious Cook (1776), in his attempt to circumnavigate the northern shores of America or Asia by way of the Straits of Bering, entirely damped, for the next forty years, the spirit of Arctic discovery ; but hope revived when it became known that Captain Scoresby, on a whaling expedition in the Greenland seas (1806), had attained $81^{\circ} 30^{\prime}$ N. lat., and thus approached the pole to within 540 miles. No previous navigator had ever reached so far to the north; an open sea lay temptingly before him, and the absence of the ice-blink proved that for miles beyond the visible horizon no ice-field or snow-covered land opposed his onward course; but as the object of Scoresby's voyage was strictly commercial, and he himself answerable to the owners of his vessel, he felt obliged to sacrifice his inclinations to his duty, and to steer again to the south.

During the Continental war, indeed, England had but little leisure to prosecute discoveries in the Arctic Ocean; but not long after the conclusion of peace, four stout vessels (1818) were sent out on that mission by Government. Two of these, the "Dorothea," Captain Buchan, and the "Trent," Commander Lieutenant John Franklin, were destined to proceed northward by way of Spitzbergen, and to endeavor to cross the Polar Sea. After unnumbered difficulties, the expedition was battling with the ice to the north-west of that wintry archipelago, when, on July 30 , a sudden gale compelled the commander, as the only chance of safety, to "take the ice "- that is, to thrust the ships into an opening among the moving masses that could be perceived. In this very hazardous operation, the "Dorothea"-having received so much injury that she was in danger of sinking-was therefore turned homeward as soon as the storm subsided, and the "Trent" of necessity accompanied her.

The other two ships, which sailed in the same year, the "Isabella," commanded by Captain John Ross, and the "Alexander," by Lieutenant William Edward Parry, had been ordered to proceed up the middle of Davis's Strait to a 
high northern latitude, and then to stretch across to the westward, in the hope of being able to pass the northern extremity of America, and reach Bering's Strait by that route. As respects the purposes for which it was sent out, this expedition likewise ended in disappointment; for though Ross defined more clearly the Greenland coast to the north of the Danish possessions between Cape Melville and Smith's Sound, he was satisfied with making a very cursory examination of all the great channels leading from Baffin's Bay into the Polar Sea. After sailing for some little distance up Lancaster Sound, he was arrested by the atmospheric deception of a range of mountains, extending right across the passage, and concluding it useless to persevere, he at once-to the great astonishment and mortification of his officers-abandoned a course which was to render his successor illustrious. As may easily be imagined, the manner in which Ross had conducted this expedition failed to satisfy the authorities at home; and thus, in the following year, the "Hecla " and "Griper" were commissioned for the purpose of exploring the sound, whose entrance only had been seen by Baffin and Ross. The former ship was placed under the Command of Parry, and the latter under that of Lieutenant Matthew Liddon.

With this brilliant voyage, the epoch of modern discoveries in the Arctic Ocean may properly be said to begin. Sailing right through Lancaster Soünd, over the site of Ross's imaginary Croker Mountains, Parry passed Barrow's Strait, and after exploring Prince Regent Inlet, whence the ice compelled him to return to the main channel, he discovered Wellington Channel (August 22), and soon after had the satisfaction of announcing to his men that, having reached $110^{\circ} \mathrm{W}$. long., they were entitled to the king's bounty of $£ 5000$, secured by order of council to "such of His Majesty's subjects as might succeed in penetrating thus far to the west within the Arctic Circle." After passing and naming Melville Island, a little progress was still made westward; but the ice was now rapidly gathering, the vessels were soon beset, and, after getting free with great difficulty, Parry was only too glad to turn back and settle down in Winter Harbor. It was no easy task to attain this dreary port, as a canal, two miles and a third in length, had first to be cut through solid ice of seven inches average thickness; yet such was the energy of the men that the herculean labor was executed in three days. The two vessels were immediately unrigged, the decks housed over, a heating apparatus arranged, and every thing made as comfortable as possible. To relieve the monotony of the long winter's night, plays were acted every fortnight, a school established, and a newspaper set on foot-certainly the first periodical ever issued in so high a latitude. During the day the men were employed for exercise in banking up the ships with snow or making excursions within a certain distance; and when the weather forbade their leaving shelter, they were obliged to run round the decks to the tune of a barrel-organ.

In January the cold became more and more intense. On the 12th it was $51^{\circ}$ below zero in the open air, and on the 14 th the thermometer fell to $54^{\circ}$. On February 24 a fire broke out in a small house which had been built near the ships, to serve as an observatory for Captain Sabine, who accompanied the expedition as astronomer. All hands rushed to the spot to endeavor to sub- 
due the flames, but having only snow to throw on it, it was found impossible to extinguish it. The snow, however, covered the astronomical instruments, and secured them from the fire. The thermometer was at the time $44^{\circ}$ below zero, and the faces of nearly the whole party grew white and frost-bitten after five minutes' exposure, so that the surgeon and two or three assistants were busily employed in rubbing the faces of their comrades with snow, while the latter were working might and main to extinguish the flames. One poor fellow, in his anxiety to save the dipping-needle, carried it out without putting on his gloves; his hands were so benumbed in consequence, that when plunged into a basin of cold water it instantly froze, from the intense coldness imparted to it, and it was found necessary to resort, some time after, to the amputation of a part of four fingers on one hand and three on the other.

February 3 was a memorable day - the sun being visible from the maintop of the "Hecla," from whence it was last seen on November 11. The weather got considerably milder in March; on the 6th the thermometer rose to zero, for the first time since December 17, and on April 30 it stood at the freezingpoint, which it had not done since September 12.

At length May appeared, bringing the long summer's day of the high northern latitudes; but as many a week must still pass before the vessels could move out of their ice-bound harbor, Parry started on June 1 to explore the interior of the island, which at this early period of the season still wore a very dreary aspect. But such was the rapidity of vegetation, that by the end of the month the land, now completely clear of snow, was covered with the purple-colored saxifrage in blossom, with mosses, and with sorrel, and the grass was from two to three inches long. The pasturage appeared to be excellent in the valleys, and, to judge by the numerous tracks of musk-oxen and reindeer, there was no lack of animals to enjoy its abundance.

It was not hciore August 1 that the ships were released from their ten months' blockade in Winter Harbor, when Parry once more stood boldly for the west ; but no amount of skill or patience could penetrate the obstinate masses of ice that blocked the passage, or insure the safety of the vessels under the repeated shocks sustained from them. Finding the barriers insuperable, he gave way, and steering homeward, reached London on November 3, 1820, where, as may well be imagined, his reception was most enthusiastic.

While Parry was engaged on this wonderful voyage, Lieutenant Franklin and Dr. Richardson, accompanied by two midshipmen, George Back and Robert Hood, and a sailor, John Hepburn, to whom were added during the course of the journey a troop of Canadians and Indians, were penetrating by land to the mouth of the Coppermine River for the purpose of examining the unexplored shores of the Polar Sea to the east. An idea of the difficulties of this undertaking may be formed, when I mention that the travellers started from Fort York, Hudson's Bay, on August 30, 1819, and after a boat voyage of 700 miles up the Saskatchewan arrived before winter at Fort Cumberland. The next winter found them 700 miles farther on their journey, established during the extreme cold at Fort Enterprise, as they called a log-house built by them on Winter Lake, where they spent ten months, depending upon fishing and the 
success of their Indian hunters. During the summer of 1821 they accomplished the remaining 334 miles to the mouth of the Coppermine, and on July 21 Franklin and his party embarked in two birch-bark canoes on their voyage of exploration. In these frail shallops they skirted the desolate coast of the American continent 555 miles to the east of the Coppermine as far as Point Turnagain, when the rapid decrease of their provisions and the shattered state of the canoes imperatively compelled their return (August 22). And now began a dreadful land-journey of two months, accompanied by all the horrors of cold, famine, and fatigue. An esculent lichen (tripe de roche), with an occasional ptarmigan, formed their scanty food, but on very many days even this poor supply could not be obtained, and their appetites became ravenous. Sometimes they had the good-fortune to pick up pieces of skin, and a few bones of deer which had been devoured by the wolves in the previous spring. The bones were rendered friable by burning, and now and then their old shoes were added to the repast. On reaching the Coppermine, a raft had to be framed, a task accomplished with the utmost difficulty by the exhausted party. One or two of the Canadians had already fallen behind, and never rejoined their comrades, and now Hood and three or four more of the party broke down and could proceed no farther, Dr. Richardson kindly volunteering to remain with them, while Back, with the most vigorous of the men, pushed on to send succor from Fort Enterprise, and Franklin followed more slowly with the others. On reaching the log house this last party found that wretched tenement desolate, with no deposit of provisions and no trace of the Indians whom they had expected to meet there. "It would be impossible," says Franklin, "to describe our sensations after entering this miserable abode and discovering how we had been neglected; the whole party shed tears, not so much for our own fate as for that of our friends in the rear, whose lives depended entirely on our sending immediate relief from this place." Their only consolation was a gleam of hope afforded them by a note from Back, stating that he had reached the deserted hut two days before, and was going in search of the Indians. The fortunate discovery of some cast-off deer-skins and of a heap of acrid bones, a provision worthy of the place, sustained their flickering life-flame, and after eighteen miserable days they were joined by Dr. Richardson and Hepburn, the sole survivors of their party, Lieutenant Hood, a young officer of great promise, having been murdered by a treacherous Canadian, whom Richardson was afterwards obliged to shoot through the head in self-defense.

"Upon entering the desolate dwelling," says Richardson, "we had the satisfaction of embracing Captain Franklin, but no words can convey an idea of the filth and wretchedness that met our eyes on looking around. Our own misery had stolen upon us by degrees, and we were accustomed to the contemplation of each other's emaciated figures ; but the ghastly countenances, dilated eyeballs, and sepulchral voices of Captain Franklin and those with him were more than we could at first bear." At length, on November 7, when the few survivors of the ill-fated expedition (for most of the voyagers died from sheer exhaustion) were on the point of sinking under their sufferings, three Indians sent by Back, whose exertions to procure them relief had been beyond all praise, 
brought them the succor they had so long been waiting for. The eagerness with which they feasted on dried meat and excellent tongues may well be imagined; but severe pains in the stomach soon warned them that after so long an abstinence they must be exceedingly careful in the quantity of food taken. In a fortnight's time they had sufficiently recruited their strength to be able to join Back at Moose Deer Island, and in the following year they returned to England.

Parry's second voyage of discovery (1821-1823) was undertaken for the purpose of ascertaining whether a communication might be found between Regent's Inlet and Rowe's Welcome, or through Repulse Bay and thence to the north-western shores of America. The first summer (1821) was spent in the vain attempt of forcing a way through Frozen Strait, Repulse Bay, the large masses of ice in these waters holding the ships helplessly in their grasp, and often carrying them back in a few days to the very spot which they had left a month before. Owing to these rebuffs, the season came to an end while their enterprise was yet scarcely begun, and the ships took up their quarters in an open roadstead at Winter Island to the south of Melville Peninsula. Besides the winter amusements and occupations of the first voyage, the monotony of the winter was pleasantly broken during February by friendly visits from a party of Esquimaux. Among these a young woman, Iligliuk, distinguished herself by her talents. Her love for music amounted to a passion, and her quickness of comprehension was such that she soon became an established interpreter between her own people and the English. The nature of a map having been explained to her, she readily sketched with chalk upon the deck the outlines of the adjoining coast, and continuing it farther, delineated the whole eastern shore of Melville Peninsula, rounding its northern extremity by a large island and a strait of sufficient magnitude to afford a safe passage for the ships. This information greatly encouraged the whole party, whose sanguine anticipations already fancied the worst part of their voyage overcome, and its truth was eagerly tested as soon as the ships could once more be set afloat, which was not till July 2.

After running the greatest dangers from the ice, they at length reached the small island of Igloolik, near the entrance of the channel, the situation of which had been accurately laid down by the Esquimaux woman. But all their efforts to force a passage through the narrow strait proved vain, for after struggling sixty-five days to get forward, they had only in that time reached forty miles to the westward of Igloolik. The vessels were therefore again placed in winter-quarters in a channel between Igloolik and the land; but having ascertained by boat excursions the termination of the strait, Parry thought it so promising for the ensuing summer that he at once named it the "Hecla and Fury Strait." But his hopes were once more doomed to disappointment by the ice-obstructed channel, and he found it utterly impossible to pass through it with his ships. His return to England with his crews in health, after two winters in the high latitudes, was another triumph of judgment and discipline.

In the following year two new expeditions set sail for Polar America. Captain Lyon was sent out in the "Griper," with orders to land at Wager River 
off Repulse Bay, and thence to cross Melville Peninsula, and proceed overland to Point Turnagain, where Franklin's journey ended. But a succession of dreadful storms so crippled the "Griper," while endeavoring to proceed onward up Rowe's Welcome, that it became necessary to return at once to England.

Such was the esteem and affection Parry had acquired among the companions of his two former voyages, that when he took the command of a third expedition, with the intention of seeking a passage through Prince Regent's Inlet, they all volunteered to accompany him. From the middle of July till nearly the middle of September (1824), the "Hecla" and the "Fury" had to contend with the enromous ice-masses of Baffin's Bay, which would infallibly have crushed vessels less stoutly ribbed; and thus it was not before September 10 that they entered Lancaster Sound, which they found clear of ice, except here and there a solitary berg. But new ice now began to form, which, increasing daily in thickness, beset the ship, and carried them once more back again into Baffin's Bay. By perseverance, however, and the aid of a strong easterly breeze, Parry regained the lost ground, and on September 27 reached the entrance of Port Bowen, on the eastern shore of Prince Regent's Inlet, where he passed the winter. By July 19 the vessels were again free, and Parry now sailed across the inlet to examine the coast of North Somerset; but the floating ice so injured the "Fury" that it was found necessary to abandon her. Her crew and valuables were therefore received on board the "Hecla ;" the provisions, stores, and boats were landed, and safely housed on Fury Point, off North Somerset, for the relief of any wandering Esquimaux, or future Arctic explorers who might chance to visit the spot, and the crippled ship was given up to the mercy of the relentless ice, while her companion made the best of her way to England.

In spite of the dreadful sufferings of Franklin, Richardson, and Back during their first land journey, we find these heroes once more setting forth in 1825, determined to resume the survey of the Arctic coasts of the American continent. A far more adequate preparation was made for the necessities of their journey than before; and before they settled down for the winter at "Fort Franklin," on the shores of Great Bear Lake, a journey of investigation down the Mackenzie River to the sea had been brought to a successful end. As soon as the ice broke in the following summer, they set out in four boats, and separated at the point where the river divides into two main branches, Franklin and Back proposing to survey the coast-line to the westward, while Richardson set out in an easterly direction to the mouth of the Coppermine River. Franklin arrived at the mouth of the Mackenzie on July 7, where a large tribe of Esquimaux pillaged his boats, and it was only by great prudence and forbearance that the whole party were not massacred. A full month was now spent in the tedious survey of 374 miles of coast, as far as Return Reef, more than 1000 miles distant from their winter-quarters on great Bear Lake. The return journey to Fort Franklin was safely accomplished, and they arrived at their house on September 21, where they had the pleasure of finding Dr. Richardson and Lieutenant Kendall, who, on their part, had reached the Coppermine, thus connect- 
ing Sir John Franklin's former discoveries to the eastward in Coronation Gulf with those made by him on this occasion to the westward of the Mackenzie. The cold during the second winter at Fort Franklin was intense, the thermometer standing at one time at $58^{\circ}$ below zero; but the comfort they now enjoyed formed a most pleasing contrast to the squalid misery of Fort Enterprise.

When Franklin left England to proceed on this expedition, his first wife was then lying at the point of death, and indeed expired the day after his departure. But with heroic fortitude she urged him to set out on the very day appointed, entreating him, as he valued her peace and his own glory, not to delay a moment on her account. His feelings may be imagined when he raised on Garry Island a silk flag which she had made and given him as a parting gift, with the instruction that he was only to hoist it on reaching the Polar Sea.

While Parry and Franklin were thus severally employed in searching for a western passage, a sea expedition under the command of Captain Beechey had been sent to Bering's Straits to co-operate with them, so as to furnish provisions to the former and a conveyance home to the latter-a task more easily planned than executed; and thus we can not wonder that when the "Blossom" reached the appointed place of rendezvous at Chamisso Island, in Kotzebue Sound (July 25, 1826), she found neither Parry (who had long since returned to England) nor Franklin. Yet the barge of the "Blossom"-which was dispatched to the eastward under charge of Mr. Elson-narrowly missed meeting the latter; for when she was stopped by the ice at Point Barrow, she was only about 150 miles from Return Reef, the limit of his discoveries to the westward of the Mackenzie.

In the year 1827 the indefatigable Parry undertook one of the most extraordinary voyages ever performed by man; being no less than an attempt to reach the North Pole by boat and sledge travelling over the ice. His hopes of success were founded on Crosby's authority, who reports having seen ice-fields so free from either fissure or hummock, that had they not been covered with snow, a coach might have been driven many leagues over them in a direct line; but when Parry reached the ice-fields to the north of Spitzbergen, he found them of a very different nature, composed of loose, rugged masses, intermixed with pools of water, which rendered travelling over them extremely arduous and slow. The strong flat-bottomed boats, specially prepared for an amphibious journey, with a runner attached to each side of the keel, so as to adapt them for sledging, had thus frequently to be laden and unladen, in order to be raised over the hummocks, and repeated journeys backward and forward over the same ground were the necessary consequence. Frequently the crew had to go on hands and knees to secure a footing. Heavy showers of rain often rendered the surface of the ice a mass of slush, and in some places the ice took the form of sharppointed crystals, which cut the boots like penknives. But in spite of all these obstacles, they toiled cheerfully on, until at length, after thirty-five days of incessant drudgery, the discovery was made that, while they were apparently advancing towards the pole, the ice-field on which they were travelling was drifting to the south, and thus rendering all their exertions fruitless. Yet, though disappointed in his hope of planting his country's standard on the northern 
axis of the globe, Parry had the glory of reaching the highest authenticated latitude ever yet attained $\left(82^{\circ} 40^{\prime} 30^{\prime \prime}\right)$. On their return to the "Hecla," which awaited them under Captain Forester in Treurenberg Bay, on the northern coast of Spitzbergen, the boats encountered a dreadful storm on the open sea, which obliged them to bear up for Walden Island-one of the most northerly rocks of the archipelago-where, fortunately, a reserve supply of provisions had been deposited. "Every thing belonging to us," says Sir Edward Parry, "was now completely drenched by the spray and snow; we had been fifty-six hours without rest, and forty-eight at work in the boats, so that by the time they were unloaded we had barely strength to haul them up on the rocks. However, by dint of great exertion, we managed to get the boats above the surf, after which, a hot supper, a blazing fire of drift-wood, and a few hours' quiet rest restored us." He who laments over the degeneracy of the human race, and supposes it to have been more vigorous or endowed with greater powers of endurance in ancient times, may perhaps come to a different opinion when reading of Parry and his companions.

Thus ended the last of this great navigator's Arctic voyages. Born in the year 1790, of a family of seamen, Parry at an early age devoted himself, heart and soul, to the profession in which his father had grown old. In his twentyeighth year he discovered Melville Island, and his subsequent expedition confirmed the excellent reputation he had acquired by his first brilliant success. From the years 1829 to 1834 we find him in New South Wales, as Resident Commissioner of the Australian Agricultural Company. In the year 1837 he was appointed to organize the mail-packet service, then transferred to the Admiralty, and after filling the post of Captain Superintendent of the Royal Naval Hospital at Haslar, was finally appointed Governor of Greenwich Hospital. $\mathrm{He}$ died in the summer of 1855 at Ems.

Ten years had elapsed since Captain John Ross's first unsuccessful voyage, when the veteran seaman, anxious to obliterate the reproach of former failure by some worthy achievement, was enabled, through the munificence of Sir Felix Booth, to accomplish his wishes. A small Liverpool steamer, bearing the rather presumptuous name of the "Victory," was purchased for the voyage, a rather unfortunate selection, for surely nothing can be more unpractical than paddleboxes among ice-blocks; but to make amends for this error, the commander of the expedition was fortunate in being accompanied by his nephew, Commander James Ross, who, with every quality of the seaman, united the zeal of an able naturalist. He it was who, by his well-executed sledge journeys, made the chief discoveries of the expedition; but the voyage of the "Victory" is far less remarkable for successes achieved than for its unexampled protraction during a period of five years.

The first season ended well. On August 10, 1829, the "Victory" entered Prince Regent's Inlet, and reached on the 13th the spot where Parry, on his third voyage, had been obliged to abandon the "Fury." The ship itself had been swept away; but all her sails, stores, and provisions on land were found untouched. The hermetically sealed tin canisters in which the flour, meat, bread, wine, spirits, sugar, etc., were packed had preserved them from the attacks of 
the white bears, and they were found as good after four years as they had been on the day when the "Fury" started on her voyage. It was to this discovery that the crew of the "Victory" owed their subsequent preservation, for how else could they have passed four winters in the Arctic wastes?

On August 15 Cape Garry was attained, the most southern point of the inlet which Parry had reached on his third voyage. Fogs and drift-ice greatly retarded the progress of the expedition, but Ross moved on, though slowly, so that about the middle of September the map of the northern regions was enriched by some 500 miles of newly-discovered coast. But now, at the beginning of winter, the "Victory" was obliged to take refuge in Felix Harbor, where the useless steam-engine was thrown overboard as a nuisance, and the usual preparations made for spending the cold season as pleasantly as possible.

The following spring (from May 17 to June 13) was employed by James Ross on a sledge journey, which led to the discovery of King William's Sound and King Wiiliam's Land, and during which that courageous mariner penetrated so far to the west that he had only ten days' provisions-scantily measured out-for a return voyage of 200 miles through an empty wilderness.

After twelve months' imprisonment, the "Victory" was released from the ice on September 17, and proceeded once more on her discoveries. But the period of her liberty was short, for, after advancing three miles in one continual battle against the currents and the drift-ice, she again froze fast on the 27th of the same month.

In the following spring we again see the indefatigable James Ross extending the circle of his sledge excursions, and planting the British flag on the site of the Northern Magnetic Pole-which, however, is not invariably fixed to one spot, as was then believed, but moves from place to place within the glacial zone.

On August 28, 1831, the "Victory"-after a second imprisonment of eleven months-was warped into open water; but after spending a whole month to advance four miles, she was encompassed by the ice on September 27, and once more fettered in the dreary wilderness.

As there seemed no prospect of extricating her next summer, they resolved to abandon her and travel over the ice to Fury Beach, there to avail themselves of the boats, provisions, and stores, which would assist them in reaching Davis's Straits. Accordingly, on May 29, 1832, the colors of the "Victory" were hoisted and nailed to the mast, and after drinking a parting glass to the ship with the crew, and having seen every man out in the evening, the captain took his own leave of her. "It was the first vessel," says Ross, " that I had ever been obliged to abandon, after having served in thirty-six, during a period of forty-two years. It was like the last parting with an old friend, and I did not pass the point where she ceased to be visible without stopping to take a sketch of this melancholy desert, rendered more melancholy by the solitary, abandoned, helpless home of our past years, fixed in immovable ice, till time should perform on her his usual work."

After having, with incredible difficulty, reached Fury Beach, where, thanks to the forethought of Sir Edward Parry, they fortunately found a sufficient num- 
ber of boats left for their purpose, and all the provisions in good condition, they set out on August 1-a considerable extent of open sea being visible-and after much buffeting among the ice, reached the north of the inlet by the end of the month. But here they were doomed to disappointment, for, after several fruitless attempts to run along Barrow's Strait, the ice obliged them to haul their boats on shore and pitch their tents. Day after day they lingered till the third week in September, but the strait continuing one impenetrable mass of ice, it was unanimously agreed that their only resource was to fall back again on the stores at Fury Beach, and there spend a fourth long winter within the Arctic Circle. They were only able to get half the distance in the boats, which were hauled on shore in Batty Bay on September 24, and performed the rest of their journey on foot, the provisions being dragged in sledges. On October 7 they once more reached the canvas hut, dignified with the name of "So.nerset House," which they had erected in July on the scene of the "Fury's" wreck, and which they had vainly hoped never to see again.

They now set about building a snow-wall four feet thick round their dwelling, and strengthening the roof with spars, for the purpose of covering it with snow, and by means of this shelter, and an additional stove, made themselves tolerably comfortable, until the increasing severity of the cold and the furious gales confined them within-doors, and sorely tried their patience. Scurvy now began to appear, and several of the men fell victims to the scourge. At the same time, cares for the future darkened the gloom of their situation; for, should they be disappointed in their hopes of escaping in the ensuing summer, their failing strength and diminishing stores gave them but little hope of surviving another year.

It may easily be imagined how anxiously the movements of the ice were watched when the next season opened, and with what beating hearts they embarked at Batty Bay on August 15. Making their way slowly among the masses of ice with which the inlet was encumbered, they to their great joy found, on the 17th, the wide expanse of Barrow's Strait open to navigation.

Pushing on with renewed spirits, Cape York soon lay behind them, and, alternately rowing and sailing, on the night of the 25th they rested in a good harbor on the eastern shore of Navy Board Inlet. At 4 o'clock on the follow. ing morning they were roused from their slumber by the joyful intelligence of a ship being in sight, and never did men more hurriedly and energetically set out; but the elements were against them, and the ship disappeared in the distant haze.

After a few hours' suspense, the sight of another vessel lying to in a calm relieved their despair. This time their exertions were successful, and, strange to say, the ship which took them on board was the same "Isabella"-now reduced to the rank of a private whaler-in which Ross had made his first voyage to the Arctic Seas.

The seamen of the "Isabella" told him of his own death-of which all England was persuaded-and could hardly believe that it was really he and his party who now stood before them. But when all doubts were cleared away, the rigging was instantly manned to do them honor, and thundering cheers wel- 
comed Ross and his gallant band on board! The scene that now followed can not be better told than in Ross's own words.

"Though we had not been supported by our names and characters, we should not the less have claimed from charity the attentions that we received; for never was seen a more miserable set of wretches. Unshaven since I know not when, dirty, dressed in rags of wild beasts, and starved to the very bones, our gaunt and grim looks, when contrasted with those of the well-dressed and well-fed men around us, made us all feel (I believe for the first time) what we really were, as well as what we seemed to others. But the ludicrous soon took the place of all other feelings; in such a crowd and such confusion, all serious thought was impossible, while the new buoyancy of our spirits made us abundantly willing to be amused by the scene which now opened. Every man was hungry, and was to be fed; all were ragged, and were to be clothed; there was not one to whom washing was not indispensable, nor one whom his beard did not $\mathrm{de}_{1}$ rive of all human semblance. All, every thing too, was to be done at once: it was washing, dressing, shaving, eating, all intermingled: it was all the materials of each jumbled together, while in the midst of all there were interminable questions to be asked and answered on both sides; the adventures of the 'Victory,' our own escapes, the politics of England, and the news, which was now four years old. But all subsided into peace at last. The sick were accommodated, the seamen disposed of, and all was done for us which care and kindness could perform. Night at length brought quiet and serious thoughts, and I trust there was not a man among us who did not then express where it was due his gratitude for that interposition which had raised us all from a despair which none could now forget, and had brought us from the borders of a most distant grave to life, and friends, and civilization. Long accustomed, however, to a cold bed on the hard snow or the bare rocks, few could sleep amidst the comfort of our new accommodations. I was myself compelled to leave the bed which had been kindly assigned me, and take my abode in a chair for the night; nor did it fare much better with the rest. It was for time to reconcile us to this sudden and violent change, to break through what had become habit, and to inure us once more to the usages of our former days."

The "Isabella" remained some time longer in Baffin's Bay to prosecute the fishery, and thus our Arctic voyagers did not return to England before October 15,1833 , when they were received as men risen from the grave. Wherever Ross appeared, he was met and escorted by a crowd of sympathizers; orders, medals, and diplomas from foreign states and learned societies rained down upon him. London, Liverpool, Bristol, and Hull presented him with the freedom of their respective cities; he received the honor of knighthood; and, though last, not least, Parliament granted him $£ 5000$ as a remuneration for his pecuniary outlay and privations.

It may easily be imagined that his long-protracted absence had not been allowed to pass without awakening a strong desire to bring him aid and assistance. Thus, when Captain (afterwards Rear-admiral Sir George) Back, that noble Paladin of Arctic research, volunteered to lead a land expedition in quest of Ross to the northern shore of America, $£ 4000$ were immediately raised by 
public subscription to defray expenses. While deep in the American wilds, Back was gratified with the intelligence that the object of his search had safely arrived in England; but, instead of returning home, the indefatigable explorer resolved to trace the unknown course of the Thlu-it-scho, or Great Fish River, down to the distant outlet where it pours its waters into the Polar Seas.

It would take a volume to relate his adventures in this expedition, the numberless falls, cascades, and rapids that obstructed his progress; the storms and snow-drifts, the horrors of the deserts through which he forced his way, until he finally (July 28) reached the mouth of the Thlu-it-scho, or, rather, the broad estuary through which it disembogues itself into the Polar Sea. His intention was to proceed to Point Turnagain, but the obstacles were insurmountable, even by him. For ten days the exploring party had a continuation of wet, chilly, foggy weather, and the only vegetation (fern and moss) was so damp that it would not burn; being thus without fuel, they had only during this time one hot meal. Almost without water, without any means of warmth, and sinking knee-deep as they proceeded on land, in the soft slush and snow, no wonder that some of the best men, benumbed in their limbs, and dispirited by the prospect before them, broke out for a moment in murmuring at the hardness of their inty.

O: 1 1n wnst 15 , seeing the impossibility of proceeding even a single mile farther, $5.1 \%$ anded the men around him, and unfurling the British flag, which was suluta : with three cheers, he announced to them his determination to retim. 'Tle dificulties of the river were of course doubled in the ascent, from having to ang ainst the stream. All the obstacles of rocks, rapids, sand-banks, and lo:1 portages had to be faced. They found, as they went on, that many of tire depusits of provisions, on which they relied, had been destroyed by wolves. After thus toiling on for six weeks, they were ultimately stopped by one most formidable perpendicular fall, which obliged them to abandon their boat; and proceeding on foot-each laden with a pack of about 75 lbs. weight - they ultimately arrived at their old habitation, Fort Reliance, after an absence of nearly four months, exhausted and worn out, but justly proud of having accomplished so difficult and dangerous a voyage.

The Fish River has since been named Back's River, in honor of its discoverer ; and surely no geographical distinction has ever been more justly merited.

This indefatigable explorer had scarcely returned to England (Sept. 8, 1835), when he once more set out on his way to the Arctic regions; but his ship, the "Terror," was so disabled by the ice that she was scarcely able to accomplish the return voyage across the Atlantic, without allowing her to make any new discoveries.

The land expedition sent out by the Hudson's Bay Company (1837-39), under the direction of Peter Warren Dease, one of their chief factors, and Mr. Thomas Simpson, proved far more successful. Descending the Mackenzie to the sea, they surveyed, in July, 1837, that part of the northern coast of America which had been left unexamined by Franklin and Elson in 1825, from Return Reef to Cape Barrow.

Although it was the height of summer, the ground was found frozen several 
inches below the surface, and the spray froze on the oars and rigging of their boats, which the drift-ice along the shore ultimately obliged them to leave behind.

As they went onward on foot, heavily laden, the frequent necessity of wading up to the middle in the ice-cold water of the inlets, together with the constant fogs and the sharp north wind, tried their powers of endurance to the utmost; but Simpson, the hero of the expedition, was not to be deterred by any thing şhort of absolute impossibility; nor did he stop till he had reached Point Barrow. Indeed, no man could be more fit than he to lead an expedition like this, for he had once before travelled 2000 miles on foot in the middle of winter from York Factory to Athabasca, walking sometimes not less than fifty miles in one day, and without any protection against the cold but an ordinary cloth mantle.

After wintering at Fort Confidence, on Great Bear Lake, the next season was profitably employed in descending the Coppermine River, and tracing nearly 140 miles of new coast beyond Cape Turnagain, the limit of Franklin's survey in 1821. The third season (1839) was still more favored by fortune, for Simpson succeeded in discovering the whole coast beyond Cape Turnagain as far as Castor and Pollux River (August 20, 1839), on the eastern side of the vast arm of the sea which receives the waters of the Great Fish River. On his return voyage, he traced sixty miles of the south coast of King William's Islancr, and a considerable part of the high, bold shores of Victoria Land, and reached Fort Confidence on September 24, after one of the longest and most successful boat voyages ever performed in the Polar waters, having traversed more than 1600 miles of sea.

Unfortunately he was not destined to reap the rewards of his labor, for in the following year, while travelling from the Red River to the Mississippi, where he intended to embark for England, he was assassinated by his Indian guides; and thus died, in the thirty-sixth year of his age, one of the best men that have ever served the cause of science in the frozen north.

On May 26, 1845, Sir John Franklin, now in the sixtieth year of his age, and Captain Crozier, sailed from England, to make a new attempt at the north-west passage. Never did stouter vessels than the "Erebus" and "Terror," welltried in the Antarctic Seas, carry a finer or more ably commanded crew; never before had human foresight so strained all her resources to insure success; and thus, when the commander's last dispatches from the Whalefish Islands, Baffin's Bay (July 12), previous to his sailing to Lancaster Sound, arrived in England no one doubted but that he was about to add a new and brilliant chapter to the history of Arctic discovery.

His return was confidently expected towards the end of 1847 ; but when the winter passed and still no tidings came, the anxiety at his prolonged absence became general, and the early part of 1848 witnessed the beginning of a series of searching expeditions fitted out at the public cost or by private munificence, on a scale exceeding all former examples. The "Plover" and the "Herald" (1848) were sent to Bering's Straits to meet Franklin with supplies, should he sucized in getting thither. In spring Sir John Richardson hurried to the shores 
of the Polar Sea, anxious to find the traces of his lost friend. He was accompanied by Dr. Rae, who had just returned from the memorable land expedition (1846-47), during which, after crossing the isthmus which joins Melville Peninsula to the mainland, he traced the shores of Committee Bay and the east coast of Boothia as far as the Lord Mayor's Bay of Sir John Ross, thus proving that desolate land to be likewise a vast peninsula.

But in vain did Rae and Richardson explore all the coasts between the Mackenzie and the Coppermine. The desert remained mute; and Sir James Ross ("Enterprise") and Captain Bird ("Investigator"), who set sail in June, 1848, three months after Dr. Richardson's departure, and minutely examined all the shores near Barrow Strait, proved equally unsuccessful.

Three years had now passed since Franklin had been expected home, and even the most sanguine began to despair; but to remove all doubts, it was resolved to explore once more all the gulfs and channels of the Polar Sea. Thus in the year 1850 no less than twelve ships sailed forth, some to Bering's Straits, some to the sounds leading from Baffin's Bay.* Other expeditions followed in 1852 and 1853, and though none of them succeeded in the object of their search, yet they enriched the geography of the Arctic World with many interesting discoveries, the most important of which I will now briefly mention.

Overcoming the ice of Baffin's Bay by the aid of their powerful steam-tugs, Austin, Ommaney, and Penny reached the entrance of Lancaster Sound. Here they separated, and while the "Resolute" remained behind to examine the neighborhood of Pond's Bay, Ommaney found at Cape Riley (North Devon) the first traces of the lost expedition. He was soon joined by Ross, Austin, Penny, and the Americans, and a minute investigation soon proved that Cape Spencer and Beechey Island, at the entrance of Wellington Channel, had been the site of Franklin's first winter-quarters, distinctly marked by the remains of a large storehouse, staves of casks, empty pemmican-tins, and, most touching relic of all, a little garden shaped into a neat oval by some flower-loving sailor, and filled with the few hardy plants which that bleak clime can nourish. Meanwhile winter approached, and little more could be done that season; so all the vessels which had entered Barrow's Strait now took up their winter-quarters at the southern extremity of Cornwallis Land; with the exception of the "Prince Albert," which set sail for England before winter set in, and of the Americans,

\footnotetext{
* 1850-1854. " "Investigator," Captain M'Clure, ?

1850-1855. " "Enterprise," Captain Collinson, $\zeta$

$\left.\begin{array}{l}\text { 1850 1851. "Resolute," Captain Austin, } \\ \text { 1850, 1851. "Assistance," Captain Ommaney, }\end{array}\right\}$ Lancaster Strait and Cornwallis Island.

Accompanied by two steam tenders, officered by Lieutenant Sherard Osborne and Lieutenant F. L. M'Clintock.

1850, 1851. "Lady Franklin," Master Penny, accompanied by the "Sophia," Master A. Stewart, under Admiralty Orders, to Lancaster Strait and Wellington Channel.

1850. "Prince Albert," Captain Forsyth, belonging to Lady Franklin, to Regent's Inlet and Beechey Island.

1850 1851. " "Advance," Lieutenant De Haven, U.S.N.)

1850, 1851. " "Rescue,"S. P. Griffin, Esq., U.S.N. S

Fitted at the expense of H. Grinnell, Esq., of New York, to Lancaster Strait and Wellington Channel.
} 
who, perceiving the impolicy of so many ships pressing to the westward on one parallel, turned back, but were soon shut up in the pack-ice, which for eight long months kept them prisoners. The "Rescue" and "Advance" were drifted backward and forward in Wellington Channel until in December a terrific storm drove them into Barrow's Strait, and still farther on into Lancaster Sound. Several times during this dreadful passage they were in danger from the ice opening round them and closing suddenly again, and only escaped being "nipped" by their small size and strong build, which enabled them to rise above the opposing edges instead of being crushed between them. Even on their arrival in Baffin's Bay the ice did not release them from its hold, and it was not till June 9, 1851, that they reached the Danish settlement at Disco. After recruiting his exhausted crew, the gallant De Haven determined to return and prosecute the search during the remainder of the season; but the discouraging reports of the whalers induced him to change his purpose, and the ships and crews reached New York at the beginning of October, having passed through perils such as few have endured and still fewer have lived to recount.

Meanwhile the English searching expeditions had not remained inactive. As soon as spring came, well-organized sledge expeditions were dispatched in all directions, but they all returned with the same invariable tale of disappointment.

As soon as Wellington Channel opened, Penny boldly entered the ice-lanes with a boat, and, after a series of adventures and difficulties, penetrated up Queen's Channel as far as Baring Island and Cape Beecher, where, most reluctantly, he was compelled to turn back.

A fine open sea stretched invitingly away to the north, but his fragile boat was ill-equipped for a voyage of discovery. Fully persuaded that Franklin must have followed this route, he failed, however, in convincing Captain Austin of the truth of his theory, and as, without that officer's co-operation, nothing could be effected, he was compelled to follow the course pointed out by the Admiralty squadron, which, after two ineffectual attempts to enter Smith's and Jones's Sounds, returned to England.

The "Prince Albert" having brought home in 1850 the intelligence of the discoveries at Beechey Island, it was resolved to prosecute the search during the next season, and no time was lost to refit the little vessel and send her once more on her noble errand, under the command of William Kennedy (1851-52), to examine Prince Regent's Inlet, on the coast of North Somerset. Finding the passage obstructed by a barrier of ice, Kennedy was obliged to take a temporary refuge in Port Bowen, on the eastern shore of the inlet. As it was very undesirable, however, to winter on the opposite coast to that along which lay their line of search, Kennedy, with four of his men, crossed to Port Leopold, amid masses of ice, to ascertain whether any documents had been leit at this point by previous searching parties. None having been found, they prepared to return; but to their dismay they now tound the inlet so blocked with ice as to render it absolutely impossible to reach the vessel either by boat or on foot. Darkness was fast closing round them, the ice-floe on which they stood threatened every instant to be shivered in fragments by the contending ice-blocks which 
crashed furiously against it: unless they instantly returned to shore, any moment might prove their last. A bitter cold night (September 10, 1851), with no shelter but their boat, under which each man in turn took an hour's rest-the others, fatigued as they were, seeking safety in brisk exercise-was spent on this inhospitable shore, and on the following morning they discovered that the ship had disappeared. The drift-ice had carried her away, leaving Kennedy and his companions to brave the winter as well as they could, and to endeavor in the spring to rejoin their vessel, which must have drifted down the inlet, and was most likely by this time imprisoned by the ice. Fortunately a dépôt of provisions, left by Sir James Ross at Whaler Point, was tolerably near, and finding all in good preservation, they began to fit up a launch, which had been left at the same place as the stores, for a temporary abode. Here they sat, on October 17, round a cheerful fire, manufacturing winter garments and completely resigned to their lot, when suddenly, to their inexpressible joy, they heard the sound of well-known voices, and Lieutenant Bellot, the second in command of the "Prince Albert," appeared with a party of seven men. Twice before had this gallant French volunteer made unavailing attempts to reach the deserted party, who soon forgot their past misery as they accompanied their friends back to the ship. In the following spring Kennedy and Bellot explored North Somerset and Prince of Wales' Land, traversing with their sledge 1100 miles of desert, but without discovering the least traces of Franklin or his comrades. Yet in spite of these frequent disappointments the searching expeditions were not given over, and as Wellington Channel and the sounds to the north of Baffin's Bay appeared to offer the best chances, the spring of 1852 witnessed the departure of Sir Edward Belcher and Captain Inglefield* for those still unknown regions.

The voyage of the latter proved one of the most successful in the annals of Arctic navigation. Boldly pushing up Smith's Sound, which had hitherto baffled every research, Inglefield examined this noble channel as far as $78^{\circ} 30^{\prime} \mathrm{N}$. lat., when stormy weather drove him back. He next attempted Jones's Sound, and entered it sufficiently to see it expand into a wide channel to the northward.

The squadron which sailed under the command of Sir Edward Belcher was charged with the double mission of prosecuting the discoveries in Wellington Channel, and of affording assistance to Collinson and $\mathrm{M}^{\circ} \mathrm{Clure}$, who, it will be remembered, had sailed in 1850 to Bering's Straits.

At Beechey Island, where the "North Star" was stationed as dépôt-ship, the squadron separated, Belcher proceeding with the "Assistance" and the "Pioneer" up Wellington Channel, while Kellett, with the "Resolute" and "Intrepid," steered to the west. Scarcely had the latter reached his winter-quarters (September 7, 1852) at Dealy Island, on the south coast of Melville Island, when

\footnotetext{
* 1852. "Isabel," Capıain E. Inglefield. Lady Franklin's vessel.

1852-1854. "Assistance," Sir Edward Belcher, to Lancaster Sound, Wellington Channel. 1852-1854. " "Resolute," Captain Kellett, Lancaster Strait, Melville, and Banks's Island.

1852-1854: " "Pioneer," Lieutenant Sherard Osborne.

1852-1854. . "Intrepid," Captain M'Clintock.

1852-1854. "North Star," Captain Pullen.
} 
parties were sent out to deposit provisions at various points of the coast, for the sledge parties in the ensuing spring.

The difficulties of transport over the broken surface of the desert when denuded of snow may be estimated from the fact, that though the distance from the north to the south coast of Melville Island is no more than thirty-six miles in a direct line, Lieutenant $\mathbf{M}^{\prime}$ Clintock required no less than nineteen days to reach the Hecla and Griper Gulf. Similar difficulties awaited Lieutenant Mechan on his way to Liddon Gulf, but he was amply rewarded by finding at Winter Harbor dispatches from M'Clure, showing that, in April, 1851, the "Investigator" was lying in Mercy Bay, on the opposite side of Banks's Strait, and that consequently the north-west passage, the object of so many heroic efforts, was at last discovered.

On March 9, 1853, the ${ }^{66}$ Resolute" opened her spring campaign with Lieutenant Pym's sledge journey to Mercy Bay, to bring assistance to $\mathrm{M}^{\circ} \mathrm{Clure}$, or to follow his traces in case he should no longer be there.

A month later three other sledge expeditions left the ship. The one under $\mathrm{M}^{\circ} \mathrm{C}$ Clintock proceeded from the Hecla and Griper Gulf to the west, and returned after one hundred and six days, having explored 1200 miles of coast-a sledge journey without a parallel in the history of Arctic research, though nearly equalled by the second party under Lieutenant Mecham, which likewise started to the west from Liddon Gulf, and travelled over a thousand miles in ninety-three days. The third party, under Lieutenant Hamilton, which proceeded to the north-east towards the rendezvous appointed by Sir Edward Belcher the preceding summer, was the first that returned to the ship, but before its arrival another party had found its way to the "Resolute"-pale, worn, emaciated figures, slowly creeping along over the uneven ice. A stranger might have been surprised at the thundering hurrahs which hailed the ragged troop from a distance, or at the warm and cordial greetings which welcomed them on deck, but no wonder that $\mathrm{M}^{\circ} \mathrm{Clure}$ and his heroic crew were thus received by their fellow-seamen after a three year's' imprisonment in the ice of the Polar Sea.

On August 1, 1850, the "Investigator," long since separated from her consort, the "Enterprise," had met the "Herald" and "Plover "* at Cape Lisburne, beyond Bering's Straits, and now planged alone into the unknown wildernesses of the Arctic Ocean. She reached the coast of Banks's Land on September 6, discovered Prince Albert Land on the 9th, and then sailed up Prince of Wales' Strait, where, on October 9 , she froze in for the winter. In the same month, however, a sledge expedition was sent to the northern extremity of the strait, which established the fact of its communication with Parry Sound and Barrow's Strait. In the following July the "Investigator," though set free, was prevented from penetrating into the sound by impassable barriers of ice. Nothing now remained but to return to the southern extremity of the strait, and then to advance along the west coast of Banks's Land to the north. This course was followed with tolerable ease till August 20, when the ship was driven between the ice and the beach a little north of Prince Albert Cape. Here she lay in compar-

* These two vessels had been sent in the year 1847 to the Polar Sea beyond Bering's Straits, when they discovered the "Herald" and "Plover" Islands. 
ative safety till the 29 th, when the immense floe to which she was attached was raised edgeways out of the water, from the pressure of surrounding ice, and lifted perpendicularly some twenty-five feet. The slightest additional pressure would have thrown the delicately-poised vessel entirely over, but fortunately a large piece from underneath was rent away, and after one or two frightful oscillations the floe righted itself and drifted onward, bearing the ship unharmed upon its course.

During the succeeding month, every day brought its perils. Now forced ashore by the pressure of the ice, now hurried along amidst its inclosing masses, the adventurers, slowiy working their way along the north coast of Banks's Land, at length found refuge in a harbor to which the appropriate name of Mercy Bay was thankfully given. Here they spent two winters-the intervening summer having failed to release the ship. In the spring of 1853 Lieutenant Pym brought them the joyful news that the "Resolute" was not far off。 Such had been the adventures of $\mathbf{M}^{\circ} \mathrm{Clure}$ up to the moment when Kellett welcomed him on board.

Meanwhile neither the sledge parties of the "Resolute," nor those which Sir Edward Belcher had sent out in all directions from his first winter-quarters in Northumberland Sound ( $76^{\circ} 52^{\prime} \mathrm{N}$. lat.), on the west side of Grinnell Peninsula, had been able to discover the least traces of Franklin. The winter (1853-54) passed, and in the following April Lieutenant Mecham found in Prince of Wales' Strait, and later on Ramsay Island, at its southern outlet, documents from Collinson, bearing date August 27, 1852, and giving full intelligence of his proceedings since his separation from the "Investigator." While M'Clure was achieving in 1850 the discovery of the north-west passage, Collinson, having arrived in Bering's Straits later in the season, was unable to double Point Barrow. In 1851, however, he succeeded in getting round that projection, and pursuing the continental channel as easily as his precursor had done, followed him through Prince of Wales' Strait; but, though he penetrated a few miles farther into Melville Sound, he found no passage, and returning to the south end of the strait passed the winter of 1851-52 in Walker Bay. Next summer he carried his ship through Dolphin and Union Straits and Dease Strait to Cambridge Bay, where he spent his second winter (1852-53). His sledge parties explored the west side of Victoria Strait, but a deficiency of coals compelled him to return the way he came, instead of attempting to force a passage through the channel. He did not, however, get round Barrow Point on his return without passing a third winter on the northern coast of America.

On returning to the "Resolute," Lieutenant Mecham found all hands busy preparing to leave the ship, Sir E. Belcher having given orders to abandon her, as well as the "Assistance," "Pioneer," and "Intrepid," which had now been blocked up above a year in the ice, and had no chance of escaping.

Thus the summer of 1854 witnessed the return to England of the "North Star," with all those brave crews which had spent so many unavailing efforts, and in numerous boat and sledge excursions had explored so many known and unknown coasts in search of Franklin; and thus also $\mathrm{M}^{\prime} \mathrm{Clure}$ and his comrades, abandoning the "Investigator" in Mercy Bay, returned home through 
Davis's Straits, after having entered the Polar Ocean at the Strait of Bering. He had, however, been preceded by Lieutenant Cresswell and Mr. Wynniat, who, on an excursion to Beechey Island in the summer of 1858, had there met with and joined the "Phœnix," Captain Inglefield, who, accompanied by his friend Lieutenant Bellot, had conveyed provisions to Sir E. Belcher's squadron, and was about to return to England. During this expedition Bellot, whose many excellent qualities had made him a universal favorite, was unfortunately drowned by a fall into an ice-crevice during a sledge excursion. A stone monument erected before Greenwich Hospital reminds England of the gallant volunteer whose name is gloriously linked with that of Franklin in Arctic history.

Years had thus passed without bringing any tidings of the "Erebus" and "Terror" since the discovery of their first winter-quarters, until at last, in the spring of 1854 , Dr. Rae, of the Hudson's Bay Company, while engaged in the survey of the Boothian isthmus, fell in with a party of Esquimaux, who informaed him that in the spring of 1850 some of their countrymen on King William's Island had seen a party of white men making their way to the mainland. None of them could speak the Esquimaux language intelligibly, but by signs they gave them to understand that their ships had been crushed by ice, and that they were now going to where they expected to find deer to shoot. At a later date of the same season, but before the breaking up of the ice, the bodies of some thirty men were discovered or the continent a day's journey from Back's Great Fish River, and five on as island near it. Some of the bodies had been buried (probably those of the first victims of famine), some were in a tent, others under the boat which had been turned over to form a shelter, and several lay scattered about in different directions. Of those found on the island, one was supposed to have been an officer, as he had a telescope strapped over his shoulder, and his double-barrelled gun lay underneath him. The mutilated condition of several of the corpses and the contents of the kettles left no doubt that our wretched countrymen had been driven to the last resource of cannibalism, as a means of prolonging existence. Some silver spoons and forks, a round silver plate, engraved "Sir John Franklin, K.C.B.," a star or order, with the motto, "Nec aspera terrent," which Dr. Rae purchased of the Esquimaux, corroborated the truth of their narrative.

Thus it was now known how part of the unfortunate mariners had perished, but the fate of the expedition was still enveloped in mystery. What had become of the ships and of the greater part of their crews? And was Franklin one of the party seen by the Esquimaux, or had an earlier death shortened his sufferings?

To solve at least this mournful secret-for every hope that he might still be alive had long since vanished-his noble widow resolved to spend all her available means-since Government would no longer prosecute the searchand with the assistance of her friends, but mostly at her own expense, fitted out a small screw steamer, the "Fox," which the gallant M'Clintock, already distinguished in perilous Polar voyages, volunteered to command. Another Arctic officer, Lieutenant Hobson, likewise came forward to serve without pay.

At first it seemed as if all the elements had conspired against the success of 
this work of piety, for in the summer of 1857 the floating ice off Melville Bay, on the coast of Greenland, seized the "Fox," and after a dreary winter, various narrow escapes, and eight months of imprisonment, carried her back nearly 1200 geographical miles, even to $63 \frac{1}{2}^{\circ} \mathrm{N}$. lat. in the Atlantic.

At length, on April 25, 1858, the "Fox" got free, and, having availed herself of the scanty stores and provisions which the small Danish settlement of Holstenburg afforded, sailed into Barrow Strait. Finding Franklin Channel obstructed with ice, she then turned back, and steaming up Prince Regent's Inlet, arrived at the eastern opening of Bellot's Strait. Here the passage to the west was again found blocked with ice, and after five ineffectual attempts to pass, the "Fox" at length took up her winter-quarters in Port Kennedy, on the northern side of the strait.

On his first sledge excursion in the following spring, $\mathrm{M}^{\prime} \mathrm{Clintock}$ met at Cape Victoria, on the south-west coast of Boothia, with a party of Esquimaux, who informed him that some years back a large ship had been crushed by the ice out in the sea to the west of King William's Island, but that all the people landed safely.

Meeting with the same Esquimaux on April 20, he learned, after much anxious inquiry, that besides the ship which had been seen to sink in deep water, a second one had been forced on shore by the ice, where they supposed it still remained, but much broken. They added that it was in the fall of the yearthat is, August or September-when the ships were destroyed; that all the white people went away to the Great Fish River, taking a boat or boats with them, and that in the following winter their bones were found there.

These first indications of the fate of Franklin's expedition were soon followed by others. On May $7 \mathrm{M}^{\circ}$ Clintock heard from an old Esquimaux woman on King William's Island that many of the white men dropped by the way as they went to the Great River; that some were buried, and some were not. They did not themselves witness this, but discovered their bodies during the winter following.

Visiting the shore along which the retreating crews must have marched, he came, shortly after midnight of May 25, when slowly walking along a gravel ridge near the beach, which the winds kept partially bare of snow, upon a human skeleton, partly exposed, with here and there a few fragments of clothing appearing through the snow.

"A most careful examination of the spot," says M'Clintock, "was of course made, the snow removed, and every scrap of clothing gathered up. A pocketbook, which being frozen hard could not be examined on the spot, afforded strong grounds for hope that some information might be subsequently obtained respecting the owner, and the march of the lost crews. The victim was a young man, slightly built, and perhaps above the common height; the dress appeared to be that of a steward. The poor man seems to have selected the bare ridge top, as affording the least tiresome walking, and to have fallen upon his face in the position in which we found him. It was a melancholy truth that the old woman spake when she said, "They fell down and died as they walked along.'" 
Meanwhile Lieutenant Hobson, who was exploring with another sledge party the north-western coast of King William's Land, had made the still more important discovery of a record giving a laconic account of the Franklin expedition up to the time when the ships were lost and abandoned. It was found on May 6 in a large cairn at Point Victory. It stated briefly that in 1845 the "Erebus" and "Terror" had ascended Wellington Channel to lat. $77^{\circ}$, and returned by the west side of Cornwallis Island to Beechey Island, where they spent the first winter. In 1846 they proceeded to the south-west, through Peel Sound and Franklin Sound, and eventually reached within twelve miles of the north extremity of King William's Land, when their progress was arrested by the ice. Sir John Franklin died on June 11, 1847, having completed-two months before his death - the sixty-first year of an active, eventful, and honorable life. On April 22, 1848, the ships were deserted, having been beset since September 12, 1846. The officers and crew, consisting of 105 souls, under the command of Captain Crozier, landed with the intention of starting for Back's Fish River, which, as we have seen, they were never destined to reach.

Quantities of clothing and articles of all kinds were found lying about the cairn, as if these men, aware that they were retreating for their lives, had then abandoned every thing which they considered superfluous.

Thus all doubts about Sir John Franklin's fate were at length removed. He at least had died on board his ship, and been spared the miserable end of his comrades as they fell one by one in the dreary wilderness.

The two wrecks have disappeared without leaving a trace behind. A single document, some coins and pieces of plate-this is all that remains of the gallant ships which so hopefully sailed forth under one of the noblest seamen that ever served in the navy of Great Britain.

It is a curious circumstance that Franklin's ships perished within sight of the headlands named Cape Franklin and Cape Jane Franklin by their discov. erer, Sir James Ross, eighteen years before. 


\title{
CHAPTER XXXIV.
}

\author{
KANE AND HAYES.
}

Kane sails up Smith's Sound in the "Advance" (18503).-Winters in Rensselaer Bay.-Sledye Journey along the Coast of Greenland. - The Three-brother Turrets. - Tennyson's Monument.-The Great Humboldt Glacier.-Dr. Hayes crosses Kennedy Channel. - Morton's Discovery of Washington Land.-Mount Parry.-Kane resolves upon a second Wintering in Rensselaer Bay.-Departure and Return of Part of the Crew.-Sufferings of the Winter.-The Ship abandoned.-Boat Journey to Upernavik._Kane's Death in the Havana (1857).-Dr. Hayes's Voyage in 1860.-He winters at Port Foulke.-Crosses Kennedy Channel.-Reaches Cape Union, the most northern known Land upon the Globe.-Koldewey.-Plans for future Voyages to the North Pole.

$\mathrm{I}^{\mathrm{N}}$ $\mathrm{N}$ point of dramatic interest, few of the Arctic expeditions can rival the second and last voyage of Dr. Kane, which, to avoid interrupting the narrative of the discovery of Franklin's fate by Dr. Rae and Sir James M'Clintock, I have refrained from mentioning in chronological order.

Weak in body, but great in mind, this remarkable man, who had accompanied the first Grinnell expedition in the capacity of surgeon, sailed from Boston in 1853, as commander of the "Advance," with a crew of 17 officers and men, to which two Greenlanders were subsequently added. His plan was to pass up Baffin's Bay to its most northern attainable point, and thence pressing on towards the pole as far as boats or sledges could reach, to examine the coastlines for vestiges of Franklin.

Battling with storms and icebergs, he passed, on August 7, 1853, the rocky portals of Smith's Sound, Cape Isabella and Cape Alexander, which had been discovered the year before by Inglefield; left Cape Hatherton-the extreme point attained by that navigator-behind, and after many narrow escapes from shipwreck, secured the "Advance" in Rensselaer Bay, from which she was destined never to emerge. His diary gives us a vivid account of the first winter he spent in this haven, in lat. $78^{\circ} 38^{\prime}$, almost as far to the north as the most northern extremity of Spitzbergen, and in a far more rigorous climate.

"Sept. $10,+14^{\circ} \mathrm{F}$.-The birds have left. The sea-swallows, which abounded when we first reached here, and even the young burgomasters that lingered after them, have all taken their departure for the south. The long " night in which no man can work" is close at hand; in another month we shall lose the sun. Astronomically, he should disappear on October 24, if our horizon were free; but it is obstructed by a mountain ridge; and, making all allowance for refraction, we can not count on seeing him after the 10 th.

"Sept. 11.-The long staring day, which has clung to us for more than two months, to the exclusion of the stars, has begun to intermit its brightness. Even Aldebaran, the red eye of the bull, flared out into familiar recollection as early as ten o'clock; and the heavens, though still somewhat reddened by the gaudy tints of midnight, gave us Capella and Arcturus, and even that lesser 
light of home memories, the polar star. Stretching my neck to look uncom. fortably at the indication of our extreme northernness, it was hard to realize that he was not directly overhead; and it made me sigh as I measured the few degrees of distance that separated our zenith from the pole over which he hung.

"Oct. 28.-The moon has reached her greatest northern declination of about $25^{\circ} 35^{\prime}$. She is a glorious object; sweeping around the heavens, at the lowest part of her curve, she is still $14^{\circ}$ above the horizon. For eight days she has been making her circuit with nearly unvarying brightness. It is one of those sparkling nights that bring back the memory of sleigh-bells and songs, and glad communings of hearts in lands that are far away.

"Nov. 7.-The darkness is coming on with insidious steadiness, and its advances can only be perceived by comparing one day with its fellow of some time back. We still read the thermometer at noonday without a light, and the black masses of the hills are plain for about five hours, with their glaring patches of snow; but all the rest is darkness. The stars of the sixth magnitude shine out at noonday. Except upon the island of Spitzbergen, which has the advantages of an insular climate, and tempered by ocean currents, no Christians have wintered in so high a latitude as this.* They are Russian sailors who made the encounter there-men inured to hardships and cold. Our darkness has ninety days to run before we shall get back again even to the contested twilight of to-day. Altogether our winter will have been sunless for one hundred and forty days.

"Nov. 9.-Wishing to get the altitude of the cliffs on the south-west cape of our bay before the darkness set in thoroughly, I started in time to reach them with my Newfoundlanders at noonday, the thermometer indicating $23^{\circ}$ below zero. Fireside astronomers can hardly realize the difficulties in the way of observations at such low temperatures. The breath, and even the warmth of the face and body, cloud the sextant-are and glasses with a fine hoar-frost. It is, moreover, an unusual feat to measure a base-line in the snow at $55^{\circ}$ below freezing.

"Nov. 21.-We have schemes innumerable to" cheat the monotonous solitude of our winter-a fancy ball; a newspaper, 'The Ice Blink;' a fox-chase round the decks.

"Dec. 15.-We have lost the last vestige of our midday twilight. We can not see print, and hardly paper; the fingers can not be counted a foot from the eyes. Noonday and midnight are alike; and, except a vague glimmer in the sky that seems to define the hill outlines to the south, we have nothing to tell us that this Arctic world of ours has a sun. In the darkness, and consequent inaction, it is almost in vain that we seek to create topics of thought, and, by a forced excitement, to ward off the encroachments of disease.

" $J a n .21$.-First traces of returning light, the southern horizon having for a short time a distinct orange tinge.

"Feb. 21.-We have had the sun for some days silvering the ice between the headlands of the bay, and to-day, towards noon, I started out to be the

* Rensselaer Harbor is situated $1^{\circ} 46^{\prime}$ higher than Sir E. Belcher's winter-quarters in Northumberland Sound, $76^{\circ} 52^{\prime}$ 。 
first of my party to welcome him back. It was the longest walk and toughes climb that I have had since our imprisonment, and scurvy and general debility have made me 'short o' wind.' But I managed to attain my object. I saw him once more, and upon a projecting crag nestled in the sunshine. It was like bath. ing in perfumed water."

Thus this terrible winter night drew to its end, and the time came for undertaking the sledge journeys, on which the success of the expedition mainly depended. Unfortunately, of the nine magnificent Newfoundlanders and the thirty-five Esquimaux dogs originally possessed by Kane, only six had survived an epizootic malady which raged among them during the winter: their number was, however, increased by some new purchases from the Esquimaux who visited the ship at the beginning of April.

Thus scantily provided with the means of transport, Kane, though in a very weak condition, set out on April 25, 1854, to force his way to the north. He found the Greenland coast beyond Rensselaer Bay extremely picturesque, the cliffs rising boldly from the shore-line to a height of sometimes more than a thousand feet, and exhibiting every freak and caprice of architectural ruin. In one spot the sloping rubbish at the foot of the coast-wall led up, like an artificial causeway, to a gorge that was streaming at noonday with the southern sun, while everywhere else the rock stood out in the blackest shadow. Just at the edge of this bright opening rose the dreamy semblance of a castle, flanked with triple towers, completely isolated and defined. These were called the "Threebrother Turrets."

"Farther on, to the north of latitude $79^{\circ}$, a single cliff of greenstone rears itself from a crumbled base of sandstone, like the boldly-chiselled rampart of an ancient city. At its northern extremity, at the brink of a deep ravine which has worn its way among the ruins, there stands a solitary column or minaret tower, as sharply finished as if it had been cast for the Place Vendôme. Yet the length of the shaft alone is 480 feet, and it rises on a pedestal, itself 280 feet high. I remember well the emotions of my party, as it first broke upon our view. Cold and sick as I was, I brought back a sketch of it which may have interest for the reader, though it scarcely suggests the imposing dignity of this magnificent landmark. Those who are happily familiar with the writings of Tennyson, and have communed with his spirit in the solitudes of a wilderness, will apprehend the impulse that inscribed the scene with his name."

But no rock formation, however striking or impressive, equalled in grandeur the magnificent glacier to which Kane has given the name of Humboldt. Its solid glassy wall, diminishing to a well-pointed wedge in the perspective, rises 300 feet above the water-level, with an unknown, unfathomable depth below it and its curved face sixty miles in length-from Cape Agassiz to Cape Forbes - vanishes into unknown space at not more than a single day's railroad travel from the pole.

In spite of the snow, which had so accumulated in drifts that the travellers were forced to unload their sledges and carry forward the cargo on their backs, beating a path for the dogs to follow in, Kane came in sight of the Great Gla- 
cier on May 4 ; but this progress was dearly earned, as it cost him the last remnant of his strength.

"I was seized with a sudden pain," says the intrepid explorer, " and fainted. My limbs became rigid, and certain obscure tetanoid symptoms of our winter enemy, the scurvy, disclosed themselves. I was strapped upon the sledge, and the march continued as usual, but my powers diminished so rapidly that I could not resist the otherwise comfortable temperature of $5^{\circ}$ below zero. My left foot becoming frozen caused a vexatious delay, and the same night it became evident that the immovability of my limbs was due to dropsical effusion. On the 5th, becoming delirious and fainting every time that I was taken from the tent to the sledge, I succumbed entirely. My comrades would kindly persuade me that, even had I continued sound, we could not have proceeded on our journey. The snows were very heavy, and increasing as we went; some of the drifts perfectly impassable, and the level floes often four feet deep in yielding snow.

"The scurvy had already broken out among the men, with symptoms like my own, and Morton, our strongest man, was beginning to give way. It is the reverse of comfort to me that they shared my weakness. All that I should remember with pleasurable feeling is that to my brave companions, themselves scarcely able to travel, I owe my preservation.

"They carried me back by forced marches. I was taken into the brig on the 14th, where for a week I lay fluctuating between life and death. Dr. Hayes regards my attack as one of scurvy, complicated by typhoid fever."

Fortunately summer was now fast approaching, with his cheering sunbeams and his genial warmth. The seals began to appear on the coast in large numbers, and there was now no want of fresh meat, the chief panacea against the scurvy. The snow-buntings returned to the ice-crusted rocks, and the gulls and eider-ducks came winging their way to their northern breeding-places.

Vegetation likewise sprang into life with marvellous rapidity, and the green sloping banks not only refreshed the eye, but yielded juicy, anti-scorbutic herbs.

Kane's health slowly but steadily improved. He was, however, obliged to give up all further sledge excursions for the season, and to leave the execution of his plans to his more able-bodied companions.

Thus Dr. Hayes, crossing the sound in a north-easterly direction, reached the opposite coast of Grinuell Land, which he surveyed as far as Cape Frazer in lat. $79^{\circ} 45^{\prime}$.

This journey was rendered uncommonly slow and tedions by the excessively broken and rugged character of the ice. Deep cavities filled with snow intervened between lines of hummocks frequently exceeding twenty or thirty feet in height. Over these the sledge had to be lifted by main strength, and it re quired the most painful efforts of the whole party to liberate it from the snow between them. Dr. Hayes returned on June 1, and a few days later Morton left the brig, to survey the Greenland coast beyond the Great Glacier. The difficulties were great, for, besides the usual impediments of hummocks, the lateness of the season had in many places rendered the ice extremely unsafe, or even entirely destroyed the ice-ledge along the shore. Thus for the last days of 
his onward journey he was obliged to toil over the rocks and along the beach of a sea which, like the familiar waters of the south, dashed in waves at his feet. Morton and his companion Hans, the Esquimaux, reached on June 26, 1854, Cape Constitution, a bold headland, where the surf rolled furiously against high overhanging cliffs, which it was found impossible to pass. Climbing from rock to rock, in hopes of doubling the promontory, Morton stood at this termination of his journey, and from a height of 300 feet looked out upon a great waste of waters, stretching to the unknown north. Numerous birds-sea-swallows, kittiwakes, brent-geese-mixed their discordant notes with the novel music of dashing waves; and among the flowering plants growing on the rocks was found a crucifer (Hesperis pygmoea), the dried pods of which, still containing seed, had survived the wear and tear of winter. From Cape Constitution the coast of Washington Land trended to the east, but far to the north-west, beyond the open waters of the channel, a peak, terminating a range of mountains similar in their features to those of Spitzbergen, was seen towering to a height of from 2500 to 3000 feet. This peak, the most remote northern land at that time known upon our globe, received the name of Mount Parry.

Meanwhile the short summer was wearing on, and, as far as the eye could reach, the ice remained inflexibly solid. It was evident that many days must still elapse before the vessel could possibly be liberated-but then most likely winter would almost have returned-a dismal prospect for men who knew by experience the long fearful night of the $79^{\circ}$ of latitude, and who, broken in health and with very insufficient supplies of provisions and fuel, were but ill armed for a second encounter. No wonder that many of Kane's companions thought it better to abandon the vessel than to tarry any longer in those frozen solitudes.

But though it was horrible to look another winter in the face, the resolution of Kane could not be shaken. On August 24, when the last hope of seeing the vessel once more afloat had vanished, he called the officers and crew together, and explained to them frankly the considerations which determined him to remain. To abandon the vessel earlier would have been unseemly, and to reach Upernavik so late in the season was next to impossible. To such of them, however, as were desirous of making the attempt, he freely gave his permission so to do, assuring them of a brother's welcome should they be driven back. $\mathrm{He}$ then directed the roll to be called, and each man to answer fo: himself. In result, eight out of the seventeen survivors of the party resolved to stand by the brig. The others left on the $28 \mathrm{th}$, with every appliance which the narrow circumstances of the brig could furnish to speed and guard them. When they disappeared among the hummocks, the stern realities of their condition pressed themselves with double force on those whom they left behind.

The reduced numbers of the party, the helplessness of many, the waning efficiency of all, the impending winter, with its cold, dark nights, the penury of their resources, the dreary sense of increased isolation-all combined to depress them. But their energetic leader, leaving them no time for these gloomy thoughts, set them actively to work to make the best possible preparations they could for the long cold night to come. 
He had carefully studied the Esquimaux, and determined that their form of habitations and their mode of diet, without their unthrift and filth, were the safest and best that could be adopted. The deck was well padded with moss and turf, so as to form a nearly cold-proof covering, and, down below, a space some eighteen feet square-the apartment of all uses-was inclosed and packed from floor to ceiling with inner walls of the same non-conducting material. The floor itself, after having been carefully caulked, was covered with Manilla oakum a couple of inches deep and a canvas carpet. The entrance was from the hold, by a low moss-lined tunnel, with as many doors and curtains to close it up as ingenuity could devise. Large banks of snow were also thrown up along the brig's sides to keep off the cold wind.

All these labors in the open air wonderfully improved the health of the exiles, and their strength increased from day to day. A friendly intercourse was opened with the Esquimaux of the winter settlements of Etah and Anoatok, distant some thirty and seventy miles from the ship, who, for presents of needles, pins, and knives, engaged to furnish walrus and fresh seal meat, and to show the white men where to find the game. Common hunting-parties were organized, visits of courtesy and necessity paid, and even some personal attachments established deserving of the name. As long as the Americans remained prisoners of the ice, they were indebted to their savage friends for invaluable counsel in relation to their hunting expeditions, and in the joint hunt they shared alike.

The Esquimaux gave them supplies of meat at critical periods, and they were able to do as much for them. In one word, without the natives, Kane and his companions would most likely have succumbed to the winter, and the Esquimaux on their part learned to look on the strangers as benefactors, and mourned their departure bitterly.

On December 12 the party which had abandoned the ship returned, having been unable to penetrate to the south, and was received, as had been prom. ised, with a brotherly welcome. They had suffered bitterly from the cold, want of food, and the fatigues of their march among the hummocks.

"The thermometer," says Kane, "was at $-50^{\circ}$; they were covered with rime and snow, and were fainting with hunger. It was necessary to use caution in taking them below; for, after an exposure of such fearful intensity and duration as they had gone through, the warmth of the cabin would have prostrated them completely. They had journeyed three hundred and fifty miles; and their last run from the bay near Etah, some seventy miles in a right line, was through the hummocks at this appalling temperature. One by one they all came in and were housed. Poor fellows! as they threw open their Esquimaux garments by the stove, how they relished the scanty luxuries which we had to offer them! The coffee, and the meat-biscuit soup, and the molasses, and the wheat bread, even the salt pork, which our scurvy forbade the rest of us to touch-how they relished it all! For more than two months they had lived on frozen seal and walrus meat."

Thus Kane, by his determination not to abandon the ship, proved the saviour of all his comrades; for what would have become of them had he been less firm 
in his resolution, or if his courage had failed him during the trials of that dreadful winter?

"February closes," says the heroic explorer; "thank God for the lapse of its twenty-eight days! Should the thirty-one of the coming March not drag us farther downward, we may hope for a successful close to this dreary drama. By April 10 we should have seals; and when they come, if we remain to welcome them, we can call ourselves saved. But a fair review of our prospects tells me that I must look the lion in the face. The scurvy is steadily gaining on us. I do my best to sustain the more desperate cases, but as fast as I partially build up one, another is stricken down. Of the six workers of our party, as I counted them a month ago, two are unable to do out-door work, and the remaining four divide the duty of the ship among them. Hans musters his remaining energies to conduct the hunt. Petersen is his disheartened, moping assistant. The other two, Bonsall and myself, have all the daily offices of household and hospital. We chop five large sacks of ice, cut six fathoms of eight-inch hawser into junks of a foot each, serve out the meat when we have it, hack at the molasses, and hew out with crowbar and axe the pork and dried apples; pass up the foul slop and cleansings of our dormitory, and, in a word, cook, scullionize, and attend the sick. Added to this, for five nights running I have kept watch from 8 P.M. to 4 A.M., catching such naps as I could in the day without changing my clothes, but carefully waking every hour to note thermometers."

With March came an increase of sufferings. Every man on board was tainted with scurvy, and there were seldom more than three who could assist in caring for the rest. The greater number were in their bunks, absolutely unable to stir. Had Kane's health given way, the whole party, deprived of its leading spirit, must inevitably have perished.

To abandon the ship was now an absolute necessity, for a third winter in Rensselaer Bay would have been certain death to all; but before the boats could be transported to the open water, many preparations had to be made, and most of the party were still too weak to move. The interval was employed by Kane in an excursion with his faithful Esquimaux to the Great Glacier.

At length on May 20, 1855, the entire ship's company bade farewell to the "Advance," and set out slowly on their homeward journey. It was in the soft, subdued light of a Sunday evening, June 17, that after hauling their boats with much hard labor through the hummocks, they stood beside the open sea-way. But fifty-six days had still to pass before they could reach the port of Upernavik. Neither storms nor drift-ice rendered this long boat-journey dangerous, but they had to contend with famine, when they at length reached the open bay, and found themselves in the full line of the great ice-drift to the Atlantic, in boats so unseaworthy as to require constant bailing to keep them afloat. Their strength had decreased to an alarming degree; they breathed heavily; their feet were so swollen that they were obliged to cut open their canvas boots; they were utterly unable to sleep, and the rowing and bailing became hourly more difficult.

It was at this crisis of their fortunes that they saw a large seal floating-as 
is the custom of these animals-on a small patch of ice, and seemingly asleep. "Trembling with anxiety," says Kane, "we prepared to crawl down upon him. Petersen, with a large English rifle, was stationed in the bow, and stockings were drawn over the oars as mufflers. As we neared the animal, our excitement became so intense that the men could hardly keep stroke. He was not asleep, for he reared his head when we were almost within rifle-shot; and to this day I can remember the hard, careworn, almost despairing expression of the men's thin faces as they saw him move; their lives depended on his capture. I depressed my hand nervously, as a signal for Petersen to fire. M'Gary hung upon his oar, and the boat slowly, but noiselessly surging ahead, seemed to me within certain range. Looking at Petersen, I saw that the poor fellow was paralyzed by his anxiety, trying vainly to obtain a rest for his gun against the cut-water of the boat. The seal rose on his fore flippers, gazed at us for a moment with frightened curiosity, and coiled himself for a plunge. At that instant, simultaneously with the crack of our rifle, he relaxed his long length on the ice, and, at the very brink of the water, his head fell helpless to one side. I would have ordered another shot, but no discipline could have controlled the men. With a wild yell, each vociferating according to his own impulse, they urged their boats upon the floes. A crowd of hands seized the seal and bore him up to safer ice. The men seemed half crazy. I had not realized how much we were reduced by absolute famine. They ran over the floe, crying and laughing, and brandishing their knives. It was not five minutes before every man was sucking his bloody fingers, or mouthing long strips of raw blubber. Not an ounce of this seal was lost."

Within a day or two another seal was shot, and from that time forward they had a full supply of food.

When Kane, after an absence of thirty months, returned on October 11, 1855 , to New York, he was enthusiastically received. Well-deserved honors of all sorts awaited him on both sides of the Atlantic; but his health, originally weak, was completely broken by the trials of his journey, and on February 16, 1857 , he died at the Havana, in the thirty-seventh year of his age. In him the United States lost one of her noblest sons, a true hero, whose name will ever shine among the most famous navigators of all times and of all nations.

In 1860, Dr. Hayes, who had accompanied Kane on his journey, once more sailed from America for the purpose of completing the survey of Kennedy's Channel, and, if possible, of pushing on to the pole itself. After several narrow escapes from ice-fields and icebergs, his schooner, the "United States," was at length compelled to take up her winter-quarters at Port Foulke, on the Greenland coast, about twenty miles in latitude to the south of Rensselaer Harbor. Thanks to an abundant supply of fresh meat (for the neighborhood abounded with reindeer), and also no doubt to the inexhaustible fund of good-humor which prevailed in the ship's company, they passed the winter without suffering from the scurvy; but most of the dogs on which Dr. Hayes relied for his sledge expeditions in the ensuing spring were destroyed by the same epidemic which had been so fatal to the teams of Dr Kane. Fortunately some fresh dogs could be purchased and borrowed of the friendly Esquimaux, and thus, 
early in April, 1861, Dr. Hayes left the schooner, to plunge into the icy wilderness. Having previously ascertained that an advance along the Greenland shore was utterly impossible, he resolved to cross the sound, and to try his fortunes along the coast of Grinnell Land. Of the difficulties which he had to encounter his own words will give the best idea.

"By winding to the right and left, and by occasionally retracing our steps when we had selected an impracticable route, we managed to get over the first few miles without much embarrassment, but farther on the tract was rough past description. I can compare it to nothing but a promiscuous accumulation of rocks closely packed together and piled up over a vast plain in great heaps and endless ridges, leaving scarcely a foot of level surface. The interstices between these closely accumulated ice-masses are filled up, to some extent, with drifted snow. The reader will readily imagine the rest. $\mathrm{He}$ will see the sledges winding through the tangled wilderness of broken ice-tables, the men and dogs pulling and pushing up their respective loads. He will see them clambering over the very summit of lofty ridges, through which there is no opening, and again descending on the other side, the sledge often plunging over a precipice, sometimes capsizing and frequently breaking. Again he will see the party baffled in their attempt to cross or find a pass, breaking a track with shovel and handspike, or again, unable even with these appliances to accomplish their end, they retreat to seek a better track; and they may be lucky enough to find a sort of gap or gateway, upon the winding and uneven surface of which they will make a mile or so with comparative ease. The snow-drifts are sometimes a help, and sometimes a hinderance. Their surface is uniformly hard, but not always firm to the foot. The crust frequently gives way, and in a most tiresome and provoking manner. It will not quite bear the weight, and the foot sinks at the very moment when the other is lifted. But, worse than this, the chasms between the hummocks are frequently bridged over with snow in such a manner as to leave a considerable space at the bottom quite unfilled; and at the very moment when all looks promising, down sinks one man to his middle, another to the neck, another is buried out of sight; the sledge gives way, and to extricate the whole from this unhappy predicament is probably the labor of hours. It would be difficult to imagine any kind of labor more disheartening, or which would sooner sap the energies of both men and animals. The strength gave way gradually; and when, as often happened after a long and hard day's work, we could look back from our eminence and almost fire a rifle-ball into our last snow-hut, it was truly discouraging."

No wonder that after thus toiling on for twenty-five days they had not yet reached half-way across the sound, and that they were all broken down. But their bold leader was fully determined not to abandon his enterprise while still the faintest hope of success remained, and, sending the main party back to the schooner, he continued to plunge into the hummocks with three picked companions-Jensen, M'Donald, Knorr-and fourteen dogs. After fourteen days of almost superhuman exertion the sound was at length crossed, and now began a scarcely less harassing journey along the coast. On the fifth day Jensen, the strongest man of the party, completely broke down, and leaving him to the 
charge of M'Donald, Dr. Hayes now pushed on with Knorr alone, until, on May 18 , he reached the border of a deep bay, where farther progress to the north was stopped by rotten ice and cracks. Right before him, on the opposite side of the frith, rose Mount Parry, the lofty peak first seen by Morton in 1854 from the shores of Washington Land; and farther on, a noble headland, Cape Union - the most northern known land upon the globe-stood in faint outline against the dark sky of the open sea. Thus Dr.Hayes divides the honor of extreme northern travel with Parry.

On July 12 the "United States" was released from her icy trammels, and Dr. Hayes once more attempted to reach the opposite coast and continue his discoveries in Grinnell Land, but the schooner was in too crippled a state to force her way through the pack-ice which lay in her course, and compelled her commander to return to Boston.

Thus ended this remarkable voyage; but having done so much, Dr. Hayes is eager, and resolved, to do still more. Fully convinced by his own experience that men may subsist in Smith's Sound independent of support from home, he proposes to establish a self-sustaining colony at Port Foulke, which may be made the basis of an extended exploration. Without any second party in the field to co-operate with him, and under the most adverse circumstances, he, by dint of indomitable perseverance, pushed his discoveries a hundred miles farther to the north and west than his predecessors; and it is surely not over-sanguine to expect that a party better provided with the means of travel may be able to traverse the 480 miles at least which intervene between Mount Parry and the pole. The open sea which both Morton and himself found beyond Kennedy Channel gives fair promise of success to a strong vessel that may reach it after having forced the ice-blocked passage of Smith's Sound, or, should this be impracticable, to a boat transported across the sound and then launched upon its waters.

Captain Sherard Osborne, who is likewise a warm partisan of this route, has been endeavoring to interest Government in its favor; but in the opinion of other scientific authorities an easier passage seems open to the navigator who may attempt to reach the pole by way of Spitzbergen. To the east of this urchipelago the Gulf Stream rolls its volume of comparatively warm water far on to the north-east, and possibly sweeps round the pole itself. It was to the north of Spitzbergen that Parry reached the latitude of $82^{\circ} 45^{\prime}$; and in 1837 the "Truclove," of Hull,* sailed through a perfectly open sea in $82^{\circ} 30^{\prime} \mathrm{N}$., $15^{\circ}$ E., and, had she continued her course, might possibly have reached the pole as easily as the high latitude which she had already attained.

The distinguished geographer, Dr. Augustus Petermann, who warmly advocates the route between Spitzbergen and Greenland, has, by dint of perseverance, succeeded in collecting among his countrymen the necessary funds for a reconnoitring voyage in this direction. Thanks to his exertions, May 24, 1868, witnessed the departure of a small ship of eighty tons, the "Germania," Captain Koldewey, from the port of Bergen, for Shannon Island ( $75^{\circ} 14^{\prime} \mathrm{N}$. lat.), the highest point on the east coast of Greenland attained by Sabine in 1823. Here the attempt to explore the unknown Arctic seas beyond was to begin; but, 
meeting with enormous masses of drift-ice on her repeated endeavors to penetrate to the north-east, the "Germania" has been obliged to return, after reaching the high latitude of $81^{\circ} 5^{\prime}$, and accurately surveying a small part of the Greenland coast hitherto but imperfectly explored. An expedition on a more extensive scale is to renew the attempt in 1869.

A third route to the pole is no less strenuously recommended by M. Gustave Lambert, a French hydrographer, who, having sailed through Bering's Strait in a whaler in 1865, is persuaded that this is the right way to reach the problematical open North Sea, which, once attained, promises a free passage to the navigator. Liberal subscriptions have been raised in Paris for the accomplishment of his plan, and an expedition under his command will most probably set out in 1869 .

Thus, after so many illustrious navigators have vainly endeavored to reach the pole, sanguine projectors are still as eager as ever to attain the goal; nor is it probable that man will ever rest in his efforts until every attainable region of the Arctic Ocean shall have been fully explored. 


\section{CHAPTER XXXV.}

\section{NEWFOUNDLAND.}

Its desolate Aspect._Forests._Marshes._Barrens._Ponds._Fur-bearing Animals._Severity of Climate.-St. John's. - Discovery of Newfoundland by the Scandinavians.-Sir Humphrey Gilbert. Rivalry of the English and French.-Importance of the Fisheries.-The Banks of Newfoundland.Mode of Fishing.-Throaters, Headers, Splitters, Salters, and Packers.-Fogs and Storms.-Sealcatching.

GENERALLY veiled with mists, Newfoundland appears at first sight G gloomy and repulsive. Abrupt cliffs, showing here and there traces of a scanty vegetation, rise steep and bare from the sea, and for miles and miles the eye sees nothing but brown hills or higher mountains, desolate and wild as they appeared in the eleventh century to the bold Norwegian navigators who first landed on its desert shore. The waves of the ocean have everywhere corroded the rocky coast into fantastic pinnacles or excavated deep grottoes in its flanks. In one of these cavities the action of the surge has produced a remarkable phenomenon, known under the name of "The Spout." In stormy weather the waves penetrate into the hollow and force their way with a dreadful noise from an aperture in the rock as a gigantic fountain visible at a distance of several miles.*

The interior of the country corresponds with the forbidding appearance of the coasts, and offers nothing but a succession of forests, marshes, and barrens. The forests, if they may thus be called, generally grow on the declivities of the hills or on the sides of the valleys, where the superfluous waters find a natural drain. The trees consist for the most part of fir, spruce, birch, pine, and juniper or larch; and in certain districts the wych-hazel, the mountain-ash, the elder, the aspen, and some others are found. The character of the timber varies greatly according to the nature of the subsoil and the situation. In some parts, more especially where the woods have been undisturbed by the axe, trees of fair height and girth may be found; but most of the wood is of stunted growth, consisting chiefly of fir-trees about twenty or thirty feet high, and not more than three or four inches in diameter. These commonly grow so closely together that their twigs and branches interlace from top to bottom, while among them may be seen innumerable old and rotten stumps and branches, or newly-fallen trees, which, with the young shoots and brushwood, form a tangled and often impenetrable thicket. The trees are often covered with lichens, and tufts of white dry moss are entangled about the branches. Other green and softer mosses spread over the ground, concealing alike the twisted roots of the standing trees and the pointed stumps of those which have fallen,

* For an account of the similar phenomena of the "Buffadero," on the Mexican coast, and of the "Souffleur," Mauritius, see "The Sea and its Living Wonders," 3d ed. p; 52. 
the sharp edges or slippery surface of the numerous rocks and boulders, and the holes and pitfalls between them. Every step through these woods is consequently a matter of great toil and anxiety. In the heat of summer, while the woods are so thick as to shut out every breath of air, they are at the same time too low and too thinly leaved at top to exclude the rays of the sun, the atmosphere being further rendered close and stifling by the smell of the turpentine which exudes from the trees.

Inclosed in these gloomy woods, large open tracts, called marshes, are found covering the valleys and lower lands, and frequently also at a considerable height above the sea on the undulating backs of the mountains. These tracts are covered to a depth sometimes of several feet with a green, soft, and spongy moss, bound together by straggling grass and various marsh-plants. The surface abounds in hillocks and holes, the tops of the hillocks having often dry crisp moss like that on the trees. A boulder or small crag of rock occasionally protrudes, covered with red or white lichens, and here and there is a bank on which the moss has become dry and yellow. The contrast of these colors with the dark velvety green of the wet moss frequently gives a peculiarly rich appearance to the marshes, so that when seen from a little distance they might easily be mistaken for luxuriant meadow-grounds, but a closer inspection soon destroys the illusion, and shows, instead of nutritious grass and aromatic flowers, nothing but a carpet of useless cryptogamic plants. Except in long-continued droughts or hard frosts, these marshes are so wet as to be unable to bear the weight of a person walking over them. A march of three miles, sinking at every step into the moss, sometimes knee-deep, and always as far as the ankle, is, it may well be supposed, toilsome and fatiguing, especially when, as must always be the case in attempting to penetrate the country, a heavy load is carried on the shoulders. This thick coating of moss is precisely like a great sponge spread over the country, and becomes at the melting of the snow in the spring thoroughly saturated with water, which it long retains, and which every shower of rain continually renews.

The "barrens" of Newfoundland are those districts which occupy the summits of the hills and ridges, and other elevated and exposed tracts. They are covered with a thin and scrubby vegetation, consisting of berry-bearing plants and dwarf bushes of various species, resembling the moorlands of the north of England, and differing only in the kind of vegetation and its scantier quantity. Bare patches of gravel and boulders and crumbling fragments of rock are frequently met with apon the barrens, and they are generally altogether destitute of vegetable soil. But only on the barrens is it possible to explore the interior of the country with any kind of ease or expedition. These different tracts are none of them of any great extent; woods, marshes, and barrens frequently alternating with each other in the course of a day's journey.

Another remarkable feature of Newfoundland is the almost incredible num. ber of lakes of all sizes, all of which are indiscriminately called ponds. They are scattered over the whole country, not only in the valleys but on the higher lands; and even in the hollows of the summits of the ridges and the very tops of the hills. They vary in size from pools of fifty yards in diameter to lakes up- 
ward of thirty miles long and four or five miles across. The number of those which exceed a couple of miles in extent must on the whole amount to several hundreds, while those of a smaller size are absolutely countless. It is supposed that a full third of the surface of the island is covered by fresh water, and this reckoning is rather below than above the mark. In a country so abundantly provided with lakes or ponds, it seems strange to find no navigable rivers. The undulating surface of the land, with its abrupt hills and deep gullies, is, without all doubt, one cause of this absence of larger streams.

Each pond or small set of ponds communicates with a valley of its own, down which it sends an insignificant brook, which takes the nearest course to the sea. The chief cause, however, both of the vast abundance of ponds and the comparative scantiness of the brooks, is to be found in the great coating of moss which spreads over the country, and retains the water like a sponge, allowing it to drain off but slowly and gradually.

The wilds of Newfoundland are tenanted by numerous fur-bearing animals, affording a great source of gain to some of the fishermen, who in winter turn furriers. Arctic foxes are here in all their variety. Beavers, once nearly extirpated, but now unmolested owing to the low value of their fur, are increasing in numbers. Brown bears are pretty numerous, and Polar bears sometimes find their way to the northern promontory of the island upon the ice which comes drifting down in spring from Davis's Straits. By way of contrast, in hot summers the tropical humming-bird has been known to visit the southern shores of Newfoundland. Reindeer are abundant, but unfortunately their enemies the wolves have likewise increased in number, since the reward given by the Colonial Government for their destruction has ceased to be paid.

Although in the same latitude as Central France and the south of Germany, Newfoundland has a long and severe winter, owing to the two vast streams of Arctic water, the Davis's Straits and East Greenland currents, which combine and run by its shores; and the summer, though sometimes intensely hot, is so short and so frequently obscured by fogs that, even were the soil less sterile, agriculture must necessarily be confined to narrow limits. The little wheat and barley, cultivated on the inside lands far above the sea-shore, is often cut green, and carrots, turnips, potatoes, and cabbages are nearly all the esculent vegetables which the land has been proved capable of producing.

Hence we can not wonder that the whole island, which is considerably larger than Scotland, has only about 90,000 inhabitants, and even these would have had no inducement to settle on so unpromising a soil if the riches of the sea did not amply compensate for the deficiencies of the land. Fish is the staple produce of Newfoundland, and the bulk of its population consists of poor fishermen, who have established themselves along the deep bays by which the coast is indented, and catch near the coast vast quantities of cod, which they bring in and cure at their leisure, in order to have it ready for the ships when they arrive. With the outer world they have little communication, and a visit to St. John's, the capital of the island, forms an epoch in their solitary lives.

This town lies at the head of a wide and secure bay, and consists of a main street fronting the water, from which narrow, dirty lanes and alleys branch out 
towards the land. The dingy, unpainted houses are built of wood, the Government edifices only being constructed of brick or stone. The long rows of fish-stages along the shore attract the stranger's attention, but he is still more astonished at the countless gin and beer shops, which at once tell him he is in a place where thirsty sailors and fishermen form the mass of the population. In the winter St. John's is comparatively deserted, as it then has no more than about 10,000 inhabitants, but their number is doubled or trebled during the fishing-season.

The island of Newfoundland, first seen and visited in the eleventh century by the Norse colonists of Greenland, and then utterly forgotten, was rediscovered in 1497 or 1498 by John and Sebastian Cabot.

The richness of its cod-fisheries soon attracted attention, and fishermen from Spain, France, Portugal, and England annually visited its banks. The best harbors along the coast were occupied by the first comers in spring-a circumstance which gave rise to frequent quarrels. To obviate this lawless state of affairs, Sir Humphrey Gilbert was sent out by Queen Elizabeth in 1583 to take possession of the land. He divided the coast about St. John's into districts, and the British settlers willingly agreed to pay a tax to Government in the expectation of seeing their interests better protected. The new arrangement had a beneficial effect on the trade of Newfoundland, for in 1615 more than 250 English vessels visited St. John's, and gradually the whole of the eastern coast of the island was occupied by English fishermen.

The French on their part colonized the north and south sides of the island, and founded the town of Placentia, once a very considerable place, but now reduced to insignificance. The rivalry of the French was naturally a great source of jealousy to a nation ill-accustomed to brook any foreign intrusion into its commercial interests. Thus, after the war of the Spanish succession, Great Britain demanded and obtained by the Treaty of Utrecht the sole possession of Newfoundland; and Louis XIV., anxious for peace on any terms, willingly acceded to this sacrifice, merely reserving for his subjects the right to dry on the shores of the island the fish they had caught on the banks. By the subsequent treaties of Paris the French were restricted to the small islands of St. Pierre and Miquelon, but not allowed to erect fortifications of any kind.

Besides the English and the French, the Americans also have the right to fish on the banks of Newfoundland; for when England acknowledged the independence of the United States, a formal article of the treaty of peace secured to the latter the fishing privileges which they had previously enjoyed as colonies.

The value of the dry codfish alone exported every year from Newfoundland is on an average about $£ 400,000$, while the total value of the exported productions in fish, oil, and skins is upward of $£ 700,000$. This, from a population of 80,000 or 90,000 , proves that the people of the island ought to be happy and prosperous; but unfortunately a system of credit renders the bulk of the fishermen entirely dependent on the merchants, and want of education is a further source of evil.

Though vast quantities of cod are taken along the shores of Newfoundland, 
yet the most important fishery is carried on on the banks at some distance from the island.

The Great Bank lies twenty leagues from the nearest point of land from latitude $41^{\circ}$ to $49^{\circ}$, and extends 300 miles in length and 75 in breadth. To the east of this lies the False Bank; the next is styled the Green Bank, about 240 miles long and 120 broad; then Banquero, about the same size, with several other shoals of less note, all abounding with fish, but chiefly with cod, the great magnet which sets whole fleets in motion. In winter the cod retire to the deeper waters, but they re-appear in March and April, when their pursuers hasten to the spot, not only from the bays and coves of Newfoundland, but from Great Britain, the United States, and France.

While fishing, each man has a space three feet and a half wide allotted to him on deck, so as not to interfere with his neighbor. The lines are from thirty to forty fathoms long-for the cod generally swims at that depth. The chief baits used are the squid, a species of cuttle-fish, and the capelin, a small salmon abounding on the North American coasts. The herring and the launce, and a shell-fish called clam, which is found in the belly of the cod, are likewise used. In spring particularly the cod rushes so eagerly upon the bait, that in the course of a single day a good fisherman is able to haul up four hundred, one after another. This is no easy task, considering the size of the fish, which on an average weighs fourteen pounds, but has been taken four feet three inches long, and forty-six pounds in weight. When a large fish, too heavy for the line, has been caught, the fisherman calls on his neighbor, who strikes a hook attached to a long pole into the fish, and then safely hauls it on board.

Mindful of the proverb which recommends us all to strike while the iron is hot, the fishermen continue to catch cod for hours, until so many are heaped on the deck that to make room it becomes necessary to "dress them down." This is done on long planks made to rest with both ends on two casks, and thus forming a narrow table. First, each man cuts out the tongues of the fish he has caught, as his wages are reckoned by their number, and then the whole crew divide themselves into throaters, headers, splitters, salters, and packers. The throater begins the operation of "dressing" by drawing his knife across the throat of the cod to the bone and ripping open the bowels. He then passes it to the header, who with a strong wrench pulls off the head and tears out the entrails, which he casts overboard, passing the fish at the same time to the splitter, who with one cut lays it open from head to tail, and almost in the twinkling of an eye with another cut takes out the backbone. After separating the sounds, which are placed with the tongues and packed in barrels as a delicacy, the backbone follows the entrails overboard, while the fish at the same moment is passed with the other hand to the salter. Such is the amazing quickness of the operations of heading and splitting, that a good workman will often decapitate and take out the entrails and backbone of six fish in a minute. Every fisherman is supposed to know something of each of these operations, and no rivals at cricket ever entered with more ardor into their work than do some athletic champions for the palm of "dressing down" after a "day's catch."

Generally the fog is so dense that one ship does not see the other, although 
both may be so near that the crews distinctly hear each other's voices. Frequently one is hardly able to see to the distance of a few feet, and the large drops of the condensed mist fall like rain from the yards. During calm weather the aspect of the sea is so dismal that it requires all the buoyant spirits of a seaman to resist its depressing influence. For days the calm remains unbroken, and no sound is heard but that of a fish darting out of the water, or the screech of a sea-bird flitting over the sea. But sometimes a storm breaks this awful silence of nature. At such times the fishing-ships, hidden in mists, run the greatest danger of striking against each other, although signal-lanterns and alarm-trumpets are used to give warning. A tremendous wave bursting on the deck often strikes them with such force as to sink them or dash them to pieces against the rocky coast. Thus many a widow and orphan has a mournful tale to relate of the dangers of the cod-fishery on the banks of Newfoundland.

In some parts of the coast where the water is sufficiently shallow the codfish are now caught in sieves or nets. This operation requires more capital to commence with than the mere boat and hooks and lines of the common fishermen, and, like all improvements, met at first with much opposition, on the plea that it must interfere with the interests of the poorer class. It is obvious, however, that the use of the net is advantageous to the trade at large, for shoals, or, as they are termed, "schools," of fish may sometimes be seen sweeping along shore, which but for the net would escape altogether. Besides, there seems such an incalculable abundance of the fish that there will always be enough to hook, enough to jig, enough to net, and more than enough to go away.

"One calm July evening," says Mr. Jukes, " "I was in a boat just outside St. John's harbor, when the sea was pretty still, and the fish were 'breaching,' as it is termed. For several miles around us the calm sea was alive with fish. They were sporting on the surface of the water, flirting their tails occasionally into the air, and as far as could be seen the water was rippled and broken by their movements. Looking down into its clear depths, codfish under codfish of all sizes appeared swimming about as if in sport. Some boats were fishing, but not a bite could they get, the fish being already gorged with food. Had the ground been shallow enough to use nets, the harbor might have been filled with fish."

Besides the cod-fishery, seal-catching is also carried on with considerable success on the eastern coast, which intercepts many immense fields and islands of ice as they move southward in the spring from the Arctic Sea. The interior parts of these drifting shoals, with the lakes or openings interspersed, remain unbroken, and on them myriads of seals may be found. In the month of March or April, as soon as the ice-fields descend with the currents from Davis's Straits, many small ships, not only from the harbors of the east coast of Newfoundland, but even from the distant Scotch ports, particularly Aberdeen, put out to sea, and boldly plunge into all the openings of the ice-fields to make war upon the seals. Armed with firelocks and heavy bludgeons, the crews surprise the animals on the ice. In this way thousands are killed yearly from the north, but their numbers have latterly decreased, and the seal-catchers pay the penalty of their heedless and indiscriminate slaughter. 


\section{CHAPTER XXXVI.}

\section{GREENLAND.}

A mysterious Region.-Ancient Scandinavian Colonists.-Their Decline and Fall.-Hans Egede.-His Trials and Success.-Foundation of Godthaab.-Herrenhuth Missionaries.-Lindenow.-The Scoresbys.-Clavering.-The Danish Settlements in Greenland.-The Greenland Esquimaux.-Seal-catching.-The White Dolphin.-The Narwhal.-Shark-fishery.-Fiskernasset.-Birds.-Reindeer-hunting.-Indigenous Plants._-Drift-wood.-Mineral Kingdom.-Mode of Life of the Greenland Esquimaux.-The Danes in Greenland.-Beautiful Scenery.-Ice Caves.

TN many respects Greenland is one of the most remarkable countries of the Arctic zone. The whole of the northern coast of continental America from Cape Lisburne to Belle Isle Straits is known; the borders of Siberia fronting the icy ocean have been thoroughly explored by water and by land; the distance of Spitzbergen and Nova Zembla from the pole has long since been determined; but how far Greenland may reach to the north we know notthough nearly a thousand years have passed since the Icelander Günnbjorn (970 A.D.) first saw its high mountain coast, and in spite of all the attempts made since that time to circumnavigate it. The interior of the island-or continent as it may perhaps more justly be called, for it has a surface of at least 750,000 square miles, and is probably larger than Australia-is also unknown; for of this vast extent of territory only the narrow shores of the coast-line seemed to be inhabitable, or even accessible to man. On penetrating into the deeper fjords, all the valleys are found blocked with glaciers, which, on climbing the heights, are seen to pass into a monotonous plateau of ice, or névé, which seems to cover and conceal the whole interior. Thus, from its physical configuration, Greenland may well be called a mysterious region; and, strange to say, the history of the decline and fall of its first colonists is as little known as its geography.

We have seen in a previous chapter that Iceland, so peaceful in the present day, was peopled in the ninth century with a highly turbulent race of jarls and vikings. One of these worthies, called Erik Rauda, or the Red, having twice dyed his hands with blood, was banished by the Althing (982) for a term of years, and resolved to pass the time of his compulsory absence in exploring the land discovered by Günnbjorn. After spending three years on its western coasts, he returned to Iceland, and made so favorable a report of the new country, which-knowing the advantages of a good name-he called Greenland, that in 986 he induced a large body of colonists to sail with him and settle there. Other emigrants followed, and in a few years all the habitable places of Southern Greenland were occupied.

The colony, which soon after its foundation adopted the Christian religion, was divided into two districts, or "bygds" (from the Icelandic " byggia," to 
inhabit), by an intervening tract of land named Ubygd, the "uninhabitable " or " uninhabited." The West Bygd reached from lat. $66^{\circ}$ down to $62^{\circ}$, and contained, in its best days, ninety farms and four churches. South of it lay the desert, "Ubygd," of seventy geographical miles, terminated by the East Bygd, consisting of 190 farms, and having two towns, Gardar and Alba, one cathedral, and eleven churches. The whole population may probably have amounted to 6000 souls. The country was governed by Icelandic laws, and the first of its eighteen bishops, Arnold, was elected in 1121, the last being Endride Andreason, who was consecrated in 1406. In spite of its poverty and distance, Greenland was obliged to contribute its mite to the revenues of the Papal chair, for we read in the ancient annalists that in 1326 its tribute, consisting of walrusteeth, was sold by the Pope's agent, Bertram of Ortolis, to a merchant of Flanders for the sum of twelve livres and fourteen sous.

The time, however, was now fast approaching when the Greenland colony was not only to cease paying tithes and Peter's pence, but to be swept away. During the course of the fourteenth century it was visited by one misfortune after another. The black death, which carried off twenty-five millions of Europeans, did not spare its distant fjords (1348-9), the Esquimaux harassed the survivors with repeated attacks, killing some, and carrying away others captive. A hostile fleet, suspected to be English, laid waste the country in 1418; and, finally, the revolutions and wars which broke out in Scandinavia after the death of Queen Margaret of Waldemar caused Greenland to be entirely neglected and forgotten. The last colonists either retreated to Iceland, or were destroyed by the Esquimaux, and many years elapsed before Greenland was again thought of as a place where Scandinavians had once been living. At length King Frederick II. of Denmark sent out Mogens Heineson, a famous "sea-cock," as the chroniclers style him, to the south-eastern coast of Greenland (1581), to see if men of a Norse origin still dwelt along those ice-bound fjords. Heineson reached the coast, but the great transparency of the air, which in the Polar regions frequently causes strange optical delusions, led him into a singular error. After having sailed for many hours in the same direction, and still seeing the mountains which seemed quite near recede as he advanced, he fancied himself fettered by an invisible power, and thus the famous "sea-cock" returned home with the report that, detained by a magnetic rock, he had not been able to reach the land.

In 1605 King Christian IV. of Denmark sent out a new Greenland expedition, consisting of three ships, under the command of Godske Lindenow, and the guidance of James Hall, an English pilot. This time no magnetic rocks intervened; but the ships having separated, Hall landed on the west coast, which had already been rediscovered and visited by Davis, Hudson, Baffin, and other Arctic navigators; while Lindenow, anchoring off Cape Farewell, kidnapped two Esquimaux, who afterwards died of nostalgia in Denmark. But neither Lindenow, who the year after again made his appearance on the western coast of Greenland, nor two later expeditions under Carsten Richardson and Dannell, were able to effect a landing on any part of the eastern coast. It was in sight, but the drift-ice made it inaccessible. They were equally unsuccessful in finding any traces of the lost colony, which came at length to be regarded as a mere 
Scandinavian myth. But while no one else cared about its existence, the ardent Hans Egede (born in Norway, January 31, 1686), pastor of Vaage, in the Lofoten Islands, still continued to cherish its memory. He had read in the ancient chronicles about the old Christian communities in Greenland, and could not believe in their total extinction. He felt the deepest concern in the fate of their descendants, and the thought that after so long a separation from the mothercountry they must needs be plunged in barbarism and heathen darkness, left him no rest by night or day. At length he resolved to devote his life to their spiritual welfare, and to become the apostle of rediscovered or regenerated Greenland. His zeal and perseverance overcame a thousand difficulties. Neither the public ridicule, nor the coldness of the authorities to whom he vainly applied for assistance, nor the exhortations of his friends, could damp his ardor. At length, after years of fruitless endeavors, after having given up his living and sacrificed his little fortune in the prosecution of his plans, he succeeded in forming a Greenland Company, with a capital of 9000 dollars, and in obtaining an annual stipend from the Danish Missionary Fund of 300 dollars, to which King Frederic IV. added a gift of 200 dollars. With three ships, the largest of which "The Hope," had forty colonists on board, Egede, accompanied by his wife and four children, set sail from the port of Bergen on May 12, 1721, and reached Greenland on July 3, after a long and tedious passage. The winds had driven him to the western coast, in latitude $64^{\circ}$, and here he resolved at once to begin his evangelical labors with the Esquimaux. A wooden chapel was speedily erected, which formed the first nucleus of the still existing settlement of Godthaab.

But if the life of worthy Egede had for many a year been full of trouble before he went to Greenland, trials still more severe awaited him during his apostolical career. He had not merely the suspicions of the Esquimaux, the enmity of their medicine-men, the severity of the climate, and not seldom even famine to contend with. His own countrymen, disappointed in their hopes of carrying on a lucrative trade with the Greenlanders, resolved to abandon it altogether, and, after ten laborious years, the Government not only withdrew all further assistance from the mission, but even ordered the colony to be broken up. All his companions, with the exception of a few volunteers who engaged to share his fortunes, now returned to Denmark; but Egede, though his health had been so shattered by almost superhuman exertions that he had long since been obliged to leave all active duties to his son, resolved, like a faithful soldier, to die at his post. In 1733 his perseverance was at length rewarded by the grateful news that the king, at the entreaty of Count Zinzendorf, the founder of Herrenhuth, had consented to bestow an annual grant of 2000 dollars on the Greenland mission, and that three Moravian brothers had arrived to assist him in his work. Thus he could at length (1735) return with a quiet heart to his native country, where he died, universally regretted, in 1758 , at the age of seventy-two.

It may easily be supposed that, during his long stay in Greenland, he anxiously sought the traces of his lost countrymen, for the desire to help them had first led him to that Arctic country. Nothing in the physiognomy of the Esquimaux or in their language pointed in any way to a European origin, and 
even their traditions said not a word of the old Norse settlers who had once inhabited the land. The ruins of some churches, and other buildings scattered here and there along the west coast, alone attested their existence, and formed a link between the past and the present. Thus if Greenland still had inhabitants of Scandinavian origin, they must necessarily be confined to the eastern coast beyond Cape Farewell. But Egede was as little able as his predecessors to penetrate through the ice-belt which, both by land and sea, completely separated it from the rest of the world.

For many years after his death it remained unknown and inaccessible; and Löwenorn, who was sent out in 1786-87 to renew the attempts of Heineson and Lindenow, had no better success. No doubt many a whaler may have admired its distant mountain peaks glowing in the evening sun, or may have been driven by the storm against its shores, but the Scoresbys were the first to determine accurately the position of part of its well-fenced coast. In the year 1817, Captain Scoresby the elder, deviating from the usual course of the whalers, steered through the western ice, and reached the east coast of Greenland beyond $70^{\circ}$. He could easily have landed; the coast which had so frequently baffled the attempts of previous navigators lay invitingly before him, but he could not sacrifice his duty as the commander of a whaler to curiosity or renown. And thus, without having set his foot on shore, he sailed back into the open sea. On a later visit, however, he landed in the sound which bears his name. In the year 1822 Scoresby the younger succeeded in more closely examining the land. Leaving the usual track of the whalers, he had steered to the west, and threaded his way through the drift-ice until, between $70^{\circ} 33^{\prime}$ and $71^{\circ} 12^{\prime} \mathrm{N}$. lat., the coast of Greenland lay before him. No coast that he had ever seen before had so majestic a character. The mountains, on which he bestowed the name of Roscoe, consisted of numberless jagged stones or pyramids, rising in individual peaks to a height of 3000 feet, and a chaos of sharp needles covered their rough declivities.

On July 24 he landed on a rocky promontory, which he named Cape Lister $\left(70^{\circ} 30^{\prime}\right)$, and, climbing its summit, continued his excursion along its back, which was between three and four hundred feet high. Here and there between the stones, which were either naked or thinly clothed with lichens, bloomed Andromeda tetragona, a Saxifraga oppositifolia, a Papaver nudicanle, or a Ranunculus nivalis. At Cape Swainson he again descended to the shore, which here formed a flat strand about 600 feet broad. Some deserted Esquimaux huts soon arrested his attention. Charred drift-wood and a quantity of ashes lay scattered about the hearths, and proved that these dwellings had not been long forsaken. Scarcely a bird was to be seen on land, but countless auks and divers animated the waters. A great number of winged insects-butterflies, bees, mosquitoe -flew or buzzed about, particularly on the hillocks between the stones. On July 25 he once more landed on Cape Hope, where he again found traces of inhabitants. Bones of hares and fragments of reindeer horns lay scattered about on the ground. The skull of a dog was planted on a small mound of earth, for it is a belief of the Greenland Esquimaux that the dog, who finds his way everywhere, must necessarily be the best guide of the innocent children to the 
land of souls. The heat, which soon put an end to this excursion, was so great that many of the plants had shed their seeds, and some were already completely dried up and shrivelled.

The part of the coast of East Greenland discovered by Scoresby, and that which was visited the year after by Clavering, lay, however, too far to the north to afford any clue about the extinct Scandinavian settlements, even supposing them, as was then still believed, to have been partly situated to the east of Cape Farewell. At length in the year 1829, Captain Graah, who had been sent out by King Frederick VI. of Denmark, succeeded in exploring the south-eastern coast of Greenland, from its southern extremity to the latitude of $65^{\circ} 18^{\prime}$, beyond which no colony could ever have existed; and as he nowhere found either the most insignificant ruins or the least traces of an ancient Christian settlement in the language and customs of the natives, it was now fully proved that the east bygd of the old chroniclers was, in reality, situated on the southwestern coast of Greenland, in the present districts of Julianshaab and Lichtenau, a coast which, in comparison with the more northern colonies of Frederikshaab and Fiskernäs, distinctly trends to the east.

The present Danish settlements, which are confined to the more sheltered fjords of its western coast, are divided into a north and south inspectorate, the former extending from lat. $67^{\circ}$ to $72^{\circ}$, and comprising the districts of Upernavik, Omenak, Jakobshavn, Christianshaab, Egedesminde, and Godhavn, on Disco Island; while the latter contains the districts of Holsteensborg, Sukkertoppen, Godthaab, Fiskernässet, Frederikshaab, and Julianshaab.

In the year 1855 the population of the South Inspectorate consisted of 6128 aboriginal Greenlanders, or Esquimaux, and 120 Europeans; that of the North Inspectorate, of 3516 of the former, and 128 of the latter; a very small number if we consider that it is scattered over a space of $12^{\circ}$ of latitude. In a country like this, such towns as Godhavn, with 150 inhabitants, or Godthaab, the most populous of all, with 330 , pass for considerable cities.

But, in spite of its scanty population, Greenland is a valuable possession of the Danish crown, or rather of the Danish company, which entirely monopolizes the trade, and manages its affairs so well that the Greenlander receives for his produce only about the sixth part of its price at Copenhagen. According to the average of six years (1850-1855), the total value of the exports from Greenland amounted to 378,588 rix-dollars; that of the importations from Denmark, to 164,215 ; but in the latter sum was included not only the price paid to the Greenlanders for their goods, but all the stores and provisions necessary for the agents and servants of the company, the missionaries, and the administration of the colony. The trifling amount which, after all deductions and charges, the poor Greenlander receives for his seal-skins or his blubber, he generally spends in tobacco, candy-sugar, coffee, and sea-biscuits, for his real wants are amply supplied by his own country, and he has not yet learned to invest his gains more profitably. Like all other Esquimaux, he depends chiefly upon the sea for his subsistence. Of the various species of Phocæ found in the Greenland waters the most valuable is the hispid seal (Phoca hispida), both from its numbers and from its frequenting the fjords during the whole 
year; while the larger Greenland seal (Phoca groenlandica) is not stationary like the former, but leaves the coast from March to May, and from July to September. The Cystophora cristata, or hooded seal, remarkable for a globular sac, capable of inflation, on the head of the male, appears in the fjords only from April till June. It is the most pugnacious of all the seals. In the southern districts, where the seal-hunting must be chiefly carried on in open water, the Greenlander relies upon his boat, the kayak. When the animal is struck, the barbed point of the harpoon detaches itself, by an ingenious mechanism, from the shaft, which otherwise would be broken by its violent contortions; and as the line is attached to a bladder, it can easily be recovered.

Among the cetaceans, the white dolphin (Delphinopterus leucas) and the narwhal (Monodon monoceros) are the most valuable to the Greenlanders of the North Inspectorate, from 500 to 600 of these huge animals being annually caught. The former makes its appearance a short time after the breaking up of the ice, and again in autumn; in summer it seeks the open sea. Sometimes large herds of the white dolphins are cut off from the sea by the closing in of the ice in the neighborhood of the land, so that several hundred may be killed in the course of a few days. The narwhal is caught only in the Omenak fjord, which it visits regularly in November. As its chase is both difficult and dandorous, the Greenlanders generally hunt it in company, so that after a narwhal has been struck with the first harpoon or lance, others are ready to follow up the advantage. The larger whales are now seldom caught, but the dead body of a fin-back is not seldom cast ashore, and affords a rich harvest to the neighborhood. Sometimes masses of oil, evidently proceeding from dead whales, are found floating in the fjords. In 1854 ninety-five tons of this matter were collected near Holsteinburg.

The fishes likewise amply contribute to supply the Greenlander's wants. The shark-fishery (Scymnus microcephalus) is of considerable importance. The entrails of seals and other offal are placed in the openings of the ice to attract these sharks to the spot, where they are caught in various ways, particularly by torch-light, which brings them to the surface. The fishermen, watching the moment, strike them with a sharp hook, and then drag them upon the ice. They are also caught with strong iron angles attached to chains. They are captured for the sake of their livers, which yield a gooil deal of oil. It has very recently been ascertained that a valuable substance resembling spermaceti may be expressed from the carcass which was formerly wasted, and for this purpose powerful screw presses are now employed. About 30,000 of these gluttonous animals are caught every year, and the fishery may be greatly ex. tended, as the bottom of the ice-fjords absolutely swarms with them. Their capture is attended with far less trouble and danger than in Iceland, where they are pursued in boats, and in a capricious and tempestuous sea. Improving upon the old Esquimaux methods of fishing or hunting, the Danish residents set nets for the white whale or the seal ; for the former, they are attached to the shore, and extend off at right angles, so as to intercept them in their autumnal southern migration, when they swim close along the rocks to avoid the grampus. When the white whale is stopped by the net, it often appears 
at first to be unconscious of the fact, and continues to swim against it, and then allows the boat to approach it from behind. If entangled in the net, it is soon drowned, as, like all the whale tribe, it is obliged to come to the surface to breathe.

A large quantity of cod are caught in various parts of the South Inspectorate, particularly at Fiskernasset, which, being less subject to fogs and more exposed to the sea-wind, offers peculiar advantages for the drying of the fish. The capelin (Mallotus villosus), which in May and June visits the coasts of Greenland in great numbers, is eaten both fresh or laid upon the rocks to dry for the winter. The sea-wolf, the lump-fish, the bull-head, the Norway haddock, the salmon-trout, are likewise important articles of food. The halibut grows to a huge size, and a smaller species (Hippoglossus pinguis) is fished for at the depth of 180 or even 380 fathoms. The banks frequented by this fish are most valuable to the neighboring Greenlanders. Many are no doubt still undiscovered, others may be known by the dead fish floating on the surface, or by the seals diving out of the water with a flat fish in their mouth. Long-tailed crabs are easily caught in many parts, and the common mussel may be gathered almost everywhere at ebb tide.

Crowds of birds nestle during the summer on the rocky shores, particularly at Upernavik, where the largest breeding-places are found. They are generally killed with small blunted arrows. In the ice-fjord of Jacobshavn the gulls are caught ingeniously by floating traps on which something brilliant or resembling a fish is fixed. The eggs of the sea-birds are gathered in vast numbers, and the feathers and skins of the eider-duck and auk are both exported and used for the lining of boots.

Compared with the wealth of the seas, the land is very poor. The chase of the reindeer is, however, important, as its skin affords both a warmer and a softer clothing than that of the seal, and serves moreover as a bed-cover or a sledge-carpet. Reindeer-hunting is a favorite summer occupation of the Greenlanders, who annually kill from 10,000 to 20,000, and export about one-half of the skins. Only a few cows, sheep, and goats are kept at Julianshaab. For want of hay they are fed with fish during the winter. In South Greenland the potato is cultivated by the European residents as a luxury. The plant never flowers, and even buds are rare. Turnips, cabbages, salad, and spinach likewise grow in South Greenland, but barley sown in the gardens scarcely ever comes to ear. In summer the windows of the houses are gay with geraniums and fuchsias and other flowers of a more temperate zone.

Among the indigenous plants, the berries of the Empetrum nigrum, Vaccinium uliginosum, and Vaccinium vitis idcea furnish the Greenlanders with their only vegetable food. While the coasts exposed to the bleak sea-winds afford scanty traces of vegetation, the valleys and hill slopes of the more sheltered fjords are green during the summer, and justify the name bestowed by Erick on the land of his adoption. Forests are of course out of the question in Greenland, though in some places the birch attains a not inconsiderable size. Thus in a dell at the upper end of Lichtenau Fjord a thicket of these trees, fifteen feet high, surrounds a little lake fed by a waterfall, the largest 
hitherto known in Greenland. More generally, however, the trees, such as the beech, the willow, the elder, etc., merely creep along the ground, where the dense matting of their roots and branches, mingled with bushes of the empetrum, or with mosses, lichens, and fallen leaves, forms a kind of turf which is used as fuel by the Danes.

In some measure the sea makes up for the want of timber by casting on the shore a quantity of drift-wood, the origin of which is still a matter of doubt, some tracing it to the North American rivers, others to those of Siberia. It consists mostly of the uprooted trunks of coniferous trees. Sometimes also large pieces of bark, such as those of which the Indians make their canoes, and sewn together with threads of hair, and drifted into the fjords.

The mineral kingdom, though it has within the last few years attracted the attention of speculators, will hardly ever realize their hopes. Several attempts to work the lead and copper ores at Nanursoak and in the Arksak fjord have miserably failed. The cost of transport is immense, and the difficulty of obtaining the necessary workmen presents an insuperable obstacle to all mining operations in Greenland.

Though the Greenlanders have now been for more than a century under the influence of Christian teachers, yet their mode of life is still much the same as that of their relatives the wild Esquimaux on the opposite continent of North America. Like them, they use the "kayak," the "oomiak," and the sledge; like them, they live in small winter huts of stone (the snow-house is unknown to them) or in summer tents hung with skins, and they are equally improvident in times of abundance. Their constant intercourse with Europeans has, however, taught them the use of many luxuries unknown to the wild Esquimaux, and they are now great consumers of coffee. They are fond of instruction, but the immense space over which the population is scattered, and their vagrant life during a great part of the year, are great hinderances to their improvement. They are also very good-natured, and live on the best terms with the Danes who reside among them. The latter, who, with the exception of the Moravian missionaries, are all in the service of the Company, soon get attached to the country, and leave it with regret; sometimes even returning to close their days in Greenland.

The climate, though severe, is very healthy, and the lover of sport finds ample opportunities for gratifying his favorite passion. In September, or at the beginning of October, the last ships leave for Europe; and then, till the next April or May--when the first English whalers appear in the ports of Godhavn or Upernavik-all communication with the civilized world is totally cut off. Towards the end of January or the beginning of February, when the days begin rapidly to lengthen, frequent sledge-parties keep up a constant interchange of visits between the various settlements. This mode of travelling over the lakes and inclosed fjords is very agreeable in May, as then the sun is pleasantly warm at noon; and though he hardly disappears below the horizon, the nights are sufficiently cold to convert the melted snow into ice hard enough to bear the weight of a sledge. This is the best time for visiting many interesting spots inaccessible at other seasons of the year, and for enjoying many a scene 
unsurpassed in Switzerland itself. Here, as on the Alps, the glacier and the snow-clad peak appear in all their grandeur; here also, in the valleys, the sum. mer brooks flow between well-clothed banks, and the Helvetian lakes are worthily rivalled by the magnificent fjords of Greenland.

In many parts, the waves, beating against the steep coasts of the islands and fjords, render access difficult, if not impossible during the summer, but in winter or spring they may easily be visited across the ice. The surf has worn many caves in these precipitous rock-walls, which are no less remarkable for their picturesque basaltic forms than for the huge masses of ice on their sides, which, in their tints and grouping, far surpass the stalactites of the most ronowned European grottoes. 


\title{
CHAPTER XXXVII.
}

\author{
THE ANTARCTIC OCEAN.
}

Comparative View of the Antarctic and Arctic Regions.-Inferiority of Climate of the former.-Its Causes.-The New Shetland Islands.--South Georgia.-The Peruvian Stream._Sea-birds. -The Giant Petrel.-The Albatross. - The Penguin._The Austral Whale.-The Hunchback. -The Fin-back. -The Grampus.-Battle with a Whale.-The Sea-elephant.-The Southern Sea-bear.-The Sealeopard.-Antarctic Fishes.

THE Antarctic regions are far more desolate and barren than the Arctic.

Here we have no energetic hunters, like the Esquimaux, chasing the seal or the walrus; no herdsmen following, like the Samoïedes or the Lapps, their reindeer to the brink of the icy ocean; but all is one dreary, uninhabitable waste. While within the Arctic Circle the musk-ox enjoys an abundance of food, and the lemming is still found thriving on the bleakest islands, not a single land quadruped exists beyond $56^{\circ}$ of southern latitude.

Summer flowers gladden the sight of the Aretic navigator in the most northern lands yet reached; but no plant of any description-not even a moss or a lichen-has been observed beyond Cockburn Island in $64^{\circ} 12^{\prime} \mathrm{S}$. lat.; and while even in Spitzbergen vegetation. ascends the mountain slopes to a height of 3000 feet the snow-line descends to the water's edge in every land within or near the Antarctic Circle.

An open sea, extending towards the northern pole as far as the eye can reach, points out the path to future discovery; but the Antarctic navigators, with one single exception, have invariably seen their progress arrested by barriers of ice, and none have ever penetrated beyond the comparatively low latitude of $78^{\circ} 10^{\prime}$.

Even in Spitzbergen and East Greenland, Scoresby sometimes found the heat of summer very great; but the annals of Antarctic navigation invariably speak of a frigid temperature. In 1773, when Captain Phipps visited Spitzbergen, the thermometer once rose to $+58 \frac{1}{2}^{\circ}$; and on July 15,1820 , when the "Hecla" left her winter-quarters in Melville Island ( $74^{\circ} 47^{\prime} \mathrm{N}$.), she enjoyed a warmth of $+56^{\circ}$. But during the summer months spent by Sir James Ross in the Antarctic Polar area, the temperature of the air never once exceeded $+41^{\circ} 5^{\prime}$. In Northumberland Sound $\left(76^{\circ} 42^{\prime} \mathrm{N}\right.$.), probably the coldest spot hitherto visited in the north, the mean of the three summer months was found to be $+30^{\circ} 8^{\prime}$, while within the Antarctic Circle it only amounted to $+27^{\circ} 3^{\prime}$.

The reader may possibly wonder why the climate of the southern polar regions is so much more severe than that of the high northern latitudes; or why coasts and valleys, at equal distances from the equator, should in one case be found green with vegetation, and in another mere wastes of snow and ice; but the predominance of land in the north, and of sea in the south, fully answers 
the question. Within the Arctic Circle we see vast continental masses projecting far to the north, so as to form an almost continuous belt round the icy sea; while in the southern hemisphere, the continents taper down in a vast extent of open ocean. In the north, the plains of Siberia and of the Hudson's Bay territories, warmed by the sunbeams of summer, become at that season centres of radiating heat, so that in many parts the growth of forests, or even the culture of the cereals, advances as high as $70^{\circ}$ of latitude; while the Antarctic lands are of a comparatively small extent, and isolated in the midst of frigid waters, whose temperature scarcely varies from $+29^{\circ} 2^{\prime}$ even in the height of summer. Mostly situated within the Antarctic Circle, and constantly chilled by cold sea-winds, they act at every season as refrigerators of the atmosphere.

In the north, the formation of icebergs is confined to a few mountainous countries, such as the west coast of Greenland or Spitzbergen; but the Antarctic coast-lands generally tower to a considerable height above the level of the sea, and the vast fragments which are constantly detaching themselves from their glaciers keep up the low temperature of the seas.

In the north, the cold currents of the Polar Ocean, with their drift-ice and bergs, have but the two wide gates of the Greenland Sea and Davis's Strait through which they can emerge to the south, so that their influence is confined within comparatively narrow limits, while the gelid streams of the Antarctic seas branch out freely on all sides, and convey their floating ice-masses far and wide within the temperate seas. It is only to the west of Newfoundland that single icebergs have ever been known to descend as low as $39^{\circ}$ of latitude; but in the southern hemisphere they have been met with in the vicinity of the Cape of Good Hope ( $35^{\circ} \mathrm{S}$. lat.), near Tristan d'Acunha, opposite to the mouth of the Rio de la Plata, and within a hundred leagues of Tasmania. In the north, finally, we find the Gulf Stream conveying warmth even to the shores of Spitzbergen and Nova Zembla; while in the opposite regions of the globe, no traces of warm currents have been observed beyond $55^{\circ}$ of latitude.

Thus the predominance of vast tracts of flat land in the boreal hemisphere, and of an immense expanse of ocean in the Antarctic regions, sufficiently accounts for the rstival warmth of the former, and the comparatively low summer temperature of the latter.

It is unnecessary to describe in detail each of the desolate lands which modern navigators have discovered among the Antaretic ice-fields, but it may not be uninteresting to compare one or two of these dreary wastes with the lands of the north, situated in analogous latitudes.

The New Shetland Islands, situated between $61^{\circ}$ and $63^{\circ}$ of Southern latitude, were originally discovered by Dirck Gheritz, a Dutch navigator, who, in attempting to round Cape Horn, was carried by tempestuous weather within sight of their mountainous coasts. Long forgotten, they were re-discovered in 1819 by Mr. Smith, a master in the royal navy-whom a storm had likewise earried thither-and in the following year more accurately examined by Edward Bransfield, whose name survives in the strait which separates them from D'Urville's Louis Philippe Land. 
In 1829, the "Chanticleer," Captain Forster, was sent to New Shetland for the purpose of making magnetic and other physical observations, and remained for several months at Deception Island, which was selected as a station from its affording the best harbor in South Shetland.

Though these islands are situated at about the same distance from the pole as the Faroe Islands which boast of numerous flocks of sheep, and where the sea never freezes, yet, when the "Chanticleer" approached Deception Island, on January 5 (a month corresponding to our July), so many icebergs were scattered about, that Forster counted at one time no fewer than eighty-one. A gale having arisen, accompanied by a thick fog, great care was needed to avoid run. ning foul of these floating cliffs. After entering the harbor-a work of no slight difficulty, from the violence of the wind-the fogs were so frequent that, for the first ten days, neither sun nor stars were seen; and it was withal so raw and cold, that Lieutenant Kendal, to whom we owe a short narrative of the expedition, did not recollect having suffered more at any time in the Arctic regions, even at the lowest range of the thermometer. In this desolate land, frozen water becomes an integral portion of the soil; for this volcanic island is composed chiefly of alternate layers of ashes and ice, as if the snow of each winter, during a series of years, had been prevented from melting in the following summer, by the ejection of cinders and ashes from some part where volcanic action still goes on. Early in March (the September of the north) the freezing over of the cove in which the ship was secured gave warning that it was high time for her to quit this desolate port. With much difficulty and severe labor, from the fury of the gales, they managed to get away, and we may fully credit Lieutenant Kendal's assertion, that it was a day of rejoicing to all on board when the shores of Deception faded from their view.

In 1775 Cook, on his second voyage, discovered the large island of South Georgia, situated in latitude $54^{\circ}$ and $55^{\circ}$, a situation corresponding to that of Scarborough or Durham. But what a difference in the climate, for "we saw not a river or stream of water," says the great navigator, "on all the coast of Georgia. The head of the bay, as well as two places on each side, was terminated by perpendicular icebergs of considerable height. Pieces were continually breaking off and floating out to sea, and a great fall happened while we were in the bay, which made a noise like a cannon. The inner parts of the country were not less savage and horrible. . The wild rocks raised their lofty summits till they were lost in the clouds, and the valley lay covered with everlasting snow. Not a tree was to be seen, not a shrub even big enough to make a toothpick. The only vegetation was a coarse strong-bladed grass growing in tufts, wild burnet, and a plant like moss, which sprang from the rocks. The lands, or rather rocks, bordering on the sea-coast were not covered with snow like the inland parts, but all the vegetation we could see on the clear places was the grass above mentioned.' To find scenes of a similar wintry desolation, we must travel in the north as far as Nova Zembla or Spitzbergen, which are $20^{\circ}$ or $24^{\circ}$ nearer to the pole!

Thus the influence of the cold Antarctic waters extends far within the temperate zone. We can trace their chilling effects in Kerguelen Land $\left(50^{\circ} \mathrm{S}\right.$. 
lat.), which when visited by Cook in the height of summer was found covered with snow, and where only five plants in flower were collected; in Tierra del Fuego $\left(53^{\circ} \mathrm{S}\right.$. lat.), where the mean summer temperature is fully $9 \frac{1}{2}^{\circ}$ lower than that of Dublin $\left(53^{\circ} 21^{\prime} \mathrm{N}\right.$. lat.) ; in the Falkland Islands $\left(51^{\circ} 30^{\prime}\right)$, which, though flat and low and near Patagonia, have, according to Mr. Darwin, a climate similar to that which is experienced at the height of between one and two thousand feet on the mountains of North Wales, with less sunshine and less frost, but more wind and rain; and finally along the south-west coast of America, where the Peruvian current and the cold sea-winds so considerably depress the snowline, that while in Europe the most southern glacier which comes down to the sea is met with, according to Von Buch, on the coast of Norway in lat. $67^{\circ}$; the "Beagle" found a glacier fifteen miles long and in one part seven miles broad descending to the sea-coast in the gulf of Penas, in a latitude $\left(46^{\circ} 50^{\prime}\right)$ nearly corresponding with that of the Lake of Geneva.

"The position of this glacier," says Mr. Darwin, "may be put even in a more striking point of view, for it descends to the sea-coast within less than $9^{\circ}$ from where palms grow; within $4 \frac{1}{2}^{\circ}$ of a region where the jaguar and puma range over the plains, less than $2 \frac{1}{2}^{\circ}$ from arborescent grasses, and (looking to the westward in the same hemisphere) less than $2^{\circ}$ from orchideous parasites, and within a single degree of tree-ferns!" As the influence of the tropical gulf stream reaches as far as Spitzbergen, so that of the cold Peruvian stream, which issues from the Antarctic Seas, extends even to the equator, and not seldom reduces the temperature of the waters about the Galapagos to less than $+58 \frac{1}{2}^{\circ}$, so that reef-building corals, which require a minimum warmth of $+60^{\circ}$, are unable to grow near islands situated directly under the line.

Though the Antarctic lands are so bleak and inclement that not a single quadruped is to be found within $60^{\circ}$ of latitude, yet they are the resort of innumerable sea-birds which, belonging to the same families as those of the north, generally form distinct genera or species, for with rare exceptions no bird is found to inhabit both the Arctic and the Antarctic regions.

Thus in the petrel family we find the fulmar (Procellaria glacialis) and the glacial petrel $(P$.gelida) of the high north represented in the Antarctic Seas by the giant petrel (Procellaria gigantea), which extends its flight from Patagonia to the ice-banks of the south, where the Antarctic and the snowy petrels ( $P$. antarctica et nivea) first appear, cold-loving birds which never leave those dreary waters, and are often seen in vast flocks floating upon the drift-ice.

The giant petrel, which has received from the Spaniards the significant appellation of "quebranta huesos," or "break-bones," is a more powerful bird than the fulmar. It is larger than a goose, with a strong beak $4 \frac{1}{2}$ inches long. Its color is a dirty black, white below, and with white spots on the neck and back. In its habits and manner of flight it closely resembles the albatross, and, as with the albatross, a spectator may watch it for hours together without seeing on what it feeds. Like the fulmar it feasts upon fishes, or the carcasses of seals and cetaceans, but it also chases other birds. At Port Saint Antonio it was seen by some of the officers of the "Beagle" pursuing a diver, which tried to escape by diving and flying, but was continually struck down, and at last killed by a blow 
on its head. Such is its voracity that it does not even spare its own kind, for a gigantic petrel having been badly wounded by a shot from the "Terror," and falling at too great a distance for a boat to be sent after it, was immediately attacked by two otbers of the same kind and torn to pieces. It is a common bird both in the open sea and in the inland channels of Tierra del Fuego, and the south-west coast of America.

The wandering albatross (Diomedea exulans), closely allied to the petrels, and rivalling the condor in size and strength of wing, may truly be ranked among the Antarctic birds, as it is seldom seen in a lower latitude than $36^{\circ}$, and in. creases in numbers towards the south. Freyssinet saw it most frequently between $55^{\circ}$ and $59^{\circ} \mathrm{S}$. lat., and it probably knows no other limits than those of the Polar ice. It is found in every meridian of this enormous zone, but the regions of storms - the Cape of Good Hope and Cape Horn-are its favorite resorts. Here it may frequently be seen in the full majesty of its flight.

The auks of the northern hemisphere are represented, in the austral regions, by the penguins, who, as Buffon remarks, are the least bird-like of all birds. Their small wing-stumps, covered with short rigid scale-like feathers, are altogether incapable of raising the body in the air, but serve as admirable paddles in the water, and on land as fore feet, with whose help they so alertly scale the grassy cliffs that they might easily be mistaken for quadrupeds. Their feet, like those of the auks, are placed so far back that the body is quite upright when the bird is standing on the ground, a position which renders their gait uncommonly slow and awkward, but greatly facilitates their movements in the water. When at sea and fishing, the penguin comes to the surface for the purpose of breathing with such a spring, and dives again so instantaneously, that at first sight no one can be sure that it is not a fish leaping for sport. Other seabirds generally keep a considerable part of their body out of the water while swimming, but this is not the case with the penguin, whose head alone appears above the surface, and thus rowing at the same time with its wings and feet, it swims so quickly that many fishes would fail to keep up with it. Sir James Ross once saw two penguins paddling away a thousand miles from the nearest land. Protected against the cold by a thick layer of fat and a warm great-coat of feathers, it remains for months on the high seas, and seeks land only in the surnmer for the purpose of breeding. At this time it is found in vast numbers on the Falkland Islands, Kerguelen's Land, New Shetland, or wherever in the Antarctic Seas, perhaps even to the pole itself, a convenient coast invites its stay. On Possession Island, for instance, a desolate rock, discovered by Sir James Ross in lat. $71^{\circ} 56^{\prime}$, myriads of penguins covered the whole surface of the land, along the ledges of the precipices, and even to the summit of the hills. Undaunted by the presence of beings whom they had never seen before, the birds vigorously attacked the British seamen as they waded through their ranks, and pecked at them with their sharp beaks, a reception which, together with their loud coarse notes, and the insupportable stench of their guano, made our countrymen but too happy to depart, after having loaded their boat with geological specimens and penguins. There are several species of this singular bird. The largest and rarest (Aptenodytes Forsteri) is generally found sin- 


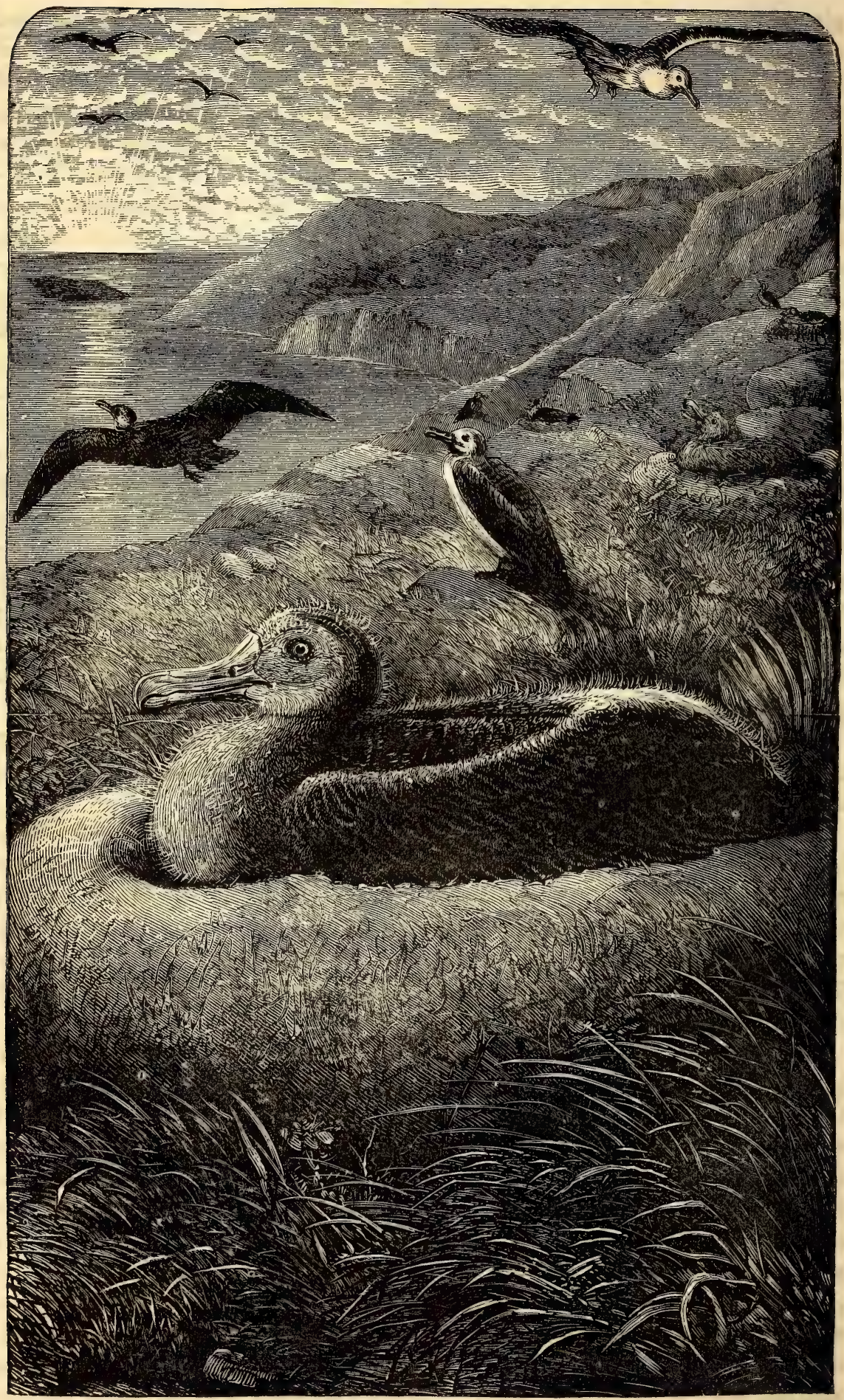


gly, while the smaller species always associate in vast numbers. Several were caught in lat. $77^{\circ}$ by Sir James Ross and brought on board alive; indeed it was a very difficult and a cruel operation to kill them, until hydrocyanic acid was resorted to, of which a tablespoonful effectually accomplished the purpose in less than a minnte. These enormous birds varied in weight from sixty to seventy-five pounds. They are remarkably stupid, and allow a man to approach them so near as to strike them on the head with a bludgeon, and sometimes, if knocked off the ice into the water, they will almost immediately leap upon it again as if eager for a fight, though without the smallest means either of offense or defense. They were first discovered during Captain Cook's voyage to the Antarctic regions, but Sir James Ross was fortunate in bringing the first perfect specimens to England, some of which were preserved entire in casks of strong pickle, that the physiologist and comparative anatomist might have an opportunity of thoroughly examining their structure. The principal food of the great penguin consists of various species of crustaceous animals, and in its stomach are frequently found from two to ten pounds' weight of pebbles, swallowed no doubt to promote digestion. "Its capture," says Sir James Ross, " afforded great amusement to our people, for when alarmed and endeavoring to escape, it makes its way over deep snow faster than they could follow it: by lying down on its belly and impelling itself by its powerful feet, it slides along upon the surface of the snow at a great pace, steadying itself by extending its fin-like wings, which alternately touch the ground on the side opposite to the propelling leg."

Though the Antarctic Seas possess neither the narwhal nor the morse, they abound, perhaps even more than the Arctic waters, in whales, dolphins, and seals, at least in the higher latitudes.

The austral smooth-backed whale (Balcena australis) differs from his Greenland relative in many respects : the head is comparatively smaller, being only about one-fourth of the total length, the mouth is broader, the baleen shorter, the pectoral fins are larger and pointed, and the color is almost totally black, the white on the lower surface being confined to a small part of the abdomen. The skull is also differently formed; and while the Greenland whale has only thirteen pairs of ribs, the austral smooth-back has fifteen.

According to Mr. Bennett, the austral smooth-back seldom attains a greater length than fifty feet; but as it yields on an.average from eighty to ninety barrels of oil, its capture amply rewards the whaler's trouble. Though met with in the highest latitudes, and roaming over the whole extent of the Antarctic Seas, it resorts in spring to the sheltered bays of New Zealand, Australia, Kerguelen's Land, Chili, the Falkland Islands, Algoa Bay, etc., for the purpose of bringing forth its young. This of course makes its capture easier, but must at the same time lead to its extirpation, or drive it to the most inaccessible regions of the Polar Ocean. Even now the whale-fishery of the southern seas, which twenty or thirty years ago employed hundreds of vessels, has much diminished in importance: it is chiefly carried on by the Americans, the French, and our Australian colonies, which have the advantage of being more conveniently situated than the mother-country. 
In the higher latitudes of the Antarctic zone the hunch-back and fin-back whales abound; but as the former is meagre and hardly worth the boiling, and the latter, like the rorquals of the north, dives with such rapidity that he snaps the harpoon-line or drags the boat along with him into the water, they are seldom hunted. Hence they will most likely continue to prosper in their native seas, unless the improved missiles recently introduced in the whale-fishery can be made to conquer them. The hunch-back is distinguished by the great length of his pectoral fins, which extend to full eighteen feet, while these organs are comparatively small in the fin-back. A kind of broad-nosed whale likewise makes its appearance in the Antarctic Seas, but it is not yet determined whether all these fin-backed whales of the south are distinct species from those of the Arctic waters. A circumstance which seems to speak for their identity is that fin-backs are met with in the intervening temperate and tropical seas, so that no limits appear to have been set to their excursions.

The sperm whale, or cachalot, though partial to the equinoctial ocean, is also found in the cold Antarctic waters. It was met with by Sir James Ross among the icebergs in $63^{\circ} 20^{\prime} \mathrm{S}$. lat.; and near Possession Island ( $71^{\circ} 50^{\prime} \mathrm{S}$. lat.), where the hunch-backs were so abundant that thirty were counted at one time in various directions, and during the whole day wherever the eyes turned their blasts were to be seen. A few sperm whales were also distinguished among them by their peculiar manner of blowing or spouting.

Among the dolphins of the Antarctic Ocean we find a species of grampus no less formidable and voracious than that of the northern seas. On January 20, 1840, the American ship "Peacock," while cruising in the Antarctic waters, witnessed a conflict between one of them and a whale. The sea was perfectly smooth, so that the whole combat could be distinctly seen. At first the whale was perceived at some distance from the ship lashing the water into foam, and apparently making desperate efforts to shake off some invisible enemy. On approaching, they found that an enormous grampus had seized it with its jaws. The whale vainly turned and twisted itself in every direction, and its blood tinged the water far around. The grampus had evidently the advantage, and the other whales, of which there were many in sight, instead of assisting their comrade, seemed only intent on their own safety. The grampus had a brown back, a white abdomen, and a large fin on its back. The speed at which the monstrous animals shot through the water prevented the Americans from witnessing the issue of the fight. The classical dolphin of the ancients has been seen near the Cape of Good Hope, and most likely wanders far to the south, as he is proverbial for his arrow-like rapidity, and can easily traverse a couple of hundred miles in a single day. In the Strait of Magellan and about Cape Horn are frequently seen the Delphinus superciliosus, whose turned-up mouth-corners give his countenance a peculiarly benevolent and friendly expression, belied by his ravenous propensities, and the Delphinus leucoramphus, who, like the bjeluga of the north, has no dorsal fin, and by the liveliness of his movements emulates the classical dolphin of the Mediterranean.

The seal family plays a no less important part in the zoology of the Antarctic Seas than in that of the northern waters. Here we find the monstrous sea- 
elephant (Macrorhinus elephantinus), so called not only from his size attaining a length of twenty-five feet, and a girth at the largest part of the body of from fifteen to eighteen, but also from the singular structure of his elongated nostrils, which hang down when he is in a state of repose, but swell out to a proboscis a foot long when he is enraged. This gives the animal a very formidable appearance, which, along with his bellowing and his widely-gaping jaws armed with tusk-like canines, might strike terror into the boldest heart. But in reality the sea-elephant is a most defenseless creature, for on land it moves its unwieldy carcass with the utmost difficulty, and a single blow upon the snout with a club suffices to stretch it lifeless on the ground. It used to be met with in considerable numbers on all the flat shores or islands between $35^{\circ}$ and $62^{\circ} \mathrm{S}$. lat., but as it yields a large quantity of excellent oil, and as its skin, though merely covered with thick short bristles, is of some value from its great strength and thickness, incessant persecution has greatly thinned its ranks, and in some parts extirpated it. Thus Sir James Ross relates that the sea-elephant and several other species of seals, which were formerly in great abundance at Kerguelen's Land, annually drew a number of fishing-vessels to its shores. But at the time of his visit (1840), after so many years of slaughter, they had quite deserted the place. The flesh of the sea-elephant is black, and of an oily taste, but Anson and his companions, after having been tossed about for several months on a tempestuous sea and reduced to great distress by scurvy, relished it at Juan Fernandez. The tongue is said to be a great delicacy.

As the soft jet-black fur of the young southern sea-bear (Arctocephalus falclandicus) is no less valuable than that of its northern relative, the eagerness with which it is pursued may easily be imagined. Formerly vast herds of seabears used to resort every summer to the New Shetland Islands, but soon after the rediscovery of the group the American and English sealers made their appearance on its desolate shores, and in the short time of four years extirpated the ursine seals, thus destroying by wasteful destruction what might have been a permanent source of profit.

The southern sea-lion (Otaria jubata) is a larger animal than his northern namesake; and while the latter is furnished only with an erect and curly hairtuft at the neck, a complete mane flows round his breast. The remainder of the tawny body is covered with short smooth hairs or bristles. The sea-lioness, who is much smaller than her mate, has no mane; and as she is of a darker color and has a differently shaped head, is frequently mistaken for another species, and called wolf, or lobo, by the inhabitants of the south-western coast of America. The fore flippers of the sea-lion have the appearance of large pieces of black tough leather, showing, instead of nails, slight horny elevations ; the hind fins, which are likewise black, have a closer resemblance to feet, and the five toes are furnished with small nails. It is a formidable-looking beast, particularly when full grown to a length of ten feet and more. The sea-leopard (Leptonyx Weddelli), which owes its name to its spotted skin, is peculiar to the southern seas. This large seal is from eight to nine feet long; the hind feet have no nails, and greatly resemble the tail of a fish.

The Antarctic seals, dolphins, and petrels chiefly prey upon a genus of fish 
discovered at Kerguelen's Land, and named Notothenia by Dr. Richardson. These fish, which are of an elongated eel-like shape, conceal themselves from the persecutions of their enemies in the small cracks and cavities of the packice, and were frequently noticed by Sir James Ross when driven from shelter by the ship as it struck and passed over their protecting pieces of ice. They in their turn live upon the smaller cancri and limacinæ, and these again upon creatures of a still more diminutive size, until finally the chain of created beings terminates in the diatoms, ${ }^{*}$ which are found filling these seas with the minutest forms of organic life.

* "The Sea and its Living Wonders," p. 403. 


\section{CHAPTER XXXVIII.}

\section{ANTARCTIC VOYAGES OF DISCOVERY.}

Cook's Discoveries in the Antarctic Ocean-Bellinghausen.-Weddell.-Biscoe.-Balleny.-Dumont d'Urville.-Wilkes.-Sir James Ross crosses the Antarctic Circle on New Year's Day, 1841.--Discovers Victoria Land.-Dangerous Landing on Frankiin Island.-An Eruption of Mount Erebus. The Great Ice Barrier.-Providential Escape.-Dreadful Gale-Collision.-Hazardous Passage be tween two Icebergs. - Termination of the Voyage.

$\mathrm{B}$ EFORE Cook, no navigator had left Europe with the clear design of penetrating into the Antarctic regions. Dirk Gheritz indeed had been driven by a furious storm far to the south of Cape Horn, and became the involuntary discoverer of the New Shetland Islands in 1600 ; but his voyage was soon forgotten, and in an age when the love of gold or the desire of conquest were the sole promoters of maritime enterprise, no mariner felt inclined to follow on his track, and to plunge into a sea where most probably he would find nothing but ice-fields and icebergs to reward his efforts. Nearly two centuries later a more scientific age directed its attention to the unknown regions of the distant south, and Cook sailed forth to probe the secrets of the Antarctic Seas. This dangerous task he executed with an intrepidity unparalleled in the annals of navigation. Beyond $60^{\circ}$ of southern latitude, he cruised over a space of more than $100^{\circ}$ of longitude, and on January 30,1774 , penetrated as far as $71^{\circ}$ of southern latitude, where he was stopped by impenetrable masses of ice. Such were the difficulties encountered from dense fogs, snow-storms, intense cold, and every thing that can render navigation dangerous, that in his opinion the lands situated to the southward of his discoveries must forever remain unknown.

Again for many a year no one attempted to enter a field where the most celebrated of modern mariners had found but a few desert islands (South Georgia, Sandwich's Land, Southern Thule) until Smith's casual rediscovery of New South Shetland in 1819 once more turned the current of maritime exploration to the Antarctic Seas.

Soon afterwards a Russian expedition under Lazareff and Bellinghausen discovered (January, 1821), in $69^{\circ} 3^{\prime} \mathrm{S}$. lat., the islands Paul the First and Alexander, the most southern lands that had ever been visited by man.

The year after Captain Weddell, a sealer, penetrated into the icy ocean as far as $74^{\circ} 15^{\prime} \mathrm{S}$. lat., $3^{\circ}$ nearer to the pole than had been attained by Cook. The sea lay invitingly open, but as the season was far advanced, and Weddell apprehended the dangers of the return voyage, he steered again to the north.

In 1831 Biscoe discovered Enderby Land, and soon afterwards Graham's Land, to which the gratitude of geographers has since given the discoverer's name. In 1839 Balleny revealed the existence of the group of islands called 
after him, and of Sabrina Land $\left(69^{\circ} \mathrm{S}\right.$. lat.). About the same time three considerable expeditions, fitted out by the governments of France, the United States, and England, made their appearance in the Antarctic Seas.

Dumont d'Urville discovered Terre Louis Philippe ( $63^{\circ} 31^{\prime}$ S. lat.) in February, 1838 , and Terre Adélie ( $66^{\circ} 67^{\prime} \mathrm{S}$. lat.) on January 21, 1840. Almost on the same day, Wilkes, the commander of the United States Exploring Expedition, reached an ice-bound coast, which he followed for a length of 1500 miles, and which has been called Wilkes's Land, to commemorate the discover. er's name.

But of all the explorers of the southern frozen ocean, the palm unquestionably belongs to Sir James Ross, who penetrated farther towards the pole than any other navigator before or after, and made the only discoveries of extensive land within the area bounded by the Antarctic Circle.

On New Year's Day, 1841, the "Erebus," Captain James Clark Ross, and the "Terror," commanded by Francis Crozier, who died with Franklin in the Arctic Sea, crossed the Antarctic Circle, and after sustaining many severe shocks in breaking through the pack-ice, emerged on January 9 into a clear sea of great extent; but the fog and snow-showers were so thick that the navigators could seldom see more than half a mile before them. On the following day the fog began to disperse, and on the 11th, Victoria Land, rising in lofty peaks entirely covered with perennial snow, was seen at a distance of more than one hundred miles. On steering towards Mount Sabine, the highest mountain of the range, new chains of hills were seen extending to the right and left. After sailing for a few days to the south along the ice-bound coast, a gale forced the ships to stand out to sea; but on the morning of January 15, the weather becoming beautifully clear, allowed a full view of a magnificent chain of mountains stretching far away to the southward. Ross was most anxious to find a harbor in which to secure the ships, but every indentation of the coast was found filled with snow drifted from the mountains, and forming a mass of ice several hundred feet thick. It was thus impossible to enter any of the valleys or breaks in the coast where harbors in other lands usually occur. Yet these inhospitable shores $\left(72^{\circ} 73^{\prime} \mathrm{S}\right.$. lat.) are situated but one or two degrees nearer to the pols than Hammerfest, the seat of an active commerce on the Norwegian coast.

Favored by northerly winds and an open sea, the ships reached on January 22 a higher southern latitude $\left(74^{\circ} 20^{\prime} \mathrm{S}\right.$.) than that which had been attained by Weddell. Pursuing their way to the southward along the edge of the pack-ice, which now compelled them to keep at a considerable distance from the coast, they came on the 27 th within two or three miles of a small island connected by a vast ice-field with the extreme point of the mainland. Eager to set his foot on the most southerly soil $\left(76^{\circ} 8^{\prime} \mathrm{S}\right.$. $)$ he had as yet discovered, Ross left the "Erebus," accompanied by several officers, and, followed by Crozier and a party from the "Terror," pulled towards the shore. A high southerly swell broke so heavily against the cliffs and on the only piece of beach which they could see as they rowed from one end of the island to the other, as almost to forbid their landing. 
By great skill and management Ross succeeded in jumping on to the rocks. By means of a rope some of the officers landed somewhat more easily, but not without getting thoroughly wetted, and one of them nearly lost his life in this difficult affair. The thermometer being at $22^{\circ}$, every part of the rocks washed by the waves was covered with a coating of ice, so that in jumping from the boat he slipped from them into the water between her stern and the almost perpendicular rock on which his companions had landed. But for the promptitude of the men in the boat in instantly pulling off, he must have been crushed between it and the rock. He was taken into the boat without having suffered any other injury than being benumbed by the cold.

The island, which received the name of Franklin, bore not the smallest trace of vegetation, not even a lichen or piece of sea-weed growing on the rocks; but the white petrel and the skua-gull had their nests on the ledges of the cliffs, and seals were seen sporting in the water.

The following day was memorable for the discovery of the southernmost known land of the globe, a magnificent mountain chain, to which the name of Parry was given, in grateful remembrance of the honor which that illustrions navigator had conferred on Ross, by calling the most northern land at that time known by his name. It is not often that men are able to reciprocate such compliments as these! The most conspicuous object of the chain was Mount Erebus ( $77^{\circ} 5^{\prime}$ S.), an active volcano, of which Ross had the good-fortune to witness a magnificent eruption. The enormous columns of flame and smoke rising two thousand feet above the mouth of the crater, which is elevated 12,400 feet above the level of the sea, combined with the snow.white mountain chain and the deep-blue ocean to form a magnificent scene. An extinct volcano to the eastward of Mount Erebus, and a little inferior in height, being by measurement 10,900 feet high, was called "Mount Terror." A brilliant mantle of snow swept down the sides of both these giants of the south, and projected a perpendicular icy cliff several miles into the sea.

Gladly would Ross have penetrated still farther to the south, but all his efforts were baffled by a vast barrier of ice, forming an uninterrupted wall, 450 miles in length, and rising in some parts to a height of 180 feet above the sea-level. While sailing along this barrier, the ships were frequently obliged by the wind and the closely-packed ice to keep at a considerable distance; but on February 9, having entered the only indentation which they had perceived throughout its whole extent, they had an excellent opportunity of getting quite close to it, though at no little hazard. This bay was formed by a projecting peninsula of ice, terminated by a cape 170 feet high ; but at the narrow isthmus which connected it with the great barrier it was not more than fifty feet high, affording Ross the only opportunity he had of seeing its upper surface from the mast-head. It appeared to be quite smooth, and conveyed to the mind the idea of an immense plain of frosted silver. Gigantic icicles depended from every projecting point of its perpendicular eliffs, proving that it sometimes thawed, which otherwise could not have been believed; for at a season of the year equivalent to August in England, the thermometer at noon did not rise above $14^{\circ}$, and the young ice formed so quickly in the sheltered bay as to warn 
them of the necessity of a speedy retreat. Favored by the breeze, and by dint of great exertion, they ultimately emerged from their dangerous position, but scarcely had they escaped when the wind came directly against them, so that had they lingered but half an hour longer near the barrier they would certainly have been frozen up.

On February 13 the approach of winter convinced Ross that it was high time to relinquish the further examination of the barrier to the eastward; and as no place of security where it was possible to winter could be found upon any part of the land hitherto discovered, he reluctantly resolved to recross the Antarctic Circle, and postpone all attempts to reach the pole to the next season. The return voyage was difficult and dangerous. On March 7, the ships, while endeavoring to find a way through the pack-ice in lat. $65^{\circ}$, had a narrow escape from imminent destruction. The wind having ceased, they found themselves at the mercy of a heavy easterly swell, which was driving them down upon the pack, in which were counted from the mast-head eighty-four large bergs, and some hundreds of smaller size. As they rapidly approached this formidable chain, no opening could be discovered through which the ships could pass; the waves were beating violently against the bergs, and dashing huge masses of pack-ice against their precipitous faces, now lifting them nearly tc their summit, then forcing them again far beneath their water-line, and sometimes rending them in a multitude of brilliant fragments against their projecting points. "Sublime and magnificent," says Ross, " as such a scene must have appeared under different circumstances, to us it was awful, if not appalling. For eight hours we had been gradually drifting towards what to human eyes appeared inevitable destruction; the high waves and deep rolling of our ships rendered towing with the boats impossible, and our situation the more painful and em. barrassing from our inability to make any effort to avoid the dreadful calamity that seemed to await us. ..... We were now within half a mile of the range of bergs. The roar of the surf, which extended each way as far as we could see, and the crashing of the ice, fell upon the ear with fearful distinctness, whilst the frequently averted eye as immediately returned to contemplate the awful destruction that threatened in one short hour to close the world, and all its hopes, and joys, and sorrows upon us forever. In this our deep distress ' we called upon the Lord, and He heard our voices out of His temple, and our cry came before Him.' A gentle air of wind filled our sails; hope again re. vived, and the greatest activity prevailed to make the best use of the feeble breeze; as it gradually freshened, our heavy ships began to feel its influence, slowly at first, but more rapidly afterwards, and before dark we found ourselves far removed from every danger."

After passing the winter at Hobarton, the capital of Tasmania, Sir James Ross, in the following year, once more crossed the Antarctic Circle to examine the icy barrier which in his previous voyage had blocked his progress to the south, and to renew his attempts to pass round or through it. But there were new dangers to be encountered. On January 17, 1842, a fearful storm came on as the "Erebus" and "Terror" were making their way through the pack-ice, which was this time met with in a more northern latitude than the year before. 
The sea broke all the hawsers which held them to a large piece of floe, and drove them helplessly along into the heavy pack. They were now involved in an ocean of rolling fragments of ice, which were dashed against them by the waves with so much violence that their masts quivered as if they would fall at every successive blow. The loud crashing noise of the straining and working of the timbers and decks, as they were driven against some of the heavier pieces, might well appall the stoutest heart, and thus hour passed away after hour. During this terrible scene the ships were at one time so close together that when the "Terror" rose to the top of one wave, the "Erebus" was on the top of the wave next to leeward of her, the deep chasm between them being filled with heavy rolling masses; and as the ships descended into the hollow between the waves, the maintopsail-yard of each could be seen, just level with the crest of the intervening wave, from the deck of the other. The night, which now began to draw in, rendered their condition, if possible, more hopeless and helpless than before; but at midnight the snow, which had been falling thickly for several hours, cleared away, as the wind suddenly shifted to the westward; the swell began to subside, and the shocks which the ships still sustained, though strong enough to shatter any vessel less strongly ribbed, were feeble compared with those to which they had been exposed. On the following day, the wind having moderated to a fresh breeze, the crippled ships, whose rudders had been sorely shattered, were securely moored to a large floe-piece in the now almost motionless pack, where, by dint of unceasing labor, the damages were repaired in the course of a week, and the vessels once more fitted to fight their way to the south.

On February 22 the great barrier was seen from the mast-head, just before midnight, and the following day, the wind blowing directly on to its cliffs, they approached it within a mile and a half, in lat. $78^{\circ} 11^{\prime}$, the highest ever attained in the southern hemisphere. From this point, situated about $5^{\circ}$ of longitude farther to the east than the indentation where the ships had so narrowly escaped being frozen fast in the preceding year, the barrier trended considerably to the northward of east, so that Ross was obliged to give up all hope of rounding it, and extending his explorations towards the pole, as the season was already considerably advanced. On his return voyage to the Falklands, where he intended to pass the winter, he had already reached the latitude of $60^{\circ}$, and thought himself out of danger of meeting with bergs, when, in the afternoon of March 12, the southerly wind changed to a strong north-westerly breeze. In the evening the wind increased so much, and the snow-showers became so incessant, that he was obliged to proceed under more moderate sail. Small pieces of ice were also met with, warning him of the presence of bergs, concealed by the thicklyfalling snow, so that before midnight he directed the topsails of the "Erebus" to be close-reefed, and every arrangement made for rounding to until daylight, deeming it too hazardous to run any longer. "Our people," says the gallant explorer, " had hardly completed these operations, when a large berg was seen ahead and quite close; the ship was immediately hauled to the wind on the port tack, with the expectation of being able to weather it ; but just at this moment the 'Terror' was observed running down upon us, under her topsail and 
foresail; and as it was impossible for her to clear both the berg and the 'Erebus,' collision was inevitable. We instantly hove all aback to diminish the violence of the shock; but the concussion when she struck us was such as to throw almost every one off his feet ; our bowsprit, foretopmast, and other smaller spars, were carried away, and the ships hanging together entangled by their rigging, and dashing against each other with fearful violence, were falling down upon the weather face of the lofty berg under our lee, against which the waves were breaking and foaming to near the summit of its perpendicular cliffs. Sometimes the 'Terror' rose high above us, almost exposing her keel to view, and again descended, as we in our turn rose to the top of the wave, threatening to bury her beneath us, whilst the crashing of the breaking upper-works and boats increased the horror of the scene. Providentially the ships gradually separated before we drifted down amongst the foaming breakers, and we had the gratification of seeing the 'Terror' clear the end of the berg, and of feeling that she was safe. But she left us completely disabled; the wreck of the spars so encumbered the lower yard that we were unable to make sail so as to get headway on the ship; nor had we room to wear round, being by this time so close to the berg that the waves, when they struck against it, threw back their spray into the ship. The only way left to us to extricate ourselves from this awful and appalling situation was by resorting to the hazardous expedient of a stern board, which nothing could justify during such a gale but to avert the danger which every moment threatened us of being dashed to pieces. The heavy rolling of the vessel, and the probability of the masts giving away each time the lower yard-arms struck against the cliffs, which were towering high above our mast-heads, rendered it a service of extreme danger to loose the mainsail; but no sooner was the order given, than the daring spirit of the British seaman manifested itself-the men ran up the rigging with as much alacrity as on any ordinary occasion; and, although more than once driven off the yard, they after a short time succeeded in loosing the sail. Amidst the roar of the wind and sea, it was difficult both to hear and to execute the orders that were given, so that it was three-quarters of an hour before we could get the yards braced by, and the main tack hauled on board sharp aback-an expedient that perhaps had never before been resorted to by seamen in such weather; but it had the desired effect; the ship gathered sternway, plunging her stern into the sea, and with her lower yard-arms scraping the rugged face of the berg, we in a few minutes reached its western termination; the ' under-tow,' as it is called, or the reaction of the water from its vertical cliffs, alone preventing us being driven to atoms against it. No sooner had we cleared it than another was seen directly astern of us, against which we were running; and the diffculty now was to get the ship's head turned round and pointed fairly through between the two bergs, the breadth of the intervening space not exceeding three times her own breadth. This, however, we happily accomplished; and in a few minutes, after getting before the wind, she dashed through the narrow channel between two perpendicular walls of ice, and the foaming breakers which stretched across it, and the next moment we were in smooth water under its lee. The 'Terror's' light was immediately seen and answered; she had rounded to, wait- 
ing for us . . . . , and, as soon as day broke, we had the gratification of learning that she had not suffered any serious damage."

On December 17 Sir James Ross sailed from the Falkland Islands, with the intention of following the track of Weddell, as, from the account of that daring navigator, he had every reason to expect to find a clear sea, which would enable him considerably to extend the limits of geographical knowledge towards the pole. He was disappointed, for though he discovered some new land $\left(63^{\circ}-\right.$ $64^{\circ} 30^{\prime}$ S. lat., $55^{\circ}-57^{\circ} \mathrm{W}$. long.) to the south of D'Urville's Terre Louis Philippe, yet the pack-ice so blocked his progress that the farthest point he could attain was in lat. $71^{\circ} 30^{\prime} \mathrm{S}$., long. $14^{\circ} 51^{\prime} \mathrm{W}$. On March 1 he recrossed the Antarctic Circle, and on the 28th of the same month dropped his anchors at the Cape. Thus ended this most remarkable voyage, so honorable to all engaged in it, for, as Sir John Richardson justly remarks, "the perseverance, daring, and coolness of the commanding officer, of the other officers, and of the crews of the 'Erebus' and 'Terror,' was never surpassed, and have been rarely, if ever, equalled by seamen of any nation."

Since then the "Pagoda," which had been sent out by the Admiralty for the purpose of observing magnetic phenomena in a quarter of the Antarctic Seas that had not been visited by Sir James Ross, attained the 73d parallel, but no more recent expedition has been fitted out to prosecute his discoveries, and no man after him has seen Mount Erebus vomiting forth its torrents of flame, or traced the stupendous barrier which stopped his progress to the pole. 


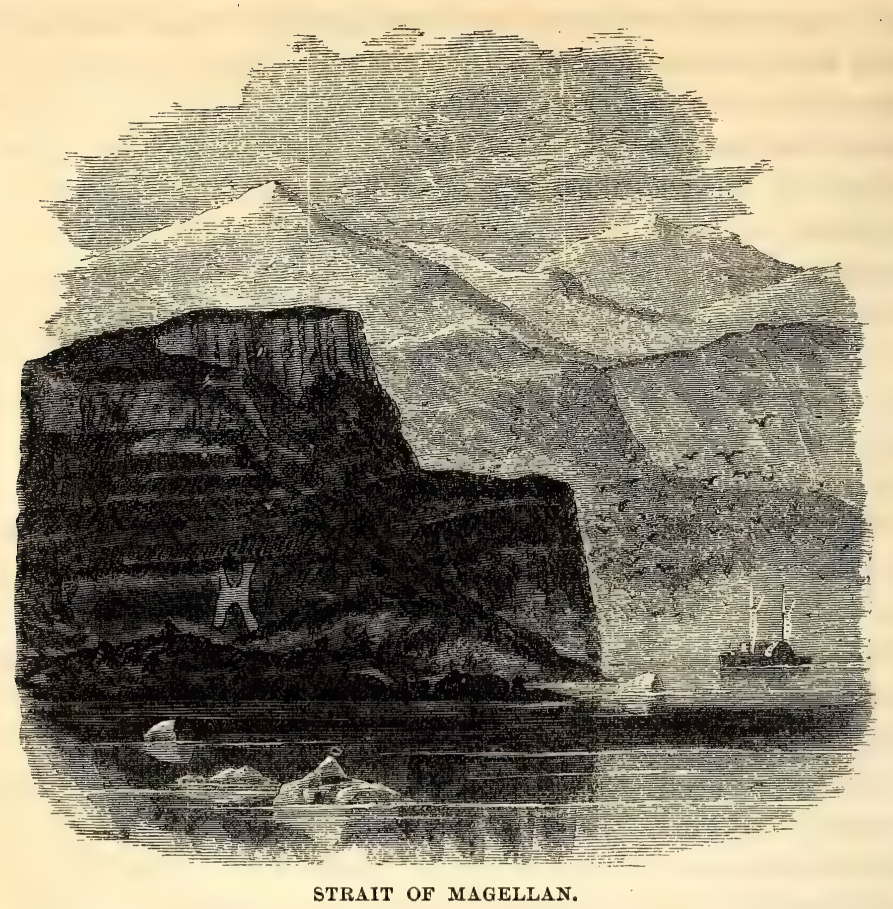

\section{CHAPTER XXXIX.}

\section{THE STRAIT OF MAGELLAN.}

Description of the Strait. -Western Entrance.-Point Dungeness.-The Narrows.-Saint Philip's Bay. - Cape Froward.-Grand Scenery.-Port Famine.-The Sedger River.-Darwin's Ascent of Mount Tarn._The Bachelor River._English Reach.-Sea Reach._South Desolation.-Harbor of Mercy._Williwaws.-Discovery of the Strait by Magellan (October 20, 1521).-Drake.-Sarmiento.-Cavendish.-Schouten and Le Maire.-Byron.-Bougainville.-Wallis and Carteret.-King and Fitzroy.-Dettlement at Punta Arenas.-Increasing Passage through the Strait.-A future Highway of Commerce.

THE celebrated strait which bears the name of Magellan is generally pictured as the scene of a wild and dreary desolation; but though its climate is far from being genial, and its skies are often veiled with mists and rain, yet nature can smile even here.

A glance at the map shows us the extreme irregularity of its formation, as it is constantly changing in width and direction; now swelling almost to the magnitude of a Mediterranean Sea, and then again contracting to a narrow passage; sometimes taking a rapid turn to the north, and at others as suddenly deviating to the south. Islands and islets of every form-some mere naked rocks, others clothed with umbrageous woods-are scattered over its surface; promontories without number, from the Patagonian mainland or the Fuegian archipelago, protrude their bold fronts into its bosom, as if with the intention 
of closing it altogether; and countless bays and havens are scooped into its rocky shores, as if the sea in a thousand different places had striven to open a new passage to her waters.

The western entrance of this remarkable strait is formed by Queen Catherine's Foreland (Cape Virgins) and Point Dungeness, the latter having been thus named from its resemblance to the well-known Kentish promontory at the eastern mouth of the channel. Although it rises at most nine feet above lowwater mark, the snow-white breakers which the tides are constantly dashing over its sides render it visible from a great distance. It is generally the resort of a number of sea-lions. When the wind comes blowing from the north-east, the passing mariner-who, from the shallow nature of the shore, is obliged to keep at some distance from the Ness-hears their hoarse bellowing, which harmonizes well with the wild and desolate character of the scene. Albatrosses and petrels hover about them, while rows of grave-looking penguins seem to contemplate their doings with philosophic indifference.

Beyond these promontories the strait widens into Possession Bay, which at Punta Delgada and Cape Orange contracts to a narrow passage. This leads into a wide basin, to which the Spaniards have given the name of Saint Philip's Bay, and which again terminates in a second narrow passage or channel, a formation resembling on a small scale the Sea of Marmora, which, as we all know, has likewise the semblance of a lake, receiving and discharging its waters through the Dardanelles and the Strait of Constantinople. During the rising of the flood, a strong current flows through all these bays and narrows from the west, so as to allow ships an easy passage, even against the wind; but during ebb tide the current turns to the east, so that at this time a vessel, even when favored by the wind, makes but little progress, or is even obliged to anchor to avoid losing ground. When Magellan, after sailing round Cape Virgins, penetrated into the strait, this circumstance at once convinced that great navigator that he was not in an inclosed bay, but in an open channel, which would lead him into another ocean. Thus far the country on both sides of the strait consists of nearly level plains, like those of Patagonia; but beyond the second Narrows the land begins to assume the more bold and picturesque appearance which is characteristic of Tierra del Fuego. Mountains rise above mountains with deep intervening valleys, all covered by one thick, dusky mass of forest; while farther to the east scarcely a bush clothes the naked soil. The trees reach to an elevation of between 1000 and 1500 feet, and are succeeded by a band of peat, with minute Alpine plants, and this again is succeeded by the line of perpetual snow, which, according to Captain King, descends to between 3000 and 4000 feet.

The finest scenery about the Strait of Magellan is undoubtedly to the east of Cape Froward, the most southerly point of the mainland of South America. This promontory, which consists of a steep mass of rock about 800 feet high, abutting from a mountain chain of about 2000 or 3000 feet in height, forms the boundary between two very different climates, for to the east the weather is finer and more agreeable than to the west, where wind and rain are almost perpetual. 
On the Patagonian plains, the drought and the want of protection against the piercing winds almost entirely impede vegetation; but the country between Cape Negro-a little within the second Narrows-and Cape Froward, or the eastern shore of Brunswick Peninsula, is shielded by its situation against the almost perpetual storms from the west, and enjoys, moreover, a sufficiency of rain, and now and then serene weather. As, moreover, the soil in this central part of the strait consists of disintegrated clay-slate, which is most favorable to the growth of trees, the forests, from all these causes, are finer here than anywhere else.

The country about Port Famine is particularly distinguished for the richness of its vegetation; and both for this reason, and from its central situation, this harbor has become a kind of chief station for the ships that pass through the strait. Several unfortunate attempts at colonization have been made at Port Famine; here many a naturalist has tarried, and thus no part of the strait has been oftener described or more accurately observed.

"The anchorage," says Dumont d'Urville, who, in December, 1837, spent several days at Port Famine, "is excellent, and landing everywhere easy. A fine rivulet gives us excellent water, and the neighboring forests might furnish whole fleets with the necessary fuel. The cliffs along the shore are literally covered with mussels, limpets, and whelks, which afford a delicious variety of fare to a crew tired of salt beef and peas. Among the plants I noticed with pleasure a species of celery, which, with another herb resembling our corn flower in form and taste, gives promise of an excellent salad.

"I made use of my first leisure to visit the romantic banks of the Sedger River, which discharges its waters on the western side of the port. At its mouth the swampy strand is completely covered with enormous trees heaped upon the ground. These naked giants, stripped of their branches, afford a remarkable spectacle: they might be taken for huge bones bleached by time. No doubt they are transported from the neighboring forest by the waters of the river, which, when it overflows its banks, after a deluge of rain, tears along with it the trees it meets with in its course. Arrested by the bar at the mouth of the stream, they are cast out upon its banks, ... there temain when the waters sink to their usual level.

"Having crossed the river, I entered the large and fine forest with which it is bordered. The chief tree is the Antarctic beech (Fagus betuloides), which is often from sixty to ninety feet high, and about three feet in diameter. Along with this are two other trees, the winter's bark (Winteria aromatica), and a species of berberis, with a very solid wood; but they are much less abundant, and of a much smaller size. With the exception of mosses, lichens, and other plants of this order, these forests afford but little that is interesting to the naturalist-no quadrupeds, no reptiles, no land-snails; a few insects and some birds are the only specimens to be gained after a long search. After collecting a good supply of mosses and lichens, I returned to the boat for the purpose of rowing up the river. Although the current was tolerably rapid, we advanced about two miles, admiring the beauty of its umbrageous banks. On my return I shot two geese that were crossing the river over our heads, and 
whose excellent meat amply supplied my table for several days. This, together with the little gobies which were abundantly caught with hand-lines, the large mussels we detached from the rocks, and the celery-salad, gave me dinners fit for an alderman. How often since have I regretted the plenty of Port Famine!"

In the month of February (1834), in the height of the Antarctic summer, Mr. Darwin ascended Mount Tarn, which is 2600 feet high, and the most elevated point in the vicinity of Port Famine. "The forest," says our great naturalist, "commences at the line of high-water mark, and during the first two hours I gave over all hopes of reaching the summit. So thick was the wood that it was necessary to have constant recourse to the compass, for every landmark, though in a mountainous country, was completely shut out. In the deep ravines the death-like scene of desolation exceeded all description; outside it was blowing a gale, but in these hollows not even a breath of wind stirred the leaves of the tallest trees. So gloomy, cold, and wet was every part, that not even the fungi, mosses, or ferns could flourish. In the valleys it was scarcely possible to crawl along, they were so completely barricaded by great mouldering trunks, which had fallen down in every direction. When passing over these natural bridges, one's course was often arrested by sinking knee-deep into the rotten wood; at other times, when attempting to lean against a tree, one was startled by finding a mass of decayed matter, ready to fall at the slightest touch. We at last found ourselves among the stunted trees, and then soon reached the bare ridge, which conducted us to the summit. Here was a view characteristic of Tierra del Fuego ; irregular chains of hills, mottled with patches of snow, deep yellowish-green valleys, and arms of the sea intersecting the land in many directions. The strong wind was piercingly cold, and the atmosphere rather hazy, so that we did not stay long on the top of the mountain. Our descent was not quite so laborious as our ascent; for the weight of the body forced a passage, and all the slips and falls were in the right direction."

To the west of Cape Froward the strait extends in a north-westerly, almost rectilinear direction, until it finally opens into the Pacific, between Cape Pillar and Cape Victory. Here a day rarely passes without rain, hail, or snow. Where the dreadful power of the prevailing winds has free play, the mountain sides are naked and bare, but in every sheltered nook the damp climate produces a luxuriant vegetation. The trees, however, do not attain any great height, and at Port Gallant the beech is already decidedly stunted in its growth. This is no doubt caused by the excessive humidity of the soil, which in all lower situations is converted by the continual rains into a deep morass. The trunks and the branches are covered with a thick layer of moss, and the tree becomes rotten in its youth. But many shrubs, herbs, and mosses thrive under the perpetual del. uge; the latter particularly, covering large patches of ground with a spongy carpet. It may easily be imagined how difficult, or rather impossible it must be to penetrate into the interior of such a country. Yet even these wild inhospitable regions can boast of many a romantic scene. Thus the English Reach, which extends from Cape Froward to Carlos Island, is bounded on both sides by lofty 
mountains, their cones or jagged peaks covered with eternal snow. Its south. ern bank, formed by Clarence Island, is intersected with bays and channels, two of which, Magdalena Sound and Barbara Channel, lead through a maze of islands into the open sea. Several glaciers descend in a winding course from the upper great expanse of snow to the sea-coast, and many a cascade comes dashing down from rock to rock. Skogman* draws an enthusiastic picture of the beauty of York Roads near the mouth of the small Bachelor River. To the south, behind Carlos Island, mountains rise above mountains, and snow-fields above snow-fields; to the north lies the jagged colossus, which from its solitary grandeur has been called Bachelor Peak, and at whose foot the crystal river now hides itself beneath a shady wood, and now rolls its crystal waters through a green lawn, decorated with clumps of fuchsias. But in spite of its romantic beauty, the want of life gives a melancholy character to this solitary vale. Beyond Carlos Island in Long Reach, the banks of the strait become yet more bare and desolate. Vegetation descends lower and lower into the valleys, and even here the trees are misshapen and dwarfish. But the mountain scenery has still all the majesty which snow-fields and glaciers of a beryl-like blue impart to an Alpine landscape. As Sea Reach shows itself, vegetation is almost totally extinct, and on approaching the mouth of the strait, the mountains become lower, their forms are less picturesque, and instead of the stern grandeur which marks the middle part of the strait, low, rounded, barren hills make their appearance, which completely justify the name of South Desolation, which Sir James Narborough gave to this coast, "because it was so desolate a land to behold."

It may easily be imagined that the prevailing winds beyond Cape Froward are extremely troublesome to ships sailing to the western mouth of the strait, and that if not entirely beaten back, they can frequently only force the passage after many efforts. Fortunately, the deeply indented coasts possess a number of small havens which may serve the mariner as stations during his gradual advance. Thus, close to the mouth of the strait, where, between Cape Victory and Cape Pillar, the sea during and after storms is so boisterous that even steamers require their utmost strength not to be dashed against the rocks, a secure port, appropriately called "Harbor of Mercy," allows the vessels to watch for more tranquil weather, and to seize the first favorable opportunity for emerging into the open sea. But even these harbors and bays are subject to peculiar dangers from sudden gusts of wind that come sweeping down from the mountains, and are known among the seal-catchers who frequent these dangerous waters under the name of williwaws, or hurricane squalls. For when the wild south-west storms come rushing against the mountain-masses of Tierra del Fuego, the compressed air precipitates itself with redoubled violence over the rock-walls, and then suddenly expanding, flows down the valleys or gullies, tearing up trees by the roots, and hurling rocks into the abyss. Where such a gust of wind touches the surface of the water, the sea surges in mighty waves, and volumes of spray are whirled away to a vast distance. If a ship comes under its influence, its safety depends mainly upon the strength of its anchor ropes.

Some situations are particularly subject to williwaws, and then the total want

* Voyage of the Swedish ship "Eugénie." 
of vegetation and the evident marks of ruin along the mountain slopes warn the mariner to avoid the neighborhood. In Gabriel Channel Captain King saw a spot where the williwaws, bursting over the mountains on the south side, had swept down the declivities, and then rushing against the foot of the opposite hills, had again dashed upward with such fury as to carry away with them every thing that could possibly be attached from the bare rock.

It was a memorable day in the annals of maritime discovery (October 20, 1521) when Magellan reached the eastern entrance of the strait that was to lead him, first of all European navigators, from the broad basin of the Atlantic into the still wider expanse of the Pacific Ocean. It was the day dedicated in the Catholic calendar to St. Ursula and her eleven thousand virgins, and he consequently named the promontory which first struck his view "Cabo de las Virgines." The flood tide, streaming violently to the west, convinced him that he was at the mouth of an open channel, but he had scarcely provisions for three months-a short allowance for venturing into an unknown world, and thus before he attempted the passage he convoked a council of all his officers. Some were for an immediate return to Europe, but the majority voted for the continuation of the voyage, and Magellan declared that should they even be reduced to eat the leather of their shoes he would persevere to the last, and with God's assistance execute the commands of his imperial master Charles V. He then at once gave orders to enter the strait full sail, and on pain of death forbade any one to say a word more about a return or the want of provisions.

Fortunately the winds were in his favor, for had the usual inclemencies of this stormy region opposed him, there is no doubt that with such crazy vessels, and such discontented crews, all his heroism would have failed to insure success. It was the spring of the southern hemisphere, and the strait showed itself in one of its rare aspects of calm. Many fish were caught, and, as Pigafetti, the historian of the voyage, relates, the aromatic winter's bark which served them for fuel "wonderfully refreshed and invigorated their spirits."

The fires kindled by the savages on the southern side during the night induced Magellan to give that part of the country the name of Tierra del Fuego, or Fireland; while from their high stature and bulky frames, he called the inhabitants of the opposite mainland Patagonians (patagon being the Spanish augmentative of pata, foot). Although several days were lost in exploring some of the numerous passages and bays of the straits, its eastern mouth was reached on November 28, and Magellan saw the wide Pacific expand before him.

In 1525 Charles V. sent out a new expedition of six vessels, under Garcia de Loaisa, to circumnavigate the globe. The vice-admiral of the squadron was Sebastian el Cano, who, after the death of Magellan, had brought the illustrious navigator's ship safely back to Europe, and as a reward had been ennobled with the globe in his coat of arms, and the motto, "Primus circumdedisti me." Loaisa entered the strait on January 26, 1526, but he was beaten back by storms as far as the River Santa Cruz. On April 8 he once more attempted the passage, and emerged into the Pacific on May 25. Simon de Alcazaba, who in 1534 attempted to pass the Magellans with a number of emigrants for Peru, 
was less successful, but in 1539, Alfonso de Camargo, having lost two vessels in the strait, passed it with the third, and reached the port of Callao.

Until now the Spanish flag had alone been seen in these remote and solitary waters, but the time was come when they were to open a passage to its most inveterate foes. On August 20, 1579, Francis Drake, commissioned by Queen Elizabeth to plunder and destroy the Spanish settlements on the west coast of America, ran into the strait, and on December 6 sallied forth into the Pacific.

To meet this formidable enemy, the Viceroy of Peru sent out in the same year two ships under Pedro Sarmiento de Gamboa. His orders were to intercept Drake's passage through the strait and then to sail on to Spain. Though he failed in the object of his mission, yet Sarmiento displayed in the navigation of the intricate and dangerous passages along the south-west coast of America, the courage and skill of a consummate seaman, and he gave the first exact and detailed account of the land and waters of Fuegia. His voyage, according to the weighty testimony of Captain King, deserves to be noted as one of the most useful of the age in which it was performed.

On his arrival in Spain, Sarmiento strongly pointed out the necessity of establishing a colony and erecting a fort in the strait (at that time the only known passage to the Pacific), so as effectually to prevent the recurrence of a future hostile expedition like that of Drake. Commissioned by Philip II. to carry his plans into execution, he founded a colony, to which he gave the name of Ciudad de San Felipe, but a series of disasters entirely destroyed it; and when, a few years later, Cavendish, who had fitted out three ships at his own expense to imitate the example of Drake, appeared in the strait, he found but three survivors of many hundreds, and gave the scene of their misery the appropriate name of Port Famine, which it has retained to the present day.

After Cavendish and Hawkins (1594), the Dutch navigators De Cordes (1599), Oliver Van Noort (1599), and Spilberg (1615), attempted, with more or less success, to sail through the strait with the intention of harassing and plundering the Spaniards on the coast of the Pacific.

Strange to say, no attempt had been made since Magellan to discover a passage farther to the south, so universal and firmly established was the belief that Fuegia extended without interruption to the regions of eternal ice, until at length, in 1616, the Dutchmen Schouten and Le Maire discovered the passage round Cape Horn. Two years later Garcia de Nodales sailed through the Strait of Le Maire, and, returning through the Magellans into the Atlantic, was thus the first circumnavigator of Fuegia. In 1669, Sir John Narborough having been sent out by King Charles II. to explore the Magellanic regions, furnished a good general chart of the strait, and many plans of the anchorage within it.

More than sixty years now elapsed before any expedition of historical renown made its appearance in the strait. The dangers and hardships which had assailed the previous navigators discouraged their successors, who all preferred the circuitous way round Cape Horn to the shorter but, as it was at that time considered, more perilous route through the strait. After this long pause, Byron (December, 1764) and Bougainville (February, 1765) once more attempted 
the Magellans. The difficulties encountered by them were surpassed by those of Wallis and Carteret. The former spent nearly four months (from December 17, 1766, to April 11, 1767) in a perpetual conflict with stormy weather while slowly creeping through the strait; and the latter required eighty-four days for his passage from Port Famine to Cape Pillar. No wonder that the next circumnavigators, Lütke, Krusenstern, Kotzebue, preferred sailing round Cape Horn, and that adventurous seal-hunters became for a long time the sole visitors of these ill-famed waters. At length the British Government came to a resolution worthy of England, and resolved to have the Magellanic regions carefully surveyed, and to conquer them, as it were, anew for geographical science. Under the command of Captain King, the "Adventure" and the "Beagle" were engaged in this arduous task from 1826 to 1830 ; but such were the dangers they had to encounter, that Captain Stokes, the second in command, after contending for four months with the storms and currents which frequently threatened to dash his vessel against the cliffs, became so shattered in mind and body, that after his return to Port Famine he committed suicide in a fit of melancholy.

From 1831 to 1834 Captain Fitzroy was engaged in completing the survey of Patagonia and Tierra del Fuego, and the result of all these labors was a collection of charts and plans which have rendered navigation in those parts as safe as can be expected in the most tempestuous region of the globe.

While formerly the passage round Cape Horn was universally preferred, the more accurate knowledge of the Strait of Magellan, for which navigation is indebted to the labors of King and Fitzroy, has since then turned the scale in favor of the latter.

For a trading-vessel, with only the ordinary number of hands on board, the passage through the strait from east to west is indeed very difficult, and even dangerous; but in the opposite direction, the almost constant westerly winds render it commodious and easy particularly during the summer months, in which they are most prevalent.

For small vessels - clippers, schooners, cutters - the passage in both directions is, according to the excellent authority of Captain King, much to be preferred. Such vessels have far more reason for fearing the heavy seas about Cape Horn ; they can more easily cross against the west winds, as their manœuvres are generally very skillful, and they find in the Sound itself a great number of anchoring-places, which are inaccessible to larger vessels.

For steamers the advantage is entirely on the side of the Strait, and they consequently now invariably prefer this route. Here they find plenty of wood, which enables them to save their coals; and moreover, from Cape Tamar as far as the Gulf of Penas, an easy navigation for about 360 sea miles through the channels along the west coast of America.

As the trade of the Pacific is continually increasing, and the Strait of Magellan more frequented from year to year, we can not wonder that the old project of settling a colony on its shores should have been revived in our days. About the year 1840 the Government of Chili established a penal colony at Punta Arenas and Port Famine, which miserably failed in consequence of a mutiny ; but 
in 1853 about one hundred and fifty German emigrants were settled at Punta Arenas, and when the "Novara" visited the strait in 1858, they were found in a thriving condition. Should the project of stationing steam-tugs in the strait, and of erecting lighthouses at Cape Virgins and at the entrance of Smyth Channel be executed, the Magellans would become one of the high-roads of commerce, and the dangers which proved so dreadful to the navigators of former days a mere tale of the past.

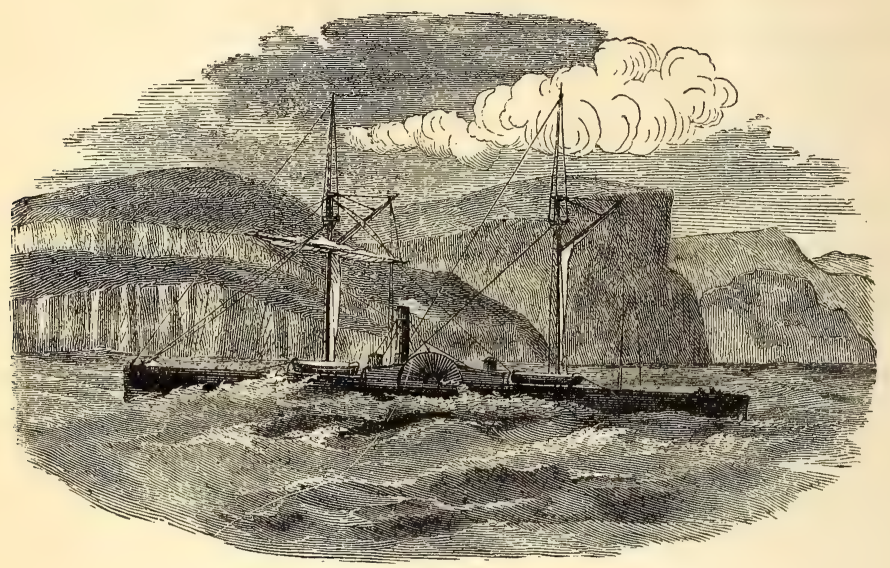

A HIGHWAY OF COMMERCE. 


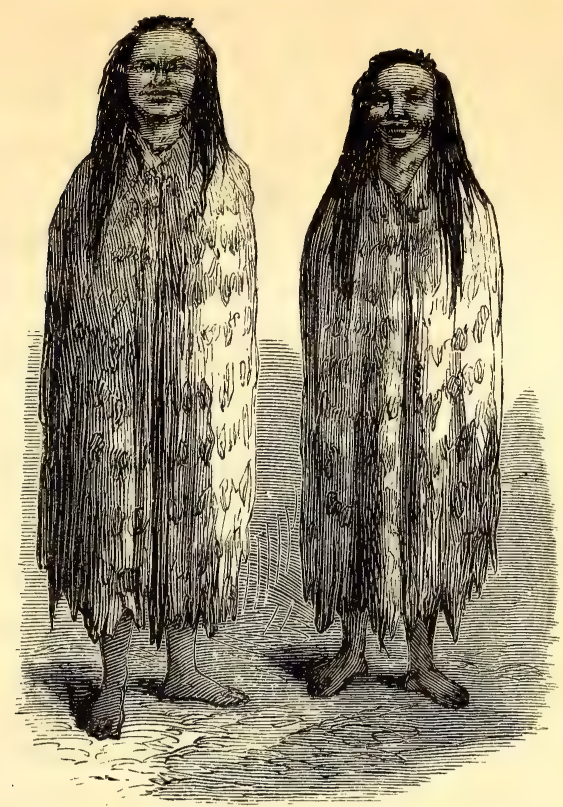

patagonians.

\section{CHAPTER XL.}

\section{PATAGONIA AND THE PATAGONIANS.}

Difference of Climate between East and West Patagonia._-Extraordinary Aridity of East Patagonia.Zoology.-The Guanaco. - The Tucutuco.-The Patagonian Agouti. - Vultures. - The Turkey-buzzard.-The Carrancha._The Chimango._-Darwin's Ostrich._-The Patagonians._Exaggerated Accounts of their Stature.-Their Physiognomy and Dress._Religious Ideas. - Superstitions. - Astronomical Knowledge.-Division into Tribes.-The Tent, or Toldo.-Trading Routes.-The great Cacique.-Introduction of the Horse.-Industry.-Amusements.-Character.

Patagonia, the southern extremity of the American continent, is divided 1 by the ridge of the Andes into two parts of a totally different character. Its western coast-lands, washed by the cold Antarctic current and exposed to the humid gales of a restless ocean, are almost constantly obscured with clouds and drenched with rain. Dense forests, dripping with moisture, clothe the steep hill-sides; and, from the coldness of the summer, the snow-line is so low that for 650 miles northward of Tierra del Fuego almost every arm of the sea which penetrates to the interior higher chain is terminated by huge glaciers descending to the water's edge.

East Patagonia, on the contrary, a vast plain rising in successive terraces from the Atlantic to the foot of the Cordillera, is one of the most arid regions of the globe. The extreme dryness of the prevailing westerly winds, which have been totally deprived of their humidity before crossing the Andes, and the well-rounded shingles which compose the soil, have entailed the curse of 
sterility on the land. Monotonous warm tints of brown, yellow, or light red everywhere fatigue the eye, which vainly seeks for rest in the dark blue sky, and finds refreshing green only on some river-banks.

Many broad flat vales transsect the plains, and in these the vegetation is somewhat better. The streams of former ages have no doubt hollowed them out, for the rivers of the present day are utterly inadequate to the task. On account of the dryness of the atmosphere, the traveller may journey for days in these Patagonian plains without finding a drop of water. Springs are rare, and even when found are generally brackish and unrefreshing. While the "Beagle" was anchoring in the spacious harbor of Port St. Julian, a party one day accompanied Captain Fitzroy on a long walk round the head of the harbor. They were eleven hours without tasting any water, and some of the party were. quite exhausted. From the summit of a hill, to which the appropriate name of "Thirsty Hill" was given, a fine lake was spied, and two of the party pro. ceeded, with concerted signals, to show whether it was fresh water. The dis' appointment may be imagined when the supposed lake was found to be a snow-white expanse of salt, crystallized in great cubes.

The extreme dryness of the air, which imparts so sterile a character to the country, favors the formation of guano deposits on the naked islands along the coast, which are frequented by sea-birds. Protracted droughts are essential to the accumulation of this manure, for repeated showers of rain would wash it into the sea, and for this reason no guano deposits are found on the populous bird-mountains of the north. A similar dryness of the atmosphere favors the deposit at Ichaboe on the African coast, at the Kooria Nooria Islands in the Indian Ocean, and at the Chincha Islands on the Peruvian coast; and this kind of climate appears also to be particularly agreeable to the seabirds.

Considering the excessive aridity of Patagonia, it seems surprising that the country should be traversed from west to east by such considerable rivers as the Rio Negro, the Gallegos, and the Santa Cruz; but all these have their sources in the Andes, and are fed by mountain torrents, which no doubt derive their waters from the atmospherical precipitations of the Pacific.

The zoology of Patagonia is as limited as its flora, and greatly resembles in its character that of the mountain regions of Chili, or of the Puna or high table-land of the tropical Andes of Peru and Bolivia, the height of which varies from 10,000 to 14,000 feet above the level of the sea.

In all these countries, situated in such different latitudes, the explorer is astonished to find not only the same genera, but even animals of the same species. The forest-loving race of monkeys is nowhere to be founā in treeless Patagonia. None of the quadrumana ventures farther south than $29^{\circ}$ lat., but on the borders of the Rio Negro, the northern boundary of Patagonia, some small bats are seen fluttering about in the twilight.

The dark-brown yellow-headed Galictis vittata, an animal allied to the Civets and Genets, is likewise found there, but much more frequently its relation the Zorilla, which ranges from $30^{\circ}$ lat. to the Strait of Magellan, and, like the skunk of the north, has the power of discharging a fluid of an intolerably fetid odor. 
The guanaco is the characteristic quadruped of the plains of Patagonia, where it is no less useful to man than the wild reindeer to the savage hunters of the north. It ranges from the Cordillera of Peru as far south as the islands near Cape Horn, but it appears to be more frequent on the plains of South Patagonia than anywhere else. It is of greater size than the llama, and resembles it so much that it was supposed to be the wild variety, until Tschudi, in his "Fauna Peruana," pointed out the specific difference between both. The guanaco is a more elegant animal, with a long, slender neck and fine legs; its fleece is shorter and less fine; its color is brown, the under parts being whitish. It generally lives in small herds of from half a dozen to thirty in each; but on the banks of the Santa Cruz Mr. Darwin saw one herd which contained at least five hundred. Though extremely shy and wary, it is no match for the cunning of the savage; and, before the horse was introduced into Patagonia, man most probably could not have existed in those arid plains without the guanaco. It easily takes to the water, and this accounts for its presence on the eastern islands of Fuegia, where it has been followed by the puma, or American lion, who likewise pursues it on the plateaus of the Cordillera, 12,000 feet above the level of the sea.

The Brazilian fox (Canis Azarce) is also met with as far as the strait. It is somewhat smaller than our fox, but more robustly built. In Patagonia it preys chiefly upon the small rodents, with which the land, in spite of its sterility, is perhaps more richly stocked than any other country in the world. Among these the tucutuco (Ctenomys magellanica), which may briefly be described as a gnawer with the habits of a mole, is one of the most remarkable. It abounds near the strait, where the sandy plain is one vast burrow of these creatures. This curious animal makes, when beneath the ground, a very peculiar noise, consisting of a short nasal grunt, monotonously repeated about four times in quick succession, the name tucutuco being given in imitation of the sound. Where the animal is abundant, it may be heard at all times of the day, and sometimes directly beneath one's feet. The tucutuco is nocturnal in its habits; its food consists chiefly of roots, the search after which seems to be the cause of its burrowing.

Among the indigenous quadrupeds of Patagonia we find, moreover, a species of agouti (Dasyprocta patagonica), which in some measure represents our hare, but is about twice the size, and has only three toes on its hind feet; the elegant long-eared mara (Dolichotis patagonicus), which, unlike most burrowing animals, wander's, commonly two or three together, for miles from its home; the Didelphis Azarce, a species of opossum; and the pichy (Dasypus minutus), a small armadillo, which extends as far south as $50^{\circ}$ lat.

It would be vain to seek among the Patagonian birds for the splendid plumage of the tropical feathered tribes; their colors are simple and monotonous, as those of the naked plains which are their home. Many birds of prey of the warmer regions of America likewise frequent the arid wastes of Patagonia. When a horse chances to perish from fatigue or thirst, the turkey-buzzard (Vultur aura?) begins to feast upon its carcass, and then the carrancha (Polyborus brasiliensis) and the chimango (Polyborus chimango) pick its bones 
clean. Though these birds, which well supply the place of our carrion-crows, magpies, and ravens, generally feed in common, they are by no means on a friendly footing. When the carrancha is quietly seated on the branch of a tree or on the ground, the chimango often continues for a long time flying backward and forward, up and down, in a semicircle, trying each time, at the bottom of the curve, to strike its larger relative, which takes little notice except by bobbing its head. The carrancha, which is common in the dry and open countries, and likewise on the arid shores of the Pacific, is also found inhabiting the forests of West Patagonia and Tierra del Fuego. The chimango is much smaller than the carrancha. Of all the carrion feeders, it is generally the last which leaves the skeleton of a dead animal, and may frequently be seen within the ribs of a horse, like a prisoner behind a grating. It is frequently found on the sea-coast, where it lives on small fishes.

The condor may likewise be reckoned among the Patagonian birds, as it follows its prey, the guanaco, across the Strait of Magellan as far as the eastern lowlands of Tierra del Fuego. In the winter especially, when the cold forces vast numbers of geese and ducks to quit the Antarctic islands in the higher latitudes, all these birds of prey, to which the crowned falcon (Circcetes coronalus), the three-colored buzzard (Buteo tricolor), the Aguia eagle) Halicetus aguia), and several others must be added, live in luxury. Most of them are likewise migratory birds, and disappear in summer, with the defenseless tribes on which they prey. The Magellanic thrush (Turdus magellanicus) leaves in winter the stormy banks of the strait, and retires to the milder skies of the Rio Negro, where it meets the tuneful Patagonian warbler (Orpheus patagonicus), the nimble troglodyte (Troglodytes pallida), and the inconstant fly-catcher (Muscicape parvulus).

A peculiar species of ostrich, the nandu (Rhea Darwini), roams over the plains of Southern Patagonia as far as the Strait of Magellan. It is smaller than the South American ostrich (Rhea americana), which inhabits the country of La Plata as far as a little south of the Rio Negro; but it is more beautiful, as its white feathers are tipped with black at the extremity, and its black ones in like manner terminate in white.

In the same high latitude one is surprised to meet with a member of the parrot tribe (Psittacus patagonicus) feeding on the seeds of the winter's bark, and to see humming-birds (Trochilus forficatus) flitting about during the snowstorms in the forests of Tierra del Fuego.

The plains of Patagonia are inhabited by a race of Indians supposed to be gigantic, but the descriptions of modern travellers have dispelled the idea. Thus Pigafetti, the companion of Magellan, relates that the Europeans only reach to the waist of the Patagonians; Simon de Weert tells us that they are from ten to eleven feet high; Byron, who visited them in the last century, reduces them to seven feet, and Captain King finally, who accurately measured them, found the medium height of the males about five feet eleven inches. As the Patagonians have most likely not degenerated within the last few centuries, we may infer from these various accounts that the travellers of the present day are less prone to exaggeration than those of more ancient times. So much is 
certain, that the Patagonians are a fine athletic race of men, with remarkably broad shoulders and thick muscular limbs. The head is long, broad, and flat, and the forehead low, with the hair growing within an inch of the eyebrows, which are bare; the eyes are often placed obliquely, and have but little expression; the forehead and the large lips are prominent, so that if a perpendicular line were drawn between the two, the thick flat nose would hardly reach it, and but seldom project beyond it. In spite of these coarse features the physiognomy of the young girls is by no means unpleasant, as it has an amiable, lively ex. pression. All of them have small hands and feet, and D'Orbigny says that they have the finest shapes of all the savages he saw. Though they have a wide mouth and thick lips, this fault is redeemed by their beautiful white teeth, which never fall out even in old age.

The color of the Patagonians is much darker than that of the Pampas Indians and others farther to the north, and most closely resembles that of the mulatto; a fact totally at variance with the common belief that the darkness of the human skin increases on approaching the equator.

The chief garment is the manuhé, a wide, square mantle-eight feet long and nearly as broad-which they wear after the fashion of the ancient Greeks and Romans, with one end hanging down to the earth. It generally consists of guanaco skins neatly sewn together with ostrich sinews. In cold weather the manuhé, which serves also as a blanket, is worn with the hair inside; the even surface is therefore ornamented with red drawings. Sometimes they wear boots of horse-leather, like the Gauchos, from whom they have learned to make them; formerly sandals of guanaco skin were alone in use. Their long black hair is tied behind with a thong of leather or a piece of ribbon; the women plait and adorn it with a number of ornaments of glass and copper. The tace is generally painted red, white, and black, and a Patagonian is never seen without the little pouch in which he carries the necessary colors. A remarkable custom, common to all the Indian tribes as far as Bolivia, is that of eradicating the hairs of the beard, and the men may frequently be seen plucking them out with a pair of pincers.

The religious ideas of the Patagonians greatly resemble those of their neighbors the Aucas and the Puelches. The divine Achekenat Kanet is reverenced as the genius of both good and evil; but beside this chief deity they have a number of inferior spirits, generally of a malignant nature, which can be held in check only by the arts of their magicians. Like the shamans, or medicinemen of the north, these impostors work themselves into an ecstatic state, in which they predict things to come, or announce the will of the unseen gods; but their trade does not seem to be very lucrative if we may judge from the bad condition of their mantles. They also act as physicians, for all diseases are invariably ascribed to the agency of evil spirits.

The Patagonians are quite as superstitious as the Indians of the high northern latitudes. They seldom cut their hair, but when they do, they cast it into the river or carefully burn it, so that it may not fall into the hands of some malignant magician, who might use it to the hurt of its quondam owner. When, on journeying along a river, they see some trunks of trees descending with the 
current, they take them for evil spirits, and address them with a loud voice. If by chance the trees are swept by less rapidly or are driven round in a whirlpool, they believe that this takes place for the purpose of hearing them. They then make them liberal promises, which they faithfully keep. They cast their weapons, their ornaments, sometimes even their horses with bound feet, into the water, fully persuaded that by this sacrifice they have averted the misfortunes that otherwise would have befallen them. Like many other savage nations, they believe in a future paradise, where they expect to find again all that they prized on earth. For this reason they immolate over the graves of their friends all the animals that belonged to them, and inter with them all they possesse 1 .

The astronomical knowledge of the Patagonians is surprising in a people ranking so low in the scale of civilization. Continually migrating over their arid land, they soon felt the necessity of directing their movements during the day by the position of the sun, during the night by the stars; and thus they gradually learned to observe the march of the constellations, and to note the times of their appearance and disappearance, giving them names, so as to be able to communicate their observations to each other. Their lively fancy traces in the starry firmament the picture of the Indian's hunting expedition. The Milky Way is the path on which he follows the ostrich; the "Three Kings" are the bolas, or balls, with which he strikes the bird whose feet form the Southern Cross; and the Magellanic clouds are heaps of its feathers that have been collected by its pursuer.

When the Patagonians speak of the direction they intend to follow, from north to south or from east to west, they always indicate the constellations; so that in these South American plains, as in those of Chaldea, a similar necessity has led man to lay the first foundations of astronomical knowledge.

The Patagonians are divided into a number of small migratory tribes, each consisting of, at the utmost, thirty or forty families. As they live exclusively by the chase, it is evident that a few days wonld suffice to destroy or to drive away the game of a great extent of territory were they to assemble in larger numbers. Not to perish of want, they are thus compelled to wander from place to place in small companies, and to carry along with them their leathern toldos, or tents. The toldo reposes on a frame of poles stuck into the earth, and is scarcely higher than six feet in its centre, so that one can hardly imagine how a family of tall Patagonians can live in so small a space. The door is invariably to the east, so that early in the morning the chief of the family may sprinkle before it a few drops of water as an offering to the rising sun, for were this sacrifice to be neglected, the evil spirits would infallibly wreak their vengeance upon the inmates of the tent. Horse-hides, or guanaco skins coarsely sewn together, cover the frame, and afford but a scanty protection against the rain and the much more frequent wind. At the top, as in the Laplander's hut, an opening is left to let out the smoke. The hearth is in the middle, and close by lie some earthen vases, and large volute shells which serve as drinking-horns. The inmates lie on skins, or sit in a corner cross-legged, after the Oriential fashion. The excessive filth of these wretched tenements makes their poverty appear still 
more squalid than it really is. Thirty or forty toldos form a migratory village, or tolderia. Though the dreadful small-pox epidemic from 1809 to 1812 destroyed whole tribes of Patagonians, their present number may still be estimated at from eight to ten thousand; a small one, when compared with the size of the country, yet large enough when we consider the sterile nature of its soil and the vast space of desert needed to feed a sufficient number of guanacos and horses for the wants of even a scanty population. Each tolderia appears to have its territory limited by the hunting-grounds of its neighbors, but commercial transactions take place between the various tribes, and occasion longer journeys. One of the chief trading routes runs along the eastern foot of the Andes from the Strait of Magellan to the Rio Negro, as water is here everywhere found; another, leading parallel with the coast from the Rio Negro to Port St. Julian and Port Desire, is only frequented in the rainy season, and even then there are wide spaces without any sweet water, and where it is necessary to travel night and day so as to avoid the danger of dying of thirst.

Every year the various Patagonian tribes wander to the sources of the Rio Negro, where they provide themselves with araucaria seeds, which serve them as food, or with apples, which have multiplied on the eastern spurs of the Andes in the same astonishing manner as the peach-trees near the mouths of the La Plata. The apple-tree was introduced by the first Spaniards who inhabited the Chilian Andes soon after the conquest; and when later the intruders were expelled by the victorious Araucanians, the natives found their country enriched by this valuable acquisition.

One of the chief bartering rendezvous is the island Cholechel, which is formed by two arms of the Rio Negro, about eighty leagues from the mouth of the river. Here the Patagonian exchanges his guanaco skins for the articles which the Puelches, his northern neighbors, either fabricate themselves or procure in a more easy manner by stealing them from the white settlers in their neighborhood. This bartering trade is very ancient, and has always existed excepting in times of war. In this manner the Patagonians were provided with horses soon after the introduction of this valuable animal into the New World, and thus also articles of Spanish manufacture soon found their way as far as the Strait of Magellan.

At present there seems to be peace among all the Patagonian tribes, which consider themselves as brothers, though frequently separated several hundred leagues from each other.

Their system of government is very simple. The whole nation has a chief, or great cacique, whom they call carasken, and whose authority is very limited. In war he presides in the assembly of the minor chiefs, and has the supreme command in battle. In peace his sway is confined to his own tribe. He is as poor as his subjects, and, far from enjoying a copious civil list, is obliged to hunt for his subsistence like every other Patagonian; the only advantage he owes to his exalted station being a somewhat larger share of the products of the chase ; and this he is obliged to distribute among the more needy of his followers, to maintain his influence. The dignity of carasken is not always hereditary. To succeed his father, the son must first prove by his eloquence, his 
courage, and his liberality that he is worthy to succeed him; and if he is found wanting, the Indian most distinguished by his moral and intellectual qualities is elected in his place.

The Patagonians are very awkward fishermen; they merely catch what chance throws into their hands, and are unacquainted with nets or any other piscatorial artifice. In this respect they are totally different from the Fuegians, who derive their chief subsistence from the sea. They have ever been a nation of hunters, and before the introduction of the horse, they pursued their game on foot, using their bolas with great dexterity for the destruction of the guanaco and the ostrich. Their dogs afforded them a valuable assistance, and since they have become accomplished horsemen, their fleet coursers enable them to overtake with ease all the animals of the wilderness. In times of scarcity they dig for a small root, which is either eaten fresh or preserved dry. Horse-fiesh is their favorite food.

The Patagonian toldos and their weapons are very rudely made, but their skin mantles are not untastefully ornamented with rectilinear figures. In their war-dress they have a very hideous appearance, and it would be difficult to imagine a more diabolical figure than that of a tall Patagonian ready for a fight, his broad face painted scarlet, with black or blue stripes under the eyes, and his coarse features distorted with fury. Their arms are bows and arrows, with points of flint loosely attached with sinews, so as to remain sticking in the wound. They are excellent archers, and use with skill the sling, the javelin, and above all their formidable bolas, which serve them both for bringing the guanaco to the ground or for breaking the skull of an enemy. When not engaged in war or in the chase, the men, like most savages, pass their time in absolute idleness, leaving all the household work to the women. Amusements they have but few. The use of dice they have learned from the Spaniards. They are said to be a false and deceitful people, but their hospitality and goodnature have been frequently extolled by travellers. 


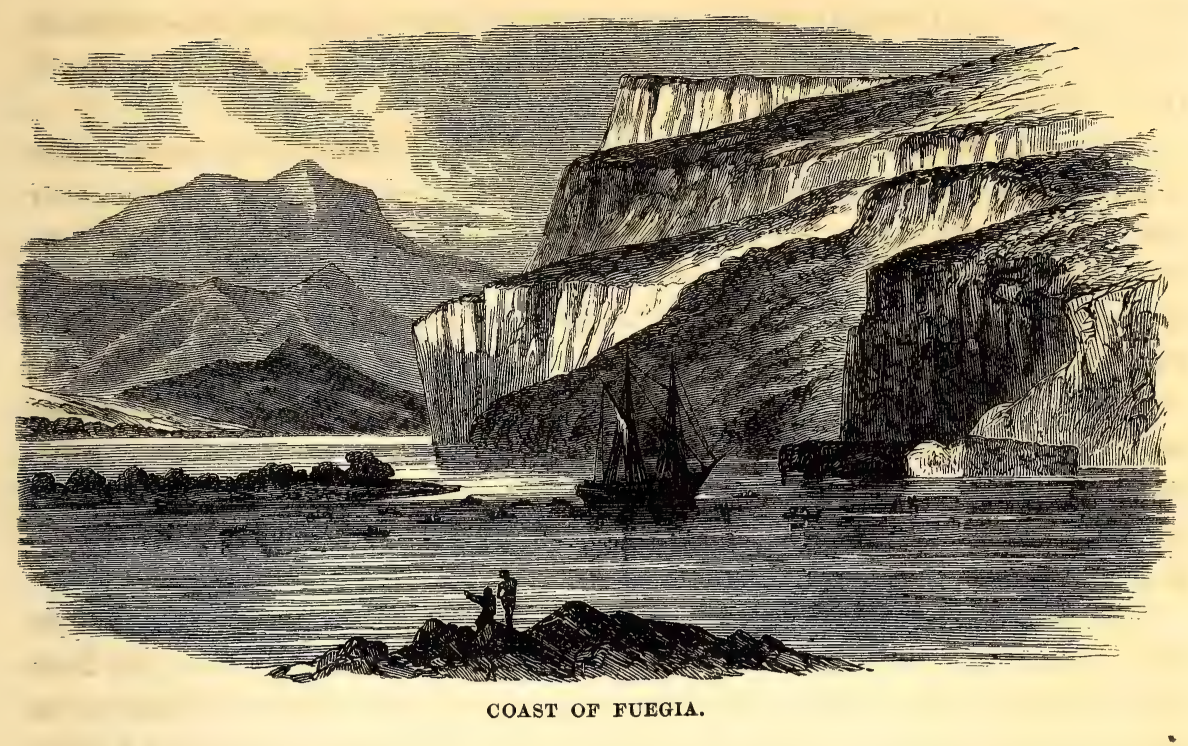

CHAPTER XLI.

THE FUEGIANS.

Their miserable Condition. - Degradation of Body and Mind.-Powers of Mimicry. - Notions of Barter. - Causes of their low State of Cultivation.-Their Food.-Limpets.-Cyttaria Darwini.-Constant Migrations.-The Fuegian Wigwam.-Weapons.-Their probable Origin.-Their Number, and various Tribes. - Constant Feuds. - Cannibalism. - Language._Adventures of Fuegia Basket, Jemmy Button, and York Minster.-Missionary Labors. - Captain Gardiner.-His lamentable End.

THE wilds of Tierra del Fuego are inhabited by a race of men generally sup1 posed to occupy the lowest grade in the scale of humanity. In a far more rigorous climate, the Esquimaux, their northern antipodes, exhibit skill in their snow huts, their kayaks, their weapons, and their dress ; but the wretched Fuegians are ignorant of every useful art that could better their condition, and contrive scarcely any defense against either rain or wind.

But even among the Fuegians there are various grades of civilization-or rather barbarism. The eastern tribes, which inhabit the extensive plains of King Charles's South Land, seem closely allied to the Patagonians, and are a very different race from the undersized wretches farther westward. A mantle of guanaco skin, with the wool outside-the usual Patagonian garmentloosely thrown over their shoulders, and leaving their persons as often exposed as covered, affords them some protection against the piercing wind. The condition of the central tribes inhabiting the south-western bays and inlets of this dreary country is much more miserable. Those farther to the west possess seal-skins, but here the men are satisfied with an otter skin or some other covering scarcely larger than a pocket-handkerchief. It is laced across the breast by strings, and according as the wind blows it is shifted from side to side. 
But all have not even this wretched garment, for near Wollaston Island Mr. Darwin saw a canoe with six Fuegians, one of whom was a woman, naked. It was raining heavily, and the fresh water, together with the spray, trickled down their bodies. In another harbor not far distant, a woman, who was suckling a recently-born child, came one day alongside the vessel, and remained there out of mere curiosity, whilst the sleet fell and thawed on her naked bosom and on the skin of her naked baby! These poor wretches were stunted in their growth, their faces bedaubed with white paint, their skins filthy, their hair entangled, their voices discordant, and their gestures violent.

The Fuegians whom Cook met with in Christmas Sound were equally wretched. Their canoes were made of the bark of trees stretched over a framework of sticks, and the paddles, which served to propel these miserable boats were small, and of an equally miserable workmanship. In each canoe sat from five to eight persons; but instead of greeting the strangers with the joyful shouts of the South Sea Islanders, they rowed along in perfect silence; and even when quite close to the vessel, they only uttered from time to time the word "Pescheräh!" After repeated invitations some of these savages came on board, but without exhibiting the least sign of astonishment or curiosity. None were above five feet four inches high; they had large heads, broad faces, with prominent cheek-bones, flat noses, small and lack-lustre eyes; and their black hair, smeared with fat, hung in matted locks over their shoulders. Instead of a beard, their chin exhibited a few straggling bristles, and their whole appearance afforded a striking picture of abject misery. Their shoulders and breast were broad and strongly built, but the extremities of the body so meagre and shrivelled that one could hardly realize the fact that they belonged to the upper part. The legs were crooked, the knees disproportionately thick. Their sole garment consisted of a small piece of seal-skin, attached to the neck by means of a cord, otherwise they were quite naked; but even these miserable creatures had made an attempt to decorate their olive-brown skin with some stripes of ochre. The women were as ugly as the men. Their food consisted of raw, half-putrid seal's flesh, which made them smell so horribly, that it was impossible to remain long near them. Their intelligence was on a par with the filth of their bodies. The most expressive signs were here of no avail. Gestures which the most dull-headed native of any South Sea island immediately understood, these savages either did not, or would not give themselves the trouble to comprehend. Of the superiority of the Europeans they appeared to have no idea, never expressing by the slightest sign any astonishment at the sight of the ship and the various objects on board. It would however be doing the Fuegians injustice to suppose them all on a level with these wretches. According to Forster, they were most likely outcasts from the neighboring tribes.

Mr. Darwin, as well as Sir James Ross, describes the Fuegians whom they met with in the Bay of Good Success and on Hermit Island as excellent mimics. "As often as we coughed or yawned," says the former, "or made any odd motion, they immediately imitated us. Some of our party began to squint and look awry, but one of the young Fuegians (whose whole face was painted 
black, excepting a white band across his eyes) succeeded in making far more hideous grimaces. They could repeat with perfect correctness each word in any sentence we addressed them, and they remembered such words for some time. Yet we all know how difficult it is to distinguish apart the sounds in a foreign language."

Close to the junction of Ponsonby Sound with the Beagle Channel, where Mr. Darwin and his party spent the night, a small family of Fuegians soon joined the strangers round a blazing fire. They seemed well pleased, and all joined in the chorus of the seamen's songs. During the night the news had spread, and early in the morning other Fuegians arrived. Several of these had run so fast that their noses were bleeding, and their mouths frothed from the rapidity with which they talked; and with their naked bodies all bedaubed with black, white, and red, they looked like so many demons.

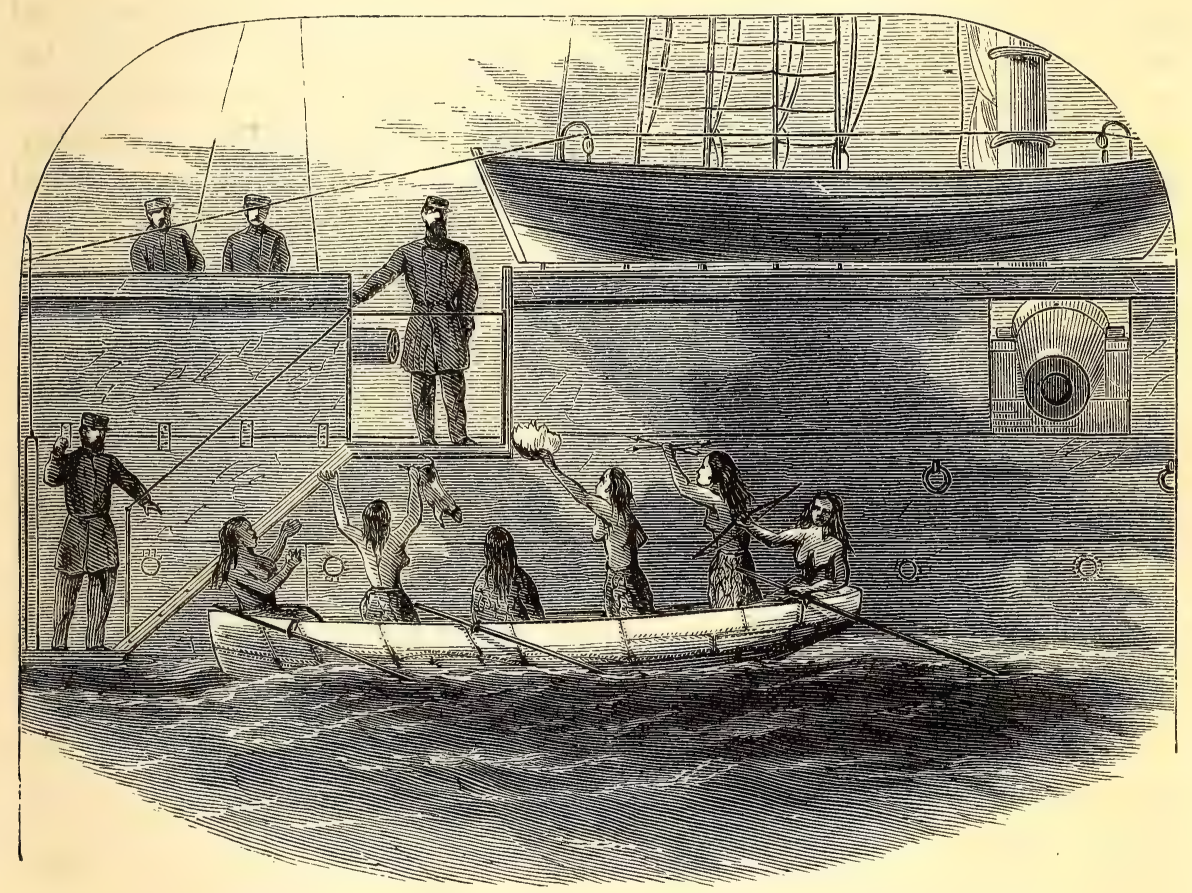

FUEGIAN TRADERS.

These people plainly showed that they had a fair notion of barter. Mr. Darwin gave one man a large nail (a most valuable present) without making any signs for a return; but he immediately picked out two fish, and handed them up on the point of his spear. Here at least we see signs of a mental activity favorably contrasting with the stolid indifference of the Fuegians seen by Forster at Christmas Harbor; and Mr. Darwin is even of opinion that in general these people rise above the Australians in mental power, although their actual acquirements may be less.

The reason why the Fuegians are so little adranced in the arts of life, 
are partly to be sought for in the nature of the land, and partly in their political state. The perfect equality among the individuals in each tribe must retard their civilization; and until some chief shall arise with power sufficient to secure any acquired advantage, such as the domesticated animals, it seems scarcely possible that their condition can improve. But the chief causes of their wretchedness are doubtless the barrenness of their country and their constant forced migrations.

With the exception of the eastern part, the habitable land is reduced to the stones on the beach. In search of food they are compelled to wander from spot to spot; and so steep is the coast that they can only move about in their canoes. Whenever it is low water, winter or summer, night or day, they must rise to pick limpets from the rock; and the women either dive to collect seaeggs, or sit patiently in their boats, and with a baited hair-line, without any hook, jerk out little fish. If a seal is killed, or the floating carcass of a putrid whale discovered, it is a feast; and such miserable food is assisted by a few tasteless berries, chiefly of a dwarf arbutus, or by a globular bright yellow fungus (Cyttaria Darwini), which grows in vast numbers on the beech-trees. When young, it is elastic, with a smooth surface; but, when mature, it shrinks, becomes tougher, and has its entire surface deeply pitted or honey-combed. In this mature state it is collected in large quantities by the women and children, and is eaten uncooked. It has a mucilaginous, slightly sweet taste, with a faint smell like that of a mushroom.

The necessity of protecting themselves against the extremity of cold, and of obtaining their food from the sea, or by the chase of the reindeer or the white bear, forces the Esquimaux to exert all their faculties, and thus they have raised themselves considerably higher in the scale of civilization than the Fuegians, whose mode of life requires far less exertion of the mind. To knock a limpet from the rock or to collect a fungus does not even call cunning into exercise. Living chiefly upon shell-fish, they are obliged constantly to change their abode, and thus they hardly bestow any thought on their dwellings, which are more like the dens of wild beasts than the habitations of human beings. The Fuegian wigwam consists of a few branches stuck in the ground, and very imperfectly thatched on one side with a few tufts of grass and rushes. The whole can not be the work of an hour, and it is only used for a few days. At intervals, however, the inhabitants of these wretched huts return to the same spot, as is evident from the piles of old shells, often amounting to several tons in weight. These heaps can be distinguished at a distance by the bright green color of certain plants, such as the wild celery and scurvy grass, which invariably grow on them.

The only articles in the manufacture of which the Fuegians show some signs of ability are a few ornaments and their weapons, which again are far inferior to those of the Esquimaux. Their bows are small and badly shaped, their arrows, which are between two and three feet long, feathered at one end and blunted at the other. The points are only attached when the arrow is about to be used, and for this purpose the archer carries them about with him in a leathern pouch. The shaft of their larger spears is about ten feet long, 
and equally thick at both ends. At one of the extremities is a fissure, into which a pointed bone with a barbed hook is inserted and tightly bound with a thread. With this weapon tney most probably attack the seals; they also use it to detach the shell-fish from the rocks below the surface of the water. A second spear, longer and lighter than the first, with a barbed point, serves most likely as a weapon of war; and a third one, much shorter and comparatively thin, may perhaps be destined for the birds. The females know how to make

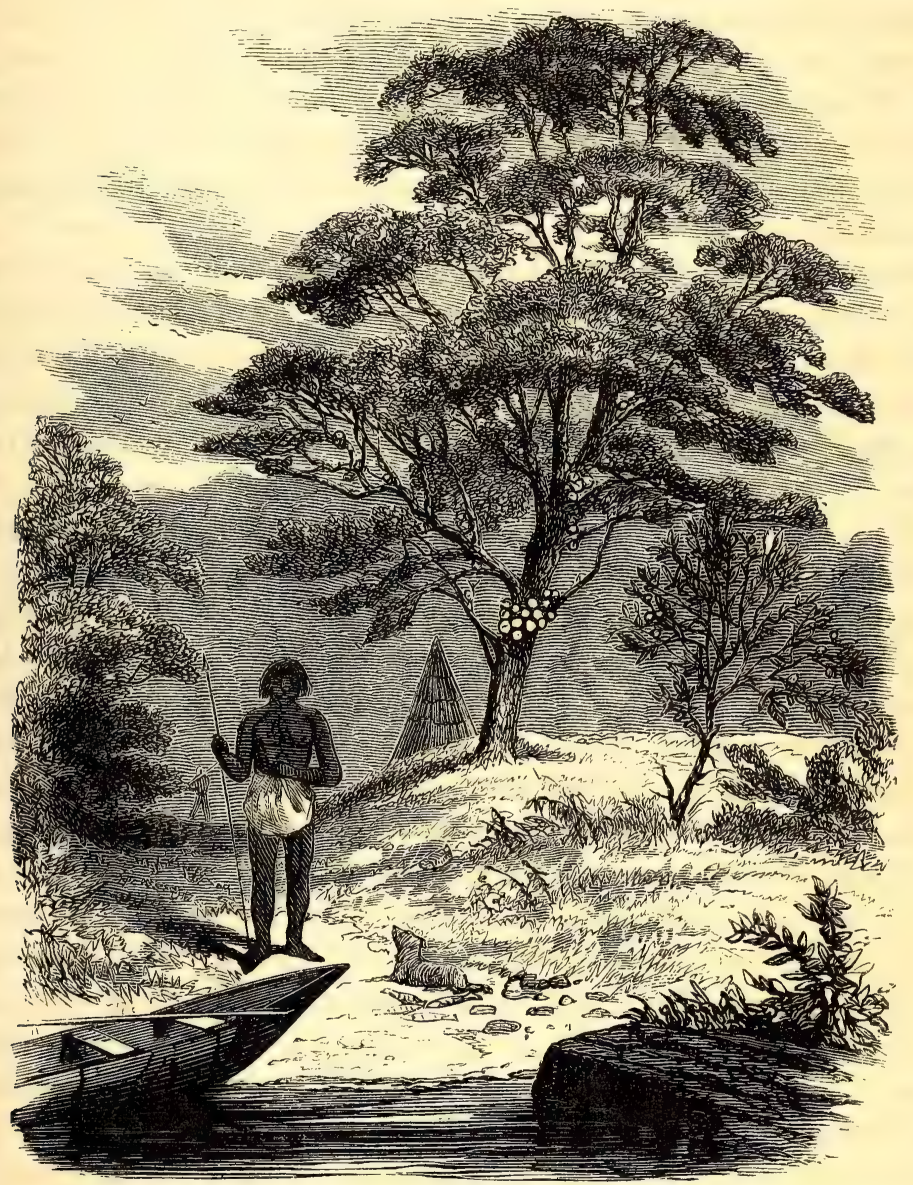

A FUEGIAN AND HIS FOOD.

pretty necklaces of colored shells and baskets of grass stalks. Here, as with all other races of mankind, we find the germs of improvement, which only require for their development the external impulse of more favorable circumstances.

If it be asked whether they feel themselves as miserable as their wretched appearance would lead us to believe them, it must be replied that most travellers describe them as a cheerful, good-humored, contented people; and as Mr. Darwin finely remarks, "Nature, by making habit omnipotent and its effects 
hereditary, has fitted the Fuegian to the climate and the productions of his country."

The number of these savages is no doubt very small, as seldom more than thirty or forty individuals are seen together. The interior of the mountainous islands, which is as little known as the interior of Spitzbergen, is no doubt completely uninhabited; as the coasts alone, with the exception of the eastern and more level part of the country, where the guanaco finds pasture, are able to furnish the means of subsistence. The various tribes, separated from each other by a deseried neutral territory, are nevertheless engaged in constant feuds, as quarrels are perpetually arising about the possession of some limpetbank or fishing-station. When at war they are cannibals ; and it is equally certain that when pressed in winter by hunger they kill and devour their old women before they kill their dogs, alleging as an excuse that their dogs catch otters, and old women do not.

It has not been ascertained whether they have any distinct belief in a future life. They sometimes bury their dead in caves, and sometimes in the mountain forests. Each family or tribe has a wizard, or conjuring doctor. Their language, of which there are several distinct dialects, is likewise little known; it is, however, far inferior to the copious and expressive vocabulary of the Esquimanx.

In 1830, while Captain Fitzroy was surveying the coasts of Fuegia, he seized on a party of natives as hostages for the loss of a boat which had been stolen, and some of these natives, as well as a child belonging to another tribe, whom he bought for a pearl button, he took with him to England, determining to educate them at his own expense. One of them afterwards died of the smallpox; but a young girl, Fuegia Basket, and two boys, Jemmy Button (thus named from his purchase-money) and York Minster (so called from the great rugged mountain of York Minster, near Christmas Sound), were placed in a school at Walthamstow, and moreover had the honor of being presented to King William and Queen Adelaide. Three years Jemmy and his companions remained in England, at the end of which time Captain Fitzroy was again sent out to continue the survey, and took with him these three Fuegians, intending to return them to the place whence they had come. In this, however, he was disappointed; but at their own request York and Fuegia were, with Jemmy, deposited at Woollya, a pleasant looking spot in Ponsonby Sound, belonging to Jemmy's tribe. His family, consisting of his mother and three brothers, was absent at the time, but they arrived the following morning. Jemmy recognized the stentorian voice of one of his brothers at a prodigious distance, but the meeting, as Mr. Darwin, who witnessed the scene, relates, was less interesting than that between a horse turned out into a field and an old companion. There was no demonstration of affection; they simply stared for a short time at each other. Three large wigwams were built for them, gardens planted, and an abundant supply of every thing landed for their use. Jemmy, who had become quite a favorite on board, was short and fat, but vain of his personal appearance; he used always to wear gloves, his hair was neatly cut, and he was distressed if his well-polished shoes were dirtied. York was somewhat coarse 
and less intelligent, though in some things he could be quick. He became attached to Fuegia, and as both were of the same tribe, they became man and wife after their return to Tierra del Fuego. She was the most intelligent of the three, and quick in learning any thing, especially languages.

Thus these semi-civilized savages were left among their barbarous countrymen, with the hope that they might become the means of improving their whole tribe; but when Captain Fitzroy returned to the spot twelve months after, he found the wigwams deserted and the gardens trampled under foot. Jemmy came paddling up in his canoe, but the dandy who had been left plump, clean, and well-dressed, was now turned into a thin, haggard savage, with long, disordered hair, and naked, except a bit of a blanket round his waist. He could still speak English, and said that he had enough to eat, that he was not cold, and that his relations were very good people. He had a wife besides, who was decidedly the best-looking female in the company. With his usual good feeling, he brought two beautiful otter skins for two of his best friends, and some spearheads and arrows made with his own hands for the captain. He had lost all his property. York Minster had built a large canoe, and with his wife Fuegia had, several months since, gone to his own country, and had taken farewell by an act of consummate villainy. He persuaded Jemmy and his mother to come with him, and then on the way deserted them by night, stealing every article of their property. It was the opinion of all on board that the cunning rogue had planned all this long before, and that with this end in view he had desired so earnestly to remain with Jemmy's tribe rather than be landed on his own country. Eight years after an English vessel put into a bay in the Magellans for water, and there was found a woman, without doubt Fuegia Basket, who said, "How do? I have been to Plymouth and London." York Minster was also seen in 1851. From Captain Suow, commander of the mission yacht "Allen Gardiner," we have the last accounts of Jemmy Button in 1855. Twenty-three years had not obliterated his knowledge of the English language, but he was as wild and shaggy as his untaught countrymen. In spite of his superior knowledge, he was treated as a very inferior personage by the members of his tribe; yet he declared that though he loved England, he loved his country still better; that nothing should induce him to leave it, and that he would never allow any of his children to quit their native soil.

Other efforts have been made to civilize the Fuegians. A Spanish vessel having been shipwrecked on the eastern coast in 1767 , its crew was hospitably treated by the natives, who even assisted in saving the cargo. Out of gratitude, the Grovernor of Buenos Ayres sent out some missionaries, who, however, totally failed to make any impression on the savages.

A no less unsuccessful attempt was made about the year 1835 by English missionaries ; and the expedition of Captain Gardiner, who, accompanied by a surgeon, a catechist, and four Cornish fishermen, sailed to Fuegia in 1851, with the intention of converting the natives, proved equally fruitless, and had a far more tragic end. His measures for securing the necessary supplies of food were so ill calculated that the whole party died of hunger in Spaniards' Harbor, on the southern coast. Captain Morshead, of the "Dido," had received orders on his 


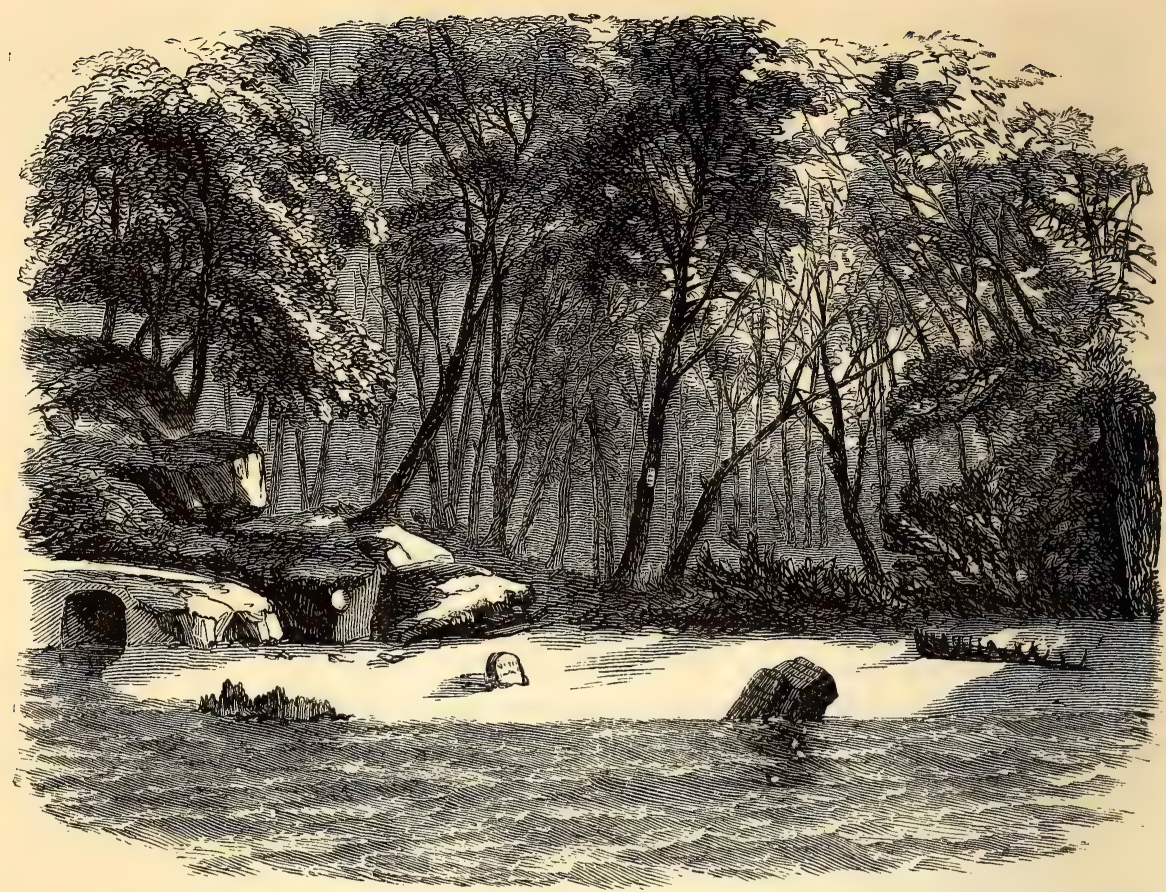

STARVATION BEACH.

way to Valparaiso to visit the scene of the mission, and afford Captain Gardiner any aid he might require, but, on arriving at the cove, he found it deserted. After a few days' search the bodies were discovered, and fragments of a journal written by Captain Gardiner gave proof of the sufferings which they had endured before death relieved them from their misery. The spot has received the name of Starvation Beach. 


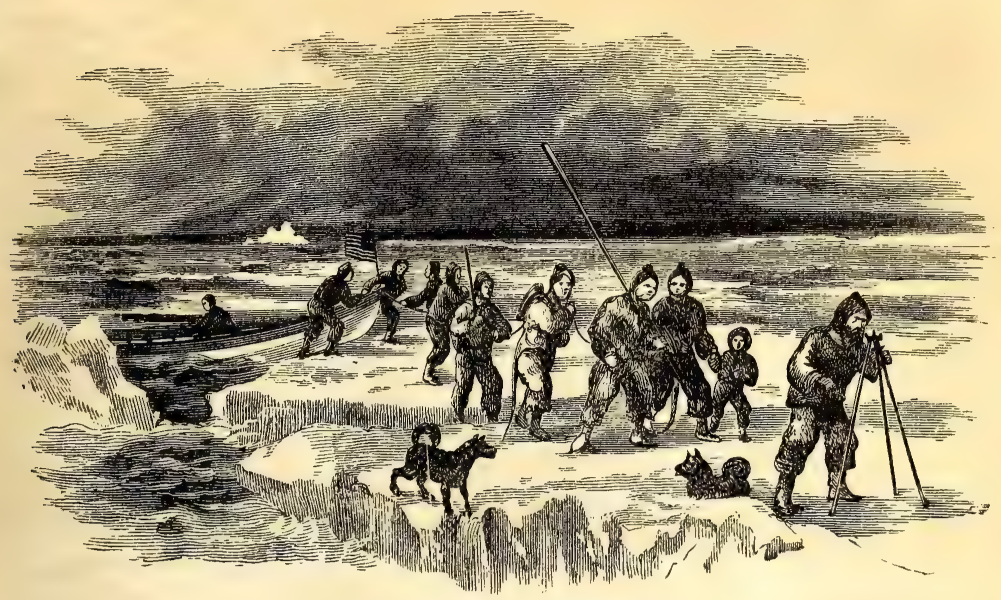

SURVEYING IN GREENLAND.

\section{CHAPTER XLII.}

\section{CHARLES FRANCIS HALL AND THE INNUITS.}

Hall's Expedition.-His early Life.-His reading of Arctic Adventure.-His Resolve.-His Arctic Outfit.-Sets Sail on the "George Henry."-The Voyage._Kudlago._Holsteinborg, Greenland.-Population of Greenland._-Sails for Davis's Strait.-Character of the Innuits.-Wreck of the "Rescue." -Ebierbing and Tookoolito.-Their Visit to England.-Hall's first Exploration._-European and Innuit Life in the Arctic Regions.-Building an Igloo.-Almost Starved.-Fight for Food with Dogs. -Ebierbing arrives with a Seal.-How he caught it.-A Seal-feast.-The Innuits and Seals. - The Polar Bear.-How he teaches the Innuits to catch Seals.-At a Seal-hole.-Dogs as Seal-hunters.Dogs and Bears.-Dogs and Reindeers.-Innuits and Walruses.-More about Iglons.-Innuit Implements.-Uses of the Reindeer.-Innuit Improvidence.-A Deer-feast.-A frozen Delicacy.-Whaleskin as Food.-Whale-gum. - How to eat Whale Ligament._Raw Meat.-The Dress of the Innuits. -A pretty Style.-Religious Ideas of the Innuits.- Their kindly Character.-Treatment of the Aged and Infirm.-A Woman abandoned to die.-Hall's Attempt to rescue her.-The Innuit Nomads, without any form of Government.-Their Numbers diminishing.-A Sailor wanders away.-Hall's Search for him.-Finds him frozen to death.- The Ship free from Ice.-Preparations to return.Reset in the Ice-pack.-Another Arctic Winter.-Breaking up of the Ice.-Departure for Home.Tookoolito and her Child "Butterfly."-Death of "Butterfy."-Arrival at Home.-Results of Hall's Expedition.-Innuit Traditions.-Discovery of Frobisher Relics.-Hall undertakes a second Expedition.-His Statement of its Object and Prospects.-Last Tidings of Hall.

MONG the most remarkable expeditions ever undertaken in the Polar world is that of Charles Francis Hall, performed during the years 1860, 1861, and 1862. Its primary object was to discover the survivors of Sir John Franklin's party ; for at this time there was good reason to believe that out of the 105 who were known to be living on the 25th of April, 1848, some were still surviving. Towards the main purpose of the undertaking nothing was indeed accomplished. Hall came upon no traces of Franklin and his men; but he acquired a more accurate knowledge of the Esquimaux - or rather as they call themselves, and as we shall call them, the Innuits-a word meaning simply "men" or "people"and their mode of life than was ever before, or is likely to be hereafter, gained 


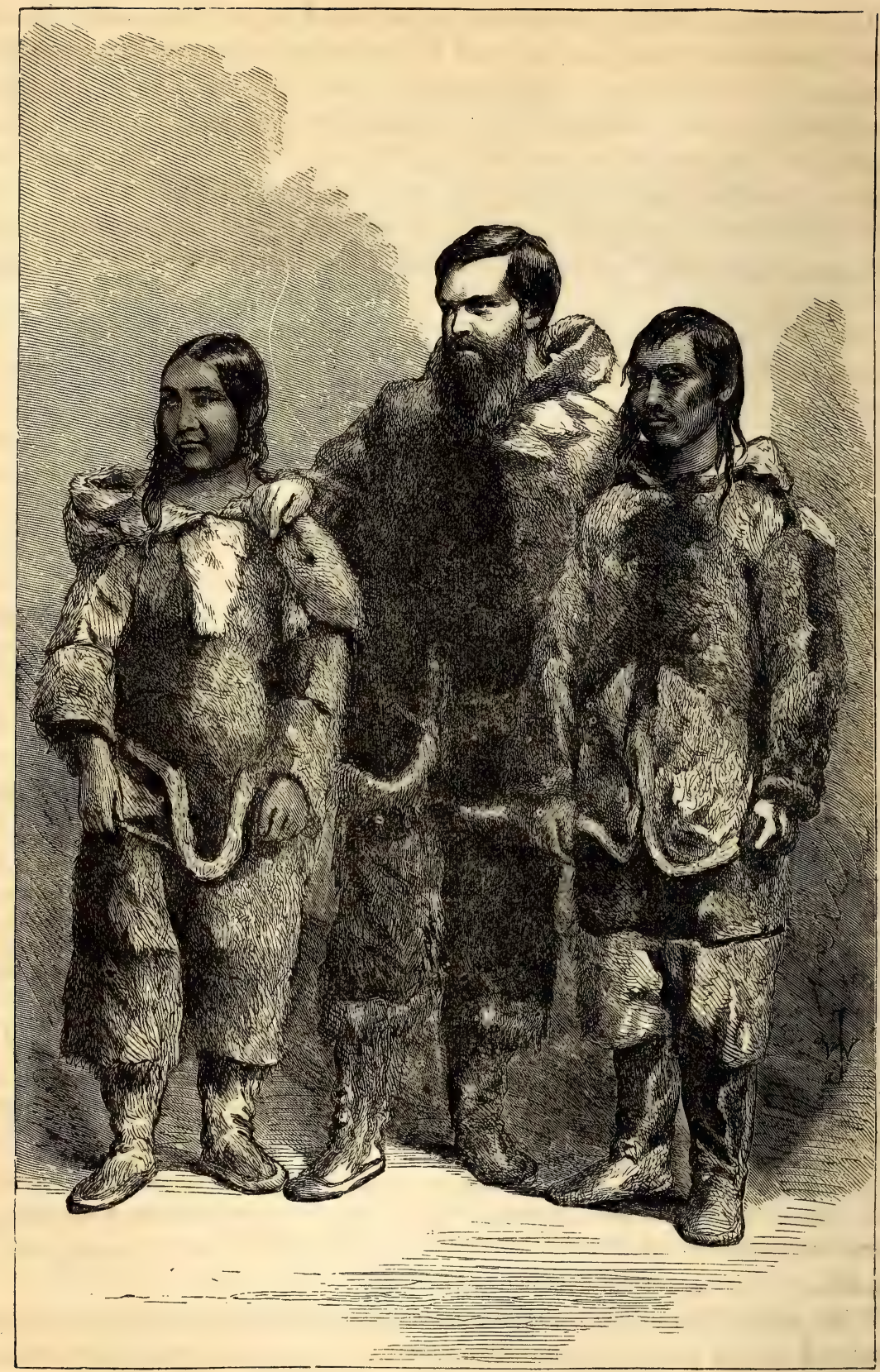

HALL AND COMPANIONS, IN INNUIT COSTUME.

by any other white man capable of telling what he saw, and a part of which he was. The remarkable book in which Mr. Hall describes his expedition* seems not to have come under the notice of Dr. Hartweg. It is proposed in this chapter to supplement the account of the Innuits from this work of Mr. Hall.

* Arctic Researches, and Life among the Esquimaux. By Chardes Frascis Hald. New York, 1866. 
Up to middle life Hall had resided in the inland city of Cincinnati. He had eagerly read every thing that he could find on record of the searches made for Franklin. Large ships and small ships had been sent out. Brave hearts and stout hands had been enlisted in the search, but with no tangible result beyond ascertaining the spot where the surviving 105 were when they abandoned their ships and took to the shore, hoping to make their way to their homes. Only two of these men were proven to have died; and it was more than probable that of the 105 known to have been living in 1848, some would yet be alive in 1860 , for not a few of these men, if living, would be still of middle age.

Hall had read the story of the sufferings of Kane's party during the long months of the Arctic winter, but he had come to the conclusion that most of these resulted from the mode of life adopted by them. The Innuits, he knew, lived to a good old age through a succession of such winters, and he believed that a civilized man could live where a savage could. This conviction was confirmed by one of Kane's companions, who told him, "When we lived like the Esquimaux, we immediately recovered, and enjoyed our usual health. If Providence had so ordered it that we should cast our lot with the Esquimaux, I have no doubt that we would have lived quite as long, and in quite as good health as in the United States or England. White men can live where Esquimaux can, and frequently when and where they can not."

So Hall grew into the conviction that some of these lost ones could yet be found; and he writes, "It seemed to me as if I had been called, if I may so speak, to try and do the work. My heart felt sore at the thought of so great a mystery in connection with any of our fellow-creatures, especially akin to ourselves, yet remaining unsolved." How should he obey this call? His own means, beyond a stout frame and strong will, were of the smallest. He broached the project at the West, where it was received with favor. Then he came East, and was met with like consideration. Funds were raised, and the expedition which Hall contemplated was fitted out.

This expedition consisted simply of Hall himself. The cash contributed for the outfit was just $\$ 980$, of which more than a third was contributed by Henry Grinnell, of New York. In addition to this was about a quarter as much in the way of presents. "These," says Hall, "constituted all the means and material I had to carry out the great undertaking my mind had led me to embark in." Hall's list of the articles on his outfit for a three years' residence and exploration is worthy of record. It shows in what way his $\$ 980$ in cash was expended.

"My outfit," he writes, "for the voyage and the whole of my expedition, consisted of:- $\mathrm{a}$ boat, length twenty-eight feet, beam seven feet, depth twentynine and one-half inches, drawing eight inches of water when loaded with stores and a crew of six persons; one sledge; one half-ton of pemmican; two hundred pounds of Borden's meat biscuit; twenty pounds pork scrap; one pound preserved quince; one pound preserved peaches; two hundred and fifty pounds powder; a quantity of ball, shot, and percussion caps ; one rifle, six double-barrelled guns; one Colt's revolver; beads, needles, etc., for presents; two dozen pocket-knives; some tin ware; one axe, two picks, files, etc.; tobacco and pipes ; 
wearing apparel for self, and red shirts for natives; stationery and journalbooks; watch, opera-glass, spy-glass ; sextant, pocket sextant, artificial horizon, azimuth compass, common compass, two pocket compasses ; three ordinary and two self-registering thermometers. Some navigation-books and several Arctic works, with my Bible and a few other volumes, formed my library." The boat and fixtures cost one hundred and twenty-five dollars; meat, biscuit, pemmican, etc., about two hundred and fifty dollars; astronomical instruments, about one hundred dollars; guns and accoutrements, about two hundred and twenty-five dollars; clothing, fifty dollars ; pipes and tobacco, twenty dollars; travelling expenses and express payments, seventy-five dollars; dog-team, bought in Greenland, fifty dollars. The other items making up the nine hundred and eighty dollars are all duly given. It will be seen that the balance left for minor, but necessary, expenditures was very small.

New London, Connecticut, is the port from which vessels mainly sail for the Arctic whale-fishery. Here was the place of business. Williams and Haven largely engaged in that enterprise. They relieved Hall of a great load of anxiety by a brief note, in which they said: "As a testimony of our personal regard, and the interest we feel in the proposed expedition, we will convey it and its required outfit, boats, sledges, provisions, instruments, etc., free of charge, on the barque 'George Henry,' to Northumberland Inlet; and, whenever desired, we will give the same free passage home in any of our vessels."

On the 29th of May, 1860, the "George Henry" set sail, with a crew, officers and men, of twenty-nine souls. Accompanying as tender was a schooner, which had a history. She was now known as the "Amaret ;" but under the name of the "Rescue" she had won fame in Arctic research, for in her Kane had made his first Arctic voyage. Hall always calls her by her old name, and the account of her loss forms a striking episode in his narrative.

We have said that Hall's expedition consisted of himself alone. But when he started he had with him a companion, who he hoped would greatly aid him.

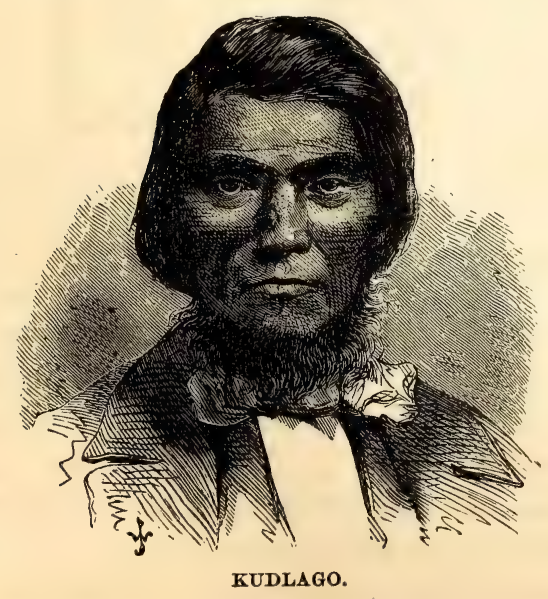

This was Kudlago, an Innuit, who had acquired some knowledge of our language in Greenland from whalers, had come to the United States on a whaling-vessel, and was now anxious to return to Greenland. But he fell sick on the voyage, and died on the 1st of July. His last words were, "Do you see the ice?" for he knew that the appearance of ice at this season would show that he was near his home. He died three hundred miles at sea, and was committed to the ocean, Hall reading the funeral service. A great iceberg - the slender one represented on page 48 of this volume-was drifting close by, and Hall named it "Kudlago's Monument."

On the 7th of July they reached Holsteinborg, the capital of the Danish col- 
ony of Greenland, a town consisting of twenty-four houses. The entire population of Greenland is estimated at about 2450, of whom 2300 are Innuits, and the remainder Europeans. Of the Innuits, 1700 live by sealing, and 400 by fishing; the others being mainly mechanics and sailors, besides twenty native catechists. Of the Europeans, thirty-one are "First and Second Governors ;" twenty-four missionaries and priests; thirty-six clerks; the others mechanics and sailors. The forty-four native and European missionaries receive, in all, 13,600 Danish paper dollars, equal to about $\$ 8500$ in specie. The head-schoolmaster has one hundred and twenty-five paper dollars; three others receive one hundred dollars each; three, twenty-five dollars; two, six dollars. Of these last, one teaches his own two children, who are the only ones in his district. There are also four women, who get a dollar a year each for teaching children their letters. The sixteen Government employés get from forty to ninety dollars a year, besides provisions for themselves and their families. Bread is baked for then every fortnight. The currency of the colony is paper, the "six-skilling" note being worth about three cents.

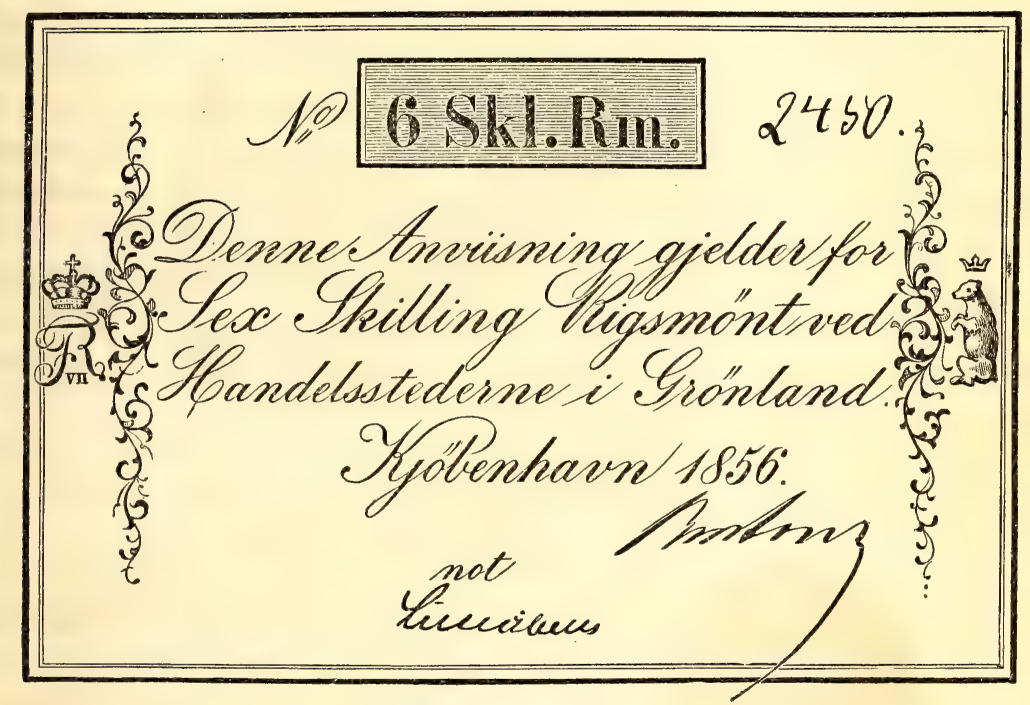

GREENLAND CURRENCY.

The native Greenlanders are by no means deficient in intelligence. Mr. Hall gives a fac-simile of a wood-cut representing a woman and child drawn and engraved by one of them who had received no instruction in art, and no education of any sort beyond that of the majority of his countrymen. The great festival of Greenland is the birthday of the King of Denmark, in which all the population, native and European, who can be assembled, take part, his Majesty furnishing the cheer. Hall gives a view of this celebration, taken from a drawing made by a native. The original drawing was full of character.

The "Rescue" having rejoined her consort, the "George Henry," from whom she had been separated on the voyage, the captain proposed to set sail for his proposed whaling-ground on the west side of Davis's Strait. They sailed on the 
24th of July, Hall accompanying. Three days after, they encountered a violent snow-storm, and were beset by icebergs. On the 8th of August they anchored in a bay in latitude $63^{\circ} 20^{\prime}$, called by the natives Ookoolear, but by Hall named Cornelius Grinnell Bay. Here and hereabouts the whalers went to work, and Hall began his acquaintance with the Esquimanx at home.

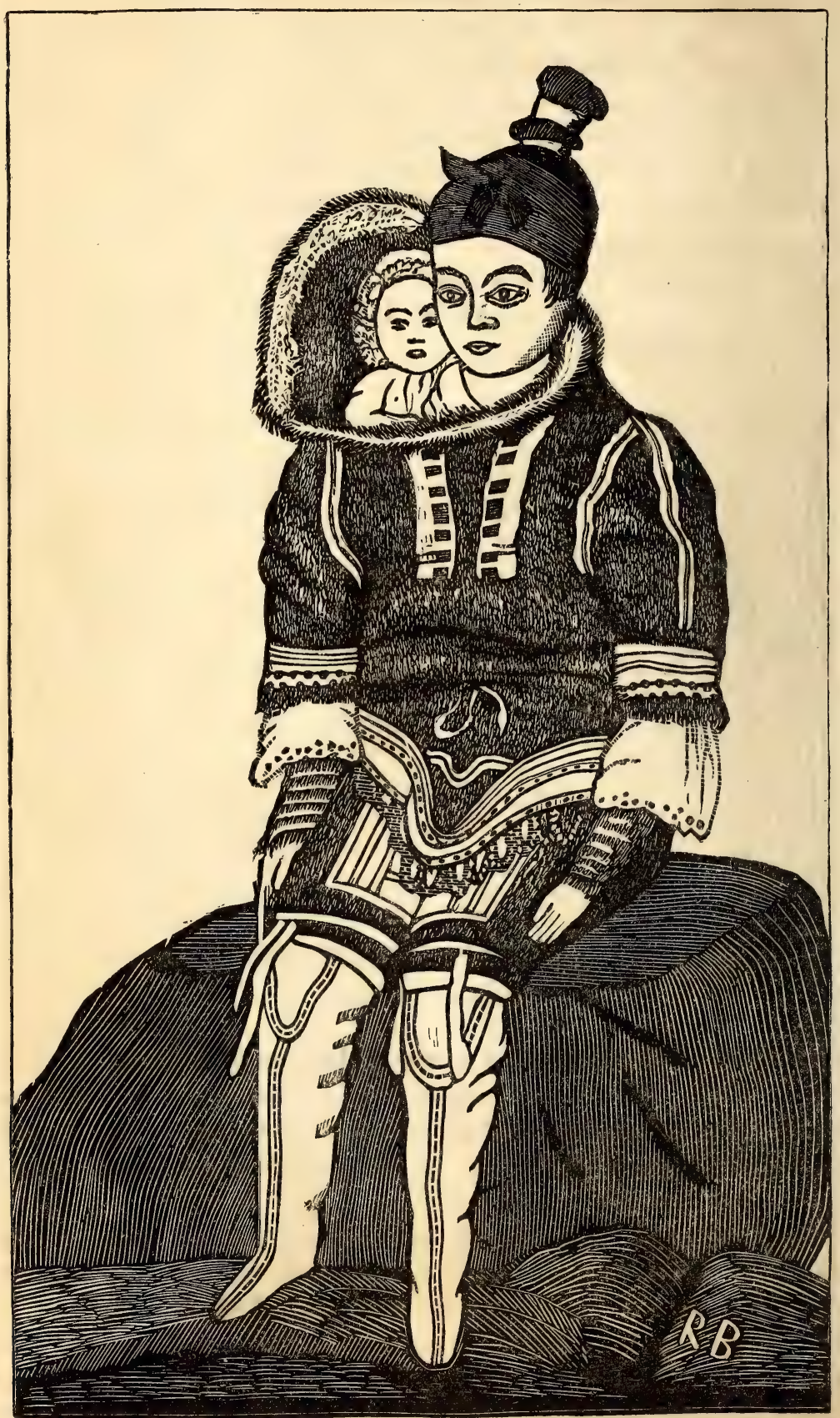

WOMAN AND CHILD. (Drawn and Engraved by AN INNUTT.) 
Among these was Kookerjabin, the widow of Kudlago, and of three others. "The Innuits," writes Hall, " are a happy people. As they crowded our decks,

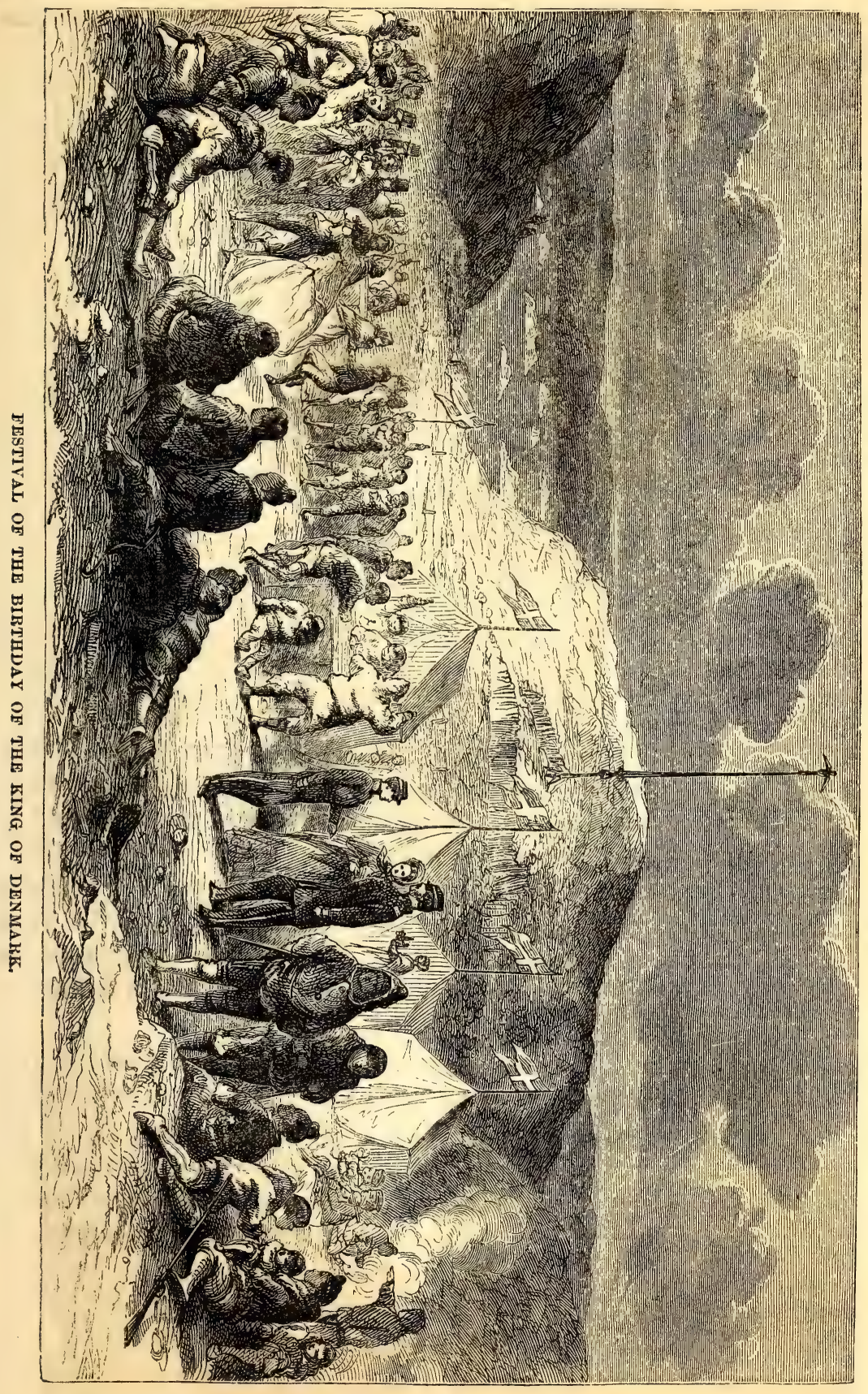

I ole day noticed about a dozen women seated, and busily engaged at their work. Two were mending one of the boat's sails, some were chewing seal-skins for 


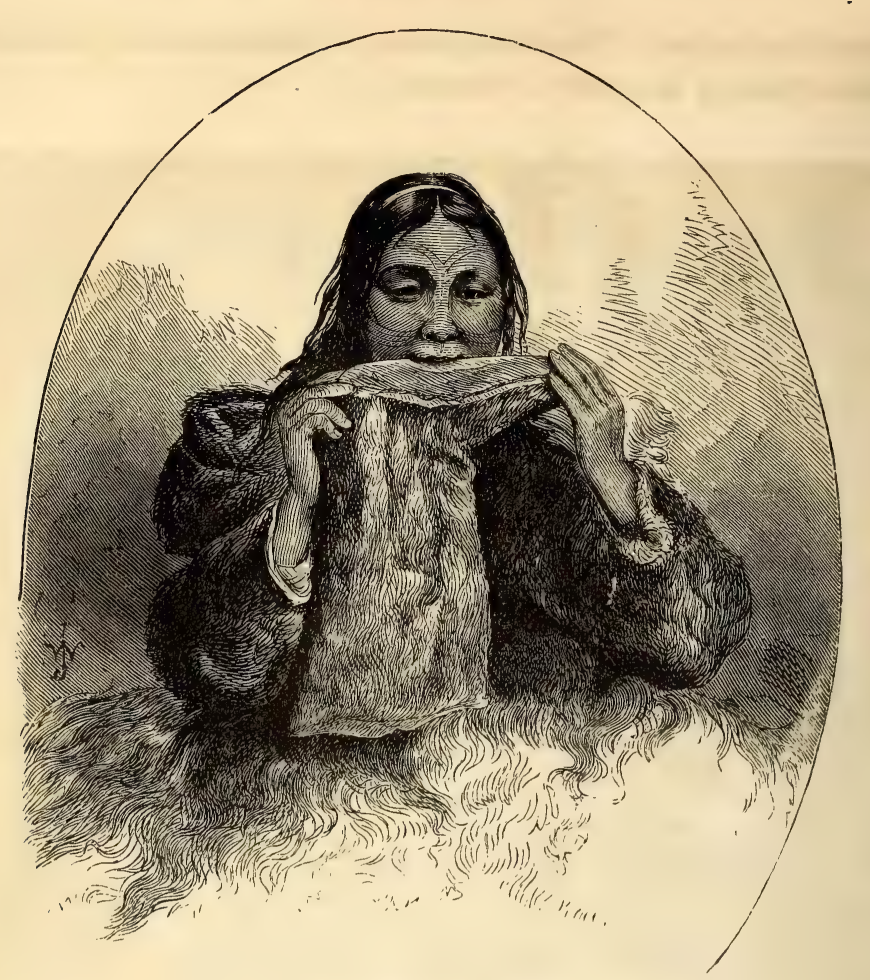

PRePaRING BOOT-SOLES.

boot-soles, others were sewing, while one was tending a cross baby. It is rare to find an Innuit child who is not very quiet, but this little fellow had eaten a piece of raw blubber, which had disordered him. Some of the amusing tricks played by these Esquimaux women are especially deserving of notice. The variety of games performed by a string tied at the ends, similar to a 'cat's cradle,' completely throws into the shade our adepts at home. I never before witnessed such a number of intricate ways in which a simple string could be used. One arrangement represented a deer; another, a whale; a third, the walrus ; a fourth, the seal; and so on without end."

The short Arctic summer soon came to a close. On the morning of the 26 th of September came light winds from the north-west; by noon it began to snow, the wind increasing to a gale. The whaling-boats all came in, and preparations were made for bad weather. During the night the storm grew hourly fiercer. The "Rescue" dragged her anchor, and was dashed upon the rocks an utter wreck. Hall's little boat, upon which he had so much relied, was torn from its moorings and lost, "dooming me," says Hall, "to a wreck of disappointment in the hopes I had cherished concerning her. The 'George Henry' was also in imminent peril, but outrode the tempest; but on her next voyage, eighteen months later, was lost at a point hardly a hundred miles distant."

The "George Henry" was soon after laid up in winter-quarters, fairly blocked in by ice. Hall in the mean time had made himself acquainted with the Es- 
quimaux of the region. Prominent among these were a couple-husband and wife-whose history is worthy of record.

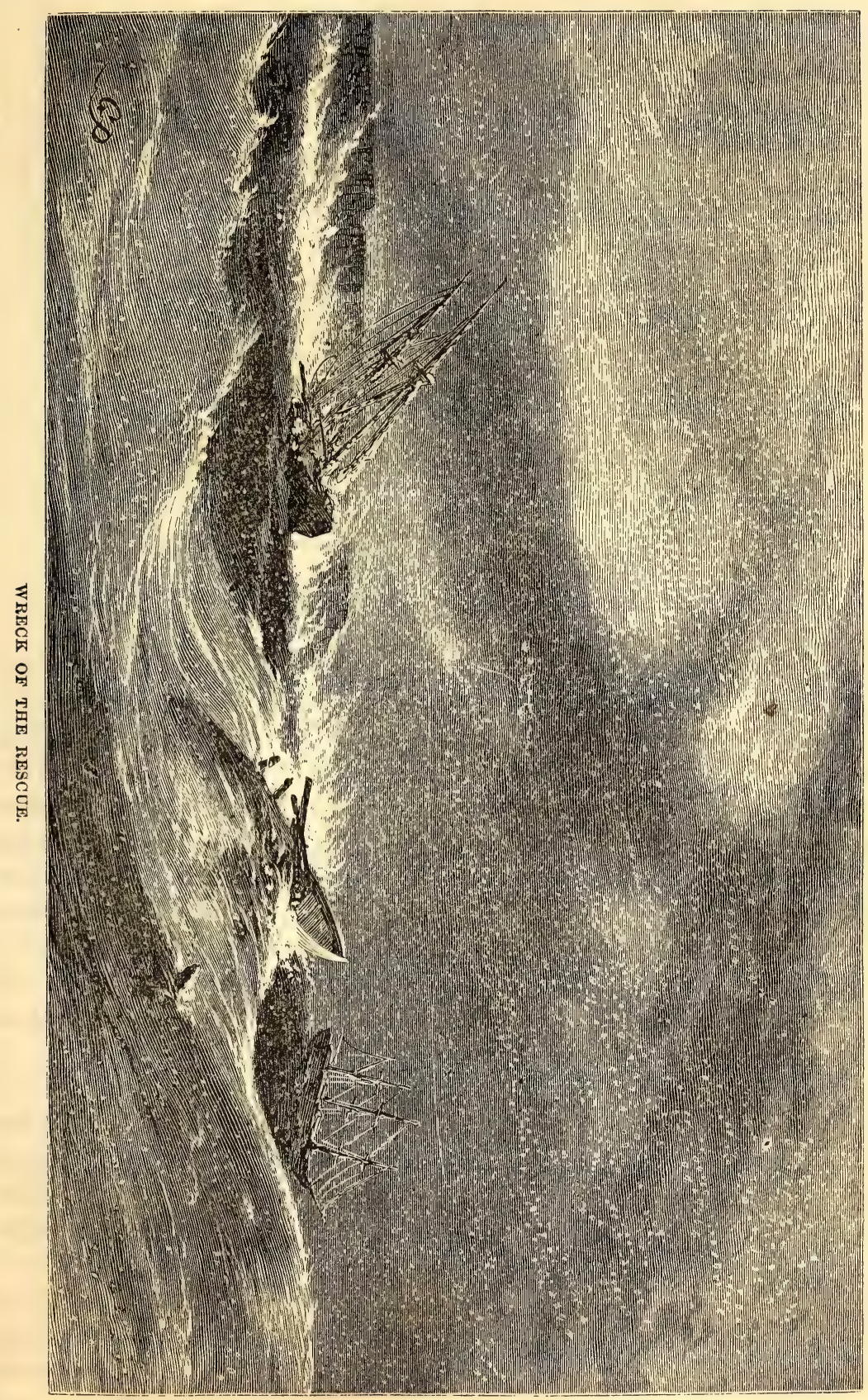

One day-it was November 2-while Hall was writing in his cabin, he heard a Iow, sweet voice saying, "Good-morning, Sir." Looking up, he saw a comely woman, dressed in very good imitation of civilized costume. He had heard of 


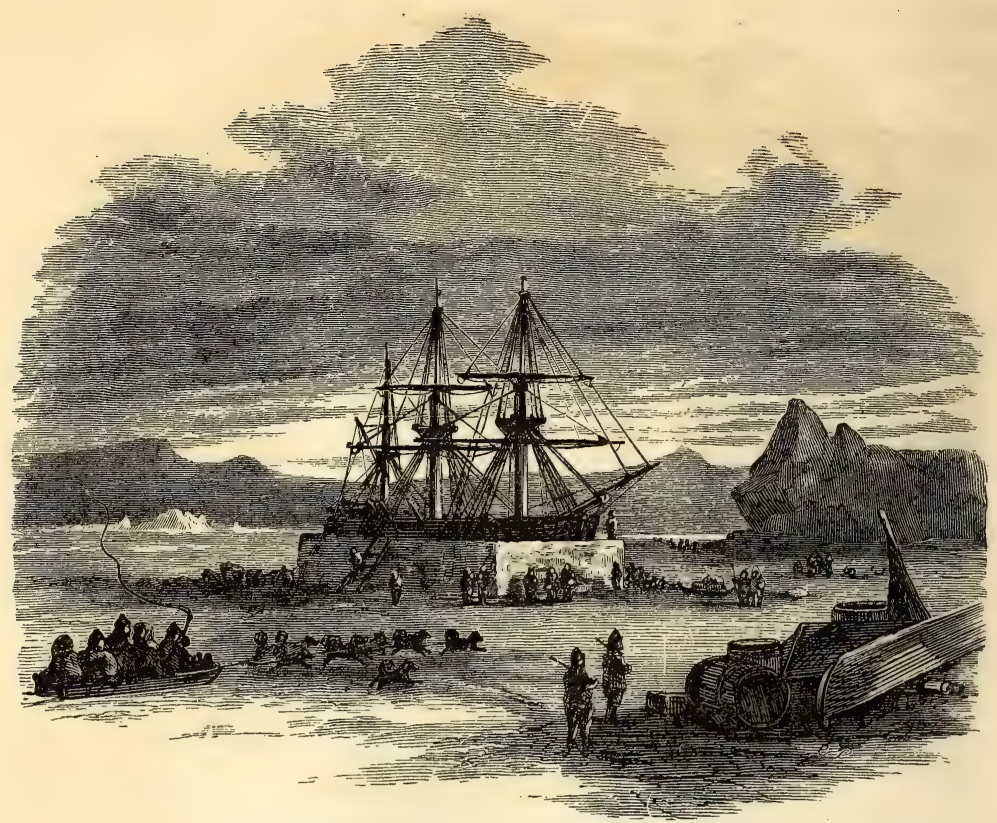

THE GEORGE HENRY LAID UP FOR THE WINTER.

her before. Her name was Tookoolito. She was the wife of Ebierbing, a rather famous seal-hunter and pilot. Seven years before a British whaler had taken them to England, where they were received as the lions of the day. They dined with Prince Albert, and were introduced to the Queen. Ebierbing thought that the Queen was "very pretty;" indeed she bore no very distant likeness to his own wife. Tookoolito thought Prince Albert was a "very kind, good man." Both agreed that the Queen had "a very fine place." Tookoolito, as many thousands in the United States afterwards had occasion to know, spoke English almost perfectly. Her husband was less fluent, but still quite intelligible. This pair became Hall's constant companions in the Arctic regions; came with him upon his return to the States, remained there with him for two years, and went back with him upon his second expedition, which now (September, 1869) is not completed.

Early in January Hall resolved to make an exploring expedition with the dog-team which he had bought at Holsteinborg. The party consisted of himself, Ebierbing, Tookoolito, and another Esquimaux, named Koodloo. The sledge was drawn by ten dogs-five of which belonged to Hall, and five to Ebierbing. They relied for food mainly upon the proceeds of their hunting, taking with them only a pound and a half of preserved mutton, three pounds of salt pork, fifteen pounds of sea-bread, three pounds of pork scraps for soup, and a little coffee, pepper, and molasses. The trip lasted nearly a month and a half, during which time Hall learned to live like the Esquimaux in their snow cabins, and subsisted mainly upon raw seal flesh. When he returned to the ship it was hard for him to accustom himself to the change from the pure atmospinere of a snow-house to the confined air of a small cabin. 


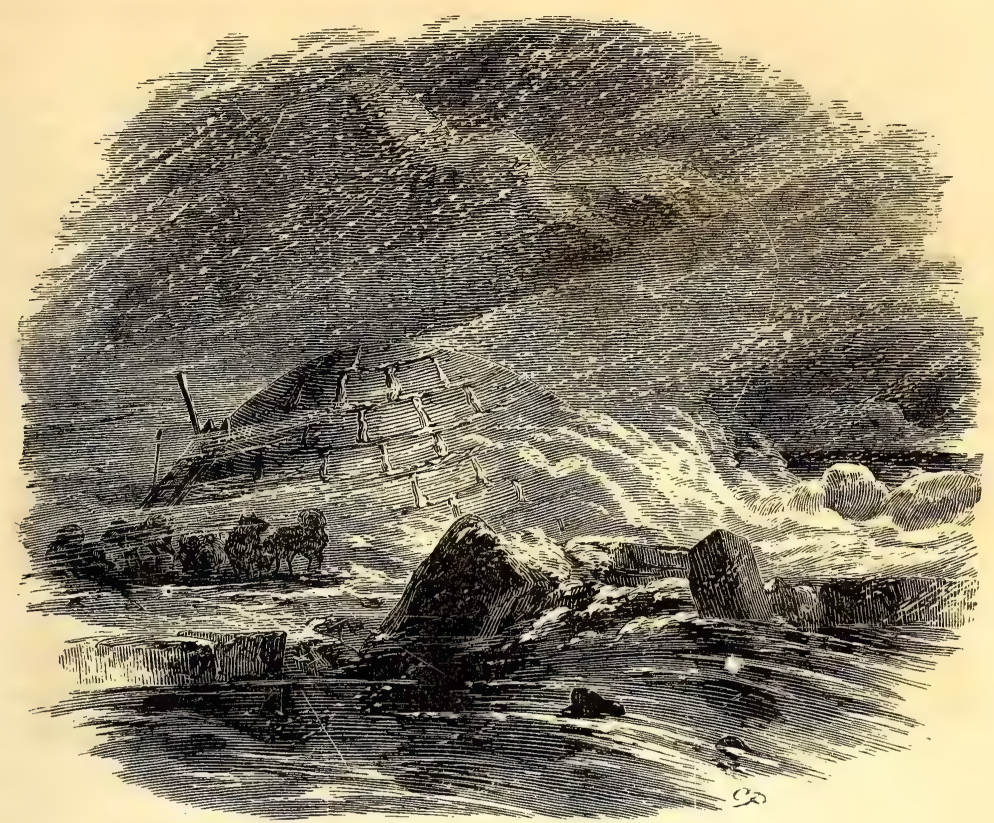

STORM-BOUND.

Had Kane but known how to pass an Arctic winter, the world would never have had occasion to read one of the most pathetic accounts ever written of suffering. Buddington, the captain of the "George Henry," had learned the lesson by dear experience. Five years before, when in command of another vessel, he had lost thirteen of his men by scurvy. " "But," said he, "I am not now afraid of losing any more men by scurvy while I have command over them. Whenever there are appearances of it on board, I will have every pork and beef barrel-salt provisions of every kind-headed up at once, and every man shall live upon bread and fresh provision, such as whale, walrus, seal, deer, bear, ptarmigan, duck, and the like. It is not a little remarkable that persons afflicted with scurvy seem madly inclined to salt provisions, which they know to be in their case absolute poisons. They will go any length to obtain salt pork, even when they have fresh food in abundance."

Hall's first night in an igloo may stand as a sample of many more. We cite, with much abridgment, from his journal :

"We encamped at 5 P.M., having found good material for building a snowhouse. Ebierbing and Koodloo at once commenced sawing out snow-blocks, while I carried them to a suitable spot for erecting the igloo, which took us one hour to make. As soon as it was completed Tookoolito entered, and commenced placing the stone lamp in its proper position. It was trimmed, and soon a kettle of snow was over it, making water for coffee and soup. She then placed several pieces of board, which we had brought with us, on the snow platform where our beds were to be made. Upon these were placed canvas and deer-skins, and our sleeping accommodations were complete. The drying of any thing that has become wet during the day falls to the lot of the woman. 


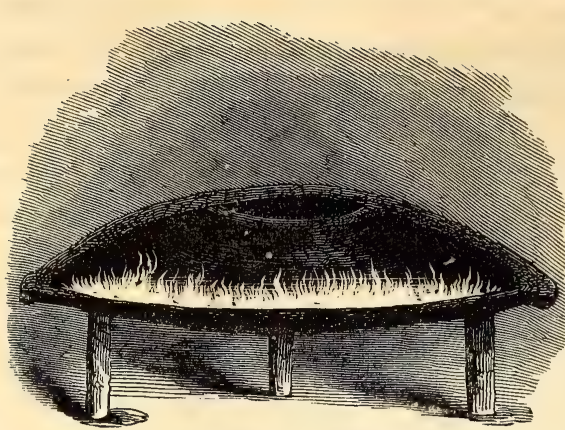

INNUIT STONE LAMP.

She places them in a net hung over the lamp and attends to them through the night, meanwhile mending all articles of clothing that need repairs. Presently our evening meal was ready. It consisted of Cincinnati 'crackling' soup, a bit of raw salt pork, half a biscuit for each, and coffee."

A snow-house, built in an hour, is abandoned when the use for it is over. The dogs are suffered to enter, and appropriate any thing that is left which suits their taste. Nothing comes amiss to them. On the third night Hall had his hair cut by Tookoolito, and the clippings were left on the floor. The dogs swallowed these, among other things. Stormy weather soon came on. There was no hunting or sealing, and the party had nothing to eat except some bits of raw, frozen whale's-skin which they found in a cache, which a party from the ship had made a few weeks before. Not far off was an igloo belonging to an Innuit named Ugarng, whom they knew. Hall went to it hoping to find something to eat. Ugarng had just come in, having spent two whole days and a night in watching over a seal-hole without success. He had heard the seal blow, and that was all. He bore his disappointment coolly. "Away I go tomorrow again," he said. He went next day, remained all night over the sealhole, and came back with nothing. "This was very bad for the whole of us," says Hall. How bad it was for the poor wife of Ugarng and her children may be inferred from her own words. They were without food or light; her infant was restless from hunger. She said simply, "Me got no milk, meat all gone, blubber too ; nothing to eat, no heat ; must wait till get seal."

Hall was about as near starvation as were the Innuits. All he had to eat was a bit of the "black skin" of a whale, and this he relished; he could have eaten any thing which would have gone to keep up internal heat, and make bone and flesh. Ebierbing was away hunting. At length Tookoolito managed to extemporize a warm dinner. From the black skin she tried out enough oil to fill the lamp and heat some snow-water. This was thickened with a couple of ounces left of a quart of meal which formed a part of the stores with which they set out. The pair shared the "pudding," and thought it excellent. The cold was severe. Within the dark igloo the thermometer stood at about zero; outside, $25^{\circ}$ to $52^{\circ}$ below zero. Under these circumstances Hall kept at his journal, sitting wrapped in furs to keep from freezing. So passed ten days. Ebierbing had gone back to the vessel in order to bring back some food. Day by day Hall went to the top of a hill, straining his eyes over the snowy waste in hope of seeing the approach of the messenger. On the evening of the 24th of January, fourteen days after their starting upon the expedition, they were reduced to their last ration of food, which was a piece of black skin two inches long, an inch and a half wide, and three-quarters of an inch thick.

At midnight footsteps were heard approaching; Hall sprang from his bed 
and opened the snow-block door. There was "Jack," an Innuit, who had gone out on a hunt, with his spear strung with strips of seal-blubber. Hall's favorite dog had been allowed to sleep in the igloo. The half-starved creature scented the blubber, gave a desperate leap, and grasped a portion of the food, and in spite of all the efforts of Hall and the others swallowed it. Before the door could be closed all the other dogs outside were aroused, and fighting for a share. Among them they got nearly the whole. Next morning Hall went out,

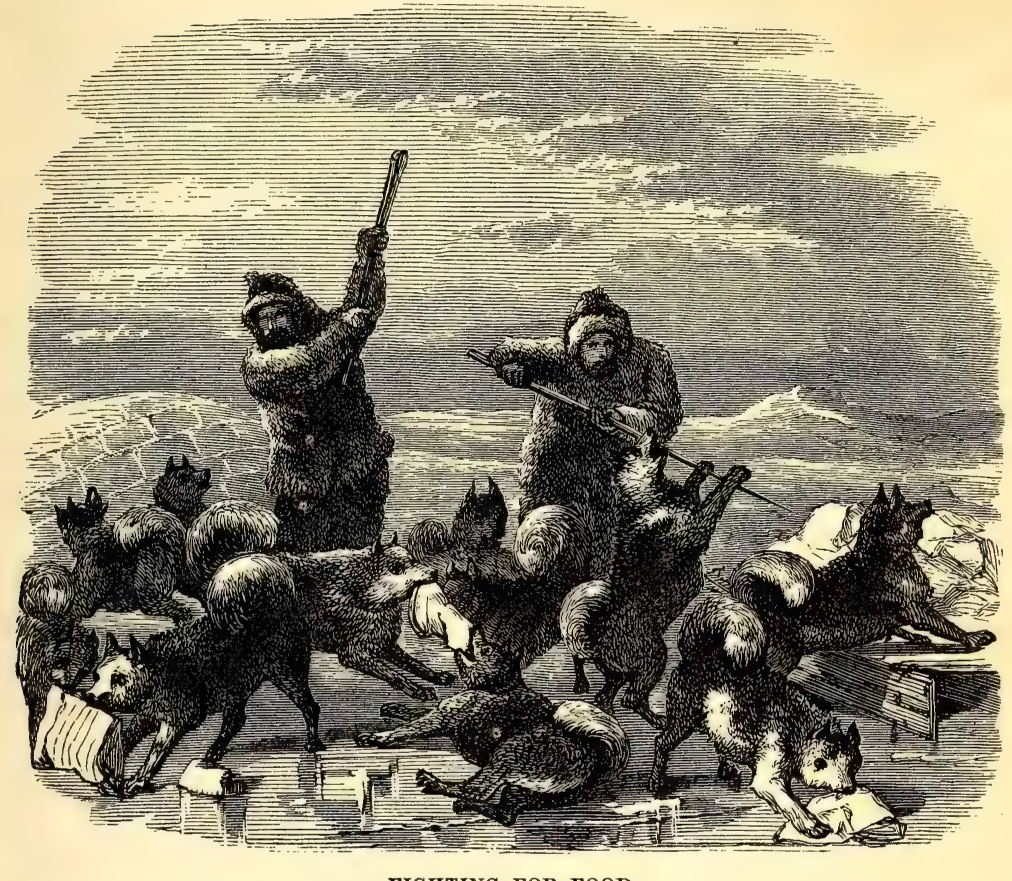

FIGHTING FOR FOOD.

and gazing in the direction from which the approach of Ebierbing was hoped for, saw something black moving over the snow. It was Ebierbing with dogs and a sledge, loaded with provisions from the ship, and also with a seal which he had caught that morning. A great seal-feast took place at once, which Hall thus describes:

"According to Innuit custom, an immediate invitation was given by the successful hunter's family for every one to attend a seal-feast. Our igloo was soon crowded. My station was on the dais, or bed-place, so that I could watch what was going on. The first thing done was to consecrate the blubber by sprinkling water over it. Then our host proceeded to separate the blubber and skin from the meat and skeleton of the seal. The body was then opened, and the blood scooped out. The blood is considered very precious. The liver came next, cut into pieces and eaten raw, I getting a share. Then followed distributing the ribs, for social picking, also eaten raw, I doing my duty, and becoming quite an Innuit in all except in the quantity eaten. This I might challenge any white man to do. No human stomach but an Innuit's could possibly 


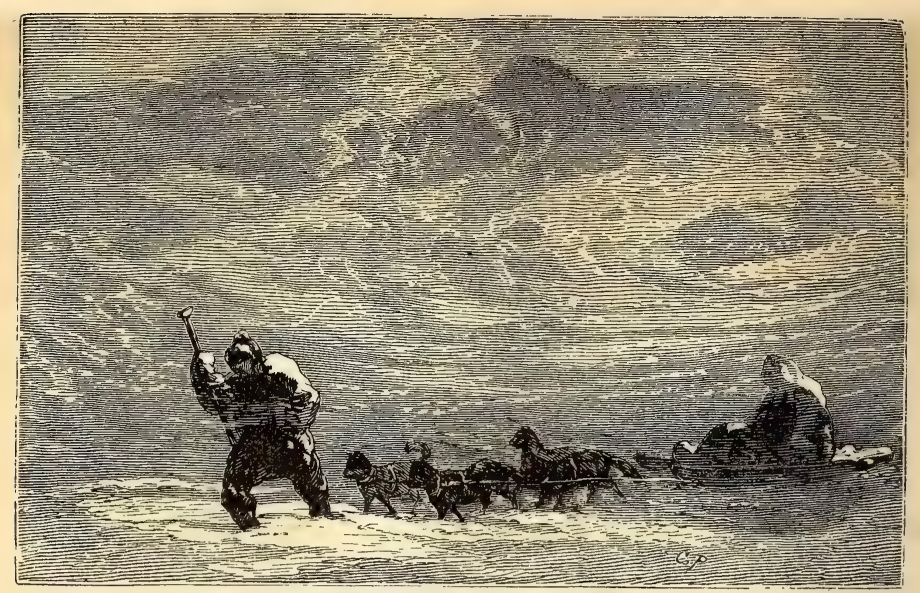

THKOUGH THE SNOW.

hold what I saw these men and women devour. When the feast was ended, the company dispersed. Tookoolito then sent around bountiful gifts of sealblubber for fire-lamps, also some seal-meat and blood. This is the usual custom among the Innuits. They share each other's success, and bear each other's wants. Generally if it is found that one is short of provisions, it may be known that all are so."

The manner in which Ebierbing secured that precious seal is a striking example of Innuit patience. On his way to the ship the dogs discovered a sealhole. He marked the spot by making a small pile of snow close by, and squirting a mouthtul of tobacco-juice upon it by way of mark. On his return he found the hole, and determined to try to secure the animal. So wrapping his feet and legs in furs taken from the sledge, he took his position, spear in hand, over the seal-hole. It was buried two feet deep under the snow. He thrust his spear through the snow again and again until he found the little aperture leading through the ice; then in the dark night he seated himself close by, waiting to hear the blowing of the seal. Towards morning the welcome sound was heard. One well-aimed thrust of the spear secured the prize. Ebierbing was nearly frozen, his nose being frostbitten; but he suffered more from thirst than from cold. There was indeed snow all around, but in that intense cold the mouth does not retain sufficient caloric to melt a piece of snow placed in it. His first call when he reached the igloo was for water. To watch all night at a seal-hole would seem to be a sufficient trial of patience and endurance; but Hall notes another time when Ebierbing passed two whole days and nights without food by a hole, and then failed to secure the seal.

To the Innuit the seal is, in the broadest sense, the staff of life. It is to them all that flocks and herds, grain-fields, forests, coal mines, and petroleum wells are to dwellers in more favored lands. It furnishes to them food, fuel, and clothing. The seal is the most wary and suspicious of creatures; to capture him demands a patience and dexterity which throws into the shade all the exploits of deer-stalkers and lion-hunters. "Nutchook," for so the Innuits name the seal, has good reason for wariness, for his chief enemy, "Ninoo," the bear, 


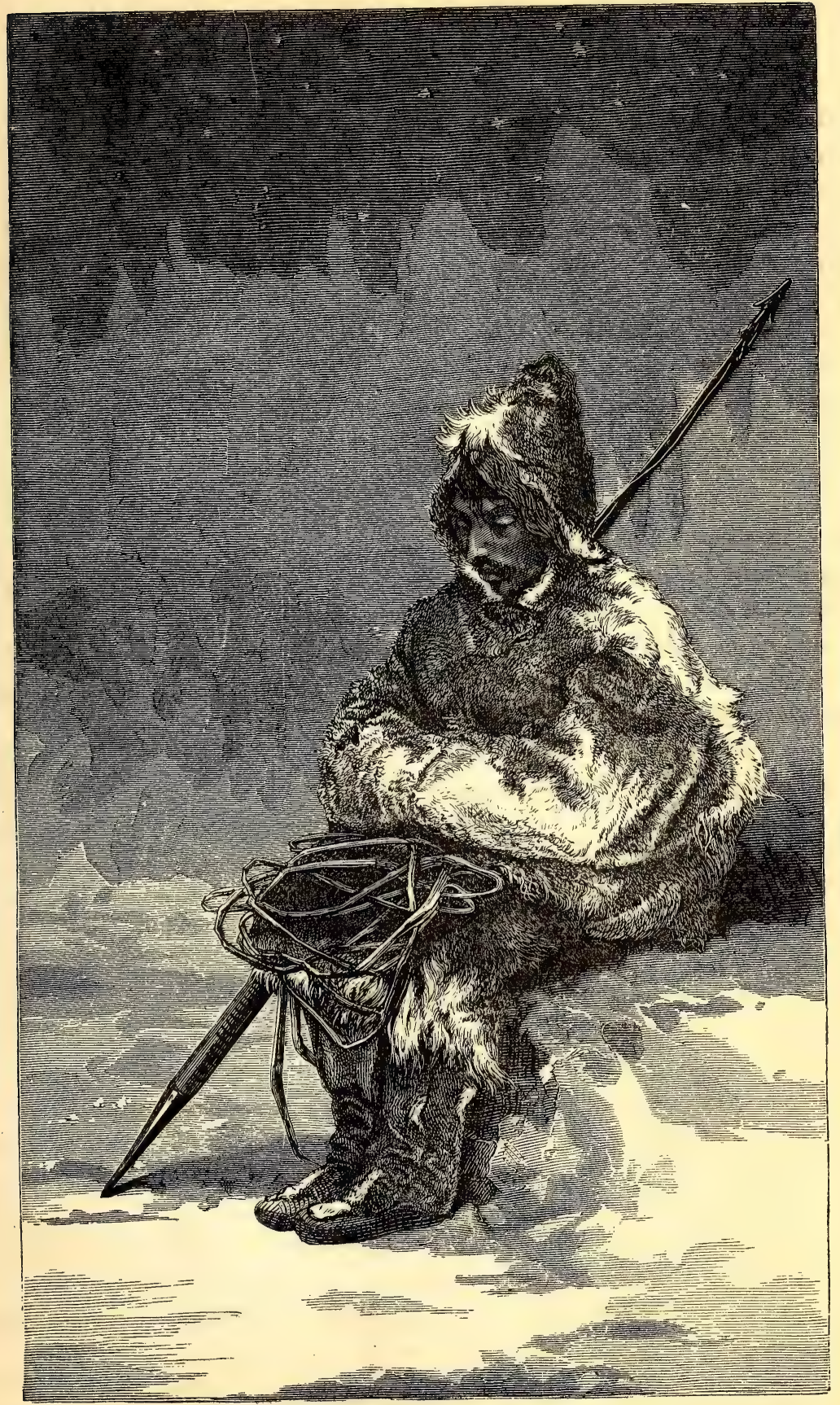

WAITING BY A SEAL-HOLE.

against whom he has to keep constant watch, is a keen hunter. The Innuits acknowledge that "Ninoo" has taught them how to catch " Nutchook," the common seal, and his big cousin "Oookgook," the great seal. Hall, no contemptible sportsman, acknowledges that he was never able to get within rifle- 
shot of a seal when basking upon the ice; yet Ninoo catches them with his own paws; and the Innuits, taught by him, come within the distance of a spear's cast.

The way Ninoo goes to work at seal-hunting upon the ice, according to Innuit accounts, is this: He sees far away upon the ice a black spot, which he knows to be a seal resting at the edge of his hole, and taking a succession of "cat naps," hardly ten seconds long, lifting up his head between times, and narrowly surveying the whole horizon. Ninoo flings himself upon his side, and creeps along when the seal's head is down. The moment the seal's head is raised the bear stops short, and begins "talking" to the seal. The sound which he utters is quite distinct from his ordinary voice. The seal is charmed, suspects no harm, and down goes his head for another nap. Forward goes Ninoo, and so on for a long time, until he gets within leaping distance; then wne spring, and it is all over with Nutchook. The Innuits say that if they could only talk to Nutchook as cleverly as Ninoo does, they would catch more seals. The Innuit imitates Ninoo.

Hall describes one of these hunts, the main actor being an Innuit named Koojesse: "Koojesse had 'talk' with seals, and it was with great interest that I watched him. He lay down on one side, and crawled by hitches or jerks towards his victim; then as the seal raised its head Koojesse would stop, and commenced pawing with his right hand and foot, while he uttered his ' sealtalk.' On this the seal would feel a charm, raise and shake its flippers both fore and aft, and roll over on its side and back as if perfectly delighted; after

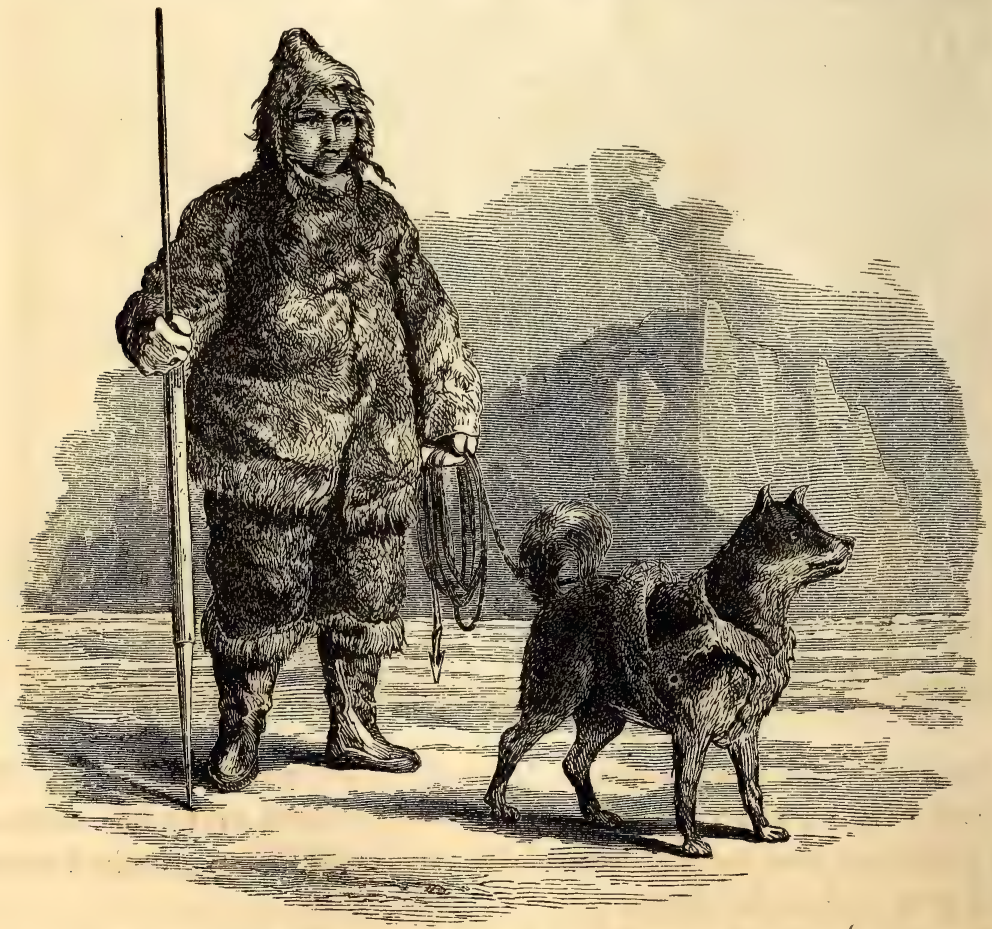

LOOKING FOR SEALS. 


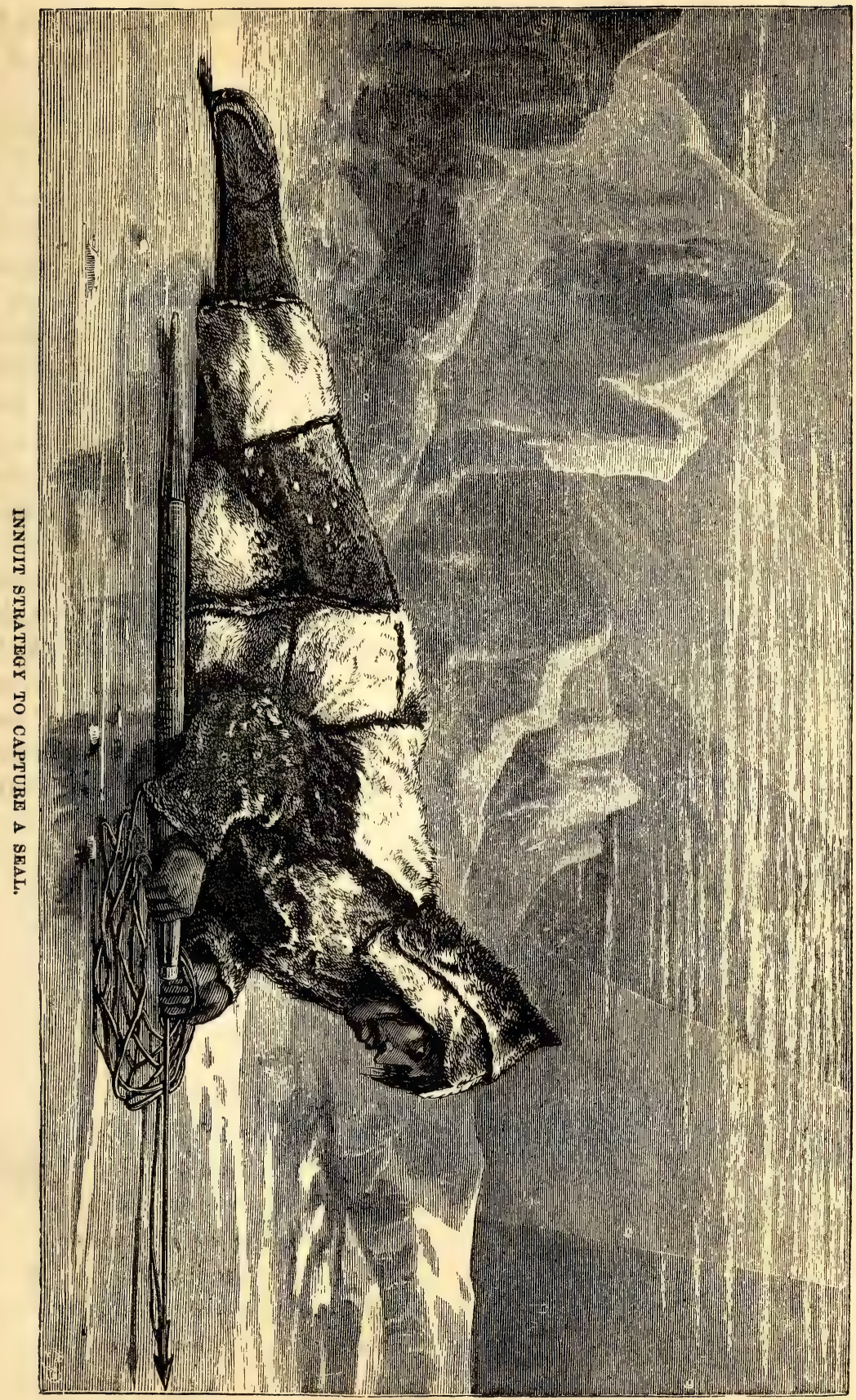

this it would drop its head to sleep. Then Koojesse would hitch along till the seal's head would pop up again, which usually occurred every few moments." In this particular case the seal escaped, for the Innuit had approached too near, and had thus broken the charm.

In the winter, when the seal lives under the ice, its capture requires great 
skill and perseverance. She, for somehow the male seal seems now not to be noticed, has a breathing-hole through the ice, to which she must come now and then for air. Upon the surface of the solid ice, which is covered with snow, the prospective mother constructs an igloo for her progeny. She scrapes off the snow until she has formed a dome, carrying away the snow down through the hole in the ice. Upon the shelf of ice surrounding the hole the young one is born, and there it is egularly visited by the mother. None but very keen-scented animals, such as the bear, fox, and dog, can discover such an igloo. The dog sometimes captures a seal. Hall describes such an ever "Ebierbing had one day been out with dogs and sledge where the ice was still firm, when suddenly a seal was noticed

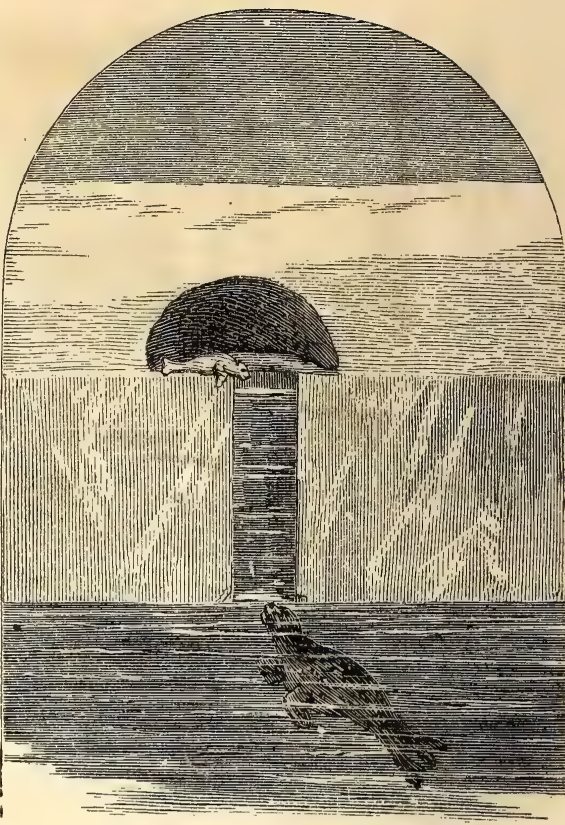

SEAL-HOLE AND IGLOO. ahead. In an instant the dogs were off towards the prey, drawing the sledge after them at a marvellous rate. The seal for a moment acted as if frightened, and kept on the ice a second or two too long, for just as he plunged, Smile, the best seal and bear dog I ever saw, caught him by the tail and flippers. The

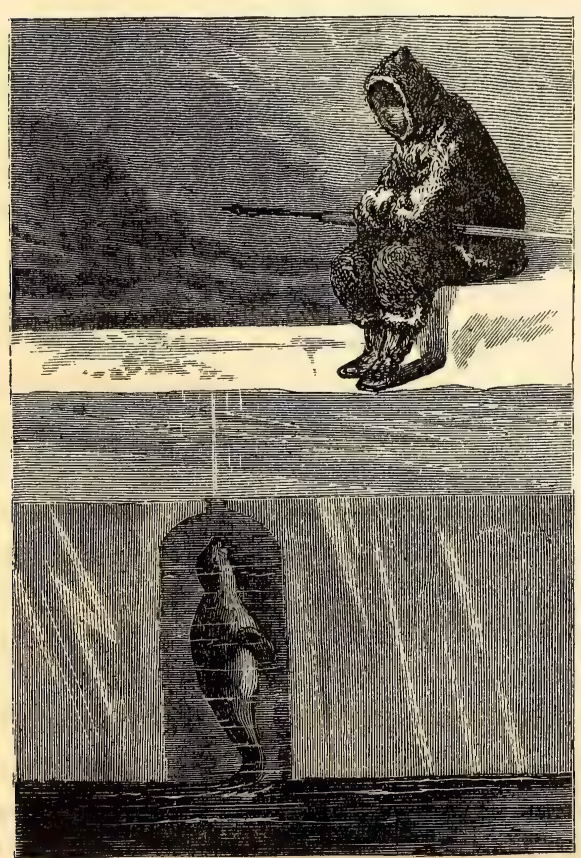

WAITING FOR A BLOW. seal struggled violently, and so did Smile; but in a moment more the other dogs laid hold, and aided in dragging the seal out of his hole, when Smile took it in charge. The prize was secured wholly by the dogs."

Dogs seem to hunt the seal only upon their master's account; but the fox and the bear capture him for them. selves. How the fox contrives to get into a seal igloo we are not told; but as they manage to break open the best packed provision-cases, we may assume that they know how to commit burglary upon the igloo of a poor seal. If the Innuits are to be believed, the way the bear goes to work is this: When he has scented out the precise position of an igloo he goes back a little distance, so as to get a good run; and then, giving a high leap, comes down 


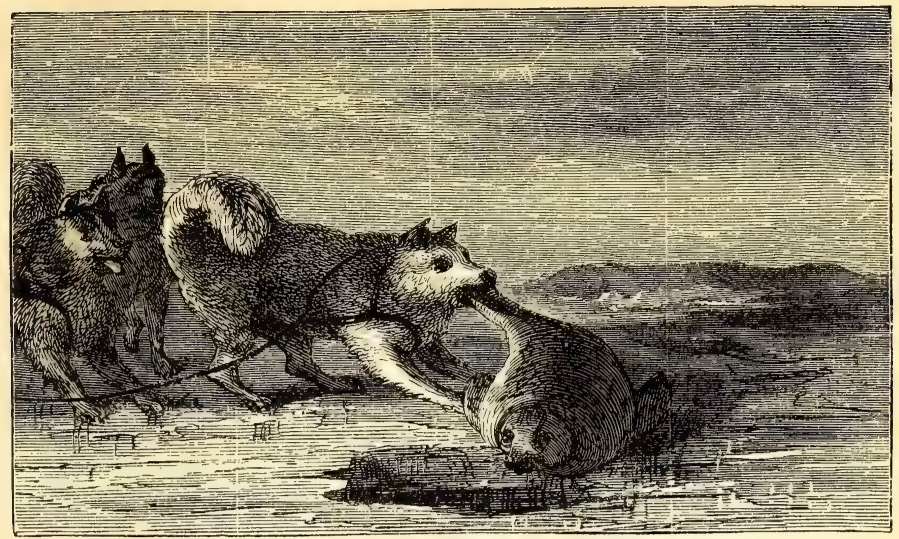

DOG AND SEAL.

with all his weight upon the roof of the dome, crushes it in, and with his paw seizes the young seal, who was quietly asleep upon the ice-shelf. The cunning bear is not always satisfied with the little infant seal, but uses it as a bait to catch its mother. Having caught the young one, and holding it fast by the hind flippers, the bear scrapes away all the snow, and lets the young seal paddle about in the water; its cries draw the mother to the hole, and within reach of the bear's paw, when one grab is given, and the anxious mother is secured. At all events the Innuits practise this sort of strategy with the seal, and they declare that they have learned it from the bear.

The bear is to the Innuits the embodiment of all wisdom. They tell stories of his sagacity which are hard to believe. Thus they say that when he sees a walrus basking upon the ice at the foot of a high cliff, he mounts to the summit of the cliff, and picking up a big stone flings it down with perfect aim upon the head of the walrus and crushes its thick skull. If it should happen that the walrus is only stunned, the bear crawls down the cliff, picks up a stone, and with it hammers away at the head of the walrus until the skull is broken. This story of the Innuits needs confirmation, though Hall seems to credit it.

The dog is essential to the existence of the Innuits. As they have never domesticated the reindeer, without the dog they could not travel from place to place, which they are obliged to do in order to follow the migrations of the seal and walrus, upon which they mainly subsist. Without him they could never find out the holes in the ice through which the seal comes up to breathe in the winter. Their doos seem to be much more intelligent and docile than those of any other of the Polar tribes. When one is found to be more than usually intelligent he is carefully trained as a seal-dog. When the dog scents a sealhole, which he does though it is covered deep under the snow, he unerringly follows the scent to the very spot.

The Innuit proceeds to "prospect" by driving the slender spear through the snow until he finds the small opening in the ice which leads to the main hole. He then withdraws the spear, taking the utmost care not to disturb the snow, and seats himself close by to await the coming of the seal. He watches for hours, and sometimes for days, before he hears the welcome "blow." At 


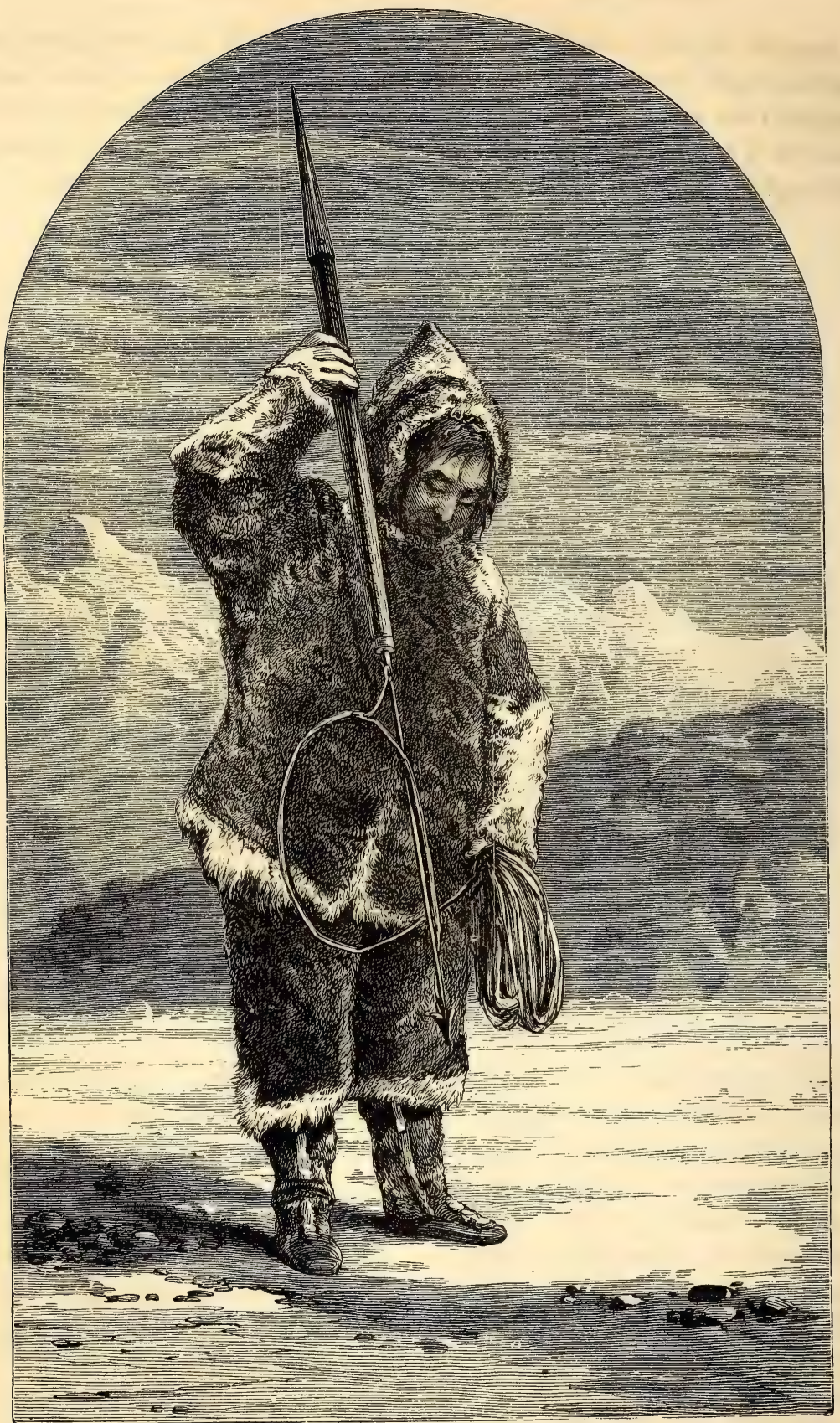

SPEARING THROUGH THE SNOW.

the second or third puff, he knows that the nose of the seal is at the bottom of the breathing-hole, perhaps two yards below the spot where he is standing. The spear must be thrust with perfect accuracy; for an error of a quarter of an inch on either side would miss the hole, and the spear-point would strike the 
solid ice, and the seal would be away in an instant. If the blow is well-aimed and at the right instant, it pierces the head of the unseen seal, who instantly dives, and runs out the eight or ten fathoms of line which, fastened to the harpoon, is tied around the waist of the Innuit. The snow is then dug away, the breathing-hole enlarged, so as to permit the seal to be drawn through.

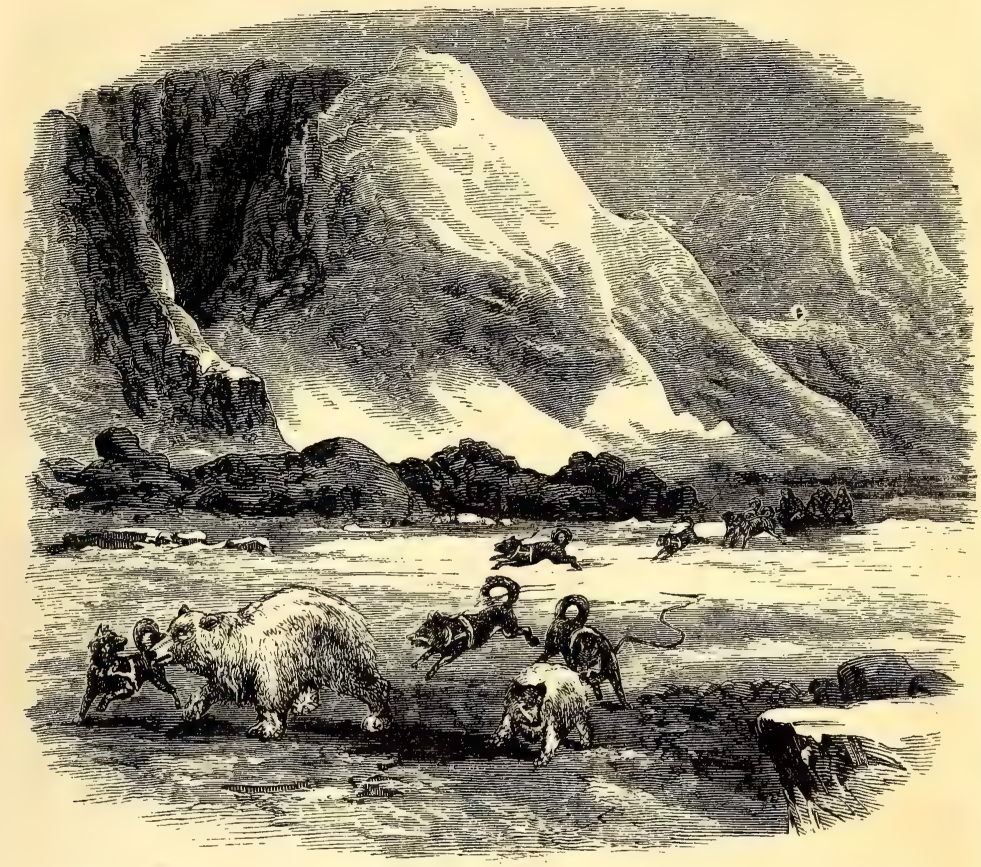

DOGS AND BEAR.

The dogs also take special delight in hunting the bear. When a team scent a bear it is impossible to restrain them. Once when Hall was on a journey a bear with her cub was seen on the ice at the foot of a high mountain. When within two hundred yards, the leading dog was cut loose, and he made straight for the bear; one by one the others were set free from the sledge, and all were in hot pursuit. One dog set upon the cub, and finally separated it from its mother; another caught the dam; and both rolled down a precipice, up which the bear scrambled again and escaped, for it was so steep that the dogs could not follow. All the dogs, eleven in number, now set upon the cub. Hall coming up, the young brute made at him; he ran it through with his spear. He expected that the Innuits would applaud his courage and dexterity; but they shook their heads and said nothing at the time. They soon showed the utmost determination to leave the neighborhood, and explained by saying that the old bear would come back at night, smell the blood of the cub, and become enraged, and kill them all. The Innuits avoid killing a young bear until they have dispatched the old one, for they say that knowing the death of her young makes her a hundred times more terrible. Although the liver of the seal is 


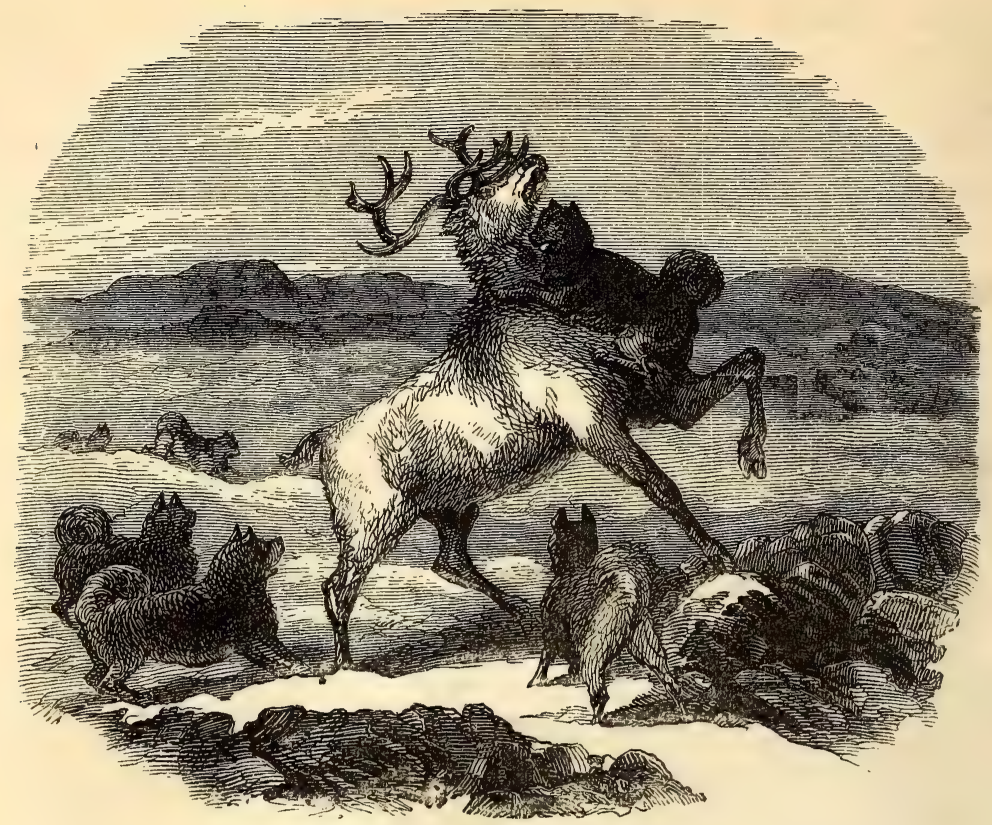

BARBEKARK AND THE REINDEER.

held to be a great delicacy, the Innuits never eat that or the head of the bear; nor, if they can prevent it, will they suffer their dogs to do so.

The Innuit dogs also sometimes hunt the reindeer. Hall's dogs one day gave chase to a deer, and one of them, Barbekark, sprung at its throat, and bit through skin, windpipe, jugular, and tongue, taking out the piece as clearly as though it had been cut with a knife. Barbekark was brought to the United States by Mr. Hall, and died there. His stuffed skin showed him to be a noble beast of unusual size.

The walrus enters largely into the supplies of the Innuits. They manifest much courage and skill in harpooning these ungainly beasts. The hunter goes out armed with a lance and a peculiar harpoon made for that purpose. A long hide-rope is attached to the head of the harpoon, and coiled around the neck of the hunter, who crawls along until he comes within striking distance of the walrus, who lies basking upon the ice. The walrus dives at once; the hunter slips the coil off from his neck, and fastens the end of it to a spear driven into the ice; thus tethering the animal. As soon as the walrus comes up he is dispatched with a long

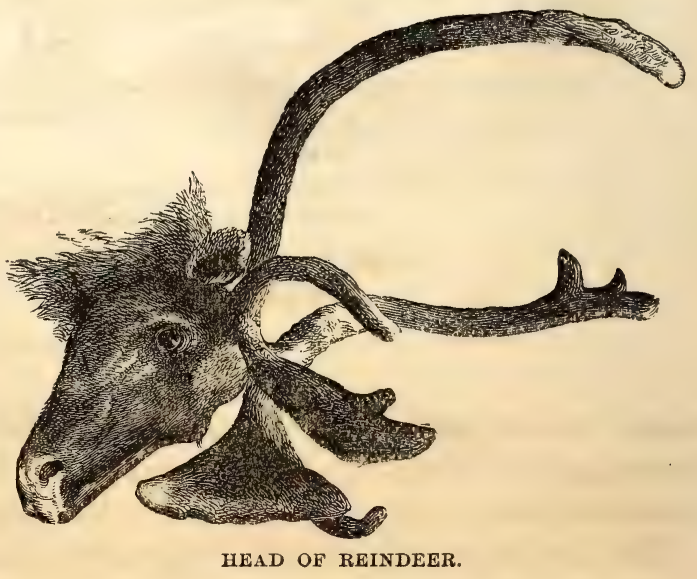




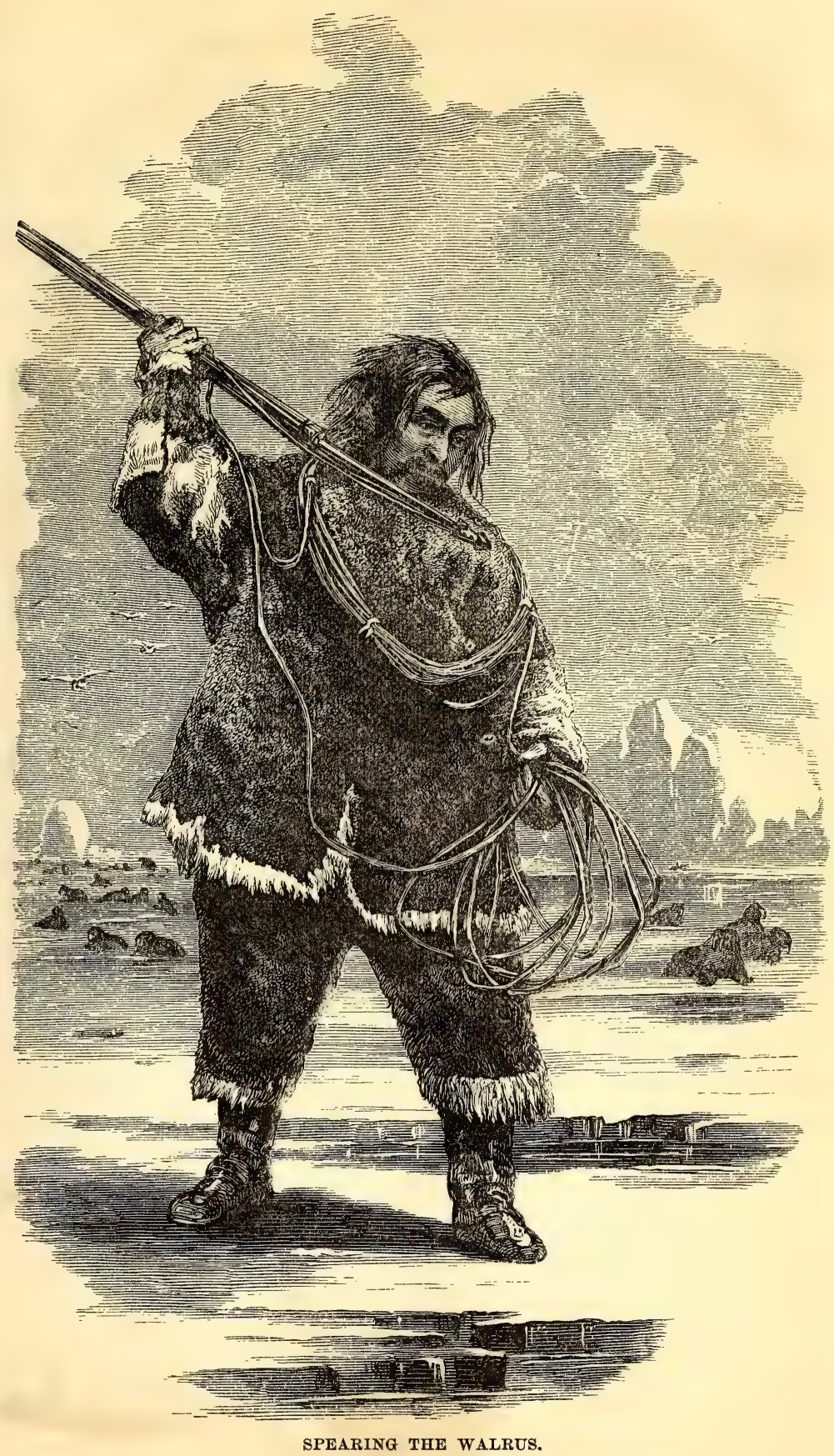

lance. Should the Innuit fail to slip off the coil in time, he would infallibly be drawn into the water, and almost certainly lose his life; but as Hall records no instance of such a catastrophe, we infer that these rarely happen.

The Innuits show remarkable ingenuity in availing themselves of every fa- 
cility afforded by their inhospitable country. Of their igloos or snow-houses we have already spoken. In half an hour a couple of men will build one of these, which answers very well for a temporary shelter. When one is to be built for a longer residence, more care is taken in the construction. A site is chosen where the snow is hard-if possible, over a running stream, so that they

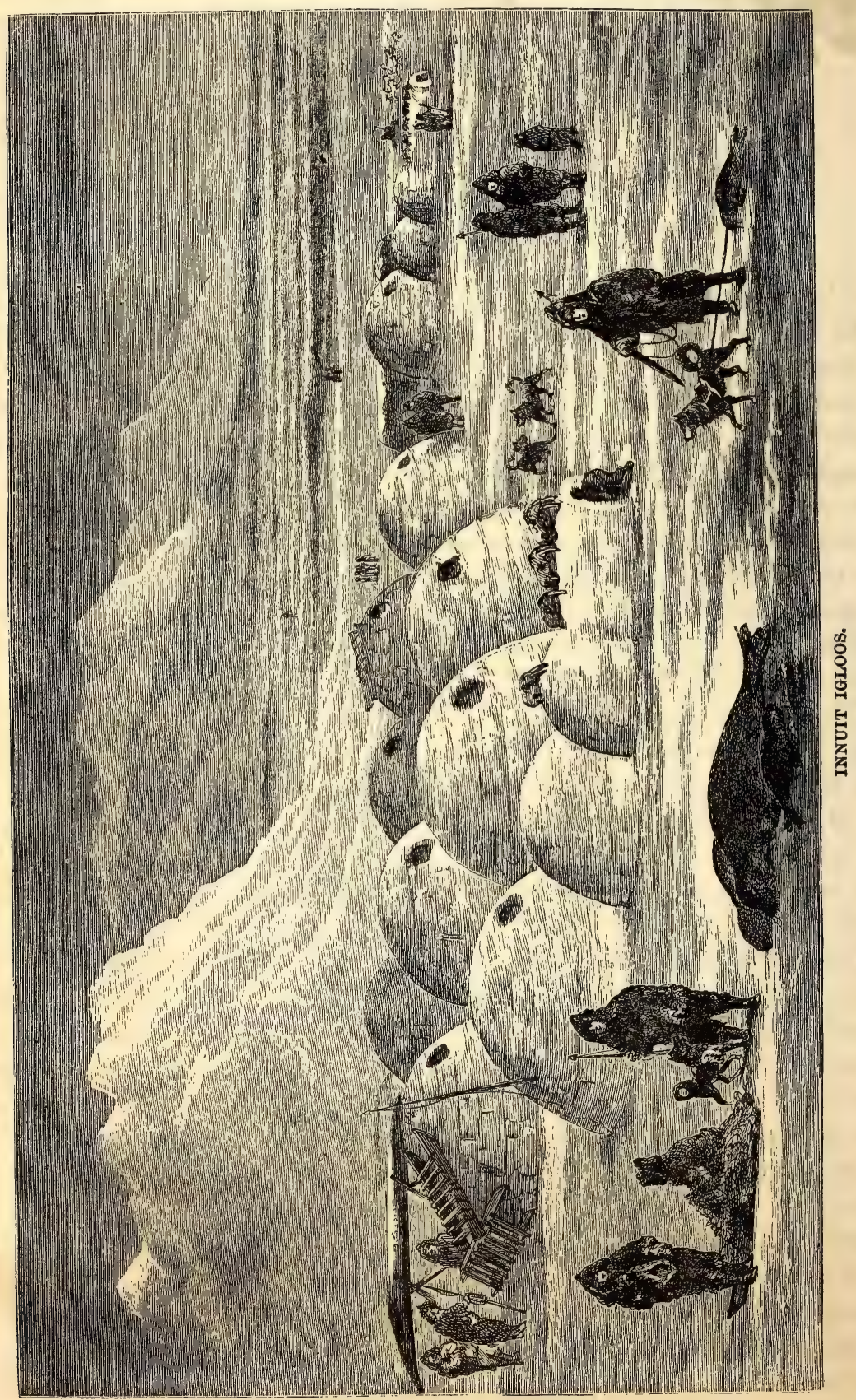




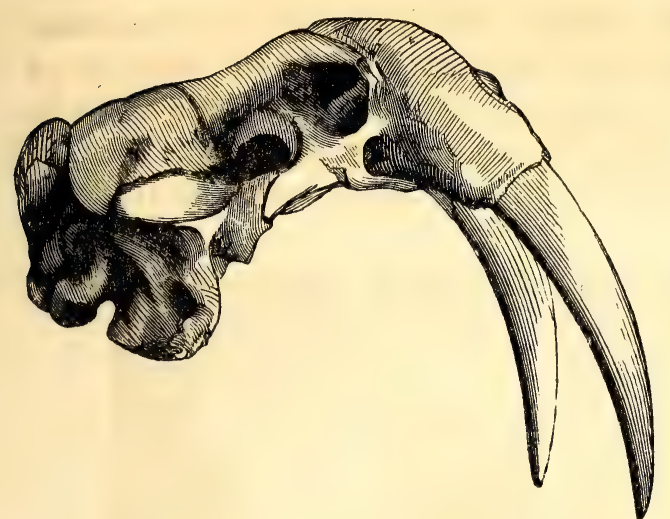

WALRUS SKULL AND TUSKS.

can obtain water without the labor of melting the ice. A circle is marked out for the ground plan. Blocks of snow are cut with a large knife or saw. These blocks are three feet long, eighteen inches wide, and six inches thick, shaped rounding, so that each block forms the segment of a circle of the proposed diameter of the igloo. The blocks are slightly tapered off on the inner side, and are laid spirally, one man building from within, while the other brings the blocks from without. The courses grow smaller and smaller as the dome rises, until there is only a narrow open circle, into which a block of snow is dropped by way of keystone, binding the whole dome firmly together. The man within now carefully examines every part, and if there are any openings left they are stopped up with snow. A hole for a door is then cut; and through this are passed the snow-blocks to build the divan, which forms the seats and bed. A tunnel-like passage is then dug and covered over. This is so low and narrow that one must crawl on all fours to pass through it. The outer door of the passage consists of a block of ice or hard snow fitting closely to the opening and turning upon a sort of pivot. The usual diameter of a family igloo is twelve or sixteen feet, and its height about eight. It will accommodate ten or a dozen people.

When newly built, an igloo is one of the most beautiful structures conceivable. The blocks are more transparent than the clearest alabaster and whiter than the purest marble, but they soon become defaced by the smoke and the filth of all kinds which rapidly accumulates. Apart from the divan, almost the only article of furniture is the stone lamp, which serves the purpose both of lamp and furnace. It reminds one of an implement common among civilized people, and known as an "Etna."

The Innuits show great dexterity in the construction of their implements and in the fabrication of their clothing. Their canoes have been the admiration of every voyager in the Arctic regions, and they are wonderfully dexterous in the management of them. Their sledges have the runners made of bits of bone ingeniously tied together with the sinews of the deer. When they wish them to run very smoothly they shoe them with ice, by simply squirting from their mouths a thin stream of water upon the runner, where it congeals in an instant. 'The "oodloo," or woman's knife, is shaped like our common meat-chopper. It is made of bone, merely edged with iron; but in the hands of an Innuit woman it takes the place of the knife, hatchet, scraper, and shears of

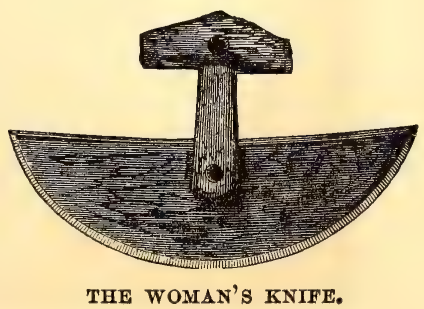




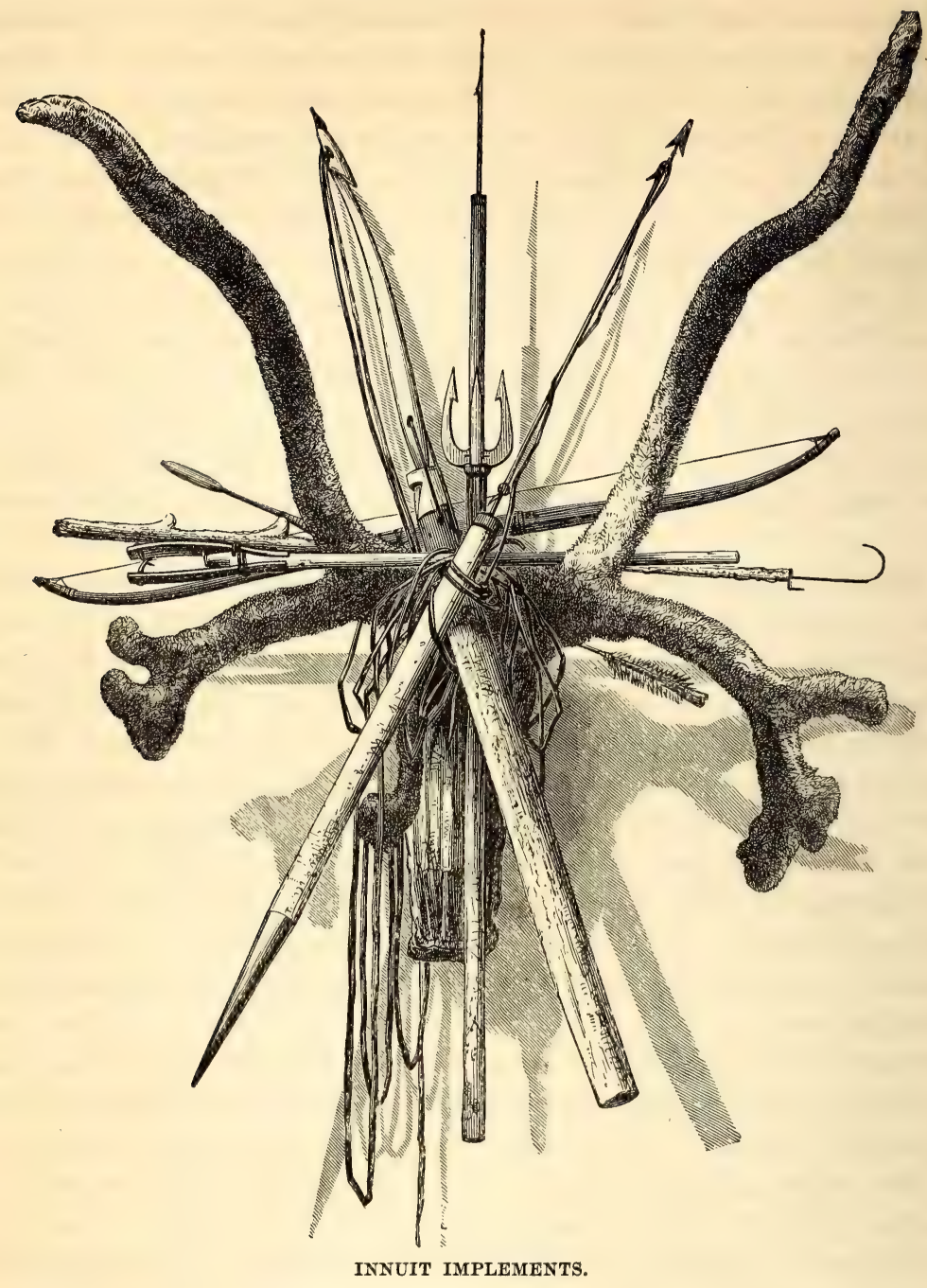

her civilized sisters. The different kinds of spears and harpoons used in capturing the seal, walrus, and whale are admirably adapted for their purpose. We doubt whether we could improve upon the design, and, with all our facilities in the way of material, very much in the way of execution. The Innuits have clearly given their whole minds to the fabrication of these weapons. They have the bow and arrow, and are quite clever in its employment; but for them it is of little use except in the shooting of birds, for a seal or walrus would not even feel an arrow shot from the strongest bow.

Although the Innuits have never domesticated the reindeer, it yet plays a great part in their economy. Their clothing and bedding is composed almost wholly of deer-skin, which is one of the best non-conductors of heat known. Even when the thermometer marks 70 degrees below the freezing-point, they never use but one for bedding; and Mr. Hall says that he has slept under a 
dozen of the best woollen blankets and been almost frozen, while a single slender skin kept him abundantly warm. During the summer the deer furnishes a great part of the food of the people. The grass and mosses upon which the deer live are very abundant. Nowhere, except on the prairies of the West, had Hall ever seen such luxuriant pasturage, and the deer in August were so plentiful that they were killed merely for the sake of their hides and tallow, which is a great luxury, fully equal, in Hall's opinion, to the finest butter. If the Innuits would only store up their provisions in the season of plenty, they need never suffer from famine; but they never do this, and the consequence is that from November till May they are almost always on the verge of starvation, while during the rest of the year they revel in plenty.

As a pendant to Mr. Hall's account of a seal-feast, we give his description of a reindeer-feast. The date is December, the season of scarcity。 ${ }^{66}$ Four months before, they had more deer-meat than they could eat-and the quantity that an Innuit and his dog can consume is something almost incredible. But one day a man came in from a hunting excursion bearing with him a portion of the carcasses of two deer, frozen as hard as a rock. A general invitation for a feast was of course given out; and the entire population, about thirty in all, rushed in. Sampson, the giver of the feast, acted as master of ceremonies. He first made the ladies on the bed give away, so as to clear a space whereon he might do the carving. Then he placed a huge seal-skin on this spot, by way of tablecloth, upon which the frozen carcass was laid. This he began to carve with a hatchet. Slabs of its siaje were chopped and peeled off; chips of ice flew here and there into the faces of the guests at each stroke of the axe. As fast as the fragments of venison rolled off, other men took the pieces, and by means of a saw and seal-knives reduced them to a size adapted for handling. Then Sampson distributed these bits, one to each, till every mill had its grist to grind. Thus for half an hour Sampson carved; then his hatchet-handle broke off close up to the head. Another axe was sent for, and meanwhile, with the half of a saw, the two saddles were divided into the proper number of pieces, ready for distribution. The carcass was ther once more attacked, and the shell was broken, split, and sawed to pieces. In it was the 'kernel,' to which all looked with anxious eyes; this was at last divided into as many pieces as there were pieces of saddle, and then one of each was given to every guest. I received my share with gratitude, and, with a piece in each hand, began eating. I bit off a mouthful of the saddle-piece; it was good. I took a morsel of the other; it was delightful: its flavor was a kind of sorrel acid; it had an ambrosial taste; it fairly melted in my mouth. When nearly through, I had the curiosity to crowd my way to a light to see what this delicious frozen food was, for where I sat I was shaded by large forms between me and the firelight. I looked at it, rolled it over, and looked again. Behold, it was the contents of a reindeer's paunch! On this discovery I stopped feasting for that night."

Mr. Hall passes judgment upon various other articles of Innuit food. Seal's blood, smoking hot, is excellent. The skin of the whale, three-quarters of an inch thick, looking like India-rubber, even when raw, is good eating; but when boiled and soused in vinegar, is most excellent. The "gum "' of the whale, that 
is, the substance in which whalebone is set, is a special Innuit delicacy; it looks like cocoa-nut meat, and tastes like unripe chestnuts. Hall could not fully appreciate this ; but he adds savingly, "If the struggle was for life, and its preservation depended upon the act, I would undoubtedly eat whale's gum until I got something better to my liking." Once a substance which looked like a choice bit from a turkey's breast was handed to him. He thought he had stumbled upon a delicacy, but after vainly trying to masticate it for half an hour, he found it as solid as when he began. This substance was the ligament lying between the vertebræ of the whale. He had made a mistake in the way of disposing of it. The Innuit mode is to take a huge piece into the mouth, lubricate it thoroughly, and then bolt it whole, as the boa-constrictor swallows a deer. Hall thinks well of the Innuit practice of eating their meat raw, in a sanitary point of view; but he never quite liked it. He never fully came up to the opinion of Mansfield Parkyns, the Abyssinian traveller, who assures us that no man knows what a good beef-steak is until he has eaten it raw, before it has had time to get cold.

The costume of the Innuits is admirably adapted to the climate. The winter dress, commencing with the feet, is thus composed : Long stockings of reindeer skin, with the hairy side next to the person; socks of eider-duck skin, with the feathers on both sides, and of seal-skin with the hair outside; boots, the legs of reindeer skin with the hair outside, the soles of seal-skin. The jacket is of reindeer skin, fitting rather loosely; those of the women have long tails reaching almost to the ground. The ornamentation of the fernale dress depends on the means and taste of the wearer. One "very pretty style,' mentioned by Mr. Hall, had a fringe of colored beads across the neck, bowls of Britannic-metal tea-spoons down the front flap, and a double row of copper cents, surmounted by a small bell, down the tail, which was bordered by a beading of leaden shot. The jacket has no opening before or behind, but is slipped on over the head. The women's jacket has a hood which serves a variety of purposes, among others, that of carrying the children. The breeches reach below the knee, and are fastened by a string drawn about the waist. Finger-rings and a head-band of bright brass, complete the fashionable costume.

The religious ideas of the Innuits are very vague. They believe that there is one Supreme Being who created the earth, sea, and stars; and also a secondary divinity, his daughter, who created all things having life, whether animal or vegetable. She is the tutelary deity of the Innuits. They believe in a heaven and a hell, but have no very well defined ideas about them. According to Tookoolito, heaven was upward; it is light there all the time, and there are no ice or storms. Hell is downward; no sun there, but storms and snows all the while; it is cold, and there is a great deal of ice there. Any one who has been killed by accident goes straight to heaven. They have a kind of priests, or rather conjurers, called Angekos, whose business is to charm away sickness, and secure good hunting-seasons, with an abundance of seals, walrus, and deer, and an early disappearance of the ice. When his services are called for, he is always, like a wise man, careful to get his pay in advance, and it is generally 


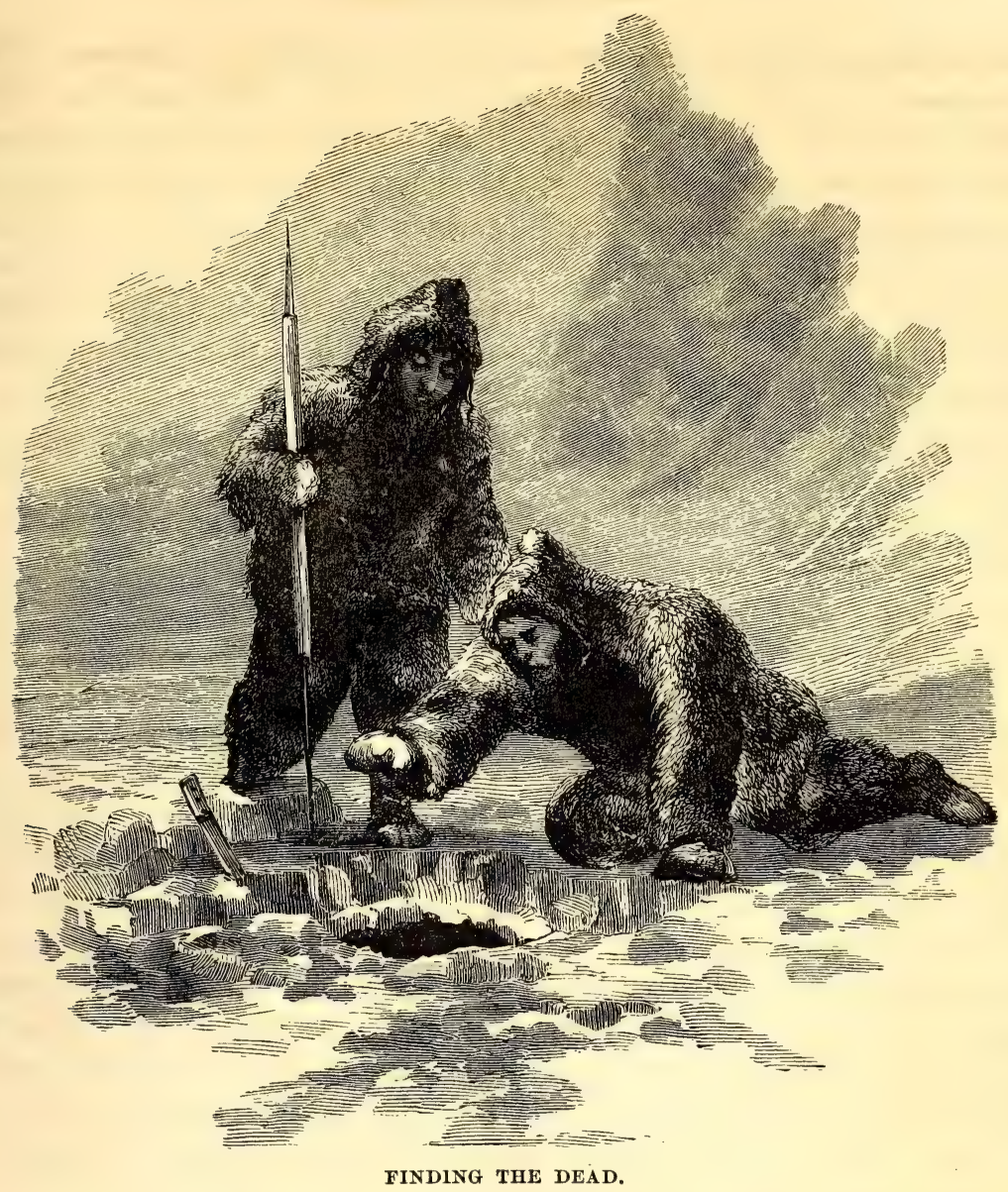

understood that the success of his incantations depends greatly upon the amount of his fee.

Upon the whole, the Innuits must be regarded as an amiable and kindly people. They are exceedingly tender parents, and not unaffectionate husbands and wives. The main exception to their general kindness is their treatment of the aged and infirm. When one, especially a woman, is hopelessly sick or infirm, she is not untrequently abandoned. Mr. Hall relates several incidents of this kind which came within his own knowledge. In one case the husband, when he found that his wife was hopelessly sick of consumption, abandoned her, and took another while the poor creature was still alive. The deserted woman lingered several weeks, supplied with food by the neighbors. In another case a sick woman, in the depth of winter, was left behind in an igloo, with a small quantity of provisions. Hall, learning of this, made an attempt to go to her rescue. But in the mean time a heavy snow-storm had come on, and the igloo was entirely buried, so that no traces of it could be found. A few days after, Hall, accompanied by Ebierbing, made another attempt. The spot was finally found, though the snow lay level above the ice-hut, the position of 
which could be ascertained only by exploring with their spears. They broke through the roof, and, looking down, saw the woman frozen as solid as a marble statue. She had been dead for days, and the indications showed that she had perished from cold very soon after being abandoned. There wcre supplies of whale-skin for food, and blubber to keep up the fire, but she was too feeble to rise from the bed and replenish the lamp.

The Innuits of the present day are a purely nomadic race, roaming from place to place, following the seal, walrus, and deer. But their wanderings appear to be confined to the region of the coast, never extending far into the in. terior. Their dwellings are therefore constructed for mere temporary occupation, being snow-huts (igloos) for winter, and tents (tupics) for summer. But

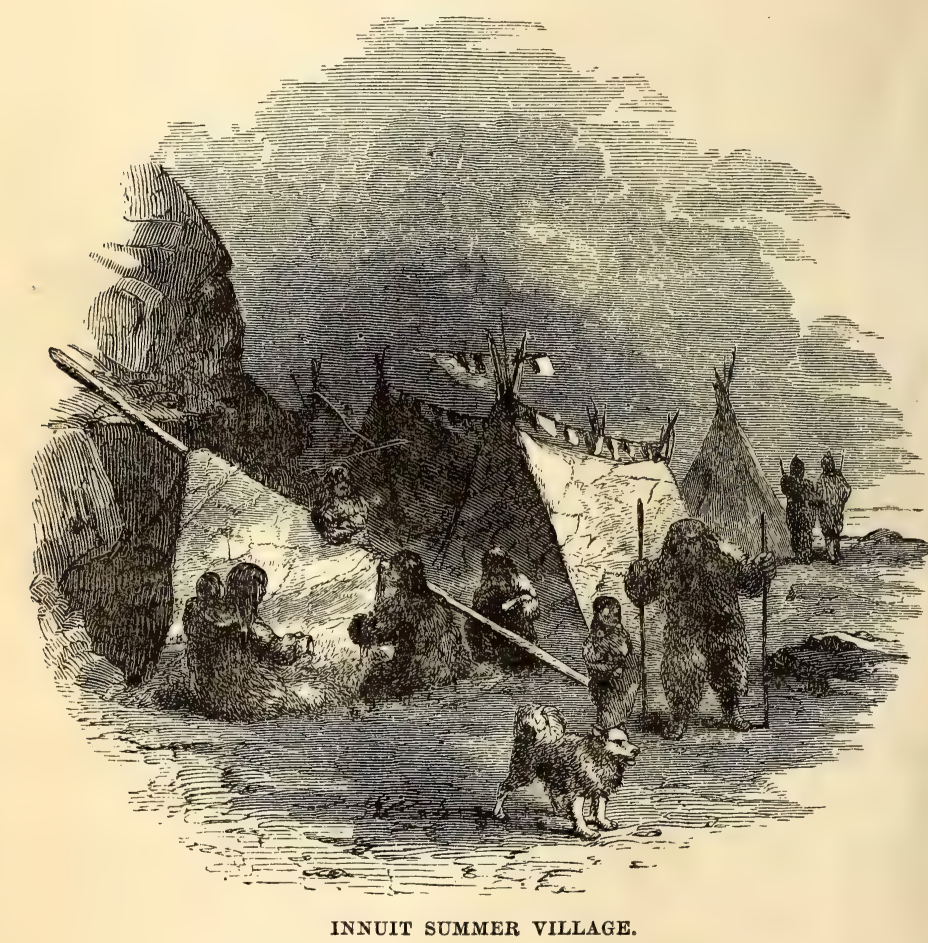

there are indications in the form of trenches and excavations which show that they formerly led a more settled life, and constructed more permanent habitations. Their numbers have been gradually diminishing ever since they have come into contact with the whites. How this comes to pass is a mystery. There is nothing to show that the climate has become more rigorous, or that the animals which constitute their food have grown scarcer or less easy of capture. The Indians of America have been destroyed by the occupation of their hunting-grounds, by whisky, and the small-pox, introduced by the whites. The natives of the South Sea Islands have been eaten up by nameless diseases, contracted from their licentious white visitors. There is scarcely a trace of either drunkenness or licentiousness among the Innuits. Consumption is the great 


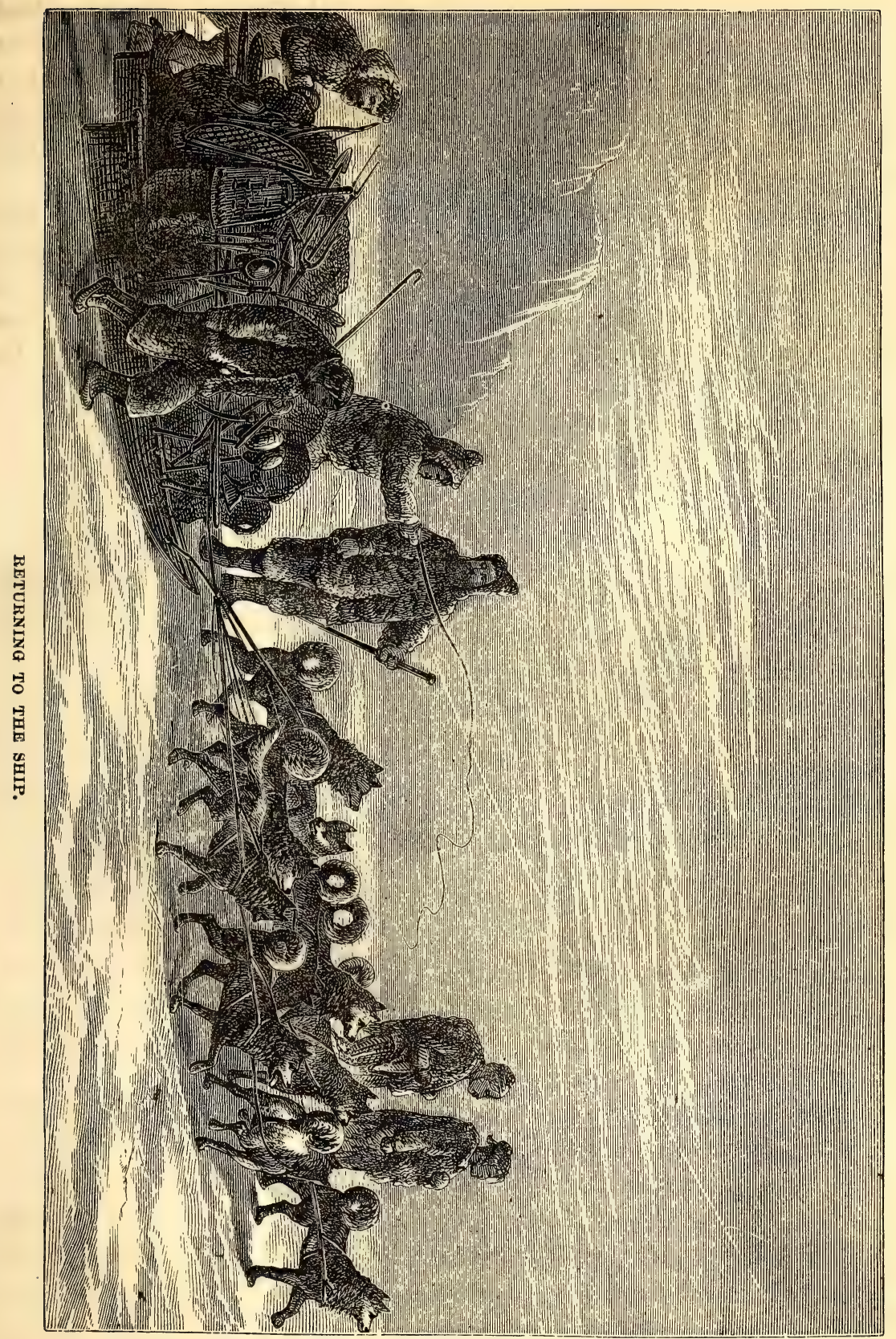

destroyer among them; but we can see no reason why this should be more prevalent now than it was generations ago.

It seems that in former times there were chiefs among the Innuits, but at the present time there is no trace of any thing like government among them. In each community there is usually some one who, from age, persongl prowess 


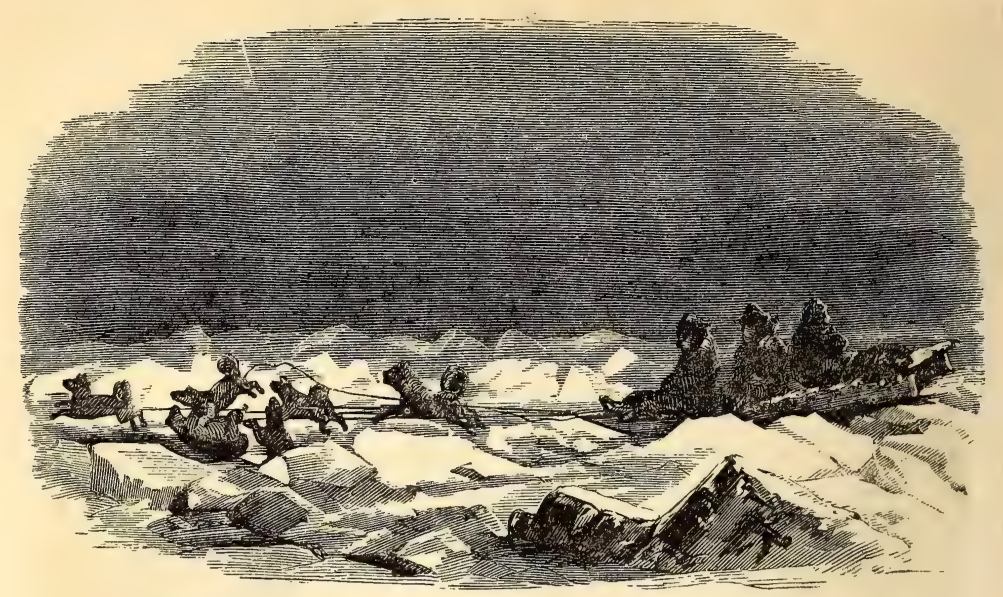

OVER THE ICE.

as a hunter, or native shrewdness, is looked up to with respect, and his opinions are regarded with deference; but he has no sort of authority except that which each person voluntarily concedes to him.

We left Mr. Hall near the close of January, 1861, when he was just returning to the ship after his first overland expedition. We do not propose to follow him through the course of his personal narrative, although it abounds with striking incidents and details of hardship and peril. Thus, one day in March, John Brown, one of the ship's crew, in company with two Innuits, started off from an igloo a few miles distant to rejoin the ship. Somehow he got separated from his companions, but the next morning he had not arrived. The night had been intensely cold, the thermometer marking 57 degrees below freezing. point. A party of a dozen set off in the attempt to find him. In two hours they came upon the tracks of the wanderer, but only Hall and four others could hold out; the others, one by one, fell back. They kept on, following the tracks, which now began to grow faint, being partly filled up with snow. For a time the tracks went straight for the ship; then they began to waver, now in one direction, and then in another, showing that the man had lost his way. They followed the tracks, in the intense cold, 60 degrees below freezing-point. They were tormented by thirst, which they attempted to allay by the use of ice. The first fragment which Hall put into his mouth froze it fast. He managed to reduce the temperature of the ice by holding the fragments in his mittened hand, so that he could place them in his mouth. After six hours, Hall's companions said they could go no farther and must return; for they had brought along no snow-knife, with which they could build an igloo for the night; and if a storm should spring up, they must all be inevitably lost. Hall went on alone. One of the crew named Johnston soon overtook him, saying, "Brown was my shipmate, and I loved him. I will go on with you. If I were to go back now, I shall always regret it." They followed the tracks, which now began to run in circles, interlocking one another. There were twelve of these 


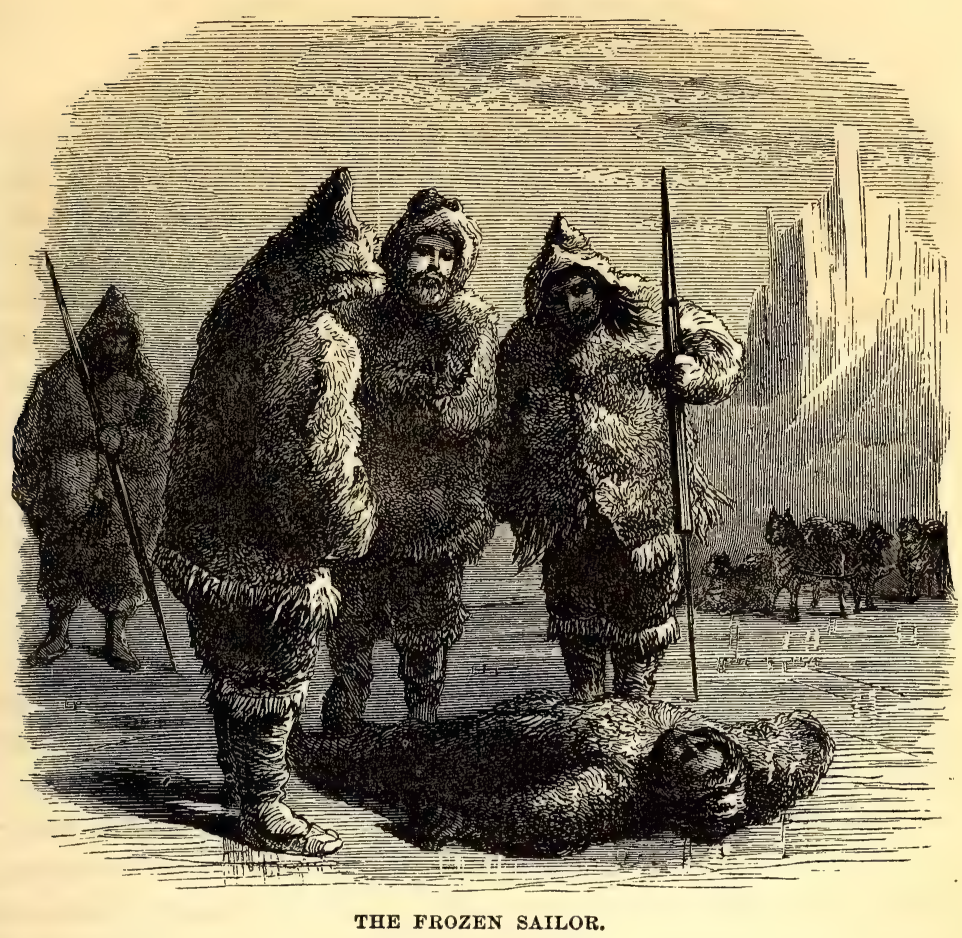

within less than two miles. Every little while they came upon places where the wanderer had lain down to rest. At five o'clock, nine hours after setting out, they were overtaken by Captain Buddington, with two sailors and two Innuits, accompanied by a dog-team. They all pressed on with renewed vigor, and in a few minutes came upon poor Brown, frozen dead. They could not convey the corpse to the ship, fully ten miles away, and so buried him in the snow upon the spot where he was found.

It was the middle of July before the ship was released from her icy prison. The whalers went to work, and Hall made several important expeditions by land and water, living nearly all the while with the Innuits. Towards the middle of October the captain began to prepare for returning home. But he was a few days too late. The ship was beset in the ice-pack, with no hope of escape. There was nothing left but to make up their minds to spend another winter in the ice.

We must pass wholly over the incidents and adventures of this second winter. It is the old tale of suffering and privation. On the 12th of January the thermometer fell to 72 degrees below the freezing point. One of the men who had left to visit an Innuit encampment came back, saying that he thought he had frozen his toe. Upon pulling off his boots both feet were found to be frozen stiff, and as hard as ice. The usual attempts to save the members were made in vain; mortification began, and, to save the man's life, the captain was obliged to amputate portions of both his feet.

This year, 1862, the ice held on unusually late; but on the 8th of August it 
was found that the pack had broken up. The way home was apparently open; and all hands were summoned on board. The vessel spread her canvas and sailed off, the Innuits surrounding her in their canoes, and shouting farewell.

Tookoolito and Ebierbing resolved to accompany Hall to the States, taking with them Tukeliketa ("Butterfly"), their infant, a year old. The child died a few months after their arrival in the States, and lies buried in the graveyard at Groton, Connecticut. "I never saw," says Hall, " a more animated, sweet-tempered, and engaging child." For days the mother was delirious; then she longed to die, that she might be with her lost Butterfly. Upon his grave were laid, according to the custom of his people, all his childish playthings. They were sacred to the dead. The mother went to the grave one day, and found that one article, a gayly-painted little tin pail, had been taken away. She was inconsolable. "Poor little Butterfly," she said, "how he will miss his beautiful pail!"

The homeward voyage was speedy and prosperous. On the 13th of Septem. ber the "George Henry" dropped anchor at New London, whence she had sailed two years and three and a half months before.

The net results of Hall's expedition were these: Many new discoveries were made in Arctic geography; much information was gathered in relation to the inhabitants ; and experience acquired of immense value to all future Arctic explorers. Mr. Hall also made a very interesting discovery in regard to the fate of the expedition of Martin Frobisher, undertaken almost three centuries ago. He found a tradition among the natives that many years ago white men in ships had visited a place still called "White Man's Island." Hall compared these traditions with the accounts extant in books respecting this voyage, and was struck with their remarkable coincidence. He visited the place designated as the white man's encampment, and found many things which had evidently been left by Europeans. Among these was a heap of coal amounting to several tons, a large fragment of iron, and some bricks. Every thing was covered over with moss whose thick growth showed that they must have remained there undisturbed for ages.

The bearing of this upon the possibility of revealing the whole mystery of the fate of Franklin is evident. If the Innuits have preserved tolerably accurate traditions of what took place three centuries ago, it is not to be doubted that they still have information of what took place within a single generation. It is now past hoping that any members of Franklin's expedition are yet living; but there must be Innuits who can tell how and where they died.

To further this investigation Hall resolved upon a second expedition. He spent nearly two years in preparing his book for publication, and in making preparations for this enterprise. Abundant facilities were now placed at his disposal; and on the 30th of July, 1864, he again set sail. In the preface to his book, written on board the vessel, he says:

"I am persuaded that among the Innuits may be sought, by one competent, with every chance of complete success, the sad history of Sir John Franklin's men. To make myself competent for this more interesting and important research, I patiently acquired the language and familiarized myself with the habits 
of the Esquimaux. I now return to their country able to speak with them, to live among them, to support my life in the same manner that they do theirs; to migrate with them from place to place, and to traverse and patiently explore all the region in which it is reasonable to suppose Franklin's crew travelled and perished. I shall be accompanied by the two intelligent Esquimaux, Ebierbing and Tookoolito, who, having accompanied me on my return from my first expedition, and after remaining with me for two years, now go back with me on this second voyage. I enter upon this undertaking with the liveliest hope of success. I shall not, like previous explorers, set my foot on shore for a few days or weeks, or, like others, journey among men whose language to me is unintelligible. I shall live for two or three years among the Esquimaux, and gain their confidence; and I have the advantage of understanding their language, and of making all my wishes known to them."

This second expedition of Hall, instead of the two or three years which he had anticipated, occupied more than five years, during a great part of which he was shut out from all communication with the world. Up to 1867, he wrote as opportunity afforded to his fast friend and warm supporter, Henry Grinnell; but his letters gave only faint indications of what he hoped to accomplish. He had expected to return in 1868 , but in that year no whaling vessels came back from the Arctic seas, and he was doomed to another year in that region. Late in 1869 he returned, and was received with plaudits not less warm than those which had welcomed Kane, fifteen years before. Congress in a few months passed a bill making adequate appropriations for a national expedition to the Arctic regions, to be placed under the direction of Hall. On the day following Christmas, 1870, I met Hall in New York. He was little changed in appearance from the aspect which he had borne five years before, as shown upon page 434 of this volume. He was busily engaged in preparations for his new voyage, and was in high spirits. "I have demonstrated in my own person," he said, "that white men can live, with no extraordinary sufferings, for years in the depths of the Arctic regions. I have lived there for years, and can teach my associates how to do so. Upon this new expedition I shall be amply provided with all means for a thorough exploration. I shall have with me a scientific observer, a naturalist fully qualified to report upon every thing in his department, and an artist and photographer, who will be able to depict every thing relating to the Arctic regions. Thus abundantly supplied, and aided by my own experience of more than ten years, I think that I shall be able to accomplish something worthy of the means placed at my disposal."

About the time when these pages meet the eye of the reader, Hall will have set out on his third expedition. We bid him, by anticipation, "Hail. and farewell."

Livingstone says that he found it easier to perform his African journeys than write the account of them. Something like this may be the case with Hall; at all events, so fully has he been occupied in fitting out his third expedition that he has not found time to prepare the narrative of the one which 
he has just completed. But his journals and drawings are preserved, and will undoubtedly see the light. Of their value, as they stand, I have means of knowing something; and trust that he may return safely, and be able to revise them for publication. In a few weeks he will have set out on his third voyage. From the capacity which he has manifested in two expeditions, occupying together more than ten years, and from the abundant resources now at his disposal, there is every reason to hope that he will be able to solve the remaining problems relating to the Arctic regions. If there be, as there is good reason to suppose, an open sea surrounding the North Pole; and if that sea is accessible to man, by land or by water, we can hardly doubt that Hall, certainly the first of white men, and most likely first of all men, will make his way to it.

Until such time as he shall have returned from his present voyage, we bid him hail and farewell. And also, copying his own last drawing made during his first expedition, we bid farewell to the Innuits - that interesting people whom he is the first fairly to introduce to the world; since he was the first white man who ever lived with them, faring summer and winter as they fared, and experiencing with them the pleasures and the sorrows of their hyperborean life.

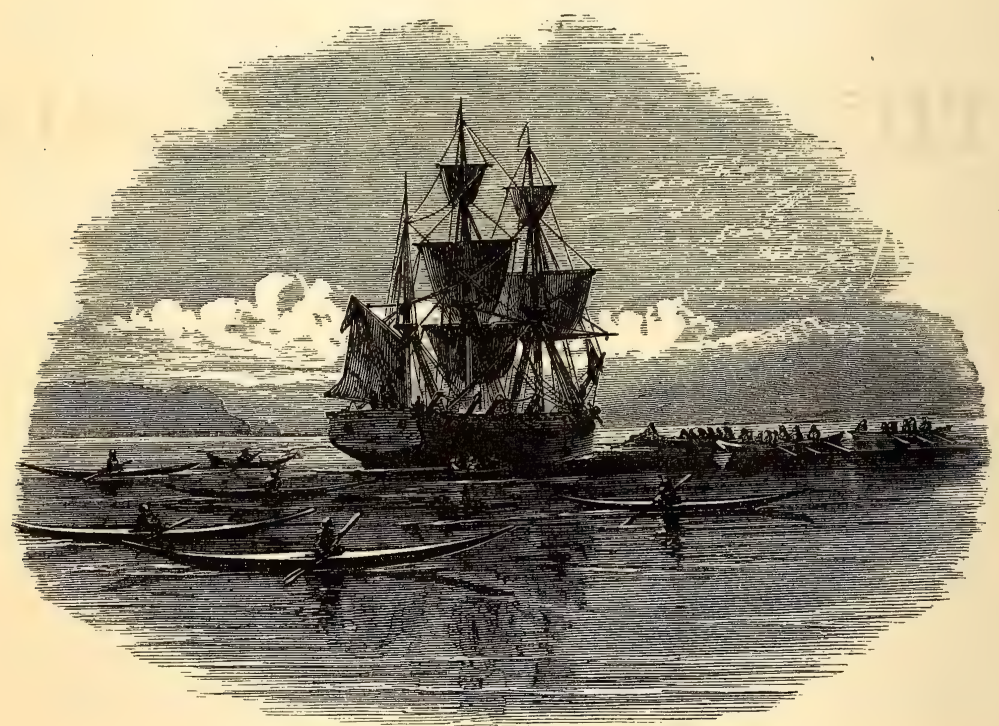

FAREWELL OF THE INNUITS.

[Barely two years after the foregoing was written, tidings came of the death of Hall, and the probable failure of his expedition. In an additional chapter at the close of this volume will be found an account, so far as is now known, of this expedition.] 
THE TROPICAL WORLD. 


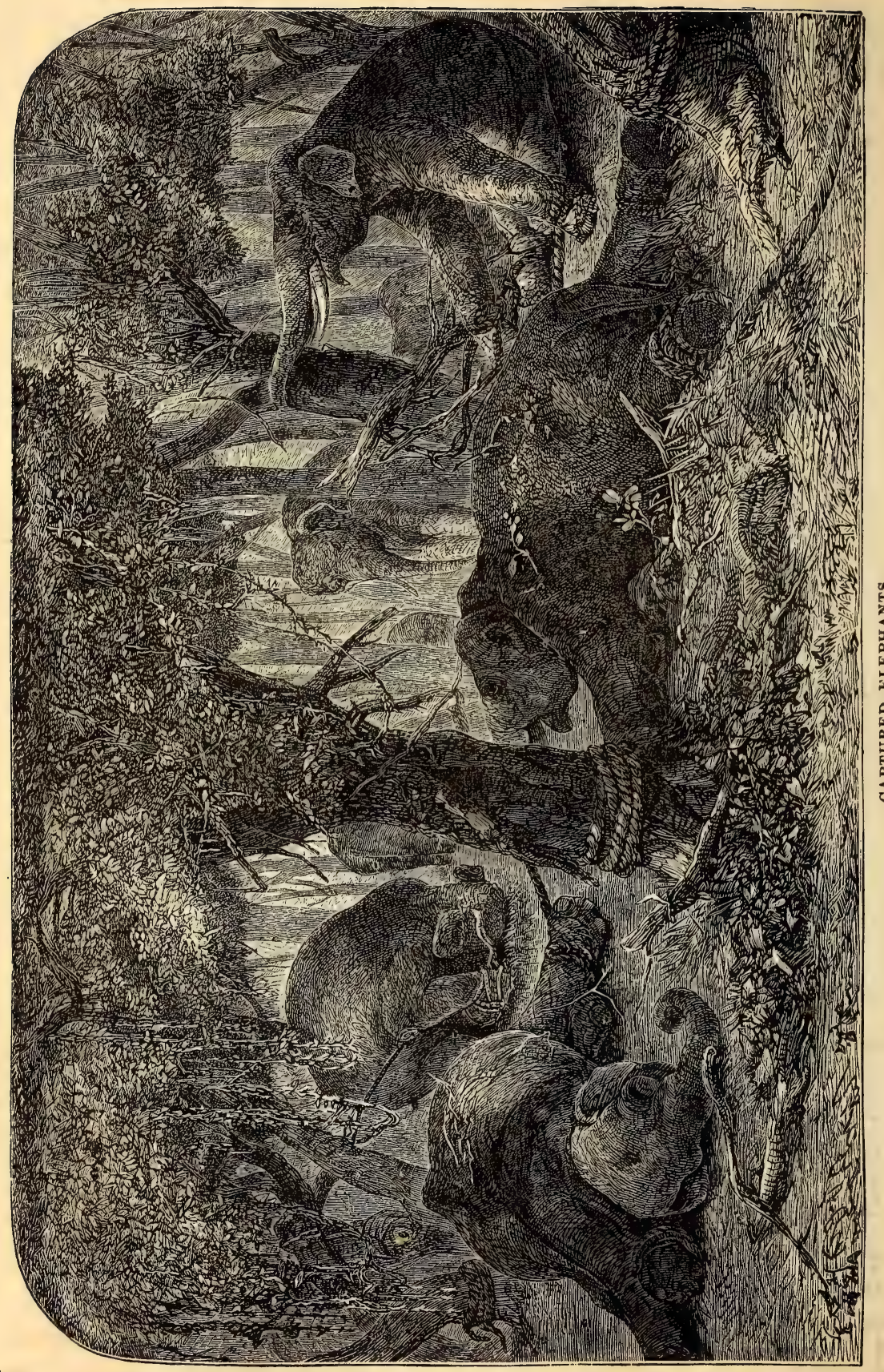




\section{THE TROPICAL WORLD.}

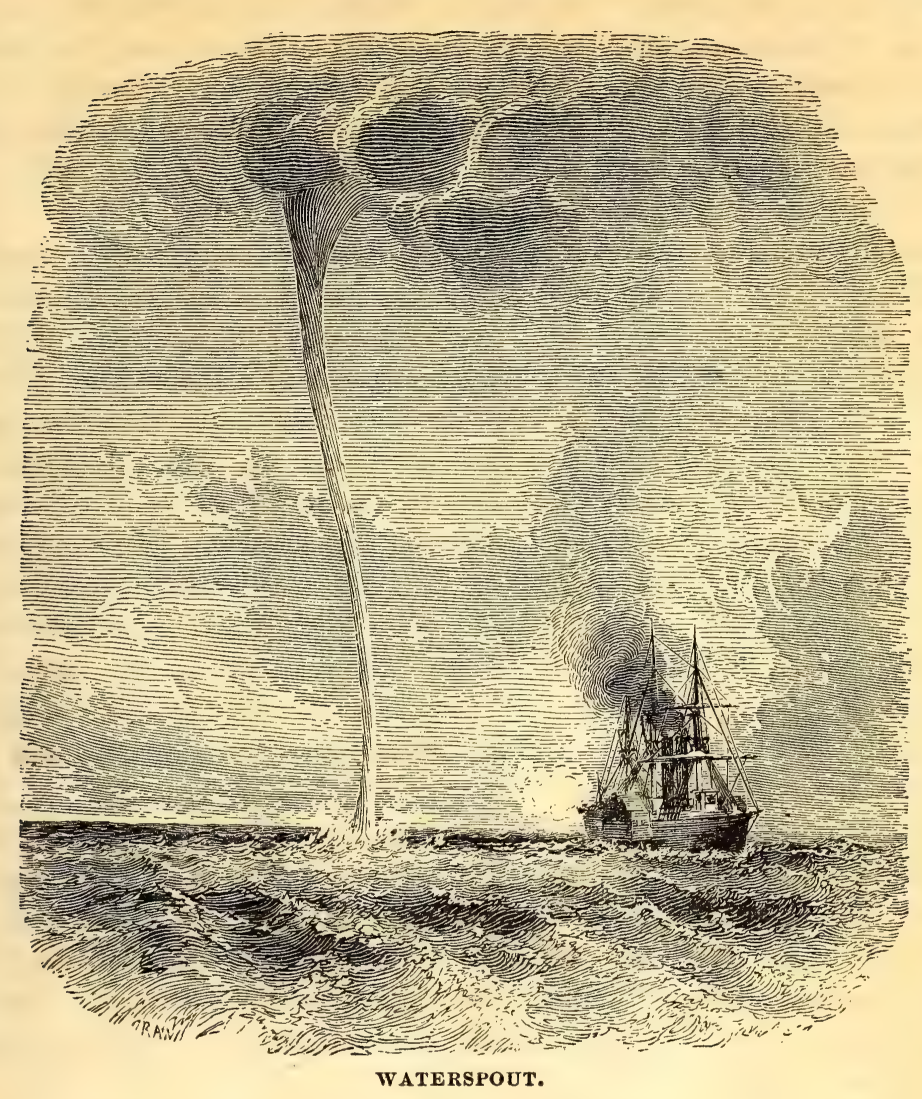

\section{CHAPTER I.}

\section{THE OCEAN AND ATMOSPHERE OF THE TROPICAL WORLD.}

Characteristics of the Polar and Tropical Worlds-Geographical and Climatic Limits of the Zones-Distribution of Land and Water-Climatic Importance of the Ocean-Currents of the Ocean-The Gulf Stream-Influence of the Gulf Stream upon the Climate of EuropeThe Sargasso Sea-Columbus and the Gulf Stream-The Pacific and Indian CurrentsHeat and Force-Relative Positions of Hot and Cold Currents-Currents of the Air-The Trade Winds-Atmospheric Currents and Climate-The Calm Belt near the EquatorRainfall of Different Regions-Rainy and Dry Seasons within the Tropics-The Monsoons -Winds as Regulators of Rains-Annual Rainfall-Whirlwinds-Their Rotary MotionTropical Islands-Volcanic Islands-Coralline Islands-Atolls and Reefs-Influence of the Ocean upon Life in the Tropical Islands.

H ROM a wide survey of the Polar World, we now turn to the tropical regions, 1 where nature assumes aspects of an entirely different character. In the Polar World there is a constant struggle between all sorts of life and cold. As we approach the poles, cold gains more and more the mastery; life nearly ceases upon the land, 
and exists mainly in the waters which sweep around the ice-bound shores. In the Tropical World, of which we are now to speak, the intense rays of the vertical sun call into being an exuberance of animal and vegetable life unknown to other regions.

Here, in the outset, it is well to define, as nearly as may be done, the geographical limits of the zones or belts of the earth, and especially of that with which we are now most immediately concerned, which we designate as Tropical, as distinguished from the Temperate Zones which lie upon each side of it, and the Polar, which lie on each side still farther beyond, to the north and the south.

As used by geographers, the Tropical Zone includes that belt of the earth's surface extending $23 \frac{1}{2}{ }^{\circ}$ on each side of the equator, bounded on the north by an imaginary line called the Tropic of Cancer, on the south by the Tropic of Capricorn.

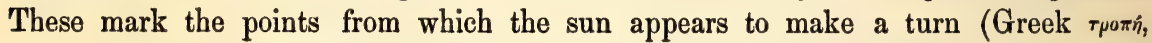
tropé, whence the name) toward the equator, from its utmost declination toward the north and south. It is only between these points that the sun ever appears directly overhead; north of these it is always seen to the south, and south of them to the north. This forms the Torrid Zone, or belt of extreme heat. But as the prevailing forms of vegetable and animal life which characterize this zone extend considerably further in both directions, we shall use the word Tropical in a somewhat wider sense, and by the Tropical World shall designate all that part of the earth's surface between the equator and the thirtieth parallel of latitude on each side, forming a single belt of $60^{\circ}$ in width. Perhaps the best single characteristic of this zone is, that within it alone the various species of the palm tree have their home.

The Polar World, as we have used the phrase, designates the zones at the north and south where the cold is so excessive as to prevent the growth of grains and esculent plants suited to the use of man. The parallels of $60^{\circ}$, north and south, are the approximate boundaries of these zones, although the actual limit is sometimes above and sometimes below this. Thus in Europe and on the western coast of America, the polar limit is as high as $65^{\circ}$; while on the eastern coast of America, as in Labrador, it sinks as low as $50^{\circ}$.

The Temperate Zones comprise the surface of the globe between the parallels of $30^{\circ}$ and $60^{\circ}$ north and south latitude.

These great climatic divisions shade into each other; but it may be said in general terms that each occupies a space of $60^{\circ}$ of latitude, as follows :

The Polar Zones, $90^{\circ}$ to $60^{\circ}$ north and south.

The Temperate Zones, $60^{\circ}$ to $30^{\circ}$ north and south.

The Tropical Zones from the equator to $30^{\circ}$ north and south.

The whole of Europe, more than nine-tenths of Asia, a narrow strip of Africa, and all of North America except Mexico, and a small portion of Texas and Florida, lie north of the tropical limit. Patagonia, the bare southern extremity of Africa, half of Australia, and the almost unknown land around the southern pole, with a few islands, are all the land south of the tropics. The Tropical World comprises Mexico, Central America, nearly the whole of South America and Africa, and nearly all the great islands of the globe, including the West India Islands, Polynesia, the islands of the Indian Ocean, and half of Australia.

The ocean covers three-fourths of the surface of the globe. Of the land, threequarters is in the northern hemisphere, and one-quarter in the southern. The Arctic 



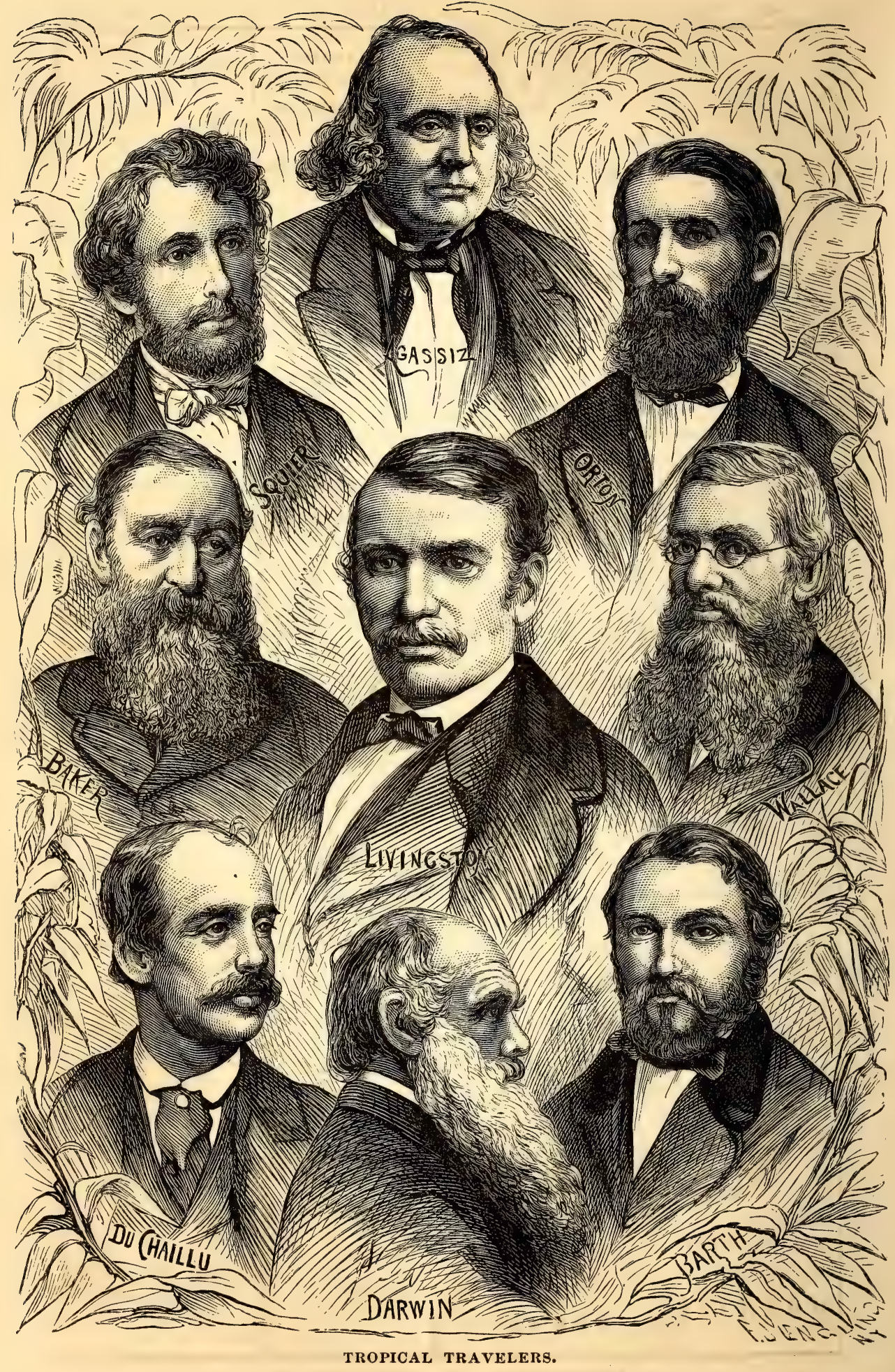



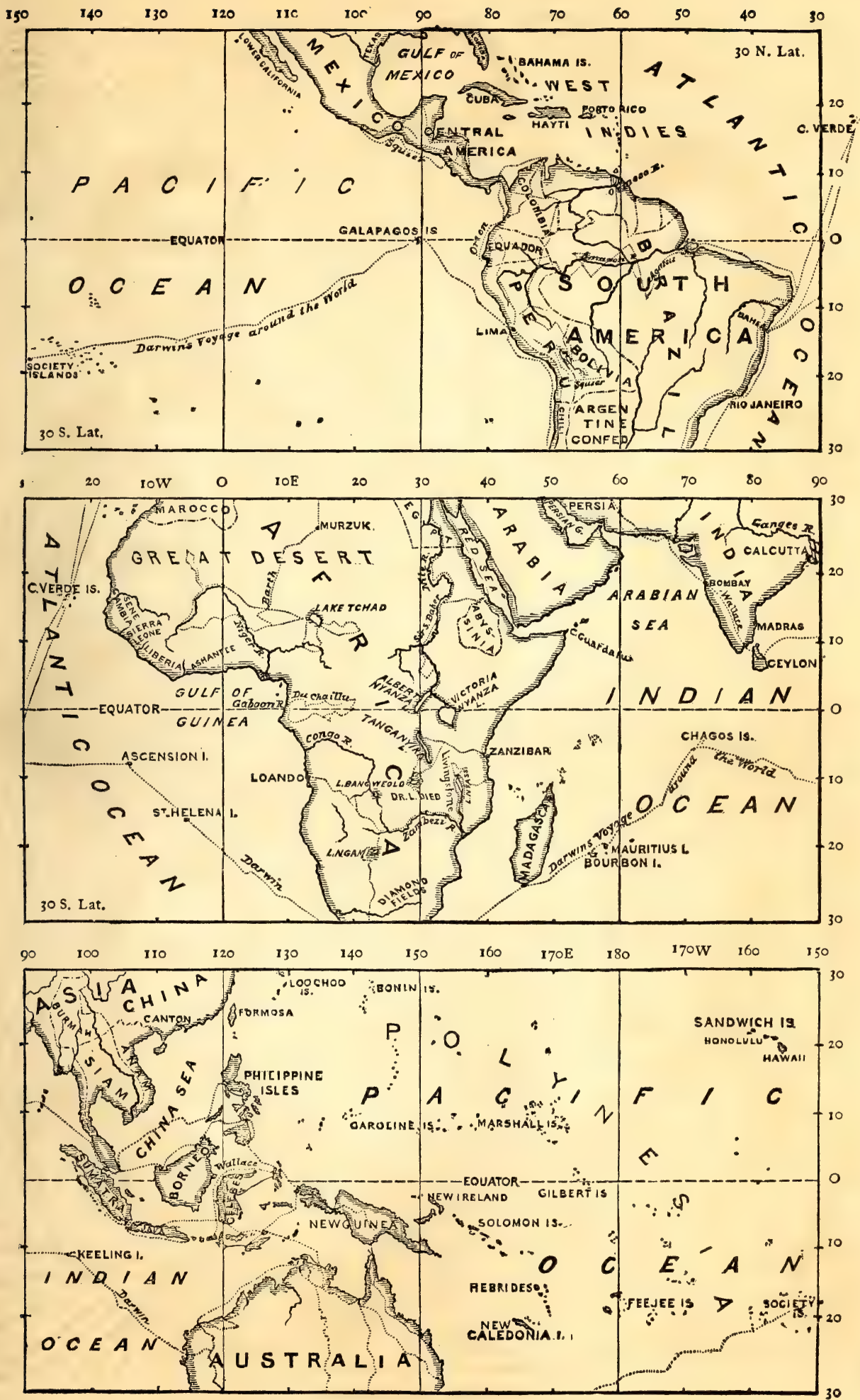

TROPICAL WORLD. 

and North Temperate Zones are not very unequally divided between land and water. The ocean covers four-fifths of the Tropical Zone, and rolls in an almost unbroken mass over the southern temperate and Antarctic regions. This great preponderance of water over land between the tropics is one of the most important facts in physical geography. Were the proportions reversed, sterility would be the rule all over the globe, for without water there can be no vegetable or animal life. All the water that wells up in fountains, or flows in brooks and rivers, comes from the ocean, whence it is raised by evaporation and borne along the viewless channels of the air to be precipitated in the form of rain and snow, sometimes thousands of miles from the spot where it commenced its aerial journey. It is computed that nearly 200,000 cubic miles of water are annually raised from the ocean in the form of vapor. Threequarters of this is raised within the tropies, and a great part falls beyond them. If the extent of the tropical ocean were diminished by half, there is hardly a part of the Temperate Zone which would not be parched by perpetual drought, and hardly a river whose bed would not become a dry ravine. The hidden springs of the Amazon, Mississippi, and the Danube lie in the Pacific. The water which fills the great lakes of North America, and thundering down the cataract of Niagara finds its way through the St. Lawrence River into the ocean almost on the verge of the polar world, only a few weeks before, perhaps, laved the coral reefs of the tropical seas.

Moreover, if any considerable part of the tropical ocean were converted into land, the heat of the Torrid Zone would become so greatly enhanced that no animal life, such as now exists, could endure it; and as the vegetation of a climate is adapted to the prevailing temperature, the trees and plants which now flourish would become extinct. Water in being converted into a gaseous form by the process of evaporation absorbs heat from surrounding objects, or, as we say, produces cold. Thus the burning rays of a vertical sun pouring down upon the ocean in a measure quench themselves. The same rays which falling upon the ocean never raise the water beyond a grateful temperature, falling upon the land produce an intolerable heat. To step on a summer's day from the cool water upon the sandy beach is like treading upon a plate of heated metal.

The conformation of the land within the tropics likewise goes far to counterbalance or mitigate the excessive heat of a vertical sun. The most casual glance over a map shows that the land here is mostly insular, laved on all sides by the surrounding waters, or stretches in a narrow length between two oceans, thus multiplying the surface over which the sea is enabled to exert its cooling influence.

The great extent of the tropical seas is also the primary cause of those mighty ocean currents which sweep from the equatorial to the polar regions. Cool as is the water of the tropics when compared with the land, it is yet warm when compared with the other parts of the ocean. The water thus heated becomes specifically lighter than that of colder regions, is lifted up, and, in obedience to the law of gravitation, runs off in both directions toward the poles. There having become cooled, the salt waters are heavier than the comparatively fresh ones of the polar regions, and, sinking beneath them, return in an under current to their starting-place.

This great equatorial current, or rather series of currents, is the marvel of physical geography. Let us follow that of the Atlantic in its long career. Starting on the line of the equator, it flows north-westward along the coast of South America, enters the 
Caribbean Sea and the Gulf of Mexico, from which it derives the name of the Gulf Stream. It passes out through the Straits of Bemini, between Florida and Cuba, a great river 32 miles wide, 2,200 feet deep, flowing at the rate of four miles an hour. Its volume is a thousand times greater than that of the Amazon or the Mississippi, and its banks of cold water are more clearly defined than are those of either of these rivers at flood. So clear is the line of demarkation between the warm water of the river and its cool liquid banks, that a ship sailing along may be half in one and half in the other; and a bucket of water dipped from one side will be twenty degrees cooler than one from the other. Skirting the coast at a distance of about 100 miles, its width is increased and its velocity diminished. Striking the projecting banks of Newfoundland, its course is deflected almost due east, until it arrives at mid-ocean. Here it spreads out like a fan, skirting the shores of Spain, France and Great Britain. It then divides, one branch sweeping around the west coast of Iceland, the other approaching the shores of Norway, and its temporary influence is perceptible in the ameliorated climate of Spitzbergen.

It is owing to this great ocean river that the temperature of the western shores of Europe is so much higher than that of the eastern shore of America in the same latitudes. Maury estimates that the amount of heat which the Gulf Stream diffuses over the northern Atlantic in a winter's day is sufficient to raise the whole atmosphere which covers France and Great Britain from the freezing point to summer heat. The olives of Spain, the vines of France, the wheat-fields of England, and the green expanse of the Emerald Isle, are the gifts of the tropical seas, dispensed through the Gulf Stream.

Near the Azores another branch of the Gulf Stream encounters the return flow from the Arctic Ocean, bends around, and skirting the coast of Africa, returns to its starting-place in the Gulf of Guinea, leaving in its great bend near the Azores an expanse of almost motionless waters larger than the whole of France. This is known as the Sargasso Sea, from the surface being covered with a seaweed called the Sargassum natans. So thick is the covering of weeds that at a little distance it seems solid enough to walk upon. Another curious species of seaweed, the Macrocrystis pyrifera, is found in this grassy sea. The stem, not thicker than a man's finger, is from 1,000 to 1,500 feet long, branching upward in filaments like pack-thread. Most of these weeds probably grow on the spot; but many are borne along by the Gulf Stream, for everything that floats from other parts of the Atlantic tend to its eastern side. The discovery of the bodies of strange animals and unknown trees and plants flung ashore at the Azores suggested to Columbus the idea that there was land lying beyond the western ocean; so that to the Gulf Stream we are indebted for the discovery of the New World. Bottles have been thrown overboard at various points in the Gulf Stream, containing the date and position of the ship. Many of these have been picked up. From these it appears that the stream takes eight months to flow from the Gulf of Mexico to the shores of Europe, and the broader and slower current takes a year to travel from the Bay of Biscay back to the Gulf of Mexico.

The Gulf Stream, though the best known, and in many respects the most remarkable of the great equatorial currents, is by no means the largest. The great current of the Pacific and Indian Oceans may be regarded as one mighty stream flowing from east to west. It crosses the Pacific in a sheet nearly 3,500 miles broad, spreading 
over almost half of the distance from pole to pole. Another great current originates in the Indian Ocean, flows into the China Sea through the Straits of Malacca, thence into the North Pacific between the coast of Asia and the Philippine Islands; thence crosses the ocean to the north-westward, modifying the climate of Oregon and Alaska.

All the heated water thus poured from the tropical ocean, and all raised from it by evaporation and transported through aerial channels to feed the rivers of the temperate and polar regions, must find its way back by counter currents. Heat, according to the dictum of modern science, may be reduced to force. The force of the sun's rays poured upon the tropical oceans is sufficient to raise thousands of yards into the air five hundred cubic miles of water every day, and to put and keep in motion the mighty currents which sweep back and forth from the equator to the poles. The study of the course, direction, and elevation of these currents has as yet only begun. We know that sometimes, as on the eastern coast of America, the currents of warm and cold water run side by side in opposite directions; sometimes a warm current is on the surface, and sometimes below it. In the Gulf Stream the warm current is above, the cold below; while on the coast of Japan a cold current from the Sea of Okhotsk runs on the surface, giving rise to a fishery not inferior in magnitude to that caused on the banks of Newfoundland by the cold current from Baffin's Bay. Enough, however, is now known of oceanic currents to warrant the assumption that they are mainly governed by the great law of gravitation. The lighter water flows upon the surface, the heavier flows underneath. But the specific gravity of ocean water depends upon two things, the temperature and the amount of salts contained. The heated water from the tropics is rendered lighter than that which surrounds it of the same saltness, and so floats on the surface; but the cold currents from the poles are less saline, and consequently lighter than the tropical waters of the same temperature. When these two opposing currents meet there is a struggle; but at length the one which is really specifically heavier sinks, while the lighter rises. So facile is the movement of fluids among each other, that a difference in gravity which we can hardly detect with our nicest instruments may be abundantly sufficient to decide which of two opposing currents shall run above and which below.

The air has currents as well as the ocean, and these have much to do in modifying the climate of the Tropical World. Rarified by the intense heat of a vertical sun, the air within the tropics rises in perpendicular columns high above the surface of the earth, and thence flows off toward the poles; while, to fill up the void, cold air currents come rushing in from the Arctic and Antarctic regions; but the rotation of the earth gradually diverts the direction of these cold currents, and changes them into the trade winds which regularly blow over the greater part of the tropical ocean from east to west, and materially contribute to the health and comfort of the navigator whom they waft over the equatorial waters.

These atmospheric currents in another way still more powerfully influence the climate and productions of the Tropical World ; for upon them, in conjunction with the character and direction of the great mountain ranges, depends the supply of water upon the surface of the globe, and thus determine the fertility or barrenness of the soil. It may be laid down as a rule that wherever within the tropics there is an abundant supply of moisture, vegetation grows in rank luxuriance; and wherever this is wanting, the land is a desert; and wherever, as in the llanos of Southern America, 
there is a regular alternation of long periods of rain and drought, there is at different seasons a wonderful interchange between apparent desolation and a profusion of vegetable and animal life. The aspects of these regions will be more fully described hereafter.

The great mountain ranges run mainly north and south. The great atmospheric currents at the surface of the earth in tropical regions blow mainly from east to west. The moisture in these winds is condensed when they strike the cold mountains, and descends in the form of rain or snow. Hence, in general, the eastern sides of tropical mountains are better watered than the western slopes.

We have spoken of the trade winds as extending over the whole breadth of the Tropical World. But to this there is a notable exception. Near the equator, but a little to the north of it, the two currents from the Arctic and Antarctic regions meet and neutralize each other, producing a belt of calms, which sailors call the "Doldrums," of about six degrees in breadth. Here it rains almost every day during the year, for the ascending currents of heated air loaded with moisture become suddenly cooled in the higher regions, and are forced to give up the water which they have lifted from the ocean. Towards noon dense clouds form in the sky, and dissolve in torrents of rain. Towards evening the vapors disperse, and the sun sets in a cloudless horizon. The quantity of rain which here falls during the year is enormous. In the United States the annual rainfall is from 25 to 70 inches; in Europe from 15 to 104 ; in the Atlantic doldrums it reaches 225. So copious is the rainfall at times that fresh water has been dipped up from the surface of the tropical seas.

Proceeding north or south from the belt of calms, we come to a region characterized by two rainy and two dry seasons. The rainy seasons take place while the sun is passing the zenith, and more or less neutralizing the influence of the trade winds. In Jamaica, for example, the first rainy season begins in April, the second in October; the first dry season in June, the second in December. Towards the verge of the tropics follow the zones characterized by a single rainy and a single dry season; the rains lasting from the vernal to the autumnal equinox.

The two rainy seasons which characterize the middle zone between each tropic and the equator have a tendency to merge into one rainy season of six months' duration on advancing toward the tropics, and into a perpetual rainy season on approaching the equator. As the sun goes north or south he opens the flood-gates of the heavens, and closes them behind him as he passes to the other hemisphere; while he keeps them continually open where he is always vertical. But this general state of things, which would be the normal condition of the tropical regions if their surface was an unbroken sheet of water, and no disturbing forces existed, is liable to great modifications. Thus in the monsoon region, extending from the eastern coast of Africa to the northern part of Australia, and from the tropic of Capricorn to the Himalayas and China, it is not the sun directly, but the winds that regulate the periodical rains. Thus in India and the Malayan peninsula the western coasts are watered during the south-west monsoon, which prevails from April to October; and the eastern coasts during the northeast monsoon, from October to April. For example, the south-west wind condenses its vapor on the western side of the Ghauts, the north-east on the eastern, so that violent rains fall daily on the coast of Coromandel, while it is the reverse on that of Malabar, and vice versa. In the southern hemisphere the rainy season corresponds with 
the north-western monsoon, the dry season with the south-eastern. In South Africa and Australia winter is the rainy season. In South America, in the same latitudes, summer is the rainy season on the eastern side of the Cordilleras, and winter on the western side.

At sea, it rains almost daily within the calm belt, rarely within that of the trade winds. On the land within the tropics the rainfall is in many regions enormous. The average annual fall in the most favored parts of the temperate zone is about 40 inches ; in the tropics it exceeds 100. In some portions it is vastly greater. On the western Ghauts the mean annual quantity is 300 inches. On the Himalayas, Mr. Yule measured 264 inches in the single month of August, of which 150 inches fell in five successive days. Hooker and Thomson measured here 500 inches in seven months; and during a terrific shower 30 inches fell in four hours, and Castlenau measured the same quantity during a single storm on the Amazon.

Tornados and hurricanes rage in the Tropical World with a frequency, extent and violence unknown in other climates. They sometimes move with a direct velocity of 45 miles an hour; but the violence and destructiveness of a whirlwind depend less upon the velocity with which the whole storm moves than upon the speed with which the wind whirls around and in upon the center. The great Bahama hurricane of 1866 moved forward at the rate of 30 miles an hour; but the velocity of its whirling motion was from 80 to 100 , and for short intervals from 100 to 120 miles an hour. The diameter of the great storms of the tropical Atlantic is often from 600 to 1,000 miles; those of the Indian Ocean 1,000 to 1,500. These, however, move but slowly. The smaller storms are usually more rapid than the larger ones.

The revolving motion accounts for the sudden and violent changes observed during hurricanes. In consequence of this rotation, the wind blows in opposite directions on each side of the axis of the storm; the violence increases from the circumference inward; but at the center the air is in repose. Hence, when the body of the storm passes over a place, the wind begins to blow moderately, and increases to a hurricane as the center of the whirlwind approaches; then in a moment a dead calm succeeds, suddenly followed by a renewal of the storm in all its violence, but now blowing in a direction opposite to that which it had before. From this rotary motion it follows that the direction of the wind at any moment is no indication of the direction which the body of the storm is pursuing. The progressive motion may continue for days in one direction, while the wind accomplishes many gyrations from every point of the compass. During a part of the course of a storm the wind blows in just the opposite direction from that which the hurricane is taking, just as when a carriage-wheel, and every point of its circumference, is really moving forward, during a part of each revolution any point in the circumference is at the same time moving back with a still greater velocity.

We have already referred to the insular character of a considerable portion of the Tropical World. Nine-tenths of the islands which dot the ocean lie within the tropics. These islands are divided into two great classes. The one class is of volcanic origin, upheaved from the depths of the ocean; or, rather, they are peaks of lofty mountains whose sides and base lie deep in the water. There are two opposite theories to account for the existence and present appearance of these islands. According to one theory, a continent once occupied a large part of the Pacific Ocean within the tropics, 
a great portion of which has sunk beneath the waters, and these islands are but the peaks and table-lands of that lost continent. The other theory is that these islands have been for unknown ages, and now are, slowly being lifted up from the depths below. Both theories rest upon so wide an induction of facts that both must be accepted as true; or rather as parts of the one great truth, that the crust of the earth which we are wont to consider so firm and stable is now, as it always has been, rising and falling, as truly as the surface of the water rises and falls by the attraction of the sun and moon; only that these periodic changes are measured by ages instead of by hours. Who shall say that in the higher knowledge which we shall gain during the ages of the future we may not attain to the understanding that the rise and sinking of continents is like that of the tides governed by law, and that we may not be able to express in figures, which will then be quite finite to us, though now seeming infinite, the years that have elapsed since when " in the beginning heaven and earth rose out of chaos?"

Volcanic islands are found in all oceans. Iceland has its Heckla, Sicily its Etna, Hawaii its Mauna Kea and Mauna Loa, Niphon its Fusiyama. From Sumatra, Java, and Sumbawa, Ternate and Tidore, Borneo, Celebes, and Gilolo, close by the equator, thence northward and north-westward to the Kurile Islands, hard by the frozen coast of Kamchatka, is one great belt of volcanic islands, spreading out like a fan through Polynesia. But in the tropical seas, and there alone, are coralline islands, built up, grain by grain, by minute living beings.

The simplest form of these coral islands is a ring enclosing a portion of the ocean. Sometimes this ring is barely two miles in diameter; sometimes it reaches a hundred miles, rising only a half-score of feet above the level of the water, and owing to the convexity of the surface of the ocean invisible from the deck of a ship at a distance of a mile or two, unless they happen to be covered with tall palms or pandanus. The roar of the surf dashing upon their windward side is often heard long before the island itself comes into view. On the outer side this ring, or atoll, slopes gradually for a hundred yards or more, to a depth of twenty-five fathoms, and then plunges sheer down into the waters with a descent more rapid than the cone of any volcano. At a distance of five hundred yards no bottom has been reached with a sounding line of a mile and a half in length. All below the surface of the water to the depth of 100 feet is alive, all above and below this section dead, for the coral insect can live only within this range.

These atolls assume every form and condition. Sometimes they are solitary specks in the waste of waters. Oftener they occur in groups. The Caroline Archipelago has sixty groups extending over a space of a thousand square miles. Sometimes a group of atolls becomes partially joined into one, the irregular ring encircling an island-studded lagoon, with openings through which a ship may enter. Sometimes these coral formations take the form of long reefs bordering an extensive coast. Such a reef runs parallel to the coast of Malabar for nearly five hundred miles. It consists of a series of atolls arranged in a double row, separated by a sea whose depths no line has sounded; yet from outer to inner edge of the double row is a space of but fifty miles. Such a broken coral reef often girdles a volcanic island. Tahiti, the largest of the Society group, is a fine example of this kind. The island rises in mountains 7,000 feet high, with only a narrow plain along the shore. The lagoon which encom. 
passes it like a great moat is thirty fathoms deep, and is shut out from the ocean by a coral band at a distance of from half a mile to three miles.

But there are coral reefs of far greater magnitude. The grandest is that extending along the north-east coast of Australia. Rising from an unfathomed ocean, it extends for a thousand miles along the coast, with a breadth of from two hundred yards to a mile, and at an average distance of twenty or thirty miles, though sometimes double that space. This long, narrow lagoon is never less than ten fathoms deep, and often six times as much, so that the "Great Eastern," the hugest vessel that ever floated, if it once passed through one of the openings in the reef, might sail as though in a tranquil harbor for a thousand miles in sight of land on either side, without its keel for an instant reaching half way to the bottom.

The direct influence of the ocean upon the islands of the Tropical World is great in every respect. It gives an almost temperate climate to low lands lying under the equator, and thus modifies their fauna and flora, in accordance with known laws of nature. But the ocean and air in their currents also determine the vegetable, animal, and buman life of the islands of the Tropical World in an accidental manner.

Time was when the voleanic islands of the tropics were masses of naked rock, the coraline islands patches of barren sand. The elements disintegrated the surface of the rock and ground the coral into soil. Some day a fruit, perbaps a cocoa or breadfruit, drifted along by currents, touched the island, or a bird swept far out to sea having in its crop an undigested seed, rested its weary wing upon solid land. The chance-planted fruit or seed took root, and grew, and produced its kind, and in time the waste island was clothed with verdure. Other birds found a home in the new forests, built their nests, and raised their young, so that the islands became populous with the winged tribes. Animals, of course, could only rarely cross the waste of waters. Hence the comparative paucity of this form of life in islands remote from the main land. Swine were almost the only quadrupeds which the early European navigators found in Polynesia; and they were doubtless brought there by human means. Mankind reached the islands in a like accidental manner. Perhaps a canoe from the Malayan shores drifted upon the Fiji Islands, and its rowers became the progenitors of the black cannibals; or a junk from China or Japan was cast away upon Tahiti or Hawaii. These wanderers, cut off from intercourse with the rest of the world, developed their barbarism or semi-civilization in their own way, under the influence of altered conditions, climate and productions. The story of the "Bounty," and the first settlement of Pitcairn's Island, too well known to require more than a passing allusion, shows that such a canoe or junk voyage is altogether possible, and how widely in the course of a single generation a group of isolated individuals deviate from their original stock. 


\section{CHAPTER II.}

\section{TABLE-LANDS AND PLATEAUS OF THE TROPICAL WORLD.}

Influence of Elevation upon Climate-The Puna of Peru: Squier's Description of the FanaThe Soroche or Veta-View from La Portada-Effects of the Soroche-The Sarumpe - The Veruga Water-Effects of the Veta on Animals-Vegetation of the Puna-The Llama-The Huanacu-The Alpaca-The Vicuna-Hunting the Vicuna-The Hunts of the Ancient Incas-Enemies of the Vicuna-Other Native Animals-The Ox, Horse, Mule and Sheep-Waterfowl-Warm Valleys-Rapid Change of Climate According to Elevation.-Lake Titicaca: The Sacred Island of Titicaca-Manco Capac, the First IncaHis Journey from Lake Titicaca to Cuzco-Fact and Myth respecting Manco CapacExtent of the Inca Empire-Inca Civilization originated in the Puna, near Lake Titicaca -The Sacred Rock on the Island-Ruins and Relics on the Island-The Hacienda on the Island-The Eve of St. John-The Bath of the Incas-Other Sacred Islands-Ruins at Tihuanico-Some more ancient than the Incas-Immense Monolithic Gateways and Hewn Stones-Inca Civilization-The Great Military Roads-System of Posts and Post-Stations.-The Valley of Quito: Approach to the Valley from the Pacific Coast-A Tropical Region-Climbing the Cordillera-Scenes by the Way-Quito-Climate of the ValleyAstronomical Site-Trees, Fruits, Vegetables, and Flowers-Animals-Birds-Insects, Reptiles, and Fish-The Population of the Valley-Indians-Half-Breeds-WhitesCourtesy of the People-A Polite Message-Scenery of the Valley-Volcanoes-Imbabura-Destruction of Otovalo-Cayamba-Guamani-Antisana-Sincholagua-Cotopaxi -The Inca's Head-Tunguragua-Altar-Sangai-Its perpetual Eruption-ChimborazoCaraguarizo-Illinza-Corazon-Pichincha-Its immense Crater-Descent into the Crater -Eruptions of Pichincha.-The Table-Land of Bogotá: Voyage up the Magdalena-Ascent to the Plateau-Bogotá and the Bogotános-Traveling at Bogotá-Table-Land of Mexico: Its Extent-The Tierra Calienta-The Tierra Templada-The Tierra Fria-The Valley of Anahuac-The Volcanoes of Orizaba, Popocatapetl, Iztacihuatl, and Toluca - The Sikkim Slope: Approach and Ascent-Dorjiling-The Sikkim Peaks-Altitude of Kinchinjunga-Flight of the Condor.

ITHIN the gengraphical limits of the Tropical World is found every variety of climate upon the globe. There are great mountain ranges which even at the equator rise above the limits of perpetual snow. Their summits, untrodden by man and unvisited by any other form of animal life, must be more desolate than the extremest polar regions to which explorers have been able to penetrate. Of living creatures the strong-winged condor only has reached so high. Then, below these, yet rising far into the air, are broad plateaus whose desolate character reminds one of the tundras of Siberia and the wastes stretching across the American continent from Hudson's Bay to Behring's Straits.

One of the most notable of these lofty tropical plateaus is that extending between the parallel mountain chains of the Cordilleras in South America. It is known as the Puna or Altos of Peru. In the popular language of the region a part of it is called 
the Despoblado, or "Uninhabited." It extends through a great part of the length of Peru and Bolivia, at a hight of from ten to fourteen thousand feet above the level of the sea. "It is," says Squier, "that cold and rugged region which forms the broad summit of the Cordillera. It has the aspect of an irregular plain, and is diver-

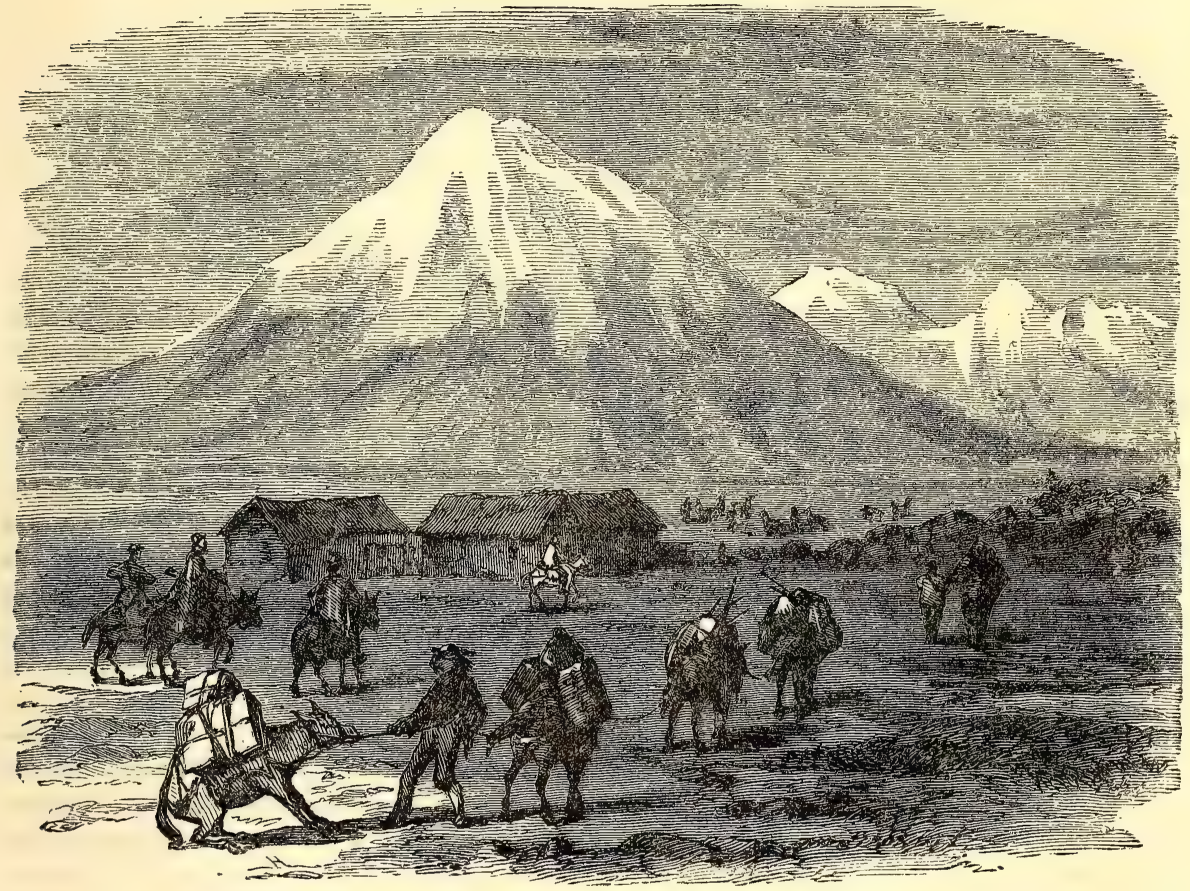

THF PUNA OF PERU.

sified with mountain ridges and snowy volcanic peaks, imposing in their proportions, notwithstanding that they rise from a level of 14,000 feet above the sea." Squier, in a few graphic sentences, describes the varying aspects of nature as one climbs up the ascent of the Puna: "Pacla is a poor but picturesque little village, with a small, white church gleaming out against the dull brown of the bare mountain side. It is 9,700 feet above the sea. There were some scant fields of maize and lucern around it, and the lower slopes of the mountains were thinly sprinkled with stems of the columnar cactus." Still ascending, "our mules hegan to pant under the influence of the soroche or rarification of the air, but which the drivers insisted was from the veta, or influence due to the vetas or veins of metal in the earth. At La Portada, 12,600 feet above the level of the sea, and 1,000 feet higher than the Hospice of the Grand St. Bernard, I witnessed a scene more wild and desolate than I have beheld in crossing the Alps by the routes of the Simplon, the Grand St. Bernard, or the St. Gothard. There is neither tree nor shrub; the frosty soil cherishes no grass, and the very lichens find scant hold on the bare rocks. The aguardiente, or native rum, which I had purchased for making a fire for preparing my coffee, refused to burn, and extinguished the lighted match thrust into it, as if it were water. I was obliged to abstract some 
refined alcohol from my photographic stores to supply its place." At the pass of Guaylillos, 14,750 feet above the level of the sea, "one of our companions fell from his saddle under the effects of the soroche. On lifting him from the ground we found him nearly senseless, with blood trickling from his mouth, ears, nostrils, and the corners of his eyes. Copious vomitings followed, and we administered the usual restoratives with good effect. In doing this I drew off my gloves, and was surprised to find my hands swollen and covered with blood, which appeared as if it had oozed from a thousand minute punctures."

Other travelers give similar accounts of the climate of the Puna Cold winds from the icy Cordilleras, whose summits often rise 8,000 feet above the plateau, sweep over their surface, and during eight months of the year they are daily visited by fearful storms. In a few hours the change of the temperature often amounts to forty or fifty degrees, and the sudden fall is rendered still more disagreeable to the traveler by the biting winds which irritate the hands and face. The lips suffer especially, breaking out into deep rents which heal with difficulty. The eyes also suffer intensely. The rapid changes from a cloudy sky to the brilliancy of a snow-field, glistening in the sun, produces an affection which the natives call the sarumpe. So intolerable is the burning and stinging that even the stoical Indian, when attacked, will fling himself on the ground uttering cries of anguish and despair. Chronic ophthalmia, suppuration of the eyelids, and total blindness, are frequent consequences of the sarumpe, against which the traveler over the highlands endeavors to guard himself by wearing green spectacles or a dark veil.

The first symptoms of the vela or soroche usually appear at an elevation of some 12,000 feet above the level of the sea. They frequently manifest themselves in those who ride, but are greatly aggravated when the traveler ascends on foot. The giddiness and nausea are accompanied with an insupportable sense of lassitude, difficulty of breathing, and riolent palpitation of the heart, followed by spitting of blood and a bloody diarrhoea. This last affliction is, however, to a considerable extent occasioned by the noxious character of the water. "All the water of the Despoblado," says Squier, "even that which does not display any evidence of foreign or mineral sub. stances in solution, is more or less purgative, and often productive of very bad effects. In many parts the thirsty traveler discovers springs as bright and limpid as those of our New England hills; yet when he dismounts to drink, his muleteer will rush forward in affright, with the warning cry, 'Beware, es agua de Veruga!' The Veruga water is said to produce a terrible disease called by the same name, which manifests itself outwardly in both men and animals in great bleeding boils and carbuncles, which occasion much distress, and often result in death."

The veta shows itself also in animals unaccustomed to mountain traveling. They proceed more and more slowly, frequently stop, trembling all over, and fall to the ground. If not allowed to rest they inevitably die. The natives are accustomed to slit the nostrils of their mules and horses in order to allow a greater influx of air. Mules and asses are less affected by the veta than horses; but it is fatal to cats, who are unable to live at the hight of more than 13,000 feet.

Another consequence of the diminished pressure of the air is that water boils at so low a temperature that meat, vegetables and eggs can not be boiled sufficiently to be edible, and whoever wishes a warm meal in the Puna must have it baked or roasted. 
Agriculture is of course confined within the narrowest limits. In some parts barley will grow; but it never ripens, and is cut green for forage. The only cultivated vegetable is the mata, the tuberous roots of which resemble the potato, and form a great part of the food of the inhabitants. It grows best at an elevation of more than 12,010 feet. Vegetation is scanty. Here and there is a solitary dwarfed quinua, or wild olive, or patch covered with reddish brown ratania shrubs, which, with the droppings of the llamas and vicunas, constitute the sole fuel of the region. The whole landscape presents a scene of bare rock, or of steppe-like expanses covered with dun meagre herbage. The profusion of flowers which appear in many Alpine regions is here utterly wanting.

The animal kingdom is more amply represented on this bleak table-land. But its native members are almost wholly confined to the camelida family, of which there are four well-marked species,-the llama, the alpaca, the vicuña, and the huanacu,-who find nourishment in the grassy patches. Before the advent of the Europeans these llamas constituted the only beasts of burden, and even now they are largely employed for that purpose. To the ancient Peruvians they were what the camel is to the Arabs. Their flesh and milk served as food, their skins for a mantle, and from their wool a coarse cloth was manufactured; and they formed the only means except human labor of transporting burdens from one place to another. Even now, when to a great extent superseded by the stronger horse and mule, there are regions where they are indispensable. The silver mines are often approached only by precipices so abrupt that even the hoof of the sure-footed mule would find no foot-hold. The ordinary load of a llama is a hundred pounds ; but as they never feed after sunset, they must be allowed to graze on the way, so that they can travel only ten or fifteen miles a day. The llama is the only animal ever domesticated by the aborigines of America.

The llama is about the size of the deer, but bears a strong resemblance to the camel, having the same formation of toes and stomach, and the same callosities upon the breast and knees, but the unsightly hump is wanting. The microscope reveals that the resemblance extends even to the globules of the blood, which are elliptical in the camelides and some species of deer, but circular in all other quadrupeds.

The huanacu was long supposed to be only the wild variety of the llama; but naturalists now point out specific differences. The huanacu is larger; its wool is shorter and coarser; it presents no variety of color. They are very shy, and live in small troops of from five to seven. When caught young they may be tamed, but still show traces of their wild nature, and can hardly ever be trained to carry burdens.

The alpaca is smaller than the llama, and bears some resemblance to the sheep; but its neck is longer, and it has a more elegantly formed head. Its wool is long, fine, of a silky lustre, varying in color from almost white to black. The wool is especially valuable since it can be woven with common wool, silk, or cotton, and within a few years has become an article of considerable commercial value. Attempts, none of which have as yet proved successful, have been made to introduce the alpaca into other countries. They are kept in large herds grazing all the year round upon the bleak table-lands, and are only driven to the pens to be shorn.

The vicuña is of a more graceful shape than the llama; its wool is shorter and more curly, and of such extreme fineness as to be very valuable. It inhabits the most secluded valleys, and during the rainy season climbs far up the sides of the Cor. 
dilleras, but never ventures upon the bare summits, for its hoofs are tender. The cry of the vicuña is a shrill whistle, so loud that it may be heard at a long distance. Like the camel and llama, it has the habit of spitefully ejecting a mass of saliva and halfdigested food in the face of those who come within reach. In the case of the vicuna this is peculiarly offensive, has a disgusting smell, and stains the skin of a dark green color, which can be effaced only with difficulty.

The annual hunt of the vicuna, which takes place in April or May, is the great event in life of the Indians of the Puna. They collect in bands from all the villages, bearing bundles of poles and ropes, and set out for the lofty summits whither the animals have retired. With the poles and ropes a circular enclosure, called a chacu, is formed, often several hundred paces wide. The hunters form a ring, sometimes miles in circumference, and gradually drive the animals into the chacu. The vicunas are shy and do not venture to leap over the cords, and are easily dispatched by the hunters. If, however, a huanacu happens to be driven into the enclosure, he bounds over the cord, and is followed by the herd of vicuñas in a mass, just as a flock of sheep will follow a leader. The flesh of the vicuña is rank and unsavory. Squier says that it is just preferable as an alternative to starvation. But when it has been dried and pounded, and disguised by an abundance of the hot red pepper, its taste is not altogetber unpleasant to one who has learned to like that fiery condiment.

The number caught in one of these bunts is often considerable. At one in which Von Tschudi took part there were 122 killed, and the produce of their skins was appropriated to building a new altar in the village church. In the times of the Incas the vicuña chase in the Puna was conducted upon a far more magnificent scale. Every year a great hunt was held. Twenty-five or thirty thousand of the Indians were assembled, who drove all the animals within a circuit of many leagues into an enormous enclosure. As the circle narrowed, the lines of the hunters were doubled and trebled. All the pernicious animals were killed, but only a limited number of the deer, huanacus, and vicunas, for those wise rulers were too provident to take the lives of these creatures merely for sport. The battue, apart from the destruction of noxious animals, was rather a royal spectacle than a hunt.

Excepting man, the vicuña has few enemies capable of penetrating its lofty strongholds. A sneaking puma now and then creeps up from the regions below; or a condor swoops down from above and pounces upon the young. But the numbers of the vicunas has undergone no diminution from age to age. Now, however, that their wool has become an article of commerce, we may anticipate their gradual extermination; for, unlike the alpacas, they are incapable of domestication, and man the arch-destroyer wages fatal war upon all animals which he can not domesticate. Their only alternative is death or subjection.

Several animals of the deer tribe are also indigenous to the Puna. Among these is the stag-like tarush, whose horns consist of but two branches. The half wild Puna dogs are especially annoying to the traveler, for they have a peculiar antipathy to the white race; and it is often dangerous for a European to approach an Indian hut guarded by these spiteful creatures, who, like the bull.dog, do not hesitate to attack enemies far stronger than themselves. The bisacha, allied to the chinchilla, which it resembles in the quality of its fur, is often seen perched in front of its burrow, to which it retreats on the approach of danger. 
To the aboriginal animals of the Puna have been added, since the Spanish conquest, the ox, the horse, the mule, and the sheep. These do not inhabit the bleak Despoblado, though the horse and the mule, under the guidance of man, traverse as beasts of burden its bleakest wastes and most rugged passes. The herds of oxen and sheep are, during the wet season, driven far up into the Altos, often to the hight of 15,000 feet; but when the cold frosty nights of the dry season arrive, they are driven down to the valleys which furrow the table-land. Here there are haciendas, or estates, the owners of which possess 60,000 sheep and 500 cows. These herds seldom see the face of man, and have relapsed into a half savage state, rendering traveling dangerous in many parts of the Puna. Von Tschudi, whose journeyings in this region are more extensive than thase of any other European, was more than once compelled to save his life from the attacks of a wild bull by a well-aimed shot from his rifle.

The frequent showers and snow-falls of the Puna give rise to numerous swamps and lagoons which afford nourishment to an abundance of birds. There is the huacha goose, with a snow-white body and dark green wings shining with metallic lustre; the lic.i, a species of plover; the long-legged ibis and flamingo; and the gigantic coot, which, unable to fly in the air, dives in the cold waters, and builds its nest on the bare stones which rise above the surface.

The frosts of winter and a perpetual spring are nowhere found in closer proximity than in these Peruvian highlands ; for deep valleys furrow the windy Puna, and when the traveler, benumbed by the cold blasts of the mountain plains, descends into these sheltered gorges, he finds himself transported almost at once from the rigors of a polar climate to a terrestrial paradise. They are so high that the rays of the tropical sun are not felt; and protected by their abrupt rocky walls from the keen blasts of the mountains, these pleasant valleys enjoy all the advantages of a mild and genial sky. Rich corn-fields and green lucerne meadows would almost persuade the European traveler that he had been by magic transported to his own home, were it not that the sight of agaves and cactuses upon the rocky sides by day, and new constellations by night, remind him that he is in another hemisphere. There are regions here where the traveler may in the morning leave the snow-covered Puna hut in which he has shivered over night, and before sunset pluck pine-apples and bananas on the cultivated margin of a tropical forest, and repose under the feathery leaves of gigantic palms.

But in this vast highland region there is nothing which possesses so deep a human interest as Iake Titicaca, for in it is embosomed the sacred island, to which the Incas traced their origin, and which to this day is to their descendants all that Jerusalem and Mecea are to Hebrews, Christians, and Mohammedans. The lake lies at an elevation of 12,864 feet above the sea, less than 3,000 feet lower than the summit of Mont Blanc, and higher than any point in Europe except the ten loftiest peaks of the Alns. It is 120 miles long and 50 or 60 wide. It never freezes over, though ice forms near its shores. It exercises a very important influence on the climate of the cold and desolate region in which it is situated, for during the winter months the temperature of the waters is ten or twelve degrees above that of the atmosphere. Wherever the shores are low they afford pasturage for herds of cattle; and multitudes of waterfowl find shelter among the reeds and rushes. On the little islands barley, peas and maize ripen, although they are not prolific.

The largest of the islands is the sacred Island of Titicaca, bold, bare, and rocky, 
six miles long and three or four wide. Here, according to tradition, Manco Capac, and Mama Oella, at once his sister and wife, both children of the sun and commissioned by that luminary, started on their errand to civilize the barbarous tribes that occupied the country. Manco Capac was directed to travel northward until he reached a spot where his golden staff should sink into the ground of its own accord; and there he was to fix the seat of his empire. He traveled slowly along the western shore of the lake, through the broad bleak Puna lands, crossing the water-shed which separates the streams which find their outlet through the La Plata from those which form the mighty A mazon, whose mouths lie 2,500 miles apart in a straight line. Striking the river Vileanota, an affluent of the Ucayali, one of the main branches of the Amazon, he descended its valley, until, after a journey of three hundred miles, his golden staff sank into the ground upon the spot where the eity of Cuzeo now stands. Here he fixed his seat, and here arose the City of the Sun, the capital of the Inca empire, which in time spread over a length of $37^{\circ}$ of latitude, and in breadth from the eastern base of the Andes westward to where the Pacific beats against the deeply planted feet of the Cordillera.

So runs the legend; but there is much mythical matter incorporated into the traditions respecting Manco Capac. We find this counterpart in the Fohi of the Chinese, the Buddha of the Hindus, the Osiris of Egypt, the Odin of Seandinavia, the Jatza coal of Mexico, the Votan of Central America. Still there can be no doubt that he is a real historical eharacter, to whom, however, have been attributed many of the achievements of those who preceded him, and perhaps of some who followed him. The time when he lived is altogether uncertain. Some. studying the quippus or knotted cords, which are the only records of ancient Peruvian history, place his advent back to within five centuries after the deluge. But the best authorities give the date approximately at about four centuries before the arrival of the Spaniards under Pizarro, or about 1000 A. D., the period when all Christendom was hurling itself in the crusades upon the Holy Land.

The rule of Manco Capac was at first limited to the region elose by Cuzco; but under his successors the Inca dominion, by alliances and conquests, spread far and wide. The greatest of the Inca monarehs was Huayna Capac, who in 1475 led his forces as far northward as Quito, a distance of 1,200 miles from Cuzco. He made Quito his residence. At his death the empire was divided between his two sons, Huascar, who reigned at Cuzeo, and Atahuallpa at Quito. Civil war ensued, Huascar was defeated and slain, and Atahuallpa remained sole Inca. During the war Pizarro, coasting down from the Isthmus of Darien, landed at Tumbez, conquered Atahuallpa, and overthrew the Inca civilization.

This civilization, in some respects one of the most remarkable which the world has ever seen, had its origin in the lofty table-land of the Puna, which we are now considering; and far and wide as the reign of the Incas subsequently extended, they and their subjects always retained their reverence for the little rocky islet in Lake Titicaca, where it had its origin. At the northern end of the island is a frayed and water-worn mass of red sandstone, about 225 feet long and 25 feet high. This is the sacred rock of Manco Capac, the most holy spot in all Peru. Upon it, as was believed, no bird would alight, no animal venture, and upon which no human being not of the royal blood dared set his foot. From this rock the sun first rose to dispel the primal vapors 
and illuminate the world. It was, so says the legend, plated all over with gold and silver, and, except upon the most solemn occasions, covered with a vail of cloth of costly materials and gorgeous color. The gold and silver plating and the gorgeous covering have long ago disappeared, and what is now seen is a bare rock, on the crest of the island, which rises 2,000 feet above the waters of the lake. Yet even now, when the Indian guides come within sight of it, they raise their hats, bow reverently, muttering words of mystic import, which they themselves, most likely, only partly comprehend. In front of the rock is a level artificial terrace 372 feet long and 125 feet broad, supported by a low stone wall. According to tradition, the soil which once covered this terrace was conveyed upon the backs of men from the distant valleys of the Amazon, so that it might nourish a vegetation denied by the hard ungrateful soil of the island.

Everywhere on the holy island are the ruins of Inca structures, and the sites of the most sacred spots are still shown. Here is the sheltered bay where the Incas landed when they came to visit the spot consecrated to the sun. Half way up the ascent are the "foot-prints" of the great Inca Tupanqui, marking the spot where he stood when, catching his first view of the hallowed rock, he removed the imperial covering from his head in token of adoration of the divinity whose shrine rose before him. These so-called foot-prints look not unlike the impressions of a gigantic foot, thirty-six inches long and of corresponding breadth. They are formed in outline by hard ferruginous veins around which the softer rock has been worn away, leaving them in relief.

The sacred island of the Incas is now the property of a resident of Puna, a city on the shore of the lake containing 7,000 inhabitants. It is the loftiest spot on the globe which is the site of any considerable town. It stands 12,870 feet above the level of the sea. The mining town of Potosi is indeed 500 feet higher, and there are among the Andes post-stations and farms much higher. The station of Rumihuasi, in the Puna, the loftiest permanently inhabited spot in the New World, is 15,542 feet highonly 242 feet below the summit of Mont Blanc; and the gold mine of Thok Jalung in Thibet is 18,330 feet above the sea. The proprietor of the sacred island has a hacienda close by the "Bath of the Incas." "It consists," says Squier, "of three small buildings, occupying as many sides of a court. One is a kitchen and dormitory, another a kind of granary or storebouse, and in the third is an apartment reserved for the proprietor when he visits the island. The room is neatly whitewashed, the floor matced, and there are two real chairs from Connecticut, and a table that may be touched without falling in pieces. The night was bitterly win," continues Squier, " and we had no covering except our saddle-cloths, having declined some sheep-skins which the alcalde would have taken from the poor people of the establishment. A sheep skin, or the skin of a vicuña, spread on the mud floor of his hut, is the only bed of the Indian from one year's end to the other. It is always filthy, and frequently full of vermin. Before going to bed we went out into the frosty, starry night, and were surprised to see fires blazing on the topmost peaks of the island, on the crest of Coati, and on the headland of Copobanca. Others, many of them hardly discernible in the distance, were also burning on the peninsula of Tiquina, and on the bluff Bolivian shores of the lake, their red light shimmering like golden lances over the water. Our first impression was that some mysterious signalling was going on, con- 
nected perhaps with our visit. We ascertained, however, that this was the Eve of St. John, which is celebrated in this way throughout the Sierra. On that night fires blaze on the hill-tops in all the inhabited districts of Peru and Bolivia, from the desert of Atacama to the Equator." Thus have the rites of Christianity superseded the old worship of the Incas.

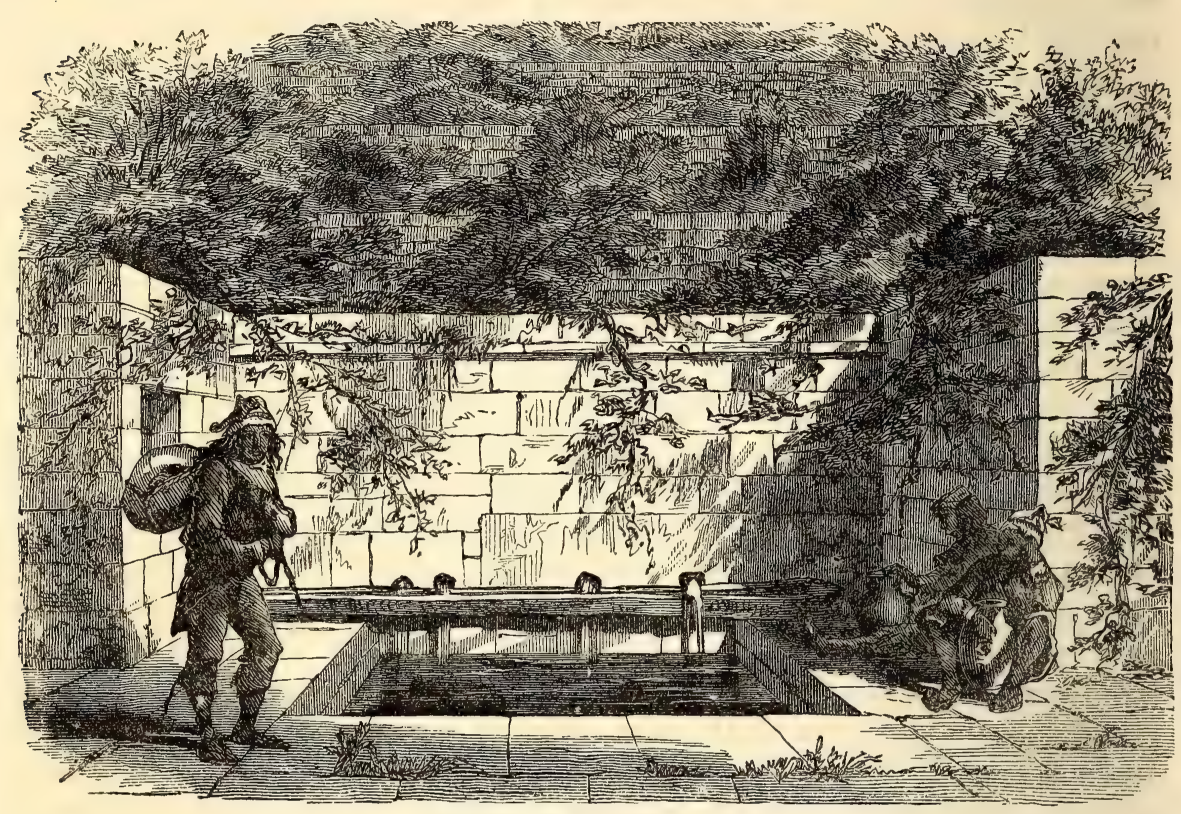

Fountain of the incas.

The Fountain of the Incas is situated in a sheltered nook, surrounded with terraces upon which grow patches of maize with ears not longer than one's finger. The bath itself is a pool forty feet long, ten wide, and fire deep, built of worked stones. Into this pour four jets of water, as large as a man's arm, from openings cut in the stones behind. "The water comes through subterranean passages from sources now unknown, and never diminishes in volume. It flows to-day as freely as when the Incas resorted here and cut the steep hill-sides into terraces, bringing the earth all the way from the Valley of Yucay, or 'Vale of Imperial Delights,' four hundred miles distant. Over the walls droop the tendrils of vines; and what with the odors and the tinkle and patter of the water, one might imagine himself in the court of the Alhambra."

Besides the sacred island of Titicaca, there are eight smaller ones in the lake. Soto was the Isle of Penitence, where the Incas were wont to resort for fasting and humiliation. Coati was sacred to the moon, the wife and sister of the sun, and on it is the palace of the Virgins of the Sun, one of the most remarkable and best preserved remains of aboriginal architecture on the continent of America.

At Tihuanico, on the border of the lake, are immense ruins which clearly antedate the time of the Incas. They were ruins when the Spaniards made their appearance, and the natives could give no account of them. They supposed that they were built 
by divine architects in a single night. Cieza de Leon, one of the companions of Pizarro, writes of them: "What most surprised me was that the enormous gateways were formed on other great masses of stone, some of which were thirty feet long, fifteen wide, and six thick. I can not conceive with what tools or instruments these stones were hewn out, for they must have been vastly larger than we now see them. It is supposed that some of these structures were built long before the dominion of the Incas; and I have heard the Indians affirm that these sovereigns constructed their great building at Cuzco after the plans of the walls of Tihuanico." The most remarkable thing in these ruins are the great doorways of a single block of stone. The largest of these is ten feet high and thirteen broad, the opening cut through it being six feet four inches high, and three feet two inches wide. The whole neighborhood is strewn with immense blocks of stone elaborately wrought, equalling if not surpassing in size any known to exist in Egypt, India, or any other part of the world. Some of these are thirty feet long, eighteen broad, and six thick.

All these gigantic remains of a past civilization are found in the lofty table-land of the Puna. When these come to be fully described and illustrated, it will be seen that here, in a climate so cold that hardly a vegetable will grow which man can use for food, were planted the seeds of a civilization as remarkable as any which ever existed. More wonderful, perhaps, than these great architectural works were the great military roads constructed by the Incas. One reached from Cuzco down to the ocean. The other stretched from the capital, along the very crest of the Cordilleras, and down their ravines, to Quito, 1,200 miles distant. The length of these great roads, including branches, was not less than 3,000 miles. Modern travelers compare them with the best in the world. They were from 18 to 25 feet broad, paved with immense blocks of stone, sometimes covered with asphaltum. In ascending steep mountains, broad steps were cut in the rock; ravines were filled with heavy embankments flanked with parapets, and, wherever the climate permitted, lined with shade trees and shrubs, with houses at regular distances for the accommodation of travelers, and especially serving as post stations. For there was a regular postal service by which the Incas could send messages from one extremity of their dominions to the other. This service was performed by runners; for, as has been said, the Peruvians had no beasts of burden stronger or swifter than the llama. These messengers were trained to great speed. On approaching a station they gave a loud shout to warn the next courier of their approach, so that he might be ready to take the message or parcel without delay. In this manner it is said that dispatches were sent at the rate of 150 miles a day, a speed unequaled until within our own times, when the railway and the telegraph have brought the ends of the world almost together.

Lying lower than the desolate Puna, but more than twice as high as the loftiest summits of Great Britain, and higher by half than the topmost peaks in North America east of the Rocky Mountains, is a series of valleys and table lands which form a marked feature in the Tropical World. The principal of these, going northward from the equator, are those of Quito in Equador, Bogota in Columbia, and Mexico.

The valley of Quito, with a breadth of thirty miles, is two hundred miles in length from north to south, the equator running upon its northern border. It is in reality a great table-land occupying the summit of the Cordilleras, only overtopped and sur- 
rounded by a series of peaks the most picturesque, and, after the highest peaks of the Himalayas, among the loftiest on the globe. The valley is 10,000 feet above the level

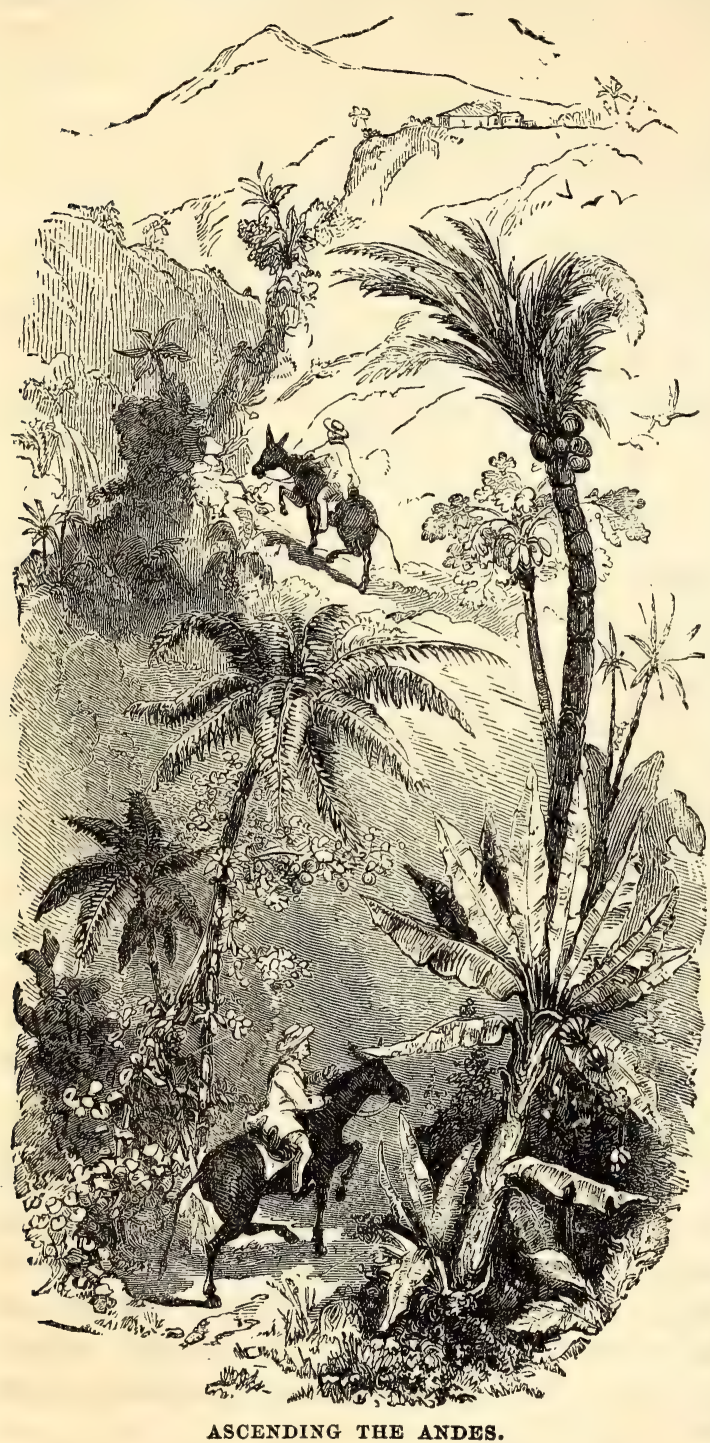
of the sea, which, by the rule of allowing 300 feet in elevation to be equivalent to a degree of latitude, would give a climate approximating to that of Florida and Georgia; but this is much modified by other circumstances, especially by the snow-clad peaks which surround it, and by the more abundant rainfall.

This lofty valley is approachable by the great Inca road of which we have spoken, leading across the crest of the Cordilleras. But for generations probably no man has ever thus reached it. Some day it will be visited from the east by steaming up the Amazon to the foot of the Andes, and ascending the mountains. At present it is approached from Guayaquil on the Pacific. We will accompany Mr. Orton,* an American traveler, who in 18678 , at the head of a scientific expedition, made the journey thither; and thence, descending the Amazon, crossed the entire continent almost on the line of the equator. Landing at Guayaquil, the seaport of Ecuador, we embark on a little steamer which carries us seventy miles up the turbid river Guayas. The Eucadorian government, however, does not patronize the steamer, but sends the mails up the river in a canoe. The river runs first through an almost impenetrable jungle; then come vast plantations of cocoa and coffee ; then follow groves of oranges, lemons, plantains and mango. Leaving the boat, we hire mules with which to make the ascent of the Andean Cordilleras. $\dagger$ We plunge at once by a narrow path into a dense forest.

* The Andes and the Amazon, by James Orton, Professor in Vassar College, Poughkeepsie, N. Y.

$\dagger$ Cordillera, literally a long ridge, is usually applied to a longitudinal subdivision of the Andes, as the east and west Cordilleras, enclosing the valley of Quito. A Sierra is a jagged spur of the mountains. 
Superb bananas, with glossy leaves eight feet long, slender bamboos, and lofty palms overarch the way. Soon we begin to climb the mountain sides. The path-the present royal road to Quito-grows steeper, running sometimes through a gully so narrow that the traveler must throw up his legs to save them from being crushed. Before night we have reached an altitude where the air is sensibly cold. We stop near a rude hut; but there is room for only a part of us within; the others sleep outside on the ground, upon beds which we have brought with us. But we have reached a comparatively passable road.

As the sun goes down we have a view which amply repays us for our weary travel. We are on the summit of a sierra 8,000 feet high. Still above us is a wild chaos of mountains, their sides broken into ravines. Looking westward, the mountains tumble down to verdurous hills, which in the distance melt into plains, dipping into the great Pacific. Upward rise the lofty peaks, over all of which towers Chimborazo, its pure white dome piercing the unclouded azure. The road now slopes gently down the side of the Sierra, climbs again still higher, and brings us at evening to the sleepy little town of Guaranda. The people seem to have nothing to do but to eat potato soup, and keep themselves warm by wrapping themselves in their ponchos and basking in the sun. The place is of note in one respect, for it is the capital of the region which produces the chinchona, whence comes quinine. The trees grow at elevations of from 2,000 to 9,000 feet, the richest species occupying moist situations in the highest altitudes. Close by we are shown the spot where Church painted one of the views for his magnificent composition, "The Heart of the Andes."

Still ascending, we find ourselves in a wilderness of crags and treeless mountains, clothed with long, coarse grass. The summit of the pass, known as the arenal, is a sandy plain of a league in length, at an elevation of more than 14,000 feet. In the afternoon it is swept by cold winds, and often by violent snow-storms. It is said that some of the Spanish soldiers were frozen to death here. Then again we begin to descend along a gray, barren waste. Not a tree or a human habitation is in sight. Icy rivulets and mule-trains are the only moving objects. We pass the night in a dirty, mud hovel, the halting-place for all the caravans between the capital and its seaport. For food we have the invariable potato soup, to which have been added cheese and eggs. It is well that the potatoes are small, for water boils at this altitude before it is fairly hot. Descending in all 6,000 feet from the summit of the pass, we come to Ambato, a town of 15,000 inhabitants, beautifully situated in a deep ravine. It has also an inn-the first since leaving Guayaquil. Once more upward, through vast deposits of rocks and pumice dust, thrown out by the volcano of Cotopaxi, and we gain the last summit which we are to surmount. Fifteen hundred feet below us, and seemingly at our very feet, lies Quito, nestled in its lovely valley, sentinelled on each side by the lofty peaks of Pichincha and Antisana, while behind us tower Chimborazo and Tunguragua. Pichincha, the lowest of these four peaks, is 7,000 feet above the plain ; Chimborazo, the highest, is 12,000; and it is almost 10,000 feet more before the level of the sea is reached.

The climate of the valley of Quito is the most absolutely perfect of any on earth. The thermometer never rises above $70^{\circ}$ or sinks below $45^{\circ}$; its mean is $60^{\circ}$, the temperature of a mild spring day in New York. There is no cold winter and no hot summer; it is always spring and autumn; but each day furnishes a change just 
sufficient to give a pleasing variety. The coldest hour is at sunrise; the warnest two or three hours after noon. Nobody talks about the weather, for it is always pleasant; conversation begins with a blessing, and ends with a benediction. In healthfulness it is unequaled. Consumption is unknown. One will hear more coughing during a Sunday service in a New England church than in all Quito for a six-month. The intermittent fevers so prevalent on the coast are rare. Asthma, induced measurably by the rarity of the atmosphere, and typhoid fẹvers, are the prevalent diseases. In Quito, with 40,000 inhabitants, there are but three drug-stores. Still, owing to indolence, filth, and bad diet, comparatively few natives attain old age. With proper habits of living, there is probably no spot on earth where the death rate would be so low. The atmosphere is of unsurpassed transparency. Humboldt, with the naked eye, saw the poncho of a horseman at a distance of eight miles. The sky is of a deep blue, and the stars shine with great brilliancy; the dark openings between them have been compared by Humboldt to "tubes through which we look into the remotest depths of space." An adequate observatory at Quito would, perhaps, make more additions to astronomical science than anywhere else on the globe; for, in addition to the constant purity of the atmosphere, it is situated on the very line of the equator, so that the constellations of both hemispheres are visible. Low in the north the "pointers" of the Great Bear are visible, while low in the south the Southern Cross can be discerned.

Contrary to what one would expect, the valley of Quito is almost destitute of trees. There is not such a thing as a forest from one end to the other; the trees stand singly or in small clumps. The aliso, a species of birch, is the most common tree; the walnut is the best timber; oaks and pines are not found. The variety of fruits is good. There are alligator-pears, guavas, granadillas, oranges, lemons, plums and quinces. Peaches and pears are found, but of poor flavor. The favorite fruit is the chirimoya, which grows on a tree fifteen feet high; the ripe fruit sometimes weighing sixteen pounds. Markham calls it " a spiritualized strawberry." Our common garden vegetables, such as onions, beets, carrots, turnips, cabbages, and tomatoes, flourish. The potato is indigenous here, but is inferior to ours, which have improved by transplanting. The Spaniards carried the potato to Spain from Quito, three-quarters of a century before Raleigh introduced it into England from Virginia. Flowers are numerous and in great variety.

Animal life presents few species and few individuals in each. There is strictly no beast of prey, no large native quadruped, and few of the smaller tribes. The ornithology of the valley is limited; it is only when we descend into the valley of the Amazon that we find the feathered tribes in their glory. The condor and the humming-bird, the extremes in size of the feathered tribes, are the most noticeable among the mountains. Butterflies abound of all colors from emerald green to snowy white Mosquitoes and flies hardly exist; but fleas and other "small deer" find congenial pasturage in the filthy garments and unkempt hair of the Indians. Serpents are so unfrequent, that in three months the members of the American expedition saw only a single snake; and there are not frogs enough in the valley to furnish a respectable chorus of brek-ke-kex-koax. There is in all the valley only a single species of fish, small and of a black color. Multitudes of these have been thrown up during volcanic eruptions from the bowels of the earth. 
Of the population of the entire valley Indians constitute a great majority. Though reduced to absolute serfdom, and sunk deep in degradation, they still retain a menory of the days of Incarial greatness. This is particularly the case with the inhabitants of the mountains. Mr. Orton noticed that some of those who descended to the plain wore a black poncho underneath their bright-colored one, and was told that they were in mourning for the last Inca. In Quito itself there are about 8,000 of Spanish descent; perhaps 10,000 of pure Indian blood; the remaining 22,000 being Cholos, the offspring of whites and Indians, the Indian blood largely predominating. These almost exclusively carry on what of industry exists. They are the artisans, tradesmen, and soldiers. The whites constitute the governing class. They have fair natural capacity, but lack education, industry, and energy. They are, however, courteous and refined in manners and deportment. Their courtesy, even in the most common intercourse, is carried to a point which we can hardly appreciate. Mr. Hassaurek, the late American minister to Ecuador, gives the following as a specimen of a message sent by one fair Quitonian to another: "Go," she says to her servant, " to the Senorita So-and-So, and tell her that she is my heart and the dear little friend of my soul; tell her that I am dying for not having seen her, and ask her why she does not come to see me; tell her that I have been waiting for her more than a week, and that I send her my best respects and considerations; and ask her how she is, and how her husband is, and how her children are, and whether they are all well in the family. And tell her that she is my little love, and ask her whether she will be kind enough to send me that pattern which she promised me the other day."

Before bidding adieu to the lofty tropical valley, let us take one glance at the grand scenery which environs it. There are fifty-one volcanic peaks in the Andean chain, twenty of which girdle the valley of Quito, three being active, five dormant, and twelve extinct. Looking toward the eastern Cordillera, the first mountain to the north is Imbabura, 18,000 feet high. At its foot stood the city of Otovalo, destroyed in the great earthquake of August, 1868; here alone out of 10,000 inhabitants 6,000 perished. The first shock, which came without hardly a premonitory sign, lasted but one minute ; at the end of that minute not a house or a wall a yard high remained standing. Next, exactly on the equator, comes square-topped Cayamba, 19,500 feet high, and in full view from the plaza of Quito. Ten miles south is the bare Guamani range, over which, at a hight of 15,000 feet, the traveler must pass before he begins to descend into the valley of the Amazon. Its culminating peak, Sara-Urcu, threw out ashes as late as 1856. Then comes Antisana, 19,000 feet high, clothed in snow for 3,000 feet. It is now dormant; but the lava streams down its side show how tremendous was its former activity. One of these streams is ten miles long and five hundred feet deep. Its last eruption occurred in 1590 ; but smoke issued from it in 1802. Next comes ragged Sincholagua, 16,500 feet high ; and then Cotopaxi, " the shining," more than 2,000 feet higher, the loftiest of active volcanoes, though its great eruptions occur only at intervals of a century; but deep rumblings, and a constant cloud of smoke issuing from its crater, down which no man has looked, show that it is only sleeping. Its last great eruption occurred in 1803. Far down its south side lies a huge porphyritic rock, called the Inca's Head, which tradition avers to have once been the summit of the volcano, torn off and hurled down on the very day when Atahuallpa was murdered by Pizarro. Sixty miles further south rises the perfect 
cone of Tunguragua, 16,500 feet high. A cataract on it springs from the very edge of the perpetual snow, coming down 1,500 feet in three leaps. Its last eruption, which lasted seven years, began in 1773 . Close by, 17,500 feet high, rises Altar, called by the Indians Capac-Urcu, "The Chief." They say that it once overtopped Chimborazo ; but that, after an eruption which lasted eight years, the lofty walls of its crater fell in. Twenty miles further is Sangai, 17,000 feet high, the most active voleano on the globe. Without a moment's intermission it has for three hundred years poured forth a stream of fire, water, mud, and ashes. Its ashes are almost always falling at Guayaquil, a hundred miles distant; and its explosions, generally occurring every hour or two, are often heard in that city. It sometimes rouses itself to unwonted activity. In 1849 Wisse counted 267 explosions in an hour,-more than two in every three seconds.

We have thus far followed the eastern Cordillera southward. We now turn to the western range, which runs parallel to it, at a distance of from thirty to sixty miles, and go northward back to Quito. First and foremost, but not "sole monarch of the vale," comes Chimborazo, "the Snowy Mountain," 21,470 feet high. Ages ago its now silent summit glowed with volcanic fires. Its sides are seamed with huge rents and dark chasms, in some of which Vesuvius could be hidden away out of sight. Next, and separated from it only by a narrow valley, is Caraguarizo, 19,000 feet high, called by the Indians " the wife of Chimborazo." A century and three-quarters ago the top of this mountain fell in, and torrents of mud containing multitudes of the little fishes of which we have spoken poured out. Journeying onward, passing peaks scarcely lower than these, some of them extinct volcanoes, such as Illinza, 17,000 feet high, and heart-shaped Corazon, we reach Pichincha, "the Boiling Mountain," 16,000 feet high, whose smoking crater lies only five miles distant from Quito. It is the only Eucadorean volcano which has not a cone shaped crater. Such an one it doubtless once had; but some convulsion of nature far beyond the reach of history or tradition, has hollowed out from its now flattened summit an enormous funnel-shaped basin 2,500 feet deep, three-quarters of a mile in diameter at the top, and 1,500 feet at the bottom. It is the deepest crater on the globe: That of Kileaua is but 600 feet deep, Orizaba 500, Etna 300, Hecla 100.

The brink of the erater of Pichincha was first reached by the French Academicians in 1742. Sixty years later Humboldt reached the edge, but pronounced its bottom " inaccessible on account of its great depth and precipitous descent." The crater was first entered in 1844 by Morena, now President of Ecuador, and Wisse, a French engineer. Mr. Orton and his associates, after one unsuccessful attempt, succeeded in accomplishing the perilous descent in October, 1867. Scrambling down the steep sides, sometimes of rocks covered with snow, sometimes a mass of loose, treacherous sand; now leaping a chasm, now letting themselves down from cliff to cliff, threatened by huge rocks which perpetually loosed themselves and went bounding past them, in two and a half hours they reached the bottom of the crater. It was found to consist of a deeply furrowed plain, strewn with ragged rocks, with here and there a patch of vegetation, and half a dozen species of flowers. In the center was an irregular heap of stones 260 feet high, and 800 in diameter. In its top and sides were seventy vents, sending forth steam, smoke, and sulphurous gas. The central vent, or chimney, gives forth a noise like that of a bubbling eauldron. 
There have been five eruptions of Pichincha since the Spanish conquest, the last being in 1660. That of 1566 covered Quito three feet deep with ashes and stones, while boiling water and bitumen poured forth in torrents. In 1867 the column of smoke did not rise above the crest of the crater; but on the 19th of March, 1868, violent rumblings were beard in Quito, followed three days afterward by great columns of vapor. Since the great earthquake of August, 1868, the mountain has continued to send forth columns of smoke, and so much fine sand that it was not possible to reach the crater. It may be that the volcano is preparing to rouse itself from its slumber of two centuries. The Quitonians, however, congratulate themselves that the edge of the crater is considerably lower on the side facing the city; so that sbould an eruption occur, the volcano will pour its fiery contents away from them into the wilds of the Esmeralda.

We leave the valley of Quito, whose mighty surrounding volcanoes present one of the most striking aspects of nature within the Tropical World.

The next great table-land is that of Bogota. Its elevation is 8,700 feet above the sea,-1,300 feet less than that of Quito; but although barely five degrees from the equator, the climate is much colder. To reach the table-land, we ascend the great river Magdalena for three hundred and fifty miles, through a low country covered with tropical vegetation; then, leaving the stream, we set our faces toward the mountain range upon whose summit lies the table-land, fifty miles away, between us and it intervening several sharp ridges, which might easily be skirted. But the road, with a thorough contempt for all engineering devices, runs straight over them. In the course of a single day we twice ascend a mountain 3,000 feet high, only to descend as far on the opposite side, giving us in the space of twenty miles an unnecessary ascent of a mile, and an equal descent. At length we come to the outer rim of the great plain of Bogota, rising sheer up like a wall before us; up this the path winds by sharp turns and zigzags like a circular staircase. Pile the Catskills upon the summit of Mount Washington, and then level off upon the summit a marshy plateau half as large as the State of Connecticut, and heap around it mountains some thousands of feet higher, and we have the great plain of Bogota, which the inhabitants believe to be the most delightful spot on earth.

The temperature of the plain is so low that it produces only a little wheat, grass, barley, and a few esculent roots. The greater part of it is owned in vast estates by a few rich land-holders, who have the reputation of being excessively stupid. The people of the city call them Orejones, "Big-Ears." The markets of Bogotá are supplied mainly from the warm country below. An Indian and his wife will toil up the steep path bearing enormous loads of fish or plantains, trudge across the weary breadth of the marshy plain, occupying three days in the journey, and think themselves lucky if they find a purchaser for their load. Sometimes these patient bearers will be seen descending the mountains which tower above the city, loaded with plantains, oranges, and other tropical productions. These could not have grown upon the mountains, but have been brought over their summits from the warmer regions lying far down on the opposite slopes. Bogotános sometimes descend to the plains to thaw out. The favorite place for pleasurable resort is the village of Fusagasuga, which lies far down on the slope. To reach it one must first climb up a thousand feet higher than the 
plain, and then descend three times as far. There are two modes of traveling : muleback and man-back. It requires some preparation for such a pleasure-trip. As it is always cold and usually rainy, the traveler has his face well bundled up to protect it. His hat has a covering of oiled silk; his poncho, or cloak, which must serve also as a blanket by night, is fastened to his saddle-bow, when not upon his shoulders; and a pair of Jeather overalls is drawn over his lower garments. Behind him comes a mule driven by a peon, bearing a huge bundle resembling an enormous feather bed. This is called a vaca, "cow," but no cow's hide would be sufficient to hold it. Besides the usual baggage of a traveler, it contains a mattress, which the pleasure-seeker must carry with him or do without. Women usually, and men not unfrequently, travel by silla. A rude bamboo chair is fastened to the back of a man by two belts-one crossing over the chest and another passing over the forehead. The rider, seated with his back to his bearer, is completely helpless. A story is told, and the scene of it pointed out near Bogotá, where a Spaniard wearing huge spurs mounted his sillero, whom he goaded as though he were a mule. The sillero, by a sudden jerk, pitched his rider sheer down a precipice, then took to the woods and was never caught.

The plateau of Bogotá is, upon the whole, a most uninteresting region. It is most noteworthy on account of its showing how elevation and local circumstances affect the climate of the tropical regions. Lying just north of the equator, in a latitude indeed in which, rather than under the equator, the hottest regions of the earth are found, it reminds one not a little of the interior of Kamchatka and Alaska, which almost touch the Arctic Circle.

If the table-land of Quito is the most lovely, that of Mexico is by extent and variety the most remarkable of the lofty tropical plateaus. Commencing at the Isthmus of Tehuantepec, in latitude $16^{\circ}$, it stretches with varied breadth to the limits of the Tropical Zone. With the exception of a narrow strip along the shores of the oceans, it occupies in Mexico the whole breadth of the continent. It rises almost by steps into broad, well-defined terraces sloping upwards, each presenting the climate and productions of different portions of the Temperate Zone. Its highest level is traversed by mountain ranges, sometimes rising into lofty peaks ; but its general surface is almost as level as the ocean. A road from the city of Mexico northward for more than a thousand miles would run over a dead level, hardly varying from an altitude of 7,500 feet.

There is not upon the globe a great region which nature has more assiduously striven to render a fit habitation for civilized man than the greater part of Mexico. There is no one in which man has so persistently set himself at work to counteract the designs of nature.

Let us, starting from Vera Cruz, make the journey to and across these table-lands. The Gulf bordered by a broad zone of lowlands, called the tierra calienta, or " hot lands," which has the normal hot climate of the tropics. Parched and sandy plains dotted with mimosas and prickly plants alternate with savannas overshadowed by groves of palms, and glowing with the exuberant splendor of equinoctial vegetation. The branches of the stately forest trees are festooned with vines and creepers, whose flowers present the most brilliant hues ; while the thick undergrowth of prickly aloes, matted with the wild rose and honeysuckle, often forms an impenetrable thicket. In this wilderness of sweet-scented buds and flowers flutter clouds of butterflies of 
resplendent hues, and birds of gorgeous plumage. Many of these birds have notes of exquisite melody. But the malaria engendered by the decomposition of the rank vegetation and the dank soil renders the region one of the most insalubrious upon the globe, and almost uninhabitable by man from the vernal to the autumnal equinox. Here is the birthplace of the dreaded vomito, or yellow fever.

Passing this fatal belt, after twenty leagues the traveler finds bimself ascending into a purer atmosphere. The vegetation changes at every league. One by one the vanilla, the indigo plant, the sugar cane, and the plantain disappear; until at the hight of 4,000 feet the unchanging green of the rich foliage of the liquidamber indicates that the traveler has reached the elevation where the clouds and mists settle in their passage from the Gulf, and maintain a perpetual moisture.

Here are the confines of the tierra templada, or temperate region, where the evergreen oaks remind him of the forests of Central Europe. The features of the scenery become imposing. The ascending road sweeps along the base of mighty mountains, now snow-clad, but bearing traces of former volcanic fires. The flanks of the mountains are rent with huge barancas or ravines, down whose steep sides be can look for more than a thousand feet. Cactuses, euphorbia, dracæna, and a multitude of other plants cling to the rocky walls; while at the bottom of the gorge, to which he might apparently almost leap, stand huge laurels and fig-trees. Upward still, he passes fields waving with yellow wheat and broad-leaved maize, with plantations of the agave, from which the Mexicans prepare, as they did in the days of the Montezumas, their national beverage of pulque.

At an elevation of 8,000 feet, the forests of sombre pine announce that the tierra fria, or " cold region," the last of the three great terraces, has been reached. Here in the valley of Anahuac, yet at an elevation of 7,500 feet, rests the city of Mexico, the famous capital of the Montezumas, with its shallow lakes, and surrounded by elliptical plains, enclosed by frowning ridges of basaltic and porphyrite rocks. On the south-eastern side rises the snow-crowned cone of Orizaba, whose ever blazing summit, shining like a star through the darkness of night, gained for it its Aztec name of Citlaltepetl, "the Mountain of the Star ;" farther west rise Popocatepetl, Iztacihuatl, and Toluca, altogether forming a magnificent volcanic circuit, only equaled by that which girdles the valley of Quito. If the traveler chooses to climb the sides of these volcanoes, in a few days' journey he will have passed through every variety of climate and every zone of production, from the fiercest tropical heat to the confines of perpetual winter; from the towering palm to the lichen which hardly lifts its head above the sterile rock.

Sikkim, on the southern side of the Himalayas, may be considered a vast sloping plain, rising in a gradual ascent from the foot of the chain to the base of the peaks, the highest on the globe. From the shores of the Bay of Bengal is a level plain of a hundred miles in breadth to the foot of the Himelayas. Thence the land rises gently 7,000 feet in eighty miles. Here is the British sanitarium of Dorjiling, where the Enropean debilitated by the burning climate of the lowlands may breathe air as cool and refreshing as those of his native land. Eighty miles further brings him 9,000 feet higher to the limits of perpetual snow. Then arise more steeply, 12,000 feet higher, the lofty summits, rather than peaks, of the Himalayas, looking down upon 
the magnificently wooded region below. The highest of these Sikkim peaks is Kin chin-junga - the third, but until recently believed to be the first, in hight upon the globe. It falls but a hundred feet below the Dipsang or Karkakorum peak, and about eight hundred below Gaurisanker, which the British have re-named Mount Everest. Kinchin-junga rises to the altitude of 28,172 feet. Not only is its summit untrodden by man or beast, but nothing that breathes has ever mounted so high into the air. The condor, who in his flight looks down upon the dome of Chimborazo, never mounts to within thousands of feet of the hight of Kinchin-junga.*

* Humboldt's statement that the condor flies higher than Chimborazo (21,420 feet) has been questioned. But Orton has seen numbers of them hovering at least a thousand feet above Pichincha (16,000 feet), and does not doubt that they fly much higher. Müller, in his ascent of Orizaba, saw falcons flying fully 18,000 feet high; and it is affirmed that wild geese fly over the peak of Kunchan-ghow (22,000 feet). There can be little doubt that the condor attains an elevation greater than any other bird, and that no other creature ever voluntarily ascends so high. 


\section{CHAPTER III.}

\section{SAVANNAS AND DESERTS OF THE TROPICAL WORLD.}

Water and Life-Characteristics of the Savannas.-The Llanos: The Dry Season-Effects upon Vegetable Life-Effects upon Animal Life-Approach of the Rainy Season-Revival of Vegetable and Animal Life-Vast Migrations of Animals.-The Pampas: Horses and Cattle in the New World-Effects of their Introduction upon the Character of the Population-The Mauritia Palm-Living in the Tree-tops.-The Grand Chaco-Its Indian Inhabitants-The Guachos-The Lasso and Bolas.-The Plains of Southern Africa: Thorny Bushes-Excessive Droughts-A Great Hunting Ground-Species of Game-VegetationWatery Tubers-Esculent Gourds-Possibility of Wells-Water-Pits in the KalahariMode of Pumping Up the Water-Livingstone's Theory of Water-Making Ants-More Probable Explanation-Inhabitants of Southern Africa-The Lake Region of Equatorial Africa: Little Known-Explorations of Livingstone and Burton-Speke's Journey-His Notices of the Country-Moderate and Equable Temperature-The Inhabitants-Characteristics of a Real Desert.-The Atacama of Peru: Its Arid Character-The Mule the Ship of this Desert.-The Australian Desert: Its Utter Desolation.-Sturt's ExplorationLeichardt-Lost Rivers.-The Sahara: Extent and General Characteristics-The Capital of Fezzan-Perilous Adventure of Barth-Plains and Hills-Oases-Luxuriant Vegetation of the Oases-Contrasts of Light and Shade-The Khamsin or Simoom-Animals and Reptiles-The Ostrich and its Chase-Fluctuations of Animal and Vegetable Life according to the Seasons.

$\mathrm{T}$

HE presence or absence of water in the Tropical World exerts an influence upon all forms of animal and vegetable life not less important than the temperature. Wherever water is absolutely wanting the country is given over to barrenness. Wherever water is perpetual and abundant, the soil is clothed with lofty forests and a profusion of lush vegetation. Midway between these extremes are vast tracts dry at one season and wet at another. These regions, which we may call savannas, embrace the pampas of the Argentine Republic and the llanos of Venezuela and New Granada, and a considerable portion of Southern Africa. They are in general to be characterized as vast plains, never of more than moderate elevation, covered with grass and shrubs ; but, except on the banks of the rivers, destitute of extensive forests, the trees standing singly or in small clumps.

There can be no more striking contrast than that presented at different seasons of the year by the great llanos of Venezuela. When the rainy season is over and the sun for weeks blazes in an unclouded sky, pouring his vertical rays upon the thirsty plains, the calcined grass-plains present the aspect of an interminable, monotonous waste. Like the ocean they stretch out till in the distance hazy and quivering with heat, their boundary blends upon the horizon with the sky in an indistinct line. The water pools which nourished the scattered clumps of the Mauritia palm disappear one by one. The tall, dry reeds which indicate the spot which had been a swamp, bear 
high up their stalks the encrusted mud which marks the hight of ooze and slime of the rainy season. The grass has long since withered, and stands a mass of dry stems, ready at the touch of fire to break out into a conflagration which outstrips the speed of the swiftest horse.

Animal life seems to have become extinct. The deer, the aguti, and the peccary, taught by instinct, have migrated to less arid regions, followed by their natural enemies the Indian, the puma, and the jaguar. The vast herds of wild horses and cattle which roamed over the savanna perish in countless numbers, or rush about bellowing, and neighing, and snuffing the thirsty air, seeking to scent out the neighborhood of some pool where a little moisture has survived the general drought. Buried far down in the stiff clay of the dried-up pools, the alligator and huge water snake lie torpid in a long summer sleep, as the bear slumbers through the dreary Aretic winter.

At length, when all nature seems to have expired or to be expiring for want of water, welcome signs announce the approach of the rainy season. The blue, cloudless sky begins to assume a leaden hue ; the atmosphere becomes obscured by condensing vapors; the stars which shone with a mild planetary lustre now twinkle faintly even in the zenith, while the bright Southern Cross, low down in the horizon, is hardly discernible, and the phosphoric gleam of the Magellanic clouds expires. Banks of vapor rise in mountainous forms on the horizon, increasing in density, and mounting higher and higher, until at length they burst into rains which pour down in torrents. Searcely have the showers had time to moisten the thirsty land, when a change comes over the face of nature. The dull, tawny surface of the savanna is transformed as if by magie into an expanse of vivid green, enameled with flowers of every hue. The mimosas expand their delicate foliage, and the Mauritia palm, " the tree of life," puts forth its feathery fronds.

Animal life awakens from its long torpor. On the borders of the swamps the moistened clay heaves, and slowly bursts asunder, and from the tomb in which he lay embedded, rises the form of some huge alligator or water-snake. The newly formed pools swarm with water-fowl. The herds of horses and oxen rejoice in the thick grasses, under whose covert not unfrequently erouches the jaguar waiting for his prey. On the very same spot where a few weeks before the horse anxiously snuffed the air, half-mad with thirst, he is now obliged to lead an almost amphibious life. The mares retreat with their foals to the higher banks, which rise like islands from a lagoon, and swim about in quest of the grasses which lift their heads above the waters. Not unfrequently they become the prey of alligators that strike them down with their scaly tails, and seize them with their enormous jaws. "This sight," says Humboldt, " involuntarily reminds the reflecting observer of the great pliability with which nature has endowed several species of plants and animals. Along with the fruits of Ceres, the horse and the ox have followed man over the whole earth from the Ganges to the Plata, and from the coast of Africa to the mountain plain of Antisana, overlooking the Valley of Quito. Here, the northern birch-tree, and there the tropical date-palm, protects the tired ox from the heat of the sun. The same species of animal which in eastern Europe contends with bears and wolves, is attacked in another zone by the tiger and the crocodile."

It is scarcely three centuries since the horse and the ox were first introduced into America by the Spaniards. The latter has flourished to such a degree that it is not 
improbable that in the pampas and llanas of South America there are more cattle than in all the rest of the globe. Strain, who rode across the pampas, was told that in a single year ten millions of hides were exported from Buenos Ayres. Knowing that the census of 1840 gave but fifteen millions in the United States, this statement seemed incredible. But when day after day he saw from every slight swell herd after herd, blackening the whole expanse, until they became mere specks in the distance, and re-

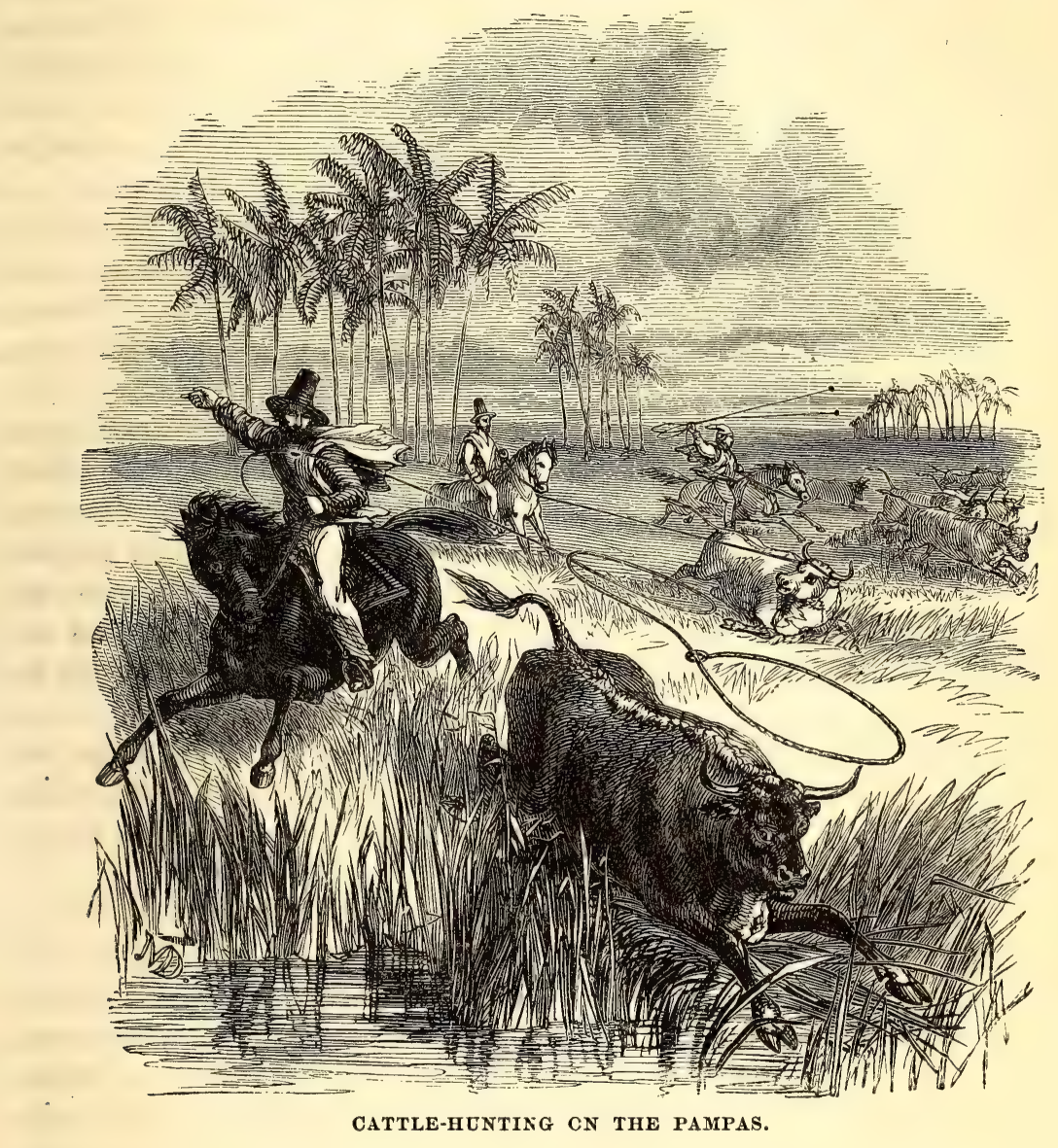

flected that the millions upon millions which he saw were but fractions of those spread for hundreds of thousands of square miles, he could give credit to the statement. The annual slaughter of millions seems to have no sensible effect in diminishing the numbers of the survivors. These herds belong mainly to wealthy estancieros. The extent of some of these estancias and the number of the herds is almost incredible. The estate of San José, belonging to Urquiza, late President of the Argentine Confederation, covered an area of several hundred square miles, and upon it he had 2,000 horses, 40,000 head of cattle, and 70,000 sheep, and this is but one out of his many estates.*

* Page's La Plata, 52, 59. 
The introduction of the horse and the ox has wrought an entire change in the character of the Indians of the great plains of North and South America. When the Spaniards first visited the llanos and pampas they found them almost destitute of inbabitants, for the Indians were wholly unacquainted with agriculture. They could exist only in the spots where grew the Mauritia palm. This tree grows to the hight of a hundred feet, its slender trunk surmounted by a magnificent tuft of great fanshaped fronds, under which grow in large clusters scaly fruit, resembling pine cones. Like the banana they differ in taste according to the stage of ripeness; and the trunk affords a nutritious pith like sago, which when dried forms a large part of the food of the natives. From its sap they prepared an intoxicating drink; its leaves covered their huts; from the fibres of the petiole they manufactured threads and cordage, and the sheaths at their base served for sandals. The Mauritia grew abundantly near the mouth of the Orinoco ; and among its branches the Guaranas dwelt like monkeys, high above the reach of the great inundations. They built platforms, floored with its leaves, from trunk to trunk, a patch of moist clay serving for a fire-place. The early voyagers were by night astonished at the light of their fires, gleaming like beacons up among the dark foliage.

The Grand Chaco, lying along the Paraguay and Parana rivers, is one of the most remarkable of the pampa regions. It covers an area of 200,000 square miles, nearly equal to France, and is nominally partitioned among the neighboring governments; but is really in the possession of hordes of Indians, who acknowledge no allegiance except to their own eaçiques. Neither time nor intercourse with the whites has mitigated their deep feeling of hostility against the whites for the wrongs inflicted upon their race. The horse, the gift of the Spaniards, has put them upon an equality with their enemies, and given them the means of making continual predatory inroads. When pursued by a military force they scatter and are lost in the depths of the forest. They are admirable horsemen, using neither saddle or bridle, but control their animals by a rude rein of raw-hide passing around the lower jaw, and secured by a thong of the same material.

The guachos, or herdsmen, inhabiting the pampas are of Spanish descent, but have relapsed into an almost savage state. The wild life of a guacho begins from infancy. As soon as he can walk he has a little lasso made of twine, with which he amuses himself in catching the chickens and dogs. By the time he is four years old he is put upon horseback, which be soon learns to consider the only place for a man, thinking it degrading to walk for any considerable distance. He early acquires skill in the use of the lasso and bolas. With the former he will capture the wildest bull or stallion, throwing from horseback the noose with unerring aim over the horns, or around a leg of the animal. He is equally dextrous in the use of the bolas. This consists of three balls, about three inches in diameter, joined together in a common center by thongs a yard long. Holding one ball in his hand, the guacho whirls the other around his head, and then flings the whole at his victim. The instant one thong strikes the leg of an animal, all wind themselves around, each by its own independent motion, and the more the victim struggles the more inextricably does be become entangled.

The so-called deserts of Southern Africa, including the great Kalahari, are savannas rather than deserts. This region has of late years been thoroughly described by 
travelers, most of them allured thither in pursuit of game. It may be considered as bounded by the parallels of $20^{\circ}$ and $30^{\circ}$ south of the equator, and from $17^{\circ}$ to $30^{\circ}$

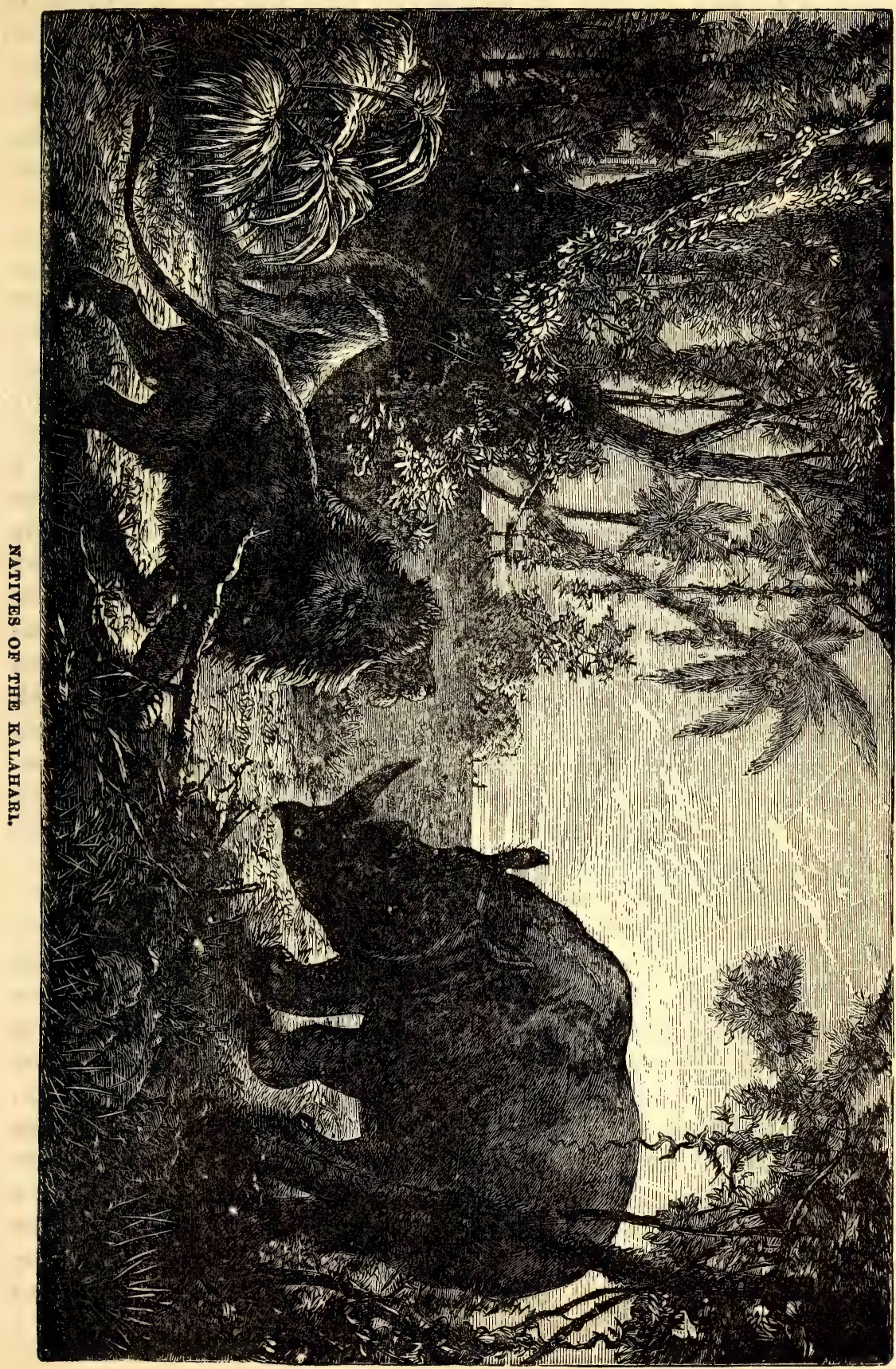

of longitude, covering an area of 1,000 miles by 700. The great Kalahari occupies its center. The physical aspects of so vast a region of course vary. Taking its outside 
rim, it may in general be described as a series of broad plains intercepted by rugged mountains of no great hight. These plains during the wet season ibound with juicy herbage, which disappears, fairly burned off, in the dry season, leaving the ground parched and dusty. Sometimes there are immense tracts overgrown with low, thorny bushes, standing so closely together that the traveler must chop his way through them step by step. The most common of these bushes is called by the colonists the "waita-bit," for its short hook-like thorns present a standing invitation to the passer to wait a bit at every foot of his advance. Andersson mentions once coming upon a considerable forest of thornless trees. "I do not think," he says, "that I was ever so surprised in my life. I hesitated to trust my senses. Even the dull faces of my native attendants seemed for a few seconds to relax from their usual heavy, unintelligent cast, and to express joy at the novel scene." The brief wet season, when the rain falls in torrents, is succeeded by months of absolute drought, when water is found only at long intervals in solitary fountains and stagnant pools. The books of travelers in this region present a continual record of sufferings endured by man and beast from lack of water.

But uninviting as this region otherwise is, it is the paradise of the sportsman. In other regions of the globe he is limited to a few species of the larger game. On our western prairies he is confined to bison; in India he must satisfy himself with tigers and wild hogs; in Ceylon he may bag tuskless elephants and buffalos; in Siberia he has only bears and wolves. But Southern Africa is a vast zoological garden. Giraffes raise their long necks above the stunted acacia trees, stooping to crop their topmost twigs. Gigantic boars, and their still bigger cousins the unwieldy hippopotami and rhinoceroses, abound. Leopards and hyenas find abundant prey in numerous species of antelopes, and in turn afford rich sport to the hunter. Lions are everywhere, from the sneaking brute who crawls stealthily upon his ignoble prey, to the ferocious " maneater," in whom the taste of human flesh has awakened a new faculty which induces him to despise all meaner food, and to leap boldly into the camp of the hunter in search of a human victim. Elephants wander about singly, or in pairs and groups, or troop in vast herds to the lonely pools where they ean quench their thirst. "They walk about as thick as cattle," said a native to Andersson, who had occasion to verify the statement; and Barth once counted two hundred elephants in a single herd on the banks of Lake Tschad. Besides these, there are ostriches, zebras, quaggas, and an almost innumerable variety of the deer tribe, such as oryxes, koodoos, inyalas, gnus, elands, springbocks, gemsbocks, hartebeests, leches, pallabs, and others whose very names have as yet found no place in books of natural history.

Such a superfluity of animal life presupposes no inconsiderable amount of vegetation even in these arid regions; for all animals directly or indirectly subsist upon vegetable food. The lion devours the deer; but he could find no deer to devour unless the deer could find grass and leaves to eat. Nature has also gifted these animals with an instinct which leads them to wander far and wide for food, and to divine where it is likely to be found. In so wide a pasture-ground all parts will not be parched at once; and beasts of prey follow in the tracks of their victims. Moreover, ther are species of plants peculiar to these regions which go far to modify the apparent sterility, and store up food and even water beneath what appears to be dry sand. Such a plant is the leroshúa, whose low stalk is hardly larger than a crow's quill; but it sends its 
roots deep down into the soil, which, at the depth of a foot or two, expand into a tuber of the size of a small melon, which is a mass of watery cellular tissue, like a young turnip. The mokuri, a low creeper, expands under ground into a cluster of tubers, some of them as large as a man's head. The clusters spread out in a circle of a yard in diameter. When a native suspects the existence of such a cluster, he pounds with stones around until a hollow sound tells him that he has found the spot. Many of the animals have sharp hoofs, and instinct points out to them the sites of these watery tubers, to reach which they dig away the sand, as the reindeer digs the snow which conceals the moss which is his food. The kengwe, a kind of gourd, a favorite with man and beast, sometimes covers immense tracts. Macabe once crossed the desert, in a favorable season, and found them so numerous that his cattle lived on them for three weeks, during which they had no water, and when this was reached they seemed quite indifferent to it. Another gourd, the naras, covers many of the low sand-hills. Its fruit, the size of a turnip, is on the outside of a greenish yellow, within of a deep orange, and for three months in the year constitutes the chief food of man and beast in the neighborhood of Walfisch Bay. Its seeds, something like an almond in looks and taste, are carefully gathered, dried, and preserved for food when the fruits have disappeared.

Judging from the geological character of this African semi-desert, there can be little doubt that water might be found by deep boring almost everywhere ; for as the rainfall is great during the wet season, and as hardly any of it finds an outlet through rivers, much of it must sink into the sandy soil until it is arrested by beds of clay or underlying rock, and by digging down to these the water would be reached. Wherever and whenever water here exists, there is fertility; and it may be that the time will come when these now arid plains will be honey-combed with artesian wells, and thereby transformed into a garden. When that time comes, farewell to elephants and lions, to deer and antelopes. Wells, or rather pits, of slight depth, but which contain water throughout the year, except when two years of drought happen together, are not unfrequently found in the Kalahari. These pits are hidden with the utmost care. Sometimes the natives fill them up with loose sand, and build a fire over the spot; the ashes would naturally be taken as an indication that here at least no water was to be found beneath the surface. They are careful to establish their huts at a considerable distance from their hidden mine of liquid treasure. When they wish for water, the women set out from the village, carrying their water vessels, which consist of ostrichshells, with a little hole in the end. A reed of nearly a yard in length, with a bunch of grass fastened to the end, is sunk down through the sand, which is then rammed closely around. By sucking through the reed a vacuum is made in the sponge-like bunch of grass ; into this the water flows and passes through the reed into the mouth, whence it is squirted into the shells. This natural pump is really very efficacious for the shallow depth at which it is used.

Livingstone relates another circumstance which seems conclusive as to the fact that water exists in the Kalahari, at no very great distance below the surface of the ground. During two successive seasons of extreme drought, in neither of which the rainfall exceeded five inches, and every thing was parched, and the ground so hot that beetles placed upon the surface died in a few seconds, as though they had been placed on a heated plate of iron, a certain species of ants, who form long and deep galleries, were 
always as active and merry as ever ; and upon opening their chambers the walls were invariably moist. In reply to the question, whence these insects derived their water, Livingstone suggests that they have the power by vital force of combining the oxygen of the air with the hydrogen of their food, and so making water. $\mathrm{He}$ instances, in support of this theory, other insects which he found in Angola, where a colony of in. sects on the branch of a tree would distill several pints of water in a single night; and he satisfied himself, by cutting off the branch, and so stopping the flow of sap, that this water was not derived from the juices of the tree. But in this case the atmosphere was surcharged with moisture; while in the Kalahari it was so dry that the best hygrometric tests at his disposal failed to detect moisture in the air. A needle exposed for months in the open air did not rust ; there was no dew on the ground, and a mixture of sulphuric acid and water parted with all its water to the air, instead of imbibing more from it, as it usually does. We know of no facts to confirm Livingstone's theory of this insect manufacture of water. Our theory is that the ants went down far enough to find water in the soil. Paradoxical as it may seem, the extraordinary heat- $132^{\circ}$ to $134^{\circ}$ at a depth of three inches-and the absolute dryness of the air, would diminish the distance before moisture was reached; for the surface would soon be baked so as to be as hard as sandstone, thus precluding evaporation from any con. siderable depth, by forming a solid crust through which no water could escape. He dug wells deep into the bed of the dried-up river near by, but found no water. We imagine that if he had followed Solomon's injunction to "go to the ant and be wise," and dug down close by one of their habitations, he would have come to moist sand at no great depth; and this moisture would, by natural laws, have flowed into his well.

The human inhabitants of this wide African semi-desert are of very varied character. A large portion of them, Caffres, Bechuanas, and the like, belong to the lowest grade of humanity, perhaps a little above the aborigines of Australia, and some tribes in Borneo, which, could we admit of any connecting link between men and monkeys, we would designate as semi-human. There are other tribes, such as the Balakahari, which rise far higher in the scale of being; and are, we judge, quite susceptible of civilization. They have garden patches which they cultivate with great care, and rear small herds of goats, although they are often in the dry season obliged to dip up for them water absolutely in spoonfuls. They are also keen traders in their small way, bartering the skins of animals for spears, knives, tobacco, and dogs. These tribes merge almost imperceptibly into the Makalaka and Makalolo, whom Livingstone found in the more favorable region to the North, around Lake Ngami.

There is also in Africa another vast region which belongs apparently to the savannas rather than to what we consider the proper tropical regions. For want of a better term we may designate it as the "Lake Region," for in it lie great lakes, inferior only to those of North America, whose very existence was until within a few years unknown to the civilized world. Geographically it is purely equatorial, for it lies within five degrees of the equator on either side; and its elevation is not such as oi itself suffcient to greatly modify its climate; but other circumstances give it an aspect wholly unexpected. In general it may be described as a plateau of 3,000 to 4,000 feet above the ocean, with little outcropping hills of granite, and many fertilizing springs 
in the valleys. This region has been, if we may use the term, only pricked into by travelers. Burton just touched upon its borders, Livingstone, in his second expedition, did the same, and it is here that he has been for five years lost to the civilized world, save for vague and sometimes contradictory accounts that have reached us. If the most recent reports are to be trusted, there is good reason to hope that he will yet return, and then we shall learn something of this as yet almost unknown region. $A_{\text {H }}$ yet Speke and Hanning are the only ones who have brought back any thing like an account of this vast region, and their journey of 1,500 miles, although it occupied nearly thirty months, from Zanzibar on the Indian Ocean to Khartoum, where the two main branches of the Nile unite, at a distance of 1,500 miles from the great river of Egypt, was almost on a single line. Speke died in the belief that he had solved the mystery of the Nile, by the discovery of the origin of its main branch in Lake Victoria N'yanza, hardly a mile from the equator ; but the subsequent explorations of Baker render it almost certain that Speke discovered only one, and that by no means the largest of the sources of the river, which, as far as we know, is the sole outlet of the waters of a region larger than that drained by St. Lawrence.

From all that we now know, this great region is one admirably adapted for the abode of civilized man. Here and there in Speke's Journal occur passages like the following: "The hill-sides and tops are well covered with bush and small trees, among which the bamboo is most conspicuous, while the bottoms, having a soil still richer and deeper, produce fine large fig-trees of exceeding beauty, the huge calabash, and a variety of other trees." Again: "Our day's march bas been novel and very amusing. The hilly country surrounding us brought back to recollection many happy days which I had once spent with the Tartars in the Thibetan Valley of the Indus; only this was more picturesque; for though both countries are wild and thinly inhabited, this was greened over with grass, and dotted here and there on the higher slopes with thick bushes of acacias, the haunts of the rhinoceros, both white and black; while in the flat of the valleys herds of hartebeest and fine cattle roamed about like the kiyang and tame yâk of Thibet." Again : "We descended into the close valley of the Uthenga, bound in by steep hills hanging over us more than a thousand feet high, as prettily clothed as the mountains of Scotland; while in the valley there were not only magnificent trees of extraordinary hight, but also a surprising amount of the richest cultivation, among which the banana may be said to prevail." At Karagué, on Lake N'yanza, 5,100 feet above the level of the ocean, Speke kept a record of the thermometer for six months, from November to April. The lowest point was $65^{\circ}$, in April, the highest $70^{\circ}$, in November, for the mean temperature of a day. The highest absolute point at any hour of the day was $85^{\circ}$. As, strictly speaking, there is no summer and winter at the equator, one six months of the year will be the same as the other; the mean temperature of the whole year is put down at $68^{\circ}$.

Here and there Speke came upon an isolated tribe living in almost pastoral quietness ; but they were under perpetual apprehensions of attacks from their fierce neighbors ; for, as a general rule, the life of these tribes is one of perpetual war. The main object of predatory inroads is to procure slaves. These slaves are bartered from tribe to tribe, the survivors ultimately falling into the hands of the Portuguese slavetraders on the coast. 
From the savannas and semi-deserts of the Tropical World, we now turn to the great deserts themselves, which constitute a striking feature in that portion of the globe which is now under review. A desert, in the strict sense in which we use the term, is an extensive region wherein there is no regular rainfall, and in which, moreover, there exists no other means of irrigation. It is a land doomed to irremediable sterility ; for, as we have again and again pointed out, water is the great requisite to life. We have taken Southern Africa, and even the Kalahari, out of the category of deserts, because during a part of the year rain falls there, and therefore vegetable life, and by consequence, animal life, may exist, and often does exist in great profusion. The Valley of the Nile, including all Egypt, is rainless, and would be a desert, were it not that the lower course of the river, supplied from rainy regions, overflows its banks, and for the rest of the year it is irrigated by waters raised by human labor from the abounding river. Egypt is the " gift of the Nile," and is redeemed from barrenness by being, as described by the great Hebrew lawgiver, a land "watered by the foot."

In America the only great tropical desert is that of Atacama, the "sand-coast of Peru." It is a long, narrow strip of land lying between the parallels of $3 \circ$ and $21^{\circ}$ south latitude, bounded on the west by the Pacific Ocean, and on the east by the Cordilleras. Its length is 1,600 miles, its breadth from 15 to 60 miles. It is traversed by spurs from the mighty mountain range, which sometimes sink into the level of the plain, and sometimes jut out in steep promontories into the ocean. Here and there, at wide intervals, a brook fed from the snowy Andes, makes a brief course across the narrow plain, forming a narrow strip of verdure only sufficient to break the general monotony. The few inhabitants carefully husband the last drop of water from these scanty streams to irrigate their arid fields. Here the mule takes the place of the African camel as the "ship of the desert." The horse can not support thirst for more than forty-eight hours without becoming so weak as to be scarcely able to carry its rider; yet if urged by his master he will stagger on until he falls dead in his tracks. The mule, more obstinate, as we say, but in fact more wise, when he feels himself verging upon the limits of endurance, stops short, and no urgency of whip or spur will force him to move, until he has rested. Yet notwithstanding the great power of endurance of the mules, many of them succumb to the fatigue of the journey, and the roads across the Atacama are marked by their skulls and bones, as the caravan routes across Sahara are whitened by the skeletons of camels.

Perhaps the most absolute desert tract on the face of the globe is that which occupies the interior of the great island, or, as it may not improperly be styled, continent, of Australia. The island has an area of something more than three millions of square miles, nearly equal in extent to Europe. For a great part of its circumference it is bounded by a continuous range of mountains or highlands, nowhere rising to a great hight, and for long distances consisting of plateaus or table-lands. There is, however, a continuous range of water-shed, which is never broken through, and which never recedes to any great distance from the coast. The habitable portions of Australia are limited to the slopes of the mountains and the narrow space between them and the eoast, in all not exceeding a width of three hundred miles. The interior, as far as is known, or as can be inferred from physical geography, is an immense depressed plain, more hopelessly barren and uninhabitable than the great desert of Sahara. 
The interior of this desert has probably never been traversed by the foot of man or beast; and only three or four exploring expeditions have penetrated far into its depths, In 1844 Sturt made his way some four hundred miles beyond the habitable regions, which brought him near the geographical center of the island. This space he found to be occupied by an immense plain covered with ridges of drifting sand, often rising to a hight of eighty or a hundred feet, and stretching away in either direction beyond the range of vision. Here and there grew a few solitary tufts of grass, nourished by infrequent showers. Permanent water there was none, and the sand was heated to such a degree that a match dropped upon it became ignited at once. The thermometer on one occasion rose to $153^{\circ}$ in the coolest place to he found. In the midst of this sterile tract was a desert of still deeper gloom, which was traced for a distance of eighty miles in one direction, and thirty-five in another. Its surface was paved by a solid bed of dark iron-stone, upon which the horses' hoofs rung as upon a metallic floor, without making the slightest indentation. There was not a trace of water or vegetation. Leichardt, a German naturalist, succeeded in penetrating from the settlements on the eastern coast, through the unexplored interior of the island, to its northern side. But his course led him only along the skirts of the great desert; yet even here he was more than once saved from perishing by following the flight of a bird winging its way to some solitary sink or water-hole. In 1846 be set out on a new journey, intending to pass from the east through the desert to the colony on the western shore. This journey was expected to occupy two and a half years. Eighteen months after he set out, a letter was received from him written on the extreme verge of habitation. After that he disappeared, and it was not until years after that it was discovered that he had been murdered by his native guides.

When it was ascertained that no rivers from the interior reached the sea-coast, while considerable streams poured from the hills towards the interior, it was supposed that there must be a great central lake. Sturt followed the Victoria, the most considerable of these rivers, which poured a considerable current into the interior; but the farther be followed it the less became the stream, which at length dwindled into a succession of water-holes, and was finally lost among the barren sands. It is probable that the same is the case with all the streams running into the interior; and that all their water is exhausted by evaporation long before the center of the island is reached.

But the great desert of the Tropical World is the African Sahara, occupying the central portion of the northern half of the continent from the latitude $17^{\circ}$ to that of $29^{\circ}$, although in many parts fruitful districts penetrate its bounds like peninsulas jutting into the sea. No European traveler has followed its southern limits from east to west; and of its interior little is known, except along the caravan routes traced across it for centuries. One scarcely strikes the northern border of the Sahara before he finds himself in a region beset with perils.

The first portion, after leaving Tripoli, following the caravan route, known as the Hamada, is an elevated plateau, six days' journey wide, barren and stony, except here and there where there is a patch of verdure upon which the patient camel browses with delight. Here is found a little bird called the asfir, which lives wholly upon the vermin which it picks from the feet of the camels. Then comes a broad, sandy, treeless plain, crossed by shifting sand-ridges so steep that the traveler is often obliged to 
flatten them down in order to enable his camels to proceed. Upon the verge of this stands Murzuk, the capital of Fezzan, a clay-built town in a sand-pit, shut in on all sides by barren ridges. Near by, in an occasional favored spot, grow a few pomegranates, figs, and peaches. Onions are the principal vegetables, and the only milk to be obtained is a little furnished by goats. Yet the traveler into the desert will look back to it almost as to a paradise.

Barth came near losing his life almost on the edge of the desert. Taking with him only a few dry biscuits and dates, he left his caravan one day alone to ascend a steep hill, the summit of which the natives supposed to be inhabited by demons. The mountain seemed to recede before him as he advanced; but before noon he gained the summit. The fierce desert sun glared down, and the broad, sandy waste lay spread out before him. Looking around, he could discern no trace of the caravan. He dared only sip a few drops of his small stock of water, and could only swallow a morsel of his dry biscuit. He then plunged wildly down the mountain side in the supposed direction of the caravan. Parched with intolerable thirst, he swallowed all his water at a draught; but the relief was only momentary. He grew bewildered, and lost his course. Again and again he fired his pistols, listening eagerly for an answering shot; but the stillness of the desert was unbroken. Day began to decline, and he threw himself in despair upon the hot sand. Once he thought he caught a glimpse of the long line of the caravan, but it was only an illusion of the imagination. There were a few trees around, but he had not strength to light a fire, which might have served as a signal to his friends. He was utterly broken down and exhausted. Darkness fell around, and then he saw far across the plain the light of a fire. It must mark the encampment of his comrades. He fired his pistols, but received no reply. The distance was too great for the sound to traverse. Still the steady fire gleamed, marking the position of the friends whom he might never again behold. The long, sleepless night wore away, and the sun rose hotter and hotter in the east. He had barely strength to move so as to keep his head within the scanty shade of the leafless tree under which he lay. The torments of thirst became unendurable. He bit his arm, and sucked the blood which flowed from the wound. Then he fell into a delirious trance, from which he did not awake till the sun had sunk behind the hills. As he cast a despairing look through the gathering gloom over the pitiless waste, he heard the cry of a camel. No music ever sounded so sweetly. Raising himself a little, he saw, not far off, a man mounted on a camel, looking eagerly around. It was one of his escort, who had come upon his tracks in the sand, and was following upon his trace. Barth cried out feebly for water. The man heard him, and, after bathing his head, gave him a draught. So swollen was his throat that he could hardly swallow. He was then put upon the camel and borne to the caravan. The natives scarcely believed that he could be alive; for they say that no man can live in the desert without water for more than twelve hours. Save with his own blood, Barth had not moistened his parched lips for eight-and-twenty hours.

Until within the last years, the Sahara was supposed to be a low plain, partly situated even below the level of the ocean; but the journeys of Barth, Overweg, and Vogel, have proved it, on the contrary, to be a high table-land, rising 1,000 or 2,000 feet above the sea. Nor is it the uniform sand-plain which former descriptions led one to imagiue; for it is frequently traversed by chains of hills, as desolate and wild 
as the expanse from which they emerge. But the plains also have a different character in various parts : sometimes over a vast extent of country the ground is strewed with blocks of stone or small boulders, no less fatiguing to the traveler than the loose drift sand, which, particularly in its western part (most likely in consequence of the prevailing east winds), covers the dreary waste of the Sahara. Often also the plain is rent by deep chasms, or hollowed into vast basins. In the former, particularly on the northern limits of the desert, the rain descending from the gulleys of the Atlas, sometimes forms streams, which are soon swallowed up by the thirsty sands, or dried by the burning sunbeams.

The deeper basins of the Sahara are frequently of great extent, and sometimes contain valuable deposits of salt. Wherever perennial springs rise from the earth, or wherever it has been possible to collect water in artificial wells, green oases, often many days' journey apart from each other, break the monotony of the desert. They might be compared with the charming islands that stud the vast solitudes of the South Sea ; but they do not appear, like them, as elevations over surrounding plains of sea, but as depressions, where animals and plants find a sufficient supply of water, and a protection, not less necessary, against the terrific blasts of the desert.

A wonderful luxuriance of vegetation characterizes these oases of the wilderness. Under and between the date-palms, that are planted about six paces apart, grow apricot and peach trees, pomegranates and oranges, the henneh, so indispensable to oriental beauty; and even the apple-tree, the pride of European orchards. The vine twines from one date palm to another, and every spot susceptible of culture bears grain, particularly dourrah or barley, and also clover and tobacco. With prudent economy the villages are built on the borders of the oases on the unfruitful soil, so that not a foot of ground susceptible of culture may be lost.

The vast tracts of sterile sand, where not even the smallest plants take root, and which might be called the "desert of the desert," present the greatest conceivable contrast to its green oases. With the vegetable world the animal kingdom likewise disappears, and for days the traveler pursues his journey without meeting with a single quadruped, bird, or insect. Nowhere are the transitions of light and shade more ab. rupt than in the desert, for nowhere is the atmosphere more thoroughly free of all vapors. The sun pours a dazzling light on the ground, so that every object stands forth with wonderful clearness, while all that remains in the shade is sharply defined, and appears like a dark spot in the surrounding glare.

The stillness of these wastes is sometimes awfully interrupted by the loud voice of the khamsin or simoom. The crystal transparency of the sky is veiled with a hazy dim. ness. The wind rises and blows in intermittent gusts, like the laborious breathing of a feverish patient. Gradually the convulsions of the storm grow more violent and frequent; and although the sun is unable to pierce the thick dust-clouds, and the shadow of the traveler is scarcely visible on the ground, yet so suffocating is the heat, that it seems to him as if the fiercest rays of the sun were scorching his brain. The dun atmosphere gradually changes to a leaden blackness; the wind becomes constant; and even the camels stretch themselves upon the ground and turn their backs to the whirling sand-storm. At night the darkness is complete; no light or fire burns in the tents, which are hardly able to resist the gusts of the simoom. Silence reigns throughout the whole caravan, yet no one sleeps ; the bark of the jackal or the bowl of the hyena 
alone sounds dismally from time to time through the loud roaring of the storm. The sultry breath of the desert is felt far beyond its bounds. It blows over Italy, where it is known as the sirocco, and crosses even the Alps, where, under the name of the Fonwind, it rapidly melts the snow of the higher valleys, and causes dangerous inundations. The dust of the desert, whirled high into the air, frequently falls upon the decks of vessels crossing the Atlantic, far from the coast of Africa, and flies in clouds over the Red Sea - a greeting from Nubia to Arabia.

When we consider the scanty vegetation of the Sahara, we can not wonder that animal life is but sparingly scattered over it. The lion, whom our poets so frequently name the "king of the desert," only shows himself on its borders; and on asking the nomades of the interior whether it is ever seen in their parts, they gravely answer that in Europe lions may perhaps feed on shrubs or drink the air, but that in Africa they cannot exist without flesh and water, and therefore avoid the sandy desert. In fact, they never leave the wooded mountains of the Atlas, or the fruitful plains of the Soudan, to wander far away into the Sahara, where snakes and scorpions are the only dangerous animals to be met with. The snakes, which belong to the genus Cerastes, which is distinguished by two small horns upon the head, have a deadly bite, and are remarkable for their almost total abstinence from water. When a caravan, on first entering the desert, meets with one of these venomous reptiles, it is not killed, "for it is of good omen to leave evil behind;" but farther on the snakes are mercilessly destroyed wherever they are seen. Among the animals which inhabit those parts of the desert which are covered with prickly shrubs, we find hares and rabbits, hyenas and jackals, the hedgehog and the porcupine. Several lizards inhabit the desert. among others, a large gray monitor, and a small white skink, with very short legs, called zelgague by the Arabs. Its movements are so rapid that it seems to swim on the sand like a fish in the water, and when one fancies he has caught it, it suddenly dives under the surface. Its traces, however, betray its retreat, and it is easily extracted from its hole, - a trouble which, in spite of the meagre booty, is not consid. ered too great when provisions are scarce.

The ostrich, which is proverbially said to drink only every five days when there is water, and to be able to endure thirst for a much longer period when there is none, and the gazelle, which even the greyhound finds it difficult to catch, venture deeper into the desert. The chase of the gazelle is a favorite amusement of the Saharians. On seeing a herd at a distance they approach as cautiously as possible; and when about a mile distant, they unleash their greyhounds, who dart off with the rapidity of arrows, and are excited, by loud cries, to their utmost speed. Yet they only reach the flying berd after a long chase; and now the scene acquires the interest of a drama. The best greyhound selects the finest gazelle for his prey, which uses all its cunning to avoid its pursuer, springing to the right, to the left, now forwards, then backwards, sometimes even right over the greyhound's head; but all these zigzag evolutions fail to save it from its indefatigable enemy. When seized it utters a piteous scream, the signal of the greyhound's triumph, who kills it with one bite in the neck.

According to the seasons animal life fluctuates in the Sahara from north to south. In winter and spring, when heavy rains, falling on its northern borders, provide wide districts, thoroughly parched by the summer heat, with the water and pasturage needed for the herds, the nomadic tribes wander farther into the desert with their camels, horses, 
sheep, and goats, and retreat again to the coast lands as the sun gains power. At this time of the year the wild animals-the lion, the gazelle, and the antelope-also wander farther to the south, which at that time provides them, each according to its taste, with the nourishment which the dry summer is unable to bestow; while the ostrich, who during the summer ranged farther to the north, then retreats to the south; for hot and sandy plains are the paradise in which this singular bird delights to roam.

In the southern part of the Sahara the tropical rains, whose limits extend to $19^{\circ}$ north latitude, and in some parts still farther to the north, produce similar periodical changes in the character of the desert. Under their influence the sandy plains are soon covered with grasses and shrubs. In the dry season, on the contrary, the green carpet disappears, and the country then changes into an arid waste, covered with stubbles and tufts of mimosas. This beneficial change, however, does not take place every year ; for the tropical rains frequently fail to appear on their northern boundaries, and thus disappoint the hopes of the thirsty desert. 


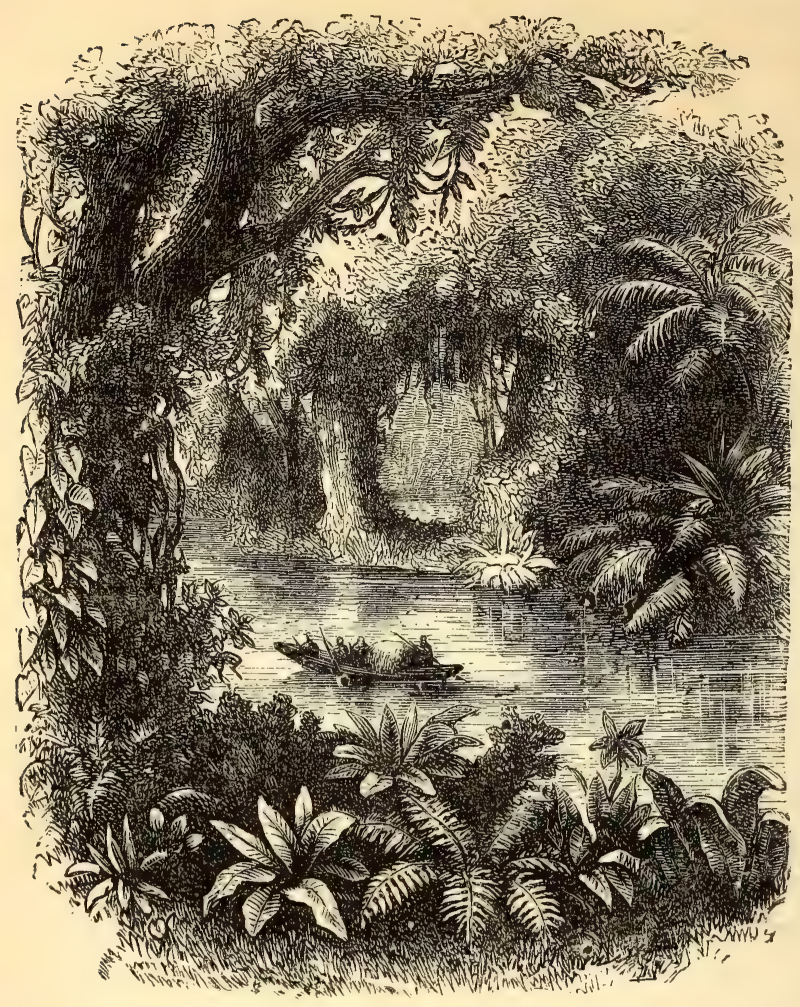

IGARIPE, OR CANOE-PATH ON THE AMAZON.

\section{CHAPTER IV.}

\section{TROPICAL FORESTS.-VALLEY OF THE AMAZON.}

Characteristics of the Tropical Forests-Variety of Trees and Plants-Aspect During the Rainy Season-Beauty After the Rainy Season-A Morning Concert-Repose at NoonAwakening at Evening-Nocturnal Voices of the Forest.-The Amazon: Course of the River-Size of its Basin-The Tide at its Mouth-Rising of the River-Igaripes, or CanoePaths-Inundations of the Amazon-Vast Variety of its Vegetation-Fishes-Agassiz's Specimens-Alligators and Turtles-Turtle-Hunting-Insects-Ants-Butterflies-Spiders -Lizards-Frogs and Toads-Snakes-Paucity of Mammalia-The Jaguar-Scantiness of Human Population-Indian Tribes-Mundurcu Tattooing-Travelers' Accounts of the Tribes-Men with Tails-Orton's Summary of their Character-His Own Experienœe Favorable-He finds them Honest and Peaceable-Agassiz's Notices of the Indians-Their Familiarity with Animals and Plants-Whites-Negroes-Mixed Breeds-Agassiz and Orton on the Capacity of Amazonia.

$\mathrm{H}$

AVING passed in review the lofty plateaus, the broad savannas, and the burning deserts, which form striking though exceptional features of the Tropical World, we proceed to the forests, which constitute the most distinctive feature of the regions which lie bordering the equator. Reserving for a separate chapter some of the most notable trees specially characteristic of the tropics, we propose to 
take a survey of the general aspects of the great forests, and especially of that which covers, with scarcely an interruption, the valley of the Amazon, in whose almost uninhabited depths the whole habitable part of Europe might be hidden away.

The peculiar charms of the tropical primitive forest are enhanced by the mystery of its impenetrable thickets; for however lovely its lofty vaults and ever-changing forms of leaf or blossom may be, fancy paints scenes still more beautiful beyond, where the eye cannot penetrate, and where, as yet, no wanderer has ever strayed. In the boundless forests of tropical America, the jaguar sometimes loses himself in such impenetrable thickets that, unable to hunt upon the ground, he lives for a long time on the trees, a terror to the monkeys. Here the padres of the mission-stations, which are not many miles apart in a direct line, often require more than a day's navigation to visit each other, following the windings of small rivulets in their courses, as the forest renders communication by land impossible. The matted bush-ropes, climbing along the trunks and branches, extend like the rigging of a ship from one tree to another, and blossom at such a giddy hight that it is frequently as impossible to reach these flowers as it is to distinguish to which of the many interlacing stems they may belong. Nor is it possible to drag down one of these inaccessible creepers; for, owing to their strength and toughness, it would be easier to pull down the tree to which it attaches itself than to force the liana from its hold. No botanist ever entered a primitive forest without envying the bird to whom no blossom is inaccessible; who, high above the loftiest trees, looks down upon the sea of verdure, and enjoys prospects whose beauty can hardly be imagined by man.

A majestic uniformity is the character of our woods, which often consist but of one species of tree, while in the tropical forests an immense variety of families strive for existence, and even in a small space one neighbor scarcely ever resembles the other. Within the space of half a mile square, Agassiz counted one hundred and seventeen different kinds of wood, many of them fitted for the finest cabinet work. Even at a distance this difference becomes apparent in the irregular outlines of the forest, as here an airy dome-shaped crown, there a pointed pyramid, rises above the broad flat masses of green, in ever varying succession. On approaching, the differences of color are added to the irregularities of form; for while our forests are deprived of the ornament of flowers, many tropical trees have large blossoms, mixing in thick bunches with the leaves, and often entirely overpowering the verdure of the foliage by their gaudy tints. 'Thus splendid white, yellow, or red colored crowns are mingled with those of darker or more humble hue. At length when, on entering the forest, the single leaves become distinguishable, even the last traces of harmony disappear. Here they are delicately feathered, there lobed; here narrow, there broad; here pointed, there obtuse; here lustrous and fleshy, as if in the full luxuriance of youth, there dark and arid, as if decayed with age. In many the inferior surface is covered with hair; and as the wind plays with the foliage, it appears now silvery, now dark green, now of a lively, now of a melancholy, hue. Thus the foliage exhibits an endless variety of form and color; and where plants of the same species unite in a small group, they are mostly shoots from the roots of an old stem. Where so many thousand forms of equal pretensions vie for the possession of the soil, none is able to expand its crown or extend its branches at full liberty. Hence there is a universal tendency upwards; for it is only by overtopping its neighbors that each tree can hope to attain the region of free- 
dom and of light; and hence also the crowns borne aloft on those high columnar trunks are comparatively small.

In the deep lowlands the forest assumes a severe and gloomy character: dense erowns of foliage form lofty vaults almost impenetrable to the light of day; no underwood thrives on the swampy ground; no parasite puts forth its delicate blossoms where the mighty trees stand in interminable confusion; and only mushrooms sprout abundantly from the humid soil. Nothing ean equal the gloom of these forests during the rainy season. Thick fogs obscure the damp and sultry air, and clouds of mosquitoes whirl about in the mist. The trees drip with moisture; the flowers expand their petals only during the few dry hours of the day, and every animal seeks shelter in the thicket. No bird, no butterfly comes forth; the snorting of the capybaras, and the monotonous croaking of frogs and toads, are the only sounds that break the dull silence; except when the roar of the jaguar, or the howlings of the stentor-monkey, issue like notes of distress from the depth of the melancholy woods.

After the wet season the woods appear in their full beauty. Before the first showers, the long continued drought had withered their leaves, and dried up many of the more tender parasites; during its continuance the torrents of rain despoiled them of all ornament; but when the clouds disperse and the animals come forth from their retreats to stretch their stiffened limbs in the warm sunshine, then also the vegetable world awakens to new life; and where, a few days before, the eye met only with green in every variety of shade, it now revels in the luxuriance of beautiful flowers, which embalm the air with exquisite fragrance. These fairy bowers are enlivened by birds of splendid plumage, particularly in the early morning, when the luscious green of the high palm-fronds or the burning yellow of the lofty leopoldinias, touched by the first rays of the sun, suddenly shines forth. Then hundreds of gaudy parrots fly across the river; numberless colibris dart like winged gems through the air; whole herds of cotingas flutter among the blossoms; ducks of brilliant plumage cackle on the branches of submerged trees; on the highest tree-tops the toucan yelps his loud pia-po-ko! while, peeping from his nest, the oriole endeavors to imitate the sound; and the scarlet ibis flies in troops to the coast, while the white egrette flutters along before the boat, rests, and then again rises for a new career.

In general the morning hours are loudest in the primitive forest; for the animals that delight in daylight, though not more numerous than the nocturnal species, have generally a louder voice. Their full concert, however, does not begin immediately after sunrise; for they are mostly so chilled by the colder night, that they need to be warmed for some time before awakening to the complete use of their faculties. First, single tones ring from the high tree-crown, and gradually thousands of voices join in various modulation,-now approaching, now melting into distance. Pre-eminent in loudness is the roar of the howling monkeys, though without being able fully to stifle the discordant cries and chattering of the noisy parrots. But the sun rapidly ascends towards the zenith, and one musician after the other grows mute and seeks the cool forest shade, until finally the whole morning concert ceases to be heard.

As the heat grows more intense, the stillness of the forest is only interrupted at intervals by single animal voices. The deepest silence reigns at noon, when the sun becomes too powerful even for the children of the torrid zone; and many creatures, 
particularly birds, sink into a profound sleep. Then all the warm-blooded animals seek the shade, and only the cold reptiles,-alligators, lizards, salamanders, - stretch themselves upon the glowing rocks in the bed of the forest-streams, or on sunny slopes, and, with raised head and distended jaws, seem to inhale with delight the sultry air.

As evening approaches, the noise of the morning begins to re-awaken. With loud cries the parrots return from their distant feeding-grounds to the trees on which they are accustomed to rest at night; and, as the monkeys saluted the rising sun, so chattering or howling, they watch him sinking in the west. With twilight a new world of animals, - which, as long as the day lasted, remained concealed in the recesses of the forest,-awakens from its mid-day torpor, and prepares to enjoy its nightly revels. Then bats of hideous size wing their noiseless flight through the wood, chasing the giant hawk-moths and beetles, which have also waited for the evening hour, while the felidæ quit their lairs, ready to spring on the red stag near some solitary pool, or on the unwieldy tapir, who, having slept during the heat of the day, seeks, as soon as evening approaches, the low-banked river, where he loves to wallow in the mud. Then also the shy opossum quits his nest in hollow trees, or under some arch-like vaulted root, to search for insects or fruits, and the cautious agouti sallies from the bush.

In our forests scarcely a single tone is heard after sunset; but in the tropical zone many loud voices celebrate the night, where, for hours after the sun has disappeared, the cicadas, toads, frogs, owls, and goatsuckers chirrup, cry, croak, howl, and wail. The quietest hours are from midnight until about three in the morning. Complete silence, however, occurs only during very short intervals; for there is always some cause or other that prompts some animal to break the stillness. Sometimes the din grows so loud, that one might fancy a legion of evil spirits were celebrating their orgies in the darkness of the forest. Humboldt supposes the first cause of these tumults to be a conflict among animals, which, arising by chance, gradually swells to larger dimensions. The jaguar pursues a horde of pecaris or tapirs which break wildly through the bushes. Terrified by the noise, the monkeys howl, awakening parrots and toucans from their slumber; and thus the din spreads through the wood. A long time passes before the forest returns to its stillness. Towards the approach of day the owls, the goatsuckers, the toads, the frogs, howl, groan, and croak for the last time; and as soon as the first beams of morning purple the sky, the shrill notes of the cicadas mix with their expiring cries.

The valley of the Amazon is the great forest of the globe. This mighty river, rising in the small mountain lake of Lauricocha, only sixty miles from the Pacific, runs clear across the breadth of the continent, almost on the line of the Equator, and ernpties into the Atlantic. Its whole length is $* 2,740$ miles, following its windings, or 2,050 in a straight line. From north to south its tributaries stretch 1,750 miles. At a distance of 2,000 miles above its mouth it has a breadth of a mile and a half, afterwards it spreads to ten miles, then expands until it presents to the Atlantic a front of one hundred and eighty miles. The lake which is the source of the main stream lies just below the limits of perpetual snow. For the first five hundred miles the stream flows through a deep valley, before reaching the level of the great plain.

The region drained by the Amazon dwarfs that of any other river. The Mississippi drains an area of a million and a quarter square miles, the Amazon almost twice as 
much, a space equal to two-thirds of all Europe. Into this basin the United States might be packed without touching its boundaries. It would hold the basins of the Mississippi, the Nile, the Danube, and the Hoang-Ho.

Dangerous sand-banks guard the giant's threshold ; and no less perilous to the navigator is the famous Pororocea, or the rapid rising of the spring-tide at the shallow mouths of the cbief stream and some of its embranchments, - a phenomenon which, though taking place at the mouth of many other rivers, such as the Hooghly, the Indus, the Dordogne, and the Seine, nowhere assumes such dimensions as here, where the colossal wave frequently rises suddenly along the whole width of the stream to a hight of twelve or fifteen feet, and then collapses with a roar so dreadful that it is heard at the distance of more than six miles. Then the advancing flood-wave glides almost imperceptibly over the deeper parts of the river bed, but again rises angrily as soon as a more shallow bottom arrests its triumphant career.

The territory drained by the Amazon is so vast that, at the sources of its northern and southern tributaries, the rainy season takes place at opposite times of the year. So wonderful is the length of the stream that, while at the foot of the Andes it begins to rise early in January, the Solinoens swells only in February; and below the Rio Negro the Amazon does not attain its full hight before the end of March. The swelling of the river is colossal as itself. In the Solimoens and farther westward the water rises above forty feet; and Von Martius even saw trees whose trunks bore marks of the previous inundation fifty feet above the hight of the stream during the dry season. Then for miles and miles the swelling giant inundates his low banks, and, majestic at all times, becomes terrible in his grandeur when rolling his angry torrents through the wilderness. The largest forest-trees tremble under the pressure of the waters, and trunks, uprooted and carried away by the stream, bear witness to its power. Fishes and alligators now swim where a short while ago the jaguar lay in wait for the tapir, and only a few birds, perching on the highest tree-tops, remain to witness the tumult which disturbs the silence of the woods.

Meanwhile the waters stimulate vegetation; numberless blossoms break forth from the luxuriant foliage; and while the turbid waters still play round the trunks of the submerged trees, the gayest flowers enamel their green crowns, and convert the inundated forest into an enchanted garden. When at length the river retires within its usual limits, new islands have been formed in its bed, while others have been swept away; and in many places the banks, undermined by the floods, threaten to crush the passing boat by their fall,-a misfortune which not seldom happens, particularly when high trees come falling headlong down with the banks into the river.

Countless lagunes stretch along the course of the Amazon and its tributaries. These lagunes, called by the natives igaripés, or canoe-paths, are a characteristic feature of the river. One may paddle from Santarem a thousand miles up the Amazon, and never, unless he chooses, enter the river itself. Most of these lagunes communicate with the larger currents by channels, which, however, are generally dried up before the rainy season sets in. The magical beauty of tropical vegetation reveals itself in all its glory to the traveler who steers his boat through the solitudes of these aquatic mazes. Here the forest forms a canopy over his head; there it opens, allowing the sunshine to disclose the secrets of the wilderness; while on either side the eye penetrates through beautiful vistas into the depths of the woods. Sometimes, on a higher 
spot of ground, a clump of trees forms an island worthy of Eden. A chaos of bushropes and creepers flings its garlands of gay flowers over the forest, and fills the air with the sweetest odor. Numerous birds, partly rivaling in beauty of color the passifloras and bignonias of these hanging gardens, animate the banks of the lagune, while gaudy macaws perch on the loftiest trees; and, as if to remind one that death is not banished from this scene of Paradise, a dark-robed vulture screeches through the woods, or an alligator rests, like a black log of wood or a sombre rock, on the tranquil waters. Well he knows that food will not be wanting; for river tortoises and large fish are fond of retiring to these lagunes.

The inundations of the Amazon, which often extend many miles inland, essentially modify the character of the bordering forest; for it it only beyond their verge that the enormous fig and laurel trees appear in all their grandeur. As here the underwood is less dense and more dwarfish, it is easy to measure the colossal trunks, and to admire their proportions, often towering to a hight of 120 feet, and measuring fifteen feet in diameter above the projecting roots. Enormous mushrooms spring from the decayed leaves, and numberless parasites rest upon the trunks and branches. The littoral forest, on the contrary, is of more humble growth. The trunks, branchless in their lower part, clothed with a thinner and a smoother bark, and covered with a coat of mud according to the hight of the previous inundation, stand close together, and form above a mass of interlacing branches. These are the sites of the cacao-tree and of the prickly sarsaparilla, which is here gathered in large quantities for the druggists of Europe. Leafless bush-ropes wind in grotesque festoons among the trees, between whose trunks a dense underwood shoots up, to perish by the next overflowing of the stream. Instead of the larger parasites, mosses and jungermannias weave their carpets over the drooping branches. But few animals besides the numerous water-birds inhabit this damp forest zone, in which, as it is almost superfluous to add, no plantation has been formed by man.

The many windings of the water channels which traverse the littoral woods are so overgrown with bushes, that the boat can only with difficulty be pushed onwards through these retreats, whose silence is only broken by the splashing of a fish or the snorting of a crocodile. The many islands of the delta of the Amazon are everywhere encircled by mangroves; but sailing stream upwards, the monotonous green of these monarchs of the shore is gradually replaced by flowers and foliage, which, in every variety of form and color, for hundreds and hundreds of miles characterize the banks of the river.

During the dry season prickly astricarias, large musaceæ, enormous bamboo-like grasses, white plumed ingas, and scarlet poivreas, are most frequently seen among the numberless plants growing along the bank of the stream, or projecting over its margin; while above the shrubbery of the littoral forest numberless palms tower, like stately columns, to the hight of a hundred feet; others of a lower stature are remarkable for the size of their trunks, on which the foot-stalks of the fallen leaves serve as supports for ferns and other parasites. On the trees which often lie floating on the river, though still attached by their roots to the bank on which they had flourished, petrels or scarlet ibises frequently perch; and as a boat approaches, hideous bats, disturbed in their holes, fly out of the mouldering trunks.

It stands to reason that in a length of more than 3,000 miles the species of plants 
must frequently change; yet the low banks of the Amazon, and of its vassals, as soon as they have emerged from the mountains where they rise, have everywhere a similar character. " No spot on the globe," says Orton, " contains so much vegetable matter as the valley of the Amazon. From the grassy steppes of Venezuela to the treeless pampas of Buenos Ayres expands a sea of verdure, in which we may draw a circle of eleven hundred miles in diameter, which shall include an ever green unbroken forest. There is a most bewildering diversity of grand and beautiful trees; a wild, unconquered race of vegetable giants, draped, festooned, corded, matted, and ribboned with climbing and creeping plants, woody and succulent in endless variety. The exuberance of nature displayed in these million square acres of tangled, impenetrable forest, offers a bar to civilization nearly as great as its sterility in the African deserts. The moment you land, (and it is often difficult to get a footing on the bank,) you are confronted by a wall of vegetation. A macheta is a necessary predecessor, for you must literally cut your way at every step." The mass of the forests on the banks consists of palms, of which there are about thirty species, leguminous or pod-bearing trees, broad-leaved bananas, and giant grasses. Among the trees which might be useful are the palo de sangre and the moria-pinima, or " tortoise-shell tree," the most beautiful ornamental wood in the world. Enough of this is annually wasted to veneer all the palaces of the civilized world.

The great river is a crowded aquarium. Agassiz brought back more than 80,000 specimens of fishes, which are yet to be classified and arranged. Alligators abound beyond all example elsewhere. "It is scarcely exaggerating," remarks Bates, " to say that the waters of the Amazon are as well stocked with large alligators in the dry season as a ditch in England is in summer with tadpoles." Turtles are the most important product at present of the Amazon. The hunting of its eggs is the great business of the inhabitants. They are used chiefly for the purpose of extracting their oil, which is used for illumination. It is calculated that fifty millions of eggs are annually destroyed.

The Amazonian forests are apparently almost bare of animal life. But this barrenness is more apparent than real; for so wide is the field that myriads exist, but they are widely scattered and very shy. Insects are rare in the dense forests, being mostly confined to the open country along the banks of the rivers and lagoons. The most numerous family is that of ants. Termites abound. Their special duty is to hasten the decomposition of decaying vegetation; but they work their way into houses and trunks. They have a special fondness for paper; so that, according to Humboldt, "it is rare to find papers in tropical America older than fifty years." Butterflies swarm in numbers and gorgeousness of coloring elsewhere unknown. Within half an hour's walk from Pará 700 species have been collected, while all Europe furnishes but 390 species, and the British islands only 66 . Of spiders there are 8,000 species, more than three times as many as exist in England. The largest of these, the Mygale Blondii, is five inches long. Lizards are met everywhere, in houses, roads, and forests. They run with such speed that it is almost impossible to catch them. Frogs and toads are the chief musicians of the Amazonian forest. They are of all sizes, from an inch to a foot in diameter. This latter size is attained by a toad of a dull gray color, studded all over with enormous warts, who has a good right to his name, Bufo gigas. Of snakes there is no lack. There are in South America 150 species, half as many as are 
found in the East Indies. The serpentine family is led by the enormous boa, while the rear is brought up by the Amphisbænas, or "double-headers," who crawl one end foremost as well as the other, so that it is no easy matter to make head or tail of them. The greater part of the South American species are not venomous.

Amazonia is remarkably poor in terrestrial mammals, and the species are of small size. The elephants and rhinoceroses of the Old World are represented by a single species of the tapir, and this is rare and shy. The lion tribe finds its only representative in the puma. The jaguar, representing the tiger and leopard, is the fiercest and most powerful beast of prey of the New World. He is marked something like the leopard; but his spots are angular instead of rounded, and have a central dot. In size it exceeds the leopard. Humboldt, indeed, saw a jaguar whose length surpassed that of any of the tigers of India whose skins he had seen in the collections of Europe. There are but three species of deer, all small. A peccari, a wild dog, opossums, anteaters, armadilloes, capybaras, pacas, agoutis, and monkeys, conclude the list of Amazonia. Monkeys are the most numerous, about forty species inhabiting the valley.

Man makes an insignificant figure in the vast solitudes of the Amazon. There is but one human being to every four square miles. Put them down at equal distances apart, and each one would be two miles from his nearest neighbor. From what we know and can infer, there is no part of the globe in itself capable of supporting a more dense population. It is safe to say that a third of the present population of the globe could find food in these now almost unpeopled wastes. The most zealous disciple of Malthus may dismiss his fears that the world will, within any reasonable number of centuries, become so over-peopled that population will outrun means of sustenance.

There are said to be several hundred Indian tribes in Amazonia, each having a different language unintelligible to all others. The most numerous are the Mundaraucus, who number about 10,000. They are far from being savages, are friendly to the whites, and are industrious, making considerable journeys to sell sarsaparilla, India rubber, and tonqua beans. They are noted for the elaborate manner in which they are tattooed. Agassiz figures two of these Indians who came from a long distance. The woman had the upper part of the face clear,-except that a black line was drawn across the nose and from the outer corner of the eyes to the ears, presenting precisely the appearance of a pair of spectacles. The chin was tattooed in a pattern of net. work. The upper part of the breast was wrought in open work, headed by two straight lines around the shoulders, as if to represent a lace finish. The man was far more fully ornamented. The whole face was tattooed in bluish black, looking like a fine wire mask, the jaws and chin having a broad pattern. The neck, breast, and arms were wrought all over in a broad pattern with belts, lozenges, and squares, looking very like the netted shirts sometimes worn by laborers with us. To make a full suit of tattoo costs more time than to produce any other article of dress worn by human beings-a Cashmere shawl or the feathered cloak of a Polynesian noble not excepted. Ten full years are required, for so painful is the operation that only a bit can be made at a time; but when once made the garment lasts a life-time.

Of the character of the numerous tribes little is positively known. The few notices of travelers are vague, often contradictory, and not seldom wholly incredible. Thus Castlennau gravely assures us that on the banks of the Teffe "dwell the Canamas and Uginas; the former dwarfs, the latter having tails a palm and a half long-a hybrid 
from an Indian and a monkey." Orton sums up their general characteristics as follows: "Skin of a brown color, with a yellowish tinge, often nearly of the tint of mahogany ; thick, straight, black hair ; black, horizontal eyes; low forehead, somewhat compensated by its breadth ; beardless ; of middle hight, but thick-set; broad, muscular chest; small hands and feet; incurious, unambitious, impassive, undemonstrative; with a dull imagination and little superstition; with no definite idea of a Supreme Being, few tribes having a nıme for God, though one for the Demon; with no belief in a future state; and, excepting civility, with virtues all negative. Yet a little while," he says, " and the race will become as extinct as the Dodo. He has not the supple organization of the European, enabling him to accommodate himself to diverse conditions." And yet in the very same paragraph he says: "The South American Indian seems to have a natural aptitude for the arts of civilized life not found in the red man of our continent." He makes brief mention of thirty or more of the tribes. Some are described as cannibals. Others are mentioned in quite different terms. Thus the Mauhes are "an agricultural tribe, well-formed, and of a mild disposition." The Uaupés "have permanent abodes in the shape of a parallelogram, with a semicircle at each end of a size to contain several families. One of them was 115 feet long by 75 broad, and about 30 feet high. The walls are bulletproof." The Passés and Jurís are "peaceable and industrious, and have always been friendly to the whites." The Tucúnas are " an extensive tribe, leading a settled agricultural life, each horde having a chief and a 'medicine-man,' or priest of their superstitions." The Cucamas are "shrewd hard-working canoe-men, notorious for the singular desire for acquiring property." And so on.

Mr. Orton's personal acquaintance with the Indians was rather limited; yet his brief notices of them give a favorable idea of their character. For a month and a half parties of them served him as peons and boatmen. The first party, consisting of twenty, undertook to carry his luggage a distance of thirteen days' journey through the dense forest. "Not a transportation company in the United States," he says, " ever kept its engagement more faithfully than did these twenty peons, and this too though we paid them in advance, according to the custom of the country." His canoe-men "were always in good humor, and during the whole voyage of a month we did not see the slightest approach to a quarrel. At no time did we have the least fear of treachery or violence. When it rained they invariably took off their ponchos; but in all our intercourse with these wild men we never noticed the slightest breach of modesty. They strictly maintained a decent arrangement of such apparel as they possessed."

The almost incidental notices given by Agassiz in his "Journey in Brazil " certainly place the Indians of the Amazon in a light far more favorable both for character and intelligence than that in which they are usually represented. That the men are disinclined to labor is true ; but this they share with men all over the globe. "The women are said, on the contrary, to be very industrious; and those whom we have had an opportunity of seeing justify this reputation. The wife of Laudigari is always busy at some household work or other,-grating mandioca, drying farinha, packing tobacco, cooking, or sweeping. Her children are active and obedient, the older ones making themselves useful in bringing water, washing mandioca, or in taking care of the younger ones. She can hardly be called pretty, but she has a pleasant smile and a remarkably sweet voice, with a kind of childlike intonation which is very winning." 
Of another pair he says : "Our host and hostess do what they can to make us comfortable, and the children as well as the parents show that natural courtesy which has struck us so much among these Indians. My books and writing seem to interest them much, and while I was reading the father and mother came up, and after watching me for a few minutes in silence the father asked me if I had any leaves from an old book, or even a part of a newspaper to leave with him when I went away. He said he had once known how to read a little, and he seemed to think if he had something to practice upon he might recover the lost art. Then he added that one of his boys was very bright, and he was sure that he could learn if he had the means of sending him to school." Again of a still different group : "The familiarity of these children of the forest with the natural objects about them-plants, birds, insects, fishes, etc.-is remarkable. They frequently ask to see the drawings, and on turning over a pile containing several hundred colored sketches of fishes, they scarcely make a mistake, even the children giving the name instantly." And again: "A large number of the trees forming these forests are still unknown to science; and yet the Indians, those practical botanists and zoölogists, are well acquainted not only with their external appearance, but also with their various properties. So intimate is their practical knowledge of the natural objects about them, that I believe it would greatly contribute to the progress of science if a systematic record were made of all the information thus scattered through the land; and an encyclopæedia of the woods, as it were, taken down from the tribes which inhabit them. I think it would be no bad way of collecting to go from settlement to settlement, sending the Indians out to gather all the plants they know, to dry and label them with the names applied to them in the locality, and writing out under the heads of these names all that may thus be ascertained of their medicinal and otherwise useful properties, as well as their botanical character." These notices certainly go far to throw discredit upon the sweeping descriptions given by other travelers of the savage character of the natives of Amazonia.

The other inhabitants of the Amazon are Whites, Negroes, and Mixed Breeds. Excepting a few English, French, German, and Portuguese emigrants, who come to the country temporarily and with a purpose to return home when they have acquired a fortune, few of the so-called Whites are of pure Caucasian descent, the emigration having for many years been almost wholly of the male sex. Indeed it is considered in rather bad taste to boast of purity of descent. All travelers speak in warm terms of the courtesy of the Brazilians; and although they are generally inclined to indolence, yet of late years especially not a few of them have shown no inconsiderable energy and enterprise. Certainly the Empire of Brazil is by far the most promising of all the South American nations. It is the only one which is not in an almost chronic revolutionary condition.

In the valley of the Amazon negroes are confined to the lower portion; yet they have imparted a decided tinge to the character of the population. The mixed races comprise a very considerable part of the inhabitants. Fully five-and-twenty different classes of these are enumerated, each with its own distinctive name. Mamelucos, or White and Indian, are the most common; Mulattoes, are White and Negro ; Cafuzos or Zambos are Indian and Negro; Curibocos are Cafuzo and Indian; Xibaros are Cafuzo and Negro ; and so on through different degrees of intermixture. Von Tschudi gives the following summation of the character of the mixed races: "As a general rule 
it may be said that they unite in themselves all the faults without any of the virtues of their progenitors. As men they are generally inferior to the pure races, and as members of society they are the worst class of citizens." Orton quotes this, but makes decided qualifications to the generalization. "They display," he says, " considerable talent and enterprise; a proof that mental degeneracy does not necessarily result from the mixture of white with Indian blood. Our observations do not support the opinion that the result of amalgamation is ' a vague compound lacking character and expression.' The moral part is perhaps deteriorated ; but in tact and enterprise they often exceed their progenitors." We have already, in Chapter II., quoted his statement that in Quito, where he had the best opportunity of becoming acquainted with them, "They are the soldiers, artisans, and tradesmen who keep up the only signs of life in Quito."

Agassiz thus sums up some of the leading capacities of the basin of the Amazon : "Its woods alone have an almost priceless value. Nowhere in the world is there finer timber either for solid construction or for works of ornament. The rivers which flow past these magnificent forests seem meant to serve first as a water-power for the sawmills which ought to be established on their borders, and then as a means of transportation for material so provided. Yet all the lumber used is brought from Maine. Setting aside the woods as timber, what shall I say of the mass of fruits, resins, oils, coloring matter, textile fabrics which they yield? What surprised me most was to find that a great part of this region was favorable to the raising of cattle. An empire might esteem itself rich in any one of the sources of industry which abound in this valley; and yet the greater part of its vast growth rots on the ground, and goes to form a little more river-mud, or to stain the waters on the shores of which its manifold products die and decompose. Although the rivers abound in delicious fish, large use is made of salt cod imported from other countries; and bread and butter are brought from the United States and England."

Orton says of the Valley of the Amazon: "It possesses the most agreeable and enjoyable climate in the world, with a brilliant atmosphere only equaled by that of Quito, and with no changes of seasons. Life may be maintained with as little labor as in the Garden of Eden. Perhaps no country in the world is capable of yielding so large a return for agriculture. Nature, evidently designing this land as the home of a great nation, has heaped up her bounties of every description : fruits of richest flavors, woods of the finest grain, dyes of gayest colors, drugs of rarest virtues, and left no sirocco or earthquake to disturb its people."

\footnotetext{
*Note.-The length of the Amazon is very variously given by different authors, according as they consider one or another of the great rivers which unite to furm it, to be the main stream; for it happens that the longer ones are not the larger. Thus from Lake Lauricocha to Pará, the distance including windings is estimated at 2,740 miles; but if we consider the Ucayali as the main aftluent, the distance is about 3,000 miles. Lieutenant Herndon, considering the still longer but smaller Huallaga to be the true Amazon, estimates the total length at 3,944 miles, which others reduce to about 3,795 miles. The statement in the text is the one which, on the whole, seems to be the most accurate.

APRIL, 1874.
} 


\section{CHAPTER V.}

\section{CHARACTERISTIC FORMS OF TROPICAL VEGETATION.}

General Features of Tropical Forests-Number of Species of Plants-The Baobab-Its Gigantic Size-Age of the Great Trees-Dragon-Trees-The Great Dragon-Tree of OrotavaThe Sycamore-The Banyan-The Sacred Bo-Tree-The Oldest Historical Tree-The Teak-The Satin-wood-The Sandal Tree-The Ceiba-The Mahogany Tree-The Mora -The Guadua-Bamboos-The Aloe-The Agave-The Cactus-The Screw PineMimosas-Lianas-Climbing Trees-Epiphytes-Water Plants-Buttressed Trees-'Trees with Fantastic Roots-Mangroves-Marsh Forests-Palms-The Cocoa Palm-The Sago Palm-The Saguer Palm-The Areca Palm-The Palmyra Palm-The Talipot PalmRatans-The Date Palm-Oil Palms-Variety of Size, Form, Foliage and Fruit-Future Commercial Value of the Palm.

$\mathrm{W}^{\mathrm{H}}$

HEREVER in the tropical regions periodical rains saturate the earth, vegetable life expands in a wonderful variety of forms. In the higher latitudes of the frozen north, a rapidly evanescent summer produces but few and rare flowers in sheltered situaiions, soon again to disappear under the winter's snow ; in the temperate zones, the number, beauty and variety of plants increase with the warmth of a genial sky; but it is only where the vertical rays of an equatorial sun awaken and foster life on humid grounds that ever-youthful Flora appears in the full exuberance of her creative power. It is only there we find the majestic palms, the elegant mimosas, the large-leafed bananas, and so many other beautiful forms of vegetation alien to more cold and variable climes. While our trees are but sparingly clad with scanty lichens and mosses, they are there covered with stately bromelias and wondrous orchids. Sweetsmelling vanillas and passifloras wind round the giants of the forest, and large flowers break forth from their rough bark, or even from their very roots.

"The tropical trees," says Humboldt, " are endowed with richer juices, ornamented with a fresher green, and decked with larger and more lustrous leaves than those of the more northerly regions. Social plants, which render European vegetation so monotonous, are but rarely found within the tropics. Trees, nearly twice as high as our oaks, there glow with blossoms large and magnificent as those of our lilies. On the shady banks of the Magdalena river, in South America, grows a climbing Aristolochia, whose flower, of a circumference of four feet, the children, while playing, sometimes wear as a helmet; and in the Indian Archipelago the blossom of the Rafflesia measures three feet in diameter, and weighs more than fourteen pounds."

The number of known plants is estimated at about 200,000, and the greater part of this vast multitude of species belongs to the torrid zone. But if we consider how very imperfectly these sunny regions have as yet been explored,-that in South America 
enormous forest lands and river basins have never yet been visited by a naturalist,that the vegetation of the greater part of Central Africa is still completely hidden in

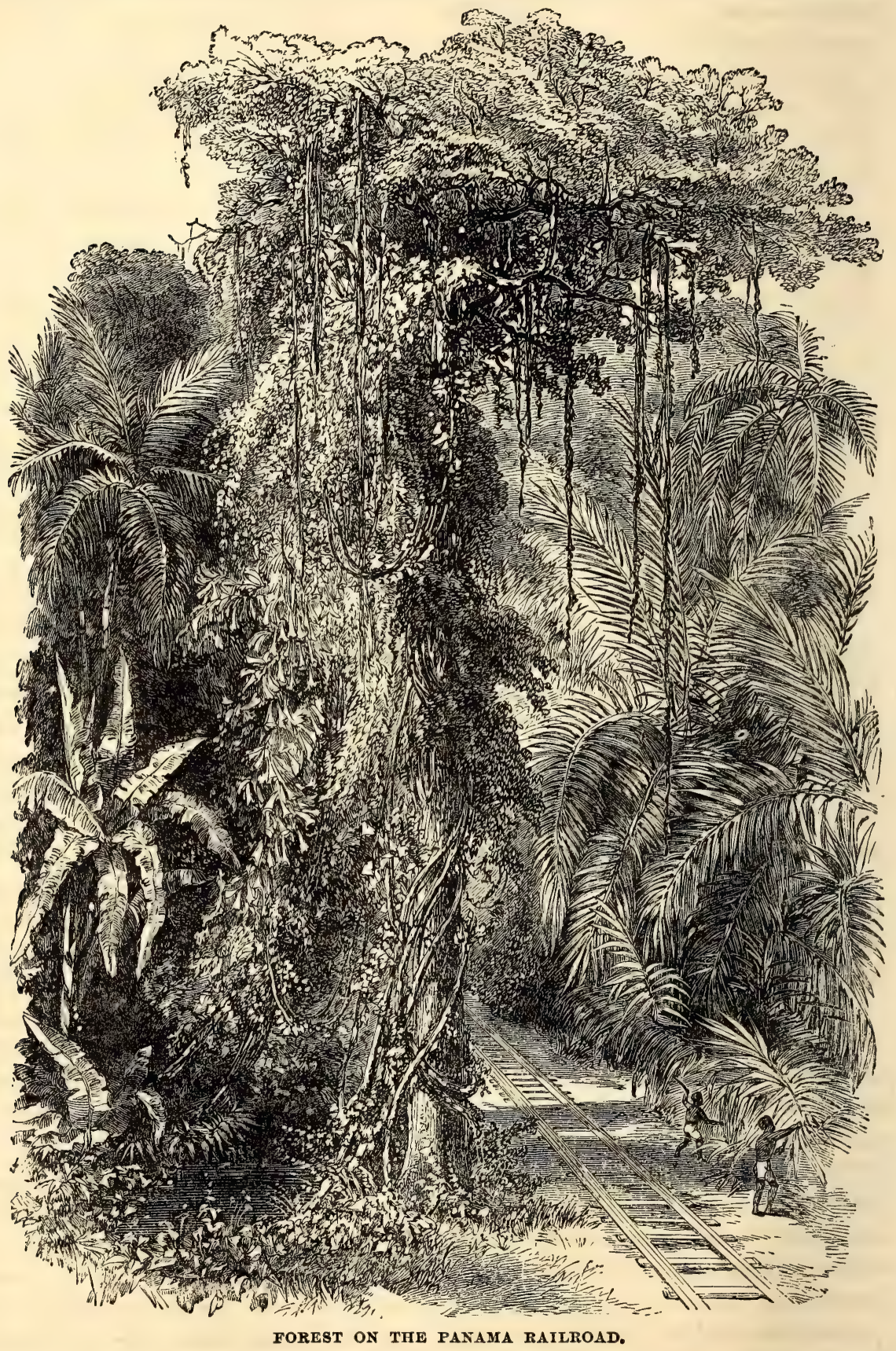

mystery, - that no botanist has ever yet penetrated into the interior of Madagascar, Borneo, New Guinea, South-western China, and Ultra-Gangetic India,-and that, 
moreover, many of the countries visited by travelers have been but very superficially and hastily examined,-we may well doubt whether even one-fourth part of the tropical plants is actually known to science. What a vast field for future naturalists! What prospects for the trade and industry of future generations!

After these general remarks on the variety and exuberance of tropical vegetation, I shall now briefly review those plants which, by their enormous size, their singularity of form, or their frequency in the landscape, chiefly characterize the various regions of the torrid zone in different parts of the globe.

The African Baobab, or "monkey-bread tree," (Adansonia digitata,) may justly be called the elephant of the vegetable world. Near the village Gumer, in Fassokl, Russegger saw a baobab thirty feet in diameter and ninety-five in circumference; the horizontally outstretched branches were so large that the negroes could comfortably sleep upon them. The Venetian traveler Cadamosto (1454) found, near the mouths of the Senegal, baobabs measuring more than a hundred feet in circumference. As these vegetable giants are generally hollow, they are frequently made use of as dwellings or stables. Livingstone mentions one in which twenty or thirty men could lie down and sleep, as in a hut. As the baobab begins to decay in the part where the trunk divides into the larger branches, and the process of destruction thence continues downwards, the hollow space fills, during the rainy season, with water, which keeps a long time, from its being protected against the rays of the sun. The baobab thus forms a vegetuble cistern.

The hight of the baobab does not correspond to its bulk, as it seldom exceeds sixty feet. As it is of very rapid growth, it acquires a diameter of three or four feet and its full altitude in about thirty years, and then continues to grow in circumference. The larger beam-like branches, almost as thick at their extremity as at their origin, are abruptly rounded, and then send forth smaller branches, with large, light green, pal. mated leaves. The bark is smooth and greyish. The oval fruits, which are of the size of large cucumbers, and brownish yellow when ripe, hang from long twisted spongy stalks, and contain a white farinaceous substance, of an agreeable acidulated taste, enveloping the dark brown seeds. They are a favorite food of the monkeys, whence the tree has derived one of its names. From the depth of the incrustations formed on the marks which the Portuguese navigators of the fifteenth century used to cut in the large baobabs which they found growing on the African coast, and by comparing the relative dimensions of several trunks of a known age, Adanson concluded that a baobab of thirty feet in diameter must have lived at least 5,000 years; but a more careful investigation of the rapid growth of the spongy wood has reduced the age of the giant tree to more moderate limits, and proved that, even in comparative youth, it attains the hoary aspect of extreme senility.

The baobab belongs to the same family as the mallow or the hollyhock. It ranges over a wide extent of Africa, particularly in parts where the summer rains fall in abundance, as in Senegambia, in Soudan, and in Nubia. Livingstone admired its colossal proportions on the banks of the Zouga and the Zambesi; under a great baobab near this river lie the remains of his wife, who bore him company during his journeyings; and William Peters found it on the eastern coast, near $26^{\circ}$ south latitude. It forms a conspicuous feature in the landscape at Manaar in Ceylon. Tennent found one of the largest, measuring upwards of thirty feet in circumference, 
and another at Putten, since destroyed by the digging of a well under part of its roots, which, though but seventy feet high, was forty-six feet in girth.

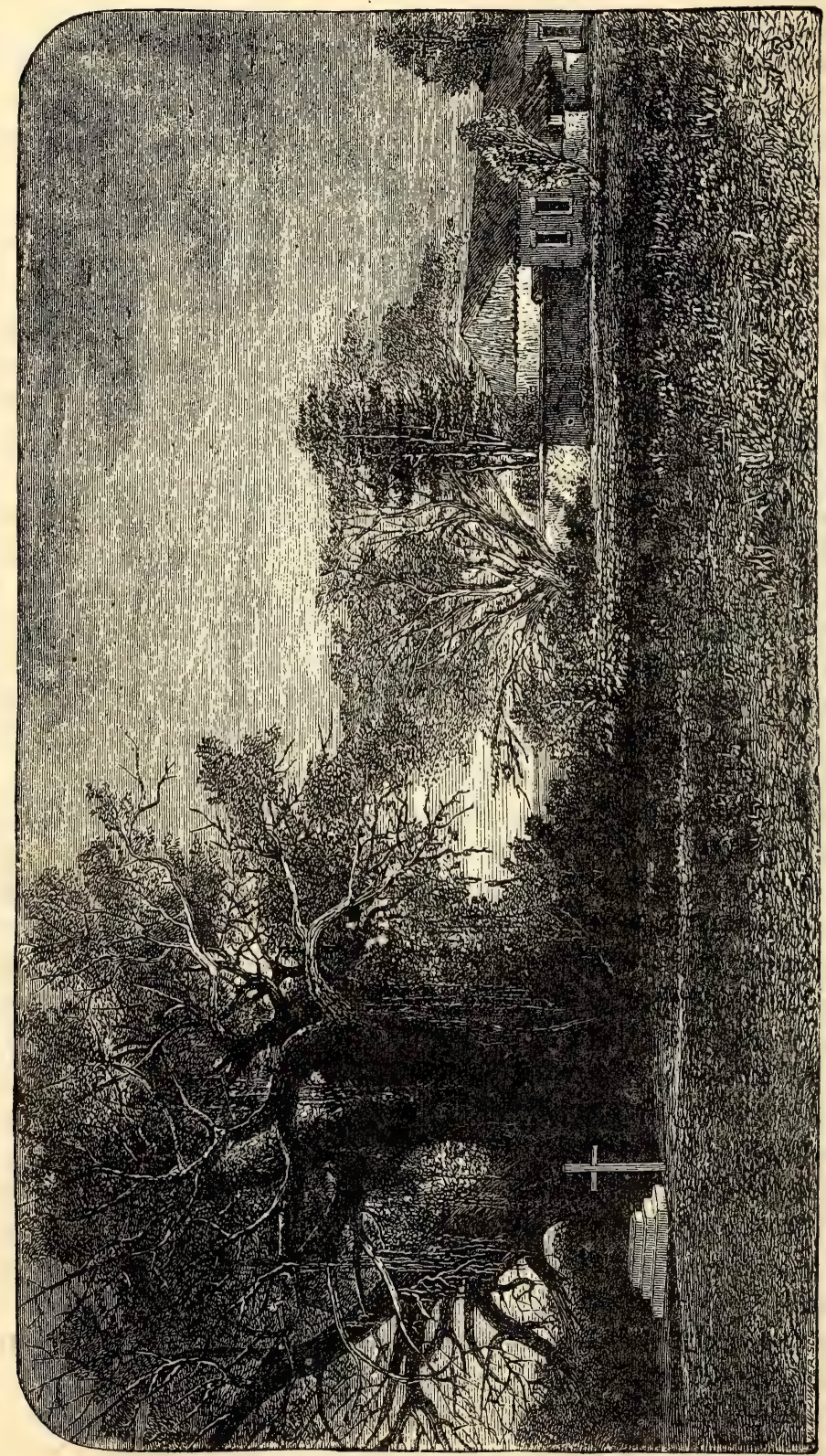

窟

Draccenas, or "dragon-trees," are found growing on the west coast of Africa and in the Cape Colony, in Bourbon and in China ; but it is only in the Canary Islands, in Madeira, and Porto Santo, that they attain such gigantic dimensions as to entitle them to rank among the vegetable wonders of the world. Near Orotava, in Tene- 
riffe, still flourishes the venerable dragon-tree, which was already reverenced for its age by the extirpated nation of the Guanches, the aboriginal inhabitants of the island, and which the adventurous Bethencourts, the conquerors of the Canaries, found hardly less colossal and cavernous in 1402 than Humboldt, who visited it in 1799. Above the roots, the illustrous traveler measured a circumference of forty-five feet; and according to Sir George Staunton, the trunk has still a diameter of four yards, at an elevation of ten feet above the ground. The whole hight of the tree is not much above sixty-five feet. The trunk divides into numerous upright branches, terminating in tufts of evergreen leaves, resembling those of the pine-apple.

Next to the baobab and the dracæna, the Sycamore (Ficus sycomorus) holds a conspicuous rank among the giant trees of Africa. It attains a hight of only forty or fifty feet, but in the course of many centuries its trunk swells to a colossal size, and its vast crown covers a large space of ground with an impenetrable shade. Its leaves are about four inches long and as many broad, and its figs have an excellent flavor. In Egypt it is almost the only grove-forming tree; and most of the mummy coffins are made of its incorruptible wood.

No baobab rears its monstrous trunk on the banks of the Ganges; no dragon-tree of patriarchal age here reminds the wanderer of eenturies long past ; but the beautiful and stately Banyan (Ficus indica) gives him but little reason to regret their absence. Each tree is in itself a grove, and some of them are of an astonishing size, as they are continually increasing, and, contrary to most other animal and vegetable productions, seem to be exempted from decay; for every branch from the main body throws out its own roots, at first in small tender fibers, several yards from the ground, which contin. ually grow thicker, until, by a gradual descent, they reach its surface, where, striking in, they increase to a large trunk and become a parent-tree, throwing out new branches from the top. These in time suspend their roots, and, receiving nourishment from the earth, swell into trunks and send forth other branches, thus continuing in a state of progression so long as the first parent of them all supplies her sustenance. The Hindoos are peculiarly fond of this tree ; they consider its long duration, its outstretching arms and overshadowing beneficence, as emblems of the Deity ; they plant it near their temples; and in those villages where there is no structure for public worship they place an image under a banyan, and there perform a morning and evening sacrifice.

Many of these beautiful trees have acquired an historic celebrity; and the famous "Cubbeer-burr," on the banks of the Nerbuddah, thus called by the Hindoos in memory of a favorite saint, is supposed to be the same as that described by Nearchus, the admiral of Alexander the Great, as being able to shelter an army under its far-spreading shade. High floods have at various times swept away a considerable part of this extraordinary tree, but what still remains is near 2,000 feet in circumference, measured round the principal stems; the overhanging branches not yet struck down cover a much larger space; and under it grow a number of custard-apple and other fruit trees. The large trunks of this single colossus amount to a greater number than the days of the year, and the smaller ones exceed 3,000, each constantly sending forth branches and hanging roots, to form other trunks and become the parents of a future progeny. In the march of an army it has been known to shelter 7,000 men. Such is the banyan - more wonderful, and infinitely more beautiful and majestic, than all the temples and palaces which the pride of the Moguls has ever reared! 
The nearly related Pippul of India, or Bo-tree (Ficus religiosa), which differs from the banyan by sending down no roots from its branches, is reverenced by the Buddhists as the sacred plant, under whose shade Gotama, the founder of their religion, reclined when he underwent his divine transfiguration. Its heart-shaped leaves, which like those of the aspen, appear in the profoundest calm to be ever in motion, are supposed to tremble in recollection of the mysterious scene of which they were the witnesses. The sacred Pippul at Anarajapoora, the fallen capital of the ancient kings of Ceylon, is probably the oldest historical tree in the world; as it was planted 288 years before Christ, and hence is now 2,150 years old. The enormous age of the baobabs of Senegal, and of the wondrous sequoias of California, can only be conjectured; but the antiquity of the Bo-tree is matter of record, as its preservation has been an object of solicitude to successive dynasties; and the story of its fortunes has been preserved in a series of continuous chronicles amongst the most authentic that have been handed down by mankind. The olives in the garden of Gethsemane were full-grown when the Saracens were expelled from Jerusalem, and the cypress of Somma in Lombardy is said to have been a tree in the time of Julius Cæsar. Yet the Bo-tree is older than the oldest of these by a century, and would almost seem to verify the prophecy pronounced when it was planted, that it would "flourish and be green forever." The degree of sanctity with which this extraordinary tree has been invested in the imagination of the Buddhists, may be compared to the feeling of veneration with which Christians would regard the attested wood of the cross. At the present day the aspect of the tree suggests the idea of extreme antiquity : the branches which have rambled at their will far beyond the outline of its inclosure, the rude pillars of masonry that have been carried out to support them, the retaining walls which shore up the parent stem, the time-worn steps by which the place is approached, and the grotesque carvings that decorate the stone-work and friezes, all impart the conviction that the tree which they encompass has been watched over with abiding solicitude, and regarded with an excess of veneration that could never attach to an object of dubious authenticity.

Although far inferior to these wonders of the vegetable world in amplitude of growth, yet the Teak tree, or Indian oak (Tectona grandis), far surpasses them in value, as the ship-worm in the water, and the termite on land, equally refrain from attacking its closegrained strongly-scented wood; and no timber equals it for ship-building purposes. It grows wild over a great part of British India ; in the mountainous districts along the Malabar coast, in Guzerat, the valley of the Nerbuddah, in Tenasserim and Pegu. In Java also the teak forests, both those of natural growth and those that have been planted by the Dutch, are carefully administered. This tree, which requires a century to attain its full diameter of four feet, loses its leaves in the dry season, when the grass and undergrowth of shrubbery is burnt, as the heat which is developed does the trees no injury. The ashes afford an excellent manure, and the fire makes crevices and rents in the soil, through which the fertilizing rain can afterwards more easily penetrate to the roots. In Java the teak tree attains only a hight of eighty feet, inferior to its loftier Hindostanic stature.

Among the numerous timber-trees of Ceylon, the Satinwood (Chloroxylon Swietenia) is by far the first, in point of size and durability. All the forests around Batticaloa and Trincomalee, and as far north as Jaffna, are thickly set with this valuable tree, under whose ample shade the traveler rides for days together. It grows to the 
hight of a hundred feet, with a rugged, gray bark, small, white flowers, and polished leaves, with a somewhat unpleasant odor. Owing to the difficulty of carrying its heavy beams, the natives cut it only near the banks of the rivers, down which it is floated to the coast, whence large quantities are exported to every part of the colony. The richly colored and feathery pieces are used for cabinet-work, and the more ordinary logs for building purposes, every house in the eastern province being floored and timbered with satin-wood.

The Sandal-tree, which furnishes the sweet-scented, fine-grained wood, so bighly prized by the Chinese, and so much used in small cabinets, escritoires, and similar articles, because no insect can exist within its influence, also deserves to be noticed as one of the most valuable productions of the Malabar coast. It chiefly grows on rocky hills, and, if permitted, would attain a tolerable size, but, from its great value, is generally cut down at an early stage. On low land and a richer soil it degenerates, and is in all respects less esteemed. A variety of the same tree, but furnishing a wood of inferior quality, grows on many of the South Sea Islands; but in many parts the excessive avidity of the traders has almost caused its total extirpation. The sandal is a beautiful tree; the branches regular and tapering; the leaf like that of the willow, but shorter and delicately soft. The blossoms hang in bunches of small flowers, either red or white, according to the color of the wood.

On turning our attention to America we find that Nature, delighting in infinite varieties of development, and disdaining a servile copy of what she had elsewhere formed, covers the earth with new and no less remarkable forms of vegetation. Thus, while in Africa the baobab attracts the traveler's attention by its colossal size and peculiarity of growth, the gigantic Ceiba (Bombax ceiba), belonging to the same family of plants, raises his astonishment in the forests of Yucatan. Like the baobab, this noble tree rises only to a moderate hight of sixty feet, but its trunk swells to such dimensions that fifteen men are hardly able to span it, while a thousand may easily screen themselves under its canopy from the scorching sun. The leaves fall off in January; and then at the end of every branch bunches of large, glossy, purple-red flowers make their appearance, affording, as one may well imagine, a magnificent sight. In Guiana the savages take refuge upon the ceiba trees during the inundations. The seeds have an agreeable taste, and are frequently eaten, as well as the young and mucilaginous leaves.

In British Honduras, in the neighborhood of Balize, and along the Motagua river, the Mahogany tree (Swietenia mahagoni) is found scattered in the forests, attracting the woodman's attention from a distance by its light-colored foliage. Such are its dimensions, and such is the value of peculiarly fine specimens, that in October, 1823, a tree was felled which weighed more than seven tons, and cost, when landed at Liverpool, above $£ 375$; here it was sold for $£ 525$, and the expense of sawing amounted to $£ 750$ more ; so that the wood of this single tree, before passing into the hands of the cabinet-maker, was worth as much as a moderately sized farm. The African mahogany wood is furnished by the near related Khaya senegalensis, which likewise towers to the hight of a hundred feet, and has been transplanted to the Antilles.

"Heedless and bankrupt in all curiosity must he be," says Waterton, "who can journey through the forests of Guiana without stopping to take a view of the towering Mora. Its topmost branch, when naked with age, or dried by accident, is the favorite resort of the toucan. Many a time has this singular bird felt the shot faintly strike 
him from the gun of the fowler beneath, and owed his life to the distance betwixt them. The wild fig tree, as large as a common English apple tree, often rears itself from one of the thick branches at the top of the mora; and when its fruit is ripe, to it the birds resort for nourishment. It was to an indigested seed passing through the body of this bird, which had perched on the mora, that the fig tree first owed its elevated station there. The sap of the mora raised it into full bearing; but now, in its turn, it is doomed to contribute a portion of its own sap and juices towards the growth of different species of vines, the seeds of which also the birds deposited on its branches. These soon vegetate and bear fruit in great quantities; so what with their usurpation of the resources of the fig tree, and the fig tree of the mora, the mora, unable to support a charge which Nature never intended it should, languishes and dies under its burden; and then the fig tree and its usurping progeny of vines, receiving no more succor from their late foster-parent, droop and perish in their turn." Our stateliest oaks would look like pigmies near this "chieftain of the forests," who raises his dark green cupola over all the neighboring trees, and deceives the traveler, who fancies that a verdant hill is rising before him. Its wood is much firmer than that of the fir.

The graceful tapering form of the Graminea, or grasses, belongs to every zone; but it is only in the warmer regions of the globe that we find the colossal Bambusacea, rivaling in grandeur the loftiest trees of the primeval forest. Such is the rapidity of their growth, that in the Royal Botanical Garden of Edinburgh, a bamboo was observed to increase six inches a day in a temperature of from $65^{\circ}$ to $70^{\circ}$. The Bambusa gigantea of Burmah has been known to grow eighteen inches in twenty-four hours; and as the Bambusa Tulda in Bengal attains its full hight of seventy feet in a single month, its average increase can not be less than an inch per hour. In New Grenada and Ecuador the Guadua, one of these giant grasses, ranks next to the sugar-cane and maize as the plant most indispensable to man. It forms dense jungles, not only in the lower regions of the country, but in the valleys of the Andes, 5,000 feet above the level of the sea. The culms attain a thickness of six inches, the single joints are twenty inches long, and the leaves are of indescribable beauty. A whole. hut can be built and thatched with the guadua, while the single joints are extensively used as water vessels and drinking cups.

India, South China, and the Eastern Archipelago are the seats of the real bamboos, which grow in a variety of genera and species, as well on the banks of lakes and rivers in low marshy grounds, as in the nore elevated mountainous regions. They chiefly form the impenetrable jungles, the seat of the tiger and the python. Sometimes a hundred culms spring from a single root, not seldom as thick as a man, and towering to a hight of eighty or a hundred feet. Fancy the grace of our meadow grasses, united with the lordly growth of the Italian poplar, and you will have a faint idea of the beauty of a clump of bamboos.

The variety of purposes to which these colossal reeds can be applied almost rivals the multifarious uses of the cocoa-nut palm itself. Splitting the culm in its whole length into very thin pieces, the industrious Chinese then twist them together into strong ropes, for tracking their vessels on their numerous rivers and canals. The sails of their junks, as well as their cables and rigging, are made of bamboo; and in the southern province of Sechuen, not only nearly every house is built solely of this 
strong cane, but almost every article of furniture which it contains-mats, screens, chairs, tables, bedsteads, bedding-is of the same material. From the young shoots they also fabricate their fine writing paper. In Mysore and Orizza the seeds of several species are eaten with honey; and in Sikkim the grain of the Praong, a small bamboo, is boiled, or made into cakes, or into beer. In Java, the prickly bamboo, whose wood is of such flinty hardness that sparks are emitted on its being struck with an axe, and whose formidable thorns project from every node, is used to form impenetrable hedges.

The Aloes form the strongest contrast to the airy lightness of the grasses, by the stately repose and strength of their thick, fleshy, and inflexible leaves. They generally stand solitary in the parched plains, and impart a peculiarly austere or melancholy character to the landscape. The real aloes are chiefly African, but the American yuccas and agaves have a similar physiognomical character. The Agave Americana, the usual ornament of our hot-houses, bears on a short and massive stem a tuft of fleshy leaves, sometimes no less than ten feet long, fifteen inches wide, and eight inches thick. After many years a flower stalk twenty feet high shoots forth in a few weeks from the heart of the plant, expanding like a rich candelabrum, and clustered with several thousands of greenish yellow aromatic flowers. But a rapid decline succeeds this brilliant efflorescence, for it is soon followed by the death of the exhausted plant.

In Mexico, where the agave is indigenous, and whence it has found its way to Spain and Italy, it is reckoned one of the most valuable productions of Nature. At the time when the flower-stalk is beginning to sprout, the heart of the plant is cut out, and the juice, which otherwise would have nourished the blossom, collects in the hollow. About three pounds exude daily, during a period of two or three months. Thus a single agave, or maguey, gives about a hundred and fifty bottles. But the use of the agave is not confined to the production of a vinous liquor, as the tough fibres of its leaves furnish an excellent material for the strongest ropes, or the formation of coarse cloth. Long before the conquest of the country by Cortez, the aborigines applied the agave to a great variety of purposes. From it they made their paper (pieces of which of various thickness are still found covered with curious hieroglyphic writing), their threads, their needles (from its sbarp points), and many articles of clothing and cordage.

The Pandanus odoratissimus, or Sweet smelling Screw-pine, whose fruits, when perfectly mature, resemble large richly-colored pine-apples, plays an important part in the household economy of the coral-islanders of the South Sea. The inhabitants of the Mulgrave Archipelago, where the cocoa-nut is rare, live almost exclusively on the juicy pulp, and the pleasant kernels of the fruit. The dried leaves serve to thatch their cottages, or are made use of as a material for mats and raiment. The wood is hard and durable. They string together the beautiful red and yellow colored nuts for ornaments, and wear the flowers as garlands. When the tree is in full blossom, the air around is impregnated with delicious aromas.

The grotesque forms of the Cactuses possess the stiff rigidity of the aloes. Their fleshy stems, covered with a gray-green coriaceous rind, generally exhibit bunches of bair and thorns instead of leaves. The angular columns of the Cerei, or torch cactuses, rise to the hight of sixty feet,-generally branchless, sometimes strangely ramified, as candelabras, while others creep like ropes upon the ground, or hang, snake- 
like, from the trees, on which they are parasitically rooted. The Opuntias are unsymmetrically constructed of thick, flat joints springing one from the other, while the melon shaped Echinocacti and Mammillariæ, longitudinally ribbed or covered with warts, remain attached to the soil. The dimensions of these monstrous plants are exceedingly variable. One of the Mexican echinocacti ( $E$. Visnaga) measures four feet in hight, three in diameter, and weighs about two hundred pounds; while the dwarf-cactus ( $E$. nana) is so small that, loosely rooted in the sand, it frequently remains sticking between the toes of the dogs that pass over it. The splendid purple flowers of the cactuses form a strange contrast to the deformity of their stems, and the spectator stands astonished at the glowing life that springs forth from so unpromising a stock. These strange compounds of ugliness and beauty are in many respects useful to man. The pulp of the melocacti, which remains juicy during the driest season of the year, is one of the vegetable sources of the wilderness, and refreshes the traveler after he has carefully removed the thorns. Almost all of them bear an agreeable acid fruit, which, under the name of the Indian fig, is consumed in large quantities in the West Indies and Mexico. The light and incorruptible wood is admirably adapted for the construction of oars and many other implements. The farmer fences his garden with the prickly opuatias; but the services which they render, as the plants on which the valuable cochineal insect feeds and multiplies, are far more important.

The cactuses prefer the most arid situation, naked plains, or slopes, where they are fully exposed to the burning rays of the sun, and impart a peculiar physiognomy to a great part of tropical America. None of the plants belonging to this family existed in the Old World previously to the discovery of America; but some species have since then rapidly spread over the warmer regions of our hemisphere. The Nopal (Cactus opuntia) skirts the Mediterranean along with the American agave, and from the coasts has even penetrated far into the interior of Africa, everywhere maintaining its ground, and conspicuously figuring among the primitive vegetation of the land. Although chiefly tropical, the cactuses have a perpendicular range, which but few other families enjoy. From the low sand-coasts of Peru and Bolivia they ascend through vales and ravines to the highest ridges of the Andes.

What a contrast between these deformities and the delicately feathered Mimosas, unrivaled among the loveliest children of Flora in the matchless elegance of their foliage! Our acacias give but a faint idea of the beauty which these plants attain under the fostering rays of a tropical sun. In most species the branches extend horizontally, or umbrella-shaped, somewhat like those of the Italian pine, and the deepblue sky shining through the light green foliage, whose delicacy rivals the finest embroidery, has an extremely picturesque effect. Fndowed with a wonderful sensibility, many of the mimosas seem, as it were, to have outstepped the bounds of vegetable life, and to rival in acuteness of feeling the coral polyps and the sea-anemones of the submarine gardens. The Porliera hygrometrica foretells serene or rainy weather by the opening or closing of its leaves. Large tracts of country in Brazil are almost entirely covered with sensitive plants. The tramp of a horse sets the nearest ones in motion, and, as if by magic, the contraction of the small gray-green leaflets spreads in quivering circles over the field, making one almost believe, with Darwin and Dutrochet, that plants have feeling

Among the most remarkable forms of tropical vegetation, the creeping plants, bush- 
ropes, or Lianas, that contribute so largely to the impenetrability of the forests, hold a conspicuous rank. Often three or four bushropes, like strands in a cable, join tree to tree, and branch to branch; others, descending from on high, take root as soon as their extremity touches the ground, and appear like shrouds and stays supporting the mainmast of a line-of-battle ship; while others send out parallel, oblique, horizontal, and perpendicular shoots in all directions. Frequently trees above a hundred feet high, uprooted by the storm, are stopped in their fall by these amazing cables of Nature, and are thus enabled to send forth vigorous shoots, though far from their perpendicular, with their trunks inclined to every degree from the meridian to the horizon. Their heads remain firmly supported by the bushropes; many of their roots soon refix themselves in the earth, and frequently a strong shoot will sprout out perpendicularly from near the root of the reclined trunk, and in time become a stately tree. No less pliable than tough, the lianas of the western hemisphere are used by the Brazilians as cordage to fasten the rafters of their houses, in the same manner as the equally flexible ratans are employed throughout the East Indian world.

The enormous Climbing Trees, that stifle the life of the mightiest giants of the forest, offer a still more wonderful spectacle. At first, these emblems of ingratitude grow straight upwards like any feeble shrub, but as soon as they have found a support in other trees, they begin to extend over their surface; for, while the stems of other plants generally assume a cylindrical form, these climbers have the peculiarity of divesting themselves of their rind when brought into contact with an extraneous body, and of spreading over it, until they at length enclose it in a tubular mass. When, during this process, the powers of the original root are weakened, the trunk sends forth new props to restore the equilibrium; and thus this tough and hardy race continually acquires fresh strength for the ruin of its neighbors.

Several species of the fig-trees are peculiarly remarkable for this distinctive property, and from the facility with which their seeds take root where there is a sufficiency of moisture to permit of germination, are formidable assailants of ancient monuments. Sir Emerson Tennent mentions one which had fixed itself on the walls of a ruined edifice at Polanarrua, and formed one of the most remarkable objects of the place, its roots streaming downwards over the walls as if their wood had once been fluid, and following every sinuosity of the building and terraces till they reached the earth.

On the borders of the Rio Guama, the celebrated botanist, Von Martius, saw whole groups of Macauba palms encased by fig-trees that formed thick tubes round the shafts of the palms, whose noble crowns rose high above them; and a similar spectacle occurs in India and Ceylon, when the Tamils look with increased veneration on their sacred pippul thus united in marriage with the palmyra. After the incarcerated trunk has been stifled and destroyed, the grotesque form of the parasite, tubular, cork-serew like, or otherwise fantastically contorted, and frequently admitting the light through interstices like loopholes in a turret, continues to maintain an independent existence among the straight-stemmed trees of the forest,-the image of an eccentric genius in the midst of a group of steady citizens.

Like the mosses and lichens of our woods, Epiphytes of endless variety and almost inconceivable size and luxuriance (ferns, bromelias, tillandsias, orchids, and pothos) cover in the tropical zone the trunks and branches of the forest trees, forming hanging gardens, far more splendid than those of ancient Babylon. While the Orchids are 
distinguished by the eccentric forms and splendid coloring of their flowers, sometimes resembling winged insects or birds, the Pothos family attracts attention by the beauty of their large, thick-veined, generally arrow-shaped, digitated, or elongated leaves, and form a beautiful contrast to the stiff bromelias or the hairy tillandsias that conjointly adorn the knotty stems and branches of the ancient trees.

In size of leaf, the Pothos family is surpassed by the large tropical water plants, the Nymphras and Nelumbias, among which the Victoria regia, discovered in 1837 by Robert Schomburgk in the river Berbice, enjoys the greatest celebrity. The round, light-green leaves of this queen of water-plants measure no less than six feet in diameter, and are surrounded by an elevated rim several inches high, and exhibiting the pale carmine-red of the under surface. The odorous white blossoms, deepening into roseate hues, are composed of several hundred petals; and, measuring no less than fourteen inches in diameter, rival the colossal proportions of the leaves.

The trunk of several tropical trees offers the remarkable peculiarity of bulging out in the middle like a barrel. In the Brazilian forests, the Pao Barrigudo arrests the attention of every traveler by its odd ventricose shape, nearly half as broad in the centre as long, and gradually tapering towards the bottom and the top, whence spring a few thin and scanty branches.

In other trees which, struggling upwards to air and light, attain a prodigious altitude, or from their enormous girth and the colossal expansion of their branches require steadying from beneath, we find buttresses projecting like rays from all sides of the trunk. They are frequently from six to twelve inches thick, and project from five to fifteen feet, and, as they ascend, gradually sink into the bole and disappear at the hight of from ten to twenty feet from the ground. By the firm resistance which they offer below, the trees are effectually protected from the leverage of the crown, by which they would otherwise be uprooted. Some of these buttresses are so smooth and flat as almost to resemble sawn planks; as, for instance, in the Bumbax ceiba, one of the most remarkable examples of this wonderful device of Nature.

In other cases we find the roots fantastically spreading and reveling in a variety of grotesque shapes, such as we nowhere find in the less exuberant vegetation of Europe. Thus, in the india rubber tree (Ficus elastica), masses of the roots appear above ground, extending on all sides from the base, and writhing over the surface in serpen. tine undslations, so that the Indian villagers give it the name of the snake-tree. Sir Emerson Tennent mentions an avenue of these trees leading to the botanical garden of Peradenia, in Ceylon, the roots of which meet from either side of the road, and have so covered the surface, as to form a wooden frame work, the interstices of whieh retain the materials that form the roadway. These tangled roots sometimes trail to such an extent, that they have been found upwards of 140 feet in length, whilst the tree itself was not thirty feet high.

The thorns and spines with which many European plants are armed, give but a faint idea of the size which these defensive weapons attain in the tropical zone. The cactuses, the acacias, and many of the palm trees, bristle with sharp-pointed shafts, affording ample protection against the attacks of hungry animals, and might appropriately be called vegetable hedge-hogs, or porcupines. The Toddalia aculeata, a climbing plant, very common in the hill jungles of Ceylon, is thickly studded with knobs, about half an inch high, and from the extremity of each a thorn protrudes, as large 
and sharp as the bill of a sparrow-hawk. The black twigs of the buffalo-thorn (Acacia latronum), a low shrub, abounding in northern Ceylon, are beset at every joint by a pair of thorns set opposite each other, like the horns of an ox, as sharp as a needle, from two to three inches in length, and thicker at the base than the stem they grow on; and the Acacia tomentosa, another member of the same numerous genus, has thorns so large as to be called the jungle-nail by Europeans, and the elephant-thorn by the natives. In some of these thorny plants, the spines grow, not singly, but in branching clusters, each point presenting a spike as sharp as a lancet; and where these shrubs abound, they render the forest absolutely impassable, even to animals of the greatest size and strength. The formidable thorny plants of the torrid zone, which are often made use of by man to protect his fields and plantations against wild beasts and robbers, have sometimes even been made to serve as a bulwark against hostile invasions. Thus Sir Emerson Tennent informs us, that during the existence of the Kandyan kingdom, before its conquest by the British, the frontier forests were so thickened and defended by dense plantations of thorny plants, as to form a natural fortification impregnable to the feeble tribes on the other side; and at each pass which led to the level country, movable gates, formed of the same thorny beams, were suspended as an ample security against the incursions of the naked and timid lowlanders.

In the tropical zone, wherever the reflux of the tide exposes a broad belt of alluvial soil, the shores of the sea, particularly along the estuaries of rivers or in the shallow lagoons, are generally found fringed with a dense vegetation of Mangroves. For no plants are more admirably adapted for securing a footing on the unstable brink of the ocean,-none are better formed to lead an amphibious life. The growth of these saltwater loving trees is equally peculiar and picturesque. The seeds germinate on the branches, and, increasing to a considerable length, finally fall down into the mud, where they stick, with their sharp point buried, and soon take root. The fruits of many plants are furnished with wings, that the winds may carry them far away and propagate them from land to land; others, enveloped in hard, water-proof shells, float on the surface of the sea, and are wafted by the currents to distant coasts; but here we have a plant, the seeds of which were destined to remain fixed on an uncertain soil, close to the parent-plant, and surely this end could not have been attained in a more beautiful manner! As the young mangrove grows upwards, pendulous roots issue from the trunk and low branches, and ultimately strike into the muddy ground, where they increase to the thickness of a man's leg; so that the whole has the appearance of a complicated series of loops and arches, from five to ten feet high, supporting the body of the tree like so many artificial stakes. Their influence in promoting the growth of land is very great, and in course of time they advance over the shallow borders of the ocean. Their matted roots stem the flow of the waters, and, retaining the earthy particles that sink to the bottom between them, gradually raise the level of the soil. As the new formation progresses, thousands of seeds begin to germinate upon its muddy foundation, thousands of cables descend, still farther to consolidato it; and thus foot by foot, year after year, the mangroves extend their empire and encroach upon the maritime domains.

A whole world of interesting discoveries would here, no doubt, reward the naturalist's attention; but the mangroves know well how to guard their secrets, and to repel the curiosity of man. Should he attempt to invade their domains, clouds of blood- 
thirsty insects would instantly make him repent of his temerity; for the plague of the mosquitoes is nowhere more dreadful than in these thickets. And supposing his scientific zeal intense enough to bid defiance to the torture of their stings, and to scorn the attacks of every other visible foe-insect or serpent, crocodile or beast of preythat may be lurking among the mangroves, yet the reflection may well bid him pause, that poisonous vapours, pregnant with cholera or yellow fever, are constantly rising from that muddy soil. Even in the temperate regions of Europe the emanations from marshy grounds are pregnant with disease, but the malaria ascending from the sultry morasses of the torrid zone is absolutely deadly. Thus there cannot possibly be a hetter natural bulwark for a land than to be belted with mangroves; and if Borneo, Madagascar, Celebes, and many other tropical islands and coasts, have to the present day remained free from the European yoke, they are principally indebted for their independence to the miasms and tangles of a mangrove girdle, bidding defiance alike to the sharp edge of the axe or the destructive agency of fire.

Next to the mangroves, the Bruguieras, the Avicennias, the Sonneratias, and various species of palms, such as the Nipa fruticans and the Phœnix paludosa, a dwarf datetree, which literally covers the islands of the Sunderbunds, at the delta of the Ganges, form conspicuous features in the marsh-forests of the torrid zone. The magnificent Avicennia tomentosa, which, with a more majestic growth than the rhizophora, raises its crown to the hight of seventy feet, and is said to flourish throughout the whole range of the tropics as far as the flood extends, mixes with the mangroves, standing like them on overarching roots. The Sonneratias (acida, alba) grows along the marshy banks of the large rivers of India, the Moluccas, and New Guinea; their roots spread far and wide through the soft mud, and at various distances send up, like the avicennias, extraordinarily long spindle-shaped excrescences four or five feet above the surface. These curious formations spring very narrow from the root, expand as they rise, and then become gradually attenuated, occasionally forking, but never throwing out shoots or leaves, or in any way resembling the parent root. For lining insectboxes and making setting-boards they are unequalled, as the finest pin passes in easily and smoothly, and is held so firmly and tightly that there is no risk of the insects becoming disengaged. In fact Nature, while forming them, seems to have had the entomologist in view, and to have studied how to gratify his wishes.

But of all trees none are so distinctively characteristic of the Tropical World as the different species of the Palm. They assume every variety of form, but all are beautiful. We shall undertake to mention only a few of those which are of special utility to man. The graceful Acanthus gave the imaginative Greeks the first idea of the Corinthian capital; but the shady canopy of the Cocoa-nut tree would form a still more beautiful architectural ornament of architecture, were it possible for art to imitate its feathery fronds and carve their delicate tracery in stone. No cathedral has a pillared aisle so magnificent as the famous Avenue of Palms in the Botanical Garden of Rio de Janeiro. The tall stems rise to the hight of eighty feet, and their overarching branches interlace, forming a roof whose beauty human hands can never imitate.

Essentially littoral, this noble palm requires an atmosphere damp with the spray and moisture of the sea to acquire its full stateliness of growth; and while along the bleak shores of the Northern Ocean the trees are generally bent landward by the rough sea breeze, and send forth no brenches to face its violence, the cocoa, on the 
contrary, loves to bend over the rolling surf, and to drop its fruits into the tidal wave. Wafted by the winds and currents over the sea, the nuts float along without losing their germinating power, like other seeds which migrate through the air; and thus, during the lapse of centuries, the cocoa-palm has spread its wide domain from coast to coast throughout the whole extent of the tropical zone. It waves its graceful fronds over the emerald islands of the Pacific, fringes the West Indian shores, and from the Philippines to Madagascar crowns the atolls, or girds the sea-board of the Indian Ocean. But nowhere is it met with in such abundance as on the coasts of Ceylon, where for miles and miles one continuous grove of palms, preëminent for beauty, encircles the "Eden of the eastern wave." Multiplied by plantations and fostered with assiduous care, the total number in the island cannot be less than twenty millions of full-grown trees; and such is its luxuriance in those favored districts, where it meets with a rare combination of every advantage essential to its growth, a sandy and pervious soil, a free and genial air, unobstructed solar heat, and abundance of water, that, when in full bearing, it will annually yield as much as a ton's weight of nuts-an example of fruitfulness almost unrivalled even in the torrid zone.

No other tree in the world, no other plant cultivated by man, contributes in so many ways to his wants and comforts as this inestimable palm. Besides furnishing their chief food to many tribes on the coast within the torrid zone, the nut contains a valuable oil, which burns without smoke or smell, and serves, when fresh, for culinary purposes.

The fibrous rind or husk of the nut furnishes the coir of commerce, a scarce less

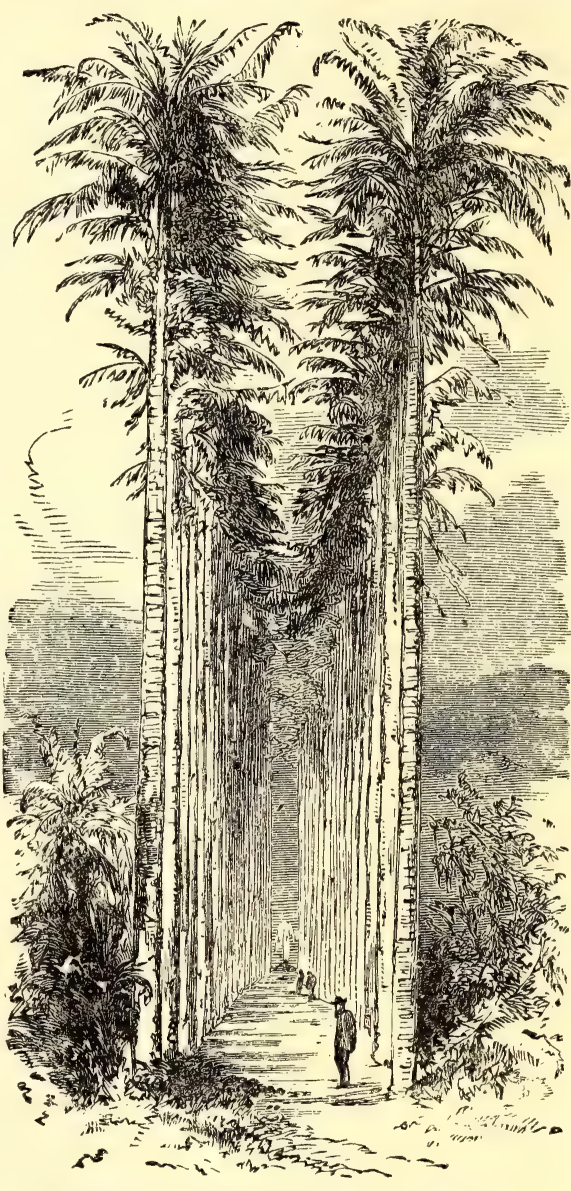

AVENUE OF PALMS-RIO DE JANEIRO. inportant article of trade than the oil itself. It is prepared by being soaked for some months in water, for the purpose of decomposing the interstitial pith, after which it is beaten to pieces until the fibres have completely separated, and ultimately dried in the sun. Ropes made of coir, though not so neat in appearance as hempen cords, are superior in lightness, and exceed them in durability, particularly if wetted frequently by salt water. From their elasticity and strength they are exceedingly valuable for cables. Besides cordage of every calibre, beds, cushions, carpets, brushes, and nets are manufactured from the filaments of the cocoa-nut husk, while the hard shell is fashioned into drinking-cups, spoons, beads, bottles, and knife-handles. From the 
spathes of the unopened flowers a delicious " toddy" is drawn, which, drunk at sunrise before fermentation has taken place, acts as a cooling, gentle aperient, but in a few hours changes into an intoxicating wine, and may be distilled into arrack. The strong tough foot-stalks of the fronds, which attain a length of from eighteen to twenty feet, are used for fences, for yokes, for carrying burdens on the shoulders, for fishing-rods; the leaflets serve for rooffing, for mats, for baskets, for cattle-fodder ; and their midribs form good brooms for the decks of ships. Cooked or stewed, the cabbage or cluster of unexpanded leaves is an excellent vegetable, though rarely used, as it necessarily involves the destruction of the tree; and even the tough web or network, which sustains the foot-stalks of the leaves, may be stripped off in large pieces and used for straining. After the cocoa-nut tree has ceased to bear, its wood serves for many valuable purposes-for the building of ships, bungalows, and huts, for furniture and farming implements of every description; and, as it admits of a fine polish, and its reddish ground color is beautifully veined with dark lines, it is frequently imported into England under the name of porcupine-wood. When we consider the many benefits conferred upon mankind by this inestimable tree, we cannot wonder at the animation with which the islander of the Indian Ocean recounts its "hundred uses," or at the superstition which makes him believe that by some mysterious sympathy it pines when beyond the reach of the human voice.

In every zone we find nations in a low degree of civilization living almost exclusively upon a single animal or plant. The Laplander has his reindeer, the Esquimau his seal, the Sandwich Islander his taro-root; and thus also we find the natives of a great part of the Indian Archipelago living almost exclusively upon the pith of the Sago palm. Of this tree, which is of such great importance to the indolent Malay, as it almost entirely relieves him of the necessity of labor, we shall speak hereafter, in connection with its use as furnishing nutrition to man.

The Saguer or Gomuti, the ugliest of palms, but almost rivaling the cocoa-nut tree by the multiplicity of its uses, is likewise a native of the Indian Archipelago. On seeing its rough and swarthy rind, and the dull dark-green color of its fronds, the stranger wonders how it is allowed to stand, but when he has tasted its delicious wine he is astonished not to see it cultivated in greater numbers. Although the outer covering of the fruit bas venomous qualities, and is used by the Malays to poison springs, the nuts have a delicate flav's, and the wounded spathe yields an excellent toddy, which, like that of the cocoa nut and the palmyra palm, changes by fermentation into an intoxicating wine, and on being thickened by boiling furnishes a kind of black sugar, much used by the natives of Java and the adjacent isles. The reticulum or fibrous net at the base of the petioles of the leaves constitutes the gumatty, a substance admirably adapted to the manufacture of cables, and extensively used for cordage of every de. scription. The gumatty is black as jet, the hairs extremely strong, and resembling coir, except that they are longer and finer. The small, hard twigs found mixed up with this material are employed as pens, besides forming the shafts of the sumpits, or little poisoned arrows of the Malays, and underneath the reticulum is a soft silky material, used as tinder by the Chinese, and applied as oakum in caulking the seams of ships, while from the interior of the trunk a kind of sago is prepared.

The Areca palm (Areca Catechu) bears a great resemblance to the cocoa-nut tree, hut is of a still more graceful form, rising to the hight of forty or fifty feet, without 
any inequality on its thin polished stem, which is dark-green towards the top, and sustains a crown of feathery foliage, in the midst of which are clustered the astringent nuts, for whose sake it is carefully tended. In the gardens of Ceylon the areca palm is invariably planted near the wells and water-courses, and the betel plant, which imme. morial custom has associated to its use, is frequently seen twining round its trunk.

The Palmyra palm, the sacred Talgaha of the Brahminical Tamils of Ceylon, extends from the confines of Arabia to the Moluccas, and is found in every region of Hindostan from the Indus to Siam, the cocoa and the date tree being probably the only palms that enjoy a still wider geographical range. In northern Ceylon, and particularly in the peninsula of Jaffna, it forms extensive forests; and such is its importance in the Southern Dekkan and along the Coromandel coast, that its fruits afford a compensating resource to seven millions of Hindoos on every occasion of famine or failure of the rice crop. Unlike the cocoa-nut palm, which gracefully bends under its ponderous crown, the palmyra rises vertically to its full hight of seventy or eighty feet, and presents a truly majestic sight when laden with its huge clusters of fruits, each the size of an ostrich's egg, and of a rich brown tint, fading into bright golden at its base. The Palmyra rivals the cocoa-nut and the gomuti by its many uses, and Hindoo poets celebrate the numerous blessings it confers upon mankind.

The Talipot of the Singalese rises to the hight of one hundred feet, and expands into a crown of enormous fan-like leaves, each of which when laid upon the ground will form a semicircle of sixteen feet in diameter, and cover an area of nearly two hundred superficial feet. These gigantic foliaceous expansions are employed by the Singalese for many purposes. They form excellent fans, umbrellas, or portable tents, one leaf being sufficient to shelter seven or eight persons; but their most interesting use is for the manufacture of a kind of paper, so durable as to resist for many ages the ravages of time. The leaves are taken whilst still tender, cut into strips, boiled in spring water, dried, and finally smoothed and polished, so as to enable them to be written on with a style, the furrow made by the pressure of the sharp point being rendered visible by the application of charcoal ground with a fragrant oil. The leaves of the palmyra similarly prepared are used for ordinary purposes; but the most valuable books and documents are written to-day, as they have been for ages past, on olas or strips of the talipot.

The Ratans, a most singular genus of creeping palms, luxuriate in the forests of tropical Asia. Sometimes their slender stems, armed with dreadful spines at every joint, climb to the summit of the highest tree; sometimes they run along the ground; and while it is impossible to find out their roots among the intricate tangles of the matted underwood, their palm-like topes expand in the sunshine, the emblems of successful parasitism. They frequently render the forest so impervious, that the distinguished naturalist Junghuhn, while exploring the woods of Java, was obliged to be accompanied by a vanguard of eight men, one half of whom were busy cutting the ratans with their hatchets, while the others removed the stems. These rope-like plants frequently grow to the incredible length of four or even six hundred feet, often consisting of a couple of hundred joints two or three feet long, and bearing at every knot a feathery leaf, armed with thorns on its lower surface. Tennent mentions having seen a specimen two hundred and fifty feet long and an inch in diameter, without a single irregularity, and no appearance of foliage other than the bunch of feathery leaves 
at the extremity. Though often extremely disagreeable to the traveler, yet the ratans are far from being useless. The natives of Java and the other islands of the Eastern Archipelago cut the cane into fine slips, which they plait into beautiful mats, manufacture into strong and neat baskets, or twist into cordage; and they are also extensively exported to Europe, where they are chiefly employed for the making of chair bottoms.

On turning from Asia to the adjoining continent of Africa, we find a new world of palms, several of which are no less valuable than the cocoa-nut or the palmyra, either as affording food, or enriching by their produce the commerce of the world.

The Date-tree, sung from time immemorial by the poets of the East, is as indispensable as the camel to the inhabitants of the wastes of North Africa and Arabia, and, next to the "ship of the desert," the devout Mussulman esteems it the chief gift of Allah. Few palms have a wider range, for it extends from the Persian Gulf to the borders of the Atlantic, and flourishes from the twelfth to the thirty-seventh degree of northern latitude. Groves of dates adorn the coasts of Valencia in Spain; near Genoa its plantations afford leaves for the celebration of Palm Sunday; and in the gardens of southern France a date tree sometimes mixes among the oranges and olives. But it never bears fruit on these northern limits of its empire, and thrives best in the oases on the borders of the sandy desert. Here it is cultivated with the greatest care, and irrigated every morning; for, though it will grow on an arid soil, it absolutely requires water to be fruitful. It is not to be wondered at that the tribes of the desert so bighly value a tree which, by enabling a family to live on the produce of a small spot of ground, extends as it were the bounds of the green islands of the desert, and rarely disappoints the industry that has been bestowed on its culture. It is considered criminal to fell it while still in its vigor, and both the Bible and the Koran forbid the warriors of the true God to apply the axe to the date trees of an enemy.

Thus various forms of palms flourish along the banks of the Nile, but in general Africa has a less number of these trees to boast of than either Asia or America. On the other hand, neither India nor Brazil have palms of such vast commercial importance as the Cocos butyracea, and the Elais guineensis, the oil-teeming fruit trees of tropical West Africa. The productiveness of the Elæis may be inferred from its bearing clusters of from 600 to 800 nuts, larger than a pigeon's egg, and so full of oil that it may be pressed out with the fingers.

Besides the hight of the shaft, the position of the leaves serves chiefly to impart a more or less majestic character to the palms: those with drooping leaves being far less stately than those whose fronds shoot more or less upwards to the skies. Nothing can exceed the elegance of the Jagua palm, which along with the splendid Cucurito adorns the granite rocks in the cataracts of the Orinoco at Atures and Maypures. The fronds, which are but few in number, rise almost perpendicularly sixteen feet high, from the top of the lofty columnar shaft, and their feathery leaflets of a thin and grass-like texture play lightly round the tall leaf-stalks, slowly bending in the breeze. The physiognomy of the palms depends also upon the various character of their efflorescence. The spathe is seldom vertical, with erect fruits; generally it hangs downwards, sometimes smooth, frequently armed with large thorns.

In the palms with a feathery foliage, the leaf-stalks rise either immediately from the brown rugged ligneous trunk (cocoa-nut, date), or, as in the beautiful Palma Real of 
the Havana, from a smooth, slender, and grass-green shaft, placed like an additional column upon the dark-colored trunk. In the fan-palms, the crown frequently rests upon a layer of dried leaves, which impart a severe character to the tree.

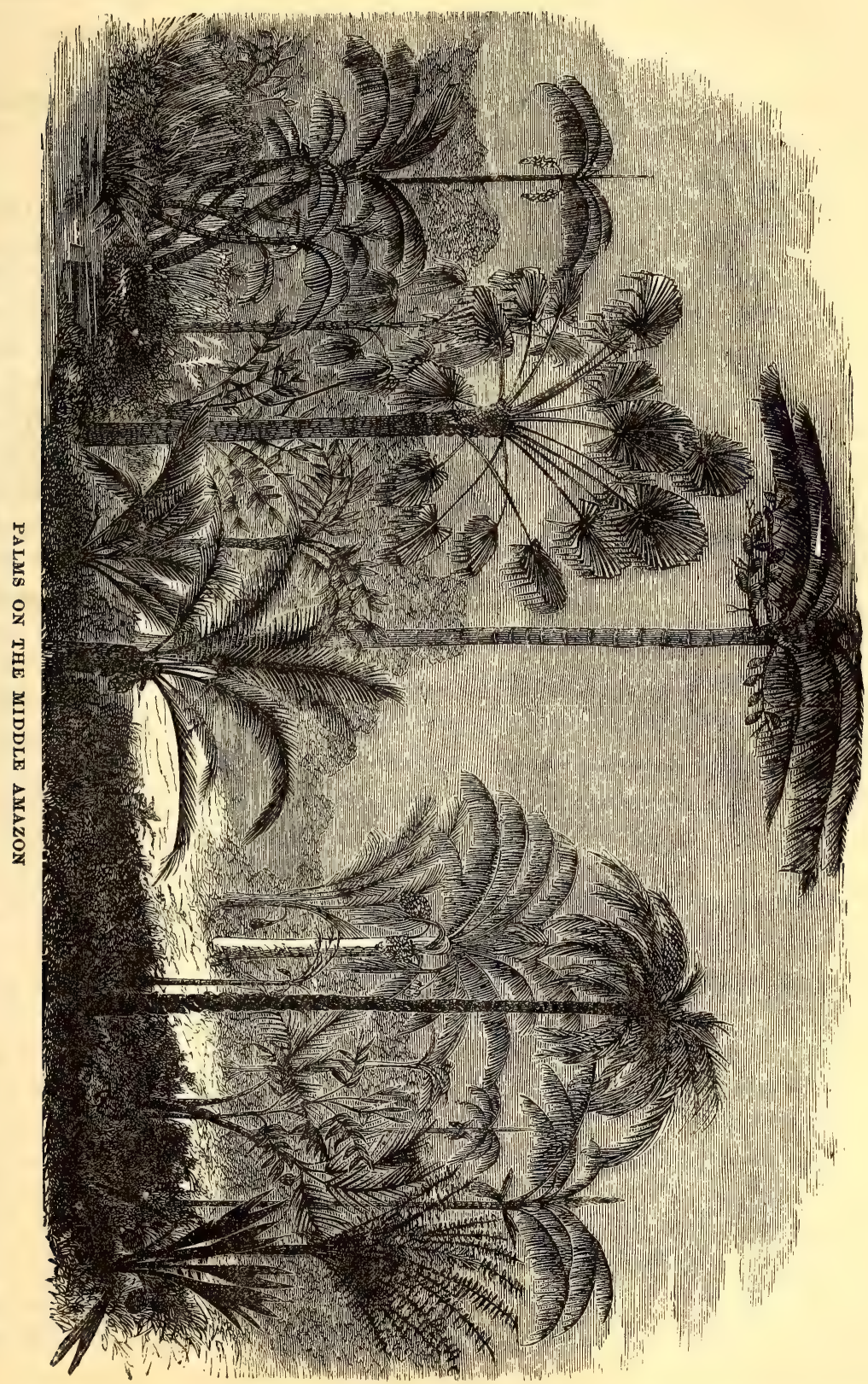

The form of the trunk also varies greatly, sometimes almost entirely disappearing, as in Chamarops humilis; sometimes, as in the Calami, assuming a bush-rope appearance, smooth or rugged, unarmed or bristling with spines. In the American Yriarteas, 
the trunk, as in the mangroves, and many of the screw-pines, rests upon a number of roots rising above the ground. Thus the $Y$. exorrhiza, which grows on the banks of the Amazon to the hight of a hundred feet, frequently stands upon a dozen or more supports, embracing a circumference of twenty feet, and the trunk begins only six or eight feet from the ground. The Yriartea ventricosa is still more curious, as the spindle-shaped trunk, which at the top and at the bottom is scarce a foot thick, swells in the middle to a threefold diameter, and, from its convenient form, is frequently used by the Indians for the construction of their canoes.

The form and color of the fruits is also extremely various. What a difference between the large coco de mer and the date-between the egg shaped fruits of the Mauritia, whose scaly dark rind gives them the appearance of fir-cones, and the gold and purple peaches of the Pirijao, hanging in colossal clusters of sixty or eighty from the summit of the majestic trunk. Notwithstanding the fecundity of the palms, generally but few individuals of each species are found growing wild, partly in consequence of the frequent abortive development of the fruits, but chiefly on account of the large number of animals-from the grub to the monkey-that are constantly feeding upon them.

When we consider the enormous range of territory over which the palm-trees extend, and how very few of their many hundred species have hitherto been multiplied and improved by cultivation, we can not doubt that many benefits are yet to be expected from them, and that they will at some day rank high in the commercial annals of the world. 


\section{CHAPTER VI.}

\section{THE CHIEF NUTRITIVE PLANTS OF THE TROPICAL WORLD.}

Rice-Aspects of Rice-Fields at Different Seasons-The Rice-Fields of Ceylon-Ladang and Sawa Rice-Rice in South Carolina-The Rice-Bird-Paddy-Maize-When first brought to Europe-Appearance of the Plant-Its Enormous Productiveness-Freedom from Disease-Wide Extent of its Cultivation-Benjamin Frank!in's Account of Maize-MilletThe Bread-Fruit-Its Taste-Modes of Cooking-The Banana and Plantain-Their Great Productiveness-The Sago Palm-Manufacture of Sago-Sago Bread-Cheap Living-A Siesta and Starvation-The Cassavd-Yams-The Sweet Potato-Arrow Root-The Taro Root-Tropical Fruits-The Chirimoya-The Litchi-The Mangosteen-The MangoThe Durion-Its Taste and Smell-Large Fruit on Tall Trees.

$\mathrm{O}$

$\mathrm{F}$ all the cereals there is none that affords food to so many human beings as the Rice-Plant, (Oryza sativa,) upon whose grains from time immemorial the countless millions of South-eastern Asia have chiefly subsisted. It forms the staple, one might almost say the only food, of a third of the inhabitants of the globe. The failure of the rice crop for a single season in India or China causes a famine compared with which the potato famine of Ireland was nothing. From its primitive seat in India, the rice-plant has graaually spread not only over the whole Tropical World, but far beyond its bounds; for it thrives alike in the swamps of South Carolina and upon the plains bordering the Danube and the Po. Along the low river banks, in the delta-lands which the rains of the tropics annually change into a boundless lake, or where, by artificial embankments, the waters of the mountain streams have been collected into tanks for irrigation, the rice-plant attains its utmost luxuriance of growth, and but rarely deceives the hopes of the husbandman.

The aspect of the lowland rice-fields of India and its isles is very different at various seasons of the year. Where, in Java, for instance, you see to-day long-legged herons gravely stalking over the inundated plain partitioned by small dykes, or a yoke of indolent buffaloes slowly wading through the mud, you will three or four months later be charmed by the view of a gracefully undulating wheat-field. Cords, to which scarecrows are attached, traverse the field in every direction, and converge to a small watch-house, erected on high poles. Here the attentive villager sits, like a spider in the center of its web, and, by pulling the cords, puts them from time to time into motion, whenever the wind is unwilling to undertake the office. Then the grotesque and noisy figures begin to rustle and to eaper, and whole flocks of the neat little ricebird or Java sparrow rise on the wing, and hurry off with all the haste of guilty fright. After another month has elapsed, and the waters have long since evaporated or been withdrawn, the harvest takes place, and the rice-fields are enlivened by a motley crowd, for all the villagers, old and young, are busy reaping the golden ears. 
The rice-fields offer a peculiarly charming picture when, as in the mountain valleys of Ceylon, they rise in terraces along the slopes. "Selecting," says Sir Emerson Tennent, "an angular recess where two hills converge, the Kandyans construct a series of terraces, raised stage above stage, and retiring as they ascend along the slope of the acclivity, up which they are carried as high as the soil extends. Each terrace is furnished with a low ledge in front, behind which the requisite depth of water is retained during the germination of the seed, and what is superfluous is permitted to trickle down to the one below it. In order to carry on this peculiar cultivation the streams are led along the level of the hills, often from a distance of many miles, with a skill and perseverance for which the natives of these mountains have attained a great renown. Many of the tanks, though partially in ruins, cover an area from ten to fifteen miles in circumference. They are now generally broken and decayed; the waters, which would fertilize a province, are allowed to waste themselves in the sands; and hundreds of square miles, capable of furnishing food for all the inhabitants of Ceylon, are abandoned to solitude and malaria ; whilst rice for the support of the nonagricultural population is annually imported from the opposite coast of India."

Rice does not invariably require the marsh or the irrigated terrace for its growth, as there is a variety which thrives on the slopes of hills, where it is not continuously watered. In the mountain regions of Sumatra, rains fall at almost every season of the year, though dry weather is more frequent from April to July. In August, the rainy days are as three to one, and this is the time generally chosen for the sowing of the Ladang, or mountain rice. After the harvest, the field is sown a second time with maize; it then lies fallow for a few years, and is soon covered with a thick vegetation of wild shrubbery, generally with glagah, a species of grass which attains a hight of twelve feet. When the field is again to be cultivated, fire is resorted to, to destroy the dense jungle, in which the tiger has made his lair, or where the rhinoceros grazes. At night, these fires, ascending the slopes of the mountains, present a fine sight; during the day time, they cover the land with a dun mist. The rapidity with which the dry culms of the glagah take fire is not seldom dangerous to the traveler when his path leads him across the slope of a hill at whose foot the grass-field begins to burn, for the rustling fire-columns ascend with the swiftness of the wind, and soon wrap the side of the mountain in a sheet of flame. The ashes of the glagah afford the richest manure, so that these fields are only surpassed in fertility by the virgin soil of the cleared forest, a laborious work, which is seldom undertaken in this thinly-populated country.

Sawa is the general Malay name for artificially-irrigated rice-fields. In the Indian Archipelago, the sawa, or marsh-rice, is at first thickly sown in small beds, and transplanted after a fortnight into the fields, the soil of which has been softened by water. As the plant grows, copious irrigations supply it with the necessary moisture; but as maturity approaches, the field is laid dry, and about two months later the ears assume the rich golden color so pleasing to the husbandman. Fach field could easily be made to produce two annual harvests; but, when not compelled to labor, the tropical peasant never thinks of taxing his industry beyond the supply of his immediate wants.

The swamps of South Carolina, both those which are occasioned by the periodical visits of the tides, and those which are caused by the overflowing of the rivers, are admirably adapted to the production of rice; yet the culture of the valuable cereal on 
this congenial soil is of comparatively modern date. About the beginning of the last century, a brigantine from the island of Madagascar happened to put in at Carolina, having a little seed-rice left, which the captain gave to a gentleman of the name of Woodward. From part of this, the latter had a very good crop, but was ignorant for sume years how to clean it. It was soon dispersed over the colony, and, by frequent experiments and observations, the planters ultimately raised the culture to its present perfection. By the introduction of this water-loving cereal, various swamps which previously had only afforded food to frogs and water-birds, have been changed into the most fruitful fields, so that South Carolina not merely supplied the whole of the United States with all the rice they require, but also annually exported more than a hundred thousand large casks to the various markets of Europe.

Besides the devastations which the atmosphere of the rice-fields causes among his laborers, the planter frequently suffers heavy losses in consequence of the depredations of the rice-bunting (Dolichonyx oryzivorus), a species of ortolan, known familiarly by the name of bobolink. This bird is about six or seven inches long; its head and the under part of its body are black, the upper part is a mixture of black, white, and yellow, and the legs are red. It migrates over the continent of America from Labrador to Mexico, and over the Great Antilles, appearing in the southern extremity of the States about the end of March. During the three weeks to which its unwelcome visit to the rice-fields is usually limited, it grows so fat upon the milky grains of its favorite cereal, that its flesh becomes equal in flavor to that of the European ortolan. As long as the female is sitting, the song of the male continues with little interruption: it is singular and pleasant, consisting of a jingling medley of short, variable notes, confused, rapid and continuous.

Large quantities of rice are supplied to Europe from Brazil, Java, Bengal, and of late years from Arracan and Pegu. Most of the Arracan rice is exported in the unshelled state, or as paddy, and cleaned in Europe, where the operation can be more effectually and cheaply performed than in the country of production. The loss by waste is also found to be less on the transport of paddy than of shelled rice.

Maize is no less important to the rapidly growing nations of America than the riceplant to the followers of Buddh or of Brama; and when hereafter the banks of the Mississippi, of the Amazon, and of the Orinoco, shall be covered by as dense a population as the plains of Bengal, the number of maize eaters will probably be greater than that of the consumers of any other species of grain. Even now it is second in this respect only to rice.

The time when the cereals of the old world-wheat, rye, barley-were first transplanted from their unknown Asiatic homes to other parts of the world is hidden in legendary obscurity; but the epoch when maize was for the first time seen and tasted by Europeans lies before us in the broad daylight of authentic history. For, when Columbus discovered Cuba, in the year 1492, he found maize cultivated by the Indians, and was equally pleased with the taste of the roasted grains and astonished at their size. In the following year, when he made his triumphant entry into Barcelona, and presented his royal patrons-Ferdinand and Isabella-with specimens of the various productions of the New World, the maize spikes he laid down before their throne, though but little noticed, were in reality of far greater importance than the heaps of gold which were so falsely deemed to be the richest prizes of his grand 
discovery. In this manner maize, which is found growing wild from the Rocky Mountains to Paraguay, and had been cultivated from time immemorial, as well in the Antilles as in the dominions of the Mexican Aztecs and of the Peruvian Incas, was first conveyed from the New World to Spain, whence its cultivation gradually extended over the tropical and temperate zone of the eastern hemisphere. Round the whole basin of the Mediterranean, maize has found a new home, and its grain now nourishes the Lombard and the Hungarian, as it does the Egyptian fellah or the Syrian peasant.

While other cereals only produce a pleasing effect when covering extensive fields, but are individually too insignificant to claim attention, the maize plant almost reminds the spectator of the lofty Bambusaceæ of the tropical world. Dark green, lustrous leaves spring alternately from every joint of this cereal, streaming like pennants in the wind. The top produces a bunch of male flowers of various colors, which is called the tassel. Each plant likewise bears one or more spikes or ears, the usual number being three, though as many as seven have been seen occasionally on one stalk. These ears proceed from the stem, at various distances from the ground, and are closely enveloped by several thin leaves, forming a sheath, or husk. They consist of a cylindrical substance of the nature of pith, which is called the $c o b$, and over the entire surface of which the seeds are ranged and fixed, in eight or more straight rows. Each of these has generally as many as thirty or more seeds, and each seed weighs at least as much as five or six grains of wheat or barley. Surely a cereal like this deserves beyond all others to symbolize abundance, and, had it been known to the Greeks, it would beyond all doubt have figured conspicuously in the teeming horn of Amalthea.

While the British farmer is satisfied with an increase of twenty for one, the productiveness of maize, under the circumstances most favorable to its growth, is such as almost to surpass belief. In the low and sultry districts of Mexico, it is quite a common thing, in situations where artificial irrigation is practised, to gather from 350 to 400 measures of grain for every one measure that has been sown; and some particularly favored spots have even been known to yield the incredible increase of 800 . In other situations, where reliance is placed only on the natural supply of moisture to the soil from the periodical rains, such an abundant supply is not expected; but even then, and in the least fertile spots, it is rare for the cultivator to realize less than from forty to sixty bushels for each one sown. The productiveness of maize diminishes in the more temperate climate of the United States; but even there it yields double the increase of wheat; and such is the quantity annually grown that, in spite of its low price, the value of the maize harvest more than twice surpasses that of all the other cereals.

Another great advantage attending the cultivation of maize is, that of all the cereals it is the least subject to disease. Blight, mildew, or rust are unknown to it. It is never liable to be beaten down by rain, or by the most violent storms of wind, and in climates and seasons which are favorable to its growth, the only enemies which the maize farmer has to dread are insects in the early stages, and birds in the later periods, of its cultivation. In mountainous countries, and the farther it advances beyond the tropics, maize-a child of the sun-naturally suffers from the ungenial influence of a cold and wet summer, which not only prevents the ripening of the grain, but also develops a poisonous ergot in its ears, similar to that which an inclement sky is apt to engender in rye. 
When we consider that the zone of cultivation of the maize plant extends without interruption from $49^{\circ}$ north latitude to $40^{\circ}$ south latitude, it is not to be wondered at that there are numerous varieties, from the gigantic Tlaouili of the Mexicans, which absolutely requires a hot sun, and bears ears ten inches in length and five or six inches in circumference, and the small variety with ears four or five inches long, which in ordinary seasons will ripen its grain, even under the variable and weeping sky of Fingland, and which, with ears not larger than one's finger, was found by Squier growing on the sacred island of Titicaca, at an altitude of 12,800 feet above the level of the sea.

The various uses to which the maize plant and grain may be applied cannot be better enumerated than in the words of the celebrated Dr. Franklin.

"It is remarked in North America that the English farmers, when they first arrived there, finding a soil and climate proper for the husbandry they have been accustomed to, and particularly suitable for raising wheat, they despise and neglect the culture of maize or Indian corn; but, observing the advantage it affords their neighbors, the older inhabitants, they by degrees get more and more into the practice of raising it, and the face of the country shows from time to time that the culture of that grain goes on visibly augmenting. The inducements are the many different ways in which it may be prepared so as to afford a wholesome and pleasing nourishment to men and other animals. First, the family can begin to make use of it before the time of full harvest; for the tender green ears, stripped of their leaves and roasted by a quick fire till the grain is brown, and eaten with a little salt or butter, are a delicacy. Secondly, when the grain is riper and harder, the ears boiled in their leaves and eaten with butter are also good and agreeable food. The tender green grain dried may be kept all the year, and, mixed with green kidney beans, also dried, make at any time a pleasing dish, being first soaked some hours in water and then boiled. When the grain is ripe and hard there are also several ways of using it. One is to soak it all night in a lessive or lye, and then pound it in a large wooden mortar with a wooden pestle; the skin of each grain is by that means skinned off, and the farinaceous part left whole, which, being boiled, swells into a white, soft pulp, and, eaten with milk or with butter and sugar, is delicious. The dry grain is also sometimes ground loosely so as to be broken into pieces of the size of rice, and, being winnowed to separate the bran, it is then boiled and eaten with turkeys or other fowls as rice. Ground into a finer meal, they make of it by boiling a hasty-pudding or bouilli, to be eaten with milk or with butter and sugar, that resembles what the Italians call polenta. They make of the same meal with water and salt a hasty-cake, which, being stuck against a hoe or other flat iron, is placed erect before the fire, and so baked, to be used as bread. They also parch it in this manner: An iron pot is filled with sand, and set on the fire till the sand is very hot. Two or three pounds of the grain are then thrown in, and well mixed with the sand by stirring. Each grain bursts and throws out a white substance of twice its bigness. The sand is separated by a wire sieve, and returned into the pot to be again heated, and repeat the operation with fresh grain. That which is parched is pounded to a powder in a mortar. This being sifted will keep long for use. An Indian will travel far and subsist long on a small bag of it, taking only six or eight ounces of it per day mixed with water. The flour of maize mixed with that of wheat makes excellent bread, sweeter and more agreeable than that of wheat alone. To 
feed horses it is good to soak the grain twelve hours: they mash it easier with their teeth, and it yields them more nourishment. The leaves stripped off the stalks after the grain is ripe, tied up in bundles when dry, are excellent forage for horses, cows, etc. The stalks, pressed like sugar-cane, yield a sweet juice, which, being fermented and distilled, yields an excellent spirit; boiled without fermentation it affords an excellent syrup. In Mexico fields are sown with it thickly, that multitudes of small stalks may arise, which, being cut from time to time, like asparagus, are served in desserts, their thin sweet juice being extracted in the mouth by chewing them. The meal wetted is excellent food for young chickens and the old grain for grown fowls."

In Europe, as well as in the United States, the quantity or maize grown far exceeds that of wheat or any other grain; but so little is the value of this noblest of cereals known in Great Britain, that even during the famine in Ireland it was with the utmost difficulty that the starving peasants could be induced to use the meal sent over to them from America. This was doubtless in a great measure owing to their unacquaintance with the proper manner of cooking it. A delegation of colored "mammies" from Virginia, skilled in the mysteries of "pone" and "hoe-cake," would have been of inestimable service.

In light sandy soils, under the scorching rays of the sun, and in situations where sufficient moisture cannot be obtained for the production of rice, numerous varieties of Millet (Sorghum vulgare) are successfully cultivated in many tropical countries-in India, Arabia, the West Indies, in Central Africa, and in Nubia, where it is grown almost to the exclusion of every other esculent plant. Though the seeds are by much the smallest of any of the cereal plants, the number borne upon each stalk is so great as to counterbalance this disadvantage, and to render the cultivation of millet as productive as that of any other grain.

The Bread-fruit tree (Artocarpus incisa) is the great gift of Providence to the fairest isles of Polynesia. No fruit or forest tree in the north of Europe, with the exception of the oak or linden, is its equal in regularity of growth and comeliness of shape ; it far surpasses the wild chestnut, which somewhat resembles it in appearance. Its large oblong leaves, frequently a foot and a half long, are deeply lobed like those of the fig tree, which they resemble not only in color and consistence, but also in exuding a milky juice when broken. About the time when the sun, advancing towards the Tropic of Capricorn, announces to the Tahitians that summer is approaching, it begins to produce new leaves and young fruits, which commence ripening in October, and may be plucked about eight months long in luxuriant succession. The fruit is about the size and shape of a new-born infant's head; and the surface is reticulated, not much unlike a truffle; it is covered with a thin skin, and has a core about as big as the handle of a small knife. The eatable part lies between the skin and the core; it is as white as snow, and somewhat of the consistence of new bread; it must be roasted before it is eaten, being first divided into three or four parts; its taste, according to some, is insipid, with a slight sweetness, somewhat resembling that of the crumb of wheaten bread mixed with boiled and mealy potatoes. But Wallace, who met with it in the island of Amboyna, speaks of it in very different terms. He says : " Here I enjoyed a luxury I have never met with either before or since-the true bread-fruit. It is baked entire in the hot embers, and the inside scooped out with a spoon. I compared it to Yorkshire pudding; others thought it was like mashed 
potatoes and milk. It is generally about the size of a melon, a little fibrous toward the center, but everywhere else quite smooth and puddingy, something between yeastdumplings and batter-pudding. We sometimes made curry or stew of it, or fried it in slices; but it is in no way so good as simply baked. With meat and gravy it is a vegetable superior to any I know either in temperate or tropical countries. With sugar, milk, butter, or treacle, it is a delicious pudding, having a very slight and delicate but characteristic flavor, which, like that of good bread and potatoes, one never gets tired of."

When the season draws to an end, the last fruits are gathered just before they are perfectly ripe, and, being laid in heaps, are closely covered with leaves. In this state they undergo a fermentation and become disagreeably sweet; the core is then taken out entire, which is done by gently pulling out the stalk, and the rest of the fruit is thrown into a hole, which is dug for that purpose, generally in the house, and neatly lined in the bottom and sides with grass; the whole is then covered with leaves, and heavy stones laid upon them; in this state it undergoes a second fermentation, and becomes sour, after which it will suffer no change for many months.

It is taken out of the hole as it is wanted for use, and, being made into balls, it is wrapped up in leaves and baked: after it is dressed it will keep five or six weeks. It is eaten both cold and hot, and the natives seldom make a meal without it, though to Europeans the taste is as disagreeable as that of a pickled olive generally is, the first time it is eaten. The fruit itself is in season eight months in the year, and the Mahei or sour paste formed in the manner above described fills up the remaining cycle of the year.

To procure this principle article of their food costs the fortunate South Sea Islanders no more trouble than plucking and preparing it in the manner above described; for, though the tree which produces it does not grow spontaneously, yet, if a man plants but ten of them in his lifetime, which he may do in about an hour, he will, as Cook remarks, "as completely fulfil his duty to his own and future generations, as the native of our less genial climate by plowing in the cold of winter and reaping in the summer's heat as often as the seasons return." Though it has a far extended range over the islands and coasts of the Indian and Pacific Ocean, yet its importance as an article of food is chiefly confined to the Tahitian, Friendly, Samoan, Fiji, and Marquesan groups, while in most parts of the Indian Archipelago it is either neglected or only used for fuel.

The wonderful luxuriance of tropical vegetation is perhaps nowhere more conspicuous and surprising than in the magnificent Musacea, the Banana (Musa sapientum), and the Plantain (Musa paradisiaca), whose fruits most probably nourished mankind long before the gifts of Ceres became known. A succulent shaft or stem, rising to the hight of fifteen or twenty feet, and frequently two feet in diameter, is formed of the sheath-like leaf-stalks rolled one over the other, and terminating in enormous light green and glossy blades, ten feet long and two feet broad, of so delicate a tissue that the slightest wind suffices to tear them transversely as far as the middle rib. A stout foot-stalk, arising from the center of the leaves, and reclining over one side of the trunk, supports numerous clusters of flowers, and subsequently a great weight of several hundred fruits about the size and shape of full grown cucumbers. On seeing the stately plant, one might suppose that many years had been required for its 
growth; and yet only eight or ten months were necessary for its full development. Each shaft produces its fruit but once, when it withers and dies; but new shoots spring forth from the root, and before the year has elapsed unfold themselves with the same luxuriance. Thus, without any other labor than now and then weeding the field, fruit follows upon fruit and harvest upon harvest. A single bunch of bananas often weighs from sixty to seventy pounds, and Humboldt has calculated that thirtythree pounds of wheat and ninety-nine pounds of potatoes require the same space of ground to grow upon as will produce 4,000 pounds of bananas.

This prodigality of nature, seemingly so favorable to the human race, is, however, attended with great disadvantages; for where the life of man is rendered too easy, his best powers remain dormant, and he almost sinks to the level of the plant which affords him subsistence without labor. Exertion awakens our faculties as it increases our enjoyments, and well may we rejoice that wheat and maize, and not the banana, ripen in our fields.

As the seeds of the cultivated plantain and banana never, or very rarely, ripen, they can only be propagated by suckers. "In both hemispheres," says Humboldt, " as far as tradition or history reaches, we find plantains cultivated in the tropical zone. It is as certain that African slaves have introduced, in the course of centuries, varieties of the banana into America, as that before the discovery of Columbus the pisang was cultivated by the aboriginal Indians."

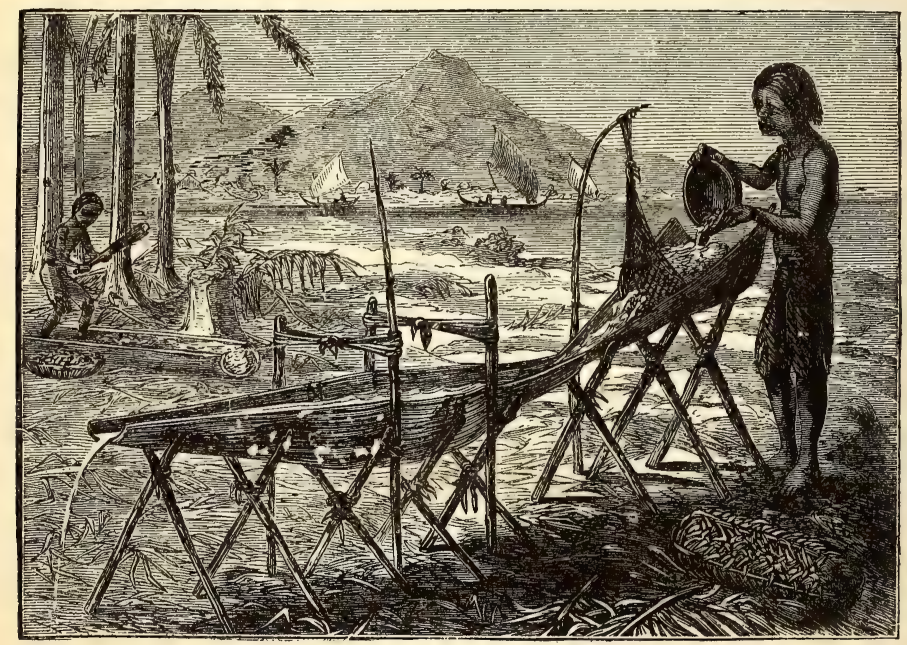

MANUEACTURE OF SAGO.

The Sago-Palm may fairly dispute with the plantain the honor of producing upon a given space the greatest amount of human food. It grows all over the islands of the Malayan Archipelago, the most productive district being in Ceram, whence large quantities are exported. The tree, says Mr. Wallace,* is a palm thicker and larger than the cocoa-nut tree, although rarely so tall, and having immense pinnate spiny leaves, which completely cover the trunk until it is several years old. Whon it is

* Malayan Archipelago, 382-385. 
about ten or fifteen years old it sends up an immense terminal spike of flowers, after which it dies.

For making sago the tree must be used just before it is going to flower. It is cut down close to the ground, which, large as the tree is, costs no great labor, for the woody shell is only half an inch thick; the rest is all pith. The leaves and leafstalks are cleared away, and a broad strip of bark taken off the upper side of the trunk, laying bare the pithy matter, which is of a rusty color near the bottom, but higher up of a pure white, about as bard as a mealy apple, with woody fibres running through it, about a quarter of an inch apart. This pith is broken up into a coarse powder by a heavy wooden club or pounder, having a piece of hard quartz imbedded into the end. By means of this, strips of the pith are cut away, which fall down into the cylinder formed by the tough bark, until the whole trunk is cleared out, leaving a skin of not more than half an inch in thickness. This material is carried to the washing machine, which answers the purpose of a grist-mill for preparing the flour. This washing machine is composed wholly from the tree itself. The great sheathing bases of the leaves make excellent troughs; and their ribs, as thick as a man's arm, and lighter and tougher than a bamboo, furnish the supporting props; while the fibrous covering of the leaf-stalks forms the strainer. Water is poured on the mass of pith, which is kneaded and pressed against the strainer until the starch is all washed out, when the fibrous refuse is thrown away. The water, charged with the starch, passes into another deep trough, where the sediment is quickly deposited, the water running off. This mass of starch is made up into packages of thirty pounds, covered with sago leaves. This constitutes the "raw sago," and will keep for years. Boiled with water, it forms a thick glutinous mass, which is eaten with salt, limes, or Chili peppers.

More frequently it is used for making bread. The raw sago is broken up, dried in the sun, and powdered into a coarse meal. The oven is a square clay pan, divided into compartments six or eight inches square, and three-quarters of an inch thick. This is heated over a clear fire of embers, filled with the flour, and covered with a piece of sago bark. In five minutes the bread, or rather batch of cakes, is baked. When hot they are very palatable with butter; and the addition of a little sugar and grated cocoa-nut forms quite a delicacy. They are soft, and not unlike our "Johnnycakes" made of maize flour, but have a slight characteristic flavor which is wanting in the prepared sago. When not wanted for immediate use, the cakes are dried in the sun for several days; they will then keep for years. They are hard, rough, and dry; but the natives do not mind that, and it is a common sight to see children gnawing away at them, as our children do at a crust of bread. Dipped in water and toasted, they become almost as good as when fresh; soaked and boiled, they make a good pudding. We see no reason why these sago biscuit should not form a welcome addition to ship-stores in tropical regions.

A good-sized tree will afford 900 pounds of raw sago. This will make 600 pounds of bread. Two cakes, weighing three to the pound, are as much as a man can well eat at a meal; five are considered a full day's allowance. One tree will therefore supply a man with food for a whole year. Two men will easily finish a tree in five days; so that a man may in ten days raise and make his flour for a year. If he chooses to bake his year's supply of bread at once, another ten days is quite enough; so that the labor of twenty days will give him food for a year. This is on the sup- 
position that he happens to own sago trees. If he does not, he can buy one standing for two dollars. As the price of a man's labor in this region is estimated at ten cents a day, the cost of food ready cooked for a man is four dollars a year. Yet, unaccountable as it seems to us, the natives, with these great natural flour-barrels, (only that each contains three of our barrels,) standing around them, suffer from hunger. Agassiz notices the same thing on the Amazon. If the people of any country really prefer to go hungry rather than spend three weeks of the year in weeding a plantainfield, or preparing sago, there seems no good reason why any one should interfere with their way of enjoying themselves. By all means let them take their siesta and starve afterwards.

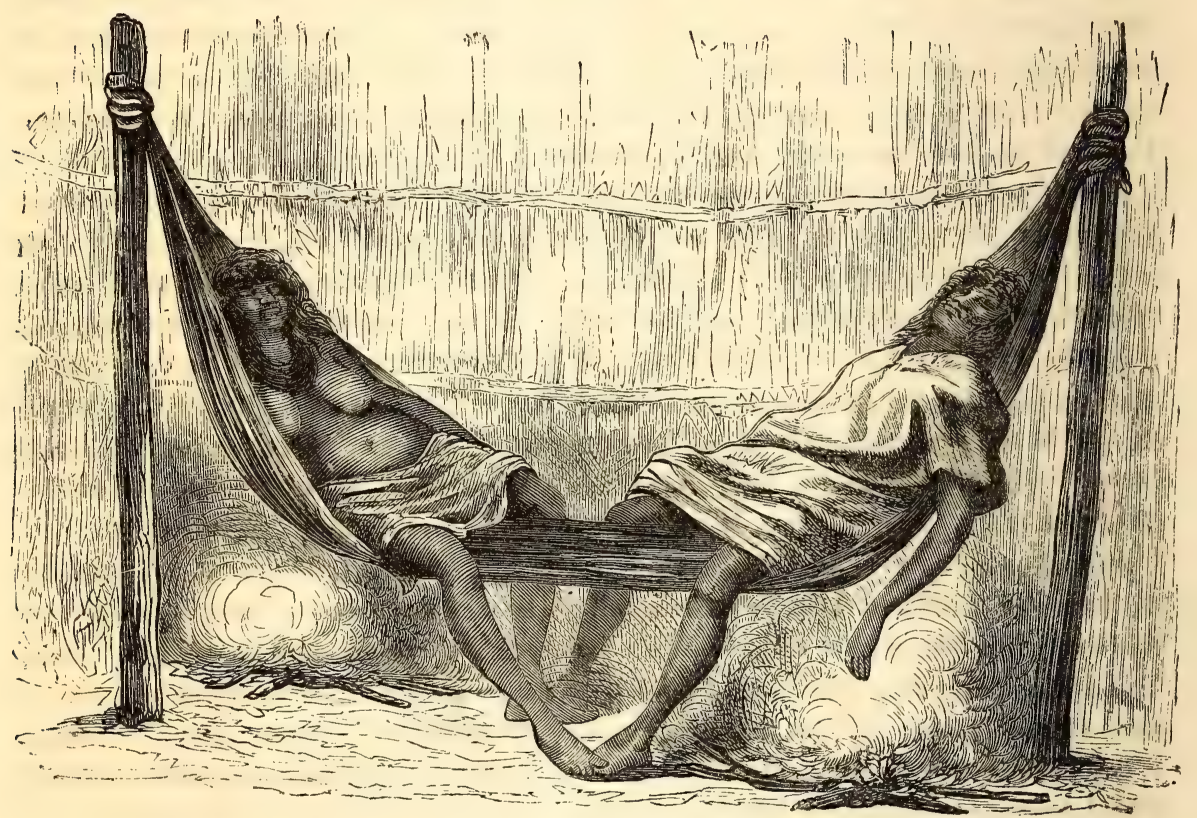

A SIESTA ON THE AMAZON.

Life and death are strangely blended in the Cassava or Mandioca root (Iatropha manihot). The juice a rapidly destructive poison, the meal a nutritious and agreeable food, which, in tropical America, and chiefly in Brazil, forms a great part of the people's sustenance. The hight to which the cassava attains varies from four to six feet. It rises by a slender, woody, knotted stalk, furnished with alternate palmated leaves, and springs from a tough branched woody root, the slender collateral fibres of which swell into those farinaceous, parsnip-like masses, for which alone the plant is cultivated. It requires a dry soil, and is not found at a greater elevation than 2,000 feet above the level of the sea. It is propagated by cuttings, which very quickly take root, and in about eight months from the time of their being planted the tubers will generally be in a fit state to be collected; they may, however, be left in the ground for many months without sustaining any injury. The usual mode of preparing the cassava is to grind the roots after pealing off the dark-colored rind, to draw out the poisonous juice, and finally to bake the meal into thin cakes on a hot iron hearth. 
Fortunately the deleterious principle is so volatile as to be entirely dissipated by exposure to heat; for when the root has been cut into small pieces, and exposed during some hours to the direct rays of the sun, cattle may be fed on it with perfect safety. If the recently extracted juice be drunk by cattle or poultry, the animals soon die in convulsions; but if this same liquid is boiled with meat and seasoned, it forms a wholesome and nutritious soup. The Iatropha janipha, or Sweet Cassava, though very similar to the Manihot or bitter variety, and wholly innocuous, is far less extensively cultivated. A palatable and wholesome bread is made of both kinds; and although its taste may be thought somewhat harsh by persons accustomed to soft fermented bread made from wheaten flour, yet those who have been accustomed to its use are so fond of it, that Creole families who have gone to live in Europe frequently have it sent to them from the West Indies. The kind of starch so well known under the name of tapioca is prepared from the farina of cassava roots. A large quantity is exported from Brazil to Europe, and may well be considered as a more useful production than all the diamonds of Minas Geraes.

The Yam roots, which are so frequently mentioned in narratives of travel through the tropical regions, are the produce of two climbing plants-the Dioscorea sativa and Alata - with tender stems of from eighteen to twenty feet in length, and smooth, sharppointed leaves on long foot-stalks, from the base of which arise spikes of small flowers. The ronts of the Dioscorea sativa are flat and palmated, about a foot in breadth, white within and externally of a dark brown color, almost approaching to black; those of the D. alata are still larger, being frequently about three feet long, and weighing about thirty pounds. Both kinds are cultivated like the common potato, which they resemble in taste, though of a closer texture. When dug out of the earth, the roots are placed in the sun to dry, and are then put into sand or casks, where, if guarded from moisture, they may be preserved for a long time without being in any way injured in their quality. The Dioscoreæ are natives of South Asia, and are supposed to have been thence transplanted to the West Indies, as they have never been found growing wild in any part of America; while in the island of Ceylon, and on the coast of Malabar, they flourish in the woods with spontaneous and luxuriant growth. They are now very extensively cultivated in Africa, Asia, and America, as their large and nutritious roots amply reward the labor of the husbandman.

The Spanish or Sweet Potato, (Convolvulus batatas,) commonly cultivated in the tropical climates both of the Eastern and the Western hemispheres, is an herbaceous perennial, which sends out many trailing stalks, extending six or eight feet every way, and putting forth at each joint, roots which in a genial climate grow to be very large tubers, so that from a single plant forty or fifty large roots are produced. The leaves are angular, and stand on long petioles, the flowers are purple. The batata is propagated by laying down the young shoots in the spring; indeed in its native climate it multiplies almost spontaneously, for if the branches of roots that have been pulled up are suffered to remain on the ground, and a shower of rain falls soon after, their vegetation will recommence. From its abundant growth, it is surprising that in Brazil the mandioc should be cultivated in preference as food for the negro, the batata being raised more as a luxury for the planter's table.

Arrowroot is chiefly obtained from two different plants-the Murantha arundinacoa and the Tacca pinnatifida. The former, a native of Souta America, is an herba- 
ceous perennial and is propagated by parting the roots. It rises to the height of two or three feet, has broad, pointed leaves, and is crowned by a spike of small, white flowers It is much cultivated, both for domestic use and for exportation in the West Indies, and in some parts of Hindostan. The arrowroot is obtained by first pounding the long, stalky roots in a large, wooden mortar, and pouring a quantity of water over them. After the whole has been agitated for some time, the starch, separated from the fibres, collects at the bottom of the vessel, and having been cleansed by repeated washings is dried in the sun.

The Tacca pinnatifida, likewise an herbaceous plant with pinnated leaves, an umbelliform blossom, and large potato-like roots, is scattered over most of the South Sea Islands. It is not cultivated in the Hawaiian group, but found growing wild in abundance in the more elevated districts, where it is satisfied with the most meagre soil, and sprouts forth among the lava blocks of those volcanic islands. Arrowroot is prepared from it in the same manner as from the West Indian Marantha, but, as the improvident Polynesians only think of digging it out of the earth, and never give themselves the trouble of replanting the small and useless tubers, its quantity has very much diminished.

The Caladium esculentum, an aquatic plant, furnishes the large Taro roots which form the chief food of the Sandwich Islanders, and are extensively cultivated in many other groups of the South Seas. It grows like rice on a marshy ground, the large, arrow-shaped leaves rise on high foot-stalks, immediately springing from the root, and are likewise very agreeable to the taste, but are more seldom eaten, as they are used for propagation. Severed from the root, they merely require to be planted in the mud to produce after six months a new harvest of roots. The growth is so abundant that 1,500 persons can live upon the produce of a single square mile. The South Sea Islanders make a thick paste out of the root, which, under the name of poé, forms their staple diet.

It may easily be imagined that the tropical sun, which distills so many costly juices and fiery spices in indescribable multiplicity and abundance, must also produce a variety of fruits. But man has as yet done but little to improve by care and art these gifts of nature, and, with rare exceptions, the delicious flavor for which our native fruits are indebted to centuries of cultivation, is found wanting in those of the torrid zone.

Yet there are exceptions to the rule, and among others the Peruvian Chirimoya (Anona tripetala) is vaunted by travelers in such terms of admiration that it can hardly be inferior to, and probably surpasses, the most exquisite fruits of European growth. Hänke calls it in one of his letters a masterpiece of nature, and Tschudi says that its taste is quite incomparable. It grows to perfection at Huanuco, where it attains a weight of from fourteen to sixteen pounds. The fruit is generally heart-shaped, with the broad base attached to the branch. The rind is green, covered with small tubercles and scales, and encloses a snow-white, juicy pulp, with many black kernels. Both the fruit and the blossoms exhale a delightful odor. The tree is about twenty feet high, and has a broad, dull-green crown.

The Litchi (Nephelium litchi, ) a small insignificant tree, with lanceolate leaves, and small greenish-white flowers, is a native of China and Cochin-China, but its cultivation has spread over the East and the West Indies. The plum-like, scarlet fruit is generally eaten by the Chinese with their tea, but it is also dried in ovens and exported. 
In order to cbtain the fruit in perfection, for the use of the Imperial Court, the trees, as soon as they blossom, are conveyed from Canton to Pekin on rafts, at a very great troubie and expense, so that the plum may just be ripe on their arrival in the northern capital.

The beautiful Mangosteen (Garcinia mangostana,) a native of the Moluccas, and thence transplanted to Java, Siam, the Philippines, and Ceylon, resembles at a distance the citron tree, and bears large flowers like roses. The dark-brown capsular fruit, about the size of a small apple, is described as of unequalled flavor-juicy and aromatic, like a mixture of strawberries, raspberries, grapes, and oranges. It is said that the patient who has lost an appetite for every thing else still relishes the mangosteen, and that the case is perfectly hopeless when he refuses even this.

The stately Mango, (Mangifera indica,) is frequently represented on the silk tissues of the Hindoos, who venerate, under the ugly form of the ape Huniman, the transformed hero who first robbed the gardens of a Ceylonese giant of its sweet fruit, and presented their forefathers with this inestimable gift. The mango bears beautiful girandoles of flowers, followed by large plum-like fruits, of which, however, but four or five ripen on each branch.

In Borneo and the other islands of the Malayan Archipelago grows the Durion, a fruit utterly unknown in Europe and America, which alone of all vegetable productions possesses the opposite qualities of extreme offensiveness to one sense, and of the highest gratefulness to the other sense most closely allied to it. Its smell is like that of rotten onions, while its taste is such that those who have once partaken of it prefer it to all other fruit. Wallace* thus describes the fruit:

"The durion grows on a large and lofty forest tree, somewhat resembling an elm in its general character, but with a more smooth and scaly bark. The fruit is round, or slightly oval, about the size of a large cocoa-nut, of a green color, and covered all over with short, stout spines, the bases of which touch each other, and are consequently somewhat hexagonal, while the points are very strong and sharp. It is so completely armed that, if the stalk is broken off, it is a difficult matter to lift one from the ground. The outer rind is so thick and tough that from whatever hight it may fall it is never broken. From the base to the apex five very faint lines may be traced, over which the spines arch a little; these are the sutures of the carpels, and show where the fruit may be divided with a heavy knife and a strong hand. The five cells are white within, and are each filled with an oval mass of cream-colored pulp, imbedded in which are two or three seeds about the size of chestnuts. The pulp is the eatable part, and its consistence and flavor are indescribable. A rich, butter-like custard, highly flavored with almonds, gives the best general idea of it; but intermingled with it come wafts of flavor that call to mind cream-cheese, onion-sauce, brown sherry, and other incongruities. Then there is a rich glutinous smoothness in the pulp which nothing else possesses, but which adds to its delicacy. It is neither acid, nor sweet, nor juicy; yet one feels the want of none of these qualities, for it is perfect as it is. It produces no nausea, or other bad effect, and the more you eat of it the less you feel inclined to stop. In fact, to eat durions is a new sensation worth a voyage to the East to experience.

"When the fruit is ripe it falls of itself, and the only way to eat durions in perfec- 
tion is to get them as they fall, and the smell is then less overpowering. In a good fruit season large quantities are preserved salted, and kept the year round, when it acquires a most disgusting odor to Europeans, but the natives appreciate it highly as a relish with their rice. It would not, perhaps, be correct to say that the durion is the best of all fruits, because it can not supply the place of the sub-acid juicy kinds, such as the orange, grape, mango, and mangosteen, whose refreshing and cooling qualities are so wholesome and grateful; but as producing a food of the most exquisite flavor it is unsurpassed. If $I$ had to fix on two only as representing the perfection of the two classes, I should certainly choose the durion and the orange as the king and queen of fruits.

"The durion is, however, sometimes dangerous. When the fruit begins to ripen it falls daily and almost hourly, and accidents not unfrequently happen to persons walking or working under the trees. When it strikes a man in the fall, it produces a dreadful wound, the strong spines tearing open the flesh, while the blow itself is very heavy. Poets and moralists, judging from the European trees and fruits, have said that small fruits alone grow on lofty trees, so that their fall should be harmless to man, while the larger ones trail on the ground. But this generalization would be much modified by an acquaintance with tropical trees and fruits. Three of the largest, most solid and heavy fruits that exist-the cocoa-nut, the Brazil-nut, and the duriongrow on lofty forest trees, from which they fall as soon as they are ripe, and often wound or kill the inhabitants. From this we may learn, mortifying as it is to our vanity, that trees and fruits, as well as many species of the animal kingdom, do not appear to be organized with exclusive reference to the use and convenience of man."

When the durion is brought into a house, its odor is so offensive that many persons can not bring themselves to taste it. This was the case with Mr. Wallace for a long time. Try his best to eat it, and the nose put in its absolute veto. But one day he happened when out of doors to find a ripe fruit, and eating it there, he thenceforward became a confirmed durion-eater. 


\section{CHAPTER VII.}

\section{SUGAR-COFFEE-CHOCOLATE-COCA-SPICES.}

Sugar: Its Importance-The Home of the Sugar-Cane-Ancient Theories about Sugar-The Introduction of the Cane into Earope and America-Characteristics of the Plant-Mode of Cultivation-Coffee: Its Home-Introduction into Egypt and Europe, and elsewherePresent Coffee Countries-Coffee Culture in Brazil-Agassiz's Description of a Coffee Estate-The West Indies and Ceylon-The Coffee-Plant-Methods of Preparing the Berries -The Enemies of the Plant-The Golunda-The Coffee Bug-The Coffee Moth.-Carao, or Chocolate: Its Culture and Preparation.-Coca: Description of the Plant-Mode of its Use - lts Effects-Indian superstitions connected with it.-Cinnamon: Known to the AncientsCinnamon in Ceylon-Mode of Culture and Preparation-General Account of this SpiceNutmegs and Cloves-Enormities of the Dutch Monopoly-Pepper-Pimento-Ginger.

7 THERE is a class of products of which, although not strictly articles of food, 1 enter largely into human consumption either as furnishing beverages, or as condiments to give flavor to food, or as luxuries. With the exception of tea, which belongs to the temperate zone, these belong almost exclusively to the Tropical World; and they rank among the most important articles of commerce. We shall enumerate the principal of these, viz.: Sugar, Coffee, Cacao, Coca, Vanilla, Cinnamon, Nutmegs, Cloves, Pepper, and Pimento.

Next after the great cereals, which have been described, sugar will rank as the most valuable product of the vegetable kingdom. It is produced in greater or less quantities from the juices of most fruits and vegetables, and the sap of many kinds of trees. We shall, however, speak only of that derived from the sugar-cane, a plant so exclusively tropical that its cultivation increases greatly in cost the moment we enter the confines of the temperate zones. Even in the great sugar region of Louisiana, with all the advantages of capital aided by science, the production of sugar is only rendered profitable by the imposition of protective duties upon that of foreign countries.

The original home of this plant-for which, doubtless, the lively fancy of the ancient Greeks, had they been better acquainted with it, would have invented a peculiar god, as for the vine or the cereals-is most likely to be sought for in Southeastern Asia, where the Chinese seem to have been the first people that learnt the art to multiply it by culture, and to extract the sugar from its juice. From China its cultivation spread westwards to India and Arabia, at a time unknown to history; and the conquests of Alexander the Great first made Europe acquainted with the sweetjuiced cane, while sugar itself had long before been imported by the Phœnicians as a rare production of the Eastern world. At a later period, both the plant and its produce are mentioned by several classical authors. They were, however, ignorant 
of the manner of its production, and set forth many fanciful theories upon the subject. According to some it was a kind of honey, which formed itself without the assistance of bees. Others thought it, like the manna in the wilderness, a shower from heaven which fell upon the leaves of blessed seed. Others, more nearly correct, believed it to be a concretion of the juices, formed by the plant itself in the manner of a gum.

During the dark ages which followed the fall of the Roman Empire, all previous knowledge of the Oriental sugar-plant became lost, until the Crusades, and, still more, the revival of commerce in Venice and Genoa reopened the ancient intercourse between the Eastern and the Western world. From Egypt, where the cultivation of the sugarcane had, meanwhile, been introduced, it now extended to the Morea, to Rhodes, and Malta; and at the beginning of the twelfth century we find it growing in Italy, on the sultry plains at the foot of Mount Etna. After the discovery of Madeira by the Portuguese, in the year 1419, the first colonists added the vine of Cyprus and the Sicilian sugar-cane to the indigenous productions of that lovely island; and both succeeded so well, as to become after a few years the objects of a lively trade with the mother country.

Yet, in spite of this extension of its culture, the importance of sugar as an article of international trade continued to be very limited, until the discovery of tropical America by Columbus opened a new world to commerce. As early as the year 1506 the sugarcane was transplanted from the Canary Islands to Hispaniola, where its culture, favored by the fertility of a virgin soil and the heat of a tropical sun, was soon found to be so profitable, that it became the chief occupation of the European settlers, and the principal source of their wealth. The Portuguese, in their turn, conveyed the cane to Brazil ; from Hispaniola it spread over the other West Indian Islands; thence wandered to the Spanish main, and followed Pedrarias and Pizarro to the shores of the Pacific.

Towards the middle of the last century, the Chinese or Oriental Sugar-cane had thus multiplied to an amazing extent over both hemispheres, when the introduction of the Tahitian variety, which was found to attain a statelier growth, to contain more sugar, and to ripen in a shorter time, began to dispossess it of its old domains. This new and superior plant is now universally cultivated in all the sugar-growing European colonies; and if Cook's voyages had produced no other benefit than making the world acquainted with the Tahitian Sugar-cane, they would for this alone deserve to be reckoned by the political economist among the most successful and important ever performed by man.

The sugar-cane bears a great resemblance to the common reed, but the blossom is different. It has a knotty stalk, like most grasses, frequently rising to the height of fourteen feet, and produces at each joint a long, pointed, and sharply serrated leaf or blade. The joints in one stalk are from forty to sixty in number, and the stalks rising from one root are sometimes very numerous. As the plant grows up, the lower leaves fall off. A field of canes, when agitated by a light breeze, affords one of the most pleasing sights, particularly when, towards the period of their maturity, the golden plants appear crowned with plumes of silvery feathers, delicately fringed with a lilac dye. The cane has this peculiarity, that each joint while contributing its share to the general growth and nutriment, is at the same time, by a separate system of vessels and chambers, providing for its own development. Thus every joint is in a manner a distinct plant; and if placed in the ground will send up a perfect cane. This is 
indeed the only manner in which it is now propagated. There is not and probably has not been for ages, a single plant raised from the seed. In Louisiana, a third of the crop is required for seed. In Cuba, much less is required, as the cane requires planting only every ten or twelve years ; while in Louisiana it must be renewed every two or three years. To this is mainly due the advantage as a sugar country of Cubs over Louisiana.

As the cane is a rank, succulent plant, it requires a strong, deep soil to bring it to perfection, and generally grows best in a low, moist situation. On the eastern, wellwatered slopes of the Andes, however, it still thrives at a height of 6,000 feet above the level of the sea. In preparing a field for planting with the cuttings of cane-for the cultivator nowhere resorts to the sowing of seed, which in America at least, has never been known to vegetate-the ground is marked out in rows, three or four feet apart, and in these lines holes are dug, from eight to twelve inches deep, and with an interval of two feet between the holes. In these the cuttings are inserted, which invariably consist of the top joints of the plant, because they are less rich in saccharine juice than the lower parts of the cane, while their power of vegetation is equally strong. While the shoots are growing and progressing to ripeness, great care must be taken to irrigate and weed the field. The canes annually yield fresh shoots, or rattoons, but as they have a tendency to deteriorate-at least in size-it is customary in all well-managed estates to renew every year one sixth part of the plantation.

The manufacture of sugar has been greatly improved by the introduction of steampower, which thoroughly presses out all the juice of the canes on their being passed but once between the three iron rollers which the crushing-machine sets in motion. The sap is collected in a cistern, and must be immediately heated, to prevent its becoming acid-an effect which frequently commences in less than an hour from the time of its being expressed. A certain quantity of lime is added to promote the separation of the feculent matters contained in the juice, and these being removed, the cane liquor is then subjected to a very rapid boiling, to evaporate the watery particles and bring the syrup to such a consistency that it will granulate on cooling.

In order to separate the granulated or crystallized sugar from the molasses, which are incapable of crystallization and even attract the moisture of the air, it is placed in a large square iron and air-tight case, divided into two compartments by a sieve-like bottom of wire with narrow meshes. The sugar is placed in the upper compartment, and the lower one communicates with two air-pumps, which are set in motion by the same engine which crushes the canes. On the air being exhausted in this lower compartment, the liquid molasses come pouring in to fill up the void, while the crystallized mass remains almost thoroughly purified at the top. This used formerly to be a very tedious operation: the sugar was placed in large casks whose bottoms were pierced with holes, and though left to drain for at least eight days, it still retained a quantity of molasses, while by the new process the cleansing is most effectually performed in a couple of hours, and the sugar, which has of course a much better appearance, can immediately be packed in hogsheads and cases ready for shipment.

Our space will not permit us to give a full description of the entire process of cultivating the cane and manufacturing sugar. In Harper's Magazine for November, 1853, and February, 1865, will be found fully illustrated articles describing these processes as carried on in Louisiana and Cuba. 
The mountain regions of Enarea and Caffa, situated to the south of Abyssinia, are most probably the countries where the Coffee-Tree was first planted by nature, as it has here not only been cultivated from time immemorial, but is everywhere found growing wild in the forests.

Here also the art of preparing a beverage from its berries seems to have been first discovered. Arabic authors inform us that about four hundred years ago Gemaledie, a learned mufti of Aden, having become acquainted with its virtues on a journey to the opposite shore of Africa, recommended it on his return to the dervises of his convent as an exsellent means for keeping awake during their devotional exereises. "The example of these holy men brought coffee into vogue, and its use spreading from tribe to tribe, and from town to town, finally reached Mecca about the end of the fifteenth century. There fanaticism endeavored to oppose its progress, and in $1511 \mathrm{a}$ council of theologians condemned it as being contrary to the law of Mahomet, on account of its intoxicating like wine. The Sultan of Egypt, however, who happened to be a great coffee-drinker himself, convoked a new assembly of the learned, who declared its use to be not only innocent, but healthy; and thus coffee advanced rapidly from the Red Sea and the Nile to Syria, and from Asia Minor to Constantinople, where the first coffee-house was opened in 1554, and soon called forth a number of rival establishments. But here also the zealots began to murmur at the mosques being neglected for the attractions of the ungodly coffee divans, and declaimed against it from the Koran, which positively says that coal is not of the number of things created by God for good. Accordingly the mufti ordered the coffee-houses to be closed; but his successor declaring coffee not to be coal, unless when over-roasted, they were allowed to re-open, and ever since the most pious mussulman drinks his coffee without any scruples of conscience. The commercial intercourse with the Levant could not fail to make Europe acquainted with this new source of enjoyment. In 1652, Pasqua, a Greek, opened the first coffee house in London, and twenty years later the first French cafés were established in Paris and Marseilles.

As the demand for coffee continually increased, the small province of Yemen, the only country which at that time supplied the market, could no longer produce a suffcient quantity, and the high price of the article naturally prompted the European governments to introduce the cultivation of so valuable a plant into their colonies. The islands of Mauritius and Bourbon took the lead in 1718, and Batavia followed in 1723. Some years before, a few plants had been sent to Amsterdam, one of which found its way to Marly, where it was multiplied by seeds. Captain Descleux, a French naval officer, took some of these young coffee-plants with him to Martinique, desirous of adding a new source of wealth to the resources of the colony. The passage was very tedious and stormy; water began to fail, and all the gods seemed to conspire against the introduction of the coffee-tree into the new world. But Descleux patiently endured the extremity of thirst that his tender shoots might not droop for want of water, and succeeded in safely bringing over one single plant, the parent stock whence all the vast coffee-plantations of the West Indies and Brazil are said to have derived their origin.

On examining the present state of coffee-production throughout the world, we find that it has undergone great revolutions within the last thirty years, as some of the countries that were formerly prominent in this respect now occupy but an inferior 
rank, while in others the cultivation of coffee has rapidly attained gigantic proportions. Thus Brazil, which at the beginning of the century was hardly known in the coffee market, now furnishes nearly as much as all the rest of the world besides. Its exportation, which in 1820 amounted to 97,500 sacks, rose to a million in 1840 , and attained in 1855 the enormous quantity of $2,392,100$ sacks, or more than 350 millions of pounds!

Java ranks next to Brazil among the coffee-producing countries, for though slavery does not exist in this splendid colony, yet the Dutch have introduced a system which answers the purpose fully as well. Every Javanese peasant is obliged to work sixtysix days out of the year for government; and the residents or administrators of the various districts distribute this compulsory labor among thi several plantations, which are all in the hands of private individuals. Thus the latter are provided with the necessary hands at a very cheap rate; but on the other hand they are compelled to sell their whole produce to the Handels Maatschappy, or Dutch East India Company, at a price fixed by the government, which of course takes care to secure the lion's share of the profit.

Within the last forty years the progress of coffee cultivation in Ceylon has been no less remarkable than its rapid extension in Java or Brazil. Though the plant was found growing in the island by the Portuguese, and is even supposed by some to be indigenous, yet it was only after the subjugation of the ancient kingdom of Kandy by the English in 1815, and the opening of roads in the hill country, that it began to be cultivated on a more extensive scale; so that in an incredibly short time the mountain ranges in the centre of the island became covered with plantations, and rows of coffeetrees began to bloom upon the solitary hills around the very base of Adam's Peak.

Brazil is, however, the great coffee country of the world. According to Agassiz* " more than half the coffee consumed in the world is of Brazilian growth. And yet the coffee of Brazil has little reputation, and is even greatly underrated, simply because a great deal of the best produce of the Brazilian plantations is sold under the name of Java or Mocha, or as the coffee of Martinique or Bourbon. Martinique produces only 600 sacks of coffee annually; Guadaloupe, whose coffee is sold under the name of the neighboring island, yields 6,000 sacks, not enough to provide the market of Rio de Janeiro for twenty-four hours; and the Isle of Bourbon hardly more. A great part of the coffee which is bought under these names, or under that of Java coffee is Brazilian; while the so-called Mocha coffee is often nothing but the small round beans of the Brazilian plant, found at the summit of the branches, and very carefully selected." "If," continues Agassiz, "the provinces adjacent to Rio de Janeiro offer naturally the most favorable soil for the production of coffee, it must not be forgotten that coffee is planted with advantage in the shade of the Amazonian forest, and even yields two annual crops whêrever pains are taken to plant it. In the province of Ceara, where the coffee is of superior quality, it is not planted on the plains or in the low grounds, or in the shadow of the forest, as in the valley of the Anjazon, but on the slopes of the hills and on the mountain hights, at an elevation of from 1,500 to 2,000 feet and more above the sea, in the Serras of Aratanha and Baturité and in the Serra Grande."

" A thriving coffee plantation," says Agassiz elsewhere, $\dagger$ " is a very pretty sight ; the rounded regular outline of the shrubs gives a tufted look to the hill-sides on which

* Journey in Brazil, 506, 507.

† Journey in Brazil, 71, 113, 114. 
they grow, and their glittering foliage contrasts strikingly with their bright berries. One often passes, however, coffee plantations which look ragged and thin ; and in this case the trees are either suffering from the peculiar insect so injurious to them, (a kind of tinea,) or have run out and become exhausted. The ordinary roads on the coffee plantations are carried straight up the side of the hills, between the lines of the shrubs, gullied by every rain, and offering besides so steep an ascent that even with eight or ten oxen it is often impossible to drive the clumsy, old-fashioned cart up the slope, and the negroes are obliged to bring a great part of the harvest down on their heads. They are often seen bringing enormous bundles on their heads down almost vertical slopes."

Agassiz, however, describes one plantation which he visited which appears to be a model : "On Senhor Lage's estate all these old roads are abandoned, except where they are planted here and there with alleys of orange-trees for the benefit of the negroes; and he has substituted for them winding roads in the sides of the hill, with a very gradual ascent, so that light carts dragged by a single mule can transport all the harvest from the summit of the plantation to the drying-ground. It was the harvesting season, and the sight was a very pretty one. The negroes, men and women, were scattered about the plantations, with broad shallow trays, made of plaited grass or bamboo, over their shoulders, and supported at their waists. Into these they were gathering the coffee, some of the berries being brilliantly red, some already beginning to dry and turn brown; while here and there was a green one not yet quite ripe but soon to ripen in the scorching sun. Little black children were sitting on the ground. and gathering what fell under the bushes, singing at their work a monotonous but rather pretty snatch of song, in which some took the first and others the second, making a not inharmonious music. As their baskets were filled they came to the administrator to receive a little metal ticket on which the amount of their work was marked. A task is allotted to each one-so much to a full-grown man, so much to a woman with young children, so much to a child - and each one is paid for whatever he may do over and above it. The requisition is a very moderate one, so that the industrious have an opportunity of making a little money independently. At night they all present their tickets, and are paid on the spot for any extra work. From the harvesting-ground we followed the carts down to the place where their burden is deposited. On their return from the plantation the negroes divide the day's harvest, and dispose it in little mounds on the drying-ground, which is paved in a dazzling white cement, from the glare of which the eye turns wearily away, longing for a green spot on which to rest. When pretty equally dried, the coffee is spread out in thin even layers over the whole enclosure, where it is baked in the sun for the last time. It is then hulled by a very simple machine, in use on almost all the fazendas, and the process is complete.

"The coffee plantations cover all the hill-sides for miles around. The seed is planted in nurseries especially prepared, where it undergoes its first year's growth. It is then transplanted to its permanent bome, and begins to bear in about three years, the first crop being a very light one. From that time forward, under good care and with favorable soil, it will continue to bear, and even to yield two crops or more annually for thirty years in succession. At that time the shrubs and the soil are alike exhausted, and according to the custom of the country the fazendeiro cuts down a new forest and begins a new plantation, completely abandoning his old one, without a 
thought of redeeming or fertilizing the exhausted land. One of the long-sighted reforms undertaken by our host, however, is the manuring of all the old deserted plantations on his estate. He has already a number of vigorous young plantations which promise to be as good as if a virgin forest had been sacrificed to produce them. He wishes not only to preserve the wood on his own estate, and to show that agriculture need not be pursued at the expense of taste and beauty, but also to remind his countrymen that, extensive as their forests are, they will not last forever; and that it will be necessary to emigrate before long to find new coffee grounds, if the old ones are to be considered worthless."

In the West Indies the culture of coffee has greatly diminished. Hayti, which before the revolution of 1791 exported to France 76,000,000 pounds, now produces less than half that quantity. The British West Indies, which in 1827 exported nearly $30,000,000$ pounds, now produce but 4,000,000. Cuba, the product of which in 1833 was $40,000,000$ pounds, now produces less than half as much. This is, however, owing to the fact, that it is found that under their system of slave-labor the cultivation of sugar, for which the climate is so favorable, has been found more profitable than that of coffee. In Ceylon the production of coffee has increased enormously within the present generation. It rose from less than 2,000,000 pounds in 1833 to more than $67,000,000$ pounds in 1857 ; since which time it has still further increased.

When left to the free growth of nature, the coffee-tree attains a hight of from fifteen to twenty feet; in the plantations, however, the tops are generally cut off in order to promote the growth of the lower branches, and to facilitate the gathering of the crop. Its leaves are opposite, evergreen, and not unlike those of the bay tree; its blossoms are white, sitting on short footstalks, and resembling the flower of the jasmine. The fruit which succeeds is a green berry, ripening into red, of the size and form of a large cherry, and having a pale, insipid, and somewhat glutinous pulp, enclosing two hard and oval seeds or beans, which are too well known to require any further description. The tree is in full bearing from its fourth or fifth year, and continues during a long series of seasons to furnish an annual produce of about a pound and a half of beans. The seeds are known to be ripe when the berries assume a dark red color, and if not then gathered, will drop from the trees.

The planters in Arabia do not pluck the fruit, but place cloths for its reception beneath the trees, which they shake, and the ripened berries drop readily. These are afterwards spread upon mats, and exposed to the sun until perfectly dry, when the husk is broken with large heavy rollers made either of wood or of stone. The coffee, thus cleared of its husk, is again dried thoroughly in the sun, that it may not be liable to heat when packed for shipment. This method may, in some measure, account for the superior quality of the Arabian coffee; but in the large plantations of Brazil, Java, Ceylon, and other European colonies, it is necessary to follow a more expeditious plan, to pluck the berries from the trees as soon as they ripen, and immediately to pass them through a pulping mill, consisting of a horizontal fluted roller turned by a crank, and acting against a movable breast-board, so placed as to prevent the passage of whole berries between itself and the roller. The pulp is then separated from the seeds by washing them, and the latter are spread out in the sun to dry; after which the membranous skin, or parchment, which immediately covers the beans, is removed by means of heavy rollers or stamping. 
To be cultivated to advantage, the coffee-tree requires a climate where the mean temperature of the year amounts to at least $68^{\circ}$, and where the thermometer never falls below 55०. It is by nature a forest tree requiring shade and moisture, and thus it is necessary to screen it from the scorching rays of the sun by planting rows of umbrageous trees at certain intervals throughout the field. These also serve to protect it from the sharp winds which would injure the blossoms. It cannot bear either excessive heat or a long-continued drought; and where rain does not fall in sufficient quantity, artificial irrigation must supply it with the necessary moisture. From all these circumstances it is evident that the best situations for the growth of coffee are not the sultry alluvial plains of the tropical and sub-tropical lands, but the mountain slopes to an elevation of 4,500 feet.

Like every other plant cultivated by man, the coffee-tree is exposed to the ravages of many enemies. Wild cats, monkeys, and squirrels prey upon the ripening berries, and hosts of caterpillars feed upon the leaves. Since 1847 the Ceylon plantations have been several times invaded by swarms of the golunda, a species of rat which inhabits the forests, making its nest among the roots of the trees, and, like the lemmings of Norway and Lapland, migrating in vast numbers when the seeds of the nîlloo-shrub, its ordinary food, are exhausted. "In order to reach the buds and blossoms of the coffee, the golunda eats such slender branches as would not sustain its weight, and feeds as they fall to the ground; and so delicate and sharp are its incisors, that the twigs thus destroyed are detached by as clean a cut as if severed with a knife. The Malabar coolies are so fond of its flesh that they evince a preference for those districts in which the coffee plantations are subject to its incursions, frying the rats in oil or converting them into curry."

Another great plague is the Lecanium coffece, known to planters as the coffee bug, but in reality a species of coccus, which establishes itself on young shoots and buds, covering them with a noisome incrustation of scales, from the influence of which the fruit shrivels and drops off. A great part of the crop is sometimes lost, and on many trees not a single berry forms from the invasion of this pest, which was first observed in 1843 on an estate at Lapalla Galla, and thence spreading eastward through other plantations, finally reached all the other estates in the island. No cheap and effectual remedy has as yet been found to stay its ravages, and the only hope is that, as other blights have been known to do, it may wear itself out, and vanish as mysteriously as it came.

Mrs. Agassiz* gives an interesting description of the larva of the Brazilian coffee moth: "For some time Mr. Agassiz has been trying to get living specimens of the insect so injurious to the coffee-tree, the larva of a little moth akin to those which destroy the vineyards of Europe. At last he succeeded in obtaining some, and among them was one just spinning his cocoon on the leaf. We watched him for a long time with the lens as he wove his filmy tent. He had arched the threads upwards in the center, so as to leave a little hollow space into which he could withdraw. This tiny vault seemed to be completed at the moment we saw him, and he was drawing threads forward and fastening them at a short distance beyond, thus lashing his house to the leaf, as it were. The exquisite accuracy of the work was amazing. He was spinning the thread with his mouth, and with every new stitch he turned bis body backward, 
attached his thread to the same spot, then drew it forward and fastened it exactly on a line with the last, with a precision and rapidity that machinery could hardly imitate. It is a curious question how far this perfection of workmanship in many of the lower animals is simply identical with their organization, and therefore to be considered as a function as inevitable in its action as digestion or respiration, rather than as an instinct. In this case the body of the little animal was his measure. It was amazing to see him lay down his threads with such accuracy, till one remembered that he could not make them longer or shorter; for, starting from the center of his house, and stretching his body to its full length, they must always reach the same point. The same is true of the so-called 'mathematics' of the bee. The bees stand as close as they can together in their hive, for the economy of space; and each one deposits his wax around him, his own form and size being the mould for the cells, the regularity of which when completed excites so much wonder and admiration. The 'mathematical' secret of the bee is to be found in his structure, not in his instinct. But in the industrial work of some of the lower animals-the ant, for instance,-there is a power of adaptation which is not susceptible of the same explanation. Their social organization, too intelligent, it seems, to be the work of any reasoning powers of their own, yet does not appear to be directly connected with their structure. While we were watching our little insect, a breath stirred the leaf, and he instantly contracted himself and drew back under his roof; but presently came out again and returned to his work."

"Theobroma,"-food for gods,- - the Greek name given by Linnæus to the Cacao or Chocolate tree, sufficiently proves how highly he valued the flavor of its seeds. Indigenous in Mexico, it had long been in extensive cultivation before the arrival of the Spaniards, who found the beverage which the Indians prepared from its beans so agreeable, that they reckoned it among the most pleasing fruits of their conquest. From Mexico they transplanted it into their other dependencies, so that in America its present range of cultivation extends from $20^{\circ}$ North latitude to Guayaquil and Bahia. It has even been introduced into Africa and Asia, in return for the many useful trees that have been imported from the old into the new world.

The cacaotree seldom rises above the height of twenty feet, its leaves are large, oblong, and pointed. The flowers, which are of a pale red color, spring from the large branches, and even from the trunk and roots. The fruits are large, oval, pointed pods, about five or six inches long, and containing in five compartments from twenty to forty seeds-the well-known cacao of commerce-enveloped in a white, pithy substance.

The trees are raised from seed, generally in places screened from the wind. As they are incapable of bearing the scorching rays of the sun, particularly when young, bananas, maize, manioc, and other broad-leaved plants are sown between their rows, under whose shade they enjoy the damp and sultry heat which is indispensable to their growth, for the Theobroma Cacao is essentially tropical, and requires a warmer climate than the coffee-tree or the sugar-cane. Two years after having been sown, the plant attains a height of three feet, and sends forth many branches, of which, however, but four or five are allowed to remain. The first fruits appear in the third year, but the tree does not come into full bearing before it is six or seven years old, and from that time forward it continues to yield abundant crops of beans during more than twenty years. At first the tender plants must be carefully protected from weeds and 
insects, but in after years they demand but little attention and labor, so that one negro suffices for keeping a thousand trees in order and collecting their produce. According to Herndon,* the annual produce of a thousand full-grown trees, in the plantations along the lower banks of the monarch of streams, amounts to fifty arrobes, that sell in Peru from two and a half to three milrees the arrobe; and Wagner informs us that in Costa Rica a thousand trees yield about 1,250 pounds, worth twenty dollars the hundred weight.

The beans when first collected from the tree are possessed of an acrimony, which requires a slight fermentation to change into the aromatic principle, to which they are indebted for their agreeable flavor. For this purpose they are thrown into pits, where they remain three or four days covered with a light layer of sand, care being taken to stir them from time to time. They are then taken out, cleaned, and laid out upon mats to dry in the sun. The management of the beans requires some caution, for if the fermentation is allowed to continue too long, they acquire a mouldy taste and smell, which they only lose on being roasted. When thoroughly dried (which is known by their hollow sound when shaken, and by the husk easily separating from the seed when pressed), they are packed in sacks or cases, and sent as soon as possible to the market, a rapid sale being extremely desirable, as it is very difficult to preserve them from insects, more particularly from the cockroaches. Cacao is chiefly used under the form of chocolate. The beans are roasted, finely ground, so as to convert them into a perfectly smooth paste, and improved in flavor by the addition of spices, such as the sweetscented vanilla, a short notice of which will not be out of place.

Like our parasitical ivy, the Vanilla aromatica, a native of torrid America, climbs the summits of the highest forest-trees, or creeps along the moist rock crevices on the banks of rivulets. The stalk, which is about as thick as a finger, bears at each joint a lanceolate and ribbed leaf, twelve inches long and three inches broad. The large flowers, which fill the forest with their delicious odors, are white intermixed with stripes of red and yellow, and are succeeded by long and slender pods containing many seeds imbedded in a thick oily and balsamic pulp. These pods seldom ripen in the wild state, for the dainty monkey knows no greater delicacy, and his agility in climbing almost always enables him to anticipate man. At present the vanilla is cultivated not only in Mexico, where the villages Papantla and Misantla annually produce about 19,000 pounds or two millions of pods (worth at Vera Cruz a shilling the pod), but in Java, where the industrious Dutch have acclimatized it since 1819. It is planted under shady trees on a damp ground, and grows luxuriantly; but as a thousand blossoms on an average produce but one pod, it must always remain a rare and costly spice. $\mathrm{Had}$ the ancients known vanilla they would, no doubt, have deemed it more worthy to be the food of the Olympic gods than their fabled ambrosia.

Although but little known beyond the confines of its native country, Coca (to be carefully distinguished from Cocoa and Cacao), is beyond all doubt one of the most remarkable productions of the tropical zone, and deserves the more to be noticed as the time is, perhaps, not far distant, when it will assume a conspicuous rank in the markets of the world. 
The sultry valleys on the eastern slopes of the Peruvian and Bolivian Andes are the seat of the Erythroxylon Coca, which like the coffee-tree bears a lustrous green foliage, and white blossoms ripening into small, scarlet berries. These, however, are not used, but the leaves, which when brittle enough to break on being bent, are stripped from the plant, dried in the sun, and closely packed in sacks. The naked shrub soon gets covered with new foliage, and after three or four months its leaves are ready for a second plucking, though in some of the higher mountain-valleys it can only be stripped once a year. Every eight or ten years the plantations require to be renewed, as the leaves of the old shrubs are less juicy, and consequently of inferior quality. Like the coffee-tree, the coca shrub thrives only in a damp situation, under shelter from the sun; and for this reason maize, which rapidly shoots up, is generally sown between the rows of the young plants. At a later period, when they no longer need this protection, care must be taken to weed the plantation, and to loosen the soil every two or three months.

The local consumption of coca is immense, as the Peruvian Indian reckons its habitual use among the prime necessaries of life, and is never seen without bis leathern pouch or chuspa, filled with a provision of the leaves, and containing besides a small box of powdered unslaked lime. At least three times a day he rests from his work to chew his indispensable coca. Carefully taking a few leaves out of the bag, and removing their midribs, he first masticates them into the shape of a small ball, which is called an acullico; then repeatedly inserting a thin piece of moistened wood like a toothpick into the box of unslaked lime, he introduces the powder which remains attached to it into the acullico until the latter has acquired the requisite flavor. The saliva, which is abundantly secreted while chewing the pungent mixture, is mostly swallowed along with the green juice of the plant. When the acullico is exhausted, another is immediately prepared, for one seldom suffices. The corrosive sharpness of the unslaked lime requires some caution, and an unskilled coca-chewer runs the risk of burning his lips, as, for instance, the celebrated traveler Tschudi, who, by the advice of his muleteer, while erossing the high mountain passes of the Andes, attempted to make an acullico, and instead of strengthening himself as he expected, merely added excru. ciating pain to the fatigues of the journey. The taste of coca is slightly bitter and aromatic, like that of bad green tea, but the addition of lime or of the sharp ashes of the quinoa, renders it less disagreeable to the European palate.

It is a remarkable fact that the Indians who regularly use coca require but little food, and when the dose is augmented are able to undergo the greatest fatigues, without tasting almost anything else. Pöppig ascribes this astonishing increase of endurance to a momentary excitement, which must necessarily be succeeded by a corresponding collapse, and therefore considers the use of coca absolutely hurtful. Tschudi, however, is of opinion that its moderate consumption far from being injurious, is, on the contrary, extremely wholesome, and cites the examples of several Indians who, never allowing a day to pass without chewing their coca, attained the truly patriarchal age of one hundred and thirty years. The ordinary food of these people consists almost exclusively of roasted maize or barley, which is eaten dry without any other addition : and the obstinate obstructions caused by these mealy aliments are obviated by the tonic effects of the coca, which thus removes the cause of many maladies. It may be remarked, that a similar reason is assigned for the custom of areka and betel chewing 
in Southern Asia. As an instance of the wonderful strengthening properties of the coca, Tschudi mentions the case of an Indian called Hatun Huamang or the "Great Vulture," whom he employed during five consecutive days and nights in making the most laborious excavations, and who never ate anything all the time, or slept more than two hours a night. But every three hours he chewed about half an ounce of the leaves, and constantly kept his acullico in his mouth. When the work was finished, this Indian accompanied Tschudi during a ride of twenty-three leagues, over the high mountainplains, constantly running alongside of the nimbly-pacing mule, and never resting but for the purpose of preparing an acullico. When they separated, the "Great Vulture" told Tschudi that he would willingly do the same work over again, provided only he had a plentiful allowance of coca. He was sixty-two years old, according to the testimony of the village priest, and had never been ill all his life.

Tschudi often found that coca is the best preservative against the asthmatic symptoms which are produced by the rapid ascension of high mountains. While hunting in the Puna, at an elevation of 14,000 feet above the level of the sea, he always drank a strong infusion of coca before starting, and was then able to climb among the rocks, and to pursue his game, without any greater difficulty in breathing than would have been the case upon the coast. Even after drinking a very strong infusion, he never experienced any symptoms of cerebral excitement, but a feeling of satiety, and though he took nothing else at the time, his appetite returned only after a longer interval than usual.

If the mokerate use of coca is thus beneficial in many respects, its abuse is attended with the same deplorable consequences as those which are observed in the oriental opium-eaters and smokers, or in our own incorrigible drunkards. The confirmed cocachewer, or coquero, is known at once by his uncertain step, his sallow complexion, his hollow, lack-lustre black-rimmed eyes, deeply sunk in the head, his trembling lips, his incoherent speech, and his stolid apathy. His character is irresolute, suspicious, and false ; in the prime of life he has all the appearances of senility, and in later years sinks into complete idiocy. Avoiding the society of man, he seeks the dark forest, or some solitary ruin, and there, for days together, indulges in his pernicious habit. While under the influence of coca, his excited fancy riots in the strangest visions, now revelling in pictures of ideal beauty, and then baunted by dreadful apparitions. Secure from intrusion, he crouches in an obscure corner, his eyes immovably fixed upon one spot; and the almost automatic motion of the hand raising the coca to the mouth, and its mechanical chewing, are the only signs of consciousness which he exhibits. Sometimes a deep groan escapes from his breast, most likely when the dismal solitude around him inspires his imagination with some terrific vision, which he is as little able to banish as voluntarily to dismiss his dreams of ideal felicity. How the coquero finally awakens from his trance, Tschudi was never able to ascertain, though most likely the complete exhaustion of his supply at length forces him to return to his miserable hut.

No historical record informs us when the use of the coca was introduced, or who first discovered the hidden virtues of its leaves. When Pizarro destroyed the empire of Atahualpa he found that it played an important part in the religious rites of the Incas, and that it was used in all public ceremonies, either for fumigation or as an offering to the gods. The priests chewed coca while performing their rites, and the 
favor of the invisible powers was only to be obtained by a present of these highly valued leaves. No work begun without coca could come to a happy termination, and divine honors were paid to the shrub itself.

After a period of more than three centuries, Christianity has not yet been able to eradicate these deeply rooted superstitious feelings, and everywhere the traveler still meets with traces of the ancient belief in its mysterious powers. To the present day, the miners of Cerro de Pasco throw chewed coca against the hard veins of the ore, and affirm that they can then be more easily worked,-a custom transmitted to them from their forefathers, who were fully persuaded that the Coyas, or subterranean divinities, rendered the mountains impenetrable unless previously propitiated by an offering of coca. Even now the Indians put coca into the mouths of their dead, to insure them a welcome on their passage to another world; and whenever they find one of their ancestral mummies, they never fail to offer it some of the leaves.

During the first period after the conquest of Peru, the Spaniards endeavored to extirpate by all possible means the use of coca, from its being so closely interwoven with the Indian superstitions; but the proprietors of the mines soon became aware how necessary it was for the successful prosecution of their undertakings; the planters also found after a time that the Indians would not work without it. Private interest prevailed, as it always does in the long run, over religious zeal and despotic interdictions, and in the last century we even find a Jesuit, Don Antonio Julian, regretting that the use of coca had not been introduced into Europe instead of tea or coffee. When we consider its remarkable properties, it is indeed astonishing that it has so long remained unnoticed. Were it concealed in the interior of Africa, or extremely difficult to procure, this neglect could be more easily accounted for; but hundreds of vessels annually frequent the harbors of Peru and Bolivia, where it may be obtained in large quantities, and yet it has only been rarely and in small quantities imported into Europe, and, as far as I can learn, never into the United States.

Although the Cinnamon tree, that beautiful laurel, whose bark furnishes the most exquisite of all the spices of the East, is indigenous in the forests of Ceylon; yet as no author previous to the fourteenth century mentions its aromatic rind among the productions of the island, there is every reason to believe that the cinnamon, which in the earlier ages was imported into Europe through Arabia, was obtained first from Africa, and afterwards from India. Cinnamon figures largely among the ingredients used by the Hebrews for the holy anointing oil and sacred perfumes. Some, indeed, but with no good reason, have supposed that the substance so designated was the gum of a species of the aloe, and aver that cinnamon itself was unknown to the Hebrews, Greeks and Romans. That the Portuguese, who had been mainly attracted to the East by the fame of its spices, were nearly twenty years in India before they took steps to obtain a footing at Colombo, proves that there can have been nothing very remarkable in the quality of the spice at the beginning of the sixteenth century, and that the high reputation of the Ceylon cinnamon is comparatively modern, and attributable to the attention bestowed upon its preparation for market by the Portuguese, and afterwards on its cultivation by the Dutch. Long after the appearance of Europeans in Ceylon, cinnamon was only found in the forests of the interior, where it was cut and brought away by the Chalias, an emigrant tribe, which, in consideraticn 
of its location in villages, was bound to go into the woods to cut and deliver, at certain prices, a given quantity of cinnamon properly peeled and ready for exportation. This system remained unchanged so long as Portugal was master of the country; but the forests in which the spice was found being exposed to constant incursions from the Kandyans, who sought every opportunity to obstruct and harass the Chalias and peelers, the Dutch were compelled to form enclosed plantations of their own within range of their fortresses. The native chieftains, fearful of losing the profits derived from the labor of the Chalias, who were attached as serfs to their domains, and whose work they let out to the Dutch, were at first extremely opposed to this innovation, and endeavored to persuade the Hollanders that the cinnamon would degenerate as soon as it was artificially planted. The withering of many of the young trees seemed to justify the assertion; but on a closer examination it was found that boiling water had been poured upon the roots. A law was now passed declaring the wilful injury of a cinnamon plant a crime punishable with death, and by this severity the project was saved.

The extent of the trade during the time of the Dutch may be inferred from the fact, that the five principal cinnamon-gardens around Nejombo, Colombo, Barberyn, Galle, and Maduro were each from fifteen to twenty miles in circumference. Although they were only first planted in the year 1770, yet before 1796, when Colombo was taken by the English, their annual produce amounted to more than $400,000 \mathrm{lbs}$. of cinnamon, as much as the demands of the market required. The profits must have been enormous, for cinnamon was then at least ten times dearer than at present, the trade being exclusively in the hands of the Dutch East Indian Company, which, in order to keep up the price, restricted the production to a certain quantity, and watched over its monopoly with the most jealous tyranny. Nó one was allowed to plant cinnamon or to peel it, and the selling or importing of a single stick was punished as a capital offence.

When the English took possession of the island, the monopoly was ceded to the East India Company for an annual sum of $£ 60,000$ until 1823, when the colonial government undertook the administration of the cinnamon-gardens for its own account. In 1831 the produce sank to $£ 16,000$ sterling, and in the following year the ancient monopoly was abandoned; the government ceased to be the sole exporters of cinnamon, and thenceforward the merchants of Colombo and Galle were permitted to take a share in the trade, on paying to the crown an export duty of three shillings a pound. This was afterwards reduced to one shilling, and ultimately totally abolished; as not alone India and Java, but also Martinique, Guiana, and Mauritius, where the cinnamon tree had been introduced, were found capable of producing the spice; and the cheap substitute of Cassia, a still more formidable competitor, was arriving in Europe in large quantities from South China and the Trans-Gangetic peninsula. In Java alone the export of cinnamon, which in the year 1835 amounted only to $2,200 \mathrm{lbs}$, increased so rapidly that in 1845 it had already risen to $134,000 \mathrm{lbs}$, and as it can there be more cheaply produced, and the Dutch government was wise enough to limit the export duty to one half-penny a pound, an unrestricted free trade was evidently the only means for preventing Ceylon from being entirely supplanted in the markets of the world. Under these circumstances, the Singhalese cinnamon has lost its ancient excellence, less care has been given of late years to the production of the finest qualities for the European market, and the coarser and less valuable shoots bave been 
cut and peeled in larger proportions than formerly. Hence the gross quantity exported from Ceylon in 1857 ( 887,959 lbs.) was nearly double that of 1841 .

The cinnamon gardens, whose beauty and luxuriance has been so often vaunted by travelers, have partly been sold, partly leased to private individuals; and though less than a century has elapsed since they were formed by the Dutch, they are already becoming a wilderness. Those which surround Colombo on the land side exhibit the effects of a quarter of a century of neglect, and produce a feeling of disappointment and melancholy. The beautiful shrubs which furnish this spice have been left to the wild growth of nature, and in some places are entirely supplanted by an under. growth of jungle, while in others a thick cover of climbing plants conceals them under heaps of verdure and blossom. It would, however, be erroneous to suppose that the cinnamon-gardens have been universally doomed to the same neglect, and many beautiful gardens still exist. The aspect of a well-conditioned cinnamongarden is rather monotonous; for, though the trees when left to their full growtb attain a hight of forty or fifty feet, and a thickness of from eighteen to twenty inches, yet, as the best spice is furnished by the shoots that spring from the roots after the chief stem has been removed, they are kept as a kind of coppice, and not allowed to rise higher than ten feet. The shrubs planted in regular rows, four or five feet apart, consist of four or five shoots whose slender stems, very much resembling those of the hazel tree, are leafed from top to bottom. The leaf when first developed is partly of a bright red, and partly of a pale yellow ; it soon, however, assumes a green hue, and when at its full growth is on the upper surface of a dark olive color, and on the under side of a lighter green; it somewhat resembles that of the bay, but is longer and narrower. The flowers bloom in January, and grow on foot-stalks rising from the axillæ of the leaves and the extremities of the branches, clustering in bunches, which resemble in size and shape those of the lilac, but they are white with a brownish tinge in the center. Though their smell has been frequently extolled as very fragrant, yet it is weak, and by no means agreeable, resembling that of animal albuminous liquids. The flowers are followed by one-seeded berries, of the shape of an acorn, but not so large as a common pea.

The plants are propagated by seeds or saplings. In two years the shoots are fit for cutting, being then about half an inch thick; but as the shoots are continually cut as soon as they have obtained the proper size, a full-grown trunk never forms, so that the more or less voluminous root-stalk is the only criterion of age. The peeling of the rind takes place twice a year, from May to June, and in November, as at that time, in consequence of the heavier rains, and the increase of sap, it can be more easily detached from the wood. The epidermis having been scraped off, the bark is placed on mats to dry in the sun, when it curls up, and acquires a darker tint. The smaller pieces are then put inside the larger, and the whole closes together into the tubular form, in which it is sold in the shops. The finer sort is as thin as parchment, light brown, and extremely aromatic.

From the American "Cyclopædia of Biblical Literature" we abridge an admirable acrount of this plant: "Cinnamon was probably an article of commerce in ancient Babylon. The Hebrews received it through the Midianites and Nabathæans, who brought it from the Arabian Gulf. It seems that the Arabians at an early period had commercial intercourse with Ceylon and Continental India. The term itself occurs in 
many Greek authors. Herodotus, writing 400 years before the Christian era, describes Arabia as the last inhabited country toward the south, and the only region which produces frankincense, myrrh, cinnamon, cassia, and ledanum. He states that the Arabians, however, were ignorant of the particular spot where cinnamon grew. It was not till the time of Dioscorides, Galen, and the circumnavigation of the Erythræan Sea (B. C. 200, that we get any definite information. Galen says that cinnamon and cassia are so much alike that it is not an easy matter to distinguish one from the other. Cinnamon of the best quality is imported at the present day from Ceylon and the Malabar coast. It comes in bales and chests, the bundles weighing about a pound each. The pieces consist of slender compound quills about three feet long, each enclosing several smaller quills. These are thin, smooth, and of a brownish color; of a warm, sweetish, and agreeable taste, and fragrant odor; but several kinds are known in modern markets, as they were in ancient times. The best kinds of cinnamon are obtained from twigs and shoots; those of less than half an inch, or more than three inches in diameter, are not peeled. When the bark is partially dry the smaller quills are introduced into the larger ones, and in this way congeries of quills are formed, often measuring forty inches in length. The quills are then thoroughly dried in the sun, and made into bundles with pieces of split bamboo twigs.

"An oil of cinnamon is prepared by macerating the coarser pieces of the bark, after being reduced to a coarse powder, in sea-water for two days, and then distilling it. A fatty substance is also obtained by bruising and boiling the ripened fruit, when an oily substance floats on the surface, which on cooling concretes into a whitish, rather hard, fatty matter. As the oil burns with a delightful fragrance, the kings of Kandy used to burn it in their audience chambers when receiving foreign ambassadors. The wood also is pervaded with the same grateful perfume, and walking-sticks and small articles of furniture made from it are highly prized.

"Cassia bark is with difficulty distinguished from Cinnamon, except by experts. During the palmy Dutch days there were professional tasters who were able to discriminate between balf a score of different qualities of cinnamon; and they were required when on duty to live wholly on rice, bread, and fruits, so as not to impair the keenness of their gustatory sensibilities. They, of course, were quite able to distinguish between cinnamon and cassia; the more readily because the latter left a bitter taste in the mouth. Chemistry distinguishes them still more readily; for a decoction of cassia, when treated with a tincture of iodine, gives a blue color, which cinnamon does not. At the present day, cinnamon has to a great extent lost its favor as a condiment. The principal consumers of it are the chocolate-makers of France, Spain, Italy and Mexico. The Germans, Turks and Russians prefer cassia, on account of its stronger flavor. Not very long since a large quantity of cinnamon, worth a dollar a pound, was sent by mistake to Constantinople, where it could not be sold even at the price of cassia, worth only a seventh as much, which was in great demand."

Nutmegs and Cloves, the costly productions of the remotest isles of the Indian Ocean, were known in Europe for centuries before the countries where they grow had ever been heard of. Arabian navigators brought them to Egypt, where they were purchased by the Venetians and sold at an enormous profit to the nations of the west. But, as is well known, the commercial grandeur of the city of the Lagunes was 
suddenly eclipsed after Vasco de Gama discovered the new maritime road to the East Indies, round the Cape of Good Hope (1498); and when, a few years later, the countrymen of the great navigator conquered the Moluccas (1511), they for a short time monopolized the whole spice trade much more than their predecessors had ever done before. But here also as in Ceylon the Portuguese were soon obliged to yield to a stronger rival; for the Dutch now appeared upon the scene, and by dint of enterprise and courage soon made themselves masters of the Indian Ocean. In 1605 they drove the Portuguese from Amboyna, and before 1621 had elapsed, the whole of the Moluccas were in their possession. Five-and-twenty years later, Ceylon also fell into their hands, and thus they became the sole purveyors of Europe with cinnamon, cloves and nutmegs. Unfortunately, the scandalous manner in which they misused their power throws a dark shade over their exploits. For the better to secure the monopoly of the spice trade, they declared war against nature itself, allowed the trees to grow only in particular places, and extirpated them everywhere else. Thus the planting of the nutmeg tree was confined to the small islands of Banda, Lonthoir, and Pulo Aij, and that of the clove to Amboyna. Wherever the trees were seen to grow in a wild state, they were unsparingly rooted out, and the remainder of the Moluccas were occupied and subjugated for no other reason.

The natives were treated with unmerciful cruelty, and blood flowed in torrents to keep up the prices of cloves and nutmegs at an usurious hight. When these spices accumulated in too large a quantity for the market, they were thrown into the sea or destroyed by fire. Thus M. Beaumare, a French traveler, relates that on June 10, 1760, he beheld near the Admiralty at Amsterdam a blazing pile of these aromatics, valued at four millions of florins, and an equal quantity was to be burnt the next day. The air was perfumed with their delicious fragrance, the essential oils freed from their confinement distilled over, mixing in one spicy stream, which flowed at the feet of the spectators; but no one was suffered to collect any of this, or, on pain of heavy punishment, to rescue the smallest quantity of the spice from the flames. But the reign of monopoly has ceased even in the remote Moluccas, and their ports are now, at length, thrown open to the commerce of all nations; for the spice trees having been transplanted into countries beyond the control of the Dutch, the ancient system could not possibly be maintained any longer.

The clove tree belongs to the far-spread family of the myrtles; the small lanceolate evergreen leaves resemble those of the laurel, the flowers growing in bunches at the extremity of the branches. When they first appear, which is at the beginning of the rainy season, they are in the form of elongated greenish buds, from the extremity of which the corolla is expanded, which is of a delicate peach-blossom color. When the corolla begins to fade, the calyx turns yellow, and then red; the calyces with their embryo-seed are in this stage of their growth beaten from the tree, and, after being dried in the sun, are known as the cloves of commerce. If the fruit be allowed to remain on the tree after arriving at this period, the calyx gradually swells, the seed enlarges, and the pungent properties of the clove are in great part dissipated. The whole tree is highly aromatic, and the foot-stalks of the leaves have nearly the same pungent quality as the calyx of the flowers. Clove trees as an avenue to a residence are perhaps unrivalled; their noble hight, the beauty of their form, the luxuriance of their foliage, and, above all, the spicy fragrance with which they perfume the air, 
produce, on driving through a long line of them: a degree of exquisite pleasure only to be enjoyed in the clear, light atmosphere of these latitudes.

Cloves contain a very large proportion of essential oil, which combined with a peculiar resin gives them their pungent aroma. It seems, however, to require a combination of favorable circumstances of climate and soil for the full development of their virtues; for, though the tree is found in the larger islands of Eastern Asia, and in Cochin China, it has there little or no flavor, and the Moluccas seem to be the only place where the clove comes to perfection without being cultivated. Though it is at present planted in Zanzibar, Cayenne, Bourbon, Trinidad, and other places, yet Amboyna still furnishes the best quality and the largest quantity, exporting annually about a million of pounds.

In spite of the endeavors of the Dutch to confine the Nutmeg tree to the narrow precincts of Banda, it has likewise extended its range not only over Sumatra, Mauritius, Bourbon, and Ceylon, but even over the western hemisphere. It is of a more majestic growth than the clove, as it attains a hight of fifty feet, and the leaves, of a fine green on the upper surface, and gray beneath, are more handsome in the outline, and broader in proportion to the length. When the trees are about nine years old, they begin to bear. They are dicecious, having male or barren flowers upon one tree, and female or fertile upon another. The flowers of both are small, white, bell-shaped, without any calyx ; the embryo-fruit appearing at the bottom of the female flowers in the form of a little reddish knob. When ripe, it resembles in appearance and size a small peach, and then the outer rind, which is about half an inch thick, bursts at the side, and discloses a shining black nut, which seems the darker from the contrast of the leafy network of a fine red color with which it is enveloped. The latter forms the Mace of commerce, and having been laid to dry in the shade for a short time, is packed in bags and pressed together very tightly. The shell of the nut is larger and harder than that of the filbert, and could not, in the state in which it is gathered, be broken without injuring the nut. On that account the nuts are successively dried in the sun and then by fire-heat, till the kernel shrinks so much as to rattle in the shell, which is then easily broken. After this the nuts are three times soaked in sea-water and lime; they are then laid in a heap, where they heat and get rid of their superfluous moisture by evaporation. This process is pursued to preserve the substance and flavor of the nut, as well as to destroy its vegetative power. The kernel contains both a fixed oil, which is obtained by pressure, a pound generally yielding three ounces, and a transparent volatile oil, which may be obtained by distillation in the proportion of one thirty-second part of the weight of nutmeg used. The outer rinds are likewise not without use to the natives. They are laid in large heaps, and allowed to putrefy, when they get covered with a blackish mushroom, which is esteemed as a great delicacy.

Pepper, although not so costly as cloves or cinnamon, is of a much greater commercial value, as its consumption is at least a hundred times greater. It grows on a beautiful vine, which, incapable of supporting itself, twines round poles prepared for it; or, as is more common in the Travancore plantations, the pepper vines are planted near mango and other trees of straight high stems. As these are stripped of 
the lower branches, the vine embraces the trunk, covering it with elegant festoons and rich bunches of fruit in the style of the Italian vineyards. The leaf of the pepper plant is large, resembling that of the ivy, and of a bright green ; the blossoms appear in June, soon after the commencement of the rains; they are small, of a greenish white, and are followed by the pungent berries, which hang in large bunches, resembling in shape those of grapes, but the fruit grows distinct on little stalks like currants. This valuable spice grows chiefly on the Malabar coast, in Sumatra, Borneo, Java, Singapore; its cultivation has also been introduced in Cayenne and the West Indies. The black and white sorts of pepper are both the produce of the same plant. The best white peppers are supposed to be the finest berries which have dropped from the tree, and, lying under it, become somewhat bleached by exposure to weather; the greater part of the white pepper used as a condiment is, however, the black merely steeped in water, and decorticated, by which means the pungency and real value of the spice are diminished; but having a fairer and more uniform appearance when thus prepared, it fetches a higher price.

Jamaica is the chief seat of the magnificent myrtle (Myrtus pimenta), which furnishes the Pimento-commonly called, by way of eminence, " Spice," or "Allspice" -of commerce. This beautiful tree grows to the height of about thirty feet, with a smooth, brown trunk, and shining green leaves resembling those of the bay. In July and August a profusion of white flowers, filling the air with their delicious odors, forms a very pleasing contrast to the dark foliage of its wide-spreading branches. It grows spontaneously in many parts of the island, particularly on the northern side, in high spots near the coast. When a new plantation is to be formed, no regular planting or sowing takes place, for, as Edwards observes, "the pimento tree is purely a child of nature, and seems to mock all the labors of man in his endeavors to extend or improve its growth; not one attempt in fifty to propagate the young plants, or to raise them from the seeds in parts of the country where it is not found growing spontaneously, having succeeded. For this reason, a piece of land is chosen, either in the neighborhood of a plantatation already formed, or in a part of the woodland where the pimento-myrtles are scattered in a native state. The land is then cleared of all wood but these trees, which are left standing, and the felled timber is allowed to remain, where it falls to decay, and perishes. In the course of a year, young pimento plants are found springing up on all parts of the land, produced, it is supposed, in consequence of the ripe berries having been scattered there by the birds, while the prostrate trees protect and shade the tender seedlings. At the end of two years the land is thoroughly cleared, and none but the most vigorous plants, which come to maturity in about seven years, are left standing." The berries are carefully picked while yet green, since, when suffered to ripen, they lose their pungency. One person on the tree gathers the sinall branches, and three others, usually women and children, find full employment in picking the berries from them. The produce is then exposed to the sun for about a week, when the berries lose their green hue and become of a reddish brown. When perfectly dry, they are in a fit state for exportation. In favorable seasons, which, however, seldom occur above once in five years, the pimento crop is enormous, a single tree having been known to yield one hundred weight of the dried spice. From its combining the flavor and properties of many of the oriental 
aromatics, pimento has derived its popular name of allspice, and, from its being cheaper than black pepper, its consumption is very great.

Though but a lowly root, Ginger almost vies in commercial importance with the aromatic rind of the cinnamon-laurel, or the pungent fruit of the nutmeg-myrtle. The plant which produces this valuable condiment belongs to the tropical family of the Scitamineæ, or spice-lilies, which also reckons among its members the Cardomum and the Curcuma. Its jointed tubers creep and increase under ground, and from each of them springs up an annual stem about two feet and a half high, with narrow and lanceolate leaves. The flowering stalk rises directly from the root, ending in an oblong, scaly spike; from each of these scales a single white and blue flower is produced. Ginger is imported into this country, under the form of dried roots and as a preserve. We receive it both from the East and West Indies, but that from the latter is much superior in quality to the former. 



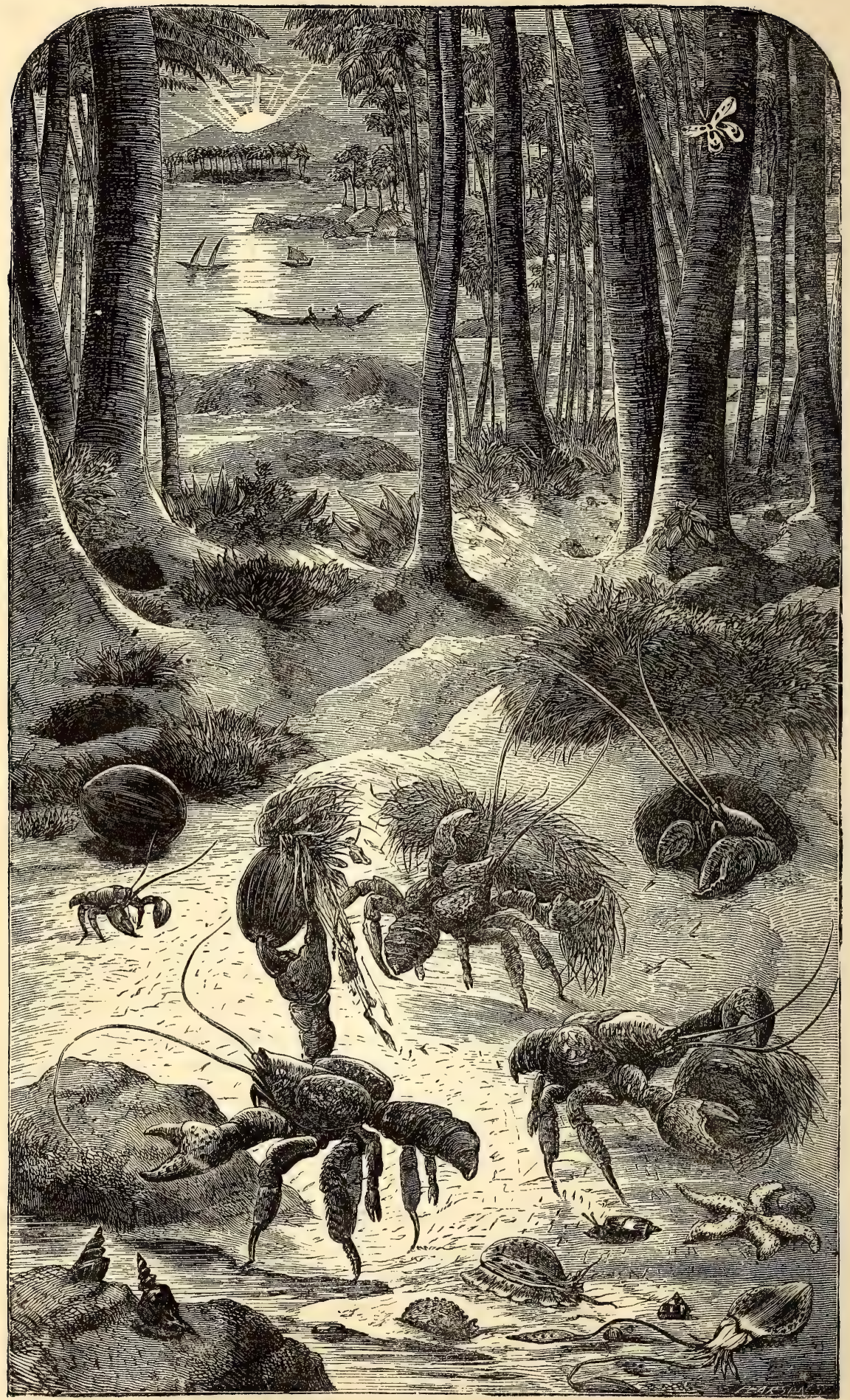

THE ROBBER CRAB-MALAY ARCHIPELAGO.-See page 634. 


\section{ANIMALS OF THE TROPICAL WORLD.}

\section{CHAPTER VIII.}

\section{INSECTS.}

Multitude of Tropical Insects-Beetles-Dragon Flies-Leaf Moths-The Leaf ButterfyFire Flies-Insect Plagues: Mosquitoes-Chigoes, or Jiggers-The Filaria MedinensisThe Bête Rouge-Ticks-Land-Leeches-The Tsetsé Fly-The Tsalt-Salya LocustsCockroaches-Enemies of the Cockroach.-Useful Insects: The Silk-Worm-The Cochineal Insect-The Gum-Lac Insect-Edible and Ornamental Beetles.

$\mathrm{H}$ AVING thus passed in rapid survey over the characteristic forms of the Vegetable World of the Tropics, we now proceed to the Animal Kingdom, commencing with Insects, and proceeding to Reptiles, Birds and Beasts.

On advancing from the temperate regions to the pole, we find that insect life gradually diminishes in the same ratio as vegetable life declines. The reverse takes place on advancing towards the equator; for, as the sun rises more and more to the zenith, we find the insects gradually increasing with the multiplicity of plants, and at length attaining the greatest variety of form, and the highest development of number, in those tropical lands where moisture combines with heat in covering the ground with a dense and everlasting vegetation. Thus while not a single species of beetle is found on Melville Island, Greenland boasts of 11 ; Lapland of 813 ; Sweden of 2,083. In the milder climate of England their number increases to 2,263; in France it rises to 4,200; and the hothouse temperature of Brazil, from Rio Janeiro to Bahia, fosters no less than 7,500 specific forms of beetle life. In Borneo Mr. Wallace collected 2,000 distinct species of beetles within the space of a single square mile; some of them of forms to the oddity of which no parallel can be found elsewhere. Thus, also, while the whole of Europe and Siberia haraly possess more than 250 butterflies, the explored parts of Brazil, which are very inferior in extent, have already furnished the naturalist with no less than 600 species, and no doubt contain many more.

In the countries which, from the never failing abundance of food, and constant warmth, are most favorable to the multiplication of insects, these creatures may naturally be expected to attain the greatest size. Thus the European rhinoceros beetle, though an inch and a quarter long, is far surpassed by the Megasominac of torrid America. The colossal Hercules beetle attains a length of five or even six inches, and is distinguished, like the other species of the genus, by the singular hornshaped processes rising from the head and thorax, which give it a very grotesque and even formidable appearance. Though but little is yet known of its economy, it most likely subsists upon putrescent wood, and evidently leads a tree life, like the other 
members of the family - the Elephant, the Neptune, the Typhon, the Hector, the Mars-whose very names indicate that they are giants in the insect world. These beeties excavate burrows in the earth, where they conceal themselves during the day, or live in the decomposed trunks of trees, and are generally of a dark, rich brown, or chestnut color. . On the approach of night they run about the footpaths in woods, or fly around the trees to a great hight with a loud humming noise. Resembling the large herbivorous quadrupeds by their comparative size and horn-like processes, they are still further like them in their harmless nature, and thus deserve in more than one respect to be called the elephants among the insect tribes.

The Goliaths of the coast of Guinea are nearly as large as the American giant beetles, and surpass them in brilliancy of coloring. Some years ago these huge beetles, which live exclusively on the juice of trees, were very rare, and brought extravagant prices. Thus, Mr. Swainson mentions $£ 30$ having been offered and refused for a single specimen, the proprietor demanding $£ 50$. The South American Inca beetles greatly resemble the African Goliaths, equalling them in size and beauty.

Many of the tropical dragon-flies, grasshoppers, butterflies, and moths, are of no less colossal dimensions in their several orders than the giants among the beetles. The Libellula lucretia, a South American dragon-fly, measures five inches and a half in length; the giant Phasma is a span long; and the cinnamon-eating Atlas-moth of Ceylon often reaches the dimensions of nearly a foot in the stretch of its superior wings.

In the tropical zone, where the prodigality of life multiplies the enemies which every creature has to encounter, we may naturally expect to find the insects extremely well provided with both passive and active means of defence. Many so closely resemble in color the soil or object on which they are generally found, as to escape even the eye of a hungry enemy. The wings of several Brazilian moths appear like withered leaves that have been gnawed round their margins by insects; and when these moths are disturbed, instead of flying away, they fall upon the ground like the leaf which they resemble, so that it is difficult, if not impossible, on such occasions to know what they really are.

The illusion is still more complete when the likeness of form is joined to that of color, as in the walking leaf and walking-stick insects. Some, of an enormous length, look so exactly like slender dead twigs covered with bark, that their insect nature can only be discovered by mere accident. Upon being handled they feign death, and their legs are often knobbed, like the withered buds of trees. Some resemble living twigs, and are green; others such as are decayed, and are therefore colored brown. The wings of many put on the resemblance of dry and crumpled leaves, while those of others are vivid green, in exact accordance with the plants they respectively inhabit. Mr. Wallace describes the Kallima paralekta, a large beautifully colored butterfly when flying, but which, when alighted, can not be distinguished from a dead leaf, except upon the closest scrutiny. He had often seen it flying, but had never been able to capture one. At last actually saw one alight close by where he was standing; but it disappeared as if by magic. At last he detected it; and having secured it, was able to perceive how it was able to hide itself, when in plain view. The upper end of the wings terminates in a fine point, while the lower wings are lengthened out into a short thick tail; between these points runs a dark line like the midrib of a leaf, 
with marks on each side resembling leaf-veins. When the wings are closely pressed together, the whole outline is exactly like that of a half-shrivelled leaf, which it then resembles in color. The tail of the hind wings forms a perfect stalk, and rests upon the twig, while the insect is supported by the middle pair of legs, which are hardly to be distinguished from the twigs around. The head is drawn back between the wings, at whose base is a notch to let it in. Knowing all this, one must look closely at the picture which he gives in order to distinguish the alighted butterfly from a leaf.

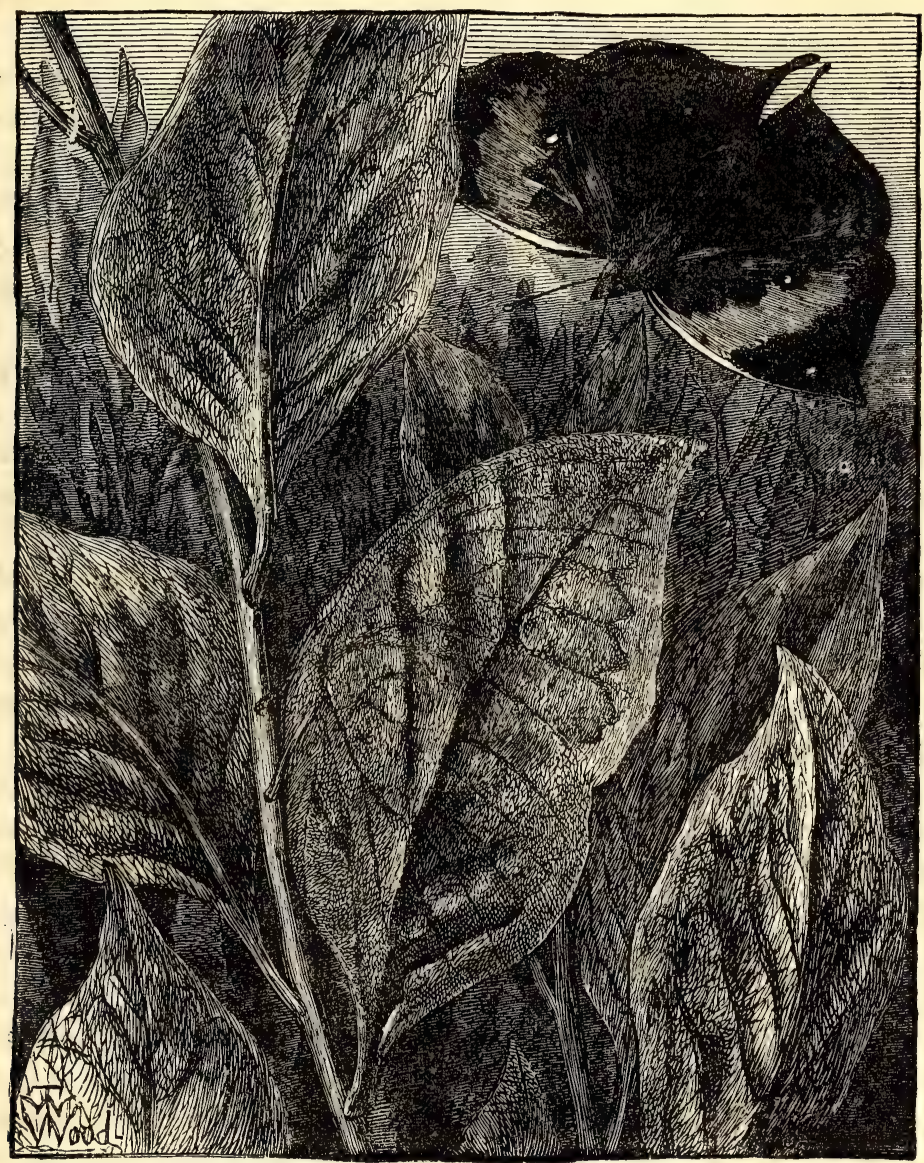

THE LEAF BUTTERFLY

Another singular insect is the Mantis, or "Soothsayer," notable for its apparently feeble structure and voracious appetite. It is of slow movement, yet flies constitute a great part of its food. It steals cautiously upon its prey, and, when near enough, flings out its long fore-legs and grasps its prey. These legs are curiously constructed; the tibia can be shut upon the sharp edge of the thigh, like a pair of shears, with which it can cut any slender substance, and even give a decidedly unpleasant nip upon the finger of the naturalist who incautiously seizes it.

The Mantis, by the attitude it assumes when lurking for its prey or advancing upon it-which is done by the support of the four posterior legs only, whilst the head and 
prothorax are raised perpendicularly from the body, and the exterior legs are folded in front-greatly resembles a person praying. Hence, in France it is called Le Prêcheur, or Le Prie Dieu; the Turk says it points to Mecca; and several African tribes pay it religious observances. In reality, however, its ferocity is great; and the stronger, preying on the weaker of their own species, unmercifully cut them to pieces. Thus, two Mantes which Sir E. Tennent enclosed in a box were both found dead a few hours after, severed limb from limb in their deadly fight. Within the space of a week, Burmeister saw a Mantis devour daily some dozens of flies, and occasionally large grasshoppers and young frogs, consuming, now and then, lizards three times its own length, as well as many large fat caterpillars. Hence it may be judged what ravages these strangely formed creatures must cause among all weaker beings which incautiously approach them, and that, far from being the saints, they are, in reality, the tigers of the insect world.

Though the great majority of luminous animals are marine, frequently lighting up the breaking wave with millions of moving atoms, or spreading over the beach like a sheet of fire, yet several insects are also endowed with the same wonderful property. Our own fire-flies afford a charming spectacle. But this brilliancy is far surpassed by that of the phosphorescent beetles of the torrid zone. Thus the Cocujas of South America glows with such intensity, that if eight or ten of them are put into a vial the light will be sufficiently good to admit of writing by it. In Cuba is a magnificent fire-fly, which ladies often enclose in gauze nets, and wear as ornaments in the ballroom. When the Spaniards first visited Mexico, the wandering sparks of fire-flies were once mistaken for an army approaching with matchlocks; and in the West Indies the English, under Cavendish and Dudley, seeing an innumerable body of these insects, fancied that the Spaniards were advancing upon them in force, and fled to the vessels from which they had just landed.

The insect tribes hold a kind of universal empire over the earth and its inhabitants, for nothing that possesses, or has possessed, life is secure from their attacks. To secure himself from their attacks, man must wage a perpetual warfare, and maintain an ever-wakeful vigilance, for, though destroyed by thousands, new legions ever make their appearance, and to repose after a victory is equivalent to a defeat. In our temperate zone, where a higher cultivation of the ground tends to keep down the number of the lower animals, their persecutions, though frequently annoying, may still be borne with patience; but in the tropical regions, where man is generally either too indolent or not sufficiently numerous to set bounds to their increase, the insects constitute one of the great plagues of life. We will first speak of some of these insect plagues :

Along the low river-banks, and everywhere on hot and swampy grounds, the bloodthirsty mosquitoes appear periodically in countless multitudes, the dread of all who live in warm climates. Scarcely has the sun descended below the horizon, when these insects arise from the morass to disturb the rest of man and to render existence a torment. Not satisfied with piercing the flesh with their sharp proboscis, which at the same time forms a kind of syphon through which the blood flows, these malignant gnats, of which there are many species, inject a poison into the wound, which causes inflammation, and prolongs the pain. 
In Angola, Livingstone found the banks of the river Seuza infested by legions of the most ferocious mosquitoes he ever met with during the course of his long travels. The torment which they inflicted was, he says, " at least equal to a nail through the heel of one's boot, or the toothache." Edwards, on his voyage up the Amazon, was no less tormented by these troublesome pests. "Nets were of no avail, even if the oppressive heat would have allowed them; for those which could not creep through the meshes would in some other way find entrance in spite of every precaution. Thick breeches they laughed at, and the interior of the cabin seemed a bee-hive. This would not do, so we tried the deck, but fresh swarms continually poured over us,

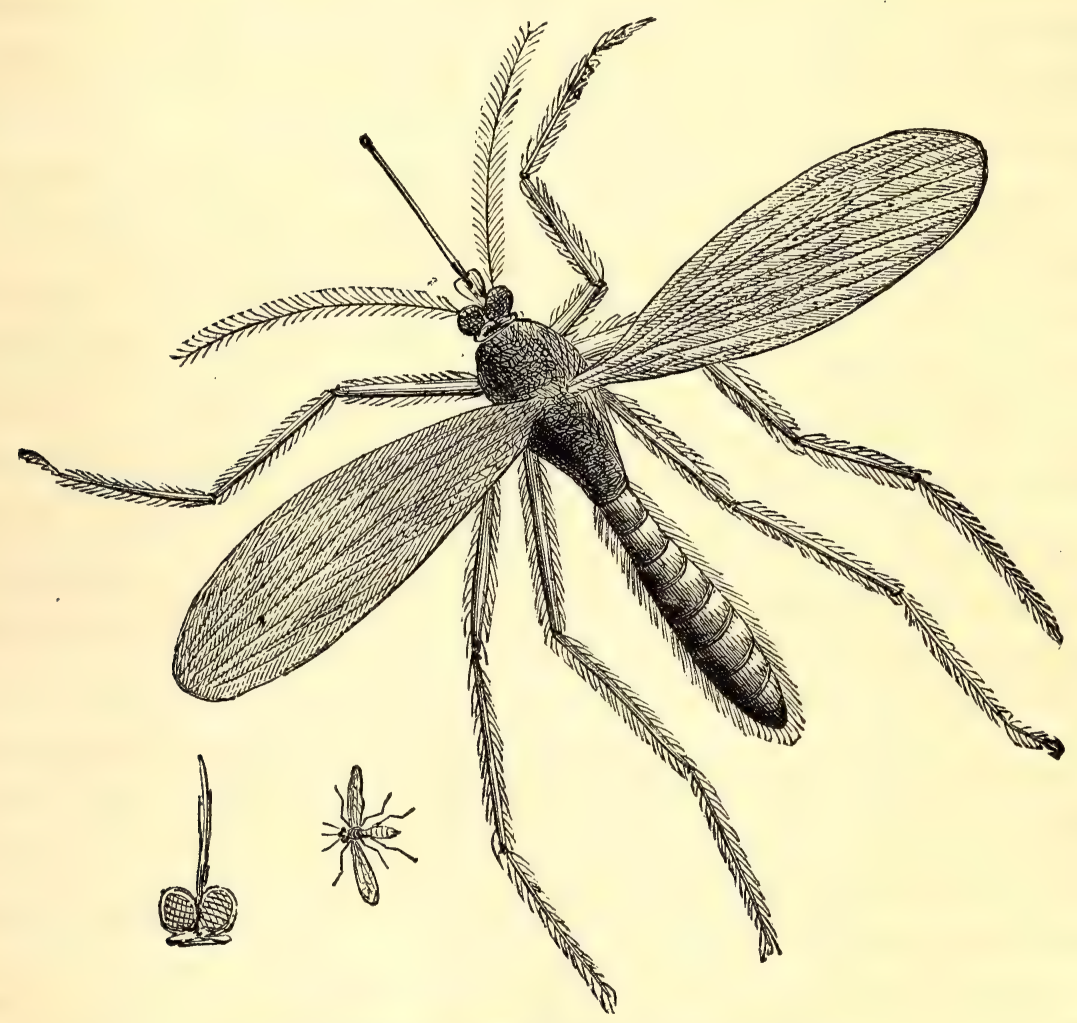

THE MOSQUiTO-NATURAL SIZE, AND MAGNIFIED.

and all night long we were foaming with vexation and rage." During his sojourn in the Peruvian forests, Tschudi lay for several days almost motionless, with a swollen head and limbs, in consequence of the bite of these intolerable flies; and although by degrees the skin became more accustomed to the nuisance, and swelling no longer followed, yet their sting never failed to cause great pain. During three months of the year they infest the province of Maynas to such a degree, that even the stoical Indians utter loud complaints, and the dogs endeavor to escape them by burying themselves in the sand.

The Chegoe, Pique, or Jigger of the West Indies (Pulex penetrans), is another great torment of the hot countries of America. It looks exactly like a small flea, and 
a stranger would take it for one. However, in about four and twenty hours he would have several broad hints that he had made a mistake in his ideas of the animal. It attacks different parts of the body, but chiefly the feet, betwixt the toe-nails and the flesh. There it buries itself and causes an itching, which at first is not unpleasant, but after a few days gradually increases to a violent pain. At the same time a small white tumor, about the size of a pea, and with a dark spot in the centre, rises under the skin. The tumor is the rapidly growing nest of the chegoe, the spot the little plague itself. And now it is high time to think of its extirpation, an operation in which the negro women are very expert. Gently removing with a pin the skin from the little round white ball or nest, precisely as we should peel an orange, and pressing the flesh all round, they generally succeed in squeezing it out without breaking, and then fill the cavity with snuff or tobacco, to guard against the possibility of a fresh colony being formed by some of the eggs remaining in the wound. New comers are particularly subject to these creatures. "Every evening," says Waterton, " before sundown, it was part of my toilet to examine my feet and see that they were clear of chegoes. Now and then a nest would escape the scrutiny, and then I had to smart for it a day or two after." If the prompt extraction of the chegoe's nests is neglected, the worm-like larvæ creep out, continue the mining operations of their parent, and produce a violent inflammation, which may end in the mortification of a limb. It not unfrequently happens that negroes from sheer idleness or negligence in the first instance have been lamed for life and become loathsome to the sight. In such a state, these miserable objects are incurable, and death only puts an end to their sufferings.

A still more dangerous plague, peculiar to the coast of Guinea and the interior of tropical Africa, to Arabia, and the adjacent countries, is the Filaria medinensis of Linnæus. This dreadful worm comes to the herbage in the morning dew, from whence it pierces the skin, and enters the feet of such as walk without shoes, causing the most painful irritations, succeeded by violent inflammation and fever. The natives extract it with the greatest caution by twisting a piece of silk round one extremity of the body and withdrawing it very gently. When we consider that this insidious worm is frequently twelve feet long, although not thicker than a horse-hair, we can readily imagine the difficulty of the operation. If, unfortunately, the animal should break, the part remaining under the skin grows with redoubled vigor, and frequently occasions a fatal inflammation.

Among the plagues of Guiana and the West Indies is a little insect in the grass and on the shrubs, which the French call Bête-rouge. It is of a beautiful scarlet color, and so minute that you must bring your eye close to it before you can perceive it. It abounds most in the rainy season. Its bite causes an intolerable itching, which, according to Schomburgk, who writes from personal experience, drives by day the perspiration of anguish from every pore, and at night makes one's hammock resemble the gridiron on which Saint Lawrence was roasted. The best way to get rid of the plague is to rub the part affected with lemon-juice or rum. "You must be careful not to scratch it," says Waterton. "If you do so and break the skin, you expose yourself to a sore. The first year I was in Guiana the bête-rouge and my own want of knowledge, and, I may add, the little attention I paid to it, created an ulcer above the ankle which annoyed me for six months."

The blood-sucking Ticks are also to be classed among the intolerable nuisances of 
many tropical regions. A large American species called Garapata (Ixodes sanguisuga) fixes on the legs of travelers, and gradually buries its whole head in the skin, which the body, disgustingly distended with blood, is unable to follow. On being violently removed, the former remains in the wound, and often produces painful sores. The Indians returning in the evening from the forest or from their field labor generally bring some of these creatures along with them, swollen to the size of hazel-nuts. These ticks seem to have no predilection for any particular animal, but indiscriminately fasten on all, not even sparing the toad or the lizard.

Though countless hosts of ticks infest the Ceylonese jungle, though musquitoes without number swarm over the lower country, yet the Land-Leeches which beset the traveler in the rising grounds are a still more detested plague. In size they are about an inch in length, and as fine as a common knitting-needle, but capable of distention till they equal a quill in thickness and attain a length of nearly two inches. Their structure is so flexible that they can insinuate themselves through the meshes of the finest stocking, not only seizing on the feet and ankles, but ascending to the back and throat, and fastening on the tenderest parts of the body. The coffee planters who live among these pests are obliged; in order to exclude them, to envelop their legs in "leech-gaiters," made of closely woven cloth. "In moving, they have the power of planting one extremity on the earth and raising the other perpendicularly to watch for their victim. Such is their vigilance and instinct that, on the approach of a passer-by to a spot which they infest, they may be seen amongst the grass and fallen leaves, on the edge of a native path, poised erect, and preparing for their attack on man and horse. On descrying their prey, they advance rapidly by semicircular strides, fixing one end firmly and arching the other forwards, till by successive advances they can lay hold of the traveler's foot, when they disengage themselves from the ground and ascend his dress in search of an aperture to enter. In these encounters the individuals in the rear of a party of travelers in the jungle invariably fare worst, as the leeches, once warned of their approach, congregate with singular celerity. Their size is so insignificant, and the wound they make so skilfully punctured, that both are certainly imperceptible, and the first intimation of their onslaught is the trickling of the blood, or a chill feeling of the leech when it begins to hang heavily on the skin from being distended by its repast. Horses are driven wild by them, and stamp the ground in fury to shake them from their fetlocks, to which they hang in bloody tassels. The bare legs of the palankin-bearers and coolies are a favorite resort, and their hands being too much engaged to be spared to pull them off, the leeches hang like bunches of grapes round their ankles; and I have seen the blood literally flowing over the edge of a European's shoe from their innumerable bites. In healthy constitutions the wounds, if not irritated, generally heal, occasioning no other inconvenience than a slight inflammation and itching; but in those with a bad state of body, the punctures, if rubbed, are liable to degenerate into ulcers, which may lead to the loss of limb or of life. During the march of the troops in the mountains, when the Kandyans were in rebellion, in 1818, the soldiers, and especially the Madras Sepoys, with the pioneers and coolies, suffered so severely from this cause that numbers of them perished."

Among the many noxious insects destructive to the property of man, there is, perhaps, none more remarkable than the South African Tsetsé-fly (Glossina morsitans), whose peculiar buzz, when once heard, can never be forgotten by the traveler 
whose means of locomotion are domestic animals; for it is well known that the bite of this poisonous insect is certain death to the ox, horse, and dog. Fortunately it is limited to particular districts, frequently infesting one bank of a river while the other contains not a single specimen, or else traveling in South Africa would be utterly impossible, and we should now know no more of Lake Ngami or the Zambesi than we did thirty years since. In one journey Livingstone lost no less than forty-three fine oxen by the bite of the tsetsé. A party of Englishmen once attempted to reach Libebé, but they had only proceeded seven or eight days' journey to the north of the Ngami, when both horses and eattle were bitten by the fly, and the party were in consequence compelled to make a hasty retreat. One of the number was thus deprived of as many as thirty-six horses, excellent hunters, and all sustained heavy losses in cattle.

A most remarkable feature in the bite of the tsetsé is its perfect harmlessness in man and wild animals, and even calves, so long as they continue to suck the cow. The mule, ass, and goat enjoy likewise the same immunity, and many large tribes on the Zambesi can keep no domestic animals except the latter, in consequence of the scourge existing in their country. Dr. Livingstone's children were frequently bitten, yet suffered no harm; and he saw around him numbers of zebras, buffaloes, pigs, pallahs and other antelopes, feeding quietly in the very habitat of the tsetsé, yet as undisturbed by its bite as oxen are when they first receive the fatal poison, which acts in the following manner: After a few days the eyes and nose begin to run, the coat stares as if the animal were cold, a swelling appears under the jaw, and, though the animal continues to graze, emaciation commences, accompanied with a peculiar flaccidity of the muscles; and this proceeds unchecked until, perhaps months afterwards, purging comes on, and the animal, no longer able to graze, perishes in a state of extreme exhaustion. Those which are in good condition often perish, soon after the wound is inflicted, with staggering and blindness, as if the brain were affected by it. Sudden changes of temperature, produced by falls of rain, seem to hasten the progress of the complaint, but in general the emaciation goes on uninterruptedly for months; and, do what one may, the poor animals perish miserably, as there is no cure yet known for the disease.

The Abyssinian Tsalt-salya, or Zimb, described by Bruce, seems identical with the tsetsé, or produces at least similar symptoms. At the season when this plague makes its appearance, all the inhabitants along the sea-coast, from Melinde to Cape Gardafui, and to the south of the Red Sea, are obliged to retire with their cattle to the sandy plains to preserve them from destruction.

The French traveler, D'Escayrac, tells us of a fly in Soudan which leaves the ox uninjured, but destroys the dromedary. On account of this plague the camel is confined to the northern boundary of the Soudan, while the oxen graze in safety throughout the whole country. This fly has caused more migrations among the Arabs of the Soudan than all their wars; and in the dry season it even drives the elephant from Lake Tsad by flying into its ears.

Though Locusts not seldom extend their ravages to the steppes of southern Russia, though they have been known to burst like a cloud of desolation over Transylvania and Hungary, and stray stragglers now and then even find their way to England, yet their chief habitat and birthplace is the torrid zone. They wander forth in countless 
multitudes, and at very irregular periods; but how it comes that they are multiplied to such an excess in particular years, and not in others, has never yet been ascertained, and perhaps never will be. They are armed with two pairs of strong mandibles; their stomach is of extraordinary capacity and power; they make prodigious leaps by means of their muscular and long hind legs; and their wings even carry them far across the sea. On viewing a single locust, one can hardly conceive how they can cause such devastations, but we cease to wonder on hearing of their numbers.

From 1778 to 1780 the whole empire of Morocco was so laid waste by swarms of these insects, that a dreadful famine ensued. Mr. Barrow, in his travels, states that in the southern parts of Africa the whole surface of the ground might literally be said to be covered with them for an area of nearly 2,000 square miles. When driven into the sea by a north-west wind, they formed upon the shore, for fifty miles, a bank three or four feet high; and when the wind was south east, the stench was such as to be smelt at the distance of 150 miles. Major Moore observed at Poonah an army of locusts, which devastated the whole country of the Mahrattas, and most likely came from Arabia. Their columns extended in a width of 500 miles, and were so dense as to darken the light of the sun. It was a red species (not the common Gryllus migratorius), whose bloody color added to the terror of their appearance.

In Central Africa, Anderson met with vast numbers of the larvæ of the locust commonly called by the Boers "Voet-gangers," or pedestrians. In some places they might be seen packed in layers several inches in thickness, and myriads were crushed and maimed by the wagon and cattle. Towards nightfall they crawled on the bushes and shrubs, many of which, owing to their weight and numbers, were either bowed down or broken short off. They were of a reddish color, with dark markings; and as they hung thus suspended, they looked like clusters of rich fruit. These larvæ are justly dreaded by the colonists, as nothing seems capable of staying their progress. Even rivers form no barrier to their march, as the drowning multitudes afford the survivors a temporary bridge; endeavors to diminish their numbers would appear like attempting to drain the ocean by a pump. On traveling on, next morning, the locust itself was encountered, and in such masses as literally to darken the air. The wagon, or any other equally conspicuous object, could not be distinguished at the distance of one hundred paces. The noise of their wings was not unlike that caused by a gale of wind whistling through the shrouds of a ship at anchor. During their flight numbers were constantly alighting - an action which has not inaptly been compared to the falling of large snow-flakes. It is, however, not until the approach of night that the locusts encamp. Woe to the spot they select as a resting-place! The sun sets on a landscape green with all the luxuriance of tropical vegetation; it rises in the morning over a region naked as the waste of the Sahara.

We are not wholly unacquainted with Cockroaches. The tropical plague of the cockroaches has been introduced into the temperate zone; but, fortunately, the giant of the family, the Blatta gigantea, a native of many of the warmer parts of Asia, Africa, and South America, is a stranger to our land; and the following truthful description of this disgusting insect at home gives us every reason to be thankful for its absence:- “ They plunder and erode all kinds of victuals, dressed and undressed, and damage all sorts of clothes, especially such as are touched with powder, pomatum, and similar substances; everything made of leather; books, paper, and various other 
articles, which if they do not destroy, at least they soil, as they frequently deposit a drop of their excrement where they settle, and, some way or other, by that means damage what they cannot devour. They fly into the flame of candles, and sometimes into the dishes; are very fond of ink and of oil, into which they are apt to fall and perish, in which case they soon turn most offensively putrid-so that a man might as well sit over the cadaverous body of a large animal as write with the ink in which they have died. They often fly into persons' faces or bosoms, and their legs being armed with sharp spines, the pricking excites a sudden horror not easily described. In old houses they swarm by myriads, making every part filthy beyond description wherever they harbor, which in the daytime is in dark corners, behind clothes, in trunks, boxes, and, in short, every place where they can lie concealed. In old timber and deal houses, when the family is retired at night to sleep, this insect, among other disagreeable properties, has the power of making a noise which very much resembles a pretty smart knocking with the knuckle upon the wainscoting. The Blatta gigantea in the West Indies is, therefore, frequently known by the name of the 'Drummer.' Three or four of these noisy creatures will sometimes be impelled to answer one another, and cause such a drumming noise that none but those who are very good sleepers can rest for them. What is most disagreeable, those who have not gauze curtains are sometimes attacked by them in their sleep; the sick and dying have their extremities attacked; and the ends of the toes and fingers of the dead are frequently stripped both of the skin and flesh."

According to Tschudi, the Cucaracha and Chilicabra-two large species of the cockroach-infest Peru in such numbers as almost to reduce the inhabitants to despair. Greedy, bold, cunning, they force their way into every hut, devour the stores, destroy the clothes, intrude into the beds and dishes, and defy every means that is resorted to for their destruction. Fortunately, they are held in check by many formidable enemies, particularly by a sinall ant, and a pretty little bird (Troglodytes audax) belonging to the wagtail family, which has some difficulty in mastering the larger cockroaches. It first of all bites off their head, and then devours their body, with the exception of their membranaceous wings. After having finished his repast, the bird hops upon the nearest bush, and there begins his song of triumph.

Many other insect plagues might be added to the list, but those I have already enumerated suffice to reconcile us to our misty climate, and to diminish our longing for the palm groves of the torrid zone.

After having described the miseries which the tropical insects inflict upon manhow they suck his blood, destroy his rest, exterminate his cattle, devour the fruits of his fields and orchards, ransack his chests and wardrobes, feast on his provisions, and plague and worry him wherever they can-I turn to the more agreeable task of recounting their services, and relating the benefits for which he is indebted to them.

Among the insects which are of direct use to us, the silk-worm (Bombyx mori) is by far the most important. Originally a native of tropical or sub-tropical China, where the art of making use of its filaments seems to have been discovered at a very early period, it is now reared in countless numbers far and wide over the western world, so as to form a most important feature in the industrial resources of Europe. Thousands of skilful workmen are employed in spinning and weaving its lustrous 
threads, and thousands upon thousands, enjoying the fruits of their labors, now clothe themselves, at a moderate price, in silken tissues which but a few centuries back were the exclusive luxury of the richest and noblest of the land.

Besides the silk-worm, we find many other moths in the tropical zone whose cocoons might advantageously be spun, and only require to be better known to become considerable articles of commerce. The tusseh-worm (Bombyx mylitta) of Hindostan, which lives upon the leaves of the Rhamnus jujuba, furnishes a dark-colored, coarse, but durable silk; while the Arandi ( $B$. cynthia), which feeds upon the foliage of the castor-oil plant (Ricinus communis), spins remarkably soft threads, which serve the Hindoos to weave tissues of uncommon strength. In America there are also many indigenous moths whose filaments might be rendered serviceable to man, and which seem destined to great future importance, when trade, quitting her usual routine, shall have learnt to pry more closely into the resources of Nature. While the Cocei, or plant-bugs, are in our country deservedly detested as a nuisance, destroying the beauty of many of our garden plants by their blighting presence; while, in 1843, the Coccus of the orange trees proved so destructive in the Azores that the island of Fayal, which annually exported 12,000 chests of fruit, lost its entire produce from this cause alone, two tropical members of the family, as if to make up for the misdeeds of their relations, furnish us-the one with the most splendid of all scarlet dyes, and the other with gum-lac, a substance of hardly inferior value.

Our gardeners spare no trouble to protect their hot and greenhouse plants from the invasion of the Coccus hesperidum; but the Mexican haciendero purposely lays out his Nopal plantations that they may be preyed upon by the Coccus cacti, and rejoices when he sees the leaves of his opuntias thickly strewn with this valuable parasite. The female, who from her form and habits might not unaptly be called the tortoise of the insect world, is much larger than the winged male, and of a dark-brown color, with two light spots on the back, covered with white powder. She uses her little legs only during her first youth, but soon she sucks herself fast, and henceforward remains immovably attached to the spot she has chosen, while her mate continues to lead a wandering life. While thus fixed like an oyster, she swells or grows to such a size that she looks more like a seed or berry than an insect; and her legs, antennæ, and proboscis, concealed by the expanding body, can hardly be distinguished by the naked eye. Great care is taken to kill the insects before the young escape from the eggs, as they have then the greatest weight, and are most impregnated with coloring matter. They are detached by a blunt knife dipped in boiling water to kill them, and then dried in the sun, when they have the appearance of small, dry, shriveled berries, of a deep-brown purple or mulberry color, with a white matter between the wrinkles. The collecting takes place three times a year in the plantations, where the insect, improved by human care, is nearly twice as large as the wild coccus, which in Mexico is gathered six times in the same period. Although the collecting of the cochineal is exceedingly tedious-about 70,000 insects going to a single pound-yet, considering the high price of the article, its rearing would be very lucrative, if both the insect and the plant it feeds upon were not liable to the ravages of many diseases, and the attacks of numerous enemies. The conquest of Mexico by Cortez first made the Spaniards aequainted with cochineal. They soon learnt to value it as one of the most important products of their new empire; and in order to secure its monopoly, prohibited, under 
pain of death, the exportation of the insect, and of the equally indigenous Nopal, or Cactus cochinellifer. Cochineal is now produced in the Canary Islands, Java, and Brazil ; but Mexico still furnishes the greater part produced.

The Coccus which produces lac, or gum-lac, is a native of India, and thrives and multiplies best on several species of the fig-tree. A cheap method having been discovered within the last years of separating the coloring matter which it contains from the resinous part, it has greatly increased in commercial importance.

In the tropical zone we find that not only many birds and several four-footed animals live chiefly, or even exclusively, on insects, but that they are even consumed in large quantities, or eaten as delicacies, by man himself. The locust-swarms are welcomed with delight by the Arab of the Sahara and the South African Bushman. After being partially roasted, they are either eaten fresh, or dried in hot ashes and stored away. The natives reduce them also to powder or meal, which, eaten with a little salt, is palatable even to Europeans; so that Livingstone, who, during his residence among the Bakwains, was often obliged to put up with a dish of locusts, says he should much prefer them to shrimps, though he would avoid both if possible. They evidently contain a great deal of nourishment, as the Bushmen thrive wonderfully on them, and hail their appearance as a season of plenty and good living. The food of John the Baptist was locusts and wild honey.

Several of the large African caterpillars are edible, and considered as a great delicacy by the natives. On the leaves of the Mopané tree, in the Bushman country, the small larvæ of a winged insect, a species of Psylla, appear covered over with a sweet gummy substance, which is collected by the people in great quantities, and used as food. Another species in New Holland, found on the leaves of the Eucalyptus, emits a similar secretion, which, along with its insect originator, is scraped off the leaves and eaten by the aborigines as a saccharine dainty.

The chirping Cicada, or frog-hoppers, which Aristotle mentions as delicious food, though maccaroni has long supplanted them in the estimation both of the modern Greeks and of the Italians, are still in high repute among the American Indians. With the exception of one species (Cicada Anglica), these insects, equally remarkable for the rapidity of their flight and their faculty of emitting a loud noise, are un known in temperate zones. Several of the exotic species, when their wings are expanded, measure six inches in extreme length-a size superior to that of many of the humming-birds. The Goliath beetles of the coast of Guinea are roasted and eaten by the natives, who doubtless, like many other savages, not knowing the value of that which they are eating, often make a bonne bouche of what an entomologist would most eagerly desire to preserve.

The Chinese, who allow nothing edible to go to waste, after unraveling the cocoon of the silk-worm, make a dish of the pupæ, which the Europeans reject with scorn; and the grubs of several insects which thrive and increase in the Sago-tree, the Areca, and the Cocoa, are considered as great delicacies ; and many similar examples might be cited.

Several of the more brilliant tropical beetles are made use of as ornaments, not only by the savage tribes, but among nations which are able to command the costliest gems of the East. The golden elytra of the Sternocera chrysis and Sternocera sternicornis serve to enrich the embroidery of the Indian zenana, while the joints of the legs are 
strung on silken threads, and form bracelets of singular brilliancy. The ladies in Brazil wear necklaces composed of the azure green and golden wings of lustrous Chrysomelidæ and Curculionidæ, particularly of the Diamond beetle (Entimus nobilis); and in Jamaica, the elytra of the Buprestis gigas are set in ear-rings, whose gold green brilliancy rivals the rare and costly Chrysopras in beauty.

The House-building Insects, Ants, Termites, Spiders, etc., form so notable a feature of the Insect World of the Tropics, that they deserve a chapter by themselves. 


\section{CHAPTER IX.}

\section{ANTS-TERMITES-ANT-EATERS-SPIDERS-SCORPIONS.}

Ants: Vast Numbers of Ants in the Tropical World-Pain caused by their Bites-The Ponera Clavata-The Black Fire-Ant-The Dimiya of Ceylon-The Red Ant of Angola-The Vivagua of the West Indies-The Umbrella Ant-Household Plagues-Troubles of Naturalists-The Ranger Ants-The Bashikouay of Western Africa-House-Building Ants -Slaveholding Ants-Aphides, or Plant-Lice-Insect Cow-Keepers.-Termites: Their Ravages among Books and Furniture-Their Citadels-Domestic Economy-Defensive Warfare-American Termites-The Enemies of the Termites-How to Catch, Cook, and Eat them-The Marching Termite-Ant-Eaters: The Great Ant-Bear-His Mode of Hunting-Mode of Defense-Anatomical Structure-Lesser Ant-Bears-Manides and Pangolins-The Aard-Vark-Armadillos-The Porcupine Ant-Eater.-Spiders; Their Physical Structure-Their Webs-Means of Protection-Mode of Catching their Prey-Maternal Instinct-Their Enemies-Uses of Spiders.-Scorpions: Their Aspects and Habits-Their Venom.

THE family of Ants is undoubtedly the most numerous of any in the whole circle L of winged insects, as its colonies are not confined to one particular region, but are thickly planted over the greatest part of the habitable world. There is with us scarcely a field that does not contain millions; we cannot rest upon a bank without reclining upon the walls of their cities; their chief quarters, however, are established in the torrid zone, where they may truly be said to hold a despotic sway over the forest and the savanna, over the thicket and the field. It is hardly possible to penetrate into a tropical wood without being reminded, by their stings and bites, that they consider the visit as an intrusion, while they themselves unceremoniously invade the dwellings of man, and lay ruinous contributions on his stores. The inconceivable number of their species defies the memory of the naturalist, to whom many are even still entirely unknown. From almost microscopical size to an inch in length, of all colors and shades between yellow, red, brown, and black, of the most various habits and stations, the ants of a single tropical land would furnish study for years to a zealous entomologist. Every family of plants has its peculiar species, and many trees are even the exclusive dwelling-place of some ant nowhere else to be found. In the scathes of leaves, in the corollas of flowers, in buds and blossoms, over and under the earth, in and out of doors, one meets these ubiquitous little creatures, which are undoubtedly one of the great plagues of the torrid zone.

While the ants of the temperate zones cause a disagreeable burning on the skin, by the secretion of a corrosive acid peculiar to the race, the sting or bite of many tropical species causes the most excruciating tortures. "I have no words," says Schomburgk, "to describe the pain inflicted upon me by the mandibles of the Ponera clavata, a 
large, and, fortunately, not very common ant, whose long black body is beset with single hairs. Like an electric shock the pain instantly shot through my whole body, and soon after acquired the greatest intensity in the breast, and over and under the arm-pits. After a few minutes I felt almost completely paralyzed, so that I could only with the greatest difficulty, and under the most excruciating tortures, totter towards the plantation, which, however, it was impossible for me to reach. I was found senseless on the ground, and the following day a violent wound fever ensued." The Triplaris Americana, a South American tree, about sixty or eighty feet high, the branches of which are completely hollow and transversely partitioned at regular intervals, like the stems of the bamboo, is the retreat of one of the most terocious ants. Woe to the naturalist who, ignorant of the fact, endeavors to break off a shoot of the Triplaris, or only knocks against the tree, for thousands will instantly issue from small round lateral openings in the plant, and fall upon him with inconceivable fury. The touch of a hot iron is not more painful than their bite, and the inflammation and pain last for several days after.

The black fire-ant of Guiana, though very small, is capable of inflicting excessive pain. "These insects," says Stedman, "live in such amazing multitudes together, that their hillocks have sometimes obstructed our passage by their size, over which, if one chances to pass, the feet and legs are instantly covered with innumerable hosts of these creatures, which seize the skin with such violence in their pincers, that they will sooner suffer the head to be parted from the body than let go their hold. The burning pain which they occasion cannot, in my opinion, proceed from the sharpness of the pincers only, but must be owing to some venomous fluid, which they infuse, or which the wound imbibes from them. I can aver that I have seen them make a whole company hop about as if they had been scalded with boiling water."

Of the more than seventy species of ants which occur in Ceylon alone, Sir E. Tennent describes the Dimiya, or great red ant, as the most formidable. "Like all their race, these ants are in perpetual motion, forming lines on the ground, along which they pass in continual procession to and from the trees on which they reside. They are the most irritable of the whole order in Ceylon, biting with such intense ferocity as to render it difficult for the unclad native to collect the fruit from the mango-trees, which the red ants especially frequent. They drop from the branches upon travelers in the jungle, attacking them with venom and fury, and inflicting intolerable pain both upon animals and man. On examining the structure of the head through a microscope, I found that the mandibles, instead of meeting in contact, are so hooked as to cross each other at the points, whilst the inner line is sharply serrated throughout its entire length, thus occasioning the intense pain of their bite, as compared with that of the ordinary ant."

"Having, while in Angola, accidentally stepped upon a nest of red ants," says Livingstone, " not an instant seemed to elapse before a simultaneous attack was made on various unprotected parts, up the trousers from below, and on my neck and breast above. The bites of these furies were like sparks of fire, and there was no retreat. It is really astonishing how such small bodies can contain so large an amount of illnature. They not only bite, but twist themselves round after the mandibles are inserted, to produce laceration and pain more than would be effected by the single wound."

But however formidable the weapons of the ants may be, yet the injuries they in- 
flict upon the property of man, pouring over his plantations like a flood, and sweeping away the fruits of his labors, are of a much more lasting and serious nature than their painful bite or venomous sting.

In the West Indies, the brown-black Viviagua, about one-third of an inch long, and with a prickly thorax, is the greatest enemy of the coffee plantations. In one day it will rob a full grown tree of all its leaves. It digs deep subterranean passages of considerable dimensions and irregular forms, with a great number of hand-high galleries branching out from the sides, and does even more harm to the coffee-plants by its mining operations, than by robbing them of their foliage. Attacked in their roots, they fall into what may be called a consumptive state, bear no fruit, and die after a few months' lingering. The complete extirpation of the nest, and keeping up for some time a strong fire in the excavation, is the only means to subdue the evil, which leads to incalculable losses, when, through negligence, the Viviagua has once been allowed to multiply its numbers.

Other species are no less destructive to the sugar plantations, either by settling in the interior of the stalks (like the Formica analis), or by undermining the roots (like the Formica saccharivora), so that the plant becomes sickly and dies. About eighty years ago the island of Grenada was overrun by hosts of these devastating in. sects. Many household animals died from their attacks, and they effectually cleared the land of rats, mice, and reptiles. Streams of running water failed to interrupt their progress, and fire was vainly used to stop them, for millions rushed into the flames, and served as a bridge for the myriads that followed. All the means employed to save the sugar plantations from their fury proved ineffectual, until in the year 1780 the plague was swept away at once by a dreadful tornado, accompanied by a deluge of rain.

The Atta cephalotes, a species of ant distinguished by its large bead, is the most formidable enemy of the banana and cassava fields. It lies in the ground and multiplies amazingly; in a very short time it will strip off the leaves of an entire field, and carry them to its subterranean abodes. Even where their nest is a mile distant from a plantation, these arch depredators know how to find it, and soon form a highway, about half a foot broad, on which they keep up the most active communications with the object of their attack. In masterly order, side by side, one army is seen to move onwards towards the field, while the other is returning to the nest. In the last column each individual carries a round piece of leaf, about the size of a sixpence, horizontally over its head-a circumstance from which the insect has also been named the Umbrella Ant. If the distance is too great, a party meets the weary carriers half way, and relieves them of their load. Although innumerable ants may thus be moving along, yet none of them will ever be seen to be in the other's way; and all goes on with the regularity of clock work. A third party is no less actıvely employed on the scene or destruction, cutting out circular pieces of the leaves, which, as soon as they drop upon the ground, are immediately seized by the attentive and indefatigable carriers. Neither fire nor water can prevent them from proceeding with their work. Though thousands may be killed, yet in less than an hour all the bodies will have been removed. Should the highway be closed by an insurmountable obstacle, another is soon laid out, and after a few hours the operations, momentarily disturbed, resume their former activity. The ants themselves, particularly the winged females, are considered a great delicacy by 
the Indians, who eat the abdomen, either raw or roasted. The taste is said to be agreeably saccharine.

Not satisfied with devouring his harvests, the tropical ants, as I have already mentioned, leave man no rest even within doors, and trespass upon his household comforts in a thousand various ways. In Mains.s, a province on the Upper Amazon, Professor Pöppig counted no less than seven different species of ants among the tormenting inmates of his lut. The diminutive red Amache was particularly fond of sweets. Favored by its smallness, it penetrates through the imperceptible openings of a cork, and the traveler was often obliged to throw away the syrup which in that humid and sultry country replaces the use of crystallized sugar, from its having been changed into an ant-comfit. This troublesome lover of sweets lives under the corner-posts of the hut, so that it is quite impossible to dislodge him. The number of the Puca ticse, a red ant, of the ordinary size, was still greater; the trunks and papers were swarming with it, in spite of every precaution, so that it was quite incomprehensible how it found means to overcome all the obstacles that had been devised against it.

"The only possible way," says Stedman, "of keeping the ants from the refined sugar is by hanging the loaf to the ceiling by a nail, and making a ring of dry chalk around it, very thick, which crumbles down the moment the ants attempt to pass it. I imagined that placing my sugar-boxes in the middle of a tub, and on stone surrounded by deep water, would have kept back this formidable enemy; but to no purpose : whole armies of the lighter sort, to my astonishment, marched over the surface, and but very few of them were drowned. The main body constantly scaled the rock, and, in spite of all my efforts, made their entry through the keyholes, after which, the only way to clear the garrison is, to expose it to a hot sun, which the invaders can not bear, and all march off in a few minutes."

The devastations of the house-ants are peculiarly hateful to the naturalist, whose collections, often gathered with so much danger and trouble, they pitilessly destroy. Schomburgk suspended boxes with insects from the ceiling by threads strongly rubbed over with arsenic soap; but when, on the following morning. he wished to examine his treasures, instead of his rare and beautiful specimens he found nothing but a set of infamous red ants, who, crawling down the threads, had found means to invade the boxes and utterly to destroy their valuable contents.

Wallace gives a feeling description of the ants of Dorey, one of the islands of the Indian Ocean: "One small black kind was excessively abundant." Almost every shrub and tree was more or less infested with it, and its large papery nests were everywhere to be seen. They immediately took possession of my house, building a large nest in the roof, and forming papery tunnels down almost every post. They swarmed on my table as I was at work setting out my insects, carrying them off from under my very nose, and even tearing them off from the cards on which they were gummed, if I left them for an instant. They crawled continually over my hands and face, got into my hair, and roamed at will over my whole body, not producing much inconvenience till they began to bite, which they would do on meeting with any obstruction to their passage, and with a sharpness which made me jump again, and rush to undress and turn out the offender. They visited my bed also, so that night brought no relief from their persecutions; and I verily believe that during my three and a half months' residence at Dorey I was never for a single hour free from them. 
They were not nearly so voracious as many other kinds, but their numbers and ubiquity rendered it necessary to be constantly on guard against them."

In countless multitudes the Ranger ants break forth from the primeval forest, marching through the country in compact order, like a well-drilled army. Every creature they meet in their way falls a victim to their dreadful onslaught. On the west coast of Africa is found a formidable species of the Ranger ant, there named the Bashikouay, of which Paul du Chaillu* furnishes a description, which we give, somewhat abridged:

"But more potent than snakes, lions, leopards, or gorillas, is a species of ant called the Bashikouay. It is the dread not only of man, but of every living thing from the elephant down to the smallest insect. A half inch is about the average length of one of these ants, though some are found of twice that length. Individually they are bold; the bull-dog has not more pluck and tenacity of grip. But their great power lies in the immense armies into which they organize themselves, and the military order which they preserve." When on the march, they often go in a column two inches broad and miles in length. Du Chaillu once saw such a column formed in close order, which occupied twelve hours, from sunrise to sunset, in passing the spot from which he watched them ; and as they marched by night as well as by day, he did not know how long the column had been passing before he saw it. All along the line were larger ants, evidently officers, standing outside the column until their squads had passed, when they moved on and joined them. How many millions upon millions there were in this army he did not venture to estimate. When on the march such a column comes to a small stream, they fling across it a living bridge. Choosing a place where the branch of a tree reaches nearly from one bank to the other, only somewhat lower down, the second of the pontoneers, as we may fairly call them, with his foreclaws grasps the hind-claws of the one in front, and lowers him over. A third does the same by the second; and so on until the line is long enough to reach the desired point. Line after line is thus formed until a suspension bridge is constructed wide enough for the whole army to pass over. Imagine the strength of muscle which these creatures must possess to enable them to maintain their hold for hours.

The marching column throws itself into line of battle with wonderful precision. When it sweeps over a country nothing can stay its progress. Du Chaillu was once plodding through the forest in search of game. Suddenly he was startled by a strange sound. It was caused by a rush of wild beasts. He thought he caught a glimpse of a gorilla; he was sure that he heard the heavy tread of elephants; and this was followed by a heavy crash as though a herd of these great creatures were rushing through the forest. Soon the air grew thick with insects. While wondering what this might mean, he felt the torments of innumerable bites, and in an instant he was almost covered by ants. He had encountered the skirmishers of a Bashikouay army. He set off at his utmost speed in the direction which the other fugitives had taken. Luckily his speed was greater than that of the ants, and as soon as he thought himself safe he stripped off his clothing. It fairly swarmed with ants who had buried themselves in the garments, striking their pincers clear through into the flesh beneath. They never let go their grip until they have taken out the flesh. Pull at one till his body is separated from the head, and the jaws still keep their hold. He

* Wild Life under the Equator. 
had just resumed his garments when the main army came up, and he again took to flight, never stopping until he had crossed a stream and taken refuge in a swamp beyond.

The Bashikouay can not bear the heat of the sun, and hence they are only found in regions covered by forests. If while on a march they come to an open place, they dig a tunnel three or four feet under ground, through which they pass to the jungles on the opposite side. When they enter a village the inhabitants run for their lives. In an incredibly short space of time every hut is cleared of vermin, and the only trace left of the invaders is the bones of rats and mice, and the horny wing-cases of insects. Nothing that breathes comes amiss to them. An antelope which had been shot by Du Chaillu was picked to the bones in a few hours. The careass of an elephant would be cleared away as quickly as by a kraal of natives. They sometimes come upon a huge snake, lying torpid and gorged with food. In this case all is soon over with his serpentine majesty. But rats, mice, roaches, centipedes, scorpions, spiders, and such small pests, are the special prey of the Bashikouay. A swarm of them will kill a rat in two minutes, and devour him in about the same space of time. Upon the whole, they are a blessing to the human race in Western Africa, by keeping down the vermin, which would otherwise render the whole country uninhabitable. They will not touch vegetable matter. One might almost suppose that the author of the Book of Revelations had the Bashikouay in his mind when he speaks of the swarms of "locusts" which rose from the bottomless pit at the sounding of the fifth trumpet, to whom " it was commanded that they should not hurt the grass of the earth, neither any green thing, neither any tree;" but whose "torment was as the torment of a scorpion when he striketh a man." Certain it is that the description fits the Bashikouay, while it is altogether inapplicable to the creature which we call the "locust," whose only food is green things, and who have no tormenting bite.

The wonderful societies of the ants, their strength and perseverance, their unwearied industry, their astonishing intelligence, are so well known, and have been so often and so admirably described, that it would be trespassing on the patience of my readers were $I$ to enter into any lengthened details on the subject. And yet, the observations of naturalists have chiefly been confined to the European species, while the economy of the infinitely more numerous tropical ants, confined to countries or places hardly ever visited, or even unknown to eivilized man, remains an inexhaustible field for future inquiry.

The study of their various buildings alone, from the little we know of them, would occupy a zealous entomologist for years. Here we have an American species that forms its globular nest of the size of a large Dutch cheese, of small twigs artistically interlaced; here another, which constructs its dwelling of dried excrements, attaching it to a thick branch; while a third (Formica bispinosa) uses the cotton of the Bombaceæ for its building material, and through the chemical agency of its pungent secretion converts it into a spongy substance.

On the west coast of Borneo, Mr. Adams noticed two kinds of ants' nests-one species of the size of a man's hand, adhering to the trunk of trees, resembling, when cut through, a section of the lungs; the other was composed of small withered bits of sticks and leaves, heaped up in the axils of branches, somewhat in the form of flat- 
tened cylinders and compressed cones. A third species, still more ingenious, constructs its domicile out of a large leaf, bending the two halves by the weight of united millions till the opposite margins meet at the under surface of the mid-rib, where they are secured by a gummy matter. The stores and larvæ are conveyed into the nest so made by regular beaten tracks along the trunk and branches of the tree.

On the large plains near Lake Dilolo, where water stands so long annually as to allow the lotus and other aqueous plants to come to maturity, Livingstone had occasion to admire the wonderful sagacity of the ants, whom he declares to be wiser than some men, as they learn by experience. When all the ant horizon is submerged a foot deep, they manage to exist by ascending to little houses, built of black tenacious loam, on stalks of grass, and placed higher than the line of inundation. This must have been the result of experience, for if they had waited till the water actually invaded their habitations on the ground, they would not have been able to procure materials for their higher quarters, unless they dived down to the bottom for every mouthful of clay. Some of these upper chambers are about the size of a bean, and others as large as a man's thumb.

Two species of continental Europe, the Formica rubescens and sanguinea, are remarkable or infamous for their slave-making expeditions. Unable or unwilling to work themselves, they make war upon others for the sole purpose of procuring bondsmen, who literally and truly labor for them, and perform all the daily domestic duties of the community.

The Aphides, or plant-lice, eject a sweet, honey-like fluid, which may be correctly termed their milk, and which is so grateful to the ants, that they attend on the honeyflies for the sole purpose of gathering it, and literally milk them as we do our cows, forcing them to yield the fluid, by alternately patting them with their antennæ. But the most extraordinary part of these proceedings is, that the ants not only consider the Aphides as their property, but actually appropriate to themselves a certain number, which they enclose in a tube of earth or other materials near their nest, so that they may be always at hand to supply the nourishment which they may desire. The yellow ant, the most remarkable "cow.keeper" among our indigenous species, pays great attention to its herds, plentifully supplying them with proper food, and tending their young with the same tenderness which it exhibits towards its own. With the same provident care a large black ant of India constructs its nest at the root of the plant upon which its favorite species of aphis resides. The ants of tropical America, where no Aphides are found, derive their honey from another family of insects, the numerous and grotesquely-formed Membracidæ, which are most abundant in the regions of Brazil. According to Mr Swainson, many of these little Membracidæ live in families of twenty or thirty, all clustered together on the panicles of grasses, and on the tops of other plants, like the European plant-lice. These are regularly visited by parties of a little black ant, which may be seen going and coming to their heads, and attending them with the same care which the European ants bestow on the Aphides. To render the similarity with cattle still more complete, the Membracidæ possess horns growing out of their heads, or are otherwise armed, while their large abrupt heads remind the entomologist of the bull or cow. The Mexican honey ants (Myrmecocystus Mexicanus) are, if possible, still more remarkable, for here we see an animal rearing others of the same species for the purpose of food. Some of these ants are mainly distin- 
guished by an enormous swelling of the abdomen, which is converted into a mass like honey, and being unable, in their unwieldy condition, to seek food themselves, are fed by the laborers, until they are doomed to die for the benefit of the community. Whether this vast distension is the result of an intestinal rupture, caused by an excessive indulgence of the appetite, or whether they are purposely selected, confined, and overfed, or wounded for the purpose, has not yet been ascertained.

The Termites, or white ants, as they are commonly called, though they in reality belong to a totally different order of insects, are spread in countless numbers over all the warmer regions of the earth, emulating on the dry land the bore-worm in the sea; for when they have once penetrated into a building, no timber except ebony and ironwood, which are too hard, or such as is strongly impregnated with camphor and aromatic oils, which they dislike, is capable of resisting their attacks. Their favorite food is wood, and so great are their multitudes, so admirable their tools, that in a few days they devour the timber work of a spacious apartment. Outwardly, the beams and rafters may seem untouched, while their core is completely consumed, for these destructive miners work in the dark, and seldom attack the outside until they have previously concealed themselves and their operations by a coat of clay. Scarcely any organic substance remains free from their attacks; and forcing their resistless way into trunks, chests, and wardrobes, they will often devour in one night all the shoes, boots, clothes, and papers they may contain. It is principally owing to their destructions, says Humboldt, that it is so rare to find papers in tropical America of an older date than fifty or sixty years. Smeathman relates that a party of them once took a fancy to a pipe of fine old Madeira, not for the sake of the wine, almost the whole of which they let out, but of the staves, which, however, may not have proved less tasteful from having imbibed some of the costly liquor. On surveying a room which had been locked up during an absence of a few weeks, Forbes observed a number of advanced works in various directions towards some prints and drawings in English frames; the glasses appeared to be uncommonly dull, and the frames covered with dust. On attempting to wipe it off, he was astonished to find the glasses fixed to the wall, not suspended in frames as he left them, but completely surrounded by an incrustation cemented by the white ants, who had actually eaten up the deal frames and backboards and the greater part of the paper, and left the glasses upheld by the incrustation or covered way which they had formed during their depredations.

On the small island of Goree, near Cape Verde, the famous naturalist, Adanson, lived in a straw hut, which, though quite new at the time he took up his residence in it, became transparent in many places before the month was out. This might have been endured, but the villainous termites ravaged his trunk, destroyed his books, penetrated into his bed, and at last attacked the naturalist himself. Neither sweet nor salt water, neither vinegar nor corrosive liquids, were able to drive them away, and so Adanson thought it best to abandon the premises, and to look out for another lodging.

One night, in Brazil, Von Martius was awakened by a disagreeable feeling of cold across his body. Groping in the dark, he found a cool greasy mass erawling right over the bed, and on a light being brought, saw to his astonishment that his rest had been disturbed by an innumerable host of white ants. The room having been unin- 
habited for some time, they had formed a clay nest in one of the corners, communicating with similar constructions under the roof, and the whole colony was now busy migrating. They formed a column about a foot and a half broad, and their multitudes poured along in one continuous stream, regardless of the fate of thousands of their companions, whom the naturalist scalded to death with boiling water. Their march ceased only with the dawn of day, and several baskets were filled with the bodies of the slain.

But if the greedy termite destroys like the bore-worm many a useful work of man, its ravages are perhaps more than compensated by its services in removing decayed vegetable substances from the face of the earth, and thus contributing to the purity of the air and the beauty of the landscape. If the forests of the tropical world, where thousands of gigantic trees succumb to the slow ravages of time, or are suddenly pros. trated by lightning or the hurricane, still appear in all the verdure of perpetual youth, it is chiefly to the unremitting labors of the termites that they are indebted for their freshness.

Though belonging to a different order of the insect world, the economy of the termites is very similar to that of the real ants. They also form communities, divided into distinct orders-laborers (larva), soldiers (neuters), perfect insects; and they also erect buildings, but of a far more astonishing structure. Several of their species erect high, dome-like edifices, rising from the plain, so that at first sight they might be mistaken for the hamlets of the negroes; others build on trees, often at a considerable hight above the ground. These sylvan abodes are frequently the size of a hogshead, and are more generally found in the new world.

The clay-built citadels or domes of the Termes bellicosus, a common species on the west coast of Africa, attain a hight of twelve feet, and are constructed with such strength that the traveler often ascends them to have an uninterrupted view of the grassy plain around. Only the under part of the mound is inhabited by the termites, the upper portion serving principally as a defence from the weather, and to keep up in the lower part the warmth and moisture necessary to the hatching of the eggs and sherishing of the young ones. In the center, and almost on a level with the ground, is placed the sanctuary of the whole community-the large cell, where the queen resides with her consort, and which she is doomed never to quit again, after having been once enclosed in it, since the portals soon prove too narrow for her rapidly increasing bulk. Encircling the regal apartment extends a labyrinth of countless chambers, in which a numerous army of attendants and soldiers is constantly in waiting. The space between these chambers and the external wall of the citadel is filled with other cells, partly destined for the eggs and young larvæ, partly for store-rooms. The subterranean passages which lead from the mound are hardly less remarkable than the building itself. Perfectly cylindrical, and lined with a cement of clay, similar to that of which the hill is formed, they sometimes measure a foot in diameter. They run in a sloping direction, under the bottom of the hill, to a depth of three or four feet, and then ramifying horizontally into numerous branches, ultimately rise near to the surface at a considerable distance. At their entrance into the interior of the hill, they are connected with a great number of smaller galleries, which ascend the inside of the outer shell in a spiral manner, and winding round the whole building to the top, intersect each other at different hights, opening either immediately into the dome 
in various places, and into the lower half of the building, or communicating with every part of it by other smaller circular passages. The necessity for the vast size of the main galleries underground, evidently arises from the circumstance of their being the great thoroughfare for the inhabitants, by which they fetch their clay, wood, water, or provisions, and their gradual ascent is requisite, as the termites can only with great difficulty climb perpendicularly.

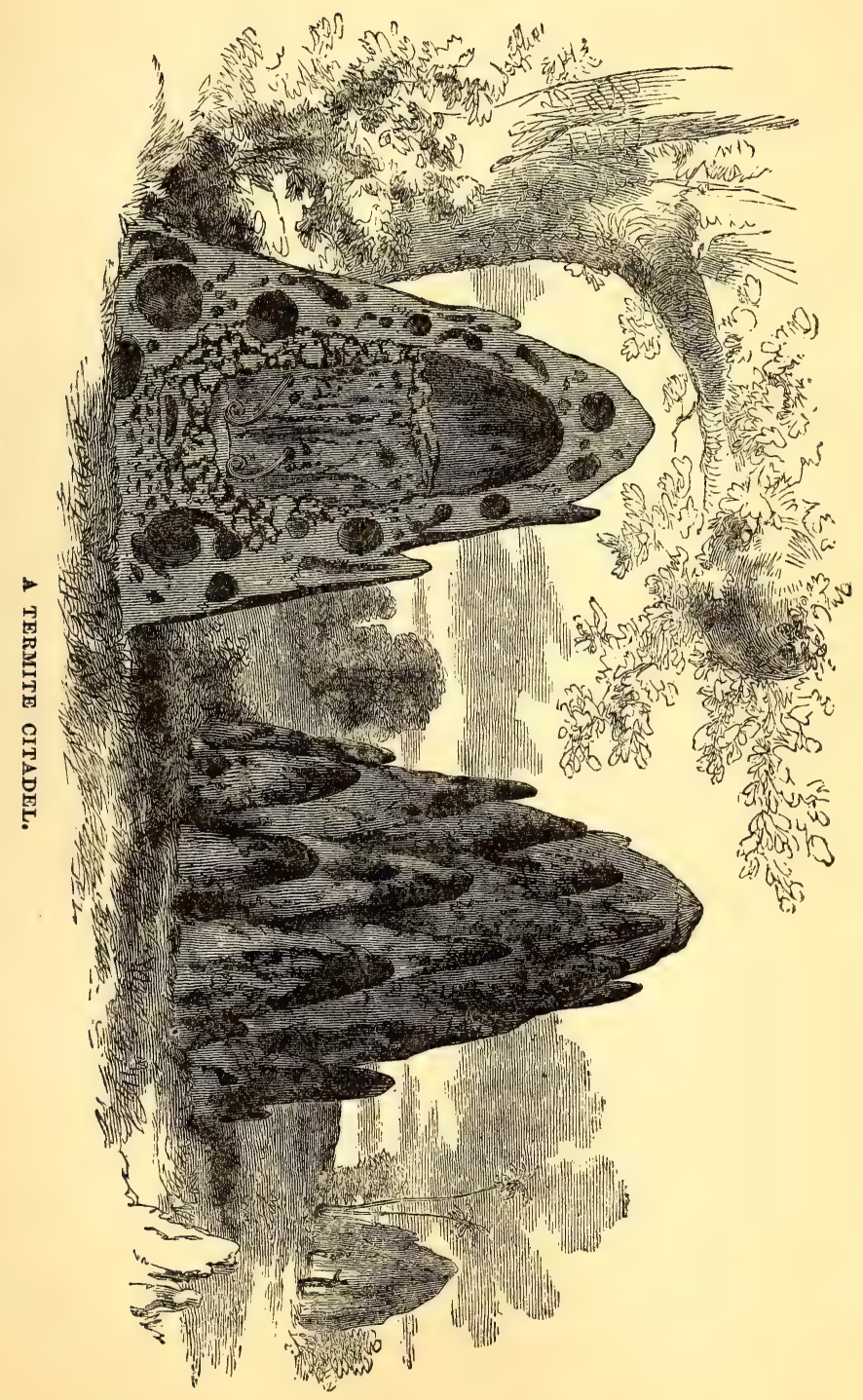

It may be imagined that such works require an enormous population io their construction; and, indeed, the manner in whicb an infant colony of termites is formed and grows, until becoming, in its turn, the parent of new migrations, is not the least wonderful part of this wonderful insect's history. At the end of the dry season, as 
soon as the first rains have fallen, the male and female perfect termites, each about the size of two soldiers, or thirty laborers, and furnished with four long, narrow wings, folded on each other, emerge from their retreats in myriads. After a few hours their fragile wings fall off, and on the following morning they are discovered covering the surface of the earth and waters, where their enemies-birds, reptiles, ants-cause so sweeping a havoc that scarce one pair out of many thousands escapes destruction. If by chance the laborers, who are always busy prolonging their galleries, happen to meet with one of these fortunate couples, they immediately, impelled by their instinct, elect them sovereigns of a new community, and, conveying them to a place of safety, begin to build them a small chamber of clay, their palace and their prison-for beyond its walls they never again emerge. Soon after the male dies, but, far from pining and wasting over the loss of her consort, the female increases so wonderfully in bulk that she ultimately weighs as much as 30,000 laborers, and attains a length of three inches, with a proportional width. This increase of size naturally requires a corresponding enlargement of the cell, which is constantly widened by the indefatigable workers. Having reached her full size, the queen now begins to lay her eggs, and as their extrusion goes on uninterruptedly, night and day, at the rate of fifty or sixty in a minute, for about two years, their total number may probably amount to more than fifty millions. This incessant extrusion of eggs necessarily calls for the attention of a large number of the workers in the royal chamber, to take them as they come forth, and carry them to the nurseries, in which, when hatched, they are provided with food, and carefully attended till they are able to shift for themselves, and become in their turn useful to the community.

In widening their buildings according to the necessities of their growing population, from the size of small sugar-loaves to that of domes which might be mistaken for the hovels of Indians or negroes, as well as in repairing their damages, the termite workers display an unceasing and wonderful activity; while the soldiers, or neuters, which are in the proportion of about one to every hundred laborers, and are at once distinguished by the enormous size of their heads, armed with long and sharp jaws, are no less remarkable for their courage and energy. When any one is bold enough to attack their nest and make a breach in its walls, the laborers, who are incapable of fighting, immediately retire, upon which a soldier makes his appearance, obviously for the purpose of reconnoitering, and then also withdraws to give the alarm. Two or three others next appear, scrambling as fast as they can ono after the other; to these succeed a large body, who rush forth with as much speed as the breach will permit, their numbers continually increasing during the attack. These little heroes present an astonishing, and at the same time a most amusing spectacle. In their haste they frequently miss their hold, and tumble down the sides of their hill; they soon, however, recover themselves, and being blind, bite everything they run against. If the attack proceeds, the bustle increases to a tenfold degree, and their fury is raised to its highest pitch. Woe to him whose hands or legs come within their reach, for they will make their fanged jaws meet at the very first stroke, drawing their own weight in blood, and never quitting their hold, even though they are pulled limb from limb. The courage of the bull-dog is as nothing compared to the fierce obstinacy of the termitesoldier. So soon as the injury has ceased, and no further interruption is given, the soldiers retire, and then you will see the laborers hastening in various directions towards 
the breach, each carrying in his mouth a load of tempered mortar half as big as himself, which he lays on the edge of the orifice, and immediately hastens back for more. Not the space of the tenth part of an inch is left without laborers working upon it at the same moment ; crowds are constantly hurrying to and fro ; yet, amid all this activity, the greatest order reigns-no one impedes the other, but each seems to thread the mazes of the multitude without trouble or inconvenience. By the united labors of such an infinite host the ruined wall soon rises again; and Mr. Smeathman has ascer. tained that in a single night they will restore a gallery of three or four yards in length.

In numbers and architectural industry the American Termites are not inferior to those of the old world. In the savannas of Guiana their sugar-loaf or mushroom. shaped, pyramidal or columnar hills are everywhere to be seen, impenetrable to the rain, and strong enough to resist even a tropical tornado. In many parts of the Brazilian campos or savannas the termite-hills, which are there generally of a more flattened form, are so numerous that one is almost sure to meet with one of them at the distance of every ten or twenty paces. The great ant bear digs deep holes into their sides, where afterwards small owls build their nests. Similar termite structures, of a dark-brown color, and a round form, are attached to the thick branches of the trees, and you will scarcely mect with a single specimen of the tall candelabra-formed cactuses (Cerei), so common on those high grass-plains, that is not loaded with their weight.

In spite of their working in the dark, in spite of their subterranean tunnels, their strongholds, and the fecundity of their queens, the termites, even when their swarms do not expose themselves to the dangers already mentioned, are subject to the attacks of innumerable foes. One of their most ferocious enemies is a species of black ant, which, on the principle of setting one thief to eatch another, is used by the negroes of Mauritius for their destruction. When they perceive that the covered ways of the termites are approaching a building, they drop a train of syrup as far as the nzarest encampment of the hostile army. Some of the black ants, attracted by the smell and taste of their favorite food, follow its traces and soon find out the termite habitations. Immediately part of them return to announce the welcome intelligence, and after a few hours a black army, in endless columns, is seen to advance against the white-ant stronghold. With irresistible fury (for the poor termites are no match for their poisonous sting and mighty mandibles), they rush into the galleries, and only retreat after the extirpation of the colony. Mr. Baxter once saw an army of black ants returning from one of these expeditions. Each little warrior bore a slaughtered termite in his mandibles, rejoicing no doubt in the prospect of a comfortable meal, or a quiet dinnerparty at home. Even man is a great consumer of termites, and they are esteemed a delicacy by negroes and Indians, both in the old and in the new world.

In some parts of the East Indies the natives have an ingenious way of emptying a termite hill, by making two holes in it, one to the windward and the other to the leeward, placing at the latter opening a pot rubbed with an aromatic herb to receive the insects, when driven out of their nest by a fire of stinking materials made at the former breach. Thus they catch great quantities, of which they make, with flour, a variety of pastry. In South Africa the general way of catching them is to dig into the ant-hill, and when the builders come forth to repair the damage, to brush them off quickly into the vessel, as the ant-eater does into his mouth. They are then parched 
in iron pots over a gentle fire, stirring them about as is done in roasting coffee, and eaten by handfuls, without sauce or any other addition, as we do comfits. According to Smeathman, they resemble in taste sugared cream, or sweet almond paste, and are, at the same time, so nutritious, that the Hindoos use them as a restorative for debilitated patients.

While most termites live and work entirely under covered galleries, the Marching Termite (T. viarum) exposes itself to the day. Mr. Smeathman on one occasion, while passing through a dense forest, suddenly heard a loud hiss like that of a serpent; another followed, and struck him with alarm; but a moment's reflection led him to conclude that these sounds proceeded from white ants, although he could not see any of their huts around. On following this noise, however, he was struck with surprise and pleasure at perceiving an army of these creatures emerging from a hole in the ground, and marching with the utmost swiftness. Having proceeded about a yard, this immense host divided into two columns, chiefly composed of laborers, about fifteen abreast, following each other in close order, and going straight forward. Here and there was seen a soldier, at a distance of a foot or two from the columns; many other soldiers were to be seen, standing still or passing about, as if upon the look-out lest some enemy should suddenly surprise their unwarlike comrades. But the most extraordinary and amusing part of the scene was exbibited by some other soldiers, who having mounted some plants, ten or fifteen inches from the ground, hung over the army marching below, and by striking their jaws upon the leaves at certain intervals, produced the noise above mentioned; to this signal the whole army immediately returned a hiss, and increased their pace. The soldiers at these signal-stations sat quite still during these intervals of silence, except now and then making a slight turn of the head, and seemed as solicitous to keep their posts as regular sentinels. After marching separately for twelve or fifteen paces, the two columns of this army again united, and then descended into the earth by two or three holes. Mr. Smeathman watched them for more than an hour, without perceiving any increase or diminution of their numbers.

Here, although quite out of place in a scientific point of view, we may introduce a few paragraphs respecting a class of animals known as Ant-eaters. and the modes in which they manage to secure their prey.

The great Ant-bear is undoubtedly one of the most extraordinary denizens of the wilds of South America; for that a powerful animal, measuring above six feet from the snout to the end of the tail, should live exclusively on ants, seems scarcely less remarkable than that the whale nourishes his enormous body with minute pteropods and medusæ.

The vast mouth of the leviathan of the seas has been most admirably adapted to his peculiar food, and it was not in vain that Nature gave such colossal dimensions to his head, as it was necessary to find room for a gigantic straining apparatus, in which, on rejecting the engulphed water, thousands upon thousands of his tiny prey might remain entangled; but the ant-bear has been no less wonderfully armed for the capture of the minute animals on which he feeds; and if, on considering the use for which it was ordained, we become reconciled to the seeming disproportion of the whale's jaws, the small and elongated snout-like head of the ant-bear will also appear 
Iess uncouthly formed when we reflect that it is in exact accordance with the wants of the animal. For here no deep cavity was required for the reception of two rows of powerful teeth, as in most other quadrupeds, but a convenient furrow for a long and extensile tongue-the use of which will immediately become apparent on following the animal into the Brazilian campos, where the wonderful cities of the white ant are dispersed over the plains in such incalculable numbers. Approaching one of these structures, the ant-bear strikes a hole through its wall of clay with his powerful crooked claws, and as the ants issue forth by thousands to resent the insult, stretches out his tongue for their reception. Their furious legions, eager for revenge, immediately rush upon it, and, vainly endeavoring to pierce its thick skin with their mandibles, remain sticking in the glutinous liquid with which it is lubricated from two very large glands situated below its root. When sufficiently charged with prey, the ant-bear suddenly withdraws his tongue and swallows all the insects.

Without swiftness to enable him to escape from his enemies, for man is superior to him in speed; without teeth, the possession of which would assist him in self-defence; without the power of burrowing in the ground, by which he might conceal himself from his pursuers; without a cave to retire to, the ant-bear still ranges through the wilderness in perfect safety, and fears neither the boa nor the jaguar, for he bas full reliance on his powerful fore-legs and their tremendous claws. Schomburgk had an opportunity of witnessing a young ant-bear make use of these formidable weapons. On the enemy's approach it assumed the defensive, but in such a manner as to make the boldest aggressor pause; for, resting on its left fore-foot, it struck out so desperately with its right paw as would undoubtedly have torn off the flesh of any one that came in contact with its claws. Attacked from behind, it turned round with the rapidity of lightning, and on being assailed from several quarters at once, threw itself on its back, and, desperately fighting with both its fore-legs, uttered at the same time an angry growl of defiance. In fact, the ant-bear is so formidable an opponent that he is said not unfrequently to vanquish even the jaguar, the lord of the American forests, for the latter is often found swimming in his blood, with ripped up bowels, a wound which, of all the beasts of the wilderness, the claws of the ant-bear are alone able to inflict. On seizing an animal with these powerful weapons, he hugs it close to his body, and keeps it there till it dies through pressure or hunger. Nor does the ant-bear, in the meantime, suffer much from want of aliment, as it is a well-known fact that he can remain longer without food than perhaps any other quadruped, so that there is very little chance indeed of a weaker animal's escaping from his clutches.

Peaceable and harmless, the ant bear when unprovoked never thinks of attacking any other creature; and as his interests and pursuits do not interfere with those of the more formidable denizens of the wilderness, he would, without doubt, attain a good old age, and be allowed to die in peace, if, unfortunately for him, his delicate flesh did not provoke the attacks of the large carnivora and man. To be sure, the Indian fears his claws, and never ventures to approach the wounded ant-bear until he has breathed his last; nor can he be hunted with dogs, as his skin is of a texture that perfectly resists a bite, and his hinder parts are effectually protected by thick and shaggy hair; yet, armed with the dreadful wourali poison, the Indian knows how to paralyze in a few minutes his muscular powers, and to stretch him dead upon the earth. A perfect forest vagabond, the ant-bear has no den to retire to, nor any fixed 
abode; his immense tail is large enough to cover his whole body, and serves him as a tent during the night, or as a waterproof mantle against the rains of the wet season, so that he might boast, like Diogenes, of carrying all he required about him.

The peculiar position of his paws, when he walks or stands, is worthy of notice. He goes entirely on the outer side of his fore-feet, which are quite bent inwards, the claws collected into a point and going under the foot. In this position he is quite at ease, while his long claws are disposed of in a manner to render them harmless to him, and are prevented from becoming dull and worn, which would inevitably be the case did their points come in actual contact with the ground, for they have not that retractile power which is given to animals of the feiine race, enabling them to preserve the sharpness of their claws on the most flinty path. In consequence of its resting perpetually on the ground, the whole outer side of the foot is not only deprived of hair, but hard and callous, while, on the contrary, the inner side of the bottom of the foot is soft and bairy.

Besides the great ant-bear, there are two other species of American ant-eaters, one nearly the size of a fox, and the smallest not much larger than a rat. Being provided with prehensile tails, they are essentially arboreal, while the great ant-bear, incapable of climbing, always remains on the ground, where, thanks to the abundance of his prey, he is always sure of obtaining a sufficient supply of food with very little trouble.

The Manides, Pangolins, or scaly Ant-eaters of South Africa and Asia, resemble their kindred of America in having a very long extensile tongue, furnished with a glutinous mucus for securing their insect food, and in being destitute of teeth, but differ wholly from them in having the body, limbs, and tail covered with a panoply of large imbricated scales, overlapping each other like those of the lizard tribes, and also in being able to roll themselves up when in danger, by which their trenchant scales become erect, and present a formidable defensive armor, so that even the tiger would vainly attempt to overcome the Indian pangolin. The manides are inoffensive animals, living wholly on ants and termites, and chiefly inhabit the most obscure parts of the forest, burrowing in the ground to a great depth, for which purpose, as also for extracting their food from ant hills and decaying wood, their feet are armed with powerful claws, which they double up in walking, like the ant-bear of Brazil.

Besides several species of manides, Africa possesses a peculiar class of ant-eaters in the Orycteropi, which are found from the Cape to Senegambia and Abyssinia, all over the sultry plains where their food abounds. Their legs are short, and provided with claws fit for burrowing in the earth, which they can do with great rapidity; and when once the head and fore-feet have penetrated into the ground, their hold is so tenacious that even the strongest man is incapable of dragging them from their hole.

The Orycteropi, or earth-hogs (Aard varks) as they are called by the boors, from their habit of burrowing and their fancied resenblance to small short-legged pigs, have an elongated head, though less tapering than that of the American myrmecophagi, and are provided with peculiarly formed teeth, with a flat crown and undivided root, which is pierced with a multitude of little holes, like those of a ratan-cane when cut transversely, while the ant-bears have no teeth at all. Their way of feeding is the same, and to enable them to retain their nimble-footed prey, their tongue is likewise lubricated with a glutinous liquid. Their flesh is considered very wholesome and palatable, and at the Cape they are frequently hunted both by the colonists and the Hot- 
tentots. There are several species, all rery much resembling each other : their stout body measures about five feet from the tip of the snout to the end of the tail, the latter being nearly half the length of the body.

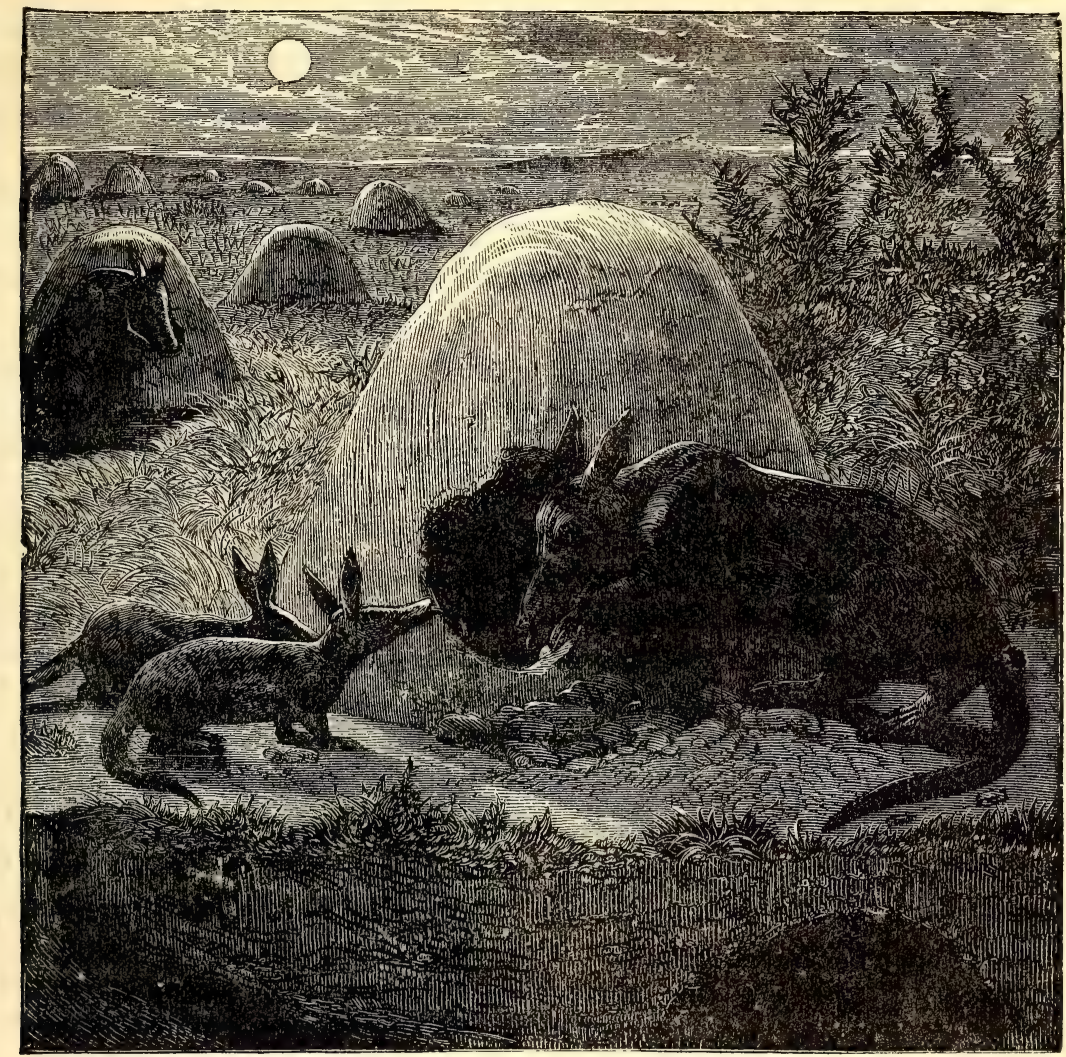

THE AARD-VARK.

The American Armadillos have many points in common with the myrmecophagi, manides, and orycteropi. They have neither fore nor canine teeth, but a number of conical grinders, and are distinguished by having the upper part of their bodies defended by a complete suit of armor, divided into joints or bands, folding one over the other like the parts of a lobster's tail, so as to accommodate themselves to all the mo. tions of the animal. In life this shell is very limber, so that the armadillo is able to go at full stretch, or to roll himself up into a ball as occasion may require. These animals are very common both in the forests and in the open plains of South America, where they burrow in the sand-holes like rabbits. The armadillo is seldom seen abroad during the day, and when surprised he is sure to be near the mouth of his hole; but after sunset he sallies forth in search of roots, grain, worms, insects, and other small animals, and when disturbed, coils himself up in his invulnerable armor like the hedge-hog, or squats close to the ground, or, if he has time enough, escapes by digging into the earth, a work which he performs with masterly dexterity. "As it often takes a considerable time to dig him out of his hole," says Mr. Waterton, "it would be a long and laborious business to attack each hole indiseriminately, without knowing 
whether the animai were there or not. To prevent disappointment, the Indians carefully examine the mouth of the hole, and put a short stick down it. Now if, on introducing the stick, a number of mosquitos come out, the Indians know to a certainty that the armadillo is in it; whenever there are no mosquitos in the hole, there is no armadillo. The Indian having satisfied himself that the armadillo is there by the mosquitos which come out, he immediately cuts a long and slender stick, and introduces it into the hole; he carefully observes the line the stick takes, and then sinks a pit in the sand to catch the end of it; this done, he puts it further into the hole, and digs another pit, and so on, till at last he comes up with the armadillo, which had been making itself a passage in the sand till it had exhausted all its strength through pure exertion. I have been sometimes three quarters of a day in digging out one armadillo, and obliged to sink half a dozen pits, seven feet deep, before I got up to it. The Indians and negroes are very fond of the flesh, but I considered it strong and rank. On laying hold of the armadillo, you must be cautious not to come in contact with his feet; they are armed with sharp claws, and with them he will inflict a severe wound in self-defence ; when not molested, he is very harmless and innocent."

But even the giant armadillo is a pigmy when compared to the extinct mail-clad animals, which at times of unknown antiquity peopled the plains of South America. Mr. Darwin saw, in the possession of a clergyman near Montevideo, the fragment of a tail of one of these monsters of the past, from which he conjectured that it must have been from six to ten feet long; and the glyptodon, of which the British College of Surgeons possesses an admirable specimen, and which, like the armadillos of the present day, was covered with a tesselated bony armor, was equal in size to the rhinoceros! How formidable must have been the enemies which made it necessary for an animal like this to move about with harness on its back !

The curious Echidna, or Porcupine Ant-eater (Echidna hystrix) of Australia is a striking instance of those beautiful gradations so frequently observed in the animal kingdom, by which creatures of various tribes or genera are blended, as it were, or linked together, and of the wonderful diversity which Nature has introduced into the forms of creatures destined to a similar mode of life. It has the general appearance and external coating of the porcupine, with the mouth and peculiar generic characters of the ant-eaters. It is about a foot in length, and burrows with wonderful facility by means of its short muscular fore-feet and its sharp-pointed claws. When attacked, it rolls itself into a ball like the hedgehog, erecting the short strong, and very sharp spines with which the upper parts of the body and tail are thickly coated. Australia is likewise the native country of another ant-eating animal, the marsupial Myrmecobius fasciatus. It is formed like a squirrel, and is of the size of the rat; its brown-red fur, with six or seven light yellow transverse bands over the back, gives it an elegant appearance. It was discovered about thirty years ago in the neighborhood of Swan River.

Here, as connected with the Ant family by their house-building character, and by their irritating bite, we may introduce the Spiders.

An insect, half of whose body is generally fixed to the other by a mere thread, whose soft skin is unable to resist the least pressure, and whose limbs are so loosely attached to the body as to be torn off by the slightest degree of force, would seem utterly incapable of protecting its own life and securing that of its progeny. Such, 
however, is the physical condition of spiders, who would long since have been extirpated, if nature had not provided them with the power of secreting two liquids, the one a venom ejected by their mandibles, the other of a glutinous nature, transuded by papillæ at the end of their abdomen. These two liquids amply supply the want of all other weapons of attack or defence, and enable them to hold their own against a host of enemies. With the former they instantly paralyze insects much stronger and much more formidable in appearance than themselves; while with the latter they spin those threads which serve them in so many ways, to weave their wonderful webs, to traverse the air, to mount vertically, to drop uninjured, to construct the hard cocoons intended to protect their eggs against their numberless enemies, or to produce the soft down which is to preserve them from the cold.

Preying on other insect tribes, which they attack with the ferocity of the tiger, or await in their snares with the patient artifice of the lynx, the spiders may naturally be expected to be most numerous in the torrid zone, where nature has provided them with the greatest abundance of food. There also, where so many beetles, flies, and moths attain a size unknown in temperate regions, we find the spiders growing to similar gigantic dimensions, and forming webs proportioned to the bulk of the victims which they are intended to ensnare.

By means of their monstrous webs many giant-spiders of the tropical zone are enabled to entangle not only the largest butterflies and moths, but even small birds. Tremeyer tells us that there are spiders in Mexico which extend such strong nets across the pathways, that they strike off the hat of the passer by ; and at Goree and in Senegal several spiders spin threads so strong as to be able to bear a weight of several ounces, and which no doubt would be made use of for twine, if the negroes did not already possess vegetable fibres in abundance fit for the purpose. In the forests of Java, Sir George Staunton saw spider webs of so strong a texture that it required a sharp knife to cut one's way through them ; and many other similar examples might be mentioned. These-large spiders so temptingly suspended in mid-air in the forest-glades, seem very much exposed to the attacks of birds, but in many cases it has pleased nature to invest them with large angular spines sticking out of their bodies in every kind of fashion. Some are so protected by these long prickles that their bodies resemble a miniature "chevaux-de-frise," and could not by any possibility be swallowed by a bird without producing a very unpleasant sensation in his throat. One very remarkable species (Gasteracantha arcuata) has two enormous recurved conical spines, proceeding upwards from the posterior part of the body, and several times longer than the entire spider.

Other araneæ, to whom these means of defence have been denied, are enabled by their color to escape the attacks of many enemies, or to deceive the vigilance of many of their victims. Thus, those that spend their lives among the flowers and foliage of the trees are, in general, delicately and beautifully marked with green, orange, black, and yellow, while those which frequent gloomy places are clothed with a dark-colored and dingy garb, in accordance with their habits. In the forests about Calderas, in the Philippine Archipelago, Mr. Adams saw handsomely colored species of theridia crouching among the foliage of the trees: while numbers of the same genus of a black color were running actively about among the dry dead leaves that strewed the ground, looking, at a little distance, like odd-shaped ants, and no doubt deceiving many an 
antagonist by this appearance. One species, which knew it was being watched, placed itself upon a diseased leaf, where it remained quite stationary until after the departure of the naturalist, who, had he not seen the sidelong movement of the cunning little creature in the first instance, would not have been able to distinguish its body from the surface of the leaf. While, in this case, dulness of color served as a defence, the rividly-colored spiders that live among the foliage and flowers no doubt attract many flies and insects by reason of their gaudily-tinted bodies. An exception to the general rule is, however, found in those very large and powerful species, which, if not rendered somewhat conspicuous to the sight of other insects, might do too much damage to the tribes which they keep in check. Most of these, therefore, have the thorax and abdomen margined with a light color that contrasts strongly with that of their bodies, and, in many cases, gives timely warning of their approarh.

The spiders of temperate zones have generally a very repulsive appearance, while many of the tropical species are most splendidly ornamented, or rather illuminated, many of them by the vividness of their colors resembling the gaudy missals painted by monks in the Middle Ages. Thus, among the epeiras of the Philippian isles, are found white figures on a red ground; red, yellow, and black, in alternate streaks; orange marbled with brown, light green with white ocelli, yellow with light brown festoons, or ash-colored and chestnut bodies with crescents, horse-shoes, Chinese characters, and grotesque hieroglyphics of every description. Unfortunately, these colors. lustrous and metallic as the feathers of the humming bird, are, unlike the bright colors of the beetle, totally dependent on the life of the insect which they beautify, so that it is impossible to preserve them.

While most spiders obtain their food either by patiently waiting in ambush or by catching it with a bound, the enormous mygales, or trap-door spiders, run about with great speed, in and out, behind and around every object, searching for what they may devour, and from their size and rapid motions exciting the horror of every stranger. Their body, which sometimes attains a length of three inches, while their legs embrace a circle of half a foot in diameter, is covered all over with brown, reddish brown, or black hair, which gives them a funereal appearance, while their long feelers armed with sharp hooks proclaim at once what formidable antagonists they must be to every insect that comes within their reach. Though some species are found in Southern Europe, in Chili, or at the Cape, yet they are chiefly inhabitants of the torrid zone, both in the Old and the New World. Some of them weave cells ketween the leaves, in the hollows of trees or rocks, while others dig deep tubular holes in the earth, which they cover over with a lid, or rather with a door formed of particles of earth cemented by silken fibres, and closely resembling the surrounding ground. This door or valve is united by a silken hinge to the entrance at its upper side, and is so balanced that, when pushed up, it shuts again by its own weight; nay, what is still more admirable, on the interior side opposite to the hinge a series of little holes may be perceived, into which the mygale introduces its claws to keep it shut, should any enemy endeavor to open it by force. The interior of the nest, which is sometimes nine inches deep, is lined with a double coat of tapestry, the one nearest the wall, which is of a coarser tissue, being covered with a pure white silken substance like paper.

All species of spiders are gifted with the same maternal instinct, and resort to various methods for the purpose of securing their cocoons. The Theridion, when a seizure of the precious burden is threatened, tumbles together with it to the ground, 
and remains motionless, while the Thorinsa covers it with its body, and when robbed of it, wanders about disconsolate. In a forest of the Sooloo Islands, Mr. Adams found the ground literally overrun with a small black agile species of Lycosa, many of which had a white flattened globose cocoon affixed to the ends of their abdomen. It was most amusing to watch the care with which these jealous mothers protected the cradles of their little ones, allowing themselves to fall into the hands of the enemy rather than be robbed of the silken nests that contained them.

If the spiders are at war with all other insects, and contribute to keep them within bounds by the destruction they cause among their ranks, they in their turn have to suffer from the attacks of many enemies. Several species of monkeys, squirrels, liz. ards, tortoises, frogs, and toads catch and devour them wherever they can. In Java and Sumatra, we even find several birds belonging to the order of sparrows that have been named Arachnothere, from their living almost exclusively on spiders. Armed with a prodigiously long recurved and slender beak, they know how to pursue them and drag them forth from the most obscure recesses.

It is amongst the insects themselves, however, that the spiders have to fear their most numerous and formidable enemies. Independently of those which they find in their own class, the centipedes seize them beyond the possibility of escape; while several species of philanthus, pompilius, and sphex, more savage and poisonous than themselves, will rush upon spiders eight times their size and weight, and benumbing them with a sting, bear them off to their nests, to serve as food for their larvæ. But the insects which in appearance are the tiniest and most delicate, are perhaps those which most .cruelly wound the spiders, by attacking them in their eggs, which they watch over with such affection, as to be ever ready for them to make the sacrifice of their own lives. The Pimpla Arachnitor pierces with its invisible gimlet the tender skin of the spider's egg, and, without tearing it, introduces its own eggs into the liquid. The pimpla's egg soon comes to maturity, and the larva devours the substance of that of the spider, from whence a winged insect bursts forth-a phenomenon which made some naturalists, too hasty to judge from appearances, believe that spiders were able to procreate four-winged flies.

Notwithstanding the disgust or horror which they generally inspire, the spiders are, with very rare exceptions, by no means injurious to man. However promptly their venom may act upon insects, even that of the largest species of Northern Europe produces, on coming into contact with our skin, no pain or inflammation equalling in virulence that of the wasp, the bee, the gnat, or other insects of a still smaller size. The giant spiders of a sunnier sky, armed with more formidable weapons, naturally produce a more painful sting; but even here the effects have been much exaggerated, and the wonderful stories about the Sicilian tarantula's bite, which we read of in Brydone and other authors, are nothing but fables raised upon a very slender foundation of truth. Azara mentions that several of his negroes having been bitten by the large Avicular mygale ( $M$. avicalaria) of South America, a slight ephemeral fever was the only result.

If thus, among the many species of spiders, hardly a single one may be said to be fcrmidable to man, the indirect services which they render him-by diminishing the number of noxious insects, or keeping in eheck the legions of gnats which irritate and annoy him by their attacks-are far from inconsiderable. Nor are they entirely without direct use. Several savage nations eat spiders, and the inhabitants of New Cale- 
donia reckon a large species of Epeira amongst the choicest delicacies of the land. Even in Europe some people enjoy a spider, and the famous astronomer Lalande was far from being singular in this respect. They are said to taste like filberts, and the proper way to eat them is to take off the legs, and to swallow the abdomen, after having washed and rubbed it with butter. The property of spiders' webs to stop an hemorrhage or the bleeding of a wound is a well-known fact, and they have also been recommended as an anti-febrifuge. In several countries where the insects cause great ravages, the services of the spiders are duly appreciated. Thus in the West Indies, a large and formidable trap-door spider, which would make a European start back with horror, is looked upon with pleasure by the islanders of the torrid zone, who respect it as a sacred animal, by no means to be disturbed or harmed, as it delivers them from the cockroaches, which otherwise would overrun their dwellings. Those who do not possess these spiders take good care to purchase and transport them into their houses, expecting from them similar services to those we derive from a good domestic cat.

When we consider the large size of many of the tropical spiders, and the strength of their threads, it seems probable that their cocoons might be put to some use. We are told by Azara, in his " Travels to Paraguay," that a spider exists in that country the silk of whose spherical cocoons, measuring an inch in diameter, is spun on account of its permanent orange color. The eyes and noses of the women employed in unravelling the cocoons are said to water considerably, though without their perceiving any pungent smell, or feeling any other inconvenience. This spider is, perhaps, the same as that which, according to M. de Bomare, is known in the interior of South America under the name of the silk-spider. Its cocoon is of the size of a pigeon's egg, the silk is soft, and can be easily carded. Attempts have also been made in Europe to utilize the threads of the large indigenous spiders. About the beginning of the last century, M. Bon, a Frenchman, who seems to have been the first that ever put the idea into practice, collected a sufficient quantity to make some stockings and gloves, which he presented to the king, Louis XIV., and to the Academy of Sciences in Paris. His discovery caused some sensation at the time, and his dissertation on the subject was translated into all European languages, and at a later period even into the Chinese, by order of the Emperor Kien-Long. The celebrated Reaumur, however, who was commissioned by the Academy to report on M. Bon's discovery, pointed out how difficult it would be to put it to any extensive use, as it would require no less than 55,296 of the Epeira diadema to produce a single pound of silk; and how were all these to be provided with flies?

If the extreme fineness of the spider's threads is an obstacle to their being spun and woven, this property, united with their metallic brilliancy, renders them an excellent material for the construction of the micrometers used for astronomical purposes: the finest silver thread which it is possible to spin having a diameter of $\frac{1}{9} \frac{1}{4}$ of an inch, while spiders' threads measure only $\frac{1}{400} \overline{0}$ or even $\frac{1}{80} \overline{0}$. Troughton, an eminent English instrument maker, first thought of substituting them for the silver-threads then in use, and they were found to answer so well that since that time they have been constantly employed.

The Scorpions, which even in Europe are reckoned among the most malignant insects, are truly terrific in the torrid zone, where they frequently attain a length of 
six or seven inches. Closely allied to the spiders, their aspect is still more repulsive. Were one of the largest scorpions menacingly to creep up against you, with extended claws and its long articulated sharply-pointed tail projecting over its head, I think, despite the strength of your nerves, you would start back, justly concluding that a creature of such an aspect must necessarily come with the worst intentions. The poison of the scorpion is discharged like that of the snake. Near the tip of the crooked sting, namely, which terminates the tail, we find two or three very small foramina, through which, on pressure, the venom of the gland with which they are connected immediately issues forth. By means of this weapon, even the small European scorpions are able to kill a dog, while the tropical giants of the race inflict wounds that become fatal to man himself. The sting of several South American scorpions produces fever, numbness of the limbs, tumors on the tongue, weakness of the sight, and other nervous symptoms, lasting twenty-four or forty-eight hours; but the African scorpions seem to be still more formidable. Mr. Swainson informs us that the only means of saving the lives of English soldiers who were stung by those of Egypt, was the amputation of the wounded limb; and Professor Ehrenberg, who, while making his researches on the Natural History of the Red Sea, was stung five times by the Androctonus quinquestriatus, and funestus, says he can well believe, from the dreadful pains he suffered, that the poison of these scorpions may become fatal to women and children. A servant of Mr. Russegger, while emptying a trunk, was stung in the breast by a large scorpion, which had concealed itself among the linen. For hours the pain was dreadful, shooting from time to time through the whole nervous system, and almost depriving the patient of consciousness. A cold perspiration covered his brow, and it was only after the internal and external application of ammonia, one of the chief remedies for sustaining the sinking flame of life, that he at length felt some relief, though he had still to suffer several days from a strong fever.

The scorpions live mostly on the ground, in gloomy recesses, and even in the nooks and corners of dwelling-houses, so that, in countries where they are known to abound, it is necessary to be very cautious in remoring stones, pieces of wood, \&c. Of a ferocious, cruel disposition, they are not only the foes of all other animals, but carry on a war of extermination among themselves, and are even said to kill and devour their own progeny, without pity, as soon as they are born ; thus rendering good service to the community at large. Maupertuis once inclosed a hundred scorpions-a select and delightful party-in a box. Immediately a furious battle ensued-one against all, all against one-and in an hour's time scarcely one of the combatants survived the conflict.

The poison of the scorpion is lodged in its tail, but that of the centipede is in its jaws. These are likewise among the pests of tropical climates; for, although several are found in Europe, yet, from their small size, they are harmless to man. Those of India and South America, on the other hand, are enormous, frequently six or seven inches long, and their sting is no less painful and virulent than that of the dreaded acorpion itself. 


\section{CHAPTER $\mathrm{X}$. \\ SERPENTS-LIZARDS-FROGS AND TOADS.}

Serpents: Rarity of Venomous Serpents-Habits and External Characteristics of SerpentsThe Labarri-The Trigonocephalus-Antidotes to the Poison of Serpents-Sucking out the Venom-The Poison-Fangs-The Bush-Master-The Echidna Ocellata-Rattlesnakes - Their Enemy the Hog-The Cobra de Capello-The Haje-The Cerastes-Boas and Pythons-The Boa-constrictor-The Water Boa-Fascination by Snakes-Henderson's Argument against It-Thorpe's Reasons in its Favor-Du Chaillu on the Subject-Enemies of Serpents-The Secretary Bird-The Adjutant Bird-The Mongoos-Serpents Eating Serpents-The Locomotion of Serpents-Anatomy of their Jaws-A Serpentine MealPet Serpents-Tree Snakes-Water Snakes-Stories of Enormous Snakes-Du Chaillu's Big Snake-Wallace's Bigger One.-Lizards: The Geckoe-Anatomy of its Feet-Their Wide Distribution-The Anolis-Its Combativeness-The Chameleon-Its Habits, Change of Color, and Characteristics-The Iguana-The Teju-Water Lizards-Flying DragonsThe Basilisk.-Frogs and Toads: The Pipa Frog-Tree Frogs-Wallace's Flying FrogThe Bahia Toad-The Giant Toad-The Musical Toad.

$\mathrm{O}^{2}$ $\mathrm{N}$ penetrating for the first time into a tropical forest, the traveler is moved by many conflicting emotions. This luxuriance of vegetation, this abundance of blossoms, unite in raising the soul to the fullest enjoyment of the moment; and yet the heart is, at the same time, chilled with vague fears, that mix like a discordant sound with the harmonies of this sylvan world. For in the hollows of the tangled roots and in the dense underwood of the forest a brood of noxious reptiles loves to conceal itself, and who knows whether a snake, armed with poisonous fangs, may not dart forth from the rustling foliage. Gradually, however, these reflections wear away, and time and experience convince one that the snakes in the tropical woods are hardly more to be feared than in our own forests. These reptiles are, indeed, far from being of so frequent occurrence as is generally believed; and on meeting with a snake, there is every probability of its belonging to some harmless species, which show themselves much more frequently by day, and are by far more numerous. Even in India and Ceylon, where serpents are said to abound, they make their appearance so cautiously that the surprise of long residents is invariably expressed at the rarity with which they are to be seen. Dr. Russell, who particularly studied the serpents of India, found that, out of forty-three species which he himself examined, not more than seven were found to possess poisonous fangs; and Davy, whose attention was carefully directed to the snakes of Ceylon, came to the conclusion that but four out of the twenty species he could collect were venomous, and that of these only two were capable of inflicting a wound likely to be fatal to man.

Sir E. Tennent, who frequently performed journeys of two to five hundred miles through the jungle without seeing a single snake, never heard, during his long resi- 
dence in Ceylon, of the death of a European which was caused by the bite of one of these reptiles; and in almost every instance accidents to the natives happened at night, when the animal, having been surprised or trodden on, had inflicted the wound in self-defence. Thus, to avoid danger, the Singhalese, when obliged to leave their houses in the dark, carry a stick with a loose ring, the noise of which, as they strike it on the ground, is sufficient to warn the snakes to leave their path. During his five years' travels through the whole breadth of tropical America, from the Atlantic to the Pacific, M. de Castelnau, although ever on the search, collected no more than ninetyone serpents, of which only twenty-one were poisonous.

The habits of the venomous snakes, and the external characters by which they are distinguished from the harmless species, likewise tend to diminish the danger to be apprehended from them. Thus, their head is generally flat, broad, lanceolate; they have an aperture or slit on each cheek, behind the nostrils, and an elongated vertical pupil like many other nocturnal animals. They are also generally slower and more indolent in their motions, and thus are more easily avoided. No venomous snake will ever be found on a tree; and on quietly approaching one in the forest or in the savanna, it will most likely creep away without disputing the path, as it is not very anxious uselessly to squander the venom which nature gave it as the only means for procuring itself food.

" There is not much danger in roving amongst snakes," says Waterton, who, from spending many a month in tropical wilds, may justly be called an excellent authority, "provided only that you have self-command. You must never approach them abruptly; if so, you are sure to pay for your rashness; because the idea of selfdefence is predominant in every animal, and thus the snake, to defend himself from what he considers an attack upon him, makes the intruder feel the deadly effect of his envenomed fangs. The labarri snake is very poisonous, yet I have often approached within two yards of him without fear. I took care to advance very softly and gently, without moving my arms, and he always allowed me to have a fine view of him, without showing the least inclination to make a spring at me. He would appear to keep his eye fixed on me, as though suspicious, but that was all. Sometimes I have taken a stick ten feet long and placed it on the labarri's back; he would then glide away, without offering resistance. However, when I put the end of the stick abruptly to his head, he immediately opened his mouth, flew at it, and bit it." But although accidents from venomous snakes are comparatively rare, yet the consequences are dreadful when they do take place, and the sight of a cobra or a trigonocephalus preparing for its fatal spring may well appall the stoutest heart.

Prince Maximilian of Neu Wied, having wounded a tapir, was following the traces of his game along with his Indian hunter, when suddenly his companion uttered a loud scream. He had come too near a labarri snake, and the dense thicket prevented his escape. Fortunately the first glance of the distinguished naturalist fell upon the reptile, which with extended jaws and projecting fangs was ready to dart upon the Indian, but at the same moment, struck by a ball from the prince's rifle, lay writhing on the ground. The Indian, though otherwise a strong-nerved man, was so paralyzed by fear that it was some time before he could recover his self-possession-a proof, among others, that it is superfluous to attribute a fascinating power to the venomous snakes, as the effects of terror are quite sufficient to explain why smaller animals, unable to flee the 
impending danger, become their unresisting victims, and even seem, as it were, wan. tonly to rush upon destruction. But upon this subject we shall have more to say.

A poor Indian girl that accompanied Schomburgk on his travels through the forests of Guiana was less fortunate than the Prince of Neu Wied's companion. She was bitten by a trigonocephalus, and it was dreadful to see how soon the powers of life began to ebb under the fatal effects of the poison. The wound was immediately sucked, and spirits of ammonia, the usual remedy, profusely applied both externally and inwardly, but all in vain. In less than three minutes, a convulsive trembling shook the whole body, the face assumed a cadaverous aspect, dreadful pains raged in the heart, in the back, less in the wound itself ; the dissolved blood flowed from the ears and nose, or was spasmodically ejected by the stomach ; the pulse rose to 120-130 in the minute; the paralysis which first benumbed the bitten foot spread farther and farther, and in less than eight minutes the unfortunate girl was no longer to be recog. nized. The same day the foot swelled to shapeless dimensions, and she lay senseless until, after an agony of sixty-three hours, death relieved her from her sufferings.

A great many antidotes have been recommended against serpentine poison, but their very number proves their inefficacy. It is a well known fact that serpentine poison may be swallowed with impunity; it shows its effects only on mixing directly with the blood. A tight ligature above the wound, along with sucking, burning, or cutting it out, are thus very rational remedies for preventing the rapid propagation of the venom. Suction is, however, not always unattended with danger to the person who undertakes the friendly office. Thus Schomburgk relates the misfortunes of a poor Indian, whose son had been bitten in the cheek. The father instantly sucked the wound, but a hollow tooth conveyed the poison into his own body. His cheek swelled under excruciating pains, and without being able to save his son, his own health and vigor were forever lost; for such are the dreadful consequences of this poison, that they incurably trouble the fountains of life. The wound generally breaks open every year, emitting a very offensive odor, and causes dreadful pains at every change of the weather. Although all the venomous snakes produce morbid symptoms nearly similar, yet the strength of the poison varies according to the species of the serpent, and to the circumstances under which it is emitted. It is said to be most virulent during very hot weather, or when the animal is about to cast its skin. The effects are naturally more powerful and rapid when a larger quantity of poison flows into the wound, and a snake with exhausted supplies from repeated bitings will evidently strike less fatally than another whose glands are inflated with poison after a long repose.

Before describing some of the most conspicuous of the venomous serpents, a few words on the simple but admirable mechanism of their delicate but needle-like fangs will not be out of place. Towards the point of the fang, which is invariably situated in the upper jaw, there is a little oblong aperture on the convex side of it, and through this there is a communication down the fang to the root, at which lies a little bag containing the poison. Thus, when the point of the fang is pressed, the root of the fang also presses against the bag and sends up a portion of the poison it contained. The fangs being extremely movable, can be voluntarily depressed or elevated; and as from their brittleness they are very liable to break, nature, to provide for a loss that would be fatal, has added behind each of them smaller or subsidiary fangs ready to take their place in case of accident. 
Tnrivalled in the display of every lovely color of the rainbow, and unmatched in the effects of his deadly poison, the Bushmaster or Counacutchi (Lachesis rhombeata) glides on, sole monarcis of the forests of Guiana or Brazil, as both man and beast fly before him. In size $k_{0}$ surpasses most other venomous species, as he sometimes grows to the length of fourteen feet. Gencrally conceaied among the fallen leaves of the forest, he lives on small birds, reptiles, and mammalians, whom he is able to pursue with surprising activity. Fortunately, the bushmaster is a rare serpent, frequenting only the deepest shades of the thicket, where in the day-time he generally lies coiled upon the ground. Still rarer, though if possible yet more formidable, is a small brown viper (Echidna ocellata), which infests the Peruvian forests. Its bite is said to be able to kill a strong man within two or three minutes. The Indian, when bitten by it, does not even attempt an antidote against the poison, but stoically bids adieu to his comrades, and lays himself down to die.

The ill famed, wide extended race of the rattlesnakes, which ranges from South Brazil to Canada, belongs exclusively to the new world. They prefer the more elevated, dry, and stony regions, where they lie coiled up in the thorny bushes, and only attack such animals as come too near their lair. Their bite is said to be able to kill a horse or an ox in ten or twelve minutes; but, fortunately, they are afraid of man, and will not venture to attack him unless provoked. When roused to anger they are, however, very formidable, as their fangs penetrate through the strongest boot. One of the most remarkable features of their organization is a kind of rattle terminating the tail, and consisting of a number of pieces inserted into each other, all alike in shape and size, hollow, and of a thin, elastic, brittle substance, like that of which the scales are externally formed. When provoked, the strong and rapid vibratory motions imparted to the rattle produce a sound which has been compared to that of knife grinding, but it is never loud enough to be heard at any distance, and becomes almost inaudible in rainy weather.

Naturalists distinguish at least a dozen different species of rattlesnakes, the commonest of which are the Boaquira (Crotalus horridus), which frequents the warmest regions of South America, and the Durissus ( $C$.durissus), which has chosen the United Etates for its principal home. The chief enemy of this serpent is the hog, whom it dreads so much that on seeing one it immediately loses all its courage, and instantly takes to flight. But the hog, who smells it from afar, draws nearer and nearer, his bristles erected with excitement, seizes it by the neck, and devours it with great com. placency, though without touching the head. As the hog is the invariable companion of the settler in the backwoods, the rattlesnake everywhere disappears before the advance of man, and it is to be hoped that a century or two hence it will be ranked among the extinct animals. The American Indians often regale on the rattlesnake. When they find it asleep, they put a small forked stick over its neck, which they keep immovably fixed to the ground, giving the snake a piece of leather to bite, and this they pull back several times with great force, until they perceive that the poison-fangs are torn out. They then cut off the head, skin the body, and cook it as we do eels. The flesh is said to be white and excellent.

None of the American snakes inhabit the Old World, but in the East Indies and Ceylon other no less dangerous species appear upon the scene, among which the celebrated Cobra de Capello is one of the most deadly.

A few years since, a cobra 
in the British Zoological Gardens destroyed its keeper. In a fit of drunkenness, the man, against express orders, took the reptile out of its cage, and placing its head inside his waistcoat, allowed it to glide round his body. When it had emerged from under his clothes on the other side, apparently in good humor, the keeper squeezed its tail, when it struck him between his eyes. In twenty minutes his consciousness was gone, and in less than three hours he was dead. As long as the cobra is in a quiet mood, its neck is nowhere thicker than its head or other parts; but as soon as it is excited, it raises vertically the anterior part of its trunk, dilates the hood on each side of the neck, which is curiously marked in the center in black and white, like a pair of spectacles, and then swells out to double its former proportions, and advances against the aggressor by the undulating motion of the tail. It is not only met with in the cultivated grounds and plantations, but will creep into the ho ases and insinuate itself among the furniture. This is the snake so frequently exhibited by the Indian jugglers, who contrive by some unknown method to tame them so far that they will perform certain movements in cadence, and dance to the sound of music, with which the cobra seems much delighted, keeping time by a graceful motion of the head, erecting about half its length from the ground and following the few simple notes of the conjuror's flute with gentle curves like the undulating lines of a swan's neck.

The Egyptian Haje (Naja Haje), a near relation of the Indian cobra, is most likely the asp of ancient authors, which the celebrated Cleopatra chose as the instrument of her death, to avoid figuring in the triumph of Augustus. Like the cobra, it inflates its neck when in a state of excitement, and as it raises its head on being approached, as if watchful for its safety, it was venerated by the ancient Egyptians as a symbol of divinity, and as the faithful guardian of their fields. Divine honors have, however, much more frequently been paid to the venomous snakes from the terror they inspire, than from far-fetched notions of beneficence. The Cerastes, or horned-viper, one of the most deadly serpents of the African deserts, is frequently exhibited by Egyptian jugglers, who handle and irritate it with impunity : they are supposed to render themselves invulnerable by the chewing of a certain root, but most likely, as in the case of the cobra-charmers, their secret consists in their courage and perfect knowledge of the animal's nature.

Although the Boas and Pythons are unprovided with venomous fangs, yet, from their enormous size, they may well be ranked among the deadly snakes; for, as Waterton justly remarks, "it comes to nearly the same thing in the end whether the victim dies by poison from the fangs, which corrupts his blood and makes it stink horribly, or whether his body be crushed to mummy and swallowed by a Python." The kingly Jiboya (Boa-constrictor) inhabits the dry and sultry localities of the Brazilian forests, where he generally conceals himself in crevices and hollows in parts but little frequented by man, and sometimes attains a length of thirty feet. To catch his prey he ascends the trees, and lurks, hidden in the foliage, for the unfortunate agutis, pacas, and capybaras, whom their unlucky star may lead within his reach. When full-grown he seizes the passing deer; but in spite of his large size he is but little feared by the natives, as a single blow of a cudgel suffices to kill him. Prince Maximilian of Neu Wied tells us that the experienced hunter laughs when asked whether the Jiboya attacks and devours man.

The Sucuriaba, Anaconda, or Water Boa (Eunectes murinus), as it is variously 
named, attains still larger dimensions than the constrictor, as some are said to have been found of a length of forty feet. It inhabits the large rivers, lakes, and marshy grounds of tropical America, and passes most of its time in the water, now reposing on a sand-bank, with only its head above the surface of the stream, now rapidly swimming like an eel, or abandoning itself to the current of the river. Often, also, it suns itself on the sandy margin of the stream, or patiently awaits its prey, stretched our upon some rock or fallen tree. With sharp eye it observes all that swims in the waters as well as all that flies over them, or all that comes to the banks to quench its thirst ; neither fish nor aquatic bird is secure from the swiftness of its attack, and wos to the capybara that comes within the grasp of its folds. Such is its voracity, that Firmin found in the stomach of an Anaconda a large sloth, an Iguana nearly four feet long, and a tolerably-sized Ant-bear, all three nearly in the same state as when they were swallowed-a proof that their capture had taken place within a short time. As is commonly the case with reptiles, the water-boa is very tenacious of life, and though the head may be nearly severed from the trunk, the entrails taken out of the body, and the skin detached, it will still move about for a considerable time. The boas principally inhabit America, although some species are likewise met with in Asia. But the more formidakle pythons are confined to the hot regions of the Old World. They are said to enlace even the tiger or the lion in their fatal embrace; and to judge by their size and strength, this assertion seems by no means improbable.

The alleged power of fascination in snakes is now abandoned by most naturalists; and all the authenticated facts in relation to it seem to be capable of being otherwise explained. Dr. Henderson, a very close American observer, relates* some incidents bearing on this question. "Some field hands, " he says, "while at work in the field, killed a rattlesnake of such unusual size that they were induced to bring it to the house that the family might see it. Its head was chopped off and left in the field. The snake was laid under some shade trees, upon the branches of which a pair of mocking-birds had built their nest. The birds soon discovered the snake, and at once sounded their notes of alarm and distress. They commenced approaching, and finally came in immediate contact with the snake. In short, they exhibited all the phenomena of the fascinated in perfection, except that they did not jump into the snake's mouth, which, fortunately for them, was a mile distant. I have frequently heard it asserted that the snake, after fascinating the bird, opens its mouth and the bird jumps into it. To test the truth of this, I caught a black adder, and tying one end of a piece of twine around his neck, I made the other end fast to some shrubbery in which a pair of mocking-birds had made their nests. The snake was soon discovered by the birds, and in a short time they were as much fascinated as birds ever become. They approached the reptile with feathers reversed, uttering their notes of alarm, and were a dozen times in contact with him. On the other hand, the snake seemed only bent on escaping, and bad neither time nor inclination to exert his famed power of fascination. It was exerted, however, to its fullest extent, as far as the birds were concerned. At length the snake, in his efforts to escape, brought his body so far through the loop of twine around his neck that he was suffocated. This made ne difference, and the birds continued to be as much fascinated after as before his death. They were several times driven away, but would as often return. In these instances 
what becomes of the alleged wonderful power of the serpent's eye? Two kirds were apparently charmed at one and the same time by a single snake, and that a dead one. The real fact is, that the so-called fascination is seen in perfection only during the period of incubation, and while the birds are rearing their young. There is a marked difference between the actions of the birds during this period and at other times. Now, animals of every species either eat or are eaten by other species; and each race has its own peculiar modes of attack, defence, and escape. The snake knows that other animals hold him in great terror; but that birds will approach him if he remains perfectly still. When he perceives that the birds have seen him, he remains perfectly still. The birds know that their young will approach the snake and fall a prey to him. If it be in the breeding season, parental instinct or affection impels them to attack the enemy, and so it often sacrifices its own life to save that of its offspring. Parental solicitude overcomes its natural timidity. Indeed the birds on these occasions seem to lose their senses altogether, precisely as a human parent might do under similar circumstances."

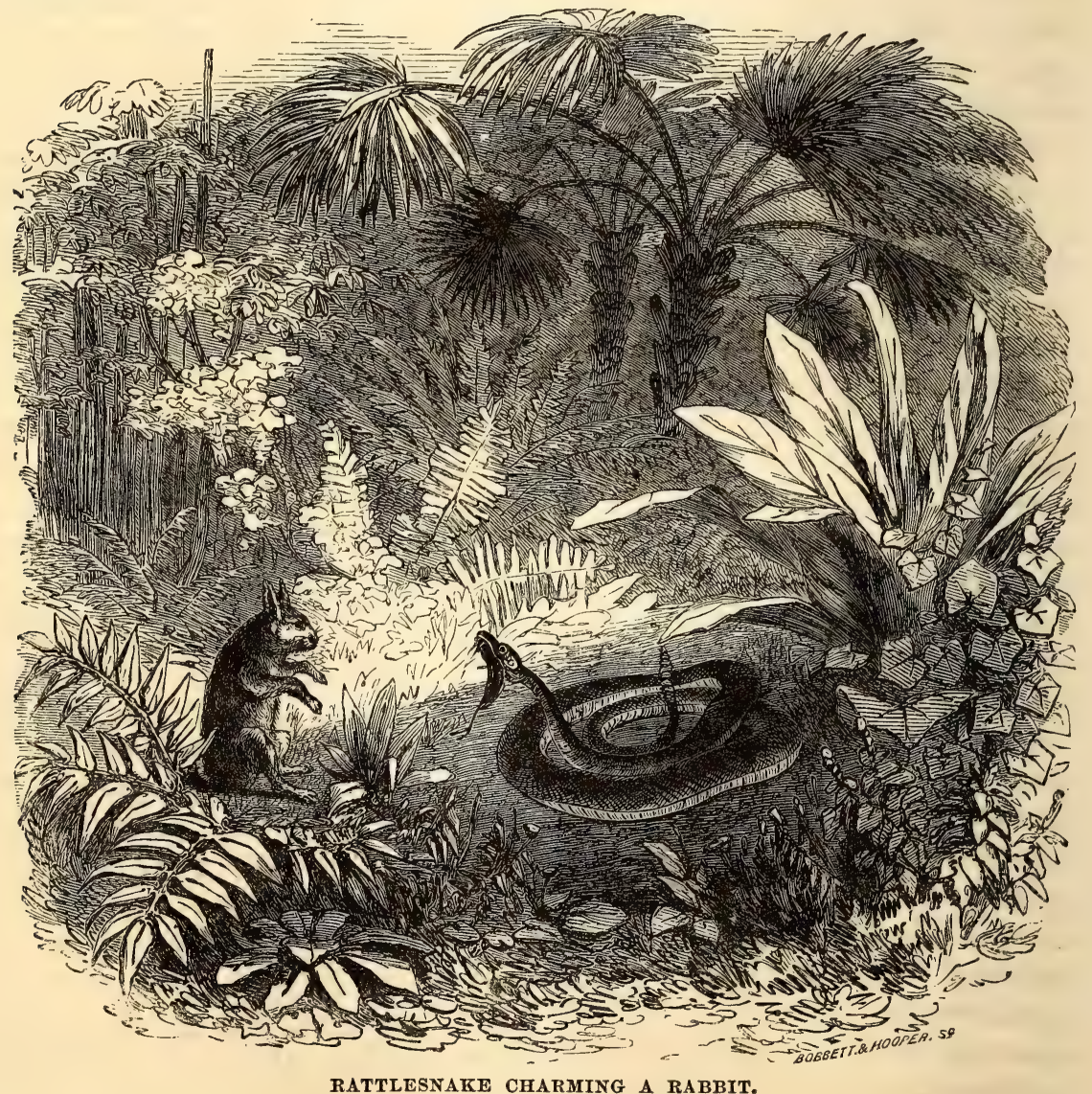

Still, however, we must admit that the subject of snake fascination is in a measure an open question. Mr. T. B. Thorpe, another close observer of the habits of the animal world, is fully convinced of the existence of this power, and cites many inci- 
dents in proof of his theory, accompanying them with drawings of the reptile in flagrante delictu.* He shows one snake in the attitude, as he believes, of charming a wild-cat; and another when charming a rabbit. In this latter illustration the rabbit certainly looks as though he was fascinated. He believes also that they have this power over man, and adduces several instances in corroboration. And even further, he believes that this power exists in the dead reptile. He sums up his conclusions thus: "The food of the rattlesnake is in a great measure composed of small animals or birds superior to it in fleetness, and it has no power to seize its prey except when it is coiled up, and consequently incapable of giving chase. In addition, the reptile, while attempting to seize its prey, emits a strong odor, which no doubt has a stupefying effect upon its victim. Now, as the rattlesnake never steals upon any object, and is perfectly incapable of seizing its food except when it is coiled up and stationary, how would it ever obtain subsistence if nature had not given it the power to attract its prey within its deadly reach? Although it is disputed by most naturalists that snakes have the power of fascination, yet to me it seems as if nothing relating to their natural history is more fully substantiated. People living in crowded cities who receive from abroad 'specimens' preserved in alcohol and bottled, or write dissertations from examination of the 'stuffed skin,' must be assured, from what they see before them, that the power of fascination is a fable; and as doubting is a safe form of unbelief, it is freely expressed. The rattlesnake, nevertheless, has certainly an eye of command as had Napoleon; and the power of the reptile's gaze is not only acknowledged by the humbler class of animals, but man, with all his superior powers, has felt a thrill of helplessness pass through his soul as he beheld that mysterious eye glaring full upon him. Approach a rattlesnake, and with the first convenient thing dash out his brains; but dare not to make a close examination of the death-dealing object before you. If its spiral motions once find a response in the music tune-markings of your own mind; if you look into those strange orbs that seem to be the openings into another world; if that forked tongue plays into your presence until you find it as vivid as the lightning's flash; and, meanwhile, the hum of those rattles begins to confuse your absorbed senses, you will be conscious of some terrible danger; that you stand upon some dread precipice; that your blood is starting back from your heart; and you can only break through the charm with an effort that requires the whole of your resolution."

Paul du Chaillu also-no mean authority on the subject-firmly believes in this power of fascination; and gives an instance in point : $\dagger$ " I shall never forget that one day, as I lay ill under that big tree, I spied an enormous snake folded among the branches of another tree not far from me. My attention had been drawn to that tree by the cries of a squirrel. The snake was charming the poor little squirrel. How nice the squirrel was; how beautiful his little tail; how black and bright seemed his little eyes. His little feet were moving onward toward the snake; his little tail was up, and he chippered as he advanced toward certain death. The snake was still as death; not one of his folds could have been seen moving. How black and shiny the ugly creature was, and what a contrast with the green leaves of the trees. Part of his body was coiled on the limb of the tree. How fixedly he looked on the squirrel. His head was triangular, and he belonged to that family of snakes that spend the

* Harper's Magazine, March, 1855.

† Wild Life Under the Equator, 161. 
greatest portion of their lives on trees. Nearer and nearer the squirrel came; louder and louder were his chipperings; he tried to run away, but could not. At last he came within a foot of the snake. There was a pause; then suddenly, like a flash of lightning, the snake sprang. The poor little squirrel was in the folds of the ugly reptile, and I soon saw his body gradually disappearing into its inflated mouth, and the broken silence of the forest resumed its sway." Here I leave the vexed question of serpentine fascination, with the expression of my own opinion that, while much can be said on both sides, yet, upon the whole, the nays have it.

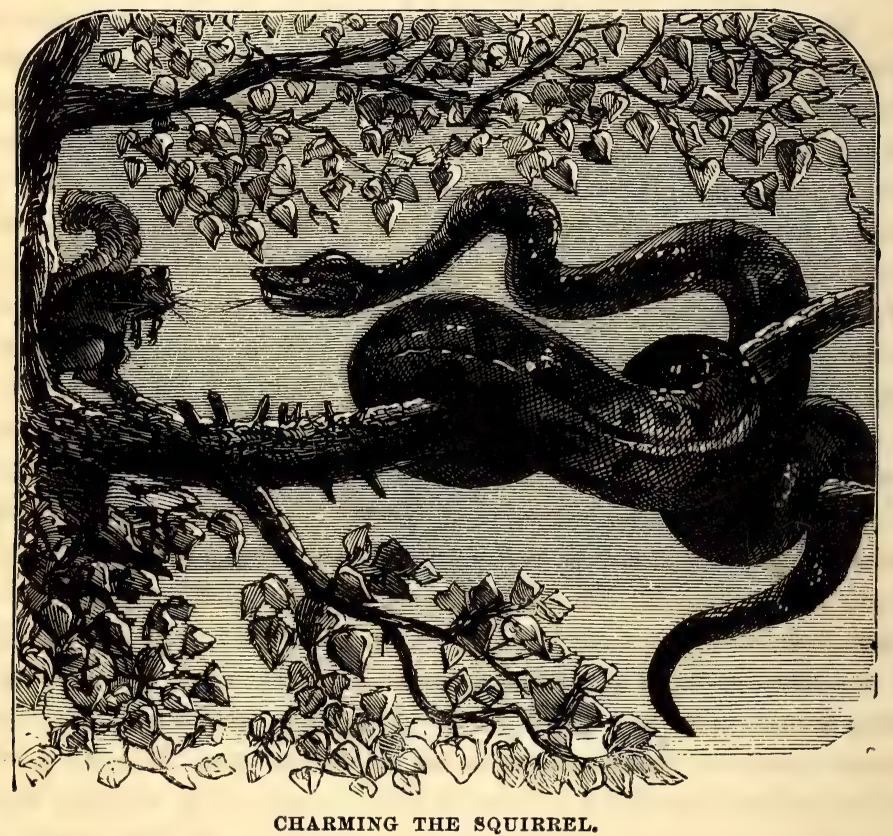

The various serpent tribes are exposed to the attacks of many enemies, who fortunately keep their numbers within salutary bounds, and avenge the death of the count. less insects, worms, toads, frogs, and lizards, that fall a prey to their strength or their venom. Several species of rapacious and aquatic birds live upon snakes, the American ostrich thins their ranks wherever he can, and the African "Secretary" is renowned for his prowess in serpentine warfare. "The battle was obstinate," says Le Vaillant, describing one of these conflicts, " and conducted with equal address on both sides. The serpent, feeling the inferiority of his strength, in his attempt to flee, and regain his hole, employed that cunning which is ascribed to him, while the bird, guessing his design, suddenly stopped him, and cut off his retreat by placing herself before him at a single leap. On whatever side the reptile endeavored to make its escape, his enemy was still found before him. Then, uniting at once bravery and cunning, he erected himself boldly to intimidate the bird, and hissing dreadfully, displayed his menacing throat, inflamed eyes, and a head swollen with rage and venom. Sometimes this threatening appearance produced a momentary suspension of hostilities, but the bird soon returned to the charge, and covering her body with one of her wings as a buck- 
ler, struck her enemy with the horny protuberances upon the other, which, like little clubs, served the more effectually to knock him down as he raised himself to the blow; at Jast he staggered and fell, the conqueror then despatched him, and with one stroke or her bill laid open his skull." The secretary-eagle has now been successfully acclimatized in the West Indies, where he renders himself useful by the destruction of the venomous snakes with which the plantations are infested.

Gravely, "with measured step and slow," like a German philosopher cogitating over the nature of the absolute, but, as we shall presently see, much more profitably engaged, the "Adjutant" wanders among the reeds on the banks of the muddy Ganges. The aspect of this colossal bird, measuring six feet in hight and nearly fifteen from tip to tip of the wings, is far from being comely, as his enormous bill, his naked head and neck, except a few straggling curled hairs, his large craw hanging down the forepart of the neck like a pouch, and his long, naked legs, are certainly no features of beauty. Suddenly he stops, dips his bill among the aquatic plants, and immediately raises it again triumphantly into the air, for a long snake, despairingly twisting and wriggling, strives vainly to escape from the formidable pincers which hold it fast. The bird throws back his head, and the reptile appears notably diminished in size; a few more gulps, and it has entirely disappeared. And now the sedate bird continues his stately promenade with the self-satisfied mien of a merchant who has just made a successful speculation, and is engaged in the agreeable calculation of his gains. But lo! again the monstrous bill descends, and the same scene is again repeated. The good services of the Giant Heron in clearing the land of noxious reptiles, and the havoc he is able to make among their ranks, may be judged of by the simple fact, that on opening the body of one of them, a land-tortoise ten inches long and a large black cat were found entire within it, the former in the pouch, as a kind of stock in trade, the latter in the stomach, all ready for immediate consumption.

Trusting to his agility and the certainty of his eye, the Indian Ichneumon or Mongoos attacks without hesitation the most venomous serpents. The cobra, which drives even the leopard to flight, rises before the little creature with swelling head and fury in its eye ; but swift as thought, the ichneumon, avoiding the death-stroke of the projecting fangs, leaps upon its back, and fastening his sharp teeth in the head, soon despatches the helpless reptile.

The serpents sometimes even feed upon their own brethren. Thus a rat-snake in the Zoölogical Gardens was once seen to devour a common Coluber natrix, but not having taken the measure of his victim, he could not dispose of the last four inches of his tail, which stuck out rather jauntily from the side of his mouth, with very much the look of a cigar. After a quarter of an hour the tail began to exhibit a retrograde motion, and the swallowed snake was disgorged, nothing the worse for his living sepulchre with the exception of the wound made by his partner when he first seized him. A python in the same collection, who had lived for years on friendly terms with a brother nearly as large as himself, was found one morning sole tenant of his den. As the cage was secure, the keeper was puzzled to know how the serpent had escaped. At last it was observed that the remaining inmate had swollen remarkably during the night, when the truth came out. It was, however, the last meal of the fratricide, for in some months he died.

When we consider that the snakes have neither legs, wings, nor fins, and are indeed 
deprived of all the usual means of locomotion, the rapidity of their progr ess is not a little surprising. On examining the anatomical structure of their body, however, it will be remarked that while we have only twelve pair of ribs united in front by the breast-bone and cartilage, the snake has often more than three hundred, unconnected in front, and consequently much more free in their motions, a faculty which is still increased by the great mobility of the spondyli of the backbone. Between the ribs and the broad transverse scales or plates which exist on the belly of all such serpents as move rapidly, we find numerous muscles connecting them one with another, and thus, amply provided with a whole system of strong pulleys and points of attachment, the reptile, bringing up the tail towards the head, by bending the body into one or more curves, and then again resting upon the tail and extending the body, glides swiftly along, not only upon even ground, but even sometimes from branch to branch, as the smallest hold suffices for its stretching out its body a foot's length into the air, and thus reaching another sallying point for further progress.

The anatomy of the serpent's jaws is no less remarkable than the mechanism of its movements. In spite of their proverbial wisdom, snakes would not be able to exist unless they were able to swallow large animal masses at a time. For, however rapid their motions may be, those of their prey are in general still more active, and thus they are obliged to wait in ambush till a fortunate chance provides them with a copious meal. The victim is often much more bulky than the serpent itself; but still, without tearing it to pieces, it is able to engulph it in his swelling maw. For the two halves of its lower jaw do not coalesce like ours into one solid mass, but are merely connected in front by a loose ligament, so that each part can be moved separately. The bones of the upper jaw and palate are also loosely attached or articulated one with the other, and thus the whole mouth is capable of great distension. By this mechanism, aided by the numerous sharp teeth, which are so many little hooks with the point curved backwards, each side of the jaws and mouth being able to act as it were independently of the other, alternately hooks itself fast to the morsel, or advances to fasten itself farther on in a similar manner, and thus the reptile draws itself over its prey, somewhat in the same way as we draw a stocking over our leg, after having first, by breaking the bones, fashioned it into a convenient mass, and rendered its passage more easy by lubricating it with its saliva. Slowly the huge lump disappears behind the jaws, descends lower and lower beneath the scales, which seem ready to burst asunder with distension, and then the satisfied monster coils himself up once more to digest his meal in quiet. The time required for this purpose varies of course according to the size of the morsel; but often weeks, or even months, will pass before a boa awakens from the lethargic repose in which-the inage of disgusting gluttony-he lies plunged after a superabundant meal.

A huge python in the Zoölogical Gardens fasted the almost incredible time of twenty-two months, having probably prepared himself for his abstinence by a splendid gorge; and Duméril mentions a rattlesnake in the Jardin des Plantes which likewise took no nourishment during twenty-one months, but then, as if to make up for lost time, swallowed three hares within five days. The reptiles in the British Zoölogical Gardens are offered food once a week, but even then their appetites are frequently not yet awakened, though great care is taken never to spoil their stomachs by excess.

Though generally the objects of abhorrence and fear, yet serpents sometimes render 
themselves useful or agreeable to man. Thus the rat-suake of Ceylon (Coryphodon Blumenbachii), in consideration of its services in destroying vermin, is often kept as a household pet, and so domesticated by the natives as to feed at their table. The beautiful coral-snake (Elaps corallinus) is fondled by the Brazilian ladies, but the domestication of the dreaded cobras as protectors in the place of dogs, is still more remarkable. They glide about the house, going in and out at pleasure, a terror to thieves, but never attempting to harm the inmates.

The Tree-snakes offer many beautiful examples of the adaptation of color to the animal's pursuits, which we have already had occasion to admire in our brief review of the tropical insect world. They are frequently of an agreeable green or bluish hue, so as hardly to be distinguishable from the foliage among which they seek their prey, or where they themselves are liable to be seized upon by their enemies. They are often able vertically to ascend the smoothest trunks and branches, in search of squirrels and lizards, or to rifle the nests of birds.

The Water-snakes which infest some parts of the tropical seas, though far from equalling in size the vast proportions of the fabulous sea-serpent, are very formidable from their venomous bite. They have the back part of the body and tail very much compressed and raised vertically, so as to serve them as a paddle with which they rapidly cleave the waters.

Of enormous snakes, whose dimensions exceed all credibility, the old writers are full. One can there find them of any length he pleases, a few yards more or less being of no consequence. Thus the famous serpent which in Africa stopped the march of the Roman army of Atilius Regulus, is said to have been one hundred and twenty feet in length. A recent traveler in Ceylon, while acknowledging that thirty feet was the utmost for which he was prepared to vouch personally, was, as he says, credibly assured that one had been lately killed which measured forty-five feet in length, with a circumference of six feet; and he was told of another, killed in India not long ago, which attained the respectable length of sixty feet. But passing over these quite suspicious narratives, we find accounts of serpents quite long enough to satisfy any reasonable desire.

Equatorial Africa appears to be a favorite abode for the serpentine family ; and if any of monstrous size exist there, they could hardly escape the keen eyes of Paul du Chaillu. He thus describes the death of the largest one of which we notice any mention in his books: "After resting a little while we continued our course till we reached the top of a very high mountain, whence I could see all the country round. I was sitting under a very large tree, when suddenly looking up, I saw an immense serpent coiled upon the branch of a tree just above me. I rushed out, and taking good aim with my gun, I shot my black friend in the head. He let go his hold, tumbled down with great force, and after writhing convulsively for a time, he lay before mo dead. He measured thirteen feet in length, and his ugly fangs proved that be was venomous. My men cut off the head of the snake, and divided the body into as many parts as there were people. Then they lighted a fire, and roasted and ate it on the spot. They offered me a piece, but though I was very hungry, I declined. When the snake was eaten, I was the only individual in the company that had an empty stomach." 
But Wallace goes beyond $\mathrm{Du}$ Chaillu in his accounts of the actual size of serpents existing in the almost unexplored Malayan islands. He says :* "One day my boy Ali came home with a story of a big snake. He was walking through some high grass, and stepped on something which he took for a small fallen tree; but it felt cold and yielding to his feet, and far to the right and left there was a waving and rustling of the herbage. He jumped back in affright, and prepared to shoot; but could not get

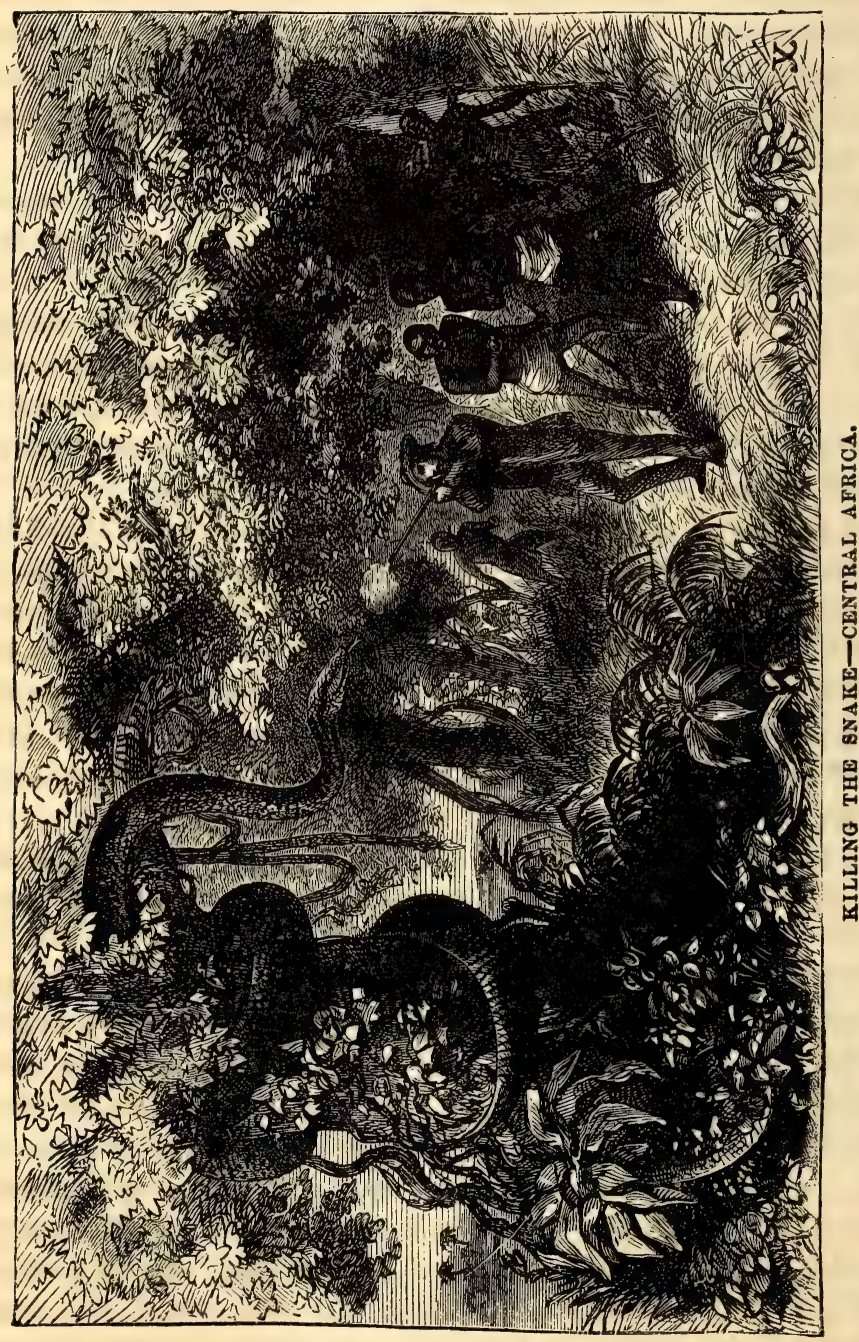

a good view of the creature, and it passed away, he said, like a tree being dragged through the grass. As he had several times already shot large snakes, which he declared were all as nothing compared with this, I am inclined to believe it must have really been a monster. Such creatures are rather plentiful here, for a man close by showed me on his thigh the marks where he had been seized by one close to his house. 
It was big enough to take the man's thigh in his mouth, and he would probably have been killed and devoured by it, had not his cries brought out his neighbors who destroyed it with their choppers. As far as I could make out, it was about twenty feet long ; but Ali's was probably much larger."

The Tropical World may well be called the head-quarters of the lizard race, as nowhere else do these reptiles appear in such multitudes or in such diversified forms of genera and species. The stranger is astonished by their numbers as soon as he sets foot on a tropical shore ; for on all sides, on the sands and in the forests, on soft banks and hard rocks, on trees and on the ground, lizards of every variety of size, form, and color, are seen darting, climbing, crawling, and rustling.

The Geckoes, one of the family, may be fairly claimed as belonging to domestic animals, since they take up their abode in the dwellings of man, where they make themselves useful by the destruction of spiders, flies, and other noxious or disagreeable insects, which they almost always swallow whole, their throat being as broad as the opening of their jaws. During the daytime they generally remain concealed in some dark crevice or chink, but towards evening they may be seen running along the steepest walls with marvelous rapidity, in keen pursuit of their prey, frequently standing still, nodding with their head, and uttering shrill tones, most likely by smacking their tongue against the palate. Their flattened flexible body seems to mould itself into the hollows, in which they often remain motionless for hours, and their generally dull color harmonizes so well with their resting-places, as to render them hardly distinguishable; a circumstance which answers the double purpose of masking their presence from the prey for which they lie in wait, and from the enemies that might be inclined to feast upon them. Among these, some of the smaller birds of prey-hawks and owls-are the most conspicuous, not to mention man, the arch-persecutor of almost every animal large enough to attract his notice.

How comes it that these nocturnal lizards, seemingly in defiance of the laws of gravitation, are thus able to adhere to our ceilings or any other overhanging surfaces? An inspection of the soles of their broad feet will soon solve the enigma, for all their toes are considerably dilated on their margins, and divided beneath into a number of transverse lamellæ, parallel to each other, and generally without any longitudinal furrow. From these a fluid exudes which serves to attach the animal to the surface. They are also generally provided with sharp and crooked claws, retractile and movable, like those of a cat, and which render them good service in climbing the trees.

In spite of their harmless nature, the Geckoes-their real utility being forgotten over imaginary grievances-nowhere enjoy a good reputation, probably in consequence of their ugliness and the wild expression of their large eyes. They are accused of tainting with a virulent secretion every object they touch, and of provoking an eruption on the skin merely by running over it-a popular prejudice which naturally causes many a poor inoffensive Gecko's death. They abound all over the torrid zone, even in the remote islands of the Pacific, such as Tahiti and Vanikoro. Duméril enumerates fifty-five different species, only two of which are indigenous in Southern Europe, while India monopolizes no less than thirteen for her share.

The graceful Anolis are peculiar to America. By the structure of their feet, provided with long unequal toes, they are related to the Geckoes, but are distinguished 
from them by a more slender form of body, by their extremely long thin tail, and a large neck-pouch, which dilates under the influence of excitement. These small and nimble creatures, the largest species seldom exceeding eight inches in length, are as touchy as fighting cocks. On approaching them, they instantly blow up their pouch, open widely their diminutive jaws, and spring upon the aggressor, striving to bite him with their teeth, which, however, are too small to do much harm. Among each other they live in a perpetual state of warfare. As soon as one Anolis sees another, he makes a rapid advance, while his adversary awaits him with all the courage of a gallant knight. Before beginning the conflict, they make all sorts of menacing gestures, convulsively nodding their heads, puffing up their pouches, until finally they close in desperate struggle. If they are of equal strength, the battle remains for some time undecided. At length the vanquished Anolis turns and runs away, but he may think himself fortunate if he escapes with the loss of his tail. Many of them are thus deprived of this ornamental appendage, which they voluntarily leave behind to avoid a still greater disaster, and then they become timid, melancholy, and fond of retirement, as if ashamed of being seen, only regaining their spirits when, by a wonderful power of reproduction, the amputated tail has been replaced by another.

Like many other lizards, the Anolis possesses the faculty of changing color when under the influence of excitement; but of all animals, whether terrestrial or marine, none is more famous or remarkable in this respect than the Chameleon. It frequently happens that man, not satisfied with the wonders which nature everywhere exposes to his view, adds to their marvels others of his own invention, and thus many a fable has been told about the Chameleon. It has been said, for instance, that it could emulate all the colors of the rainbow; but the more accurate observations of modern naturalists have shown that the whole change, which takes place most frequently when the Chameleon is exposed to full sunshine or under the influence of emotion, consists in its ordinary bluish-ash color turning to a green or yellowish hue, with irregular spots of a dull red. Like many other reptiles, the Chameleon has the power of inflating its lungs and retaining the air for a long time, so as one moment to appear as fat and well fed as an alderman, and the next as lean and bony as a hungry disciple of the muses. These alternating expansions and collapses seem to have a great influence on the change of color; which, however, according to Milne Edwards, is principally owing to the skin of the animal consisting of two differently colored layers, placed one above the other, and changing their relative positions under the influence of excitement.

In our northern regions the captive Chameleon cuts but a sorry figure; but in his own sunny regions, which extends from southern Spain and Sicily to the Cape, and eastwards from Arabia and Hindostan to Australia, it is said to be by no means deficient in beauty, in spite of its strangely-formed keel-like head, its enormously pro. jecting eyes, and its granulated skin. Its manner of hunting for the little winged insects that form its principal food is very peculiar. Although the movements of its head are very limited, on account of the shortness of its neck, this deficiency is amply supplied by the wide range of its vision, each eye being able to move about in all directions independently of the other. Thus, while one of them attentively gazes upon the heavens, the other minutely examines the ground, or while one of them rolls in its orbit, the other remains fixed; nay, their mobility is so great, that without even 
moving its stiff head, this wonderful lizard, like Janus, the double-faced god of ancient Rome, can see at the same time all that goes on before and behind it. When an insect comes flying along, the chameleon, perched on a branch, and half concealed between the foliage, follows it in all its movements by means of his powerful telescopes, until the proper moment for action appears. Then, quick as thought, he darts forth, even to a distance of five or six inches, his long fleshy glutinous tongue, which is moreover furnished with a dilated and somewhat tubular tip, and driving it back with the same lightning-like velocity, engulfs his prey. This independence of the eyes is owing to the imperfect sympathy which subsists between the two lobes of the brain and the two sets of nerves which ramify throughout the opposite sides of its frame. Hence also one side of the body may be asleep while the other is vigilant, one may be green while the other is ash-blue, and it is even said that the Chameleon is utterly unable to swim, because the muscles of both sides are incapable of acting in concert. Destined for a life upon trees, he is provided with organs beautifully adapted for supporting himself on the flexible branches; for besides the cylindrical tail nearly as long as his body which he coils round the boughs, his five toes are united two and three by a common skin, so as to form, as it were, a pair of pincers or a kind of hand, admirably suited for a holdfast.

Among the Iguanas, a huge lizard tribe, characterized by a keel-like back and tail, and a large full-toothed throat-pouch, the common or great American Guana (Iguana tuberculata) deserves particular notice, as its white flesh is considered a great delicacy in Brazil and the West Indies. Notwithstanding its large size, for it not seldom attains a length of four or five feet, aud the formidable appearance of its serrated back, it is in reality by no means of a warlike disposition, and so stupid that, instead of endeavoring to save itself by a timely flight, it merely stares with its large eyes, and inflates its pouch, while the noose is passing round its neck to drag it forth from its hole. The Bahama islands abound with Guanas, which form a great part of the subsistence of the inhabitants. They are caught by dogs, trained for the purpose, in the hollow rocks and trees where they nestle, and are either carried alive for sale to Carolina, or kept for home consumption. They feed wholly on vegetables and fruit, particularly on a kind of fungus, growing at the roots of trees, and on the fruits of the different kinds of ananas, whence their flesh most likely acquires its delicate flavor.

The famous South American monitory lizard or Teju, (Tejus monitor,) is one of the largest and most beautiful of the whole race, as he measures no less than five feet from the snout to the tip of the tail, which is nearly twice as long as the body, while his black color, variegated with bright yellow bands and spots, produces an agreeable and pleasing effect. The head is small, the snout gradually tapers, the limbs are slender, and the tail, which is laterally compressed, gradually decreases towards the extremity. The Teju lives in cavities and hollows, frequently under the roots of trees. When pursued, he runs rapidly straight forward to his burrow; but when his retreat is intercepted, he defends himself valiantly, and proves a by no means contemptible antagonist, as he is able to bite through a thick boot, and a stroke with his strong and muscular tail will completely disable a dog. Though the Monitor generally lives on land, he is an excellent swimmer, and catches many a fish in its native element. His chief food, however, consists in various fruits, rats, mice, birds, and he also devours a large number of the eggs and young of the alligator. 
The large Water-lizards (Hydrosauri) frequent the low river banks or the margins of springs, and although they may be seen basking on rocks or on the dead trunk of some prostrate tree in the heat of the sun, yet they appear more partial to the damp weeds and undergrowth in the neighborhood of water. Their gait has somewhat more of the awkward lateral motion of the crocodile, than of the lively action of the smaller saurians. When attacked, they lash violently with their tail, swaying it sideways with great force like the cayman. These modern types of the Mososaurus and Iguanodon have a graceful habit of extending the neck, and raising the head to look about them, and as you follow them leisurely over the rocks, or through the jungle, they frequently stop, turn their heads round, and take a deliberate survey of the intruder. They are by no means vicious, though they bite severely when provoked, acting, however, always on the defensive. On examining their stomachs, crabs, locusts, beetles, the remains of jumping fish, the scales of snakes, and bones of frogs and other small animals are discovered. Like that of the Iguanas, their flesh is delicate eating, resembling that of a very young sucking-pig.

The formidable name of Flying Dragons has been given to a genus of small lizards, remarkable for the expansible cutaneous processes with which the sides are furnished, and by whose means they are enabled to spring with more facility from branch to branch, and even to support themselves for some time in the air, like the bat or flyingsquirrel. The tiny painted Dragon of the East, the Flying Lizard of the woods, is fond of elinging with its wings to the smooth trunks of trees, and there remaining immovable, basking in the sun. When disturbed, it leaps and shuffles away in an awkward manner. One Mr. Adams had in his possession, reminded him of a bat when placed on the ground. Sometimes the strange creature would feign death, and remain perfectly motionless, drooping its head, and doubling its limbs, until it fancied the danger over, then cautiously raising its crouching form, it would look stealthily around, and be off in a moment. The dragon consumes flies in a slow and deliberate manner, swallowing them gradually; its various species belong exclusively to India and the islands of the Eastern Archipelago.

Who has not heard of the fatal glance of the Basilisk, which, according to poetical fancy obliged all other poisonous animals to keep at a respectful distance. The truth is, that the lizards that bear this dreaded name, which has been given them from the fanciful resemblance of their pointed occipital crest to a regal crown, are quite as harmless and inoffensive as the flying dragon. They are chiefly inhabitants of South America, where they generally lead a sylvan life, feeding on insects.

A few words on Frogs and Toads shall close this rather miscellaneous chapter. Of the former there is none more famous than the hideous Pipa Surinamensis, which considerably exceeds in size the common toad, and whose deformity is often aggravated by a phenomenon unexampled in the rest of the animal world, namely, the young in various stages of exclusion, proceeding from cells dispersed over the back of the parent. It was for a long time supposed that the ova of this extraordinary reptile were produced in the dorsal cells without having been first excluded in the form of spawn; but it is now thoroughly ascertained that the female Pipa deposits her eggs or spawn at the brink of some stagnant water, and that the male collects or amasses the heap of ova, and deposits them with great care on the back of the female, 
where, after impregnation, they are pressed into the cellules, which are at that period open for their reception, and afterwards close over them; thus retaining them till the period of their second birth, which happens in somewhat less than three months, when they emerge from the back of the parent in their complete state. This species inhabits the obscure nooks of houses in Cayenne and Surinam, avoiding the light of day as if conscious of its unrivaled hideousness.

A Brazilian tree-frog (Hyla crepitans), which adheres to the large leaves, not merely with its widened toes, but with its constantly viscid body, has a voice which sounds like the cracking of a large piece of wood, and generally proceeds from many throats at a time. On wandering through the forests of Brazil, Prince Maximilian of Neu Wied was often surprised by this singular concert issuing from the dark shades of the forest. A Surinam tree-frog (Hyla micans) has the singular property of secreting a luminous slime, so as to look in the dark like a yellowish will-o'-the-wisp. Its voice is most disagreeable, and is said at times completely to overpower the orchestra of the theatre in Paramaribo, thus emulating the stentorian achievements of the Virginian bull-frog.

Wallace describes a Flying Frog, of which he discovered a single specimen in the Island of Borneo. It was brought to him by a Chinese workman, who declared that he had seen it coming down in a slanting direction from the top of a high tree as it flew. Its toes were long, and fully webbed to the very extremities, so that when expanded they offered a surface much larger than the body. As the toes had dilated dises for adhesion, showing the creature to be a true tree-frog, it is difficult to imagine that this immense membrane of the toes, occupying in all twelve square inches, could be for the purpose of swimming only, which rendered the Chinaman's account credible. Wallace believes this to be the first instance known of a flying frog. The picture which he gives of this creature is very remarkable. One can get a fair idea of it by imagining an ordinary frog, with a large expanded fan attached to each of the four limbs.

Mr. Darwin thus describes a remarkable species of toad he noticed at Bahia. "Amongst the Batrachian reptiles, I found only one little toad, which was most singular from its color. If we imagine, first, that it had been steeped in the blackest ink, and then, when dry, allowed to crawl over a board freshly painted with the brightest vermilion, so as to color the sides of its feet and parts of its stomach, a good idea of its appearance will be gained. If it is an unnamed species, surely it ought to be called diabolicus, for it is a fit toad to preach in the ear of Eve. Instead of being nocturnal in its habits as other toads are, and living in damp and obscure recesses, it crawls during the heat of the day about the dry sand hillocks and arid plains, where not a single drop of water can be found. It must necessarily depend on the dew for its moisture, and this probably is absorbed by the skin, for it is known that these reptiles possess great powers of cutaneous absorption. At Maldonado I found one in a situation nearly as dry as at Bahia Blanca, and, thinking to give it a great treat, carried it to a pool of water; not only was the little animal unable to swim, but I think without help would soon have been drowned."

The giant-toad (Bufo gigas, agua), frequents the Brazilian campos in such numbers that in the evening or after a shower of rain, when they come forth from their hidingplaces to regale on the damp and murky atmosphere, the earth seems literally to swarm 
with them. They are double the size of our common toad, and are even said to attain, with their outstretched hind legs, a foot's length, with a proportionate girth. Covered with unsightly warts, and of a dull gray color, their aspect is repulsive, and when excited, they eject a liquid which is very much feared by the natives. Their voice is loud and disagreeable, while Guinea possesses, in the Breviceps gibbosus, a small toad which is said to sing delightfully, "charming the swamps with their melodious notes."

There is a very remarkable burrowing crustacean called the Robber Crab, (Page 580,) Birgus latro. The Robber Crab inhabits the islands of the Indian Ocean, and is one of those crustacea which are able to exist for a long time without visiting the water, the gills being kept moist by means of a reservoir on each side of the cephalothorax, in which the organs of respiration lie. Only once in twenty-four hours does this remarkable crab visit the ocean, and in all probability enters the water for the purpose of receiving the supply which preserves the gills in working order. While walking, it presents a curious aspect, being lifted nearly a foot above the ground on its two central pairs of legs; and if it be intercepted in its retreat, it brandishes its formidable weapons, clattering them loudly, and always keeping its face towards the enemy. The food of the Robber Crab is of a very peculiar nature, consisting chiefly, if not entirely, of the cocoa-nut. According to Mr. Darwin, the crab seizes upon the fallen cocoa-nuts, and with its enormous pincers tears away the outer covering, reducing it to a mass of raveled threads. When the crab has freed the nut from the husk, it introduces the small end of a claw into one of the little holes which are found at one end of the cocoa nut, and by turning the claw backward and forward, as if it were a brad-awl, the crab contrives to scoop out the soft substance of the nut.

According to the observations of Messrs. Tyerman and Bennett, the well-known missionaries to the South Seas, the Robber Crab has another method of getting at the cocoa-nut, and displays an instinctive knowledge of political economy which is very remarkable. "These animals live under the cocou-nut trees, and subsist upon the fruit which they find upon the ground. With their powerful front claws they tear off the fibrous husk ; afterward, inserting one of the sharp points of the same into a hole at the end of the nut, they beat it with violence against a stone until it cracks; the shell is then easily pulled to pieces, and the precious fruit within devoured at leisure." We are informed that if the long and delicate antennae of these robust creatures be touched with oil, they instantly die.

They are not found on any of these islands except the small coral ones, of which they are the principal occupants. The people here account them "delicious food." Mr. Darwin mentions that, in the Seychelles and elsewhere, there is a species which is in the habit of husking the nuts on the ground and then tapping one of the eyes with its great claw, in order to reach the kernel. Its congener here ascends the cocoanut trees, end having thrown down the nuts, husks them on the ground; this operation performed, again ascends with the nuts, which he throws down, generally breaking them at the first attempt, but if not successful, repeating it till the object is attained.

"The female differs from the male in having three flippers, well furnished with strong borers, on the right side of the sac." When full grown, this crab is more than two feet in length, and as may be seen by the illustration, is stoutly made in proportion to its length. The color of the creature is very pale brown, with a decided tinge of yellow. 


\section{CHAPTER XI.}

\section{ALLIGATORS-CROCODILES-TORTOISES AND TURTLES.}

Aluyators and Crocodiles: Their Habits-Caymen, Gavials and Crocodiles-Mode of Seizing their Prey-Size of Alligators-Alligators on the Amazon-Alligator and Crane-ManEating Alligators-Their Contests-Tenacity of Life-Laying their Eggs-Tenderness for their Young-Their Enemies-Torpidity in the Dry Season-"Playing 'Possum."-Tortoises and Turtles: The Galapago Islands-The Elephantine Tortoise-Rate of TravelingMarsh Tortoises-Manufacture of Tortoise Oil-Turtles on the Amazon-Sea-TurtlesTheir Enemies-Modes of Capturing Turtles-The Green Turtle-The Hawksbill Turtle -Barbarous Modes of Removing the Shell, and Selling the Meat-The Coriaceous Turtle.

$\mathrm{T}$

HERE was a time, long before man appeared upon the scene, when huge crocodiles swarmed in the rivers of the temperate zone. But the day when the ferocious, bone-harnessed Saurians lorded it in these streams has passed, never to return; the diminished warmth of what are now the temperate regions of the globe having long since confined them to the large rivers and lagunes of the torrid zone. The scourge and terror of all that lives in the waters which they frequent, they may with full justice be called the very images of depravity, as perhaps no animals in existence bear in their countenance more decided marks of cruelty and malice. The depressed head, so significant of a low cerebral development; the vast maw, garnished with formidable rows of conical teeth, entirely made for snatch and swallow; the elongated mud-colored body, with its long lizard-like tail, resting on short legs, stamp them with a peculiar frightfulness, and proclaim the baseness of their instincts. The short-snouted, broad-headed Alligators, or Caymen, belong to the New World; the Gavials, distinguished by their straight, long, and narrow jaw, are exclusively Indian; while the oblong-headed Crocodiles are not only found in Africa and Asia, but likewise infest the swamps and rivers of America. All these animals, however, though different, in form and name, have everywhere similar habits and manners ; so that, in general, what is remarked of the one may be applied to the others.

Awkward and slow in their movements on the land, they are very active in the water, darting along with great rapidity by means of their strong muscular tail and their webbed hind feet. They sometimes bask in the sunbeams on the banks of the rivers, but oftener float on the surface, where, concealing their head and feet, they appear like the rough trunk of a tree, both in shape and color, and thus are enabled the more easily to deceive and catch their prey. In America, many a slow-paced Capybara, or Water-pig, coming in the dusk of evening to slake its thirst in the lagune, has been suddenly seized by this insidious foe; and the Gangetic Gavial is said to make even the tiger his prey. When the latter quits the thick cover of the jungle to drink at the stream, the Gavial, concealed under water, steals along the 
bank, and, suddenly emerging, furiously attacks the tiger, who never declines the combat; and though in the struggle the Gavial frequently loses his eyes and receives dreadful wounds on the head, he at length drags his adversary into the water, and there devours him.

On the American streams, the stillness of the night is often interrupted by the clacking of the alligator's teeth, and the lashing of his tail upon the waters. The singular and awful sound of his voice can also readily be distinguished from that of all the other beasts of the wilderness. It is like a suppressed sigh, bursting forth all of a sudden, and so loud as to be heard above a mile off. First, one emits this horrible noise; then another answers him; and far and wide the repetition of the sound proclaims that the alligators are awake.

As in the case of snakes, the size to which alligators and crocodiles attain is grossly exaggerated. Thorpe was gravely assured by a gentleman; " not given to big stories," that he once saw an alligator whose jaws opened at least five feet; and another gentleman, and a Congressman to boot, persisted that he once shot in the Bay of Pascagoula an alligator twenty-one feet long. But a planter of a scientific turn of mind, residing in the noted alligator region of the Red River in Arkansas for years, made a standing offer of a hundred dollars for an alligator dead or alive, of more than twelve feet in length. It is probable that since the introduction of steamers upon the Mississippi, and its lower tributaries, that the alligator finds so many enemies that he is cut off before reaching his full stature; for Audubon expressly affirms that he saw one who he judged to be some centuries old, who measured seventeen feet in length. In his time these monsters must have had a jolly time of it in the Red River, where he often saw hundreds of them at once, the smaller ones riding on the backs of the larger, and all of them groaning and bellowing like so many mad bulls ready for a fight, and so utterly indifferent to the presence of man that, unless shot at, they would take no notice of a boat at a few yards' distance.

South America is yet a secure home of the alligator, where undisturbed by man he attains his full size. Orton in ascending the river Guayas on the western coast, says that* " the chief representative of animal life is the lazy, ugly alligator. Large numbers of these monsters may be seen on the mud-bank basking in the hot sun, or asleep with their mouths wide open. But upon the Amazon they bear the palm for ugliness, size, and strength. In the summer the main river swarms with them; in the wet season they retreat to the interior lakes and forests. About Obidos where many of the pools dry up in the fine months, the alligator buries itself in the mud, and sleeps till the rainy season returns. It is scarcely exaggerating to say that the waters of the Solimoens are as well stocked with large alligators in the dry season as a ditch with us is with tadpoles in the summer. There are three or four species in the Amazon. The largest, the Jucaré-uassú of the natives, attains a length of twenty feet. Sluggish on land, the alligator is very agile in its native element. It never attacks man when on his guard, but is cunning enough to know when it may do this with safety. It lays its eggs, about twenty, at some distance from the river bank, covering them with sticks. They are about four inches long, of an elliptical shape, with a rough calcareous shell. Negro venders sell them cooked in the streets of Para."

* The Andes and the Amazon, 35, 296 
Thorpe gives an account of the alligator's method of securing his prey :* "The tail of the alligator is his most efficient weapon of defense and attack. If one can keep out of its way, comparatively little harm may be expected. If any animal that he seeks for his prey is standing upon the edge of the water, the reptile will take its bearing and swim noiselessly toward the shore, occasionally bringing an eye to the surface for reconnoissance, then suddenly rising within striking distance will whirl round his tail with lightning rapidity, and generally bring the victim into his jaws. I was fishing on one occasion upon the Bayou Sara, a wild, desolate stream, and on the opposite bank I noticed a tall crane which for half an hour had been standing perfectly still and half-leg deep in the water, either refizcting upon the mutability of ornithological affairs, or watching for minnows. My attention was also arrested by the apparent phenomenon of a limb of a tree taking upon itself motion, and cautiously moving down the bank of the bayou toward the crane. The alligator-for such it was-by a strange sidelong motion, gradually reached his prey, but seemed in no haste to seize it. For a long while he appeared to be sleeping on the bank; when suddenly he contracted himself into a half circle around the bird, opened his jaws, and drove the bird into them with a terrible certainty, and then with a nimble spring disappeared beneath the muddy current."

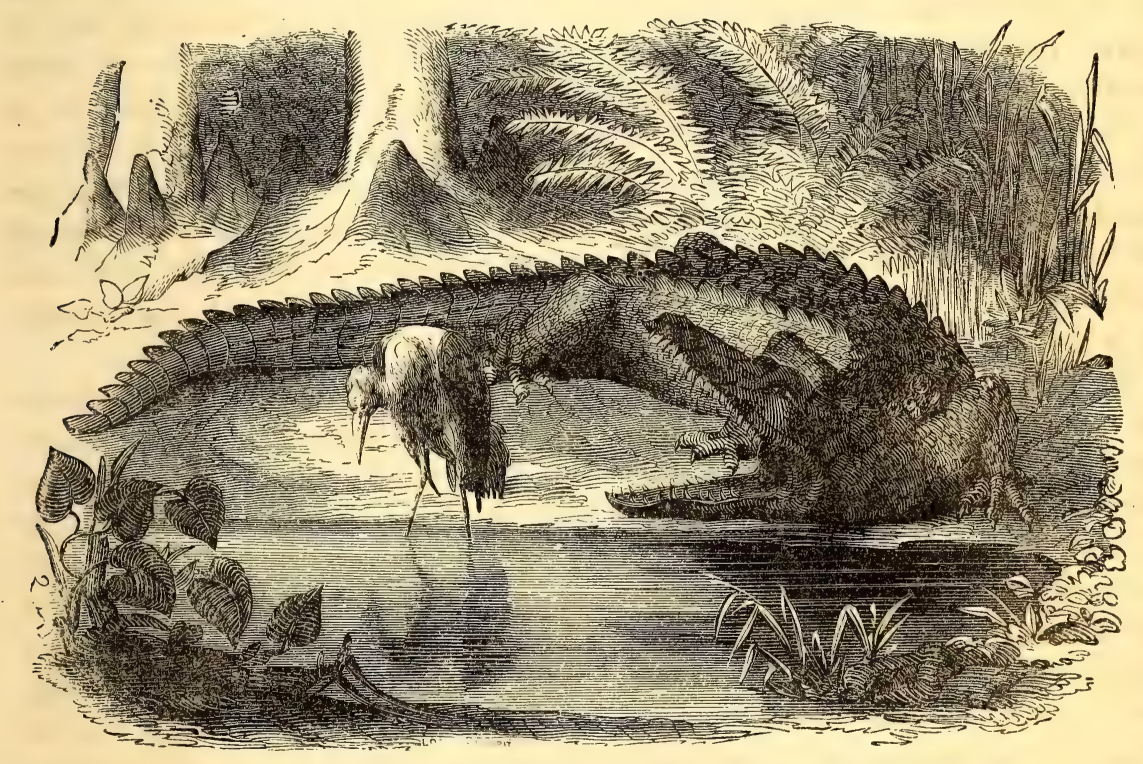

ALLIGATOR AND CRANE.

The statement of Orton, that alligators rarely attack man, is hardly borne out by other authorities. Indeed it is said that as in the case of the lion, when they have once tasted human flesh they prefer it to that of any other animal. During Humboldt's stay at Angostura, a monstrous Cayman seized an Indian by the leg while he was busy pushing his boat ashore in a shallow lagune, and immediately dragged him down into the deeper water. The cries of the unfortunate victim soon attracted a large number of spectators, who witnessed the astonishing courage with which he 
searched in his pocket for a knife. Not finding the weapon, he then seized the reptile by the head, and pressed his fingers into its eyes-a method which saved Mungo Park's negro from a similar fate. In this case, however, the monster did not let go his hold, but disappearing under the surface with the Indian, came up again with him as soon as he was drowned, and dragged the body to a neighboring island. "One Sunday evening," says Waterton, " as I was walking with Don Felipe de Yriarte, Governor of Angostura, on the bank of the Orinoco- 'Stop here a minute or two,' said he to me, 'while I recount a sad accident. One fine evening, last year, as the people of Angostura were sauntering up and down in the Alameda, I was within twenty yards of this place, when I saw a large Cayman rush out of the river, seize a man, and carry him down, before anybody had it in his power to assist him. The screams of the poor fellow were terrible, as the Cayman was running off with him. He plunged into the river with his prey; we instantly lost sight of him, and never saw or heard him more." " Humboldt also relates that, during the inundations of the Orinoco, alligators will sometimes make their appearance in the very streets of Angostura, where they have been known to attack and drag away a human prey.

Even among each other, these ferocious animals frequently engage in deadly conflict. Thus Schomburgk once saw a prodigiously large Cayman seize one of a smaller species by the middle of the body, so that the head and tail projected on both sides of its muzzle. Now both of them disappeared under the surface, so that only the agitated waters of the otherwise calm river announced the death-struggle going on beneath; and then again the monsters reappeared, wildly beating the surface; so that it was hardly possible to distinguish here a tail, or there a monstrous head, in the seething whirlpool. At length, however, the tumult subsided, and the large Cayman was seen leisurely swimming to a sand-bank, where he immediately began to feed upon his prey.

The same traveler relates an interesting example of the Cayman's tenacity of life. One of them having been wounded with a strong harpoon, was dragged upon a sandbank. Here the rays of the sun seemed to infuse new life into the monster, for, awaking from his death-like torpidity, he suddenly snapped about him with such rage that Schomburgk and his assistants thought it prudent to retreat to a safer distance. Seizing a long pole, the bravest of the Indians now went towards the Cayman, who awaited the attack with wide-extended jaws, and plunged the stake deep into his maw - a morsel which the brute did not seem to relish. Meanwhile two other Indians approached him from behind, and kept striking him with thick clubs upon the extremity of the tail. At every blow upon this sensitive part, the monster bounded in the air and extended his frightful jaws, which were each time immediately regaled with a fresh thrust of the pole. After a long and furious battle, the Cayman, who measured twelve feet in length, was at last slain. Another remarkable instance of the vitality of the common crocodile is mentioned by Sir E. Tennent. A gentleman at Galle having caught on a baited hook an unusually large one, it was disembowelled by his coolies, the aperture in the stomach being left expanded by a stick placed across it. On returning, in the afternoon, with a view to secure the head, they found that the creature had crawled for some distance, and made its escape into the water.

Like the sea-turtles, the crocodiles generally deposit their eggs, which are about the size of those of a goose, and covered with a calcareous shell, in holes made in the 
sand, leaving them to be hatched by the warm rays of the tropical sun. In some parts of America, however, they have been observed to resort to a more ingenious method, denoting a degree of provident instinct which could hardly have been expected in a cold-blooded reptile. Raising a small hillock on the banks of the river, and hollowing it out in the middle, they collect a quantity of leaves and other vegetable matters, in which they deposit their eggs. These are covered with the leaves, and are batched by the heat extricated during their putrefaction, along with that of the atmosphere.

The female Cayman continues for some time after their birth to watch over her young with great care. One day, as Schomburgk, accompanied by an Indian, was busy fishing on the banks of the Essequibo, he suddenly heard in the water a strange noise, resembling the mewing of young cats. With eager curiosity he climbed along the trunk of a tree overhanging the river, about three feet above the water, and saw beneath him a brood of young alligators, about a foot and a half long. On his seizing and lifting one of them out of the water, the mother, a creature of prodigious size, suddenly emerged with an appalling roar, making desperate efforts to reach her wriggling and screeching offspring, and increasing in rage every time Schomburgk tantalized her by holding it out to her. Having been wounded with an arrow, she retired for a few moments, and then again returned with redoubled fury, lashing the waters into foam by the repeated strokes of her tail. Schomburgk now cautiously retreated, as in case of a fall into the water below, he would have had but little reason to expect a friendly reception, the monster pertinaciously following him to the bank, but not deeming it advisable to land, as here it seemed to feel its helplessness. The scales of the captured young one were quite soft and pliable, as it was only a few days old, but it already had the peculiar musk-like smell which characterizes the full-grown reptile.

The young of the crocodiles have no less numerous enemies than those of the snakes. Many an egg is destroyed in the hot sand by small carnivora, or birds, before it can be hatched; and as soon as the young creep out of the broken shell, and instinctively move to the waters, the Ichneumon-a kind of weasel, to whom, on this account, the ancient Egyptians paid divine homage-or the long-legged Heron gobble up many of them, so that their span of life is short indeed. In the water they are not only the prey of various sharp-toothed fishes, but eren of the males of their own species, while the females do all they can to protect them. Even the full-grown crocodile, in spite of its bony harness, is not exempt from attack. Thus, in the river of Tabasco, a tortoise of the genus Cinyxis, after having been swallowed by the alligator, and, thanks to its shelly case, arriving unharmed in its stomach, is said to have eaten its way out again with its sharp beak, thus putting the monster to a most excruciating death. Even man not only kills the hideous reptiles in self-defence, or for the sake of sport, but for the purpose of regaling upon their flesh. In the Siamese markets and bazaars, crocodiles, large and small, may be seen hanging in the butchers' stalls, instead of mutton or lamb; and Captain Stokes, who more than once supped off alligators steaks, informs us that the meat is by no means bad, and has a white appearance like veal.

I have already mentioned, in the chapter on the Llanos, that in many tropical countries the aridity of the dry season produces a similar torpidity in reptile life to that which is caused by the cold of winter in the higher latitudes. In Ceylon, when the water-courses begin to fail and the tanks become exhausted, the marsh-crocodiles are 
sometimes encountered wandering in search of water in the jungle; but generally. during the extreme drought, they bury themselves in the sand where they remain in a state of torpor, till released by the recurrence of the rains. Sir Emerson Tennent, whilst riding across the parched hed of a tank, was shown the recess, still bearing the form and impress of the crocodile, out of which the animal had been seen to emerge the day before. A story was also related to him of an officer who, having pitched his tent in a similar position, had been disturbed during the night by feeling a movement of the earth below his bed. from which, on the following day, a crocodile emerged, making its appearance from beneath the matting.

Like many other of the lower animals, the crocodile, when surprised, endeavors to save itself by feigning death. Sir Emerson Tennent relates an amusing anecdote of one that was found sleeping several hundred yards from the water. "The terror of the poor wretch was extreme when he awoke and found himself discovered and completely surrounded. He was a hideous creature, upwards of ten feet long, and evidently of prodigious strength, had he been in a condition to exert it; but consternation completely paralyzed him. He started to his feet, and turned round in a circle, hissing and clacking his bony jaws, with his ugly green eye intently fixed upon us. On being struck, he lay perfectly quiet and apparently dead. Presently he looked round cunningly, and made a rush towards the water; but on a second blow he lay again motionless, and feigning death. We tried to rouse him, but without effect; pulled his tail, slapped his back, struck his hard scales, and teased him in every way, but all in vain. Nothing would induce him to move, till, accidentally, my son, a boy of twelve years old, tickled him gently under the arm, and in an instant he drew it close to his side, and turned to avoid a repetition of the experiment. Again he was touched under the other arm, and the same emotion was exhibited, the great monster twisting about like an infant to avoid being tickled."

In the South Sea, exposed to the vertical beams of the equatorial sun, lies a large group of uninhabited islands, on whose sterile shores you would look in vain for the palms, bananas, or bread-fruit trees of more favored lands, as rain falls only upon the hights, and never descends to call forth plenty on the arid coasts. And yet this desolate group offers many points of interest to the naturalist, for the Galapagos or Tortoise Islands represent, as it were, a little world in themselves, a peculiar creation of animals and plants, reminding us, more strongly than the productions of any other land, of an earlier epoch of planetary life. Here are no less than twenty-six different species of land-birds, which, with one single exception, are found nowhere else. Their plumage is homely, like the flora of their native country; their tameness so great that they may be killed with a stick. A sea-mew, likewise peculiar to this group, mixes its shriek with the hoarse-resounding surge; lizards, existing in no other country, swarm about the shore; and the gigantic land-tortoise (Testudo indica, elephantina), although now spread over many other countries, is supposed by Mr. Darwin to have had its original seat in the Galapagos, where it was formerly found in such vast numbers as to have given the group its Spanish name. If the seafarer visits these treeless shores, which as yet produce nothing else worth gathering, it is chiefly for the purpose of eatching a few of these huge animals, which, in spite of frequent persecutions, still amply reward a short sojourn with a rich supply of fresh 
meat. Their capture costs nothing but the trouble, for man has not yet drawn the boundary marks of property over the tenantless land. The elephantine tortoise inhabits as well the low and sterile country, where it feeds on the fleshy leaves of the cactus, as the mountainous regions where the moist trade-wind calls forth a richer vegetation of ferns, grasses, and various trees. On this meagre food, which seems hardly sufficient for a goat, it thrives so well that three men are often scarcely able to lift it, and it not seldom furnishes more than 200 pounds of excellent meat.

The tortoises, when moving towards any definite point, travel by night and day, and arrive at their journey's end much sooner than would be expected. The inhabitants, from observations on marked individuals, consider that they can move a distance of about eight miles in two or three days. One large tortoise, which I watched, I found walked at the rate of sixty yards, in ten minutes, that is, three hundred and sixty in the hour, or four miles a day, allowing also a little time for it to eat on the road. The flesh of this animal is largely employed, both fresh and salted, and a beautifully clear oil is prepared from the fat. When a tortoise is caught, the man makes a slit in the skin near its tail, so as to see inside its body, whether the fat under the dorsal plate is thick. If it is not, the animal is liberated, and it is said to recover soon from this strange operation.

The marsh tortoises, or Emydo, have their chief seat in tropical America and the Indian Archipelago, where an abundance of swamps, lagoons, lakes, pools, and gentlyflowing rivers favors the increase of their numbers. They play an important part in the domestic economy of the Indians along the great streams of the New World, the deep rolling Orinoco or the thousand-armed Amazon. During the dry season, all the neighboring tribes are busy collecting the countless eggs which the cold-blooded creatures confide to the life-awakening powers of the heated sands: partly for their own consumption, and partly for the manufacture of oil. According to Herndon* from five to six thousand jars of mantega, or tortoise-oil are annually gathered on the banks of the Marañon. Each animal furnishes on an average eighty eggs, and forty tortoises are reckoned for each jar, which contains forty-five pounds, and is worth about six shillings on the spot. The manufacturing process, which is carried on in a most primitive manner, exhales an insupportable stench. The eggs, namely, are thrown into a boat, and trodden to pieces with the feet. The shells having been removed, the rest is left for several days to putrefy in the sun. The oil which collects on the surface of the decomposing mass is then skimmed off, and boiled in large kettles. The neighboring strand swarms with carrion vultures, and the smell of the offal attracts a number of alligators, all hoping to come in for their share of the feast.

"Turtles," says Orton, $\dagger$ " are perhaps the most important product of the Amazon. The largest and most abundant species is the Tortaruga grande. It measures, when full grown, nearly three feet in length and two in breadth. Every house has a little pond in the back yard to hold a stock of turtles in the wet season. It furnishes the best meat on the Upper Amazon. We found it very tender, palatable, and wholesome : those who are obliged to live on it for years, however, say that it is very cloying. Every part of the creature is turned to account. The entrails are made into soup ; sausages are made of the stomach ; steaks are cut from the breast, and the rest is roasted in the shell. The turtle lays its eggs, generally between midnight and dawn, on the central 
and highest part of the islets in the river, or about a hundred feet from the shore. The Indians say it will lay only where itself was hatched out. With its hind flippers it digs a bole two or three feet deep, and deposits in it from eighty to one hundred and sixty eggs. These are covered with sand, and the next comer makes another deposit on the top, and so on until the pit is full. The Indians are very expert in finding the nests. Guided approximately by the tracks of the turtle, they thrust a stick into the sand, and whenever it goes down easily they commence digging with their hands, and invariably strike eggs. The turtles are caught for the table as they return to the river after laying their eggs. To secure them it suffices to turn them over on their backs. The turtles certainly have a hard time of it. Alligators and large fishes swallow the young ones by hundreds; jaguars pounce upon the full grown ones as they crawl over the plains, and vultures and ibises attend the feast. But man is their most formidable foe. The destruction of turtle life on the Amazon is incredible. It is calculated that fifty millions of eggs are annually destroyed. Thousands of those that escape capture in the egg are collected as soon as hatched, and devoured; the remains of the yolk in their entrails being considered a great delicacy. An unknown number of full-grown turtles are eaten by the natives on the banks, while every steamer, schooner and canoe that descends the Amazon is laden with turtles for the tables of Manáos, Santarem, and Pará. When we consider also that all the mature turtles that are taken are females, we wonder that the race is not well-nigh extinct. They are in fact rapidly decreasing in numbers. A large turtle which twenty years ago could be bought for fifty cents, now commands three dollars. One would suppose that the males being unmolested, would far outnumber the other sex; but they are in fact immensely less numerous than the females."

The marsh-tortoises may be said to form the connecting link between the eminently aquatic marine, and river chelonians and the land-tortoises, as the formation of their feet, armed with sharp claws or crooked nails, and furnished with a kind of flexible web, connecting their distinct and movable toes, allows them both to advance much quicker on the dry land than the latter, and to swim rapidly either on the surface or in the depth of the waters. According to the more or less terrestrial habits of the various species, the feet are more or less webbed, for in those that habitually remain on the banks of the lagoons, the connecting membrane is confined to the basis of the toes, while in others, that but rarely come on shore, it sometimes reaches to the extremity of the claws, another beautiful example of the foresight of the Almighty in adapting organic structure to the wants of His creatures. The marsh-tortoises, being endowed with more rapid power of locomotion, are not vegetarians like the land-tortoises, but chiefly live on mollusks, fishes, frogs, toads, and annelides. Although the eggs are palatable, the flesh is generally too coarse even for the craving appetite of an Indian.

Sea turtles differ in many respects from those of the rivers. During the Brazilian summer (December, January, February), colossal turtles are seen everywhere swimming about along the coast, raising their thick round heads above the water, and waiting for the approach of night to land. The neighboring Indians are their bitterest enemies, killing them whenever they can. Thus these dreary sand coasts, bounded on one side by the ocean and on the other by gloomy primeval forests, offer on all sides pictures of destruction, for the bones and shells of slaughtered turtles everywhere bestrew the ground. Two parallel grooves indicate the path of the turtle after landing; 
they are the marks of the four large and long fin-shaped feet or paddles, and between them may be seen a broad furrow where the heavy body trailed along the ground. On following these traces about thirty or forty yards shore-upwards, the huge animal may be found sitting in a flat excavation formed by its circular movements, and in which onehalf of its body is imbedded. It allows itself to be handled on all sides without making the least attempt to move away, being probably taught by instinct how useless all endeavors to escape would be. A blowing or snorting like that of a goose when any one approaches its nest, at the same time inflating its neck a little, are the sole signs of defence which it exhibits. Similar scenes take place during the dry season, throughout the whole of the tropical zone, on every sandy, unfrequented coast : for the same instinct which prompts the salmon to swim stream-upwards, the cod to seek elevated submarine banks, or the penguin to leave the high seas and settle for the summer on some dreary rock, attracts also the turtles from distances of fifty or sixty leagues to the shores of desert islands or solitary bays.

The enemies of the marine chelonians are no less numerous than those of the terrestrial or fluviatile species. While the full-grown turtles, as soon as they leave the water, are exposed to the attacks of many ravenous beasts, from the wild dog to the tiger or jaguar, storks, herons, and other strand or sea-birds devour thousands upon thousands of the young before they reach the ocean, where sharks and other greedy fishes still further thin their ranks, so that but very few escape from the general massacre, and the whole race can only maintain itself by its great fecundity.

Of all the foes of the turtle tribe there is, however, none more formidable than man, as even on the most lonely islands the seafarer lies in wait, eager to relieve the monotony of his coarse fare by an abundant supply of their luscious flesh. On the Isle of Ascension, the head-quarters of the finest turtle in the world, all the movements of the poor creatures are carefully watched, and when, after having deposited their eggs in the sand, they waddle again towards the sea, their retreat is often intercepted, for two stout men running up to the unfortunate turtle after the completion of her task, one seizes a fore-flipper and dexterously shoves it under her belly, to serve as a purchase; whilst the other, avoiding a stroke which might lame him, cants her over on her back, where she lies helpless. From fifteen to thirty are thus turned in a night. In the bays, when the surf or heavy rollers prevent the boats being beached to take on board the turtles when caught, they are hauled out to them by ropes.

The way by which the turtles are most commonly taken at the Bahama Islands is by striking them with a small iron peg of two inches long, put in a socket at the end of a staff of twelve feet long. Two men usually se' out for this work in a canoe, one to row and gently steer the boat, while the other stands at the end of it with his weapon. The turtles are sometimes discovered by their swimming with their head and back out of the water, but they are more often seen lying at the bottom, a fathom or more deep. If a turtle perceives he is discovered, he starts up to make his escape ; the men in the boat, pursuing him, endeavor to keep sight of him, which they often lose and recover again by the turtle putting his nose out of the water to breathe.

On Keeling Island, Mr. Darwin witnessed another highly interesting method of catching turtle: "The channel was exceedingly intricate, winding through fields of delicately-branched corals. We saw several turtles, and two boats were then employed in catching them. The method is rather curious: the water is so clear and 
shallow that, although at first a turtle quickly dives out of sight, yet in a canoe, os boat under sail, the pursuers, after no very long chase, come up to it. A man, standing ready in the bows, at this moment dashes through the water upon the turtle's back; then clinging with both hands by the shell of the neck, he is carried away till the animal becomes exhausted and is secured. It was quite an interesting chase to see the two boats thus doubling about, and the men dashing into the water trying to seize their prey."

The Green turtle (Chelonia midas), which bas been known to attain a length of seven feet, and a weight of $900 \mathrm{lbs}$., is most prized for its flesh; but the Hawksbill (Chelonia imbricata), which hardly reaches one third of the size, is of far greater commercial value, the plates of its shell being stronger, thicker, and clearer than those of any other species. It is eaught all over the tropical seas, but principally near the Moluceas, the West Indian and the Fiji Islands, where it is preserved in pens by the chiefs, who have a barbarous way of removing the valuable part of the shell from the living animal. A burning brand is beld close to the outer shell, until it curls up and separates a little from that beneath. Into the gap thus formed a small wooden wedge is then inserted, by which the whole is easily removed from the back. When stripped, the animal is again put into the pen, where it has full time for the growth of a new shell-for though the operation appears to give great pain, it is not fatal.

A similar cruel method of removing the tortoise's shell by heat is resorted to in Ceylon; but the mode in which the flesh of the edible turtle is sold piecemeal, while it is still alive, by the fishermen of that island, is still more repulsive, and a disgrace to the Colonial Government, which allows it to be openly practised. "The creatures," says Sir Emerson Tennent, " are to be seen in the market-place undergoing this frightful mutilation, the plastron and its integuments having been previously removed, and the animal thrown on its back, so as to display all the motions of the heart, viscera, and lungs. A broad knife, from twelve to eighteen inches in length, is first inserted at the left side, and the women, who are generally the operators, introduce one hand to scoop out the blood, which oozes slowly. The blade is next passed round till the lower shell is detached and placed to one side, and the internal organs exposed in full action. Each customer, as he applies, is served with any part selected, which is cut off as ordered, and sold by weight. Each of the fins is thus successively removed. with portions of the fat and flesh, the turtle showing by its contortions that each act of severance is productive of agony. In this state it lies for hours writhing in the sun, the heart and head being usually the last pieces selected; and till the latter is cut off, the snapping of the mouth, and the opening and closing of the eyes, show that life is still inherent, even when the shell has been nearly divested of its contents."

The Coriaceous turtle (Sphargis coriacea), of a more elongated form than the other species, and whose outer covering, marked along its whole length by seven distinct, prominent, and tuberculated ridges, is not of a horny substance, but resembles strong leather, grows to the greatest size of all the marine chelonians, some having been taken above eight feet in length, and weighing no less than $1,600 \mathrm{lbs}$, , so that even the crocodile can hardly be compared to it in bulk. While the land-tortoises can scarcely be said to have a voice, merely hissing or blowing when irritated or seized, the coriaceous turtle, when taken in a net or seriously wounded, utters loud shrieks or cries which may be heard at a considerable distance. 


\title{
CHAPTER XII.
}

\author{
BIRD-LIFE IN THE TROPICAL WORLD.
}

Difficulties of the Subject-Wide Range of Birds-The Toucan-Humming-Birds-Cotingas - The Campanero, or Bell-Bird-The Realejo, or Organ-Bird-The Manakins-The Cock of the Rock-The Troopials-The Baltimore Oriole-The Cassiques-The Mocking-Bird -The Toropishu-The Tunqui-Goat-Suckers-The Cilgero-Elamingos-The IbisSpoon-Bills-Birds of the New and the Old World-Sun-Birds-Honey-Eaters-The Ocellated Turkey-The Lyre-Bird-Birds of Paradise-Fables respecting them-Their Character and Habits-Their Dancing-Parties-Mode of Shooting and Snaring them-The Australian Bower-Bird-The Brush-Turkey-The Adjutant-The Copper-Smith-The Indian Baya-The Tailor-Bird-The Grosbeak-The Korwé-Parrots-The Brazilian Love-Parrot-Their Powers of Mimicry-Cockatoos-Macaws-The Ara-ParoquetsThe Ostrich-His Swiftness of Foot-Modes of Capturing it-Stratagems to Save its Young -Its Enemies-Its Young-Resemblance to the Camel-Its Powers of Digestion-Uses of its Eggs-The Rheas-The Cassowary-The Emu.

$\mathrm{U}$ SEFUL in many respects to man, no class of animals are more agreeable to him than that of birds, whether they are considered for the beauty of their plumage, the grace of their movements, the melody of their voice, or the ingenuity with which they construct their nests. Their study forms one of the most attractive departments in the range of natural history. But it is also one of the most difficult, especially in regions which are covered with dense and matted forests. Thus it is by no means surprising that so many secrets yet veil the life of tropical birds, and comparatively little is known of their habits and modes of existence. We can hope only to present a few of the salient features of bird-life in the tropics, reserving for another chapter the birds of prey.

Many families of birds have a wide range over the whole earth. Falcons hover over the Siberian fir-woods as over the palm-forests of the Amazon. In every zone are found woodpeckers, owls, and martins; while thrushes enliven with their song both the shades of the beech-woods and the twilight of the cocoa-nut groves. In the north and in the south, fly-catchers carry destruction among the numerous insect tribes; in every latitude, crows cleanse the fields of vermin; and swallows, pigeons, ducks, gulls, petrels, divers, and plovers frequent the fields and lakes, the banks and shores, in all parts of the world.

Thus the class of birds shows us a great similarity in the distribution of its various forms all over the earth; and we find the same resemblance extending also to their mode of life, their manners, and their voice. The woodpeckers make everywhere the forest resound with the same clear note, and the birds of prey possess in every clime the same rough screech so consonant to their habits, while a soft cooing everywhere characterizes the pigeon-tribes. But, notwithstanding this general uniformity and this 
wide range of many families of birds, each zone has at the same time its peculiar ornithological features, that blend harmoniously with the surrounding world of plants and animals, and, taking a prominent part in the aspect of nature, at once attract the attention of the stranger. In this respect, as in so many others, the warmer regions of the globe have a great advantage over those of the temperate and glacial zones; and here, where warmth and moisture call forth an exuberant vegetation, they produce an equal multiplicity of animal forms, among which many birds rival the most gorgeous flowers by the splendor of their plumage.

On turning to each continent in particular, we again find each endowed with its peculiar genera of birds, and thus, though tropical America has many of its feathered tribes in common with the torrid zone of the Old World, it enjoys the exclusive pos. session of the Toucans, Colibris, Crotophagi, Jacamars, Anis, Dendrocolaptes, Manakins, and Tangaras; while the Calaos, the Souimangas, the Birds of Paradise, and many others, are confined to the eastern hemisphere. A complete review of all these various forms of the feathered creation would fill volumes. My narrow limits necessarily confine me to a brief account of those tribes which are either the most remarkable, or the most widely different from the birds which we are accustomed to see in the temperate zones.

By their enormous bill, which might seem rather adapted to a bird of ostrich-like dimensions than to one not much larger than a crow, the toucans are distinguished from all the other feathered races of America. The use of this enormous beak puzzles naturalists. "How astonishing are the freaks of nature," writes Sydney Smith. "To what purpose, we say, is a bird placed in the woods of Cayenne, with a bill a yard long, making a noise like a puppy-dog, and laying eggs in hollow trees? The toucan, to be sure, might retort, 'To what purpose are certain foolish, prating members of Parliament created, pestering the House with their ignorance and folly, and impeding the business of the country?' There is no end to such questions; so we will not enter into the metaphysies of the toucan." The bill, though certainly much less than a yard long, is big enough to give the bird a very awkward appearance ; but the beauty of its coloring soon reconciles the eye to its disproportionate size : for the brightest red, variegated with black and yellow stripes on the upper mandible, and a stripe of the liveliest sky-blue on the lower, contribute to adorn the bill of the Bouradi, as one of the three toucan species of Guiana is called by the Indians. Unfortunately, these briiliant tints fade after death. The plumage of this strange bird rivals the beak in beauty of coloring, and the feathers are frequently used as ornaments by the Brazilian ladies, as well as by the Indian tribes that roam through the vast forests of South America. The toucans are generally seen in small flocks or troops, and from this it might be supposed they were gregarious ; " but upon a closer examination," says Waterton, " you will find it has only been a dinner-party which breaks up and disperses towards roosting time." While thus assembled, discord never ceases to reign, for there is hardly a more quarrelsome and imperious bird than the toucan. A bird with so strange a beak must naturally be expected to feed and drink in a strange manner. When the toucan has seized a morsel, he throws it into the air and lets it fall into his throat; when drinking, he dips the point of his mandibles into the water, fills them by a powerful inspiration, and then throws back the head by starts. The tongue is also of a very singular form, being narrow and elongated, and laterally barbed like a feather. The toucans are very 
noisy birds. In rainy weather their clamor is heard at all hours of the day, and in fair weather at morning and evening. The sound which the Bouradi makes is like the clear yelping of a puppy dog, and you fancy he says "pia-po-o-co," and thus the South American Spaniards call him Piapoco.

To paint the Humming-bird with colors worthy of its beauty, would be a task as difficult as to fix on canvas the glowing tints of the rainbow, or the glories of the setting sun. The Indians of the Amazon call it "a living sun-beam." Unrivalled in the metallic brilliancy of its plumage, it may truly be called the bird of paradise; and had it existed in the Old World it would no doubt have claimed the title instead of the splendid bird which has now the honor to bear it. See with what lightning speed it darts from flower to flower ; now hovering for an instant before you, as if to give you an opportunity of admiring its surpassing beauty, and now again vanishing with the rapidity of thought. But do not fancy that these winged jewels of the air, buzzing like bees round the blossoms less gorgeous than themselves, live entirely on the honeydew collected within their petals ; for on opening the stomach of one of them, dead insects are almost always found there, which its long and slender beak, and cloven extensile tongue, like that of the woodpecker, enable it to catch at the very bottom of the tubular corollas.

The torrid zone is the chief seat of the humming-birds, but in summer they wander far beyond its bounds, and follow the sun in his annual declensions to the poles. Thus, in the north, they appear as flying visitors on the borders of the Canadian lakes, and on the southern coast of the peninsula of Alaska; while in the southern hemisphere they roam as far as Patagonia, and even as Tierra del Fuego; visiting in the northern hemisphere the confines of the walrus, and reaching in the south the regions of the penguins and the lion-seal; advancing towards the higher latitudes with the advance of summer, and again retreating at the approach of autumn. All attempts to transport them alive to Europe have hitherto been fruitless. Latham relates that a young man cut off the branch on which a humming-bird was breeding, and took it on board the ship which conveyed him to England. The mother soon grew tame, and took the biscuit and honey, that was offered her; she also continued to breed during the passage, but died as soon as the young crept out of the shell. These came alive to England, and withstood during two months the uncongenial climate.

Next to the humming-birds the Cotingas display the gayest plumage. They are, however, not often seen, for they lead a solitary life in the moist and shadowy forests, where they feed on the various seeds and fruits of the woods. One species is attired in burning scarlet, others in purple and blue, but they are all so splendidly adorned that it would be difficult to say which of them deserved the prize for beauty. Most of the Cotingas have no song; the nearly related snow-white Campanero or Bell-Bird, however, amply makes up for the deficient voice of his cousins, by the singularity and sweetness of bis note. He is about the size of a jay. On his forehead rises a singular spiral tube nearly three inches long. It is jet black, dotted all over with small white feathers. It has a communication with the palate, and when filled with air looks like a spire, when empty it becomes pendulous. "His note is loud and clear, like the sound of a bell, and may be heard at the distance of three miles," says Waterton. "Three miles!" exclaims Sydney Smith, dubiously; "this little bird being more powerful than the belfry of a cathedral ringing for a new dean! It is impossible to con- 
tradict a gentleman who has been in Cayenne; but we are determined as soon as a Campanero is brought to England, to make him toll in a public place, and have the distance measured." "In the midst of these extensive wilds," continues Waterton, "generally on the dried top of an aged mora, almost out of gun-reach, you will see the Campanero. No sound or song from any of the winged inhabitants of the forest causes such astonishment as his toll. With many of the feathered race he pays the common tribute of a song to early morn, and even when the meridian sun has shut in silence the mouths of almost the whole of animated nature, the Campanero still cheers the forest; you hear his toll, and then a pause for a minute; then another toll, and then a pause again, and then a toll and again a pause. Then he is silent for six or eight minutes, and then another toll, and so on. He is never seen to feed with the other Cotingas, nor is it known in what part of Guiana he makes his nest." But the most remarkable songster of the Amazonian forest is the Realejo, or Organ-Bird. Its notes are as musical as the flageolet. It is the only songster which makes any impression on the natives.

In the deep forests, which they never quit for the open plains, reside the Manakins (Pipra,) pretty little birds, whose largest species scarcely attain the dimensions of the sparrow, while the smallest are hardly equal to the wren. The plumage of the fullgrown male is always black, enlivened by brilliant colors, that of the female and of the young birds greenish. Their flight is rapid but short, and they generally roost on the middle branches of the trees. In the morning they unite in little troops, and seek their food, which consists of insects, and small fruit, uttering at the same time their weak but melodious notes. As the day advances they separate and seek the deepest forest-shades, where they live in solitude and silence.

The famous orange-colored Cock of the Rock of Guiana (Rupicola aurantia,) which owes its name to its comb-like crest, is nearly related to the manakins. It is a great rarity, even in its own country, and as it dwells in the most secluded forests, is but seldom seen by travelers. Schomburgk relates the following wonderful story of the bird, which, if not proceeding from so trustworthy a source, might almost be considered fabulous. "A troop of these beautiful birds was celebrating its dances on the smooth surface of a rock; about a score of them were seated on the branches as spectators, while one of the male birds, with proud self-confidence, and spreading tail and wings, was dancing on the rock. He scratched the ground or leaped vertically into the air, continuing these saltatory movements until he was tired, when another male took his place. The females, meanwhile, looked on attentively, and applauded the performance of the dancers with laudatory cries. As the feathers are highly prized, the Indians lay in wait with their blow-pipes near the places where the Rupicolas are known to dance. When once the ball has begun, the birds are so absorbed by their amusement, that the hunter has full time to shoot down several of the spectators with his poisoned arrows, before the rest take the alarm."

On penetrating into the wilds of Guiana, the pretty songsters called Troopials, pour forth a variety of sweet and plaintive notes. Resembling the starling by their habits, they unite in troops, and live on insects, berries, and seeds. The Variegated Troopial (Oriolus varius) displays a wonderful instinct in the construction of his nest, which he generally builds on fruit-trees; but when circumstances force him to select a tree whose branches have far less solidity, as, for instance, the weeping willow, his instinct almost 
rises to a higher intelligence. First, he binds together, by means of bits of straw, the small and flexible branches of the willow, and thus forms a kind of conical basket in which he places his nest, and instead of the usual hemispherical form, he gives it a more elongated shape, and makes it of a looser tissue, so as to render it more elastic and better able to conform to the movements of the branches when agitated by the wind.

The neat little black and orange Baltimore Oriole (Icterus Baltimore) constructs a still more marvellous nest on the tulip trees, on whose leaves and flowers be seeks the caterpillars and beetles which constitute his principal food. When the time comes for preparing it, the male picks up a filament of the Tillandsia usneoides and attaches it by its two extremities to two neighboring branches. Soon after, the female comes, inspects his work, and places another fibre across that of her companion. Thus by their alternate labors a net is formed, which soon assumes the shape of a nest, and as it advances towards its completion, the affection of the tender couple seems to increase. The tissue is so loose as to allow the air to pass through its meshes, and as the parents know that the excessive beat of summer would incommore their young, they suspend their nest so as to catch the cooler breeze of the north-east when breeding in Louisiana; while in more temperate regions, such as Pennsylvania and New York, they always give it a southern exposure, and take care to line it with wool or cotton. Their movements are uncommonly graceful; their song is sweet; they migrate in winter towards more southerly regions, Mexico or Brazil, and return after the equinox to the United States.

The Cassiques, which are nearly related to the troopials or orioles, are no less remarkable for their architectural skill. They suspend their large pendulous nests, which are often above four feet long, at the extremities of branches of palm trees, as far as possible from all enemies that might by climbing reach the brood, often choosing, for still further protection, trees on which the wasps or maribondas have already built their nests, as these are adversaries whose sharp stings no tiger-cat or reptile would desire to face. The nest of the Cassicus cristatus is artificially woven of lichens, bark-fibres, and the filaments of the tillandsias, while that of the Tupuba (Cassicus ruber), which is always suspended over the water, consists of dry grasses, and has a slanting opening in the side, so that no rain can penetrate it. On passing under a tree, which often contains hundreds of eassique nests, one cannot help stopping to admire them, as they wave to and fro, the sport of every storm and breeze, and yet so well constructed as rarely to be injured by the wind. Often numbers of one species may be seen weaving their nests on one side of a tree, while numbers of another species are busy forming theirs on the opposite side of the same plant; and what is, perhaps, even still more wonderful than their architectural skill, though such near neighbors, the females are never observed to quarrel !

The Cassicus persicus, a small black and yellow bird, somewhat larger than the starling, has been named the Mocking-Bird, from his wonderful imitative powers. He courts the society of man, and generally takes his station on a tree close to his house, where for hours together be pours forth a succession of ever-varying notes. If a toucan be yelping in the neighborhood, he immediately drops his own sweet song, and answers him in equal strain. Then he will amuse his audience with the cries of the different species of the woodpecker, and when the sheep bleat he will distinctly answer them. Then comes his own song again, and if a puppy dog or a guinea fowl interrupt 
him, he takes them off admirably, and by his different gestures during the time, you would conclude that he enjoys the sport.

Wild and strange are the voices of many of the American forest-birds. In the Peruvian woods the black Toropishu (Cephalopterus ornatus) makes the thicket resound with his hoarse cry, resembling the distant lowing of a bull ; and in the same regions the fiery-red and black-winged Tunqui (Rupicola Peruviana) sends forth a note, which might readily be mistaken for the grunting of a hog, and strangely contrasts with the brilliancy of his plumage. But of all the startling cries that issue from the depths of the forest, none is more remarkable than the Goatsucker's lamentable wail. "Suppose yourself in hopeless sorrow," says Waterton, "begin with a high loud note, and pronounce ha, ha, ha, ha, ha! each note lower and lower till the last is scarcely heard, pausing a moment or two between every note, and you will have some idea of the mourning of the largest goatsucker in Demarara. Four other species of goatsucker articulate some words so distinctly, that they have received their names from the sentences they utter, and absolutely bewilder the stranger on his arrival in these parts. The most common one sits down close by your door, and flies or alights three or four yards before you, as you walk along the road, crying, "Who are you, who-who-whowho are you ?" Another bids you, "Work away, work-work-work away." A third cries mournfully, "Willy come go, Willy-Willy-Willy come go." And high up in the country, a fourth tells you to, "Whip-poor-Will, whip-whip-whip poor-Will."

While the goatsucker makes the forest resound with his funereal tones, other birds of the forest pour forth the sweetest notes. Dressed in a sober cinnamon brown robe, with blackish olive-colored head and neck, the Organist (Troglodytes leucophrys) enlivens the solitude of the Peruvian forests. The astonished wanderer stops to listen to the strain, and forgets the impending storm. The Cilgero, a no less delightful songster, frequents the mountain regions of Cuba, and the beauty of his notes may be inferred from the extravagant price of several hundred dollars, which the rich Havanese are ready to pay for a captive bird.

The same beauty of plumage which characterizes so many of the American forestbirds, adorns, likewise, the feathered tribes of the swamp and the morass, of the river and the lake. Nothing can exceed in beauty a troop of deep red Flamingos (Phoenicopterus ruber) on the green margin of a stream. Raised on enormous stilts, and with an equally disproportionate length of neck, the flamingos would be reckoned among the most uncouth birds, if their splendid robe did not entitle them to rank among the most beautiful. They always live in troops, and range themselves, whether fishing or resting, like soldiers, in long lines. One of the number acts as sentinel, and on the approach of danger gives a warning scream, like the sound of a trumpet, when, instantly, the whole troop, expanding their flaming wings, rise loudly clamoring into the air. These strange-formed birds build in the swamps high conical nests of mud, in the shape of a hillock with a cavity at top, in which the female generally lays two white eggs of the size of those of a goose, but more elongated. The rude construction is sufficiently high to admit of her sitting on it conveniently, or rather riding, as the legs are placed on each side at full length. Their mode of feeding is no less remarkable. Twisting their neck in such a manner that the upper part of their bill is applied to the ground, they at the same time disturb the mud with one of their webbed. feet, thus raising up from the water insects and spawn, on which they chiefly subsist. 
The Rose colored Flamingo, with red wings and black quills, adorns the creeks and rivers of tropical Africa and Asia, and in warm summers extends his migrations as far northwards as Strasburg on the Rhine. The sight of a troop of flamingos approaching on the wing, and describing a great fiery triangle in the air, is singularly majestic. When about to descend, their flight becomes slower, they hover for a moment, then their evolutions trace a conical spire, and, finally alighting, they immediately arrange themselves in long array, place their sentinels, and begin their fishing operations.

The scarlet American Ibis, with black-tipped wings, though inferior in size to his celebrated cousin, the sacred bird of the Egyptians, far surpasses him in beauty. Six feet high, stately as a grenadier of the guards, the American Jabiru stalks along the banks of the morasses. His plumage is white, but his neck and head are black, like his long legs; his conical, sharp, and powerful black bill, is a little recurved, while that of the stork, to whom he is closely related, is straight. He destroys an incredible number of reptiles and fishes, and, being very shy, is difficult to kill. Two similar species, respectively inhabit Western Africa and Australasia. The roseate American Spoon-bill is particularly remarkable for his curious large beak, dilating at the top into a broad spoon or spatula, which, though not possessed of great power, renders him excellent service in disturbing the mud and seizing the little reptiles and worms he delights to feed on. The Jacana possesses enormously long and slender toes, armed with equally long spine-like claws. While pacing the ground they seem as inconvenient as the snow-shoes of a Laplander, and yet nothing can be more suitable for a bird destined to stalk over the floating leaves of the Nelumbos and Nymphæas, and to seek for water insects on this unstable foundation. The jacana is found all over tropical America, and is also called the "Surgeon," from the nail of his hinder toe being sharp and pointed like a lancet.

All these strange and wondrous birds, and numberless others, whose mere enumer. ation would be fatiguing to the reader, justify the ornithological reputation of the woods and swamps of tropical America. And indeed the feathered races nowhere find a richer field for their development than here, where the vegetable world revels in luxuriant growth ; and myriads of insects, peopling the forest, the field, and the water, furnish each kind according to its wants with an inexhaustible supply of food. The circumstance that man but thinly inhabits these wilds, is another reason which favors the multiplication of the feathered tribes ; for, in Europe also, birds would no doubt be far more numerous, if the farmer, the sportsman, and so many other enemies were not continually thinning their ranks. To these elements of destruction they are far less exposed in tropical America, and being comparatively but little disturbed, they reign, as it were, over the forest and the open field, over the mountain and the plain, over the river and the lake.

Although in the torrid zone we hardly ever meet with a single aboriginal species of plant or animal common to both hemispheres, yet the analogy of climate everywhere produces analogous organic forms, and when on surveying the feathered tribes of America, we are struck by any bird remarkable for its singularity of shape or mode of life, we may expect to find its representative in Asia, Africa, or Australia. Thus the enormous beak of the toucan is emulated or surpassed by that of the Indian Calao, or Rhinoceros Hornbill, whose twelve-inch long, curved, and sharp-pointed bill is, moreover, surmounted with an immense appendage, in the form of a reverted horn, the use of 
which belongs as yet to the secrets of nature. While the toucans are distinguished by a gaudy plumage, the calaos are almost entirely decked with a robe black as that of the raven, and enhancing the beautiful red and orange colors of their colossal beak. Generally congregating in small troops like the toucans, they inhabit the dense forests, where they live chiefly on fruits, seeds, and insects, which they also swallow whole, throwing them up into the air and catching them as they fall. The clapping together of their mandibles causes a loud and peculiar noise, which towards evening interrupts the silence of the forest. The flight of a bird burdened with such a load must naturally be short : they hop upon their thick clumsy feet, and generally roost upon the highest trees.

The brilliant Sun-birds or Suimangas (Cinnyris, ) belonging to the order of the Certhias or creepers, are the colibris of the old world, equally ethereal, gay, and sprightly in their motions, flitting briskly from flower to flower, and assuming a thousand lively and agreeable attitudes. As the sunbeams glitter on their bodies, they sparkle like so many gems. As they hover about the honey-laden blossoms, they vibrate rapidly their tiny pinions, producing in the air a slight whirring sound, but not so loud as the humming noise produced by the wings of the colibris. Thrusting their slender beaks into the deep-cupped flowers, they probe them with their brush-like tongues for insects and nectar. Some are emerald green, some vivid violet, others yellow with a crimson wing, and rivalling the colibris by the metallic lustre of their plumage, they surpass them by their musical powers, for while the latter can only hum, the sun-birds accompany their movements with an agreeable chirp.

The nearly-related Melithreptes, or Honey-eaters of the South Sea Islands, distinguished by a very long curved beak, and a tongue split into two slender filaments, furnish the chief ornaments of the Polynesian kings and chieftains. Thus the famous royal mantle of Taméhaméha the Great is completely covered with the golden plumage of the Melithreptes pacificus, and as this not very common brown-colored bird has only three or four yellow feathers in each wing, it may easily be conceived that the most costly brocades of Lyons are far from equalling in value this splendid robe of state, which is no less than ten feet long and seven feet broad. Even the small diadems made of the feathers of this bird, which are worn by the ladies of rank in the Sandwich Islands, are worth several hundred dollars. Idols or mantles of the Polynesians, decorated with the scarlet feathers of the Melithreptes vestiarius are frequently met with in ethnographical museums.

While the superb Ocellated Turkey of Honduras (Meleagris ocellata) displays with all the pride of a peacock, the eye-like marks of his tail and upper coverts, the no less beautifully spotted Argus, a bird nearly related to the gold and silver pheasants which have been introduced from China into the European aviaries, conceals bis splendor in the dense forests of Java and Sumatra. The wings of this magnificent creature, whose plumage is equally remarkable for variety and elegance, consist of very large feathers, nearly three feet long, the outer webs being adorned with a row of large eyes, arranged parallel to the shaft; the tail is composed of twelve feathers, the two middle ones being about four feet in length, the next scarcely two, and gradually shortening to the outer ones. Its voice is plaintive and not harsh, as in the Indian peacock, which Alexander the Great is said to have first introduced into Europe, though its feathers had many centuries before been imported by the Phoenicians. The Peacosk is still found wild in many parts of Asia and Africa, but more particularly in the fertile plains 
of India. Another species, nearly similar in size and proportions, but distinguished by a much longer crest, inhabits the Javanese forests.

Though of less dazzling splendor than this peacock's tail, that of the Menura, or Lyre-bird, is unrivalled for its elegance. Fancy two large, broad, black and brownstriped feathers, curved in the form of a Grecian lyre, and between both, ather feathers whose widely-distanced silken barbs envelope and surınount them with a light and airy gauze. No painter could possibly have imagined anything to equal this masterpiece of nature, which its shy possessor conceals in the wild bushes of Australia.

The lyre-bird is constantly engaged in traversing the brush from mountain top to the bottom of the gullies, whose steep and rugged sides present no obstacle to its long legs and powerful muscular thighs. When running quickly through the brush, it carries the tail horizontally, that being the only position in which it could be borne at such times. Besides its loud, full cry, which may be heard at a great distance, it has an inward and varied song, the lower notes of which can only be heard when you have stealthily approached to within a few yards of the bird when it is singing. Its habits appear to be solitary, seldom more than a pair being seen together. It constructs a large nest, formed on the outside of sticks and twigs, like that of a magpie, and lined with the inner bark of trees and fibrous roots.

But of all the tropical birds there are none so absolutely distinctive of the equatorial regions as the Birds of Paradise, which are found only in some of the islands of the Malay Archipelago. Until about 1868 really nothing was known to Europeans respecting these birds, which in gorgeousness of coloring and elegance of form and plumage surpass all others. Stuffed skins of these birds, curiously prepared, have long been found in European museums, and from these the strangest descriptions have been given, which still find place in books upon Natural History. When the early navigators reached the Moluceas in search of cloves and nutmegs, they were presented with dried skins of a kind of bird so beautiful as to excite even their wonder and admiration. Malay traders called them "God's Birds," and the Portuguese re-named them "Birds of the Sun." A learned Dutchman, who wrote in Latin, gave them the name which they now bear. These skins were always without feet or wings, and it was said, and currently believed, that no one had ever seen one of them alive; that they lived only in the air, and, being destitute of feet, never alighted; but as they were equally without wings, how they managed to keep afloat in the air was a mystery of which no solution was attempted. It was not till generations had passed that it was discovered that the natives, in preparing the skins, cut off their very serviceable legs and wings, and so arranged what was left as to give the greatest possible prominence to their flowing tail-plumage. One fable was thus displaced; but everything else remained unknown.

In $1862 \mathrm{Mr}$. Alfred Russell Wallace, an English naturalist, set himself seriously at work to investigate the Natural History of the Malay Islands; and to his work, published in 1868 , which we have already had frequent occasion to cite, we are indebted for about all that is really known respecting the Birds of Paradise; and this cost him five successive voyages, each occupying in preparation and execution nearly a year. He describes and illustrates eighteen different species. In all of these, it must be borne in mind that the brilliant colors and remarkable plumage belong to the 
males ; the females being throughout very plain looking personages. "The Birds of Paradise," he says, "are a group of moderate-sized birds, allied in structure and habits to crows and starlings; but they are characterized by extraordinary developments of plumage which are unequaled by any other family of birds. In several

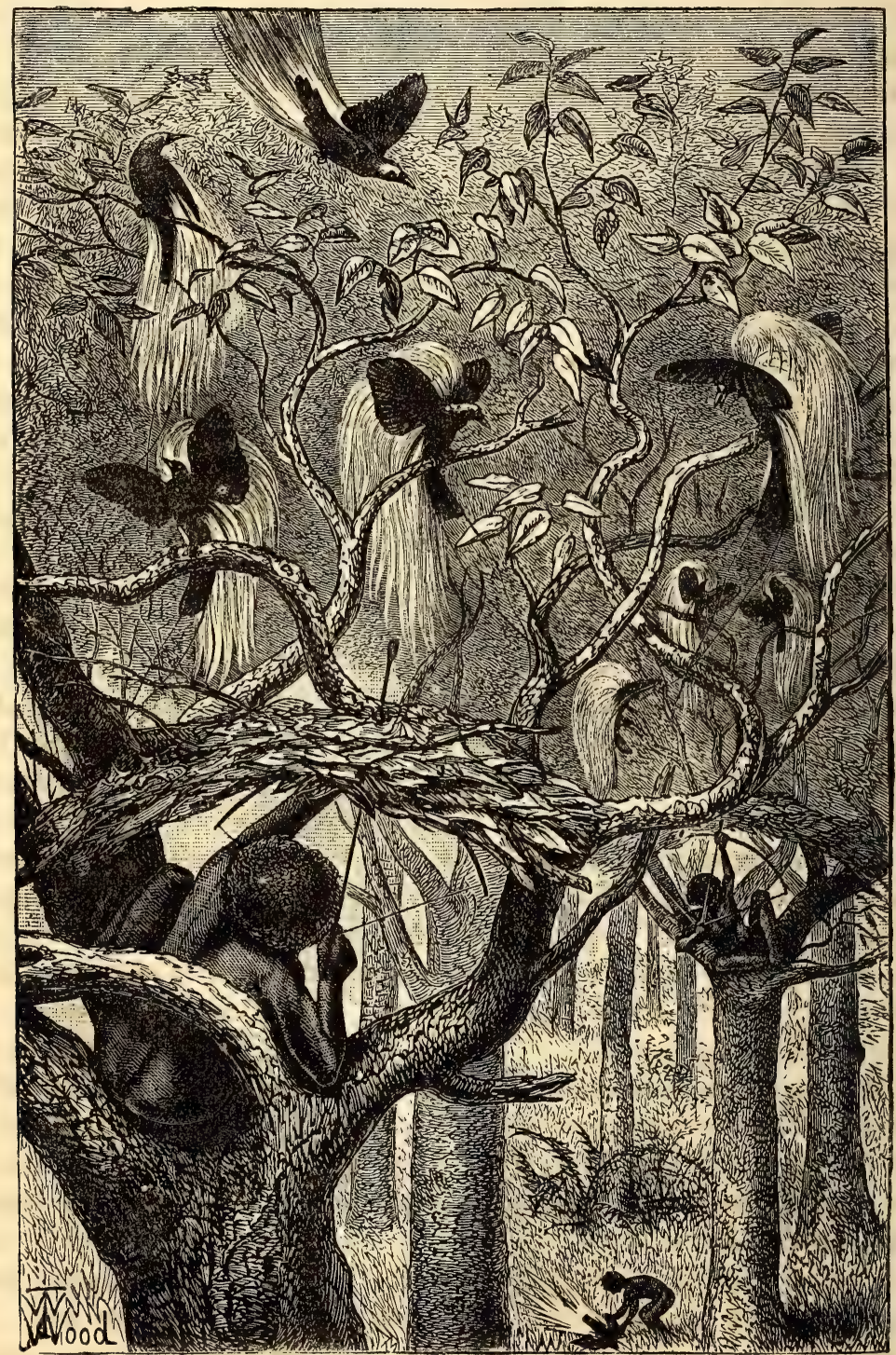

NATIYES OF ARU SHOOTING THE GREAT BIRD OF PARADISE.

species large tufts of delicate, bright-colored feathers spring from each side of the body beneath the wings, forming trains, fans, or shields ; and the middle feathers of the tail are often elongated into wires, twisted into the most fantastic shapes, or adorned with the most brilliant metallic tints. In another set of species these accessory plumes 
spring from the head, the back, or the shoulders; while the intensity of color and of metallic lustre displayed by their plumage is not to be equaled by any other birds, except perhaps by the Humming-birds, and is not surpassed even by these."

Of the eighteen species described by Mr. Wallace, perhaps the most remarkable is the great Bird of Paradise (Paradisea apoda) which measures seventeen or eighteen inches from the beak to the tip of the tail. The body, wings, and tail are brown, deepening on the breast to purple. The head is yellow, the throat of emerald green. From each side of the body, beneath the wings, springs a dense tuft of long delicate plumes, sometimes two feet in length, of the most intense golden-orange color, very glossy, but changing towards the tips into a pale brown. This tuft of plumage can be elevated and spread out at pleasure, so as almost to conceal the body of the bird. They moult in January and February; and are in full plumage in May. At this time the males assemble early in the morning to exhibit themselves in a singular manner which the natives call their "Saccleli" or dancing-parties. The ball-room is a huge tree, whose wide branches afford them abundant space for display. On one of these trees a score of males will assemble, raise their wings, and keep them in constant vibration; flying now and then from branch to branch, so that the whole tree is alive with their waving plumes. When at the utmost point of excitement, the wings are raised over the head, the plumes expanded until they form two magnificent fans, overshadowing the whole body, while the yellow head and green throat form a foundation and support for the golden glory which waves above. When seen in this attitude the Bird of Paradise really deserves its name, and must be ranked as one of the most beautiful of living things.

This habit enables the natives of Aru to obtain specimens with more ease. As soon as they find that the birds have fixed upon a tree on which to assemble, they build a little shelter of palm-leaves in a convenient place among the branches, and the hunter ensconces himself in it before daylight, armed with his bow and a number of arrows terminating in a round knob. A boy waits at the foot of the tree, and when the birds come at sunrise, and a sufficient number have assembled, and have begun to dance, the hunter shoots with his blunt arrow so strongly as to stun the bird, which drops down and is secured without its plumage being injured by a drop of blood. The rest take no notice, and fall one after another till some of them taike the alarm.

Another species, the Red Bird of Paradise, found in some parts of New Guinea, is caught in a very ingenious manner. There is a large tree bearing a red fruit of which these birds are especially fond. The hunters fasten this fruit on a stout forked stick, and provide themselves with a fine strong cord. They then find out some tree in the forest upon which these birds are accustomed to perch; and climbing up it, fasten the stick to a branch, and arrange the cord in a noose so ingeniously that when the bird comes to eat, its legs are caught; and by pulling the end of the cord, which hangs to the ground, it comes down free from the branch, and brings down the bird. Sometimes when this favorite food is abundant elsewhere, the hunter sits from morning to night under his tree, and often for two or three whole days in succession, without getting even a bite; while at other times, if very lucky, he may get two or three birds a day.

The ornithological wonders of Australia are inferior to those of no other part of the world. Can anything, for instance, be more extraordinary than the constructions of 
the Bower-birds, which are built not for the useful purpose of containing the young, but purely as a playing place or an assembly room? "The structures of the spotted bower-bird," says Mr. Gould, " are in many instances three feet in length. They are outwardly built of twigs, and beautifully lined with tall grasses, so disposed that their heads nearly meet; the decorations are very profuse, and consist of bivalve shells, crania of small mammalia, and other birds. Evident and beautiful indications of design are manifest throughout the whole of the bower and decorations formed by this species, particularly in the manner in which the stones are placed within the bower, apparently to keep the grasses with which it is lined fixed firmly in their places. These stones diverge from the mouth of the run on each side, so as to form a little path, while the immense collection of decorative materials, bones, shells, \&c., are placed in a heap before the entrance of the avenue, this arrangement being the same at both ends. I frequently found these structures at a considerable distance from the rivers, from the borders of which they alone could have procured the shells and small round pebbly stones; their collection and transportation must, therefore, be a task of great labor and difficulty. As these birds feed almost entirely upon seeds and fruits, the shells and bones can not have been collected for any other purpose than ornament; besides, it is only those that have been bleached perfectly white in the sun, or such as have been roasted by the natives, and by this means whitened, that attract their attention." For what purpose these curious bowers are made is not yet, perbaps, fully understood; they are certainly not used as a nest, but as a place of resort, where the assembled birds run through and about the bower in a playful manner, and that so frequently that it is seldom entirely deserted. The proceedings of these birds have not been sufficiently watched to render it certain whether the runs are frequented throughout the whole year or not, but it is highly probable that they are merely resorted to as a rendezvous or playing ground at the pairing time, and during the period of incubation.

The Talegalla or Brush-turkey is no less interesting. In appearance it is very like the common black turkey, but is not quite so large : the extraordinary manner in which its eggs are hatched constitutes its singularity. It collects together a great heap of decaying vegetables as the place of deposit of its eggs, thus making a hot-bed, arising from the decomposition of the collected matter, by the heat of which the young are hatched. This mound varies in quantity from two to four cart loads, and is of a perfectly pyramidical form : it is not, however, the work of a single pair of birds, but is the result of the united labor of many, and the same site appears to be resorted to for several years in succession. "The mode," says Mr. Gould, "in which the materials composing these mounds are accumulated is equally singular, the bird never using its bill, but always grasping a quantity in its foot, throwing it backwards to one common center, and thus clearing the surface of the ground to a considerable distance so completely that scarcely a leaf or blade of grass is left." The heap being accumulated and time allowed for a sufficient heat to be engendered, the eggs, each measuring not less than four inches in length-an enormous size, considering the bulk of the birdare deposited, not side by side, as is ordinarily the case, but planted at the distance of nine or twelve inches from each other, and buried at nearly an arm's depth perfectly upright, with the large end upwards; they are covered up as they are laid, and allowed to remain until hatched. After six weeks of burial, the eggs, in succession 
and without any warning, give up their chicks-not feeble, but full-fledged and strong, so that at night they scrape holes for themselves, and lying down therein are covered over by the old birds and thus remain until morning. The extraordinary strength of the newly-hatched birds is accounted for by the size of the shell, since in so large a space it is reasonable to suppose that the young ones would be much more developed than is usually found in eggs of smaller dimensions.

It is not to be wondered at that in the tropical world, where lizards, snakes, and frogs attain such extraordinary dimensions, the cranes or stork tribes, which chiefly live upon these reptiles, should also grow to a more colossal size than their European representatives. Thus, while torrid America boasts of the Jabiru, Africa and India possess the still larger Argala, or Adjutant, whose feeding exploits and ugliness have already been mentioned in the chapter on snakes. His beak, measuring sixteen inches in circumference at the base, corresponds with his appetite. $\mathrm{He}$ is soon rendered familiar with man, and when fish or other food is thrown to him, he catches it very nimbly and immediately swallows it entire. A young bird of this kind, about five feet in hight, was brought up tame and presented to a chief on the coast of Guinea, where Mr. Smeathman lived. It regularly attended the hall at dinner-time, placing itself behind its master's chair, frequently before any of the guests entered. The servants were obliged to watch it carefully, and to defend the provisions by beating it off with sticks; still it would frequently snatch off something from the table, and one day purloined a whole boiled fowl, which it swallowed in an instant. It used to fly about the island, and roost very high among the silk-cotton trees; from this station, at the distance of two or three miles, it could see when the dinner was carried across the court, when, darting down, it would arrive early enough to enter with some of those who carried in the dishes. Sometimes it would stand in the room for half an hour after dinner, turning its head alternately as if taking a deep interest in the conversation. These birds are found in companies, and when seen at a distance near the mouths of rivers, advancing towards an observer, it is said that they may be easily mistaken for canoes on the surface of a smooth sea; and when on the sand-banks, for men and women picking up shell fish on the beach.

The tropical forests of the eastern hemisphere resound with bird-cries no less appalling, wild, or strange than those of the western world. In the close jungles of Ceylon one occasionally hears the call of the Copper-smith (Megalasara Indica, ) whose din resembles the blows of a smith hammering a caldron, or the strokes of the great orange-colored Woodpecker (Brachypterus aurantius, ) as it beats the decaying trees in search of insects; but of all the yells that fancy can imagine there is none to equal that of the Singhalese Devil-bird, or Gualama. "Its ordinary cry," says Mr. Mitford, "is a magnificent clear shout like that of a human being, and which can be heard at a great distance, and has a fine effect in the silence of the closing night. It has another cry like that of a hen just caught; but the sounds which have earned for it its bad name, and which I have heard but once to perfection, are indescribable; the most appalling that can be imagined, and scarcely to be heard without shuddering. I can only compare it to a boy in torture, whose screams are being stopped by being strangled. On hearing this dreadful note the terrified Singhalese hurries from the spot, for should he chance to see the bird of ill omen he is sure that his death is nigh. A servant of Mr. Baker's, who had the misfortune of seeing the dreaded gualama, 
from that moment took no food, and thus fell a victim to his superstitious despair. This horror of the natives explains the circumstance that it is not yet perfectly ascertained whether the devil-bird is an owl (Syrnium) or a night-hawk.

The wonderful pendulous nests of the American Cassiques are equalled, if not surpassed, by those of the Indian Baya. These birds are found in most parts of Hindostan; in shape they resemble the sparrow, as also in the brown feathers of the back and wings; the head and breast are of a bright yellow, and in the rays of a tropical sun have a splendid appearance when flying by thousands in the same grove. They make a chirping noise, but have no song; they associate in large communities, and cover clumps of palmyras, acacias, and date-trees with their nests. These are formed in a very ingenious manner by long grass woven together in the shape of a bottle, and suspended by so slender a thread to the end of a flexible branch that even the squirrel dare not venture his body on so fragile a support, however his mouth may water at the eggs and prey within. These nests contain several apartments, appropriated to different purposes : in one the hen performs the office of incubation; another, consisting of a little thatched roof, and covering a perch without a bottom, is occupied by the male, who cheers the female with his chirping note.

The Tailor-bird of Hindostan (Sylvia sutoria) is equally curious in the structure of its nest, and far superior in the elegance and variety of its plumage, which in the male glows with the varied tints of the colibri. The little artist first selects a plant with large leaves, and then gathers cotton from the shrub, spins it to a thread by means of its long bill and slender feet, and then, as with a needle, sews the leaves neatly together to conceal its nest.

On turning to the wilds of Africa, the Grosbeak affords us a no less wonderful example of nest-building; for here we find, not one single pair, but hundreds living under the same roof, perfectly resembling that of a thatched house, and with a projecting ridge, so that it is impossible for any reptile to approach the entrances concealed below. "Their industry," says Paterson, " seems almost equal to that of the bee. Throughout the day they appear to be busily employed in carrying a fine species of grass, which is the principal material they employ for the purpose of erecting this extraordinary work, as well as for additions and repairs. Though my short stay in the country was not sufficient to satisfy me, by ocular proof, that they added to their nest as they annually increased in numbers, still from the many trees which I have seen borne down by the weight, and others which I have observed with their boughs completely covered over, it would appear that this really was the case. When the tree which is the support of this aerial city is obliged to give way to the increase of weight, it is obvious they are no longer protected, and are under the necessity of rebuilding in other trees. One of these deserted nests I had the curiosity to break down, so as to inform myself of its internal structure, and I found it equally ingenious with that of the external. There are many entrances, each of which forms a separate street with nests on both sides, at about two inches distant from each other."

Though far less ingenious, yet the nest of the Korwé (Tockus erythrorynchus) is too curious to be passed over in silence. The female having entered her breedingplace, in one of the natural cavities of the mopane tree, a species of bauhinia, the male plasters up the entrance, leaving only a narrow slit by which to feed his mate, and which exactly suits the form of his beak. The female makes a nest of her own 
feathers, lays her eggs, hatches them, and remains with the young till they are fully fledged. During all this time, which is stated to be two or three months, the male continues to feed her and the young family. The prisoner generally becomes quite fat, and is esteemed a very dainty morsel by the natives, while the poor slave of a husband gets so lean and weak, that on the sudden lowering of the temperature, which sometimes happens after a fall of rain, he is benumbed, falls down, and dies.

All pensile birds are remarkable for the eccentricity of shape and design which marks their nests; though they agree in one point, that they dangle at the end of twigs, and dance about merrily at every breeze. Some are long, others short; some have the entrance at the side, others at the bottom, others near the top. Some are hung like hammocks from one twig to another; others are suspended to the extremity of the twig itself; while others built in palms, which have no true branches, and no twigs at all, are fastened to the extremities of the leaves. Some are made of fine fibres, and others of the coarsest straws. Some are so loose in their texture that the eggs can be plainly seen through them; while others are so strong and thick, that one might suppose them to be constructed by a professional thatcher.

The illustration on the following page presents a group of nests of several species of the African Weavers. In the right-hand upper corner are the curious nests of the Mahali Weaver (Pliopasser mahali) accompanied by the birds themselves. Although the bird measures only six inches in length its nest is of considerable size, and is formed of quite stout substances. In shape it is not unlike an ordinary Florence flask, only three times the size, with the neck shortened and widened. Its surface, however, is rough, the large straws of which it is composed pointing downwards to the entrance of the nest, which is at the bottom. Next below are three rows of the nests of the Spotted-back Weavers (Ploceus spilonatus), which are represented as attacked by monkeys, some of whom, assailed by the birds, are getting well-ducked for their pains. Still below, rather in the background, are two nests of the Ploceus Capensis, woven into palm-leaves. Below this, in the left corner, is a nest of the YellowWeaver (Ploceus ocularius), shaped somewhat like a chemist's retort, with the bulb uppermost, or more nearly like a huge old fashioned pistol, hanging butt upward. The nest is made of grass about as large as a small twine, interwoven with great skill. This is only partly shown. At the right corner is a nest of the Taha Weaver (Euplectes taha), a pretty little bird, which is no great favorite with the African farmers, for it is very numerous, especially in cultivated regions, and has no scruples about helping itself to the produce of the gardens, whose owners are obliged to keep up a keen watch if they expect to secure a fair share of the crops. Lastly, in the bottom centre, is the nest of the Yellow capped Weaver (Ploceus icterocephalus). This nest is remarkable for the extreme neatness and compactness of its structure. The body of the nest is of seed-stems so closely interwoven that it can be handled, or even kicked like a foot-ball, without being destroyed. The interior is lined with layers of flat leaves, kept in place by their own elasticity, which afford a smooth, soft resting-place for the eggs and young birds.

Parrots have so many points of resemblance to monkeys in their tastes and habits, that notwithstanding their different appearance, one might almost be tempted to call them near relations. As the monkey never sets foot on the ground if he can help it, but springs from branch to branch of trees, so the parrot is rarely seen walking. His 


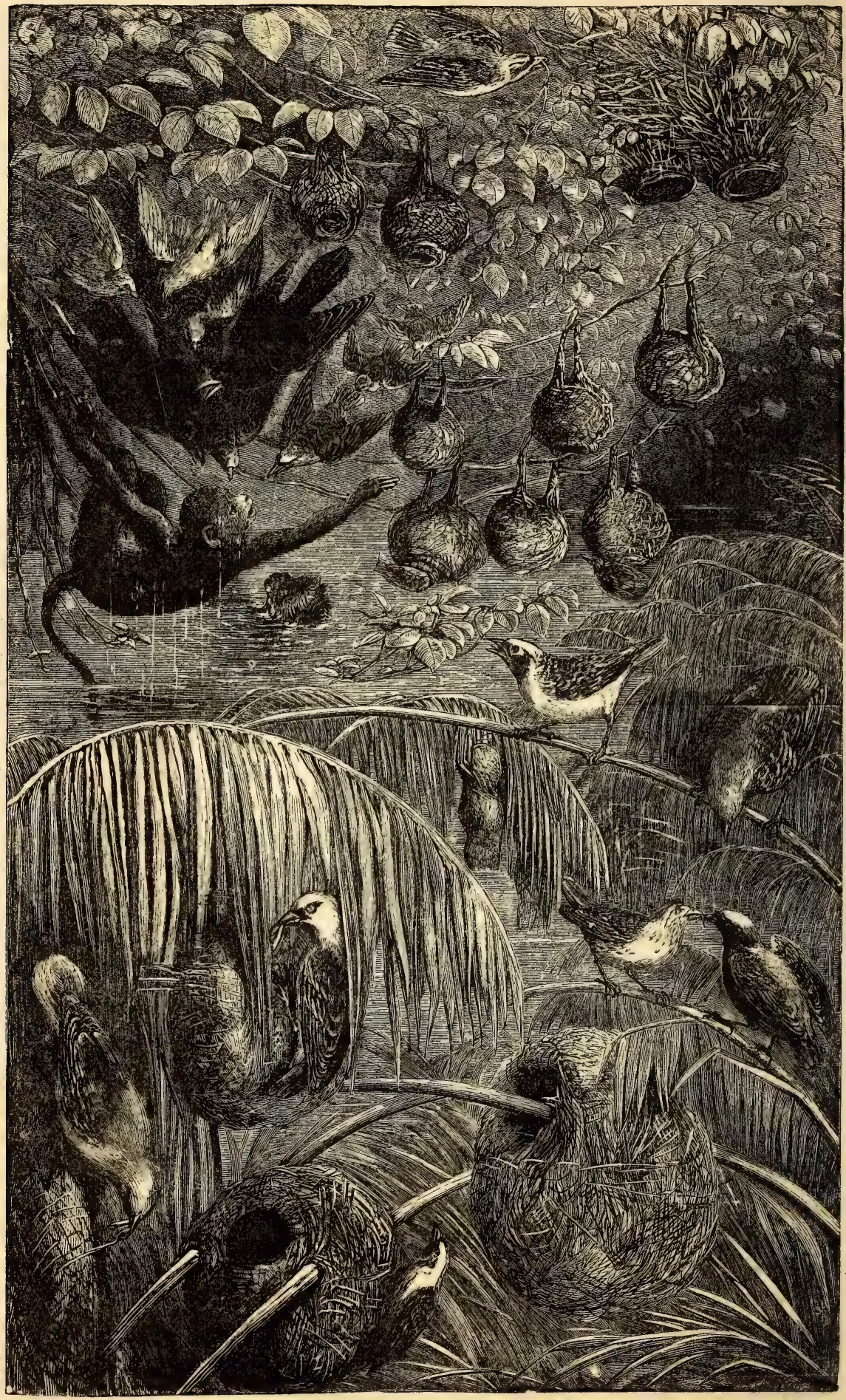


flight is rapid, but of short duration ; so that evidently neither the ground nor the air was destined for his habitual abode. In climbing, however, he shows an uncommon expertness and agility, unlike that of any other quadruped or bird, as the organ he chiefly uses for the purpose is his beak. He first seizes with his powerful mandibles the branch he intends to ascend, and then raises his body one foot after the other; or, if he happens to have a sweet nut in his bill which he is anxious to preserve, he presses his lower mandible firmly upon the branch, and raises himself by the contraction of the muscles of his neck. On descending, he first bends his head, lays the back of his beak upon the branch, and while the extended neck supports the weight of the body, brings down one foot after the other. While accidentally walking on even ground, he also frequently uses his upper mandible as a kind of crutch, by fixing its point or its back upon the ground; for the formation of his toes is such, that he can walk but very slowly, and consequently requires the aid of that singular support. But if the toes of the parrot are but ill adapted for walking, they render him valuable services in seizing or grasping his food. They even form a kind of hand, with which, like the monkey, he conveys the morsel to his beak. This easily cracks the hardest nutshells, after which the broad and fleshy tongue adroitly extracts the kernel.

In his free state the parrot lives only upon nuts and seeds ; when captive, however, he becomes omnivorous, like man his master, eats bread and meat, sugar and pastry, and is very fond of wine, which has a most exhilarating effect on his spirits. Like most monkeys, the parrots are extremely social. At break of day they generally rise in large bands, and with loud screams fly away to seek their breakfast. After having feasted together, they retire to the shady parts of the forest as soon as the heat begins to be oppressive, and a few hours before the setting of the sun reappear in large troops.

If the monkeys are distinguished by a strong affection for their young, the parrots may well be cited as models of connubial love, for when once a pair has been united, its attachment remains unaltered unto death. Far more than the turtle-dove, the little passerine parrot (Psittacus passerinus) of Brazil, or the Psittacus pullarius, or loveparrot of Guinea, deserves to be celebrated by poets as the emblem of conjugal affection. Never seen but in each other's company, each delights to imitate the actions of the other, feeding, sleeping, bathing together; and when one dies, the other soon follows its partner. A gentleman who had lost one of a pair of these inseparables, attempted to preserve the other by hanging up a looking-glass in its cage. At first the joy of the poor bird was boundless, as he fancied his mate restored to his caresses ; buc soon perceiving the deception, he pined away and died.

Another point of resemblance between the parrots and monkeys is their talent for mimicry; but while the latter, favored by the similarity of their organization to that of man, strive to copy his gestures and actions, the former endeavor to imitate his voice and to repsat his words, an attempt facilitated by the extreme mobility of their tongue and upper mandible, no less than by the peculiar construction of their larynx or windpipe. The talent of speech has not been given to all the parrots alike. The beautiful American Aras, for instance, are in this respect remarkably stupid, while the purple Lory of the East Indies, and the gray African parrot (Psittacus erithacus,) are remarkable for their linguistic attainments. They are often able to retain whole songs and sentences, and to repeat them with astonishing exactness. Thus Le Vaillant mentions a gray parrot he saw at the Cape, who was able to repeat the whole of the 
Lord's Prayer in Dutch, throwing himself at the same time on his back, and folding the toes of both his feet. The gray parrot not only imitates the voice of man, but has also a strong desire to do so, which he manifests by his attention in listening, and by the continuous efforts he makes to repeat the phrases he has heard. He seems to impose upon himself a daily task, which even occupies him during sleep, as he speaks in his dreams. His memory is astonishing, so that a cardinal once gave a hundred gold crowns for one of these birds that correctly repeated a long prayer; and M. de la Borde told Buffon he had seen one that was fully able to perform the duties of a ship's chaplain.

All parrots are more or less susceptible of education, and, particularly when caught young, grow very much attached to the master that feeds them. Those that are sent to Europe are generally taken from the nest, and thus never have experienced the sweets of freedom; but they are also frequently caught full grown. The South American Indians know how to strike them with small arrows, whose points are blunted with cotton, so as to stun without killing them ; or else, under the trees on which they perch, they light a fire of strong-smelling weeds, whose vapors cause them to drop to the ground. These captives are frequently extremely stubborn; but blowing the fumes of tobacco into their face until they fall asleep is an infallible remedy to cure them of their obstinacy, this operation being so little to their taste that it need hardly ever be repeated twice. Parrots are known to attain a very great age. One that was brought to Florence in 1633, and belonged to the Grand Duchess of Tuscany, died in 1743, having thus lived more than a century in exile. Although preeminently tropical, like the colibris, several parrots range far within the temperate zone, as they are found in the Southern hemisphere at the Straits of Magellan and on the Macquarie Islands, and in the Northern, in Ohio and Kentucky, where the Carolina parrot is often seen in great numbers during the summer.

The Cockatoos are distinguished from the other parrots by a crest or tuft of elegant feathers on the head, which they can raise and depress at pleasure. They inhabit the East Indies and Australia, and have generally a white or roseate plumage. Their chief resorts are dense and humid forests, and they frequently cause great devastations in the rice plantations, often pouncing to the number of six or eight hundred upon a single field, and destroying even more than they devour, as they seem to be possessed of the mania to break and tear everything their beak can lay hold of. They walk less awkwardly than most other parrots. The great white cockatoo (Cacatua cristata), who is able to erect his beautiful yellow crest to the hight of five inches, as a cock does his comb, is the species most frequently seen in Europe. This bird is half-domesticated in several parts of India, as it builds its nest under the roofs of houses, and this tameness results from its intelligence, which seems superior to that of other parrots. It listens attentively, but vainly strives to repeat what is said. As Australia, the land of anomalies in natural history, possesses a black swan, it also gives birth to a splendid black cockatoo (Cacatua Banksii), the finest and the rarest of the whole genus.

The magnificent Macaws, or Aras, of South America are distinguished by having their cheeks destitute of feathers, and their tail feathers long. Their size and splendid plumage render them fit ornaments of princely gardens, but their loud and piercing screams would prove a great annoyance to the inmates of humbler dwellings. "Supe- 
rior in size and beauty to every parrot of South America," says Waterton, "the Ara (Macrocercus macao) will force you to take your eyes from the rest of animated nature, and gaze at him : his commanding strength; the flaming scarlet of his body; the lovely variety of red, yellow, blue, and green, in his wings; the extraordinary length of his scarlet and blue tail, seem all to form and demand for him the title of Emperor of all the parrots."

The Paroquets, or Parakeets, are smaller than the common parrots, and have longer tails. There are numerous species, some distinguished by a very long pointed tail, and collar-like mark round the neck, which inhabit the Asiatic continent and islands; and others, natives of Australia, which are distinguished by their color being gorgeously variegated and peculiarly mottled on the back, by their tail feathers not being pointed, and by their being furnished with elongated tarsi adapted for running on the ground. To the former belongs the beautiful ring paroquet, which is supposed to have been the first bird of the parrot kind known to the ancient Greeks, having been brought from the island of Ceylon, after the Indian expeditions of Alexander the Great ; to the latter, the elegant green parakeet, which in the hot seasons congregates about the pools in almost incredible numbers. Though capable of a rapid and even flight, and frequently at great altitudes, it is generally found running over the ground, and treading its way among the grasses to feed on the seeds. It can easily be domesticated, and a more elegant or beautiful pet can scarcely be conceived.

It is a strange fact that the parrots, that will eat nux vomica without danger, expire in convulsions after having tasted parsley, another proof of the truth of the saying that what is poison for one creature is food for another.

In the African plains and wildernesses, where the lion seeks his prey, where the pachyderms make the earth tremble under their weighty strides, where the giraffe plucks the high branches of the acacia, and the herds of the antelope bound along: there also dwells the Ostrich, the king of birds, if size alone give right to so proud a title; for neither the condor nor the albatross can be compared in this respect to the ostrich, who raises his head seven or eight feet above the ground, and attains a weight of from two to three hundred pounds. His small and weak wings are incapable of carrying him through the air, but their flapping materially assists the action of his legs, and serves to increase his swiftness when, flying over the plain, he "scorns the horse and its rider." His feet appear hardly to touch the ground, and the length between each stride is not unfrequently from twelve to fourteen feet, so that for a time he might even outstrip a locomotive rushing along at full speed.

Not only by his speed is the ostrich able to baffle many an enemy, the strength of his legs also serves him as an excellent means of defence; and many a panther or wild dog coming within reach of his foot has had reason to repent of its temerity. But in spite of the rapidity of his flight, during which he frequently flings large stones backwards with his foot, and in spite of his strength, he is frequently obliged to succumb to man, who knows how to hunt him in various ways. Unsuspicious of evil, and enjoying the full liberty of the desert, a troop of ostriches wanders through the plain, the monotony of which is only relieved here and there by a clump of palms, a patch of candelabra-shaped tree-euphorbias, or a vast and solitary baobab. Some leisurely feed on the sprouts of the acacias, the hard dry leaves of the mimosas, or the prickly naras, whose deep orange-colored pulp forms one of their farorite repasts; others 
agitate their wings and ventilate the delicate plumage, the possession of which is sonn to prove so fatal to them. No other bird is seen in their company-for no other bird. leads a life like theirs; but the zebra and the antelope are fond of associating with the ostrich, desirous perhaps of benefiting by the sharpness of his eye, which is capable of discerning danger at the utmost verge of the horizon. But in spite of its vigilance, misfortunes are already gathering round the troop, for the Bedouin has spied them out, and encircles them with a ring of his fleetest coursers. In vain the ostrich seeks to escape. One rider drives him along to the next, the circle gradually grows narrower and narrower, and, finally, the exhausted bird sinks upon the ground, and receives the death-blow with stoical resignation. But the exertion of a long protracted chase is not always necessary to catch the ostrich; for before the rainy season, when the heat is at its hight, he is frequently found upon the sand with outstretched wings and open beak, and allows himself to be caught after a short pursuit by a single horseman, or even by a swift-footed Bushman.

To surprise the cautious seal the Northern Esquimaux puts on a skin of the animal, and imitating its motions mixes among the unsuspicious herd; and, in South Africa, we find the Bushman resort to a similar stratagem to outwit the ostrich. He forms a kind of saddle-shaped cushion, and covers it over with feathers, so as to resemble the bird. The head and neck of an ostrich are stuffed, and a small rod introduced. Preparing for the chase, he whitens his black legs with any substance he can procure, places the saddle on his shoulders, takes the bottom part of the neck in his right hand, and his bow and poisoned arrows in his left. Under this mask he mimics the ostrich to perfection, picks away at the verdure, turns his head as if keeping a sharp look-out, shakes his feathers, now walks, and then trots, till he gets within bow-shot, and when the flock runs, from one receiving an arrow, he runs too. Sometimes, however, it happens that some wary old bird suspects the cheat, and endeavors to get near the intruder, who then tries to get out of the way, and to prevent the bird from catching his scent, which would at once break the spell. Should one of the birds happen to get too near in pursuit, he has only to run to windward, or throw off his saddle, to avoid a stroke from a wing which would lay him prostrate.

The Bushman frequently has recourse to a much simpler plan. Having discovered the nest of an ostrich, he removes the eggs as the first fruits of conquest, and then, concealing himself in the empty cavity, patiently waits for the return of the bird, which he generally dispatches with one of those poisoned arrows which make incred. ible havoc among the wild herds of the bush or the savannah. According to Dr. Livingstone, the venom most generally employed is the milky juice of the tree-euphorbia, which is particularly hurtful to the equine race. When it is mixed with the water of a pond, a whole herd of zebras will fall dead from the effects of the poison before they have moved away two miles; while on oxen and men it acts as a drastic purgative only. This substance is used all over the country, though in some places the venom of serpents and a certain bulb, Amaryllis toxicaria, are added, in order to increase the virulence. A slender reed only slightly barbed with bone or iron, but imbued with this poison, is sufficient to destroy the most powerful animal. Thus we find the African savage subdues the beasts of the field by similar means to those which are used by the wild nations on the banks of the Orinoco or the Amazon.

The ostrich generally passses for a very stupid animal, yet to protect its young it 
has recourse to various cunning stratagems. Thus Andersson and Galton, while traversing a barren plain, once hit upon a male and female ostrich, with a brood of young ones about the size of ordinary barn-door fowls. This was a sight they had long been looking for, having been requested by Professor Owen to procure a few craniums of the young ostrich, in order to settle certain anatomical questions; so forthwith dismounting from their oxen, they gave chase, which proved of no ordinary interest. Says Andersson: "The moment the parent birds became aware of our intention, they set off at full speed, the female leading the way, the young following in her wake, and the male, though at some little distance, bringing up the rear of the family party. It was very touching to observe the anxiety the old birds evinced for the safety of their progeny. Finding that we were quickly gaining upon them, the male at once slackened his pace, and diverged somewhat from his course; but, seeing that we were not to be diverted from our purpose, he again increased his speed, and with wings drooping, so as almost to touch the ground, he hovered round us, now in wide circles, and then decreasing the circumference till he came almost within pistol-shot, when he abruptly threw himself on the ground and struggled desperately to regain his legs, as it appeared, like a bird that had been badly wounded. Having previously fired at him, I really thought he was disabled, and made quickly towards him. But this was only a ruse on his part; for on my nearer approach he slowly rose, and began to run in an opposite direction to that of the female, who by this time was considerably ahead with her charge. After about an hour's severe chase, we secured nine of the brood ; and though it consisted of about double that number, we found it necessary to be con. tented with what we had bagged."

While breeding, the ostrich likewise resorts to various artifices to remove intruders from its rude nest, which is a mere cavity scooped out a few inches deep in the sand and about a yard in diameter. Thus Thunberg relates that riding past a place where a hen-ostrich sat on her nest, the bird sprang up and pursued him, in order to draw off his attention from her young ones or her eggs. Every time the traveler turned his horse toward her, she retreated ten or twelve paces, but as soon as be rode on, pursued him again. Is it not truly wonderful how parental affection at the approach of danger seems to rouse the intelligence of an animal to higher exertions, and to raise it above its usual sphere!

The instinct of the ostrich in providing food for its young is no less remarkable, for it is now proved that this bird, far from leaving its eggs, like a cold blooded reptile, to be vivified by the sun, as was formerly supposed, not only hatches them with the greatest care, but even reserves a certain portion of eggs to provide the young with nourishment when they first burst into life : a wonderful provision, when we consider how difficult it would be for the brood to find any other adequate food in its sterile haunts. In Senegal, where the heat is extreme, the ostrich, it is said, sits at night only upon those eggs which are to be rendered fertile, but in extra-tropical Africa, where the sun has less power, the mother remains constant in her atteutions to the eggs both day and night. The number of eggs which the ostrich usually sits upon is ten; but the Hottentots, who are very fond of them, upon discovering a nest, seize fitting opportunities to remove one or two at a time; this induces the bird to deposit more, and in this manner she bas been known, like the domestic hen, to lay between forty and fifty in a season. 
But the ostrich has other enemies besides the savage or the hungry traveler to fear for its young brood. Thus the natives about the Orange River assert that, when the birds have left their nest in the middle of the day in search of food, a white vulture may be seen soaring in mid air, with a stone between his talons. Having carefully surveyed the ground below him, he suddenly lets fall the stone, and then follows it in rapid descent. On running to the spot you will find a nest of probably a score of eggs, some of them broken by the vulture who used this ingenious device for procuring himself a dainty meal.

Almost as soon as the chicks of the ostrich (which are ahout the size of pullets) have escaped from the shell, they are able to walk about and to follow the mother, on whom they are dependent for a long time. And here again we find a wonderful provision of nature in providing the young of the ostrich with a color and a covering admirably suited to the localities they frequent. The color is a kind of pepper-and-salt, agreeing well with the sand and gravel of the plains, which they are in the habit of traversing, so that you have the greatest difficulty in discerning the chicks even when crouching under your very eyes. The covering is neither down nor feathers, but a kind of prickly stubble, which no doubt is an excellent protection against injury from the gravel and the stunted vegetation amongst which they dwell.

The ostrich resembles in many respects the quadrupeds, and particularly the camel, so that it may almost be said to fill up the chasm which separates the mammalia from the birds, and to form a connecting link between them. We indeed hesitated in this work whether to place the ostrich among birds or animals. Both the ostrich and the dromedary have warty excrescences on the breast upon which they lean whilst reposing, an almost similarly formed foot, the same muscular neck; and when we consider that they both feed upon the most stunted herbage, and are capable of supporting thirst for an incredibly long time, being, in fact, both equally well formed for living on the arid plains, it is certainly not to be wondered at that the ancients gave the ostrich a name betokening this similitude (Struthiocamelus,) and that the fancy of the Arabs ascribes its original parentage to a bird and to a dromedary.

It is difficult to ascertain what the tastes of the ostrich may be while roaming the desert, but when in captivity no other bird or animal shows less nicety in the choice of its food, gobbling down with avidity stones, pieces of wood and iron, spoons, knives, and other articles of equally light digestion that may be presented to it. Thus it has always been far-famed for the wonderful powers of its stomach, and many amusing anecdotes are told of its voracity. A batch of these birds having once been brought to a small town for the inspection of the curious, a respectable matron, anxious to obtain a sight of the strange creatures, hastily shut up her house, and, key in hand, hurried to the spot where they were kept. Scarcely had she arrived, when one of them gravely stalked up, as if to thank her for her visit, and suddenly bending its long neck, to her horror, snatched the key out of her hand, and swallowed it in a trice; so that the indignant old lady-thus shut out of her own house-vowed that if all the beasts of Africa were to pass her door, she would not so much as open it to look at them. "Nothing," says Methuen, speaking of a domesticated ostrich, "disturbed its digesiion-dyspepsia (happy thing) was undreampt of in its philosophy. One day a Muscovy-duck brought a promising race of ducklings into the world, and with maternal pride conducted them forth into the yard. Up with solemn and measured stride walked the 
ostrich, and, wearing the most mild and benignant cast of face, swallowed them all, one after the other, like so many oysters, regarding the indignant hissings and bristling plumage of the hapless mother with stoical indifference." Baron Aucapitaine relates that he every evening used to regale a tame ostrich with a newspaper, which the bird completely swallowed, thus literally stuffing itself with all the knowledge of the day.

The costly white plumes of the ostrich, which are ehiefly oltained from the wings, form a considerable article of commerce, having been prized in all ages for the elegance of their long, waving, loose, and flexible barbs. The thinner the quill and the longer and more wavy the plume, the more it is prized. From seventy to ninety feathers go to the pound; but a single bird seldom furnisaes more than a dozen, as many of them are spoilt by trailing or some other accident.

In the Tell, or the cultivated coast districts of Algeria, the ostrich is often domesticated, particularly on account of its eggs, which weigh three pounds, and are equiva. lent to twenty-four of the common fowl's eggs. It might be supposed that one of these giant eggs would be too much for the most vigorous appetite, yet Andersson saw two natives despatch five of them in the course of an afternoon, besides a copious al. lowance of flour and fat. According to the taste of this Swedish Nimrod, they afford an excellent repast; while Dr. Livingstone tells us they have a strong, disagreeable flavor, which only the keen appetite of the desert can reconcile one to. But as there is no accounting for tastes, the Romans seemed to have prized it ; and Firmus, one of their pseudo-emperors, most likely desirous of emulating the gormandizing powers of the bird on which he fed, is said to have devoured a whole ostrich at one sitting. Even the egg-shell has its value, and is an excellent vessel for holding liquids of any kind. The Bushmen have hardly any other household utensil. By covering it with a light network it may be carried slung across the saddle. Grass and wood serve as substitutes for corks.

Though not possessing the true camel-bird, America has the large Rheas, which from their size and similar habits have been styled the ostriches of the New World, though differing in many essential characters. One species, the Rhea Darwinii, inhabits Patagonia, while the Emu or Nandu (Rhea Americana) is found throughout the whole eastern part of South America, from Buenos Ayres to the Orinoco, wherever open plains, pampas, campos, or savannas, invite it to take up its residence. The nandu is not near so tall as the true ostrich, scarcely rising above four feet, and is of a uniform gray color except on the back, which has a brown tint. The back and rump are furnished with long feathers, but not of the same rich and costly kind as those which adorn the African ostrich. Its feeble wings merely serve to accelerate its flight, serving it as oars or sails, particularly when running with the wind. It is not easily caught, as it not only runs very fast, but in zigzag lines, so that the horse, rendered giddy by so many evolutions, at length drops down with its rider.

The galeated Cassowary, (Casuarius galeatus), thus called from its head being surmounted by a kind of horny helmet, is a native of Java and the adjacent isles. The skin of the head and upper part of the neck is naked, of a deep blue and fiery red tint, with pendant caruncles similar to those of the turkey-cock. It is much inferior in size to the ostrich, and its wings are reduced to so rudimentary a state, consisting merely of five long bristles, without any plumes, that they are even unable to assist it in running. All its feathers are of the same kind, being entirely designed for cover. 
ing, and resemble at a little distance a coat of coarse or hanging hair. It feeds on fruits, eggs of birds, and tender herbage, and is said to be as voracious as the ostrich. The cassowary is a very swift runner; striking out alternately with one of its robust powerful legs, it projects its body violently forward with a bounding motion far surpassing the speed of the horse.

The Australian Emu (Dromaius Nova Hollandia) is allied to the cassowary, though differing in many external characters. Both the helmet, and the long pens or quills observable in the wings of the latter, are here wanting; its neck and legs are longer, its feathers, for the most part gray and brown mixed, are not so filiform, and its beak also is differently shaped. In size it more nearly approaches the ostrich, . rising to a hight of seven feet, and from its great muscular power is able to run so quickly as to distance the swiftest greyhound. Incessant persecutions have driven it far away from the colonized parts of the country; but it has still a vast range in the wilds of the interior. It lives on fruits, eggs, and even small animals, which it swal. lows entire. 


\title{
CHAPTER XIII.
}

\author{
THE CLIMBERS: BATS, SLOTHS, AND SIMIZE.
}

Bats: Their Wonderful Organization-The Fox-Bat-Eaten by the Malays-Vampire Bats - Their Blood-sucking Propensities-The Horseshoe Bat-The Nycteribia-The Flying Squirrel-The Galeopithecus-The Anomalurus.-The Sloth: Pitiful Description given of Him-His beautiful Organization for his peculiar Mode of Life-His rapid Movements in the Trees-His Means of Defense-His Tenacity of Life-The Unau-The AiGigantic Primeval Sloths.-Monkeys: Good Climbers, but bad Walkers-Imperfectly known to the Ancients-Similitudes and Differences between Man and Apes-The Chimpanzee-The Gorilla-Du Chaillu's First Encounter with a Gorilla-The Gorilla and her Young-The Orang-Utan, or Mias-Wallace's Accounts of Shooting the Orang-Their Tenacity of Life-Size of the Orang-The Orang as a Combatant-The Orang fighting the Crocodile and Python-Habits of the Orang-Wallace's Young Pet Orang-The Gibbons-Monkeys of the Old and New Worlds-The Semnopitheci-The Proboscis Monkey-The Sacred Ape of the Hindus-The Cercopitheci-The Magots-The Cynocephali, or Baboons-The Maimon-The Great Baboon of Senegal-The Derryas-The Loris-Monkeys of the New World-Monkeys Distinguished by their Tails and TeethThe Wourali Poison-The Indian Blow-Pipe-Mildness of American Monkeys-The Howling Monkeys-The Spider-Monkeys-The Fox-tail Monkeys-The Saimaris-Nocturnal Monkeys-The Domesticated Nocturnals-The Squirrel-Monkey.

$\mathrm{W}^{\mathrm{n}}$ E are accustomed to consider all animals as embraced in one of three great divisions: Beasts, or those that walk upon the earth; Birds, or those that fly in the air; Fishes, those that swim in the water. But closer investigation shows us that this division is wholly inaccurate. There are walkers upon earth, as the ostrich, which are not beasts; swimmers in the water, as the whale, which are not fishes; and flyers in the air, like the bat, which are not birds. Then there are others whose bome is neither upon the earth, in the air, nor in the water. Though some are able to fly a little in the air, others to walk a little on the ground, their home is upon the branches of trees, their occupation is climbing. We will, regardless of other peculiarities, designate them as climbers; and will in this chapter group together a few species which are notably characteristic of the Tropical World; commencing with those which, like the bat, most nearly resemble birds, and ending with those which, like the monkey tribe, most nearly resemble man.

When the sun has disappeared below the horizon. and night falls on the landscape, which a little while ago was bathed in light, then from hollow trees, and creviced rocks, and ruined buildings, a strange and dismal race comes forth. Silently hovering through the glades of the woods, or skimming along the surface of the streams, it eatches the crepuscular or nocturnal moths, and serves like the swallow by day to check the exuherant multiplication of the insect tribes. But while man loves the 
swallow, and suffers him to build his nest under the eaves of his dwelling, he abhors the bat, which like an evil spirit avoids the light of day, and seems to feel happy only in darkness. The painter gives to his angels the white pinions of the swan, while his demons are made to bear the black wings of the bat.

And yet most species of the bat are most inoffensive creatures; while a closer inspection of their wonderful organization proves them to be far more deserving of admiration than of repugnance. Can anything be better adapted to its wants than the delicate membrane, which, extending over the long, slim fingers, can be spread and folded like an umbrella, so as to form a wing when the animal wishes to fly, and to collapse into a small space when it is at rest? How slight the bones, how light the body, how beautifully formed for flight! Admire also the tiny unwebbed thumb. which serves the bat to hook itself fast while resting, or to clip off the wings of the flies or moths, which it never devours with the rest of the body. But the exquisite acuteness of the senses of smell, feeling, and hearing in the bat is still more wonderful than its delicate flying apparatus. Naturalists, more curious than humane, bave blinded bats, and seen, to their astonishment, that they continued to fly about, as if still possessed of the power of vision. They always knew how to avoid branches suspended in the room in which they were flitting, and even flew betwixt threads hung perpendicularly from the ceiling, though these were so near each other, that they were obliged to contract their wings in order to pass through them. To explain these wonderful phenomena, Spallanzani and other naturalists of the last century believed the bats to be endowed with a sixth sense ; but Carlyle found that, on closing the ears of the blinded creatures, they lose their wonderful power, and hit against the sides of the room, without being at all aware of their situation. How they are able to distinguish night from day when shut up in a dark box, is a fact still unexplained. As long as the sun stands above the horizon, they will remain perfectly quiet, but as soon as twilight begins to darken the earth, a strange piping and chirping and scratching is heard within the lightless dungeon, and scarcely has the lid been raised, when the prisoners rapidly escape.

Though the temperate regions possess many bats, yet they are most numerous and various in the woody regions of the tropical zone, where the vast numbers of the insect tribes and forest fruits afford them a never-failing supply of food. There also they attain a size unknown in our latitudes, so that both from their dimensions and their physiognomy, many of the larger species have obtained the name of flying dogs or flying-foxes.

On approaching a Javanese village, you will sometimes see a stately tree, fronn whose branches hundreds of large black fruits seem to be suspended. A strong smell of ammonia and a piping noise soon, however, convince you of your mistake, and a closer inspection proves them to be a large troop of Kalongs or Fox-bats (Pteropus) attached head downwards to the tree, where they rest or sleep during the day time, and which they generally quit at sunset, though some of them differ so much from the usual babits of the family as to fly about in the broad light of day.

It is said that it must have been a very hungry man who first ate an oyster; and we are not told that the omniverous Chinese have yet got as far as to include bats. among their edibles; but Mr. Wallace* assures us that the natives of Batchian, one 
of the Malay islands, "consider the great ugly flying-foxes an especial delicacy. At about the beginning of the year they come in large flocks to eat fruit, and congregate during the day on some small islands in the bay, hanging by thousands on the trees, especially on dead ones. They can then be easily caught or knocked down with sticks, and are brought home by basketfuls. They require to be carefully prepared, as the skin and fur has a powerful foxy odor; but they are generally cooked with abundance of spices and condiments, and are really very good eating, something like hare."

The phyllostomidx, a species of bat distinguished by having the orifices of the nostril placed in a kind of membranous scutcheon, surmounted by a leaf-like expansion, like the head of a lance, and supposed to extend in an extraordinary degree the sense of smelling, are exclusively confined to the western continent. These phyllostomidre are remarkable for their blood-sucking propensities, and under the name of Vampires have brought the whole race of the large tropical bats into evil repute.

Prince Maximilian of Neu Wied often saw by moonshine, or in the twilight, the Guandiru (Phyllostoma hastatum), a bat five inches long, and measuring twenty-three inches with outstretched wings, hover about his horses and mules while grazing after their day's journey. The animals did not seem incommoded by its presence, but on the following morning, he generally found them covered with blood from the shoulders to the hoofs. The muscular under-iip of the phyllostoma can be completely folded together in the shape of a sucking-tube, which, after the sharp canine teeth have penetrated the skin, continues to pump forth the blood. Even man himself is liable to the attacks of the larger phyllostomidæ.

“ Some years ago," says Mr. Waterton, “I was in Demarara with a Scotch gentleman, by name Tarbet. We hung our hammocks in the thatched loft of a planter's house. Next morning I heard this gentleman muttering in his hammock, and now and then letting fall an imprecation or two, just about the time he ought to have been saying his morning prayers. ' What is the matter, Sir ?' said I, softly: ' is anything amiss?' 'What's the matter?' answered he surlily; 'why, the vampires have been sucking me to death.' As soon as there was light enough, I went to his hammock, and saw it much stained with blood. 'There,' said he, thrusting his foot out of the hammock, 'see how these infernal imps have been drawing my life's blood.' On examining his foot, I found the vampire had tapped his great toe: there was a wound somewhat less than that made by a leech ; the blood was still oozing from it. I conjectured he might have lost from ten to twelve ounces of blood. Whilst examining it, I think I put him into a worse humor by remarking that an European surgeon would not have been so generous as to have blooded him without making a charge. He looked up in my face, but did not say a word; I saw he was of opinion that I had better have spared this piece of ill-timed levity."

Captain Stedman, while in Surinam, was attacked in a similar way. "On waking." he says, " about four o'clock one morning in my hammock, I was extremely alarmed at finding myself weltering in congealed blood, yet without feeling any pain whatever. Having started up, I ran for the surgeon, with a fire-brand in one hand, and all over besmeared with gore. The mystery, however, was soon solved, for I then found I had been bitten by the vampire or spectre of Guiana." Other instances of the same kind are mentioned by Tschudi, Schomburgik, Azara (who was phlebotomized no less than four times by the vampire,) and other naturalists of equal repute, so that there is no 
reason to doubt the fact. The general food of the phyllostomidæ consists, however, in vespertine and nocturnal moths, and Waterton is of opinion that they also partake of vegetable food. The Vampire (Phyllostoma spectrum) in general, measures about twenty-six inches from wing to wing extended, so that his dimensions are not equal to those of the oriental kalong. Like the flying foxes, he may sometimes be seen in the forest hanging in clusters, head downwards, from the branch of a tree. Some of the phyllostomidæ have a tongue once as long again as the head, and armed at the extrem. ity with recurved bristles, like that of the wood-pecker, no doubt a very serviceable instrument for extracting insects from the narrow hollows and crevices of trees and rocks.

The Rhinolophi or Horse-shoe Bats of the old continent, have also a more or less complicated nasal appendage, or foliaceous membrane at the end of the nose, but differing in its conformation, from that of the phyllostomidæ. They are insectivorous, like most of their order, and none of them seem to indulge in the blood-sucking propensities of the large American vampires. They chiefly inhabit the tropical regions of Africa and Asia, and more particularly the Indian archipelago, but the Rhinolophus unihastatus ranges in Europe as far as England.

Numerous genera and species of tropical bats, distinguished from each other by the formation of their teeth, lips, nostrils, heads, wings, and tails, have already been classified by naturalists ; but many, no dcubt, still live unknown in their gloomy retreats, for who is able to follow them into the obscure nooks of the forest, or in intricate caverns, and accurately to observe them during their nocturnal rambles? It may give an idea of their vast numbers throughout the torrid zone, when we hear that in Ceylon alone about sixteen species bave been identified, and of these two varieties are peculiar to the island. Unlike the sombre bats of the northern climates, the colors of some of them are as brilliant as the plumage of a bird, bright yellow, deep orange, or of a rich ferruginous brown, thus contradicting the general belief which attires nocturnal animals in vestures as dark as their pursuits.

The torrid zone, which produces the largest bats, also gives birth to the tiniest representatives of the order, such as the minute Singhalese variety, (Scotophilus Coromandelicus,) which is not much larger than the humble-bee, and of a glossy black color. "It is so familiar and gentle," says Sir J. E. Tennent, "that it will alight on the cloth during dinner, and manifests so little alarm that it seldom makes any effort to cscape before a wine-glass can be inverted to secure it." The fur of this pretty little creature, like that of many other bats, is frequently found infested with a most singul.ar insect. Unlike most parasites, which are either extremely sluggish in their movements, or even condemned to utter immobility, the velocity of the Nycteribia is truly marvellous; and, as its joints are so flexible as to yield in every direction, it tumbles through the fur of the bat, rotating like a wheel on the extremities of its spokes, or like the clown in a pantomime, hurling himself forward on hands and feet alternately. To assist its mountebank movements, each foot is armed with two sharp hooks, with elastic pads opposed to them, so that the hair can not only be rapidly seized and firmly clasped, but as quickly disengaged as the creature whirls away in its headlong career. But the strangest peculiarity of the Nycteribia is the faculty which it possesses of throwing back or inverting its head so completely, that the under side becoming uppermost, the mouth, the eyes, and the antennæ are completely hid between its shoulders, 
and then again projecting it forward by a sudäen jerk of its long, flexible neck. By means of this wonderful organization, ine nimble parasite feels completely at home in the furry coat which has been assigned to it as a pasture ground, and whisks along as easily through the hairy thicket as the monkey through the bush-ropes of the forest.

Though incapable of a prolonged flight like the bats, several other tropical quadrupeds have been provided with extensions of the skin, which give them the power of supporting themselves for some time in the air, and of making prodigious leaps. Thus, by means of an expansile furry membrane reaching from the fore feet to the hind, the Flying Squirrels (Pteromys) bound, or rather swiftly sail, to the distance of twenty fathoms or more, and thus pass from one tree to another, always directing their flight obliquely downwards. They very rarely descend to the ground, and when taken or placed on it, run or spring somewhat awkwardly with their tail elevated, beginning to climb with great activity as soon as they reach a tree.

The Galeopitheci are in like manner enabled to take long sweeping leaps from tree to tree, by means of an extension of their skin between the anterior and posterior limbs on each side, and between the posterior limbs, including also the tail. These extraordinary animals are natives of the islands of the Indian archipelago. They inhabit lofty trees in dark woods, to which they cling with all four extremities. During the day time, they suspend themselves like bats from the branches, with their heads downwards, but at night they rouse themselves and make an active search for food, which consists of fruits, insects, eggs, and birds. They are inoffensive, but on attempting to seize them, they inflict a sharp scratch with their trenchant nails.

The Anomaluri of the west coast of Africa, which have only been known to the world since 1842, and possess a most remarkable tail, covered on the lower surface of its base with imbricated horny scales, resemble the galeopitheci by the wing like expansion of their skin, and no doubt the investigations of travelers will bring to light other animals endowed with similar parachutes.

"The piteous aspect, the sorrowful gestures, the lamentable cry of the Sloth ali combine to excite commiseration. While other animals assemble in herds, or roam in pairs through the boundless forest," so writes an eminent naturalist, " the sloth leads a lonely life in those immeasurable solitudes, where the slowness of his movements exposes him to every attack. Harmless and frugal, like a pious anchorite, a few coarse leaves are all he asks for his support. On comparing him with other animals, you would say that his deformed organization was a strange mixture of deficiency and superabundance. He has no cutting teeth, and though possessed of four stomachs, he still wants the long intestines of ruminating animals. His feet are without soles? nor can he move his toes separately. His hair is coarse and wiry, and its dull color reminds one of grass withered by the blasts of surly winter. His legs appear deformed by the manner in which they are attached to the body, and his claws seem disproportionately long. Surely a creature so wretched and ill-formed stands last on the list of all the four-footed animals, and may justly accuse Nature of step-motherly neglect!"

When seeing a captured sloth painfully creeping along on even ground, sighing and moaning, and scarcely advancing a few steps after hours of awkward toil, the observer might well be disposed to acquiesce in the foregoing remarks, and to fancy he had 
discovered a flaw among the general beauty of the Creator's works; but let him view the animal in the situation for which it was ordained, and he will soon retract his hasty judgment, and discover it to be no less perfect in its kind, and no less admirably fitted for its sphere of existence, than the most highly organized of the mammalian tribes. For the sloth, in his wild state, spends his whole life in the trees, and never once touches the earth but through force or by accident. Like the monkey, he has been formed for an exclusively sylvan life, high above the ground, in the green canopy of the woods; but while the nimble simiæ constantly live upon the branches, the sloth is doomed to spend his whole life under them. He moves, he rests, he sleeps suspended from the boughs of trees, a wonderfully strange way of life, for which no other four footed animal of the Old or the New World has been destined.

And now examine his organization with reference to this peculiar mode of existence, and all his seeming deficiencies and deformities will appear most admirably adapted to his wants, for these strong, muscular, preposterously long fore-feet, while the hinder extremities are comparatively short and weak, these slender toes armed with enormous claws, are evidently as well suited for clasping the rugged branch as the enormous hind legs of the kangaroo for bounding over the arid plain. Indeed, in every case, we shall find the fundamental type or idea of the four extremities belong. ing to the vertebrated animals most admirably modified according to their wants: here shortened, there prolonged; here armed with claws, there terminating in a hoof; here coalescing to a tail, there assuming the shape of a fin; here clothed with feathers to cleave the air, there raised to the perfection of the human hand, the wonderful instrument of a still more wonderful intelligence; and who, seeing all this, can possibly believe that the world is ruled by chance, and not by an all-pervading and almighty power? Thus the sloth, so helpless when removed from his native haunts, is far from exhibiting the same torpidity in his movements when seen in the place for which Nature fitted him.

“ One day, as we were crossing the Essequibo," says Mr. Waterton, “I saw a large sloth on the ground upon the bank; how he had got there nobody could tell; the Indian said he had never surprised a sloth in such a situation before : he would hardly have come there to drink, for both above and below the place the branches of the trees touched the water, and afforded him an easy and safe access to it. Be this as it may, though the trees were not above twenty yards from him, he could not make his way through the sand time enough to escape before we landed. As soon as we came up to him, he threw himself upon his back, and defended himself in gallant style witb his fore legs. 'Come, poor fellow !' said I to him, ' if thou hast got into a hobble to-day, thou shalt not suffer for it; I'll take no advantage of thee in misfortune; the forest is large enough both for thee and me to rove in. Go thy ways up above, and enjoy thyself in these endless wilds; it is more than probable thou wilt never have another interview with man. So fare thee well.' On saying this I took up a long stick which was lying there, held it for him to hook on, and then conveyed him to a high and stately mora. He asconded with wonderful rapidity, and in about a minute he was almost at the top of the tree. He now went off in a side direction, and caught hold of the branch of a neighboring tree; he then proceeded towards the heart of the forest. I stood looking on, lost in amazement at his singular mode of progress. I followed him with my eye till the intervening branches closed in betwixt us, and then 
lost sight forever of the sloth. I was going to add that I never saw a sloth take to his heels in such earnest, but the expression will not do, for the sloth has no heels."

The Indians, to whom no one will deny the credit of being acute observers of animal life, say that the sloth wanders principally when the wind blows. In calm weather he remains still, probably not liking to cling to the brittle extremity of the branches, lest they should break under his weight in passing from one tree to another; but as soon as the breeze rises, the branches of the neighboring trees become interwoven, and then he seizes hold of them and pursues his journey in safety. There is seldom an entire day of calm in the forests of Guiana. The trade-wind generally sets in about ten o'clock in the morning, and since the sloth, as we have just seen, is able to travel at a good round pace when he has branches to cling to, there is nothing to prevent him making a considerable way before the sun sinks and the wind goes down. During night, and while reposing in the day-time, the sloth constantly remains suspended by his feet, for his anatomy is such that he can feel comfortable in no other position. In this manner he will rest for hours together, expressing his satisfaction by a kind of purring, and from time to time his dismal voice may be heard resounding through the forest, and awakening at a distance a similar melancholy cry.

The color of the sloth's hair so strongly resembles the hue of the moss which grows on the trees, that the European finds it very difficult to make him out when he is at rest, and even the falcon-eyed Indian, accustomed from his earliest infancy to note the slightest signs of forest life, is hardly able to distinguish him from the branches to which he clings. This no doubt serves him as a protection against the attacks of many enemies; but, far from being helpless, his powerful claws and the peculiarly enduring strength of his long arms, make very efficient weapons of defence against the large treesnakes that may be tempted to make a meal of him.

The sloth possesses a remarkable tenacity of life, and withstands the dreadful effects of the wourali poison of the Macushi Indians longer than any other animal. Schomburgk slightly scratched a sloth in the upper lip, and rubbed a minimum of the venom in the wound, which did not even emit a drop of blood; he then carried the animal to a tree, which it began to climb, but after having reached a hight of about twelve feet, it suddenly stopped, and swinging its head about from side to side, as if uncertain which way to go, tried to continue its ascent, which, however, it was unable to accomplish. First it let go one of its fore-feet, then the other, and remained attached with its hind legs to the tree until, these also losing their power, it fell to the ground, where, without any of the convulsive motions or the oppressive breathing which generally mark the effect of the wourali, it expired in the thirteenth minute after the poison had been administered.

The slotbs attain a length of about two feet and a half, and form two genera-the Unaus, with two-toed fore-feet, and three-toed hinder extremities, and the Ais, with three toes on each foot. The former have forty-eight ribs, the latter only thirty-two. Their way of living is the same, and their range is limited to the forests of Guiana and the Brazils. They bring forth and suckle their young like ordinary quadrupeds, and the young sloth, from the moment of its birth, adheres to the body of its parent till it acquires sufficient size and strength to shift for itself.

Sloth-like animals of colossal dimensions-Megatheriums, Mylodons-extinct long before man appeared upon the scene, inhabited the forests of South America during 
the tertiary ages of the world. From the dentition of the mylodon, it may be concluded that, like the sloth of the present day, this monstrous animal fed on the leaves or slender terminal twigs of trees; but while the former, from the comparatively light weight of his body, is enabled to run along the under side of the boughs till he has reached a commodious feeding-place, the elephantine bulk of the mylodon evidently rendered all climbing utterly impossible. First scratching away the soil from the roots of the tree on whose foliage he intended to feast, he next grasped it with his long fore. legs, and rocking it to and fro, to right and left, soon brought it to the ground, for "extraordinary must have been the strength and proportions of that tree," says Professor Owen, "which in such an embrace could long withstand the efforts of its ponderous assailant."

In the midst of tropical vegetation, the Simiæ, or Monkey and Ape tribes, lead a free forest life, for which they might well be euvied. The green canopy of the woods protects them at every season of the year from the burning rays of a vertical sun, flowers of the most delicious fragrance embalm the air they breathe, and an endless supply of fruits and nuts never allows them to know want, for should the stores near at hand be exhausted, an easy migration to some other district soon restores them to abundance. With an agility far surpassing that with which the sailor ascends the rigging, and climbs even to the giddy top of the highest mast, they leap from bushrope to bush-rope, and from bough to bough, mocking the tiger-cat and the boa, which are unable to follow them in their rapid evolutions. Formed to live on trees, and not upon the ground, they are as excellent climbers as they are bad pedestrians. Both their fore and hind feet are shaped as hands, generally with four fingers and a thumb, so that they can seize or grasp a bough with all alike.

Buffon erroneously remarks of the chimpanzee, that he always walks erect, even when carrying a weight; but this ape, as well as the other anthropomorphous simiæ, proves by the slowness and awkwardness of his movements, when by chance he walks upon even ground, that this position is by no means natural to him, or congenial to his organization. Man alone, of all creatures, possesses an upright walk; the ape, on the contrary, always stoops, and not to lose his equilibrium when walking, is obliged to place his hands upon the back of his head, or on his loins. Thus, in his native wilds, he rarely has recourse to this inconvenient mode of progression, and when forced by some chance or other to quit the trees, he leans while walking upon the finger-knuckles of his anterior extremities, a position which in fact very much resembles walking on all-fours. It is, indeed, only necessary to compare the long, robust, and muscular arms of the chimpanzee with his weaker and shorter hind-feet, to be at once convinced that he was never intended for walking. But see with what rapiaity, with what power and grace he moves from branch to branch, his hind-legs serving him only as holdfasts, while his chief strength is in his arms. The tree is, without all doubt, for him what the earth is for us, the air for the bird, or the water for the fish.

We cannot wonder at the ancients having known but few species of the simiæ, as these animals chiefly belong to the torrid zone, with which the Greeks and Romans were so imperfectly acquainted. It is only since a wide extent of the tropical regions has been opened by trade or conquest to European research, that many of the mysteries of monkey-existence have been brought to light from the darkness of the pri- 
meval forest, and particularly within the last twenty years, naturalists and travelers have devoted so much attention to this interesting family, that while in the year 1840 only 128 species were known, their numbers had increased in 1852 to no less than 210 , a stately list, to which, since then, many more have been added, and which even now is far from being closed.

The simiæ of the Old World are all distinguished by the common character of a narrow septum or partition of the nose like that of man, and by the same number of teeth, each jaw being provided with ten grinders, two canine teeth, and four incisors, as in the human race.

The large apes, or tailless monkeys, resemble us besides in many other respects, as well in their external appearance as in their anatomical structure; and form, as it were, the caricature of man, both by their gestures and by glimpses of a higher intelligence.

Creatures so remarkably endowed have naturally at all times attracted a great share of attention, for if even the lowest links in the chain of animated beings lay claim to our interest, how much more must this not be the case with beings whose faculties seem almost to raise them to the rank of our relations. The question how far this similarity extends has naturally given rise to many acute investigations and been differently answered, according as naturalists were more or less inclined to depress man to the level of the ape, or to widen the gulf between them. The former, pointing to the brutality of the lowest savages, would willingly make us believe that we are nothing but an improved edition of the Uran, while the latter complacently cite in favor of their opinion, the incommensurable distance which exists between even the most degraded specimens of humanity and the most perfect quadrumana. Man alone is capable of continually progressive improvement; in him alone each generation inherits the acquirements of its fathers and transmits the growing treasure to its sons, while the ape, like all other animals, constantly remains at the same point. The lowest savage knows how to make fire; the ape, though he may have seen the operation performed a thousand times, and have enjoyed the genial warmth of the glowing embers, will never learn the simple art. His hairy skin is a sufficient proof of his low intellect, an infallible sign that, as he never would be able to provide himself with an artificial clothing, Nature was obliged to protect him against the inclemencies of the cold nights and the pouring rain. As man advances in age, his mind acquires a greater depth and a wider range. In the ape, on the contrary, signs of a livelier intelligence are only exhibited during youth, and as the animal waxes in years, its physiognomy acquires a more brutal expression; its forebead recedes, its jaws project, and instead of expanding to a higher perfection, its mental faculties are evidently clouded by a premature decline.

Both in Africa and Asia, we find large anthropomorphous apes, but while the chimpanzee and the gorilla exclusively belong to the African wilds, the orang and the gibbons are confined to the torrid regions of South Asia.

The Chimpanzee (Simia troglodytes) attains a hight of about five feet, but seems much smaller from his stooping attitude. He inbabits the dense forests on the west coast of Africa, particularly near the river Gaboon, and as his travels are facilitated by his fatherland not being too far distant from Europe, there is bardly a Zoological Garden of any note that does not exhibit a chimpanzee among its lions. Une of the 
finest specimens ever seen was kept a few years since in the Jardin des Plantes in Paris, where the mild climate, agreeable diet (he drank his pint of Bordeaux daily), and lively society of the French maintained him in wonderful health and spirits.

The body of the chimpanzee is covered with long hair on the head, shoulders, and back, but much thinner on the breast and belly. The arms and legs are not so disproportionate as those of the orang, the fore fingers not quite touching the knees when the animal stands upright. The upper part of the head is very flat, with a retiring forehead, and a prominent bony ridge over the eye-brows, the mouth is wide, the ears large, the nose flat, and the face of a blackish-brown color.

From this short notice it will be seen at once that while the Chimpanzee has not the least claim to beauty, he is yet far from equalling the hideous deformity of the Gorilla, whom M. Du Chaillu, the first white man who ever saw the creature alive, has so prominently introduced to public notice. This savage animal, which is covered with black hair like the chimpanzee, and resembles it in the proportion of its body and limbs, though its form is much more robust, unites a most ferocious and undaunted temper with an herculean bodily strength, and is said to bold undisputed dominion of the hill-forests in the interior of Lower Guinea, forcing even the panther to ignominious flight. To kill a gorilla is considered by the negroes as a most courageous exploit; and Dr. Savage, an American missionary on the coast of Guinea, who, in a memoir published at Boston in the year 1847, was the first to point out the generic differences between this formidable ape and the chimpanzee, tells us that a slave having shot a male and female gorilla, whose skeletons afterwards came into his possession, was immediately set at liberty and proclaimed the prince of hunters.

Du Chaillu's description* of his first encounter with an adult gorilla, which entirely agrees with the accounts given to Dr. Savage by the natires of the mode of attack of this monstrous creature, shows that this distinction was by no means unmerited, and that it requires all the coolness and determination of an accomplished sportsman to face an animal of such appalling ferocity and power.

"The underbrush swayed rapidly just ahead, and presently before us stood an immense male gorilla. He had gone through the jungle on his all-fours, but when he saw our party he erected himself, and looked us boldly in the face. He stood about a dozen yards from us, and was a sight I think I shall never forget. Nearly six feet high (he proved four inches shorter,) with immense body, huge chest, and great muscular arms, with fiercely glaring, large, deep-gray eyes, and a hellish expression of face, which seemed to me like some nightmare vision; thus stood before us the king of the African forest. He was not afraid of us. He stood there and beat his breast with his huge fists, till it resounded like an immense bass-drum, which is their mode of offering defiance, meantime giving vent to roar after roar. The roar of the gorilla is the most singular and awful noise heard in these African woods. It begins with a sharp bark like an angry dog, then glides into a deep bass roll which literally and closely resembles the roll of distant thunder along the sky, for which I have been sometimes tempted to take it when I did not see the animal. So deep is it that it seems to proceed less from the mouth and throat than from the deep chest and vast paunch. His eye began to flash deeper fire as we stood motionless on the defensive, and the crest of short hair which stands on his forehead began to twitch rapidly up and

* Explorations and Adventures in Equatorial Africa, 98. 
down, while his powerful fangs were shown as he again sent forth a thunderous roar. And now truly he reminded me of nothing but some hellish dream-creature; a being of that hideous order, half-man, half-beast, which we find pictured by old artists in some representations of the infernal regions. He advanced a few steps, then stopped to utter that hideous roar again, advancel again, and finally stopped when at a distance of about six yards from us. And here, just as he began another of his roars, beating his breast in rage, we fired and killed him. With a groan which had something terribly human in it, and yet was full of brutishness, he fell forward on his face. The body shook convulsively for a few minutes, the limbs moved about in a struggling way, and then all was quiet-death had done its work, and I had leisure to examine the buge body. It proved to be five feet eight inches high, and the muscular derelopment of the arms and breast showed what immense strength he had possessed."

$\mathrm{Du}$ Chaillu's account of the gorilla was at first received with incredulity by some prominent British naturalists; they could not believe that it was left for a young American to bring to light a creature so far exceeding in size and ferocity anything of the kind before known. But fortunately he had brought home with him a number of skeletons, skulls, and stuffed skins of the creatures; and among them, as it happened, was the skin of the very one whose death is described above. This skin measured about five feet eight inches as it stood stuffed. Had the lower limbs of the animal been as long in proportion to its hight as those of a man, the whole hight would have considerably exceeded six feet; while the muscular developments were enormous. If one will imagine a boxing-glove furnished with huge fingers and claws, he will get a fair idea of the paw. This collection after having been inspected by thousands in America, was shipped to London, and the impugners of Du Chaillu came to signal grief. Many of these specimens were purchased for the British Museum, where they now are. Du Chaillu, in another work,* gives some account of the gorilla at home, and in the bosom of his family:

"Now and then I could see the foot prints of gorillas that had wandered, like myself, through the woods, but these foot-prints were several days old. I came to a place where pine-apple plants were abundant, and where the gorillas had evidently feasted on the leaves, for thousands of them had been plucked out, and only the white part eaten. Here and there a young pine-apple had been partially eaten away, one or two bites taken, and the fruit then thrown aside. I had to be very careful in walking, for fear of making a noise, for the forest not being dense, gorillas could have seen me at a long distance. After awhile I came to a place where a large male gorilla had been. The foot-prints were of enormous size, and he must have been a monstrous fellow. I could see by the foot prints of the monster that he had been on all fours, and suddenly had raised himself to an erect posture ; while the bending of a branch about eight or nine feet high, just above the marks, showed that the animal had supported bimself by it. I left the place, and continued my ramble; when in the far distance I spied a gorilla. It was a female, and she did not see me. I hid myself behind a tree, and watched all her movements unseen. She was seated on the ground before a cluster of pine-apples, quietly eating one. She soon threw it away, and plucked some of the leaves. She grinned now and then, probably from the pleasure the food gave her; when suddenly, to my utter astonishment, a little gorilla, about two and a

* Wild Life under the Equator, 78. 
half feet in hight, came running to its mother, who gave a kind of chuckle that very much resembled the 'click' of the Bushmen of Southern Africa. I began to be terribly excited. I must kill the mother, and try to capture the young one. Unfortunately there were many intervening trees, and she was about a hundred yards off. How could the bullet from my rifle reach her? I had just left my place of concealment, when she perceived me. She uttered a piercing cry, and disappeared, with her young one following her."

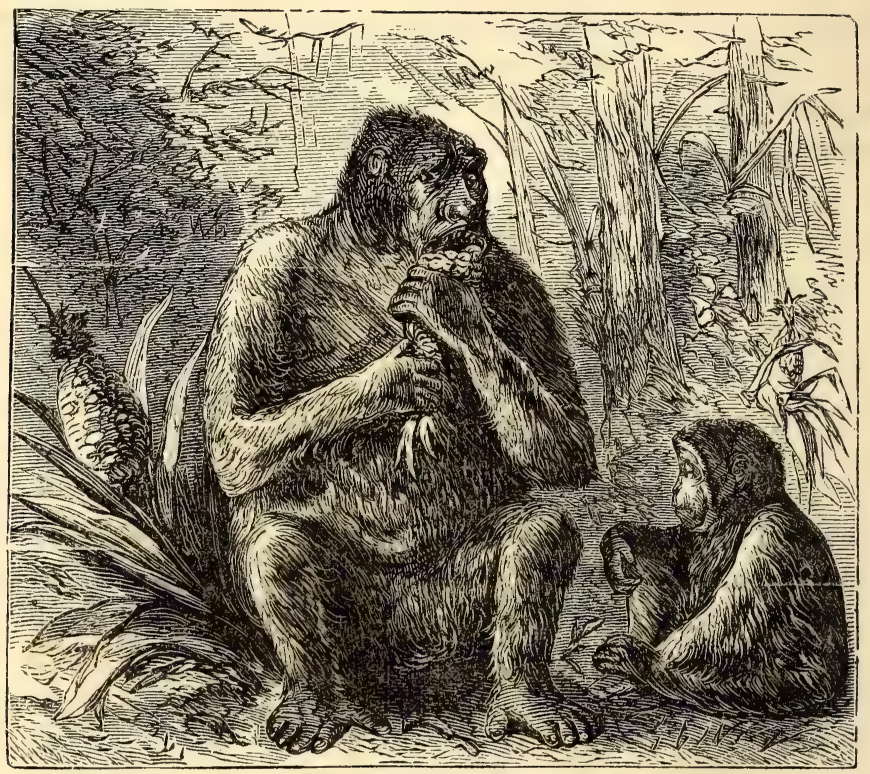

FEMALE GORILLI AND YOUNG.

$\mathrm{Du}$ Chaillu, in his various expeditions, which occupied in ail tweive years, brought away thirty-one gorilla skins and skeletons, captured more than a dozen young ones, and altogether saw more than three hundred of the animals. We give from his book last cited one more picture of the domestic life of the gorilla :

"The bog was like one of the worst kind we have in America in the overflowed and woody land of the Western country; only here were creepers, thorny bushes, hanging lianas, and grass that cuts like a razor. We entered the swamp, and came to a dry spot, when we spied a female gorilla and her young baby. The baby was very small, and a very dear little baby it was to its mother, for she appeared to look at it with great fondness. I was spell-bound, and could not raise my gun to fire; there was something too human in that mother and her offspring. It hung by her breast; but unlike our babies, who have to be entirely supported, its little hands clutched its mother's shoulder and helped to support itself. The little fellow gave a shrill and plaintive cry, and crawled from its mother's arms to her breast to be fed; and the mother lowered her head and looked at her child, while with its little fingers it pressed her breast so that the milk should come more treely. On a sudden the mother gave a tremendous ery, and before I knew it she had disappeared in the forest."

As the gorilla is wholly confined to a belt in equatorial Africa, so the great Orang: outang (Simia satyrus) or Mias, as it is called by the natives, is only found in Borneo 
and Sumatra. To Mr. Wallace we are indebted for by far the most reliable account of this great ape, which until Du Chaillu's discovery of the gorilla was supposed to be the largest of the species. We give, much abridged, portions of his account:

"I was out collecting insects, not more than a quarter of a mile from the house, when I heard a rustling in a tree near, and looking up saw a large red-haired animal moving slowly along, hanging from the branches by its arms. It passed on from tree to tree till it was lost in the jungle. About a fortnight afterward I heard that one was feeding in a tree in the swamp, and taking my gun I was fortunate enough to find it. As soon as I approached, it tried to conceal itself among the foliage; but I got a shot at it, and the second barrel caused it to fall down almost dead, the two balls having entered the body. This was a male, about half-grown, being scarcely three

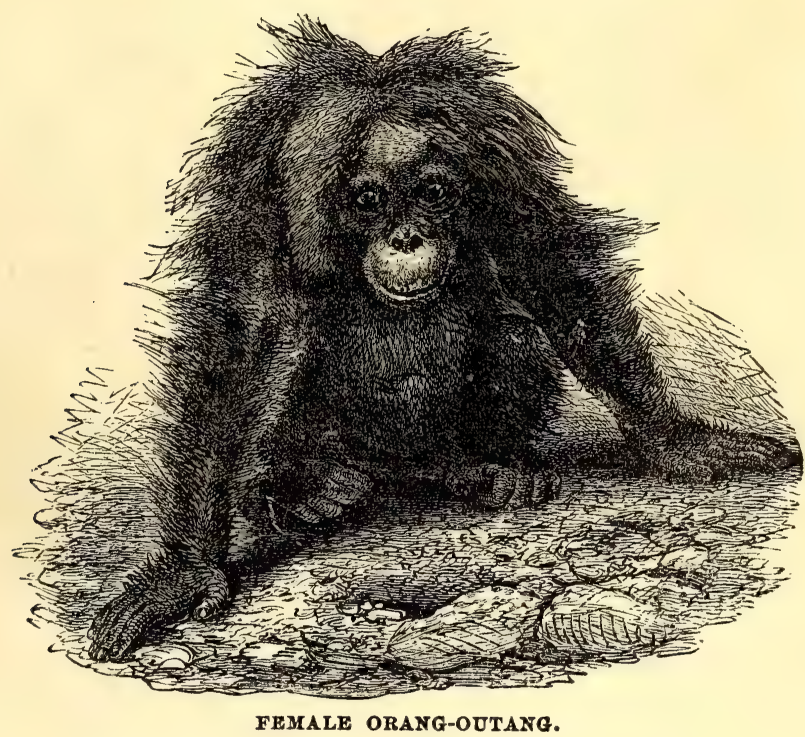

feet high. Soon after I shot another about the same size. I gave it two shots, one of which lodged in the body, the other broke its arm. Two Dyaks ran up to it, and each seized hold of a hand. But although one arm was broken, and it was only halfgrown, it was too strong for them, drawing them up towards its mouth notwithstanding all their efforts so that they were obliged to let go. It now began climbing the tree, and $I$ shot it through the heart. A week after, I fired at one on a high tree. On seeing me it began howling in a strange voice like a cough, and seemed in a great rage, breaking off branches with its hands, and throwing them down, and then made off over the tree-tops. A week after I found another, which behaved in a similar manner. I shot at it five times, and it remained dead on the top of the tree, supported in a fork, whence it was brought down by some Dyaks who climbed up for it. This was the first full-grown specimen I had obtained; but it was a female, and not nearly so large or remarkable as the full-grown males. It was, however, three feet six inches high, and its arms stretched out to a width of six feet six inches. I preserved the skin of this animal, from which the above picture, from a photograph, was taken.

"Ten days after, I succeeded in shooting a full grown male. My assistant told 
me that a great mias was feeding in the woods. Accompanied by two Dyaks, we hurried to the place. I heard a slight rustling sound overhead, but could see nothing. Then I again heard the rustling, but louder, and perceived a great red hairy body and a huge black face gazing down from a great hight, as if wanting to know what was making such a disturbance below. I fired, and he made off, so that I could not then tell whether I had hit him. We followed and I got four more shots at hin, but he was always more or less protected by a huge branch on which he was walking. Once, while loading, I had a splendid view of him, moving along the limb in a semi-erect posture, and showing him to be an animal of the largest size. At length he got to one of the loftiest trees of the forest, and we could see one leg banging down useless, having been broken by a ball. He now fixed himself in a fork, and seemed disinclined to move. I therefore fired again, when he moved off, and was obliged to get on some lower trees, on the branches of one of which he fixed himself in such a position that he could not fall, and lay all in a beap, as if dead or dying. I sent for axes, and the tree was soon cut through ; but it was so held up by jungle-ropes and climbers to the adjoining trees that it only fell in a sloping position. The mias did not move, and I began to fear that after all we should not get him, as it was near evening, and half a dozen more trees would have to be cut down before the one be was on would fall. As a last resource, we all began pulling at the creepers, which shook the tree very much, and be came down with a crash and a thud like the fall of a giant. And a giant he was, his head and body being full as large as a man's. His hight, measuring fairly from the top of the head to the heel, was four feet two inches. The body just below the arms was three feet two inches round, and was quite as long as a man's, the legs being exceedingly long in proportion. On examination we found he had been terribly wounded. Both legs were broken, one hip-joint and the root of the spine completely shattered, and two bullets were found flattened on his neck and jaws; yet he was still alive when he fell. Another individual of about the same size was afterwards twice shot, causing him to loose his hold of the branch and fall flat on his face half buried in the swamp, where he lay for some minutes groaning and panting. Suddenly he raised himself up nearly erect, and catching hold of a small tree, began to ascend it. Another shot through the back caused him to fall down dead. A flattened bullet was found in his tongue, having entered the lower part of the abdomen, and completely traversed the body, fracturing the first cervical vertebra. Yet it was after receiving this fearful wound that he had risen and began climbing with considerable facility."

These two orangs are the largest of which we have any reliable accounts; although there are doubtful stories in various books of individuals much larger-as high as five feet two inches. How easy it is to be deceived in estimating, without actual measurement, the hight of these animals, is shown in the case of a Sumatran orang, whose skin is now in the Calcutta museum. The captain and crew who killed him declared that he looked taller than the tallest man, and they supposed him to be at least seven feet high; but when he was killed and lay upon the ground, they found that he was only about six feet. The skin shows that he was really less than four feet. Mr. Wallace admits that the largest orangs are much less than the gorilla. "I have myself," he says, "examined seventeen freshly-killed orangs, all of which were carefully measured; and also obtained skeletons of two killed by others. Of these sixteen 
were adults, nine being males and seven females. The large adult males only varied from four feet one inch to four feet two inches in hight, measured fairly to the heel, so as to give the hight of the animal as if it stood perfectly erect. The extent of the outstretched arms was from seven feet two inches to seven feet eight inches; and the width of the face from ten to thirteen and a half inches. The largest orang measured by Temminck was four feet high. Of twenty-five specimens collected by Schlegel and Müller, the largest measured four feet one inch; and the largest skeleton in the Calcutta museum was four feet one and a half inch. My specimens were all from the north-west coast of Borneo, those of the Dutch from the south and.west coasts; and no specimen has yet reached Europe exceeding these dimensions, although the total number of skins and skeletons must exceed a hundred."

The orang is a formidable opponent. "One day," says Wallace, "some Dyaks saw a large orang feeding by the river side. On being alarmed be fled to the jungle, and a number of men armed with spears and choppers ran out to intercept him. The man in front tried to run his spear through the animal's body; but the orang seized it in his hinds, and in an instant got hold of the man's arm, which he seized in his mouth, making the teeth meet in the flesh above the elbow, which he tore and lacerated in a dreadful manner. Had not the others been close behind, the man must have been more seriously injured, if not killed, for he was quite powerless; but they soon destroyed the creature with their spears and choppers. The man remained ill for a long time, and never fully recovered the use of his arm. The Dyaks declare that the orang is attacked by only two creatures. One old chief, of whom I inquired, said to me, 'No animal is strong enough to hurt the mias, and the only creature he ever fights with is the crocodile. When he goes to seek food by the river, the crocodile sometimes tries to seize him ; but the mias gets upon him and beats him with his hands and feet, and tears him and kills him. I once saw such a fight, and believe that the mias is always the victor.' Another chief told me, 'The mias has no enemies; no animals dare attack it but the crocodile and the python. He always kills the crocodile by main strength, standing upon it, pulling open its jaws, and ripping up its throat. If a python attacks a mias, be seizes it with his hands, and then bites it, and soon kills it. The mias is very strong; there is no animal in the jungle so strong as he.'"

The habits of the orang, as described by Wallace are somewhat peculiar: "In making his way through the forest, he walks deliberately along some of the larger branches, in the semi-erect attitude which the great length of his arms and the shortness of his legs cause him naturally to assume; and the disproportion between these limbs is increased by his walking on his knuckles, and not on the palm of his hand, as we should do. He seems always to choose those branches which intermingle with an adjoining tree, on approaching which he stretches out his long arms, and seizing the opposing boughs grasps them together with both hands, and then deliberately swings across to the next branch, on which he walks along as before. He never jumps or springs, or appears to hurry himself, and yet manages to get along almost as fast as a person can run through the forest beneath. He makes a nest in which to sleep, by breaking off boughs and laying them across each other. The natives say that he makes a new one each night, but I think this hardly probable, or their remains would be much more abundant. The Dyaks say that when it is very wet, he covers himself 
over with large leaves or ferns, which has perhaps led to the story of his making a hut in the trees. He does not leave his bed till the sun has well risen, and has dried the dew upon the leaves. He feeds all through the middle of the day, but seidom returns to the same tree two days in succession. They do not seem much alarmed at man, as they often stared down upon me for several minutes, and then only moved away slowly to an adjoining tree. I never saw two full-grown animals together; but both males and females are sometimes accompanied by half-grown young ones, while at other times three or four young ones were seen in company. Their food consists almost wholly of fruit, with occasionally leaves, buds, and young shoots. They seem to prefer unripe fruits, some of which are very sour. others intensely bitter. In other cases they eat only the small seeds of a large fruc, and they almost always waste and destroy more than they eat. The durion* is an especial favorite, and quantities of this delicious fruit are destroyed whenever it grows surrounded by forest. but they will not cross clearings to $\mathrm{gr}^{\mathrm{r}}$, at them. It seems wonderful how the animal can tear open this fruit, the outer co' ring of which is so thick and tough, and closely covered with strong conical spines. They probably bite off a few of these at first, and then, making a small hole, tear open the fruit with their powerful fingers. The orang rarely descends to the ground except when, pressed by hunger, it seeks for succulent shoots by the river-side, or in very dry weather, has to search for water, which it generally finds in the hollows of leaves. Once only I saw two half-grown orangs on the ground in a dry hollow. They were playing together, standing erect, and grasping each other by the arms. It may be safely stated, however, that the orang never walks erect, unless when using its hands to support itself by branches overhead, or when attacked. Representations of its walking with a stick are entirely imaginary."

Mr. Wallace once caught a very young orang, not more than a foot long, which proved a very amusing pet, quite unlike a young gorilla which $\mathrm{Du}$ Chaillu attempted to tame. "While carrying it home," he says, "it got his fingers in my beard, and grasped so tightly that I had great difficulty in getting free, for the fingers are habitually bent inward at the last joint, so as to form complete hooks. I had no milk to give it, and was obliged to feed it with rice-water from a bottle with a quill in the cork, which after a few trials it learned to suck very well. When I put my finger in its mouth, it sucked with great vigor, drawing in its cheeks with all its might, and only after persevering a long time would it give up in disgust, and set up a scream, very like that of a baby in similar circumstances. When handled or nursed, it was very quiet and contented, but when laid down by itself would invariably cry. I found it necessary to wash it every day, and it soon began to like the operation, and when it was dirty would begin crying, and not leave off until I carried it to the spout, when it immediately became quiet, though it would wince a little at the first rush of the cold water, and make ridiculously wry faces while the stream was running over its head. It enjoyed the wiping and rubbing dry amazingly, and when I brushed its hair seemed to be perfectly happy. After the first week I found I could feed it better with a spoon, and gave it a little more varied and more solid food. Well-soaked biscuit, mixed with a little egg and sugar, and sometimes sweet potatoes were readily eaten. It would lick its lips, draw in its cheeks, and turn up its eyes with an expression of the most supreme satisfaction when it had a mouthful particularly to its taste;

* Concerning this fruit see ante, 557 . 
but when its food was not sufficiently sweet or palatable, it would turn the mouthful about with its tongue for a moment, as if trying to extract what flavor there was, and then push it all out between its lips. If the same food was continued, it would sot up a scream, and kick about violently exactly like a baby in a passion. After I had had the little mias about three weeks I obtained a young monkey which, though small was very active, and could feed itself. I placed it in the same box with the mias, and they soon became excellent friends, neither exhibiting the least fear of the other. The little monkey would sit upon the other's stomach, or even on its face, without the least regard for its feelings. While I was feeding the mias, the monkey would sit by: picking up all that was spilt, and as soon as I had finished would pick off what was left sticking to the mias's lips, and then pull open its mouth to see if any was left inside; afterwards lying down on the poor creature's stomach as on a comfortable cushion. The little helpless mias would submit to all these insults with the most exemplary patience, only too glad to have something warm near it, which it could clasp affectionately in its arms. After five weeks it cut its two upper front teeth; but in all this time it had not grown the least bit, remaining both in size and weight the same as when I first procured it. This was no doubt owing to the want of milk or other equally nourishing food. At length it was taken seriously ill, the symptoms being exactly those of intermittent fever, accompanied by watery swellings on the feet and head. It lost all appetite for its food, and after lingering a week, a most pitiable object, it died, having been in my possession nearly three months. I much regretted the loss of my little pet, which I had at one time looked forward to bringing up to years of maturity, and taking home to England. It had afforded me daily amusement by its curious ways and the inimitably ludicrous expression of its little countenance. Its weight was three pounds nine ounces, its hight fourteen inches, and the spread of its arms twenty-three inches."

We have dwelt at some length upon the Gorilla and the Orang-outang, because they are the largest of the monkey tribes; and because until within a few years very little has been positively known of them; and it is believed that no living specimen of either has ever been seen away from their native homes. We shall pass rapidly over a few of the most remarkable of the monkey tribes.

The series of the large anthropomorphous apes closes with the Gibbons. Their arms, which reach to the ankle joints when the animal is standing erect, are longer than those of the uran; their brain, and consequently their intelligence, is less developed; and moreover, like all the following simiæ of the Old World, they possess callosities on each side of the tail. Their size is inferior to that of the orang, and their body is covered with thicker hair, gray, brown, black, or white - according to the species - but never parti-colored, as is the case with many of the long-tailed monkeys. To the gibbons belong the black Siamang of Sumatra - who, assembled in large troops, hail the first blush of early morn, and bid farewell to the setting sun with dreadful clamors - the black, white-bearded Lar of Siam and Malacca, and the WouWou (Hylobates leuciscus) who, hanging suspended by his long arms, and swinging to and fro in the air, allows one to approach within fifty yards, and then, suddenly dropping upon a lower branch, climbs again leisurely to the top of the tree. He is a quiet, solitary creature of a melancholy peaceful nature, pursuing a harmless life, feeding apon fruits in the vast untrodden recesses of the forest; and his peculiar noise is in 
harmony with the sombre stillness of these dim regions, commencing like the gurgling of water when a bottle is being filled, and ending with a long, loud wailing cry, which resounds throughout the leafy solitude to a great distance, and is sometimes responded to from the depths of the forest by another note as wild and melancholy.

We shall see that the American monkeys are totally different from those of the Old World ; but also in the eastern hemisphere, each part of the world has its peculiar families and genera of simiæ. Thus, besides the orang outang and the gibbon, Asia exclusively possesses the semnopitheci and the macaques, while Africa, besides the chimpanzee and the gorilla, enjoys the undivided honor of giving birth to the families of the cercopitheci, mangabeys, colobi, magots, and baboons. The Semnopitheci are characterized by a short face, rounded ears, a slender body, short thumbs, and a strong muscular tail, terminated by a close tuft of hair, and surpassing in length that of all the other quadrumana of the Old World. To this genus belongs the celebrated Prohoscis Monkey (Semnopithecus nasicus) of Borneo, who is distinguished from all other simiæ by the possession of a prominent nasal organ, which lends a highly ludicrous expression to the melancholy aspect of his physiognomy. When excited and angry, the female resembles some tanned and peevish hag, snarling and shrewish. When they sleep, they squat on their hams, and bow their heads upon the breast. When disturbed, they utter a short impatient cry, between a sneeze and a scream, like that of a spoilt and passionate child. When they emit their peculiar wheezing or hissing sound, they avert and wrinkle the nose, and open the mouth wide. In the male, the nose is a curved, tubular trunk, large, pendulous, and fleshy; but in the female it is smaller, recurved, and not flesh-like.

Under the ugly form of the Huniman (Semnopithecus entellus), the Hindoos venerate the transformed hero who abstracted the sweet fruit of the mango from the garden of a giant in Ceylon, and enriched India with the costly gift. As a punishment for this offense he was condemned to the stake, and ever since his hands and face have remained black. Out of gratitude for his past services, the Hindoos allow him the free use of their gardens, and take great care to protect him from sacrilegious Europeans. While the French naturalist Duvaucel was at Chandernagore, a guard of pious Brahmins was busy scaring away the sacred animals with cymbals and drums, lest the stranger, to whom they very justly attributed evil intentions, might be tempted to add their skins to his collection.

The semnopitheci are scattered over Asia in so great a multiplicity of forms, that Ceylon alone possesses four different species, each of which has appropriated to itself a different district of the wooded country, and seldom encroaches on the domain of its neighbors. When observed in their native wilds, a party of twenty or thirty of the Wanderoos of the low country, the species best known in Europe (Presbytes cephalop terus), is generally busily engaged in the search for berries and buds. They are seldom to be seen on the ground, and then only when they have descended to recover seeds or fruit that have fallen at the foot of their favorite trees. In their alarm, when disturbed, their leaps are prodigious, but generally speaking their progress is made not so much by leaping as by swinging from branch to branch, using their powerful arms alternately, and when baffled by distance, flinging themselves obliquely so as to catch the lower bough of an opposite tree; the momentum acquired by their descent being sufficient to cause a rebound, that carries them again upwards till they can grasp 
a higher branch, and thus continue their headlong flight. 'In these perilous achievements wonder is excited less by the surpassing agility of these little creatures, frequently encumbered as they are by their young, which cling to them in their career, than by the quickness of their eye and the unerring accuracy with which they seem to calculate almost the angle at which a descent would enable them to cover a given distance, and the recoil to elevate themselves again to a higher altitude. The African Colobi greatly resemble the Asiatic Semnopitheci, but differ by the remarkable circumstance of having no thumb on the hands of their anterior extremities. The Cercopitheci likewise possess a large tail, which is, however, not more or less pendulous, as in the semnopitheci, but generally carried erect over the back. They have also a longer face, and their cheeks are furnished with pouches, in which, like the pelican or the hamster, they are capable of stowing part of their food.

The tribes of the mangabeys, macaques, magots, and cynopitheci form the links between the cercopitheci and the baboons. Their shape is less slender than that of the former, their frontal bone is more developed, particularly above the eye-brows, and their face is longer. They are all of them provided with cheek-pouches. Several of the macaques have a very short tail, and the magots, or Barbary apes, and the cynopithecus of the Philippine Islands, have none, thus resembling the large anthropomorphous apes, but widely differing from them in other respects. The Magot is the only European species, and seems exclusively confined in that part of the world to the rock of Gibraltar, though some authors affirm that it is found in other parts of Andalusia, and even in the province of Grenada.

The Cynocephali (Baboons and-Mandrills) show at once by their Greek name that a dog-like snout gives them a more bestial expression than belongs to the rest of the monkey tribes, and that of all the simiæ of the Old World they are most widely distant from man. In size they are only surpassed by the gorilla and the orang; and if in the latter the physiognomy becomes more brutal in its expression with advancing age, this degradation is much greater in the baboons. Their canine teeth in particular acquire a greater sharpness than those of almost every other carnivorous animal, so that these malignant and cruel animals, armed with such powerful weapons, may well be reckoned among the most formidable of the wild beasts of Africa. As if to render them complete pictures of depravity, their manners also are so shamelessly filthy that the curiosity they excite soon changes into horror and disgust.

The short-tailed mandrills inhabit the west coast of Africa. The Maimon is the most remarkable of the whole genus for brilliancy and variety of color ; its furrowed cheeks are magnificently striped with violet, blue, purple, and scarlet, so as more to resemble an artificial tattooing than a natural carnation. As the creature increases in age, the nose also becomes blood-red. On the loins the skin is almost bare, and of a violet-blue color, gradually altering into a bright blood-red, which is more conspicuous on the hinder parts, where it surrounds the tail, which is generally carried erect.

The real baboons are distinguished from the mandrills by a long tail, terminated by a tuft of hair. The great baboon of Senegal (Cynocephalus sphinx) is by no means devoid of intelligence, and learns many tricks when taught from early youth. His temper, however, is brutal and choleric, though less so than that of the Chacma (Cynocephalus porcarius), or pig-faced baboon, which is found in the vicinity of Cape Town, amung others on the celebrated Table Mountain. It frequently commits great devasta. 
tions in the fields. Young chacmas are often kept as domestic animals, performing the offices of a mastiff, whom they greatly surpass in strength. Thus they immediately announce by their growling the approach of a stranger, and are even employed for a variety of useful purposes which no dog would be able to perform. Here one is trained to blow the bellows of a smith; there another to guide a team of oxen. When a stream is to be crossed, the chacma immediately jumps upon the back of one of the oxen, and remains sitting till he has no longer to fear the wet, which he loves as little as the cat.

In Abyssinia, Nubia, and South Arabia we find the Derryas (C. hamadryas), which enjoyed divine honors among the ancient Egyptians. The general color of the hair is a mixture of light-gray and cinnamon, and in the male that of the head and neck forms a long mane, falling back over the shoulders. The face is extremely long, naked, and of a dirty flesh-color. This ugly monkey was revered as the symbol of Thoth, the divine father of literature and the judge of man after death. Formerly temples were erected to his honor, and numerous priests ministered to his wants; but now, by a sad change of baboon fortune, he is shot without ceremony, and his skin pulled over his ears to be stuffed and exhibited in profane museums.

In the forests of tropical Africa and Asia we find a remarkable group of animals, which, though quadrumanous like the monkeys, essentially differs from them by possessing long curved claws on the index, or also on the middle finger of the hinder extremities; by a sharp, projecting muzzle, and by a different dentition. The Loris, remarkable for the slowness of their gait and their large glaring eyes, are exclusively natives of the East Indies; the Galagos, which unite the organization of the monkeys with the graceful sprightliness of the squirrels, are solely confined to Africa, where they are chiefly found in the gum-forests of Senegal ; the Tarsii, thus named from their elongated tarsii, giving to their hinder limbs a disproportionate length, are restricted to part of the Indian archipelago ; but the large island of Madagascar, where, strange to say, not a single monkey is found, is the chief seat of the family, being the exclusive dwelling place of the short-tailed Indri, (whom, from his black, thick fur and anthropomorphous shape, one would be inclined to reckon among the gibbons), and of the long-tailed Lemurs or Makis. All these gentle and harmless animals are arboreal in their habits, avoid the glaring light of day under the dense covert of the forest, and awaken to a more active existence as soon as night descends upon the earth. Then the loris, who during the day have slept clinging to a branch, prowl among the forest boughs in quest of food. Nothing can escape the scrutiny of their large, glaring eyes; and when they have marked their victim, they cautiously and noiselessly approach till it is within their grasp. The Galagos have at night all the activity of birds, hopping from bough to bough on their hind limbs only. They watch the insects flitting among the leaves, listen to the fluttering of the moth as it darts through the air, lie in wait for it, and spring with the rapidity of an arrow, seldom missing their prize, which is eaught by the hands. They make nests in the branches of trees, and cover a bed with grass and leaves for their little ones. The tarsii leap about two feet at a spring, and feed chiefly on lizards, holding their prey in their fore-hands, while they rest on their haunches.

The monkeys of the New World differ still more widely from those of the Old than the copper-colored Indian from the woolly negro. One sees at once on comparing 
them that whole oceans roll between them, that they have not migrated from one hemisphere to another, but belong to two different phases of creation. While the nasal partition of the Old World simiæ is narrow as in man, it is broad without exception in all the American monkeys, so that the nostrils are widely separated and open sideways. The dental apparatus is also different, for while the monkeys of the eastern hemisphere have thirty-two teeth, those of the western world generally possess thirty. six. The tailless monkeys or apes, and the short-tailed baboons, with a dog-like projecting snout and formidable fangs, are peculiar to the eastern hemisphere, and it is only there that we find almost voiceless simiæ, while the American quadrumana are all of them tailed, short-snouted, and generally endowed with stentorian powers. Finally, it would be as useless to look among the western monkeys for cheek-pouches and sessile callosities, as among those of the Old World for prehensile tails.

In the boundless forests of tropical South America, the monkeys form by far the greater part of the mammalian inhabitants, for each species, though often confined within narrow limits, generally consists of a large number of individuals. The various arboreal fruits which the savage population of these immeasurable wilds is unable to turn to advantage, fall chiefly to their share; many of them also live upon insects. They are never seen in the open campos and savannas, as they never touch the ground unless compelled by the greatest necessity. The trees of the forest furnish them with all the food they require in inexhaustible abundance. For their perpetual wanderings from branch to branch, nature has bountifully endowed many of them not only with robust and muscular limbs, and large hands, whose moist palms facilitate the seizure of a bough, but in many cases also with a prehensile tail, which may deservedly be called a fifth hand, and is hardly less wonderful in its structure than the proboscis of the elephant. Covered with short hair, and completely bare underneath towards the end, this admirable organ rolls round the boughs as though it were a supple finger, and is at the same time so muscular, that the monkey frequently swings with it from a branch like the pendulum of a clock.

Scarce has he grasped a bough with his long arms, when immediately coiling his fifth hand round the branch, he springs on to the next, and secure from a fall, hurries so rapidly through the crowns of the highest trees that the sportsman's ball has scarce time to reach him in his flight. When the Miriki (Ateles hypoxanthus), the largest of the Brazilian monkeys, sitting or stretched out at full length, suns himself on a high branch, his tail suffices to support him in his aerial resting-place, and even when mortally wounded, he remains a long time suspended by it, until life being quite extinct, his heavy body, whizzing through the air, and breaking many a bough as it descends, falls with a loud crash to the ground. The famous wourali poison is alone capable of instantly annihilating his muscular powers, and of sparing the wounded animal a long and painful agony. Slow and with noiseless step, so as scarcely to disturb the fallen leaves beneath his feet, the wily Indian approaches. His weapons are strange and peculiar, and of so slight an appearance as to form a wondrous contrast to their terrific power. A colossal species of bamboo (Arundinaria Schomburgkii), whose perfectly cylindrical culm often rises to the hight of fifteen feet from the root before it forms its first knot, furnishes him with his blow-pipe, and the slender arrows which he sends forth with unerring certainty of aim are made of the leaf-stalks of a species of palm tree (Maximiliana regia), hard and brittle, and sharp-pointed as a 
needle. One would hardly suppose these fragile missiles capable of inflicting the slightest wound at any distance, and yet they strike more surely and effectually than the rifleman's bullet, for their point is dipped in the deadly juice of the Strychnos Urari, whose venomous powers are not inferior to those of the dreaded bushmaster or the fatal cobra.

The savage tribes of the South American woods know how to poison their arrows with the juices of various plants, but none equals this in virulence and certainty of execution, and yearly the Indians of the Orinoco, the Rio Negro, and even of the Amazon, wander to the Camuku Mountains to purchase by barter the renowned Urari or Wourali poison of the Macusis. How they made the discovery of its powers is unknown; at all events the combination of so many means for the attainment of the end in view - the preparation of the poison, the blow-pipe, the arrows - denotes a high degree of ingenuity, and shows at once the infinite superiority of the savage over the monkey. In a less concentrated" or diluted form the wourali poison merely benumbs or stuns the faculties without killing, and is thus made use of by the Indians when they wish to catch an old monkey alive and tame him for sale. On his falling to the ground they immediately suck the wound, and wrapping him up in a straightjacket of palm leaves, dose him for a few days with sugar-cane juice, or a strong solution of saltpetre. This method generally answers the purpose, but should his stubborn temper not yet be subdued, they hang him up in smoke. Then after a short time his rage gives way, and his wild eye, assuming a plaintive expression, humbly sues for deliverance. His bonds are now loosened, and even the most unmanageable monkey seems henceforward totally to forget that he ever roamed at liberty in the boundless woods.

In general, however, the American simiæ are distinguished by a much milder disposition than those of the eastern hemisphere, and retain at an advanced age the playful manners of their youth. They are commonly more easy to tame, and learn many little tricks which are taught with much greater difficulty to their restless Asiatic or African cousins. Their weakness, their short canine teeth, their good temper, render them harmless play-fellows, and thus they are generally preferred in Europe to the Old World monkeys, though they are not so lively, and constantly have a more or less dejected mien, as if they still regretted the primitive freedom of the forest.

The American monkeys may be conveniently divided into two large groups; with or without a prehensile tail. To the first great subdivision belong the Howling Monkeys or Aluates (Mycetes), the Spider Monkeys (Ateles), the Sajous, and several other intermediate genera.

The Aluates are chiefly remarkable for their stentorian powers, which no other animal can equal or approach. When the nocturnal howl of the large red Aluate (Mycetes ursinus) bursts forth from the woods, you would suppose that all the beasts of the forest were collecting for the work of carnage. Now it is the tremendous roar of the jaguar as he springs on his prey; now it changes to his terrible and deep-toned growlings as he is pressed on all sides by superior force; and now you hear his last dying moan, beneath a mortal wound. Some naturalists have supposed that these awful sounds can only proceed from a number of the red monkeys howling in concert, but one of them alone is equal to the task. In dark and cloudy weather, and just before a squall of rain, the aluate often howls in the day-time; and on advancing 
cautiously to the high and tufted tree where he is sitting, one may then have a wonderful opportunity of seeing the large lump in his throat, the sounding-board which gives such volume to his voice, move up and down as he exerts his stentorian lungs. Poppig compares the howling of the aluate to the noise of ungreased cart wheels, but very much stronger, and affirms that it may be heard at the distance of a league.

Like the African Colobi, the Ateles, or Spider Monkeys, have no thumb on their fore-hands; their voice is a soft and flute-like whistling, resembling the piping of a bird. It is said that when a mother burthened with her young hesitates to take too wide a leap, paterfamilias seizes the branch she intends to reach, and swings himself to and fro with it, until his companion is able to attain it by a spring. But when a young monkey that is already sufficiently strong is fearful, the mother, to give him courage, repeats the manœuvre several times before him. The spider monkeys live in more or less numerous troops, and chiefly subsist on insects, though when near the sea they will also come down upon the beach and feed on mollusks, particularly on oysters, whose shells they are said to crack with a stone.

The second group' of American monkeys, consisting of those with a non-prehensile tail, comprises the sakis, the saimiris, the ouistitis, etc. The Sakis, or Fox-tailed Monkeys, are distinguished by their bushy tail, which, however, in some species, is very short. They usually live in the outskirts of forests, in small societies of ten or twelve. Upon the slightest provocation, they display a morose and savage temper, and, like the howling monkeys, utter loud cries before sunrise and after sunset.

The elegant ease of their movements, their soft fur, the large size of their brilliant eyes, and their little round face, entitle the Saimiris to be called the most graceful of monkeys. Humboldt, who frequently observed them in tropical America, tells us that they are extremely affectionate, and that when offended, their eyes immediately swim in tears. On speaking to them for some time, they listen with great attention, and soon lay their tiny hand upon the speaker's mouth, as if to catch the words as they pass through his lips. They recognize the objects represented in an engraving even when not colored, and endeavored to seize the pictured fruits or insects. The latter, and particularly spiders, which they catch most dexterously with their lips or hands, seem to be their favorite food. The weak little creatures are very fond of being carried about by larger monkeys, and cling fast to their back. At first the animal to which they thus attach themselves endeavors to get rid of its burden; but finding it impossible, it soon becomes reconciled to its fate, and after a short time an intimate affection arises between them, so that when the saimiri is busy chasing insects, his friend, before leaving the spot, first gives him notice by a gentle cry. A similar dependent and affectionate intercourse is not rare among other species of monkeys.

The habits of the Nyctopitheci, or nocturnal monkeys, bear a great resemblance to those of the bats or flying foxes. The shy and quiet little animals sleep by day concealed in the dense thickets of the forest. Their eye and motions are completely feline. Those which Von Martius observed in his collection, crept by day into a corner of the cage, but after sunset their agility made up for their diurnal torpor.

In Guiana, Schomburgk met with the Nyctipithecus trivirgatus as a domestic animal. "A very neat little monkey, shy of light as the owl or the bat. A small round head, extremely large yellow eyes, shining in the dark stronger than those of the cat, and tiny short ears, give it a peculiarly comical appearance. When disturbed 
in its diurnal sleep and dragged forth to the light, its helpless movements excite compassion; it gropes about as if blind, and lays hold of the first object that comes within its reach, often pressing its face against it to escape the intolerable glare. The darkest corner of the hut is its seat of predilection, where it lies during day in a perfect asphyxia, from which it can only be roused by blows. But soon after sunset it leaves its retreat, and then it is impossible to see a more lively, active, and merry creature. From hammock it springs to hammock, generally licking the faces of the sleepers, and from the floor to the rafters of the roof, overturning all that is not sufficiently fastened to resist its curiosity." Its voice is remarkably strong, and, according to Humboldt, is said to resemble the jaguar's roar, for which reason it is called the Tiger Monkey in the missions along the Orinoco. It lives chiefly on nocturnal insects, thinning their ranks like the bat, but is also said to prey upon small birds like the owl.

The Ouistitis, or Squirrel Monkeys, are distinguished from all the other American quadrumana by the claws with which all their fingers except the thumbs of their hands are provided, and which render them excellent service in climbing. They have a very soft fur, and are extremely light and graceful in their movements, as well as elegant in their forms. The young are often not bigger than a mouse, and even a full-grown ouistiti is hardly larger than a squirrel, whom it resembles both in its mode of life, and by its restless activity, as its little head is never quiet. They use their tail, which in many species is handsomely marked by transverse bars, as a protection against the cold, to which they are acutely sensitive. Their numerous species are dispersed over all the forests of tropical America, where they live as well upon fruits and nuts as upon insects and eggs; and when they can catch a little bird, they suck its brain with all the satisfaction of an epicure. They are easily tamed, but very suspicious and irritable. Audouin made some interesting observations on a pair of tame ouistitis, which prove their intelligence to be far superior to that of the squirrels, to whom they are so often compared. One of them having one day, while regaling on a bunch of grapes, squirted some of the juice into its eye, never failed from that time to close its eyes while eating of the fruit. In a drawing they recognized not only their own likeness, but that of other animals. Thus the sight of a cat, and what is still more remarkable, that of a wasp, frightened them very much, while at the aspect of any other insect, such as a cricket or a cockchafer, they at once rushed upon the engraving, as if anxious to make a meal of the object that deluded them with the semblance of life. 


\section{CHAPTER XIV.}

\section{TROPICAL BEASTS AND BIRDS OF PREY.}

Variety of Carnivorous Creatures.-Birds of Prey: The Condor-His Marvelous Flight-His Cowardice-Modes of Capturing them-The Turkey-Buzzard, or Carrion Vulture-The King of the Vultures-The Urubu-Capable of Domestication-The Harpy EagleThe Sociable Vulture-The Bacha-The Fishing Eagle-The Musical Sparrow-HawkThe Secretary Eagle.-Beasts of Prey: The Lion-Fictitious Character ascribed to him -Mode of Seizing his Prey-Lions and Giraffe-Lion and Hottentot-Andersson and a Lion-Livingstone's narrow Escape-Lion-Hunting in the Atlas-By the Bushmen-Capturing their Young-Former and present Range of the Lion-Lion and RhinocerosLivingstone's Estimate of the Lion-The Tiger-Their Ravages in Java-Wide Range of the Tiger-Tiger-Hunting in India-Escape from a Tiger-Animals announcing the Approach of a Tiger-Turtle-hunting Tigers-The Panther and Leopard-The CheetahThe Hyena-The Spotted and Brown Hyenas-The Felidæ of New World-The Jaguar -Hunting the Jaguar-The Cougar, or Puma-The Ocelot-The Jaguarandi-The Tiger-Cat.

A LMOST all birds and a considerable proportion of animals are carnivorous, and notwithstanding their differences in size, may be strictly designated as Birds and Beasts of Prey. The fox and weasel are as strictly beasts of prey as the lion and the tiger ; the sparrow and robin, although seeds and fruit form part of their food, are as truly birds of prey as the eagle and the vulture. A sparrow will, indeed, in the course. of a single day, probably destroy more individual living creatures than an eagle will in his whole life-time; a fox in a year more than a lion in the half century which he is supposed to live. We shall here, however, confine ourselves wholly to the larger species of birds and beasts of prey, commencing with the former.

The flight of the Condor is truly wonderful. From the mountain-plains of the Andes, the royal bird, soaring aloft, appears only like a small black speck on the sky, and a few hours afterwards he descends to the coast and mixes his loud screech with the roar of the surf. No living creature rises voluntarily so high, none traverses in so short a time all the climates of the globe. He rests at night in the crevices of the rocks, or on some jutting ledge; but as soon as the first rays of the sun light the summits of the mountains, while the darkness of night still rests upon the deeper valleys, he stretches forth his neck, shakes his head as if fully to rouse himself, stoops over the brink of the abyss, and flapping his wings, dives into the aerial ocean. At first his flight is by no means strong; he sinks as if borne down by his weight, but soon he ascends, and sweeps through the rarified atmosphere without any perceptible vibratory motion of the wings. "Near Lima," says Mr. Darwin, "I watched several condors for nearly half an hour without once taking off my eyes. They moved in large curves, sweeping in circles, descending and ascending without once flapping. 
As they glided close over my head, I intently watched from an oblique position the outlines of the separate and terminal feathers of the wing; if there had been the least vibratory movement these would have blended together, but they were seen distinct against the blue sky. The head and neck were moved frequently and apparently with force, and it appeared that the extended wings formed the fulcrum on which the movements of the neck, body, and tail acted. If the bird wished to descend, the wings were for a moment collapsed, and then, when again expanded with an altered inclination, the momentum gained by the rapid descent seemed to urge the bird upwards with the even and steady movement of a paper kite."

According to Humboldt and D'Orbigny, the condor is a contemptible coward, whom the stick of a child is able to put to flight. Far from venturing to attack any fullgrown, larger animal-the llama, the ox, or even man, as former travelers assertedhe feeds, like other vultures, only upon dead carcasses, or on new-born lambs and calves, whom he tears from the side of their mothers. He thus does so much damage to the herds, that the shepherds pursue and kill him whenever they can. As even a bullet frequently glances off from his thick feathery coat, the natives never use firearms for his destruction, but make use of various traps, of the sling, or of the bolas, which they are able to throw with such marvelous dexterity. In the Peruvian province of Abacay, an Indian provided with cords conceals himself under a fresh cow's skin, to which some pieces of flesh are left attached. The condors soon pounce upon the prey, but while they are feasting he fastens their legs to the skin. This being accomplished, he suddenly comes forth, and the alarmed birds vainly flap their wings, for other Indians hurry towards them, throw their mantles or their lassos over them, and carry the condors to their village, where they are reserved for the next bull-fight. For a full week before this spectacle is to take place, the bird gets nothing to eat, and is then bound upon the back of a bull which has previously been scarified with lances. The bellowing of the poor animal, lacerated by the famished vulture, and vainly endeavoring to cast off its tormentor, amuses what may well be called the "swinish multitude." In the province of Huarochirin there is a large natural funnel-shaped excavation, about sixty feet deep, with a diameter of about eighty feet at the top. A dead mule is placed on the brink of the precipice. The tugging of the condors at the dead carcass causes it to fall into the hole; they follow it with greedy haste, and having gorged themselves with food, are unable again to rise from the narrow bottom of the funnel. Tschudi saw the Indians kill at once, with sticks, twenty-eight of the birds which had been thus entrapped. In a somewhat similar manner condors are caught in Peru, Bolivia, and Chili, as far as their range extends, and are frequently brought to Valparaiso and Callao, where they are sold for a few dollars to the foreign ships, and thence conveyed to Europe.

The condor, though a very large bird, about four feet long, and measuring at least three yards from tip to tip of his extended wings, is far from attaining the dimensions assigned to him by the earlier writers and naturalists, who, emulating Sindbad the Sailor, in his account of the roc, described him as a giant whose bulk darkened the air. Fortunately the works of nature do not require the exaggerations of fiction to be rendered interesting, and the marvels of organic nature which scientific inquiries reveal are far more wonderful than any which romancers may invent.

While the condor is considered an enemy to man, the Gallinazos, Turkey-buzzards, 
or common American Carrion Vultures (Vultur aura, $V$. urubu), are very serviceable to him, by consuming the animal offals which, if left to putrefaction, would produce a pestilence. Thus they generally, in tropical America, enjoy the protection of the law, a heary fine, amounting in some towns to $\$ 300$, being imposed upon the offender who wantonly kills one of these scavengers. It is consequently not to be wondered at that, like domestic birds, they congregate in flocks in the streets of Lima, and sleep upon the roofs of the houses. In 1808, Waterton saw the vultures in Angostura as tame as barn-fowls; a person who had never seen one would have taken them for turkeys. They were very useful to the citizens; bad it not been for them, the refuse of the slaughter-houses would have caused an intolerable nuisance. The Aura is darkbrown black, with a red and naked head and neck, covered with wrinkles and warts; the Urubu is very similar, only the head and neck are gray-black, but equally wrinkled and ugly. The latter ranges over South America in countless numbers, as D'Orbigny witnessed on a visit to a hacienda on the river Plata, where 12,000 oxen had been killed for salting. During this wholesale massacre, which lasted several months, the bones and entrails were cast along the banks of the stream, where at least 10,000 urubus had congregated to enjoy the banquet. It is a remarkable fact that, though hundreds of gallinazos may be feeding upon a carcase, they immediately retire when the King of the Vultures (Sarcoramphus papa) makes his appearance, who yet is not larger than themselves. Perching on the neighboring trees, they wait till his majesty - a beautiful bird, with head and neck gaudily colored with scarlet, orange, blue, brown and white-has sufficiently gorged himself, and then pounce down with increased voracity upon their disgusting meal. According to Humboldt, they are intimidated by the greater boldness of the sarcoramphus. The true reason of their homage, however, seems to be the fear they entertain for the more powerful beak of the "king," who, from a similar motive, gives way to the still mightier condor.

The Indians of Guiana sometimes amuse themselves with catching one of the urubus by means of a piece of meat attached to a hook, and decking him with a variety of strange feathers, which they attach to him with soft wax. Thus travestied, they turn him out again among his comrades, who, to their great delight, fly in terror from the nondescript; and it is only after wind and weather have stripped him of his finery that the outlaw is once more admitted into urubu society. When full of food this vulture, like the other members of his tribe, certainly appears an indolent bird. He will stand for hours together on the branch of a tree, or on the top of a house, with his wings drooping, or after rain, spreading them to catch the rays of the sun. But when in quest of prey, he may be seen soaring aloft on pinions which never flutter, and which at the same time carry him with a rapidity equal to that of the golden eagle. Scarcely has he espied a piece of carrion below, when, folding his broad wings, he descends with such speed as to produce a whistling sound, resembling that of an arrow cleaving the air.

The gallinazos when taken young can be so easily tamed that they will follow the person who feeds them for many miles. Relying on their inviolability, the gallinazos, like chartered libertines, are uncommonly bold, and during the distributions of meat to the Indians, which regularly take place every fortnight in the South American Missions, they not seldom come in for their share by dint of impudence. In Concepcion de Mojos, an Indian told M. D'Orbigny, who was present on one of those occasions, 
that he would soon have the opportunity of seeing a most notorious thief, well known by his lame leg; and the bird, making his appearance soon after, completely justified his reputation. The traveler was also informed that this urubu knew perfectly well the days of distribution in the different missions; and eight days later, while witnessing a similar scene at Magdalena, twenty leagues distant, he heard the Indians exclaim, and looking up saw his lame acquaintance of Concepcion hurrying to the spot, with the anxious mien of one that is afraid of missing a meal. The padres in both missions assured him that the vulture never failed to make his appearance at the stated time; a remarkable instance of memory, or highly developed instinct in a bird. "If you dissect a vulture," says Waterton, "that has just been feeding on carrion, you must expect that your olfactory nerves will be somewhat offended with the rank effluvia from his craw, just as they would be were you to dissect a citizen after the lord-mayor's dinner. If, on the contrary, the vulture be empty at the time you commence the operation, there will be no offensive smell, but a strong scent of musk."

The Harpy Eagle (Thrasaëtus harpyia) is one of the finest of all the rapacious birds. The enormous development of his beak and legs, and his consequent strength and power in mastering his prey, correspond with his bold and noble bearing, and the fierce lustre of his eye. His whole aspect is that of formidably organized power, and even the crest adds much to his terrific appearance. "Among many singular birds and curiosities," says Mr. Edwards, in his "Voyage up the Amazon," "that were brought to us, was a young harpy eagle, a most ferocious looking character, with a harpy's crest and a beak and talons in correspondence. He was turned loose into the garden, and before long gave us a sample of his powers. With erected crest and flashing eyes, uttering a frightful shriek, he pounced upon a young ibis, and quicker than thought had torn his reeking liver from his body. The whole animal world there was wild with fear."

The harpy attains a greater size than the common eagle. He chiefly resides in the damp lowlands of tropical America, where Prince Maximilian of Neu Wied met with him only in the dense forests, perched on the high branches. The monkey, vaulting by means of his tail from tree to tree, mocks the pursuit of the tiger-cat and boa, but woe to him if the harpy spies him out, for, seizing him with lightning-like rapidity, he cleaves his skull with one single stroke of his beak. Fear seems to be totally unknown to this noble bird, and he defends himself to the last moment. D'Orbigny relates that one day, while descending a Bolivian river in a boat with some Indians, they severely wounded a harpy with their arrows, so that it fell from the branch on which it had been struck. Stepping out of the canoe, the savages now rushed to the spot where the bird lay, knocked it on the head, and tearing out the feathers of its wings, brought it for dead to the boat. Yet the harpy awakened from his trance, and furiously attacked his persecutors. Throwing himself upon D'Orbigny, he pierced his hand through and through with the only talon that had been left unhurt, while the mangled remains of the other tore his arm, which at the same time he lacerated with his beak. Two men were hardly able to release the naturalist from the attacks of the ferocious bird.

On turning from the New to the Old World, we find other but not less interesting predatory birds sweep through the higher regions of the air in quest of prey. The gigantic oricou, or Sociable Vulture (Vultur auricularis), inhabits the greater part of 
Africa, and builds his nest in the fissures of rocks on the peaks of inaccessible mountains. In size he equals the condor, measuring upwards of ten feet across the wings expanded, and his flight is not less bold; leaving his lofty cavern at dawn, he rises higher and higher, till he is lost to sight; but, though beyond the sphere of human vision, the telescopic eye of the bird is at work. The moment any animal sinks to the earth in death, the unseen vulture detects it. Does the hunter bring down some large quadruped beyond his powers to remove, and leave it to obtain assistance?-on his return, however speedy, he finds it surrounded by a band of vultures, where not one was to be seen a quarter of an hour before. Le Vaillant having once killed three zebras, hastened to his camp, at about a league's distance, to fetch a wagon; but on returning he found nothing but the bones, at which hundreds of oricous were busy picking. Another time having killed a gazelle, he left the carcase on the sand, and retired into the bushes to observe what would happen. First came crows, who with loud croakings wheeled round the dead animal ; then, after a few minutes, kites and buzzards appeared, and finally he saw the oricous descending in spiral lines from an enormous hight. They alighted upon the gazelle, and soon hundreds of birds of prey were assembled. Thus the small robbers had first pointed out the way to those of middle size, who in their turn roused the attention of the bandits of a higher order ; and none of them came too short, for after the powerful oricous had dismembered the carcase, some very good morsels remained for the buzzards, and the bones furnished excellent pickings for the crows.

The Bacha (Falco bacha) inhabits India and Africa, where he sits for days on the peak of precipitous cliffs, on the look out for rock-rabbits (Hyrax capensis). These poor animals, who have good reason to be on their guard, venture only with the greatest caution to peep out of their caves and crevices in which they take up their abode, and to which they owe their Dutch name of "klipdachs." Meanwhile the bacha remains immovable, as if he were part of the rock on which he perches, his head muffled up in his shoulders, but watching with a sharp eye every movement of his prey, until, finally, some unfortunate klipdachs venturing forth, he darts upon him like a thunderbolt. If this rapid attack proves unsuccessful, the bacha slinks away, ashamed, like a lion that has missed his spring, and seeks some new observatory, for he is well aware that no rock-rabbit in the neighborhood will venture to stroll out during the remainder of the day. But if he succeeds in seizing the klipdachs before it has time to leap away, he carries it to a rocky ledge, and slowly tears it to pieces. The terrible cries of the animal appear to sound like music in his ears, as if he were not only satisfying his hunger but rejoicing in the torments of an enemy. This scene of cruelty spreads terror far and wide, and for a long time no klipdachs will be seen where the bacha has keld his bloody repast.

The Fishing Eagle of Africa (Haliatus vocifer), first noticed by Le Vaillant, may be seen hovering about the coasts and river-mouths of that vast continent. He is never found in the interior of the country, as the African streams are but thinly stocked with fish, which form his principal food. Elastic and buoyant, this agile dweller in the air mounts to soaring heights, scanning with sharp and piercing eye the motions of his prey below. Energetic in his movements, impetuous in his appetites, he pounces with the velocity of a meteor on the object of his wishes, and with a wild and savage joy tears it to pieces. His whole sense of existence is the procuring of food, and for 
this he is ever on the alert, ever ready to combat, to ravage, and destroy. He generally devours his prey on the nearest rock, and loves to return to the same spot where the bones of gazelles and lizards may be seen lying about, a proof that his appetite is not solely confined to the finny tribes. When these birds are sitting, they call and answer each other with a variously-toned shriek, which they utter under curious movements of the head and neck.

While all other predatory birds croak or shriek, the musical Sparrow-Hawk of Africa (Melierca musicus) pours forth his morning and evening notes to entertain his mate while she is performing the duties of incubation. Every song lasts a minute, and then the hunter may approach, but during the pause he is obliged to remain perfectly quiet, as then the bird hears the least noise and immediately flies away.

The prowess of the Secretary-eagle (Serpentarius cristatus) attacking the most venomous serpents has already been mentioned in the chapter on those noxious reptiles. The long legs of this useful bird, which owes its name of "Secretary" to the crest on the back of its head, reminding one of the pen stuck behind the ear, according to the custom of writing clerks, might give one reason to reckon it, at first sight, among the cranes or storks, but its curved beak and internal organization prove it to belong to the falcon tribe. Its feet being incapable of grasping, it keeps constantly on the ground in sandy and open places, and runs with such speed as to be able to overtake the most agile reptiles. The destruction it causes in their ranks must be great indeed, for Le Vaillant mentions that having killed one of these birds he found in its erop eleven rather large lizards, three serpents of an arm's length, and eleven small tortoises, besides a number of locusts, beetles, and other insects.

The majestic form, the noble bearing, the stately stride, the fine proportions, the piercing eye, and the dreadful roar of the Lion, striking terror into the heart of every other animal, all combine to mark him with the stamp of royalty. All nerve, all muscle, his enormous strength shows itself in the tremendous bound with which he rushes upon his prey, in the rapid motions of his tail, one stroke of which is able to fell the strongest man to the ground, and in the expressive wrinkling of his brow. No wonder that, ever inclined to judge from outward appearances, and to attribute to external beauty analogous qualities of mind, man has endowed the lion with a nobility of character which he in reality does not possess. For modern travelers, who have had occasion to observe him in his native wilds, far from awarding him the praise of chivalrous generosity and noble daring, rather describe him as a mean spirited robber, prowling about at night-time in order to surprise a weaker prey.

The lion is distinguished from all other members of the feline tribe by the uniform solor of his tawny skin, by the black tuft at the end of his tail, and particularly by the long and sometimes blackish mane, which he is able to bristle when under the influence of passion, and which contributes so much to the beauty of the male, while it is wanting in the lioness, who is very inferior in size and comeliness to her stately mate. His chief food consists of the flesh of the larger herbivorous animals, very few of which he is unable to master, and the swift-footed antelope has no greater enemy than he. Concealed in the high rushes on the river's bank, he lies in ambush for the timorous herd, which at night-fall approaches the water to quench its thirst. Slowly and cautiously the children of the waste advance ; they listen with ears erect, they strain their 
eyes to penetrate the thicket's gloom, but nothing suspicious appears or moves along the bank. Long and deeply they quaff the delicious draught; but suddenly with a giant spring, like lightning bursting from a cloud, the lion bounds upon the unsuspecting revellers, and the leader of the herd lies prostrate at his feet, while his companions fly into the desert.

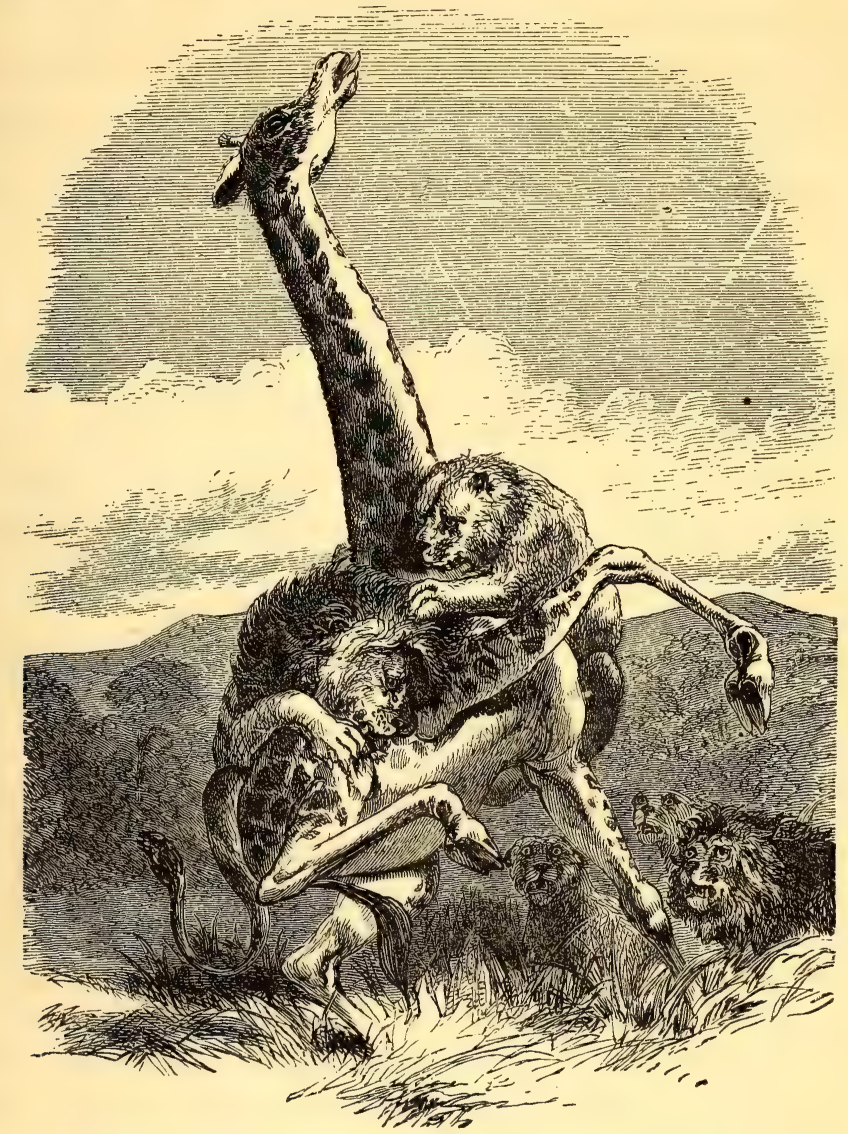

LioNS PULLING DOWN A GIRAFFE.

Andersson is one of the very few who have ever had an opportunity of seeing the lion seizing his prey in broad daylight. Late one evening he had badly wounded a lion; and on the following morning set out with his attendants, following the bloody tracks of the animal. " "Presently," he writes, "we came upon the 'spoor' of a whole troop of lions, as also that of a solitary giraffe. So many tracks confused us, and while endeavoring to pick out from the rest those of the wounded lion, I observed my native attendants suddenly rush forward, and the next instant the jungle re-echoed with the shouts of triumph. Thinking they had discovered the lion we were in pursuit of, I also hurried forward; but imagine my surprise when emerging into an opening in the jungle I saw, not a dead lion, as I expected, but five living lions-two males and three females-two of whom were in the act of pulling down a splendid giraffe, the other three watching close at hand, and with devouring louks, the deadly 
strife. The scene was of so imposing a nature that for the moment I forgot I carried a gun. The natives, however, in anticipation of a glorious gorge, dashed madly forward, and with the most piercing shrieks and yells compelled the lions to a hasty retreat. When I reached the giraffe, now stretched at full length on the sand, it made a few ineffectual attempts to raise its neck; its body heaved and quivered for a moment, and the nezis instant the poor animal was dead. It had received several deep gashes about the franks and chest, caused by the claws and teeth of its fierce assailants. The strong and tough muscles of the neck were also bitten through. All thought of pursuing the wounded lion was now out of the question. The natives remained gorging on the carcass of the giraffe until it was devoured. A day or two afterward, however, I had the good fortune to fall in with my royal antagonist, and finished him without difficulty."

During the day-time the lion seldom attacks man, and sometimes even when meeting a traveler he is said to pass him by unnoticed; but when the shades of evening deseend, his mood undergoes a change. After sunset it is dangerous to venture into the woody and wild regions of Mount Atlas, for there the lion lies in wait, and there one finds him stretched across the narrow path. It is then that dramatic scenes of absorbing interest not unfrequently take place. When, so say the Bedouins, a single man thus meeting with a lion is possessed of an undaunted heart, he advances towards the monster brandishing his sword or flourishing his rifle high in the air, and, taking good care not to strike or to shoot, contents himself with pouring forth a torrent of abuse: "Oh, thou mean-spirited thief! thou pitiful waylayer! thou son of one that never ventured to say no! think'st thou I fear thee? Knowest thou whose son I am? Arise, and lei me pass !" The lion waits till the man approaches quite near to him ; then he retires, but soon stretches himself once more across the path; and thus by many a repeated trial puts the courage of the wanderer to the test. All the time the movements of the lion are attended with a dreadful noise, he breaks numberless branches with his tail, he roars, he growls ; like the cat with the mouse, he plays with the object of his repeated and singular attacks, keeping him perpetually suspended between hope and fear. If the man engaged in this combat keeps up his courage,if, as the Arabs express themselves, "he holds fast his soul," then the brute at last quits him and seeks some other prey. But if the lion perceives that he has to do with an opponent whose courage falters, whose voice trembles, who does not venture to utter a menace, then to terrify him still more he redoubles the described mancourres. He approaches his victim, pushes him from the path, then leaves him and approaches again, and enjoys the agony of the wretch, until at last he tears him to pieces.

The lion is said to have a particular liking for the flesh of the Hottentots, and it is surprising with what obstinacy he will follow one of these unfortunate savages. Thus Mr. Barrow relates the adventure of a Namaqua Hottentot, who, endeavoring to drive his master's cattle into a pool of water enclosed between two ridges of rocks, espied a huge lion conching in the midst of the pool. Terrified at the unexpected sight of such a beast, that seemed to have his eyes fixed upon him, he instantly took to his heels. In doing this he had presence of mind enough to run through the herd, concluding that if the lion should pursue he would take up with the first beast that presented itself. In this, however, he was mistaken. The lion broke through the herd, making directly after the Hottentot, who, on turning round and perceiving that the monster 
had singled him out, breathless and half dead with fear, scrambled up one of the treealoes, in the trunk of which a few steps had luckily been cut out to come at some birds' nests that the branches contained. At the same moment the lion made a spring at him, but missing his aim, fell upon the ground. In surly silence he walked round the tree, casting at times a dreadful look towards the poor Hottentot, who screened himself from his sight behind the branches. Having remained silent and motionless for a length of time, he at length ventured to peep, hoping that the lion had taken his departure, when, to his great terror and astonishment, his eyes met those of the animal, which, as the poor fellow afterwards expressed himself, flashed fire at him. In short, the lion laid himself down at the foot of the tree, and did not remove from the place for twenty-four hours. At the end of this time, becoming parched with thirst, he went to a spring at some distance in order to drink. The Hottentot now, with trepidation, ventured to descend, and scampered off home, which was not more than a mile distant, as fast as his feet could carry him.

On account as well of the devastations which he causes among the herds as of the pleasure of the chase, the lion is pursued and killed in North and in South Africa wherever he appears: a state of war which, as may well be supposed, is not without danger for the aggressive party. Thus Andersson once fired upon a black-maned lion, one of the largest he ever encountered in Africa. Roused to fury by the slight wound he had received, the brute rapidly wheeled, rushed upon him with a dreadful roar, and at the distance of a few paces, couched as if about to spring, having his head imbedded, so to say, between his fore paws. Drawing a large hunting-knife, and slipping it over the wrist of his right hand, Andersson dropped on one knee, and thus prepared, awaited the onset of the lion. İ wã an awful moment of suspense, and his situation was critical in the extreme. Still his presence of mind, (a most indispensable quality in a South African hunter,) never for a moment forsook him ; indeed, he felt that nothing but the most perfect coolness and absolute self-command would be of any avail. He would now have become the assailant; but as, owing to the intervening bushes and clouds of dust raised by the lion's lashing his tail against the ground, he was unable to see his head, while to aim at any other part would have been madness, he refrained from firing. Whilst intently watching every motion of the lion, the animal suddenly made a prodigious bound; but whether it was owing to his not perceiving his intended victim, who was partially concealed in the long grass, and instinctively threw his body on one side, or to miscaiculating the distance, be went clear over him, and alighted on the ground three or four paces beyond. Quick as thought Andersson now seized his advantage, and wheeling round on his knee, discharged his second barrel; and as the lion's broadside was then towards him, lodged a ball in his shoulder, which it completely smashed. The infuriated animal now made a second and more determined rush; but, owing to his disabled state, was happily avoided, though only within a hair's breadth, and giving up the contest, he retreated into a neighboring wood, where his carcass was found a few days after.

Dr. Livingstone once had a still more narrow escape, for he was actually under the paws of a lion, whose fury he had roused by firing two bullets at him. "I was upon a little hight; he caught my shoulder as be sprang, and we both came to the ground below together. Growling horribly close to my ear, he shook me as a terrier-dog does a rat. The shock produced a stupor, similar to that which seems to be felt by a mouse 
after the first shake of the cat. It caused a sort of drowsiness in which there was no sense of pain nor feeling of terror, though quite conscious of all that was happening. It was like what patients partially under the influence of chloroform describe, who see all the operation, but feel not the knife. This singular condition was not the result of any mental process; the shake annihilated fear, and allowed no sense of horror in looking round at the beast. This peculiar state is probably produced in all animals killed by the carnivora; and if so, is a merciful provision by our benevolent Creator for lessening the pain of death. Turning round to relieve myself of the weight, as he had one paw on the back of my head, I saw his eyes directed to Mebalwé, who was trying to shoot him at a distance of ten or fifteen yards. His gun, a flint one, missed fire in both barrels; the lion immediately left me, and attacking Mebalwé, bit his thigh. Another man attempted to spear the lion while he was biting Mebalwé. He left Mebalwé and caught this man by the shoulder; but at that moment the bullets he had received took effect, and he fell down dead. The whole was the work of a few moments, and must have been his paroxysm of dying rage. A wound from this animal's tooth resembles a gun-shot wound; it is generally followed by a great deal of sloughing and discharge, and pains are felt in the part periodically ever afterwards. I had on a tartan jacket on the occasion, and I believe that it wiped off all the virus from the teeth that pierced the flesh, for my two companions in this affray have both suffered from the peculiar pains, while I have escaped with only the inconvenience of a false joint in my limb. The man whose shoulder was wounded showed me his wound actually burst forth afresh on the same month of the following year."

In the Atlas, the lion is hunted in various ways. When he prowls about the neighborhood of a Bedouin encampment, his presence is announced by various signs. At night his dreadful roar resounds; now an ox, now a foal is missing from the herd; at length even a member of the tribe disappears. Terror spreads among all the tents, the women tremble for their children, everywhere complaints are heard. The warriors decree the death of the obnoxious neighbor, and congregate on horse and on foot at the appointed hour and place. The thicket in which the lion conceals himself during the day-time has already been discovered, and the troop advances, the horsemen bringing up the rear. About fifty paces from the bush they halt, and draw up in three rows, the second ready to assist the first in case of need, the third an invincible reserve of excellent marksmen. Then commences a strange and animated scene. The first row abusing the lion, and at the same time sending a few balls into his covert to induce him to come out, utters loud exclamations of defiance. "Where is he who fancies bimself so brave, and ventures not to show himself before men? Surely it is not the lion, but a cowardly thief, a son of Scheitan, on whom may Allah's curse rest!"

At length, the roused lion breaks forth. A momentary silence ensues. The lion roars, rolls flaming eyes, retreats a few paces, stretches himself upon the ground, rises, smashes the branches with his tail. The front row gives fire, the lion springs forward, if untouched, and generally falls under the balls of the second row, which immediately advances towards him. This moment, so critical for the lion, whose fury is fully excited, does not end the combat till he is hit in the head or in the heart. Often his hide has been pierced by a dozen balls before the mortal wound is given, so that sometimes in case of a prolonged contest several of the hunters are either killed or wounded. The horsemen remain as passive spectators of the fray so long as the lion 
keeps upon hilly ground; but when driven into the plain, their part begins, and a new combat of a no less original and dramatic character commences; as every rider, according to his zeal or courage, spurs his horse upon the monster, fires upon him at a short distance, then rapidly wheels as soon as the shot is made, and reloads again, to prepare for a new onset. The lion, attacked on all sides and covered with wounds, fronts everywhere the enemy, springs forward, retreats, returns, and only falls after a glorious resistance, which must necessarily end in his defeat and death, as he is no match for a troop of well-mounted Arabs. After he has spent his power on a few monstrous springs, even an ordinary horse easily overtakes him. One must have been the witness of such a fight, says Dumas, to form an idea of its liveliness. Every rider utters loud imprecations, the white mantles that give so spectral an appearance to their dusky owners, fly in the air like "streamers long and gay," the carbines glisten, the shots resound, the lion roars; pursuit and flight alternate in rapid succession Yet in spite of the tumult accidents are rare, and the horsemen have generally nothing to fear but a fall from their steed, which might bring them under the claws of their enemy, or, what is oftener the case, the ball of an incautious comrade.

The Arabs have noticed that the day after the lion has carried away an animal, he generally remains in a state of drowsy inactivity, incapable of moving from his lair. When the neighborhood, which usually resounds with his evening roar, remains quiet, there is every reason to believe that the animal is gorged with his gluttonous repast. Then some huntsman, more courageous than his comrades, follows his trail into the thicket, levels his gun at the lethargic monster, and sends a ball into his head. Sometimes even, a hunter, relying on the deadly certainty of his aim, and desirous of acquiring fame by a display of chivalrous courage, rides forth alone into the thicket, on a moonlight night, challenges the lion with repeated shouts and imprecations, and lays him prostrate before he can make his fatal bound.

Dr. Livingstone informs us that the Bushmen likewise avail themselves of the torpidity consequent upon a full meal, to surprise the lion in his slumbers : but their mode of attack is very different from that practiced by the fiery Arabs of Northern Africa. One discharges a poisoned arrow from the distance of only a few feet, while his companion simultaneously throws his skin-cloak over the beast's head. The sudden surprise makes him lose his presence of mind, and he bounds away in the greatest confusion and terror. The poison which they use is the entrails of a caterpillar named N'gwa, half an inch long. They squeeze out these, and place them all around the bottom of the barb, and allow the poison to dry in the sun. "They are very careful in cleaning their nails after working with it, as a small portion introduced into a scratch acts like morbid matter in dissection wounds. The agony is so great that the person cuts himself, calls for his mother's breast, as if he were returned in idea to his childhood again, or flies from human habitations_a raging maniac. The effects on the lion are equally terrible. He is heard moaning in distress, and becomes furious, biting the trees and ground in rage."

The Arabs of the Atlas consider it much less dangerous to hunt the lion himself than to rob him of his young. Daily about three or four o'clock in the afternoon, the parent lions roam about, most likely to espy some future prey. They are seen upon a rising ground surveying the encampment, the smoke arising from the tents, the places where the cattle are preserved, and soon after retire with a deep growl. During 
this absence from their den, the Bedouins cautiously approach to seize the young, taking good care to gag them, as their cries would infallibly attract the parent lion. After a razzia like this, the whole neighborhood increases its vigilance, as for the next seven or eight days the fury of the lion knows no bounds.

In ancient times, the lion was an inhabitant of south-eastern Europe. Herodotus reiates that troops of lions came down the. Macedonian mountains, to seize upon the baggage camels of Xerxes' army, and even under Alexander the Great, the animal, though rare, was not yet completely extirpated. In Asia also, where the lion is at present confined to Mesopotamia, the northern coast of the Persian Gulf, and the north-western part of Hindostan, he formerly roamed over far more extensive domains. The Asiatic lion differs from the African, by a more compressed form of the body, a shorter mane, which sometimes is almost entirely wanting, and a much larger tuft of hair at the end of the tail. Africa is the chief seat of the lion, the part of the world where he appears to perfection with all the attributes of his peculiar strength and beauty. There he is found in the wilds of the Atlas as in the high mountain-lands of Abyssinia, from the Cape to Senegal, and from Mozambique to Congo ; and more than one species of the royal animal, not yet accurately distinguished by the naturalists, roams over this vast expanse. The lion is frequently brought to Europe and America, and forms one of the chief objects of attraction in zoological gardens. When taken young, he easily accustoms himself to captivity, and even propagates within his prison bounds, but the cubs born in our climate generally die young.

That the lion is at times bold and ferocious enough is abundantly testified by all the hunters who within the last few years have narrated their adventures in Southern Africa, but all of them also give equal testimony to his usual cowardice, when not pressed by hunger. Livingstone, indeed, has a most republican contempt for the socalled "royal-beast," although he bears on his person proofs that he is not to be wholly despised. According to him the lion is nothing better than an overgrown hulking cat, not a match in fair fight for the buffalo, and always careful to give a wide berth to the rhinoceros. Andersson relates the only instance which has come within our observation where a lion assailed a rhinoceros. He had wounded a rhinoceros, and, he writes, "while following up the trail of the animal, we eame to a spot where one or two lions, taking advantage of his crippled condition, had evidently attacked him, and after a desperate struggle bad been compelled to beat a precipitate retreat. This is the only instance I know of linns daring to attack rhinoceroses, though I have seen it stated in print, that not only will they assail, but can master the horned monster." His picture of this scene is given on page 503 of this volume.

According to Livingstone, if a traveler encounters a lion by daylight, he turns tail and sneaks out of sight like a scared greyhound. All the talk about his majestic roar is sheer twaddle. It takes a keen ear to distinguish the voice of the lion from that of the silly ostrich. When the lion grows old, he leads a miserable life. Unable to master the larger game, he prowls about the villages in hopes to pick up a stray goat. A woman or a child does not come amiss. When the natives hear one prowling about the villages, they say, "His teeth are worn; he will soon kill men," and thereupon turn out and put an end to him; "and this," says Livingstone, "is the only foundation for the common belief that when the lion has once tasted human flesh he will eat nothing else." When an aged lion lives far from human habitations so that he can not 
get goats or children, he is often reduced to such straits as to be obliged to make his meals of mice and such small prey. "Upon the whole," concludes Livingstone, " in the dark, or at all hours when breeding, the lion is an ugly enough customer; but if a man will stay at home by night, and not go out of his way to attack him, he runs less risk in Africa of being devoured by a lion, than he does in our cities of being run over by an omnibus."

The lion reigns in Africa, but the Tiger is lord and master of the Indian jungles. A splendid animal-elegantly striped with black on a white and golden ground; graceful in every movement, but of a most sanguinary and cruel nature. The lengthened body resting on short legs wants the proud bearing of the lion, while the naked head, the wildly rolling eye, the scarlet tongue constantly lolling from the jaws, and the whole expression of the tiger's physiognomy indicate an insatiable thirst of blood, a pitiless ferocity, which he wreaks indiscriminately on every living thing that comes within his grasp. In the bamboo jungle on the banks of pools and rivers, he waits for the approaching herd; there he seeks his prey, or rather multiplies his murders, for he often leaves the carcase of the axis or the nylghau still writhing in the agony of death to throw himself upon new victims, whose bodies he rends with his claws, and then plunges his head into the gaping wound to absorb with deep and luxurious draughts the blood whose fountains he has just laid open.

Nothing can be more delightful than the aspect of a Javanese savannah, to which clumps of noble trees, planted by Nature's hand, impart a park-like character; yet even during the day-time, the traveler rarely ventures to cross these beautiful wilds without being accompanied by a numerous retinue. In Italy armed guards are necessary to scare the bandit; here the tiger calls for similar precautions. The horses frequently stand still, trembling all over, when their road leads them along some denser patch of the jungle, rising like an island from the grassy plain, for their acute scent informs them that a tiger lies concealed in the thicket, but a few paces from their path. It is a remarkable fact that the peacock and the tiger are so frequently seen together. The voice of the bird is seldom heard during the day-time, but as soon as the shades of evening begin to veil the landscape, his loud and disagreeable screams awaken the echoes, announcing, as the Javanese say, that the tiger is setting forth on his murderous excursions. Then the traveler carefully bolts the door of his hut, and the solitary Javanese retreats to his palisaded dwelling, for the tyrant of the wilderness is abroad. At night his dreadful roar is heard, sometimes accompanied by the peacock's discordant voice. Even in the villages, thinly scattered among the grass or alangwilds of Java, there is no security against his attacks, in spite of the strong fences with which they are enclosed, and the watch fires carefully kept burning between these and the huts.

India, South China, Sumatra, and Java, are the chief seats of the tiger, who is unknown both in Ceylon and Borneo, while to the north he ranges as far as Manchuria and the Upper Obi, and Yennisei, $\left(55^{\circ}-56^{\circ} \mathrm{N}\right.$. lat.) A species of tiger identical with that of Bengal is common in the neighborhood of Lake Aral, near Sussac (45 3 N. lat.), and Tennant mentions that he is found among the snows of Mount Ararat in Armenia. As Hindostan is separated from these northern tiger haunts by the great mountain chains of Kuen-Lun $\left(35^{\circ} \mathrm{N}\right.$.), and of Mouztagh $\left(42^{\circ} \mathrm{N}\right.$. lat ), each covered with perpetual snows, mere summer excursions are quite out of the question, and 
it is evident that the animal is able to live in a much more rigorous climate than is commonly imagined. Even in India the tiger is by no means confined to the sultry jungle, for we learn from Mr. Hodgson's account of the mammalia of Nepaul, that in the Himalaya he is sometimes found at the very edge of the perpetual snow.

Tiger-hunting is a chief pleasure of the Indian rajahs and zemindars, who, anxious that their favorite amusement may suffer no diminution, forbid any one else to chase on their domains, however much their poor vassals may have to suffer in consequence. But the delight they take in tiger shooting never leads the cautious Nimrods so far as to endanger their precious persons. On some trees of the jungle a scaffolding is prepared, at a ludicrous hight for his highness, who, at the appointed hour, makes his appearance with all the pomp of a petty Asiatic despot. The beating now begins, and is executed by a troop of miserable peasants, who most unwillingly submit to this forced and unpaid labor, which is the more dangerous for them as they are dispersed in a long line, instead of forming a troop, the only way to secure them against the attacks of the tiger. Thus they advance with a dreadful noise of drums, horns, and pistol-firing, driving the wild beasts of the jungle towards the scaffolding of their lord and master. At first the tigers, startled from their slumbers, retreat before them, but generally on approaching the scaffolding they guess the danger that awaits them, and turn with a formidable growl upon the drivers. Sometimes, however, they summon resolution to rush with a few tremendous bounds through the perilous pass, and their flight is but rarely impeded by the ill-aimed shots of the ambuscade. Nevertheless, great compliments are paid to the noble sportsman for his ability and courage, and nobody says a word about the poor low-born wretches, that may have been killed and mutilated by the infuriated brutes.

Colonel Rice, an English hunter, managed his tiger-shooting excursions on a very different plan. Provided with excellent double-barrelled rifles, and accompanied by a troop of well-armed, well-paid drivers, and a number of courageous dogs, he boldly entered the jungle to rouse the tiger from his lair. In front of the party generally marched the shikarree or chief driver, who, attentively reconnoitering the traces of the animal, pointed out the direction that was to be followed. On his right and left hand walked the English sportsmen, fully prepared for action, and behind them the most trustworthy of their followers, with loaded rifles ready for an excbange with those that had been discharged. Then followed the music, consisting of four or five tambourines, a great drum, cymbals, horns, a bell, and the repeated firing of pistols, and convoyed by men armed with swords and long halberds. A few slingsmen made up the rear, who were constantly throwing stones into the jungle over the heads of the foremost of the party, and even more effectually than the noise of the music drove the tiger from his retreat. From time to time one of the men climbed upon the summit of a tree to observe the movements of the grass. The whole troop constantly formed a close body. The tiger in cold blood never dares to attack a company that announces itself in so turbulent a manner. If he ventures it is only with half a heart; he hesitates, stops at a short distance, and gives a hunter time to salute him with a bullet. While strictly following an order of march like the one described, the drivers run little risk, even in the thickest jungle; but the difficulty is to keep them together, as the least success immediately tempts them to disperse.

On one of these hunting expeditions Ensign Elliott, a friend of the Colonel's, had 
an almost miraculous escape. Accompanied by about forty drivers, they had entered a jungle, which did not seem to promise much sport, and had mounted with their rifles upon some small trees to await the issue of the explorations, when suddenly their people roused a beautiful tiger, who advanced slowly towards them. They remained perfectly silent, but one of their followers, posted upon another tree and fearing they might be surprised by the animal, called out to them to be upon their guard. This was enough to make the tiger change his direction, so that they had scarcely time to send a bullet after him. His loud roar announced that he was wounded, but the distance was already too great to admit of his being effectually hit a second time, so that the impatient sportsmen now pursued him with more eagerness than caution. At the head of their troop, they marched through the jungle, following the bloody trail of the animal, until at length they emerged into an open country, when all further traces were lost. In vain some of their people climbed upon the highest trees; nothing was to be perceived either in the bushes or in the high grass. Meanwhile the Englishmen slowly walked on, about twenty paces in advance, attentively gazing upon the ground, when suddenly with a terrific roar the tiger bounded upon Colonel Rice from a hollow, concealed beneath the herbage. The gallant sportsman had scarcely time to fire both his barrels at the head of the monster, who, diverted from the attack by this warm reception, now made an enormous spring at Ensign Elliott before he had time to aim. All this was the work of a moment, for, on turning towards the tiger, the Colonel saw his unfortunate friend prostrate under the paws of the furious brute. Immediately the shikarree with admirable coolness handed him a freshly loaded rifle. $\mathrm{He}$ dis. charged one of the barrels without effect, but was then obliged to pause, as the tiger had seized his friend by the arm, and was dragging him towards the hole from whence he had sprung forth. Thus it was absolutely necessary that the next shot should hit the animal in the brain, as any other wound not immediately fatal would only have increased its fury. Closely following the tiger, and watching all his movements with the most intense attention, the Colonel, after having aimed several times, at length fired and hit the temple of the tiger, who fell over his victim a lifeless corpse. Fortunately, the Ensign was not mortally wounded, the stroke of the tiger's paw, which had been aimed at his head, having been parried by his rifle. The blow, however, had been so furious as to flatten the trigger, and thus he escaped with a terrible wound in the arm.

The tiger is particularly fond of dense willow or bamboo bushes on swampy ground, as he there finds the cool shades he requires for his rest during the heat of the day, after his nocturnal excursions. It is then very difficult to detect him, but the other inhabitants of the jungle, particularly the peacock and the monkey, betray his pres ence. The scream of the former is an infallible sign that the tiger is rising from his lair; and the monkeys, who during the night are so frequently surprised by the panther or the boa, never allow their watchfulness to be at fault during the day. They are never deceived in the animal, which slinks into the thicket. If it is a deer or a wild boar, they remain perfectly quiet; but if it is a tiger or a panther, they utter a cry, destined to warn their comrades of the approach of danger. When, on examining a jungle, the traveler sees a monkey quietly seated on the branches, he may be perfectly sure that no dangerous animal is lurking in the thicket. During the night the cry of the jackal frequently announces the tiger's presence. When one of these vile animals is no longer able to hunt from age, or when he has been expelled 
from his troop, he is said to become the provider of the tiger, who, after having satiated himself on the spoil, leaves the remains to his famished scout.

The tiger, who on the declivities of the Himalaya tears to pieces the swit-footed antelope, lacerates on the desert sand coasts of Java the tardy tortoise, when at nightfall it leaves the sea to lay its eggs in the drift-sand at the foot of the dunes. Hundreds of tortoise skeletons lie scattered about the strand, many of them five feet lon: and three feet broad; some bleached by time, others still fresh and bleeding. High in the air a number of birds of prey wheel about, scared by the traveler's approach. Here is the place where the turtles are attacked by the wild dogs. In packs of from twenty to fifty, the growling rabble assails the poor sea animal at every accessitle pcint, gnaws and tugs at the feet and at the head, and succeeds by united efforts in turning the huge creature upon its back. Then the abdominal scales are torn off, and the ravenous dogs hold a bloody meal on the flesh, intestines, and eggs of their defenceless prey. Semetimes, however, the turtle escapes their rage, and dragging its lacerating tormentors along with it, succeeds in regaining the friendly sea. Nor do the dogs always enjoy an undisturbed repast, often during the night, the lord of the wilderness, the royal tiger, bursts out of the forest, pauses for a moment, casts a glance over the strand, approaches slowly, and then with one bound, accompanied by a terrific roar, springs among the dogs, scattering the howling band like chaff before the wind. And now is the tiger's turn to feast; but even he, though rarely, is sometimes disturbed by man. Thus on this lonely, melancholy coast, wild dogs and tigers wage an unequal war with the inhabitants of the ocean.

After the tiger and the lion, the Panther and the Leopard are the mightiest felidæ of the Old World. Although differently spotted-the ocelli or rounded marks on the panther being larger and more distinctly formed-they are probably only varieties of one and the same species, as many intermediate individuals have been observed. Both animals are widely diffused through the tropical regions of the Old World, being natives of Africa, Persia, China, India, and many of the Indian islands; so that they. have a much more extensive range than either the tiger or the lion. The manner in which they seize their prey, lurking near the sides of woods, and darting forward with a sudden spring, resembles that of the tiger, and the chase of the panther is said to be more dangerous than that of the lion, as it easily climbs the trees and pursues its enemy upon the branches.

The Cheetah, or hunting leopard (Gueparda jubata, guttata), whick inhabits the greater part of both Asia and Africa, exhibits in its form and habits a mixture of the feline and canine tribes. Resembling the panther by its spotted skin, it is more elevated on its legs and less flattened on the fore part of its head. Its brain is more ample, and its claws touch the ground while walking, like those of the dog, which it resembles still further by its mild and docile nature. In India and Persia, where the cheetahs are employed in the chase, they are carried chained and hoodwinked to the field in low cars. When the hunters come within view of a herd of antelopes, the cheetah is liberated, and the game is pointed out to him: he does not, however, im. mediately dash forward in pursuit, but steals along cautiously till he has nearly approached the herd unseen, when with a few rapid and vigorous bounds, he darts on the timid game and strangles it almost instantaneously. Should he, however, fail in 
his first efforts and miss his prey, he attempts no pursuit, but returns to the call of his master, evidently disappointed, and generally almost breathless.

While the sanguinary felidæ may justly be called the eagles, the carrion feeding Hyænas are the vultures, among the four-footed animals. Averse to the light of day, like the owl and the bat, they conceal themselves in dark caverns, ruins, or burrows, as long as the sun stands above the horizon; but at night-fall they come forth from their gloomy retreats with a lamentable howl or a satanic laugh, to seek their disgusting food on the fields, in churchyards, or on the borders of the sea. From the pro. digious strength of their jaws and their teeth, they are not only able to masticate tendons, but to crush cartilages and bones; so that carcases almost entirely deprived of flesh still provide them with a plentiful banquet. Though their nocturnal habits and savage aspect have rendered them an object of hatred and disgust to man, they seem destined to fill up an important station in the economy of nature, by cleansing the earth of the remains of dead animals, which might otherwiso infect the atmosphere with pestilential effluvia.

The striped hyæna is a native of Asiatic Turkey, Syria, and North Africa, as far as the Senegal, while the spotted hyæna ranges over South Africa, from the Cape to Abyssinia. Both species attain the size of the wolf, and have similar habits. As the shark follows the ship, or the crow the caravan, they are suid to hover about the march of armies, as if taught by instinct that they have to expect the richest feast from the insanity of man. The moonlight falling on the dsiz cypresses and snow-white tombs of the Oriental churches not seldom shines upon hungry hyænas, busily employed in tearing the newly buried corpses from their graves. A remarkable peculiarity of the spotted hyæna is that when he first begins to run he appears lame, so that one might almost fancy one of his legs was broken; but after a time this halting disappears, and he proceeds on his course very swiftly.

The brown hyæna, which is found in South Africa, from the Cape to Mozambique and Senegambia, and has a more shaggy fur than the preceding species, has very different habits. He is particularly fond of the crustacer which the ebbing flood leaves behind upon the beach, or which the storm casts ashore in great quantities, and exclusiveiy inhabits the coasts, where he is known under the name of the sea-shore wolf. His traces are everywhere to be met.with on the strand, and night after night he prowls along the margin of the water, examining the refuse of the retreating ocean.

The same radical differences which draw so wide a line of demarcation between the simiæ of the Old and the New World are found also to distinguish the feline races of both hemispheres, so that it would be as vain to search in the American forests and savannas for the Numidian lion, or the striped tiger, as on the banks of the Ganges or the Senegal for the tawny puma or the spotted jaguar. While in the African plains the swift-footed spring-bok, or the koodoo, unrivaled among the antelopes for his bold and widely-spreading horns, falls under the impetuous bound of the panther-or while the tiger and the buffalo engage in mortal combat in the Indian jungle-the bloodthirsty Jaguar, concealed in the high grass of the American llanos, lies in wait for the wild horse or the passing steer. The arrival of the Spaniards in the New World, so destructive to most of the Indian tribes with whom they came in contact, was beneficial at least to the large felidæ of tropical America, for they first introduced the horse and 
the ox into the western hemisphere, where these useful animals, finding a new and congenial home in the boundless savannas and pampas, which extend almost uninterruptedly from the Apure to Patagonia, have multiplied to an incredible extent. Since then the jaguar no longer considers the deer of the woods, the graceful agouti, or the slow capybara as his chief prey, but rejoices in the blood of the steed or ox, and is much more commonly met with in the herd-teeming savannas than in the comparatively meagre hunting-grounds of the forest.

Of all the carnivora of the New World, perhaps with the sole exception of the grizzly and the polar bears, the tyrants of the North American solitudes, the jaguar is the most formidable, resembling the panther by his spotted skin, but almost equaling the Bengal tiger in size and power. He roams about at all times of the day, swims over broad rivers, and even in the water proves a most dangerous foe, for when driven to extremities he frequently turns against the boat, and forces his assailants to seek their safety by jumping overboard. Many an Indian, while wandering through thinly populated districts, where swampy thickets alternate with open grass plains, has been torn to pieces by the jaguar, and in many a lonely plantation the inhabitants hardly venture to leave their enclosures after sunset, for fear of his attacks. During Tschudi's sojourn in Northern Peru, a jaguar penetrated into the hut of an Englishman who had settled in those parts, and dragging a boy of ten years out of his hammock, tore him to pieces and devoured him. Far from being afraid of man, this ferocious animal springs upon him when alone, and when pressed by hunger will even venture during the day-time into the mountain villages to seek its prey. The distinguished traveler whom I have just quoted mentions the case of an Indian in the province of Vito, who hearing during the night his only pig most piteously squealing, rose to see what was the matter, and found that a jaguar had seized it by the head, and was about to carry it away. Eager to rescue his property, he sprang forward, and seizing the pig by the hind legs, disputed its possession with the beast of prey, that with eyes gleaming through the darkness, and a ferocious growl, kept tugging at its head. This strange struggle between the undaunted Indian and the jaguar lasted for some time, until the women coming out of the hut with lighted torches put to flight the monster, which slowly retreated into the forest. The same traveler relates that in some parts the jaguars had increased to such a degree, and proved so destructive to the inhabitants, that the latter were obliged to emigrate, and settle in less dangerous districts. Thus, the village of Mayunmarca, near the road from Huanta to Anco, had been long since abandoned, and the neighborhood was still considered so dangerous that few Indians ventured to travel through it alone.

The chase of these formidable animals requires great caution, yet keen sportsmen will venture, single-handed, to seek the jaguar in his lair, armed with a blow-pipe and poisoned arrows, or merely with a long and powerful lance. The praise which is due to the bold adventurers for their courage is, however, too often tarnished by their cruelty. Thus, a famous jaguar hunter once showed Pöppig a large cavity under the tangled roots of a giant bombax-tree, where he had some time back discovered a female jaguar with her young. Dexterously rolling down a large stone, he closed the entrance, and then with fiendish delight slowly smoked the animals to death, by applying fire from time to time to their dungeon. Having lost one half of his scalp in a previous conflict with a jaguar, he pleaded his sufferings as an excuse for his barbarity. 
To attack these creatures with a lance, a sure arm, a cool, determined courage, and great bodily strength and dexterity are required; but even these qualities do not always ensure success if the hunter is unacquainted with the artifices of the animal. The jaguar generally waits for the attack in a sitting posture, turning one side towards the assailant, and, as if unconcerned, moves his long tail to and fro. The hunter, carefully observing the eye of his adversary, repeatedly menaces him with slight thrusts of his lance, which a gentle stroke of the paw playfully wards off; then seizing a favorable moment, he suddenly steps forward and plunges his weapon into his side. If the thrust be well aimed, a second is not necessary, for pressing with his full weight on the lance, the huntsman enlarges and deepens the mortal wound. But if the stroke is parried or glances off, the jaguar, roused to fury, bounds on his aggressor, whose only hope now lies in the short knife which he carries in his girdle. Those who are ltss inclined to desperate conflicts destroy the jaguar by poisoned pieces of meat, or else they lay pitfalls for him, when they kill him without running any personal risk.

The Cougar, or the Puma, as he is called by the Indians, is far inferior to the jaguar in courage, and consequently far less dangerous to man. On account of his brownish-red color and great size, being the largest felis of the New World, he has also been named the American lion, but he has neither the mane nor the noble bearing of the "king of animals." In spite of his strength he is of so cowardly a dispositirn that he invariably takes to flight at the approach of man, and consequently inspires no fear on being met with in the wilderness; while even the boldest hunter instinctively starts back, when, winding through the forest, he suddenly sees the sparkling eye of the jaguar intently fixed upon him. The puma has a much wider range than the jaguar, for while the latter reaches in South America only to the forty-fifth degree of latitude, and does not rove northwards beyond Sonora and New Mexico, the former roams from the Straits of Magellan to the Canadian lakes. The jaguar seldom ascends the mountains to a greater hight than 3,000 feet, while in the warmer lateral valleys of the Andes the puma frequently lies in ambush for the vicuñas at an elevation of 10,000 feet above the level of the sea. He can climb trees with great facility, ascending even vertical trunks, and, like the lynx, will watch the opportunity of springing on such animals as happen to pass beneath. No less cruel than cowardly, he will destroy without necessity forty or fifty sheep when the occasion offers, and content himself with licking the blood of his victims. When caught young, he is easily tamed, and, like the common cat, shows his fondness at being caressed by the same kind of gentle purrings. Tschudi informs us that the Indians of the northern provinces fre. quently bring pumas to Lima, to show them for money. They either lead them by a rope, or carry them in a sack upon their back, until the sight-seers have assembled in sufficient number.

Besides the puma or the jaguar, tropical America possesses the beautifully variegated Ocelot (Felis pardalis); the Oscolio (Felis dogaster); the spotless, black gray Jaguarundi ( $F$.jaguarundi), which is not much larger than the European wild-cat; the long-tailed, striped, and spotted Margay, or Tiger-cat, and several other felidæ. All these smaller species hardly ever become dungerous to man, but they cause the death of many an acouchi and cavy ; and, with prodigious leaps, the affrighted monkey flies from their approach into the deepest recesses of the forest. 


\section{CHAPTER XV.}

THE ELEPHANT, RHINOCEROS, HIPPOPOTAMUS, CAMEL, ZEBRA.

The Great Tropical Pachydermati.-The Elephant: Difference between the tame and wild Elephant-His Instinctive Timidity-Acuteness of His Senses-His Sagacity in Climbing Hills-His wonderful Trunk-His Tusks-Elephant Herds-The Rogue, or Solitary Elephant-The Asiatic and African Species-The African Elephant tamed in Ancient TimesPresent Range of the African Elephant-Native Modes of Hunting the African ElephantThe Elephant and the Rifle-Perils of Elephant-Hunters-Elephant-Hunting in AbyssiniaThe Asiatic Elephant-Elephant-Hunting in Ceylon-The Panickeas, or Native ElephantHunters-Elephantine Head-Work-Obstinate Brutes.-The Rhinoceros :-Range and Character of the Rhinoceros-Two Species, the Black and the White-Size of the RhinocerosAcuteness of its Senses-Its winged Attendant-Its parental Affection-Its nooturnal Habits-Modes of Hunting the Rhinoceros-The One-Horned or Indian Rhinoceros-The Two-Horned Rhinoceros of the Malay Archipelago-Rhinoceros-Paths in Java.-The Hippopotamus:-Is the Hippopotamus the Behemoth of Job?-Habits of the HippopotamusIts uncouth Aspect-Rogue Hippopotami-Intelligence of the Hippopotamus-Uses of its Skin and Teeth-Mode of Killing the Hippopotamus.-The Camel: Its Adaptation to the Tropical Sand-Wastes-Its Physical Organization adapted to its Mode of Life-Its Foot and its Stomach-Its Desert Home-The Camel and the Arab-The Two-Humped and One-Humped Camels-The Camel an immemorial Serf-Its Aspect and Temper-The Giraffe: Beauty of the Giraffe-Its Means of Defense-Its special Organization-The Lion and the Giraffe-The Giraffe known to the Ancients.-Zebra and Quaggas: Their Abundance in Southern Africa-Distinction Between the Quagga and the Zebra-Capacity for Domestication-Their Union for Defense-The Gnu, the Quagga, and the Zebra-The Zebra the Tiger-Horse of the Ancients-The African Boar-The Malayan Babirusa. Finis.

MONG the animals belonging to the Tropical World there are none more disA tinctive than the great Pachydermati, the Elephant, the Rhinoceros, and the Hippopotamus. To these huge beasts, the largest that walk the earth, we propose to devote a chapter; supplementing it with a few pages concerning the Giraffe, the Camel, and a few other animals of large size, exclusively tropical. First and foremost we will speak of the Elephant:

A tamed elephant, as we see him in menageries, compelled to go through his round of tricks for the amusement of everybody who will pay the required quarter of a dollar, is apparently a stupid beast. He seems a very mountain of flesh, ccvered with a loose and ill-fitting skin. His great, clumsy legs look like those of a gouty alderman; he writhes his huge trunk about with an air of hopeless imbecility; all his energies seem to be concentrated upon the feat of conveying to his mouth the apples and nuts held out to him by gaping urchins. A very different animal is the same elephant in his native haunts. There he is the keenest wariest, and most cunning of beasts. The little sharp eye is alight with intelligence; the ponderous ears are alive to the 
faintest sound; the long swaying trunk, merely as an organ of smell, has an acute. ness unmatched by the keenest dog that ever tracked game. He has, moreover, a courage, and when irritated, a ferocity, surpassed by no other animal; so that one needs to be a bold and wary hunter who assails him in his native haunts.

Yet, when unmolested by man, who is his chief, and almost only enemy, the elephant is the image of strength and good-nature, loving the shady forest and the secluded lake. Disliking the glare of the midday sun, he spends the day in the thickest woods, devoting the night to excursions and to the luxury of the bath, his great and innocent delight. Though the earth trembles under his strides, yet like the whale, he is timid; but this timidity is accounted for by his small range of vision. Anything unusual strikes him with terror, and the most trivial objects and incidents, from being imperfectly discerned, excite his suspicions. An instinctive consciousness that his superior bulk exposes him to danger from sources that might be harmless in the ease of lighter animals is probably the reason why the elephant displays a remarkable reluctance to face the slightest artificial obstruction on his passage. Even when enraged by a wound, he will hesitate to charge his assailant across an intervening hedge, suspecting it may conceal a snare or pitfall, but will hurry along it to seek for an opening. Unlike the horse, he never gets accustomed to the report of fire-arms, and thus he never plays an active part in battle, but serves in a campaign only as a common beast of burden, or for the transport of heavy artillery. To make up for his restricted vision, his neck being so formed as to render him incapable of directing the range of his eye much above the level of his head, he is endowed with a remarkable power of smell, and a delicate sense of hearing, which serve to apprise him of the approach of danger.

Although, from their huge bulk, the elephants might be supposed to prefer a level country, yet, in Asia at least, the regions where they most abound are all hilly and mountainous. In Ceylon, particularly, there is not a range so high as to be inacces. sible to them, and so sure-footed are they, that provided there be solidity to sustain their weight, they will climb rocks and traverse ledges, where even a mule dare not venture. Hooker admired the judicious winding of the elephant's path in the Himalayas, and Tennent describes the sagacity which be displays in laying out roads, or descending abrupt banks, as almost incredible. His first manœuvre is to kneel down close to the edge of the declivity, placing his chest to the ground, one fore-leg is then cautiously passed a short way down the slope, and if there is no natural protection to afford a firm footing, he speedily forms one by stamping into the soil, if moist, or kicking out a footing, if dry. This point gained, the other fore-leg is brought down in the same way, and performs the same work, a little in advance of the first, which is thus at liberty to move lower still. Then first one and then the second of the hindlegs is carefully drawn over the side, and the hind-feet in turn occupy the restingplaces previously used and left by the fore ones. The course, however, in such precipitous ground is not straight from top to bottom, but slopes along the face of the bank, descending till the animal gains the level below. This an elephant has done at an angle of forty-five degrees, carrying a houdah, its occupant, his attendant, and in much less time than it takes to describe the operation.

The stomach of the elephant, like that of the camel or the llama, is provided witb a cavity, serving most probably as a reservoir for water against the emergencies of thirst ; but the most remarkable feature in the organization of the "Leviatban of tho 
Land" is his wonderful trunk, which, uniting the flexibility of the serpent with a giant's power, almost rivals the human hand by its manifold uses and exquisite delicacy of touch. Nearly eight feet in length and stout in proportion to the massive size of the whole animal, this miracle of nature, at the volition of the elephant will uproot trees or gather grass; raise a piece of artillery or pick up a comfit ; kill a man or brush off a fly. It conveys the food to the mouth, and pumps up the enormous draughts of water, which, by its recurvature, are turned into and driven down the capacious throat, or showered over the body. Its length supplies the place of a long neck, which would have been incompatible with the support of the large head and weighty tusks. A glance at the head of the elephant will show the thickness and strength of the trunk at its insertion; and the massy arched bones of the face and thick muscular neck are admirably adapted for supporting and working this incomparable instrument, which is at the same time the elephant's most formidable instrument of defense, for, first prostrating any minor assailant by means of his trunk, he then crushes him by the pressure of his enormous weight.

The use of the elephant's tusks is less clearly defined. Though they are frequently described as warding off the attacks of the tiger and rbinoceros, often securing the victory by one blow, which transfixes the assailant to the earth, it is perfectly obvious, both from their almost vertical position and the difficulty of raising the head above the level of the shoulder, that they were never designed for weapons of attack. No doubt they may prove of great assistance in digging up roots, but that they are far from indispensable, is proved by their being but rarely seen in the females, and by their almost constant absence in the Ceylon elephant, where they are generally found reduced to mere stunted processes.

Elephants live in herds, usually consisting of from ten to twenty individuals, and each herd is a family, not brought together by accident or attachment, but owning a common lineage and relationship. In the forest several herds will browse in close contiguity, and in their expeditions in search of water they may form a body of possibly one or two hundred, but on the slightest disturbance, each distinct herd hastens to re-form within its own particular circle, and to take measures on its own behalf for retreat or defense. Generally the most vigorous and courageous of the herd assumes the leadership : his orders are observed with the most implicit obedience, and the devotion and loyalty evinced by his followers are very remarkable. In Ceylon this is more readily seen in the case of a " tusker" than any other, because in a herd he is generally the object of the keenest pursuit by the hunters. On such occasions the elephants do their utmost to protect him from danger; when driven to extremity, they place their leader in the centre, and crowd so eagerly in front of him that the sportsmen have to shoot a number which they might otherwise have spared:

When individuals have been expelled from a herd, or by some accident or other have lost their former associates, they are not permitted to attach themselves to any other family, and ever after wander about the woods as outcasts from their kind. Rendered morose and savage from rage and solitude, the rogue elephants become vicious and predatory; and so sullen is their disposition, that although two may be in the same vicinity, there is no known instance of their associating, or of a rogue being seen in company with another elephant. These rogue elephants seem to belong, however, wholly to the Asiatic variety; at least, we find no special mention of them by African 
hunters. Mr. S. G. Baker, now Sir Samuel Baker, since noted for his exploration of the source of the Nile, was long ago a noted elephant-hunter in Ceylon, and his book "The Rifle and the Hound in Ceylon" abounds with incidents of adventure and daring in shooting these rogues. "Deprived," he says," of the ameliorating influence of female society, the old rogue becomes doubly vicious. He appears to be in bad humor with the world generally, and with himself in particular, spending the greatest part of his time when not feeding, in pacing back and forth, with his tail cocked in the air, ready for a rush upon any one that approaches his haunts." Their pluck is equal to their cunning. When they travel in the day-time, they always go with the wind, and nothing can follow on their track without their knowledge. When the rogue is pursued in the open forest or on the naked plain he usually retreats; but the chances are ten to one that he is merely enticing the hunter to follow him into some favorite haunt among the dense jungle, from which he will charge at some unexpected moment.

The elephant inhabits both Asia and Africa, but each of these two parts of the world has its peculiar species. The African elephant is distinguished by the lozenge-shaped prominences of ivory and enamel on the surface of his grinders, which in the Indian elephant are narrow, tranverse bars of uniform breadth; his skull has a more rounded form, and is deficient in the double lateral bump conspicuous in the former; and he has only fifty-four vertebræ, while the Indian has sixty-one. On the other hand, he possesses twenty-one ribs, while the latter has only nineteen. His tusks are also much larger, and his body is of much greater bulk, as the female attains the stature of the full-grown Indian male. The ear is at least three times the size, being not seldom above four feet long, and broad, so that Dr. Livingstone mentions having seen a negro, who under cover of one of these prodigious flaps effectually screened himself from the rain. All these differences of character appeared so great to M. Cuvier as to induce him to consider the African elephant as a peculiar genus.

Ancient medals representing large-eared elephants drawing chariots, are conclusive of the fact that the Romans knew how to eatch and tame the African elephant. He was even considered more docile than the Asiatic, and was taught various feats, as walking on ropes and dancing. The elephants with which Hannibal crossed the Alps, as well as those which. Pyrrhus led into Italy, must undoubtedly have been African. At present he is only killed for his ivory, his hide, his flesh, or from the mere wantonness of destruction. The Cape colonists, to whom his services might be of great importance, have never made the attempt to tame him, nor has one of this species ever been exhibited in England; but the big-eared, large-tusked African elephant is the one best known in American menageries.

The African elephant has a very wide range, from Caffraria to Nubia, and from the Zambesi to Cape Verde, and the impenetrable deserts of the Sahara alone prevent him from wandering to the shores of the Mediterranean. Although in South Africa the persecutions of the natives, and of his still more formidable enemies the colonists and English huntsmen, have considerably thinned his numbers, and driven him farther and farther to the north, yet in the interior of the country he is still met with in prodigious numbers. Dr. Barth frequently saw large herds winding through the open plains, and swimming in majestic lines through the rivers, with elevated trunks, or bathing in the shallow lakes for coolness or protection against insects.

Livingstone gives us many interesting accounts of the different modes of South 
African elephant-hunting. The natives of the south bank of the Zambesi erect stages on high trees overhanging the paths by which the elephants come, and then use a large spear with a handle nearly as thick as a man's wrist, and four or five feet long. When the unfortunate animal comes beneath, they throw the spear, and if it enters between the ribs above, as the blade is at least twenty inches long by two broad, the motion of the handle, as it is aided by knocking against the trees, makes frightful gashes within, and soon.causes death. They kill them also by means of a spear inserted in a beam of wood, which being suspended on the branch of a tree by a cord attached to a latch, fastened in the path and intended to be struck by the animal's foot, leads to the fall of the beam, and the spear being poisoned causes death in a few hours. The Bushmen select full-moon nights for the chase, on account of the coolness, and choose the moment succeeding a charge, when the elephant is out of breath, to run in and give him a stab with their long-bladed spears. The huge creature is often bristling with missile weapons like a porcupine, and though singly none of the wounds may be mortal, yet their number overpowers him by loss of blood. On the sloping banks of the Zouga the Bayeiye dig deep pitfalls to entrap the animals as they come to drink; but though these traps are constructed with all the care of savage ingenuity, old elephants have been known to precede the herd and whisk off their coverings all the way down to the water; or, giving proof of a still more astonishing sagacity, to have actually lifted the young out of the pits into which they had incautiously stumbled.

A much more formidable enemy of this noble animal than the spears or pitfalls of the African barbarians is the rifle, particularly in the hands of a European marksman; for while the Griquas, Boers, and Bechuanas generally stand at the distance of a hundred yards or more, and of course spend all the force of their bullets on the air, the English hunters, relying on their steadiness of aim, approach to within thirty yards of the animal, where they are sure not to waste their powder. It requires no little nerve to brave the charge of the elephant, the scream or trumpeting of the brute, when infuriated, being more like what the shriek of a steam-whistle would be to a man standing on the dangerous part of a railroad, than any other eartbly sound; a horse unused to it will sometimes stand shivering instead of taking his rider out of danger, or fall paralyzed by fear, and thus expose him to be trodden into a mummy, or, dashing against a tree, crack his skull against a branch.

Fiven the most experienced hunters have many dangers to encounter while facing their gigantic adversary. Thus, on the banks of the Zouga in 1850, Mr. Oswell had one of the most extraordinary escapes from a wounded elephant perhaps ever recorded in the annals of the chase. Pursuing the brute into the dense thick thorny bushes met with on the margin of that river, and to which the elephant usually flees for safety, he followed through a narrow pathway by lifting up some of the branches, and forcing his way through the rest; but when he had just got over this difficulty, he saw the elephant, whose tail he had but got glimpses of before, now rushing full speed towards him. There was then no time to lift up the branches, so he tried to force his horse through them. He could not effect a passage, and as there was but an instant between the attempt and failure, the hunter tried to dismount; but in doing this, one foot was caught by a branch, and the spur drawn along the animal's flank; this made him spring away, and throw the rider to the ground with his face to the elephant, which, being in full chase, still went bn. Mr. Oswell saw the huge fore foot about to 
descend on his legs, parted them, and drew in his breath, as if to resist the pressure of the other foot, which he expected would next descend on his body. His relief may be imagined, when he saw the whole length of the under part of the enormous brute pass over him, leaving him perfectly unhurt.

In Abyssinia the elephant is hunted in an original manner. The men, who make this their chief occupation, dwell constantly in the woods, and live entirely upon the flesh of the animals they kill. They are exceedingly agile and dextrous, both on horseback and on foot; indispensable qualities, partly inherited and partly acquired by constant practice. Completely naked, to render their movements more easy, and to prevent their being laid hold of by the trees and bushes; two of these bold buntsmen get on horseback; one of them bestrides the back of the steed-a short stick in one hand, the reins in the other-while behind him sits his companion, armed with a sharp broad-sword. As soon as they perceive a grazing elephant, they instantly ride up to him, or cross him in all directions if he flies, uttering at the same time a torrent of abuse, for the purpose, as they fancy, of raising his anger. With outstretched trunk the elephant attempts to seize the noisy intruders, and following the perfectly trained horse, which, springing from side to side, leads him along in vain pursuit, neglects flight into the woods, his sole chance of safety, for while his whole attention is fixed on the rapid movements of the horse, the swordsman, who has sprung unperceived from its back, approaches stealthily from behind, and with one stroke of his weapon, severs the tendon just above the heel. The disabled monster falls shrieking to the ground, and incapable of advancing a step, is soon dispatched. The whole flesh is then cut off his bones into thongs, and hung like festoons upon the branches of trees till perfectly dry, when it is taken down and laid by for the rainy season.

The Asiatic elephant inhabits Hindostan, the Chin-Indian peninsula, Sumatra, Borneo, and Ceylon. In the latter island especially, he was formerly found in incredible numbers, so that thirty years ago, an English sportsman killed no less than 104 elephants in three days. Major Rogers shot upwards of 1,400; Captain Galloway has the credit of slaying more than half that number; Major Skinner almost as many, and less persevering aspirants follow at humbler distances. A reward of a few shillings a head, offered by the government for taking elephants, was claimed for 3,500 de. stroyed in part of the northern provinces alone, in less than three years prior to 1848 , and between 1851 and 1856 a similar reward was paid for 2,000 in the southern provinces. In consequence of this wholesale slaughter, it cannot be wondered at that the Ceylon elephant has entirely disappeared from districts in which he was formerly numerous, and that the peasantry in some parts of the island have even suspended the ancient practice of keeping watchers and fires by night to drive away the elephants from the growing crops. The opening of roads, and the clearing of the mountainforests of Candy for the cultivation of coffee, have forced the animals to retire to the low country, where again they have bcen followed by large parties of European sportsmen; and the Singhalese themselves being more freely provided with arms than in former times, have assisted in the work of extermination. The practice in Ceylon is to aim invariably at the head; and, generally speaking, a single ball planted in the forehead ends the existence of the noble creatures instantaneously.

In India and Ceylon, elephants have been caught and tamed from time immemorial, and when we compare their colossal strength with the physical weakness of pan, it 
surely must be considered a signal triumph of his intelligence and courage, that he is able to bend such gigantic creatures to his will. The professional elephant-catchers of Ceylon, or Panickeas, as they are called, are particularly remarkable for their daring and adroitness. Their ability in tracing their huge game, rivaling that of the American Indian in following the enemy's trail, has almost the certainty of instinct, and hence their services are eagerly sought by the European sportsmen who go down into their country in search of game. So keen is their glance, that almost at the top of their speed, like hounds running breast-high, they will follow the course of an elephant over glades covered with stunted grass, where the eye of a stranger would fail to discover a trace of its passage, and on through forests strewn with dry leaves, where it seems impossible to perceive a footstep. Here they are guided by a bent or broken twig, or by a leaf dropped from the animal's mouth on which they can detect the pressure of a tooth. If at fault, they fetch a circuit like a setter, till lighting on some fresh marks, they go ahead again with renewed vigor. So delicate is the sense of smell in the elephant, and so indispensable is it to go against the wind in approach. ing him, that the Panickeas on those occasions when the wind is so still that its direction cannot be otherwise discerned, will suspend the film of a gossamer to determine it, and shape their course accordingly.

On overtaking the game, their courage is as conspicuous as their sagacity. If they have confidence in the sportsman'for whom they are finding, they will advance to the very heel of the elephant, slap him on the quarter, and then convert his timidity into anger, till he turns upon his tormentor, and exposes his heavy front to receive the bullet which is awaiting him. So fearless and confident are they, that two men without aid or attendants will boldly attempt to capture the largest-sized elephant. Their only weapon is a flexible rope made of buffalo's hide, with which it is their object to secure one of the hind-legs. This they effect either by following in his footsteps when in motion, or by stealing close up to him when at rest, and, availing themselves of the propensity of the elephant at such moments to swing his feet backwards and forwards, they contrive to slip a noose over his hind-leg.

At other times, this is achieved by spreading the noose on the ground, partially concealed by roots and leaves, beneath a tree on which one of the party is stationed, whose business it is to lift it suddenly by means of a cord, raising it on the elephant's leg at the moment when his companion has succeeded in provoking him to place his foot within the circle, the other end having been previously made fast to the stem of the tree. Should the noosing be effected in open ground, and no tree of sufficient strength at hand round which to wind the rope, one of the Moors, allowing himself to be pursued by the enraged elephant, entices him towards the nearest grove, when his companion, dexterously laying hold of the rope as it trails along the ground, suddenly coils it round a suitable stem, and brings the fugitive to a stand still. On finding bimself thus arrested, the natural impulse of the captive is to turn on the man who is making fast the rope, a movement which it is the duty of bis colleague to prevent by running up close to the elephant's head, and provoking him to confront him by irritating gesticulations and incessant shouts of dah! dah! a monosyllable, the sound of which the elephant peculiarly dislikes. Meanwhile the first assailant having secured one noose, comes up from behind with another, with which, amidst the vain rage and struggles of the victim, he entraps a fore-leg, the rope being as before se- 
cured to another tree in front, and the whole four feet having been thus entangle 1 the capture is completed. A shelter is then run up with branches to protect him from the sun, and the hunters proceed to build a wigwam for themselves in front of their prisoner, kindling their fires for cooking, and making all the necessary arrangements for remaining day and night on the spot, to await the process of subduing and taming his rage.

Picketed to the ground like Gulliver by the Lilliputians, the elephant soon ceases to struggle, and what with the exhaustion of ineffectual resistance, the constant annoyance of smoke, and the liberal supply of food and water with which he is indulged, a few weeks generally suffice to subdue his spirit, when his keepers at length venture to remove him to their own village, or to the seaside for shipment to India. No part of the hunter's performances exhibits greater skill and audacity than this first forced march of the recently captured elephant. As he is still too morose to submit to be ridden, and it would be equally impossible to lead or drive him by force, the ingenuity of the captors is displayed in alternately irritating and eluding his attacks, but always so attracting his attention, as to allure him along in the direction in which they want him to go.

My limits forbid me entering upon a detailed account of the great elephant-hunts of India and Ceylon, where whole herds are driven into an inclosure and entrapped in one vast decoy. This may truly be called the sublime of sport, for nowhere is it conducted on a grander scale, or so replete with thrilling emotions. The keddah or corral, as the enclosure is called, is constructed in the depth of the forests, several hundred paces long, and half as broad, and of a strength commensurate to the power of the animals it is intended to secure. Slowly and cautiously the doomed herds are driven onwards from a vast circuit by thousands of beaters in narrowing circles to the fatal gate, which is instantly closed behind them, and then the hunters, rushing with wild elamor and blazing torches to the stockade, complete the terror of the bewildered animals. Trumpeting and screaming with rage and fear, they rush round the corral at a rapid pace, but all their attempts to force the powerful fence are vain, for wherever they assail the palisade, they are met with glaring flambeaus and bristling spears, and on whichever side they approach, they are repulsed with shouts and discharge of musketry. For upwards of an hour their frantic efforts are continued with unabated energy, till at length, stupified, exhausted, and subdued by apprehension and amazement, they form themselves into a circle, and stand motionless under the dark shade of the trees in the middle of the corral. The artist, on the page 470 of this volume, has given a picture of a herd of captured elephants thus " tied up."

To secure the entrapped animals, the assistance of tame elephants or decoys is necessary, who, by occupying their attention and masking the movements of the nooser, give him an opportunity of slipping one by one a rope round their feet until their capture is completed. The quickness of eye displayed by the men in watching the slightest movement of an elephant, and their expertness in flinging the noose over its foot, and attaching it firmly before the animal can tear it off with its trunk, are no less admirable than the rare sagacity of the decoys, who display the most perfect conception of the object to be attained, and the means of accomplishing it. Thus Sir Emerson Tennent saw more than once, during a great elephant hunt which he witnessed in 1847, that when one of the wild elephants was extending his trunk, and would have intercepted 
the rope about to be placed over his leg, the decoy, by a sudden motion of her own trunk, pushed his aside and prevented him ; and on one occasion, when successive efforts had failed to put the noose over the leg of an elephant who was already secured by one foot, but who wisely put the other to the ground as often as it was attempted to pass the noose under it, he saw the decoy watch her opportunity, and when his foot was again raised, suddenly push in her own leg beneath it, and hold it up till the noose was attached and drawn tight. A part from the services which from their prodigious strength the tame elephants are alone capable of rendering, in dragging out and securing the captives, it is perfectly obvious that, without their sagacious cooperation, the utmost prowess and dexterity of the hunters would not avail them to enter the enclosure unsupported, or to ensnare and to lead out a single captive.

It must not be supposed, however, that every elephant thus corraled is secured. Sometimes one will, by the use of a little "Head-work," try to get free from the cords which have bound his legs. His buttings and pitchings are a sight to bebold. At other cimes an "obstinate brute" will lie down, refuse to take food, and in a short time die

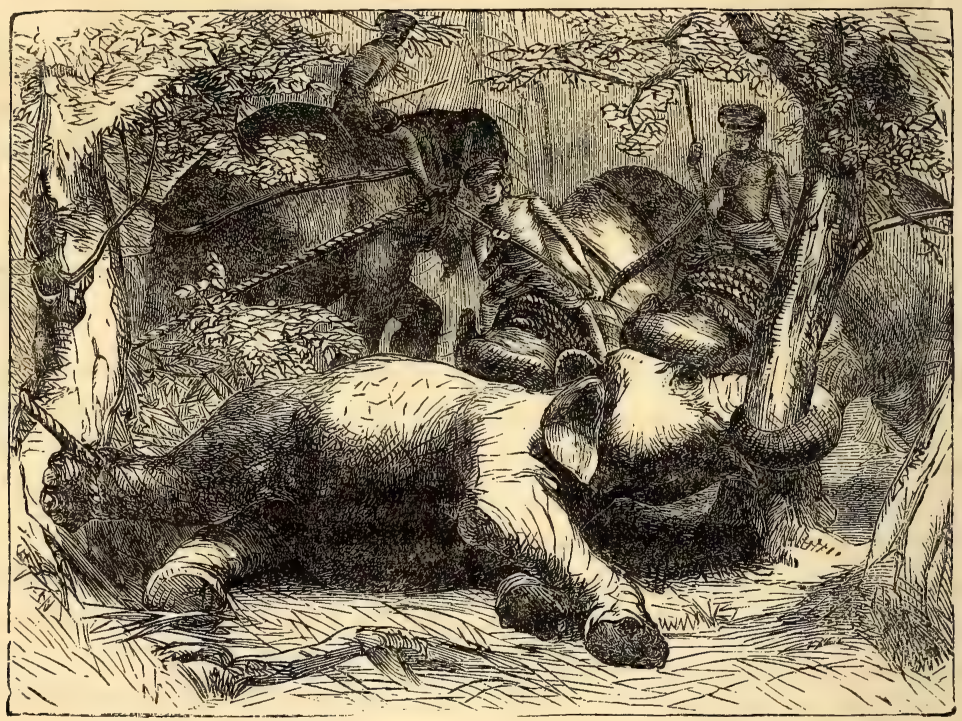

AN OBSTINATE BRUTE.

without any perceptible disease. The natives say that he dies of a broken heart, and that the animal thus lost is likely to be the very finest of the whole herd.

It may easily be imagined that the passage from a life of unfettered liberty in the cool and sequestered forest to one of obedience and labor, must necessarily put the health of the animal to a severe trial. Official records prove that more than half of the elephants employed in the public departments of the Ceylon government die in one year's servitude, and even when fully trained and inured into captivity, the work. ing elephant is always a delicate animal, subject to a great variety of diseases, and consequently often incapacitated from labor. Thus, in spite of his colossal strength, which can not even be employed to its full extent, as it is difficult to pack him without chafing the skin and wagons of corresponding dimension to his muscular powers 
would utterly ruin the best constructed roads, it is very doubtful whether his services are in proportion to his cost, and Sir Emerson Tennent is of opinion that two vigorous dray horses would, at less expense, do more effectual work than any elephant. Most likely from a comparative calculation of this kind, the strength of the elephant establishments in Ceylon has been gradually diminished of late years, so that the government stud, which formerly consisted of upwards of sixty elephants, is at present reduced to less than one-quarter of that number.

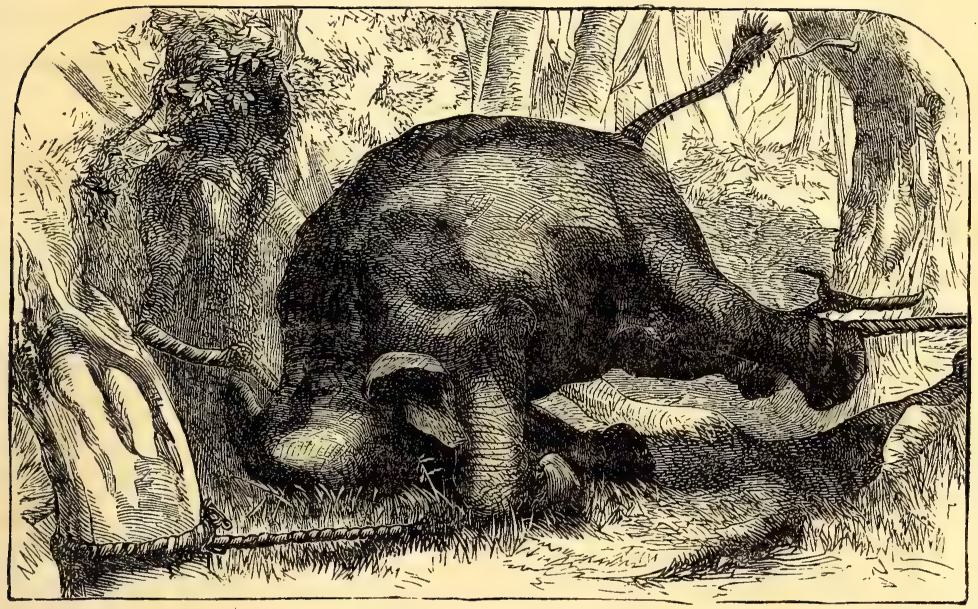

A LitTLE HEAD WORK.

The Rhinoceros has about the same range as the elephant, but is found also in the island of Java, where the latter is unknown. Although not possessed of the ferocity of carnivorous animals, the rhinoceros is completely wild and untamable; the image of a gigantic hog, without intelligence, feeling or docility; and if in bodily size and colossal strength it, of all other land animals, most nearly approaches the elephant, it is infinitely his inferior in point of sagacity. The latter, with his beautiful, goodnatured, intelligent eye, awakens the sympathy of man; while the rhinoceros might figure as the very symbol of brutal violence and stupidity.

It was formerly supposed that Africa had but one rhinoceros, but the researches of modern travelers have discovered no less than four different species, two white and two black, each of them with two horns. The black species are the Borelo of the Bechuanas, and the Keitloa, which is longer, with a larger neck and almost equal horns. In both species the upper lip projects over the lower, and is capable of being extended like that of the giraffe, thus enabling the animal to pull down the branches on whose foliage he intends to feast. Both the Borelo and the Keitloa are extremely ill-natured, and, with the exception of the buffalo, the most dangerous of all the wild animals of South Africa. The white species are the Monoho ( $R$. simus.) and the Kobaaba ( $R$. Oswellis, ) which is distinguished by one of its horns attaining the prodigious length of four feet.

Although the black and white rhinoceros are members of the same family, their mode of living and disposition are totally different. The food of the former consists almost entirely of roots, which they dig up with their larger horn, or of the branches 
and sprouts of the thorny acacia, while the latter exclusively live on grasses. Perhaps in consequence of their milder and more succulent food, they are of a timid unsuspecting nature, which renders them an easy prey, so that they are fast melting away before the onward march of the European trader; while the black species, from their great ferocity and wariness, maintain their place much longer than their more timid relations. The different nature of the black and white rhinoceros shows itself even in their flesh, for while that of the former, living chiefly on arid branches, has a sharp and bitter taste, and but little recommends itself by its meagerness and tough. ness-the animal, like the generality of ill-natured creatures, being never found with an ounce of fat on its bones-that of the latter is juicy and well-flavored, a delicacy both for the white man and the negro.

The shape of the rbinoceros is unwieldy and massive; its vast paunch hangs down nearly to the ground; its short legs are of columnar strength, and have three toes on each foot; the mis-shapen head has long and erect ears, and ludicrously small eyes; the skin, which is completely naked, with the exception of some coarse bristles at the extremity of the tail, and the upper end of the ears, is comparatively smooth in the African species, but extremely rough in the Asiatic, hanging in large folds about the animal like a mantle; so that, summing up all these characteristics, the rhinoceros has no reason to complain of injustice, if we style it the very incarnation of ugliness. From the snout to the tip of the tail, the African rhinoceros attains a length of from 15 to 16 feet, a girth of from 10 to 12 , a weight of from 4,000 to 5,000 pounds ; but in spite of its ponderous and clumsy proportions, it is able to speed like lightning, particularly when pursued. It then seeks the nearest wood, and dashes with all its might through the thicket. The trees that are dead or dry are broken down as with a cannon shot, and fall behind it and on its sides in all directions; others that are more pliable, greener, or full of sap are bent back by its weight and the velocity of its motions, and restore themselves like a green branch to their natural position, after the animal has passed. They often sweep the incautious pursuer and his horse from the ground, and dash them in pieces against the surrounding trees.

The rhinoceros is endowed with an extraordinary acuteness of smell and hearing; he listens with attention to the sounds of the desert, and is able to scent from a great distance the approach of man; but as the range of his small and deep-set eyes is impeded by his unwieldy horns, he can only see what is immediately before him, so that if one be to the leeward of him, it is not difficult to approach within a few paces. The Kobaaba, however, from its horn being projected downwards, so as not to obstruct the line of vision, is able to be much more wary than the other species. To make up for the imperfection of sight, the rhinoceros is frequently accompanied by a bird (Buphaga africana) which seems to be attached to it like the domestic dog to man, and warns the beast of approaching danger by its cry. It is called Kala, by the Bechuanas, and when these people address a superior, they call him " My Rhinoceros" by way of compliment, as if they were the birds ready to do him service.

The black rbinoceroses are of a gloomy, melancholy temper, and not seldom fall into paroxysms of rage without any evident cause. Seeing the creatures in their wild haunts, cropping the bushes, or quietly moving through the plains, you might take them for the most inoffensive, good-natured animals of all Africa, but when roused to passion there is nothing more terrific on earth. All the beasts of the wilderness are 
afraid of the uncouth Borelo. The lion silently retires from its path, and even the elephant is glad to get out of the way. Yet this brutal and stupidly hoggish animal is distinguished by its parental love, and the tenderness which it bestows on its young is returned with equal affection. European hunters have often witnessed that when the mother dies, the calf remains two full days near the body.

Although not gregarious, and most generally solitary or grazing in pairs, yet fre. quently as many as a dozen rhinoceroses are seen pasturing and browsing together. As is the case with many other inhabitants of the tropical wilderness, the huge beast awakens to a more active life after sunset. It then hastens to the lake or river to slake its thirst or to wallow in the mud, thus covering its bide with a thick coat of clay, against the attacks of flies ; or to relieve itself from the itching of their stings, it rubs itself against some tree, and testifies its inward satisfaction by a deep-drawn grunt. During the night, it rambles over a great extent of country, but soon after sunrise seeks repose and shelter against the heat under the shade of a mimosa, or the projecting ledge of a rock, where it spends the greater part of the day in sleep, either stretched at full length or in a standing position. Thus seen from a distance, it might easily be mistaken for a huge block of stone.

The rhinoceros is hunted in various manners. One of the most approved plans is to stalk the animal, either when feeding or reposing. If the sportsman keep well under the wind, and there be the least cover, he has no difficulty in approaching the beast within easy range, when, if the ball be well directed, it is killed on the spot. But by far the most convenient way of destroying the animal is to shoot it from a cover or a screen, when it comes to the pool to slake its thirst. Occasionally it is also taken in pitfalls. Contrary to common belief, a leaden ball (though spelter is preferable) will easily find its way through the hide of the African rhinoceros, but it is necessary to be within thirty or forty paces of the brute, and desirable to have a double charge of powder. The most deadly part to aim at is just behind the shoulder; a ball through the center of the lobes of the lungs is certain to cause almost instantaneous death. A shot in the head never or rarely proves fatal, as the brain, which, in proportion to the bulk of the animal, does not attain the three-hundredth part of the size of the human cerebrum, is protected, besides its smallness, by a prodigious case of bone, hide, and horn. However severely wounded the rhinoceros may be, he seldom bleeds externally. This is attributable in part, no doubt, to the great thickuess of the hide and its elasticity, which occasions the bole caused by the bullet nearly to close up, as also from the hide not being firmly attached to the body, but constantly moving. If the animal bleed at all, it is from the mouth and nostrils, which is a pretty sure sign that it is mortally hurt, and will soon drop down dead. It is remarkable that the rhinoceros, when hit by a fatal bullet, does not fall upon one side, but generally sinks on its knees, and thus breathes its last.

From what has been related of the fury of the rhinoceros, its pursuit must evidently be attended with considerable danger, and thus the annals of the wild sports of Southern Africa are full of hair breadth escapes from its terrific charge. The rhinoceros is hunted for its flesh, its hide (which is manufactured into the best and hardest leather that can be imagined), and its horns, which, being capable of a high polish, fetch at the Cape a higher price than ordinary elephant ivory. It is extensively used in the manufacture of sword-handles, drinking-cups, ramrods for rifles, and a variety of other 
purposes. Among Oriental princes, goblets made of rhinoceros-horn are in high esteem, as they are supposed to have the virtue of detecting poison by causing the deadly liquid to ferment till it flows over the rim, or, as some say, to split the cup. The number of rhinoce roses destroyed annually in South Africa is very considerable. Captain Harris, who once saw two-and-twenty together, shot four of them one after the other to clear his way. Messrs. Oswell and Varden killed in one year no less than eighty-nine; and in one journey, Andersson shot, single-handed, nearly two thirds of this number. It is thus not to be wondered at that the rhinoceros, which formerly ranged as far as the Cape, is now but seldom found to the south of the tropic. The progress of African discovery bodes no good to him or to the hippopotamus.

The single-horned Indian rhinoceros was already known to the ancients, and not unfrequently doomed to bleed in the Roman amphitheatres. One which was sent to King Emanuel of Portugal in the year 1513, and presented by him to the Pope, had the honor to be pictured in a wood cut by no less an artist than Albrecht Dürer himself. Latterly, rhinoceroses have much more frequently been sent to Europe, particularly the Asiatic species, and all the chief zoölogical gardens possess specimens of the unwieldy creature.

In its native haunts, the Indian rhinoceros leads a tranquil, indolent life, wallowing on the marshy border of lakes and rivers, and occasionally bathing itself in their waters. Its movements are usually slow, and it carries its head low like the hog, plowing up the ground with its horn, and making its way by sheer force through the jungle. Though naturally of a quiet and inoffensive disposition, it is very furious and dangerous when provoked or attacked, charging with resistless impetuosity, and trampling down or ripping up with its horn any animal which opposes it.

Besides the single-horned species which inhabits the Indian peninsula, Java, and Borneo, Sumatra possesses a rhinoceros with a double horn, which is, however, distinguished from the analogous African species by the large folds of its skin, and its smaller size. It is even asserted that there exists in the same island a hornless spe. cies, and another with three horns. There surely can be no better proof of the difficulties which Natural History has to contend with in the wilder regions of the tropical zone, and of the vast field still open to future zoölogists, than that, in spite of all investigations and travels, we do not yet even know with certainty all the species of so large a brute as the rhinoceros.

In Java, this huge pachyderm is met with in the jungles of the low country, but its chief haunts are the higher forest-lands, which contain many small lakes and pools, whose banks are covered with high grasses. Here and there, also, the woods are interspersed with dry pasture-grounds, and even in the interior of the forests, numerous species of gramineæ are found increasing in number as they rise above the level of the sea. In these solitudes, which are seldom visited by man, the rhinoceros finds all that it requires for food and enjoyment. As it is uncommonly shy, the traveler rarely meets it, but sometimes, while threading his way through the thicket, he may chance to surprise wild steers and rhinoceroses grazing on the brink of a pool, or quietly lying in the morass. The grooved paths of the rhinoceros, deeply worn into the solid rock, and thus affording proof of their immemorial antiquity, are found even on the summits of mountains above the level of the sea. They are frequently usod for the destruction uf the animal, for in the steeper places, where, on climbing up or down, it is obliged 
to stretch out its body, so that the abdomen nearly reaches the ground, the Javanese fix large scythe-like knives into the rock, which they cover with moss and herbage, thus forcing the poor rbinoceros to commit an involuntary suicide, and teaching him, though too late to profit by his experience, how difficult it is to escape the cunning of man, even on the mountain peak.

"Behold now Behemoth, which I made with thee; he eateth grass as an ox; his bones are as strong pieces of brass; his bones are like bars of iron; he lieth under the shady trees in the covert of the reed and fens. The shady trees cover him with their shadow; the willows of the brook compass him about. Behold he drinketh up a river ; he trusteth that he can draw up Jordan into his mouth." Thus, in the book of Job, we find the Hippopotamus portrayed with few words but incomparable power. How tame after this noble picture must any lengthened description appear !*

According to the inspired poet, the hippopotamus seems anciently to have inbabited the waters of the Jordan, but now it is nowhere to be found in Asia; and even in Africa the limits of its domain are perpetually contracting before the persecutions of man. It has entirely disappeared from Egypt and the rivers of the Cape Colony, where Le Vaillant found it in numbers during the last century. In many respects a valuable prize; of easy destruction, in spite, or rather on account of its size, which betrays it to the attacks of its enemies; a dangerous neighbor to plantations, it is condemned to retreat before the waves of advancing civilization, and would long since have been extirpated in all Africa, if the lakes and rivers of the interior of that vast den of barbarism were as busily plowed over as ours by boats and ships, or their banks as thickly strewn with towns and villages.

For the hippopotamus is not able, like so many other beasts of the wilderness, to hide itself in the gloom of impenetrable forests, or to plunge into the sandy desert, traversed by the Bedouin on his dromedary; it requires the neighborhood of the stream, the empire of which it divides with its amphibious neighbor the crocodile. Occasionally during the day it is to be seen basking on the shore amid ooze and mud, but throughout the night the unwieldy monster may be heard snorting and blowing during its aquatic gambols; it then sallies forth from its reed-grown coverts to graze by the light of the moon, never, however, venturing to any distance from the river, the stronghold to which it betakes itself on the smallest alarm.

In point of ugliness the hippopotamus, or river-horse, as it has also very inappropriately been named, might compete with the rhinoceros itself. Its shapeless carcass rests upon short and disproportioned legs, and, with its vast belly almost trailing upon the ground, it may not inaptly be likened to an overgrown "prize pig." Its immensely large head has each jaw armed with two formidable tusks, those in the lower, which are always the largest, attaining at times two feet in length; and the inside of the mouth is said to resemble a mass of butcher's meat. The eyes, which are placed in prominences like the garret windows of a Dutch house, the nostrils, and ears, are all on the same plane, on the upper level of the head, so that the unwieldy monster,

* It should be noted, however, that it is not altogether certain that the Hippopotamus is really the Behemoth of Job. Dr. Thomson, than whom there can hardly be better authority, in his admirable work "The Land and the Book," argues plausibly that Behemoth is the Syrian Buffalo. 
when immersed in its favorite element, is able to draw breath, and to use three senses at once for hours together, without exposing more than its snout. The hide, which is upwards of an inch and a balf in thickness, and of a pinkish brown color, clouded and freckled with a darker tint, is destitute of covering, excepting a few seattered hairs on the muzzle, the edges of the ears and tail. Though generally mild and inoffensive, it is not to be wondered at that a creature like this, which when full grown attains a length of eleven or twelve feet, and nearly the same colossal girth, affords a truly appalling spectacle when enraged, and that a nervous person may well lose bis presence of mind when suddenly braught into contact with the gaping monster.

As among the sperm-whales, sea-bears, elephants, and other animals, elderly males are sometimes expelled from the herd, and, for want of company, become soured in their temper, and so misanthropic as to attack every boat that comes near them. The herd is never dangerous except when a canoe passes into the midst of it when all are asleep, and some of them may strike it in terror. To avoid this, it is generally recommended to travel by day near the bank, and by night in the middle of the stream. The " solitaires," or "rogue-hippopotami," frequent certain localities well known to the inhabitants of the banks, and, like the outcast elephants, are extremely dangerous. Dr. Livingstone, passing a canoe which had been smashed to pieces by a blow from the hind foot of one of them, was informed by his men that, in case of a similar assault being made on his boat, the proper way was to dive to the bottom of the river, and hold on there for a few seconds, because the hippopotamus, after breaking a canoe, always looks for the people on the surface, and if he sees none, soon moves off. He saw some frightful gashes made on the legs of the people who, having had the misfortune to be attacked, were unable to dive. One of these "bachelors" one day actually came out of his lair, and, putting his head down, ran with very considerable speed after the missionary and his party ; and another time they were nearly overturned by a hippopotamus striking the canoe with its forehead. The butt was so violent as to tilt one of the boatmen out into the river, while the rest sprang to the shore, which was only about ten yards off; the beast looking all the time at the canoe, as if to ascertain what mischief it had done.

In rivers where it is seldom disturbed, such as the Zambesi, the hippopotamus puts up its head openly to blow, and follows the traveler with an inquisitive glance, as if asking him, like the "moping owl" in Grey's Elegy, why he came to molest its " ancient solitary reign?" but in other rivers, such as those of Londa, where it is much in danger of being shot, the hippopotamus takes good care to conceal its nose among waterplants, and breathe so quietly that one would not dream of its existence in the river, except by footprints on the banks. Notwithstanding its stupid look-its prominent eyes and naked snout giving it more the appearance of a gigantic boiled calf's head than anything else-the huge creature is by no means deficient in intelligence, knows how to avoid pitfalls, and has so good a memory that, when it has once heard a ball whiz about its ears, it never after ceases to be cautious and "wide awake" at the approach of danger. Being vulnerable only behind the ear, however, or in the eye, it requires the perfection of rifle-practice to be hit; and once in the water, is still more difficult to kill. It dives and swims with all the ease of a walrus or a sea-elephant, its huge body being rendered buoyant by an abundance of fat.

Its flesh is said to be delicious, resembling the finest young pork, and is considered 
as great a delicacy in Africa as a bear's paw or a bison's hump in the prairies of North America. The thick and almost inflexible hide may be dragged from the ribs in strips, like the planks from a ship's side. These serve for the manufacture of a superior description of sjambok, the elastic whip with which the Cape boer governs his team of twelve oxen or more, while proceeding on a journey. In Northern Africa it is used to chastise refractory dromedaries or servants; and among the collection brought by $\mathrm{Du}$ Chaillu from Equatorial Africa were several whips of hippopotamus-hide, which any one who has had opportunity of examination would pronounce to be among the most effective instruments of flagellation; and the ancient Egyptians employed it largely in the manufacture of shields, helmets, and javelins. But the most valuable part of the hippopotamus is its teeth (canine and incisors), which are considered greatly superior to elephant ivory, and when perfect and weighty, will fetch as much as one guinea per pound, being chiefly used for artificial teeth, since it does not readily turn yellow. Many a belle, whose fascinating "ivories" are the wonder of her admirers, is indebted for them to the ugly river-horse. All these qualities and uses to which the hippopotamus may be applied are naturally so many prices set upon its head; and the ravages it occasions in the fields are another motive for its destruction. On the White Nile the peasantry burn a number of fires, to keep the huge animal away from their plantations, where every footstep ploughs deep furrows into the marshy ground, to the great injury of the harvest. At the same time, they take care to keep up a prodigious clamor of horns and drums, to scare away the ruinous brute, which, as may well be imagined, is by no means so great a favorite with them as with the visitors of the Zoölogical Gardens.

They have besides another, and, where it takes effect far more efficacious method of freeing themselves from the depredations of this animal. They remark the places it most frequents, and there lay a large quantity of pease. When it comes on shore hungry and voracious, it falls to eating what is nearest, and fills its vast stomach with the pease, which soon occasion an insupportable thirst. The river being close at hand, it immediately drinks whole buckets of water, as if it were intent upon swallowing up not merely the little Jordan, but the whole Nile itself, which, by swelling the pease, cause it to blow up, like an overloaded mortar.

The natives on the Teoge, and other rivers that empty themselves into Lake Ngami, kill the hippopotamus with iron harpoons, attached to long lines ending with a float. A huge reed raft, capable of carrying both the hunters and their canoes, with all that is needful for the prosecution of the chase, is pushed from the shore, and afterwards abandoned to the stream, which propels the unwieldy mass gently and noiselessly forward. Long before the hippopotami can be seen, they make known their presence by awful snorts and grunts, whilst splashing and blowing in the water. On approaching the berd-for the gregarious animal likes to live in troops of from twenty-five to thirty-the most skillful and intrepid of the hunters stands prepared with the harpoons, whilst the rest make ready to launch the canoes should the attack prove successful. The bustle and noise caused by these preparations gradually subside. At length not even a whisper is heard, and in breathless silence the hunters wait for the decisive conflict. The snorting and plunging become every moment more distinct; a bend in the stream still hides the animals from view; but now the point is passed, and monstrous figures, that might be mistaken for shapeless cliffs, did not ever and anon 
one or the other of them plunge and reappear, are seen dispersed over the troubled waters. On glides the raft, its crew worked up to the highest pitch of excitement, and at length reaches the herd, which, perfectly unconscious of danger, continue to enjoy their sports. Presently one of the animals is in immediate contact with the raft. Now is the critical moment; the foremost harpooner raises himself to his full height to give the greater force to the blow, and the next instant the iron descends with unerring accuracy, and is buried deep in the body of the bellowing hippopotamus. The wounded animal plunges violently and dives to the bottom, but all its efforts to escape are as ineffectual as those of the seal when piersed with the barbed iron of the Greenlander.

As soon as it is struck, one or more of the men launch a canoe from the raft, and hastening to the shore with the harpoon line, take a round turn with it about a tree, so that the animal may either be brought up at once, or should there be too great a strain on the line, "played," like a trout or salmon by the fisherman. Sometimes botb line and buoy are cast into the water, and all the canoes being launched from off the raft, chase is given to the poor brute, who whenever he comes to the surface is saluted with a shower of javelins. A long trail of blood marks his progress. his flight becomes slower and slower, his breathing more oppressive, until at last, his strength ebbing away through fifty wounds, he floats dead on the surface.

But as the whale will sometimes turn upon his assailants, so also the hippopotamus not seldom makes a dash at his persecutors, and either with his tusks, or with a blow from his head, staves in or capsizes the canne. Sometimes even, not satisfied with wreaking his vengeance on the craft, he seizes one or other of the crew, and with a single grasp of his jaws, either terribly mutilates the poor wretch or even cuts his body fairly in two.

The natives of Southern Africa also resort to the ingenious plan of destroying the hippopotamus by means of a downfall, consisting of a $\log$ of wood with stones attached to it to increase its weight, and a harpoon affixed to its lower end. This formidable weapon depends from the branch of an overhanging tree by means of a line, which is then made to cross horizontally the pathway which the hippopotamus is in the habit of frequenting during the night, at a short distance from the ground. When the animal comes in contact with the line, which is secured on either side of the path by a small peg, it snaps at once, or is disengaged by means of a trigger. The liberated downfall instantly descends with the rapidity of lightning, and the harpoon is driven deep into the back of the monster, who, bellowing with pain, plunges into the river, where he soon after dies in excruciating torments.

A few tropical animals, for which we have heretofore found no appropriate place, yet remain to be considered. Foremost of these is the Camel. In many respects, the vast sandy deserts of Asia and Africa remind one of the ocean. There is the same boundless horizon, the same unstable surface, now rising, now falling with the play of the winds; the same majestic monotony, the same optical illusions, for as the thirsty mariner sees phantom palm-groves rise from the ocean, thus also the sand waste transforms itself, before the panting caravan, into the semblance of a refreshing lake. Here we see islands, verdant oases of the sea-there, oases, green islands of the desert: bere, sand-billows-there, water waves, separating widely different worlds of plants 
and animals; here, the ship, the camel of the ocean-there, the dromedary, the ship of the desert.

But for the camel, the desert itself would ever have remained impassable and unknown to man. On it alone depends the existence of the nomadic tribes of the Orient, the whole commercial intercourse of North Africa and South-west Asia, and no wonder that the Bedouin prizes it, along with the fruit-teeming date-palm, as the most precione gift of Allah. Other animals have been formed for the forest, the water, the savanna; to be the guide, the carrier, the companion, the purveyor of all man's wants in the desert, is the camel's destiny. Wonderfully has he been shaped for this peculiar life; formed to endure privations and fatigues under which all but he would sink. On examining the camel's foot, it. will at once be seen how well it is adapted for walking on a loose soil, as the full length of its two toes is provided with a broad, expanded, and elastic sole. Thus the camel treads securely and lightly over the unstable sands, while he would either slip or sink on a muddy ground. He can support hunger longer than any other mammiferous animal, and is satisfied with the meanest food. Frugal, like his lord the wiry Bedouin, the grinding power of his teeth and his cartilaginous palate enable him to derive nutriment from the coarsest shrubs, from thorny mimosas and acacias, or even from the stony date-kernels, which his master throws to him after having eaten the sweet flesh in which they are imbedded.

For many days he can subsist without drinking, as the pouch-like carities of his stomach-a peculiarity which distinguishes him from all other quadrupeds, perhaps, with the sole exception of the elephant-form a natural cistern or reservoir, whose contents can be forced upwards by muscular contraction to meet the exigencies of the journey. It is frequently believed that this liquid remains constantly limpid and palatable, and that in cases of extreme necessity camels are slaughtered to preserve the lives of the thirsty caravan; but according to Russegger these accounts are fabulous, $\mathrm{s}$, particularly after a long abstinence from drinking, the dromedary's supply is nothing but a most nauseous mixture of putrid water and half digested food, from which eren Tantalus would turn away disgusted. But the "ship of the desert" is not only provided with water for the voyage, but also with liberal stores of fat, which are chiefly accumulated in the hump ; so that this prominence, which gives it so deformed an appearance, is in reality of the highest utility-for should food be scarce, and this is almost always the case while journeying through the desert, internal absorption makes up in some measure for the deficiency, and enables the famished camel to brave for some time longer the fatigues of the naked waste. Yet all mortal endurance has its limits, and even the camel, though so well provided against hunger and thirst, must frequently succumb to the excess of his privations, and the bleached szeletons of the much enduring animal strewed along the road mark at once the path ef the caravat and the dreadful sufferings of a desert-journey.

But eren these horrid wastes, where the glowing Khamsin whirls the sands in suffo. cating eddies, have beauties of their own. Particularly when the full moon shines in the dark blue sky, bespangled with constellations of a brilliancy unknown to the northern firmament, when the mountains throw their dark shades far away over the yellow sands, and the picturesque effect of the scene is enhanced by the aspect of the tents, the watch-fires, and the reposing animals; then we may well conceive how tho wandering Badouin loves the desert no less than the mariner loves the ocean, or the 
Swiss peasant his snow-clad mountains; and how it inflames the imagination of the oriental poets to many a song, solacing the tediousness of the encampment, and handed on from one generation to another.

To the camel the vagrant Arab owes his immemorial liberty and independence; when attacked, he places at once the desert between the enemy and himself. Thus he has ever been indomitable, and when in other parts of the world we find that the fatal possession of an animal-the sable, the sea-otter-has entailed the curse of slavery upon whole nations, the dromedary in Arabia appears as the instrument of lasting freedom. Many a conquering horde has been stopped in its career by the desert, and while the false glory of the scourges of mankind that have so often thrown the East into bondage passed like a shadow, one century after another looks down from the hights of Sinai upon the free and unfettered sons of Ishmael.

But the Arab too often tarnishes his liberty by crime, and degrades the "ship of the desert" to be the accomplice of a robber. The Bedouin, anxious to pursue this base profession, inures himself, from an early age, to every fatigue, banishes sleep, patiently endures thirst, hunger and heat; and in the same manner accustoms his dromedary to every privation. A few days after the animal's birth he folds its legs under its body, forces it to kneel, and loads it with a weight which is gradually increased as it increases in strength. Instead of allowing it to seek its food whenever it pleases, or completely satisfy its thirst, he accustoms it to perform longer and longer journeys without eating or drinking, trains it to equal the horse in swiftness, as it surpasses him in strength-and when perfectly assured of its fleetness and endurance, loads it with the necessary provisions, rides away upon its back, waylays the traveler, plunders the secluded dwelling, and when pursued and forced to save his booty by a speedy flight, then shows what he and his dromedary can perform. Hurrying on day and night, almost without repose, or eating or drinking, he travels two hundred leagues in a week, and during this whole time his dromedary is allowed but one hour's rest a day, and a handful of meal for food. On this meagre diet the unwearied animal often speeds on seven or eight days without finding any water; and when by chance a pool or a spring lies on his way, he smells it at a distance of half a league, his burning thirst imparts new vigor to his speed, and he then drinks at once both for the past and the future, as his journeys often last several weeks, and his privations endure as long as his journeys.

While the Bactrian Camel, with a double hump, ranges from Turkestan to China, the single-hump camel or Dromedary, originally Arabian, has spread in opposite directions towards the East Indies, the Mediterranean, and the Niger, and is used in Syria, Egypt, Persia, and Barbary, as the commonest beast of burden. It serves the robber, but it serves also the peaceful merchant, or the pilgrim, as he wanders to Mecca to perform his devotions at the prophet's tomb. In long array, winding like a snake, the caravan traverses the desert. Each dromedary is loaded, according to its strength, with from six hundred to a thousand pounds, and knows so well the limit of its endurance, that it suffers no overweight, and will not stir kefore it be removed. Thus, with slow and measured pace, the caravan proceeds at the rate of ten or twelve leagues a day, often requiring many a week before attaining the end of its journey.

When we consider the deformity of the camel, we cannot doubt that its nature has suffered considerable changes from the thraldom and unceasing labors of more than 
one millenium. Its servitude is of older date, more complete, and more irksome, than that of any other domestic animal: of older date, as it inhabits the countries which history points out to us as the cradle of mankind ; more complete, as all other domestic animals still have their wild types roaming about in unrestrained liberty, while the whole camel race is doomed to slavery; more irksome, finally, as it is never kept for luxury or state like so many horses, or for the table like the ox, the pig, or the sheep, but is merely used as a beast of transport, which its master does not even give himself the trouble to attach to a cart, but whose body is loaded like a living wagon, and frequently even remains burdened during sleep. Thus the camel bears all the marks of serfdom. Large naked callosities of horny hardness cover the lower part of the breast and the joints of the legs; and although they are never wanting, yet they themselves give proof that they are not natural, but that they have been produced by an excess of misery and ill-treatment, as they are frequently found filled with a purulent matter.

The hardships of long servitude, which have thus gradually deformed the originaliy, perhaps, not ungraceful camel, have no doubt also soured its temper, and rendered its character as unamiable as its appearance is repulsive. "It is an abominably ugly necessary animal," says Mr. Russell; “ ungainly, morose, quarrelsome, with tee-totalling propensities; unaccountably capricious in its friendships and enmities; delighting to produce with its throat, its jaws, its tongue, and its stomach, the most abominable grunts and growls. Stupidly bowing to the yoke, it willingly submits to the most atrocious cruelties, and bites innocent, well-meaning persons, ready to take its part. When its leader tears its nostril, it will do no more than grunt; but, ten against one, it will spit at you if you offer it a piece of bread. For days it will march along, its nose close to the tail of the beast that precedes it, without ever making the least attempt to break from the chain; and yet it will snort furiously at the poor European who amicably pats its ragged hide." The camel seems to have been rather harshly dealt with in this description; at any rate, it may plead for its excuse that it would be too much to expect a mild and amiable temper in a toil-worn slave.

Which of all four-footed animals raises its head to the most towering hight? Is it the colossal elephant or the "ship of the desert?" No doubt the former reaches many a lofty branch with its flexible proboscis, and the eye of the long-necked camel sweeps over a vast extent of desert; but the Giraffe embraces a still wider horizon, and plucks the leaves of the mokaala at a still greater hight. A strange and most surprising animal, almost all neck and leg, seventeen feet high against a length of only seven from the breast to the beginning of the tail, its comparatively small and slanting body resting on long stilts, its diminutive head fixed at th ? summit of a column ; and yet in spite of these apparent disproportions, which seem rather to belong to the world of chimeras than to the realities of nature, of so elegant and pleasing an appearance, that it owes its Arabic name, Xirapha, to the graceful ease of its movements. The beauty of the giraffe is enhanced by its magnificently spotted skin, and by its soft and gentle eyes, which eclipse those of the far-famed gazelle of the East, and, by their lateral projection, take in a wider range of the horizon than is subject to the vision of any other quadruped, so as even to be able to anticipate a threatened attack in the rear from the stealthy lion or any other foe of the desert. 
The long, black tail, invariably curled above the back, no doubt renders it good service against many a stinging insect; and the straight horns, or rather excrescences of the frontal bone, small as they are, and muffled with skin and hair, are by no means the insignificant weapons they have been supposed to be. "We have seen them wielded by the males against each other with fearful and reckless force," says Maunder, " and we know that they are the natural arms of the giraffe most dreaded by the keeper of the present living giraffes in the Zoonlogical Gardens, because they are most commonly and suddenly put in use. The giraffe does not butt by depressing and suddenly elevating the head, like the deer, ox, or sheep, but strikes the callous obtuse extremity of the horns against the object of his attack with a sidelong sweep of the neck. One blow thus directed at full swing against the head of an unlucky attendant would be fatal. The female once drove her horns in sport through an inch board." The projecting upper lip of the giraffe is remarkably flexible, and its elongated prehensile tip, performing in miniature the part of the elephant's proboscis, is of material assistance in browsing upon the foliage and young shoots of the prickly acacia, which constitute the animal's chief food. With feet terminating in a divided hoof, and a ruminant like our ox, the giraffe has four stomachs, and an enormous intestinal length of 288 feet : a formation which bears testimony to the vast and prolonged powers of digestion necessary to extract nutrition from its hard and meagre diet.

Ranging throughout the wide plains of Central Africa, from Caffraria to Nubia, the giraffe, though a gregarious animal, generally roams about only in small herds. It is, indeed, by no means common even at its head-quarters, and Captain Harris, who traversed the desert as far as the Tropic of Capricorn, seldom found giraffes without having followed their trail, and never saw more than five-and-thirty in a day. Notwithstanding the rapidity with which the cameleopard strides along, the fore and hind leg on the same side moving together, instead of diagonally as in most other quadrupeds, Jet a full gallop quite dissipates its power; and the hunters, being aware of this, always try to press the giraffes at once to it, knowing that they have but a short space to run before the animals are in their power. In doing this the old sportsmen are careful not to go too close to the giraffe's tail ; for this animal, says Dr. Livingstone, "can swing his hind foot round in a way which would leave little to choose between a kick with it and a clap from the arm of a windmill."

After man, the giraffe's chief enemy is the lion, who often waits for it in the thick brakes on the margin of the rivers or the pools, and darts upon it with a murderous spring while it is slaking its thirst. Andersson, as we have already narrated,* once saw five lions, two of whom were in the act of pulling down a splendid giraffe, while the other three were watching close at hand the issue of the deadly strife; and Captain Harris relates that, while he was encamped on the banks of a small stream, a cameleopard was killed by a lion whilst in the act of drinking, at no great distance from the wagons. It was a noisy affair; but an inspection of the scene on which it occurred proved that the giant strength of the victim had been paralyzed in an instant. Sometimes the giraffe saves itself from the attacks of its arch-enemy by a timely flight; but when hemmed in, it offers a desperate resistance, and in spite of its naturally gentle and peaceable disposition, gives such desperate kicks with its fore-feet as to keep its antagonist at a respectful distance, and finally to compel him to retreat.

* Ante, p. 699. 
The Greeks and Romans were well acquainted with the giraffe ; and Aristotle, describing it under the name of hippardion, or panther-horse, probably knew it better than Buffon, who never saw more of it than a stuffed skin. Pliny relates that Julius Cæsar (45 в. с.) first exhibited it to the Romans in the amphitheatre, and from that time it often played a conspicuous part in the bloody spectacles with which the military despots of the declining empire used to entertain the rabble of Rome. Even during the middle ages giraffes were sometimes seen in Europe. The sultan of Egypt presented the German emperor, Frederick II., with a cameleopard ; and Lorenzo de Medicis was honored with a similar gift. But since that time three full centuries elapsed before a single giraffe was ever transported across the Mediterranean; and when at length the wily old tyrant Mehemet Ali, who knew how to flatter the French while grinding his poor Fellahs, sent one of them to the Jardin des Plantes in 1827, it raised no less a sensation than if it had been the unicorn itself. Thenceforth, the spell being broken, many giraffes have been imported into Europe and America. There are many analogies between the giraffe and the ostrich; both long-legged, long-necked, fit for cropping the tall mimosas, or scouring rapidly the plain; both, finally, defending themselves by striking their feet forwards, the one against the jackal or hyæna, the other against the assaults of the formidable lion.

As if to make up for the hideous deformity of the rhinoceros and hippopotamus, the African wilds exclusively give birth to the beautifully-striped Zebras, the most gorgeously attired members of the equine race.

The tawny-colored Quagga, irregularly banded and marked with dark brown stripes, which, stronger on the head and neck, gradually become fainter, until lost behind the shoulders, has its high crest surmounted by a standing mane, banded alternately brown and white. It used formerly to be found in great numbers within the limits of the Cape Colony, and still roams in vast herds in the open plains farther to the north. Thus, in the desert of the Meritsane, Major Harris, after crossing a park of magnificent camel-thorn trees, soon perceived large herds of quaggas and brindled gnus, which continued to join each other, until the whole plain seemed alive. The clatter of their hoofs was perfectly astounding, and could be compared to nothing but to the din of a tremendous charge of cavalry or the rushing of a mighty tempest. The accumulated numbers could not be estimated at less than 15,000, a great extent of country being actually chequered black and white with their congregated masses.

The Douw, or Burchell's Zebra, differs little from the common quagga in point of shape or size; but while the latter is faintly striped only on the head and neck, the former is adorned over every part of the body with broad black bands, beautifully contrasting with a pale yellow ground. Major Harris, who had many opportunites of seeing this fine species in a state of nature, remarks that, "Beautifully clad by the hand of nature, possessing much of the graceful symmetry of the horse, with great bones and muscular power, united to easy and stylish action, thus combining comeliness of figure with solidity of form, this species, if subjugated and domesticated, would assuredly make the best pony in the world." Although it admits of being tamed to a certain extent with the greatest facility - a half-domesticated specimen, with a jockey on its brindled back, being occasionally exposed in Cape Town for sale-it has hitherto contrived to evade the yoke of servitude. The senses of sight, hearing and smell, are 
extremely delicate. The slightest noise or motion, no less than the appearance of any object that is unfamiliar, at once rivets their gaze, and causes them to stop and listen with the utmost attention; any taint in the air equally attracting their olfactory organs.

"Instinct having taught these beautiful animals that in union consists their strength, they combine in a compact body when menaced by an attack, either from man or beast; and, if overtaken by the foe, they unite for mutual defence, with their heads together in a close circular band, presenting their heels to the enemy, and dealing out kicks in equal force and abundance. Beset on all sides, or partially crippled, they rear on their hinder legs, fly at their adversary with jaws distended, and use both teeth and beels with the greatest freedom."

The Gnu and the common quagga, delighting in the same situation, not unfrequently herd together; but Burchell's Zebra is seldom seen unaccompanied by troops of the brindled Gnu, an animal differing very materially from its brothers of the same genus, from which, though scarcely less ungainly, it is readily distinguishable at a great distance by its black mane and tail, more elevated withers, and clumsier action.

Whilst the douw and the quagga roam over the plains, the zebra inhabits mountainous regions only. The beauty of its light symmetrical form is enhanced by the narrow black bands with which the whole of the white-colored body is covered. Buffon and Daubenton wished to see this elegant creature acclimatized in Europe, which would procure us a beast of burden stronger than the ass, and more beautiful in its nakedness than the horse, even when adorned with the richest trappings. A king of Portugal used frequently to drive about with four zebras; and, about the year 1761, two of these animals that were kept in the park of Versailles had been so far tamed as to allow themselves to be mounted. In spite of the proverbial obstinacy of the zebra, there are thus no insuperable obstacles to its domestication, and a course of training, continued through several generations, would most likely subdue its reluctant nature as completely as that of the original wild horse and ass. The zebra is supposed to be the real hippotigris, or tiger-horse of the ancients ; and this is the more probable, as he ranges much farther to the north than the quagga or the douw, and approaches the regions of Africa comprised within the Roman empire. Historians inform us that in the year 202 after Christ, Plautius, a governor or prefect of Egypt sent several centurions to the island of the Erythræan Sea to fetch horses which "looked like tigers." The zebra seeks the wildest and most secluded spots, so that it is extremely difficult of approach. The herds graze on the steep hill-side, with a sentinel posted on some adjacent crag ready to sound the alarm in case of any suspicious approach to their feeding quarters; and no sooner is the alarm given than away they scamper with pricked ears, and whisking their ears aloft, to places where few, if any, would venture to pursue them.

We have styled the hippopotamus and the rhinoceros " gigantic hogs," and such they are to all seeming. But in Southern Africa the real hog itself reaches a size and strength, of which we, who know only his tame, lazy kindred, can hardly form a conception. Thus Andersson incidentally mentions these animals. "Wild boars," he says, "were rather numerous, and afforded us excellent coursing. The speed of these animals is surprisingly great. On open ground, when fairly afoot, I found the dogs no match for them. They fight desperately; and I have seen wild boars individually 
keep off most effectually half a dozen fierce assailants. I have also seen them, when hotly pursued, attack and severely wound their pursuers."

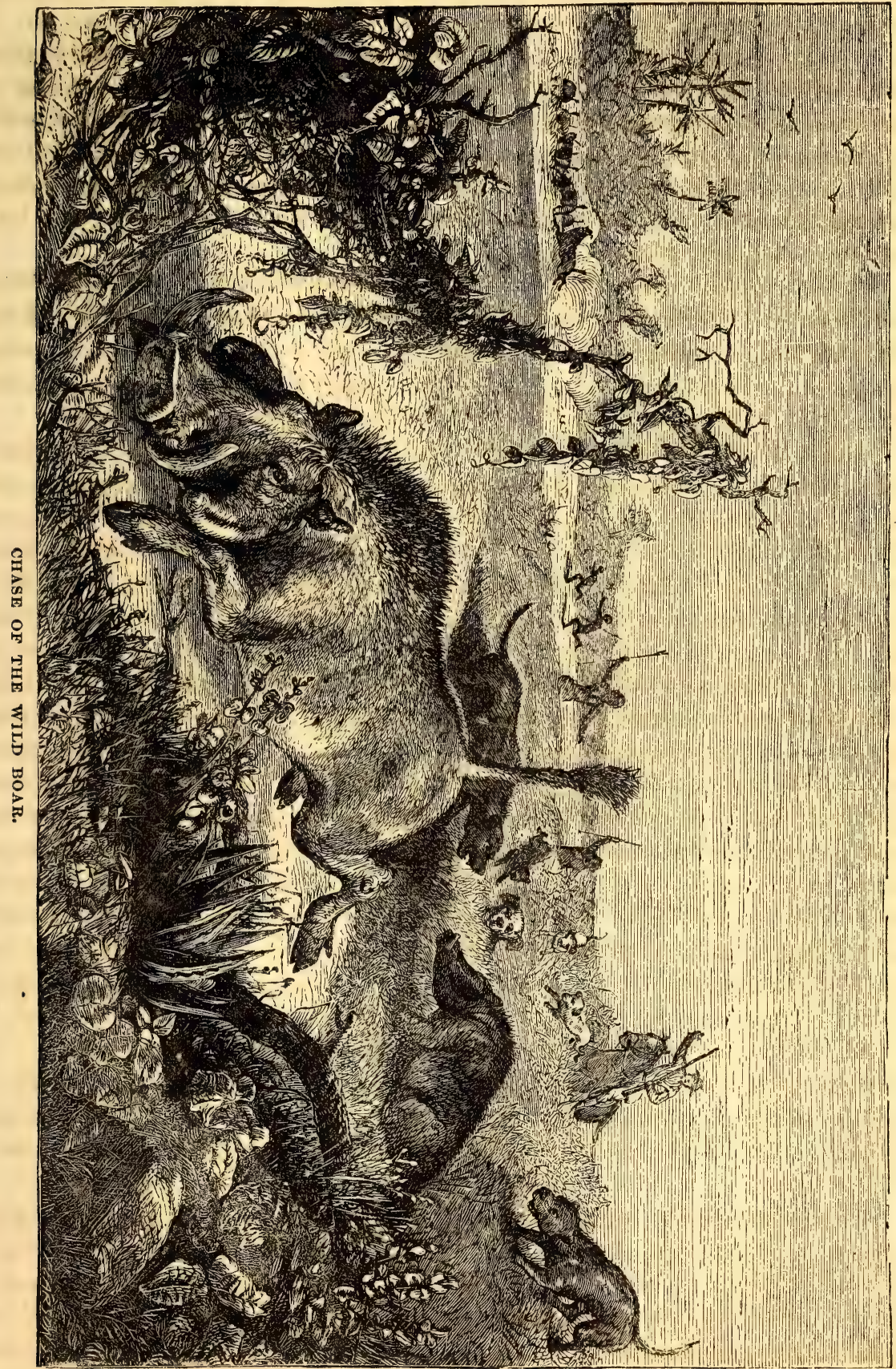

But of all the hog-tribe one of the most remarkable is the Babirusa, or "pig-deer," as it is called by the Malays, from its long and slender legs and curved tusks, which 
resemble horns. " This extraordinary animal," says Wallace, " resembles a pig in its general appearance; but it does not dig with its snout, as it feeds on fallen fruits. The tusks of the lower jaw are very long and sharp; but the upper ones, instead of growing downward in the usual way, are completely reversed, growing upward out of bony sockets, through the skin on each side of the snout, curving backward to near the eyes, and in old animals often reaching eight or ten inches in length." As far as we know, no living specimen of this extraordinary creature has ever reached Europe or America ; but its skulls, and drawings therefrom, are found in our museums. The uses of its curious tusks, like those of the elephant, are a problem which naturalists have yet to solve.

Here we bring to a close the results of our researches into some of the characteristic forms of Animal and Vegetable Life, as manifested in the Polar and Tropical Worlds. 



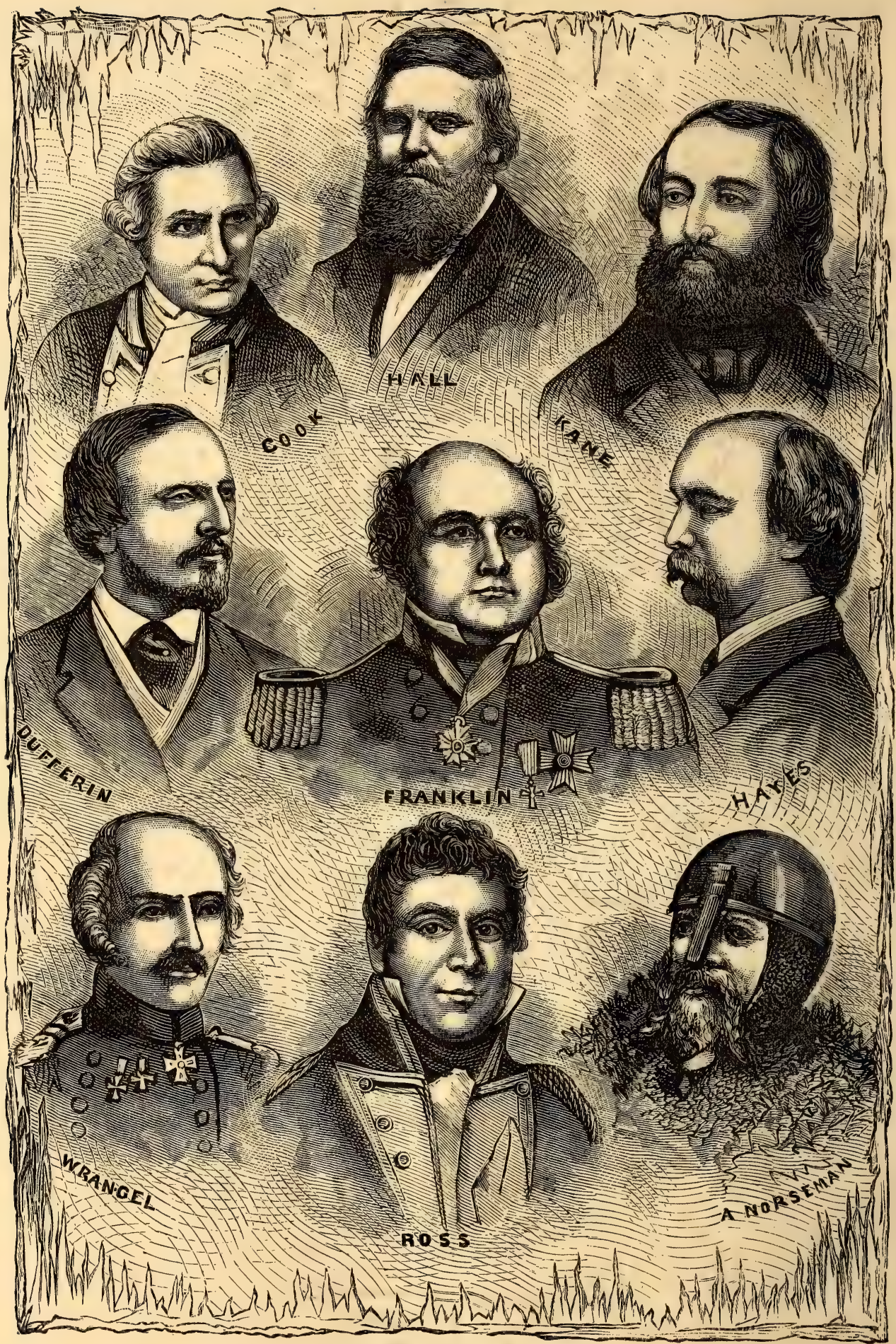

POLAR EXPLORERS. 

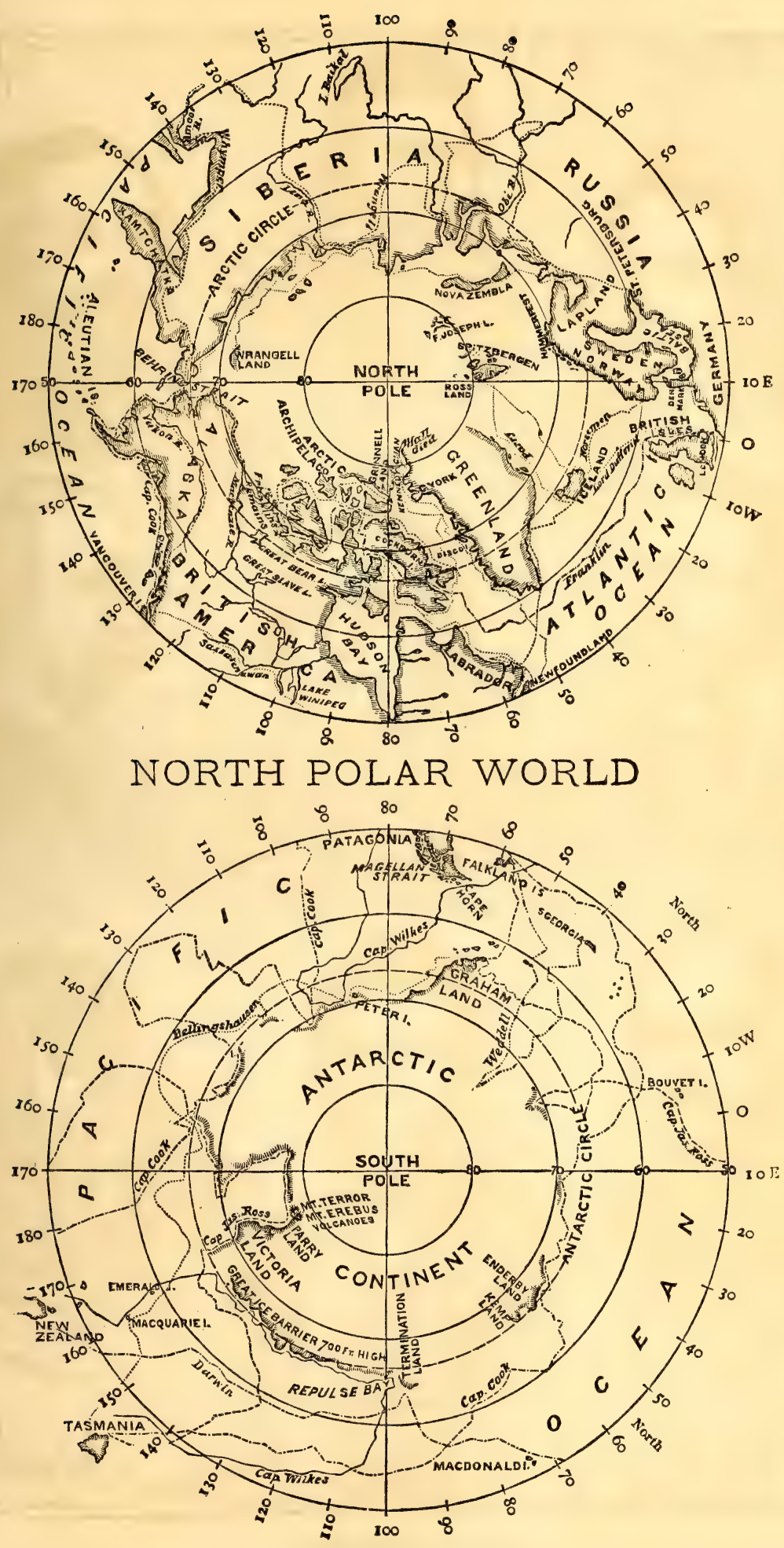

SOUTH POLAR WORLD. 



\section{ADDITIONAL CHAPTERS}

\section{To \\ "The Polar World."}

CHAPTER XLIII.

\section{SUMMARY OF ARCTIC EXPLORING EXPEDITIONS.}

Arctic America.-The Arctic Archipelago.-Baffin's Bay and its Outlets.-Hudson's Bay and its Outlets.-Limits of Arctic America.-Physical Characteristics.-Icelanders the first Arctic Explorers. - The Brothers Zeni.-The Cabots.-Frobisher.-Davis.-Barentz.The North-west Passage.-Henry Hudson.-Baffin.-Bering.-Hearne.-Phipps.-Cook.-Mackenzie.-Scoresby.-Buchan and Franklin.-Ross and Parry's first Voyage.-Parry's second Voyage.-Franklin, Richardson and Back's first Overland Expedition.-Parry's third Expedition.-Parry's fourth Expedition.-Franklin, Richardson and Back's second Overland Expedition.-Beechey.-Parry's Expedition beyond Spitzbergen.-Sir John Ross's second Expedition.-Back and King -Back's Great Fish River.-Back's next Expedition.-Dease and Simpson.-Rae.-Franklin's last Expedition-Its Sailing.-Last ever seen of it.-Expeditions in Search of Franklin.-Franklin's Movements.-Fate of his Party -Moore and Kellett.-Richardson and Rae's Overland Expedition.-Sir James Ross's Expedition.-Expeditions of 1850.-Collinson and McClure.-Austin and Ommaney's Expedition.-Sir James Ross.-Captain Penny.-The Prince Albert.-The Advance and Rescue.-First Traces of Franklin.-Sled and Boat Excursions.-Surmises.-Inglefield's Surveys.-Expeditions of 1852.-Belcher's Fleet.-Kellett's Rescue of McClure.-The Resolute.-Kane's Grinnell Expedition.-Rae's Expedition on the Mainland of America.Fate of Franklin's Men ascertained.-Anderson's Search.-McClintock's Expedition.-The Marvelous Drift of the Fox-On the track of Franklin.-Discovery of Relics.-The Mystery Solved.-Hayes's Expedition.-The most Northern Land oin the Globe.-Charles Francis Hall.-Expeditions since 1870.

$\mathrm{I}^{\mathrm{N}}$ $\mathbf{N}$ this chapter it is proposed to give in chronological order a summary of the Arctic expeditions which have been undertaken on the American continent, by land or water. Many of them have been already described in detail in preceding chapters of "The Polar World." Reference will be made to these accounts, so that this chapter will serve as index and supplement to what has gone before.

From its western extremity at the head of Bering's Straits, about $160^{\circ} \mathrm{W}$., through $65^{\circ}$ of longitude to $95^{\circ} \mathrm{W}$., the parallel of latitude of $70^{\circ} \mathrm{N}$., forms the general northern boundary of the American continent. Some capes, however, project a little further northward, and many bays indent the coast line to the south; but in about longitude $95^{\circ}$, Hudson's Bay sets deeply in, and extends southward to about latitude $51^{\circ}$. On the eastern side of the bay, the shore of the continent runs 
northward to Hudson's Straits, which open from the bay into the Northern Atlantic in about latitude $60^{\circ}$ just opposite the southern extremity of the great continental island of Greenland, ${ }^{1}$ which marks the proper line between the Atlantic and Arctic Oceans. In the Arctic Ocean, between Greenland and Europe, lies the island of Iceland ; ${ }^{2}$ north of which is Jan Meyen's island ; ${ }^{3}$ still further north, Spitzbergen ${ }^{4}$ to the east and a little south of which is Nova Zembla, ${ }^{5}$ off the northern coast of Asia, but a little south of its extreme northern headland.

To the north of the continent, and extending to an unknown distance into the Polar Ocean, is an immense archipelago, the islands of which are separated by innumerable sounds, channels, and straits, blocked up by ice during all but a few weeks in every year, and sometimes wholly so for several successive years. It is in these bays and channels and along their shores, whether island or continent, that the naval Arctic explorations have been carried on. The maps which are now added to this volume furnish a clearer view of these and their relative positions than can be given by words. A few of them deserve especial mention in connection with Arctic exploration.

The southernmost island is Southampton lying in Hudson's Bay, at its head, and just opposite Hudson's Straits. North and east of this is the great island, or probably group of islands, known as Cockburn Land, separating the channels and bays leading northward from Hudson's Bay into Baffin's Bay. Baffin's Bay, shaped not unlike the skin bottles of the ancients, with its broad mouth, Davis Straits, opening southward into the Atlantic, separates Cockburn Land from Greenland. Like the skin bottles to which we have compared it, it has several other natural openings, though these are for a great part of the year closed by ice. Opposite its mouth is Smith's Sound, leading directly northward into the presumed open Polar Sea. In the middle, answering to one of the legs of the skin bottle, is Lancaster Sound, with its continuations known as Barrow's Strait, Melville Sound, and McClure's Strait running due west, and forming a north-west passage to Bering's Straits, though it has been only once traversed, by McClure and bis party, ${ }^{6}$ and probably will not be again within the life-time of any man now living. Along the northern side of Lancaster Sound are, among others, the islands of North Devon, Bathurst, and Melville, separated by Wellington Channel and Austin Strait. Along the southern side of Lancaster Sound are the islands of Cape York, separated by Prince Regent Inlet from North Somerset island, which is separated from the island of North Wales. Lancaster Channel now expands into Melville Sound, which has on its south side Victoria Land and Prince Albert Land, possibly one island, but perhaps several, separated from Banks' Land by Prince of Wales Strait.

Hudson's Bay also communicates by a chain of winding channels and straits, or rather fiords, with Melville Sound, which together form also another north-west passage, every part of which has been traversed by some exploring vessel, though no one has been through more than a small part of it.

The 60th parallel of north latitude may be considered as the southernmost limit of Arctic America. Here ice and snow have acquired absolute mastery over vegetation, though toward the west the line of stunted forests reaches perhaps five degrees higher. All north of this is unfitted for the abode of civilized man. The whole region is a

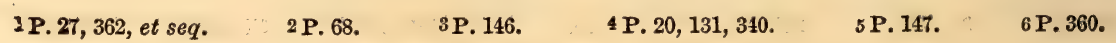


vast plain, rising only a few score yards, and never, as far as we know, more than a few hundred feet above the level of the icy sea. It was probably the first portion of the globe where dry land appeared above the waters; for, geologically speaking, all mountains and hills are of recent formation. They have risen from the ocean; and if the present order of things continues for a sufficient number of millions of years, they will, by natural laws now in operation, be removed and cast into the depths of the sea. Every drop of water which falls upon a mountain and thence makes its way to the ocean, bears with it some part of the solid rock; and so, in the course of ages, the Alleghanies and the Alps, the Andes and the Himalayas, will all be worn away. Great rivers flow sluggishly through this vast Arctic plain, and often spread out into shallow lakes. It is only by observing their course that we know that there is any watershed. So closely do their head waters interlock, that with hardly a mile of portage a canoe starting from a river falling into Hudson's Bay, might descend the Mackenzie ${ }^{1}$ whose mouth is on the Arctic Ocean, or the Yukon ${ }^{2}$ which falls into Bering's Sea, a part of the Pacific.

Leaving out of view the aborigines, of whom no man knows when or whence they came, the Icelanders were the first Arctic explorers in America. As early as 982, A. D., ${ }^{3}$ and perhaps still earlier, they discovered Greenland, and in the course of the next century founded a colony which flourished for many years. They penetrated, as far as Lancaster Sound, and built churches and convents, the ruins of which still exist along the coast of Greenland. It is evident that the climate was then far milder than it now is, probably not more severe than that of Norway or Canada in our day. ${ }^{4}$ Apparently the increase of cold has been going on steadily within the last two and a half centuries, for Hudson and Davis seem to have found no difficulty in penetrating nearly as far to the north as recent explorers have been able to do even with the aid of steam.

There is no record that the Phœnicians, the earliest navigators, ever approached the Arctic zone. The earliest Arctic voyage on record is that made in 1380 by two Venetian navigators named Zeni; but it is uncertain how far or even where they went. In 1497 and subsequently the two Cabots projected a voyage to the North pole, and went as high as the middle of Davis Straits. ${ }^{5}$ Three-quarters of a century passed before another Arctic voyage was made in America, for the Cortereals, in 1500 hardly reached latitude $60^{\circ}$, and Willoughby in 1553 did not touch even Greenland. ${ }^{6}$

In 1576-8 Frobisher made three voyages, and discovered the straits bearing his name, leading into Hudson's Bay. ${ }^{7}$ These voyages are notable as the first in which there is any account of scientific observations being made. Davis, in 1585-7 made discoveries more important than had as you been accomplished. He discovered the great strait that bears his name, and surveyed portions of the coast of Greenland. ${ }^{8}$ In 1596 Barentz, after having made two voyages to Nova Zembla, attempted the northwest passage from the west. He perished off the coast of Alaska, having barely penetrated the Arctic Ocean. ${ }^{9}$

The great object of Arctic voyages was now the discovery of a north-west passage, so that the nations of northern Europe might share in the rich commerce with India; for Spain claimed, and was then powerful enough to make the claim good, the sole right of traversing the Atlantic and Indian Oceans in that direction. In 1607 Henry
1 P. 17.
2 P. 278.
3 P. 382. 8 P. 337.
4P. 29.
5 P. 335, 379.
6P. 336.
7P. 337 9?. 138, 342 . 
Hudson was sent out by the Muscovite Company with the simple direction to steer straight for the North pole. He went between Spitzbergen and Greenland, and in the two following years between Spitzbergen and Nova Zembla, and convinced himself that there was no passage in that direction. He then shot across to Labrador, searching southward for an opening through the continent, and discovered the bay of New York and the river which bears his name. On his last voyage in 1610 he sailed through the straits and into the great inland sea named after him, and went hundreds of miles further west than man had gone before. He was, after the Icelanders, the first explorer who wintered in Arctic America. In the following spring his crew mutinied, put him and seven companions, of whom all but one were invalids, into an open boat, which was cut adrift, and he disappeared forerer from human eyes. A part of the crew were killed by the Esquimaux, and a part died of cold and famine, only a few returning to England. ${ }^{1}$

It was now fully believed that Hudson's Bay opened at its other extremity into the Pacific, and several attempts were made to perform the north-west voyage from both sides of the continent ; the most notable was that of Baffin, who in 1616 surveyed the coasts of the bay which bears his name, and sailed for some distance up Lancaster Sound. For half a century more no other man went further north or as far west as he. ${ }^{2}$

In 1741 Bering, baving previously explored along the Arctic coasts of Kamchatka and in the sea named from him, tried to go still further north and east, with the hope of making the north-west passage from the west. He never saw the strait which bears his name, which bad been discovered by Deschnew almost a century before. Although Bering touched upon the Arctic coast of America, he does not properly come within the eategory of American Arctic explorers. ${ }^{3}$

In 1743 the British Parliament offered a reward of $£ 20,000$ to the crew of the vessel which should first make the north-west passage, and between 1769 and 1772 Samuel Hearne made three overland journeys from Hudson's Bay toward the north. He discovered the Coppermine River, which he traced to its mouth in a gulf of the Polar Sea, almost midway between Bering's Strait and Baffin's Bay. The Parliamentary reward had been so far extended as to include any northern passage, and an additional reward of $£ 5,000$ was offered to any crew which should go within one degree of the North pole.

Hitberto the hope of finding a passage for commeree had been the main incentive to Arctic voyagers; but now this had been shown to be out of the question; and thereafter scientifie discovery became the main object. Capt. Phipps, afterward Lord Mulgrave, in 1773 , tried to reach the pole by way of Spitzbergen. He went as far north as $80^{\circ} 48^{\prime}$ no further than Hudscn had gone more than sixty years before. In 1778 Cook attempted the route by way of Bering's Strait, and so confident was he of success that a vessel was sent to Baffin's Bay to meet him. He however went no farther north than $70^{\circ} 45^{\prime}$, passing the extreme northern point of the American Continent, and entering the Polar Sea. He saw, or thought he saw land still further north; other navigators have seen similar appearances of land; but it is not as yet certain how far to the west the great Polar archipelago extends. He headed eastward, but soon found his way blocked by solid ice. In August he turned southward, and in February, 1779 , was killed on the island of Hawaii. ${ }^{4}$

1P. 342 .

2 P. 343.

3 P. 197, 248.

4P. 344. 
In 1789 Mackenzie, in the employment of the North-west Fur Company, made an overland journey and reached the mouth of the great Polar river named after him, half way between the Coppermine and Bering's Strait. The season appears to have been unusually mild, for he saw the dolphins sporting in a sea, open and free of ice beyond the reach of vision. If he had had a ship, in all probability he might have sailed clear to the pole. The valley of the Mackenzie forms a partial exception to the otherwise barren character of the Arctic regions, for there are forests reaching almost to the shores of the Polar sea. ${ }^{1}$

In 1806, Scoresby, the elder, in the command of a whaling vessel, passed up between Greenland and Spitzbergen, and reached the latitude of about $81^{\circ}$ within 540 miles of the pole, and within, perhaps, a score of miles as far north as a vessel has ever gone, and within sixty miles as far as was reached by Kane or Morton, or Hayes, or any other man, unless, as is said, Hall, three weeks before his death, went fifty miles beyond. Before him the sea was open, and the absence of blink showed that no snowy land or icy sea lay before him. He wished to burst into that open sea which keel has never plowed, but his was a voyage for whales, and he had to subordinate his scientific aspirations to the pecuniary interests of the owners of the vessel. ${ }^{2}$

The year 1818 is memorable for two Arctic expeditions: one under Ross and Parry to discover the north-west passage, and the other under Buchan and Lieutenant (afterwards Sir John) Franklin, to reach the pole. The latter went between Greenland and Spitzbergen, and penetrated as far north as latitude $80^{\circ} 34^{\prime}$, got caught in the ice, and was obliged to return. Ross, in command of the Isabella, and Parry, in the Alexander, sailed April 18, and on the 28th entered Lancaster Sound. After sailing sixty miles, land was seen apparently stretching from shore to shore; but the weather being threatening, the vessels were put about, and returned to England in the following month. Ross reported that the supposed sound was a mere bay, with no opening into the ocean beyond; Parry was as confident that it was a sound, and to test the correctness of this he was next year put in command of an expedition more completely equipped than any one which had ever before been fitted out. ${ }^{3}$

This expedition consisted of the Hecla, with the Griper as a consort. There were ninety-four men and provisions for two years. They sailed May 11, 1819, fell in with ice June 18, and were beleaguered on the 25th for a month. They entered Lancaster Sound, July 30, and laid their course up the channel. Parliament had offered a reward of $£ 5,000$ to the first crew which should reach the meridian of $110^{\circ}$ W. On the 4th of September, Parry announced to his men that they had reached that point, and the reward was theirs. They were now near the head of Melville Sound. On the 20th, they were beset in the ice, which did not break up till August 2 , of the following year. On the 15 th they were again fast imbedded in ice, having made but a few miles beyond the point which they had gained the previous year. They then returned to England in good health, having settled two important points : first, that there was a channel running at least half way across the continent, and presumably the whole distance ; and secondly, that it was possible for white men to winter in the Arctic regions. ${ }^{4}$

In the meanwhile, an overland expedition consisting of Franklin, Dr. (afterwards Sir John,) Richardson, Mr. (afterwards Sir George) Back, then a midshipman, Hood, 
a lieutenant, Hepburn, a seaman, and some Canadian voyageurs, set out from the shore of Hudson's Bay. They reached Fort Chipeweyan late in March, 1820, having traveled in the depth of winter on foot 856 miles, the mercury freezing solid in the bulb of the thermometer. In July they went 500 miles further to Fort Enterprise, where all the party wintered except Back who returned to Fort Chipeweyan, to send on provisions for the next year. He then returned, regaining Fort Enterprise, March 17, 1821, having traveled more than 1100 miles, sometimes being without food for three days in succession, with the thermometer ranging from $47^{\circ}$ to $57^{\circ}$ below zero; that is from $69^{\circ}$ to $79^{\circ}$ below freezing point. The whole party then set out dragging their canoes eighty miles to the Coppermine River, which they descended to the sea, and then paddled eastward along the shore. After walking about 550 miles they found themselves at the foot of a deep bay, with provisions for only three days. They made one large canoe out of their two smaller ones, and tried to ascend Hood River. Hood and some of the Canadians broke down and could go no farther; Richardson remained with these. Back, with a few of the more vigorous, pushed on in the direction of Fort Enterprise to send back succor, while Franklin and the rest of the party followed on more slowly. These last, on reaching a depot found it deserted; but there were a few rejected deer skins and almost fleshless bones. Here they staid eighteen days, in the course of which they were joined by Richardson and Hepburn. Hood had been killed by a Canadian, who was in self-defence shot by Richardson. The other Canadians who had broken down had all died. At length on the 7 th of November, when nearly all the remaining Canadians had perished, three Indians whom Back had sent thither, brought them some provisions. The survivors pushed forward and succeeded in rejoining Back, and returned to England in 1822. ${ }^{1}$ History records nothing of self-devotion which exceeds this of Richardson, Back, and Franklin, and never were honors and titles more worthily bestowed than upon them.

The results of Parry's expedition had been so considerable that another was fitted out in 1821 under his command. It consisted of the Hecla and Fury. Instead of entering Lancaster Sound they passed through Hudson's Straits, and attempted to work their way north-westward through the channels winding among the islands. If they gained a little, the floating ice would in a few days sweep them back to a point which they had left weeks before, and they were obliged to pass the first winter on Melville's peninsula which forms a part of the eastern shore of Hudson's Bay. The ice did not break up till July 2, 1822, when they shot across the head of the bay, and found themselves at the entrance of a channel opening in the very direction they wished. This channel, which they named Fury and Hecla Straits, runs between a projection of the continental shore and Cockburn Land. For sixty-five days they vainly tried to force their way through this narrow strait, and in all that time never were able to reach more than forty-five miles to the west. After passing the winter near the head of the Strait, the expedition returned to England in good health. It however gained one thing: it proved that a crew could pass two winters safely within the Polar circle. ${ }^{2}$

In 1824, the Hecla and the Fury were again refitted and put under the command of Parry. After struggling from the middle of July, all through August, and till the middle of September, with the ice in Baffin's Bay, they succeeded in entering Lan- 
caster Sound, which they found almost clear. But in a fow days ice began to form all around them, and the masses swept them back again into Baffin's Bay. They got clear, and again entered Lancaster Sound, but could get only as far west as $80^{\circ}$, fully $35^{\circ}$ east of the point which Parry had reached in 1819 . Here they wintered. In July the ice opened and they tried again; but the floating ice cut up the Fury so badly that they were obliged to abandon her, and the Hecla, with both crews, steered back for England. The expedition accomplished nothing, beyond demonstrating the absolute uncertainty of voyaging in these channels.

In 1825 the noble trio, Back, Franklin, and Richardson, started upon a new overland expedition; this time amply provided. Before winter set in they had struck Mackenzie River, and followed it down to the sea. In the summer of 1826 they separated, Franklin and Back exploring the coast to the west of Mackenzie River, and Richardson the eastern shore of the Coppermine River. In the meantime Beechy, in the Blossom, was sent to Bering's Strait to meet Parry and Franklin who it was hoped would have come together. Parry had put back, never having reached within 80 degrees of longitude of Bering's Straits ; but a boat expedition from the Blossom pushed so far eastward along the shore that it came within 150 miles of Franklin's extreme westerly point. $^{2}$

In 1827 Parry, undeterred by the ill success of his last two expeditions, undertook an overland, or rather over-ice, expedition to the North pole, going by way of Spitzbergen. A whaling captain who had gone to the north of Spitzbergen reported that the ice-fields there were free of crack or fissure so that for leagues upon leagues a sled could traverse them as if upon a smocth road. Parry's flat-bottom boats were provided with a runner on each side of the keel, so that they could be used either as sleds or boats. By one or the other or by both he hoped to reach the pole. But he found the ice soft and slushy, with frequent hummocks which rendered sailing and sledding alike difficult. Still for 35 days he toiled cheerily on; but when at last he was able to take an observation he found that the great floe upon which he moved was drifting southward just about as fast as he was traveling northward, so that though in constant movement he was day after day occupying just the same spot in space. He had, however, the honor of planting the British flag in latitude $82^{\circ} 40^{\prime} 30^{\prime \prime}$, the most northerly spot ever trodden by man, unless, indeed Hall may in his last expedition have gone as far. It is only 40 miles beyond the extreme point of Hayes, and only 80 miles north of Scoresby's extreme point, which he had reached without difficulty twenty-one years before. $^{3}$ This expedition does not, however, come within the list of Arctic explorations in America. This was Parry's last expedition, though he lived 18 years after, and rose to be a knight and an admiral, and finally governor of Greenwich Hospital.

In 1829 Captain (afterward Sir John) Ross desired to do something to make amends for his failure in 1819. Sir Peter Booth fitted him out with a small steamer called the Victory, the first time that steam was ever applied to Arctic navigation. The screw propeller was not then thought of; the Victory was an ordinary paddle wheel steamer. As second in command went his nephew, James Ross, afterward noted as an Arctic explorer. They passed through Hudson's Strait, entered Prince Regent's Inlet, August 9. The season was unusually favorable, the channel being free from ice, and by the 17 th the Victory passed beyond Parry's meridian of $110^{\circ} \mathrm{W}$., and

$$
1 \text { P. } 349 . \quad 2 \text { P. } 350 \text {. } 3 \text { P. } 351 .
$$


during the next month worked its way along 300 miles of yet undiscovered coast, and went into winter quarters, October 7. The winter lasted eleven months. On September 17, 1830, they got under weigh; the engine had been disabled and was thrown overboard. The vessel made only three miles, and on the 17 th again went into winter quarters, from which they were released August 28, 1831; but after a month's hard work, during which they only made four miles, was again laid up for the winter. Scurvy now broke out among the crew, and the experience of two years gave little ground for hope that the vessel could be extricated the next summer. It was resolved to abondon her, and with the boats fitted up as sledges make their way to the spot where the Fury had been wrecked; for they knew that her boats and stores had been left there; and there was good reason to hope still remained. They started on the $23 \mathrm{~d}$ of April, and reached their destination July 1, 1832. They found the boats and provisions; and in a month made an attempt to reach the open sea; but Barrow Strait was frozen solid, and they were forced to put back to Fury Beach, where they passed the winter of 1832-3. Several of the men died here. On the 8th of July they again put out. This time Barrow Strait was free of ice, and on the 26th of August they were descried by a vessel and taken on board. Strangely enough, this vessel was the Isabella, now a whaler, but the same which Ross had commanded on his first expedition. No one on board could at first believe that this party were Ross and his surviving companions, who had been given up as dead for more than two years. When Ross reached England, in September, 1833, he was received with honors hardly less than those which greeted Columbus in Spain on his return from his first expedition. The great towns presented him with the honorary gift of citizenship ; orders, and medals, and diplomas rained down upon him from foreign states and learned societies; the Crown conferred upon him the honor of knighthood, and Parliament awarded him a grant of $£ 5,000$. The results of this expedition were not inconsiderable. A considerable space of shore line was mapped ; the magnetic pole of that year was ascertained to be in latitude $70^{\circ} 5^{\prime} 17^{\prime \prime}$, longitude $96^{\circ} 46^{\prime} 45^{\prime \prime}$, upon a peninsula to which the name of Boothia has been given, jutting out northward from the Continent into the archipelago between the head of Hudson's Bay and Lancaster Sound. The greater part of these successes are, however, due to Commander (afterwards Sir James) Ross, of whom we shall have to speak hereafter. One other circumstance is notable in this expedition. It had passed five consecutive winters within the Arctic circle. Parry had demonstrated two winters could be passed by white men there without peril. Ross's experience, confirmed by that of others, seemed to show that this was the limit. It remained for Hall to demonstrate that with proper regimen an Arctic winter or a series of them, is not specially unfavorable to human life. ${ }^{1}$

Three overland expeditions, in a measure connected with this of Ross, must have brief mention. In February, 1833, Back, accompanied by Dr. King as surgeon and naturalist, left England in search of Ross. They reached the Great Slave lake early in August, whence they pushed on north-eastward ; but returned to winter at Fort Feliance on the Great Slave lake, about latitude $62^{\circ}$. Here they suffered terribly from scarcity of food and cold, the thermometer at one time marking $70^{\circ}$ below zero, or $102^{\circ}$ below freezing point, the lowest as yet anywhere authentically noted. In the following April, when Back was about to start north-eastward, be received tidings that Ross 
and his party had been rescued. Hence arose the punning phrase, that although Back had not got Ross, Ross had got back. Back, however, resolved to accomplish something, and pusbed north-eastward. On the 28th of June he struck a great river considerably to the east of any which had been explored. The natives called it the Thlew-ee-choh, or Great Fish. It is since styled Back's Great Fish river, and has a melancholy interest in connection with the fate of the last survivors of Franklin's expedition. Back followed this river to its mouth in a deep narrow bay which he vainly hoped would lead directly into the Polar sea. He explored a part to the east, but was finally obliged to put back about the middle of August. He reached England in September, 1835, and in the following June again set out in the Terror, hoping to fill up some blanks in Ross's surveys of the coasts lying west of Prince Regent's Inlet. But the expedition was fruitless. The vessel was so badly disabled by ice that they were obliged to put back before even entering upon their proposed field. ${ }^{1}$

Simultaneously with this, the Hudson's Bay Company sent two of their factors, Dease and Simpson, on an overland expedition. They were to strike Mackenzie River and follow it to the sea. In three successive seasons they traversed a long line of coast lying between the eastern point as yet reached from Bering's Straits, and the western point reached from Hudson's Bay.' Their discoveries in a geographical point of view were of considerable importance. They discovered two large rivers, which they named the Garry and the Colville, and saw to the north of them a great tract of land which they called Victoria Land; from an icy promontory of which they saw what appeared to them an open sea free of ice, stretching north-eastward, while the coast of the continent tended south-eastward. Their explorations nearly filled up the great gaps already left, and by the close of 1839 , different parties of explorers, by different routes, had traversed the whole space between Baffin's Bay and Bering's Straits. Simpson, the hero of the expedition, did not live to receive the rewards which he had fairly won. While traveling overland from the Red River to the head waters of the Mississippi, on his way to England, he was murdered by one of his Indian guides. ${ }^{2}$

In 1846, the Hudson Bay Company sent out Dr. John Rae, of whom we shall hear more, to settle some points in geography, which had been left undecided by Ross. The main thing established by this expedition was that the part known as Boothia was a peninsula belonging to the continent, and not an island of the northern archipelago, and that consequently there is no outlet from Prince Regent's Inlet through the Gulf of Boothia, towards the west.

We now come, in order of time, to Sir John Franklin's last expedition, to which a special interest is attached on account of its disastrous result. Franklin in 1845 was a hale man verging upon threescore. He had reached high honor in his profession, and was in possession of an ample fortune, derived only in part from his second wife, Jane Griffin, whom he had married in 1828. The achievement of a north-west passage had been the dream of his life. His early efforts in that direction have been already noted. He never forgot his aspirations while commanding a vessel in the Mediterranean, nor afterward while governor of Van Dieman's Land almost at the opposite extremity of the globe. In 1844 the British government resolved to place under his command what it was hoped would be the last expedition to solve the Arctic mystery. 
It consisted of two vessels, the Erebus and Terror, both previously tried in Arctic seas, and each now fitted up with a small steam engine and a screw propeller. If by sail and oar alone so much had been done, what might not be hoped when steam was at hand to be used in case of need? Franklin was in immediate command of the Erebus, and Capt. F. M. R. Crozier of the Terror. The vessels left England May 19, 1845 , accompanied by a tender with additional stores, which were to be taken on board in Davis's Straits. 'The tender parted with them July 12 th, bringing back the first and only dispatches ever sent. On the 26th a passing whaler caught sight of them moored fast to an iceberg near the center of Baffin's Bay, apparently awaiting an opportunity of entering Lancaster Sound. The orders from the admiralty were that he should push westward about latitude $74^{\circ} 15^{\prime}$ to longitude $98^{\circ} \mathrm{W}$., thence southward and westward to Bering's Strait ; for the long line of surveys and explorations which have been noted, when joined together showed that there was a continuous water passage skirting the northern shore of the continent; and there was, moreover, fair ground for the belief that there was no permanent obstruction by ice. It was expected that the expedition would return in about two years, in 1847 or 1848, by way of Bering's Straits, where another expedition was to be in waiting to convoy them home. All told there were rated on the ships' books 138 men; but of these, as afterwards ascertained, nine had deserted, so that in all when they parted from their convoy there were 129. Of these not one was erer seen alive by civilized man, and not a spar or rope of either vessel, after that 26th of July, 1845. Toward the close of 1847, no tidings having been received, apprehensions began to prevail that some misadventure had occurred, and during the next twelve years numerous expeditions were fitted out for the discovesy and relief of the missing men. The narrative of these relief expeditions constitutes by far the most interesting chapter in the history of Arctic exploration. Little by little isolated facts were brought to light, the sum of all being that after entering Lancaster Sound the expedition wintered in the ice, on the shore of Barrow's Strait, in latitude $70^{\circ} 5^{\prime}$, longitude $98^{\circ} 23^{\prime}$. In the summer of 1846 they ascended Wellington Channel to latitude $75 \circ$, returned by the west side of Cornwallis Island, and wintered in 1846-7 at Beechey Island, off the east shore of Cornwallis Island. Why Franklin deviated from bis general orders to push on to the west must remain forever unknown; we can only conjecture that the passage through Barrow's Strait into Melville Sound was blocked up by ice. A paper found in 1859, near a cairn on Prince William's Island, just south of latitude $70^{\circ}$, bearing date May 28, 1847, gives these particulars, and adds that all were well. Around the margin of this scrap of paper, but in a different hand, and bearing date April 25, 1848, was written, "Sir John Franklin died June 11, 1847. The ships Erebus and Terror were deserted April 22, 1848, five leagues N.N.W. of this, having been beset since September 12, 1846. The total loss by death, up to this date, has been nine officers and sixteen men. The officers and crews, under command of Capt. F. M. R. Crozier, landed here, latitude $69 \circ 37^{\prime}$, longitude $98^{\circ} 4^{\prime} 15^{\prime \prime}$, and start to-morrow, April 26, 1848, for Back's Great Fish River." This is the only written record made by any of the party of this ill-fated expedition. From September 12, 1846, to April 22, 1848, the vessels seem to have drifted in the ice about 350 miles, through the narrow channels leading southward among islands southward from Barrow's Straits. How and where Franklin died, only a fortnight from the day when all were well, must probably remain for- 
ever unknown on earth. All that we can know is that he died on his ship, locked fast in the ice, having never reached farther to the west than the place which had been set down as the real starting-point of the expedition.

Back's Great Fish River, on the continent, whither the 105 survivors bent their way, falls into a great estuary about 200 miles south of the spot where the Erebus and Terror were abandoned. Scattered indications were gatbered from time to time from 1854 to 1859 , of the fate of a portion of this party, of whom a considerable part succeeded in traversing Prince William's Island or along its coast, and crossing the narrow Simpson's Strait which separates it from the continent. In the interval from 1854 to 1859 , scraps of information were picked up hy different searching expeditions, all tending to the same point: That many years before a ship had been crushed by the ice in the deep channel lying off the north-west coast of King William's Island, and another had been driven ashore; that the people had gone away toward a great river, and that they had all died of starvation. Every indication showed that they had not suffered from any violence from the few natives of the region; and there was some reason to suppose that a portion survived until the spring of 1851. It took years to gain even this much information. How and by whom it was acquired will best be shown in the accounts which follow of these various searching expeditions.

When the year 1847 had passed, and no tidings came back from Franklin, apprehension began to be excited, and in 1848 the British government sent out three expeditions for his succor. The Plover, Commodore Moore and Herald, Captain Kellett, were to enter Bering's Strait, going at least as far up as Kotzebue Sound, just within the Arctic circle, and thence in boats examine the shore eastward. They were joined by the pleasure yacht Nancy Dawson, owned by Mr. Robert Dawson, who took an active part in all their operations. The vessels went beyond the point assigned, which they passed July 14, 1849, and stood on until they reached latitude $72 \circ 51^{\prime}$, longtitude $163^{\circ} 48^{\prime}$, when they were stopped by impassable ice. Boat expeditions had meanwhile been sent onward to search the coast as far as the mouth of Mackenzie River, about longtitude $135^{\circ}$, up which they were to make their way, and return overland. A part of these boat expeditions went on, and a part returned to the ships, August 24, having explored the coast as far as Dease Inlet, about longitude $155^{\circ}$, without, of course, finding any trace of Franklin's party, who were then dying on the other side of the continent. In the following summer, 1850, the two vessels explored the same ground, with a like want of success, and the Herald returned to England, Kellett, in the Plover, remaining, and wintering in Grantley Harbor, half way down Bering's Straits. Of Kellett we shall hear again.

Meantime a land party under Sir John Richardson and Dr. Rae had reached the Polar Sea in August, 1850, by way of Mackenzie River, whence they explored the coast for 800 miles eastward as far as the mouth of the Coppermine River about longitude 1160. Richardson returned overland to England, Rae remained behind, and in 1850 explored the shores of Wollaston Sound; but still the icy desert told no tale of the lost navigators. ${ }^{1}$ All these expeditions were confined to the region far to the west of any point reached by Franklin.

Meanwhile Sir James lioss had sailed from England, May 12, 1848, entered Lancaster Sound, and explored its south side, and in the spring of 1849 searched along 
the eastern shores of North Somerset, in a channel along whose western side Franklin had been two years before helplessly drifting. He returned to England in November, 1849 , bringing back no tidings.

In Mareh, 1849 , the British government offered a reward of $£ 20,000$ to any exploring party from any country whatsoever, which should render efficient aid to Franklin and his party. The hope of gaining this reward partly, but much more a feeling of intense interest in the fate of the missing navigators, led to numerous searching expeditions. In 1850 there were eight in all, comprising eleven vessels. The result of all that had up to this time been learned was that Franklin had never reached as far as longitude $116^{\circ}$ and that he was not to be looked for east of longitude $90^{\circ}$. There was then no indication that they had gone to the north of Lancaster Sound, or that they had anywhere reached the continent and were making their way overland. The probable field of search was thus, upon good grounds, reduced within narrow limits. They were to be looked for, with best hopes of success, among the group of ice-bound islands lying westward of Melville Island. Thither from both sides of the continent, the search was prosecuted in 1850 and the following years. In 1849 Lady Franklin, who devoted all her life and fortune to the search for her husband and his companions, had placed a supply of coals and provisions upon Cape Hay, on the south side of Lancaster Sound. Such a supply, left by Parry in 1824, had been in 1832 the means of preserving Sir John Ross and his men during their long besetment.

Apart from Rae, who as already mentioned, was continuing his searches on the continent, the first expedition of 1850 was that by way of Bering's Straits, consisting of the Enterprise, Captain Collinson, and the Investigator, Commander McClure. They were instructed to cruise in company as far to the eastward as they could go, to make friends of the natives; to make deposits of provisions here and there, in hopes that they might prove of use ; and above all, to aroid any besetment by the ice. We follow McClure in the Investigator. In August, 1850, having got separated from his consort, he rounded the western point of the continent, and plunged into the Aretic seas, and thenceforward for three years was lost to human sight. He reached the eastern coast of Bank's Land in September, 1850, and in October was frozen in and finally abandoned his ship in Mercy Bay on the north side of Bank's Land, where in 1854 he was reseued by an expedition sent by way of Baffin's Bay, and returned to England. These first and last of all men have in person made the whole north-west passage, rounding the American continent from Bering's Straits to Baffin's Bay. Collinson, in the Enterprise, followed hard after McClure, went almost as far, and made many explorations, but finally returned by the way he had gone.

The Baffin's Bay expedition, sent out from England in the spring of 1850 , consisted of the Resolute, Captain Austin, the Assistance, Captain Ommaney, sailing vessels, and the Pioneer and Intrepid, screw steamers, Capt. Sherrard Osborne. Their instructions were to the same purport as those given to McClure and Collinson. The schooner Felix, with a small tender, the Mary, was also fitted out by private subscription, and placed under command of Sir James Ross. The expedition was provisioned for eighteen months and was to go along Lancaster Sound to the westward. The Lady Franklin, fitted out by Lady Jane Franklin, and commanded by Captain Penny, also sailed from England. Lady Franklin also defrayed two-thirds of the cost of another 
expedition, consisting of the schooner Prince Albert, commanded by Charles Forsyth, and having on board William Parker Snow, a volunteer, who after much service in foreign seas, had acted as secretary to Macaulay, and aided him in the preparation of the manuscript of the History of England. An American expedition consisting of the Advance and the Rescue, under command of Lieutenant De Haven, was also sent out this year. It was fitted out nominally by the government, but mainly at the expense of Henry Grinnell, a merchant of New York, whose name is also identified with the expeditions of Charles Francis Hall. On this expedition, as surgeon, was Dr. Elisha Kent Kane, who as commander of a subsequent one won as high honor as was ever achieved by any Arctic explorer.

All these vessels cruised over the same general region, and for the one purpose of discovering Franklin and his men. The first traces of them were found at Cape Riley by Ommaney, in the Assistance, August 23, 1850. This was afterward shown to be the place where Franklin had spent the winter of 1845-6. Here and close by, mainly by the American expedition, were discovered the embankment of a house, the working places of carpenters and armorers, the site of a small garden, empty meat cans, and pieces of wearing apparel which had been thrown away; and also the graves of three men. But there were not the slightest traces to indicate in what direction Franklin had gone.

All the vessels wintered not far from each other, and the spring of 1851 was devoted to land expeditions which explored 672 miles of hitherto undescribed coast along the shores of Wellington Channel to the north and towards Melville Island to the west. One party, under Lieutenant McClintock, went farther west than had hitherto been reached, as far as longitude $114^{\circ} 20^{\prime}$. From the tameness of the animals here seen it was inferred that few if any human beings had ever been seen there. Kane came to the conclusion that after the breaking up of the ice in 1846, Franklin had gone up Wellington Channel to the north. So far he was right; but ignorant of the fact, not known for years after, that Franklin had merely rounded Cornwallis Island, and'returned almost to the same point, he supposed that Franklin had sailed on northward into the great polar open sea, whose existence had now come to be accepted.

The Prince Albert returned to England in the summer of 1851, carrying back the tidings of what had been discovered, and was sent back by Lady Franklin to explore the shores of Regent's Inlet. She returned in 1853, having discovered nothing. The American expedition returned to New York in the autumn of 1851. Sir James Ross also returned, bringing nothing but vague rumor, afterward proved to be unfounded, that the Franklin party had been murdered by the Esquimaux at Wolstenholme Sound, near the head of Baffin's Bay. Lady Franklin thereupon sent the screw steamer Isabel, Captain Inglefield, to explore this region. Inglefield left England in July, 1852, examined the Sound, but found no traces of Franklin, who had indeed never gone in that direction. He, however, sailed up Smith's Sound, heading northward from Baffin's Bay, and reached latitude $78^{\circ} 28^{\prime} 21^{\prime \prime}$, about 140 miles farther than any one had gone before on the American side of the polar regions. He thought that the climate was less rigid than it was further south; he also rendered it almost certain that Smith's Sound was a strait connecting Baffin's Bay with the Polar Ocean ; a theory which is confirmed by all subsequent explorations. 
Meantime following out Kane's Wellington Channel theory, Sir Edward Belcher was sent out in April, 1852, in the command of five vessels, the Assistance, Resolute, North Star, Pioneer, and Intrepid, the last two being steamers. The North Star was the store ship. The Assistance and Pioneer were to steer up Wellington Channel ; while the Intrepid and the Resolute, the latter commanded by Captain Kellett, were to push westward in search of McClure and Collinson, who had not been heard from since they had sailed eastward from Bering's Straits in 1850. The Resolute had a singular fate. After an unusually favorable voyage she reached Melville Island in September, 1852, and went into winter quarters, whence parties were sent out to explore the coast in various directions, one of which found a dispatch showing that MeClure had been, and probably now was, at Mercy Bay, on the opposite side of Bank's Strait. Sledge parties were sent in that direction; but before they returned they were anticipated. McClure had heard of the proximity of the Resolute, and one day a party of worn men were seen making their way over the uneven ice. It was McClure and his men. They were taken on board, and the Resolute set out upon her return voyage. She got as far as Beechey Island, when it was decided to abandon her, May 15, 1854, all on board being taken off by the other vessels of Belcher's expedition, and brought safely to England. Sixteen months after, September 15, 1855, the American whaler George Henry, Captain Buddington, vessel and captain thereafter known in connection with Charles Francis Hall's expeditions, while sailing in Baffin's Bay came across an abandoned vessel. She was encumbered by ice but perfectly tight and sea-worthy. It was the Resolute. Without human guidance she had drifted 1200 miles through those dangerous seas. Buddington brought his prize home to New Iondon, Connecticut; she was purchased by the American government, thoroughly refitted, and by order of Congress presented to Queen Victoria. The British government had her stripped and laid up in ordinary in the navy yard at Woolwich.

In April, 1853, the new American Grinnell expedition, the Advance, commanded by Dr. Kane, sailed from New York. The story of this expedition has already been fully told in this volume, ${ }^{1}$ and will not here be repeated. No account of any Arctic expedition equals in interest this as detailed by Kane himself. Although fruitless as far as its main object of finding Franklin or the remains of his expedition, was concerned, it made valuable contributions to geographical knowledge. These may be thus summed up: 1. The survey and delineation of the north coast of Greenland to its apparent termination by a great glacier. 2. The survey of this glacier and its extension northward. 3. The discovery of a large channel to the north-west, free of ice and apparently leading into an open sea. 4. The discovery and delineation of a large tract of land forming the northward extension of the American continent, or rather of Greenland. 5. The completed survey of the coast as far south and west as Cape Sabine in Smith's Strait, connecting with the previous surveys of Captain Inglefield, and completing the circuit of the straits and bays opening from Davis' Straits, and leading into the Polar Sea.

In the meantime a land expedition under charge of Dr. Rae, had been exploring on the American mainland. In April, 1854, near Pelly Bay, on the Gulf of Boothia, he found Esquimaux who had in their possession various articles which had evidently 
belonged to Franklin or his officers. Close questioning disclosed the following facts : Some four years before some of their people while hunting seals on a large island, presumably that which we know as King William's, saw a party of white men, about 40 in number, they thought, going southward along the west shore of the island, they were dragging boats and sledges along with them. There was with them no one who could speak Esquimaux; but as far as could be learned from signs, their ships had been crushed and they were trying to get to a place where there were deer to shoot. They seemed to have plenty of ammunition, but to be short of provisions. They purchased some food of the natives and went on their way. When five years later the record was found on the island that Crozier and the surviving 105 had started for Back's River, there could be no doubt that this party were those who then survived. But how many had died before this is unknown. Rae was clearly of the opinion that this party had died from starvation and not from any violence by the natives. The relics were purchased from the Esquimaux, and sent to England. Still later in the year but before the breaking up of the ice, the corpses of about thirty persons and some graves were discovered on the Continent, and on an island near by five more corpses. All the indications were that the men had broken up into small squads, who had wandere.l in different directions in search of food.

In 1855, Mr. James Anderson was sent to search the region of the disaster. On June 30, a little way from Back's River, he found natives who had many articles which had evidently belonged to the expedition. They said that the owners had all died of starvation. On the small island where the five men were said to have perished were a few articles, among others a stick upon which was rudely carved the name of Mr. Stanley, the surgeon of the Erebus, and a plank, having on it the word Terror. That was all; there were no corpses there nor a scrap of paper. This party were unable to search King William's Island, presumably the main scene of the disaster. It was not, indeed, until four years later that the scrap of paper, already mentioned, was discovered, which told where and when the vessels had been lost, and that Franklin himself had died ten months before.

In 1857, Lady Franklin fitted out, at her own expense, a new expedition in search of her husband, then dead for almost ten years, though no one as yet knew it. The Fox, a screw steamer of 177 tons, formerly a pleasure yacht, was purchased and fitted up. The crew consisted of 24 men all volunteers, and the command was confided to Captain Francis McClentock, who had already served in the Arctic Seas under Ross, Austin, and Belcher. The Fox left Aberdeen on July 1, 1857. The design was to explore a tract of about 300 miles square, lying west of Boothia, between the northern limits of the explorations of Rae and Anderson, and the southern ones of Sir James Ross and Belcher, and to the west as far as the track of McClure. By the middle of August the little vessel was far up Baffin's Bay, and on the 17th was beset by the ice near the entrance of Lancaster Sound. For eight weary months she was held fast and apparently unmovable, by the solid pack which was, however, drifting slowly southward, and when finally released, April 25, 1858, she had been borne helplessly 1395 miles. McClentock refitted at Holsteinborg, in Greenland, and boldly set out again. On the 12th of July he sailed through Barrow's Strait, and attempted to pass down through Peel's Sound, but was stopped by the ice. Then he went north-eastward, skirting North Somerset, hoping to reach the mouth of Back's River through a strait, since 
uamed Franklin's. This was obstructed by ice ; but he managed to push through on the 6th of September. Here again he was caught fast, and held for three weeks, when he took up winter quarters on the north side of the strait. Sledge expeditions were sent out in all directions; and on one of these McClentock, March 1, 1859, he learned from a party of Esquimaux a ship had been crushed by ice in deep water off the north-west shore of King William's Island. Slowly new scraps of information were gained, to the purport that when the vessel had gone down the men had moved toward a great river, that many of them had dropped down by the way, their bodies being found in the spring, and some of them huried ; but that all had died of starvation. McClentock had now got at last upon Franklin's track, or rather that of the 105 who had escaped after the wreck of the Erebus and Terror.

The first trace of the long-lost crew was found near Cape Herschell. It was a bleached skeleton on the beach; near it were some fragments of clothing, a pocketbook and a few letters, which told nothing, for they were from home, addressed to, but not written by the person to whom they had belonged. The next day they came to a boat fitted up as a sledge, in which were two skeletons, two loaded guns, ammunition, chocolate, tea, tobacco, and some articles of silver plate, the marks on which showed that they had belonged to Franklin. At last, on the 6th of May, they came to a large cairn, and lying among some stones which had fallen from its top, was the paper containing the record already mentioned, upon which was written all that man can ever know of the fate of the Franklin expedition from July 26,1845 , when the ships were seen moored to the iceberg in Baffin's Bay, to April 25,1848 , when the surviving 105 were on the point of setting off on their returnless journey towards Back River.

Captain (now Sir Francis Leopold) McClentock, had thus supplied the last of the links in the story of the Franklin expedition. He had demonstrated that there was not a human probability that a man of them could now be living. He had also solved some of the great problems which had for eleven years occupied the mind of all Arctic explorers. He had also shown that Franklin, when finally beset, had really gone over the waters which linked together the explorations made from the east and west, and was, therefore, the actual discoverer of the long sought north-west passage, whose uselessness for all purposes was also demonstrated.

Subsequent explorations are yet to be briefly noted. In July, 1860, Dr. Isaac I. Hayes succeeded, by aid of private subscriptions, in organizing an exploring expedition. It consisted of fourteen men; sailed from Boston July 6 ; late in August was frozen in in latitude $78^{\circ}$ in Smith's Sound. He made boat and sledge expeditions to the north; and finally on May 18, 1861, with a single companion stood upon a projecting headland, in latitude $81^{\circ} 35^{\prime}$, which he believed to be the most northern known land on the globe. Parry had indeed gone somewhat farther, but it was upon a floe of ice. No other man had before or has since gone so far north upon land, unless indeed Hall, three weeks before his death, in 1871, went a degree beyond; a point which will, perhaps, never be settled. Before him Hayes saw a sea then encumbered by soft ice and floes, but which he thought would be free in summer; but he bad no boat, and was obliged to turn back, reaching New York in October, 1861.

In 1860, Charles Francis Hall constituted himself an expedition to the Arctic regions. He lost his boat, and was obliged to confine his explorations within narrow 
limits. He returned to New York, after three years' sojourn, baving in the meanwhile done much for future service. In a previous chapter ${ }^{1}$ full details of the expedition have been given. In 1864 he again set out, returning in 1869. In the following chapter will be told all that is known of this expedition, of which no full record has appeared. In 1871 he once more started upon what was to be his last expedition. Of this and of the marvelous escape of a portion of his men after his death, the next chapter will contain an account.

Of late years the opinion has become prevalent that the most feasible way of reaching the open Polar Sea is by way of Spitzbergen or Nova Zembla; that is, to the eastward of Greenland, and several European expeditions have gone in that direction. It is argued that the warmer waters of the great oceanic current of the Gulf Stream, flowing as a surface current in this direction, keep the channels comparatively free of ice. Some indeed go further, and ascribe the existence of this assumed open sea to be owing to these currents. In 1868 a German expedition was organized by Dr. August Petermann of Gotha, the foremost geographer of the day. It consisted of a vessel of 80 tons, under command of Captain Koldeway, and left Bergen, in Norway, early in May. Koldeway went up between Greenland and Spitzbergen, reaching a point as high as $81{ }^{\circ} 5^{\prime}$ North, and returned in October. In 1868 the Swedish government also sent an expedition which sailed to the north of Spitzbergen, but accomplished little or nothing. In June, 1869, another German expedition of two vessels left Bremen. One of these, the Hansa, was in October wrecked in the ice near the eastern shore of Greenland. The erew escaped to an ice-field which was slowly drifting southward, and constantly diminishing in size as it came into warmer waters, until at last it was hardly larger than a raft. The men then took to their boats, and succeeded in reaching Fredericksthal, near Cape Farewell, the southern point of Greenland, and reached home in the summer of 1870. Their adventures while on this ice-field read strangely like those of the persons saved from Hall's last expedition, to be narrated in the next chapter. Meanwhile the other vessel, the Germania, which had become separated from her consort, endeavored to reach high latitudes by keeping close along the eastern shore of Greenland. She turned back as winter set in, having apparently accomplished nothing toward solving the problem. But she discovered what was supposed to be a deep indentation in the shore, running north-westward, to which was given the name of Francis Joseph Bay. Hall's last expedition discovered, on the opposite side of the Greenland coast, an apparent bay running north-eastward. Many circumstances combine to render it probable that these two supposed bays are a connected channel, forming the northern boundary of the island of Greenland. During 1869, 1870 and 1871, several other expeditions, among which was one conducted by James Lamont, an English gentleman of fortune, tried the way between Greenland and Spitzbergen, but none of them reached very high latitudes, or made any important discoveries. In June, 1871, Payer and Weyprecht, lieutenants in the Austrian navy, embarked at Tronsö, in Norway, on board a little trading vessel, and sailed hetween Spitzbergen and Nova Zembla. They reached only as high as latitude $78^{\circ} 41^{\prime}$, but entered an almost open sea, in which navigation was impeded only by very light and scattered ice. Had they been fitted out for an extended cruise there seems good reason to suppose that they would bave 
been able to sail fairly into the broad, open Polar Sea; but as it was, the vessel returned to Tronsö in October. Petermann believes that the results of this expedition were of the highest geographical importance ; that it actually penetrated into the open sea by its most available entrance. Two Norwegian captains, Tobiesen and Mack. subsequently confirmed the reports of Payer and Weyprecht. Another Norwegian, Captain Carlsen, sailed up the coast of Nova Zembla, and discovered, at the north-east extremity of the island, the remains of the winter encampment established 275 years before by the Iutch navigator Barentz, just as Hall, in his first expedition, found relics of the expedition of Frobisher, which had remained almost twenty years longer. Ulve and Smyth also sailed to the north of Spitzbergen, and found open water as high as latitude $80^{\circ} 2 \bar{\prime}^{\prime}$. In 1872 Octave Pavy, a young Frenchman resident of New Orleans, made proposals for an expedition, which was to leave San Francisco for Kamchatka, and endeavor to reach the Polar Sea by the way of Bering's Strait. He projected an India rubber raft, which when inflated would carry the crew and 10.000 pounds of freight, but which was so light that when not in use it could be packed in a barrel, and so conveyed over land. But there is no account that this idea has been carried into effect.

It remains only to describe, as far as is now known, the last Polar expedition xadertaken by Charles Francis Hall. 



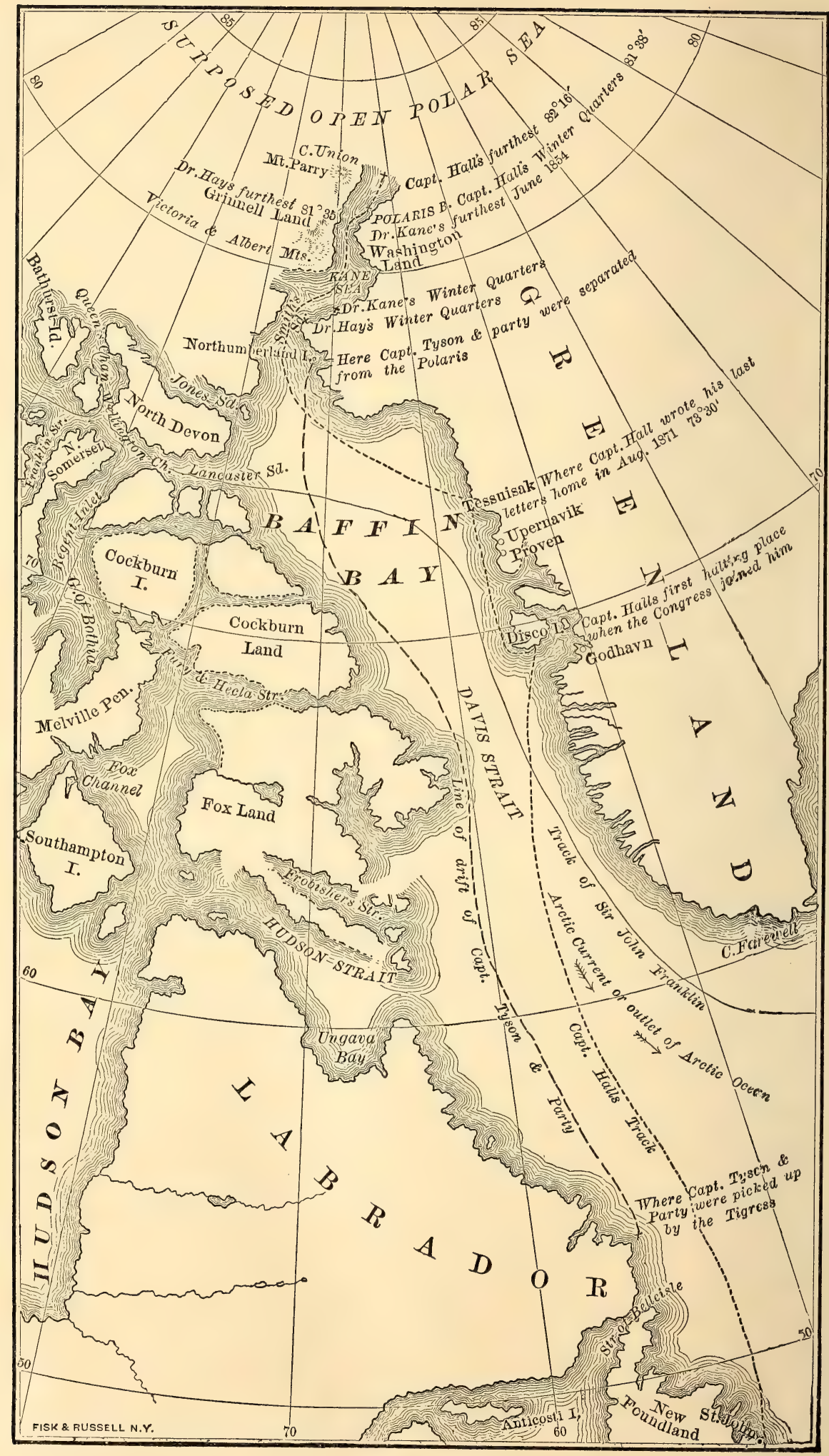




\section{CHAPTER XLIV.}

\section{THE LAST EXPEDITION OF CHARLES FRANCIS HALL.}

Charles Francis Hall.-His second Expedition.-His last Expedition.-The Polaris.-Officers and Crew.-Setting out.-A slight Dispute-Off for the Pole-Hall's farewell Dispatch. - The next Tidings.-The rescued Nineteen.-Their Story.-Voyage to the highest Latitudes.-Taking up Winter Quarters.-Hall's last Sledge Journey.-His last Dispatch. - The Return to the Polaris.-Sickness and Death of Hall--Buddington takes Command. -Winter in the Ice.-Aspects of the Region.-Accident to the Polaris.-A Boat Expedition.-Starting for Home.-The Polaris in Peril.-Taking to the Ice.-The Separation.The Parting on the Ice.-Herron's Journal-_october: Abandoned-A Fortnight's Waiting.-November: Trying for the Shore-A Godsend.-Amusements.-Beginning to Drift. -Killing the Dogs-A Thanksgiving Dinner.-December: Adrift.-Eating Seal Skin, and Fox Meat.-Game in the wrong Place.-A Christmas Dinner.-January: Unpleasant New Year's.-Drifting Southward.-Another Godsend.-A Sight of the Sun.-Drifting on.February: Snow Storms.-Narwhals and Seals.-Piles of Ice.-A Sight of Land.-Off from the Sealing Ground.-Provisions Short.-Ebierbing the main Stay.-Dovekies.March: Seals, Birds, and Icebergs.-The Floe Splitting.-On a Fragment.-More Godsends.-The first Day of Spring - Launching the Boat.-More Seals.-Rate of Drift.Floe wearing away.-April: Taking to the Boat--Ice and Water--Repairing the BoatPlenty of Seals.-Floe breaking up.-A Struggle for Existence.-Ebierbing and Hans to the Rescue.-A fearful Night.-Six Months adrift.-Stealing Food.-On short Allowance. -Thoughts of Cannibalism.-A Seal and three more Meals certain.-A dainty Repast Swept over by the Sea.-The last ten Days.-Length of the Drift.-A hungry Bear and hungrier Men.-A desperate Risk-Seals again.-In fresh Peril.-A Steamer in Sight.The Steamer Disappears.-Another Steamer in Sight.-Hopes and Fears.-The last Entry in Herron's Journal.-The Fog lifts.-The Tigress.-Saved at Last.-Wonders of the Drift.-Ebierbing the Hero.-Conduct of the Men.--Proposed Searches for the Polaris.

$\coprod \mathrm{N}$ N 1859, at a meeting of the New York Geographical Society, held in honor of Dr. Kane, a plain blunt man introduced himself to the President with the words, "I want to go and find the bones of Sir John Franklin." In a rather hesitating manner he proceeded to explain the plan which he had conceived in his Western home. Something in the manner of the man won the confidence of IIenry Grinnell, and the result was that a scanty outfit was provided, and Charles Francis Hall set out on his first expedition, which has already been described in these pages.

I first saw Hall immediately upon his return from this expedition. He brought his journal and notes to a publishing house for which I was acting as literary adviser, wishing to have them published. I saw at once that they were of unusual interest, and had no hesitation in advising that they should be prepared for the press; and while this was in course of execution, I saw Hall almost every day. Many of the very best portions of the book were exact copies of his original memoranda, written in an Esquimaux snow hut, with pencil, because ink could not be kept unfrozen. 
Of his early life he said but little. About all which I call to mind was that he was born about 1823 ; had been brought up a blacksmith, had somehow drifted into journalism in Cincinnati, and that a desire to explore the unknown Arctic regions had for years becn growing upon him, until at last he had come to look upon it as his special mission to unravel the mystery of the fate of Franklin. Even when he set out upon his second expedition, he had a strong persuasion that some members of that party were still alive and might yet be rescued.

In 1864 he sailed from New London, Conn., on his second expedition, in a whaling vessel, commanded by Captain Buddington of whom we shall hear more. With him went only the Esquimaux Ebierbing and his wife Tookoolito. He landed on the coast of Hudson's Bay, penetrated to the north as far as Hecla and Fury Bay, and thence journeyed into King William's land. In this region be spent four successive winters, living entircly among the Esquimaux, most of the time near Repulse Bay, acquiring a knowledge of their language and customs, and adapting himself to their habits and modes of life, and so fitting himself for the prosecution of a larger enterprise. By careful inquiry among the natives he satisfied himself of the truth of the reports that the bulk of Franklin's party had died of starvation on King William's land, and that only a small part of them had succeeded in passing to the main land. He brought back with him many relies, and convinced himself that before the final besetment Franklin had actually gone as far westward as any one has since gone, and was thus the actual discorerer of the long sought north-west passage. He found, howerer, no traces of the records of the expedition; and it is probable that all were lost when the vessels were hastily abandoned. That the abandonment was hasty, is shown by the fact that no stores or provisions appear to bave been saved.

Of this second expedition of Hall, the general results of which have been thus meagerly stated, I know that he had full notes; and it was his purpose, after he had made one more expedition, in which he had full confidence that he would be able to reach the pole, whether it was upon land or in water, to combine tho results of both in a work which should tell all that man could know of regions which human eye had never seen, and might not perhaps again see for generations.

For long months he labored to induce the government to fit out another expedition, in which he was at last successful. What with government aid and the assistance of private individuals, nothing which human foresight could provide seemed wanting to ensure success, if this lay within the scope of human power. A steamer of 400 tons, known as the Periwinkle, also rigged as a schooner, was purchased, and fitted up and strengthened to adapt her for the new work. Six inches of solid oak planking was placed upon her sides; her bows were built up so as to be almost a solid mass of timber, sheathed with iron and ending in a sharp iron prow. The screw was so arranged that it could be unshipped and placed upon deck, so as to be out of danger from the ice. Extra blades, rudder, spars and sails were provided. Boats were built for the special service. One of these, capable of carrying four tons, weighed only 250 pounds, and was so constructed that it might be folded up at three minutes' notice, and could be placed on a sledge, transported orer snow or ice, and launched whenever a piece of open water was reached. Nothing was spared to ensure to cfficers and men every comfort which could be attainable in the inhospitable region to which 
they were bound. Of late, indeed, men have come forward to assert that the steamer was not fit for the service. But such certainly was not the judgment of Hall or of his associates, among whom were several men inured to Arctic navigation. A better vessel might doubtless have been built for the express purpose; but it does not appear that there was then in this country, or in any other, a steamer better adapted to Arctic navigation. The vessel was fittingly rechristened the Polaris-" The Polar Star."

Extraordinary care seems to have been taken in the selection of officers and crew. As for Hall himself, a careful investigation of all that has since come to light, shows that no other man possessed so many qualifications for the command. Eight years in the Arctic regions had made him perfectly acquainted with the best means of preserving life and health. He had learned the language of the Esquimaux, of whose assistance he expected largely to avail himself. He certainly had the faculty of maintaining strict discipline, and at the same time of gaining the affection of those under him. It is true he was not a professional sailor or engineer; neither were Kane or Hayes-the two men whose names best deserve to be associated with his. In any case, even had he been a naval officer, the practical details of navigation must have been placed in charge of some one accustomed to voyaging in the ice.

As far as man could judge, no better choice could have been made for sailing master than Sydney O. Buddington. He had been in a whaling vessel in eleven voyages, extending for more than thirty years, in these very regions. He had been in command of the vessel in which Hall had sailed upon his former expedition. Hall and others who had the best means of knowing the man deemed him the one for the place. If, as there is now reason to believe, his character sadly changed in consequence of a newly-acquired passion for liquor, no one had any good reason to anticipate this. The assistant navigator was George E. Tyson; what will hereafter be said of him will evince his fitness for the post. The first mate, Hubbard . C. Chester, for aught that appears, was well chosen. As second mate went William Morton, who a score of years before had been the right-hand man of the lamented Kane. It was Morton who discovered what Kane firmly believed to be the edge of the open Polar Sea, although it is now known that this is but an expansion of Smith's Sound, and that still north of it lies a frozen strait. Like the foot of the rainbow this sea seems to recede as we try to approach it. As chief of the scientific department was Emil Bessels, who had brought with him from his native Germany the bighest testimonials; and was endorsed by Petermann and Agassiz. He had also been a member of an Arctic expedition sent out by the Prussian government. Besides these there were Emil Schumann, chief engineer, Frederick Meyer, meteorologist, R. D. W. Bryan, astronomer and chaplain, the faithful Esquimaux Ebierbing, his wife Tookoolito, and their child, "Puny," who had come to them in place of the little "Butterfly," whom they had laid in a New England grave-yard. Ebierbing was to act as interpreter and hunter, and to him in the end was mainly owing the preservation of the nineteen persons whom we know to be the survivors of this expedition. The crew of all capacities numbered seventeen, of whom about balf were Germans or Scandinavians. In Greenland they also took on board an Esquimaux, Hans Christian, to act as dogdriver, with his wife and three children, to whom another was born afterward. So that, all told, the entire expedition consisted of forty persons.

The Polaris sailed from New York June 29, 1871, and reached St. John's, New- 
foundland, July 13, where the expedition was cordially welcomed by the governor and principal citizens. Thence they steamed up Davis's Straits, reaching Holsteinborg, in Greenland, on the 31st. There they found a Swedish vessel, which was just about sailing for home. This reported that Baffin's Bay was more free from ice than it had been for years. They awaited the arrival of the transport Congress, bearing additional stores and supplies, and in the meantime purchased dogs, furs, and other requisites. On the 17th of August the Polaris bade adieu to the Congress, and fairly set out on her expedition for the pole, touching successively at Upernavik and Kong-i-toke, where more dogs were procured. On the $22 \mathrm{~d}$ they reached Tessuisac, in latitude $73^{\circ} 30^{\prime}$, probably the most northern permanent settlement on the globe. Here Hall commenced penning a dispatch, to which on the two following days he added brief postscripts.

There had been, as was reported by the Congress on her return, some disputes between Hall and his scientific associates. As far as we can judge from the scanty account, in Hall's view the main object was to reach the pole, and to this everything else was to be subordinate; in their view, quite naturally, scientific observation and research was the main thing. The instructions from the Secretary of the Nary seem to us to be so clear, as to leave no doubt that Hall's view was the correct one. So at least it was decided by the commander of the Congress, and his decision seems to have met with prompt acquiescence. The dispute, whatever it was, was adjusted, and Hall writes in the highest spirits :

"August 22, 1871. The prospects of the expedition are fine; the weather beautiful, clear, and exceptionally warm. Every preparation has been made to bid farewell to civilization for several years, if need be to accomplish our purpose. Our coal-bunkers are not only full, but we have fully ten tons on deck, besides wood, planks, tar, and rosin in considerable quantities that can be used for steaming purposes in case of any emergency. Never was an Arctic expedition more completely fitted out than this. The progress of the Polaris so far has been quite favorable, making exceedingly good passages from port to port. The actual steaming or sailing time from Washington to New York was sixty hours; and from that place to thisthe most northern civilized settlement of the world, unless there be one for us to discover at or near the North Pole-has been twenty days, seven hours, and thirty minutes. There is every reason to rejoice that everything pertaining to the expedition, under the rulings of High Heaven, is in a far more prosperous condition than $I$ had hoped or prayed for. We are making every effort to leave here to-morrow.August 23, Evening. We did not get under way to-day, as expected, because a heavy, dark fog has prevailed all day, and the same now continues. The venture of steaming out into a sea of undefined reefs and sunken rocks, under the present circumstances could not be undertaken._-August 24, 1 P. M. The fog still continues, and I decide that we cannot wait longer for its dispersion; for a longer delay will make it doubtful of the expedition securing the very high latitude I desire to obtain before entering into winter quarters. A good pilot has offered to do his very best in conducting the Polaris outside of the most imminent danger of the reefs and rocks. Now, at half-past 1, P. M., the anchor of the Polaris has just been weighed, and not again will it go down, till, as I trust and pray, a higher, a far higher, latitude has been attained than ever before by civilized man. Governor Elberg is about 
accompanying us out of the harbor and seaward. He leaves us when the pilot does. $\mathrm{He}$ has rendered to this expedition much service, and long will I remember him for his great kindness. I am sure you and my country will fully appreciate the hospitality and co-operation of the Danish officials in Greenland as relating to our North Polar Expedition.-Now, at a quarter past 2, the Polaris bids adieu to the civilized world. Governor Elberg leaves us, promising to take these dispatches back to Upernavik, and to send them to our minister at Copenhagen by the next ship, which opportunity may not be till next year. God be with us."

The annual Danish vessel had left Greenland; and, as Hall had anticipated, nearly a year passed before there was any opportunity of sending this dispatch. When these hopeful words were read in the United States, whence they had come by way of Copenhagen, their writer had been dead nine months; and, as the event proves, with him had perished all the high hopes which had been cherished of the success of his expedition.

From that 24th of August, 1871, to the 30th of April, 1873, not a word of tidings of the expedition passed through the icy barriers of the Arctic circle. On this last day the staunch little steamer Tigress, built for the sealing trade in the Greenland Seas, and owned in Newfoundland, while steaming down the coast of Labrador, in about latitude $53^{\circ}$ North, in a dense fog, came upon a patch of ice some twenty feet square-about as large as the floor of a small room. Upon this were human beings, who were taken on board and found to be a part of the crew of the Polaris. They proved to be Tyson, the assistant navigator, Meyer the meteorologist, Jackson the cook, Herron the steward, five seamen, with the Esquimaux Ebierbing and Tookoolito, and their child, Hans Christian, his wife and four children, the youngest only eight months old, six months and more of whose brief life had been passed upon the ice: in all nineteen souls.

These were brought to St. John's, Newfoundland, and in a few days the tidings of their rescue reached the United States. The Herald newspaper had at St. John's, as almost everywhere else, a capable correspondent. He interviewed the persons, and on the 21st of May a long and full report of what they could tell appeared in the Herald. Meanwhile the government had dispatched a steamer from New York to bring the party to Washington, where they arrived early in June. They were all carefully examined by a commission consisting of the Secretary of the Navy, assisted by Commodore Reynolds, the senior officer of the Navy Department, himself an experienced explorer; Professor Spencer F. Baird, Assistant Secretary of the Smithsonian Institute, among the foremost scientists of the age, a warm personal friend of Hall, and an ardent promoter of the expedition; and Captain Howgate of the Signal Service. Their narrative to the Herald correspondent, and their testimony before this commission, agree in every essential respect, and embody all that we can at present hope to know of this expedition: all that we can ever hope to know, unless the Polaris herself and the remainder of her crew shall hereafter be found.

On the 24th of August, as has been seen, the Polaris got safely out of the dangerous harbor of Tessuisak, shot across the head of the stormy Melville Bay; passed Northumberland Island, and through Smith's Sound; and meeting little obstruction from ice, entered what Kane and Morton and Hayes believed the open Polar Sea, which however proved to be a mere expansion of the Sound, and to which the name 
of Kane Sea must hereafter be given. The Sound then narrowed, but with a deep indentation setting into the Greenland shore. Steaming northward through a channel apparently twenty-five or thirty miles wide, with high land on either side, in just a week they reached their highest northern point, which by Hall's reckoning was in latitude $82^{\circ} 29^{\prime}$ but which by Meyer's subsequent and probably more accurate calculations was in latitude $82^{\circ} 16^{\prime}$, a difference of about fifteen miles. Here, on the 30th of August, the channel to which Hall gave the name of Robeson Straits, in honor of the Secretary of the Navy, was impassably blocked by heavy masses of floating ice. Hall took a boat and vainly sought to find a passage through the ice. To take a step backward was far from his purpose. He found a small bay where he hoped to make his winter quarters. A consultation was held, and, as it would seem, mainly through the influence of Buddington, it was decided not to lie up here. To this bay Hall gave the name of Refuse Harbor. The ice now took the matter into its own hands, and drifting slowly bore the Polaris southward for four days. On the $3 \mathrm{~d}$ of September the pack opened, and the Polaris headed eastward into a small cove setting into the Greenland shore. The mouth of the cove was sheltered by a huge iceberg, and here it was decided to winter. This cove, in latitude $81^{\circ} 38^{\prime}$, was named Polaris Bay, and the sheltering ice island was called Providenceberg. Here at midnight, on the $3 \mathrm{~d}$ of September, Hall landed in a boat and raised the Stars and Stripes in the name of God and the President of the United States. Polaris Bay is, if all calculations are correct, just three minutes of a degree, or about three miles further north than the farthest point reached by Hayes, by land on the opposite side of the strait, and about two hundred miles north of Kane's famous winter quarters.

The Polaris was moored fast to the iceberg, an observatory was established, and scientific work set about. Hall forthwith began to plan a sledge journey to the north. Taking with him only Chester the mate, and Ebierbing and Hans, with two sledges and fourteen dogs, he set out on the 10th of October. A fortnight, that is a week for advancing and the same for returning, was the period fixed for this expedition. On the evening of the 10th day he wrote his last dispatch, probably the last words he ever wrote, for the Secretary of the Navy. By a strange chance the draft of this dispatch has been preserved. Here follow the essential parts of it:

“ Sixth Snowhouse Encampment, latitude $82^{\circ} 3^{\prime}$, longitude $610^{\circ} 20^{\prime}$, October 20, 1871. Myself and party left the ship in winter quarters, Thank God Harbor, to discover, if possible, a feasible route inland for my sledge journey, next spring, to reach the North Pole, purposing to adopt such a route if found better than a route over the old floes and hummocks of the strait. We arrived here on the afternoon of October 17, having discovered a lake and river on our way. Along the latter our route, a most serpentine one, which led us to this bay from the top of an iceberg near the mouth of the river, we could see that this bay extended to the eastward and southward about fifteen miles. On arriving here we found the mouth of the bay open, the water having numerous seals in it, bobbing up their heads. This open water making close to both headlands, and the ice of Robeson Strait being on the move, debarred all chance of extending our journey up the strait. The mountainous land (none other being about here) will not admit of our journeying further north; and we commence our return to-morrow morning. To-day we are storm-bound at this our sixth encampment. We can see the land extending on the west side of the strait 
to the north about seventy miles, thus making the land we discovered as far as latitude $83^{\circ} 5^{\prime} \mathrm{N}$. There is the appearance of land further north, and extending more easterly, but a peculiarly dark nimbus cloud prevents my making a full determination. Up to the time I and my party left the ship all have been well, and continue with high hopes of accomplishing our great mission. We find this a much warmer country than we expected. The mountains on either side of Kennedy Channel and Robeson Strait were found entirely bare of snow and ice, with the exception of a glacier that we saw commencing in about latitude $80^{\circ} 30^{\prime} \mathrm{N}$. on the east side of the Strait, and extending in an easterly direction as far as can be seen from the mountains near Polaris Bay. We have found that the country abounds with live seals, game, geese, ducks, musk cattle, rabbits, wolves, foxes, bears, partridges, lemmings, etc., etc. Our long Arctic night commenced October 13, having seen only the upper limb of the sun above the glacier at meridian, October 13. This dispatch I finish at this moment, twenty-three minutes past eight P. M., having written it with ink in our snow hut. Thermometer outside, $7 \circ$; yesterday all day, 200-23०."

There is a postscript dated next morning: "A copy of this dispatch was placed, October 21, 1871, in a pillar at Brevoort Cape" (the northern headland of the bay on which this encampment was situated). This dispatch, found in Hall's writing desk, and first read in Washington in June, 1873, is a voice from beyond the grave certifying to the fact that up to this time nothing had occurred on the expedition to diminish the confident expectation which he entertained of complete success, and in connection with the former one is abundant refutation of the newspaper charges that there was anything lacking in the equipment of the Polaris.

The return journey was naturally more rapid than the advance had been, and on the fourth day Hall and his companions regained the Polaris. He was to all appearances in his usual robust health, and certainly in his usual buoyant spirits. His great laugh, which all who knew him knew so well, rang out in the darkness of the Arctic night, and he thanked the men for having behaved so well while he had been absent. The change from a breezy temperature of 15 or 20 degrees below zero, to one of 60 or 70 above, in the close cabin, probably somewhat affected him, and he declined any refreshments except a cup of coffee. He took a hot sponge bath, and retired to rest. In the morning he was seriously unwell, the chief symptoms boing a burning in the throat and vomiting. For a week the disease made progress, and from all the evidence was accompanied by partial paralysis and delirium. From this he partially recovered, made some attempt to resume his work, and it was supposed that he would be well in a few days. On the night of the 8 th of November he had a fresh attack, and Tyson, going into his cabin, found him lying in his berth, breathing heavily, and insensible. He died during that night, and was buried three days after in a shallow grave dug with difficulty in the frozen ground.

If the doctor was correctly understood, he pronounced the death to have been occasioned by apoplexy. Hall himself undoubtedly believed that he had been poisoned in the cup of coffee which he drank, and after his partial recovery was continually looking over medical books to find out the poison which would produce the symptoms which he experienced. Once he called the faithful Ebierbing, and pointing to some word in one of the books, said that this was what was making him sick. In his delirium he fancied that every one was trying to kill him. But the commission report: 
“ From personal examination of all the witnesses, we reach the unanimous opinion that the death of Captain Hall resulted naturally, from disease, without fault on the part of any one. During his illness he was under the medical care of Dr. Bessels, and as none of the persons now here are capable of giving a more particular account of the nature and symptoms of his fatal sickness, the return of the Polaris must be awaited for precise information."

Out of a thousand picked men it would be hard to select one whose chances of life were so good as those of Hall. He was slightly above the middle height, strongly built, with large head, broad chest, and muscular limbs. In all his habits he was strictly temperate, and even when he returned from his second expedition he presented the ideal of robust health, as he did when he set out on his last one. The instructions, however, had provided for the possible contingency of his death, in which event the command was to fall upon Buddington. The long winter was passed as usual in the Arctic regions, but without any suffering from want or even from cold. Indeed it seems fairly established that on the western continent at least the line of greatest cold runs considerably south of latitude $80^{\circ}$. The highest points where a continuous series of extreme cold have been noted are in about latitude $72 \circ$ on the American continent and in Kamchatka. Scientific observations were carefully kept up, a considerable extent of coast was surveyed, and Ebierbing and Hans Christian hunted whenever opportunity presented, and with no inconsiderable success, the storerooms of the Polaris being filled with skins and skeletons of musk oxen, bears, and other animals, with birds of many species, and their eggs, and other objects of natural history. To all appearance the waters were wholly destitute of fish; for although nets and lines were continually set, none were obtained. But marine invertebrata, such as jelly-fish and sbrimps, were abundant, which were believed to constitute the chief food of the numerous seals. Many pieces of drift wood were picked up, the walnut, ash and pine being identified. These must have been drifted from a warmer climate, and have come either through Bering Straits from the west, or around the northern coast of Greenland from the east; all the probabilities being in favor of the latter. Indeed it is more than probable that the northern coast of Greenland does not extend much nearer the pole than latitude $83^{\circ}$. As has been previously mentioned, the Germania and Hunsa expedition discovered an apparent sound stretching westward into the eastern shore of Greenland; and it is not improbable that this communicates with the one which the Polaris saw running north-eastward, and so defines the northern coast of Greenland.

Two or three weeks after the death of Hall, a strong gale swept down from the north-east, forced the Polaris to drag her anchors, and drove her against the ice-island at the mouth of the cove, to which she was then made fast, and so remained until the following June. During the winter a pack of moving ice drove her higher up the berg, where her bow remained fixed, resting upon the ice-bed, while her stern swung up and down with the rising and falling tides. The strong stem-piece was strained, some of the planking started, and when at last she settled into the water she leaked somewhat; but after being once cleared by the steam pumps, she was kept clear by working the ordinary deck pumps for about six minutes in an hour.

Early in June, Buddington ordered a boat expedition, under Chester and Tyson, to go up the shore as far as possible. One boat was crushed in the ice almost at the 
outset; but its place being supplied by the light canvas boat, before mentioned, a point was gained almost as far north as that which Hall had reached in his sledge journey. Here they remained until the middle of July, 1872, waiting for the ice to open, when they were recalled by Buddington, who had determined to return home as soon as the ice would permit. The party made their way overland, leaving the boats behind. From the data now accessible, this determination to return can hardly be censured, although Hall would not probably have consented had he been living. The Polaris had been much strained, and though there were abundance of stores from which overland parties could be supplied, the coal was getting short, and so the Polaris itself would hardly have been able to make her way again under steam far to the north.

The Polaris got free early in August, and steamed cautiously down the western shore for a day, when she was beset in the ice, and was in imminent peril. On the 16 th the ship was made fast to a huge floe, in latitude $80^{\circ} 2^{\prime}$, and drifted slowly up and down Smith's Sound for two months, during which they only gained about a dozen miles to the south, bringing them near Northumberland Island, in latitude $79 \mathrm{c}$ $53^{\prime}$. To be prepared for the worst, provisions were brought on deck, in readiness to be thrown upon the ice should it be necessary to abandon the vessel, and a canvas shelter was put up on the ice.

On the 15th of October a violent gale set in from the south, driving the ice under the ship, pressing her fairly out of the water, and throwing her over on her beam ends. Some provisions and stores were thrown over, and half of the crew were ordered out to carry them further upon the ice. All the boats were lowered. In the middle of the night, in a violent storm, the Polaris broke loose, and in a few minutes was out of sight. Upon the ice were the nineteen persons already named. All through the night they labored to save the provisions; and when morning dawned attempted to reach the shore, which was in plain sight. During the day the Polaris hove in sight, at a distance of four or five miles, apparently approaching the floe under sail and steam. Those on the ice were sure that they must be seen from the vessel, and that they would soon be taken on board. But the vessel changed her course, and soon disappeared. Not unnaturally they believed that they had been purposely abandoned. But the commission, upon a full review of all the circumstances, came to the conclusion that there was no sufficient evidence that this was the case. A few hours afterward, another glimpse was got of the Polaris. She appeared to be made fast to the shore or to the ice. From that day up to the middle of July, 1873 , when these pages are written, a period of more than nine months, no tidings of the Polaris have been received. It is indeed hoped that she is fast beset in the ice, but otherwise safe. If so, as there is no danger of starvation, it is believed that the crew, if not the vessel, may be rescued.

We now turn to the fortunes of the nineteen who were left upon the ice, and who were finally rescued by the Tigress. In all the records of adventure and peril there is nothing which, for interest, exceeds this ; and of it we have an account, unique in its kind ; the only thing approaching it being the famous journal of Bligh and his party of seamen, who were set adrift from the "Bounty" in 1789. Bligh, in an open boat, was adrift forty-six days under a torrid sun. These men, women and 
children, for 195 days, drifted upon a cake of ice all through an Arctic winter. One of the party, John Heron, the steward, thirty-one years of age, born in Liverpool, but a citizen of the United States, kept from day to day a minute journal of all that occurred. From this, greatly abridged, our narrative will be drawn, noting only the salient points, but preserving the words of the writer :

"October 15th.-Gale from the S. W. ; ship made fast to floe; bergs pressed in and nipped the ship until we thought she was going down; threw provisions overboard, and nineteen souls got on the floe to receive them and haul them up on the ice. A large berg came sailing down, struck the floe, shivered it to pieces, and freed the ship. She was out of sight in five minutes. We were afloat on different pieces of ice. We had two boats. Our men were picked up, myself among them, and landed on the main floe, which we found to be cracked in many places. We remained shivering all night. Saved very little provisions. 16th.-Morning fine; light breeze from the $\mathrm{N}$. The berg that did us so much damage half a mile to the N. E. of us. Plenty of open water. We lost no time in launching the boats, getting the provisions in and pulling around the berg, when we saw the Polaris. She had steam up, and succeeded in getting a harbor. In the evening we started with the boats for shore. $\mathrm{Had}$ we reached it we could have walked on board in one hour, but the ice set in so fast that we could not pull through it. We had a narrow escape in jumping from piece to piece until we reached the floe. We dragged the boat two or three hundred yards, and made for our provisions, which were on a distant part of the floe. We can not see our other boat; the snow drift has covered our late tracks. 23d.-With the aid of a marine glass we discovered a boat, and at some distance therefrom a tent. The ice for a few miles is very thin ; but we risked it, and returned to headquarters weak but thankful to God, and rejoicing for our increase of stores. We have now eleven bags of bread, thirteen cans of pemmican, eleven dozen cans of meats, soups, etc., and fourteen hams. 31st.-Sent Joe and Hans with a dog team to see how the ice will stand, as we intend starting to-morrow for shore. If the ice hold good we shall be there in two or three days. If we reach the shore we shall live better, as we may kill some game."

" November 2d.-Ice open and water all around us. We started before daylight with the dogs and sled, not knowing what had happened until we were nearly driven into the water. The ice closed in a little. We tried again, and ventured across on the other floe. Saved one rake, some of Joe's clothing, three guns, and a few other things. When the men returned to the crack it was just opening; they had got across just in time, as the ice opened, and the floe has not been seen since. $3 d$. -Building snow houses. No chance now of getting ashore; must now give that up. 6th.-Joe caught a seal, which is a Godsend. We are having a feast to-night ; threefourths of a pound of food to a man. Mr. Meyer made a pack of eards for us from some thick paper, and we are now playing euchre. We are a good deal further from land, and are drifting south pretty smart. 16th.-Joe saw three seals yesterday and a fox track, but got nothing. We have nothing to feed our dogs on. They got at the provisions to-day. We have shot five, leaving four. Shot some two weeks since. We are lining our new hut with canvas. 21st.-The natives caught two seals. They shot three, but lost one of them in the young ice. We shot two dogs. They got at our provisions. 28th.-Thanksgiving Day. We have had a feast : four pint 
cans of mock turtle soup, six pint cans of green corn made into scouch. Afternoon, three ounces of bread, and the last of our chocolate."

" December 2d.-No open water has been seen for several days. Cannot catch anything. Land has been seen for several days; cannot determine which shore it is, east or west. It has been so cloudy that we cannot select a star to go by. Some think it is the east land; I think it is the west. Boiled some seal-skin to-day and ate it, blubber, hair, and tough skin. The men ate it; I could not; the bair is too thick, and we have no means of getting it off. 6th.-A fox came too near the other day. Bill Lindemann shot him; skinned him, and cut him up for cooking. Fox in this country is all bones and hair. 8th.-All in good health. The only thing that troubles us is hunger; that is very severe. We feel sometimes as though we could eat each other. Very weak, but, please God, we will weather it all. 20th.-Joe found a crack yesterday and three seals. Too dark to shoot. It is a good thing to have game underneath us; it would be much better for starving men to have them on the floe. To-morrow will be our shortest day; then the sun turns back. 24th.Christmas Eve. We are longing for to-morrow, when we shall have quite a feast: half a pound each of raw ham, which we have been saving nearly a month for Christmas. A month ago our ham gave out ; so we saved this for the feast. Yesterday 9 degrees below zero; to-day 4 degrees above. 25th.-Christmas Day. This is a day of jubilee at home, and certainly here for us ; for besides the approaching daylight we have quite a feast to-day. One ounce of bread extra per man, which made our soup for breakfast a little thicker than for dinner. We had soup made from a pound of seal blood, which we had saved for a month; a two-pound can of sausage meat, the last of our canned meat; a few ounces of seal, which we saved with the blood, all cut up fine; last of our can of apples, which we saved also for Christmas. The whole was boiled to a thick soup, which I think was the sweetest meal I ever ate. This, with half a pound of ham and two ounces of bread, gave us our Christmas dinner. Then in the evening we had our usual thin soup."

“January 1, 1873.-Poor dinner for New Year's Day : mouldy bread, and short allowance. 2d.-Mr. Meyer took an observation last night. Latitude $72 \circ 10^{\prime}$, longitude $60^{\circ} 40^{\prime}$. The news was so good" [i. e. in about nine weeks they had drifted southward something more than seven degrees, about 525 miles] " that I treated myself to an extra pipe of tobacco. We are obliged to cook our meals over the lamp; slow work. Thermometer 31 degrees below zero. 16th.-Hans caught a seal to-day. Thank God, for we are very weak. Our light would have been fiuished to-morrow, and our cooking also. But God sent this seal to save us. It has been so all the time. Just as we were played out, something came along. I am afraid I have a touch of the scurvy; a little raw meat will drive it out, I hope. 19th.-Clear, light wind. Thermometer 39 degrees below zero. The sun has made his appearance today. I gave him three cheers, hoping we will be able to start" [that is in the boats] " in a month. The sun has brought us luck in the way of a seal which Joe caught. 27th.-The sun is out. Mr. Meyer took an observation. He makes latitude $69^{\circ}$ $32^{\prime \prime}$. He thinks we are 42 miles from the shore. Godhaven, on the island of Disco, is in latitude $69^{\circ} 13^{\prime \prime}$. That leaves us nineteen miles north of our store-house, which I am afraid we will never see. God knows where we will fetch up."

"February 4th. A gale from the west; very thick snow drift, I seldom see it snow 
here; for when it is blowing hard the snow comes like flour with the wind. Whether the snow falls or the wind takes it up from the ice I cannot tell; but it is so fine and thick you cannot see. There is no leaving the hut in such weather, as the snow is always either drifting or falling, with the blow, no matter from what quarter. All well but me. I have a slight touch of the scurvy; but, please God, it will soon leave me. We hope when this blow is over, we shall see land and have a little open water. 7th.-Hans caught a seal, and fired at a narwhal. Joe shot and killed a big fellow, but could not get bim. He turned belly up and sank. He would have been food for a month. There were a great many of them going north. It is their time of the year. 8th.-A pretty large crack around the floe. Shot five narwhals to-day, but could not get them, as they got away under the ice. Joe said a large fleet of them were going north, but could not find water, and so came back again. We cannot find any seals when they are about. Joe says the seals are not afraid of the narwhals; but I think they are. 16th.-Saw plenty of narwhals, I wish they would go away; they frighten the seals away, which we are so badly in want of. Our provisions are getting low. When you take a glass and look around, you see the ice in the distance piled as high as a ship's mast, so that it seems impossible to travel over it-certainly not with a boat. No land to be seen yet. We want water to escape. 19th.-The welcome cry this morning was, " land ho!" to westward, Cape Walsingham. Now we will be out of the narrows. The straits commence to widen here, so that we can travel fast if we cannot reach land. I've caught a small seal to-day. 24th. - Can see the land, but cannot start. Such a quantity of light snow has fallen, and you sink into it so that it would be impossible to get the boat through it. Land is twenty miles off, I should say, and we appear to be leaving it. My advice is to start for it. We seem to have left the sealing ground. We cannot catch anything to speak of, and we have only three weeks' provisions left. Captain Tyson and some of the men are afraid to venture in shore, and unwilling to leave the boat; so we have made up our minds to stay, come down in our provisions, and trust in God, hoping we may come on better sealing ground. I asked the Esquimaux what they would do if they had not us to influence them. They told me they would start for land directly they saw it. They do not like to speak their minds openly for fear something would happen, meaning that they would be blamed for it; so they are silent following only the advice and opinions of others. Joe caught a very small seal, which is the eighth this month. He is very much to be praised, so is his wife Hannah. We may thank them and God for our lives and the good health we are in. We could never have gotten thus far without them. If we ever get out of this difficulty, they can never be paid too much. 28th-Followed up a bear track, but at a crack lost it, where he broke through the young ice and swam across. Shot a meal of dovekies, a kind of small bird, to-day, which we will have for breakfast to-morrow morning. Saw some seals to-day, but could not get them. Thermometer 28 to 23 degrees below zero."

"March 2d.-To-day God has sent us food in abundance. Joe shot an oogehook, one of the largest kind of seals : plenty of meat and oil, and forty-two dovekies. 7th.-Immense icebergs all around the floe. There was a fearful noise all last night, which kept us all awake. The floe was cracking, splitting and working with a noise like a park of artillery and musketry. I expected to see it splitinto a thousand pieces every moment. Every man is complaining of headache from eating oogehook liver 
They say it is dangerous to eat; but what is a hungry man to do? We have eaten the seals, hair, skin and every thing about them, and are glad to get them. 11th.Blowing a strong gale yet. All hands were up last night and dressed and ready for a jump, for the ice was splitting, cracking and making a fearful noise all night. To-day has been a fearful day. Cannot see for snow drift. We know the floe is broken into small pieces. We are afloat, jumping and kicking about. 12th.-Last night was a fearful one of suspense : ice cracking and breaking; the gale roaring, and the water swashing; but where? We know it is all around us, but cannot see anything. Since one o'clock the wind has been going down, and now I can see around. A nice picture. Everything broken into small pieces. We are on the best piece. The snow houses are nearly covered. Afternoon. It has calmed down to a fine day, with a light breeze. Joe caught two seals, Hans one, and Captain Tyson one. Joe caught two dovekies, and the cook two, showing how good God is to us. 22d.-The first day of spring. The sun shines very powerfully, at least I think so. Thermometer 10 to 12 degrees below zero. Joe caught two seals to-day. 30th.-Blowing a gale from W. N. W. ; it looks fearful. Last night the sight was dreadful. I went out, and there, within ten or twelve yards of the door of our hut, was a very large and ugly looking iceberg grinding against us. Our little floe gets smaller in open water. To-day we had the pleasure of launching the boat. We saw on a piece of ice a large seal. We fired and thought we had him. When we had pulled there with the boat, we found a large bladder-nose and her pup. She showed fight, but was soon killed, and, with her pup towed to our floe. The buck was shot but got under the young ice. When opened, we found considerable milk in her; so we can have some good soup to-night, using the milk and two quarts of blood. 31st.-Strong wind W. N. W. Thick. Looks like clearing up. A seal and two calves killed by Joe; one calf by Hans. Mr. Meyer got an observation: latitude $59 \circ 41^{\prime}$. That makes twenty-three miles per day that we have drifted the last five days, besides what eddying we have made with this $\mathrm{W}$. wind. These seals have all been eaught on the ice which drifted by us. Our piece of ice gets much smaller. Open water. Sometimes we get separated from the ice and it looks like the ocean which we have on one side of us-the E. side. We are nearly off Cape Farewell. Last night ran a very heavy sea; not a bit of ice to be seen as far as the eye could reach. To-day closed around a little, but plenty of water. Dare not venture in our open boats: we must watch and wait and trust in God Caught three more calves and one more seal. Heavy weather setting in; the floe wearing away rapidly. I must hope for the best. All well."

"April 1st.-A fearful night, last night. Must leave our floe at once. Got under way at $8 \mathrm{~A}$. M., the boat taking in water, and loaded too deep. Threw overboard one hundred pounds of meat, and must throw away all our clothes. Cannot carry anything with us but the tent, a few skins to cover us, a little meat, and our bread and pemmican. Made ten or fifteen miles S. and three or four W. We landed to lighten our boat, and pitched our tent, intending to stop all night. This piece of ice is cracking, and not very safe. Caught a young seal as soon as we got on the ice, and afterward two more. 20th. - Started at 5 A. M. Worked the oars two hours; then a breeze sprung up, and increased until it blew almost a gale. We had several narrow escapes with our boat before we could find a piece of ice safe enough to land on, and when we did so the boat was making water fast. When emptied we found a hole in 
her side. Weather still very bad. We are in a bad fix. 3d.-Repaired our boat and started at $8.45 \mathrm{~A}$. M. Kept under way till 2.30 P. M., when we had to haul up on a piece of floe. We were beset by the ice and could not get through. We take seals whenever we want them, so that it is not necessary to croak any more until they get scarce. 5th.-Blowing a gale, and a fearful sea running. Two pieces broke from the floe. We are on one close to the tent. At $5 \mathrm{~A}$. M. removed our things to the center. Another piece broke off, carrying Joe's hut with it. We cannot do anything to help ourselves. If the ice breaks up much more we must break up with it 8th.-Last night, at 12 o'clock, the ice broke again right between the tent and the boat, which were so close together that a man could not walk between them. There the ice split carrying away the boat, the kyack, and Mr. Meyer. It was blowing and snowing, very cold, and a fearful sea running; the ice was breaking, lapping, and crashing. Mr. Meyer cast the kyack adrift, but it went to leeward of us. He can do nothing with the boat alone, and so they are lost to us unless God returns them. The natives went off on a piece of ice with their paddles and ice spears. We may never see them again. But we are lost without the boat, so that they are as well off. After an hour's struggle we can make out, with what little light there is, that they have reached the boat, about half a mile off. There they appear to be helpless; the ice closing in all around; and we can do nothing until daylight. Daylight at last, 3 A. M. We see them with the boat, but they can do nothing with her. The kyack is the same distance off in another direction. We must venture off, for we may as well be crushed by the ice or drowned as to remain here without the boat. Off we venture for the boat, all but two, who dare not make the attempt. We jump from one piece to another, as the swell heaves it, and the ice comes close together; one piece being high the other low, so that you watch your time to jump. All who ventured reached the boat in safety, and after a long struggle got her safe to camp again. Then we ventured for the kyack, and got it also. We have taken our tent down, and pitched it in the center of our little piece of ice, with our boat alongside. Joe has built another snow hut alongside the tent. 9th.-Blowing a gale. The sea runs very high, threatening to wash us off any minute. The ice is much slacker, and the water is coming nearer. Things look very bad. God knows how the night will end. Evening. We are washed out of our tent, and Hannah from her snow hut. Have got everything in the boat ready for a start; but she can never live in such a sea. Land in sight. The women and children are in the boat; we have not a dry place in which to walk about, nor a piece of fresh-water ice to eat. The ice is closing in fast, and the sea going down. At midnight things look so quiet, and the ice is so closed around that we have pitched our tent, intending to have a sleep, for we are worn out."

From April 10 to 16 (which completed just six months from the time when they took to the ice) they were prisoners on that bit; saw many seals, but could catch none, and starvation began to stare them in the face. Mr. Meyer froze his fingers and toes, and began to be very weak, hunger seeming to have more effect on him than on the others.

"April 16th.-Wind increasing; ice nearly the same; no swell on. My head and face have swollen to nearly twice their usual size. I do not know the cause of it. We set an hour's watch at night. Some one has been at the pemmican on his watch, and I know the man. He did the same thing in the winter, and I caught bin in the 
act on the 7th. We shot the dogs last winter for stealing our provisions. If I had my way, with the consent of all hands, I would call out and shoot down that twolegged dog who has since been at them. We have but few days' provisions left, and came down on them this morning. Weakening work, but it must be done to save life as long as we can, which cannot be long unless something good comes along, which I hope may soon happen. The only thing that troubles me is the thought of cannibalism. It is a fearful thought, but may as well be looked boldly in the face. If such things are to happen, we must submit. May God save us. 18th.-Joe saw a small hole in the water half a mile off. He took his gun and ventured over the loose ice. No sooner had he gotten there than he shot a seal, and sang out for the kyack, as the water was making rapidly. It took an hour to get the kyack there, and another to get it back. It is a nice-sized seal, and will give us three meals, raw, and save us from starvation for some days. We returned thanks to God for his mercy, for we have only a few pounds of bread and sufficient pemmican for to-night. We divided the seal very nicely, losing nothing but the gall. We divided it into sixteen parts. One man then turned his back and called out the names, each man stepping up and taking his share of meat, blubber and skin. The inside-heart, kidneys, liver, lights and stomach-were divided between the Esquimaux and us. We then gave some blubber and rags each, so that we got a fire under way and cooked some good soup from what at other times I would call offal. Cut up fine in a quart of soup, with a little blood, the mess was highly relished. 20th.-Blowing a gale somewhere. The swell is very heavy. The first warning we had, a sea struck us, washing over us, and carried away everything that was loose. This happened at 9 o'clock last night. We shipped sea after sea, five or ten minutes after each other, carrying away everything we had in our tent, skins, and most of our bed-clothes, leaving us destitute, with only the few things we could get into the boat. There we stood from 9 in the evening to 7 the next morning, enduring, I should say, what man never stood before. The few things we saved and the children were placed in the boat. The sea broke over us during that night and morning. Every fifteen or twenty minutes a sea would come, lift the boat and us with it, carry us along the ice, and lose its strength near the edge, and sometimes on it. Then it would take us the next fifteen minutes to get back to a safe place, ready for the next roller. So we stood that long hour, not a word spoken but the commands to 'Hold on, my hearties; bear down on her; put on all your weight;' and so we did, bearing down and holding on like grim death. Cold, hungry, wet, and little prospect ahead. At seven o'clock there came close to us a small piece of ice, which rode dry, and we determined to launch the boat, and reach it or perish. The cook went overboard, but was saved. All well. Tired and sleepy."

There were to be but ten more days of this weary imprisonment; but into them were crowded as much of peril and endurance, as into any other period of equal length. An observation showed that they were in latitude $53^{\circ} 57^{\prime}$. They had thus drifted through about twenty-seven degrees of latitude, a distance in a straight line from north to south of about $187 \check{j}$ miles. The entries for some days tell a uniform story: "All hands wet; hunger troubles us most; cannot get the boat through the ice, and must wait for a change ; sometimes in sight of land, and then driven off; no birds and no seals." Here is one episode in the monotony : 
"April 22d.-Weather very bad. Last night commenced with snow squalls and sleet and finished with rain. Rained all the night and until twelve o'clock to-day. Still remains very thick. The ice in pash inclosed around us. It appears to me we are the sport and jest of the elements. The other night they played with us and our boat as though we were shuttlecocks. Men would never believe, nor could pen describe, the scenes we have passed through and yet live. Here we are, half drowned, cold, and with no means of shelter. Everything wet, and no sun to dry it. The scene looks bad; nothing to eat. Everything finished if some relief does not come along. I do not know what will become of us. Fearful thoughts enter my head as to the future. Mr. Meyer is starving; he cannot last long in this state. Joe has been off on the ice three times to-day, the little way he can get, but has not seen anything. Chewed on a piece of skin this morning that was tanned and saved for clothing; rather a tough and tasteless breakfast. Joe ventured off on the ice the fourth time, and after looking a good while from a piece of iceberg saw a bear coming slowly toward us. He ran back as fast as possible for his gun. All of us lay down and remained perfectly still, Joe and Hans going out some distance to meet the bear. Getting behind a hummock, they waited for him. Along came Bruin, thinking he was coming to a meal instead of furnishing one himself. Clack, bang ! went two rifles, and down went Bruin to save a starving lot of men. The Lord be praised; this is his heavenly work! We cannot catch seal for the pash ice, and we are on a bad sealing ground. He therefore sends a bear along where bears are seldom seen, and we certainly never expected to find one. The poor bear was hungry himself; there was nothing in his stomach. Joe, poor fellow, looked very much down on our account. Everything looks bright again but the atmosphere ; it looks threatening."

" April 25th.-Wind increased to a gale last night. Raining all night and day, with snow squalls. Launched the boat at 5 A. M. The case was desperate; running with a light patched boat, damaged as she is, and patched all over. But the piece of ice we were on had wasted away so much that it would never outride the gale. Our danger was very great; a gale of wind blowing; a crippled boat, overloaded, and a fearful sea running, filled with small ice as sharp as knives. But, thank God, we got safely through it. We are all soaking wet, in every thing we have, and no chance of drying anything. We have had neither sun nor moon nor star for a week. We have struck the sealmen's grounds. I never saw such an abundance of seals before. They are in schools like porpoises. We hauled up on a floe after eight hours' pull. Joe shot some seals, but they all sunk. Hard times. 26th.-Joe shot a seal last evening, and so broke the charm. Hans shot one this morning. Ice very thick around. Started at half-past six A. M., and were beset two hours afterward. Pulled up on a small piece of ice, the best we could find. Snowing all day. Repaired the boat; and the weather cleared up in the afternoon. Got some things dried a little, and half of us turned in. Hans shot a seal, making two to-day."

April 28th.-Gale of wind sprung up; heavy sea running; all ready and standing by the boat all night. Launched the boat, but could get nowhere for the ice. Hauled up on a piece of ice at 6 A. M., and had a few hours' sleep, but were threatened to be mashed to pieces by icebergs. They were fighting quite a battle in the water, and bearing right for us. We launched the boat at 1 P. M., and got away, the 
wind blowing moderately, and the sea going down. The ice is much slacker, and there is more water than I have seen yet. At 4.30 saw a steamer right ahead, and a little to the north of us. We hoisted the colors, and pulled until dark, trying to cut her off; but she does not see us. We found a small piece of ice, and boarded it for the night. The stars are out for the first time this week, and there is a new moon. Divided into two watches, four hours' sleep each. Intend to start early. Joe had shot three young seals, which we had taken along in the boat. Cooked with a blubber fire; and kept a good one all night, so that we could be seen. 29th-Morning calm, water quiet. At daylight sighted the steamer five miles off; launched the boat and made for her. After an hour's pull gained on her a good deal; another hour and we got fast in the ice, and could go no farther. Landed on a piece of ice and boisted our colors on an elevated place. Fired three rounds from our rifles and pistols, making a considerable report, and were answered by three shots, the steamer heading for us. She headed for us N. then S. E., and kept on so all day. We tried very hard to work through the ice, but could not. Very strange. I should think any sailing vessel, much more a steamer, could get through with ease. She was not more than five miles from us. Late in the evening she steamed away, bearing S. W. We gave her up. In the evening she hove in sight again, but further off. While looking at her another steamer hove in sight, so that we have two sealers near,-one on each side of us; but I do not expect to be picked up by either of them. Hans caught a seal, very small and young, a perfect baby of a seal. Dried most of our things today."

From the next and closing entry in Herron's Journal it is probable that he was mistaken in supposing that the party had been seen from the steamer. Probably the musketry which they fired was heard, and supposed to come from some unseen vessel, and was answered by the three guns from the steamer. At all events he was fortunately mistaken in his belief that they would not be picked up by the other steamer.

“Wednesday, April 30th.-Five A. M., weather thick and foggy. Glorious sight when the fog broke : a steamer close to us. She sees us and bears down on us. We are saved, thank God! We are safe on board the Tigress of St. Johns, Captain Bartlett. He says the other steamer could not have seen us, as the captain is noted for his humanity. The Tigress musters 120 men, the kindest and most obliging I have ever met. Picked up in latitude $52 \circ 35^{\prime} \mathrm{N}$."

Here closes this most remarkable journal, of which we have given only the leading points. That a party of nineteen persons, among whom were two women, and five children, one of them only two months old, should thus have drifted well nigh 2,000) miles, for 195 days all through an Arctic winter of unusual severity, and come out not merely alive but in good health, is marvelous. Unless they had been forced to adopt Hall's theory of living there as the Esquimaux live, it is hardly probable that they could have escaped. If they had been left on the ice with an abundance of ship's stores, and so not been thrown mainly upon raw seal and blubber, most likely the scurvy would have swept them all away. But were it not for Ebierbing, or as be is here called Esquimaux Joe, they would have caught but few seals, and so would have died of starvation. It is safe to believe that had he been with Sir John Franklin, the 
crews of the Erebus and Terror would have been saved. Ebierbing stands out everywhere as the hero of this wonderful story. Hardly less is he the hero of Hall's account of his first expedition; and should the records of his second expedition ever be published, he will appear equally prominent there. The attachment of Ebierbing for Hall was something which has no counterpart, saving in that to Robinson Crusoe of his "Man Friday." To him also we owe the preservation of the last dispatch of Hall. It was contained in Hall's writing desk, which was thrown upon the ice when the Polaris was left. All through that long drift the faithful Esquimaux kept guard over it. When provisions, clothing, and almost everything else was thrown overboard, he still held fast to that priceless document. If ever a man lived who deserves an ample reward while living, and a noble monument when dead, it is this little dusky Esquimaux, whose portrait appears in this volume, on page 434.

Another thing which must strike every reader is the marvelous fidelity and brotherliness of that strange party on the ice. Saving for the three instances where one of the men appropriated a little of the scanty stock of provisions, there is not a word of imputation of blame upon one of them. The first thought of these sailors, comprising almost as many nationalities as individuals, seems to have been for the Esquimaux women and their children. And even in the case of the one person who is mentioned with blame, any one who has felt for long weeks the keen gnawings of hunger, will be slow to pass a very severe censure. All this is the more remarkable from the fact that all this self-restraint was self-imposed. There was no one who really had any right to command, or any power to enforce an order. In his testimony before the commissioners, Herron says : "Captain Tyson had command on the ice; but he never seemed to take much of a lead. Everything seemed to go on very well. There was not a great deal of commanding; it was not wanted. When we did not do as he directed it turned out wrong."

The fate of the Polaris, and of the men left on board of her, is as yet uncertain. When last seen she seemed safe from present danger. She had an abundance of provisions on board, and so there is little apprehension that her crew have suffered starvation. But she was most likely badly crippled by the storm which separated her from the ice floe, and probably laid up at or near Northumberland Island. She had not a single boat left, so that the crew could not by that means make their escape to the Greenland settlements far to the south. To ascertain the facts in the case, the Navy Department has promptly taken proper measures. The steamer Juniata, the best for the purpose at the disposal of the Department, has been sent to the Greenland ports; but it is not expected that she can penetrate the icy region to the north. If by the time, say late in July, 1873, when she reaches Disco. no tidings has reached there of the Polaris, her work will have been accomplished. Meanwhile a more effective expedition has been organized. The Tigress, built expressly for navigation in the ice, has been purchased and brought to New York, there to be fitted up for a voyage to the far north. She set sail on the 18th of July, with orders, first of all, to find if possible, the Polaris and her crew. That failing, she was to push north. ward, and endeavor to complete the work begun by Hall. At best, however, she cannot be expected to reach the icy seas during the summer of 1873 . So that, assuming that she sets out from Greenland, in the summer of 1874, and finds the 
Polaris and her crew at or near Northumberland Island, another year must pass before we can know more than we now know of the results of Hall's last expedition. Till then it is right and just that judgment should be suspended as to the real cause of the death of Hall, and the conduct of those who after that event had command in the expedition.

Thus rests the matter in the closing days of July, 1873. 


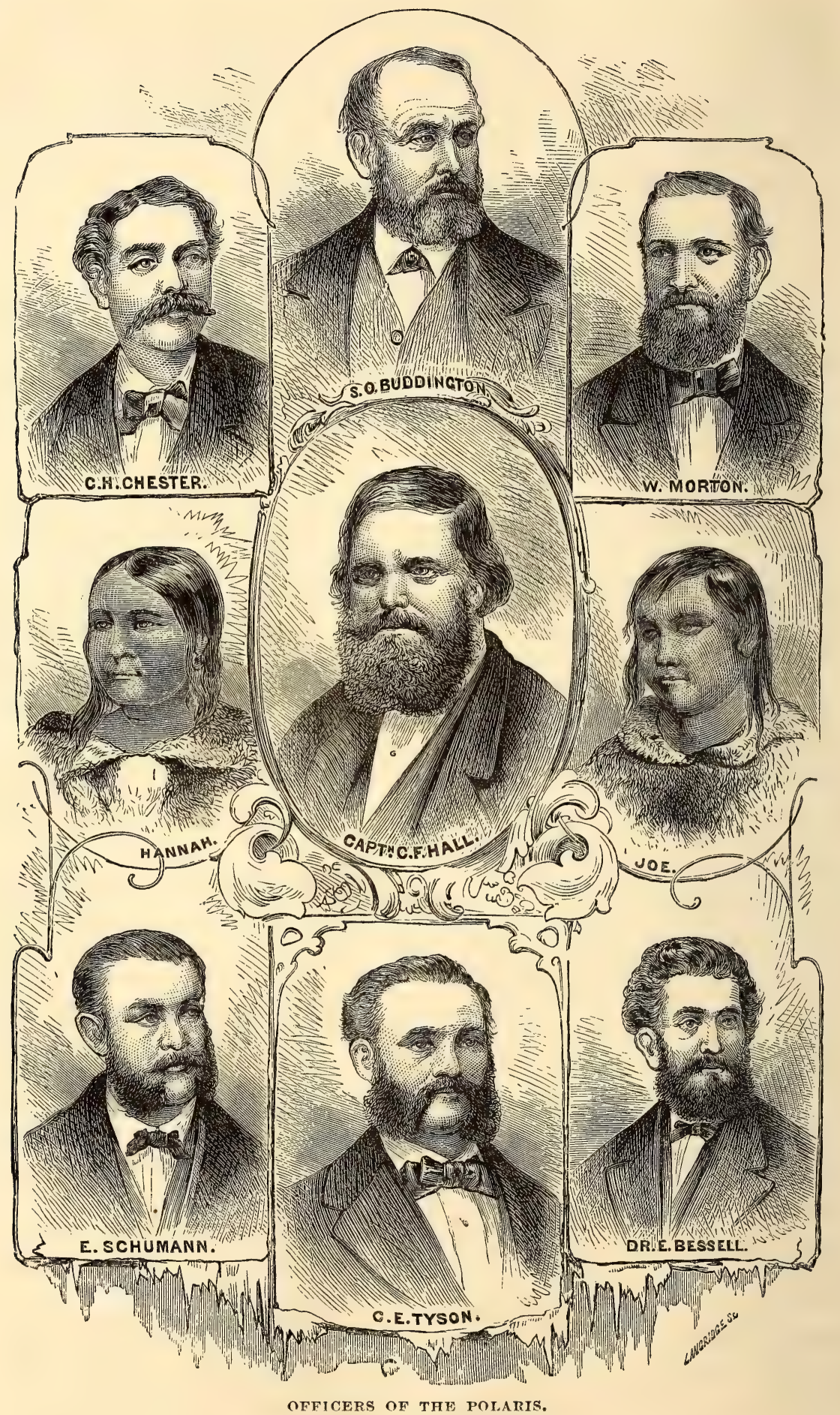




\title{
CHAPTER XLV.
}

\author{
THE FATE OF THE POLARIS.
}

The Search for the Polaris.-The First Tidings.-Second Tidings of the Safety of the Crew. - The Search for the Tigress.-At Northumberland Island.-At Littleton Island.-Greeting by the Esquimaux.-Last of the Polaris.-The Abandoned Hut.-Close of the Search. -The Escape of the Crew of the Polaris.-The Separation in the Ice-Beaching the Vessel--Preparations for the Winter.-Forebodings for the Future.-Chester, the Right Man for the Emergency.-Building the Boats.-The Scurvy.-Getting off.-Skirting the Ice.-At Hakluyt Island.-Fighting a Whale.-The Rescue.-Arrival at Dundee.-Reception of the News.-Results of the Expedition.-Finis.

$\mathrm{I}^{\mathrm{N}}$ $\mathrm{N}$ the preceding chapter has been narrated the voyage of the Polaris to the most. extreme northern point ever as yet reached by civilized man, together with the untimely death of Charles Francis Hall, her noble commander, and the wonderful adventures of that portion of her crew who, on the 15th of October, 1872, became separated from the vessels. Mention has also been made of the two vessels, the large Juniata and the small Tigress, which were sent by the government of the United States to ascertain the fate of the Polaris, and, if possible, to rescue the remainder of her crew. This chapter will narrate the results of these efforts, and bring to a close the story of this remarkable exploring expedition.

After the departure of the Tigress from New York, in July, 1873, weeks passed before any tidings came back from the Arctic regions, whither she had gone. But, on the 10th of September, the telegraph brought from St. Johns, Newfoundland, a brief dispatch to the effect, that the place where the people of the Polaris had passed the preceding winter had been found; that the vessel, herself, had been lost; but that the crew had, a few weeks before, set off southward in boats, which they had constructed, and that, in all likelihood, they had been picked up by some whaling vessel which would convey them either to Labrador or Europe.

A week later came another telegram announcing that the Polaris party had all arrived safely in Dundee, Scotland, whither they had been brought by a whaling vessel.

The story of the search is best told by Commander Green, of the Tigress ; what, in the meantime, happened to the people of the Polaris, must be learned from their own narratives.

The Tigress reached the Arctic seas in safety, and on the 11th of August, 1873, steamed northward from Upernavik, heading for Tessuisak, which Hall, two years before, had styled the most northern known civilized settlement on the globe. At Tessuisak, not a word had been heard from the Polaris since she had so hopefully de- 


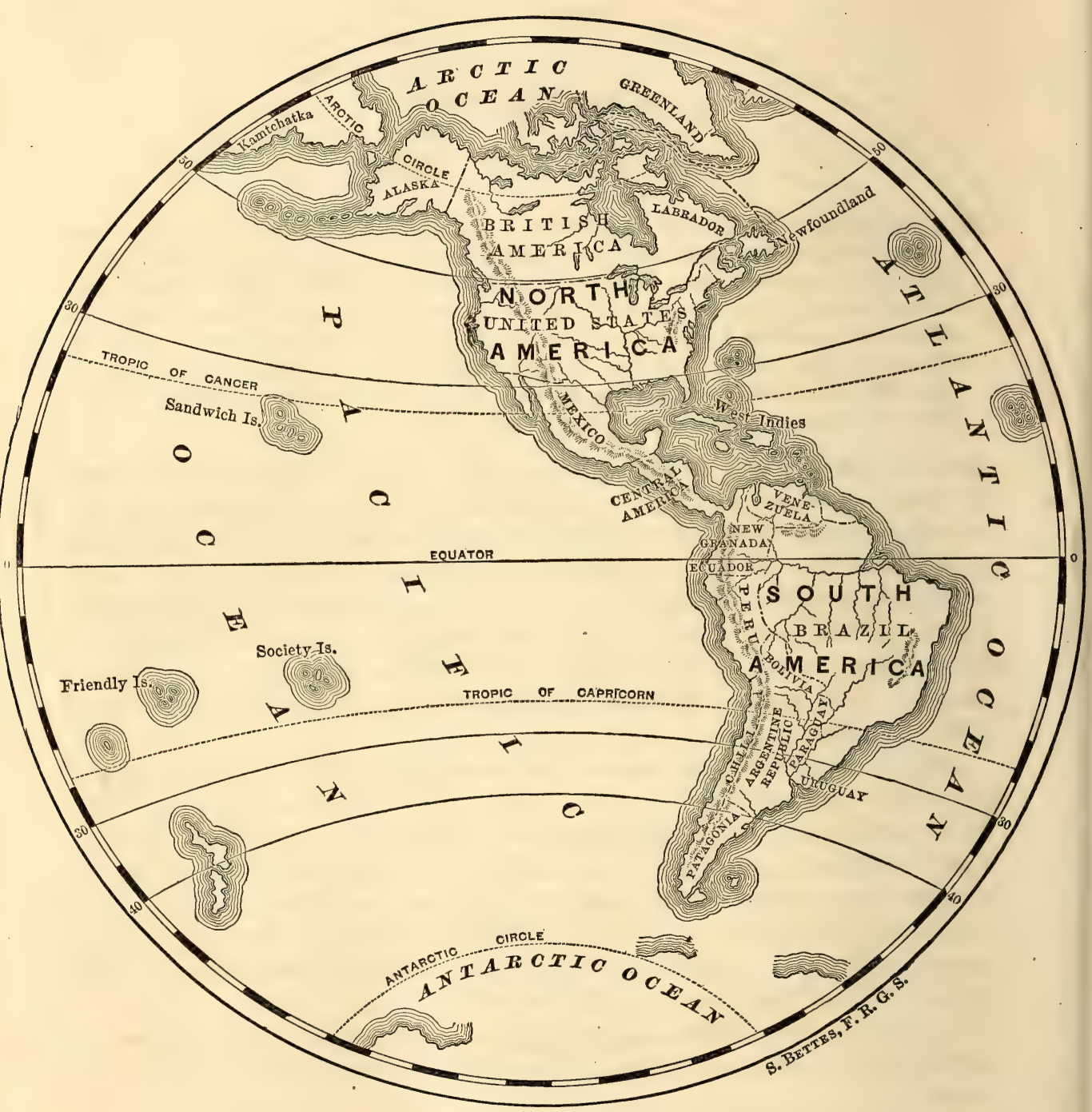

WESTERN HEMISPHERE.

[In the Western Hemisphere, the Polar World includes the space between the Pole and latitude $50^{\circ}$ North, and between the Pole and latitude $40^{\circ}$ South. The Temperate Zones are between latitude $50^{\circ}$ and $30^{\circ}$ North, and $40^{\circ}$ and $30^{\circ}$ South. Thus in the Western Hemisphere the two Polar regions are $10^{\circ}$ broader, and the Temperate Zones $10^{\circ}$ narrower than in the Eastern Hemisphere.] 


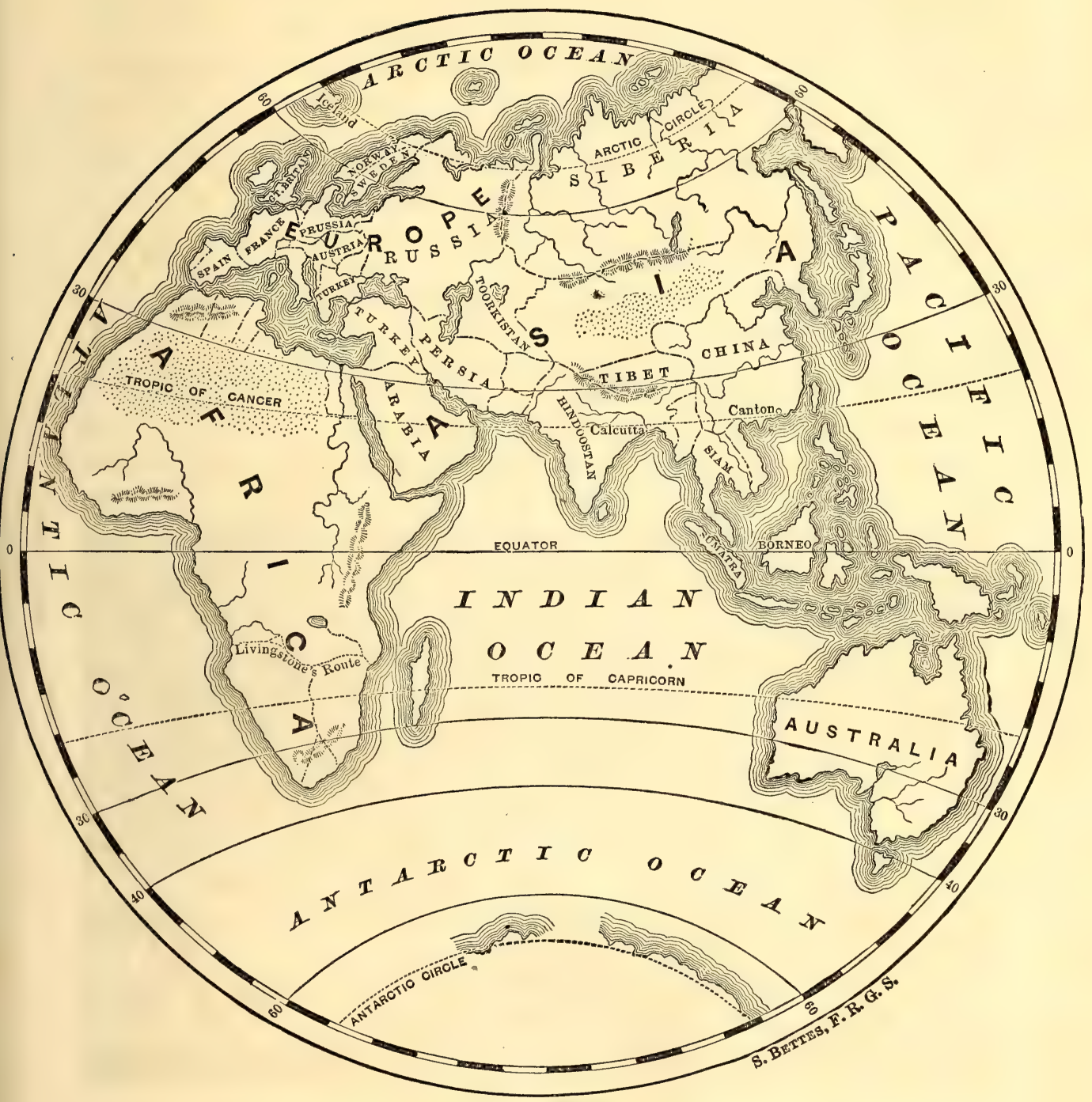

EASTERN HEMISPHERE.

[In the Eastern Hemisphere, the Polar World includes the space between the Pole and latitude $60^{\circ}$ North, and between the Pole and latitude $40^{\circ}$ South. The Temperate Zones are between latitude $60^{\circ}$ and $30^{\circ}$ North, and $60^{\circ}$ and $30^{\circ}$ South. The Tropical Zones in both hemispheres lie on each side of the Equator between latitude $30^{\circ}$ North, and $30^{\circ}$ South.] 
parted. A steam launch, the little Juniata, belonging to the large Juniata, was here. She had gone as far northward as she could, but had learned nothing of the Polaris.

On the 12th of August the Tigress pointed her prow northward, and soon passed Cape York, keeping as close to the shore as the ice would permit, and all the time watching for any signal that might be made from the land. But the ice-bound coast gave back no signal that any human being saw the smoke from the steamer.

On the 13th, the Tigress skirted Northumberland Island, near which, as was believed, and as is noted on the map, on page 756, Tyson and his party were sepa. rated from the Polaris; but some of that party, who were on board the Tigress, could not recognize the spot; and it was concluded that the separation had really taken place at some place still further northward. At 9 in the evening, of the 14th, as measured by the clock, though at this season, in these latitudes, there is scarcely any distinction between day and night, they brought up at Littleton Island, standing out darkly in the wintry sky. This looked like the place for which they were in search; and a boat was lowered and sent to shore to learn, if might be, whether the Polaris had ever been there. The boat dodged among the icebergs and was soon lost to view; but before long a faint sound of cheering was heard from the shore. In an hour or two the boat eame back with tidings. The crew had landed, and saw dimly in the distance a hut which had evidently been built by civilized men, while hurrying down to meet them were a half dozen Esquimaux, who told them, as well as they

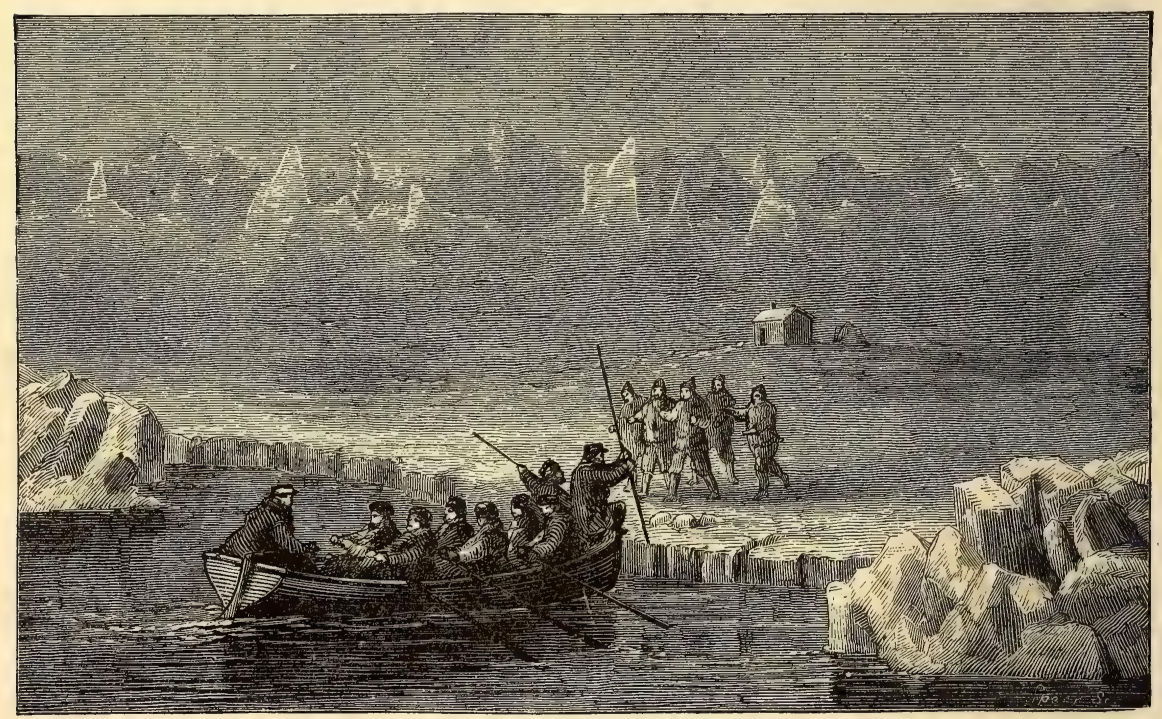

DISCOVERY OF POLARIS CAMP.

could, that this was the place where some white men had passed the preceding winter, but that they had gone away a moon or two before, about the time when the ducks began to hatch.

These Esquimaux had been on a hunting expedition, and when they came here they found the big ship tied fast to the shore, and the white men living in the hut. When they went away, their head man had told the Esquimaux that they might hare the ship, and all there was left on board. But not long after, a gale of wind came 
on; the ship broke loose, and drifted a mile or two away, and then sunk in shallow water. An ice-floe, with a couple of icebergs, also drifted down, and grounded on the wreck. The bergs were still there, and for years to come these icy mountains will form a monument grander than man has ever built, to mark the resting-place of the Polaris.

Every thing on shore confirmed the story of these Esquimaux. There stood a comfortable wooden house, built of planks and roofed with sails, with bunks, mattresses, and appliances for cooking, and a carpenter's bench with fresh shavings near it. All around the hut were scattered provisions, stores, broken instruments, and fragments of books and papers, all in a useless condition. The whole place looked like a house from which the tenant had just removed, pitching out in confusion everything not worth carrying away. There was not the slightest indication that there had been any violence, or any extraordinary suffering. The position of this camp is in latitude $78^{\circ}$ $23^{\prime}$ North, a little beyond the place which had been Hayes' winter quarters in 18601861.

The Tigress having learned here all that could be gathered from the Esquimaux, and picked up the few things worth carrying off, then steamed down Baffins' Bay, looking in at Tessuisak and Uperuavik, and reaching Disco on the 25th of August. Every thing showed that the missing men could be nowhere on the Greenland coast, and that they must either have been lost in the ice, or, as there was good reason to hope, had been picked up by some whaler. The work of search was accomplished, and the Tigress returned to New York.

We now follow the fate of the men who had been left on board the Polaris on the 15th of October, 1872. Their story in most respects confirms, and in some respects supplements that told by the nineteen from whom they had been separated.

The Polaris had for a long time been leaking so badly that it had been resolved to abandon her, it being thought certain that she could float but a little longer. All hands were engaged, some on the vessel, some on the ice, in getting out every thing which could be of use for a sojourn, the length of which no man could know, in the unhospitable North. At this moment the hawsers which held the vessel to an ice-floe parted, and she drifted helplessly away. It is hard to say which were in the more hopeless condition, those on the quivering ice or those on the leaky Polaris. In all human probability, the fate of all was sealed. It was apparently only a question of time. Those on the vessel would most likely live the longer, for they had apparently more means of preserving life for a season.

As it was clear that the Polaris could never reach any port, the most that could be done, was to endeavor to keep her afloat long enough to reach some place where she could be beached, and her provisions and stores could be saved. Her engines seem to have been frozen up so as to be useless; but luckily a crack opened in the solid ice, and the wind was blowing sharply from a direction to take the vessel through the narrow passage. Probably the distance from shore was less than half a dozen miles, but it took twelve hours to bore through the slush.

The Polaris fairly beached, the next thing was to provide a shelter on shore, and to secure the stores for the long Arctic winter, which was now setting in. The ressel was soon reduced to little more than a hulk. The timbers between deck were torn 
out, and the planks and boards removed. In a few days, a hut was constructed of these planks, and roofed over with sails. Fortunately also, the party of Esquimaux made their appearance; and for a few bits of iron, and other things which to us seem paltry, but which to them are more valuable than gold or silver, they engaged to help in conveying the provisions, coal and stores from the vessel to the hut. Moreover, they had been unusually successful in their hunting, and had an abundance of skins, of which they were glad to dispose. These furnished materials from which warm, though far from inodorous clothing might be fashioned.

The long winter, during which their nineteen comrades were performing their marvelous drift on the ice, was passed with little actual discomfort. The snow, indeed, fell furiously, but it served to bank up their hut, and exclude the cold. The Polaris was a wood-pile ready at hand, sufficient to furnish fuel for a time. Water could be had by melting the ice, of which the supply was unlimited. For a while, at least, they had provisions.

But all these supplies would in time be consumed; after which, death would stare them in the face. The great point came up, how they were to get away; for it must be borne in mind, they had no good reason to suppose that for another year at least, any report of the probable loss of the Polaris, would reach the United States, and therefore there was no likelihood that any expedition would be sent for their relief. The boats had all been lost; and they had no means of making an overland journey over the rocks and ice.

In great emergencies the right man sometimes comes to the front. So was it here. The right man for this emergency was not Buddington, the commander; it was not Bessels, the scientist; it was not Bryan, the astronomer and chaplain. It was Chester, the mate. He, with the aid of Coffin, the carpenter, undertook to build a couple of boats, or rather scows, from the fragments of boards, pierced with nailholes, which had formed the lining of the cabins. Week after week the work went slowly but surely on; and as the brief summer drew near, the boats were finished.

But now appears an enemy more formidable than even cold or darkness. The scurvy made its appearance; not, indeed, in a violent form, but there was, judging from all that the experience of others had taught, every reason to apprehend the worst. But here the teachings of the dead Hall, which he had learned during his long sojourn in the Arctic regions, came into play. The men abandoned the use of salted food, and betook themselves to raw walrus liver, and in a short time the dreaded enemy was vanquished.

Luckily, also, the season was unusually early. The ice began to give way about the middle of June, and the party embarked in their frail boats. The chances were fearfully against their ever being able to escape from the icy walls of their prison; and so, while the Juniata and Tigress were being fitted out to search for them, they were on their way.

By day they rowed along, and by night drew up their little craft upon the ice, and prepared their only warm meal for the day. Their cooking apparatus was simply a modification of the Esquimaux lamp. For fuel they had oil ; for wick, bits of rope ; for fire-place, a piece of an iron kettle. At Hakluyt Island, they were detained for several days by a violent snow-storm, which, however, proved to be a blessing in disguise ; for the island is a breeding place for the auks, who were just hatching their 
young. It was for them a land of plenty, for the birds were so abundant that the supply was only limited by their power of consumption and of carrying away.

Then they again set out, laboriously rowing through the slush, and skirting the solid ice-floes, until the 20th of July ; two days before the Tigress set out from New York in search of them, the party caught sight of a vessel. They were discovered and taken on board. This proved to be the Ravenscraig, a Scottish whaler, by which they were taken up. This whaler, not having her cargo filled up, and wishing to complete it, transferred the men to the Arctic, another steam-whaling vessel, which, being full, was starting homeward. They reached Dundee, Scotland, in the afternoon of September 17. Before night closed, the telegraph had conveyed the news from Dundee to London, and thence across the Atlantic to America ; and the New York morning newspapers, of September 19, contained the report of the safety of the men of the Polaris.

Here ends the story of the most remarkable of all Arctic voyages. Of the forty persons, men, women, and children who, at one time or another, took part in it, only one perished. But that was the one who, of all, could be least spared. With Hall, died out the heart and soul of the expedition. The men were subsequently brought to America. But so far as yet appears, they had nothing to tell of any value. Most likely the reports of the scientific portion will add a little to our knowledge of the natural history and meteorology of the Arctic regions.

Still later, other expeditions have been proposed. But it may be confidently assumed that years more will elapse before anything important will be added to what is now embodied in "The Polar World." 


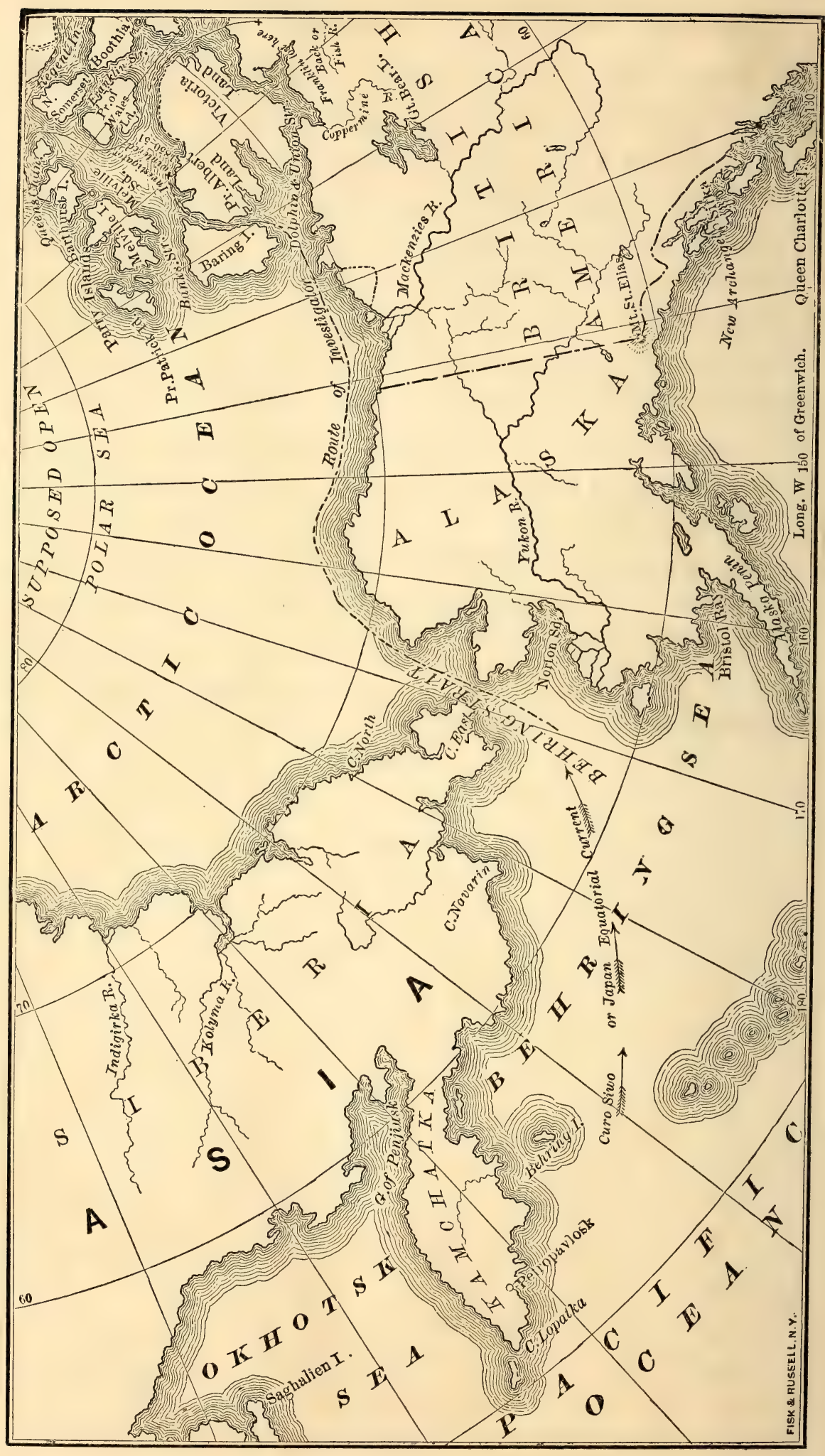




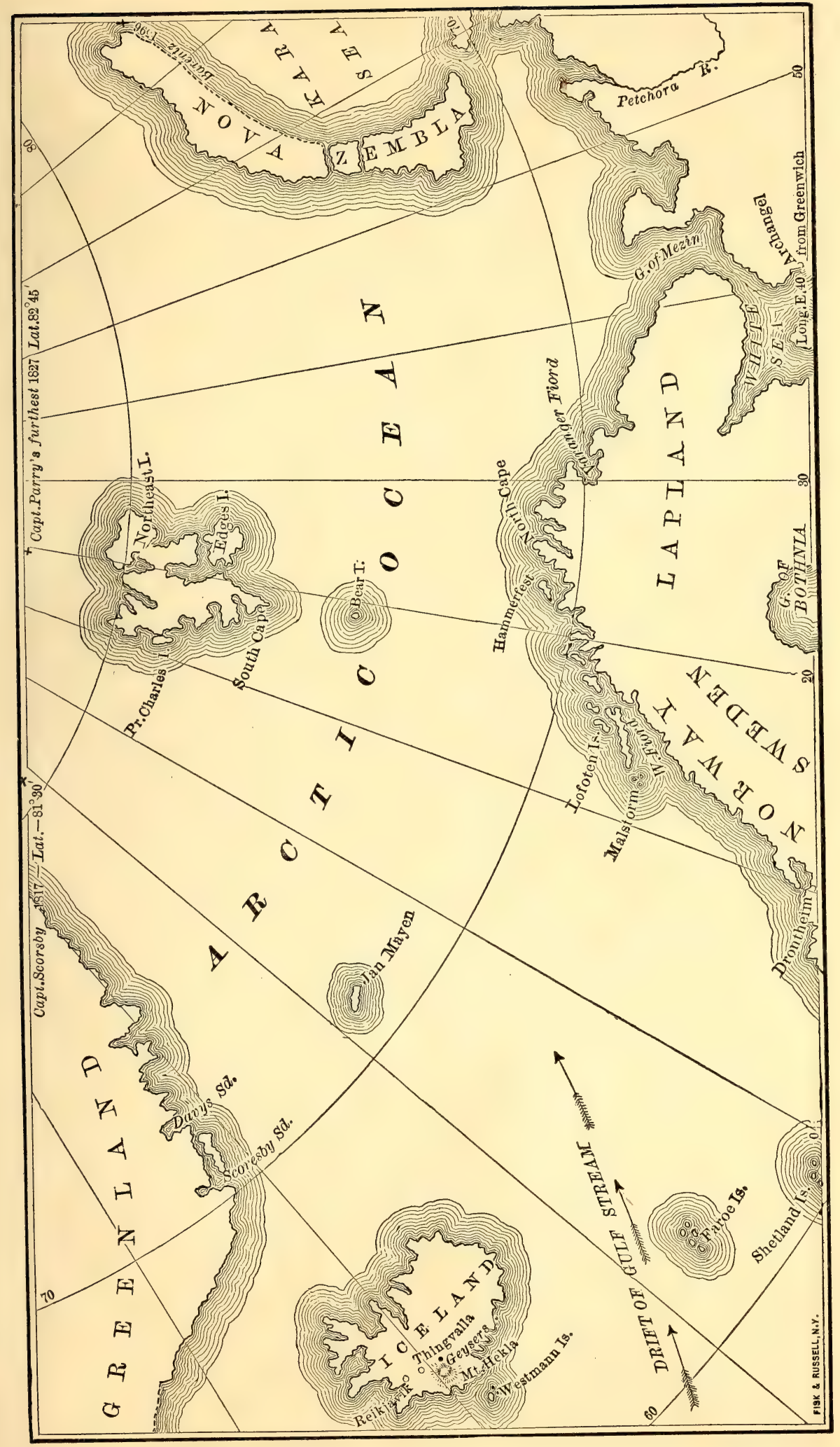





\section{N D E X.}

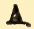

A Delie, Terre, discovery of, 402.

Agouti, the, of Patagonia, 419.

Agriculture, state of, in Iceland, 79.

Aigun, treaty of, 196.

Air, remarkable moisture of the, in Taimurland, 225.

- its perpetual motion in the Arctic zones, 225. Akurig, eider-ducks of, 81.

Albasin, the Russian fort of, built, 195 .

_- destroyed by the Chinese, but rebuilt, 196.

Albatross, wandering, of the Antarctic seas, 395.

Alcyonians on the coasts of Greenland, 59 .

Aleutian Islands, causes which led to the discovery of the, 201.

- extent of the, 270.

Aleuts, their wretched condition under their masters, 273.

- their skill and intrepidity in hunting, 273276.

Alexander, Cape, discovery of, 365 .

Island, discovery of, 401.

Algerine pirates, ravages of, in Iceland, 95 ; and in the Westman Islands, 119.

Alaska, discovery of, 202.

- climate of the, 269 .

- mountains and forests of, 269.

_- purchase of, by the Americans, 277.

- telegraph through, 278.

—, travelling in, 278-289.

- natives of, $278-289$.

- climate of, 284.

- , food in, 287.

Almannagja, description of the, 73 .

Altai Mountains, crossed by the Cossacks, 195.

Alten, copper mines of, 128.

Altenfjord, vegetation of the borders of the, 128 .

America, North, treeless zone of, 18-22.

— character of the Coniferæ of, 23, 24.

_- range of the caribou, or reindeer, of, $36-39$.

- the musk-ox of, 41.

, the white dolphin in the rivers of, 61 .

—, the black dolphin of, 61 .

- walruses of the shores of, 64 .

- history of the fur-trade of, 307 et seq.

- first discoverers and settlers of, 335 .

America, North, destruction of the Greenland colonies, 335 .

- , subsequent discoveries, 335 et seq.

- attempts to discover the north-western passage to India, 342 et seq.

America, Russian, its transfer to the United States, 272 , note.

Amoor, river, discovery of the, by the Russians, who relinquish it to the Chinese, 195, 196.

$\longrightarrow$ the country annexed by Russia, 196.
Anakerdluk, in North Greenland, buried forest oi 29.

Angekoks, or priests of the Esquimaux, 301.

Animals, comparatively small number of, in the Arctic regions, 25.

- the forests the head-quarters of many, 41.

- of the Arctic Seas, 59.

- of the coasts of Spitzbergen, 134.

- , fur-bearing, of Siberia, 209.

- the, of Taimurland, 227.

- of Nishne-Kolymsk, 235.

- of Newfoundland, 378.

- no land, in the Antarctic region, 394. of Patagonia, 418.

Aniuj, vegetation of the valley of the, 235 . - chief resource of the people of the, 237.

Anjou, Lieut., his Arctic explorations, 233.

Archangel, foundation of, 192.

- New, site of the town of, 272.

_ , fur-trade of, 273.

_. medium of exchange at, 276.

Archers, the Ostiaks as, 187.

Arctic regions, rivers of the, 17 .

-, limits of the, 18.

- the forests of the, 18-23.

_

_- in summer and winter, 19.

-

—, animal life in the, 25.

- influence of the sea and winds on the severity of the winter of the, 27.

- the lowest temperatures felt by man, 27, 28.

- how man becomes accustomed to the rigors of the winter of the, 28 .

- , proofs of a former milder climate in the northern regions of the globe, 29.

- beauties of Nature in the, 31-33.

- land quadrupeds and birds of the, 34 .

_ the seas of the, 49.

- compared with the Antarctic regions, 391.

Arctic voyages of discovery, 335 et seg. 737 et seg

Are Thorgilson, his Icelandic works, 94 .

Argali (Ovis argali) of Siberia, 41.

Arrows of the Ostiaks, 187, 188.

Ascidians on the coasts of Greenland, 59.

Ash, the, in the Arctic regions, 24.

Asia, treeless zone of, 18-22.

Athabascan Indians, hunting-grounds of the, 327.

Atlassoff, the Cossack, his treatment of the natives of Kamchatka, 198.

Atmosphere, transparency of the, in the Polar regions, 54, 55 .

, phenomena of, reflection and refraction, and their probable causes, 55 .

Auk, the giant, its rarity at present in Iceland, 85. Aurora borealis, 33 .

- splendar of the, in the Arctic regions, 33. 
Aurora borealis, ter:or of the Lapps at the, 157 . - at Nulato, 281.

Austin, Captain, his search for Franklin, 357.

Avalanches of ice in Spitzbergen, 135.

Awaklok and Myouk, their imprisonment on an iceberg, 298.

Awatscha Bay, sea-birds of, 255.

- its magnificence and extent, 256.

\section{B.}

BaAty Khan, his subjection of Russia, 191.

Bachelor river, the, 412.

Back (Mr., afterwards Sir George), his Arctic voyages, $346,347,349$.

- his search for Captain Ross, 354.

- his discovery of Great Fish River, 355.

$\longrightarrow$, voyage in $1835,355$.

Back's river, discovery of, 355 .

Badarany, desert of swamps, the, 234.

Baer, Herr von, his scientific journey to Nova Zembla, 151.

Baffin, his voyages of discovery, 343 .

Baffin's Bay, probable influence of the northerly winds on the depression of the temperature of, 27.

Baffin's Bay, walruses of the coasts of, 64 .

- discovery of, 343 .

Balleny, his discoveries in the Antarctic ocean, 401. Islands, discovery of, 401.

Banks's Land, proofs of a former milder temperature in, 29.

Bards, or Scalds, of Iceland, 94.

Barentz, William, visit of, to Spitzbergen, 138.

- , his voyages of discovery, 339 .

- his winter in Nova Zembla, 340 . , his death, 342 .

Barley, cultivation of, in Norway, 124.

Barren grounds, barrens, or tundri, Arctic belt of the, 18 .

_- causes of their barrenness, 18.

- their appearance in winter and in summer, 19.

- indistinct and irregular boundaries of the, 21 .

$\longrightarrow$ those of New foundland, 377.

Barrow Point, traffic of, 302.

Barter Reef, traffic of, 302 .

Bear, black, muskwa (Ursus americanus), value of the fur of the, 315 .

- description of him, $315,318$.

— , brown, of North America, 315.

- value of the skins of the young brown bear, 211.

- grizzly, of the Rocky Mountains (Ursus ferox), 315 .

- his skin, 315 .

- the polar, his mode of hunting, $65,446,448$.

- his favorite food and mode of seizing it, 65 , $447,450,451$.

$\longrightarrow$, anecdote of one, 65 .

- instances of his sagacity, 65 .

- parental care of the she-bear, 65 .

- her winter nursery, 65,66 .

- her internal store of food for her hybernation, 66.

immense strength of claws and teeth. 66,67 . , his unwelcome visits to Iceland, 81.

of Spitzbergen, 137.

of Nova Zembla, 149.

Lapp mode of hunting the, 164-166.

_-, Esquimaux methods of hunting the, 163.
Bear of Newfoundland, 378.

- - , abundance of, in Kamchatka, 258.

_-, sea-, value of the skins of the, in China, 374 .

- chase of the, in the Pribilow Islands, 274.

—_ families and battles, 274, 275.

- , the Austral sea-, 399.

- hunted by dogs, 453 .

Bear Island, or Cherie Island, accour t of, 143.

-

- walruses of, 144.

-_ boat-voyages of Norwegian sailors from, 145.

- - discovery of, 340 .

- - , surveyed by the Russians, 200.

Beaver (Custor fiber), its skin the standard of ex change with the Canadian Indians, 313.

- former enormous trade in the fur of the, 317. - of Newfoundland, 378.

Beaver Indians, their hunting-grounds, 327.

Bee, sand (Andrena), of Nova Zembla, 154.

Beech, Antarctic (Fagus betuloides), 410.

Beechey, Captain, his voyage to Bering's Straits, 350 .

Beerenberg mountain, 146.

Bering, Titus, never passed through the straits bear. ing his name, 197.

- his second voyage, 201.

- his second voyage of discovery, 248, 249.

- his bad conduct, 250 .

_ his death, 252.

Bering Island, Bering and Steller on, 251.

- Sea, description of the, 268.

_- barren lands at, 22.

_

_ its climate, 269 .

_ character of the shores of the, 270 .

- animals of the, 271.

Bering's Straits, view of the Old and New worlds in the, 271.

, Captain Beechey's voyage to, 350 .

Belcher, Sir Edward, his search for Franklin, 359.

Bellinghausen, his discovery of the islands Paul the First and Alexander, 401.

Bellot, Lieut., his gallant search for Franklin, 359. - his death and monument, 362 .

Beluga, or white dolphin (Delphinus leucas), description of the, 61 .

- domain of the, 61 .

Beluga Bay, visit of Von Baer's party to, 151.

Bennet, Stephen, his visit to Bear Island, 143, 144.

Berry-gathering in Nishne-Kolymsk, 238.

Bilberries of the Arctic regions, 24.

Billings, voyage of, on the coast of Siberia. 201.

Birch, paper, value of the, in North America, 304. Birch-trees in the Arctic regions, 24.

Birds, flights of wild, in summer months, in the Tundra, 19.

- their migrations to and from high latitudes, $43,44,67$.

- the polar singing-bird, the snow-bunting, 43 .

_- raptorial, of the Arctic regions, 43.

_- enormous numbers of, along the Arctic shores, 67. Icelandic, 81.

- of the coast of Norway, 124. of Spitzbergen, 133, 134, 137. of Nova Zembla, 154.

— a bird bazar, 154.

- abundance of sea-fowl on the coast of Kamchatka, 255.

_- Esquimaux mode of bird-catching, 295.

_, abundance of, on the coast of Greenland, 388. 
Birds of the coasts of the Antarctic sea, 394. of Patagonia, 419.

Birkarls, their final subjugation of the Lapps, 156.

Biscoe, his discovery of Enderby Land, and of Graham Land, 401.

Black death, ravages of the, in the North, 383 .

Blackfeet Indians, their wars with the 'Tinné and Crees, 319, 320.

Bloody Falls, on the Coppermine river, 294.

Boats of the Esquimaux, 293.

- the birch-bark canoes of North America, 304.

Bogberries of the Arctic regions, 24.

Booth, Sir Felix, his Arctic expedition, 251.

Bougainville, his voyage through the Strait of Magellan, 414.

Brandt, the Danish forester, his journey with Von Middendorff, 220.

Brandy, fondness of the Samoïedes for, 171-173. drunk at Kolymsk, 238.

Brant Ysbrantzoon, his voyages of discovery, 339.

Bread of the poor Icelanders, 79.

Bredal, Eric, his education of Lapps in Christianity, 156.

Bridges, swing, of Iceland, 111.

Browne, T. Ross, 74, 95, 104, 115.

Buchan, Captain, his Arctic voyage, 344.

Bunting, its migrations to and from the north, 43.

- the Lapland (Centrophanes Lapponicus), latitudes inhabited by the, 43,44 .

Bunting, the snow, the polar singing-bird, 44 .

Bunting, its nest and food, 44 . of Iceland, 81.

of Spitzbergen, 137.

Burglars, treatment of, in Russia, 206.

Burrough, Stephen, his voyage to discover the north-eastern passage, 336.

Busa, Jelissei, his ascent of the rivers Lena and Olekma, 195.

- his discovery of the Tana, 195 .

__ his residence among the Jukahirs, 195.

Butter made from the reindeer milk, 36 .

Butterflies in Taimurland, 227.

Byron, Commodore, his voyage through the Strait of Magellan, 414.

\section{c.}

Савот, John and Sebastian, their re-discovery of parts of North America, 335.

- their re-discovery of Newfoundland, 379

Canada, enterprise of the French settlers in, 306.

- results of the English conquest of, 306.

, history of the fur-trade of, 307.

Cano, Sebastian el, his voyage round the globe, 413

Canoes, birch-bark, of North America, 304, 305.

Cape, North, description of the, 129, 130.

Caribou, or reindeer of North America, range of the, 36 .

Carrancha, the, of Patagonia, 419, 420.

Cartier, Jacques, his voyages, 335 .

Caryophyllæ, the, of the treeless zone, 21.

Cascades of Icland, 78.

Castor and Pollux river, discovery of, 356 .

Castrén, Matthias Alexander, account of him and of his journeys, 168-178.

Catherine's Foreland, Queen, 409.

Cattle, value of, to the Icelands, 80 .

Cavendish, his royages, 414 .

Chancellor, his discovery of the passage from England to the White Sea, 192.
Chancellor, his voyage to discover the north-eastern route to China, 336 .

- his visit to Moscow, and subsequent fate, 336 .

Charles IX., King of Sweden, his kinduess to the Lapps, 156.

Chatanga river, scanty population of the, 220 .

- Middendorff's journey to the, 220, 221.

Chatangsk, Middendorff's journey to, 221.

Cheese made from reindeer milk, 36 .

Cherie Island, account of, 144.

Chess-players of the Tungusi, 246.

Chickweed, the, on the Mary Minturn river, 20.

Chimengo, the, of Patagonia, 419.

China, Castrén's journey over the mountains into, 177.

Chinese take the Russian fort of Albasin, 195; and make the treaty of Nertschinsk with the Russians, 196

-, the treaty broken by the Russians, who compel the Chinese to give them the Amoor, 196.

Chinga (Mephitis ching('), its fœetid secretion, 316.

Christian IV., King of Denmark, his treatment of the Lapp priests and sorcerers, 156.

- his expedition to Greenland, 383.

Christianity, introduction of, into Iceland, 92.

Churches of the Icelanders, 104.

Clavering, his voyage to Greenland, 386 .

Cler $g y$ of the Lapps, their poverty and self-denial, 157.

- , their sermons, 157.

_ , those of Iceland all blacksmiths, 101, note, 106. , their poverty, 106.

Coal, does not exist in Iceland, 88.

- of Spitzhergen, 137. in Coal Bay, 145.

Coal Bay, 145 .

Cochlearia fenestrata, the only esculent plant in Spitzbergen, 136. 142.

Cod and cod-fishing of the coast of Iceland, 86,87 .

—_ the, called stockfish, 87.

the cod-fishery of Norwar, 125-130.

__ wretched state of the fi-hermen, 127. -, exports of, to various countries, 129. cod-fishery of Greenland, 388. , value of the cod-fishery of Newfoundland 379,380 .

— - mode of fishing and curing the cod, 380 .

- dangers of the fishery, 381 .

- immense numbers of, 381

Cod-liver oil of Tromsö, 128.

Collinson, Captain, his search for Franklin, 359, 361.

Commodore Islands, chase of the sea-bear on the, 274.

Condor, the, of Patagnnia, 420.

Coniferæ, Arctic forests almost confined to the, 24 ,

- difference between the European and Asiatic and American species, 24.

Constitution, Cape, discovery of, 369

Cook, his attempt to discover the northwest passage, 344 .

Cook, Captain, his discovery of South Georgia, 393.

- , his Antarctic vovages, 401.

Copper mines near Drontheim, 124. of Alten, 128.

of Raipass, 128.

Coppermine river, Dr. Richardson's voyage to the, 349.

Cornelius Ryp, his voyages of discovery, 340,341 .

Cornelius Corneliszoon, his voyages of discovery, 339. 
Corniculariæ, carpets of, and the treeless zone, 21. Cortereal, his voyages of discovery, 325 .

Cossacks, Don, their depredations, 192.

_ their conquest of Siberia for the Czar, 193.

- their privileges and duties in Nishne-Kolymsk, 236.

Coureur des bois, the, of North America, 304.

Cranberries of the Arctic regions, 24.

Cree Indians, uses of the paper-birch-tree to the, 305.

- range of the various tribes of, 319 .

_- their conquests of the Tinné, but subsequent defeat, 319,320 .

- their wars with the Blackfeet, 320,321

- their character, 321.

- their customs, habits, and dress, 321, 322, 323.

- their wives and families, 323.

__ their cradles, 323.

_

__ their medicine-men and vapor-baths, 324.

—, their games and sports, 324, 325.

_

_

Kepoochican, 325.

- their notion of the Great Spirit and of the

Deluge, 325 .

- , their Tartarus and Elysium, 325.

- , prospects of Christianity amongst them, 326.

Cross, the game of, of the Cree Indians, 325.

Crowe, Mr., his copper mines at Alten, 128.

Crozier, Captain, his last voyage, 356.

- the last heard of him, 364 .

- his Antarctic voyages, 402 .

Cruciferæ, the, of the treeless zone, 20.

Crustaceans, immense numbers of, on the coast of Greenland, 59.

Cumberland Strait, Davis's discovery of, 337, 338.

Currents, magnificent system of, and their effects on the accumulation of ice, 56,57 .

\section{D.}

Dances of the Tchuktchi, 266

Darwin, Mr., his ascent of Mount Tarn, 411.

Davis, John, his voyages to discover an Arctic passage to India, 337.

__ his visit to Labrador, 338.

_. his subsequent life, 338 .

Davis's Straits, probable influence of the northerly winds on the depression of the temperature of, 27.

- Sebastian Cabot's discovery of, 335 .

Dead, reverence paid to the, by the Samoïedes, 181.

Dease, Peter Warren, his land Arctic expedition, 355.

Death, black, its ravages in Iceland, 95.

Deception Island, account of, 393.

Deer, red (Cervus elephas), its habitat and uses to man, 40.

Deer of Vogelsang and Treurenberg Bay, 137.

Deluge, Cree legend of the, 325 .

Demidoff, foundation of the family of, 219.

- their enormous wealth, 219 .

Deschnew, Semen, his the first and last voyage through Bering's Strait, 197.

Desolation, South, 412.

Detti-foss, an Icelandic cascade, Mr. Gould's description of the, 78 .

Disco bay, icebergs formed in, 49 .
Divers, their migrations to and from the north, 42.

Dog-rib Indians, hunting-grounds of the, 327.

- their character, dress, and customs, 327, 329.

-, their want of hospitality, 329.

- their honesty, 329.

- , their notions of a future life, 329.

Dog, the reindeer of the Lapps, 161.

, Wrangell's dog-sledges on the Polar sea, 239.

, Icelandic, 80.

- the, of the people of Kolymsk, 236.

- the Kamchatkan, and dog-sledges, 258, 259.

- their mode of foretelling storms, 259.

- mode of training sledge-dogs, 259.

, trained by Esquimaux to attack the bear,

297.

- description of the, and dog-sledges of the Es- imaux, 299.

qu, Dr. Kane's Newfoundland and Esquimaux, 367.

- epidemic amongst the Esquimaux, 372

Dolgorouky, Prince, his exile to Siberia, 205.

Dolphin, white, or beluga, of Nova Zembla, 155.

, Greenland fishery of the, 387 .

Dolphins of the Polar seas, $61,-398$.

- the beluga, or white dolphin, 61 .

, the black dolphin, "ca'ing " whale, or grind, 61.

, the orc, or grampus, 62 .

$\longrightarrow$ of Spitzbergen, 137.

Drake, Sir Francis, his voyage throigh the Strait of Magellan, 414.

Drifanda Foss, an icelandic cascade, 114.

Drontheim, the red deer near, 40. description of, 124.

Ducks, wild, of the Arctic regions, 19.

—, their migrations to and from the north, 42. - of Iceland, 81, 84.

Dudinka, Castren's visit to, 176.

Dungeness, Point, 409.

Durfoorth, his voyage and death, 336 .

D'Urville, Dumont, his discoveries in the Antaretic ocean, 402.

Dutch, their expeditions to discover an Arctic passage to India, 339.

E.

EAGLE, the sea- (IIaliatus albicilla), of the north, 44.

- his food, 44

—, white-tailed, of Iceland, 85.

- value of the skins of the, 85 .

_ the, on the coast of Norway, 125.

, in the Tundra in summer, 19.

Ebierbing, 441, 466, 773, 774, 758-761,

Egede, Hans, his voyage to Greenland, 384 .

Egg-väre of the coast of Norway, 124

Egilson, Olaf, the Westman clergyman, his slavery in Algiers, 118.

Eider-duck, its migrations to and from the north, 43.

- of Iceland, 81.

- , breeding of, 83 .

_ Mr. Shepherd's visit to one of its head-quar. ters, 83.

Elder, the, in the Arctic regions, 24.

Elephant, sea-, of the Antarctic ocean, 399.

Elk, or moose deer, of the forests of the north, 38 .

, Cæsar's account of it, 39.

__ its food and present habitat, 40. 
Elk, its mode of defending itself, 40.

Enara, Lake of, the Fisher Lapps of, 166. description of the, 169.

Enderby Land, discovery of, 401 .

English pirates, ravages of, in Iceland, 95.

Erebus, mount, eruption of, 403.

Eric the Red, his visit to Greenland, 382.

Ermine (Mustela erminea) beauty and importance of the fur of the, 210.

- , those of the Hudson's Bay Territory, 316.

Esk, volcano, 146.

Esquimaux (see also Innuits), their wide extension, 290.

- their own name of Innuit, 290.

_- character of the regions they inhabit, 290.

- , their physical character, habits, and manners, 290, 291.

- women, 291.

_ their dress and snow-huts, 291, 292.

_

_ their weapons, and fishing and hunting implements, 293, 294.

- enmity between them and the Red Indians, 294.

295

- their whale and seal hunts, 295, 296.

_

_ their bear and walrus hunts, 296, 298.

__ their dogs and dog-sledges, 299.

_ their games and sports, 300 .

_ constitution of their society, 300 .

- - their angekoks, or priests, 300, 301.

- their moral character, self-reliance, and in-

telligence, $301,302$.

- their maps, and predilection for commercial pursuits, 302 .

- their voracity, and seasons of abundance and distress, 302,303 .

— their dépôts of food, 302, 303.

_ their wars with the Kutchin Indians, 333.

_

_ their hunting expeditions with Dr. Kane's party, 370.

- their ravages on the Greenland coast, 383 .

Europe, treeless zone of, 18-24.

Evil Spirit of the woods of the Laplanders, 157.

Exiles, Siberian, 204, 205.

- annual number of, 206.

Eyjafialla, eruption of, in 1821, 96.

Eystein, King, his benevolence, 126.

\section{F.}

Faeroe Islands, chase of the black dolphin, or "ca'ing" whale, in the, 61 .

Falkland Islands, climate of, 394.

Famine, Port, rich vegetation of, $410,414$.

Festuca of the Arctic regions, 20.

Finback whales of Spitzbergen, 137.

Finches in the Tundra in summer, 19.

Finmark, trade and fisheries of the coast of, 129.

Finnur Johnson, the Icelander, his "Ecclesiastical History of Iceland," 98.

Fir, different species of, in Europe, Asia, and America, 24.

Fish, and fishing season of Iceland, 86.

- abundance of, in Kamchatka, 255.

- of Newfoundland, 379.

- of Greenland, 387.
Fish river, Great, Back's discovery of, 355 .

Fisher Lapps, account of the, 166.

Fiskernasset, cod-fishery of, 388.

Fitzroy, Captain, his surveys of Patagonia and Tierra del Fuego, 415.

Fjäll Lappars, or Mountain Lapps, account of the, 159.

Flatey, eider-ducks of, $81,82$.

Flat-fish, abundance of, on the coasts of Iceland, 87.

Floki, the Viking, his visit to Iceland, 90.

Flora of Spitzbergen, 136.

Flowers of the Arctic regions, 20.

of the island of St. Lawrence, 271.

of Taimurland, 226.

of Unalaschka, 269.

Fogs of the Arctic seas in summer, 54

near the island of St. Lawrence, 270.

- off Newfoundland, 380 .

Food, amount of, required by man in the Arctic re. gions, 28.

Forest regions, Arctic, 18

- extent of the, 22.

- character of the trees of the, 24.

, distinctive character of the forests, 25 .

, characters of the Arctic forests of the Miocene period, $28,29$.

- legions of gnats in the, 25 .

- changes being effected by the agency of man,

Forests, the, head-quarters of many of the Arctic fauna, 41.

153.

- of Newfoundland, 376.

Forget-me-not found in Nova Zembla, 153.

Forster, Captain, his expedition to the Antarctie sea, 393.

Fossils, Arctic, in New Siberia, 203.

Foulke, Port, Dr. Hayes's winter at, 372.

Fox, the Arctic (Canis lagopus), its mode of protecting itself from the most intense cold, 42.

Fox, the Arctic, its food and enemies, 42.

— of Spitzbergen, 137.

- in Nova Zembla, 154.

- found in Taimurland, 227.

of Newfoundland, 378 .

- black, of Siberia, value of the fur of the, 211.

, the Brazilian (Canis Azarce), of Patagonia, 419

- red (Vulpes fulvus), the, 211, 317.

, value of the fur of the, 317 .

Fox Islands, discovery of the, 201.

France, right of the people of, to fish on the banks of Newfoundland, 379.

Franklin, Lieut. (afterwards Sir John), his first Arctic voyage, 344 .

- his first land journey, 346.

- his second land journey to the shores of the Polar sea, 349.

- loss of his first wife, 350 .

- his last voyage, 356 .

-

- his fate and that of his companions, 362-364.

Franklin Island, discovery of, 403.

Fraser river, voyage of Mackenzie down the, 308 .

Frederick II., King of Denmark, his expedition to Greenland, 383 .

Frederick IV., his foundation of the Finmark mission, 156

Friedrich, the Saxon bishop, introduces Christianity into Iceland, 92. 
Fritillaria Sarrana, used as food in Kamchatka, 258. Frobisher, Martin, his endeavors to discover an Arctic passage to India, 337.

- discovery of relics of, 466.

- his subsequent career, 337.

Froward, Cape, scenery of, 410.

Frozen sailor, 464 .

Fruits of the Arctic regions, 24.

Fuego, Tierra del, climate of, 393 .

- origin of the name, 413.

- Captain Fitzroy's survey of, 415.

- account of the Fuegians, 425 .

- degradation of the Fuegians, 425, 426.

_ their powers as mimics, 426.

-

_ , causes of their low state of civilization, 427.

- their food, 428.

429 .

- their dress, huts, arms, and ornaments, 428,

— their cannibalism, 430 .

- their language, 430 .

—_ Captain Fitzroy's three Fuegians, 430, 431.

—_, missionary Jabors, 431.

, Captain Gardiner, 431.

Fuel, kinds of, used in Iceland, 89.

Fur, account of the Russian Fur Company, and its operations, 272 .

- account of the fur-trade of the Hudson's Bay Company, 304 et seq.

- trade in, at the fair of Obdorsk, 189. of Siberia, 208.

- importance of the trade in, 212.

- of the Tchuktchi, 264.

\section{G.}

Gabriel Channel, williwaws of, 412.

Gadflies which attack the reindeer, 38 .

Galictis vittata, the, of Patagonia, 418.

Gambling of the Cree Indians, 324.

Gardar, the northern pirate, his the first circumnavigation of Iceland, 90.

Gardar's Holm, or Gadar's Island, Iceland so called, 90.

Gardiner, Captain, his mission to Fuegia, and melancholy end, 431.

Gawrilow, produce of the gold mine of, 218.

Geese, wild, of the Arctic regions, 19.

- snow, their migrations to and from the north, 43.

- of Iceland, 81.

"George Henry," the ship, 436 .

George, St., climate of the island of, 270.

-, sea-lions and guillemots of, 271.

Georgia, South, discovery of, 393.

Germany, the elk or moose-deer of, in the time of Cæsar, 39.

Geysir, the Great, description of the, 71 .

Gheritz, Dirck, his discovery of the New Shetland Islands, 392.

Gilbert, Sir Humphrey, takes possession of Newfoundland, 379 .

Ginklofi, or children's disease, in the Westman Islands, 118.

Gissur, his work on his voyages to the East, 94. - , the Icelander, his learning and travels, 98.

Gjas, or chasms, in Iceland, 76, 77.

Glacier, the great, in the Gulf of Penas, 394.

Glaciers, enormous dimensions of the, of the polar regions, 50 .
Glaciers of Magdalena Bay, 135 ; ice cliffs and avalanches of, 135 .

of the Beerenberg mountain, 146.

Glottoff, Stephen, his discovery of Kadiak, 202.

Gloves, reindeer, of Tornea, 37.

Glutton, or wolverine, strength and fierceness of the, 37.

Glutton, its attack of the reindeer, 37, 38.

- its voracity, 38 .

- , found in Taimurland, $22 \%$.

$\longrightarrow$, those of North America, 316.

- value and uses of the fur of the, 316 .

Gnats, legions of, in the forests and swamps, 26.

Goda-foss, the, an Icelandic cascade, 78.

Gold diggings of Eastern Siberia, 208. , description of the gold-fields, 214 .

Gomez, his voyages of discovery, 335 .

Goose, bean (A nser segetum), of Nova Zembla, 155.

Goose, Brent, its migrations to and from the north, 43.

- its rapid flight, 43.

Graah, Captain, his explorations of the coast of Greenland, 386.

Graham Land, discovery of, 401.

Grampus, or orc (Delphinus orca), description of the, 62 .

$\longrightarrow$, his ferocity and mode of ploughing the seas, 62.

of Nova Zembla, 155

- of the Antarctic Ocean, 398.

- conflict of one with a whale, 398.

Grasses, tufted, of the Arctic regions, 20.

- of the treeless zone, 21.

, paramount importance of the grasses in Iceland, 79 .

of Taimurland, 226.

Greenland, vast ice-fields of, 27.

—, proofs of a former milder climate in, 29.

$\longrightarrow$, enormous dimensions of the glaciers of, 50.

—, the, whale, 60 .

- transparency of the water on the coast of, 59 .

-, abundance of animal life in the seas of, 60 .

_, walruses of the coasts of the north of, 64 .

- Kane's sledge journey along the coast of, 367 .

—_ unknown extent of, 382.

- ancient Scandinavian colonists of, 382 .

__ the name of, given to it, 382 .

, introduction of Christianity in, 382.

, decline and fall of the country, 383.

-, subsequent explorations of, 383 .

- Hans Egede, the pastor, his voyage to, 384 .

- , foundation of Godthaab in, 384.

- arrival of Herrenhuth mi sionaries in, 384.

— - explorations of the coast of, 385 .

_ present Danish settlements of, 386.

-

mode of life of the people of, $386,387,389$.

- , fisheries of, 388.

- poorness of the land in, 388.

- quantities of drift-wood at, 388 . minerals of, 389 .

, Christianity in, 389.

, climate, mountains, and fjords of, 389 .

, ice-caves of the coast of, 390 .

- the capital of, 437.

Greenlanders, their discovery of, and colonies in America, 335.

- destruction of their colonies, 335.

, their habits, 437.

Greiffenfeld, his imprisonment in Munkholm, 124.

Grinds. See Dolphins, black. 
Grinnell Land, vegetation of, 20.

Dr. Hayes's discoveries in, 3־2-374.

Guanaco, the, of Patagonia, 419.

Guano, circumstances which favor the dcposit of, 418.

Guillemot, on the Pribilow Islands, 271.

Gulf Stream, influence of, on the south and west coasts of Iceland, 79 ; and on the climate of Norway, 121.

Gull, Ross's, distance north at which it has been seen, 67.

Gull, ivory, in Taimurland, 227.

Gustavus I., King of Sweden, his kind treatment of the Lapps, 156.

Gustavus Adolphus, his foundation of a school for the Lapps, 156.

\section{H.}

HADDOcks, abundance of, on the coast of Iceland, 87.

Hakon, King of Norway, his annexation of Iceland, 95.

Hall, Charles Francis, his first Aretic expedition, 433 et seq. His last expedition and death, 737 et seq. , James, his voyage to Greenland, 383.

Hammerfest, description of the town of, 129 .

- traffic of, 129 .

- , the people of, 129.

- cargoes of walruses and seals brought from Spitzbergen, 143.

Hare, the fur of the, of Siberia, 212.

- ice (Lepus glaciaiis), 317.

found in Taimurland, 227.

Hare Indians, hunting-grounds of the, 327. , their women, 328.

Harold Haafager, or the Fair-haired, his establishment of an absolute monarchy in Norway, $\subseteq 0$.

- exodus caused by his tyranny, 91 .

Harp-seal of the Polar seas, 62.

Hatherton, Cape, discovery of, 365 .

Haven, Lieut. de, his search for Franklin, 357, 358.

Hawks in the Tundra, in summer, 19.

Hayes, Dr., his sledge journey over Kennedy Channel, 368.

- , his Arctic voyage in $1860,372-374$.

- , his opinion as to what may be done in the Arctic regions, 374 .

Hecla, eruptions of, since the colonization of Iceland, 95-97.

"Hecla" and "Fury" Straits, discovery of, 348.

Heemskerk, his voyages of discovery, 340 .

Heineson, Mogens, the "sea-cock," his voyage towards Greenland, 383.

Heplourn, John, the sailor, his overland journey, 346.

Herald Island, discovery of, 360 .

Heimaey, or Home Island, description of, 116.

Herring, the fishery of the coast of Norway, 125.

_- food for the rorqual, or fin-whales, 61. 87.

, abundance of the, on the coasts of Iceland,

Hesperis, the, on the Mary Minturn river, 20.

Hildringen, agriculture of, 124 .

Hobson, Lieut., his search for Franklin, 362, 364.

Holme, the, of Norway, 124.

Hood, Robert, his Arctic journey, 346 .

- murdered, 347.

Horn, Cape, discovery of the passage round, 414 .

Horse, the, in Iceland, 80.

— of the Jakuts, 230-232.
Hrafnagja, 75.

Hudson, Henry, visit of, to Spitzbergen, 138.

- his the first attempt to sail across the North

Pole, 342.

$\longrightarrow$, his subsequent voyages and discoveries, 342 . , his melancholy end, 343 .

IIudson's Bay, barren lands of, 22.

—- , characters of the Coniferæ of, 24.

_- walruses of the coasts of, 64 . , discovery of, 312.

Hudson's Bay Company, account of the fur-trade of the, 304 .

ageur of, 3144, 305 .

$\longrightarrow$, history of the, 307 .

, formation of a rival company, and subsequent amalgamation of the two, 307-310.

- palmy days of the, 310 .

- its reconstruction in $1863,310$.

, its trading-posts, and their mauagement, 310 , 311.

- its efforts to civilize the native tribes, 312

_- the standard of exchange, the beaver-skin, 313.

- extent of the fur-trade of, 313 .

, account of the fur-bearing animals of the Territory, 313, 314

Hudson river, discovery of the, 342 .

Hudson's Straits, Sebastian Cabot's discovery of, 335.

Humboldt Glacier, the Great, 50 .

_- Kane's description of the, 367

Humming-bird on the peninsula of Aliaska, 269.

- in Newfoundland, 378.

of Patagonia, 420 .

Huts of the Esquimaux, 293. of the Icelanders, 102.

Hvalö, island of, 129.

Hvita river, in Iceland, 78.

\section{I.}

ICE, vast fields of, in the plateaus of Spitzbergen Greenland, and Nova $Z$ ×mbla, 27.

_ floating masses of, in the Polar seas, 45.

- enormous extent of the Polar glaciers, 49, 50

, causes which prevent the accumulation of

Polar ice, 55, 56.

- , a bad conductor of heat, 57 .

_- ice-fields of Iceland, 69.

- glaciers, ice-cliff's, and avalanches of Spitz-

bergen, 135, 136 .

, impediments offered by the hummocks to travellers on the Polar sea, 240.

- icebergs of the Antarctic sen, 392.

_- ice-caves of Greenland, 390 .

403.

- pack-ice of the Antarctic Ocean, 404, 405.

Icebergs, 46.

-

- , origin of, 48

, localities in which most of the icebergs of the

North Atlantic are formed, 49

50

how distinguished at night and in fogs, 52.

dangers of collisions with, 52 .

protection to ships afforded by, 53 .

, dangers of anchoring to, 53 . 
Icebergs, "calving" of, 54 .

__ crumbling of, 54 .

Ice-Llink, description of the phenomenon of, 54 . , its advantages to the Arctic navigator, 54 .

Ice-fields, 46.

- hummocks on, 46 .

- collision of, 48 .

__ dangers caused by, to ships, 48 .

Ice-grotto of Surts-hellir, 77.

Iceland, volcunic origin of, 68 .

- , the country in winter and in summer, $68,79$. , sterile portions of the island, 69 .

_, its immense ice-fields, 69.

- its lava-streams, 69, 77.

_

-

- , the Great Geysir, 71.

—, the Strokkr, 72.

- crystal pools, 73 .

- , the Almannagja, 73, 74.

- , the Surts-hellir, or caves of Surtur, 77.

, rivers and cascades of, 78 .

- influence of the ocean currents on the climate, 78 .

- mean annual temperature, 79.

- absence of trees in, 79 .

-

- indigenous land quadrupeds, 80 .

- cattle of the Ic liunders, 8 ').

- beverages, 80 .

- mole of shearing she p, 80 .

-

$\longrightarrow$, the reindeer, 80,81 .

_, the p lar bear, 81 .

- the eider-duck, 81,88 .

- the giant auk, 85,86 .

_. Icelandic fish and firhing season, $86,87$.

, hospitality of the people, 87 .

- minerals of the country, 88 .

_

, history of, 89 .

Naddodr's discovery of the Ice Land, 89; which he named Snowland, 9 J.

called liy him Gardar's holm, 90.

_

him Iceland, ?0.

__ , foundation of Reykjavik by Ingolfr and Leif, 90. exodus from Norway to, 91 .

, introduction of the Norwegian language and eustoms, 91.

_

_- the ancient Althing at Thingvalla, 91, 92.

- , in:roduction of Christianity into the island,

92.

- , the golden age of Icelandic literature, 94.

, history of, annexation of the island to Norwav, 95 .

_- its subsequent misfortunes, 95 .

-

- misery caused by the curse of monopoly, 97 .

- hope for the future of the islanders, 97 .

, account of the Icelanders of the present day,

98.

Skalkott, the former capital of the island, 98. , the present capital, Reykjavik, 100

, state of trade in, 100 .

_

$\ldots$, temperate habits of the people, 101.

$\longrightarrow$, condition of agriculture, 102.
Iceland, a harvest home. 102.

- winter life, 102, 108, 109.

-

, churches, 104.

, clergymen all blacksmiths, 101 ; note, 106 ;

their poverty, 106-108.

_- the Iceland poet, John Thorlakson, 107.

- education of the clergy and children, 108, 109.

, industry and thirst for knowledge of the peo-

ple, 109 ; their lan

-

_, the Icelandic Literary Society, 110.

- Icelandic newspapers, 110.

- health of the pcople, 110.

__ difficulties and expense of travelling, 110-113.

muss, eaten and exported by the Icelanders,

79.

- moss, food for the deer of Spitzbergen, 137. in the treeless zone, 21.

Idols of the Samo:edes, 180.

Igloolik, island of, 348 .

Iligliuk, the Esquimaux, her intelligence and passion for music, 348 .

Indians, Red, their enmity with the Esquimaux, 294.

- , their decimation by smallpox and drunkenness, 308 .

_- efforts of the Hudson's Bay Company to civilize them, 312, 313 .

, the beaver skin their standard of exchange with the Company, 313 .

Inglefield, Captain, his search for Franklin, 359.

$\longrightarrow$, his discoverics, 365 .

Ingolfr, the Norwegian rarl, his visit to Iceland, anil foundation of Rerkjavik, 90.

Innuits, the. see a'so Esquimaux, 433, 467.

- , their character, $439,461$.

- amusement of, 440 .

—, their dwellings, $443,457,462$.

- distress in winter, 444.

$\longrightarrow$, seal, feasts of, 445 .

_- mode of capturing seals, 446, 448, 452 .

-

- their opinion of the bear, 451 .

- mode of hunting the walrus, 454 .

- their implements, 456.

- mode of constructing an igloo, 457.

_ thrir use of the reindeer, 458 .

— their clothing, 460.

_

_

-, their religious ideas, 460 .

_

— Gradual extinction, 462.

Insects of Taimurland, 227.

Iri h colonists on the Westman Islands, 115.

Irkutsk, extreme cold of, 208.

_-, Wrangell's visit to, 233.

_ summer flowers of, 233.

Iron mines near Drontheim, 124.

Isabella, Cape, discovery of, 365 .

Ishemsk, Castrén's visit to, 174.

, the Isprawnik of, and his wife, 174, 176.

Islands within the Arctic Circle, barren grounds of th? 18.

Isleif, the oldest chronicler of the North, 98.

Issakow, of $\mathbf{K} \mathrm{m}$, rounds the north-eascern exiremity of Nova Zembla, 150 .

Itilmenes, cruelty of their conquerors, the Russians, 198.

Ivan Wasiljewitsch I., first Czar of Russia, his defeat of the Tartars, 191. 
Ivan Wasiljewitsch I., subdues the Great Novgorod, 191.

- becomes head of the Greek orthodox Church and the first Czar, 192.

- Chancellor's visit to him at Moscow, 336.

Ivan Wasiljewitsch II., his conquest of Kasan, 192.

- his surname of the Terrible, 192.

Ivory, fossil, in the islands of New Siberia, 202.

Iwalo river, in Lapland, Castrén's journey on the, 169.

\section{J.}

J KKOWLEW family, 219.

_ their enormous wealth in gold mines. 219.

Jakuts, the, confirmed by the Czar in their possessions, 199.

_- their snares and traps, 213.

their energy and cunning, 228.

- their languagre, origin, character, and personal appearance, 228.

- their summer and winter huts, 229.

_ their horses, 230.

- their powers of endurance and sharpness of vision, 230.

_- their manufactures and articles of dress, 231.

_ their glutt -

- the universal carriers to the east of the Lena, 231.

- their superstitions, 232.

_ their offerings of horsehair to the spirit of the mountains, 232.

- their sonधs, 232.

$\longrightarrow$, wretched condition of the river, 252.

Jakutsk, mean temperature of, in summer and winter, 27.

_

- gloomy appearance of the town, 233.

- trade of, 233.

Jan Meyen, description of. 146.

Jelly, made from the horns and claws of the reindeer, 37.

Jelly-fish (Pleurobrachir pileus) in the sea of Kara, 151.

Jenissei river, Castrén's journey to the, 176.

Jeniseisk, Castrén's visit to, 177.

- the ostrog of, founded, 195.

Jyrfalcon (Fulco gyrfalco), its head-quarters in Iceland, 85.

- former trade in the, 85 .

Jilibeambaertje, or Num, the Supreme Being of the Samö̈ des, 179 .

"John, Gentleman," the English pirate, 118.

John's, St., capital of Newfoundland, 378 .

$\mathrm{J} i \mathrm{kuls}$, or ice-mountains of Iceland, 68.

Jikulka i Axarfirdi river, in Iceland, 78.

$\mathbf{J}$ kulsa river, in Iceland, 78 .

Jones's Sound, discovery of the entrance to, 343 .

Jukahires, chief resource of those of the Aniuj, 237.

- Jelissei Busa's residence among the, 195.

K.

KADIAK, island of, discovery of the, 202.

Kaiak, island of, landing of Stella on the, 249.

"Kalewala," Castrún's Swedish translation of the, 1;0.

Kamchatka, subjugation of, by the Russians, 198 .

- cruelty of the conquerors, 198.
Kamchatka, Steller's scientific journey to, 248.

- its climate and fertility, 254 .

- abundance of fish in the rivers, 255 .

- birl-catch of 255 .

- population, 255.

_- mountain chain and volcanoes, 256.

— climate and mineral springs, 256.

_- harbors and population, 256.

- healthiness of the people, 257.

, their food, 258.

- their animals, 258, 260.

- , character of the people, 260, 261.

Kane, Dr., his Arctic voyages, 365.

- his account of his first winter in Rensselaer

Bay, 365 .

_

, his sledge journey along the coast of Green-

land, $36 \pi$.

- his illness on the voyage and recoverv, 368 .

, resolves to winter a second time in Rensselaer

Bıy, 369 . 370 .

, sufferings of his party, 371 .

, abandonment of his ship, and boat journey to Upernavik, 371.

- his return to New York, and death, 372.

Kara Gate, reached by Stephen Burrough, 336.

Kara, Sea of, 147.

- expeditions to the, 147.

Kasan, Russian conquest of, 192.

Kellett, Captain, his search for Franklin, 359.

Kendall, Lieut,, his voyage to the Coppermine river, 349 .

- his account of Deception Island, 393.

Kennedy, William, his search for Franklin, 358.

$\longrightarrow$, his sledge journey with Bellot, 359 .

Kennedy Channel, Dr. Hayes's sledge journcy across, 368

- his voyage across, 373 .

Kerguelen Land, climate of, 393.

Khipsack, destruction of the empire of the Khans of, 191.

King, Captain, his survey of the Magellan Strait, 415.

King William's Island, coast of, traced by Mr. Thomas Simpson, 356.

Klofa jikul, extent of the, 69 .

Kuight, John, his melancholy Arctic vorage, 341.

- murdered by the Esquimaux, 342 .

Koldewer, Captain, his journey tow ards the North Pole, 374.

Kolwa, Castrén's visit to, 174 .

Kolyma river, inundations of the, 237.

Kolymsk, Ni hnei, foundation of the town of, 197.

_ W Wrangell's visit to, 234.

-

- vegetable and animal life, 235 .

- population of the district, 236 .

__ dwellings of the Russian residents, 236.

_ mode of life of the natives, 236, 237.

—, their dogs, 236, 237.

- berry-gathering in the district, 238.

_ famine of the people, 238. social parties at, 238 .

Koriaks, the, confirmed by the Czar in their possessions, 199

Koronnoie Filippowskoi, Von Middendorff's journey to, 221.

Kostin Schar, visit of Von Baer to, 152.

-, storm in, 152. 
Kötlugja, eruptions of, since the colonization of Lava streams of Ieeland, 69, 77. Ic siand, 95̃, 97.

Krasnojarsk, Castrén's visit to, 175, 176.

- extravagance of the gold aristocracy of, 218.

Krenitzin, his discovery of the peninsula of Aljaska, 202.

Kresdowasdwishensk, produce of the gold mine of, 218.

Krisuvik, burning mountains of, 69 .

Krotow, Lieutenant, lost off Nova Zembla, 147.

Kutchin Indians, their dwelling-place, 331.

_ , their personal appearance and dress, 331.

_ their medium of exchange, 331.

_ their women and children, 332.

_ their amusements, 332.

__ thrir wars with the Esquimaux, 333.

_. their suspicious and timorous lives, 333 .

_ their mode of pounding the moose-deer, 333.

- their frequent distress, 334.

- their huts, 334.

Kutchum Khan, his conquest of Siberia, 192.

- , defeated by Yermak the robber, at Tobossk, $193,194$.

- his revenge, 194 .

LABRADOR, barren lands of, 22.

, effect of the icy seas and cold currents on the climate of, 22.

- discovered and colonized by Greenlanders, $33 \overline{\text {. }}$

Lächow Islands, discovery of the, 202.

Lagarfliot river, in Icelaud, 78.

Lakes of Newfoundland, 377.

Lambert, M. Gustave, his opinion as to the roate to the Pole, 375 .

Lancaster Sound, discovery of the entrance to, 343 .

Lapps, their history and conversion to Christianity, 156.

- poverty and self-denial of their clergy, 157. their ancient gods and present superstitions, 156,157 .

- Evil Spirit of the woods, 157.

- sorcery and witchcraft, 158.

, their personal appearance, 158.

Lappars, the Fjall, or Mountain Lapps, 159.

-, their dwellings, 159.

- their reindeer pens, 160.

__, their summer and winter encampments, 161.

__ their sledges and skates, 161.

_. natural beauties of their country, 162 .

, their love of home, 162 .

- their mode of hunting the bear and the wolf,

$163,164$.

$\ldots$, the wealthy, and their mode of living, 164.

_ their annual visits to the fairs, $\mathbf{1 6 5 .}$

$\ldots$, their drunkenness, 16 o.

_ their worship of mammon, treasure hoarding, 165 .

-

_- their affectionate disposition, $\mathbf{1 6 6 .}$

_- the Skogslappars, or Forest Lapps, 166.

- the Fisher, 166.

Laptew, Lieut. Cheriton, his explorations of the coasts of Taimurland, 200

- his explorations to the east of the Lena. 200.

Larch, the, of Siberia, 24.

- , of the Hudson's Bay Territory, 24.

Lawrence, St., climate and vegetation of the island of. 271

- , streams of, thrown out by the great eruption of Skaptar Jokul, 95-97.

Laxaa, or Salmon river, abundance of fish caught in the, 87.

Leif, the Norwegian jarl, his visit to Iccland, 90. , murdered by his Irish slaves, 91 .

Lemming, its habitat and food. 42.

- exaggerations of Olaus Magnus and Pontoppidan respecting the, 42 .

, its enemies, and accidents to which it is liable, 42.

- of New Siberia, 27.

- of Nova Zembla, 154.

Lena river, ascended by the Cossacks, 195.

- , importance of the, 17.

- - barren grounds near the, 22.

- -, Wrangell's journey down the, 233.

Lepiosy, or "likthra," of Iceland, 110.

Lichens, gray, of the "barren grounds," 18.

- food for the reindeer, 27.

, the Lichen rangif rinus, the food of the reindeer, 36.

- of Nova Zembla, 153.

- of the Pribilow Islands, 271.

Liddon, Lieut. M., his Arctic voyages, 345 .

Lindenow, Godske, his voyage to Greenland, 383.

Lion, sea-(Otaria Stelleri), value of the skin of the, 276.

, the sea-, of the Antarctic Ocean, 399.

Lister, Cape, discovery of, 385.

Lithuania, the elk of, 39.

Loaisa, Garcia de, his voyage round the globe, 413.

Lofoten Islands, the, 125.

- cod-fishery of the, 125, 126.

Looming objects in the Arctic regions, 55 .

Loschkin, the walrus-hunter, his voyage on the coast of Nova Zembla, 147.

Löstadius, the Lapp priest, his self-denial and poverty, 157.

Loucheux. See Kutchin Indians.

Louis-Philippe Terre, discovery of, 402.

Lovunnen, puffins of, 125

Löwenorn, his voyage to Greenland, 385 .

Lütke, Admiral, his endeavors to penetrate along the coast of Nova Zembla, 147.

Isychnis, purple, of the Arctic regions, 20.

Lynx, Canada, or pishu (Lynx Canadensis), 317.

-, value of the fur of the, $212,317$.

Lyon, Captain, his unsuccessful voyage, 348 .

M.

MACKENzIE, Alexander, his voyages of discovery in North America, 308.

Mackenzie river, importanee of the, 17.

- forests and barren lands near the, 22 .

, influence of the southerly winds on the tem. perature of the valley of the, 27 .

, di covery of the, 308 .

Maesnikow, Nikita, his gold-fields in Eastern Sibe ria, $214,217,218$.

Magdalena Bay, description of, 133.

Magellan, Strait of, 408 .

- description of the, 408 .

_ entrances to, 409 .

-_ opening into the Pacific, 411.

_- discovery of the, by Magellan, 413 .

_. Sir J. Narborough's chart, 414.

$\longrightarrow$ Captains King and Fitzroy's surveys of, 415. 
Magerö, island of, 129.

Magicians of the samoïedes, $180,181$.

Malewinsky, Lieutenant, his gold mine of Olginsk, 218.

Maelstrom, the, 126.

Mammoth, fossil remains of the, in New Siberia, 202.

Man, his difficulty in establishing a footing in the Arctic regions, 17.

- how he is able to stand the rigors of an Aretic winter, 28.

Maps of the Esquimaux, 302.

Mariiusk, station of, built by the Russians, 196 . , gold mine of, 217.

Marshes of Newfoundland, 377 .

Marten, pine (Mrttes abietum), the, 316.

- value of the fur of the, 316 .

Mary Minturn river, flowers of, 20.

Matiusehkin, his sledge journey over the Polar Sea, 241.

Matoschkin Schar, visits to, 147-152.

Matthew, St., island of, inhospitable character of the, $2 \pi 1$.

Matthew's Straits, visited by Rosmysslow, Pachtussow, and Herr von Baer, 147-152.

Mc(lintock, Lieut. (now Sir Leopold), his seareh for Franklin, 360.

- his voyage in the "Fox," and discovery of the fate of Franklin and his companions, 362-364.

McClure, Captain, his search for Franklin, 359-361.

- his discovery of the north-west passage, 360 .

Mecham, Lieut, his search for Franklin, 260 .

Mediterranean, dried codfish sent to the, 129.

Medusæ, enormous numbers of, in the Polar world, 59.

- in the seas off Spitzbergen, 133.

Melville Bay, enormous glaciers of, 49, 50 .

Melville Island, discovery of, 345 .

Mentschikoff, Prince, his exile and death in Siberia, 205.

205.

Mercy Bay, discovery of, 361.

Mercy, harbor of, 412 .

Middendorff, Von, his adventures in Taimurland, 220.

- his visit to the Chatanga river, 221 .

, his fourney down the Taimur river to the

Polar Sea, 221-223.

- his return journey and illness, 223-225.

- gratitude of the Samo"edes, 224.

productions of Taimurland, 225.

Midnight, silence of, in Spitzbergen, 135.

Milk of the reindeer, 36 .

Minerals of Iceland, 88.

Mink (Vison Americanus), value of the fur of the, 316.

Misery, Mount, 145.

Mollusca, small, of the Polar Seas, 59.

Moonlight nights in the Arctic regrions, 32, 33.

Morse. See Walrus.

Morton, one of Kane's crew, 368, discovers Washington land, 369 Hall's last exped.,759.

Mosquitoes of Nishne-Kolymsk, 235.

Mosses, dingr, of the "barren grounds," 18. of Nova Zembla, 153.

of the Pribilow Islands, 270,271 .

Mourawieff, Count Nicholas, his anuexation of the Amoor, 196.

Mouse, field, of Spitzbergen, 137.
Muchamor, the fungus, used as food by the Kam. chatkans, 258.

Mud-springs, boiling, of Iceland, 70

Münich, Marshal, his exile to Siberia, 205. , his return and subsequent life, 206.

Munk, Jens, his voyages, 343.

Munkholm, castle of, 124.

Murderers, treatment of, in Russia, 206.

Muscovy Company, its endeavors to discover a north-east passage to India, 336.

Musk-ox (Ovibos moschatus), description of the, 40 . - its former and present habitat, 40, 41.

Musquash, musk-rat, or ondatra (Fiber zibethicus), 317.

— villages, 318 .

- modes of catching the animal, 318.

- value of the fur of the, 318 .

Mussels on the coast of Greenland, 59.

Myvatn, ducks of the, 84 .

N.

NADDODR, the Norwegian pirate, his discovery of Iceland, 89

Námar, or boiling mud-springs of Iceland, 70 .

Narborough, Sir John, his chart of the Strait of Magellan, 414.

Narwhal, or sea-unicorn, domain of the, 60 .

- its tusk, 61.

- Greenland fishery of the, 387.

Narrm, Castrén's visit to, $\mathbf{1 7 5}$.

Necromancy of the Samoiedes, 180.

Nertschinsk, treaty of, 196.

- criminals at the mines of, 206.

Ness, Castrén's visit to the Samo:ede village of, 172.

Newfoundland, discovered and colonized by Greenlanders, 335 .

its desolate appearance, 376

_ its forests, marshes, and barrens, 376,377 .

_ its lakes and ponds, 377,378 .

- its fur-bearing animals, 378 .

-

- its climate and inhabitants, ?78.

, its capital, St. John's, 378, 379 .

history of the island, 379

, taken possession of by the English, 379 .

, right of the French and Americans to fish

on the banks of, 379 .

- the French town of Placentia, 379

_ the whole island ceded to England, 379.

- importance of the cod-fisheries, 379.

_ the great banks of, 380 .

$\longrightarrow$, account of the mode of fishing, 380 .

_

- , seal-catching, 381 .

Newspapers of Iceland, 110.

Night of a Polar winter, Kane's description of, 366.

Nicolayevsk, station of, built by the Russians, 196 .

Noiba, gold-diggings on the, 216 .

Norfolk Bay, position and fur-trade of, 272 .

North-eastern route to India and China, Sebastian Cabot's idea of, 335.

, attempts to discover it. 335-337.

North Pole, the first attempt to sail across the, 342.

- the plan first suggested by Thorne, 342.

_- Scoresby's near approach to the, 344

_- Parry's boat and sledge journey towards the, 350 .

Dr. Haves's opinion as to the practicability of reaching the, across Kennedy Channcl. 374. 
North Pole, opinions of other scientific authorities Oraefa J̈̈kul, height of, 69. as to the best way to reach, 374 .

North-west passage $\approx 0$ India, attempts to discover the, 342,343 .

- M'Clure's discovery of the, 360 .

Company of Canada, formation and trade of the, 307 .

_ and final amalyamation, 308-310.

Northumberlan I Sound, temperature of, 28.

Notothe:ia, the, of the Antarctic seas, 400.

Norway, the lemming of the Dovrefjeld, in, 42.

- an alsolute monarchy e tablished by Hurold Haarfager in, 90.

- , causes of the mild climate of the coast of, 121. , condition of the soil, and of the cultivators of it, 121-123.

- , constitution of, and education of the peuple, 121.

- population of, 121.

-

-, Dontheim and its industry, 124.

- birds of the coast of, $124,125$.

- the herring and cod fisheries of, 125-128.

Nova Zembla, investigations of the shores of, 147.

- circumnavigatcd by Pachtussow, 147, 148.

- meteorological olsservations of Ziwolka, 150.

$\longrightarrow$, the clima e of, 151.

__, Von Buer's scientific journey, 151.

- scientific results of his journey, 152, 153.

—, vegetation of, 153.

$\ldots$, solitude and silence of, 154 .

_, rarity of inse ts in, 1.4 .

- lemmings and foxes of, 154 .

_ birds of, 154 .

- other animals of, $154,155$.

- wintering of the Dutch under Barentz at, 340.

Novgorod, the Great, subdued by the Czar Ivan I., 191.

Nowodsikoff, Michael, his discoveries, 201.

Nudibranchiata, enormous numbers of, in the Polar seas, 59 .

Nullipores on the coast of Greenland, 59.

Nun, or Jilibeambaertje, the Supreme Being of the Samo:edes, 179.

\section{O.}

Obdorsk, Castrén's visit to, 174 .

- description of the town, 188.

_. the fair at, 189.

Obi river, importance of, 17.

_- barren grounds near the, 22.

_ its importance to the Osiaks, 185.

_. Castrén's journey to the, 174.

- misery caused by the overflow of the, $\mathbf{1 7 5}$.

- - inhabitants of the banks of the, 175 .

Ochota river, the, 246.

Ochotsk, sea of, reacked by a party of Cossacks, 195.

- description of the town, 246.

Olaf Truggeson, King of Norway, sends a missionary to Iceland, 93,94 .

Olginsk, gold mine of, 218 .

Olonez, number of bears kill $d$ for their skins every year in, 212.

Ommaney, Captain, his search for Franklin, 357.

- his discovery of Frankliu's first winter-quarters, 357.

Onkilon, or sedentary 'Tchuktchi, 267.

$\longrightarrow$, their mode of life, 267. 95 .

, eruptions of, since the colonization of Iceland,

Orange Island, visited by Burentz, 339.

Ore. See Grampus.

Osborne, Captain Sherard, his opinion as to the method of reaching the North Pole, 374.

Ostiaks, their fishing-grounds on the Obi, 175.

- their summer huts and mode of life, 185, 186.

- , th ir poverty, 186.

$\ldots$, their winter huts, 186.

- , th ir attachment to their ancient customs, $186,187$.

—_, their clans, and princes, or chieftains, 187.

-

, their personal appearance, and customs, 188.

, annual tribute levied by Yermak, the rolber, on them, 194.

- confirmed by the Czar in the possession of their lands, 199.

Ostrich, Darwin's, of Patagonia, 420

Ostrownoje, town and fair of, $\Sigma 63-265$.

Otter, the sea-, or kalan (Enliydris lutris), value of the fur of the, 211,212 .

-_, deseription of, 211.

_ chase of the, in Kamchatka, 258.

- hunting of the Aleuts, 273.

Otter, the fish-(Lutra Canudensis), 317.

- , fur of the, 317.

Owl, its favorite food, 43.

- , its winter in the highest latitudes, 43.

$\mathrm{Ox}$, the, in Iceland, 80.

Oyster, most northerly limit where found, 126.

\section{P.}

PAchtussow, his circumnavigation of the southern island of Nova Zembla, 148.

- his second voyage and death, 149, 150.

Pack-ice, 46.

, its tendency to separate in calm weather, 54 .

Parkoff, his discovery of the Fox Islands, 201.

Parrots of Patagonia, 420.

Parry, Lieut. W. E. (afterwards Admiral Sir), his Arctic voyages, 344 .

— his second voyage, 348 .

- his third voyage, 349 .

—, abandonment of the "Fury," 349.

- his boat and sledge journey towards the Pole, 350 .

- his subsequent career, 351 .

Parry, Mount, discovery of, 369.

- Dr. Hayes's journey to, 373, 374 .

- Mountains, discovery of the, 403 .

P.isina river, scanty population of the, 220.

Patagonia, Captain Fitzroy's survey of, 415.

$\longrightarrow$, the people of, 417, 420 .

, difference of climate between the east and west, 417 .

- aridity of the east of, 417,418 .

$\longrightarrow$ large rivers of, 418 .

_ animals of, 418,419 .

- introduction of the horse, 424.

_ fashions of the Patagonians, 421.

, their religious ideas, 421 .

, their superstitions and astronomical knowl-

edge, 422 .

- , their division into tribes, 422.

- their huts, 422 .

—, their trading routes, 423 . 
Patagonians, their system of government, and great Razor-bill, its nests on the most nort..e:n rocks, 67 . eacique, 423.

, their arms, amusements, and character, 424.

Paul, St., climate of the island, 271.

, chase of the sea-bear on the, 313 .

Paul the First, discovery of the Island of, 27 t.

Pekan, or woodshock (.Mart, s Canadensis), fur of the, 316.

Penas, gulf of, glacier at the, 394 .

Penguin, the, of the Antarctic seas, 395.

- its food, 397.

Penny, Master, his search for Franklin, 357, 358.

Peruvian current, influence of the, 394.

Petermann, Dr. Augustus, his view of the route to the Pole, 374 .

Petrel, the giant (Proceliaria gigantea), of the Antarctic seas, 394.

Petroparlosk, its population, 257.

- unsuccessful attack of the English and French o11, 256.

Petschora river, 149.

Philip's hay, 409.

Phipps, Captain (afterwards Lord Mulgrave), his voyage to discover the north-west passage, 314 .

Pipit (Anthus pratensis), the, of Iceland, 81.

Plachina, Castrén's residence and study at, 176.

Plover island, discovery of, 360 .

P'lovers of Iceland, 81.

Poland, the elk of, 39, 40.

Pole, North, probable condition of the land (if any) at the, 27.

Popow, Fedor, his discovery of the gold fields of Eastern Siberia, 214.

Population of Norway, 122.

Po:ato, cultivation of, in Norway, 124.

Pribilow Islands, climate of, $2-1$.

- sea-lions and guillemots of, 271.

- chase of the sea-bear, 274.

Prontschischtschew, his fruitless endeavors to double the capes of Taimurland, 200.

$\longrightarrow$, death of him and his wife, 20.

Prussia, East, the elk of, 39, 40.

Ptarmigan (Lagnpus albus), its residence in the highest latitudes in winter, 43. of Spitzbergen, 137.

_ in the Tundra in summer, 19.

Pteropods, food for the Greenland whale, 60 .

Puffins of Lovumnen island, 125.

- mode of catching them, 125.

Punta Arenas, colony of Germans at, 416.

Pustosersk, visit of Castrén to, 171, 173.

Pym, Lieut., his sledge journey of search for Franklin, 360.

R.

RACOon (Procyon lotor), 315, 378.

$\longrightarrow$ value and trade in the skins of the, 316.

Rae, Dr., his search for Sir John Richardson, 35\%.

- his discoveries in the Arctic seas, 357.

- his discovery of the fate of Franklin and his crew, 362.

Raipass, copper mines at, 128.

Ranunculus, snow (Ranuncu'us nivalis), of Nova Zembla, 153.

Rat, musk-. See Musquash.

Ravens of Iceland, 84.

- , in Scandinavian mythology, $81,85$.

Red-knife Indians, their hunting-grounds, 327.

Red-pole, the, of spitzbergen, 137.

Red river colony, destruction of the, 308 .

Red sharks of Iceland, 81.

Reindeer, its summer and winter quariers in the Arctic regions, 19.

—, food found by the, in Spitzbergen, 27.

- its importance to man in the northern regions,

31.

- its formation and adaptation to the circuis.

stances in which it is placed, 34 .

_ clattering sound of its feet, 34 .

, its antlers, 34.

- its young, 35 .

, its milk, 36 .

-, its foorl and olfactory powers, 36.

-

, its geographical range in the Old and New

World, 36 .

- its love of a cold climate, 36 .

- its services to man, 37.

, its enemies, and disorders to which it is lia-

ble, 37,38 .

$\longrightarrow$, a nuisance in Iceland, 81.

of Spitzbergen, 137 .

the, pens of the Lapps, 160.

milking the, 160 .

, the, sledges of the Lapps, 161.

162 .

- , ravages of wolves in herds of, 164.

- rich Lapp owners of herds of, 164 .

- Lapp mode of killing the, $\mathbf{1 6 4 .}$

- , its two annual migrations, 2:7.

- hunts of the Jukahires of the Aniuj, 237, 238.

races of the Tchuktchi, 266.

- hunting of the Esquimaux, 295.

. the Kutchin Indian mode of pounding the, 333.

- chase of the, in Greenland, 388.

Rensselaer bay, temperature of, in mid-winter, 19, 20.

- Kane's winters at, 365, 269 .

Resanow, Jakin, his gold-fields, 214.

"Rescue," wreck of the, 440.

Reykjahlid, boiling mud-caldrons of, 70 .

Reykjavik, mean annual temperature of, 78 .

- , the present capital of Iceland, 91 .

$\longrightarrow$, account of, 99, 100 .

--, the annual fair of, 100.

- , salary of the bishop of, 106 .

$\longrightarrow$, schools and library of, 108, 109.

-

Rhinoceros remains found on the coast of $Y$ ern Siberia, 203.

Richardson, Dr. (afterwards Sir John), his Aretic land voyages, 346,349 .

, his search for Sir John Franklin, 356.

Rivers discharging their waters into the Polar ocean, 17. of Iceland, 78 .

Rocky Mountains, the wild sheep of the, 41 .

Roebuck, near Lake Baikal, 40.

Rorquals, or fin-whales, habitat and size of the, 60 .

, their food, 60 .

Rosmysslow, his investigations of the shores of Nova Zembla, 147.

, superstitions of the Icelanders respecting the, 85.

Ross, Capt. (afterwards Sir John), Aretic voyages of, $3 \pm 4$. 
Ross, Sir John, his second journey, 351 .

- , his five years in the Arctic Ocean, 351-354.

_. his return home and honors, 354 .

_- Sir James, his Arctic voyages, 351.

_ his search for Franklin, 3507 .

- his discoveries in the Antaretic Ocean, 402.

_ collision between his ships, the "Erebus" and "Terror," 405, 406.

- his danger between two icebergs, 406.

Rum, effects of, on an Iceland clergyman, 101.

Rupert's Land, held by the Hudson's Bay Company, 310.

Russia, character of the coniferæ of, 23,24 .

, the elk of the woods of the northern parts of, 40.

, conquest of, by the Tartars under Baaty

Khan, 191.

191.

-

- $\longrightarrow$ annexes the country of the Amoor, 196.

-, condition of the natives under the yoke of,

197, 198.

-

213.

- life and dwellings in Nishne-Kolymsk, 236.

- first treaty of commerce between England and, 336.

- Company, patent granted to the, to fish off Greenland, 138.

Russian Fur Company, account of the, and its trade, 272.

S.

Sabine, Mount, discovery of, 402.

Sable, value of the, to the Cossack conquerors of Siberia, 195.

- importance and beauty of the fur of the, 209 .

- hunting, 210.

Sabrina Land, discovery of, 401, 402 .

Sagamen, or historians, of Iceland, 94.

Sajan Mountains, Castrén's journey over the, 177.

Salmon, Alpine (Salmo alpinus), immense numbers of, in Nova Zembla, 155.

Salmon, shoals of, in the rivers of the Arctic regions, 19.

- abundance of, in Iceland, 87.

-

_., abundance of, in Kamchatka, 255.

Samoiedes, European, Castrén's juurney among the, 170.

— their drunkenness, 171.

_

, their barbarism, 179.

, their Supreme Being, Num, or Jilibeamlaertje, 179.

- their recourse to incantations, 180 .

, their idols, 180, 181.

—

—, their mode of taking an oath, 182.

- their personal appearance and habits, 182.

$\ldots$, their wealth in reindeer, 183, 184.

_- their entire number in Europe and Asia, 184.

- their traditions of ancient heroes, 184.

- , confirmed by the Czar in their possessions, 199.

- the companions of Von Middendorff on his journey, 221, 225.

Sämund Frode, his Icelandic works, 94.
Sand-bee (.Andrena) of Nova Zembla, 154

Sand-reed bread used in Iceland, 79.

Sarmiento, Pedro, his voyage, 414.

Sawina river, 148.

Saxifragas, the, of the treeless zone, 20.

Scalds, or vards, of Iceland, 94 .

Scandinavia, character of the coniferæ of, 22.

Schalaurow, his journeys on the coast of Siberia, 201.

Scharostin, his residence at Spitzbergen, 142.

Schelagskoi, Cape, rounded by Count Michael Staduchin, 197.

_, reached by Schalaurow, 201.

Scoresby, Dr., his visit to Spitzberger, 132.

- Captain, his near approach to the North Pule, 344.

- , his voyage to Greenland, 385, 386 .

Scotia, Nova, discovered and coloniz d by Greenlanders, 335.

Scurvy in Spitzbergen, 140-142

—, preservative against, 141.

_. Lapp mode of preventing the, 166.

Sea, influence of the, on the severity of the Arctic winter, 27.

Sea, Antarctic, compared with the Aretic regions, 391.

- absence of vegetation in the, 391 . , causes of the inferiority of the Antaretic climate, 391,392

_, immensity of the icebergs of the, 392.

- the Peruvian current, 394.

, birds of the coasts, 394 .

- cetaceans, 397-399.

—, Austral fishes, 400.

- voyages of discovery, 401.

- storms and pack-ice, 404 et seq.

Seas, Arctic, dangers peculiar to the, 45 .

- floating masses of ice, 45,46 .

—, ice-blink, 54.

_

, clearness of the atmosphere and apparent nearness of objects, 55 .

$\longrightarrow$, phenomena of reflection and refraction of the atmosphere, 55 .

- - causes which prevent the accumulation of Polar ice, 55-57.

, the animals of the, $40,43,44,59$.

, Russian discoveries off the Siberian coast, 201 et seq.

_- Von Middendorff's journey down the Taimur river to the Polar sea, 221 .

, Wrangell's nights on the Polar sea, 239.

- his observations on the Polar sea, 240:

, Matiuschkin's sledge journey, 241.

, voyages of the English and Dutch, 335 et seq.

Sea-bear of Bering's sea, 62 .

Sea-eagles of the coast of Norway, 125.

Sea-elephant of the Antarctic Ocean, 398, 399.

Sea-gulls of the coast of Norway, 124, 125 .

Sea-lion of Bering sea, 62 . of the Pribilow Islands, 271.

Seal-fishing at Spitzbergen, 142. of Nova Zembla, 155.

_ hunts of the Esquimaux. 295, 296 . - catching at New fousdland, 381.

- hunting on the coasts of Greenland, 384; 446.

Seals, the, of the Polar seas, 62 .

- their uses to man, 62, 446.

- the Antarctic. 399, 400.

_- their igloos, 449. 
Sea-otter, value of the skin and former numbers of the, 201, 202.

Sedger river, romantic scenery of the, 410 .

Semple, Governor, murder of, 303.

Sertularians on the coasts of Greenland, 59 .

$\mathrm{S}$ rvice-trees in the Arctic regions, 24.

Shark, basking, on the northern coasts of Iceland, 87.

- its uses to the islanders, 87.

- oil manufactured from its liver, 87.

_- , the northern (Scymnus micrucephalus), abundance of, off Spitzbergen, 137.

- , fishery of, on the coast of Greenland, 387.

Sheep, wild (Uis montana), of the Rocky Mountains, d-scription of the, 41 .

- the, of Iceland, and their enemies, 80. mode of sheep-shearing, 80 .

Shetland Islands, New, account of the, 392, 393.

Shrimps off Spitzbergen, 133.

Siberia, extent of the treeless zone of, 22 .

- character of the coniferæ of, 23,24 .

_

- the roebuck and red deer of, 40 .

_ t the argali, or wild sheep of, 41 .

_-, the white dolphin in the rivers of, 61 .

—

sians, 193, 194.

- final conquest of, by the Russians, and foun-

dation of Tobolsk, 195 et seq.

- condition of the natives of, under the dominion

of Russia, 197, 198.

-

- its past ages, 203.

- its extent and capabilities, 204.

- the exiles sent there, 204-206.

-, their condition there, 206.

- condition of the West Siberian peasants, 207, 208.

- resources of the country, 208.

-

__ fur-bearing animals, 209 et seq.

, the gold-fields of Eastern, and the miners, 214 216.

- value of the produce of some of the mines,

$217,218$.

- entire value of the produce of gold in 1856

and 1860, 218.

- luxury and extravagance caused by the

wealthy gold speculators, $218,219$.

- the gold of the Ural. 219.

$\longrightarrow$, New, lemmings of, 27.

_ discovery of the islands of, 201, 202.

_ fossil ivory of, 202.

Sibir, the capital of the Tartars in Siberia, 192.

194.

Simpson, Mr. Thomas, his Arctic land voyage, 355 .

- his discoveries, 356 .

- assassinated, 356 .

Sirowatsky, his discovery of the Archipelago of New Siberia, 203.

Skalholt, the ancient capital of Iceland, account of, 98.

- its present condition, 99.

_. its meadow lands and scenery, 99.

Skaptar jökul, 69

- , the great eruption of, in 1783,95 .

Skates of Lapps, 161.

Skeidara, Mr. Holland's journev across the, 111, 112.

Skjalfandafljot river in Iceland, 78.

Skogslappar, or Forest Lilpps, account of the, 166.
Sledges of the Lapps, 161.

__ , the sacred sledge, Hahengau, of the Samoïedes, 180.

Smith's Sound, temperature of, 27.

- icebergs formed in, 48 .

- discovery of the entrance to, 343,365 .

"Smoke, valley of," in Ieeland, 70.

Snorri Sturleson, the Herodotus of the North, account of him and his "Heimskringla," 94, 95.

Snow-buntings of the "barren grounds," 18.

Snow, its protection of the vegetation of the Arctic regions, 19.

, warmth caused by, 19.

, no land yet found covered to the water's edge with eternal snow, 27.

- amount of the fall of, in Taimurland, 225, 226.

_ probable diminution of the fall of, advancing towards the pole, 226 .

- its protection against cold, 226.

Socialism among the Dog-rib Indians, 329.

Solfataras of Iceland and Sicily compared, 88.

Solovetskoi, convent of, 180.

Sorcery of the Laplanders, 158.

$\longrightarrow$, of the Samoiedes, 180 .

Spain, salted cod-fish imported into, 129.

Spasy, produce of the gold mine of. 218.

Spirits, invisible, of the Samo:ed «s, 180, 181.

Spitzbergen, flowers of, 20.

-

_

—_. proofs of a former milder climate in, 29, 30.

- birds of, 43,44 .

, apparent nearness of objects at, in clear weather, 54

- , the walrus of the coast of, 64 .

-

, the west coast, 132.

, Scoresby's ascent of a mountain, and excursion along the coast, $132,133$.

__, Magdalena bay, 133-136.

- ice-cliffs and avalanches of ice, 135.

-

- flora and fauna of, 136, 137.

—_ fisheries of, 139.

- coal and drift-wood of, 137, 138.

- history of, 138.

—

_- Russian hunters' mode of wintering at, 142.

- walrus and seal-fishing at, 142.

- discovery of, 340 .

Spout, the, of Newfoundland, 376.

Springs, hot, of Icelaud, 70 .

$\longrightarrow$, the Geysir, 71.

—, the Strokkr, 72.

Spruce fir of the Hudson's Bay territory, 24.

Squirrel, value of the fur of the, 212.

Stadolski Island, visit of Pachtussow to, 148.

Staduchin, Count Michael, his foundation of the town of Nishnei-Kolymsk, 196, 197.

navigates the sea eastward of Cape Schelag skoi, 197.

Stawinen river, 148.

Steller, G. W., notice of him, 248.

, his scientific journey to Kamchatka, 248.

- ill-treated by Bering, 250.

_ his sufferings on Bering's Island, 251.

- - death of his commander, B ring, 252.

- his return to Kamchatka, 252.

- - persecuted by the Siverian authoritics, 253 bis death, 2.3 .3

Stockfish of Iceland, 87. 
Storms on the White Sea, 169. of the Tundras, $172,173$. of the Arctic zone, 225, 226. off Newfomiland, $\vdots 81$. in the Antarctic ocean, 404, 405.

the williwaws, or hurricane squalls, of the Strait of Magellan, 412.

Strogonoff, foundation of the Russian family of, 192, 193.

Strokkr, description of the, 72 .

Strongbow Indians of the Rocky Mountains, the, 327.

Sukkertoppen, seen by Davis, 337.

Sulphur of Iceland, 88.

$\longrightarrow$, compared with that of Sicily, 88.

Summer, the perpetual daylight of, 86 .

fogs of, 54 .

- in Taimurland, 225.

Sun, the midnight, effect of, on icebergs, 50-52.

Sunset, magnificence of a, 32 .

Surgut, Castrén's visit to, 175 .

Surts-hellir, or caves of Surtur, description of, 77 .

Suslik, the, of Siberia, 212.

- value of its fur, 212.

Svatoinoss, Cape, fossil ivory at. 202.

Sviatoi-noss, doubled by the Russians, 200.

Swans of Iceland, 8 !, 84 .

\section{T.}

'TABIN, the imaginary Cape, of the Dutch navigators, 339.

Tadibes, or sorcerers of the Samoïedes, 180.

- their dress and incantations, 180.

Tagilsk, Nishne, the gold-producing town of, 219 .

Taiga, melancholy character of the, 230 . , gold-fields of the, 213.

Taimur Lake, visited by Lieut. Laptew, 20 .

- storm on the, 223.

Taimur river, visited by Lieut. Laptew, 200.

— Von Middendorff's journey to the, 221-223.

Taimurland, endeavors of Prontschischtschew to double the capes of, 200

_- Middendorff's adventures in, 220, 221.

- his observations on the climate and natural productions of, 225 .

- amount of the fall of snow in, 225, 226.

Tana river, discovery of the, by Jelissei Busa, 195.

Tarn Mount, Darwin's ascent of, 411.

Tartars, their subjection of the Russians, 191.

— driven out by Ivan I., 191.

- permanently overthrown by Ivan II., 19ף.

Tattooing, Cree Indian mode of, 323.

Tchendoma, the, visited by Jelissei Busa, 195.

Tchuktchi, barren grounds in the land of the, 21, 22.

- the land of the. 262.

pipes of, 264.

, their short summer, 262.

263 .

— ladies, Matiuschkin's visit to $\mathrm{s} \sim \mathrm{me}, 265$.

-

-

- their mode of life, 267.

- population of the land of the, 267.

Tea-parties at Nishne-Kolymsk, 238.

Temperature of Rensselaer bay in mid-winter, 19, 20.

- , effect of the sea on, of the Arctic regious, 27.
Temperature, influence of the winds on, 27.

_- former milder, of the Arctic regions, 29.

, probable causes of the changes in the Arctic climate, 29.

- the lowest ever felt by man, 28.

, how man is enabled to bear extraordinary low, 28. of Iceland at different places, 78 .

Tennysou's Monument, Dr. Kane's description of$36 \overline{7}$.

Terror, Mount, 403.

Terski Lapps, Castrén's attempted journey to the, 170.

Thangbrand, Christian missionary to Iceland, 93. 94.

Thingvalla, plain of, 76 .

- , site of the ancient Icelandic Althing at, 91, 92.

- , pastor of, 104.

-

Thingvalla Lake, in Iceland, 92.

Thiorsa river, in Iceland, 78.

Thorlakson, Jon, the poet of Iceland, account of him and his works, 107.

Thorne, Robert, his suggestion for sailing across the "North Pole, 342.

Thorwald the traveller, the first Christian Icclancier, his career, $92,93$.

Tides, effect of the, in preventing the accumulation of Polar ice, 57.

Tinné Indians, defeated by the Crees, 319. , their retaliation, 320 .

- their wars with the Blackfeet, 320 .

, their wigwams. or tents, 324 .

_- various tribes of the, and their range, 327.

- their appearance, manners, and customs, 327329.

_- improvements in their condition, 329, 330.

- their wives and children, 330.

_ their cruelty to the agred, 330 .

Tjumen, the first settlement of Russians in Siberia, 195.

- Steller's grave at, 253.

Tobacco, fondness of the Lapps for, $165,167$.

_ 264.

Tobolsk, battle of, 193, 195 .

- , foundation of the city of, 195.

- condition of the southern part, $207,208$.

Tolstoi Ness, Castrén's visit to, 177 .

Tolstych, Adrian, his discoveries, 201.

Tomsk, criminals of, 206. 207.

Tornea, reindeer gloves of, 37.

Tonsteinson Jon, the martyr of the Westman Islands, 118.

Tookoolito, 442, 466, 758, 759, 761.

Train-oil of Tromsö, 128.

Transbaikalia, Castrén's visit to, 177.

Travelling in Iceland, 110, 111.

Treeless zone of Europe, Asia, and America, 18-22.

Treurenberg bay, deer of, $13 \pi$.

Trölladyngja, eruptions of, since the colonization of Iceland, 9 ก.

Tronsö, cod-fishery and cod-liver oil of, 128.

- description of the town and island, 128.

Tschirigow, his voyages, 201.

Tucutuco (Ctenomys Magellanica), the, of Patagonia, 419.

Tundri, or barren grounds of the Arctic regions, 18, 19. 
Tundri, storms of the Tundras, 172.

Tung-ower, or hot spring at Reikholt, in Iceland, 70.

Tungusi, the, their relationship to the Mantchou, 244.

, their conquests and final subjugation by the Russians, 244.

—, their intellectual development, 244.

-

_. their wretchedness, 244.

_ their manners and customs, 245.

Tunguska river, gold-fields of the Upper, 214.

Turkey-buzzard, the, of Patagonia, 419.

Turuchansk, Castren's visits to, 176, 177.

Tyudall glacier, enormous size of, 50 .

U.

UfFLIOT the Wise, his first code of laws in Iceland, 91.

Unalaschka, climate of, 269.

- vegretation of, $269,270$.

, people of, 273.

Union, Cape, Dr. Hayes's sledge vovage to, 373,374 .

United States, right of, to fish on the banks of Newfoundland, 379 .

Ural Mountains, Castrén's passage of the, 174 .

- first discovery of gold in the, 214.

, quantity of gold found in the, 219.

Ustsỵlmsk, Castrén's visit to, and ill-treatment at, $173,174$.

Utzjoki, the pastor of, 169.

Uasa river, Castrén's journey up the, 174 .

V.

VAAGE, cod-fishery of, 126

- ancient importance of, 126.

Vancouver's Island, placed under the management of the Hudson's Bay Company, 310.

Vapor baihs of the Cree Indians, 324 .

Väre, the, of Norway, 124.

Vegetation, protection afforded by snow to, 19.

- distinctive characters of the Arctic forests, 22-24.

- of the "barren grounds," 18, 21, 22.

- length of time necessary for the formation of even small stems of trees in the Arctic recrions, 25.

- harmless character of the Arctic plants, 25.

, no land yet discovered in which it is entirely

subdued by winter, 27 .

29.

, former, of the northern regions of the globe,

of Spitzbergen, 136.

of Nova Zembla, 152 .

of Taimurland, 226.

of Kamchatka, 254.

of the Bay of Awatscha, 256.

of the Pribilow Islands, 271.

of Newfoundland, 376 .

of Greenland, 388 .

, absence of, in the Anta:ctic regions, 391 .

of Port Famine, 410.

Verchnei Ostrog, in Kamchatka, built, 198.

Verazzani, his vovacres, 335 .

Vestfjord, cod-fishery of the, 126.

Victoria Land, discovery of, 402.

Videy, eider-ducks of, 81,82 .
Vigr, eider-ducks of, 83.

, Mr. Shepherd's visit to, 83,84 .

Vikings, their courage and discoveries, 89.

Virgins, Cape, 409.

Vogelsang, deer of, 137.

Vol anic eruptions in Iceland since its colonization, 95.

Volcanoes giving lirth to Iceland, 68.

-

—, the Esk, on Jan Meyen, 146.

- of Kamchatka, 256.

- eruption of Mount Erebus, 403.

Vole, field (Arvicola aconomus), indigenous to Ice. land, 80.

Voyageur, the, of North America, 304.

$\longrightarrow$, his life and character, 304, 305.

\section{W.}

WALRus, or morse (Trichechus rosmarus), descrip. tion of the, $62-64$.

- its affectionate temper, 64 .

- its parental love, 64 .

, its chief resorts and food, 64

fishing at Spitzbergen, 144.

hunted on Bear Island, 144

of Nova Zembla, 155

hunting on the coast of Aliaska, 275 .

, pieces of skin of, a medium of $\epsilon$ xchange, 276.

, Esquimaux mode of hunting it, 298.

Washington Land, discovery of, 369.

, Dr. Haves's journey to, 573 .

Wassiljew, his visit to the Lena, 195 .

Wargatz, island of, the sacred island of the Samo:edes, 180.

Weasel, the Siberian (Viverra Siberic 1 ), the fur of, 211.

Weddell, Captain, his Antarctic voyages, 401.

Welden, his visit to Bear Island, 144.

Wellington Channel, temperature of, 28 .

- , discovery of, 345 .

Wenjamin, the Archimandrie, 170.

Western, Thomas, preaches Christianity to the Lapps, 156.

Westman Islands, description of the, 114.

- difficulity of access of the, 114.

- how they became colonized, 115 .

- Heimaey, or Home Island, 116.

- food and trade of the pecple, 117 .

- population and mortality of the children, 118.

_ their sufferings from pirates, 118, 119.

Weymouth, his voyage to Hudson's Bay, 341

Whale, the Greenland (Baloena mysticetus), or smooth-back, 60 .

— off Nova Zembla, 155.

- the white, or beluga, 61 .

—, the "ca'ing," 62 .

_, a stranded, at Spitzbergen, 133.

$\longrightarrow$, the fin-back, 59,60 .

- of Spitzbergen, 137.

off Nova Zembla, 155.

_- smooth-backed, of the Antarctic seas, 397. , sperm, of the Antarctic Ocean, 398.

Whalers, their dangers, in th Arctic seas, 48.

- depressing effect of the summer fogs, 54 .

$\longrightarrow$, their operations in the Polar seas, 59.

- whale chases of the Aleuts, 275.

- , whale-hunts of the Esquiniaux, 295

- abundance of whales in the Antaretic seas. 397

- $\longrightarrow$ battle between a whale and a grampus, 398. 
Whale Sound, enormous glaciers of, 50 .

White-fish, or Coregonus, of North America, $310,311$.

White Sea, Castrén's journey to the, 170 .

- Chancellor's discovery of the passage from England to the, 192.

- , an English expedition in the, 336.

Whymper, Frederick, travels in Alaska, 277289.

Wilkes, Captain, his discoveries in the Antaretic Ucean, 402.

Wilkes's Land, discovery of, 402.

Williwaws of the Strait of Magellan, 412.

Willoughby, Sir Hugh, his voyage and death, 336.

Willow, polar (Salix polaris), of Nova Zembla, 153.

- dwarf, of the treeless zone, 21.

- dwarf, on the shores of the rivers and lakes, 24.

Wind-hole Strait of the Dutch navigators, 339.

Winds, effects of the cold sea-winds on vegetation, 22 .

- influence of the, on an Arctic climate, 27.

Winter Harbor, Parry's winter in, 345.

Winteria Aromatica, the, 410.

Witcheraft and witches of the Laplanders, 158.

Wolf, its attack of the reindeer, 37, 38.

- Lapp mode of hunting the, 164.

, in Newfoundland, 378 .

Wolverine. (See Glutton.)

- fur of the, 316 .

Wood, length of time necessary for the formation of, in the Arctic regions, 25.

Woman, dying, abandoned, 462.
Wrangell, Lieut. von, his services as an Arctie explorer, 233.

- his journey to the shores of the Polar sea, 234.

- , his winters at Koly msk, 238.

_ - his night on the Yolar sea, 239.

, his danger, and return to St. Petersburg, 241-243.

Wrestling for a wife among the Tinné Indians, 330 ; and among the Kutchin Indians, 332.

$\mathbf{Y}$

YeNISEI river, importance of, 17.

Yermak Timodajeff, the Cossack robber, 192. , his conquest of Siberia and death, 194

- his monument in Tobolsk, 194, 195.

York roads, beauty of, 412 .

Yukon river, $278-289$.

, ice in, 283.

Yukon, fort, 284.

\section{Z.}

Zembla, Nova, vast ice-fields of, 27.

- mean temperature of, in suinmer and winter, 27.

- the narwhal of the seas of, 60 .

, the walruses of the coasts of, 64 .

Zinzendorf, Count, his interest in Greenland, 384.

Ziwolka, the Russian steersman, his voyages, $149,150$.

$\longrightarrow$, his meteorological observations, 150 .

\section{THE TROPICAL WORLD.}

A.

Aranese. (See Spiders.)

Aard-vark, or earth-hog, 608.

Abyssinia, elephant-hunting in, 717.

Acacias, 537.

Adjutant bird, 625, 657 .

Africa, Savannas of, 503 ; hunting in, 504 ; lake region of, 506 ; insects of, 588,598 ; serpents of. 627 ; monkeys of, 677 ; lions of, 700 ; elephants of, 715 ; rhinoceroses of, 721 ; hippopotamus of, 725 ; camel of, 729 ; giruffe of, 731 ; zebras and quaggas of, 733 .

Alligators, of the old and new world, 635 ; their prey, 635 ; size of, 636 ; crane caught by, 637 ; men caught by, 638 ; tenacity of Jife, 638 ; their young, 639; their enemies, 639 ; torpidity in the dry season, 500, 639; feign death, 640 ; fights with the orangoutang, 683 .

Agassiz Louis : His collection of fishes, 520 ; account of natives of the Amazon, 521,522 ; estimate of the productions of $\Lambda$ mazonia,
524 ; description of Brazilian coffee-plantations, 564 ; of the coffee-moth, 566.

Agave-plant, the, 533 .

Alpaca, the, 483 .

Altos of Peru. (See Puna.)

Aluates, or howling monkeys, 690 .

Amache, ant, 597.

Amazon, River and Valley of, 517 ; extent of, 518 ; lagoons, 518 ; inundations, 519 ; vegetation of, 519 ; fishes of, 520 ; animal life of, 520 ; natives of, 521 ; siesta on, 554 ; alligators in, 636 ; turtles of, 641 .

Amphisbænas, 521

Anaconda, or water-boa, 620

Andersson, John, Notes of, 504, 665, 667, 700, 701, 704, 724, 732, 735 .

Andes, the ascent of, 490 .

Animal life, general survey of, in different zones, $5 \times 1$.

Animals : Alpaca, 483; boars, 735 ; babirusa, 736 ; camel, 728 ; dromedary, 750 ; elephants, 712; giraffes, 731; hippopotamus, 725 ; huanacu. 433 ; jaguar, 710 ; leopard, 708 ; lion, 
698; puma, 710. quagga, 733 ; rhinoceros, $7 \cdot 21$; sloth, 673 ; tiger, 705 ; vicuna, 483 ; wild-cats, 711 ; zebras, 733 .

Anomaluri, the, 673 .

Ant-bears, 606 ; ant-bear and jaguar, 607.

Ant-hills, 602 .

Ants: Their numbers, 594; pain of their bite, 595 ; destructive of plants, 596 ; household pests, 597 ; the bashikouay, 598; housebuilding ants, 599; slave-holding ants, 600 .

Apes. (See Monkeys.)

Aphides, or plant-lice, furnish honey for ants, 600.

Arabia, coffee culture in, 565 .

Arabs, mode of hunting the lion, 702.

Aras, or macaws, 662 .

Argala, or adjutant-bird, 625, 657 .

Armadillos, 609; extinct species, 610.

Arrow-root, the, 555.

Aru, how natives of, shoot birds of paradise, 654.

Atacama, Peruvian Desert, 508.

Ateles, or spider-monkeys, 690 .

Atlas, Mount, Lion-hunting in, 700 .

Atmosphere, the : currents of, 475.

Atolls, or coral islands, 478 .

Atta cephalotes, ant destructive of the banana, 596.

Australia, coral reef of, 479 ; desert of, 508 ; birds of, 655 ; bower-bird of, 656 ; the talegalla, 656 ; the emu of, 668 .

\section{B.}

BABIRUSA, the 736 .

Baboons. (See Monkeys.)

Bacha, or African falcon, the, 697.

Bamboos, uses of, 532 .

Banana, and plantain, 551.

Banyan, or Indian fig-tree, 529.

Baobab, the giant tree, 527; Mrs. Livingstone's grave under, 528 .

Barth, Henry, Notes of, 504, 510, 715.

Bashikouay ant, the, 598 .

Basilisk, the, 632 .

Bat, the, 669 ; character and habits, 670 ; the kalong, 670; eaten in Java, 670 ; the vampire, 671 ; horse-shoe bats, 672 ; small bat of Ceylon, 672 .

Beetles, abundance of in the tropical world, 581 ; used for ornament, 592.

Behemoth; is he the hippopotamus or the buf falo? 725.

Bell-bird, or campanero, 647.

Bête-rouge, the, 587 .

Birds : the condor, $480,498,693$; the asfir, 509 ; the ostrich, 512,663 ; the secretary, 624 ; the adjutant, 625 ; general view of birdlife, 645 ; the toucan, 646 ; the hummingbird, 647 ; cotingas, 647 ; the campanero, 647 ; manakins, 648 ; cock of the rock, 648 ; troopials, 648 ; orioles, 649 ; cassiques, 649 ; the mocking-hird, 649 ; the toropishu, 650 ; the tunqui, 650 ; goatsuckers, 650 ; the organ-bird, 650 ; the cilgero, 650 ; the flamingo, 650 ; the ibis, 651 ; the jabiru, 651 ; the jacana, 651; the rhinoceros hornbill, 651 ; sun-birds, 652 ; honey-eaters, 652 ; ocellated turkey, 652 ; the lyre-bird, 653 ; birds of paradise, 653 ; the bower-bird, 656 ; the talegalla, 656; the coppersmith 657 ; the devil-bird, 657; the tailor-bird, 658; the grosbeak, 658; the korwé, 658; weaving birds, 6.9 ; parrots, 659 ; cockatoos, 662 ; macaws, 662 ; paroquets, 663 ; the ostrich, 663 ; rheas, 667 ; the cassowary, 667 ; the emu, 668; the condor, his character and flight, 693 ; mode of capturing, 694 ; the carrion vulture, 695 ; the harpy eagle, 696 ; the sociable vulture, 696 ; the bacha, 697 ; the fishing eagle, 697 ; the sparrow-hawk, 698 ; the secretary eagle, 698 .

Boars, wild, chase of, 735 .

Boas, 620 ; the boa constrictor, 620 ; water boas, 500,620 .

Bogotá, table land of, 495 .

Bolas, the, 502.

Bon, M., his spider-thread stockings, 614 .

Borelo, or black rhinoceros, the, 721 .

Bo-tree, or Pippul, 530.

Bower-bird, the, 656 .

Brazil, Agassiz's estimate of its future, 523; coffee-culture in, 563 ; ants of, 601 ; toads of, 633.

Bread-fruit, 550 .

Bufo.gigas, or great toad of Brazil, 633 .

Buildings of ants, 602 .

Bushropes, or lianas, 515, 585.

Butterflies, 582.

Butterfly, the leaf, 583.

C.

CacaO, or chocolate, 567.

Cactuses, 533.

Camel, the, 728; ships of the land 728; formation of its foot, 729 ; its food, 729 ; its waterpouch, 729 ; its hump, and the uses of it, 729 ; its desert home, 729 ; the camel and its master, 730; training for robbery, 730 ; endurance of thirst, 730 ; distinction between the camel and the dromedary, 730 ; caravan journeys, 73U; changes from servitude, 731; effects upon its temper, 731 ; excuses for its ill-temper, 731.

Cameleorard. (See Giraffe.)

Campanero, or bell-bird, 647 .

Cassava, or Mandioca, 554.

Cassia. (See Cinnamon.)

Cassiques, 649

Cassowary, the, 667 .

Cattle and horses in America, 500.

Caymen. (See Alligators.)

Ceiba-tree, the, 531 .

Cerastes, the, 620 .

Ceylon, Game in, 505; parasitic and thorny plants of, 536 ; Cinnamon culture, 573; ants of, 595 ; sernents of, 616 ; alligators of, 640 ; turtles of, 644 ; birds of, 657 ; monkeys of, 686 ; elephants of, 713 ; taming elephants, 717; Panickeas, or elephant-catchers, 718; their mode of capturing the elephant, 718; elephant establishments of the government, 721.

Chacma, or pig-faced baboon, 687 .

Chaco, the grand, of Paraguay, 502.

Chameleon, the, 630 .

Charming, by serpents, 621 .

Chegoes or jiggers, 585 .

Cheetah, or hunting leopard, the, 708 .

Chelonians, or tortoises, 642.

Chimpanzee, the, 677 . 
Chirimoya, the, $492,556$.

Chocolate, 567.

Church, F. A., his painting of the Heart of the Andes 491.

Cicadæ, the, 592.

Cilgero, the. 650 .

Cinnamon, 571 ; the Dutch monopoly of, 572 ; amount produced, 572 ; historical notices of, 573 ; present consumption of, 574.

Climbers, the, 669 ; the bat, 669 ; the flying squirrel, 673 ; the galeopitheci, 673 ; the anomaluri, 673 ; the sloth, 673 ; monkeys, 676 .

Climbing plants, 535.

Cloves, 574, 576 .

Cobra de Capello, the, 619.

Coca, the leaves of, 568 ; effects of their use, 569 .

Cochineal insect, the, 591.

Cockatoos, 662.

Cock of the rock, 648 .

Cockroaches, 589.

Cocoa, Cacao, and Coca,not to be confounded, 568 .

Cocoa palm, the, 538 .

Coffee, 562; home of the plant, 562; coffee countries, 563, 565; coffee plantations in Brazil, 564; gathering the berries, 565; enemies of the plant, 566 .

Coffee-bug, the, 566 .

Coffee-moth, Mrs. Agassiz's description of, 566 .

Colobi, the 691.

Columbus, and the Gulf-stream, 474 .

Condor, the, 430, 498; his character and flight, 693 ; mode of capturing, 694.

Coppersmith, bird, the, 657.

Coqueros, or coca-chewers, 570.

Coral, reefs and islands, 478, 479

Cordilleras the, 490 .

Cotingas, 647.

Cougar, or puma, the, 711.

Crab, robber, the, 580 .

Crane, caught by alligator, 637 .

Crocodiles. (See Alligators.)

Cubbeer-burr, a famous tree, 529.

Currents of the ocean, 473 ; the equatorial current, 474 ; the Gulf Sitream, 474.

Cynocephali, monkeys, the, 687 .

\section{D.}

DaNCING parties of birds of paradise, 655 .

1)eryas, sacred monkey of Eqypt, the, 688 .

Desplobado, the, $480,482,485$.

Deserts (See also Savannas.) Of Atacama, 508; of Australia, 58 ; the Sahara, 509.

Devil-bird of Ceylon, 657.

Dioscorea or yam-plants, 555 .

Doldrums, or equatorial calm belts, 476 .

Dorey, ants of, 597.

Jouw, or Burchell's zebra, 734.

Dragon trees, 528

Dromedary, the. (See Camel.)

Du Chaillu, Paul: Account of the bashikouay ant, 598; of squirrel charmed by serpent, 624 ; kills large snake, 627 ; kills a gorilla, 678 ; female gorilla and young, 679 ; number of gorillas seen by him, 680 ; whips of hippopotamus-skin, 727 .

Durion, the, 557; favorite food of the orangoutang, 684 .

Dutch, their monopoly of spices, 572, 575 .

Dyaks, of Borneo, 681 ; contest with the orangoutang, 684 .
E.

EAGLE, the harpy, 696; the fishing, 698; the secretary, 698 .

Ecuador, characteristics of, 490 .

Edible insects, 592; edible spiders, 614.

Elevation, its influence upon climate, 480, 485.

Elephant, the, 712; difference between the tamed and wild, 712; timidity of the elephant, 713 ; his power of climbing, 713 ; his water-stomach, 713; his trunk, and its uses, 713 ; his tusks, and their possible uses, 714 ; elephant herds, 504, 714 ; tuskers, 714 ; rogue elephants, 714; distinction between African and Asiatic elephants, 715 ; elephants known to the ancients, 715 ; range of the African elephant, 715 ; how they are hunted by the natives, 716 ; by Europeans, 716 ; in Abyssynia, 716; the Asiatic elephant, 717; their abundance in Ceylon, 717 ; mode of capturing them, 718; behavior of the captured animals, 719 ; great elephant-hunts, 719 ; elephant-corral, 719 ; tied up, 470, 719; tame elephants assisting to capture wild ones, 719 ; decoy elephants, 720; an obstinate brute, 720 ; a little head-work, 720 ; dying of a broken heart, 720 ; the elephant in captivity, 720 ; value of their labor, 720 .

Elliott, Ensign, adventure with a tiger, 707. Emu, the, 667.

Emydæ, or marsh-tortoises, 641.

Enormous snakes, stories of, 627 .

Epiphytic plants, 535.

\section{F.}

Fangs, poison, of serpents, 618 .

Fascination of serpents, 621 .

Fire-ant of Guiana, 595.

Fire-flies, 584.

Fishing eagle, the, 698 .

Flamingo, the, 650 .

Flies, noxious, 587.

Flying frog, Wallace's, 633.

Flying lizards, 632.

Flying squirrels, 673.

Forests of the Tropical World, 514 .

Formica. (See Ants.)

Fox-bat, or kalong, the, 670 .

Franklin, Dr., Account of Indian corn, 549.

Frogs and toads : Gigantic of the Amazon, 520; the pipa, 632; Brazilian tree-frog, 633; Wallace's flying trog, 633; singular toad at Bahia, 633 ; the bufo gigas, 634 .

Fruits and Plants of the Tropical World; the chirimoya, 49.2, 556; the leroshua, 504; the mokuri, the kengwe, the naras, 505; the date, 542 ; the litchi, 556 ; the mangosteen, 557 ; the mango, 557 ; the durion, 557.

G.

GaldGos, semi-monkeys, the, 688 .

Galapagos, or Tortoise Islands, 640 .

Galenpitheci, the, 673.

Gallinazos, or carrion vultures, 695.

Gavials. (see Alligators.)

Ger:koes, the, 629 .

Gibbons, monkeys, the, 685 .

Ginger, 578. 
Giruffe, the, 504; pulled down by lions, 699 ; its aspect, 731 ; its weapons of defence, 732 ; its anatomical structure, 732 ; chase of the giraffe, 732 ; encounters with lions, 699 , 732 ; Aristotle and Buffon on the giraffe, 733; giraffes in Europe and America, 733; analogies between the ostrich and the giraffe, 733 . Glagah grass, the, 546 .

Gnu, the, 734.

God's birds, name for birds of paradise, 653 .

Goliath beetle, the, 582 .

Gorilla, the, 678; Du Chaillu's adventures among, 678; female and young, 679 .

Gourds, esculent, of the kalahari, 505 .

Graminea, or grasses, 532.

Grosbeak, the, 658 .

Guachos of South America, 502.

Gum-lac insect, 592.

H.

HAJE, serpent, the, 620

Harpy eagle, the, 696 .

Hendersoil, A. M., on the fascination of serpents, 621 .

Himalayas, mountains of, 497.

llippopotamus, the, 7.25 ; is it the behemoth of Job? 725 ; its ancient and present habitat, 725 ; its mode of life, 725 ; its unpleasing aspect, 725 ; its inoffensive character, 726 ; the rogue hippopotamus, 726 ; intelligence of the hippopotamus, 726 ; whips of its hide, 727 ; its ivory, 727 ; modes of destroying, 727 ; spearing the hippopotamus, 728 ; the downfall, 728 .

Historical tree, the oldest, 530 .

Hog, the, destructive to the rattlesnake, 619 .

Honey-eaters, 652.

Hornbill, the rhinoceros, 651 .

Horse, the, introduced into America, 500; influence upon the natives, 502 .

House-building ants, 599.

Humming-birds, 647 .

Huanacu, the, 483.

Humboldt, A. Von : Notes of, 498, 517, 525, 552, 601, 638, 691, 694 .

Huniman, the sacred monkey of India, 686.

Hunting, of the vicuna, 484; of the gazelle, $512 ;$ of the ostrich, 512,664 ; of the lion, 700 ; by the cheetah, 708 ; of the rhinoceros, 723 ; of the hippopotamus, 727 ; of the wild boar, 735 .

Hurricanes, velocity of, 477 .

Hyæna, the, 709 ; different species of, 709 .

Hy drosauri, or water-lizards, 632 .

I.

Iris, the, 651 .

Igaripés, or canoe paths of the Amazon, 518.

Iguanas, 631.

Incas of Peru, 486 ; origin of their civilization, 487 ; present aspect of their sacred island, 487; fountain of the Incas, 488 ; their great military roads, 489.

Indians, of Ecuador, 493 ; of southern Africa, 506 ; of the Amazon, 521 ; of the Malay islands, 552 .

Insects, abundance of within the tropics, 581; beetles, 581 ; goliath, 582 ; leaf-butterfly, 582 , mantis or soothsayer, 583; fire-flies, 584 ; mosquitoes, 585; jiggers, 585 ; the bêterouge, 586 ; ticks, 587 ; land-leeches, 587 ; the tsetsé, 587; Isalt-Salya, or zimb, 588; locusts, 588; cockroaches, 589; the silkworm, 59u; the cochineal insect, 591; the gum-lac insect, 592 ; edible insects, 592 ; ornamental insects, 593 ; aphides, or plant-lice, 600. (See also Ants, Termites, and Spiders.) India-rubber tree, the, 536 .

Inundations, of the Amazon, 519.

1slands: mostly tropical, 477 ; volcanic, 478 ; coralline, 478; volcanic, 479; how peopled, 479 .

\section{J.}

JABIRU, the, 651 .

Jacana, the, 651 .

Jaguar, the, 710 ; his ravages, 710 ; modes of hunting, 710 .

Java, coffee of, 563 ; Dutch monopoly of spices in, 575 ; bats in, 670 .

Jigger, or chegoe, the, 585 .

\section{K.}

KaLA, the rhinoceros-bud, 722 .

Kalahari, South African Savanna, 503 ; vegetation of, 505 ; water in, 505 ; insects of, 506 ; water-finding ants, 506 ; inhabitants of, 506 .

Kalong, or fox-bat, the, 670 .

Keitloa, or black rhinoceros, the, 721 .

Kengwe, an African plant, 515.

Khamsin, or simoom, the 511, 729.

Kobaaba, or white rhinoceros, the 722 .

Korwé, the, 658 .

\section{L.}

LABARRI snake, the 617.

Ladang, or mountain rice, 546 .

Lake Region of Africa, 506.

Land and Water, Proportions of, 473.

Lasso, the, 501.

Leeches, Land of, Ceylon, 587.

Leichardt, Mr., explorations in Australia, 509.

Lemurs, semi-monkeys, 688.

Leopard, the, 708; the cheetah, or hunting leopard, 708.

Leroshuá, an African plant, 504.

Llana, the, 483.

Llanos, of Venezuela, the, 499; in the dry season, 500 ; in the wet season, 500 .

Lianas. (See Bushropes.)

Life and cold, struggles between, 471.

Lion, the, 504; lion and rhinoceros, 504, 704 general characteristics of the lion, 698 ; node of seizing his prey, 699; lions and girafie, 699 ; lion and man, 700 ; hunting the lion on Mount Atlas, 700, 702; man-eating lions, 700,704 ; adventure of Hotteritot with, 701, of Andersson with, 701; of Livingstone with, 702; hunted by the Arabs, 702; by the Bushmen, 703 ; ancient range of, 704 ; present range of, 704; Livingstone's opinion of, 704.

Litchi, the, 556.

Livingstone, David: Notes of, $505,527,685$, 
Livingstone, David: Notes of, 588, 595, 600, $667,703,704,715,726,732$.

Livingstone, Mrs., Grave of, 528.

Lizards, 629; the geckoe, 629; the anolis, 630; the chameleon, 630 ; the iguana, 631 ; the teja, 631; hydrosauri, or water lizards, 632 ; flying-lizards, 632 ; the basilisk, 632 .

Locusts, 589.

Loris, semi-monkeys, 688.

Love-Parrot, the, 661 .

Lyre-bird, the, 653 .

M.

Macaws, 662.

Mace, 576.

Magdalena river, voyage up, 495.

Mahogany tree, the, 531 .

Maize, or Indian Corn, 547 ; its productiveness, 548; Franklin's account of, 549.

Malay Archipelago, the, productions and aniinals of. (See Wallace.)

Manakins, birds, 648.

Mama Oella, legends of, 486.

Manco Capac, legends of, 486.

Mandrils, monkeys, the, 687.

Mandioca, or Cassava, 554.

Mango, the, 557.

Mangosteen, the, 557.

Manides, ant-eaters, 608.

Mantis, or soothsayer, the, 583.

Marching termite, the, 606 .

Mata, a plant of the Pana, 483.

Megatherium, the, 675 .

Membracidæ, aphides, 600 .

Mexico, table-land of, 496.

Mias, or orang-outang, 680.

Millet, 550.

Mimosas, 534.

Mocking-bird, the, 649.

Mokuri, an African plant, 505.

Monitor, lizard, 631.

Monkeys, their habits and characteristics, 676 ; place in the scale of being, 677 ; distinguished from the human race, 677 ; the chimpanzee, 677 ; the gorilla, 678 ; the orang-outang, or mias, 680 ; the gibbons, 685 ; the semnopitheci, 686 ; the huniman, 686 ; the cynocephali, baboons and mandrils, 687 ; difference between monkeys of the two hemispheres, 688; abundance of monkeys in South America, 689; miriki, 689; howling monkeys, 690 ; spider-monkeys, 691; foxtail monkeys, 691; the Saïmiris, 691 ; nocturnal monkeys, 691; domesticated monkeys, 692; squirrel monkeys, 692.

Monoho, or white rhinoceros, the 721 .

Monsoons, the, 476 .

Mora-tree, the, 531 .

Mosquito, the, 585 .

Mountains: as influencing climate, 476.

Mule, the ship of the desert of Atacama, 508.

Mundaaracus, of Amazonia, 5:1.

Mylodon, the, 675.

\section{N.}

Naras, an African plant, 505.

Nests of weaving birds, 658 .

Nocturnal monkeys, 691 .

Nutmegs, 574; Dutch monopoly of, 575 .
Nutritive Plants of the Tropical World (Chapter VI. See also Fruits and Plants.) Rice, 545; Maize, 547; Millet, 550 ; bread-fruit, 550 ; banana and plantain, 551 ; the sagopalm, 552 ; eassava, or mandioca, 554 ; yams, 555 ; sweet potato, 555 ; arrow-root, 555; taro-root, 556 .

Nycteribia bats, 672 .

Nyclopitheci, or nocturnal monkeys, 691.

\section{0.}

Ocean and Atmosphere, the, 471.

Ocean, the, extent of, 472 ; influence upon climate, 473 ; laws governing them, 475 .

Okhotsk Sea, currents of, 475 .

Orang-o atang, or mias, 680 ; Wallace's account of, 681 ; portrait of female, 681 ; strength and tenacity of life, 682 ; size of the largest, 682 ; a formidable opponent, 683 ; fights with the alligator and python, 683 ; its habits and food, 683 ; Wallace's pet orang, 684 .

Orchids, 535.

Orejones, of Bogotá, 495.

Organ-bird, the, 650 .

Orioles, 648 .

Ornamental insects, 592.

Oricou, or sociable vulture, 696.

Orotava, great dragon-tree of, 528 .

Orton, James: Notes from, 490, 493, 494, 498, $520,522,5 \cdot 24,636,641$.

Orycteropi, ant-eaters, 608 .

Ostrich, the : Hunting of, 512, 664; the ostrich at home, 663 ; its enemies, 664 , 666 ; its instincts, 665 ; care for its young, 665 ; connecting link between birds and quadrupeds, 666 ; its omniverous appetite, 666 ; vaiue of its feathers and eggs, 667.

$\mathrm{Ox}$, the, introduced into America, 500 ; their vast increase, 501 .

\section{$\mathrm{P}$}

Pachyerrmati of ine tropical world, 712.

Paddy, or native rice, 547.

Palm-trees: The mauritia, 499; on the Amazon, 469, 519; general characteristics, 538, 542 ; avenue of, at Rio Janeiro, 539 ; multiplied uses of, 539 ; the saguer, and areca, 540 ; the palmyra and talipot, 541 ; the datepalm, 542; oil-palms, 542; palms on the Amazon, 543; the sago-palm, 552; future commercial value of the palm, 544 .

Pampas, of South America, 499. (See also Savannas and Llanos.) Horses and cattle in, 502.

Panama railroad, forest on, 526.

Pandanus, or screw-pine, 533 .

Pangolins, ant-eaters, 608.

Panickeas, elephant-catchers of Ceylon, 718.

Paradise, birds of, 653 ; early stories about, 653; Wallace's account of, 653 ; shooting of by natives of Aru, 654 ; the great bird of paradise, 655 ; snaring the red bird of paradise, 655 .

Parasitic plants, 535

Paroquets, 663.

Parrots, 659

Peons, in South America, 522.

Pepper, 576. 
Peru, ancient civilization of, 486.

Pichincha, volcano, descent into, 494.

Pimento, 577.

Pippul, or Bo-tree, 530.

Pique, or jigger, 585.

Plantain and banana, 551.

Plant-lice, aphides, furnish honey to ants, 600 .

Plants, nutritive. (See Fruits and Trees.) Rice, 545 ; maize, 547 ; millet, 550 ; sugar-cane, 559 ; coffee, 562 ; cacao, or chocolate, 567 ; vanilla, 568; coca, 568 ; cinnamon and cassia, 571 ; nutmegs and cloves, 574 .

Ponera clavata, ant, 594.

Porocococa, on the Amazon, 518.

Potato, the sweet, 555.

Prey, beasts and birds of, 693 .

Puma, or cougar, American lion, the, 710.

Puna, the, or table-land of Peru: its extent and character, 481 ; diseases of, 482 ; life in, 482 ; vegetation of, 483 ; animals of, 484 ; climate of, 485 . (See also Titicaca.)

Python, the, 620 ; contests with the orangoutang, 683 .

\section{Q.}

QUAGGA. (See Zebra.)

Quinua, a plant of the Puna, 483.

Quito, table-land of : its elevation, 489 ; ways of access, 490; approach from the Pacific coast, 491; the climate and productions, 492 ; its fauna and flora, 492 ; the people, 493 ; its surrounding volcanos, 494 .

\section{R.}

RABBIT, fascinated by serpent, 623 .

Rains and rain-fall, 476 ; at sea, 477 ; in various places, 477, 513.

Ratans, 541.

Rattlesnakes, 619 ; power of fascination, 621.

Realejo, or organ-bird, the, 650 .

Red ant of Ceylon, 595 .

Reefs, 478.

Rheas, or American ostriches, 667.

Rhinoceros, the, 721 ; species of, 721 ; difference between the white and the black, 721 ; general characteristics, 722 ; acuteness of its smell and hearing, 722 ; imperfection of its vision, 722 ; its bird attendant, 722 ; bad temper of the black species, 722 ; fondness for its offspring, 723; its nocturnal habits, 723 ; hunting the rhinoceros, 723 ; its vitality, 723 ; value of its ivory, 723 ; rhinoceros paths, 724 ; the Indian rhinoceros, 724.

Rice, species and culture of, 545 ; rice lands of the United States, 546 ; enemies of the riceplant, 547.

Rice-bird, the, 547.

Rice, Colonel, adventure with a tiger, 760 .

Roads of the Incas of Peru, 489.

Rogue elephants, 714 ; rogue hippopotami, 726. Robber crab, 580 and 634.

\section{S.}

SACELr, dancing parties of birds, 655 .

Sacred island in Lake Titicaca, 485,488 .
Sago, mode of manufacturing, 552 ; productiveness of the tree, 553 .

Sahara, Desert of, 509; Barth's adventure in, 510 ; oases in, 511 ; khamsin, or pestilential wind, 511 ; animals and birds of, 512 ; seasons of, 513 .

Saimiris, monkey, 691.

Sakis, the, 691.

Sandal-tree, the, 531

Sargasso Sea, the, 474.

Sarumpe, a disease on the Puna, 482.

Satinwood-tree, 530.

Savannas and Deserts (Chapter III.) The Llanos of Venezuela, 4.99; the Pampas, 500 ; the Kalahari, 502; Lake Region of Africa, 506.

Sawa, or marsh rice, 546

Scorpions, 614 ; their aspect, 615 ; their venom, 615.

Seasons, the: Changes of, in different hemispheres, 476.

Sea-weeds in the Sargasso Sea, 474.

Secretary eagle, the, 624,698 .

Semi-monkeys, lemurs, loris, etc., 688.

Semnopitheci, monkeys, the, 686 .

Serpents: Rarity of venomous species, 616 ; danger from, 617 ; antidotes to their poison, 618 ; mechanism of their poison-fangs, 618 ; the bushmaster, 619 ; rattlesnakes, 619 ; extirpated by hogs, 619 ; the cobra, 620 ; the haje, 620 ; boas and pythons, 620 ; fascination of serpents, 621 ; catching their prey, 624 ; their bird enemies, 624 ; eating each other, 625 ; anatomical structure, 625 ; the formation of their jaws, 626 ; protracted fastings, 626 ; useful serpents, 627 ; tree-snakes and water-snakes, 627 ; enormous serpents, 627; large snake killed by Du Chaillu, 627; larger one mentioned by Wallace, 628 .

Serpent-destroyers, 619,624 .

Sikkim, the table-land of, 497.

Silk-w orm, the, 590.

Silla, traveling by, 496 .

Simoom, the, 511, 729 .

Sjambok, whip of rhinoceros-hide, 727.

Slave-hunting ants, 600 .

Sloth, the, 673; helplessness on the ground, 674 ; activity on trees, 674 ; tenacity of life, 675 ; gigantic fossil sloths, 676 .

Snakes. (See Serpents.)

Soothsayer, or mantes, 583.

Soroche, a disease on the Puna, 482.

Sparrow-hawk, the, 698.

Speke, John H., Account of the Lake Region of Africa, 507.

Spices, 559; cinnamon, 571; nutmegs and cloves, 574 ; pepper, 576 ; pimento, 577 ; ginger, 578 .

Spiders : Numerous on the Amazon, 520 ; general characteristics of, 610 ; their venom, 611 ; their webs, $61 i$; neutral-colored spiders, 611 ; bright-colored spiders, 612 ; modes of life, 612 ; spider-eating birds, 613 ; insect enemies of the spider, 613 ; small effects of the bites of spiders, 613 ; edible spiders, 614 ; possible industrial uses of their filaments, 614 .

Spider-monk $\in$ ys, 691.

Spider-webs, their fineness, 614 .

Spoonbills, 651.

Squier, E. G. : Notes from, 481, 484, 487.

Squirrel, charmed by serpent, 624 ; the flying. squirrel, 673 . 
Squirrel-monkeys, 692.

Sturt, Mr., Explorations in Australia, 509.

Sugar, manufacture of, 561 .

Sugar-cane, the, 559; its introduction into America, 560; characteristics of the plant, 561.

Sun-birds, 652.

Sycamore, the, 529 .

T.

Table Lands, of Peru, 480 ; of Quito, 489; Bogotá, 495; of Mexico, 496; of the Himalayas, 497.

Tailor-bird, the, 658 .

Talegalla, or brush-turkey, the, 656 .

Tapir, the, 521.

Tarantula, spider, exaggerated accounts of its venom, 614 .

Taro-root, the, 556.

Tatooed Indians on the Amazon, 521.

Teak-tree, the, 530 .

Teju lizard, the, 631.

Tennent, Sir Emerson; Notes of, 527, 535, 616, $638,640,644,672,713,721$.

Termites, or white ants: Their habits and food, 601 ; destructiveness to books and furniture, 601 ; their uses, 602 , their communities, 602 ; their buildings, $60^{\circ}$; their industry, 603; their military operations, 604; American termites, 605 ; mode of capture, 605 ; marching termites, 606 .

Theobroma, or chocolate, 567.

Thorny plants, 504, 536.

Ticks, 586.

Thorpe, T. B., on the fascination of serpents, 622 ; on the size of alligators, 636 .

Tierras, climatic regions of Mexico, 496.

Tiger, the, 705; appearance and habits, 705 ; his ferocity, 705; his present and former range, 704 ; tiger-hunting by natives of India, 706 ; by English residents, 706; perilous adventure, 706; peacocks and monkeys warning against the tiger, 707; preying upon tortoises, 708.

Titicaca, the sacred lake and island of Peru: elevation of the lake, 485; the sacred island, 486.

Toads. (See Frogs.)

Toropishu, the, 650 .

Tortoises. (See Turtles.)

Toucan, the, 646 .

Trade winds, the, 476.

Trees and Plants of the Tropical World: Mauritia palm, 499; the wait-a-bit thorn, 504; baobab, 527; dragon trees, 528; the sycamore, 529 ; banyan, 529 ; pippul, or bo-tree, 530 ; the teak-tree, 530 ; satinwood, 530; sandal-wood, 531; ceiba, 531; mahogany, 531; mora, 531; bamboos (see under head); agave, 533 ; pandanus, 533 ; cactuses, 534 ; mimosas, 534; lianas, 535; acacias, 537; mangroves, 538; palms (see under head) ; ratans, 541 ; bread-fruit, 550 ; cinnamon, 572.

Trigonocephalus snake, the, 618 .

Troopials, 648.

Tropical World, the : Ocean and Atmosphere of, 471-479. (Chapter I.)-Table-Lands and Plateaus of, 480-498. (Chapter II.)-Savannas and Deserts of, 499-513. (Chapter III.) Forests of, 514-524. (Chapter IV.)-Charac- teristic forms of Vegetation, 525-544. (Chapter V.)-Nutritive Plants of, 545-558. (Chapter VI.)-Condiments and Spices, 559-578(Chapter VII.)-Insects of, 581-593. (Chapter VIII.)-Ants, Spiders, and Scorpions, 594-615. (Chapter IX.)-Serpents, Lizards, Frogs and Toads, 616-634. (Chapter X.)Alligators, Crocodiles, and T'urtles, 635-644. Chapter XI.)-Bird Life, 645-668. (Chapter XII.)-The Climbers, 669-692. (Chapter XIII.)-Beasts and Birds of Prey, 693-711. (Chapter XIV.)-The Elephant, Rhinoceros, Hippopotamus, Camel, and Zebra, 712-736. (Chapter XV.)

Tschudi, von, Notes from, 484, 485, 569, 585, $590,694,710,711$.

Tsetsé-fly, the, 587.

Tunqui, the 650 .

Turkey, the, ocellated, 652 ; the brush-turkey, 656.

Turkey-buzzard, the, 694 .

Turtles, 640 ; their chief habitats, 641 ; slow travelers, 641; hunting their eggs on the Amazon, 641; Marsh-tortoises, 641; seaturtles, 642 ; enemies of the turtle, 643 ; modes of taking, 643 ; barbarous treatment of, 644 ; vocal turtles, 644 .

\section{U.}

URUBU, or carrion vulture, 695 .

Urquiza, General, his vast estates, 501. Umbrella ant, the, 596 .

\section{V.}

VANILLA, 568.

Vampires, 671.

Vegetation, Tropical, characteristic Forms of, 525 .

Veruga, poisoned water of the Puna, 482.

Veta, a disease in the Puna, 482.

Victoria regia, the, 536 .

Vicuna, the, 483 ; hunts of, 484.

Vivagua-ant, the, 596.

Volcanos : of Ecuador, 494 ; of Mexico, 497.

Vulture, the carrion, 695 ; the sociable, 696.

\section{W.}

Wallace, Alfred R. : Account of the bread. fruit, 550 ; the manufacture of sago, 552 description of the durion, 557 ; of the leafbutterfly, 582; ants in Dorey, 597 ; describes huge snake, 628 ; of a flying frog, 633 ; of birds of paradise, 653 ; of edible bats, 670 . of the orang-outang, 681 ; his pet orang, 684 ; notice of the babirusa, 736 .

Water: Proportion of to land, 472; relations to fertility, 475, 499, 525; obtaining in the Kalahari, 505.

Waterton, William: Notes of, $617,637,646$, $650,672,674$.

Weaving-birds, and their nests, 659 .

Webs of spiders, 611 .

West Indies, sugar in, 561 ; coffee in, 563.

Whirlwinds, 477.

White Ants. (See Termites.)

Wild-Cats, different species of, 711 .

Winds, as regulators of rain, 476 . 
INDEX.

Woods, ornamental of the Amazon, 524.

Wourali poison, the, 690 .

Y.

$\mathrm{Y}_{\mathrm{AM}}$, the, 555 .

Yriarteas, palms, the, 543.
Z.

ZEBRA, the, 733 ; its appearance, 733 ; capacity for domestication, 733 ; habits, 733 ; ancient notices of, 734 .

Zimb-fly, the, 588 .

Zones of the Earth, Limits of, 472. 





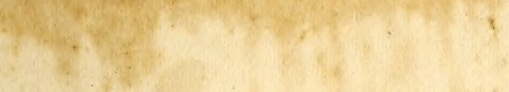

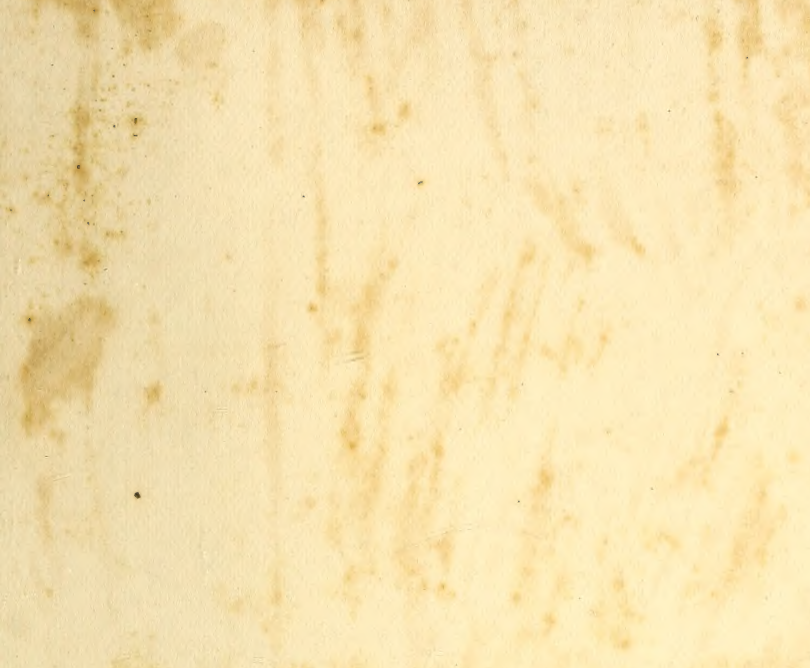

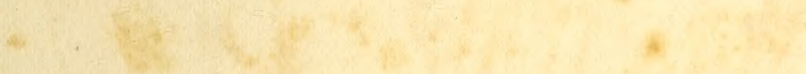
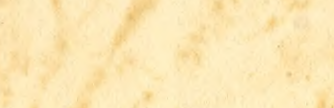

\section{.}
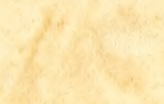

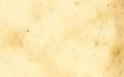

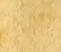

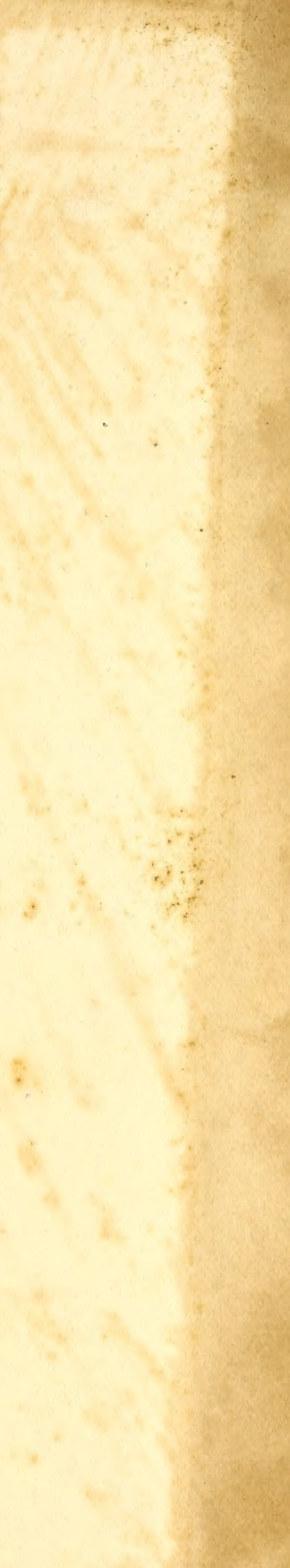

?.
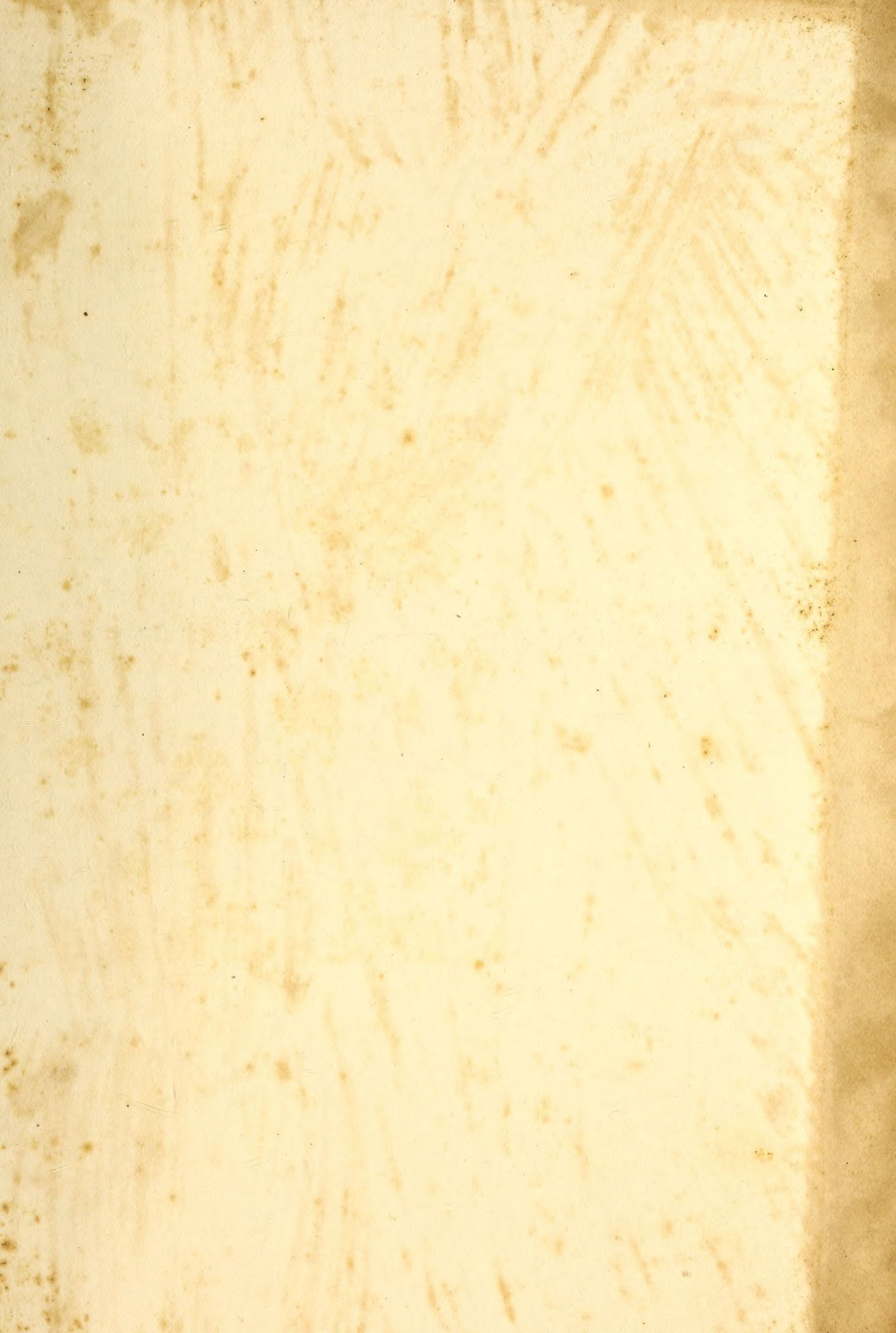

I

(3.) $x^{2}$

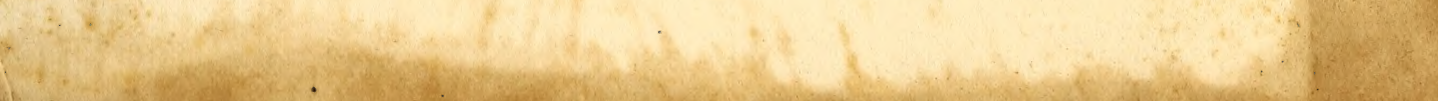




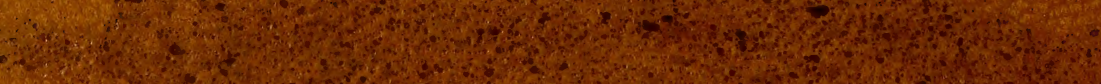

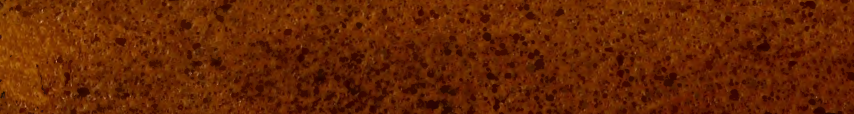

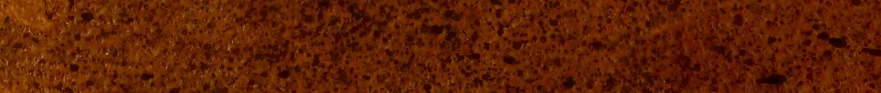

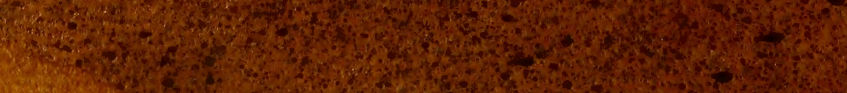

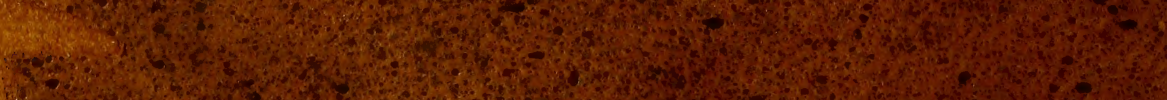

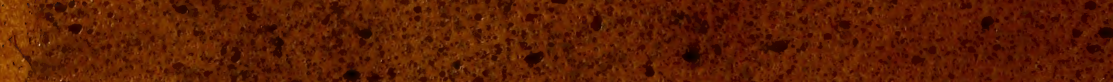

P2.0.

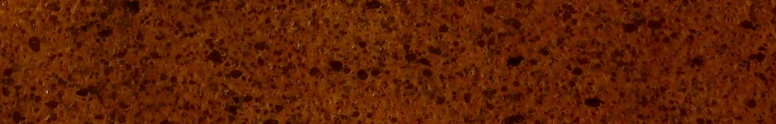

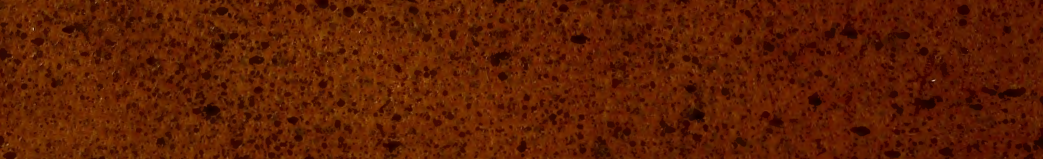

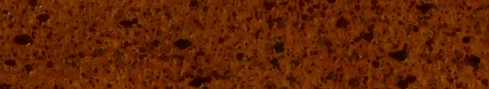

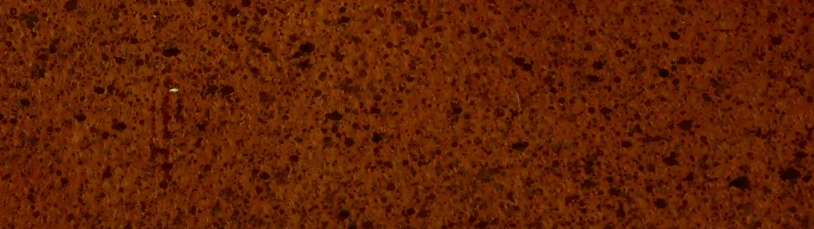

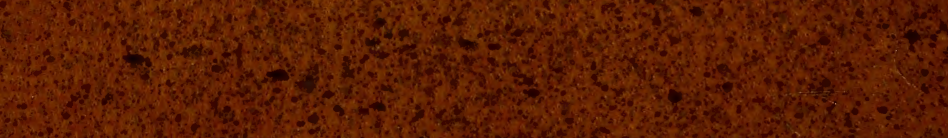

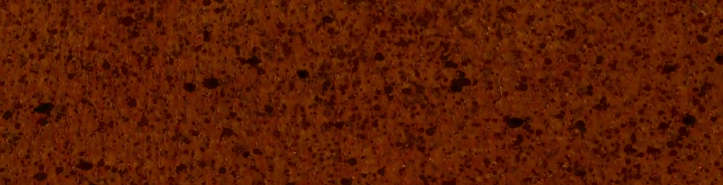

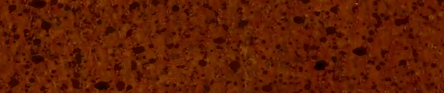

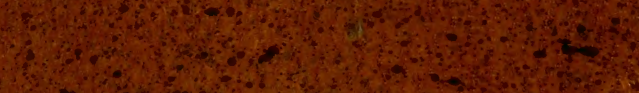

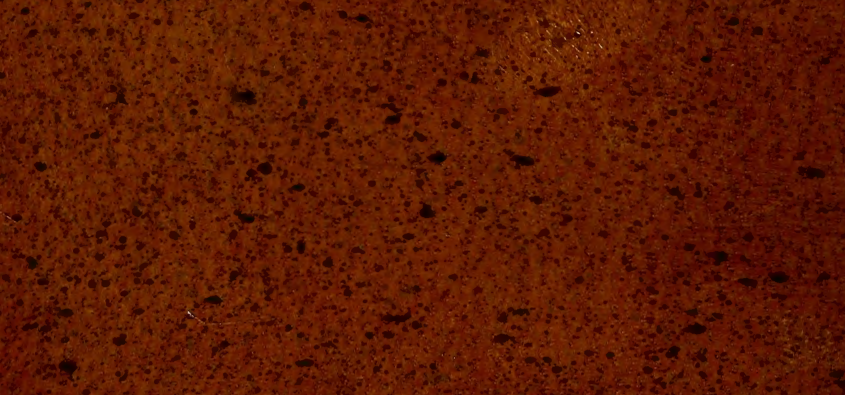

(4)

$33^{2}$

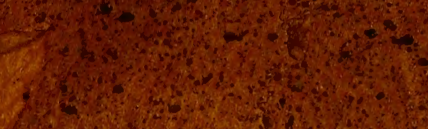

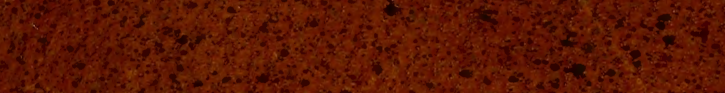

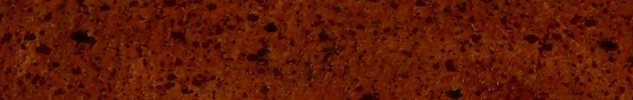

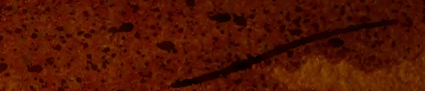

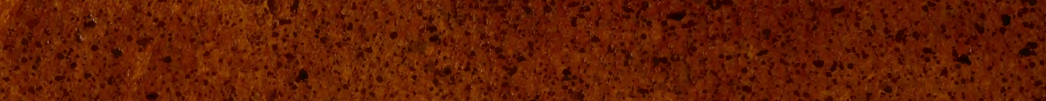

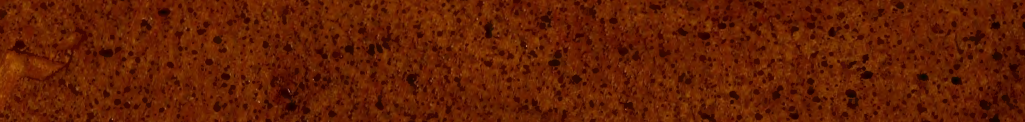

